\title{
Diferenciais de mortalidade em estratos homogêneos de vulnerabilidade social de municípios do Estado de São Paulo, 2003-2005
}

\section{MARLI DE FÁTIMA PRADO}

Tese de Doutorado apresentada ao Departamento de

Epidemiologia da Faculdade de Saúde Pública da Universidade de São Paulo para Obtenção do Grau de Doutor.

Área de concentração:

Epidemiologia

Orientador: Prof. Dr. Ruy Laurenti

São Paulo

2008 
É expressamente proibida a comercialização deste documento, tanto na sua forma impressa como eletrônica. Sua reprodução total ou parcial é permitida exclusivamente para fins acadêmicos e científicos, desde que na reprodução figure a identificação do autor, título, instituição e ano da tese. 
"Localizar significa mostrar o lugar. Quer dizer, além disto, reparar no lugar. Ambas as coisas, mostrar o lugar e reparar no lugar, são os passos preparatórios de uma localização. Mas é muita ousadia que nos conformemos com os passos preparatórios. A localização termina,

como corresponde a todo método intelectual, na interrogação que pergunta pela situação do lugar". 


\section{Agradecimentos}

Ao Professor Ruy Laurenti, meu mestre, pela orientação extremamente competente, respeitosa e dedicada.

Aos Professores: Cássia Maria Buchalla e Marco Akerman pelas contribuições extremamente pertinentes durante o processo de qualificação.

Aos Professores: Sabina Léa Davidson Gotlieb, Oswaldo Yoshimi Tanaka, Luiz Augusto Marcondes Fonseca e Luís Patrício Ortiz Flores pelas contribuições apresentadas no aprimoramento desta tese.

Aos meus pais que na sua simplicidade me induziram a buscar meus sonhos e, aos meus filhos Tamara e Diogo que me mantiveram nessa luta.

A secretária Mirian pelo acolhimento carinhoso e respeitoso no decorrer desse processo e, à equipe de Pós Graduação da Faculdade de Saúde Publica pelo apoio na tramitação de papéis e documentos necessários à vida acadêmica.

À Coordenadoria de Controle de Doenças da Secretaria de Estado da Saúde, em especial ao apoio de Cristiano Correia Marques e Clélia Maria Sarmento.

À Escola Técnica de Saúde Publica da Fundação Paulistana de Educação e Tecnologia da Prefeitura da Cidade de São Paulo, em especial a Valdirene Tizzano pelo apoio.

À Fundação Sistema Estadual de Análises de Dados - SEADE e, aos autores na pessoa de Maria Paula Ferreira pela pronta disponibilização no fornecimento dos arquivos eletrônicos dos dados do Índice Paulista de Vulnerabilidade Social.

Aos meus amigos Débora e Delzio que me estimularam a prosseguir nessa árdua caminhada não me deixando esmorecer.

À Letícia Campos pela pronta disponibilidade no auxilio à língua inglesa.

À Lilian Schiavon pelo auxilio à revisão da língua portuguesa e às normas de referências bibliográficas.

Aos amigos do cotidiano: Marcelo, Cléo, Sylia, Aparecido, Vanessa, Moisés, Vera, Eduardo, João Gomes e Andréia pelo apoio logístico ou palavras de estímulo me auxiliaram nessa caminhada. 


\section{RESUMO}

PRADO MF. Diferenciais de mortalidade em estratos homogêneos de vulnerabilidade social nos municípios do Estado de São Paulo - 2003 a 2005 . São Paulo: 2008. [Tese de Doutorado-Faculdade de Saúde Pública da USP]

Trata-se de um estudo ecológico exploratório tipo comparação de múltiplos grupos. Objetivo: descrever o padrão de mortalidade da população a partir de estratos homogêneos de vulnerabilidade social dos municípios no Estado de São Paulo de 2003 a 2005. Método: Construção de estratos homogêneos, através de indicador composto por variáveis socioeconômicas e demográficas e comparação dos padrões de mortalidade através de taxas padronizadas. Resultados: Construção de cinco estratos homogêneos de vulnerabilidade social (Muito Fraca, Fraca, Intermediária, Intensa e Muito Intensa). Estimativas de risco mais elevadas para mortes maternas (27,82 a $56,22 \% 000$ nascidos vivos), mortes infantis (12,48 a $16,20 \%$ nascidos vivos) e acidentes de transporte $(14,68$ a $24,06 \% 000$ hab.) foram mostradas nos estratos de maior vulnerabilidade declinando para os de menor vulnerabilidade. Para as Neoplasias (80,85 a 104,96 \%000 hab.) e D. Infecciosas e Parasitárias (23,21 a 27,52 a $\% 000$ hab.) as mais elevadas ocorreram nos estratos de menor vulnerabilidade, declinando para os de maior vulnerabilidade. Para Diabetes Mellitus (17,36 a 23,57\%000 hab.), D. Circulatórias (174,03 a 206,87\%000 hab.), Homicídios (11,50 a $21,24 \% 000$ hab.) e, D. Respiratórias (62,58 a 75,54 \%000 hab.), as mais elevadas situaram-se no estrato de vulnerabilidade social intermediária, declinando para os de maior vulnerabilidade, à exceção da Diabetes Mellitus. Conclusões: Foram evidenciadas desigualdades de mortalidade, apontando para grupos humanos com maiores necessidades de saúde, estratificação do risco epidemiológico e identificação de áreas críticas que indicam para a necessidade do desenvolvimento de políticas de saúde mais equitativas.

Descritores: Diferenciais de mortalidade, vulnerabilidade social, estudo ecológico, estratos homogêneos. 


\section{SUMMARY}

PRADO MF. Mortality differentials registered in homogeneous strata of social vulnerability in cities of the State of São Paulo - 2003 to 2005. São Paulo: 2008 [Doctorate thesis - Public Health College - University of São Paulo - USP]

This is an ecologic exploratory study employing multiple group comparison. Objective: to describe mortality patterns of the population from homogeneous social vulnerable strata of the cities in the State of São Paulo, from 2003 to 2005. Method: Construction of homogeneous strata employing an indicator composed of socioeconomic and demographic variables and comparison of mortality patters through standardized rates. Results: Construction of five homogeneous social vulnerability strata (Very Weak, Weak, Intermediate, Intense and Very Intense). Risk estimates higher for maternal deaths (27,82 to $56,22 \% 000$ live births), children deaths $(12,48$ to $16,20 \%$ live births) and transportation accidents (14,68 to $24,06 \% 000$ inhabitants) were shown in the strata of higher vulnerability, declining for those in lower vulnerability. For Neoplasias $(80,85$ to $104,96 \% 000$ inhabitants) and Infectious and Parasitic diseases (23,21 a 27,52 a \%000 inhabitants) higher rates corresponded to lower vulnerability strata, declining for those in higher vulnerability. Diabetes Mellitus (17,36 a 23,57\%000 inhabitants), Homicides (11,50 a 21,24\%000 inhabitants) and Respiratory Diseases (62,58 a 75,54 \%000 inhabitants) higher rates were found at the intermediate social vulnerability stratum, declining for those in higher vulnerability, except for Diabetes Mellitus. Conclusions: Mortality inequalities became evident, pointing to human groups in higher health needs, stratification of the epidemiologic risk and identification of critical areas that show the need to develop more equitable health policies.

Key Words: Mortality differentials, social vulnerability, ecologic study, homogeneous strata. 


\section{Lista de Abreviações}

$\begin{array}{ll}\text { MI } & \text { Mortalidade Infantil } \\ \text { RMM } & \text { Razão de Mortalidade Materna } \\ \text { IDH } & \text { Índice de Desenvolvimento Humano } \\ \text { IDH-M } & \text { Índice de Desenvolvimento Humano Municipal } \\ \text { DAC } & \text { Doenças do Aparelho Circulatório } \\ \text { DIP } & \text { Doenças Infecciosas e Parasitárias } \\ \text { IPVS } & \text { Índice Paulista de Vulnerabilidade Social } \\ \text { IPRS } & \text { Índice Paulista de Responsabilidade Social } \\ \text { N.V } & \text { Nascidos vivos } \\ \text { RIPSA } & \text { Rede Interagencial de Informações para a Saúde } \\ \text { OPS } & \text { Organização Pan Americana de Saúde } \\ \text { OMS } & \text { Organização Mundial de Saúde } \\ \text { PNUD } & \text { Programa das Nações Unidas para o Desenvolvimento } \\ \text { CF } & \text { Constituição Federal } \\ \text { RM } & \text { Região Metropolitana } \\ \text { PIB } & \text { Produto Interno Bruto } \\ \text { DM } & \text { Diabetes Mellitus }\end{array}$

Lista de Quadros

Quadro

1 Tipologia do Índice Paulista de Vulnerabilidade Social - IPVS.

Pág.

2 Composição dos estratos de vulnerabilidade social segundo

distribuição da população relativa Grupos agregados do IPVS.

\section{Lista de Tabelas}

Tabela

Pág.

$1 \quad$ № e \% da população segundo Índice Paulista de Vulnerabilidade Social em municípios selecionados. Estado de São Paulo, triênio 2003 a 2005.

2 № e (\%) da população por grupos agregados de vulnerabilidade social em municípios selecionados. Estado de São Paulo, média do triênio 2003 a 2005.

3 Subcategorizações internas segundo porte populacional dos municípios para a conformação dos estratos homogêneos de vulnerabilidade social .

$4 \quad$ Municípios e população (no e \%) segundo porte populacional nos Estratos de Vulnerabilidade Social. Estado de São Paulo, média do triênio 2003 a 2005.

5 Distribuição da população (\%) segundo Estrato de Vulnerabilidade Social nas regiões de saúde do Estado de São Paulo, média do triênio 2003-2005.

6 Mortalidade proporcional (\%) por faixa etária selecionada, segundo Estrato de Vulnerabilidade Social. Estado de São Paulo, média do triênio 2003 a 2005.

7 Óbitos ( $\left.\mathrm{n}^{\circ} \mathrm{e} \%\right)$ por Causas Mal Definidas, mediana e desvio padrão segundo Estrato de Vulnerabilidade Social. Estado de São Paulo, média do triênio de 2003 a 2005. 

1000 nascidos vivos), mediana, desvio padrão e razão de taxas nos Estratos de Vulnerabilidade Social. Estado de São Paulo, média do triênio 2003 a 2005.

9 Óbitos Maternos, Nascidos Vivos e Razão de Mortalidade Materna (por 100 mil nascidos vivos), mediana, desvio padrão e Razão de Taxas nos Estratos de Vulnerabilidade Social. Estado de São Paulo, média do triênio 2003 a 2005.

10 Óbitos, Taxa de mortalidade (bruta e padronizada) total e segundo sexo por Doenças Infecciosas e Parasitárias (por 100 mil hab.), mediana, desvio padrão e razão de taxas nos Estratos de Vulnerabilidade Social. Estado de São Paulo, triênio 2003 a 2005.

11 Óbitos, Taxa de mortalidade (bruta e padronizada) total e segundo sexo por Doenças Respiratórias (por 100 mil hab.), mediana, desvio padrão e razão de taxas nos Estratos de Vulnerabilidade Social. Estado de São Paulo, média do triênio 2003 a 2005.

12 Óbitos, Taxa de mortalidade (bruta e padronizada) total e segundo sexo por Doenças do Aparelho Circulatório (por 100 mil hab.), mediana, desvio padrão e razão de taxas nos Estratos de Vulnerabilidade Social. Estado de São Paulo, média do triênio 2003 a 2005.

13 Óbitos, Taxa de mortalidade (bruta e padronizada) total e segundo sexo por Diabetes Mellitus (por 100 mil hab.), mediana, desvio padrão e razão de taxas nos Estratos de Vulnerabilidade Social. Estado de São Paulo, média do triênio 2003 a 2005.

14 Óbitos, Taxa de mortalidade (bruta e padronizada) total e segundo sexo por Neoplasias Malignas (por 100 mil hab.), mediana, desvio padrão, e razão de taxas nos Estratos de Vulnerabilidade Social. Estado de São Paulo, média do triênio 2003 a 2005.

15 Óbitos e taxas de mortalidade (bruta e padronizada) total e segundo sexo por Acidentes de Transporte (por 100 mil hab.), mediana, desvio padrão e razão de taxas nos Estratos de Vulnerabilidade Social. Estado de São Paulo,média do triênio 2003 a 2005.

16 Óbitos, Taxa de mortalidade (bruta e padronizada) total e segundo sexo por Homicídios (por 100 mil hab.), mediana, desvio padrão, e razão de taxas nos Estratos de Vulnerabilidade Social. Estado de São Paulo, média do triênio 2003 a 2005.

17 Síntese de indicadores selecionados de Caracterização Demográfica dos Estratos de Vulnerabilidade Social.Estado de São Paulo, média do triênio 2003 a 2005.

18 Síntese de indicadores de mortalidade selecionados dos Estratos de Vulnerabilidade Social.Estado de São Paulo, média do triênio 2003 a 2005.

Lista de Figuras 

segundo distribuição da população relativa nos grupos agregados do IPVS.

4 Intervalos de porte populacional de classificação interna dos municípios nos Estratos de Vulnerabilidade Social. Vulnerabilidade Social. Estado de São Paulo, média triênio 2003-2005.

Estratos Vulnerabilidade Social A e B. Estado de São Paulo, média do triênio 2003-2005.

7 Distribuição espacial dos municípios segundo porte populacional no

Estrato Vulnerabilidade Social C. Estado de São Paulo, média do triênio 2003-2005.

8 Distribuição espacial dos municípios segundo porte populacional no Estratos de Vulnerabilidade Social D e E. Estado de São Paulo, média do triênio 2003-2005.

9 Distribuição espacial dos Estratos de Vulnerabilidade Social no Estado de São Paulo, média do triênio 2003-2005.

10 Proporção (\%) de habitantes na faixa etária de 0-4 anos e de 60 anos e mais segundo porte populacional dos conjuntos de municípios nos Estratos de Vulnerabilidade Social. Estado de São Paulo, média do triênio 2003 a 200

11 Razão de dependência segundo porte populacional dos conjuntos de municípios nos Estratos de Vulnerabilidade Social. Estado de São Paulo, média do triênio 2003 a 2005.

12 Pirâmide populacional segundo Estrato de Vulnerabilidade Social. Estado de São Paulo, média do triênio 2003 a 2005.

13 Razão de sexos segundo porte populacional dos conjuntos de municípios nos Estratos de Vulnerabilidade Social. Estado de São Paulo, média do triênio 2003 a 2005.

14 Mortalidade proporcional (\%) por faixa etária selecionada segundo porte populacional dos conjuntos de municípios nos Estratos de Vulnerabilidade Social. Estado de São Paulo, média triênio 2003- 2005.

15 Proporção (\%) de óbitos por Causas Mal Definidas segundo porte populacional dos conjuntos de municípios nos Estratos de Vulnerabilidade Social. Estado de São Paulo, média do triênio 2003 a 2005.

16 Taxa de mortalidade infantil (por mil nascidos vivos) segundo porte populacional dos conjuntos de municípios nos Estratos de Vulnerabilidade Social. Estado de São Paulo, média do triênio 2003 a 2005.

17 Distribuição espacial da taxa de mortalidade infantil (por mil nascidos vivos) nos municípios dos Estratos de Vulnerabilidade Social A e B, D e E. Estado de São Paulo, média do triênio 2003-2005.

18 Distribuição espacial da taxa de mortalidade infantil (por mil nascidos vivos) nos municípios do Estrato C e Estado de São Paulo. Média do triênio 2003 a 2005. 
19 Razão de mortalidade materna (por 100 mil nascidos vivos) segundo porte populacional dos conjuntos de municípios nos Estratos de Vulnerabilidade Social. Estado de São Paulo, média do triênio 2003 a 2005

20 Distribuição espacial da Razão de Morte Materna (por 100 mil nascidos vivos) dos municípios nos Estratos de Vulnerabilidade Social A e B, D e E. Estado de São Paulo, média do triênio 2003 a 2005.

21 Distribuição espacial da Razão de Morte Materna (por 100 mil nascidos vivos) nos municípios do Estrato de Vulnerabilidade Social C e Estado de São Paulo. Média do triênio 2003 a 2005.

22 Taxa de mortalidade por Doenças Infecciosas e Parasitárias segundo porte populacional dos conjuntos de municípios nos Estratos de Vulnerabilidade Social. Estado de São Paulo, média triênio 2003-2005. Distribuição espacial da taxa de mortalidade por Doenças Infecciosas e Parasitárias nos municípios dos Estratos A e B, D e E. Estado de São Paulo, média do triênio 2003 a 2005.

24 Distribuição espacial da taxa de mortalidade por Doenças Infecciosas e Parasitárias nos municípios do Estrato de Vulnerabilidade Social C e Estado de São Paulo. Média do triênio 2003 a 2005. segundo porte populacional dos conjunto de municípios nos Estratos de Vulnerabilidade Social. Estado de São Paulo, média do triênio 2003 a 2005.

26 Distribuição espacial da taxa de mortalidade por Doenças Respiratórias (por 100 mil hab.) dos municípios nos Estratos de Vulnerabilidade Social A e B, e D e E. Estado de São Paulo, média do triênio 2003 a 2005.

27 Distribuição espacial da taxa de mortalidade por Doenças Respiratórias (por 100 mil hab.) nos municípios do Estrato de Vulnerabilidade Social C e Estado de São Paulo. Média do triênio 2003 a 2005.

28 Taxa de mortalidade por Doenças do Aparelho Circulatório (por 100 mil hab.) segundo porte populacional dos conjuntos de municípios nos Estratos de Vulnerabilidade Social. Estado de São Paulo, média do triênio 2003 a 2005.

29 Distribuição espacial da taxa de mortalidade por Doenças do Aparelho Circulatório (por 100 mil hab.) nos municípios dos Estratos de Vulnerabilidade Social A e B, D e E . Estado de São Paulo, média do triênio 2003 a 2005.

30 Distribuição espacial da taxa de mortalidade por Doenças do Aparelho Circulatório (por 100 mil hab.) nos municípios do Estrato de Vulnerabilidade Social C e Estado de São Paulo. Média do triênio 2003 a 2005.

31 Taxa de mortalidade por Diabetes Melittus(por 100 mil hab.) segundo porte populacional dos conjuntos de municípios nos Estratos de Vulnerabilidade Social. Estado de São Paulo, média do triênio 2003 a 2005. 
33 Distribuição espacial da taxa de mortalidade por Diabetes Melittus (por 100 mil hab.) nos municípios dos Estratos de Vulnerabilidade Social C e Estado de São Paulo. Média do triênio 2003 a 2005.

34 Taxa de mortalidade por Neoplasias Malignas (por 100 mil hab.) segundo porte populacional dos conjuntos de municípios nos Estratos de Vulnerabilidade Social. Estado de São Paulo, média do triênio 2003 a 2005.

35 Distribuição espacial da taxa de mortalidade por Neoplasias Malignas (por 100 mil hab.) nos municípios dos Estratos de Vulnerabilidade Social A e B, D e E. Estado de São Paulo, média do triênio 2003 a 2005.

36 Distribuição espacial da taxa de mortalidade por Neoplasias Malignas (por 100 mil hab.) nos municípios do Estrato de Vulnera-bilidade Social C e Estado de São Paulo. Média do triênio 2003-2005.

37 Taxa de mortalidade por Acidentes de Transporte (por 100mil hab.)segundo porte populacional dos conjuntos de municípios nos Estratos de Vulnerabilidade Social. Estado de São Paulo, media do triênio 2003 a 2005.

38 Distribuição espacial da taxa de mortalidade por Acidentes de Transporte (por 100 mil hab.) nos municípios dos Estratos de Vulnerabilidade Social A e B, D e E. Estado de São Paulo, média do triênio 2003 a 2005.

39 Distribuição espacial da taxa de mortalidade por Acidentes de Transporte (por 100 mil hab.) nos municípios do Estrato de Vulnerabilidade Social C e Estado de São Paulo. Média do triênio 2003-2005.

40 Distribuição espacial da taxa de mortalidade por Acidentes de Transporte (por 100 mil hab.) nos municípios do Estrato de Vulnerabilidade Social C e Estado de São Paulo. Média do triênio 2003-2005.

41 Figura 41 - Malha Rodoviária do Estado de São Paulo segundo distribuição e concessão de rodovias, 2008

42 Distribuição da taxa de mortalidade por Homicídios (por100 mil hab.) segundo porte populacional dos conjuntos de municípios nos Estratos de Vulnerabilidade Social. Estado de São Paulo, média do triênio 2003 a 2005.

43 Distribuição espacial da taxa de mortalidade por homicídios (por 100 mil hab.) dos municípios nos Estratos de Vulnerabilidade Social A e B, D e E. Estado de São Paulo, média do triênio 2003 a 2005.

44 Distribuição espacial da taxa de mortalidade por Homicídios (por 100 mil hab.) dos municípios no Estrato de Vulnerabilidade C e Estado de São Paulo. Média do triênio 2003 a 2005. 
Sumário

Apresentação 14

1 Introdução $\quad 15$

1.1 Temática e Delimitação do Estudo $\quad 15$

2 Referenciais Teóricos 17

2.1 Condições de Vida e Mortalidade $\quad 17$

2.2 Desigualdades e iniqüidades 20

$\begin{array}{ll}2.3 \text { A Categoria Espaço } & 22\end{array}$

2.4 Delineamento de estudos 24

2.5 Estudos de Modelo Ecológico 26

$\begin{array}{ll}2.6 \text { As Medidas de Saúde } & 29\end{array}$

2.6.1. Informações em Saúde $\quad 31$

2.7 O Estado de São Paulo e seus contrastes 33

2.7.1 As medidas dos contrastes $\quad 35$

2.7.2 Uma medida de vulnerabilidade social 38

3 Objetivos 41

3.1 Geral 41

3.2 Específicos $\quad 41$

4 Material e Método $\quad 42$

4.1 Desenho do estudo 42

4.2 Seleção das bases de dados $\quad 42$

$\begin{array}{lll}4.3 \text { População } & 42\end{array}$

4.4 Construção dos estratos homogêneos de vulnerabilidade social 43

4.4.1 Seleção das variáveis do IPVS $\quad 43$

4.4.2 Atualização da população absoluta para os grupos do IPVS 44

4.4.3 Composição dos estratos homogêneos de vulnerabilidade 44 social

4.4.4 Critérios para a construção dos estratos homogêneos de 45 vulnerabilidade social

4.4.5 Agrupamento por vulnerabilidade social 46

4.4.6 Agrupamento dos municípios em estratos homogêneos de 48 vulnerabilidade social

Categorização interna de cada estrato $\quad 49$

4.4.7 Critérios para a construção dos estratos homogêneos de 50 vulnerabilidade social

4.5 Análise, Medidas e Indicadores Selecionados 50

5 Resultados e Discussão 53

5.1 Conformação dos Estratos Homogêneos 53

5.2 Características Demográficas 64

$\begin{array}{lll}5.3 & \text { Mortalidade proporcional por faixas etárias selecionadas } & 72\end{array}$

$\begin{array}{lll}5.4 & \text { Diferenciais das características demográficas } & 75\end{array}$

$\begin{array}{lll}5.5 & \text { Causas de Mortes Mal Definidas } & 76\end{array}$ 
$\begin{array}{lll}5.6 & \text { Mortalidade infantil } & 81\end{array}$

5.7 Mortalidade Materna 88

5.8 Mortalidade por Algumas Doenças Infecciosas e Parasitárias 97

5.9 Mortalidade por Doenças Respiratórias 105

5.10 Mortalidade por Doenças do Aparelho Circulatório 114

$5.11 \quad$ Mortalidade por Diabetes Mellitus 121

5.12 Mortalidade por Neoplasias Malignas $\quad 129$

5.13 Mortalidade por Acidentes de Transporte 136

5.14 Mortalidade por Homicídios 144

5.15 Diferenciais de Mortalidade 155

6 Considerações finais 157

$\begin{array}{ll}\text { Referências Bibliográficas } & 161\end{array}$

Anexos 168

Currículo Lattes 169 


\section{APRESENTAÇÃO}

A temática deste estudo alicerça-se na investigação do tripé mortalidade, espaço e vulnerabilidade social em agregados populacionais de municípios e, sua justificativa e hipóteses são apresentadas no Capitulo 1. Os referenciais teóricos sobre condições de vida e mortalidade, desigualdades e iniqüidades de grupos populacionais, espaço enquanto categoria de análise, delineamentos metodológicos e modelos são abordados no Capítulo 2. Ainda neste capítulo, o papel estratégico das medidas de saúde, os sistemas de informações em saúde com seus limites e potencialidades e, da macro-unidade de análise são expostos seus contrastes socioeconômicos e de vulnerabilidade social.

Descrever o padrão de mortalidade em estratos homogêneos de vulnerabilidade social conformados por municípios do Estado de São Paulo no triênio 2003-2005 e seus objetivos específicos compõem o Capítulo 4. 0 Material e Método utilizado para o alcance dos objetivos, incluindo a construção dos estratos homogêneos de vulnerabilidade social, medidas, indicadores selecionados e metodologia de análise conformam o Capitulo 5.

Nos Resultados e Discussão inicialmente são apresentados a conformação dos estratos de vulnerabilidade social e suas características demográficas. Como indicador de qualidade dos sistemas de informação sobre mortalidade foi apresentado à proporção de mortes por Causas Mal Definidas. 0 estudo da mortalidade nos estratos homogêneos de vulnerabilidade social e seus diferenciais compreenderam a Mortalidade Infantil, a Mortalidade Materna, Doenças Infecciosas e Parasitárias, Doenças Respiratórias, Doenças do Aparelho Circulatório, Diabetes Mellitus, Neoplasias, Acidentes de Transporte e Homicídios com taxas brutas e padronizadas para mortalidade (total e segundo sexo), à exceção da mortalidade infantil e materna. Os diferenciais de mortalidade, sua magnitude e distribuição espacial nos respectivos estratos de vulnerabilidade social conformando o padrão de mortalidade no Estado de São Paulo compõem o Capitulo 6. No Capitulo 7, são tecidas as considerações finais e, apontados os limites do estudo. 


\section{INTRODUÇÃO}

\subsection{TEMÁTICA E DELIMITAÇÃO DO ESTUDO}

Dados de mortalidade têm sido usados para compreender a complexidade dos fenômenos que envolvem a saúde e contribuir para a tomada de decisão em políticas de saúde. No século XX, desde as décadas de 50 e 60 na América Latina, inúmeros estudos vêm enfatizando as relações entre níveis de saúde e fatores sócio-econômicos, com especial ênfase no debate sobre saúde e desenvolvimento. No Brasil, reflexões teóricas em busca de referenciais mais adequados, identificação de fatores associados à alteração do perfil de morbimortalidade vêm ocupando o centro dos debates em universidades, congressos e órgãos públicos buscando contribuir para a reorientação das investigações para a análise da situação de saúde segundo condições de vida (PAHO, 1994).

Desigualdades sócio-espaciais no padrão de morbimortalidade de grupos populacionais têm sido reiteradas por vários estudos (BORREL 1997; SILVA e cols. 1999; DRUMOND JR \& BARROS 1999; BARRADAS 2005; BEZERRA FILHO e cols. 2007). As determinações sociais do processo saúde-doença revigoraram-se no campo da Epidemiologia sob a influência das transformações sociais ocorridas a partir da segunda metade do século XX, caracterizados pela emergência dos movimentos políticos, da luta pelos direitos civis, do fortalecimento da perspectiva crítica, da valorização do contexto sócio-cultural e político na determinação dos comportamentos humanos (BARRADAS, 2005)

Deste período, emerge também o conceito de formação socioespacial proposto por SANTOS (1978) no qual "as noções de totalidade e de estrutura, da universal e da particular, devem ser unificadas em um mesmo movimento conjunto, no qual a sociedade é reconhecida em seu diálogo com a natureza transformadora, não apenas como agente transformador, mas também como um dos seus resultados" (SANTOS, 1978 p.195). 
O espaço é a ação da sociedade sobre a natureza e deste modo, essa sociedade produz o lugar dos ricos, dos pobres, da indústria, como também estabelece fluxos de circulação de bens e serviços gerando desigualdades que, quando conjugadas com carência de serviços públicos, pobreza e baixo nível de escolaridade promovem iniqüidades. Por sua vez, o espaço produzido socialmente exerce pressões econômicas e políticas sobre esta sociedade, criando condições diferenciadas na sua utilização por grupos sociais e, atuando na segregação sócio-espacial dessa sociedade. Deste modo, um mecanismo de causação circular é gerado, em que o espaço é ao mesmo tempo produto e produtor de diferenciações sociais, expressando-se nas condições de saúde dos grupos envolvidos (BARCELLOS \& BASTOS, 1996).

Assume papel estratégico, investimentos acadêmicos e na gestão pública, para o aprimoramento da produção, análise e disseminação de informações epidemiológicas, espaciais, populacionais, socioeconômicas e de condições de vida entre outras, com ênfase em procedimentos que possibilitem o uso multisetorial e interdisciplinar (BARCELLOS \& BASTOS, 1996). Além do subsídio ao planejamento e monitoramento das políticas de saúde, estudos que consideram diferenciais sócio-espaciais são fundamentais para a compreensão e análises mais substantivas sobre riscos coletivos e, subsidiam o desenvolvimento de intervenções com abordagens mais sistêmicas no campo da saúde.

Assim a temática no desenvolvimento deste estudo foi norteada por duas motivações: a primeira no campo dos saberes - dado que a literatura científica relata amplamente lacunas existentes no desenvolvimento conceitual e metodológico do uso de informações para subsidiar o planejamento, o monitoramento e análise da situação de saúde (ALMEIDA FILHO \& ROUQUARYOL 2002; RIPSA 2002).

A segunda, no campo das práticas - referendadas por órgãos nacionais e internacionais de Saúde Publica que registram amplamente a insuficiência de iniciativas organizativas e financiadoras visando institucionalizar práticas para o processamento, uso e análise de informações como subsídio à formulação, implantação e avaliação das políticas de saúde (PAHO 1994; RIPSA 2002). 
Este estudo parte-se da hipótese que agregados populacionais com diferentes gradientes de vulnerabilidade social apontarão para diferentes gradientes de mortalidade. Nessa perspectiva, conhecer a distribuição espacial da mortalidade e sua magnitude, conjugada à identificação destes territórios apresenta-se como informação de relevância à formulação de políticas de saúde mais equitativas.

\section{REFERENCIAIS TEÓRICOS}

\section{CONDIÇÕES DE VIDA E MORTALIDADE}

As relações entre classes sociais, condições de vida e situação de saúde são encontradas em registros desde a Antiguidade, porém, foi a partir do século XVIII, com o surgimento da Medicina Social que o tema sistematicamente assumiu caráter investigativo. Em 1741, em algumas freguesias de Londres a mortalidade de crianças chegou a variar entre 80 a 90\%, impulsionando a criação do Hospital dos Enjeitados de Londres, fruto do reconhecimento do maior risco das crianças pobres (ROSEN, 1994).

Datam ainda de 1828, os estudos pioneiros sobre diferenciais de mortalidade de Villermé, demonstrando as distintas taxas de mortalidade nos bairros de Paris e suas classes sociais. John Simon, médico da Grã-Bretanha no período de 1858 a 1871 investigou condições de saúde da comunidade e, incluindo condições de moradia, número de moradores e escassez de recursos relatou a influência das péssimas condições sociais na saúde. A industrialização, a urbanização, o êxodo rural, as migrações e os processos sociais advindos desses fenômenos, a miséria e os graves problemas de saúde tornaram-se assim objetos de investigação sobre suas interações com processo saúde-doença das comunidades (ROSEN, 1994).

Com o advento da era bacteriológica, onde a unicausalidade etiológica assumiu a centralidade hegemônica das investigações, a relevância dos fatores sociais na gênese e na evolução dos problemas de saúde assumiu caráter 
secundário ou até mesmo ignorado, até o ressurgimento da Medicina Social no século XX nos Estados Unidos e Inglaterra, dada à insuficiência do modelo explicativo unicausal na determinação do processo saúde doença e, frente à emergência da morbidade moderna (ROSEN, 1994).

A partir das evidências das diferenças de morbimortalidade entre as classes sociais e, reconhecendo os problemas conceituais e metodológicos existentes na sua operacionalização, PAIM (1997) cita o modelo de determinação proposto por Possas, onde a autora faz uma hierarquia de causas utilizando-se das categorias trabalho e modo de vida, como mediadoras do conceito de classe social. Neste modelo, a inserção socioeconômica (ou sua exclusão) dos indivíduos na produção capitalista conforma as classes sociais e suas distintas frações, bem como a um dado modo de vida. Ou seja, a venda da força de trabalho por uma remuneração influencia o seu modo de vida que se decompõe analiticamente em condições de vida, garantidas por esta remuneração, ou por políticas públicas que asseguram a distribuição dos bens de consumo coletivo e, em estilo de vida, enquanto conjunto de comportamentos, atitudes, hábitos entre outros POSSAS ${ }^{1}$ apud PAIM (1997, p.10).

Deste modo, o perfil epidemiológico de uma população, enquanto componente da situação de saúde, é determinado de um lado pela estrutura de produção (processo e condições de trabalho) e, por outro pela estrutura de consumo (modo de vida) que a depender da remuneração auferida conforma as condições e o estilo de vida. E pela estrutura de consumo (modo de vida), conformam-se as condições e o estilo de vida, a depender da remuneração auferida (PAIM, 1997).

CASTELLANOS (1997) acrescenta-se ainda ao modelo proposto, a organização dos serviços de saúde e, a instância político-ideológica da estrutura social. 0 primeiro, porque a participação no mercado de trabalho pode ampliar o acesso aos serviços de saúde e, procedimentos deles derivados não ficando o

POSSAS, C - Epidemiologia e sociedade. Heterogeneidade Estrutural e Saúde no Brasil. São Paulo: HUCITEC, 1989 
indivíduo a mercê de políticas públicas. 0 segundo, partindo da premissa que a reprodução social não se realizaria apenas na infra-estrutura econômica, ou seja, atravessa todo o edifício social pela intervenção do Estado através das políticas publicas. E as instâncias político- ideológicas, nos níveis de consciência e de organização de classes para a produção de certas condições de vida.

Nessa perspectiva, o estudo das condições de vida e de determinados grupos sociais não inclui somente a distribuição de renda e o poder aquisitivo na esfera individual, mas também as ações estatais das políticas públicas no campo coletivo, ressaltando que o processo de reprodução da sociedade em um momento histórico e em determinadas condições sociais também influenciam as condições de vida de sua população (CASTELLANOS, 1997).

As relações existentes entre os contextos sociais, culturais, ambientais, econômicos e a saúde são complexas e não suficientemente conhecidas e, os fenômenos desta interação (ambiente macro-social e funcionamento biológico do corpo) temporalmente podem ser de curto prazo (alguns segundos) a várias dezenas de anos e, continuamente interativo, (CONTANDRIOPOULOS, 1998).

A despeito dos progressos da medicina e do crescimento de recursos destinados aos sistemas de saúde nos países desenvolvidos, melhorias no estado da saúde da população não vêm ocorrendo na mesma proporção. As influências das características contextuais como status social, educação, ocupação, ambiente durante a infância e suporte social entre outros, já foram evidenciadas e reconhecidas por diversos autores. É fato amplamente reconhecido que o ser biológico e o ser psicossocial interagem, porém, ainda não se compreende como mente, corpo e contexto social, em seu sentido mais amplo e, em toda sua complexidade agem sobre os indivíduos para melhorar sua saúde. De um lado há as relações entre o ambiente físico que estão na origem dos riscos ambientais e, de outro lado, o ambiente social interagindo sistemicamente (CONTANDRIOPOULOS, 1998).

A interação entre valores culturais e sua organização, em relação à estrutura econômica, política e nível de desenvolvimento de tecnologia de uma maneira geral é a origem da maior ou menor prosperidade numa sociedade. Dela advém a organização social, mecanismos de redistribuição de riquezas e a 
estrutura ocupacional que influenciam diretamente sobre o conjunto de fatores que afetam à saúde. São as condições de vida que se materializam pelas condições de acesso aos distintos bens e serviços consumidos pelas pessoas. Por outro lado, há o sistema de atenção à saúde, cujo efeito sobre a saúde será expresso pela acessibilidade e eficácia dos serviços (preventivos, diagnósticos, curativos e/ ou paliativos) oferecidos, ou seja, pela sua capacidade em curar, manter ou aumentar a competência funcional das pessoas, contribuindo assim para a sua saúde. A aparição da doença mobiliza os recursos do sistema de cuidados assistenciais e todo um ciclo de utilização de serviços de saúde se instaura até que a pessoa recupere a saúde ou parte dela, ou ocorra o óbito (CONTANDRIOPOULOS, 1998).

O sistema assistencial por sua vez obedece a uma lógica que é ditada pelos conhecimentos existentes sobre o funcionamento biológico do corpo, sendo relativamente independente do sistema de saúde em seu sentido mais amplo e não pode certamente ser tido como o responsável pelo nível da saúde da população e das desigualdades de saúde entre diferentes grupos de uma dada população. À medida que a saúde e o tratamento das doenças são considerados como direitos, cabe ao Estado agir levando em conta o bem coletivo e na sua capacidade de implantar e fazer funcionar dispositivos equitativos e eficientes da distribuição de recursos (CONTANDRIOPOULOS 1998).

\subsection{DESIGUALDADES E INIQÜIDADES}

HOUAISS (1997) define igualdade como o princípio pela qual todos os cidadãos podem invocar o mesmo direito segundo o conceito de cidadania. Igualdade corresponde à justiça, à equidade, relação entre os indivíduos em virtude dos quais todos são portadores dos mesmos direitos fundamentais que provêm da humanidade e da dignidade humana. Um sistema igualitário é aquele que preconiza a igualdade de condições para todos os membros de uma sociedade. A Carta Magna brasileira adota esse conceito de igualdade ao 
reconhecer que "todos são iguais perante a lei, sem distinção de qualquer natureza" (C. F., art. 5ํㅜ, caput).

Por outro lado, a desigualdade é sinônimo de injustiça, iniqüidade, relações onde os direitos fundamentais são desrespeitados e a dignidade ferida. Assim, diminuir desigualdades, diante da impossibilidade de eliminá-las, deve ser o objetivo central de toda política pública (VIANA e cols. 2001). E, entre os objetivos nacionais estão "erradicar a pobreza e a marginalização e reduzir as desigualdades sociais e regionais", bem como "promover o bem de todos sem preconceitos de origem, raça, sexo, cor, idade e quaisquer outras formas de discriminação" (C. F., art. 3ํㅗ III e IV).

Diferenças históricas e flagrantes entre as classes sociais mais abastadas e as mais desfavorecidas vêm progressivamente cedendo lugar às formas mais sutis de desigualdades nas sociedades modernas, onde a pobreza continua sendo fundamental na determinação dos diferenciais sociais. 0 principio da equidade reconhece que, os indivíduos são diferentes entre si e, portanto, merece tratamentos diferenciados, de modo a eliminar e, ou reduzir desigualdades (VIANA, e cols. 2001).

WEST \& CULLIS ${ }^{2}$ apud VIANA e cols. (2001 p.19) classificaram a equidade em dois tipos: a horizontal, tratamento igual para iguais que supõe o princípio da igualdade e, a vertical, tratamento desigual para desiguais que supõe que tratamentos iguais nem sempre são eqüitativos. Por outro lado, nem toda desigualdade constitui iniqüidade no sentido de injustiça, pois, a iniqüidade pode ser evitada, daí a sua importância para os tomadores de decisão.

CASTELLANOS (1997) denominou como desigualdades em saúde, aquelas que são redutíveis, isto é, desnecessárias, sendo as mesmas vinculadas às condições heterogêneas de vida. Para LORENZO (2006) o conceito de vulnerabilidade comporta um sentido de susceptibilidade, ou seja, características de exposição a um determinado risco por um evento externo qualquer que nos encontre em seu caminho, potencialmente causador de danos e de distintas naturezas. Estes podem ser desde fenômenos físicos como

\footnotetext{
${ }^{2}$ WEST, P. e CULLIS, J. Introducción a la Economía de la Salud. Oxford, 1979.
} 
tempestades e terremotos ou, como fenômenos sociais como a criminalidade e a violência, até fenômenos, onde o físico, o biológico e o social interagem sistemicamente como, por exemplo, a vulnerabilidade à fome e à doença.

Para LORENZO (2006) em saúde pública é consensual o reconhecimento de que os grupos com piores condições socioeconômicas apresentam uma maior carga de doença, tanto crônicas como agudas, maior carga de incapacidades físicas e mentais em idade mais precoce, sofrem maior número de acidentes domiciliares ou urbanos, têm menor acesso aos cuidados de saúde e, quando prestados detém menor qualidade. Assim, a redução da vulnerabilidade em saúde pública depende da formulação e implantação de políticas públicas equitativas com foco na redução das desigualdades sociais.

O reconhecimento do grau extremo e superável das desigualdades sociais expressas nos níveis de saúde, as disparidades sociais crescentes entre países e entre classes sociais e frações no interior de países e regiões e, especial a situação do Brasil quanto à elevada concentração de renda configura o monitoramento das iniqüidades sociais em saúde como um tema prioritário na formulação de políticas de saúde equitativas (MINISTÉRIO DA SAÚDE, 2002).

\section{3 - A CATEGORIA ESPAÇO}

"Who, Where e When" - os três W da língua inglesa questionam na epidemiologia o fenômeno saúde e doença conduzindo-a diretamente para a reflexão "lugar". De Hipócrates, com seus estudos "Dos Ares, Águas e Lugares" a John Snow, com os estudos sobre cólera nos distritos de Londres, aos tratados de geografia médica, os aspectos relacionados ao espaço permeiam a literatura sobre a ocorrência e a distribuição das doenças.

A princípio, de conotação apenas geográfica e, centrado apenas na valorização somente do ambiente físico, o conceito de lugar/espaço vem progressivamente incorporando os aspectos sociais na sua concepção. Com a geografia crítica de (SANTOS, 1980), o conceito espaço vem sendo utilizado na busca da compreensão das relações sociais como definidoras do padrão espacial de uma cidade onde os processos de urbanização e migrações são determinados 
pelo modo de produção econômica, ressaltando dois de seus aspectos: a paisagem, fruto da estrutura técnico-produtivo e lugar de fetichização e, outro a sociedade total, a formação social que anima o espaço (PAIM, 1997).

A utilização de unidades territoriais nos estudos epidemiológicos remonta praticamente à sua gênese, sendo recente apenas, a incorporação da noção de território como espaço-população, como resultado da interação de populações nos seus múltiplos processos físicos e sociais. Estudos qualitativos vêm evidenciando a importância das interações da etnografia e cultura nas condições de saúde de populações e, de estudos sobre reprodução social como modelo explicativo das condições de vida e perfis de saúde das populações e, da organização territorial conformar-se como objeto de intervenções e políticas públicas (BARCELLOS e cols. 1996; PAIM 1997; SILVA e cols.1999).

Se cada classe ou cada fração social possui condições de vida específicas decorrentes dos rendimentos auferidos que permitem sua configuração em estratos e, seu acesso aos bens de consumo coletivos, originários das políticas públicas é possível também usá-las na mediação dos determinantes estruturais segundo o marco conceitual proposto por POSSAS (1990). Deste modo, se grupos humanos estão dispostos em diferentes espaços de um mesmo território torna-se factível uma aproximação da realidade através de variáveis e indicadores selecionados, sem minimizar ou reduzir sua complexidade.

A multidimensionalidade das relações de agentes ou grupo de agentes que desfrutam de posições relativas em função dos distintos tipos de poder e de capital caracteriza o espaço social. BOURDIEU (1989) classificou-os como capital econômico, cultural, social e simbólico que conforma a posição de cada agente ou grupo.

PAIM e cols. (1997) afirmam que parte significativa do processo saúdedoença pode ser compreendida como resultante das posições ocupadas pelos agentes e/ou grupos no espaço social. E dependendo dessa inserção decorre à exposição aos distintos riscos à saúde. 0 tipo e a quantidade de capital acumulado conformam o acesso ao saber (no aspecto cognitivo) sobre riscos de adoecer e aos mecanismos de prevenção. O capital econômico conforma o acesso ao cuidado e às condições de vida potencializando o enfrentamento (melhor ou 
pior) do processo de adoecimento. E por fim, o capital simbólico conforma a dimensão subjetiva da satisfação das pessoas com o modo de andar a vida.

PAIM (1997) afirma que orientar políticas públicas, validar certas estratificações do espaço urbano segundo condições de vida, discriminar grupos relativamente homogêneos da população, visando o monitoramento da deterioração ou melhoria das condições de vida, importam mais do que as simples demonstrações de relações causais, pois tais análises podem ser impulsionadoras de políticas públicas saudáveis e eqüitativas contribuindo para a redução de desigualdades e melhoria da qualidade de vida e saúde das populações. À medida que o conceito de território ou de espaço conforma o loccus físico, natural, histórico e social das populações, essa categoria passa então a ser a alternativa de eleição teórico-metodológico de proxy para as condições de vida, mediando assim os determinantes estruturais e a situação de saúde.

\subsection{DELINEAMENTOS DE ESTUDOS}

Das teorias e estudos epidemiológicos que dão ênfase às relações entre os problemas de saúde das comunidades e condições de vida, Durkeim com seu célebre trabalho sobre freqüência e distribuição de suicídios entre católicos e protestantes em 1973, pode ser citado como pioneiro na articulação e no desenho de dados agregados. Na década de 30, pesquisadores da Escola de Chicago Park, como Faris e Duham já vinham aperfeiçoando desenhos de análise de dados agregados aplicando-os às questões de saúde (ALMEIDA FILHO \& ROUQUARYOL, 1998).

No estudo da saúde e doença das populações humanas, não se trata apenas de um conjunto de indivíduos, mas sim de agrupamentos de sub-populações que interagem entre si como sistemas complexos e hierárquicos que não podem ser decompostos. Ainda que existam muitas formas de agrupamento de indivíduos e populações, a abordagem individual distingue-se da populacional ao mesmo tempo em que se inter-relacionam entre si e inclusive se superpõem. A diferença não se dá pelo número de pessoas estudadas, mas pelo nível dos 
problemas e fenômenos populacionais pelos quais os estudos são abordados e, que condicionam à definiçãao dos problemas, as categorias e variáveis, os indicadores, a inferência e, conseqüentemente a respectiva análise. A organização do ser humano em sistemas e aparelhos e, estes por sua vez em moléculas e átomos tornam tais hierarquias familiares no campo da saúde (CASTELLANOS 1997).

Numa perspectiva sistêmica, o mundo real é constituído de sistemas abertos, em níveis que incluem uns aos outros de modo quase infinito e, do ponto de vista da investigação científica, traz repercussões importantes, pois qualquer fenômeno que seja objeto de estudo encontra-se afetado pelas interações que ocorrem entre os níveis acima e abaixo desta hierarquia, com distintas intensidades e repercussões (CASTELLANOS 1997).

As variações de intensidade e freqüência produzem repercussões sobre o fenômeno, sendo que as de alta freqüência e intensidade produzem variações de curto prazo e, as de baixa freqüência têm repercussão, na maioria das vezes, a longo prazo. Independentemente do nível de abordagem, as variações de alta intensidade e freqüência vinculam-se aos níveis hierárquicos inferiores e, as de baixa intensidade e freqüência costumam corresponder aos níveis superiores. Nos níveis sistêmicos, à medida que se distancia para outros níveis, sejam inferiores ou superiores, as variações de freqüência podem tornar-se tão tênues que para determinados fenômenos, a não ser pela interação, podem se tornar ou não irrelevantes para o fenômeno em foco (CASTELLANOS, 1997).

O recorte do estudo é que dará a relevância a determinados aspectos de cada nível ou, da interação entre os níveis e intra-nível, pois os sistemas podem ser decompostos de múltiplas maneiras. As variáveis do nível de abordagem, bem como aquelas imediatamente superiores e inferiores normalmente são as mais relevantes às quais são denominadas comumente estruturais, contextuais e analíticas (CASTELLANOS, 1997).

Citando SAMAJA ${ }^{3}$ (1993 p. 57) este autor lembra ainda que tais aspectos não sejam características destas, mas sim do nível de abordagem, apontando três estratégias distintas de investigação: a primeira, enquanto objeto em si mesmo, onde a relevância está nas suas qualidades (comportamentos) 
emergentes, que lhe são próprias. A segunda, enquanto composto por sistemas de menor nível, onde o importante são as formas de interação dessas unidades menores, que possibilitam a aparição das qualidades emergentes. E, a terceira, enquanto a unidade que faz parte de um sistema maior, onde o que interessa são suas interações com outras unidades do mesmo nível, que condicionam a forma como se realiza e expressa suas potencialidades de comportamento, não restando dúvidas que as três devam ser consideradas complementares dos resultados.

CASTELLANOS (1997) afirma ainda que construir adequadamente as unidades de análise reveste-se de extrema importância, pois reconhecer que cada nível de organização corresponde a um domínio de realidade, governado por princípios e leis deste nível (mesmo quando os processos estão conservados, subordinados e governados por princípios e leis de níveis inferiores). Ao definir o nível de abordagem e as unidades de análise, estar-se-á definindo o âmbito de princípios e leis nelas dominantes que, junto ao acaso, apresentarão a maior potência explicativa com relação aos fenômenos deste nível, tantos nos processos ascendentes como nos descendentes que, à medida que nos afastamos do nível de abordagem específica vai sendo diminuída.

\section{5 - ESTUDOS DE MODELO ECOLÓGICO}

Unidades operativas que tomam o agregado como objeto de estudo, os chamados estudos ecológicos, possibilitam diversas arquiteturas a depender do delineamento metodológico proposto. Tais estudos abordam áreas geográficas investigações de base territorial ou grupos de populações delimitadas - estudos de agregados institucionais, analisando comparativamente variáveis globais, na sua maioria, por meio da correlação entre indicadores de condições de vida e indicadores de situação de saúde. Os estudos de base territorial baseiam-se

\footnotetext{
3 SAMAJA, J - Epistemología y Metodologia. Elementos para una Teoria de la Investigación Científica. 1.2d. Buenos Aires: EUDEBA, 1993
} 
numa referência geográfica para a definição das unidades de informação como distrito, município, estado, regiões, país entre outros. Os de base institucional tomam organizações coletivas de qualquer referência como unidade de informação a exemplo de hospitais, unidades de saúde, escolas e indústrias (ALMEIDA FILHO \& ROUQUARYOL, 2002).

Estudos classificados como agregados observacionais podem ser transversais ou longitudinais. Os primeiros são aqueles chamados senso estrito e, os longitudinais se subdividem em: estudos de tendências ou séries temporais, estudos de caso controle de agregados e estudos de coorte de agregados. Falam a favor destes estudos a facilidade de execução, o baixo custo relativo, a simplicidade analítica e a capacidade de testar hipóteses. Na contramão, tais estudos são afetados pelo pouco desenvolvimento das técnicas de análise de dados e, a vulnerabilidade à falácia ecológica. Os diagramas, a evolução dos indicadores e análises de correlação (uni e multivariadas) tem sido eleita como as principais formas de análise nesses estudos, destacando-se um relativo atraso no desenvolvimento de técnicas analíticas adequados a desenhos ecológicos ou agregados (ALMEIDA FILHO \& ROUQUARYOL, 2002).

A chamada falácia ecológica (LILIENFELD \& LILIENFELD 1980; ALMEIDA FILHO \& ROUQUAYROL 2002) trata do erro cometido na inferência do risco individual, com base em informações correspondentes aos grupos ou à população. Baseia-se na argumentação que, os estudos ecológicos têm pouca abrangência para avaliar hipóteses de risco, pois as correlações entre grupos nem sempre existem ou se comportam de forma semelhante ou linear em nível individual, devido a uma variação dos riscos individuais no interior de cada unidade ou população, cabendo tal tarefa aos estudos de base individual que, se utilizam de grupos de indivíduos com a menor variação possível entre eles, em termo de exposição a fatores e processos de risco.

Os chamados estudos epidemiológicos sobre saúde de populações exigem o desenvolvimento de procedimentos adequados visando garantir a "coerência de nível", articulando variáveis de diferentes níveis sem violentar a especificidade de cada nível (cross nível bias). Em essência, esse tipo de viés (bias) ocorre quando uma variável preditiva ecológica é utilizada para analisar o 
comportamento de uma variável em nível individual. De relevância também é que, na maioria das vezes as variáveis de grupo são consideradas variáveis de confusão, exigindo controle no desenho do estudo, sob pena de comprometer a validade das associações encontradas. No entanto, estudos ecológicos são úteis para a geração de hipóteses causais e avaliar a efetividade das intervenções em populações (MORGENSTERN, 1982).

Estudos sobre a relação entre exposição à doença nos níveis individuais e coletivos de GREELAND \& MORGENSTERN (1992) classificaram em três componentes o coeficiente de correlação no nível ecológico os efeitos individuais, confoundings e efeitos de modificação. SCHWARTZ (1994) apontou três noções inter-relacionadas baseando-se na validade dos estudos epidemiológicos ao comentar sobre falácia ecológica: maior especificidade dos modelos de estudos individuais do que os ecológicos, as correlações ecológicas são substitutas das individuais (ou seja, quando não se podem realizar os individuais realizam-se os de grupo), variáveis de grupo não são causais (não causam doenças).

Informações de registros e dados secundários (considerados menos específicos e depurados) não inerentes aos estudos ecológicos, mas de uso freqüente neste tipo de estudo e, que apesar de suas limitações, devem ser vistos sob outro ângulo, ou seja, permitem o seu uso apesar das deficiências. 0 fato dos estudos individuais basearem-se em dados primários, ou seja, mais específicos, não lhes garantem menos viéses, porém ambos exigem a vigilância das variáveis de confusão. Os estudos ecológicos atuam em outra abordagem da realidade que não a dos indivíduos, ou seja, nenhum dos dois níveis possui capacidade absoluta de predição do comportamento de um indivíduo, mas ambos auxiliam a compreensão deste, por diferentes abordagens além do que, muitas das variáveis causais de problemas de saúde correspondem a níveis agregados e não individuais. Assim, estudos em nível individual possuem limitações para apreender a complexa dinâmica sistêmica, cabendo tal apreensão aos estudos ecológicos GREELAND \& MORGENSTEN (1992).

SUSSER (1994) argumenta que a ocorrência da falácia ecológica é possível em ambos os estudos podendo ocorrer em qualquer direção, ou seja, quando se 
fazem inferências individuais a partir de estudos de nível populacional e, quando se fazem inferências populacionais a partir de estudos individuais, contradizendo assim o mito da falácia ecológica associada unicamente a estudos ecológicos.

\subsection{AS MEDIDAS DE SAÚDE}

O desenvolvimento de indicadores de saúde busca facilitar a quantificação e a avaliação de dados de saúde podendo ser denominados medidas-síntese que contêm informação relevante sobre determinados atributos e dimensões do estado de saúde, bem como do desempenho do sistema de saúde que, em conjunto refletem a situação sanitária de uma população e apóia à vigilância à saúde.

Sua construção varia em complexidade partindo de um simples número absoluto até taxas ou índices mais sofisticados e, sua qualidade depende das propriedades dos componentes utilizados na sua formulação e da precisão dos sistemas de informações utilizados. Um conjunto de indicadores de saúde tem como propósito produzir evidência sobre a situação sanitária e suas tendências, inclusive documentando as desigualdades em saúde servindo de base empírica na identificação de grupos humanos com maiores necessidades de saúde, estratificação do risco epidemiológico e identificação de áreas críticas. Portanto, um conjunto de indicadores básicos além de prover matéria prima essencial para o conhecimento da situação de saúde de uma população, tende a facilitar o monitoramento de objetivos e metas das políticas de saúde, estimular o fortalecimento da capacidade analítica dos profissionais e equipes de saúde e, ainda promover o desenvolvimento de sistemas de informação de saúde intercomunicados (RIPSA 2002, 2008).

Numa perspectiva histórica, coube aos dados sobre mortalidade a construção dos primeiros indicadores de saúde. Sua legitimidade, validade e extensão de uso datam dos séculos XVI e XVII, muito antes do desenvolvimento do conceito de Saúde Pública. A relevância das informações sobre óbitos no conjunto de medidas de saúde ampliaram o espectro de abordagens, além das já 
consolidadas. Conceitos de morte precoce ou prematura, mortes evitáveis e mortes excessivas possibilitaram o desenvolvimento de indicadores como Anos Potenciais de Vida Perdidos, listas de mortes evitáveis, aplicação do SMR (standardized mortality ratio) na mensuração das diferenças de mortalidade que atingem populações ou subgrupos, entre outras (ALMEIDA FILHO \& ROUQUARYOL, 2002).

Indicadores de morbidade, co-morbidade, prevalência, incidência de doenças e lesões foram sendo construídos e aprimorados ao longo do tempo. Por sua vez, os indicadores compostos combinando mortalidade e morbidade, iluminam novas possibilidades de quantificação, da perda e da incapacitação produzidas por diferentes agravos e, a mensuração de fatores de risco (RIPSA 2002).

A capacidade de medir o que se pretende (a validade) pode ser julgada através da sensibilidade (medir as alterações do fenômeno eleito) ou da especificidade (medir somente o fenômeno eleito) e, de reprodução dos mesmos resultados nas mesmas condições (confiabilidade) são atributos que conferem status de excelência à medida. Importam ainda, dentro de suas características também a mensurabilidade (basear-se em dados disponíveis ou de fácil obtenção), a relevância (responder as prioridades de saúde) e, o custoefetividade (os resultados justificam o investimento de tempo e recursos). Integridade (dados completos) e consistência interna (valores coerentes e não contraditórios) estão entre os principais atributos de qualidade de uma medida (RIPSA, 2002).

A aplicação sistemática de definições operacionais e de procedimentos padronizados de medição e cálculo, os níveis de desagregação dos indicadores, a simplicidade de instrumentos e métodos utilizados são fatores que elevam a qualidade e a comparabilidade dos indicadores de saúde que, associados a uma política de disseminação da informação efetiva, dinâmica e oportuna, constituem-se em ferramenta estratégica para a gestão e a avaliação de saúde em todos os seus níveis. 


\subsection{INFORMAÇÕES EM SAÚDE}

No Brasil, a produção, utilização e disseminação de informações de saúde atualmente inserem-se num complexo de relações institucionais permeadas por vários mecanismos de financiamento e gestão. Entre os órgãos governamentais estão os três níveis de gestão do Sistema Único de Saúde - SUS (Ministério da Saúde, Secretaria de Estado da Saúde e Secretaria Municipal de Saúde), o Instituto Brasileiro de Geografia e Estatística - IBGE, setores da administração pública dos diversos níveis de governo que produzem dados e informações de interesse para a saúde além de instituições de ensino e pesquisa; associações técnico-científicas, órgãos e conselhos de categorias profissionais e ainda, as organizações não governamentais, entre outras.

Avanços crescentes e expressivos obtidos nas últimas décadas no campo das informações de saúde derivadas da incorporação tecnológica para o seu desenvolvimento, processamento e disseminação, em especial a eletrônica dos dados e, conseqüentemente a maior disponibilidade de dados e informações de saúde vêm motivando sua crescente utilização, em especial pelas instâncias gestoras de saúde pública, mas ainda persiste o árduo desafio do melhor aproveitamento dessas informações (RIPSA, 2002).

A expansão do acesso, por si só, não tem influenciado o desenvolvimento qualitativo dos sistemas de informação e as análises orientadas para a gestão de políticas públicas de saúde. A necessidade de melhorar a articulação das instituições atuantes na área de informações e, da utilização mais efetiva do conhecimento acumulado tem sido um dos maiores desafios dos países em desenvolvimento. Objeto de atenção da Organização Pan-Americana da Saúde OPAS em 1995, através da Iniciativa Regional de Dados Básicos em Saúde em conjunto com o Ministério da Saúde culminou com a formalização da Rede Interagencial de Informações para a Saúde - RIPSA, em 1996 com o propósito de promover a disponibilidade adequada e oportuna de dados básicos, indicadores e análises sobre as condições de saúde e suas tendências e, aperfeiçoar a capacidade de formulação, gestão e avaliação de políticas e ações públicas (RIPSA, 2002). 
Os sistemas nacionais de informação em saúde, na sua maioria, gerenciados pelo Ministério da Saúde utilizam-se de registros contínuos coletados nas diversas instâncias dos serviços de saúde. Com o advento da tecnologia e, dos mecanismos de disseminação eletrônica, sua utilização tem sido cada vez maior tanto nos serviços como nas atividades acadêmicas, potencializando assim sua capacidade de análise e, estimulando o aprimoramento da cobertura e qualidade dos registros.

Por conseguinte, novas tecnologias vêm sendo absorvidas a exemplo dos sistemas de informações geográficas, recurso que permite aprimorar a análise das informações num contexto espacial integrando dados de diferentes fontes. As bibliotecas virtuais em Saúde Pública que, ampliam o acesso à literatura técnico-científica e, ao mesmo tempo incorporam o tratamento de informações numéricas e de documentos não convencionais, antes de difícil difusão por estarem restritos ao âmbito interno dos serviços, também tem contribuído para tais avanços.

Em que pese ainda o longo caminho a percorrer, tem sido significativos os avanços detectados no país nos últimos anos no desenvolvimento e aprimoramento dos sistemas de informações de base nacional, com expressiva elevação de cobertura e da qualidade dos dados originários nos diversos níveis de gestão. Outros aspectos vinculados a questões técnicas e/ou tecnológicas como integração de bases de dados, padronização de registros, plataformas, interoperabilidades, segurança, ética e sigilo, compatibilidade de grandes bancos de dados e vinculação entre bases, têm sido objeto de esforços nacionais, estaduais e municipais impulsionados pelo avanço das telecomunicações e da disponibilização dos dados e informações, principalmente via internet.

VIACAVA (2002) argumentou que não obstante os avanços obtidos nos Sistemas de Informações de Saúde de registros contínuos ainda há limitações, dado à sua especificidade e, a problemas relacionados à regularidade, cobertura e qualidade das informações que, são diretamente proporcionais ao segmento ou abrangência populacional estudada. RISI JR (2002), exemplificando tais limites, afirma que para estados da região Norte e Nordeste as estimativas das taxas de mortalidade infantil ainda são mais consistentes que as obtidas pelo 
cálculo direto. Para o país, a mortalidade materna, indicador importante para avaliação da qualidade dos serviços de saúde materno-infantil tem suas estimativas influenciadas pela sub-notificação e, para dados de morbidade, salvo para as doenças de notificação compulsória que são objetos de ações intensivas para seu controle ou eliminação, as dificuldades são ainda maiores.

A relevância do papel das estatísticas de saúde e, as necessidades de reformulação de suas bases, visando ampliar suas potencialidades no monitoramento das condições e do desempenho do sistema de saúde têm sido alvos de discussões técnicas e políticas em diversos países. VIACAVA (2002) agrupou-as em quatro grandes áreas: as vitais, a produção de serviços, a vigilância e monitoramento da situação de saúde e, por último as relacionadas aos recursos públicos e orçamento do sistema de saúde.

\subsection{O ESTADO DE SÃO PAULO E SEUS CONTRASTES}

O Estado de São Paulo é subdividido em 645 municípios, 42 regiões de governo, 14 regiões administrativas e três regiões metropolitanas - RM São Paulo, Baixada Santista e Campinas. A Secretaria de Estado da Saúde compõe-se de 18 departamentos regionais de saúde (DRS) e 28 grupos de vigilância à saúde - GVE (epidemiológica e sanitária).

As transformações socioeconômicas derivadas da industrialização nos últimos 50 anos demarcaram a atual concentração populacional no Estado, que de início favoreceu a RM São Paulo e municípios circunvizinhos. Num processo posterior de desconcentração industrial em direção ao interior, as regiões situadas no centro e leste do Estado como: Campinas, S. J. Campos e Santos, em especial aquelas localizadas nos grandes eixos da malha viária de ligação com a capital pelas rodovias Bandeirantes e Anhangüera, Presidente Dutra e Carvalho Pinto, Castelo Branco, Raposo Tavares, Washington Luís e Fernão Dias foram as mais beneficiadas.

Dados do Atlas SEADE da Economia Paulista (2007) indicaram que a Região Metropolitana de São Paulo manteve-se liderando a concentração populacional e o desenvolvimento econômico paulista com $47,9 \%$ da população, 
seguida das regiões administrativas de Campinas (14,6\%), Sorocaba $(6,7 \%)$, S.J. Campos $(5,4 \%)$ e a da Baixada Santista (4,0\%). No oeste do Estado destacam-se S.J. Rio Preto (3,5\%) Barretos (1,1\%) e Registro (0,7) em 2005.

A distribuição populacional mostrou ainda que 81,2\% dos municípios possuíam até 50 mil habitantes e concentravam 17,4\% da população. Os demais, $18,8 \%$ alocavam $82,6 \%$ da população. São Paulo, Guarulhos, Campinas e São Bernardo do Campo superaram a marca de um milhão, enquanto outros seis municípios ultrapassaram 500 mil habitantes: Osasco, Santo André, S.J. Campos, Sorocaba e Ribeirão Preto. A ocupação territorial também mostrou seus contrastes: a densidade demográfica da RM São Paulo alcançou 2.376,2 hab./ $\mathrm{km}^{2}$ enquanto a região de Registro 23,6 hab. $/ \mathrm{km}^{2}$.

O Estado destacou-se ainda pela acentuada concentração da população nas áreas urbanas. De 44,1\% em 1940, seguiu tendência crescente, elevando-se para 80,3\% em 1970 e, no ano de 2005 projeções indicaram 37 milhões de hab. residentes em áreas urbanas, um grau de urbanização de 93,7\%. Em 38\% dos municípios (244), a população urbana atingiu níveis superiores a 90\%, sendo a liderança, da Baixada Santista com 99,6\%. Somente a região administrativa de Registro permaneceu com grau de urbanização inferior a 70\%.

A taxa de crescimento populacional também tem sido maior que a média nacional. Na década de 50, cresceu 3,6\% ao ano e, gradativamente foi reduzindo o ritmo de crescimento alcançando 1,8\% na década de 90 . Em 2005, apresentou incremento populacional de 1,6\%. Isto provavelmente é reflexo da atração exercida pelo Estado, dada a sua alta concentração de atividades produtivas e capacidade de geração de renda. 0 país nestes mesmos períodos alcançou 3,2\%, $1,6 \%$ e $1,4 \%$ respectivamente.

Internamente, o crescimento populacional também mostrou diferenças. No período 1991-2005, taxas negativas superiores a 3\% ao ano ocorreram em 101 municípios reduzindo para 69 municípios no período de 2000-2005. Estes se localizavam em sua maioria, na região oeste do Estado. Por outro lado, taxas mais elevadas, concentraram-se no leste paulista, áreas de maior dinamismo econômico e concentração urbana. 
A composição da população por sexo mostrou 96 homens para cada 100 mulheres, dos quais 63\% dos municípios (406) apresentaram razão de sexo inferior a 100. Economicamente o Estado caracteriza-se como o espaço mais integrado e desenvolvido da federação, por possuir cadeias industriais completas e conseqüentemente concentrando os mais modernos e significativos segmentos dos setores de serviços, construção civil e comércio de mercadorias.

No ano de 2003, o Estado respondeu por cerca de $41 \%$ do produto industrial do Brasil. Setorialmente, a indústria paulista respondeu por $64,8 \%$ da produção nos segmentos de material de transportes; 58,7\% de edição e gráfica, $57,2 \%$ de química; $56,7 \%$ de mecânica; $56,0 \%$ de eletrodomésticos e, 55,8\% de material eletroeletrônico e equipamentos de comunicação. Localização estratégica, boa infra-estrutura, mão-de-obra qualificada e, maior mercado consumidor do país são fatores que conjugados fundamentam a pujança, desenvolvimento e posição de destaque do Estado, no cenário nacional (FSEADE, 2005).

\subsubsection{As Medidas dos Contrastes}

O Índice de Desenvolvimento Humano - IDH, é um indicador composto desenvolvido pelo Programa das Nações Unidas para o Desenvolvimento PNUD. 0 índice foi desenvolvido em 1990 pelo economista paquistanês Mahbub ul Haq e, vem sendo usado desde 1993 pelo Programa das Nações Unidas para o Desenvolvimento no seu relatório anual. Composto a partir de indicadores de educação (alfabetização e taxa de matrícula escolar), longevidade (esperança de vida ao nascer) e renda (PIB per capita), o índice varia de zero (nenhum desenvolvimento) a 1 (desenvolvimento alto). Países com IDH até 0, 499 têm desenvolvimento humano considerado baixo; com índices entre 0, 500 e 0, 799 são considerados de médio desenvolvimento humano e, países com IDH maior que 0800 têm desenvolvimento humano considerado alto (PNUD, 2006).

Nos últimos nove anos (1991-2000) o país, melhorou sua posição no IDH passando de 0,709 para 0, 769. O Estado de São Paulo evoluiu de 0,773 para 0, 814 destacando-se os cinco municípios mais bem posicionados: São Caetano do 
Sul $(0,919)$, Água de São Pedro (0, 908), Santos (0, 871), Vinhedo $(0,857)$, Jundiaí (0 857). Os cinco com menores índices foram: Itapirapuã Paulista (0, 645), Barra do Chapéu $(0,646)$, Ribeirão Branco $(0,649)$, Itaóca $(0,65)$ e Barra do Turvo $(0,663)$. Em 2005, o Estado já se posicionava com IDH de 0,833 se colocando atrás, apenas de Santa Catarina e Distrito Federal (PNUD,2006).

Por sua vez, o órgão paulista da Secretaria de Planejamento e Governo do Estado de São Paulo, a Fundação Sistema Estadual de Análises Dados - FSEADE desenvolveu um indicador sintético composto pelas dimensões: longevidade, escolaridade e riqueza denominado Índice Paulista de Responsabilidade Social IPRS, já na sua terceira edição.

Este indicador também apontou para aumento expressivo da escolaridade em 2004 no Estado, decorrente principalmente da ampliação da cobertura da educação infantil e da conclusão do ensino fundamental entre os adolescentes de 15 a 17 anos. Os jovens de 15 a 17 anos com ensino fundamental completo mantiveram-se estáveis de 68,1\% para 68,3\%; aqueles com pelo menos quatro anos de estudo aumentaram de 94,5\% para 98,0\%. A participação de jovens de 18 e 19 anos com ensino médio completo oscilou de 37,8\% para 37,6\% e, a proporção de crianças de cinco e seis anos freqüentando a pré-escola aumentou de 75,1\% para 77,0\% (FSEADE, 2006).

Com exceção de Araçatuba, todas as demais regiões administrativas apresentaram ganhos no indicador de escolaridade. As regiões com desempenhos mais elevados foram Sorocaba, Franca, Registro, Marília e Presidente Prudente. A região de Araçatuba manteve-se no topo apesar de registrar estabilidade em relação a 2002 (FSEADE, 2006).

As melhorias expressivas para a dimensão longevidade teve entre seus contribuintes o decréscimo contínuo da mortalidade infantil nas ultimas décadas, além da redução de 15,3 para $14,2 \%$ nascidos vivos no período de 2002-2004 com destaque para o declínio da região de Registro de 17,1 para 14,4\%0 nascidos vivos (FSEADE, 2006).

Associa-se ainda a queda da mortalidade de pessoas entre 15 e 39 anos com a redução de 2,0 para 1,7 óbitos (por mil habitantes) destacando-se a RM de São Paulo e região da Baixada Santista, ambas com redução de 6\% em 
relação a 2002. Porém, mesmo com a evolução citada a Baixada Santista ainda ocupa o posto de pior região neste indicador enquanto as regiões de Ribeirão Preto e S.J.Rio Preto ocupam os primeiros lugares para este indicador, respectivamente (FSEADE, 2006).

Na dimensão riqueza destacou-se a RM da Baixada Santista, seguida da RM de São Paulo e, São Jose dos Campos. As regiões dos eixos da malha rodoviária Anhanguera e Presidente Dutra em direção a Capital foram as que mais se destacaram. Porem, houve progressos em todas as regiões com exceção da região de Presidente Prudente que se manteve estável. As que obtiveram menor desempenho foram as regiões de Marília, Presidente Prudente e Registro, respectivamente (FSEADE, 2006).

A concentração dos maiores níveis de riqueza se dá nos dois eixos que acompanham as principais rodovias e culminam com a Capital, compondo-se dos maiores municípios e sedes das regiões metropolitanas com os municípios classificados segundo a tipologia do IPRS: Grupo 1 - Municípios com índice elevado de riqueza e bons níveis nos indicadores sociais e, a RM da Baixada Santista, o entorno metropolitano de São Paulo e Campinas no Grupo 2Municípios com níveis de riqueza elevados, mas indicadores sociais insatisfatórios.

Pequenos municípios e com baixos níveis de riqueza, mas com bons indicadores sociais concentram-se no noroeste do Estado, os pertencentes ao Grupo 3- Municípios com baixos níveis de riqueza, mas bons indicadores sociais. Dispersos pelo Estado situaram-se os municípios que não apresentaram padrão espacial definido pertencente ao Grupo 4 - Municípios com baixos níveis de riqueza e indicadores intermediários de longevidade e/ou escolaridade (FSEADE, 2006).

No Vale do Ribeira, Pontal do Paranapanema e parcialmente, a região da Serra da Bocaina abrigaram os municípios mais pobres, os do Grupo 5 Municípios desfavorecidos tanto em riqueza como nos indicadores sociais com piora das condições socioeconômicas do Pontal, tradicional bolsão de pobreza do Estado. Entre as melhorias identificadas pelo IPRS (2004) destacaram-se melhorias dos indicadores sociais do Vale do Ribeira. As regiões de Araçatuba e Presidente Prudente são as mais bem posicionadas na dimensão escolaridade, 
embora na dimensão riqueza estejam entre as quatro regiões mais pobres. A RM de São Paulo e a Baixada Santista situaram-se entre as melhores na dimensão riqueza, mas estão entre as seis regiões com menores indicadores de escolaridade e longevidade. A região de Ribeirão Preto é a primeira na dimensão longevidade e, a de S.J. Rio Preto está dentre as três melhores, nas dimensões longevidade e escolaridade (FSEADE 2006).

\subsubsection{A Medida da Vulnerabilidade Social}

Com o objetivo de propiciar o detalhamento e identificação das condições de vida dos municípios e respectiva localização espacial intra-urbanas das referidas áreas, a Fundação Sistema Estadual de Análises Dados - FSEADE em 2005, criou o Índice Paulista de Vulnerabilidade Social - IPVS.

Para a sua construção foram consideradas as múltiplas dimensões da pobreza expressa por indicadores de renda, escolaridade e ciclo familiar, tendo a segregação espacial como contribuinte para a permanência/reprodução dos padrões que os caracteriza. A operacionalização se deu a partir das características de indivíduos e famílias nela residentes detalhados por setor censitário com dados originários do Censo Demográfico IBGE - 2000 para o Estado de São Paulo (FSEADE 2005; FERREIRA e cols. 2006).

Utilizando-se de um modelo de análise fatorial foram sintetizadas oito variáveis compostas de duas dimensões: condições socioeconômicas e ciclo de vida das famílias. A primeira compôs-se da renda familiar e, a segunda, de variáveis relacionadas ao ciclo de vida familiar. Baixos níveis de renda caracterizaram situação de pobreza enquanto que, escassez de fontes de rendimentos seguros e regulares delimitou situações concretas de riscos à pobreza (expressas pelo desemprego ou inserção precária no mercado de trabalho). A renda familiar foi expressa pela renda do chefe da família enquanto o poder de geração e manutenção regular de renda foi medido pelo nível de escolaridade do chefe (anos de estudo), considerando que a baixa instrução de um indivíduo potencializa seu risco e dificulta melhor inserção no mercado de trabalho (FSEADE 2005; FERREIRA e cols, 2006). 
Na dimensão demográfica - o ciclo de vida das famílias foi expresso pela idade do responsável e a presença de crianças com idade até quatro anos. Mesmo sem relação direta, entre o ciclo de vida e pobreza, famílias jovens com filhos pequenos em condições cognitivas e econômicas precárias encontram-se mais expostas a riscos sociais que outras. Através da técnica de análise de agrupamentos os resultados produziram uma tipologia cuja categorização resultou na conformação de seis grupos (FSEADE 2005; FERREIRA e cols. 2006) demonstrados no Quadro 1e detalhadamente apresentados no Anexo Metodológico IPVS FSEADE -28 (2005).

Quadro 1 - Tipologia do Índice Paulista de Vulnerabilidade Social - IPVS FSEADE (2005).

\begin{tabular}{|c|c|c|c|}
\hline \multicolumn{3}{|c|}{ Dimensões } & \multirow{2}{*}{ Vulnerabilidade } \\
\hline Grupo & Socioeconômico & Ciclo de Vida Familiar & \\
\hline 1 & Muito Alta & Famílias Jovens, Adultas ou Idosas & Nenhuma \\
\hline 2 & Media ou Alta & Famílias Idosas & Muito Baixa \\
\hline 3 & $\begin{array}{c}\text { Alta } \\
\text { Media }\end{array}$ & $\begin{array}{l}\text { Famílias Jovens e Adultas } \\
\text { Famílias Adultas }\end{array}$ & Baixa \\
\hline 4 & Media & Famílias Jovens & Média \\
\hline 5 & Baixa & Famílias Adultas e Idosas & Alta \\
\hline 6 & Baixa & Famílias Jovens & Muito Alta \\
\hline
\end{tabular}

* Extraído de IPVS . FSEADE (2005); FERREIRA e cols. (2006)

Os resultados mostraram que as áreas consideradas como de nenhuma vulnerabilidade somaram cerca de 2,5 milhões de pessoas (6,9\%), as classificadas como de muito baixa vulnerabilidade somaram cerca de 8,6 milhões (23.3\%), as de baixa vulnerabilidade cerca de 8,2 milhões (22,2\%), as de média vulnerabilidade cerca de 7,5 milhões (20,2\%). As áreas de alta vulnerabilidade somaram em torno de 6,5 milhões e as de muito alta vulnerabilidade somaram 3,6 milhões $(9,8 \%)$ de pessoas, das quais cerca de um terço delas vivem em áreas rurais (FSEADE 2005; FERREIRA e cols. 2006).

Para os demais grupos os setores censitários urbanos alcançaram índices superiores a 90\%. Na distribuição por porte populacional do município, o IPVS refletiu a própria estratificação populacional do Estado. Aqueles com maior diversidade econômica (acima de 100 mil habitantes) apresentaram todos os seis níveis de vulnerabilidade, ressaltando, porém que são estes que contem as 
áreas mais ricas do Estado (nenhuma vulnerabilidade) indicando a grande concentração da riqueza gerada no Estado de São Paulo nessa categoria de municípios (FSEADE 2005; FERREIRA e cols. 2006).

Por outro lado, as áreas de vulnerabilidade muito alta também localizaram predominantemente, nos municípios de maior porte, refletindo as desigualdades existentes no interior dos grandes centros urbanos. O único grupo do IPVS que se diferenciou em termos de porte populacional foi o de vulnerabilidade alta, que concentrou municípios abaixo de 25 mil hab. (297 municípios com até 10.000 hab. com cerca de $80 \%$ dos seus setores nesse grupo) e, 106 municípios com todos os seus setores censitários classificados nesse grupo. Resultados análogos foram observados para os 148 municípios com população entre 10.000 e 25.000 habitantes onde mais de $60 \%$ dos setores foram classificados também no grupo de vulnerabilidade alta. (FSEADE 2005; FERREIRA e cols. 2006). 


\section{OBJETIVOS}

Norteado pelos referenciais teóricos este estudo parte-se do pressuposto que o padrão de mortalidade de residentes num território é influenciado pelas condições de vida e, que o Estado de São Paulo esconde atrás da pujança econômica, marcantes desigualdades socioespaciais. Assim, este estudo tem como objetivo:

\subsection{GERAL}

- Descrever o padrão de mortalidade da população a partir de estratos homogêneos de vulnerabilidade social dos municípios no Estado de São Paulo no triênio de 2003 a 2005.

\subsection{ESPECÍFICOS}

- Desenvolver metodologia para construção de estratos homogêneos de vulnerabilidade social de municípios no Estado a partir dos dados brutos do Índice Paulista de Vulnerabilidade Social da Fundação SEADE (2005).

- Caracterizar os estratos homogêneos de vulnerabilidade social de municípios no Estado de São Paulo

- Identificar a distribuição espacial dos estratos homogêneos de vulnerabilidade social no território do Estado.

- Comparar e analisar o padrão de mortalidade de residentes nos estratos homogêneos de vulnerabilidade social a partir de indicadores clássicos de mortalidade. 


\section{MATERIAL E MÉTODO}

\subsection{DESENHO DO ESTUDO}

Estudo ecológico exploratório descritivo do tipo comparação de múltiplos grupos. A unidade ecológica de análise constituiu-se do Estado de São Paulo, estratos homogêneos de vulnerabilidade social e conjuntos de municípios dos estratos homogêneos.

\subsection{SELEÇÃO DAS BASES DE DADOS}

Os dados utilizados são secundários e originários das bases de dados das seguintes fontes:

- Sistema de Informações sobre Mortalidade - SIM para o estado de São Paulo disponibilizado pelo Ministério da Saúde para download no endereço eletrônico www.datasus.gov.br para os anos de 2003, 2004 e 2005.

- Censo Demográfico - IBGE 2000 e respectivas projeções para 2003, 2004 e 2005 disponíveis no endereço eletrônico: www.ibge.gov.br.

- Sistema de Informações sobre Nascidos Vivos - SINASC para o estado de São Paulo disponibilizado pelo Ministério da Saúde para download no endereço eletrônico www.datasus.gov.br para os anos de 2003, 2004 e 2005.

- Índice Paulista de Vulnerabilidade Social - IPVS (2005) produzido pela Fundação Sistema Estadual de Análise de Dados - FSEADE da Secretaria de Economia e Planejamento do Governo do Estado de São Paulo, disponível em CD-ROM e no endereço eletrônico: http://www.seade.gov.br.

\section{3- POPULAÇÃO}

Para evitar eventuais influências das flutuações aleatórias do período foi calculada a média aritmética dos dados populacionais obtidos das projeções populacionais derivadas do Censo Demográfico 2000-IBGE para triênio 2003, 2004 e 2005. 
Para a comparação entre as diferentes unidades de análise realizou-se a padronização das taxas de mortalidade para idade e sexo tomando como população de referência, a estrutura etária da população média do Estado de São Paulo do período em estudo.

\subsection{CONSTRUÇÃO DOS ESTRATOS HOMOGÊNEOS DE VULNERABILIDADE SOCIAL}

\subsection{1- Seleção das variáveis do IPVS}

As variáveis selecionadas para o estudo foram obtidas do acervo eletrônico do CD- ROM do IPVS da FSEADE (2005) descritas abaixo segundo nomeação dos seus respectivos campos:

a) Identificação do município: ID_MUN: Código numérico atribuído pelo IBGE a cada um dos 645 municípios do estado de São Paulo.

b) População Total - PT: número absoluto de habitantes classificados para cada grupo de vulnerabilidade social segundo IPVS para cada um dos 645 municípios do estado de São Paulo.

1. PT_1 - População Total - 1 - Nenhuma Vulnerabilidade

2. PT_2 - População Total - 2 - Muito Baixa Vulnerabilidade

3. PT_3 - População Total - 3 - Baixa Vulnerabilidade

4. PT_4 - População Total - 4 - Média Vulnerabilidade

5. $\quad$ PT_5 - População Total - 5 - Alta Vulnerabilidade

6. PT_6 - População Total - 6 - Muito Alta Vulnerabilidade

7. PT_7- População Total - Total de habitantes

c) Distribuição proporcional da população (\%) - PD: número relativo de habitantes segundo grupo de vulnerabilidade social - IPVS

- PD_1 - Distribuição da População (\%) - 1 - Nenhuma Vulnerabilidade

- PD_2 - Distribuição da População (\%) - 2 - Muito Baixa Vulnerabilidade

- $\quad$ PD_3 - Distribuição da População (\%) - 3 - Baixa Vulnerabilidade

- PD_4 - Distribuição da População (\%) - 4 - Média Vulnerabilidade

- PD_5 - Distribuição da População (\%) - 5 - Alta Vulnerabilidade 
- PD_6 - Distribuição da População (\%) - 6 - Muito Alta Vulnerabilidade

- $\quad$ PD_7 - Distribuição da População Total - Total da população relativa

\subsubsection{Atualização da população absoluta para os grupos do IPVS}

Considerando que a base populacional de construção do IPVS foi a população do Censo 2000 e, os dados dos eventos (óbitos e nascimentos) utilizados para este estudo referem-se ao triênio 2002-2005, procedeu-se a atualização dos dados da população absoluta do período, utilizando-se a média das projeções populacionais do IBGE para os anos 2003, 2004 e 2005. Sobre a população total de cada município foi aplicado o percentual (\%) de habitantes para cada grupo do IPVS FSEADE (2005).

\subsubsection{Composição dos Estratos Homogêneos de Vulnerabilidade Social}

Para a composição dos estratos homogêneos com base nos seis grupos de vulnerabilidade social do IPVS foram observados diferentes cenários (Tabela 1). Os dados mostram que o município 1 (IBGE 3509502), o mais populoso, somou 69,8\% da sua população no IPVS (1, 2 e 3) e, 13,9\% no IPVS 4 e 16,3\% no IPVS 5 e 6.

O município 2 (IBGE 3548807) por sua vez concentrou $82,2 \%$ da sua população no IPVS 2, 12,5\% no IPVS 1 e, apenas 5,3\% no IPVS 3.0 município 3 (IBGE 3537156) mostrou $80,9 \%$ da sua população no IPVS 3, e no IPVS 5 19,1\%.. Nestes três municípios observa-se que mais de 2/3 de suas populações se classificaram no IPVS 1,2 e 3.

O município 4 (IBGE 3525003) por sua vez situou-se com 69,7\% de sua população no IPVS 4 e, o restante 31,3\% distribuídos nos demais grupos do IPVS (1,2,3e 5) se distinguindo dos demais pela elevada concentração no IPVS 4.

Os municípios 5 e 6 (IBGE 3500204 e 3532827) apresentaram-se como os mais vulneráveis socialmente dos municípios selecionados. Nota-se que o município 5 apresentou $100 \%$ dos seus habitantes concentrados no IPVS 5 . 0 município 6, situou 76,3\% da população no IPVS 6 e, o restante $(23,7 \%)$ IPVS 5. 
A variabilidade intra-município demonstrada acima reproduziu nos demais municípios do Estado e compôs os dados brutos da base de dados do IPVS.

Tabela 1- N e \% da população segundo Índice Paulista de Vulnerabilidade Social em alguns municípios selecionados. Estado de São Paulo, triênio 2003 a 2005.

\begin{tabular}{|c|c|c|c|c|c|c|c|c|c|c|c|c|c|}
\hline \multirow[b]{2}{*}{ IBGE } & \multirow[b]{2}{*}{ IPVS 1} & \multirow[b]{2}{*}{$\%$} & \multirow[b]{2}{*}{ IPVS 2} & \multirow[b]{2}{*}{$\%$} & \multirow[b]{2}{*}{ IPVS 3} & \multirow[b]{2}{*}{$\%$} & \multirow[b]{2}{*}{ IPVS 4} & \multicolumn{3}{|c|}{ IPVS } & \multicolumn{2}{|l|}{ IPVS } & \multirow[b]{2}{*}{ Total } \\
\hline & & & & & & & & $\%$ & 5 & $\%$ & 6 & $\%$ & \\
\hline 3509502 & 184042 & 17,9 & 307423 & 29,9 & 226197 & 22,0 & 142916 & 13,9 & 76085 & 7,4 & 91507 & 8,9 & 1028170 \\
\hline 3548807 & 16955 & 12,5 & 111498 & 82,2 & 7189 & 5,3 & - & 0,0 & - & 0,0 & - & 0,0 & 135643 \\
\hline 3537156 & - & 0,0 & - & 0,0 & 2423 & 80,9 & - & 0,0 & 572 & 19,1 & - & 0,0 & 2996 \\
\hline 3525003 & 4975 & 4,7 & 741 & 0,7 & 22547 & 21,3 & 73780 & 69,7 & 1270 & 1,2 & 2540 & 2,4 & 105854 \\
\hline 3500204 & - & 0,0 & - & 0,0 & - & 0,0 & - & 0,0 & 3883 & 100,0 & - & 0,0 & 3883 \\
\hline 3532827 & - & 0,0 & - & 0,0 & - & 0,0 & - & 0,0 & 1966 & 23,7 & 6331 & 76,3 & 8297 \\
\hline
\end{tabular}

Fonte: Censo 2000 e Projeções. IBGE IPVS: Dados brutos FSEADE (2005)

Nota ${ }^{1}$ : População IPVS atualizada para o período do estudo

(-) Dado numérico igual a zero não resultante de arredondamento

\subsubsection{Critérios para a composição dos Estratos Homogêneos de Vulnerabilidade}

Para a definição dos critérios de composição dos estratos homogêneos de vulnerabilidade social, foram considerados dois aspectos: a especificidade do IPVS e a complexidade do universo em estudo. Para o primeiro, foram considerados os critérios que definiram a tipologia do IPVS. A condição de nenhuma vulnerabilidade (Grupo I) correspondeu a melhor situação observada para o IPVS e, a de vulnerabilidade muito alta (Grupo 6) à pior condição observada (Figura 1).

$\mathrm{Na}$ tipologia do IPVS os seis grupos de vulnerabilidade resultaram numa escala que num extremo situou-se o melhor grupo (nenhuma vulnerabilidade Grupo 1) e noutro extremo o pior grupo (vulnerabilidade muito alta - Grupo 6). Assim os grupos de vulnerabilidade muito baixa (Grupo 2) e o de vulnerabilidade baixa (Grupo 3) nesta escala podem ser considerados como gradientes do Grupo 1 (nenhuma vulnerabilidade).

No outro extremo, o grupo de vulnerabilidade muito alta (Grupo 6), tem como gradiente o grupo de vulnerabilidade alta (Grupo 5). Na situação 
intermediária situou-se o Grupo 4 (o ponto médio) entre os dois extremos sendo classificado como de vulnerabilidade média. Esquematicamente tais gradientes podem ser visualizados na Figura 1.

Figura 1 - Gradientes de intensidade da tipologia da vulnerabilidade social.

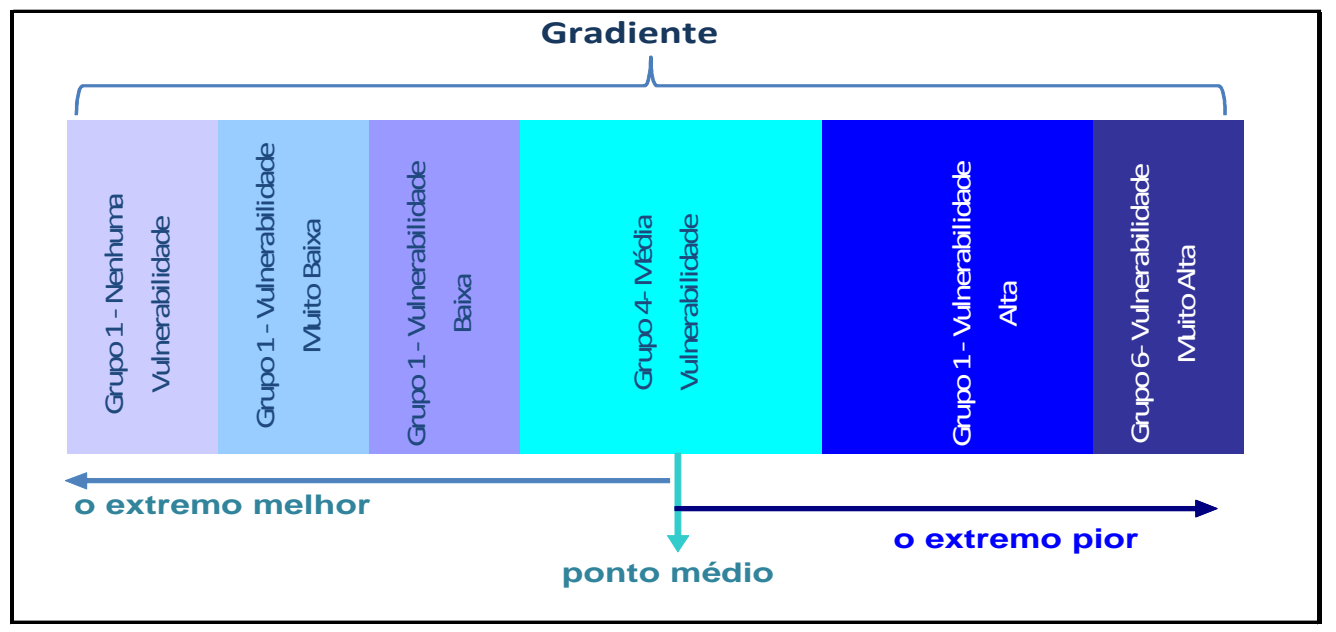

* Elaboração da autora a partir da tipologia dos grupos do IPVS. FSEADE (2005)

0 segundo, se refere à complexidade do universo em estudo - o Estado de São Paulo - composto por 645 municípios de distintos portes populacionais conformando uma unidade de análise com diferentes arranjos dos seis grupos de vulnerabilidade social propostos pela tipologia IPVS FSEADE (2005).

Agrega-se ainda a complexidade desta unidade de análise um contingente populacional expressivo (39.463.839 hab.) na média do triênio, distribuídos nos 645 municípios, situando-se num extremo o menor - Borá com 817 habitantes e noutro extremo o maior, São Paulo com 10.814.528 habitantes.

Diante desse cenário, a busca para a formação de estratos homogêneos de vulnerabilidade social do universo em estudo considerou dois critérios hierarquizados para o agrupamento dos municípios: o primeiro, a vulnerabilidade social e, o segundo, o porte populacional dos municípios de cada estrato.

\subsubsection{Agrupamento por Vulnerabilidade Social}


a) Agrupamento quantitativo (n॰ e \%) das populações nos extremos dos Grupos do IPVS retirando seus gradientes e, mantendo-as em três grupos: o pior extremo, a situação intermediária e o melhor extremo para cada unidade de análise. Dessa forma:

- O grupo de IPVS 1 (nenhuma vulnerabilidade social) e seus gradientes grupos 2 e 3 (muito baixa e baixa vulnerabilidade social) compuseram o melhor extremo.

- O grupo 6 (muito alta vulnerabilidade social) agregou seu gradiente do grupo 5 (alta vulnerabilidade social) compondo o pior extremo.

- O grupo 4 (média vulnerabilidade social) foi mantido na sua concepção original sendo denominado grupo intermediário de vulnerabilidade social.

Esse agrupamento resultou em três grandes grupos de IPVS: melhor extremo, intermediário e, o pior extremo de vulnerabilidade social que esquematicamente pode ser visualizado na Figura 2.

Figura 2- Agregação dos gradientes da tipologia de vulnerabilidade social.

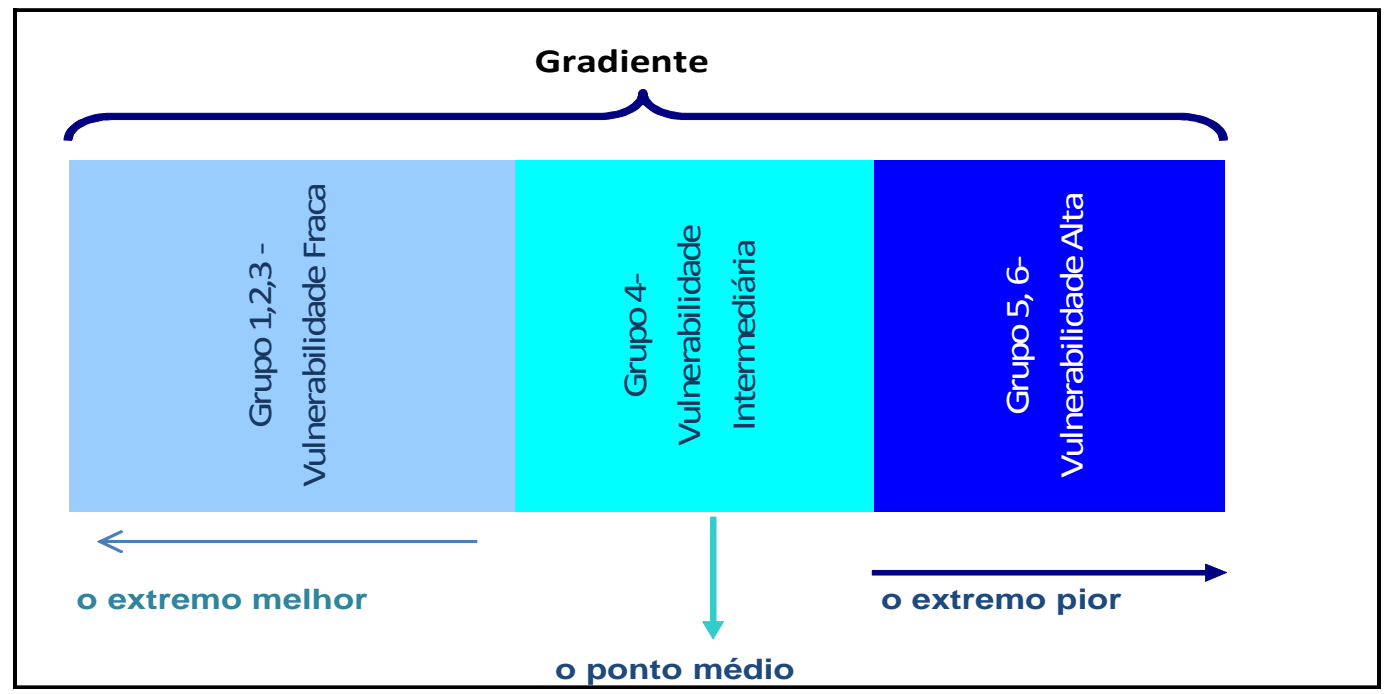

* Elaboração da autora a partir da metodologia proposta com base no IPVS.FSEADE (2005)

b) Cálculo do quantitativo da população da média do triênio (n॰ e \%) para os grupos agregados do IPVS para cada unidade de análise (município) e para o total do estado a exemplo da Tabela 2. 
Tabela 2 -N e (\%) da população por grupos agregados de vulnerabilidade social em alguns municípios selecionados. Estado de São Paulo, média do triênio 2003 a 2005

\begin{tabular}{|c|c|c|c|c|c|c|c|}
\hline IBGE & Pop. $(1,2,3)$ & $\%$ & Pop. (4) & $\%$ & Pop. $(5,6)$ & $\%$ & Pop. (média do triênio \\
\hline 3509502 & 717663 & 69,8 & 142916 & 13,9 & 167592 & 16,3 & 1028170 \\
\hline 3548807 & 135643 & 100,0 & - & 0,0 & - & 0,0 & 135643 \\
\hline 3537156 & 2423 & 80,9 & - & 0,0 & 572 & 19,1 & 2996 \\
\hline 3525003 & 28263 & 26,7 & 73780 & 69,7 & 3811 & 3,6 & 105854 \\
\hline 3500204 & & - & - & - & 3883 & 100,0 & 3883 \\
\hline 3532827 & & - & - & - & 8297 & 100,0 & 8297 \\
\hline
\end{tabular}

Elaboração da autora. Dados brutos: IPVS. FSEADE (2005)

Nota ${ }^{1}$ : $\quad$ População atualizada para o período do estudo

(-) Dado numérico igual a zero não resultante de arredondamento

\subsubsection{Agrupamento dos Municípios em Estratos Homogêneos de Vulnerabilidade Social}

Para o agrupamento dos municípios em estratos homogêneos foi utilizado como critério a magnitude da distribuição relativa da população (\%) para cada agregado dos grupos do IPVS. Foram compostos cinco (05) estratos tomando como referência a escala de Rensis Likert concebida em 1932. Esta escala de cinco pontos mostra um ponto médio (o intermediário), dois extremos (um em oposição ao outro: o ótimo e o péssimo) e gradientes de cada extremo (o bom e o ruim) (Figura 3). Esta escala tornou-se um paradigma da mensuração qualitativa quer na forma original quer em adaptações para diferentes escalas (PEREIRA 2001).

Para a classificação dos municípios nos estratos homogêneos de vulnerabilidade social utilizou-se classes da distribuição relativa do IPVS na população (Quadro 2). 
Figura 3 - Critérios da composição dos estratos de vulnerabilidade social segundo distribuição da população relativa (\%) do IPVS na população.

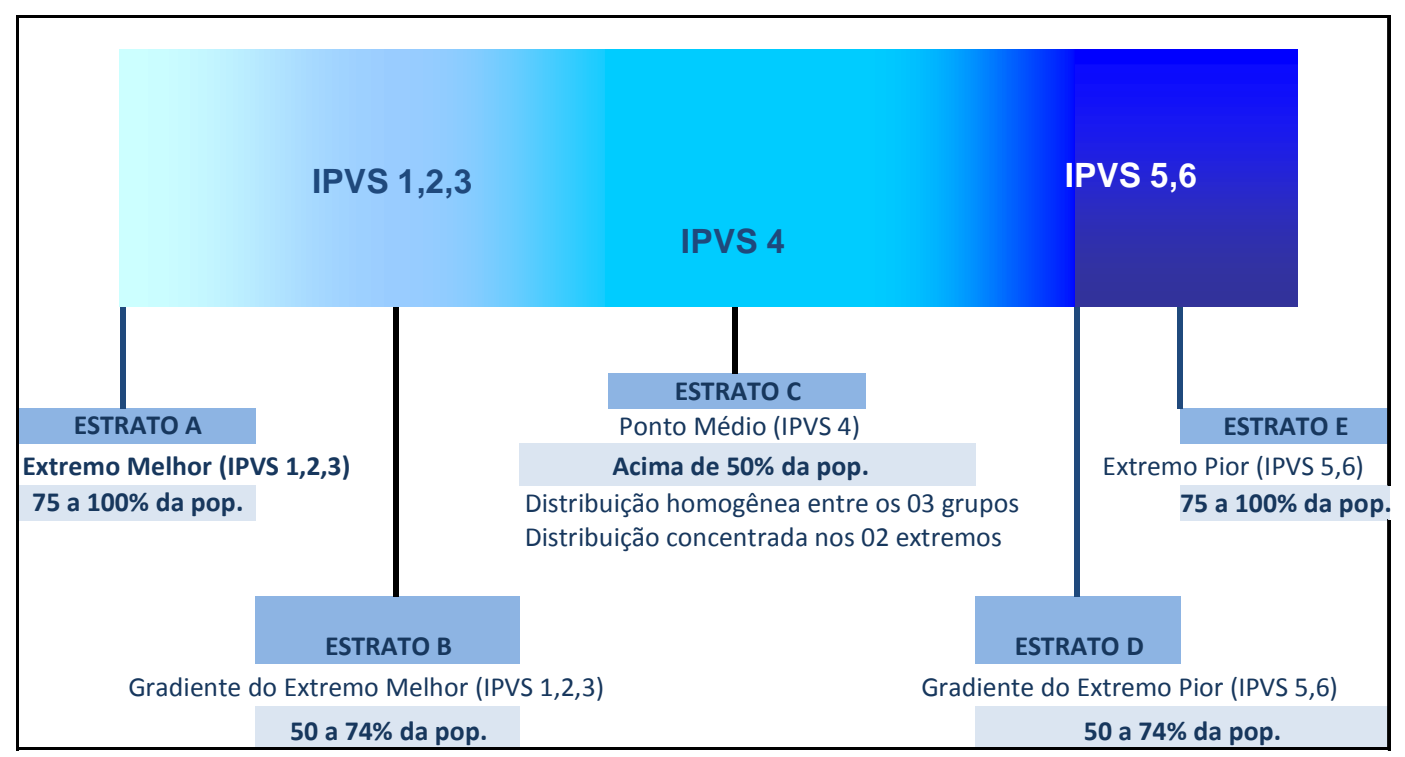

* Elaboração da autora. Dados Brutos. IPVS.FSEADE (2005)

Quadro 2 - Critérios da composição dos estratos de vulnerabilidade social segundo a predominância da distribuição relativa (\%) do IPVS na população..

\begin{tabular}{|l|l|c|}
\hline \multicolumn{1}{|c|}{ Estrato } & \multicolumn{1}{c|}{ Descrição } & Referencial populacional \\
\hline \hline A- Muito Fraca & $\mathbf{7 5}$ a 100\% da população classificadas no IPVS 1,2,3 & 2/3 ou mais da pop. \\
\hline B- Fraca & $\mathbf{5 0}$ a $\mathbf{7 4} \%$ da população classificadas no IPVS 1,2,3 & \multicolumn{1}{c|}{ Metade a 2/3 da pop. } \\
\hline C - Intermediária & $\begin{array}{l}\text { a) acima de 50\% população classificada no IPVS 4 } \\
\text { b) Distribuição concentrada homogeneamente nos } \\
\text { dois extremos. } \\
\text { c) Distribuição homogênea nos 03 grupos } \\
\text { agregados }\end{array}$ & $\begin{array}{l}\text { * Metade ou mais da pop. no } \\
\text { grupo Intermediário, } \\
\text { * Metade da pop. nos dois } \\
\text { extremos } \\
\text { *Cerca de 1/3 da pop em } \\
\text { cada grupo de IPVS }\end{array}$ \\
\hline D - Intensa & 50 a 74\% da população classificadas no IPVS 5 e 6 & Metade a 2/3 da pop. \\
\hline E - Muito Intensa & $\mathbf{7 5}$ a 100\% da população classificadas no IPVS 5,6 & 2/3 ou mais da população \\
\hline
\end{tabular}

\subsubsection{Categorização Interna de cada Estrato}

Dada a diversidade de portes populacionais dos municípios, sugerindo diferentes estruturas sociais e econômicas, às quais suas respectivas populações estão expostas, os municípios de cada estrato homogêneo foram categorizados internamente em intervalos segundo porte populacional (Figura 4). 
Figura 4 - Intervalos de porte populacional para classificação interna dos municípios nos Estratos de Vulnerabilidade Social.

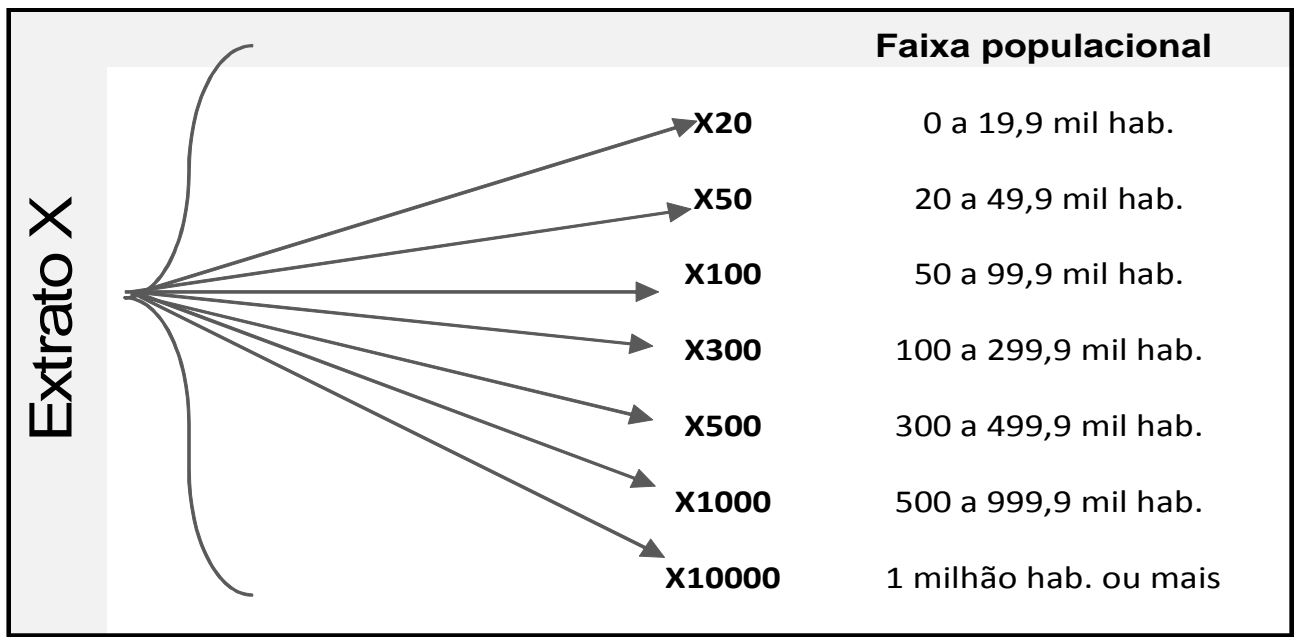

*Elaboração da autora.

Deste modo, cada um dos cinco estratos homogêneos poderia se configurar em até sete conjuntos de municípios segundo intervalo populacional. (Figura 4). Após a classificação em estratos homogêneos segundo a distribuição relativa (\%) da vulnerabilidade social na sua população, foi realizado o agrupamento interno de cada estrato segundo porte populacional (Tabela 3).

Tabela 3 - Configuração dos estratos homogêneos de vulnerabilidade social e respectivas subcategorizações internas por porte populacional.

\begin{tabular}{l|l|r|r|r|r|r}
\hline Porte (Código) & \multicolumn{1}{|c|}{ Intervalo populacional } & \multicolumn{1}{c|}{ A } & \multicolumn{1}{c|}{ B } & \multicolumn{1}{c|}{ C } & \multicolumn{1}{c|}{ D } & E \\
\hline \hline $\mathbf{2 0}$ & 0 a 19,9 mil hab. & A20 & B20 & C20 & D20 & E20 \\
\hline $\mathbf{5 0}$ & 20 a 49,9 mil hab. & A50 & B50 & C50 & D50 & E50 \\
\hline $\mathbf{1 0 0}$ & 50 a 99,9 mil hab. & A100 & B100 & C100 & D100 & E100 \\
\hline $\mathbf{3 0 0}$ & 100 a 299,9 mil hab. & A300 & B300 & C300 & D300 & E300 \\
\hline $\mathbf{5 0 0}$ & 300 a 499,9 mil hab. & A500 & B500 & C500 & D500 & E500 \\
\hline $\mathbf{1 0 0 0}$ & 500 a 999,9 mil hab. & A1000 & B1000 & C1000 & D1000 & E1000 \\
\hline $\mathbf{1 0 0 0 0}$ & Igual ou acima de 1 milhão hab. & A10000 & B10000 & 10000 & D10000 & E10000 \\
\hline *Eaboração da autora.
\end{tabular}

\subsection{ANÁLISE, MEDIDAS E INDICADORES SELECIONADOS}


A ênfase da seleção de medidas e indicadores foi essencialmente dada pela presença nas bases eletrônicas de dados censitários e suas projeções, administrativos e epidemiológicos. operados pelo Ministério da Saúde e pelo Instituto Brasileiro de Geografia e Estatística - IBGE. Estes, foram complementados pela variável independente vulnerabilidade social segundo o desenho metodológico do estudo.

Os parâmetros, medidas e indicadores selecionados compuseram-se de taxas (bruta e padronizada) total e por idade e sexo, proporções ou razões cuja qualificação e metodologia de cálculo encontram-se dispostas no Anexo 1. Para caracterização demográfica dos estratos homogêneos de vulnerabilidade social utilizou-se população absoluta e relativa, proporção de habitantes por faixas etárias selecionadas, razão de sexos, razão de dependência e mortalidade proporcional por faixas etárias selecionadas. A proporção (\%) de óbitos por Causas Mal Definidas foi utilizada como referencial da qualidade do sistema de informações sobre mortalidade.

Para o estudo do padrão de mortalidade nas unidades de análises foram utilizados a Razão de Mortalidade Materna (por 100 mil nascidos vivos) e Taxa de Mortalidade Infantil (por 1000 nascidos vivos) e, as Taxas Padronizadas de Mortalidade por Doenças Infecciosas e Parasitárias, Doenças do Aparelho Respiratório, Doenças do Aparelho Circulatório, Diabetes Mellitus, Neoplasias, Acidentes de Transporte e Homicídios por 100 mil hab.. Com exceção da razão de mortalidade materna e taxa de mortalidade infantil, as demais taxas foram apresentadas segundo mortalidade total e sexo.

Reconhecendo de antemão a existência de inúmeros indicadores, dentre os quais alguns com maior especificidade e, ou sensibilidade, optou-se pela seleção de indicadores clássicos na literatura e ainda, norteados pelos seguintes critérios:

- Disponibilidade de bases de dados

- Simplicidade e facilidade de cálculo

- Periodicidade e atualidade

- Adequação aos objetivos do estudo 
Para a mensuração dos diferenciais entre as unidades de análise foram utilizadas: média aritmética, mediana, maior e menor valor, desvio padrão e razão de taxas. Os níveis de análise compreenderam: conjuntos de municípios por porte populacional e respectivo estrato, estratos de vulnerabilidade entre si e, estratos e Estado.

Os resultados obtidos por conjunto de municípios e por Estrato de Vulnerabilidade Social foram apresentados no corpo do estudo, organizados em tabelas, quadros e figuras segundo critério de relevância. Os resultados comparativos detalhados por conjuntos de municípios e, os dados por município isoladamente encontram-se como anexos em arquivo eletrônico (CDROM) disponível na contracapa deste volume.

Para facilitar a identificação e a localização espacial, os dados apresentados em mapas tiveram como configuração da base cartográfica os departamentos regionais de saúde do Estado. Para a tabulação, preparo e apresentações dos dados foram utilizados os softwares Tabwin V.3.4 do Ministério da Saúde e, os aplicativos Acess, Excel e Word do pacote Office 2007 da Microsoft Corporation. 


\section{RESULTADOS}

\subsection{CONFORMAÇÃO DOS ESTRATOS DE VULNERABILIDADE SOCIAL}

A classificação dos municípios nos estratos de vulnerabilidade social resultou em 319 municípios (49,5\%) no Estrato E, 151 municípios (23,4\%) no Estrato D, 83 municípios (12,9\%) no Estrato C, 79 municípios (12,2\%) no Estrato B e, apenas 13 municípios (2,0\%) no Estrato A (Figura 5).

$\mathrm{Na}$ composição populacional dos estratos observou-se que mais da metade $(57,6 \%)$ da população do Estado concentrou-se no Estrato B. 0 segundo maior contingente foi classificado no Estrato C, com 21,5\%. Dentre os menos populosos, o Estrato A foi o menor com 5,2\%, seguido dos Estratos E e D que concentraram respectivamente $6,1 \%$ e 9,7\% da população.

Figura 5 - Proporção (\%) de municípios e (\%) população segundo Estrato de Vulnerabilidade Social. Estado de São Paulo, média do triênio 2003 a 2005.

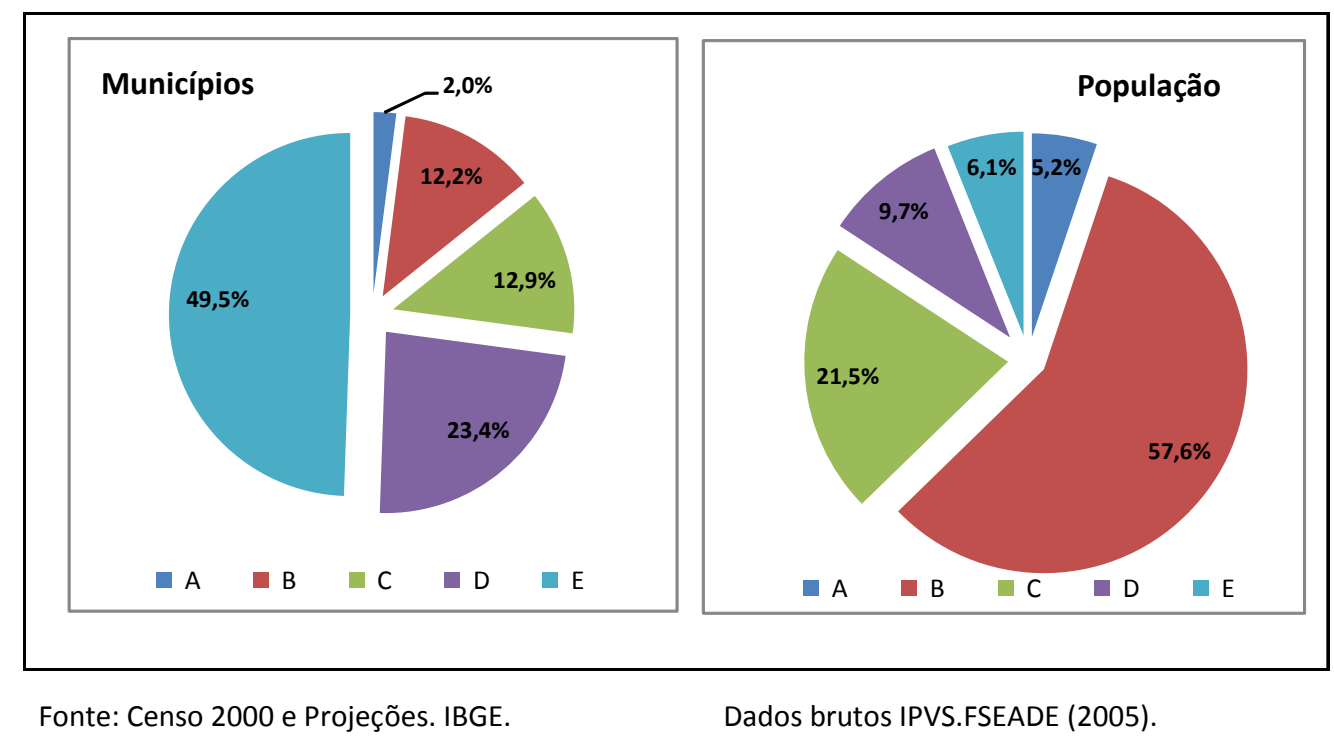

Espacialmente, o Estrato A, o menor estrato, abrigou municípios populosos (Figura 6) como Santo André e São Caetano do Sul (RM Capital), Santos (Baixada Santista), Jundiaí, Americana e Vinhedo (Campinas) e Araraquara na região central do Estado. 
O Estrato B, o mais populoso, apresentou internamente a maior concentração de municípios no Porte 300 (30,4\%) e, o maior contingente populacional no conjunto B10000 (52,0\%) composto por Campinas e São Paulo. Espacialmente, as regiões do Vale do Paraíba e Campinas concentraram o maior número de municípios seguidas de Piracicaba, Sorocaba e Bauru (Figura 6). A RM São Paulo classificou apenas 06 municípios, mas destacou-se pelo elevado contingente populacional por incluir São Paulo, Osasco, S.Bernardo do Campo, Mogi das Cruzes, Ribeirão Pires e Poá nesse estrato.

O Estrato C, segundo mais populoso, concentrou 41,8\% da sua população no conjunto de municípios Porte 300 e, o maior número de municípios $(30,1 \%)$ no Porte C50. A RM São Paulo concentrou 23 municípios nesse estrato, destacando-se Guarulhos, Itaquaquecetuba e Carapicuíba (Figura 7). As regiões de Campinas e Baixada Santista contribuíram respectivamente com 10\% e 6,7\% de seus municípios. As demais, apresentaram participação abaixo de 5\%, destacando-se as de Presidente Prudente com 0,3 \% e, a de Registro, que não mostrou participação.

O Estrato D, caracterizou-se pelo predomínio dos municípios de Porte 20 com 73 municípios $(48,3 \%)$ e, Porte 50 com 63 municípios $(41,7 \%)$, os quais se apresentaram espacialmente dispersos por todo o território paulista. As regiões de Bauru, Marília, S.J. Rio Preto, Presidente Prudente, Araraquara e Campinas apresentaram entre 17 a 10 municípios cada uma e, as demais abaixo de 10 municípios cada uma delas (Figura 7).

Espacialmente no Estado, a concentração populacional predominou nos municípios da RM de São Paulo com 55,0\%, região de Campinas com 10,4\% e, de Taubaté com 6,7\% (Estratos A e B). As demais, com participação inferior a 5\% destacando-se a de Registro cuja participação foi inferior a 0,5\% (Tabela 5).

Espacialmente, os municípios de maior vulnerabilidade social, Estratos D e E concentraram-se nas regiões de S.J. Rio Preto, Sorocaba e Bauru somando cada uma delas 10 e $12 \%$ da população, respectivamente. As demais, participaram com até $10 \%$, destacando-se a Baixada Santista com $1 \%$, a menor participação populacional nestes estratos (Tabela 5). 
Tabela 4 - Municípios e população (N e \%) segundo porte populacional nos Estratos de Vulnerabilidade Social. Estado de São Paulo, média do triênio 2003 a 2005.

\begin{tabular}{|c|c|c|c|c|c|c|c|c|c|c|c|}
\hline \multicolumn{6}{|c|}{$\begin{array}{c}\text { Estrato A - Vulnerabilidade Social } \\
\text { Muito Fraca }\end{array}$} & \multicolumn{6}{|c|}{ Estrato B - Vulnerabilidade Social Fraca } \\
\hline & \multirow[b]{2}{*}{ Habitantes } & \multicolumn{2}{|c|}{ Municípios } & \multicolumn{2}{|c|}{ População } & & \multirow[b]{2}{*}{ Habitantes } & \multicolumn{2}{|c|}{ Municípios } & \multicolumn{2}{|c|}{ População } \\
\hline & & $\mathbf{N}$ & $\%$ & $\mathbf{N}$ & $\%$ & & & $\mathbf{N}$ & $\%$ & $\mathbf{N}$ & $\%$ \\
\hline$A 20$ & 0 a $19,9 \mathrm{mil}$ & 6 & 46,2 & 38292 & 1,9 & B20 & 0 a 19,9 mil & 9 & 11,4 & 76284 & 0,3 \\
\hline A100 & 50 a $99,9 \mathrm{mil}$ & 1 & 7,7 & 53292 & 2,6 & B50 & 20 a $49,9 \mathrm{mil}$ & 16 & 20,3 & 530724 & 2,3 \\
\hline A300 & 100 a $299,9 \mathrm{mil}$ & 3 & 23,1 & 524274 & 25,7 & B100 & 50 a $99,9 \mathrm{mil}$ & 17 & 21,5 & 1293164 & 5,7 \\
\hline A500 & 300 a 499,9 mil & 2 & 15,4 & 756861 & 37,2 & В300 & 100 a $299,9 \mathrm{mil}$ & 24 & 30,4 & 3809981 & 16,8 \\
\hline \multirow[t]{2}{*}{ A1000 } & 500 a $999,9 \mathrm{mil}$ & 1 & 7,7 & 663777 & 32,6 & B500 & 300 a $499,9 \mathrm{mil}$ & 6 & 7,6 & 2072286 & 9,1 \\
\hline & Total & \multicolumn{2}{|c|}{13100,0} & 2036496 & 100,0 & B1000 & 500 a $999,9 \mathrm{mil}$ & 5 & 6,3 & 3119533 & 13,7 \\
\hline \multirow{2}{*}{\multicolumn{6}{|c|}{ Estrato C - Vulnerabilidade Social Intermediária }} & B10000 & 1 milhão ou mais & 2 & 2,5 & 11810059 & 52,0 \\
\hline & & & & & & & Total & \multicolumn{2}{|c|}{79100,0} & 22712031 & 100,0 \\
\hline & & \multicolumn{2}{|c|}{ Municípios } & \multicolumn{2}{|c|}{ População } & \multirow{2}{*}{\multicolumn{6}{|c|}{ Estrato D - Vulnerabilidade Social Intensa }} \\
\hline & Habitantes & $\mathbf{N}$ & $\%$ & $\mathbf{N}$ & $\%$ & & & & & & \\
\hline $\mathrm{C} 20$ & 0 a 19,9 mil & 15 & 18,1 & 185934 & 2,2 & & & \multicolumn{2}{|c|}{ Municípios } & \multicolumn{2}{|c|}{ População } \\
\hline C50 & 20 a 49,9 mil & 25 & 30,1 & 932319 & 11,0 & & Habitantes & $\mathbf{N}$ & $\%$ & $\mathbf{N}$ & $\%$ \\
\hline C100 & 50 a $99,9 \mathrm{mil}$ & 16 & 19,3 & 1153613 & 13,6 & D20 & 0 a 19,9 mil & 73 & 48,3 & 836705 & 21,9 \\
\hline C300 & 100 a 299,9 mil & 22 & 26,5 & 3548419 & 41,8 & D50 & 20 a 49,9 mil & 63 & 41,7 & 1956255 & 51,1 \\
\hline C500 & 300 a $499,9 \mathrm{mil}$ & 4 & 4,8 & 1467122 & 17,3 & D100 & 50 a 99,9 mil & 14 & 9,3 & 877677 & 22,9 \\
\hline \multirow[t]{2}{*}{$\mathrm{C} 10000$} & 1 milhão ou mais & 1 & 1,2 & 1199951 & 14,1 & D300 & 100 a $299,9 \mathrm{mil}$ & 1 & 0,7 & 156007 & 4,1 \\
\hline & Total & 83 & 100,0 & 8487358 & 100,0 & & Total & 151 & 100,0 & 3826644 & 100,0 \\
\hline \multirow{2}{*}{\multicolumn{6}{|c|}{ Estrato E - Vulnerabilidade Social Muito Intensa }} & & Estado & \multicolumn{2}{|c|}{ Municípios } & \multicolumn{2}{|c|}{ População } \\
\hline & & & & & & & & $\mathbf{N}$ & $\%$ & $\mathbf{N}$ & $\%$ \\
\hline & & \multicolumn{2}{|c|}{ Municípios } & \multicolumn{2}{|c|}{ População } & & Estrato A & 13 & 2,0 & 2036496 & 5,2 \\
\hline & Habitantes & $\mathbf{N}$ & $\%$ & $\mathbf{N}$ & $\%$ & & Estrato B & 79 & 12,2 & 22712031 & 57,6 \\
\hline E20 & 0 a $19,9 \mathrm{mil}$ & 301 & 94,4 & 1890672 & 78,7 & & Estrato C & 83 & 12,9 & 8487358 & 21,5 \\
\hline E50 & 20 a 49,9 mil & 17 & 5,3 & 439465 & 18,3 & & Estrato D & 151 & 23,4 & 3826644 & 9,7 \\
\hline \multirow[t]{2}{*}{ E100 } & 50 a $99,9 \mathrm{mil}$ & 1 & 0,3 & 71173 & 3,0 & & Estrato $\mathrm{E}$ & 319 & 49,5 & 2401310 & 6,1 \\
\hline & Total & 319 & 100 & 2401310 & 100,0 & & Estado & 645 & 100,0 & 39463839 & 100,0 \\
\hline
\end{tabular}

Fonte: Censo 2000 e Projeções. IBGE Dados Brutos: IPVS .FSEADE (2005)

A conformação de um padrão espacial da vulnerabilidade social no Estado apontou para a existência de dois eixos de menor vulnerabilidade social (fraca e muito fraca), sendo o primeiro deles de grande extensão e, o outro de menor extensão. Além desses eixos, mostrou ainda áreas que se insinuam como "ilhas" dispersas e isoladas no território paulista. 
Figura 6 - Distribuição espacial dos municípios dos Estratos A (Vulnerabilidade Social Muito Fraca) e Estrato B (Vulnerabilidade Social Fraca). Estado de São Paulo, média do triênio 2003-2005.

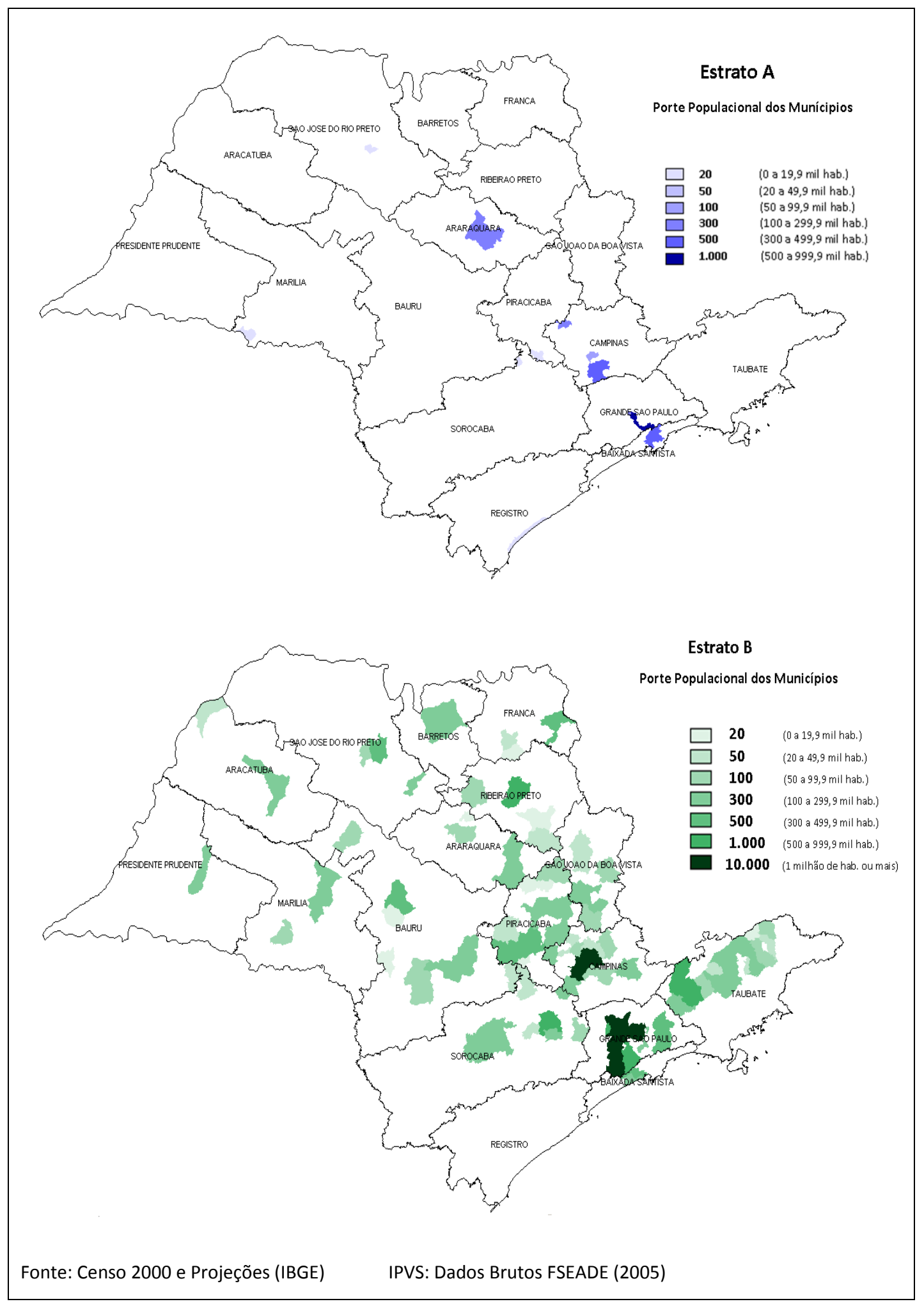


Figura 7- Distribuição espacial dos municípios do Estrato C (Vulnerabilidade Intermediária) e Estrato D (Vulnerabilidade Social Intensa). Estado de São Paulo, média do triênio 2003-2005.

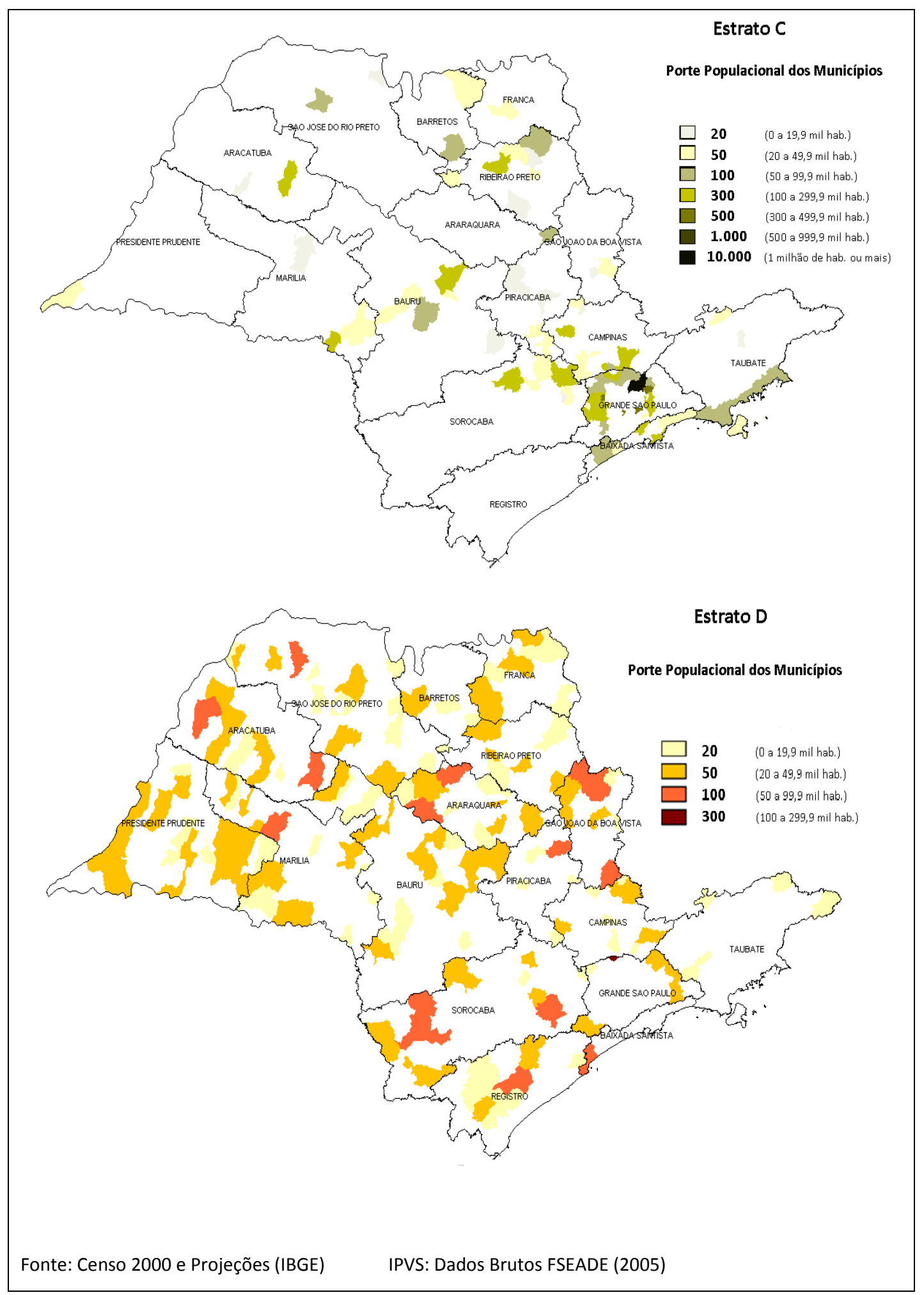


Tabela 5 - Distribuição espacial da população (\%) segundo Estrato de Vulnerabilidade Social nas regiões de saúde do Estado de São Paulo. Média do triênio 2003-2005.

\begin{tabular}{|c|c|c|c|c|c|c|c|c|c|c|c|}
\hline Região/Estrato & $\mathbf{A}$ & B & $(A+B)$ & $\%$ & $\mathrm{C}$ & $\%$ & D & E & $(D+E)$ & $\%$ & Total \\
\hline Baixada Santista & 418220 & 544042 & 962262 & 3,9 & 569364 & 6,7 & 59795 & - & 59795 & 1,0 & 1591421 \\
\hline Piracicaba & 10222 & 1026041 & 1036263 & 4,2 & 144429 & 1,7 & 131010 & 32369 & 163379 & 2,6 & 1344071 \\
\hline Taubaté & - & 1649032 & 1649032 & 6,7 & 316091 & 3,7 & 55959 & 123114 & 179073 & 2,9 & 2144196 \\
\hline Barretos & - & 107709 & 107709 & 0,4 & 114156 & 1,3 & 86909 & 95657 & 182566 & 2,9 & 404431 \\
\hline Franca & - & 360321 & 360321 & 1,5 & 44097 & 0,5 & 139970 & 86052 & 226022 & 3,6 & 630440 \\
\hline Ribeirão Preto & - & 623531 & 623531 & 2,5 & 298203 & 3,5 & 189900 & 72661 & 262561 & 4,2 & 1184295 \\
\hline Registro & 8468 & - & 8468 & - & - & - & 176675 & 102716 & 279391 & 4,5 & 287859 \\
\hline Campinas & 587369 & 1975982 & 2563351 & 10,4 & 845595 & 10,0 & 215401 & 64889 & 280290 & 4,5 & 3689236 \\
\hline RM São Paulo & 799756 & 12814011 & 13613767 & 55,0 & 5024613 & 59,2 & 297423 & 29990 & 327413 & 5,3 & 18965793 \\
\hline Araraquara & 192859 & 316759 & 509618 & 2,1 & 51433 & 0,6 & 284698 & 60276 & 344974 & 5,5 & 906025 \\
\hline Araçatuba & - & 201730 & 201730 & 0,8 & 105259 & 1,2 & 220899 & 155157 & 376056 & 6,0 & 683045 \\
\hline S. João da Boa Vista & - & 332165 & 332165 & 1,3 & 51784 & 0,6 & 297761 & 88204 & 385965 & 6,2 & 769914 \\
\hline Presidente Prudente & - & 199773 & 199773 & 0,8 & 25790 & 0,3 & 298485 & 183309 & 481794 & 7,7 & 707357 \\
\hline Marília & 2986 & 305866 & 308852 & 1,2 & 162863 & 1,9 & 357984 & 222759 & 580743 & 9,3 & 1052458 \\
\hline Bauru & - & 649624 & 649624 & 2,6 & 267062 & 3,1 & 344719 & 299907 & 644626 & 10,4 & 1561312 \\
\hline Sorocaba & 2460 & 1047544 & 1050004 & 4,2 & 381410 & 4,5 & 344044 & 359459 & 703503 & 11,3 & 2134917 \\
\hline S. Jose do Rio Preto & 14156 & 557901 & 572057 & 2,3 & 85209 & 1,0 & 325012 & 424791 & 749803 & 12,0 & 1407069 \\
\hline Estado & 2036496 & 22712031 & 24748527 & 100,0 & 8487358 & 100,0 & 3826644 & 2401310 & 6227954 & 100,0 & 39463839 \\
\hline
\end{tabular}

(-) Dado numérico igual a zero não resultante de arredondamento

População atualizada segundo projeção (IBGE) para o período e participação relativa nos grupos IPVS/FSEADE

E por fim, a terceira conformação, como grandes áreas homogêneas de maior vulnerabilidade, cujo padrão se caracterizou pelo afastamento espacial dos eixos de menor vulnerabilidade, com maior expressão nas regiões noroeste do estado, sudoeste e sul do Estado (Pontal do Paranapanema, Jales, Itapeva e Registro), regiões conhecidas como as mais pobres do Estado.

Nessa perspectiva, o Estrato C, espacialmente situou-se como zona de transição entre os extremos da vulnerabilidade social, destacando-se em algumas regiões pela localização periférica ao redor destas e, outras atuando como ponte entre essas regiões. Destacaram-se ainda, na configuração do "cinturão" ao redor das áreas menos vulneráveis na RM São Paulo e regiões de Campinas. Na Baixada Santista, conformou-se em um "braço de municípios" se estende por todo o litoral Norte. A conformação e características deste estrato mostraram coerência com a concepção metodológica desse estrato em condição de vulnerabilidade intermediária. 
Figura 8 - Distribuição espacial dos municípios dos Estratos E (Vulnerabilidade Social Muito Intensa) e Estado de São Paulo. Média do triênio 2003-2005.

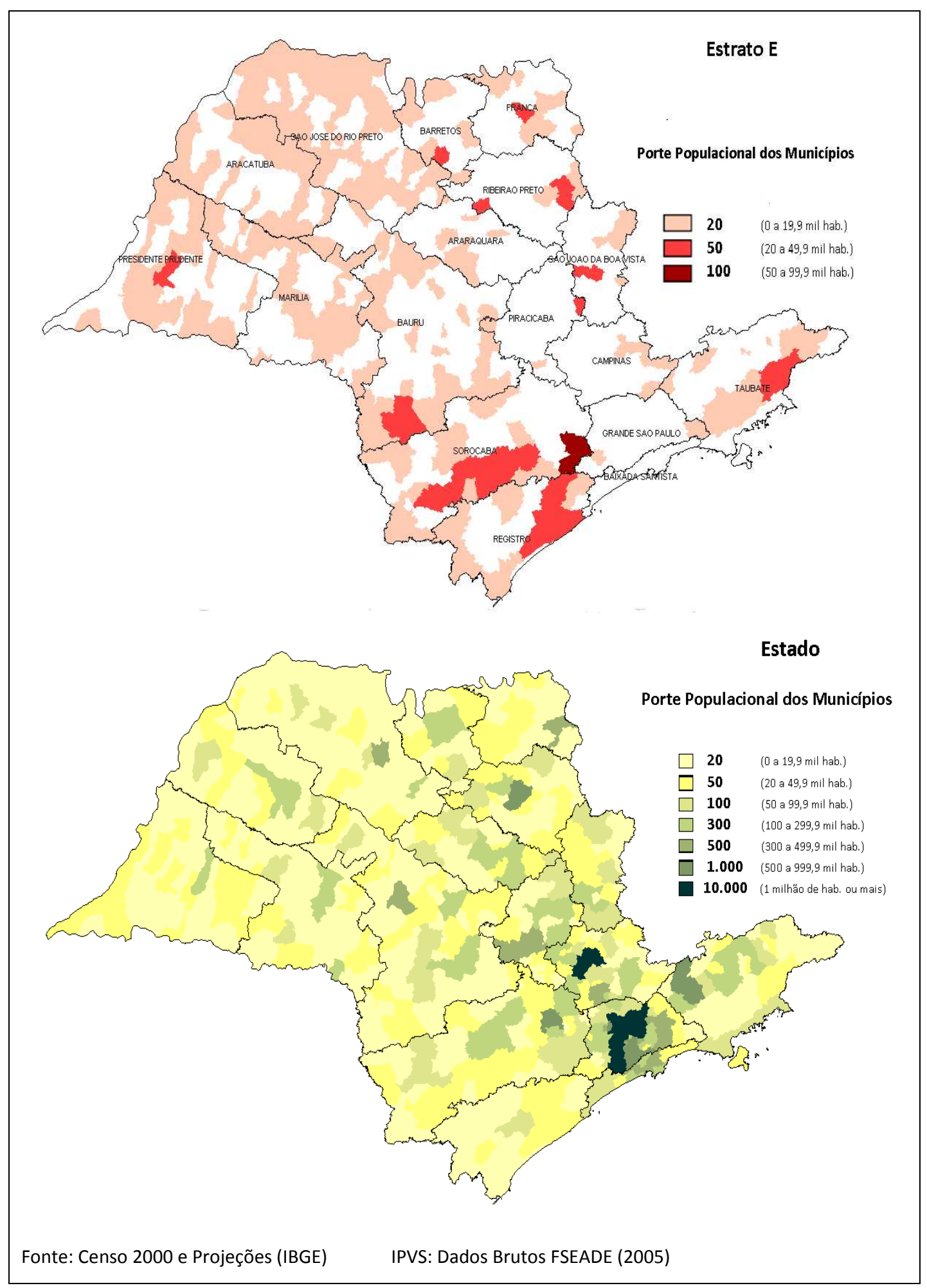


Figura 9 - Conformação espacial dos Estratos de Vulnerabilidade Social no Estado de São Paulo, média do triênio 2003-2005.

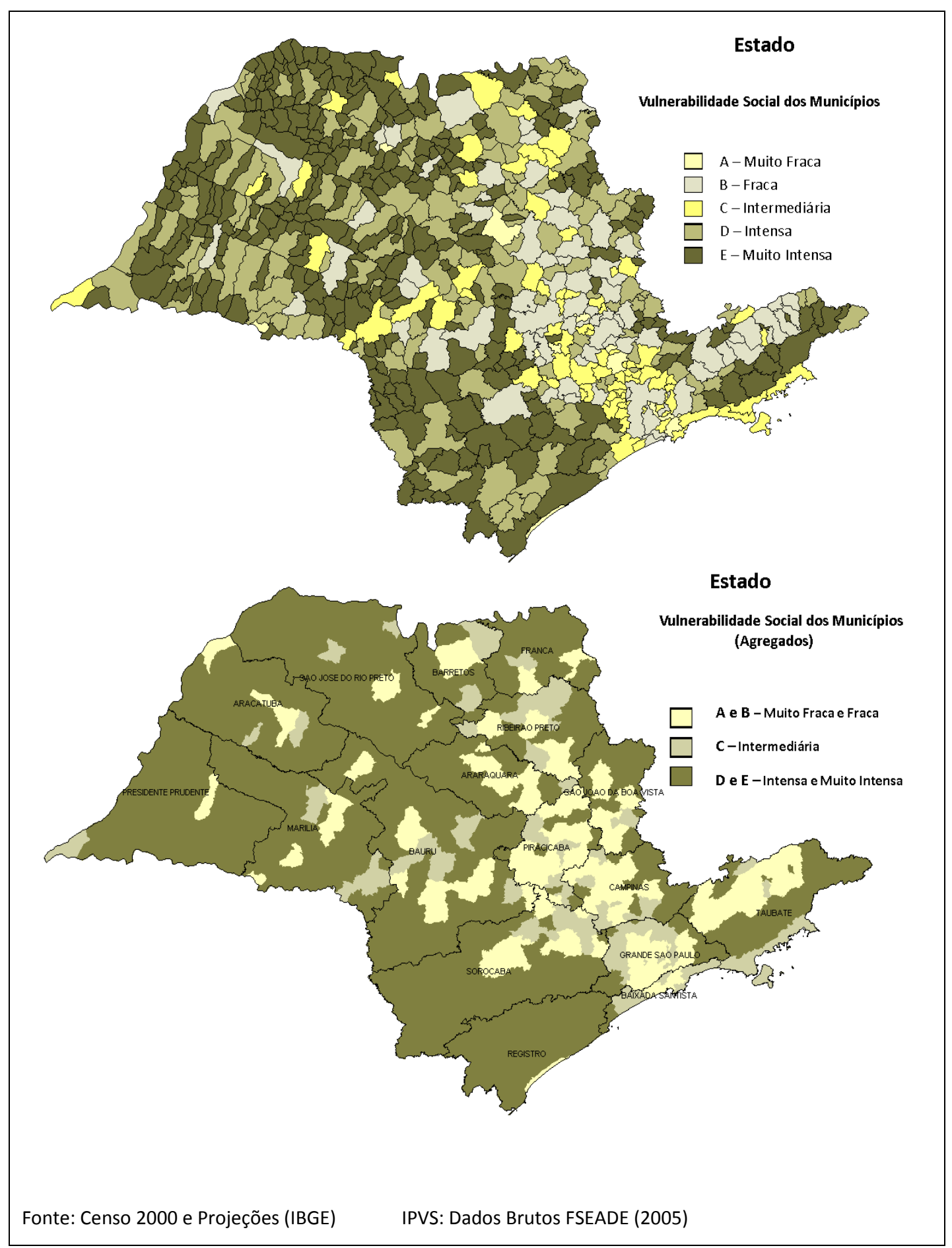

0 primeiro eixo, o de maior extensão, se insinuou como "espinha dorsal" de áreas de menor vulnerabilidade social no Estado. Situando-se num corredor 
sinuoso tem num extremo o município de Cruzeiro (região de Taubaté) e, ao longo do trajeto inclui os municípios de S. J.Campos, Pindamonhangaba e Guaratinguetá entre outros e, compreendendo basicamente a região do Vale do Paraíba, localizada às margens da rodovia Presidente Dutra (BR-116) ligando as capitais, Rio de Janeiro e São Paulo (Figura 10).

$\mathrm{Na}$ continuidade, esse eixo se estende pela RM Sao Paulo e regiões da Baixada Santista, Campinas, Araraquara, Ribeirão Preto, Franca e por fim a região de Barretos. Ao longo desse eixo, observaram-se áreas de "espraiamento" de menor vulnerabilidade variando em magnitude e, "incluindo" municípios das regiões de Sorocaba e S. J. Boa Vista. Desnecessário descrever a pujança econômica desse corredor e, a infra-estrutura de transportes e serviços que o compõe, marcado pelo intenso desenvolvimento econômico, urbanização e concentração populacional. Um segundo eixo, como um "braço"do eixo principal, englobou a região de Bauru, Avaré e Botucatu ligando se ao eixo principal, na região de Piracicaba. Nessa mesma região, isoladamente Lins, a $91 \mathrm{~km}$ da sede da região (Bauru) situou-se na condição de ilha de menor vulnerabilidade social.

Figura 10 - Padrão espacial da Vulnerabilidade Social (agregados) dos Municípios no Estado de São Paulo, média do triênio, 2003 a 2005.

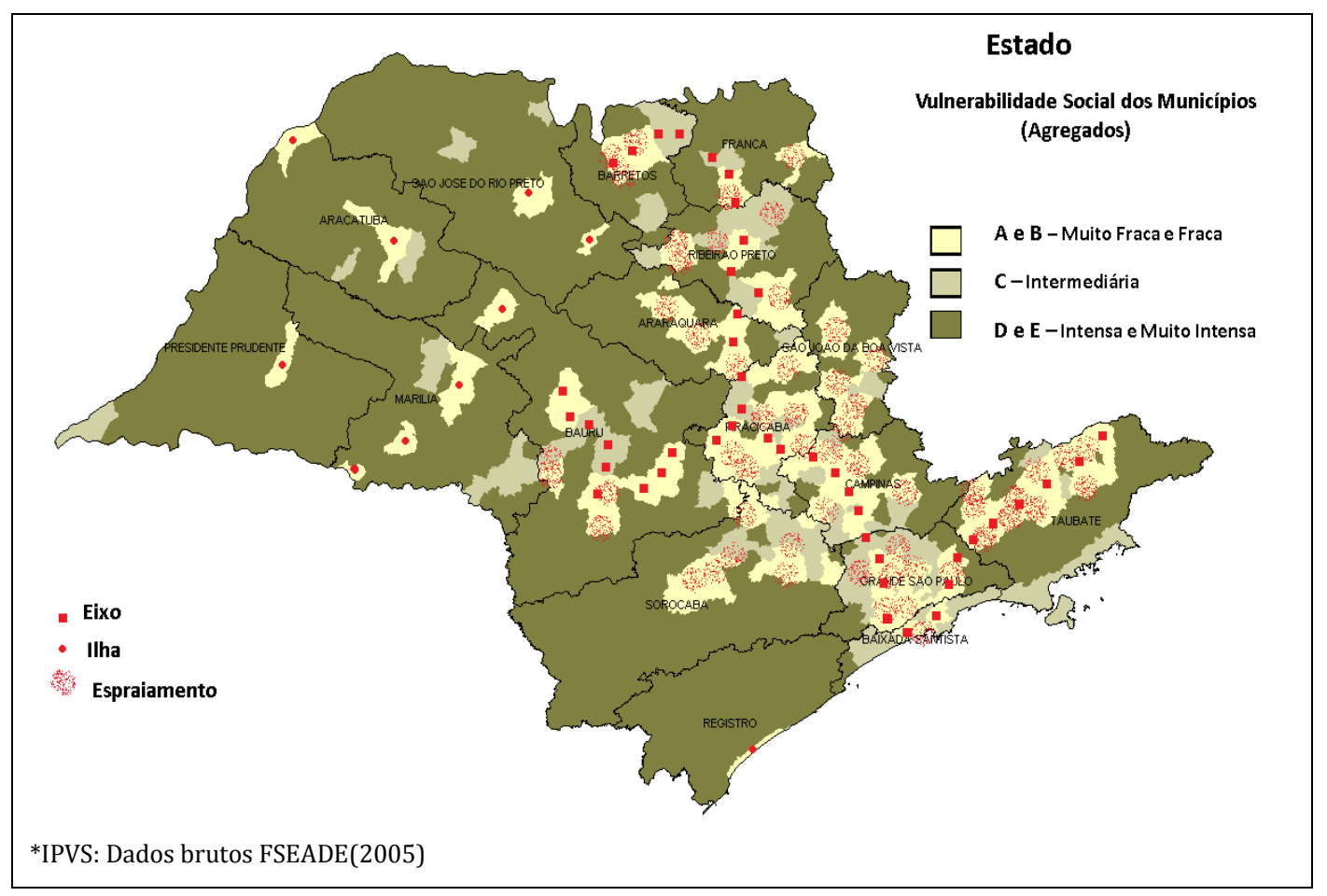


As ilhas de menor vulnerabilidade $(\mathrm{A}+\mathrm{B})$, na sua maioria, localizaram-se como sedes de regiões ou de microregiões derivadas provavelmente de investimentos focados em infra-estrutura, ensino, turismo ou governamental. A região de Registro, tradicional bolsão de pobreza do Estado, dentre as regiões foi a única a não incluir a sede da região, situando apenas o municipio de Ilha Comprida nessa condição.

As ilhas de vulnerabilidade intermediária (Estrato C), situaram-se nas regiões de S.J. Rio Preto (Orlandiúva e Votuporanga), Araçatuba (Bento de Abreu), Presidente Prudente (Rosana) e Barretos (Bebedouro). As de maior vulnerabilidade ( $D+E$ ), situaram-se nas regiões de Taubaté (Potim e Canas), RM Sao Paulo (Francisco Morato e Pirapora do Bom Jesus), Sorocaba (Boituva e Araçariguama), Campinas (Jarinú e Monte Mor), Piracicaba (Elias Fausto e Mombuca), S.João da Boa Vista (Sto Antonio do Jardim), Barretos (Colombia) e Araraquara(Descalvado).

Quando comparados os municípios componentes dos estratos homogêneos de vulnerabilidade social segundo o Índice de Desenvolvimento Humano Municipal - IDHM (2000) observaram-se variação de 0,919 a 0,795 para os municipios do Estrato A, de 0,855 a 0,770 para os do Estrato B, de 0,853 a 0,744 para os do Estrato C, de 0,832 a 0,716 para os municipios do Estrato D e, de 0,812 a 0,645 para os do Estrato E.

Tais resultados mostraram que, o maior valor e o menor valor de IDH-M dos municípios de cada estrato homogêneo declinou à medida que cresceu a vulnerabilidade social dos estratos, sugerindo coerência na concepção metodológica para a estratificação dos municipios segundo vulnerabilidade social.

FERREIRA e cols.(2006) atribuíram à existência de segmentos populacionais expostos a desigualdades de condições de vida no interior de áreas de menor vulnerabilidade, para os resultados encontrados pelo IPVS na sua gênese (áreas intra-urbanas) como derivadas do resultado de um padrão de crescimento das cidades, que não tem sido capaz de promover ou incluir parcelas importantes da população no usufruto dos benefícios do desenvolvimento econômico, com especial ênfase para os grandes centros 
urbanos. Nesse sentido, os resultados obtidos na conformação dos estratos de vulnerabilidade social sugerem processo semelhante no macro-território estadual, a julgar pelo padrão espacial desenhado pela vulnerabilidade social no Estado.

O exemplo mais emblemático desse processo de desenvolvimento concentrador e excludente, a região metropolitana de São Paulo (FERREIRA e cols.2006), cuja segregação espacial remete para a chamada Belíndia, termo usado por SZWARCWALD \& cols. (1997) para exemplificar áreas de expressivas desigualdades sociais que abrigam simultaneamente condições de vida semelhantes às da Bélgica e Índia. Exemplificando tal processo para a RM São Paulo, FERREIRA e cols. (2006) demonstraram um formato radial-concêntrico na distribuição espacial da vulnerabilidade, ou seja, a existência de um anel externo à região metropolitana denominada segregação residencial, convergente com a literatura brasileira citada por TASCHNER \& BOGUS $^{6}$ (2006, p.14).

Os resultados encontrados para a distribuição espacial da vulnerabilidade social explicitam desigualdades existentes no Estado reafirmando a necessidade de políticas focadas e mais equitativas para as distintas regiões paulistas. FERREIRA e cols. (2006) afirmam que não menos relevante, é o papel central do Estado que atua como um dos principais agentes transformadores do espaço urbano, por meio de investimentos em infra-estrutura, construção habitacional e implantação de equipamentos públicos e/ou oferta de serviços públicos tornando-o mais ou menos segregado.

\footnotetext{
${ }^{5}$ TASCHNER SP, BOGUS, L. A cidade dos anéis: São Paulo. In: QUEIROZ, L.C. (Ed.). O futuro das metrópoles: desigualdades e governabilidade. Rio de Janeiro, Revan/Fase, 2000. 


\subsection{CARACTERÍSTICAS DEMOGRÁFICAS}

O conhecimento da composição da população segundo sexo e faixa etária possibilitam a análise de fenômenos demográficos relativos à sua evolução e seu perfil de morbimortalidade. A proporção de crianças menores de cinco anos numa população total está associada aos níveis de fecundidade e natalidade dessa população que, conseqüentemente influencia sua estrutura etária. Por sua vez, a proporção de idosos (60 anos e mais) indica o peso da participação dessa faixa etária na população total refletindo o ritmo de envelhecimento dessa população (RIPSA, 2002).

No período, o Estado apresentou 8,6\% de participação de crianças de 0 a 4 anos e 8,9\% para idosos. Dentre os estratos, destacou-se o Estrato A, com 6,9\%, a menor participação de crianças nessa faixa etária e, 11,9\% de idosos, a maior entre os estratos. No oposto, destacou-se o Estrato C, com participação mais elevada de crianças com 9,8\% e, a menor para os idosos com 6,4\% (Figura 11).

Internamente, os estratos de maior vulnerabilidade (C,D e E) apresentaram oscilações maiores sobressaindo-se o conjunto de municípios D300 com $12 \%$ de crianças e $4 \%$ de idosos. Ao contrário dos demais, o Estrato E, internamente destacou-se pela maior proporção de crianças e, a menor de idosos no conjunto de municípios de maior porte (E100).

A razão de dependência que mede a participação relativa do contingente populacional potencialmente inativo que será sustentado pela população potencialmente produtiva (RIPSA, 2008) considerando os indivíduos com idade entre 15 a 60 anos como os mais aptos a participar da força de trabalho (população potencialmente ativa) e, os menores de 15 anos e os acima de 60 anos, como indivíduos dependentes (Figura 11). Valores elevados dessa razão indicam que a população em idade produtiva sustenta uma maior proporção de dependentes (LAURENTI e cols. 2006). No Brasil, a razão de dependência vem declinando nas últimas décadas, reduzindo de 72,5 em 1991 para 56,9 em 2005.

Este indicador comumente considera como pessoas idosas as pessoas de 65 anos e mais e, potencialmente produtivas as de 15 a 64 anos. No entanto, RIPSA, para manutenção de coerência com os demais indicadores e atender a 
Figura 11 - Proporção (\%) de habitantes na faixa etária de 0-4 anos e de 60 anos e mais nos Estratos de Vulnerabilidade Social. Estado de São Paulo, média do triênio 2003 a 2005.

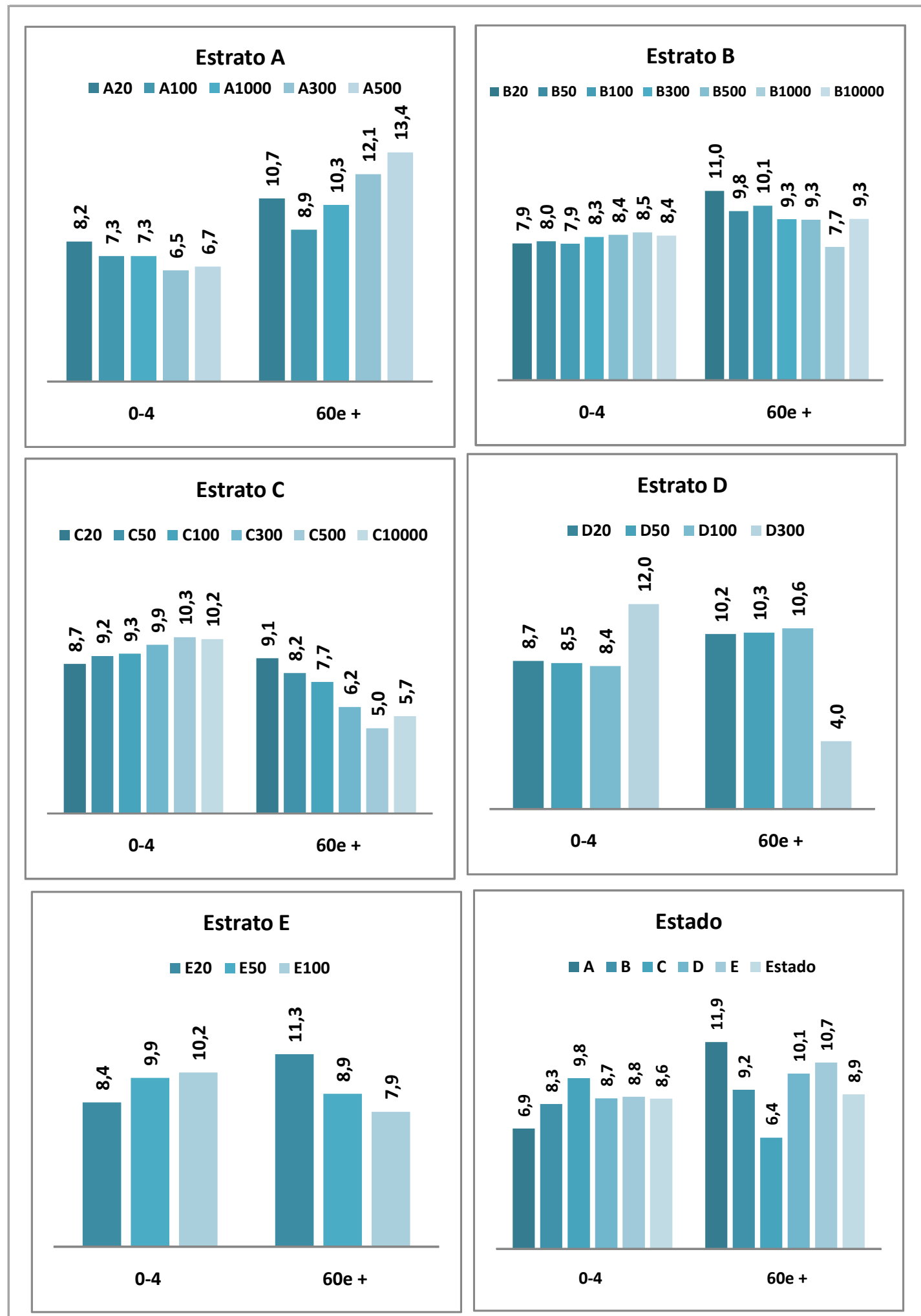

Fonte:Censo 2000 e Projeções (IBGE)

IPVS: Dados Brutos FSEADE (2005) 
segundo recomendações da Rede Interagencial de Informação para a Saúde Política Nacional do Idoso (BRASIL, 2004) recomenda-se o uso do parâmetro de 60 anos ou mais para a população de idosos e, de 15 a 59 anos para a população potencialmente produtiva (RIPSA, 2008).

No período em estudo, o Estado apresentou razão de dependência de 54,5. Com valores inferiores, situaram-se os Estratos A com 52,0 e o Estrato B com 52,8 . Os Estratos C, D e E se situaram acima da razão apresentada pelo Estado com 55,3, 59,8 e 62,7 respectivamente. A elevação do gradiente da razão de dependência se deu na mesma direção do crescimento da vulnerabilidade social dos estratos, resultado este coerente pois é esperado razões de dependência mais elevadas em municípios pequenos e de piores condições socioeconômicas.

Internamente, os estratos apresentaram razões mais elevadas nos conjuntos de municípios de menor porte populacional nos Estratos A, B e C. Ao contrário destes, os Estratos D e E apresentaram razões mais elevadas nos conjuntos de municípios de maior porte populacional (Figura 12), porém estes representaram apenas um município de 50 a 99 mil hab. e outro de 100 a 299 mil hab.

A representação gráfica da estrutura de uma população segundo sexo e idade através de pirâmides populacionais e suas formas, são elementos essenciais para a identificação das tendências demográficas e úteis na comparação entre populações (LAURENTI e cols., 2006). A pirâmide populacional do estrato $\mathrm{A}$, apresentou um estreitamento gradativo da sua base e um maior alargamento do ápice em relação às demais. Os estratos B e C apresentaram um discreto aumento da última barra mostrando oscilações na redução das suas bases. As pirâmides dos Estratos E e D se assemelham e foram as que se apresentaram mais afiladas em direção ao ápice indicando maior mortalidade (Figura 13).

$\mathrm{Na}$ população humana, o número de homens em relação ao número de mulheres tende a ser bastante estável e idealmente deveria ser um para um. A relação quantitativa entre sexos expressa-se pela razão centesimal de sexos. Se igual a $100, \mathrm{o}^{\circ}$ de homens equivale ao $\mathrm{n}^{\circ}$ número de mulheres, se acima de 
Figura 12 - Razão de dependência segundo Estratos de Vulnerabilidade Social. Estado de São Paulo, média do triênio 2003 a 2005.

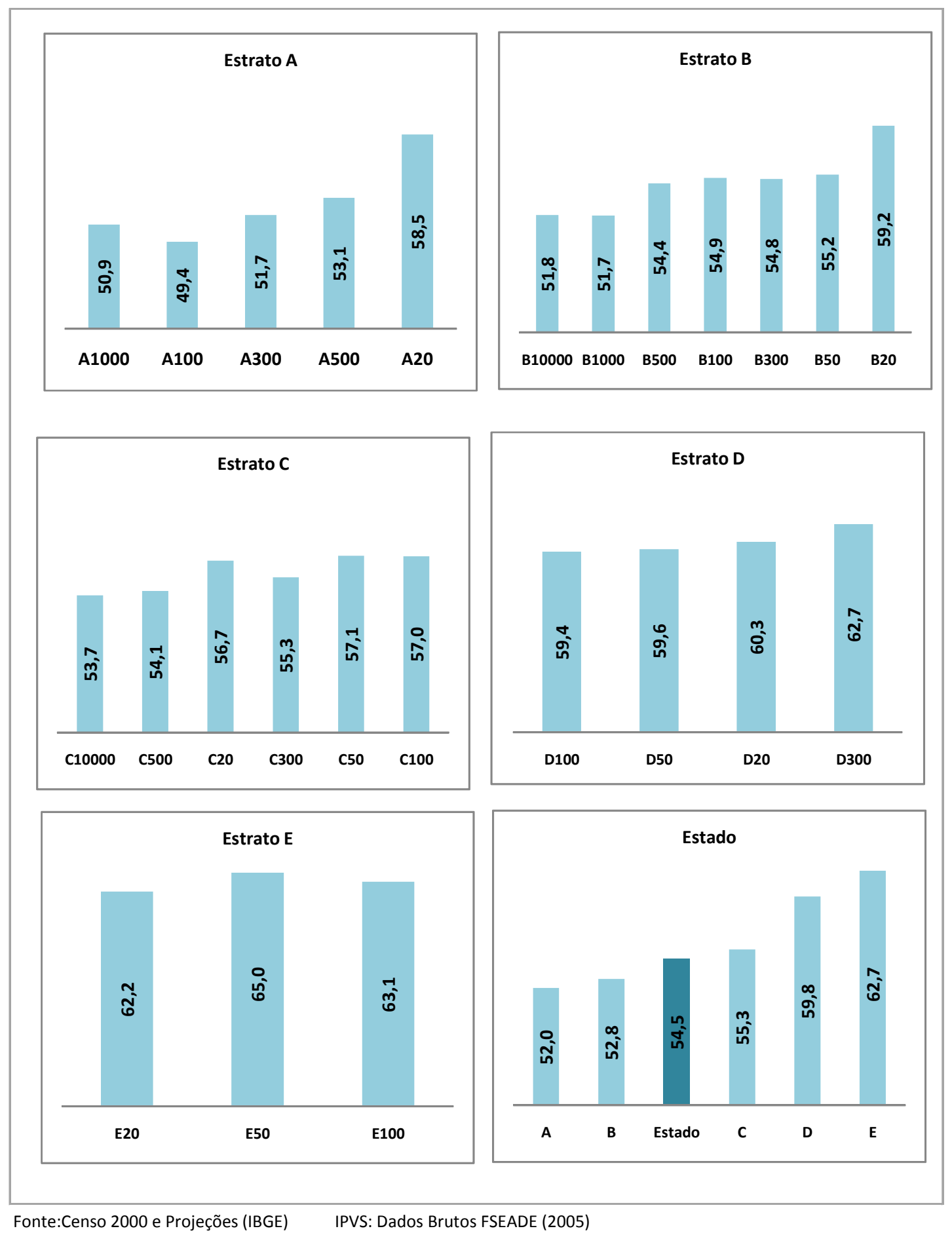


Figura 13 - Pirâmide populacional segundo Estrato de Vulnerabilidade Social. Estado de São Paulo, média do triênio 2003 a 2005.

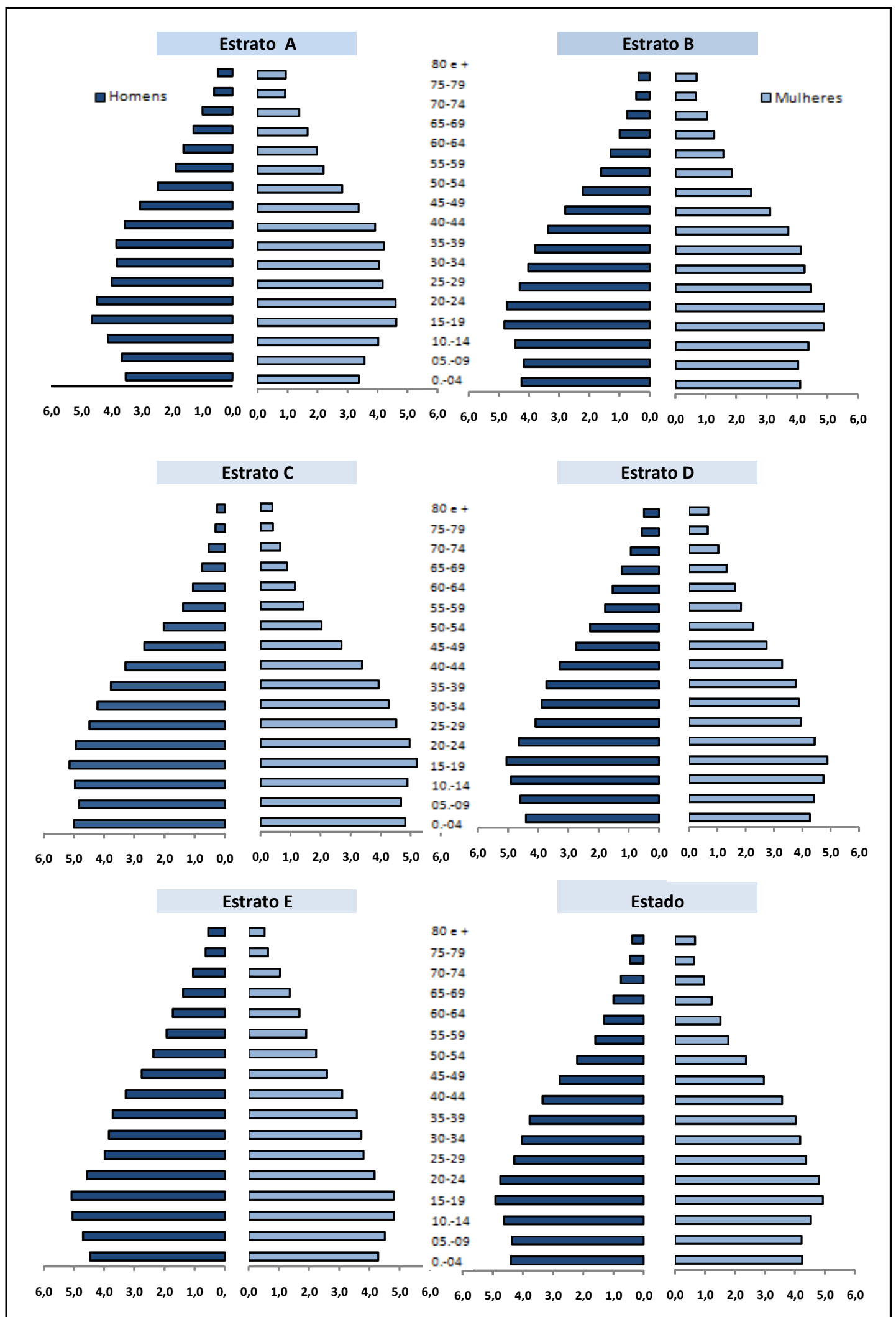

Fonte: Censo 2000 e Projeções: IBGE.

Dados brutos IPVS: FSEADE (2005) 
100, indica predominância de homens e se abaixo, indica predominância de mulheres. Movimentos migratórios e mortalidade diferenciada por sexo e idade influenciam os valores alcançados por este indicador (RIPSA 2002). Em 2005, a razão de sexos para os país foi de 96,6 e de 95,2 para a região Sudeste, a menor dentre as regiões brasileiras.

No período, a razão de sexos foi 96,1 homens/100 mulheres no Estado. Dentre os estratos, destacaram-se o A com razão de 92,8 indicando a menor relação entre homens e mulheres e, o Estrato E, a maior relação: 104,4 homens/100 mulheres. Tal qual a razão de dependência, a razão de sexos teve seu gradiente elevado à medida que aumentou a vulnerabilidade social, resultado este também esperado para municípios pequenos e com condições socioeconômicas precárias, provocando a migração principalmente dos homens para municípios maiores em busca de emprego e oportunidades.

Internamente aos estratos observou-se que os Estratos A e B apresentaram comportamentos e valores bastante semelhantes entre si. A elevação da razão ocorreu dos conjuntos de municípios de maior para os de menor porte à exceção do Estrato $\mathrm{E}$.

Os resultados deste estudo mostraram os estratos menos vulneráveis socialmente (Estrato A e B) em fases mais avançadas da transição demográfica com menor participação de crianças e maior de idosos na sua população. Os Estratos C, D e E mostraram maior participação de crianças e menor de idosos nas suas populações, sugerindo estágio mais tardio de transição demográfica. Tanto a razão de dependência como a razão de sexos apresentaram gradiente crescente à medida que cresceu a vulnerabilidade social dos estratos com maior magnitude para os conjuntos de municípios de pequeno porte (Figura 14).

As complexas inter-relações entre crescimento da população e desenvolvimento (crescimento econômico versus distribuição dos frutos do crescimento econômico) e, os possíveis efeitos do desenvolvimento sobre o crescimento populacional são desafios contemporâneos. Décadas atrás se discutia as causas e conseqüências da bomba demográfica, hoje o debate centrase nas conseqüências da transição demográfica clássica ou daquelas com especificidades próprias, que em maior ou menor velocidade atinge todas as 
regiões do planeta, com redução da fecundidade e dos níveis de mortalidade (PAIVA \& WAJNMAN, 2005). O processo de transição demográfica brasileira destaca-se por três fases distintas: a primeira, um aumento na proporção de jovens tendo como conseqüência aumento na taxa de dependência em função da queda da mortalidade infantil. A segunda, um período de redução da taxa de dependência dada à redução de jovens decorrentes da queda da fecundidade e, a terceira, a taxa de dependência volta a se elevar em função do aumento da população idosa enquanto os mais jovens chegam às idades produtivas (PAIVA \& WAJNMAN, 2005).

Como conseqüência tem-se a alteração da estrutura etária populacional reduzindo o peso relativo das crianças e, aumentando num primeiro momento, o peso dos adultos e, num período posterior, o de idosos. Projeções das Nações Unidas para o Brasil, apontam que as taxas brutas de mortalidade vão ficar praticamente estáveis, enquanto as de natalidade vão continuar caindo e, reduzindo assim o ritmo de crescimento vegetativo da população, com projeção de crescimento médio de 0,8\% de até 2030 .

A elevada taxa de urbanização, a redução do analfabetismo, a redução da mortalidade infantil, a elevação da esperança de vida além das grandes transformações nas relações de gênero, com maior autonomia das mulheres, redução do numero médio e filhos e, mais longevidade aumentaram significativamente a participação no mercado de trabalho e, ainda constituindose em fontes de riqueza para as famílias e país (IPEA, 2005).

Por outro lado, o segundo período, o do envelhecimento populacional tem sido centro do debate governamental em várias áreas, em especial na área da previdência e da economia da saúde dada a preocupação crescente com os prováveis impactos sobre os gastos públicos com previdência e saúde (MEDICI \& BELTRÃO, 1995; IPEA, 2005). A mudança de padrão de morbimortalidade torna-se crescentemente mais complexa e onerosa exigindo financiamento, reorganização de serviços, qualificação de profissionais e práticas compatíveis com o novo perfil epidemiológico, além das enormes disparidades sociais e regionais que marcam as distintas regiões do país (PAIVA \& WAJNMAN, 2005). 
Figura 14 - Razão de sexos segundo Estratos de Vulnerabilidade Social. Estado de São Paulo, média do triênio 2003 a 2005.

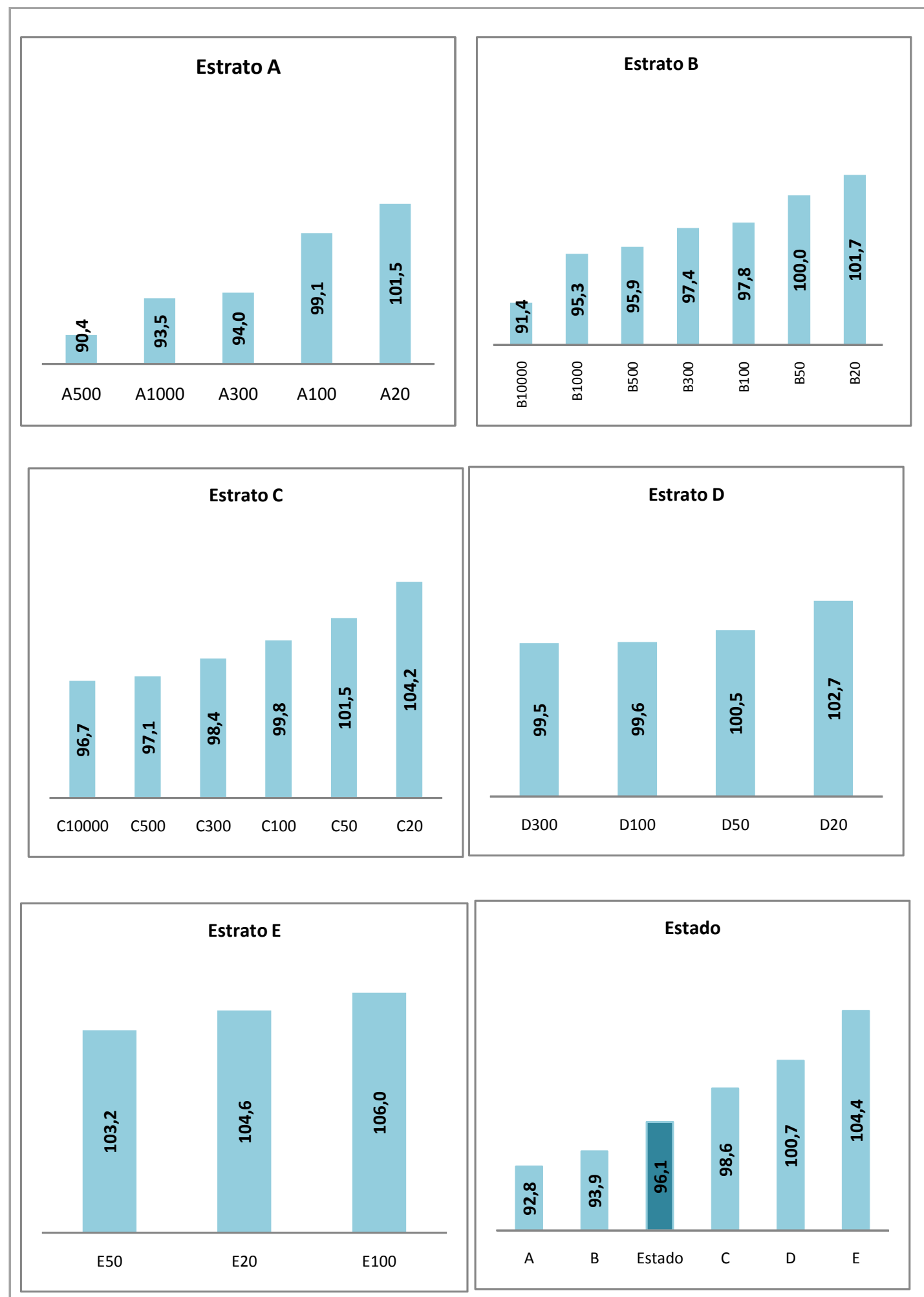

Fonte:Censo 2000 e Projeções (IBGE) IPVS: Dados Brutos FSEADE (2005) 


\subsection{MORTALIDADE PROPORCIONAL POR FAIXAS ETÁRIAS SELECIONADAS}

Numa população, a concentração de óbitos em faixas etárias mais idosas reflete a menor participação de mortes em idades mais jovens e a elevação da expectativa de vida. Por outro lado, proporções elevadas de mortes em faixas etárias mais jovens, em especial, as infantis estão associadas a más condições de vida e de saúde e, as de jovens e adultos indicam agravos à saúde derivados principalmente de causas externas como acidentes, homicídios e suicídios. Para a faixa etária de idosos (60 anos e mais), ao contrário das demais faixas etárias, espera-se que a concentração de mortes seja mais elevada indicando assim melhores condições de saúde, vida e, aumento da expectativa de vida (RIPSA, 2008).

Em 2004, no país 58,6\% dos óbitos referiam-se a população acima de 60 anos e, 60,6\% na região Sudeste (RIPSA 2008). Desigualdades na mortalidade não se restringem somente a idade, mas também a causalidade, destacando-se as infecciosas, perinatais e mal definidas nas regiões Norte e Nordeste do país, enquanto no Sul e Sudeste predominam as decorrentes do aparelho circulatório, respiratório e neoplasias. As causas externas vêm se destacando pela sua relevância na população jovem, em especial, a masculina, com destaque para os homicídios (MINISTÉRIO DA SAÚDE, 2006).

No período, ocorreram 714.356 mortes resultando numa média anual de 238.119 óbitos. Foram excluídos 6337 óbitos do triênio por não possuir identificação do município de residência no estado, idade ou sexo do falecido.

No período, o Estado apresentou 3,7\% de participação para as mortes infantis, 32,7\% para os adultos de 20 a 59 anos e, 60,5\% para os idosos. Nos estratos, destacou-se o Estrato $C$, pela maior participação de mortes infantis com 4,9\%, para os adultos com 39,1\% e, 52\% para os idosos, a menor participação. No oposto, o Estrato A, o de menor vulnerabilidade apresentou a menor participação para as mortes infantis e de adultos $22,3 \%$ e 27,4\% respectivamente) e, a mais elevada para os idosos com 68,4\% (Tabela 6). 
Tabela 6 - Mortalidade proporcional (\%) por faixa etária selecionada segundo Estrato de Vulnerabilidade Social. Estado de São Paulo, média do triênio 2003 a 2005

\begin{tabular}{lrrrrrrrrrrr}
\hline Estrato & $<\mathbf{0 1}$ ano & $\mathbf{\%}$ & $\mathbf{. 0 1 - 0 4}$ & $\mathbf{\%}$ & $\mathbf{. 0 5 - 1 9}$ & $\mathbf{\%}$ & $\mathbf{2 0 - 5 9}$ & $\mathbf{\%}$ & $\mathbf{6 0} \mathbf{e}+$ & $\mathbf{\%}$ & Total \\
\hline \hline Estrato A & 344 & 2,3 & 57 & 0,4 & 224 & 1,5 & 4065 & 27,4 & 10157 & 68,4 & 14847 \\
Estrato B & 4871 & 3,5 & 785 & 0,6 & 3288 & 2,4 & 44436 & 32,3 & 84326 & 61,2 & 137707 \\
Estrato C & 2170 & 4,9 & 370 & 0,8 & 1464 & 3,3 & 17427 & 39,1 & 23179 & 52,0 & 44610 \\
Estrato D & 915 & 3,7 & 151 & 0,6 & 478 & 1,9 & 7404 & 29,6 & 16107 & 64,3 & 25055 \\
Estrato E & 554 & 3,5 & 90 & 0,6 & 316 & 2,0 & 4557 & 28,7 & 10383 & 65,3 & 15900 \\
\hline Estado & $\mathbf{8 8 5 4}$ & $\mathbf{3 , 7}$ & $\mathbf{1 4 5 3}$ & $\mathbf{0 , 6}$ & $\mathbf{5 7 7 0}$ & $\mathbf{2 , 4}$ & $\mathbf{7 7 8 8 9}$ & $\mathbf{3 2 , 7}$ & $\mathbf{1 4 4 1 5 2}$ & $\mathbf{6 0 , 5}$ & $\mathbf{2 3 8 1 1 9}$ \\
\hline \hline
\end{tabular}

Internamente aos estratos, destacaram-se os conjuntos de municípios C500 com 44,2\%, C10000 com 41\% (Estrato C), D300 com 46,7\% (Estrato D) e o E100 com 37,1\% (Estrato E) com os mais elevados percentuais de mortes na faixa etária de 20 a 59 anos (Figura 15).

Os achados deste estudo mostraram mortalidade proporcional mais elevada em todas as faixas etárias abaixo de 60 anos no Estrato C, destacando-se a faixa etária de 20 a 59 anos, cuja mortalidade é fortemente influenciada pelas Causas Externas (NOGUEIRA, 2004), seguido do Estrato B para esta faixa etária. Estes resultados podem ser explicados pelas características dos municípios conformados nestes estratos. O Estrato C, agregou municípios de vulnerabilidade social intermediária, com elevado adensamento populacional, em especial, na RM São Paulo, localizados num cinturão periférico da região metropolitana. O Estrato B, apesar da menor vulnerabilidade social, agregou grandes municípios, com maior pujança econômica e riqueza como Campinas, São Paulo, Ribeirão Preto entre outros, mas que apesar da menor vulnerabilidade, são cercados por municípios de maior vulnerabilidade além de apresentar áreas intra-urbanas com elevadas desigualdades sociais e com elevados índices de violência (FERREIRA e cols., 2006) sugerindo para ambos maior exposição aos riscos de mortalidade por causas externas. 
Figura 15 - Mortalidade proporcional (\%) por faixa etária selecionada, segundo porte populacional dos conjuntos de municípios nos Estratos de Vulnerabilidade Social. Estado de São Paulo, média do triênio 2003 a 2005.
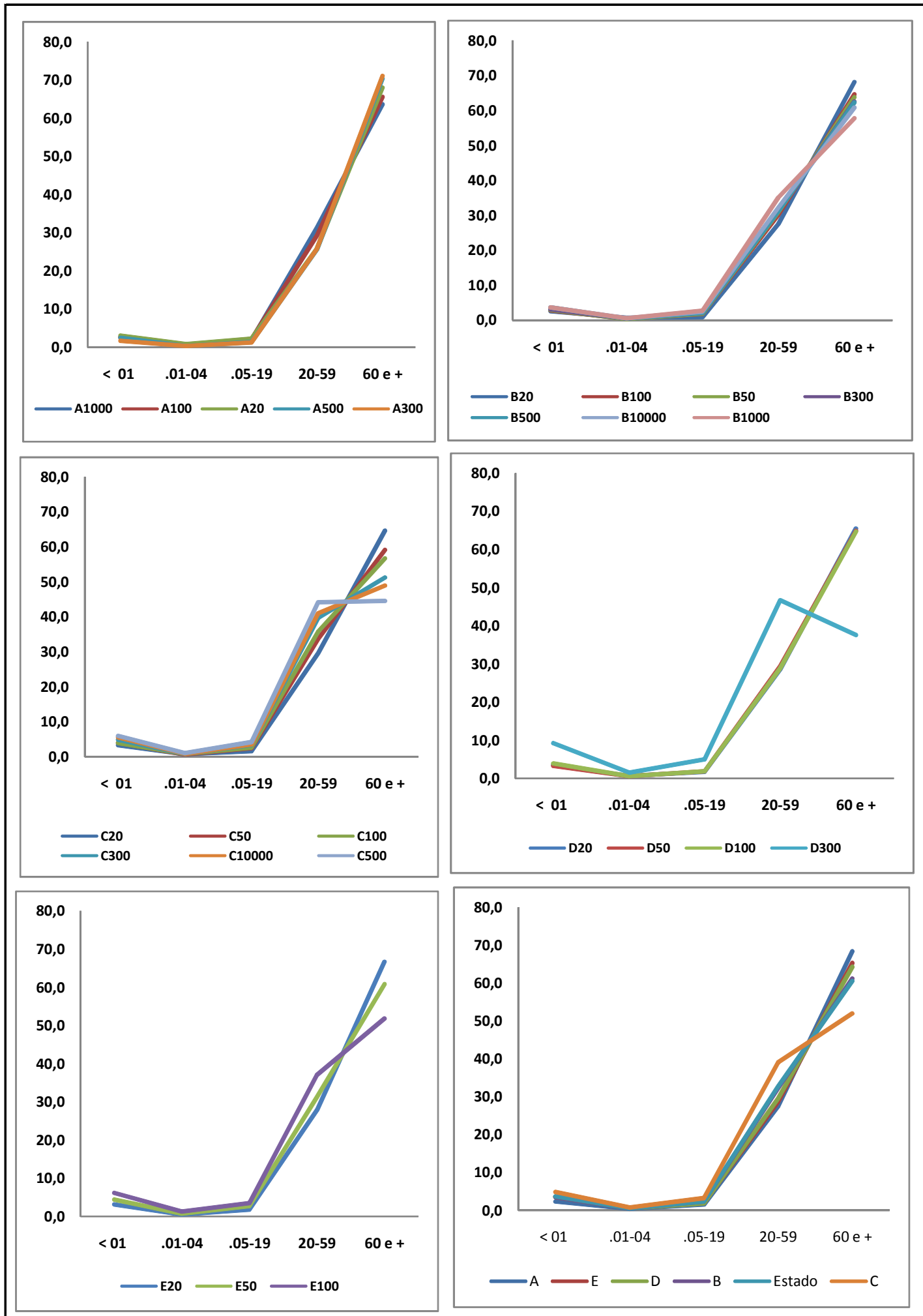

Fonte: SIM.Ministério da Saúde.

Dados Brutos: IPVS.FSEADE (2005) 


\subsection{DIFERENCIAIS DE CARACTERISTICAS DEMOGRÁFICAS}

A caracterização demográfica dos Estratos de Vulnerabilidade Social mostrou razões de dependência e de sexos com gradientes crescentes à medida que cresceu a vulnerabilidade social dos Estratos, situando-se num extremo o Estrato A, com os menores valores e, noutro o Estrato E, com os maiores valores (Tabela 7).

A distribuição da mortalidade proporcional (\%) por faixa etária selecionada apontou para o Estrato A com a menor participação relativa de óbitos em crianças e, a maior para os idosos. $\mathrm{O}$ Estrato $\mathrm{C}$, ao contrário do $\mathrm{A}$, apresentou-se com a maior participação (\%) de mortes de crianças e, a menor de idosos (\%).

Tabela 7 - Síntese dos indicadores selecionados de caracterização demográfica dos Estratos de Vulnerabilidade Social. Estado de São Paulo, média do triênio 2003-2005.

\begin{tabular}{|c|c|c|c|c|c|c|c|}
\hline Indicador / & Estrato & A & B & C & D & E & Estado \\
\hline \multicolumn{2}{|l|}{ Razão de Dependência } & 52,00 & 52,80 & 55,30 & 59,80 & 62,70 & 54,50 \\
\hline \multicolumn{2}{|l|}{ Razão de Sexos } & 92,77 & 93,90 & 98,59 & 100,69 & 104,43 & 96,10 \\
\hline \multirow[t]{3}{*}{ Mort. Proporcional (\%) } & )$<1$ ano & 2,32 & 3,54 & 4,87 & 3,65 & 3,48 & 3,72 \\
\hline & 20-59 anos & 27,38 & 32,27 & 39,07 & 29,55 & 28,66 & 32,71 \\
\hline & 60 anos $\mathrm{e}+$ & 68,41 & 61,24 & 51,96 & 64,29 & 65,30 & 60,54 \\
\hline \multirow[t]{2}{*}{ População (\%) } & 0-4 anos & 6,92 & 8,35 & 9,82 & 8,67 & 8,76 & 8,65 \\
\hline & 60 anos $\mathrm{e}+$ & 11,91 & 9,17 & 6,41 & 10,10 & 10,74 & 8,90 \\
\hline
\end{tabular}

Os resultados mostraram os estratos Estrato A e $\mathrm{B}$ em fases mais avançadas da transição demográfica em relação aos Estratos C, D e E cujas características demográficas apontam para um estágio mais tardio de transição demográfica, resultados este coerentes com a conformação dos estratos homogêneos. 
Padrões diferenciados de morbidade e mortalidade em grupos populacionais são determinados por múltiplos aspectos como distribuição desigual dos fatores de exposição e do acesso a bens e serviços de saúde, fragilidade das estruturas sociais e, insuficiência de investimentos em políticas sociais, especialmente naquelas com grande nível de concentração de renda e baixo nível de coesão social (DUARTE \& cols., 2002).

A mortalidade de crianças menores de 5 anos expressa as condições de vida uma população, pois nelas preponderam causas que seriam evitáveis pelo uso de técnicas adequadas de cuidado com a criança e com a mãe e por melhorias das condições de vida das famílias (NOGUEIRA, 2004) enquanto a mortalidade na faixa etária de 20 a 59 anos é fortemente influenciada pelas Causas Externas.

Para DUARTE \& cols. (2002) os determinantes demográficos e, aqueles relacionados ao ambiente construído e ao hiper-adensamento populacional podem ainda, agregar novos contornos às desigualdades em saúde em populações urbanas.

\subsection{CAUSAS DE MORTE MAL DEFINIDAS}

No Brasil, há décadas as causas de mortes mal definidas (Cap. XVIIISintomas, Sinais e Achados Anormais de Exames Clínicos e de Laboratório Não Classificados em Outra Parte - CID 10) como causa indeterminada, parada cardíaca, choque, caquexia, morte súbita e sinais, morte sem assistência e sintomas não relacionados a nenhuma doença específica, vem ocupando o segundo lugar como causa de óbito lugar entre todas as causas (MINISTÉRIO DA SAÚDE, 2004).

No período, as causas mal definidas foram responsáveis por 45.956 mortes no Estado. Destas foram excluídas 530, por não possuir identificação do município de residência, resultando numa média anual de 15.142 óbitos. 
Tabela 8 - Proporção (\%) de óbitos por Causas Mal Definidas segundo Estrato de Vulnerabilidade Social. Estado de São Paulo, média do triênio de 2003 a 2005

\begin{tabular}{rcccrccc}
\hline Estrato & Mal Def. & $\begin{array}{c}\text { Óbitos } \\
\text { Totais }\end{array}$ & \multicolumn{1}{c}{ \% } & Mediana & $\begin{array}{l}\text { Desvio } \\
\text { Padrão }\end{array}$ & $\begin{array}{l}\text { Maior } \\
\text { Valor }\end{array}$ & Menor Valor \\
\hline \hline Estrato A & 881 & 14853 & 5,9 & 5,1 & 6,3 & 19,2 & 9,0 \\
Estrato B & 6775 & 137774 & 4,9 & 8,9 & 6,1 & 23,6 & 0,6 \\
Estrato C & 2758 & 44645 & 6,2 & 6,8 & 5,9 & 20,7 & 0,9 \\
Estrato D & 2881 & 25070 & 11,5 & 10,8 & 5,9 & 27,4 & 0,0 \\
Estrato E & 1847 & 15908 & 11,6 & 11,1 & 7,0 & 40,0 & 0,0 \\
\hline Estado & $\mathbf{1 5 1 4 2}$ & $\mathbf{2 3 8 2 5 0}$ & $\mathbf{6 , 4}$ & $\mathbf{1 0 , 1}$ & $\mathbf{6 , 7}$ & $\mathbf{4 0 , 0}$ & $\mathbf{0 , 0}$ \\
\hline \hline
\end{tabular}

Fonte: SIM. Ministério da Saúde Dados Brutos: IPVS FSEADE (2005)

O Estado apresentou 6,4\% de mortes por estas causas destacando-se o Estrato B, com a menor participação com 4,9\% e, o Estrato E com 11,6\%, variabilidade interna $=$ DP de 11,1 e mediana de 7,0, as mais elevadas dentre os estratos. O Estrato D mostrou resultados muito semelhantes ao Estrato E com 11,5\% de mal definidas (Tabela 8).

Tais resultados são coerentes com os municípios que conformam estes dois estratos com predomínio de municípios abaixo de 50 mil hab., que dispõe de menor infra-estrutura de serviços de atenção à saúde e, com prováveis implicações para a qualidade da informação no registro sobre a causa básica da morte. Com exceção do Estrato E, os demais apresentaram internamente proporções mais elevadas de causas mal definidas nos conjuntos de municípios de menor porte populacional (Figura 16), apontando para a relação entre qualidade da informação e infra-estrutura de serviços de atenção à saúde.

0 percentual de óbitos por causas de mortes mal definidas representa a fração em que as causas da morte não foram objetivamente esclarecidas e, indica a qualidade da informação sobre causas de morte (RIPSA, 2008). Três fatores podem ainda estar relacionados à maior proporção de causas mal definidas nestes municípios: primeiro, a busca de assistência de maior complexidade em outros municípios (de referência ou não) em razão da inexistência de hospitais e/ou serviços de urgência/emergência dificultando ao médico que o atendeu (plantonista) definir com precisão as causas da morte.

O segundo, a ocorrência de óbitos domiciliares de pacientes que, mesmo com patologias definidas e com acompanhamento médico-ambulatorial buscam 
atendimento nos serviços de urgência/emergência em outras instituições hospitalares que, não dispondo de prontuário e/ou informações técnicas precisas sobre o quadro clinico do paciente, induz o médico atestante a optar pelo registro de causas mal definidas. E, por fim, o terceiro, aquele que engloba dificuldades de acesso seja do paciente em relação à assistência médica ou, institucional em relação aos serviços de verificação de óbitos para esclarecimento da causa básica da morte.

Os óbitos por causas mal definidas no país somaram 12,4\% e na região Sudeste 8,5\% em 2004 (RIPSA 2008) mostrando ainda proporções elevadas destas causas, apesar de redução importante ao longo do tempo, porém bastante distante ainda de países desenvolvidos cuja participação é da ordem de 1\% (ROZMAN \& ELUF NETO, 2006).

As causas de morte são essenciais para o uso dos dados para a identificação do perfil de morbimortalidade de uma população, cuja completude e acurácia dos registros são essenciais para subsidiar com segurança o planejamento, as intervenções e avaliação da efetividade das ações em saúde, pois proporções elevadas de causas mal definidas comprometem a real dimensão das causas definidas. Em estudos de revisão sobre dados de mortalidade pela Organização Mundial da Saúde - OMS, o Brasil foi classificado como um país de qualidade média dada à proporção de mortes classificadas como causas mal definidas, entre outros indicadores (SANTO, 2007).

Reveste-se ainda de importância o maior ou menor acesso ao Serviço de Verificação de Óbitos - SVO para elucidação e redução dessas causas, serviço este sob a responsabilidade e coordenação da Faculdade de Medicina da Universidade de São Paulo na RM São Paulo. No interior, tais serviços estão sob responsabilidade e coordenação da Faculdade de Medicina de Ribeirão Preto, também da Universidade de São Paulo. Estudos conduzidos por SANTO (2007) para o período de 1998 a 2002 mostraram que em municípios com SVO, o percentual de mal definidas alcançou 1,3\%, enquanto municípios sem SVO 
Figura 16- Proporção (\%) de óbitos por Causas Mal Definidas segundo porte populacional dos conjuntos de municípios nos Estratos de Vulnerabilidade Social. Estado de São Paulo, média do triênio 2003 a 2005.

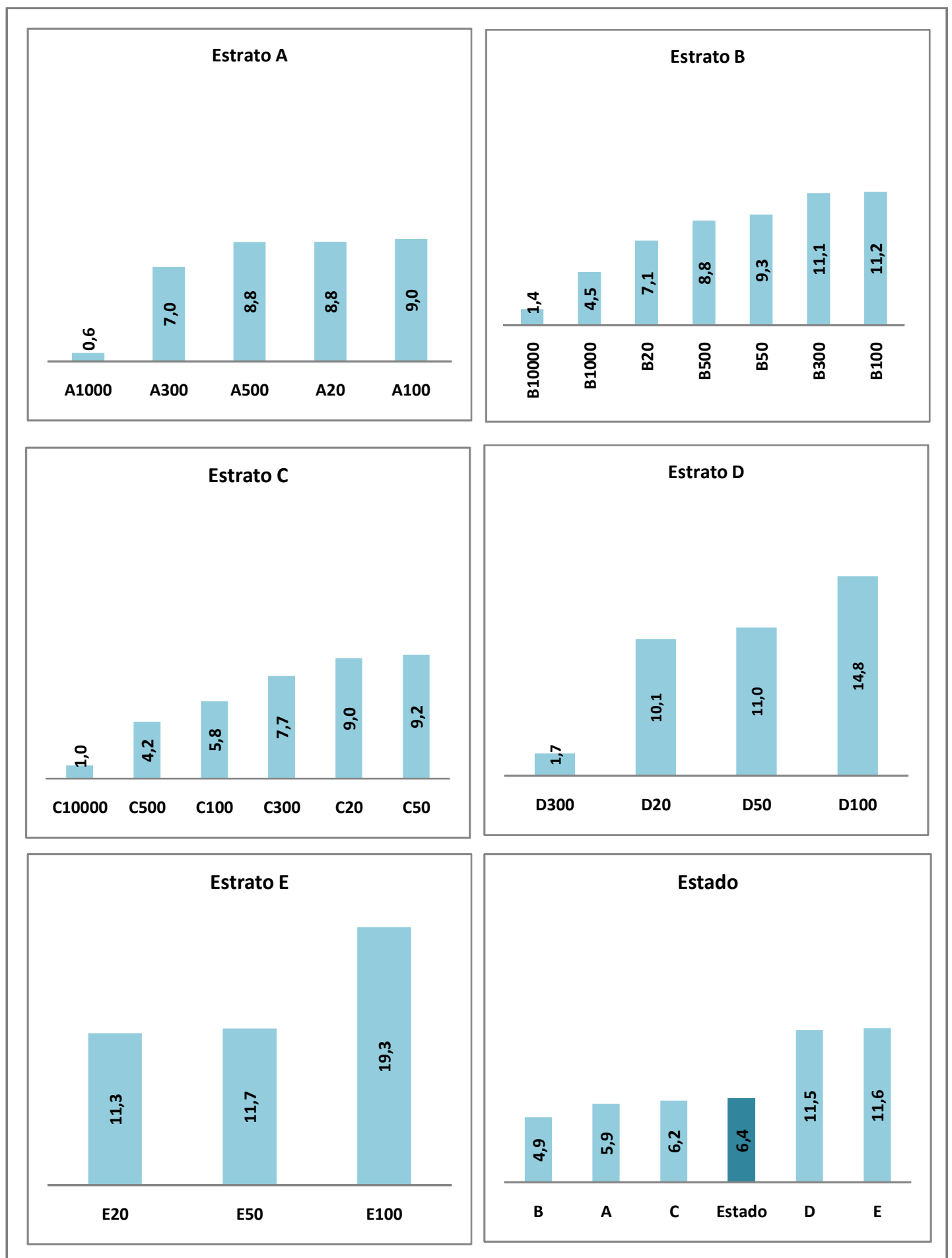

Fonte: SIM. Ministério da Saúde Dados Brutos:IPVS FSEADE (2005) 
alcançaram 10,4\%, dos quais 40,8\% ocorreram em hospital e, 60,3\% fora do hospital, chamando a atenção principalmente para os óbitos domiciliares.

O profissional médico ocupa papel central nesse processo, pois legalmente ele é o responsável direto pelo preenchimento da Declaração de Óbito - DO e o empenho desses profissionais no preenchimento das declarações de óbito fornecendo informações corretas e completas, é passo chave para a melhoria da informação sobre as causas de morte do óbito. Normatização do Conselho Federal de Medicina orienta aos profissionais o envio ao SVO e, na sua impossibilidade o registro na DO como causa a morte sem assistência (Res. CFM no 1.601/00) para casos de morte sem assistência. A não autorização da família para a necropsia por questões culturais e religiosas, também pode ser um fator contributivo para a elevação da freqüência dessas causas.

A investigação das causas da morte têm se configurado a cada dia mais como uma estratégia robusta para a melhoria da informação. Estudos conduzidos no Brasil por MELLO JORGE e col. (2002) apontaram para ganho de $63,1 \%$ de informação após investigação. A utilização desta estratégia para a melhoria da informação vem sendo estimulada entre os gestores do Sistema Único de Saúde com inclusão destas em projetos e pactos que envolvem o financiamento do sistema. Porém, tais ações, em especial para pequenos municípios, não se constituem em tarefas fáceis, pois muitos de seus óbitos, senão a maioria ocorre em outros municípios, exigindo desenvolvimento de fluxos intermunicipais e até regionais, pois as investigações são complementares (parte dela é realizada no município de residência e parte no de ocorrência) para a perfeita compreensão e análise das causas da morte e seus determinantes.

$\mathrm{Na}$ literatura, vários autores têm chamado a atenção do atual papel dos municípios na produção das estatísticas da mortalidade no país, tendo em vista que, as normativas legais do Sistema Único de Saúde delegam a estes a responsabilidade pela coleta, codificação, processamento, análise e disseminação das informações sobre mortalidade (SANTO, 2007; JORGE e cols., 2000) sob a coordenação das Secretarias Estaduais de Saúde. Pessoal 
qualificado, infra-estrutura de tecnologia e melhoria de processos são requisitos básicos para o aprimoramento das informações em saúde.

Dentre as causas mal definidas merece ainda aprofundamento a identificação real da causa da morte e respectivas faixas etárias, para aquelas registradas como sem assistência médica, tanto para o episódio que gerou o óbito, como para aquelas que se referem ao decurso da patologia, buscando identificar dificuldades de acesso bem como a qualidade da atenção ofertada pelo sistema de saúde. Estudos de COSTA \& MARCOPITO (2008) demonstraram concentração elevada dessas causas nas faixas etárias de menores de 1 ano e de idosos (acima de 60 anos) que, a depender da magnitude destas, pode contribuir para distorções de coeficientes específicos por causa definida destas faixas etárias.

\subsection{MORTALIDADE INFANTIL}

No triênio, os nascidos vivos (n.v) de mães residentes no Estado totalizaram 1.847.515 e, os óbitos infantis 26.585. Foram excluídos 778 registros de nascidos vivos e 23 óbitos por não possuírem identificação do município de residência no estado, resultando assim numa média anual de 615.579 nascidos vivos e 8.854 óbitos de menores de 1 ano para este estudo.

No Estado, a taxa de mortalidade infantil apresentada foi de $14,38 \%$ n.v e, nos estratos variou de 12,48 a 16,10\%0 n.v (Tabela 9). O gradiente de taxas elevou-se à medida que cresceu a vulnerabilidade social dos estratos. 0 maior valor (Estrato D) e o menor valor (Estrato $\mathrm{A}$ ) entre os estratos resultaram numa razão de taxas de 1,3 .

Internamente, o Estrato A variou de 8,47 a 31,91\%0 n.v, apresentando a taxa mais elevada no conjunto de municípios A20 (14,88\%0 n.v). O Estrato B com taxa, de 13,81\%0 n.v, apresentou taxa mais elevada no conjunto de municípios B500 com 15,21\%0 n.v (Figura 17). Espacialmente, nestes estratos as taxas mais elevadas foram observadas em áreas das regiões da Taubaté, 
Baixada Santista, Campinas, Sorocaba, S. J. Boa Vista, Bauru, Araçatuba e RM São Paulo (Figura 18).

Tabela 9 - N óbitos de menores de 1ano e de nascidos vivos, Taxa de Mortalidade Infantil (por 1000 nascidos vivos), mediana e desvio padrão dos Estratos de Vulnerabilidade Social. Estado de São Paulo, média do triênio 2003 a 2005.

\begin{tabular}{|c|c|c|c|c|c|c|c|}
\hline Estrato & $\begin{array}{c}\text { Nascidos } \\
\text { Vivos }\end{array}$ & $\begin{array}{c}\text { Óbitos }<1 \\
\text { ano }\end{array}$ & Taxa & Mediana & $\begin{array}{l}\text { Desvio } \\
\text { padrão }\end{array}$ & $\begin{array}{l}\text { Maior } \\
\text { Valor }\end{array}$ & $\begin{array}{l}\text { Menor } \\
\text { Valor }\end{array}$ \\
\hline Estrato A & 27556 & 344 & 12,48 & 12,73 & 6,99 & 31,91 & 8,47 \\
\hline Estrato B & 352791 & 4871 & 13,81 & 13,46 & 4,34 & 27,91 & 0,00 \\
\hline Estrato C & 144369 & 2170 & 15,03 & 13,81 & 4,07 & 26,50 & 4,63 \\
\hline Estrato D & 56472 & 915 & 16,20 & 14,71 & 5,70 & 35,79 & 0,00 \\
\hline Estrato $\mathrm{E}$ & 34391 & 554 & 16,10 & 14,76 & 10,06 & 65,22 & 0,00 \\
\hline Estado & 615579 & 8854 & 14,38 & 14,17 & 7,97 & 65,22 & 0,00 \\
\hline
\end{tabular}

O Estrato C, variou internamente de 4,63 a $26,50 \%$ n.v com taxas mais elevadas nos conjuntos de municípios de médio e grande porte (C500 e C10000). Espacialmente, taxas mais elevadas foram observadas em municípios da região de Marília, Piracicaba, Ribeirão Preto, Taubaté (litoral norte), Baixada Santista, RM São Paulo e Campinas. (Figura 18).

Os Estratos D e E, apresentaram taxas muito próximas (14,71 e 14,76\%0 n.v), porém com maior variabilidade interna $\mathrm{DP}=10,06$. Espacialmente, áreas com taxas mais elevadas foram evidenciadas nas regiões de Registro, Bauru, Marília, Presidente Prudente, Araçatuba, S.J.Rio Preto, Taubaté, Campinas, S.J. Boa Vista, Franca e RM São Paulo.

Nos Estratos, internamente observaram-se diferenciais de mortalidade expressivos em todos os estratos derivadas provavelmente de desigualdades intra-urbanas mesmo nos estratos de menor vulnerabilidade (Tabela 9). Internamente, nos estratos $\mathrm{D}$ e $\mathrm{E}$ observaram-se taxas mais elevadas nos conjuntos de municípios (E100 e D300).

No Estado, espacialmente as áreas das regiões de Sorocaba, Baixada Santista, S.J.Rio Preto, Araçatuba, Presidente Prudente, Taubaté e RM São Paulo mostraram taxas mais elevadas (Figura 19). As menores, foram mostradas na 
Figura 17 - Taxa de mortalidade infantil (por mil nascidos vivos) segundo porte populacional dos conjuntos de municípios dos Estratos de Vulnerabilidade Social. Estado de São Paulo, média do triênio 2003 a 2005.

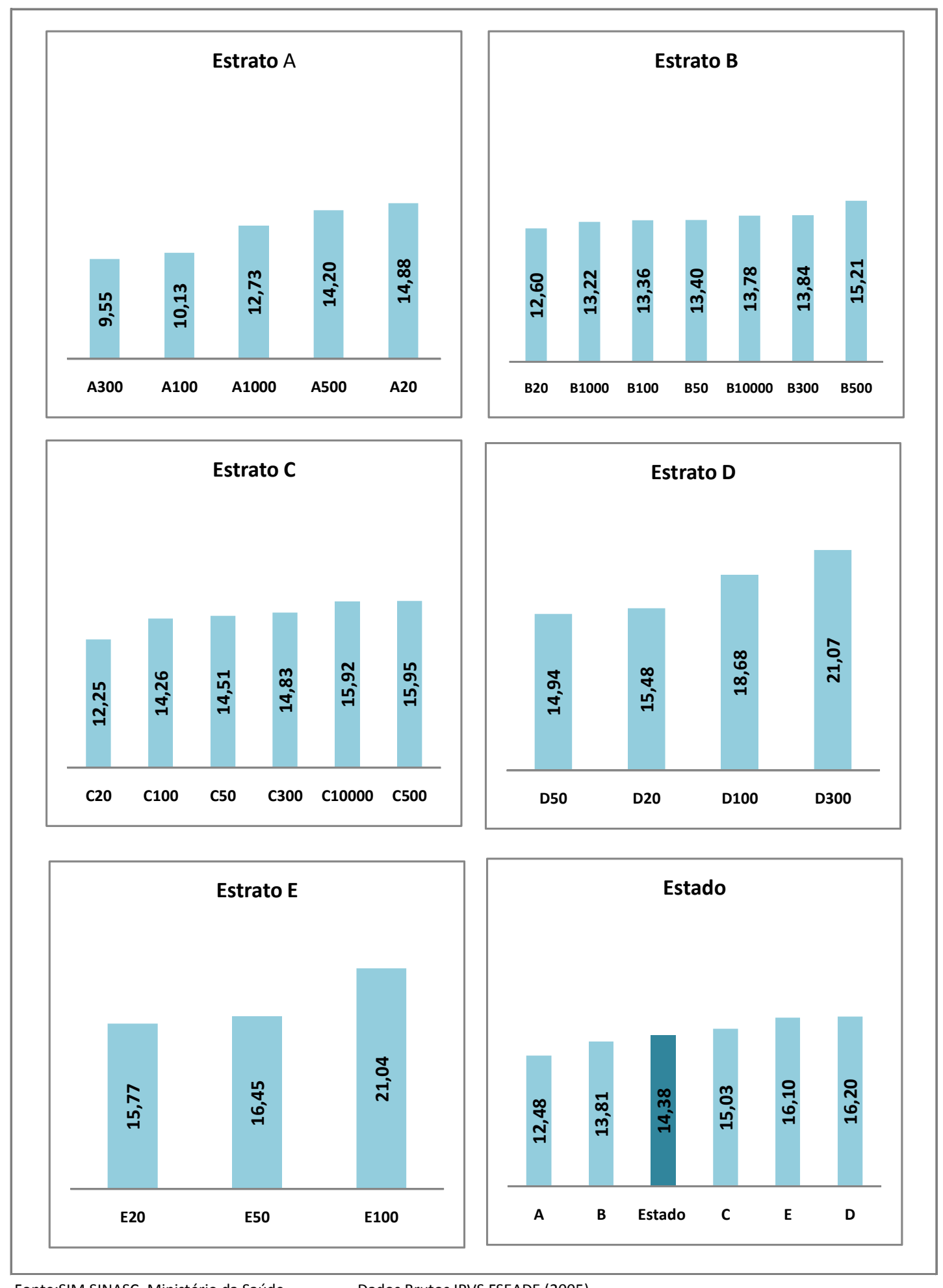

Fonte:SIM.SINASC. Ministério da Saúde

Dados Brutos IPVS FSEADE (2005) 
região central do Estado, englobando parcelas das regiões de Araraquara, Barretos e Ribeirão Preto, além de outras áreas, porém estas mais dispersas. Ao longo do tempo a mortalidade infantil tem sido reconhecida como indicador das condições de saúde da população menor de um ano refletindo as condições gerais de vida, numa perspectiva de síntese da qualidade de vida e do nível de desenvolvimento de uma população. Da década de trinta a noventa, no país declinou de 162,4\%0 para 115,0\%0 n.v (IBGE, 1999) e, em 2004 alcançou 22,6\% n.v (MINISTÉRIO DA SAÚDE, 2006). O estado de São Paulo, com taxas bastante inferiores à nacional acompanhou essa tendência declinando de 51,1 para 16,7 \%o n.v de 1980 a 2000 (ORTIZ, 2002) e, para 14,3 \%o n.v em 2004 (FSEADE, 2005).

Esta queda acentuada tem sido atribuída às políticas públicas desenvolvidas nas últimas décadas, em especial na área de saúde pública, como saneamento básico, ampliação dos programas de saúde materna infantil e de serviços médico-hospitalares, campanhas de vacinação, programas de aleitamento materno e, a implantação da terapia de reidratação oral. Somou-se ainda a estes fatores, as intensas mudanças nos padrões reprodutivos da mulher brasileira caracterizada por expressiva queda do nível de fecundidade e, ainda a elevação do nível educacional das mulheres (MELLO JORGE e cols., 2001).

0 óbito infantil é resultante de uma extensa cadeia de determinantes e condicionantes estando entrelaçado às variáveis biológicas, sociais, econômicas e demográficas, reconhecido há décadas como ocorrência "evitável" por serviços de saúde eficazes dada a existência de tecnologias em saúde, constituindo-se como um "evento sentinela" e, a sua ocorrência um indicador das potenciais deficiências do sistema de saúde em oferecer o cuidado apropriado e oportuno (RUTSTEIN e cols., 1976).

Sua maior ou a menor magnitude dependem da interação entre fatores de riscos biológicos, ambientais e de atenção à saúde à mãe no período gestacional e parto e, ao neonato até a idade de 1 ano. Entre os fatores biológicos, também referidos como endógenos incluem idade, paridade, ganho ponderal, doenças como hipertensão, diabetes e perdas perinatais prévias entre outras, para a mãe. Para o neonato, peso ao nascer, duração da gestação, condições do 
Figura 18 - Distribuição espacial da taxa de mortalidade infantil (por 1000 nascidos vivos) nos municípios dos Estratos de Vulnerabilidade Social (A e B) e C. Estado de São Paulo, média do triênio 2003-2005.

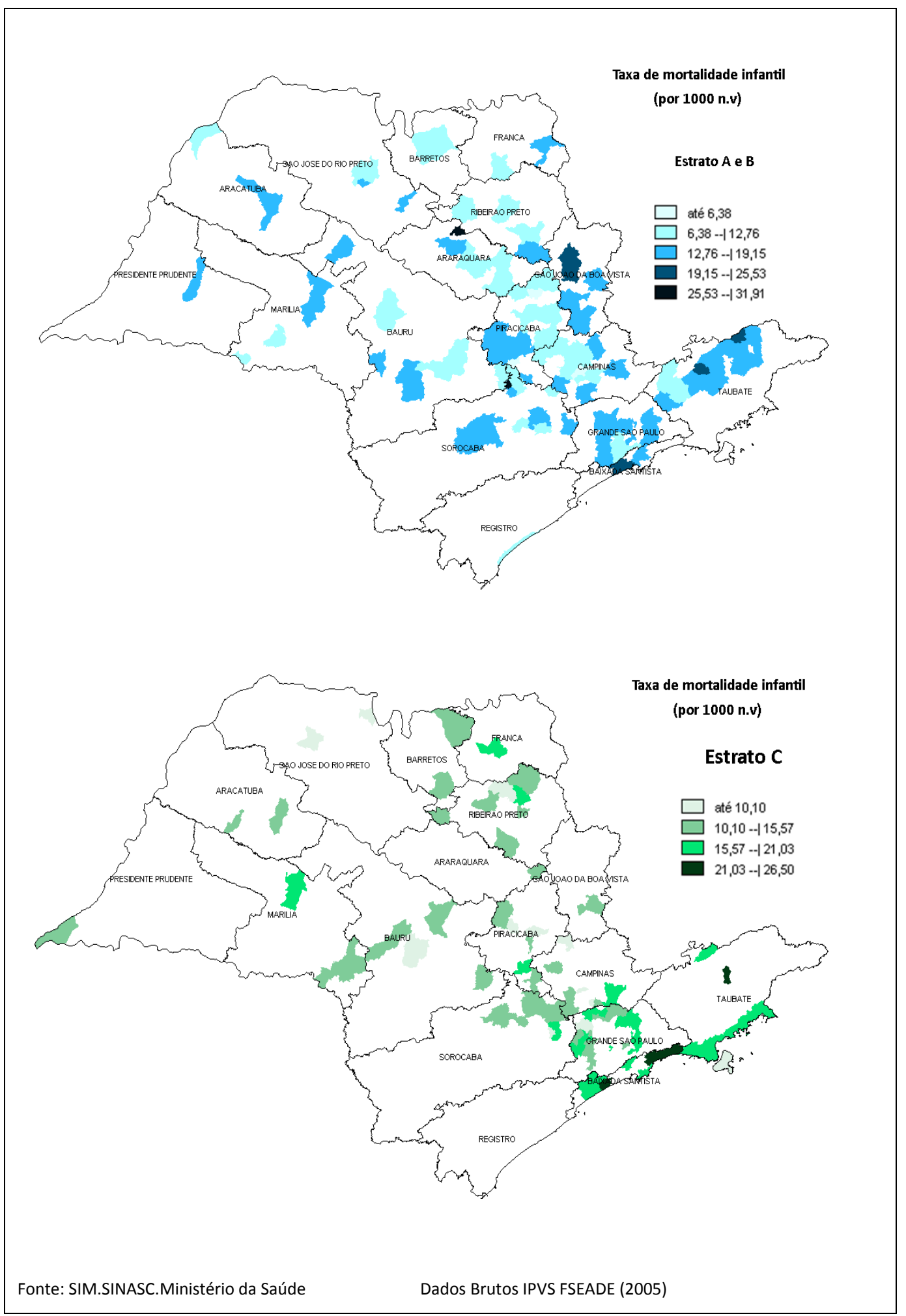


Figura 19 - Distribuição espacial da taxa de mortalidade infantil (por 1000 nascidos vivos) nos municípios dos Estratos (D e E) e do Estado de São Paulo. Média do triênio 2003 a 2005.

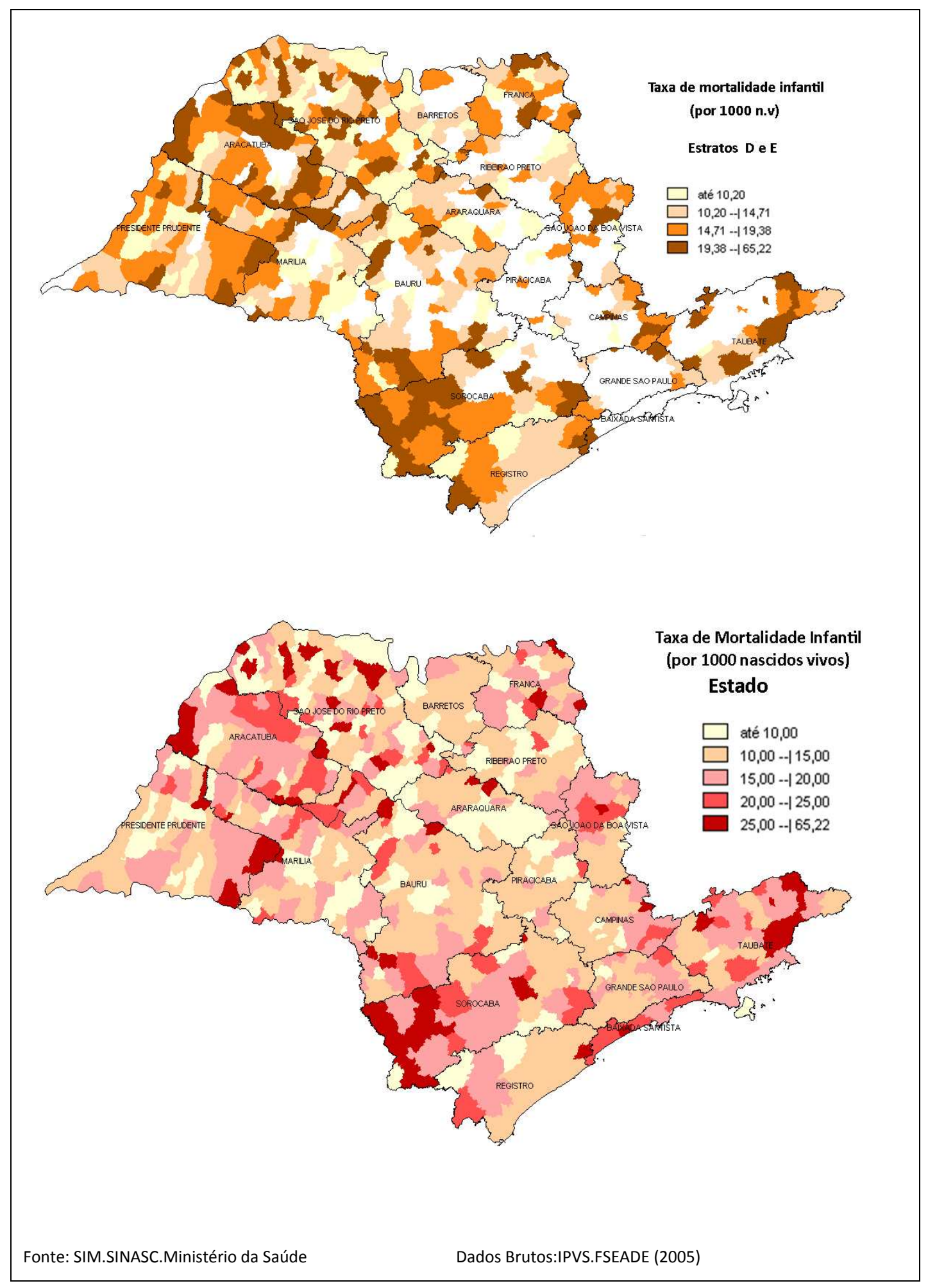


nascimento e anomalias congênitas entres outras podem ser destacados. Nos fatores ambientais ou exógenos incluem instrução da mãe, ocupação, renda familiar, condições de moradia, disponibilidade de alimentos, saneamento básico entre outros. Por atenção à saúde incluem-se acessibilidade, tecnologias, resolução e qualidade da atenção, entre outros. (CAMPOS e cols., 2008; LAURENTI e cols., 2006).

Os resultados deste estudo mostraram gradiente crescente da taxa de mortalidade infantil à medida que cresceu a vulnerabilidade social dos estratos, resultados estes coerentes com outros já citados na literatura Estudos de JOBIM \& AERTS (2008) apontaram para um maior risco para a mortalidade infantil em populações sob condições socioeconômicas precárias, reafirmando a relevância dos processos sociais que permeiam às condições de vida na determinação da mortalidade infantil ressaltando que mesmo em situações de tendência de queda, o ritmo e a intensidade se dão de maneiras desiguais nos diferentes municípios.

DUARTE e cols. (2004) mostraram desigualdades marcantes entre as regiões brasileiras em concordância com o gradiente socioeconômico, cuja estimativa de risco de morte no primeiro ano de vida foi quatro vezes maior no estado de Alagoas quando comparada ao Rio Grande do Sul. Intervenções em saúde, em especial a atenção à saúde da mãe e da criança, apresentam-se como um dos mais relevantes determinantes para a redução dos níveis de mortalidade infantil (HARTZ e cols. 1996; COSTA e cols. 2003). Nas taxas elevadas, o componente pós-neonatal costuma ser predominante e, nas baixas a neonatal, em especial, a precoce. Ao primeiro, tem sido atribuída maior facilidade de redução por tratar-se na grande maioria de fatores exógenos, diferentemente do segundo que, por tratar-se de fatores biológicos (endógenos) tem suas intervenções revestidas de maior complexidade. Altas taxas de mortalidade infantil refletem baixos níveis de saúde e de desenvolvimento socioeconômico, porém, taxas reduzidas também podem encobrir más condições de vida em segmentos sociais específicos. (RIPSA, 2008).

Altas estimativas de risco de mortes infantis e, a persistência de causas de morte evitáveis em populações menos favorecidas, sugerem dificuldades de 
acesso e de atenção adequada e, com qualidade aos serviços de saúde. Para JOBIM \& AERTS (2008) há omissão dos serviços de saúde ao não reconhecer determinadas categorias sociais ou grupos de risco com maior estimativa de risco de morte.

HARTZ e cols. (2003) afirmam que em populações onde o risco de morrer de menores de 1 ano permanece elevado, conhecer e mensurar a sua magnitude, causalidade e grupos populacionais de maior vulnerabilidade ultrapassam exigências metodológicas e, situam-se no campo da exigência ética, pois implicam em "mortalidade consentida" de crianças. Se, o condicionamento socioeconômico dos problemas de saúde é uma realidade, é responsabilidade dos sistemas de saúde ser mais acessíveis e eficazes onde os riscos são mais elevados pela precariedade do meio ambiente.

\subsection{MORTALIDADE MATERNA}

No triênio, ocorreram 641 óbitos maternos de mulheres residentes no Estado. Foram excluídos 02 óbitos por ausência de identificação do município de residência, resultando numa média anual de 213 óbitos maternos para o estudo.

No período, o Estado mostrou Razão de Morte Materna - RMM de $34,60 \% 000$ n.v, variando nos estratos de 27,82 a 56,22\%000 n.v resultando numa razão de taxas de 2,0 (Tabela 10). 0 gradiente da RMM aumentou conjuntamente ao crescimento da vulnerabilidade social nos estratos. A mais elevada, foi a do Estrato E com RMM de 56,22\%000 n.v e, também a de maior variabilidade interna com $\mathrm{DP}=161,85$.

O Estrato A, internamente apresentou conjuntos de municípios sem registros de óbitos no período (zero evento), estes de menor porte populacional (A20 e A100). 0 Estrato B, ao contrário, mostrou taxas mais elevadas com 68,10 e 53,94 \%000 n.v respectivamente nos conjuntos de menor porte (B20 e B50). Juntos, estes estratos somaram 34 municípios (36,7\%), sem registros de óbitos maternos no período (Figura 20). Espacialmente, nestes estratos os valores de 
RMM mais elevados englobaram áreas das regiões de Bauru, Sorocaba, Ribeirão Preto, RM São Paulo (região de Mogi das Cruzes), Baixada Santista, S.J Boa Vista, Campinas e Taubaté (Figura 21).

Tabela 10 - Óbitos maternos nascidos vivos, Razão de Mortalidade Materna (por 100 mil n.v), mediana e desvio padrão nos Estratos de Vulnerabilidade Social. Estado de São Paulo, média do triênio 2003 a 2005

\begin{tabular}{lcccccc}
\hline Estrato & $\begin{array}{c}\text { Óbitos } \\
\text { Maternos }\end{array}$ & Nascidos Vivos & RMM & $\begin{array}{c}\text { Desvio } \\
\text { padrão }\end{array}$ & Maior Valor & Menor Valor \\
\hline \hline Estrato A & 8 & 27556 & 27,82 & 14,68 & 42,31 & 0,00 \\
Estrato B & 108 & 352791 & 30,61 & 121,0 & 1030,93 & 0,00 \\
Estrato C & 56 & 144369 & 38,56 & 38,34 & 146,54 & 0,00 \\
Estrato D & 22 & 56472 & 39,55 & 73,51 & 454,55 & 0,00 \\
Estrato E & 19 & 34391 & 56,22 & 161,85 & 1234,57 & 0,00 \\
\hline Estado & $\mathbf{2 1 3}$ & $\mathbf{6 1 5 5 7 9}$ & $\mathbf{3 4 , 6 0}$ & $\mathbf{1 2 7 , 3 5}$ & $\mathbf{1 2 3 4 , 5 7}$ & $\mathbf{0 , 0 0}$ \\
\hline \hline
\end{tabular}

Fonte: SIM.SINASC. Ministério da Saúde Dados Brutos IPVS FSEADE (2005)

O Estrato C, com RMM de 38,56\%000 n.v, variou internamente de 7,17 a 146,54\%000 n.v, destacando-se internamente o conjunto de municípios C100 com 55,62\%000 n.v, a mais elevada. Espacialmente, os maiores valores de RMM concentraram-se em áreas das regiões de Sorocaba, Ribeirão Preto, Taubaté (mais especificamente, no litoral norte), Baixada Santista e RM São Paulo. As demais regiões mostraram áreas mais dispersas situadas nas confluências dos territórios regionais como mostra a Figura 21. Neste estrato 29 municípios $(34,5 \%)$ não registraram óbitos maternos no período.

Os estratos D e E mostraram variação de (zero) evento a 1030,93\%000 n.v. Juntos, estes estratos somaram 374 municípios $(79,4 \%)$ sem registros de óbitos maternos no período. Dos demais, 87 municípios variaram de 53,11 a 1234,57\%000 n.v, evidenciando expressivos diferenciais mortalidade nestes estratos. Espacialmente, os valores mais elevados de RMM apresentaram-se dispersos por todas as regiões do Estado derivado em parte pela localização desses municípios no território estadual (Figura 22).

Espacialmente, no conjunto do território do Estado, observaram-se a conformação de áreas com RMM mais elevadas, de maior ou menor magnitude e, localizadas na sua maioria nas zonas de confluências das regiões (Figura 22) e, que dadas as suas características podem ser classificadas em dois tipos: a 
Figura 20- Razão de mortalidade materna (por 100 mil n.v) segundo porte populacional dos conjuntos de municípios dos Estratos de Vulnerabilidade Social. Estado de São Paulo, média do triênio 2003 a 2005.

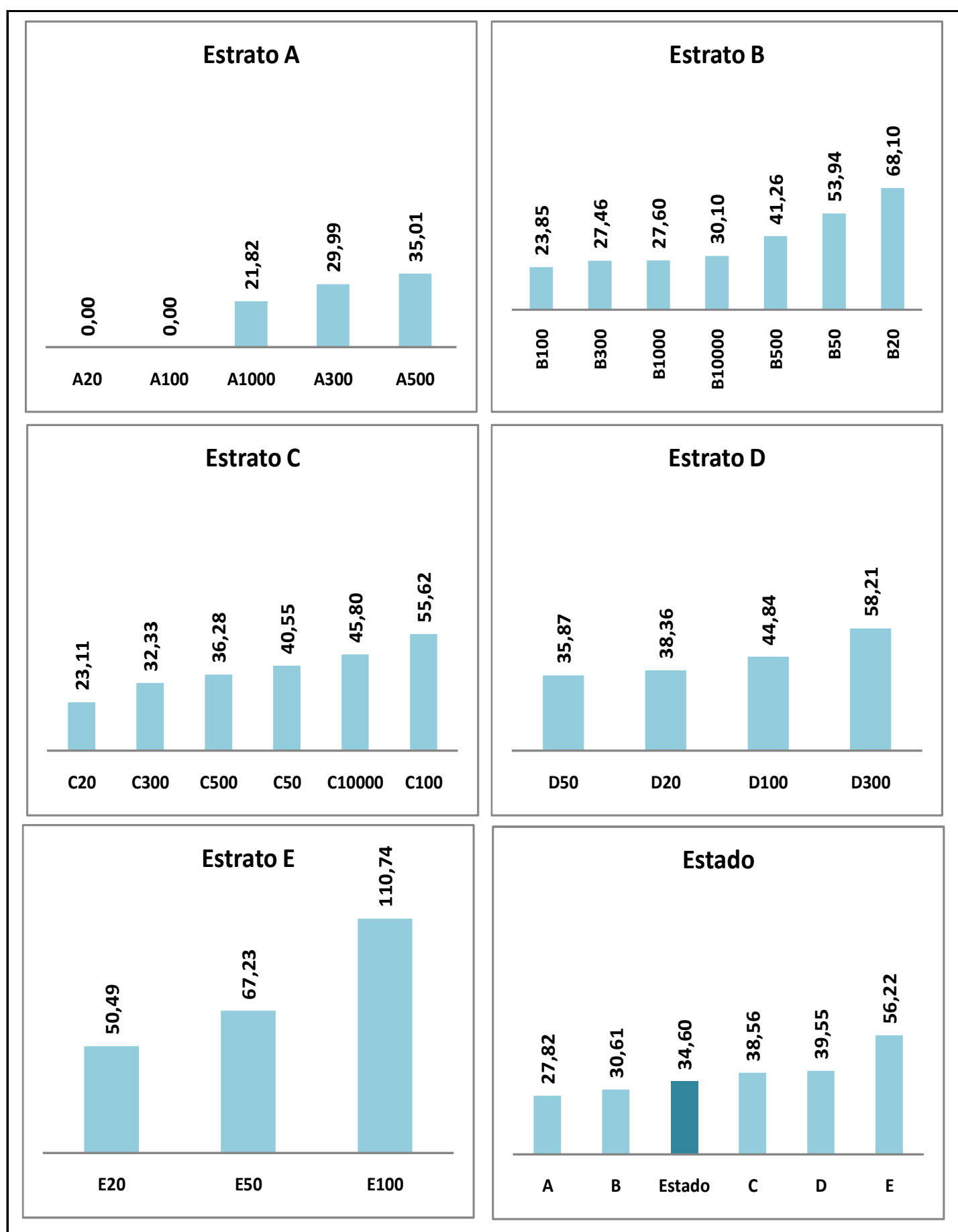

Fonte:SIM.SINASC. Ministério da Saúde

Dados Brutos IPVS FSEADE (2005) 
primeira, quando restritas ao território da região, aqui denominada de área regional de mortalidade materna elevada, a exemplo da região de Franca. A segunda, áreas regionais de maior mortalidade situadas em confluências regionais que se interligam a outras de mesma natureza e, ou de regionais vizinhas compondo uma área contígua de maior extensão, aqui denominada de área inter-regional de mortalidade materna elevada, a exemplo de (Araraquara/Bauru), (Araraquara/Piracicaba/Bauru) e (Araraquara/S. J. Boa Vista/Ribeirão Preto).

Dois outros aspectos na conformação dessas áreas ressaltaram-se: um deles refere-se às áreas regionais de mortalidade elevada, que se encontram mais ao centro ou dispersas em alguns territórios regionais nas zonas de confluência, a exemplo de Sorocaba. Num exercício de maior desagregação dessas regiões, foram identificadas espacialmente nestes territórios microrregiões, a exemplo da região de Sorocaba, que contém a micro-região de Itapeva, e a região de Marília que contém a de Assis, a região de Bauru que contém a de Botucatu, entre outras. Nesse exercício, muitas dessas áreas dispersas situaram-se em zonas de confluências, porém micro-regionais.

Outro aspecto a ser referido, trata das áreas regionais ou inter-regionais de mortalidade materna elevada que se localizam nas zonas de confluência estadual. Esta a depender, da situação da mortalidade materna do estado vizinho poderá conformar uma terceira área contígua: a área interestadual de mortalidade materna elevada, a exemplo da micro-região de Itapeva ao sul da região de Sorocaba.

A morte de uma mulher no período da gravidez, no parto ou no puerpério é um evento que finaliza, de forma trágica, o processo natural da reprodução humana. Mortes estas na sua grande maioria, evitáveis e que, retratam as condições de saúde e da atenção à saúde da mulher e suas iniqüidades. Elevadas RMM costumam estar associadas a precárias condições socioeconômicas, baixo grau de escolaridade e dificuldades de acesso a serviços de saúde de boa qualidade presentes em países subdesenvolvidos e em desenvolvimento (MINISTERIO DA SAUDE 2006, 2007; LAURENTI 2000; LAURENTI e cols. 2000, 2004, 2006; MELLO JORGE e cols. 2001). 
Figura 21 - Distribuição espacial da Razão de Morte Materna (por 100 mil n.v) dos municípios nos Estratos de Vulnerabilidade Social (A e B) e C. Estado de São Paulo, média do triênio 2003 a 2005.

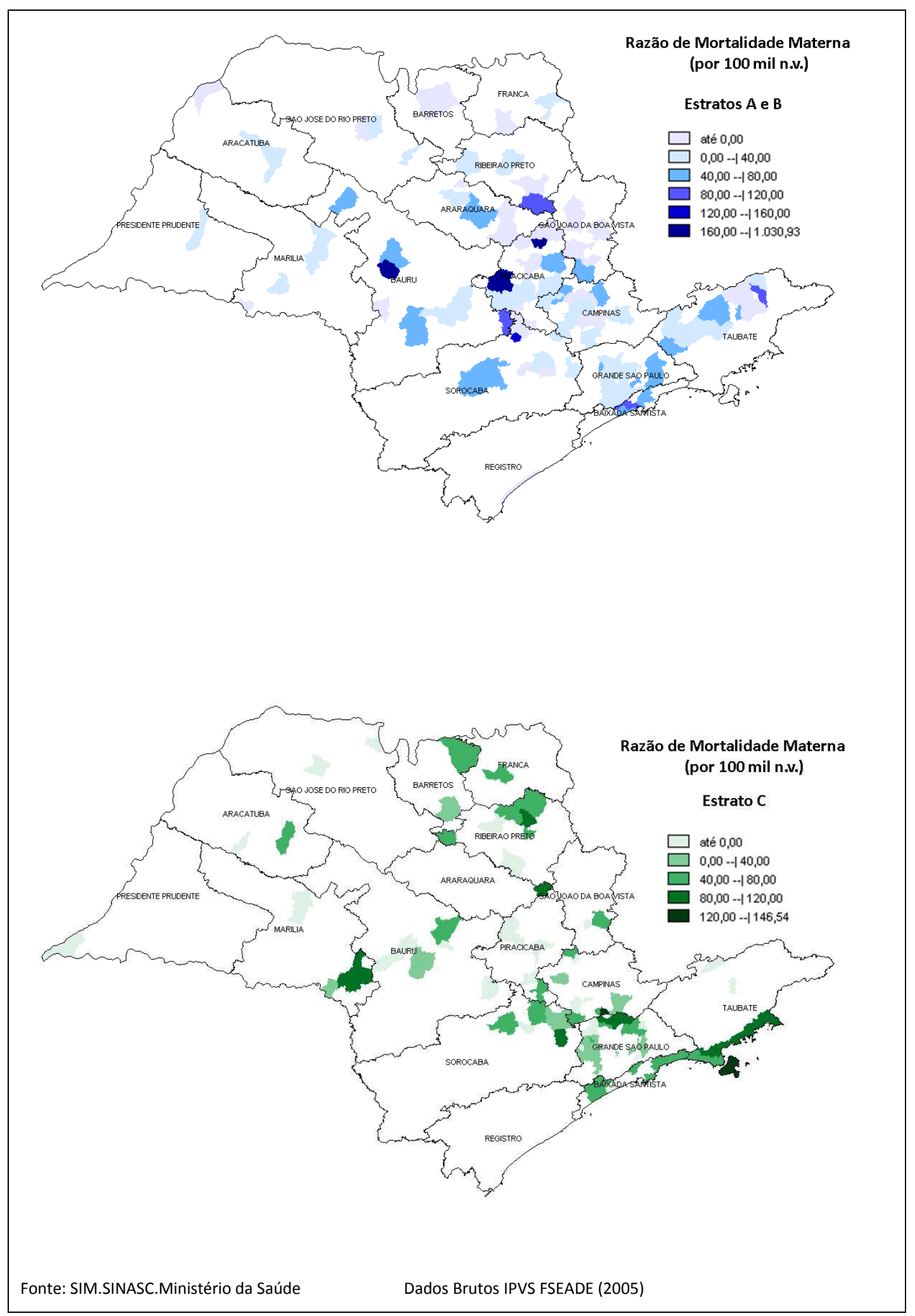


Figura 22 - Distribuição espacial da Razão de Morte Materna (por 100 mil n.v) nos municípios do Estrato de Vulnerabilidade Social C e Estado de São Paulo. Média do triênio 2003 a 2005.

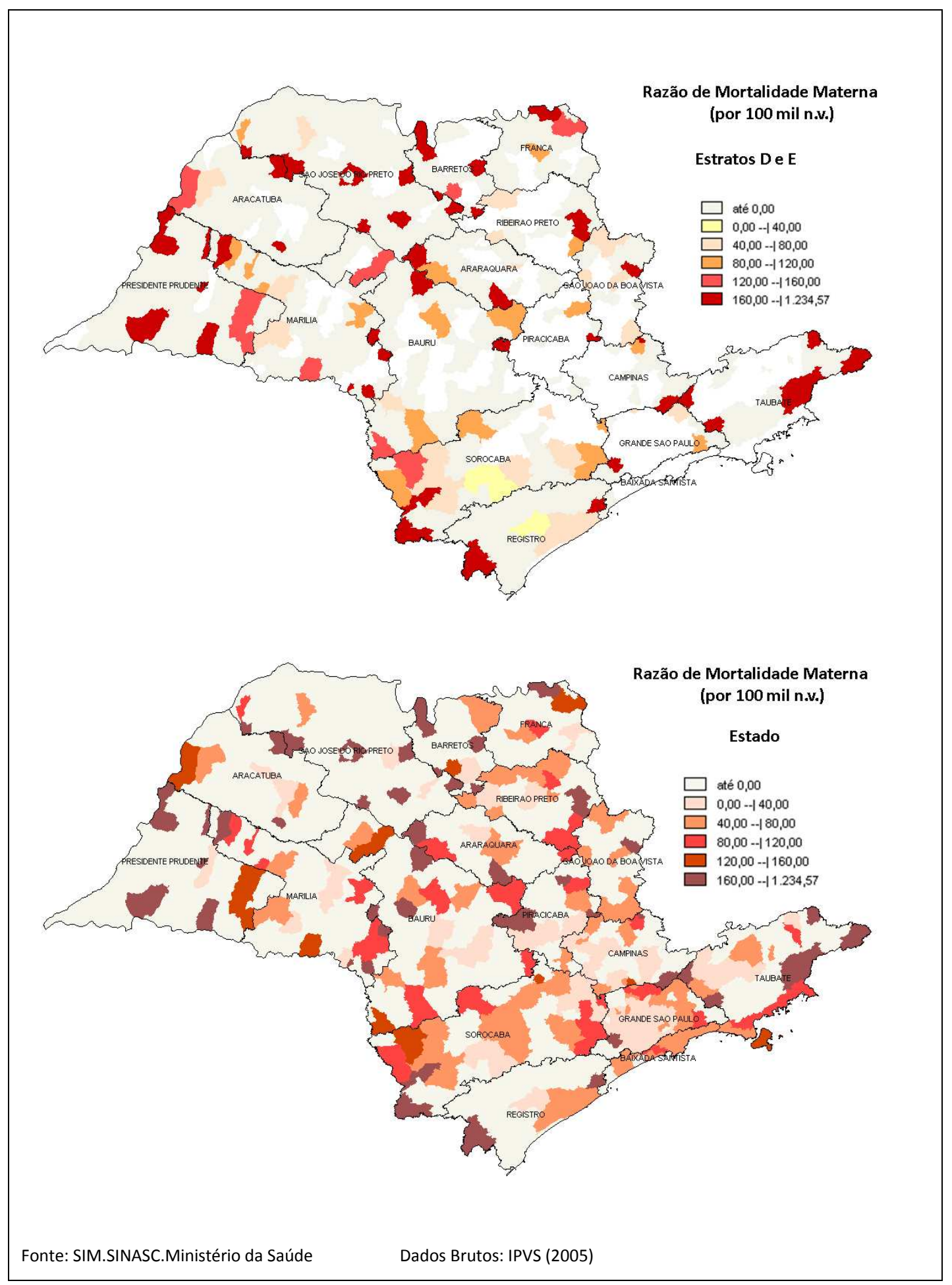


Subdivididas em mortes obstétricas diretas e indiretas, as diretas são aquelas por complicações de causas ou estados que só ocorrem no ciclo gravídico-puerperal e, as indiretas são aquelas resultantes de doenças préexistentes ou que se desenvolvem durante a gravidez, não decorrentes de causas obstétricas diretas, mas que foram agravadas pelo efeito fisiológico da gravidez. As causas obstétricas indiretas predominam quando a mortalidade materna é baixa e, quando esta é elevada quase que totalmente é representada pelas causas diretas (MELLO JORGE e cols., 2001).

No mundo, incluindo países desenvolvidos (com taxas baixas) e, os subdesenvolvidos e, os que se encontram em desenvolvimento (com taxas elevadas) convivem com limitações na mensuração precisa da mortalidade materna. Destacam-se pela sua relevância a não declaração da causa materna como a responsável pela morte da mulher ou preenchimento incorreto quando se omite que a morte teve causa relacionada com a gestação, ao parto e ao puerpério por profissionais médicos nos registros de óbitos. Tais condutas estão relacionadas a características sociais, religiosas e psicológicas além de problemas legais para causas de mortes quando relacionadas ao aborto provocado. A gestação, parto e puerpério são eventos normais, ou assim deveriam ser na vida de uma mulher e, o desfecho óbito para um evento considerado normal pode indicar problemas na assistência ao ciclo gravídico puerperal dessa mulher (MINISTERIO DA SAÚDE, 2006, 2007; LAURENTI, 2000; LAURENTI e cols.,2002, 2004; MELLO JORGE e cols., 2001).

Apesar da morte materna não ser expressiva em magnitude no conjunto de óbitos femininos, no período de 2000 a 2004 ocupou a nona causa de morte em mulheres de idade fértil no Brasil. Em países desenvolvidos a razão de morte materna oscila de 6 a 20\%000 n.v predominando os óbitos obstétricos indiretos. No Brasil, em 2004 a RMM foi 76,6\%000 n.v (com um fator de ajuste de 1,4) e, com predomínio das causas obstétricas diretas $(70,9 \%)$ (MINISTÉRIO DA SAÚDE, 2003,2006,2008).

Considerada um indicador consistente sobre a saúde da mulher retratando as iniqüidades existentes numa determinada sociedade ou país, dada a sua evitabilidade e, ao atual desenvolvimento das tecnologias médicas, a morte 
materna é considerada um evento sentinela da atenção à mulher no ciclo gravídico puerperal. Valores elevados de RMM passam a ser considerados inaceitáveis provocando mobilização dos organismos nacionais e internacionais para sua redução.

LANSKY (2005) ponderou que a redução da mortalidade materna depende do pronto reconhecimento dos riscos na gravidez, além do acesso oportuno a serviços de saúde regionalizados e qualificados. Relatou ser freqüente no país, a descontinuidade da atenção pré-natal até o final da gestação e, ao parto, assim como a peregrinação das gestantes em trabalho de parto em busca de vagas nas maternidades além do atendimento em condições inadequadas. Atribuiu estas dificuldades a não regionalização da assistência, a inexistência de transporte apropriado, a baixa qualidade dos serviços prestados ou a restrição do atendimento imposto pelos serviços por seu custo, no caso dos serviços privados.

Os achados deste estudo mostraram diferenciais de mortalidade materna nos estratos, com gradiente crescente junto à vulnerabilidade social. Nos conjuntos de municípios de intensa vulnerabilidade social aqueles de maior porte populacional, apresentaram RMM mais elevadas que os de menor porte.

Espacialmente, a concentração de maior mortalidade nas zonas de confluências regionais e micro-regionais sugere dificuldades de acesso: de caráter geográfico (distância aos serviços de referência), de caráter organizacional (acesso ao pré-natal de qualidade, atenção ao parto e puerpério, leitos hospitalares), de caráter econômico (recursos financeiros para o custeio de deslocamento e do cuidado), ou de caráter cognitivo (considerando o nível de escolaridade desses estratos identificados pelo IPVS), ou a composição do conjunto destes fatores.

Nessa perspectiva, dada a distribuição espacial da mortalidade materna faz-se necessário o aprofundamento deste estudo para a identificação da estrutura de serviços de saúde, da ambulatorial à hospitalar à gestante numa abordagem sistêmica visando melhorar a compreensão dos determinantes e condicionantes da morte materna nas áreas regionais de maior mortalidade 
materna visando especialmente identificar a interdependência de serviços e/ou profissionais na atenção a estas gestantes e a sua condição de referência formal ou informal de serviços pois sua distribuição espacial sugere exposição a riscos cuja compreensão e aprofundamento deve buscar uma olhar mais regional e menos municipal, o que necessariamente não pressupõe num olhar sobre a região de saúde constituída administrativamente.

Relevante ainda é a sub-notificação das causas de morte maternas e, as dificuldades para o resgate dessas informações em especial, àquelas derivadas de aborto, considerado prática ilegal na sociedade brasileira e, ainda as informações inadequadas que são realidades no país e no Estado, demandando investimentos em profissionais e em tecnologia para a melhoria do sistema de registro, coleta e uso das informações (LANSKY 2005; MINISTÉRIO DA SAÚDE 2006, 2007; LAURENTI 2000, LAURENTI e cols. 2002, 2004; MELLO JORGE e cols., 2001). Em conseqüência desses fatores, razões de mortalidade costumeiramente têm sido sub-enumeradas desencadeando assim recomendações de órgãos nacionais e internacionais para o uso de fatores de correção (ajuste) das taxas brutas visando corrigir a sub-enumeração citada no respectivo indicador (MINISTÉRIO DA SAÚDE, 2006,) para um grande número de países no mundo.

No Brasil, estudos desenvolvidos por LAURENTI e cols. (2002) apontaram para um fator de correção de 1,4 para a mortalidade materna nas capitais brasileiras, ou seja, uma sub-notificação de 40\%, valor este aceito pelo Ministério da Saúde e referendado como fator de ajuste mínimo a ser considerado para o país no cálculo das taxas oficiais de mortalidade materna.

A agilidade na identificação dos óbitos maternos e de seus determinantes implica num sistema de vigilância à morte materna que incluem ações técnicas (vigilância epidemiológica) e política (Comitês de Investigação de Mortes Maternas) nos diversos níveis do sistema favorecendo discussões e contribuindo para a prevenção e intervenção oportuna e, conseqüentemente para sua redução (MINISTÉRIO DA SAÚDE, 2005). 


\subsection{MORTALIDADE POR DOENÇAS INFECCIOSAS E PARASITÁRIAS}

No triênio, foram registrados 31.060 óbitos por Algumas Doenças Infecciosas e Parasitárias (Cap. I - CID 10) - DIP de residentes no Estado. Foram excluídos 262 óbitos, sem identificação de município de residência, sexo ou idade resultando numa média anual de 10.266 óbitos para este estudo. Coube aos homens, a maior proporção com 6.264 óbitos $(61,0 \%)$ e, as mulheres, a menor, com 4.002 óbitos (39,0\%).

O Estado mostrou taxa padronizada de mortalidade por DIP de 25,98\%000 hab., com sobremortalidade masculina de $32,35 \% 000$ hab. e, as mulheres com 19,87\%000 hab., resultando numa razão de taxas de 1,6 (Tabela 11). O Estrato A, com 27,52\%000 hab. apresentou a mais elevada e, o Estrato E, com 23,21\%000 hab., a menor, resultando numa razão de taxas de 1,3 (Tabela 11).

0 gradiente de taxas cresceu à medida que declinou a vulnerabilidade social, tanto para a taxa total, quanto para a taxa de mortalidade masculina. Para as mulheres, as taxas padronizadas apresentaram discretas oscilações variando de $19,22 \%$ a $20,65 \%$. A sobremortalidade masculina foi constante variando de 36,00 a $26,21 \% 000$ hab. e, resultando numa razão de taxas de 1,4.

Tabela 11- Óbitos e Taxa de Mortalidade (Bruta e Padronizada) por Doenças Infecciosas e Parasitárias (Total e segundo Sexo), mediana, desvio padrão e razão de taxas nos Estratos de Vulnerabilidade Social. Estado de São Paulo, triênio 2003 a 2005.

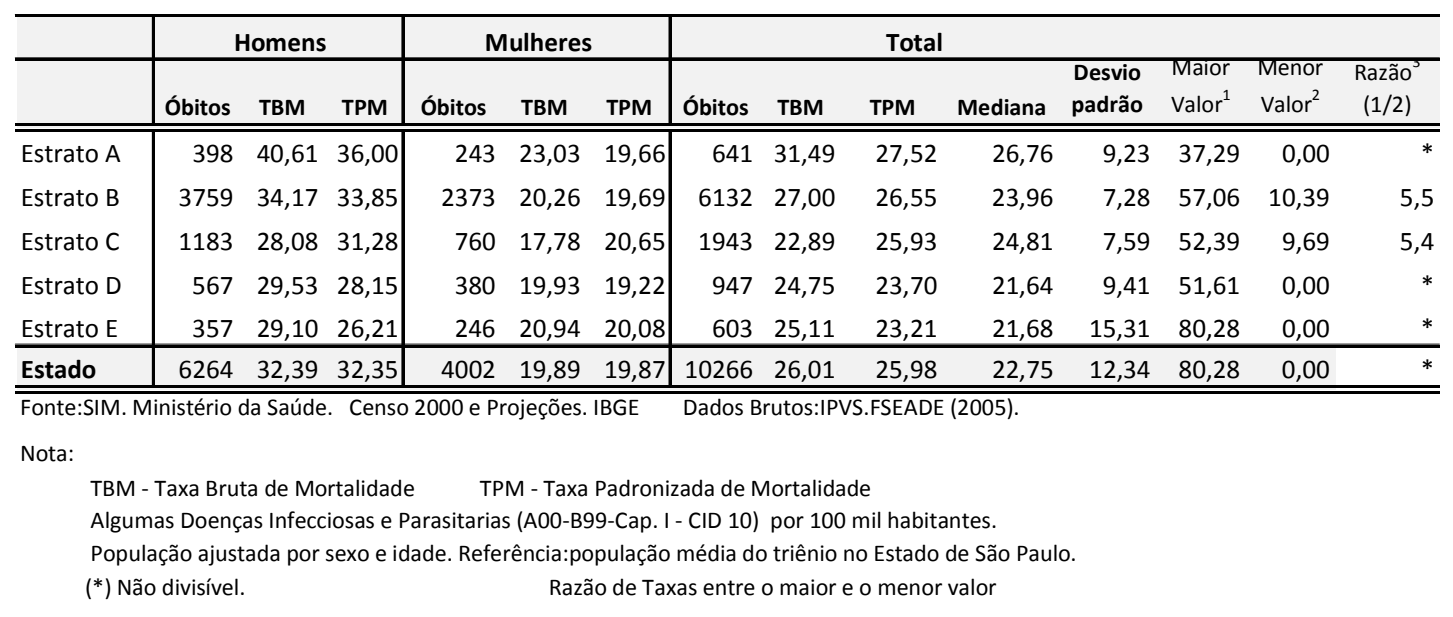


Internamente, os Estratos A e B mostraram. Espacialmente, observaram-se áreas com taxas elevadas nas regiões da Baixada Santista, Taubaté, Piracicaba, Campinas, Bauru, Marília, Ribeirão Preto, S.J.Rio Preto, Araçatuba e Barretos, esta última com valores mais elevados que as demais (Figura 24).

O Estrato C, com taxa total de 25,93\%000 hab., mostrou taxa de $31,28 \% 000$ hab. para homens e, 20,65\%000 hab. para as mulheres, esta última a mais elevada dentre os estratos. Cerca de um terço dos municípios $(33,7 \%)$ apresentaram taxa padronizada de mortalidade por DIP acima de 26,77\%000 hab.. Internamente, o conjunto de municípios C300 situou-se com a taxa mais elevada e, o C20, com a menor (Figura 23). Espacialmente, esse estrato mostrou regiões com áreas de menor mortalidade como: S.J. Boa Vista, Presidente Prudente e Araçatuba. As demais se apresentaram mais elevadas destacando-se a região de Franca.

Os Estratos D e E, com taxas de 23,70 e 23,21\% 000 hab. respectivamente situaram-se abaixo da taxa apresentada pelo Estado. O Estrato E, apresentou a maior variabilidade interna com $\mathrm{DP}=12,34$. Nesses estratos, 170 municípios $(36,1 \%)$ apresentaram taxa acima de 25,00\%000 hab.. Na distribuição espacial, destacaram-se as regiões de S.J.Rio Preto, Barretos, Franca, Ribeirão Preto, Bauru, Marília e Presidente Prudente com áreas de taxas mais elevadas.

No Estado, áreas com taxas mais elevadas foram observadas nas regiões de divisa do estado com o Mato Grosso do Sul (Franca, Barretos e S.J.Rio Preto). As regiões de Ribeirão Preto, Marília, Bauru, Araçatuba e Presidente Prudente também mostraram áreas com valores mais elevados, porém mais dispersas espacialmente. Dentre os municípios, 18 deles (2,8\%) não registraram óbitos e, 255 municípios $(39,5 \%)$ ultrapassaram a taxa de $25 \% 000$ hab..

Os resultados mostrados pela distribuição espacial das DIP no Estado acrescida de taxas de mortalidade mais elevadas nos estratos de menor vulnerabilidade social e, a sobremortalidade masculina sugere que o Estado de São Paulo convive com o padrão de mortalidade próprio da transição epidemiológica com doenças tais como as septicemias, doença de Chagas, diarréias, dengue, malária, febre amarela, hepatites, tuberculose e a AIDS que tem sido as principais causas de mortes entre as DIP no Estado, conforme já 
relatado em estudos por causas especificas (WALDMAN e cols. 1999; BUCHALLA e cols. 2003, MINISTÉRIO DA SAÚDE 2004, 2005,2006).

Dada a complexidade dos determinantes e condicionantes das doenças infecciosas e parasitárias, além da diversidade econômica e produtiva do Estado, as desigualdades de vulnerabilidade social e os diferenciais socioespaciais a apreensão destes resultados exige aprofundamento do estudo tanto para a mortalidade especifica como para causa como para grupos etários mais específicos.

Durante muitos séculos, as DIP dominaram o quadro de morbimortalidade das populações humanas caracterizando-se mundialmente como um dos principais problemas de saúde pública. Responsáveis por elevadas taxas de mortalidade e baixa expectativa de vida sua ocorrência tinha na ausência de saneamento básico, habitações precárias, trabalho insalubre, pobreza endêmica e, no reduzido nível de escolaridade da população, condições extremamente favoráveis à sua ocorrência, inclusive nos países mais desenvolvidos (BUCHALLA e cols., 2003). Tuberculose, varíola, sarampo, difteria, cólera, febre amarela, malária, tétano e, a gripe espanhola entre outras, foram responsáveis por grandes epidemias e milhares de morte.

Transformações econômicas, sociais, científicas, melhoria das condições de vida, nutrição e saneamento, elevação de escolaridade e, novas tecnologias médicas contribuíram para a acentuada queda da mortalidade por DIP, especialmente na infância. Inicialmente, nos países desenvolvidos e, mais tardia, a exemplo do Brasil, que em 1940 cerca da metade dos óbitos (46\%) eram por DIP. Em 1970, declinou para 15,7\% e, em 1989 para 6\% do total de óbitos. (PRATA, 1994).

Em 2003, a taxa padronizada de mortalidade por DIP no país foi de $26,3 \% 000$ hab. e, nas grandes regiões variou de 29,9\%000 hab. a 22,7\% 000 hab. A região Sudeste, situou-se dentre as mais elevadas com 27,3\%000 hab. os homens mostraram 31,7\%000 hab. e, as mulheres 20,9\%000 hab., com sobremortalidade masculina em todas as regiões (MINISTÉRIO DA SAÚDE, 2004). 
Figura 23 - Taxa padronizada de mortalidade por Doenças Infecciosas e Parasitárias (por 100 mil hab.) segundo conjuntos de municipios nos Estratos de Vulnerabilidade Social. Estado de São Paulo, média do triênio 2003 a 2005.

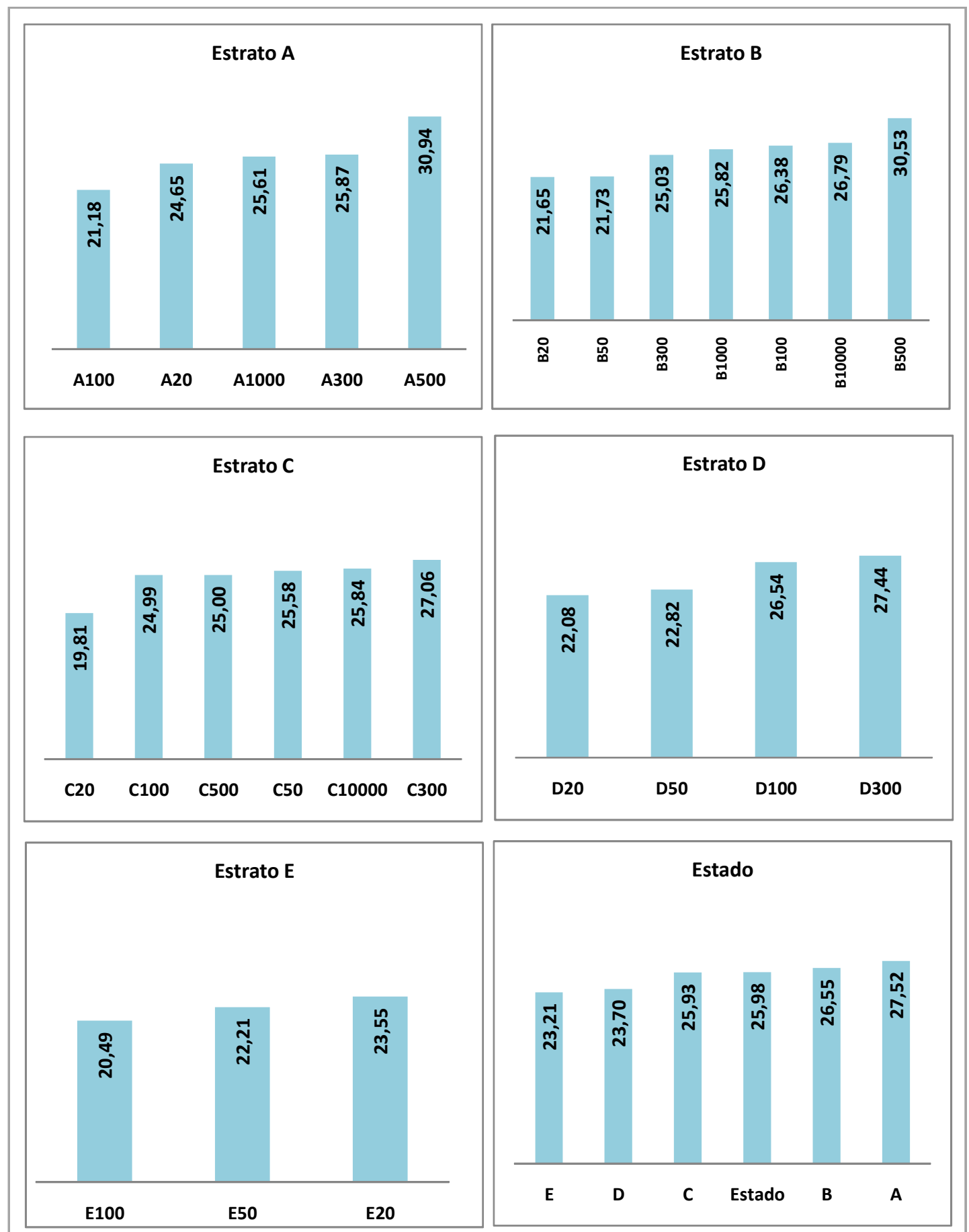

Fonte:SIM. Ministério da Saúde. Censo 2000 e Projeções. IBGE Dados Brutos:IPVS.FSEADE (2005). 
Figura 24 - Distribuição espacial da taxa padronizada de mortalidade por Doenças Infecciosas e Parasitárias (por 100 mil hab.) nos municípios dos Estratos A e B e C. Estado de São Paulo, média do triênio 2003 a 2005.

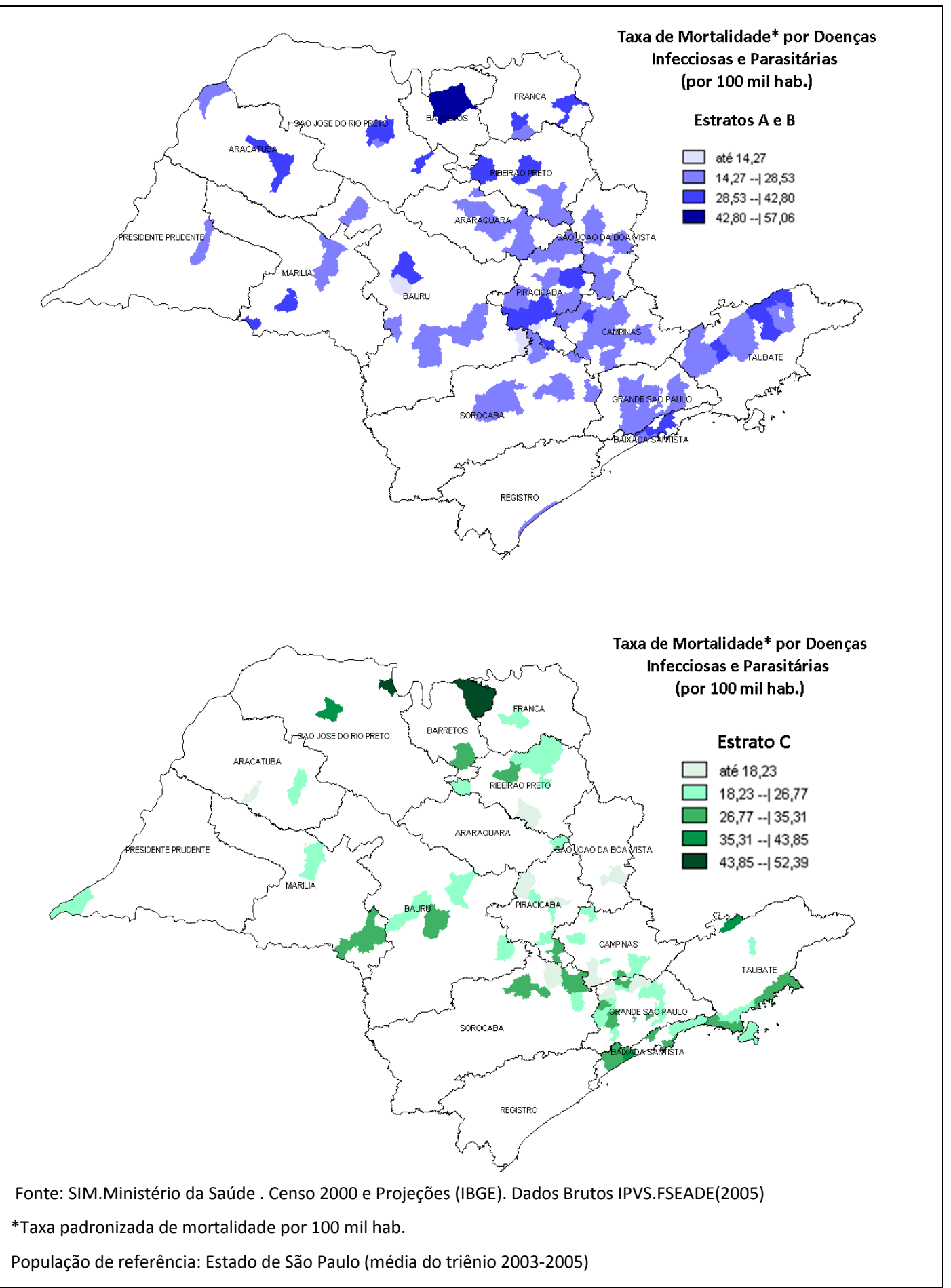


Figura 25 - Distribuição espacial da taxa padronizada de mortalidade por Doenças Infecciosas e Parasitárias (por 100 mil hab.) nos municípios do Estrato de Vulnerabilidade Social (D e E) e no Estado de São Paulo. Média do triênio 2003 a 2005.

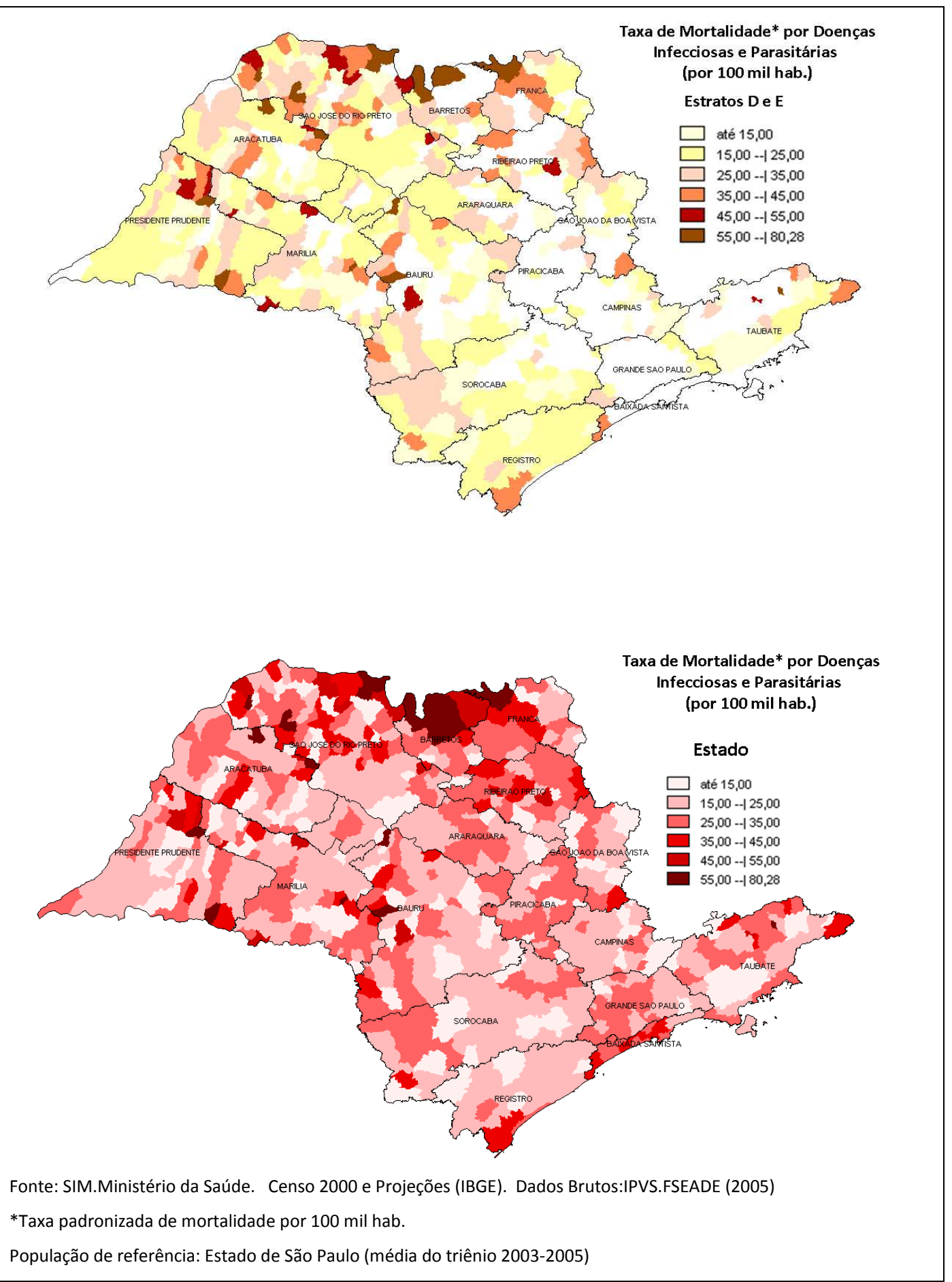


A proteção conferida pelas vacinas fez com que as doenças imunopreviníveis praticamente desaparecessem como causa de óbito a partir da metade dos anos 80 (BUCHALLA e cols.,2003). No entanto, apesar do expressivo declínio das DIP, algumas delas ainda se mantêm como importantes problemas de saúde pública pela elevada morbimortalidade tais como as septicemias,doença de Chagas, diarréias, dengue, malária, febre amarela, hepatites e, ainda a tuberculose que, juntamente com a AIDS tem sido as principais causas de mortes entre as DIP. Apesar da existência de tecnologias terapêuticas acessíveis e eficazes, a tuberculose vem apresentando inclusive tendência de aumento na atualidade. BUCHALLA e cols. (2003) atribuem à evolução e, ao longo tratamento da doença incluindo dificuldades na adesão ao tratamento pelo paciente e, ao desempenho dos serviços de saúde nas ações de vigilância à saúde (principalmente na busca ativa de novos casos e redução do abandono de tratamento) que, somados ao impacto da epidemia da AIDS tem contribuído para o recrudescimento da morbimortalidade por esta causa, na condição de co-infecção.

Descrita por OMRAN (1971) como transição epidemiológica, o deslocamento do padrão de alta morbimortalidade por DIP para as doenças crônico-degenerativas, processo este intrínseco à transição demográfica, que se expressa pela queda da mortalidade e natalidade e, a conseqüente elevação da expectativa de vida. Dentre os modelos propostos, variações na duração e intensidade marcam cada um deles: o clássico, onde as doenças degenerativas substituiriam as infecciosas como causa principal de mortalidade (a exemplo dos Estados Unidos, Suécia e Reino Unido), o acelerado com processo mais tardio, mas muito mais veloz (a exemplo do Japão) e, o contemporâneo onde a transição é recente ou mesmo incompleta. Juntamente com o abandono da proposição teórica de substituição da morbimortalidade das DIP pelas crônicas degenerativas dois outros modelos foram acrescentados, mais tarde pelo autor e outros especialistas, frente a insuficiência dos primeiros: a transitória (a exemplo da Coréia e Singapura) e, o polarizado prolongado (a exemplo do Brasil, México). 
Da pretensa erradicação das DIP derivou-se a noção de re-emergência de algumas delas, a exemplo da dengue e da malária. A primeira, restrita à transmissão silvestre foi reintroduzida pela transmissão urbana do vetor e, a segunda, cuja erradicação prometida para a década de 70 , responde ainda por cerca de 600 mil casos/ano no Brasil. A epidemia da AIDS nos Estados Unidos trouxe ainda o conceito de doenças emergentes que, ao lado do envelhecimento populacional e das doenças crônicas estão entre os grandes desafios mundiais de saúde pública na atualidade (LICIO, 2006).

$\mathrm{Na}$ sua maioria viral, tanto as emergentes como as re-emergentes, trazem à tona questões complexas relacionadas às atividades humanas. Estas alteram o meio ambiente e padrões de comportamento social, favorecem o tráfego nos continentes, de vetores e pessoas infectadas, carreiam vírus com a importação de animais, provocam modificações ecológicas de grande impacto, a exemplo da construção de grandes barragens e estradas compondo os principais mecanismos para o surgimento de novas amostras virais seja por modificações genéticas, por transposição da barreira de espécie por um vírus e, ou para a disseminação viral a partir de um nicho ecológico (SCHSTZMAYR, 2001).

WALDMAN e cols. (1999) num estudo sobre a trajetória das DIP no Brasil, reconheceram a importante redução da mortalidade por DIP mas apontaram para três cenários paradigmáticos nos grupos de patologias específicas. 0 primeiro, um cenário favorável indicando o efetivo controle e declínio substancial de ocorrência, a exemplo das gastroenterites e das imunopreviníveis (a exemplo da poliomielite, considerada eliminada desde 1994), a redução das formas graves da esquistossomose e, as boas perspectivas para a interrupção da transmissão natural da Doença de Chagas em área endêmica. Um segundo cenário indicando que a enfermidade deverá permanecer em níveis costumeiros ainda por longo tempo, a exemplo das grandes endemias urbanas como a tuberculose e hanseníase e, em áreas mais restritas a malária e as leishmanioses. E num terceiro cenário, este mais preocupante, apontando para a expansão das enfermidades a exemplo do dengue clássico e, a sua forma mais grave a hemorrágica e, da AIDS que responde ainda por milhares de mortes e, adoecimento de muitos brasileiros. 
0 enfrentamento das doenças emergentes inclui aspectos de biossegurança relacionados a novos agentes etiológicos, incluindo aqueles que podem ser utilizados como armas biológicas e, aqueles que em poucas horas possibilitam o tráfego global de agentes etiológicos entre continentes. Um segundo aspecto, trata do controle de importação de animais para experimentação (principalmente primatas) que podem ser reservatórios ou fontes de infecção de novos agentes sendo que, seu transporte, acomodação e manutenção são objetos de ação compulsória da vigilância sanitária, além de regras para manejo de suspeitos clínicos e de materiais biológicos. E por fim, um terceiro aspecto que trata do aprimoramento dos sistemas de vigilância à saúde tornando-os aptos à detecção precoce de novas doenças e agravos incluindo infra-estrutura e capacitação de técnicos para a clínica, novas técnicas laboratoriais de biologia molecular e capacitação epidemiológica para a realização das investigações de campo, monitoramento e ações de controle epidemiológico (SCHSTZMAYR, 2001; LUNA, 2002).

A forma com que são realizadas as intervenções humanas no ambiente seja no nível macro ou micro afeta de uma maneira geral a distribuição das DIP. Desenvolvimento econômico, condições ambientais e de saúde encontram-se intrinsecamente vinculadas e, deslocamento de vetores ou de agentes etiológicos num primeiro momento pode atingir populações diretamente envolvidas ou próximas a um determinada intervenção e após, atingir a periferia de grandes cidades ou até populações inteiras, a exemplo da febre amarela urbana (PIGNATTI, 2005).

Os determinantes e condicionantes do processo infeccioso e parasitário e sua dinâmica devem ser apreendidos sistemicamente, onde um todo interrelacionado e interdependente no nível dos sistemas biológico, econômico e político agem em constante interação buscando sua auto-organização e regulação e, não através de um olhar cartesiano do espaço, tempo e populações (ALMEIDA \& ROUQUAYROL,2002). 


\subsection{MORTALIDADE POR DOENÇAS RESPIRATÓRIAS}

No triênio, ocorreram 81.990 óbitos por Doenças do Aparelho Respiratório (Cap. X - CID 10). Foram excluídos 442 óbitos sem identificação do município de residência no estado, idade ou sexo resultando numa média anual de 27.183 óbitos. Desses, 4.855 óbitos $(54,7 \%)$ foram homens e mulheres foram 12.327 óbitos $(45,3 \%)$.

No período, o Estado apresentou taxa padronizada de mortalidade de 69,51\%000 hab., situando-se no Estrato C com 75,54\%000 hab., a mais elevada e, no Estrato E, a menor com 62,58\%000 hab., resultando numa razão entre taxas de 1,2. Os homens apresentaram sobremortalidade com 77,25\%000 hab. no Estado, e nos estratos variaram de 81,55\%000 hab. a 65,43\%000 hab.(Tabela 12). Internamente aos estratos, as taxas mais elevadas predominaram nos conjuntos de municípios de médio a grande porte (Figura 26) destacando-se os conjuntos C1000 e C500 com 85,84 e 79,75\%000 hab. respectivamente. A maior variabilidade ocorreu no Estrato E com $\mathrm{DP}=23,30$.

Tabela 12 - Óbitos e Taxa de Mortalidade por Doenças Respiratórias (Total e segundo Sexo), mediana, desvio padrão e razão de taxas nos Estratos de Vulnerabilidade Social. Estado de São Paulo, média do triênio 2003 a 2005.

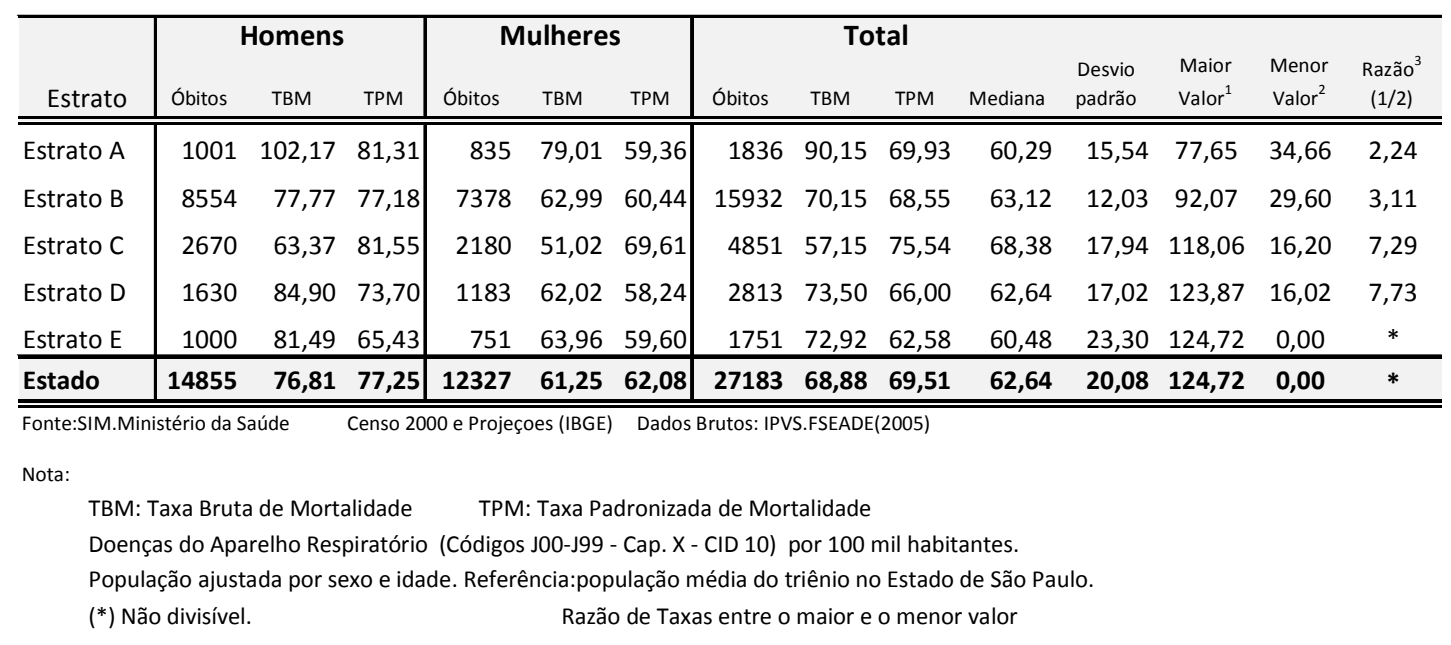


Os Estratos A e B mostraram taxas padronizadas de 29,60 a 92,07\%000 hab., dos quais 30 municípios (32,6\%) ultrapassaram 67\%000 hab.. Áreas com taxas mais elevadas foram observadas nas regiões de Taubaté, Campinas, Sorocaba, S.J. Boa Vista, Araraquara, Barretos, S.J. Rio Preto e RM São Paulo com elevação do gradiente de taxas conjunta ao porte populacional (Figura 27).

0 Estrato $C$, também com elevada variabilidade interna com $\mathrm{DP}=17,94$ e mediana de 68,38. Destacaram-se, com taxas mais elevadas os conjuntos de municípios de maior porte populacional (Figura 25). Espacialmente, a taxas mais altas situaram-se nas regiões de Campinas, Piracicaba, Sorocaba, Baixada Santista, Ribeirão Preto, Bauru e RM São Paulo. Mais de um quarto dos municípios (28,9\%) ultrapassaram a taxa de 77,32\%000 hab. (Figura 27).

Os Estratos D e E, com as menores taxas, 66,00 e 62,58\%000 hab. e DP= 17,02 e 23,30 respectivamente. Do total dos municípios desse estrato, 226 (48,0\%) ultrapassaram taxa de 62,0\%000 hab.. Espacialmente, observaram-se nas regiões de S.J. Rio Preto, Araçatuba, Presidente Prudente, Sorocaba e Registro áreas com taxas mais elevadas que as demais (Figura 27).

Mais de um terço dos municípios do Estado $(216=33,5)$ apresentaram taxa acima de 70,0\%000 hab., dos quais 26 deles ultrapassaram 100,0\%000 hab. Espacialmente, destacaram-se as regiões S.J. Rio Preto e circunvizinhas formaram uma área contígua de grande extensão. As demais, também apresentaram áreas com taxas mais elevadas, à exceção de Bauru (Figura 28). 0 organismo humano encontra-se exposto às mais diversas agressões ambientais, e particularmente o aparelho respiratório pelas funções que desempenha, freqüentemente é sede de alterações de maior ou menor, intensidade ou gravidade (GOMES, 2002). As Doenças Respiratórias foram responsáveis por 11,6\% dos óbitos por causas definidas no país em 2004 e, a Região Sudeste, destacou-se com a proporção mais elevada $(12,5 \%)$ dentre as grandes regiões. Em 2002, a taxa padronizada de mortalidade alcançou 54,25 e 63,36\%000 hab. respectivamente para o país e região (MINISTÉRIO DA SAÚDE, 2004).

Dentre os mais vulneráveis biologicamente encontram-se os idosos (acima de 60 anos) para os quais, as infecções respiratórias tem se destacado como uma das principais causas de morbimortalidade e, cujo crescimento vem sendo 
Figura 26 - Taxa padronizada de mortalidade por Doenças Respiratórias (por 100 mil hab.) segundo conjuntos de municípios dos Estratos de Vulnerabilidade Social. Estado de São Paulo, média do triênio 2003 a 2005.

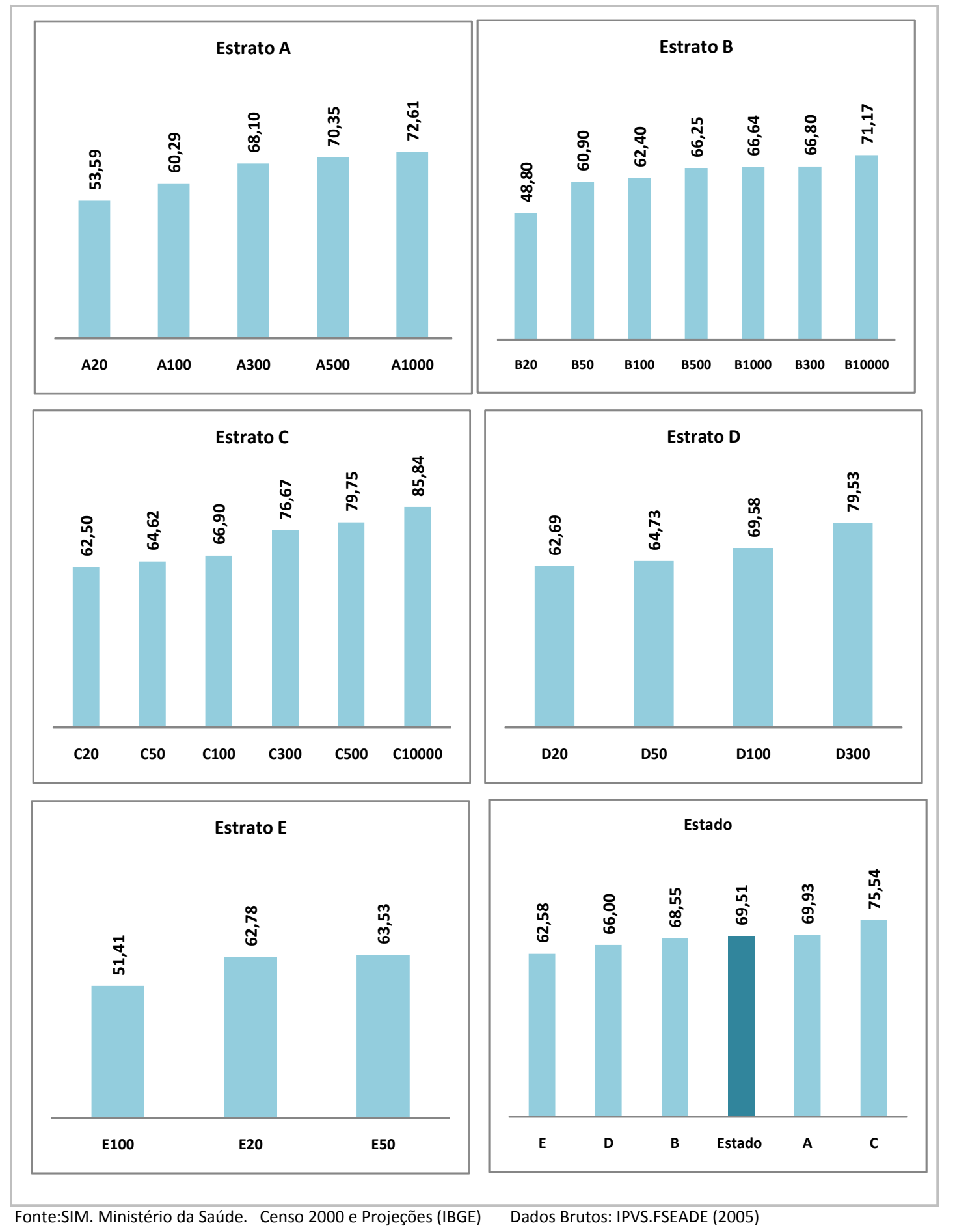


Figura 27 - Distribuição espacial da taxa de mortalidade padronizada por Doenças Respiratórias (por 100 mil hab.) dos municípios nos Estratos de Vulnerabilidade Social (A e B) e C. Estado de São Paulo, média do triênio 2003 a 2005.

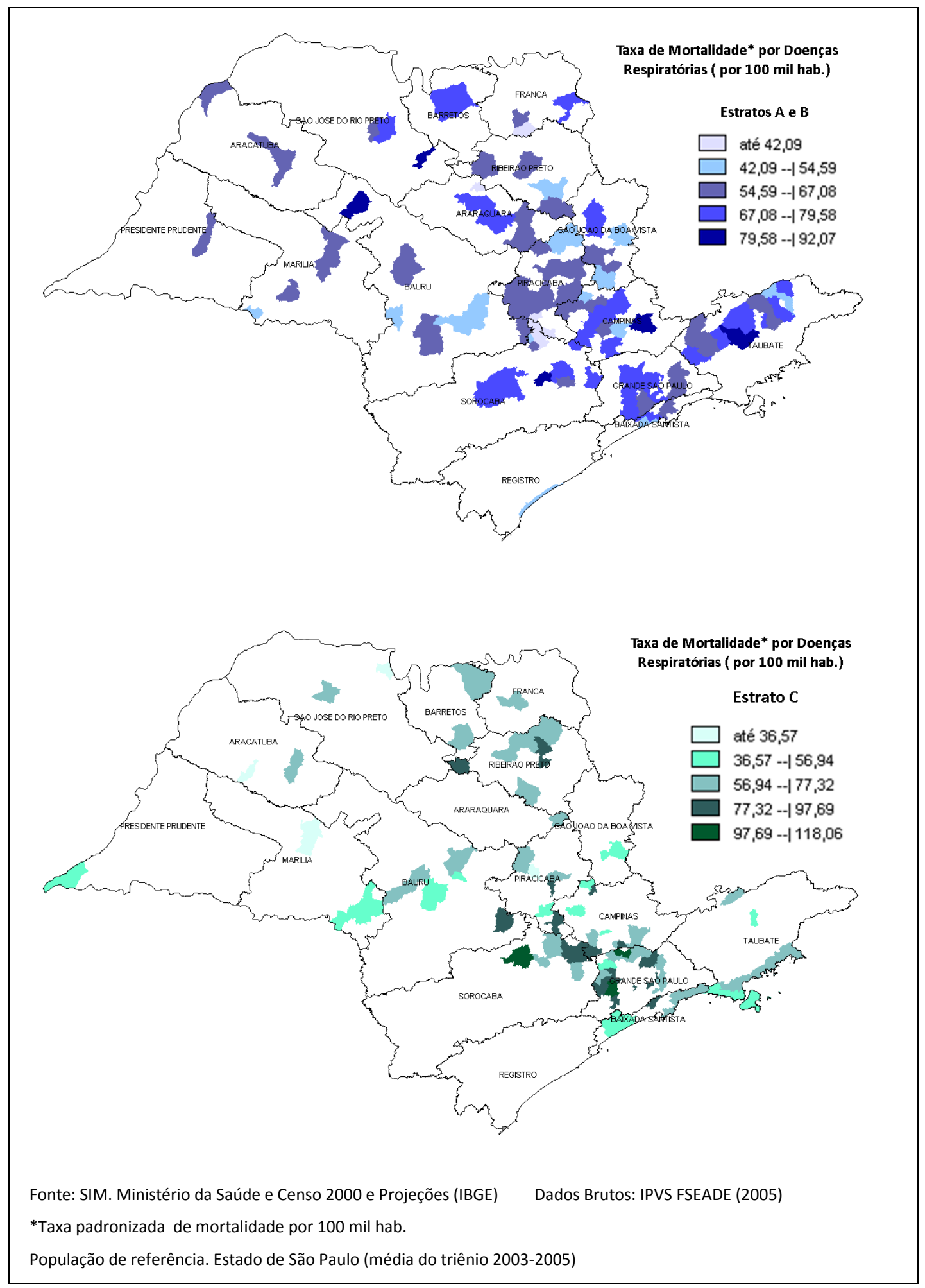


Figura 28 - Distribuição espacial da taxa padronizada de mortalidade por Doenças Respiratórias (por 100 mil hab.) nos municípios dos Estratos de Vulnerabilidade Social (D e E) e Estado de São Paulo. Média do triênio 2003 a 2005.

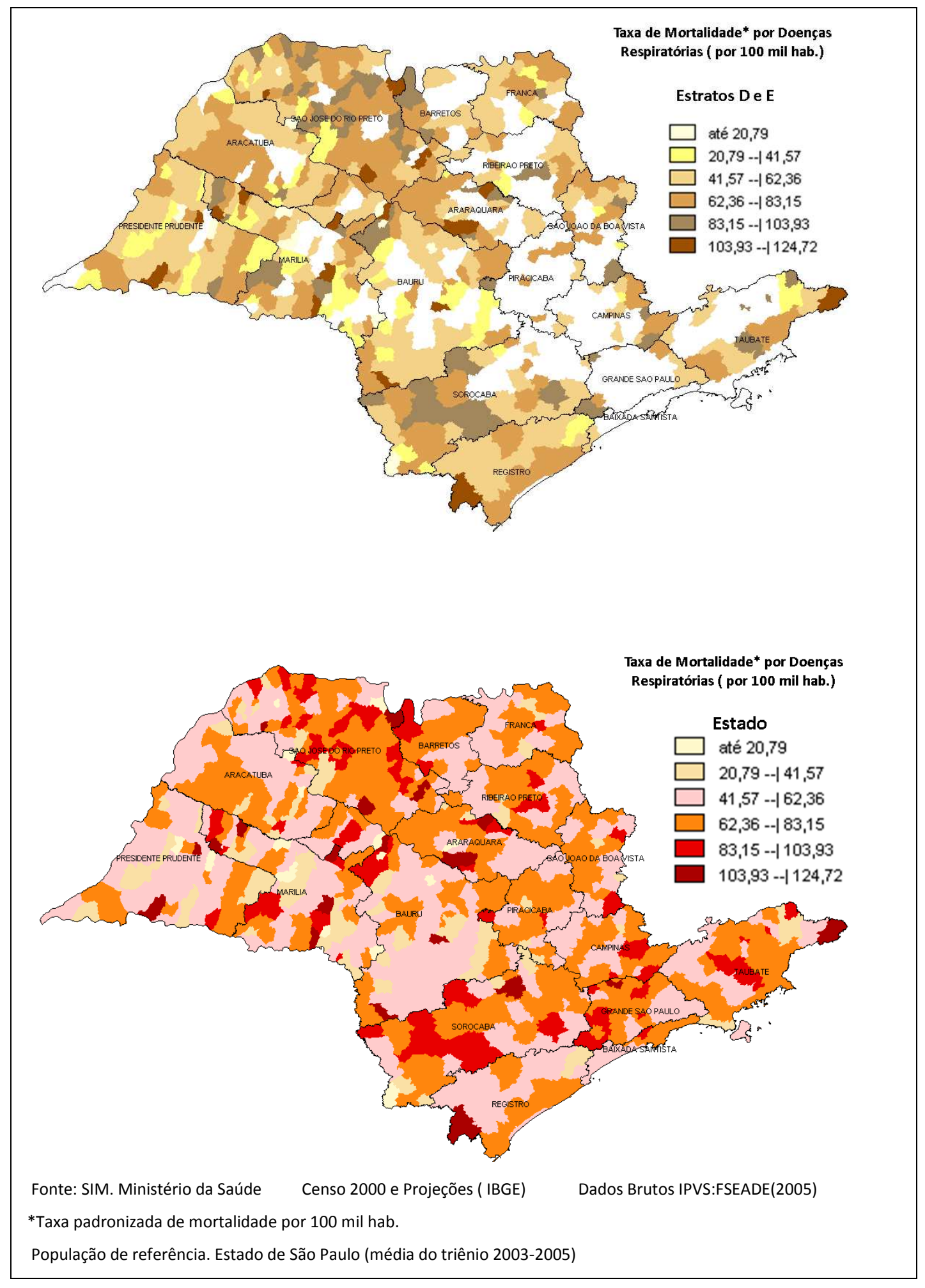


relatado em diversos países. FRANCISCO e cols. (2003) observaram incremento real das doenças respiratórias em idosos, com maior magnitude em homens na faixa etária de 80 anos ou mais, no período de 1980 a 1998, no Estado. Na infância ( 0 a 5 anos) respondendo por 15\% das mortes nessa idade, as infecções respiratórias agudas (resfriados, otites, sinusites, amidalites, problemas das vias inferiores, epiglotites, bronquites e pneumonias) tem se constituído em importante problema de saúde pública. CHIESA e cols. 2008 mostraram que as pneumonias e a influenza respondem por $85 \%$ ou mais dessas mortes.

Para BENICIO e cols. (2000), na criança o grau de exposição a agentes infecciosos e não infecciosos desencadeadores da doença e da suscetibilidade estão condicionados pela salubridade do meio ambiente (construções precárias, densidade de ocupação e presença de fumantes), nutrição (dependentes da renda familiar) e, pela capacidade da família em alocar racionalmente os recursos que dispõem (expressa pela escolaridade da mãe), fatores estes que determinam potencialmente à ocorrência da doença respiratória na infância.

CHIESA e cols. (2008) mostraram desigualdades na mortalidade por doenças respiratórias em crianças com condições socioeconômicas precárias em estratos homogêneos intra-urbanos na área de abrangência de um centro de saúde escola no município de São Paulo.

BENGUIGUI (2002) destacou para a morbimortalidade por IRA em crianças menores de cinco anos três fatores contributivos: o primeiro, relacionado ao conhecimento, as práticas e atitudes da família frente ao cuidado da criança e, ao reconhecimento da necessidade de assistência médica no decorrer da evolução da doença respiratória (imediato ou tardio). O segundo, relacionado à qualidade, oportunidade e resolução da assistência prestada pelo serviço de saúde. E, o terceiro associado às condições básicas da vida da criança e de sua família tornando-a mais, ou menos suscetível ao contágio e ou agravamento da doença.

Vem ocupando destaque crescente nos debates da comunidade cientifica e sanitária, os aspectos referentes aos possíveis efeitos adversos da exposição à poluição do ar e seus efeitos deletérios à saúde. Estudos recentes têm 
demonstrado associações significantes com doenças respiratórias mesmo em níveis médios de poluentes com repercussão na morbimortalidade geral e específica, em especial entre idosos e crianças (GOUVEIA e cols., 2003; GOMES, 2002; FREITAS e cols., 2004).

Um dos equívocos mais comuns é associar a poluição do ar apenas aos grandes centros urbanos, decorrentes da emissão de combustíveis fósseis eliminados por automóveis, caminhões e fábricas. Outra fonte importante de poluição atmosférica é a queima da biomassa em ambientes externos e internos principalmente, nos países em desenvolvimento. A queima de tipos específicos de biomassa é uma prática comum e antiga na humanidade e, uma das mais importantes fontes domésticas de energia, principalmente no meio rural (ARBEX e cols., 2004; CANÇADO e cols.,2006).

A incineração da biomassa em forma de madeira, carvão, esterco de animais ou resíduos agrícolas produz altos índices de poluição do ar em ambientes internos, lugar de maior permanência de donas de casas, crianças e idosos, especialmente nas estações frias. Estudos abordando poluição do ar em ambientes internos e efeitos sobre à saúde em especial, a Doença Obstrutiva Crônica e as Infecções das Vias Respiratórias evidenciaram importante relação causal mesmo em estudos com limitações metodológicas (ARBEX e cols., 2004).

Nos ambientes externos apesar do grande avanço tecnológico, ou até por causa dele, as queimadas, acidentais ou deliberadas de vegetação como grandes extensões de florestas e savanas geram gases tóxicos e material particulado causando impacto a curto ou longo prazo na morbimortalidade das populações expostas (ARBEX e cols., 2004; RIBEIRO, 2008).

0 material particulado é dentre todos, o que apresenta maior toxicidade sendo constituído na sua maioria (94\%) por partículas finas e ultrafinas que atingem as porções profundas do sistema respiratório e, tem sido associadas às infecções respiratórias agudas e doença pulmonar obstrutiva crônica entre outras (ARBEX e cols., 2004; CANÇADO e cols.,2006). Ressalta-se ainda que poluentes derivados de queimadas não atuam somente na sua origem, mas podem afetar regiões distantes aumentando assim o impacto sobre o número de indivíduos (RIBEIRO, 2008). 
O etanol, derivado da cana de açúcar, lançado no Brasil como um combustível alternativo, renovável e menos poluente estimulou uma enorme expansão do setor sucro-alcooleiro com a ampliação de sua participação na matriz energética brasileira. 0 país é o maior produtor e exportador de etanol do planeta, tendo a sua produção atingida 436,8 milhões de cana de açúcar na safra 2005/2006. 0 estado paulista com exceção do litoral, Serra do Mar e Vale do Ribeira responde por 60\% dessa produção (RIBEIRO, 2008).

Se o etanol enquanto combustível menos poluente reduziu a poluição nas grandes metrópoles, por outro lado, a extensa cultura de cana de açúcar no país, na fase da colheita lança mão de um procedimento singular, "a queima dos canaviais" que em nome de maior segurança e produtividade, gera grande quantidade de material particulado negro denominado "fuligem da cana de açúcar" com a chamada queimada da palha da cana de açúcar (ARBEX e cols., 2004; RIBEIRO, 2008).

Cerca de seis meses ao ano populações inteiras são expostas aos poluentes gerados da queima da biomassa e de material particulado, além das alterações ambientais delas derivadas, como a descarga de gases e de outros poluentes que provocam impacto sobre a saúde humana e, têm sido associadas ao agravamento de doenças crônicas do aparelho respiratório como a bronquite crônica, enfisema, asma e outros quadros alérgicos ligados às vias aéreas superiores (ARBEX e cols., 2004; RIBEIRO, 2008).

No estado, as regiões de Piracicaba, Araraquara e Ribeirão Preto situam-se entre as maiores produtoras de cana de açúcar do planeta. Estudos do Laboratório de Poluição Atmosférica Experimental (LPAE) do Departamento de Patologia da Faculdade de Medicina da Universidade de São Paulo realizados no município de Piracicaba mostraram aumento de 3,5 internações hospitalares por doenças respiratórias no período de queima da palha da cana de açúcar.

Inclui-se ainda os efeitos nocivos do tabaco e sua associação às doenças respiratórias, já fartamente relatado na literatura acrescendo, embora em menor grau, o aumento de queixas respiratórias em não fumantes pela inalação passiva do tabaco, em especial crianças e idosos (GOMES, 2002). 
O ambiente ocupacional e a poluição derivada das atividades produtivas também tem sido associado epidemiologicamente a uma extensa gama de doenças respiratórias como as rinossinusopatias, as disfonias, as ulcerações e perfurações do septo nasal e, a um número elevado de neoplasias da cavidade bucal, seios paranasais e sistema respiratório (BAGATIN, 2006).

Os efeitos prejudiciais da poluição atmosférica sobre a saúde e, o aparelho respiratório em particular, tem sido objeto de inúmeros estudos (GOMES, 2002; BENICIO, 2000; CANÇADO, 2006), porém medidas de prevenção ainda estão distantes das desejáveis, pois envolvem intervenções mais focadas a exemplo da exposição ocupacional e, outras ações mais amplas e globalizantes, a exemplo das ações sobre o meio ambiente.

Os resultados deste estudo mostraram taxas elevadas de mortalidade por Doenças Respiratórias distribuídas por todo o Estado com taxas de mortalidade mais elevadas nos estratos de maior vulnerabilidade social dentre os mais urbanizados e populosos e, com sobremortalidade masculina constante em todos os estratos. Dada a complexidade dos determinantes e condicionantes das doenças respiratórias, além da diversidade econômica e produtiva do Estado, as desigualdades de vulnerabilidade social e os diferenciais socioespaciais sugerindo maior exposição ao risco de agregados populacionais com maior adensamento populacional e urbanização conjugados a maior vulnerabilidade social a melhor apreensão destes resultados se dará com o aprofundamento do estudo para mortalidade especifica por causa e grupos etários.

\subsection{DOENÇAS DO APARELHO CIRCULATÓRIO}

As Doenças do Aparelho Circulatório-DAC compreendem as causas constantes no Capitulo IX da CID 10 (I00 a I99). Os grupos mais significativos de afecções do aparelho circulatório são: a Doença Isquêmica do Coração - DIC (códigos I20 a I25) e a Doença Cerebrovascular - DCV (I60 a I69). Sua maior incidência decorre da exposição a fatores de risco, como tabagismo, 
hipertensão, obesidade, hipercolesterolemia, diabetes, sedentarismo e estresse e, ainda as condições de diagnóstico e a qualidade da assistência médica disponível (RIPSA, 2008).

No triênio, ocorreram 218.238 óbitos por DAC de residentes no Estado. Foram excluídos 721 óbitos sem identificação do município de residência no estado, idade ou sexo resultando numa média anual de 72.505 óbitos dos quais 38.181 em homens $(52,7 \%)$ e 34.324 mulheres $(47,3 \%)$.

O Estado apresentou taxa padronizada de mortalidade de 184,57 \%000 hab. e, variou de 174,03\%000 hab. a 206,87\%000 hab. nos estratos. Situou-se no Estrato D, o menor valor e, no Estrato C, o maior. No Estado, os homens mostraram sobremortalidade com 195,89 \%000 hab. e, nos estratos cujas taxas variaram de 216,87 a 176,49\%000 habitantes (Tabela 13). Internamente aos estratos, com exceção do Estrato E, as taxas mais elevadas predominaram nos conjuntos de municípios mais populosos, com destaque para os conjuntos C10000, D300 e A1000, as mais elevadas Dentre todos os conjuntos (Figura 29).

Nos Estratos A e B, 26 municípios (28,3\%) mostraram taxa padronizada igual ou acima de 182,66\%000 habitantes. Espacialmente, as taxas mais elevadas concentraram-se em áreas da RM São Paulo e regiões de Taubaté, Campinas, Sorocaba, Bauru, Barretos e S.J.Boa Vista. Observaram-se áreas menores também nas regiões de Franca, Ribeirão Preto e S.J. Rio Preto (Figura 30).

Nos Estratos D e E, 189 municípios (40,2\%) apresentaram taxa igual ou acima de 173,83\%000 hab.. Espacialmente, as menores taxas concentraram-se a noroeste do Estado, na região de S.J.Rio Preto e Araçatuba. As mais elevadas mostraram-se dispersas em áreas das regiões de Bauru, S.J. Rio Preto e Taubaté.

O Estrato C, mostrou 55 dos seus municípios (66,3\%) com taxa padronizada igual ou acima de 165,23\%000 hab.. Espacialmente, com exceção da região de Araçatuba, todas as demais apresentaram áreas de mortalidade mais elevada destacando-se a região de Bauru e, a RM São Paulo com áreas mais extensas (Figura 31). o Estado, 274 municípios (42,5\%) apresentaram taxa igual ou acima de 173,83\%000 habitantes. Espacialmente, as áreas de mortalidade mais elevada situaram-se na RM São Paulo e nas regiões de Bauru, Taubaté e Campinas com áreas contíguas em grande parte de seus territórios. As demais, 
apresentaram parcelas menores de seus territórios, destacando-se as regiões de Araçatuba e Piracicaba.

Tabela 13 - Óbitos e Taxa de Mortalidade por Doenças do Aparelho Circulatório (Total e segundo Sexo), mediana, desvio padrão e razão de taxas nos Estratos de Vulnerabilidade Social. Estado de São Paulo, média do triênio 2003 a 2005.

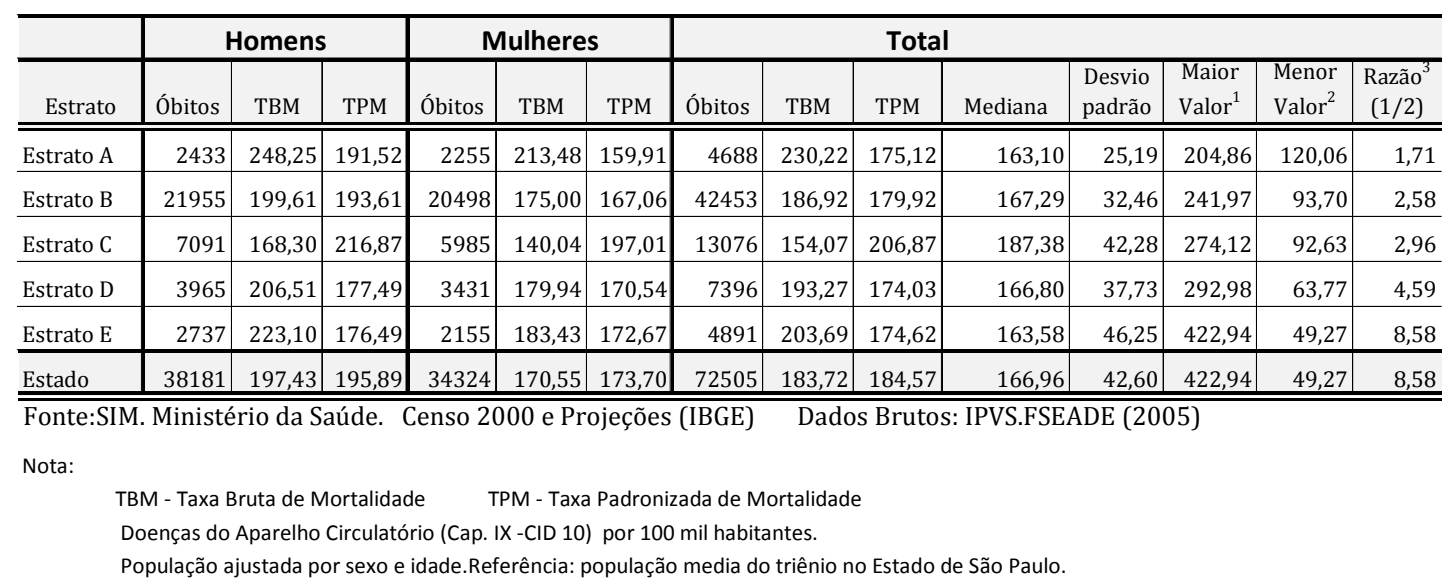

Desde meados da década de 80, a mortalidade por Doenças do Aparelho Circulatório vem declinando para o conjunto da população brasileira (MINISTÉRIO DA SAÚDE, 2004; MANSUR e cols., 2002, 2006), o que tem sido atribuído à intensificação do controle de fatores de riscos cardiovasculares, especialmente da hipertensão arterial sistêmica, novas técnicas diagnósticas, aos avanços no campo terapêutico e, à melhoria das condições socioeconômicas (OLIVEIRA e cols., 2006).

Apesar da tendência à redução, mantém-se no topo do ranking das causas de morte no país há décadas, respondendo por 32,5\% dos óbitos em 2004, e mostrando expressivas diferenças regionais. A região Sudeste, mostrou padronizada de 176,1\%000 hab.. Houve sobremortalidade masculina em todas as regiões do país com taxa padronizada de 170,0\%000 hab. e, 148,0\%000 hab. para as mulheres (MINISTÉRIO DA SAÚDE, 2006). Estudos de MANSUR e cols.(2002, 2006) mostraram aumento da mortalidade em estados e capitais com condições socioeconômicas mais precárias. GODOY e cols. (2007) observaram taxas mais elevadas por DAC em áreas com piores níveis socioeconômicos em estudos desenvolvidos em S.J Preto, alertando para riscos sócio-ambientais na 
Figura 29 - Taxa padronizada de mortalidade por Doenças do Aparelho Circulatório (por 100 mil hab.) segundo conjuntos de municípios nos Estratos de Vulnerabilidade Social. Estado de São Paulo, média do triênio 2003 a 2005.

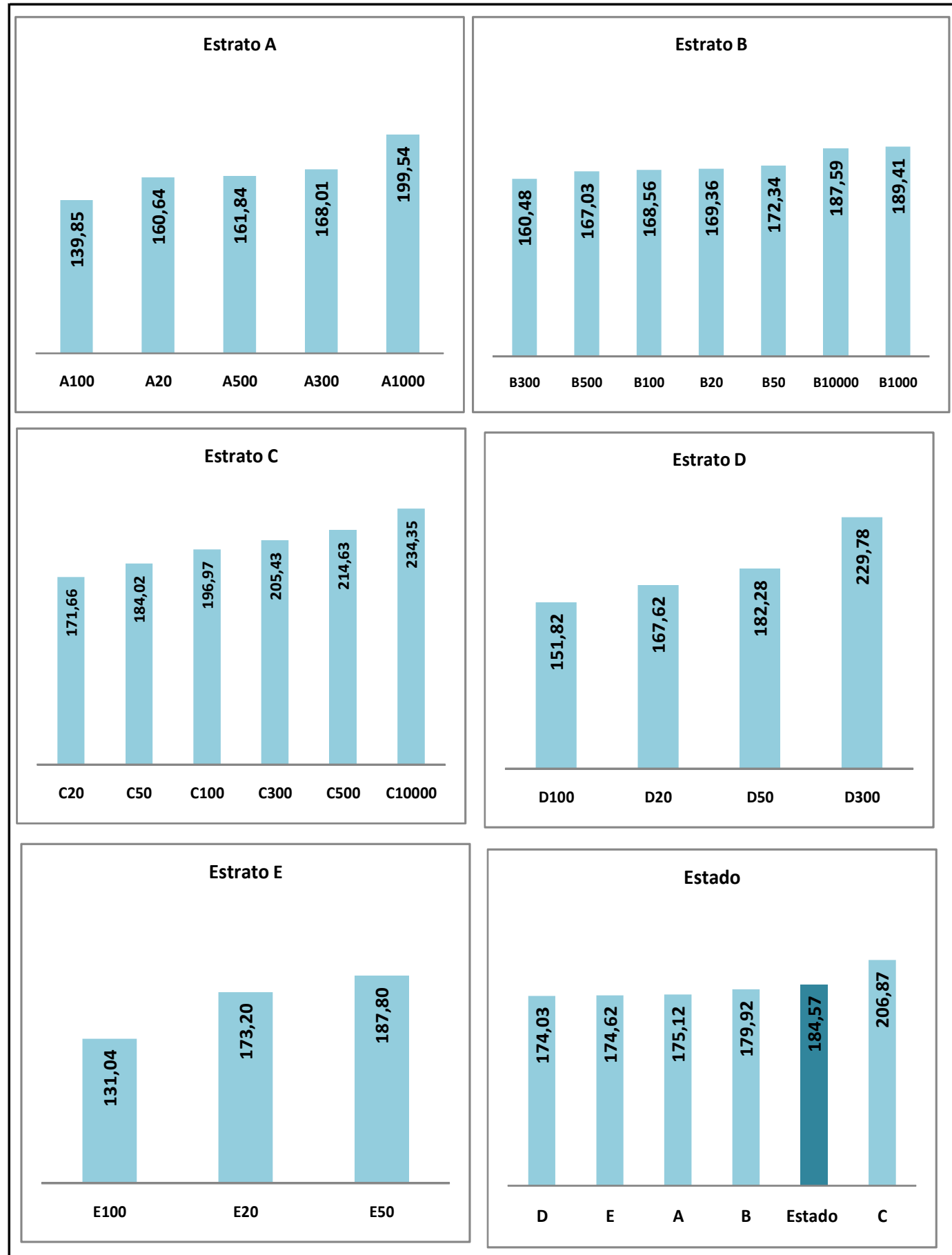

Fonte:SIM. Ministério da Saúde. Censo 2000 e Projeções (IBGE) Dados Brutos: IPVS.FSEADE (2005) 
Figura 30 - Distribuição espacial da taxa padronizada de mortalidade por Doenças do Aparelho Circulatório (por 100 mil hab.) nos municípios dos Estratos de Vulnerabilidade Social (A e B) e (D e E). Estado de São Paulo, média do triênio 2003 a 2005.

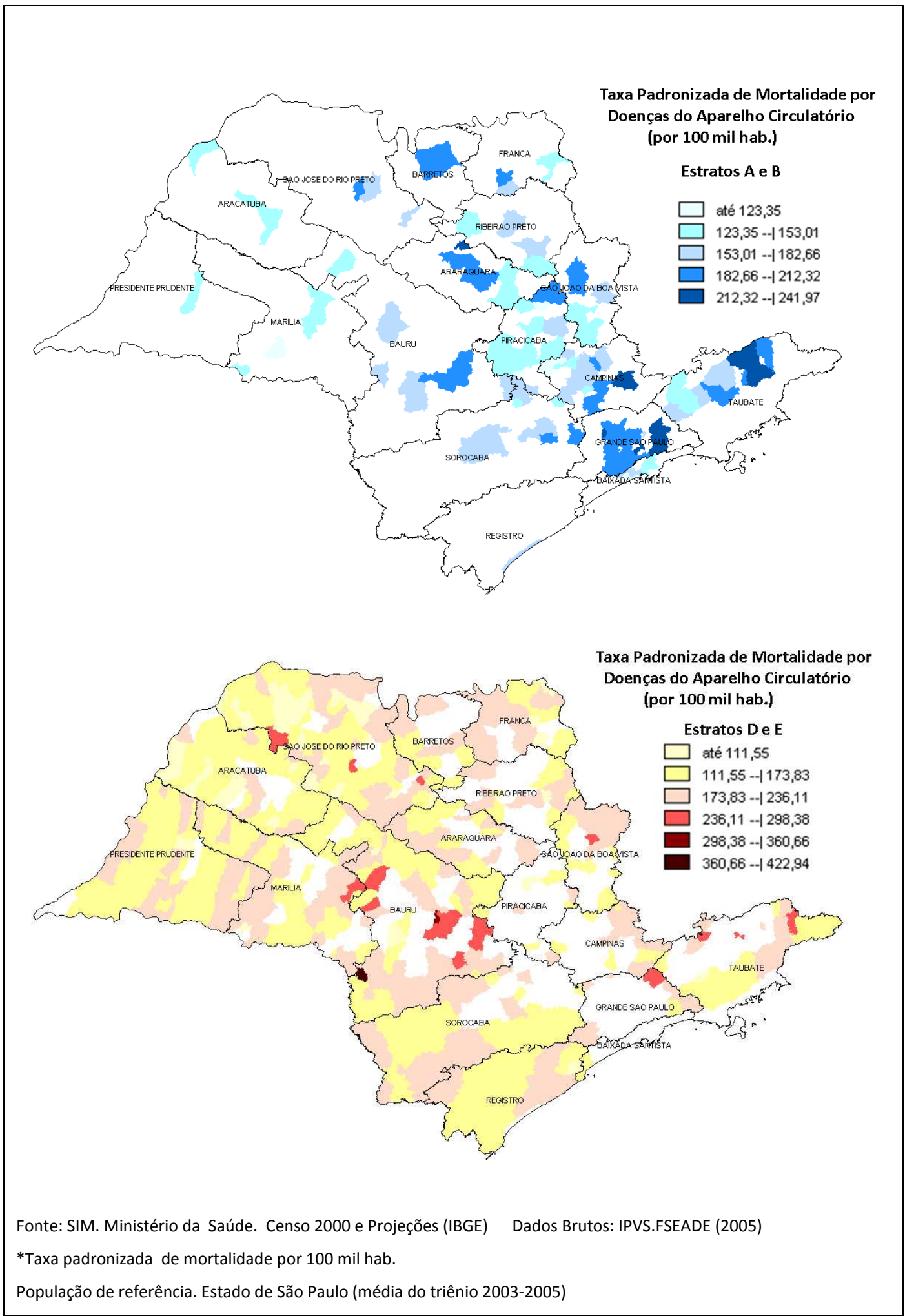


Figura 31 - Distribuição espacial da taxa padronizada de mortalidade por Doenças do Aparelho Circulatório (por 100 mil hab.) nos municípios do Estrato de Vulnerabilidade Social C e Estado de São Paulo. Média do triênio 2003 a 2005.

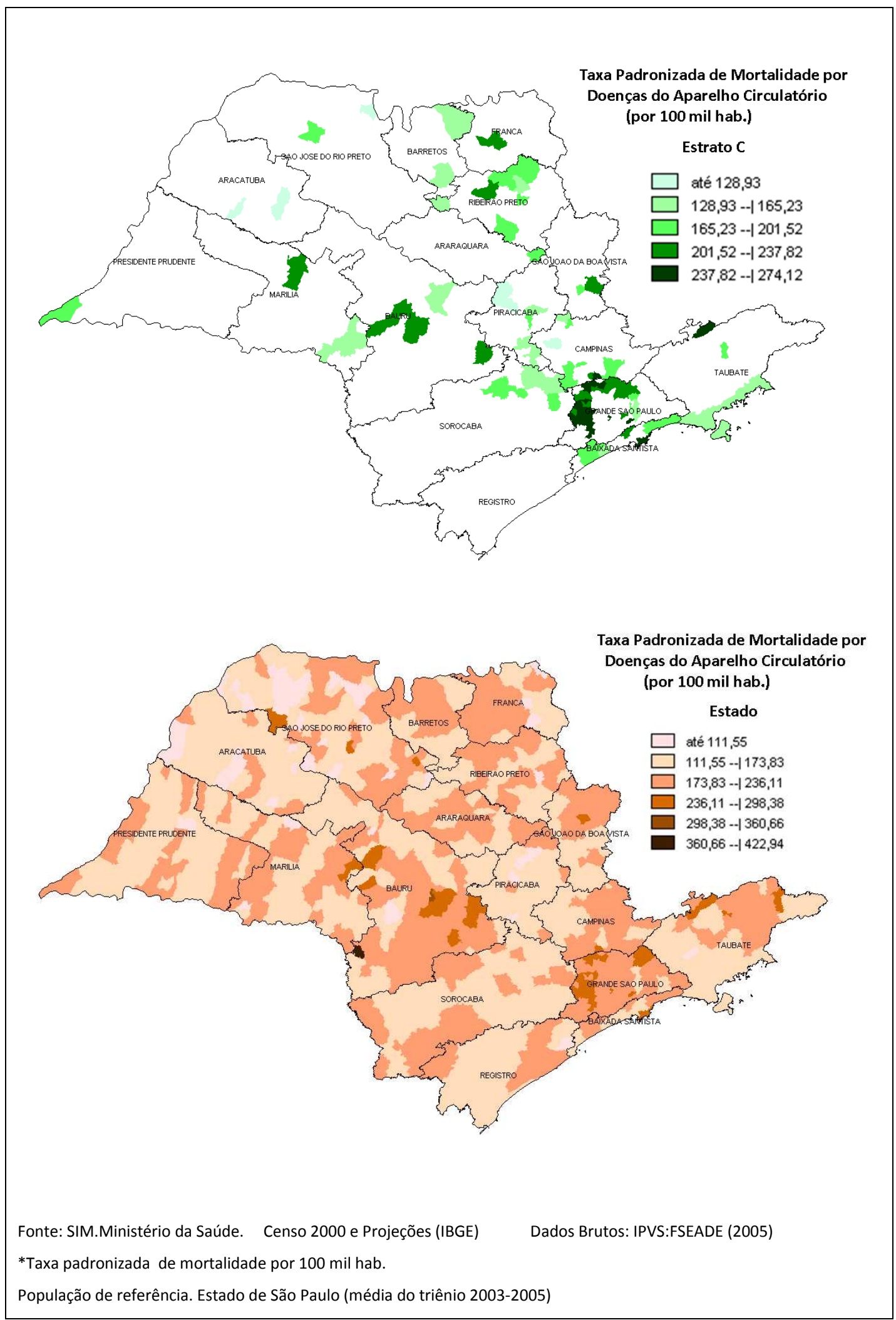


composição dos determinantes. PARAHYBA (2006) mostrou que os idosos apresentam maior prevalência de incapacidade funcional evidenciando que suportam maior carga de problemas de saúde, ainda que vivam mais.Inúmeros estudos também vêm mostrando efeitos das condições experimentadas antes do nascimento, no início da vida, no período produtivo e reprodutivo, bem como dos fatores relacionados às condições demográficas, econômicas e sociais sobre a mortalidade e à saúde no fim da vida. Educação, renda, ocupação, recursos sociais e econômicos, hábitos alimentares, auto-cuidado e acesso aos serviços de saúde, além de hábitos comportamentais como o uso de tabaco, álcool, práticas religiosas, relações afetivas, atividades físicas também apresentam influências na morbimortalidade de idosos CAMPOS (2006), OLIVEIRA e cols.(2006), LESSA (2004).

Estudos de ARBEX e cols.(2004) apontaram ainda para os efeitos deletérios da poluição atmosférica na morbimortalidade por DAC, com destaque para o material particulado fino tanto nos episódios agudos (internações e mortes) quanto nos crônicos pela exposição duradoura, tendo sido associado ao aumento da viscosidade sangüínea, de marcadores inflamatórios, progressão da arteriosclerose, alterações da coagulação, redução da variabilidade da freqüência cardíaca, vasoconstrição e aumento da pressão arterial, todos estes fatores de risco para doenças cardiovasculares.

As doenças crônicas não transmissíveis geralmente têm sua expressão clínica no indivíduo após longo tempo de exposição aos fatores de risco e de convivência assintomática com a doença ainda não diagnosticada. Logo, o diagnóstico costuma ser tardio, com complicações clínicas avançadas, ou com um desfecho que pode ser único e fatal como ocorre muitas vezes com as doenças coronarianas (LESSA, 2004). Investimentos no monitoramento e controle dos fatores de risco, característicos da prevenção primária, provocam a quebra da cadeia epidemiológica dessas doenças, cujos benefícios são inegáveis, porém tardios, se a doença já estiver instalada, mesmo quando detectada numa fase precoce.

Os fatores de risco mutáveis são na sua grande maioria comportamentais exigindo estratégias de intervenção consistentes e convincentes, que se 
revestem de complexidade à medida que implicam em mudanças culturais e comportamentais. No contexto epidemiológico e social que permeiam as doenças crônicas não transmissíveis, tanto em países desenvolvidos como naqueles em desenvolvimento ainda predominam políticas de saúde, curativas, centradas na assistência médica de urgência, emergência e, sob hospitalização, com custos sociais elevados para os indivíduos, família e sociedade e, com pesados custos financeiros para o sistema de saúde.

Os resultados mostraram mortalidade elevada por DAC no Estado, com diferenças geográficas e sociais além de sobremortalidade masculina. As taxas mais elevadas nos estratos C e B podem ser explicadas pela conformação destes estratos que conjugam elevados adensamentos populacionais, intensa urbanização e maior vulnerabilidade social para o Estrato C no seu conjunto o que não necessariamente, não exclui as desigualdades sociais internas ao estrato e intra-urbana aos municípios individualmente que não são captadas por este estudo apontando para uma maior exposição aos riscos de mortalidade por DAC nestes estratos. E, ainda o aprofundamento do estudo para mortalidade especifica para causa e grupos etários, obviamente permitirá a melhor compreensão destes resultados.

\subsection{MORTALIDADE POR DIABETES MELLITUS}

No triênio ocorreram 24.520 óbitos por Diabetes Mellitus - DM de residentes no Estado. Foram excluídos 32 óbitos sem registro residência no estado, idade ou sexo, resultando numa média anual de 8163 óbitos, dos quais, as mulheres representaram 4579 (56,1\%) e, os homens 3583 óbitos $(43,9 \%)$.

No Estado, a taxa padronizada de mortalidade por DM foi de 21,10\%000 hab., situando a mais elevada no Estrato C com 23,57\%000 hab. e, a menor no Estrato A com 17,36\%000 hab., resultando numa razão de taxas de 1,4.

Os Estratos A e E foram os que apresentaram maior variabilidade interna com $\mathrm{DP}=15,78$ e 13,91 respectivamente. No Estado, as mulheres apresentaram 
sobremortalidade com taxa de 23,24\%000 hab. e, nos estratos variando de 28,62 a 18,79\%000 hab. (Tabela 14).

Internamente aos estratos, os conjuntos de municípios de pequeno porte populacional (A20, B20 e B50) destacaram-se com as taxas mais elevadas nos Estratos A e B. Nos estratos C e E destacaram se os conjuntos C100 e E50 e somente no Estrato D, a taxa mais elevada situou-se no conjunto D300, o de maior porte populacional (Figura 32).

Tabela 14 - Óbitos e taxas (bruta e padronizada) de mortalidade por Diabetes Mellitus Total e segundo Sexo (por 100 mil hab.) nos Estratos de Vulnerabilidade Social. Estado de São Paulo, média do triênio 2003 a 2005.

\begin{tabular}{|c|c|c|c|c|c|c|c|c|c|c|c|c|c|c|}
\hline \multirow[b]{2}{*}{ Estrato } & \multicolumn{3}{|c|}{ Homens } & \multicolumn{3}{|c|}{ Mulheres } & \multicolumn{3}{|c|}{ Total } & \multirow[b]{2}{*}{ Mediana } & \multirow[b]{2}{*}{$\begin{array}{l}\text { Desvio } \\
\text { padrão }\end{array}$} & \multirow[b]{2}{*}{$\begin{array}{l}\text { Maior } \\
\text { Valor }^{1}\end{array}$} & \multirow[b]{2}{*}{$\begin{array}{l}\text { Menor } \\
\text { Valor }^{2}\end{array}$} & \multirow[b]{2}{*}{$\begin{array}{c}\text { Razão } \\
(1 / 2)\end{array}$} \\
\hline & Óbitos & TMB & TMP & Óbitos & TMB & TMP & Óbitos & TMB & TMP & & & & & \\
\hline Estrato $\mathrm{A}$ & 202 & 20,61 & 15,92 & 263 & 24,86 & 18,79 & 465 & 22,82 & 17,36 & 18,66 & 15,78 & 66,72 & 9,70 & 6,9 \\
\hline Estrato $\mathrm{B}$ & 2080 & 18,91 & 18,98 & 2545 & 21,73 & 21,09 & 4626 & 20,37 & 20,02 & 19,71 & 8,44 & 39,46 & 6,84 & 5,8 \\
\hline Estrato C & 667 & 15,83 & 20,62 & 840 & 19,65 & 26,49 & 1507 & 17,76 & 23,57 & 22,46 & 8,32 & 41,64 & 5,77 & 7,2 \\
\hline Estrato D & 377 & 19,62 & 17,73 & 573 & 30,05 & 28,62 & 950 & 24,82 & 23,03 & 21,50 & 10,21 & 63,38 & 0,00 & * \\
\hline Estrato $\mathrm{E}$ & 257 & 20,98 & 17,88 & 358 & 30,48 & 28,17 & 616 & 25,64 & 22,67 & 20,52 & 13,91 & 79,19 & 0,00 & * \\
\hline Estado & 3583 & 18,53 & 18,99 & 4579 & 22,75 & 23,24 & 8163 & 20,68 & 21,10 & 20,92 & 11,93 & 79,19 & 0,00 & * \\
\hline
\end{tabular}

Fonte:SIM. Ministério da Saúde. Censo 2000 e Projeções (IBGE) Dados Brutos: IPVS.FSEADE (2005)

$$
\begin{aligned}
& \text { TBM - Taxa Bruta de Mortalidade TPM - Taxa Padronizada de Mortalidade } \\
& \text { Diabetes Mellitus (Cap. IV - D.Endócrinas, Nutricionais e Metabólicas, Códigos E10-E14.CID 10) por } 100 \text { mil hab. } \\
& \text { População ajustada por sexo e idade.Referência população média do triênio no Estado de São Paulo. } \\
& \text { (*) Não divisível. }
\end{aligned}
$$

Nos Estratos A e B, 49 municípios (52,7\%) apresentaram taxa acima de 19,82\%000 habitantes. Espacialmente, com exceção das regiões de Presidente Prudente, São José do Rio Preto e Franca, as demais apresentaram áreas de taxas mais elevadas destacando-se as regiões de Taubaté, Campinas, Piracicaba e RM São Paulo (Figura 33).

No Estrato C, 54 municípios $(65,1 \%)$ apresentaram taxa acima de 19,80\%000 habitantes. Espacialmente, as regiões de Registro e Sorocaba se destacaram com áreas contíguas mais extensas, que também foram observadas nas regiões de Taubaté, Presidente Prudente e Araçatuba porém, estas ultimas mais esparsas (Figura 33).

Nos Estratos D e E, 247 municípios (52,6\%) mostraram taxa de mortalidade acima de 19,80\% ${ }_{000}$ habitantes. Espacialmente, as regiões de 
Figura 32- Taxa padronizada de mortalidade por Diabetes Mellitus (por $100 \mathrm{mil}$ hab.) segundo porte populacional dos conjuntos de municípios nos Estratos de Vulnerabilidade Social. Estado de São Paulo, média do triênio 2003 a 2005.

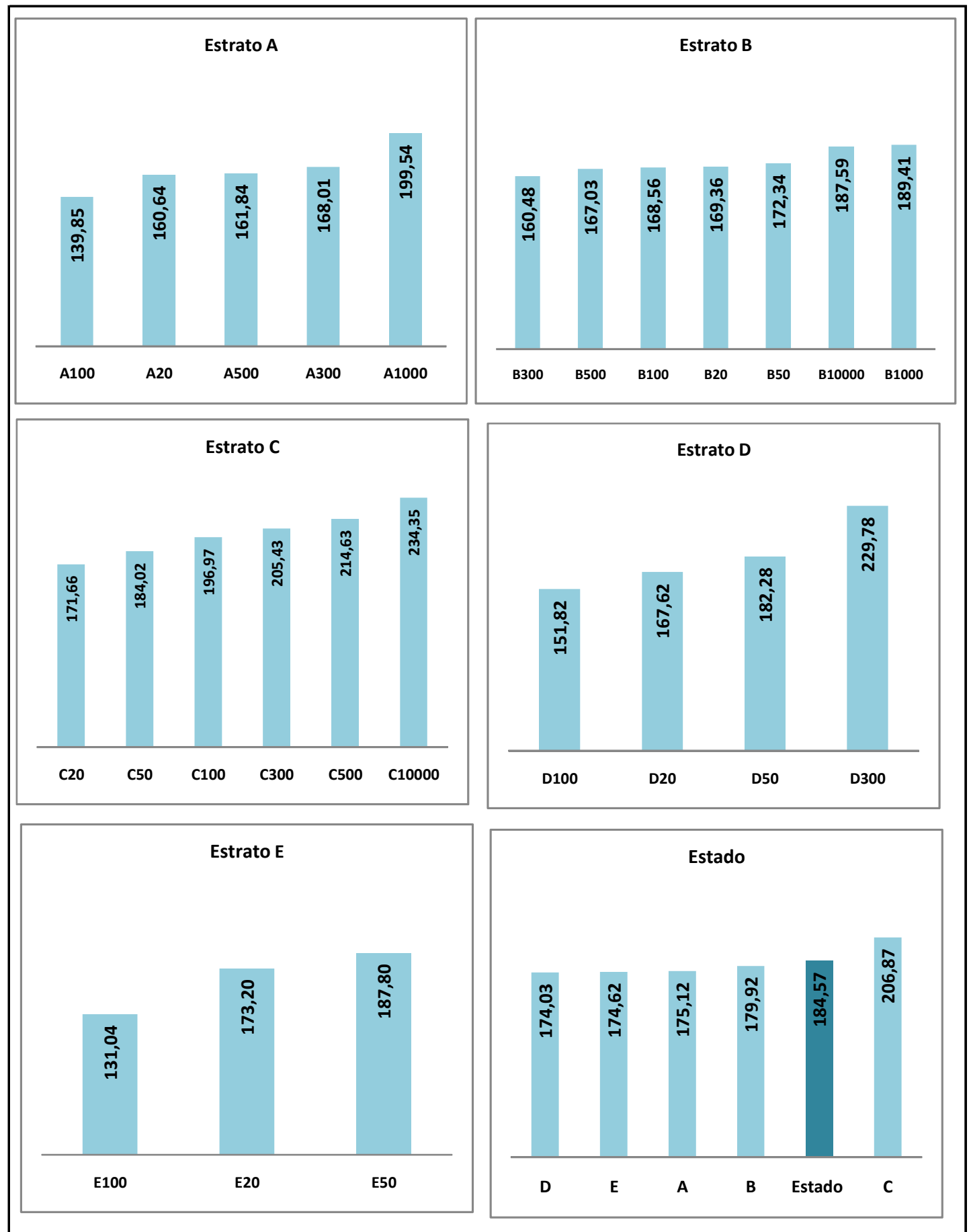

Fonte:SIM. Ministério da Saúde. Censo 2000 e Projeções (IBGE) Dados Brutos: IPVS.FSEADE (2005) 
Figura 33 - Distribuição espacial da taxa padronizada de mortalidade por Diabetes Mellitus (por 100 mil hab.) nos municípios dos Estratos de Vulnerabilidade Social (A e B) e C. Estado de São Paulo, média do triênio 2003 a 2005.

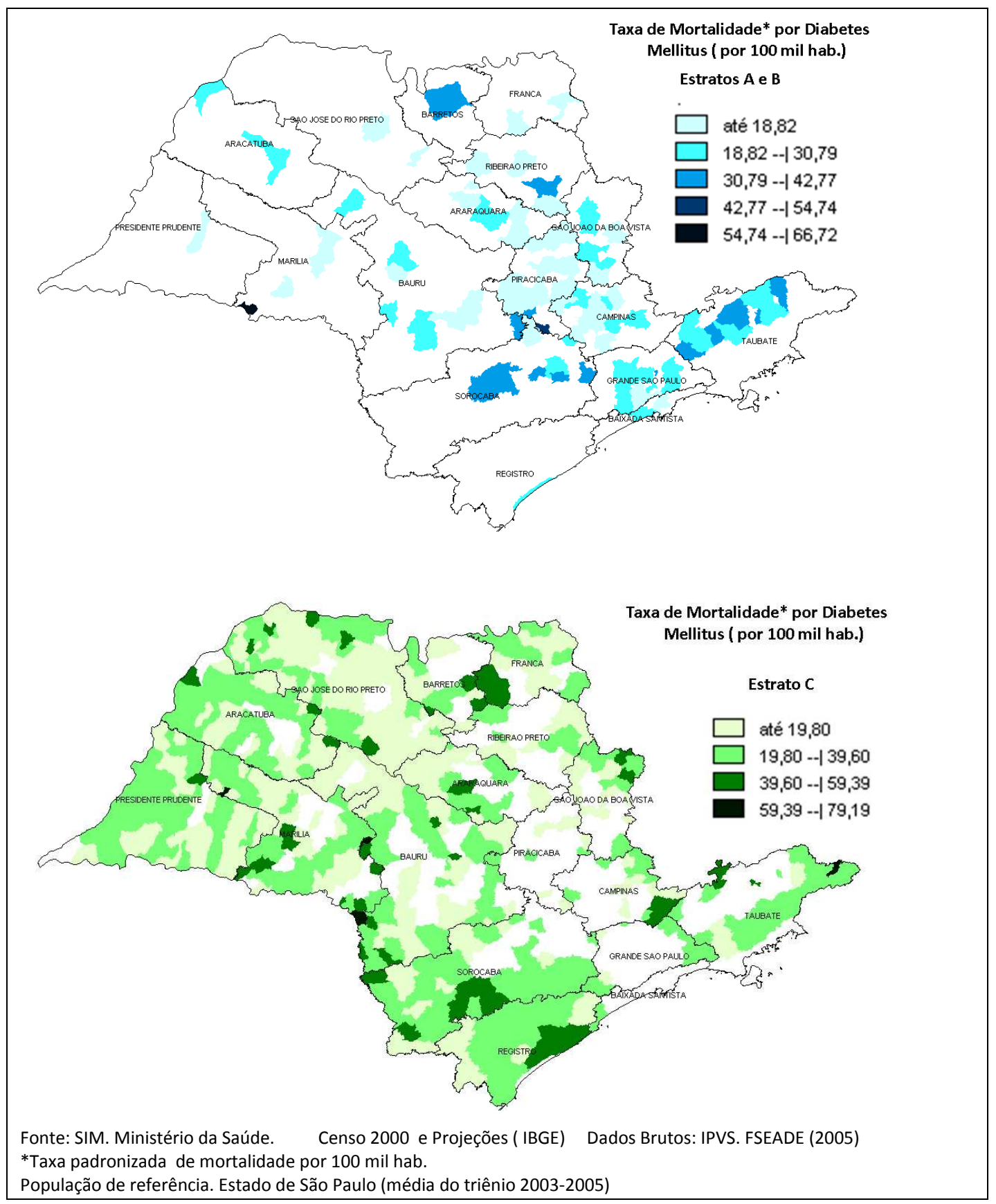


Figura 34 - Distribuição espacial da taxa padronizada de mortalidade por Diabetes Mellitus (por 100 mil hab.) nos municípios dos Estratos de Vulnerabilidade Social (D e E) e Estado de São Paulo, média do triênio 2003 a 2005.

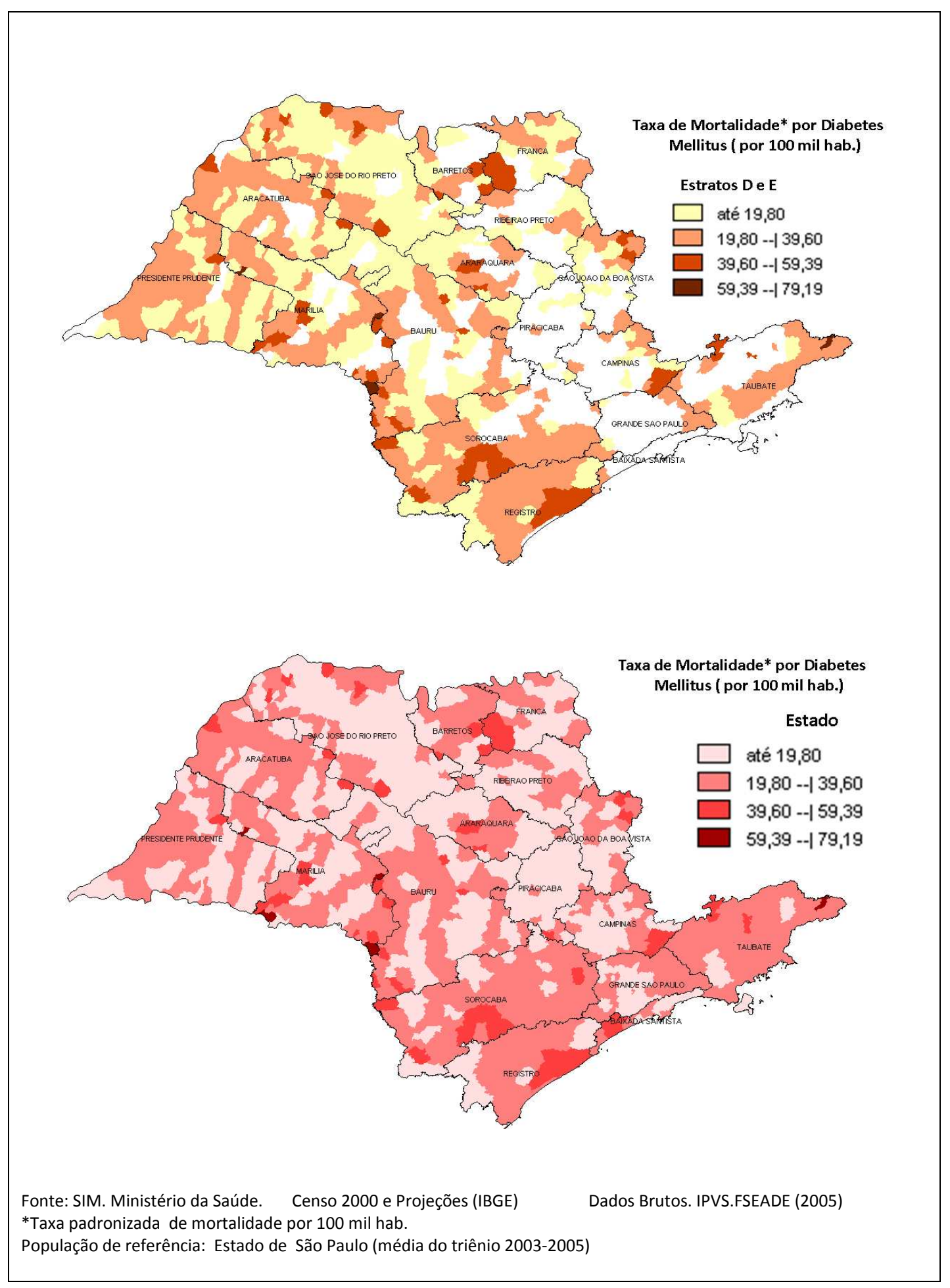


Sorocaba, Registro, Araçatuba, Taubaté Marília, Presidente Prudente e S.J.Rio Preto apresentaram expressivas parcelas dos seus territórios com maior mortalidade, destacando-se a área contígua Registro/Sorocaba que engloba ainda parcelas da Baixada Santista/RM São Paulo (Figura 34). No Estado, destacaram-se ainda 24 municípios (3,7\%), menores de 20 mil hab. sem registro de óbitos no período e, outros $343(53,2 \%)$ com as taxas acima de 20,0\%000 hab. Espacialmente, observaram-se áreas de mortalidade mais elevada a exemplo de Piracicaba, Campinas, e S. J. Rio Preto, ao contrário

das demais, que mostraram áreas de menor mortalidade e, mais dispersas, a exemplo de S. J. Boa Vista e outras, com áreas contíguas que tomaram quase todo o território a exemplo de Registro, Sorocaba, Baixada Santista, Taubaté e RM São Paulo (Figura 33).

Os achados deste estudo mostraram mortalidade mais elevada por DM no Estrato C - Vulnerabilidade Social Intermediária, seguido dos Estratos D e E, os de maior vulnerabilidade social, com sobremortalidade feminina predominante em todos os estratos. As taxas mais elevadas nos estratos C, D e E podem estar relacionadas a conformação destes estratos. O primeiro que conjuga elevado adensamento populacional, intensa urbanização e vulnerabilidade social intermediária, porém com grandes desigualdades sociais. Os Estratos D e E conjugam intensa vulnerabilidade social em municípios provavelmente com precárias infra-estrutura de atenção à saúde, o que necessariamente não supõe que o Estrato $\mathrm{C}$, disponha de infra-estrutura de atenção à saúde e/ou acesso. Os conjuntos destes fatores podem contribuir para uma maior exposição aos riscos de mortalidade por DM nestes estratos. E, ainda o aprofundamento do estudo para mortalidade especifica para causa e grupos etários obviamente permitirá a melhor compreensão destes resultados.

O Diabetes Mellitus - DM é uma síndrome de etiologia múltipla, decorrente da falta de insulina e/ou da incapacidade desta exercer adequadamente seus efeitos. Caracteriza-se por hiperglicemia crônica com distúrbios do metabolismo dos carboidratos, lipídeos e proteínas. As conseqüências do DM em longo prazo incluem disfunção e falência de vários órgãos, especialmente rins, olhos, nervos, coração e vasos sangüíneos (MINISTÉRIO DA SAÚDE 2006). 
A elevação das taxas de mortalidade acompanha o envelhecimento da população e costuma estar associado às doenças do aparelho circulatório como o acidente vascular cerebral, a doença hipertensiva, a doença isquêmica do coração e estilos de vida pouco saudáveis como sedentarismo, dieta, inadequada e obesidade entre outros (MINISTÉRIO DA SAÚDE, 2002).

GOLDENBERG e cols.(2003) num estudo multicêntrico de DM no Brasil mostraram aumento da prevalência de Diabetes na população masculina, quando acompanhado de ações de busca ativa, resultando no desaparecimento da diferença de prevalência entre a população masculina e feminina. Apontaram ainda um perfil diferenciado da população atingida não só quanto ao gênero, mas também quanto às condições sociais de existência, cujos resultados mostraram maior prevalência de DM nos segmentos sociais menos favorecidos e apontaram para um quantum de população que desconhece o risco da doença e, de doentes com a patologia já em curso, mas sem diagnóstico e conseqüentemente sem tratamento. Tais aspectos pressupõem que as formas de intervenção considerem que há uma elevada parcela da população em condições precárias de existência exposta aos riscos dada a relevância da historia familiar para o pré-diagnostico e, de doentes cuja deteç̧ão precoce traria inegáveis benefícios (GOLDENBERG e cols., 2003).

FRANCO e cols. (1998) numa série histórica de 1970 a 1992, estudando a mortalidade por DM no Estado apresentaram taxas padronizadas de mortalidade para o Estado, Interior e Capital. No Estado, a taxa total mostrou poucas oscilações (17,0 para 17,2\%00o hab.), declinou na Capital (22,3 para 17,3 \%000 hab.) e aumentou no interior do Estado (14,3 para 17,2\%000 hab.).

LAURENTI e cols. (1982) estudando a evolução da mortalidade por DM no município de São Paulo numa serie histórica no período de 1900-1978 mostraram variação de 1,30 a 16,67\%000 hab. nas taxas, representando um aumento de 13 vezes no período. 0 maior aumento ocorreu nas primeiras décadas do período e, estabilizou-se com valores de 18,00 a 20,00\%000 hab. no final do período. Concluíram os autores que o advento da insulina e dos hipoglicemiantes orais aumentou a sobrevida dos doentes "acumulando" diabéticos na população, e portanto, crescendo o risco de morte por esta causa. 
No país em 2004, a taxa padronizada de mortalidade por DM foi de 22,1\%000 hab., na região Sudeste foi de 22,0\%000 hab. e, no Estado de São Paulo de 20,3\%000 hab. (MINISTÉRIO DA SAÚDE, 2006). Ressalta-se que nos estudos de mortalidade geralmente as análises baseiam-se nas causas básicas da morte, e no caso do DM sua importância acaba sempre subestimada, pois os diabéticos em geral morrem devido às complicações crônicas da doença. Para o conhecimento real da sua magnitude deve-se considerar a menção do DM em qualquer um dos campos da causa de morte na declaração de óbito.

FRANCO e cols. (1998) em estudos conduzidos na população paulista, mostrou que o DM como causa básica representou apenas um terço da real contribuição para o total de óbitos na população. Naqueles em que a causa básica foi o DM, as DAC foram as mais freqüentemente associadas. Naqueles em que DM figurou como causa associada predominou as DAC, seguidas das Doenças do Aparelho Respiratório e após, as Neoplasias. As mulheres, no grupo etário acima de 40 anos mostraram sobremortalidade com taxa de 186,7\%000 hab. enquanto os homens apresentaram 72,4\%000 habitantes.

Embora se saiba que o estudo do DM por meio da causa básica do óbito subestima sua importância, os coeficientes de mortalidade em mulheres têm sido mais elevados que nos homens e, com maior magnitude nas faixas etárias mais avançadas. FRANCO e cols. (1998) afirmam que a sobremortalidade feminina pode ser atribuída à maior freqüência do conhecimento do diagnóstico da doença entre as mulheres.

Considerando ainda que o óbito seja o desfecho final de uma ou mais patologias e, que o envelhecimento da população brasileira e, os serviços de saúde têm grande responsabilidade na prevenção dessas patologias, seja no nível primário tais como estímulo a atividades físicas regulares, redução de consumo de gorduras, hábitos saudáveis e, na prevenção secundária e terciária buscando a detecção precoce do $\mathrm{DM}$ e, a assistência adequada à doença, evitando complicações crônicas que diminuem a qualidade e aumentam a sobrevida do diabético e, conseqüentemente reduzem a mortalidade. 


\subsection{A MORTALIDADE POR NEOPLASIAS MALIGNAS}

No triênio, ocorreram 116.402 óbitos por Neoplasias Malignas (tumores) Cap. II Códigos C00-C97 - CID 10 de residentes no Estado. Foram excluídos 130 óbitos sem identificação do município de residência no estado, idade ou sexo resultando numa média anual de 38.801 óbitos. Os homens participaram com 21.218 óbitos $(54,7 \%)$ e, as mulheres com 17.583 óbitos (45,3\%).

No Estado, a taxa padronizada de mortalidade foi de 98,87\%000 hab. com mediana de 87,30. 0 Estrato A destacou-se com 104,96\%000 hab., com taxa, mediana $(105,20)$ e, variabilidade interna $(\mathrm{DP}=36,60)$, as mais elevadas dentre os estratos. Os mais vulneráveis (D e E) mostraram taxa de 88,79 e 80,85\%000 hab., respectivamente. A razão de taxas entre o maior e o menor valor foi de 1,3 (Tabela 15). O gradiente de taxas cresceu à medida que diminuiu a vulnerabilidade social nos estratos tanto para a taxa total como segundo sexo.

Tabela 15 - Óbitos e taxa de mortalidade (bruta e padronizada) total e segundo sexo (por 100 mil hab.) por Neoplasias Malignas, mediana, desvio padrão e razão de taxas nos Estratos de Vulnerabilidade Social. Estado de São Paulo, média do triênio 2003 a 2005.

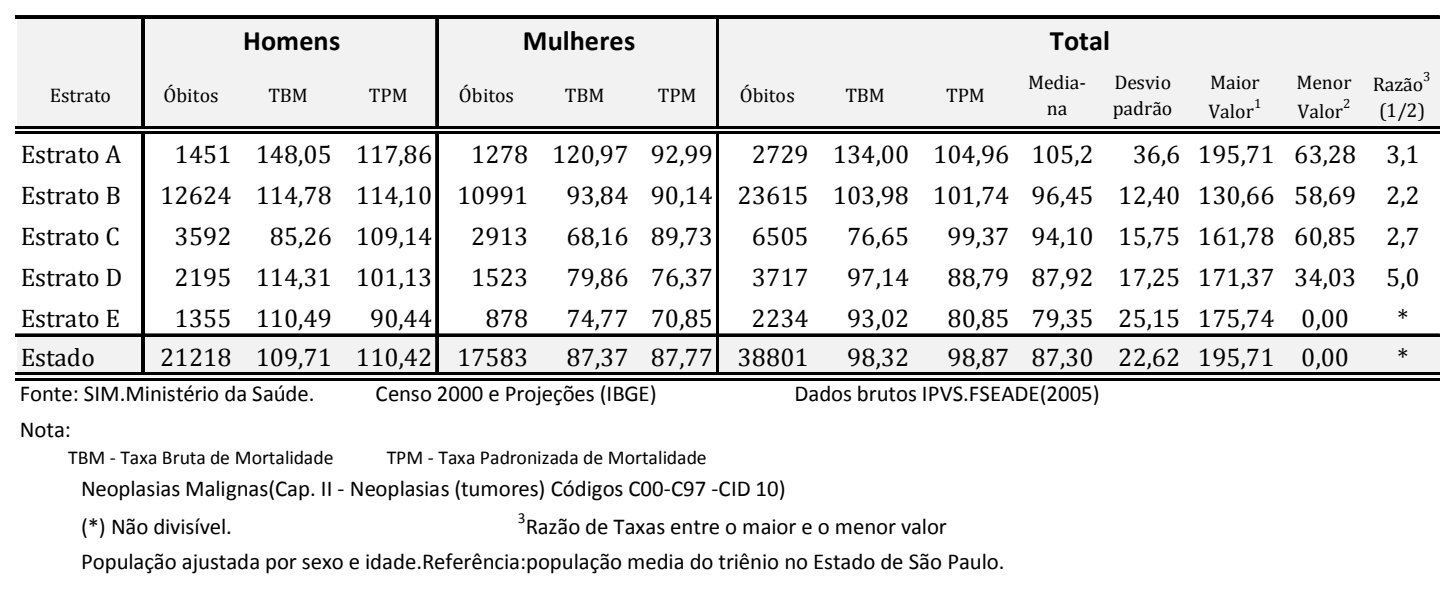

No Estado, observou-se sobremortalidade masculina com 110,42\%000 hab. As mulheres mostraram taxa de $87,77 \% 000$ hab. resultando numa razão de taxas de 1,3. A sobremortalidade masculina foi observada em todos os estratos variando de 117,86 a 90,44\%000 hab.. Internamente aos estratos, as taxas mais 
elevadas predominaram nos conjuntos de municípios mais populosos, à exceção do Estrato E.

Nos Estratos A e B, 34 municípios (36,6\%) ultrapassaram 100\%000 hab.. Espacialmente, a RM São Paulo e região de Campinas se destacaram pela magnitude das áreas de taxas mais elevadas. Nas demais regiões, a exemplo de Ribeirão Preto, Marília, Araçatuba, Piracicaba, São João da Boa Vista, Taubaté, as áreas observadas foram de menor magnitude (Figura 36).

O Estrato C mostrou taxa de 99,37\%000 hab. e desvio padrão de DP=15,75 com 21 de seus municípios (25.3\%) com taxas acima de 100,00\%000 hab.. Espacialmente, observaram-se áreas de maior mortalidade na RM São Paulo (no entorno da Capital), nas regiões da Baixada Santista e Ribeirão Preto. Áreas mais isoladas foram observadas nas regiões de Campinas, Sorocaba e Taubaté (Figura 36).

Os Estratos D e E com 88,79 e 80,85\%000 respectivamente, as menores taxas, apresentaram $340(72,3 \%)$ dos seus municípios com taxa superior a 90,00\%000 hab.. Espacialmente, predominaram áreas de maior mortalidade localizadas nas confluências regionais e até estaduais, as chamadas áreas regionais e inter-regionais de maior mortalidade (Figura 37).

No Estado, 498 municípios (77,2\%) situaram-se abaixo da taxa padronizada de mortalidade do Estado. Os demais, 147 (22,8\%) variaram suas taxas de 98,87\%000 hab. a 195,71\%000 hab. (Figura 37). Espacialmente as áreas de mortalidade mais elevada, à exceção de algumas áreas isoladas, foram observadas no eixo mais desenvolvido economicamente do Estado.

Os resultados deste estudo mostraram elevação do gradiente de mortalidade por neoplasias à medida que diminuiu a vulnerabilidade social o que provavelmente pode ser explicado pela conformação dos Estratos de vulnerabilidade social e suas características sugerindo maior exposição a riscos de mortalidade por neoplasias derivados provavelmente do adensamento populacional, poluição atmosférica e o processo-urbano industrial entre outros. 0 aprofundamento deste estudando buscando identificar a mortalidade especifica por causa e grupos etários permitirá uma maior compreensão desses resultados. 
Figura 35 - Taxa de mortalidade padronizada total por Neoplasias Malignas (por 100 mil hab.) segundo conjuntos de municípios nos Estratos de Vulnerabilidade Social. Estado de São Paulo, média do triênio 2003 a 2005.

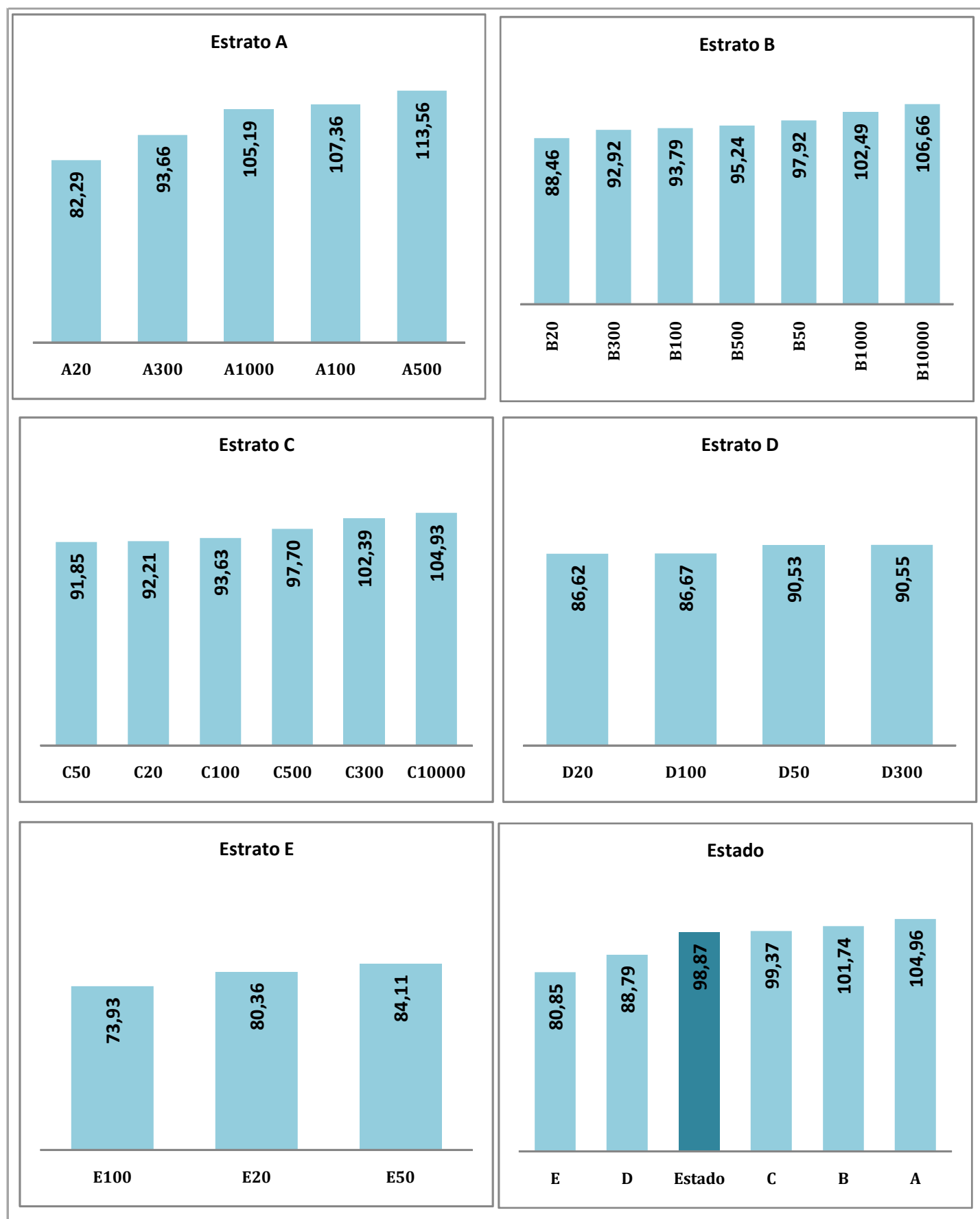

Fonte:SIM.Fonte:SIM. Ministério da Saúde. Censo 2000 e Projeções (IBGE) Dados Brutos: IPVS.FSEADE (2005) 
Figura 36 - Distribuição espacial da taxa padronizada de mortalidade por Neoplasias Malignas (por 100 mil hab.) dos municípios dos Estratos de Vulnerabilidade Social (A e B) e C. Estado de São Paulo, média do triênio 2003 a 2005.
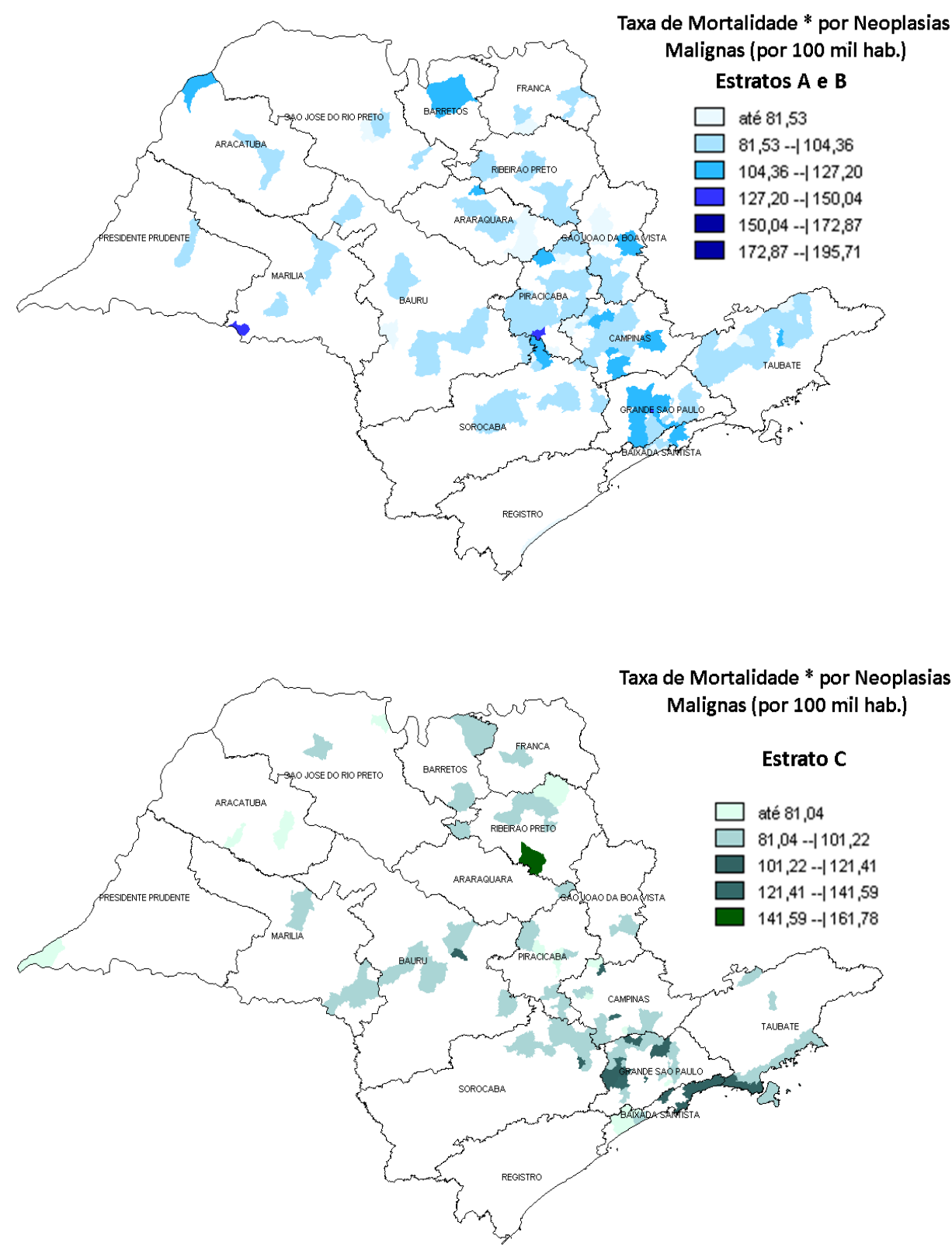

Fonte: SIM. Ministério da Saúde. Censo 2000 e Projeções (IBGE). Dados brutos. IPVS. FSEADE (2005). *Taxa padronizada de mortalidade por 100 mil hab.

Referência: População do Estado de São Paulo (média do triênio 2003-2005). 
Figura 37 - Distribuição espacial da taxa padronizada de mortalidade por Neoplasias Malignas (por 100 mil hab.) dos municípios nos Estratos de Vulnerabilidade Social (D e E) e Estado de São Paulo. Média do triênio 2003 a 2005.
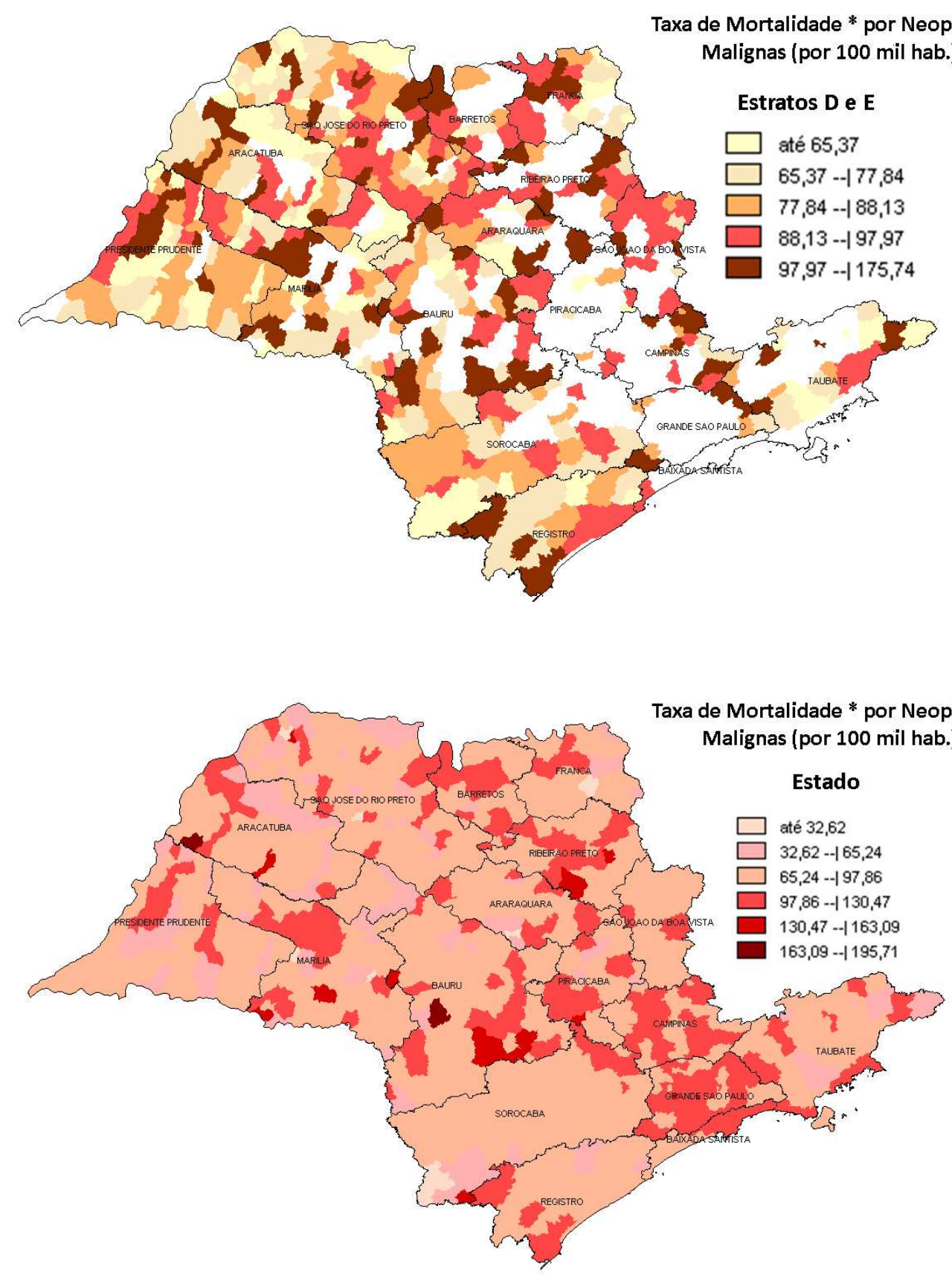

Fonte:SIM.Ministério da Saúde. Censo 2000 e Projeções (IBGE). Dados Brutos:IPVS.FSEADE (2005) *Taxa padronizada de mortalidade por 100 mil hab. 
O câncer, relativamente comum no mundo, responde pela morte de uma em cada cinco pessoas nos países desenvolvidos. Naqueles em desenvolvimento, essa relação é de $1 / 15$ pessoas, considerando ainda que as estruturas etárias destes países são mais jovens. No Brasil, há grande heterogeneidade regional na mortalidade por câncer. A estimativa de risco de morte é maior nas regiões Sul e Sudeste, porém estas vêm mostrando tendência declinante, enquanto as demais regiões vêm apresentando tendência ascendente, quando examinadas as taxas para todos os tipos de cânceres e para sexo (WÜNSCH FILHO e cols., 2002).

Diferenças regionais para tipos específicos de câncer remetem para uma multicausalidade complexa e de difícil determinação, pois inquéritos populacionais sobre fatores de risco são raros e, estudos epidemiológicos de cunho etiológico em câncer são muito recentes no país. Apesar dos fatores genéticos serem fundamentais na carcinogênese, a ocorrência do câncer também é fortemente influenciado por fatores ambientais, sendo que ambos no conjunto, respondem por 80 a $90 \%$ da incidência destas patologias (WÜNSCH FILHO e cols., 2002). Exposições específicas relacionadas à dieta e nutrição, prevalência de tabagismo, viroses, exposições ambientais e ocupacionais que direta ou indiretamente se entrelaçam às desigualdades sociais, compõem provavelmente os principais determinantes dessas tendências. Fatores temporais, geográficos socioeconômicos e políticos bem como, a oportunidade de acesso ao diagnóstico e, ao tratamento oportuno e adequado certamente influenciarão no desfecho da doença (WÜNSCH FILHO e cols., 2002).

A taxas de mortalidade por neoplasias acompanham o envelhecimento da população e, costumam estar associadas às elevadas taxas de incidência da doença neoplásica que, por sua vez associa-se a fatores de riscos específicos (dietéticos, comportamentais, ambientais e genéticos). As concentrações de tipos mais graves de neoplasias também influenciam a mortalidade bem como o acesso às condições assistenciais disponíveis, sobretudo para o diagnóstico e tratamento (MINISTÉRIO DA SAÚDE, 2006). Em 2004, as neoplasias classificaram-se como a segunda causa de morte no país com taxa padronizada de mortalidade de 78,6\%000 hab.. A região Sudeste mostrou taxa de 83,69\%000 hab. com sobremortalidade nos homens com taxa de 86,2; e 105,3\%000 hab. e, as 
mulheres com 71,1; e 85,9\%000 hab. para o país, regiões Sul e Sudeste respectivamente (MINISTÉRIO DA SAÚDE, 2006).

É importante considerar que o envelhecimento aumenta os riscos de morte por câncer em função do acúmulo de experiências potencialmente carcinogênicas capazes de produzir disfunções celulares e multiplicação atípica por um período mais longo. Logo, sua importância relativa numa população dependerá da composição etária de seus habitantes (HALLAL e cols., 2001).

A exposição ocupacional também apresenta contribuição importante na determinação do câncer. Estudos estimam em torno de 4 a 38\% de participação da exposição ocupacional, cuja variabilidade pode estar relacionada as distintas metodologias utilizadas. Embora avanços inegáveis tenham ocorrido no conhecimento sobre o câncer, acrescer a sua já complexa gênese (genéticas, ambientais, culturais entre outras), a contribuição da exposição ocupacional (tempo e natureza da exposição) para a determinação do câncer não tem se revestido de tarefa fácil (LESSA e cols.,1999).

A análise da mortalidade por câncer de populações residentes em municípios de complexos industriais, cujos fatores de risco relacionados ao trabalho, ocupacionais e ambientais, além daqueles já reconhecidos e decorrentes dos hábitos e também das condições de vida das populações são essenciais para auxiliar compreensão dessa multicausalidade. Estudos conduzidos por FARIA e cols. (1990) apontaram para um excesso de mortalidade por câncer na Baixada Santista decorrente de taxas mais elevadas dos municípios do complexo industrial-portuário. Estes, provavelmente relacionados à exposição a substâncias carcinogênicas presentes em siderúrgicas, no pólo industrial de Cubatão com predominância de indústrias químicas, petroquímicas e de petróleo nessa região.

Nas sociedades industrializadas, uma extensa gama de substâncias potencialmente carcinogênicas são utilizadas em processos produtivos, com especial destaque, para as substâncias químicas. No Brasil, como nos demais países em desenvolvimento, a industrialização apesar de acelerada, ocorre de forma desigual tanto em intensidade como, na distribuição geográfica. A morbimortalidade por câncer no país, não tem sido adequadamente 
acompanhada por estudos de riscos e agravos específicos dela decorrentes, porém a literatura vêm demonstrando morbimortalidade mais elevada nas áreas metropolitanas localizadas nas regiões Sul e Sudeste do país .com o processo urbano-industrial (LESSA e cols.,1999).

\subsection{MORTALIDADE POR ACIDENTES DE TRANSPORTE}

No triênio, foram registrados 21.603 óbitos por Acidentes de Transporte (Causas Externas de Morbidade e Mortalidade Códigos V01 a V99 Cap. XX - CID 10) de residentes no Estado de São Paulo. Foram excluídos 736 óbitos sem identificação do município de residência no estado, idade ou sexo resultando em 6.956 óbitos como média anual, dos quais 5.622 óbitos $(80,8 \%)$ foram de homens e, 1.333 óbitos (19,2\%) de mulheres.

A taxa padronizada de mortalidade alcançou para o Estado 17,68\%000 hab.. O Estrato A, apresentou a menor taxa com 14,68\%000 hab. e, o Estrato E, a maior, com 20,78\%000 habitantes. Os homens apresentaram sobremortalidade em todos os estratos com variação de 24,58 \%000 hab. a 38,89\%000 hab., mostrando uma razão de taxas de 1,6 entre o maior e o menor valor(Tabela 16).

Internamente, nos estratos as taxas mais elevadas situaram-se nos conjuntos de municípios de pequeno a médio porte populacional, com exceção do Estrato E. A taxa mais elevada situou-se no conjunto A20 com 31,84\%000 hab. e, a menor no conjunto A1000 com 8,79\%000 hab., ambos pertencentes ao Estrato A (Figura 38). No estrato B, os conjuntos de municípios mais populosos também apresentaram as menores taxas (B10000 e B1000).

Espacialmente, nos Estratos A e B, áreas de mortalidade mais elevada foram observadas em todas as regiões, exceto na RM São Paulo. A região de Registro não situou nenhum município nestes estratos. Compostos por municípios detentores de maior riqueza e desenvolvimento situados ou sediando pólos tecnológicos, industriais, agro-pecuários ou turísticos e, o intenso fluxo de pessoas e veículos, associados à produção e circulação de bens e prestação de serviços, confere-lhes características específicas. Por sua vez, para mobilidade interna ou para interligação entre estados e o país, a malha 
rodoviária que serve o Estado concentram as grandes rodovias em eixos que interligam tais pólos à capital e, a portos e aeroportos.

Muitas dessas rodovias com tráfego veloz e intenso de automóveis, ônibus e caminhões atravessam áreas urbanizadas com tráfego de pedestres, ciclistas e até veículos de tração animal criando provavelmente condições propícias à maior exposição aos riscos por acidentes de transporte. Decorrente disso provavelmente ocorra uma maior exposição aos riscos de residentes de municípios situados nas confluências de rodovias ou de divisas de regiões de Campinas, Sorocaba, Piracicaba, Ribeirão Preto, Barretos, Bauru, Marília, São José do Rio Preto, Taubaté, Baixada Santista e RM Metropolitana.

Tabela 16 - Óbitos e Taxa (bruta e padronizada) de Mortalidade por Acidentes de Transporte, Total e segundo Sexo, mediana, desvio padrão, e razão de taxas nos Estratos de Vulnerabilidade Social. Estado de São Paulo, média do triênio 2003 a 2005.

\begin{tabular}{|c|c|c|c|c|c|c|c|c|c|c|c|c|c|}
\hline \multirow[b]{2}{*}{ Porte } & \multicolumn{3}{|c|}{ Homens } & \multicolumn{3}{|c|}{ Mulheres } & \multirow[b]{2}{*}{ Óbitos } & \multirow[b]{2}{*}{ TBM } & \multirow[b]{2}{*}{ TPM } & \multicolumn{2}{|l|}{ Total } & \multirow{2}{*}{$\begin{array}{l}\text { Maior } \\
\text { Valor }^{1}\end{array}$} & \multirow{2}{*}{$\begin{array}{l}\text { Menor } \\
\text { Valor }^{2} \\
\end{array}$} \\
\hline & Óbitos & TВM & TPM & Óbitos & ТвМ & TPM & & & & Mediana & padrão & & \\
\hline Estrato A & 252 & 25,75 & 24,58 & $\bar{~} 63$ & $\overline{~ 5,93}$ & 25,49 & 315 & 15,47 & 14,68 & 17,87 & 15,35 & 52,68 & 0,00 \\
\hline Estrato B & 2982 & 27,11 & 26,88 & 749 & 6,39 & 6,31 & 3731 & 16,43 & 16,27 & 20,59 & 7,13 & 41,23 & 0,00 \\
\hline Estrato C & 1216 & 28,85 & 29,78 & 281 & 6,58 & 6,98 & 1497 & 17,63 & 18,30 & 19,58 & 8,40 & 59,58 & 0,00 \\
\hline Estrato D & 702 & 36,56 & 36,91 & 142 & 7,43 & 7,58 & 844 & 22,05 & 22,30 & 20,78 & 9,48 & 62,45 & 0,00 \\
\hline Estrato E & 470 & 38,32 & 38,89 & 99 & 8,43 & 8,58 & 569 & 23,70 & 24,06 & 20,48 & 17,82 & 143,61 & 0,00 \\
\hline Estado & 5622 & 29,07 & 29,15 & 1333 & 6,63 & 6,66 & 6956 & 17,63 & 17,68 & 20,31 & 14,13 & 143,61 & 0,00 \\
\hline \multicolumn{13}{|l|}{ Nota: } & \\
\hline $\begin{array}{l}\text { TBM - } \\
\text { Acide }\end{array}$ & $\begin{array}{l}\text { a Bruta de } N \\
\text { ces de Tran }\end{array}$ & $\begin{array}{l}\text { ortalidade } \\
\text { sporte(Có }\end{array}$ & & $\begin{array}{l}1 \text { - Taxa Pad } \\
1 \text { a V99 Ca }\end{array}$ & $\begin{array}{l}\text { onizada d } \\
\text { XX CaL }\end{array}$ & $\begin{array}{l}\text { e Mortalic } \\
\text { usas Exte }\end{array}$ & & & & & \multicolumn{2}{|c|}{ Acidentes de Transporte(Códigos V01 a V99 Cap. XX Causas Externas - CID 10) } & \\
\hline
\end{tabular}

Nos estratos D e E, 290 municípios (61,7\%) apresentaram taxas padronizadas igual ou acima de 17,95\%000 habitantes. Espacialmente, observou-se uma extensa área contígua de maior mortalidade englobando parcelas das regiões de Registro, Sorocaba e Bauru e, parcelas menores na Baixada Santista e RM São Paulo. Outra área extensa e contígua foi observada, desta vez formada por parcelas das regiões de São José do Rio Preto, Araçatuba, Barretos, Araraquara e Bauru. Observaram-se áreas isoladas e, outras, localizadas nas zonas de confluências regionais, porém mais dispersas pelo território do Estado. 
Figura 38 - Taxa padronizada de mortalidade por Acidentes de Transporte (por 100 mil hab.)segundo conjuntos de municípios dos Estratos de Vulnerabilidade Social. Estado de São Paulo, média do triênio 2003 a 2005.
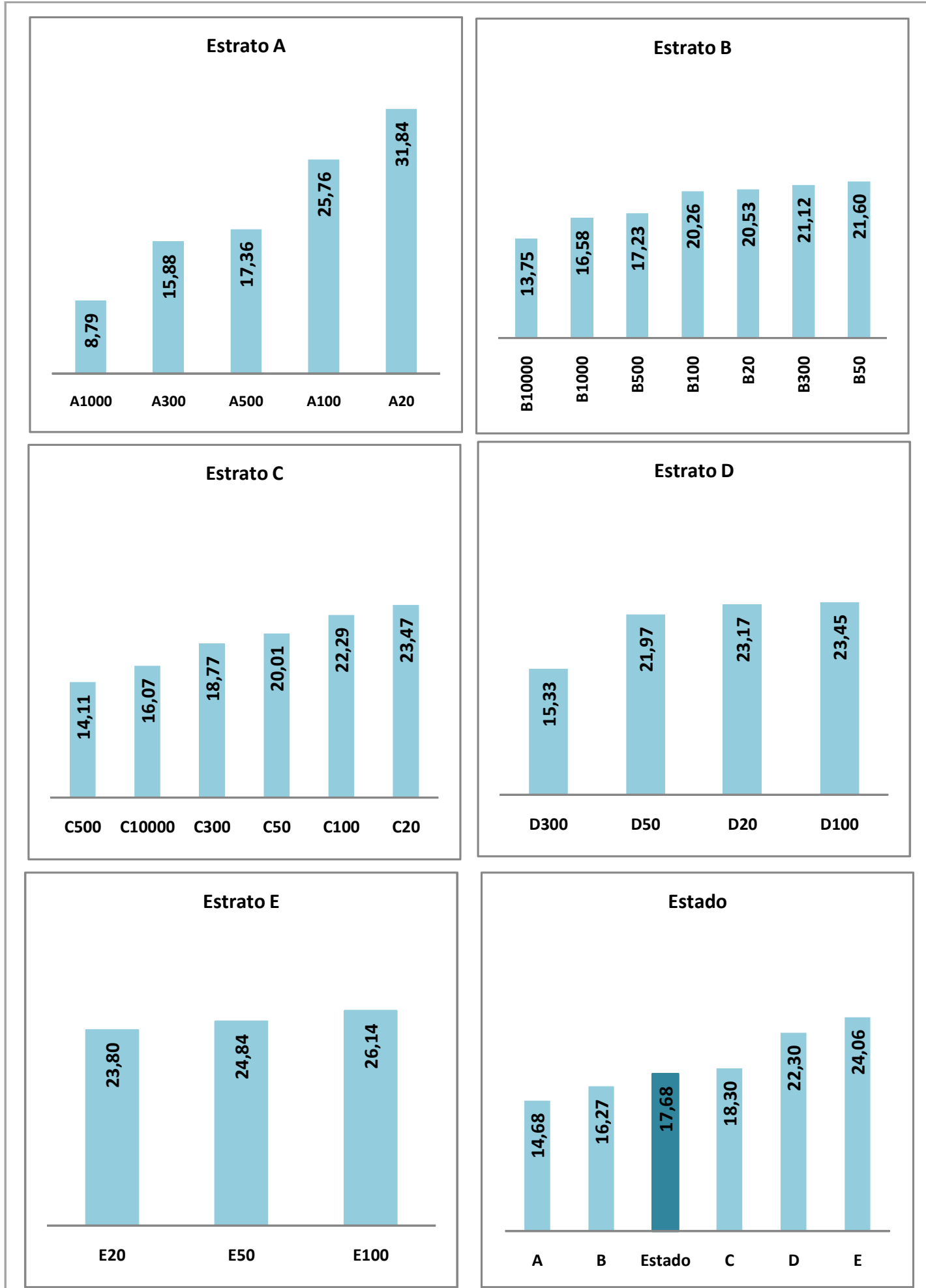

Fonte:SIM.Fonte:SIM. Ministério da Saúde. Censo 2000 e Projeções (IBGE) Dados Brutos: IPVS.FSEADE (2005) 
Figura 39 - Distribuição espacial da taxa padronizada de mortalidade por Acidentes de Transporte (por 100 mil hab.) nos municípios dos Estratos de Vulnerabilidade Social (A e B) e C. Estado de São Paulo, média do triênio 2003 a 2005.

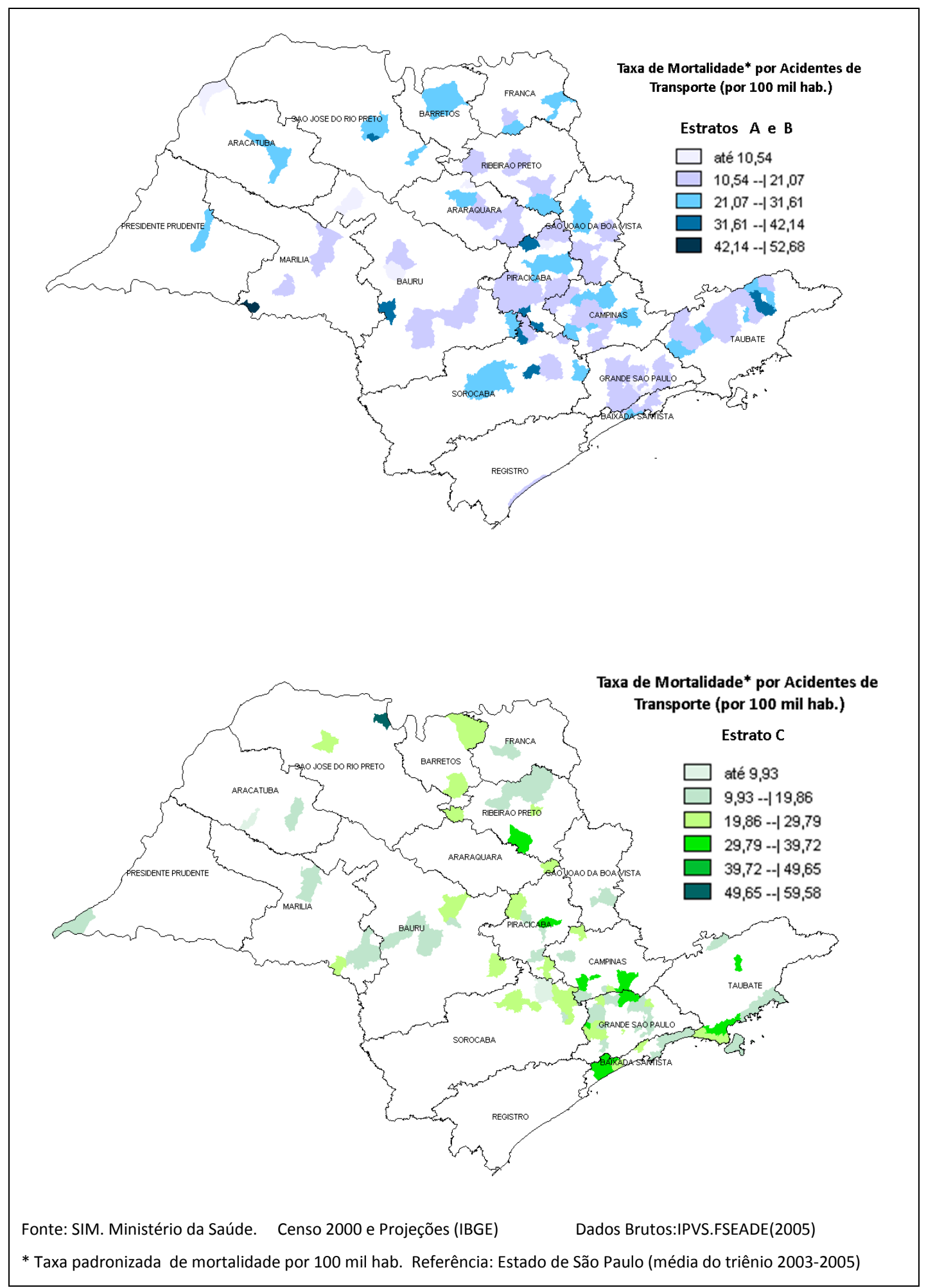


Figura 40 - Distribuição espacial da taxa padronizada de mortalidade por Acidentes de Transporte (por 100 mil hab.) nos municípios do Estrato de Vulnerabilidade Social (D e E) e Estado de São Paulo. Média do triênio 20032005.

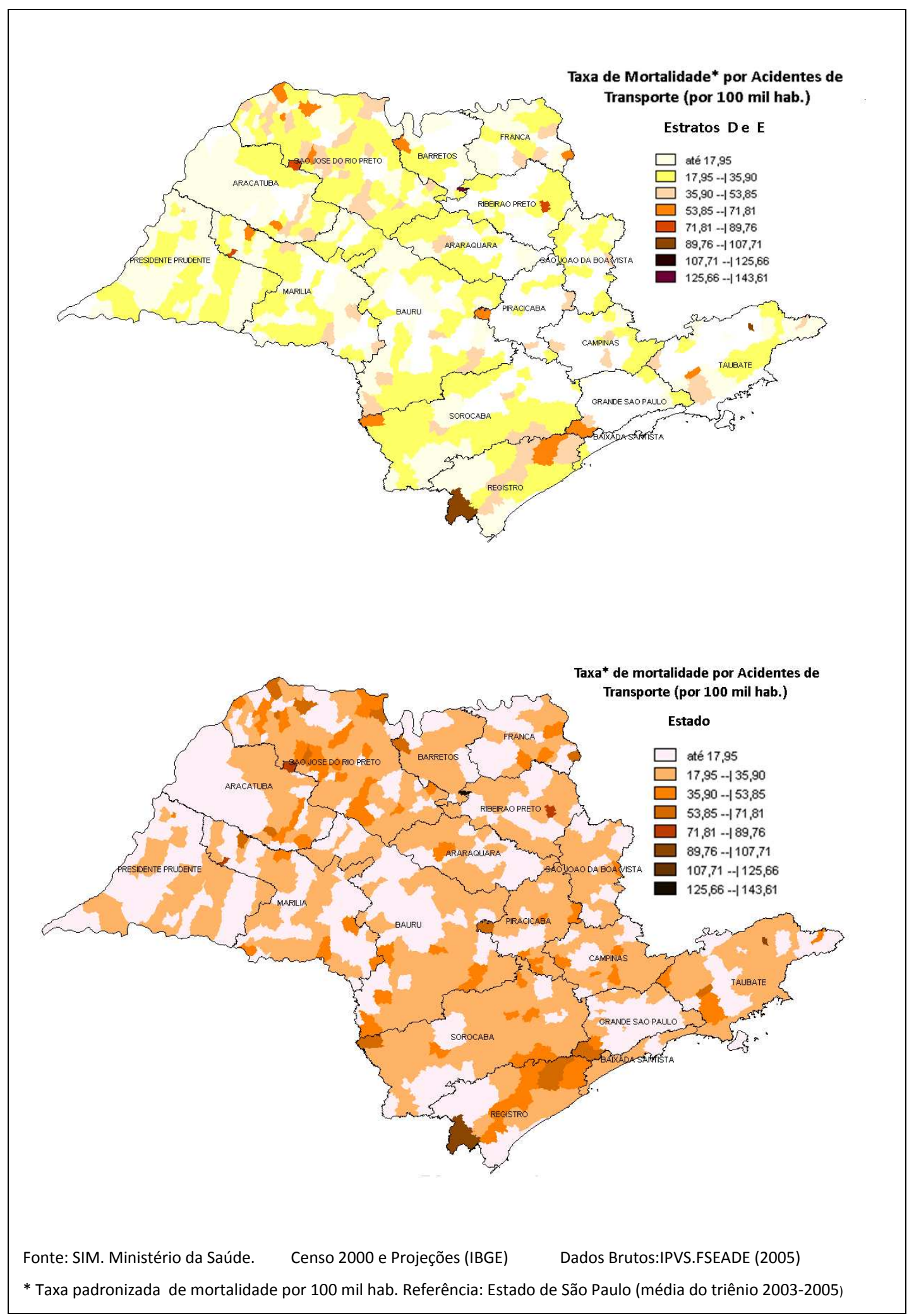


No Estado, 398 municípios $(61,7 \%)$ mostraram taxa padronizada igual ou acima de 17,95\%000 hab. mostrando elevada mortalidade por acidentes de transporte com expressivas desigualdades entre os estratos. Cerca de um terço dos municípios $(33,2 \%)$ apresentaram taxas padronizadas acima de 25,00\%000 hab. e, 28 municipios (4,3\%) não registraram nenhum óbito por acidentes de transporte no período.

Espacialmente, evidenciou-se uma área contígua de elevada mortalidade na confluência da RM São Paulo e região de Registro englobando uma pequena parcela da região de Sorocaba, em direção ao Estado do Paraná. Nesta região, localiza-se a Rodovia Régis Bittencourt (BR 116) ligando São Paulo a Curitiba e, que devido a problemas ligados a preservação do meio ambiente, não foi ainda concluída, restando ainda um trecho de pista única situada entre os municípios de Miracatu e Juquitiba. Conta com alto tráfego de veículos de carga, topografia acidentada e má conservação, decorrente desses fatores e, possui o maior índice de acidentes com vítimas fatais no país, sendo popularmente chamada de "A Rodovia da Morte" (WIKIPEDIA, 2008). Os resultados encontrados para municípios circunvizinhos ao trajeto desta rodovia parecem reforçar sua influência na maior exposição ao risco, a exemplo de Miracatu (57,57\%000 hab.), Juquitiba (55,57\%000 hab.), São Lourenço da Serra (50,95\%000 hab.) e Barra do Turvo (90,15\%000 hab.) entre outras.

$\mathrm{Na}$ região de Taubaté a área de mortalidade elevada englobou a microrregião de Mogi das Cruzes, Vale do Paraíba e Caraguatatuba, áreas estas atravessadas por importantes rodovias tanto para o escoamento da produção e fluxo turístico, a exemplo da Rodovia Presidente Dutra, Trabalhadores, Rio Santos, Carvalho Pinto cujos municípios circunvizinhos mostraram taxas elevadas a exemplo de Jambeiro (62,45\%000 hab.), Caraguatatuba $(33,18 \% 000$ hab.) São Sebastião (21,38\%000 hab.), Santa Isabel (22,33\%000 hab.), Paraíbuna (36,59\%000 hab.) e Arujá (25,54\%000 hab.) entre outros.

Na região de São José do Rio Preto, algumas áreas dispersas de mortalidade mais elevada são observadas nos municípios circunvizinhos ao trajeto paulista da Rodovia Transbrasiliana, que liga o país transversalmente no sentido norte-sul. Essa rodovia atravessa Londrina no estado do Paraná e, 
atravessa o território paulista passando por Ourinhos $(25,34 \% 000$ hab.) e Ribeirão do Sul (50,84\%000 hab.), na região de Marília (a exemplo de Getulina com 18,88\%000 hab. e José Bonifacio com 35,54\%000 hab.); na região de Araçatuba, região de S.J. Rio Preto com 21,22\%000 hab. (Bady Bassit com 39,56\%000 hab., Mirassol com 23,53\%000 hab., Nova Granada com 23,65\%000 hab.), entre outros municípios, rumo a Goiânia no estado vizinho. Outras áreas mais dispersas e menos extensas foram observadas também nas demais regiões circunvizinhas a outras rodovias que cortam o interior paulista a exemplo da Rodovia Castelo Branco e Anhanguera.

No Brasil, a taxa padronizada de mortalidade por acidentes de transportes foi de 19,5\%000 hab. e, da região Sudeste 17,8\%000 hab. em 2004. Dessas mortes, os homens participaram com $81,5 \%$ e, as mulheres com 18,5\%. Numa análise de municípios segundo porte populacional, a região Sudeste mostrou taxa padronizada de 18,5\%000 hab. para municípios até 20 mil habitantes, 21,4\%000 hab. para o porte entre 20 a $100 \mathrm{mil}, 18,7 \% 000$ hab. para o porte entre 100 a 500 mil, e 14,7\%000 habitantes para acima de 500 mil hab., sugerindo maior mortalidade por acidentes de transporte em municípios até 100 mil habitantes (MINISTÉRIO DA SAÚDE, 2006).

Para DUARTE e cols. (2004) a elevação das estimativas de riscos de morte para acidentes de trânsito parecem estar associados à menor escolaridade, maior renda e velocidade do crescimento dos espaços urbanos. Para estes autores, a conjugação do rápido crescimento populacional, grande número de automóveis per capita, maiores níveis de renda e baixa escolaridade diminuem a capacidade de ordenação urbana gerando ambientes propícios a acidentes de trânsito. A letalidade, por sua vez depende da severidade do acidente relacionados a velocidade, ao veículo, condições das vias de transporte, entre outros fatores e, pela baixa capacidade dos serviços de saúde prover a atenção adequada às vítimas.

0 gradiente de taxas cresceu juntamente com a vulnerabilidade social nos estratos, atingindo as taxas mais elevadas nos estratos E e D, os quais são compostos predominantemente por municípios de pequeno porte (abaixo de 50 mil hab.). Provavelmente o tráfego cotidiano de veículos e de pessoas no uso ou 
travessia dessas rodovias, propicie maior exposição aos riscos de mortalidade por acidentes de transporte, aliadas ainda a precariedade de infra-estrutura de serviços características desses municípios para remoção e/ou assistência às vitimas. É importante considerar ainda que as populações de pequenos municípios desenvolvem um movimento pendular (vai e volta) em direção aos pólos regionais as vezes diariamente deslocando-se para o trabalho, estudo ou

Figura 41 - Malha Rodoviária do Estado de São Paulo segundo distribuição e concessão de rodovias, 2008

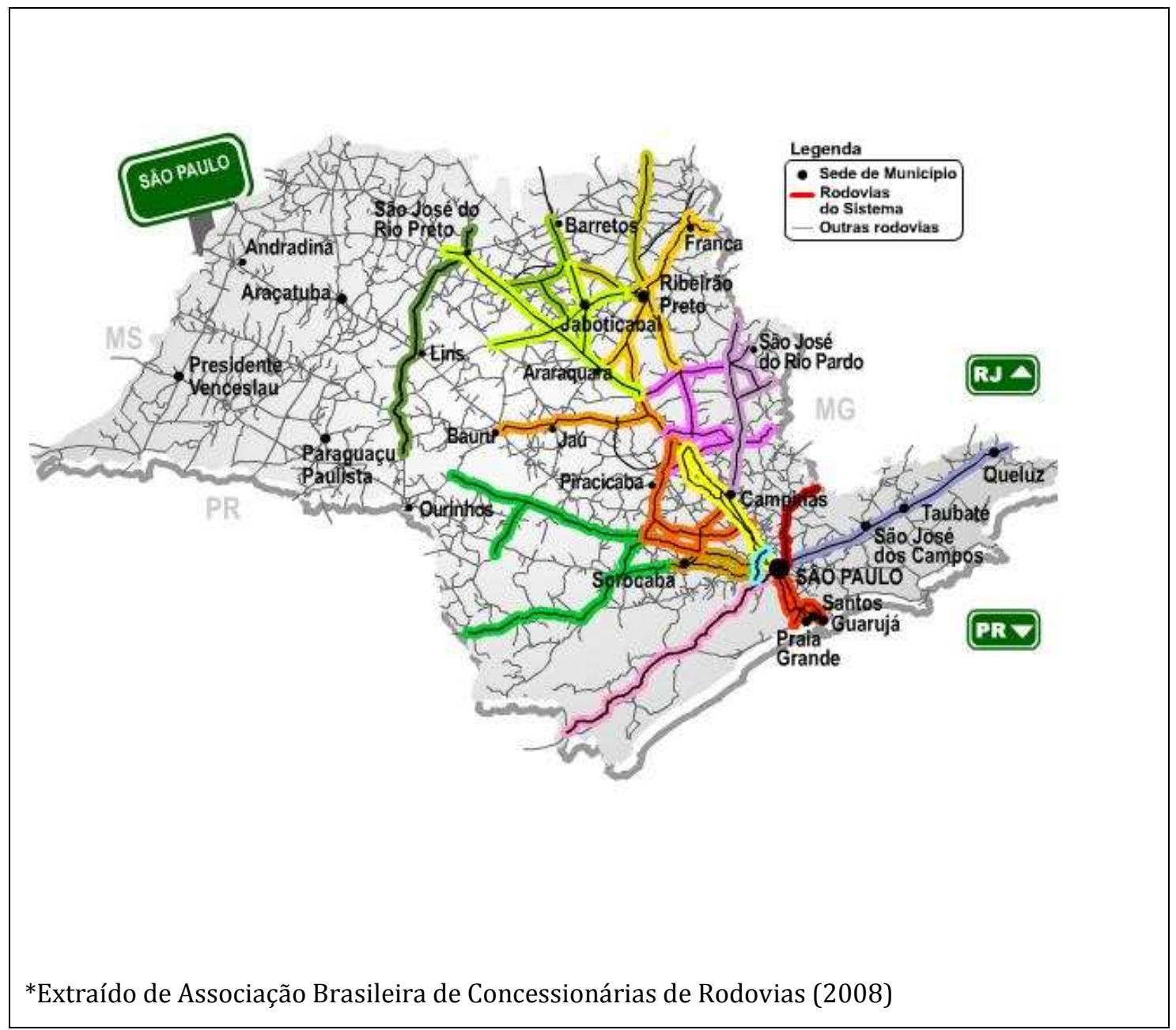

No país, foi privilegiado o desenvolvimento do transporte rodoviário em detrimento do ferroviário e hidroviário. As montadoras de automóveis 
ocuparam papel central no desenvolvimento industrial do país e, o aumento da frota de veículos em concomitância com transformações socioeconômicas e urbanização intensa conformaram um cenário de expressiva motorização não acompanhada de infra-estrutura viária adequada e segura.

Associado a este cenário, a precariedade dos programas de prevenção e educação no trânsito, repressão de infrações tem propiciado que muitos dos crimes de trânsito sejam tratados como fatalidades, quando na sua maioria, são derivados de omissões estruturais (estradas ou vias públicas, condições dos veículos, fiscalização, negligência, imprudência ou imperícia de motoristas ou pedestres) acabando não resultar em responsabilização dos transgressores e, a uma postura de omissão velada da sociedade (MINISTÉRIO DA SAÚDE, 2005).

\subsection{A MORTALIDADE POR HOMICÍDIOS}

No triênio, foram registrados 34.254 óbitos por Homicídios (Cap. XX Causas Externas de Morbidade e Mortalidade - Códigos X85 a Y09 e Y35 e Y36CID 10) de residentes no Estado. Foram excluídos 1.585 óbitos por não identificar o município de residência no Estado, idade ou sexo, resultando em 10.890 óbitos como média anual para este estudo. A participação dos homens foi de 10.053 mortes (92,3\%) e, das mulheres de 836 (7,7\%).

A taxa de mortalidade padronizada por homicídios situou-se em 27,47\%000 hab. para o Estado. Os homens apresentaram taxa de 51,72\%000 hab. e, as mulheres de 4,16\%000 hab., mostrando elevada sobremortalidade masculina com razão de taxas de 12,4 entre sexos. Entre os estratos, a menor taxa, 11,50\%000 hab. situou-se no Estrato E e, a mais elevada, no Estrato C, com 35,54\%000 hab. (Tabela 17).

Os homens apresentaram sobremortalidade em todos os estratos, com destaque para os Estratos C e B, com as taxas mais elevadas, de 66,30 e $55,20 \% 000$ hab. respectivamente (Tabela 16). Internamente a cada estrato, as taxas mais elevadas predominaram nos conjuntos de municípios de maior porte populacional (Figura 42). 
Tabela 17 - Óbitos e taxa (bruta e padronizada) de mortalidade por Homicídios (Total e segundo Sexo), mediana e desvio padrão nos Estratos de Vulnerabilidade Social. Estado de São Paulo, média do triênio 2003 a 2005.

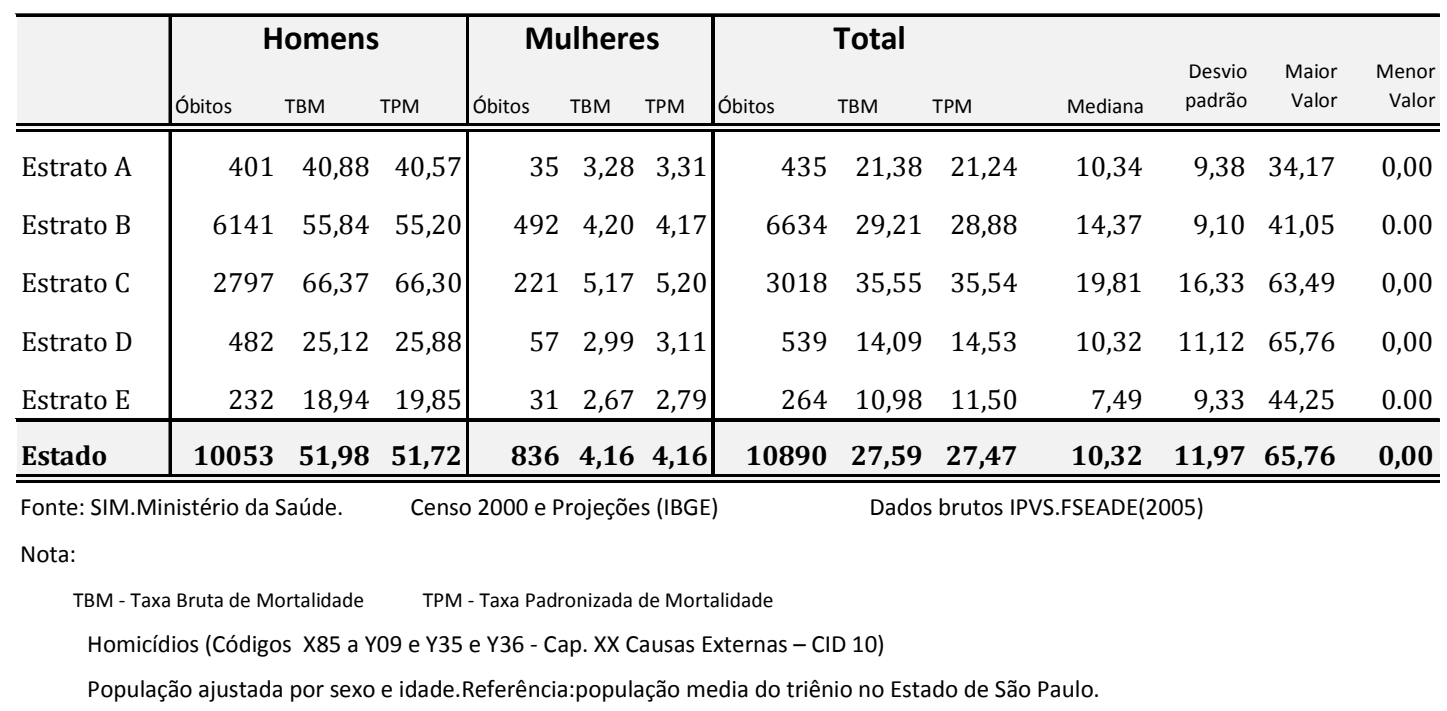

Nos estratos A e B, 20 municípios (20,6\%) apresentaram taxa padronizada acima de 24,63\%000 habitantes. Espacialmente, a mortalidade mais elevada concentrou-se em áreas das regiões de Araçatuba, Ribeirão Preto, Piracicaba, Sorocaba, Taubaté, Baixada Santista e RM São Paulo, estas duas últimas contíguas entre si (Figura 43).

O Estrato C mostrou taxa padronizada (35,54\%000 hab.), mediana $(19,81$ \%000 hab.) e, variabilidade interna com DP=16,33, as mais elevadas dentre os estratos. Dos seus municípios, 34 deles (41,0\%) situaram-se acima da taxa apresentada pelo Estado.

A distribuição espacial mostrou áreas de concentração de mortalidade mais elevada no litoral norte (região de Taubaté), Baixada Santista e RM São Paulo, esta última incluindo áreas de concentração periféricas delineadas ao redor da Capital. Outras áreas com taxas mais elevadas foram observadas nas regiões da Campinas, Sorocaba e Piracicaba (Figura 43).

Nos Estratos D e E, 38 municípios $(8,1 \%)$ apresentaram taxa igual ou acima de 24,07\%000 habitantes. Espacialmente, taxas mais elevadas nesse estrato concentraram-se em áreas da região de Registro interligando-as numa 
Figura 42 - Distribuição da taxa padronizada de mortalidade por Homicídios (por 100 mil hab.), segundo conjuntos de municípios, nos Estratos de Vulnerabilidade Social. Estado de São Paulo, média do triênio 2003 a 2005.

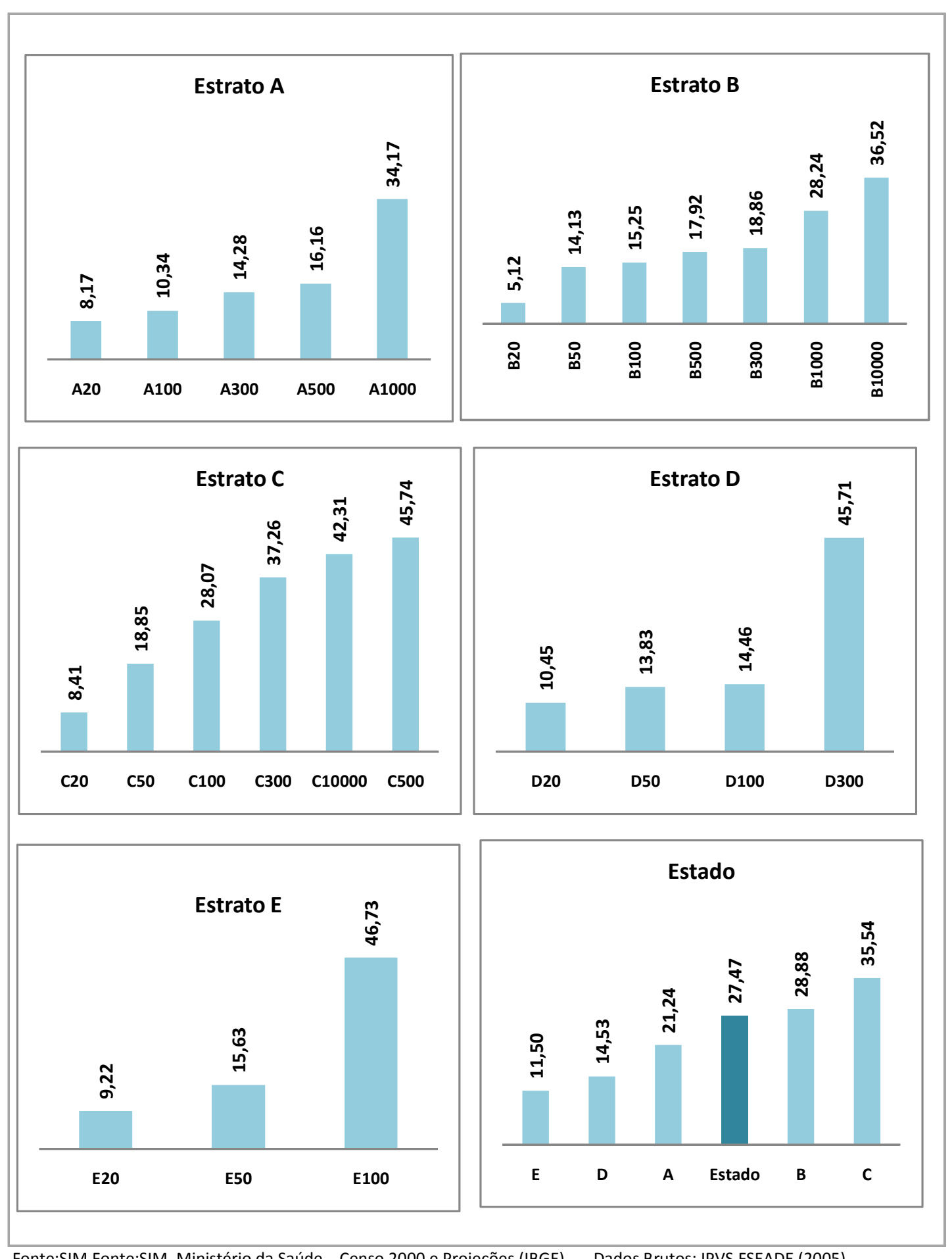

Fonte:SIM.Fonte:SIM. Ministério da Saúde. Censo 2000 e Projeções (IBGE) Dados Brutos: IPVS.FSEADE (2005) 
Figura 43- Distribuição espacial da taxa padronizada de mortalidade por Homicídios (por 100 mil hab.) nos municípios dos Estratos de Vulnerabilidade Social (A e B) e C. Estado de São Paulo, média do triênio 2003 a 2005.

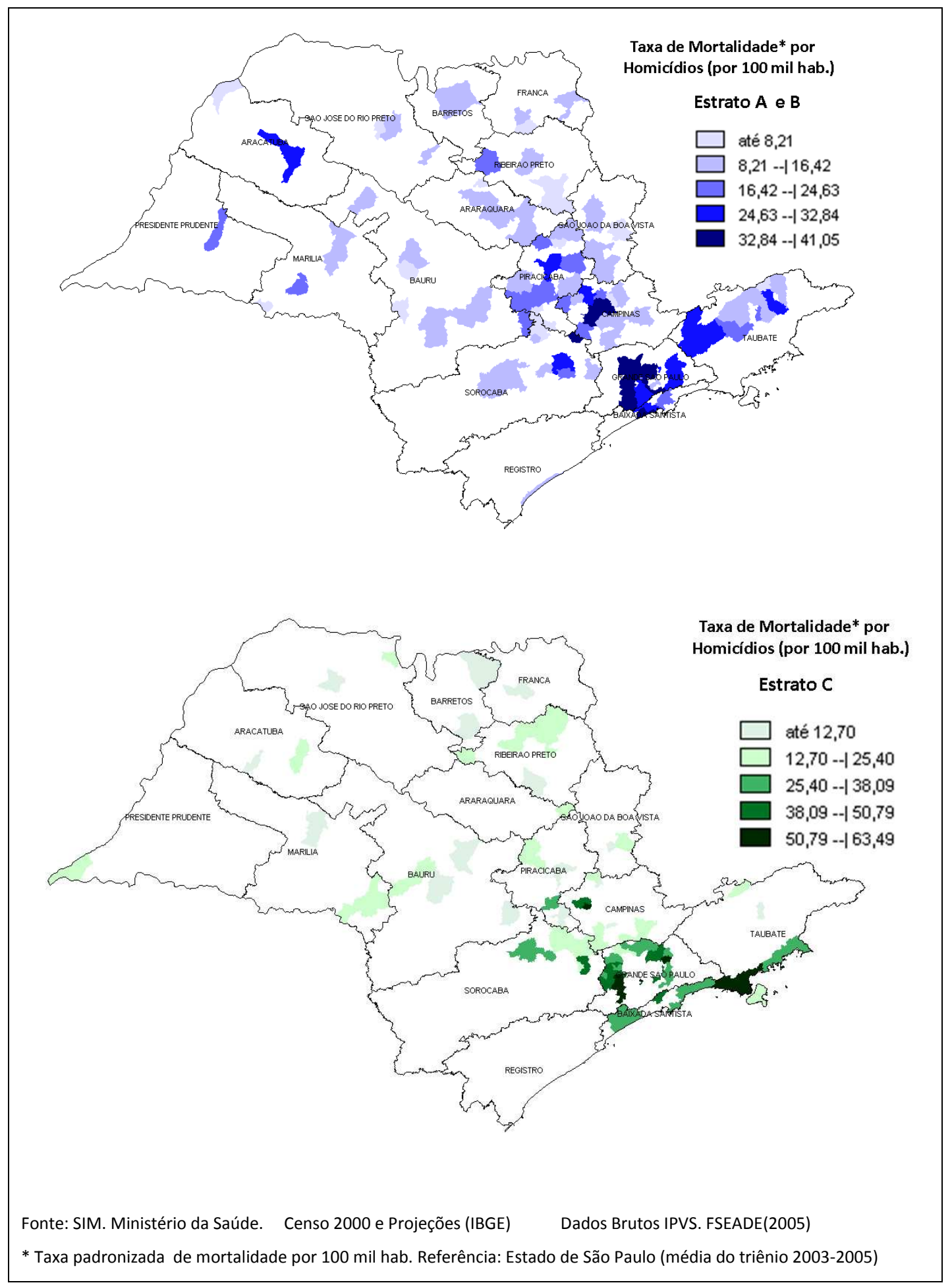


Figura 44 - Distribuição espacial da taxa de mortalidade padronizada por Homicídios no Estrato de Vulnerabilidade Social (D e E) e no Estado de São Paulo. Média do triênio 2003 a 2005.

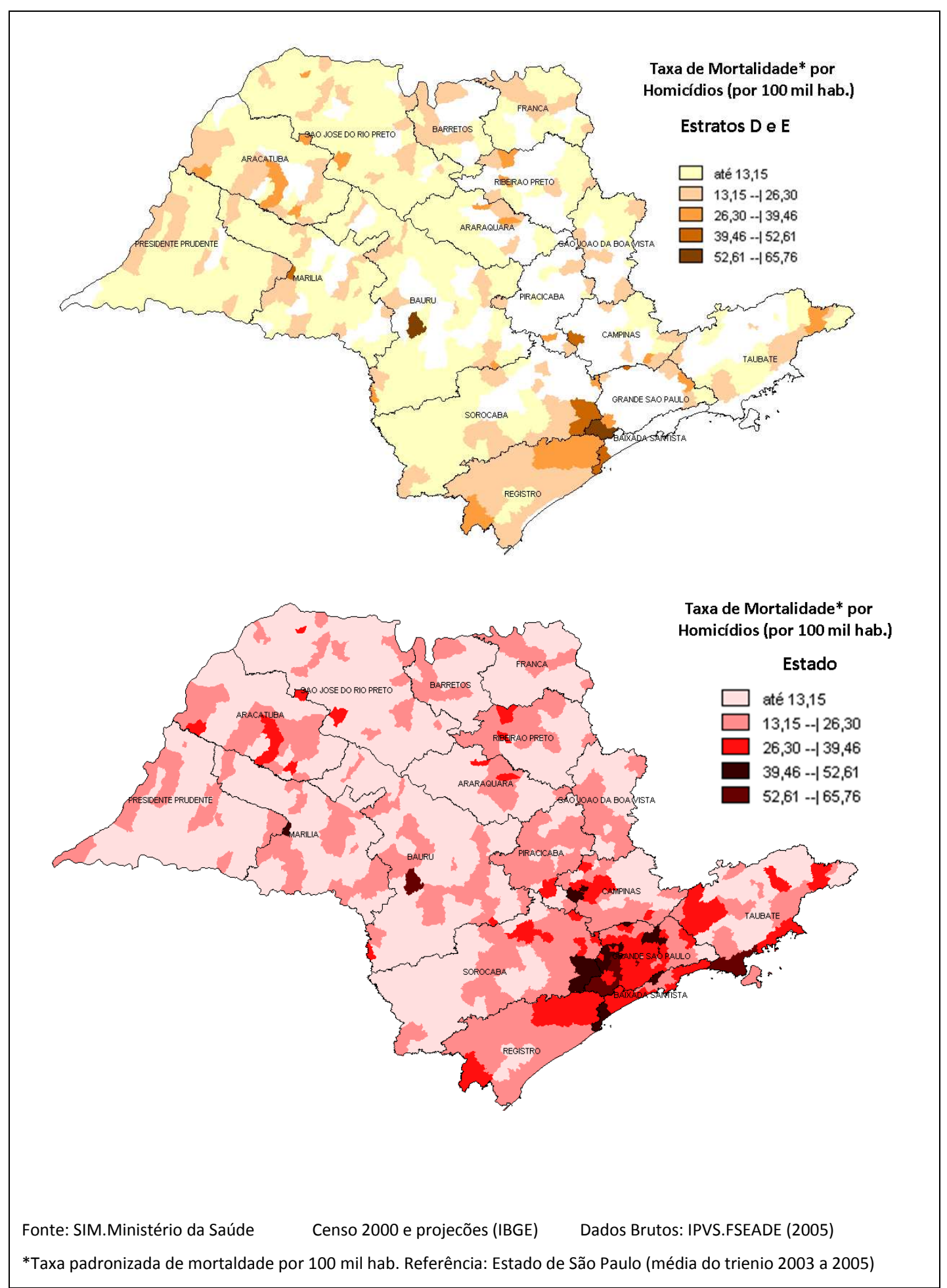


área só contígua com parcelas das regiões de Sorocaba, Baixada Santista e RM São Paulo. Outras áreas dispersas e, de menor extensão foram observadas nas regiões de Araçatuba, Franca e Taubaté e nas demais regiões (Figura 44).

0 Estado apresentou 77 municípios (11,9\%) com taxa de 26,30 a 65,76\%000 habitantes. Destes, 34 (44,2\%) pertenciam ao Estrato C. Somados, os estratos C, B e A contribuem com 47 municípios (61\%) com predomínio daqueles de maior porte populacional e, situados na RM São Paulo, Baixada Santista e Campinas. Em números absolutos os estratos C, B e A contribuíram com 10.087 mortes do total de óbitos por homicídios no período $(92,6 \%)$, justificados pelo maior contingente populacional destes estratos, porém caracterizados pela intensa urbanização. 0 número de óbitos e respectivas taxas de cada um dos municípios podem ser consultados no Anexo 26.

Espacialmente, a distribuição da mortalidade no Estado mostrou semelhança ao processo de industrialização e urbanização do Estado concentrando-se na RM Capital e, deslocando-se segundo o eixo econômico, industrial e turístico Taubaté/São Paulo/Baixada Santista/Campinas/ Piracicaba/Araraquara/Ribeirão Preto, e onde, na sua maioria, concentraram os municípios do Estrato A e B, os de maior densidade populacional. O Estrato C, por sua vez situou a maioria de seus municípios também nesse eixo, porém na condição de municípios periféricos e concentrando elevada população e urbanização porem com maior vulnerabilidade social que os Estratos A e B.

Espacialmente, observou-se uma área extensa e contígua de mortalidade mais elevada formada pela RM São Paulo, Baixada Santista e, parcelas das regiões de Registro e Taubaté. Observaram-se outras áreas dispersas nas regiões de Campinas, Sorocaba, Ribeirão Preto, S.J.Rio Preto, Araçatuba, Araraquara, Piracicaba, Bauru e Marília, das quais muitas delas são sedes regionais ou micro-regionais (Figura 43). No Estado, 136 municípios (21,1\%) não registraram óbitos por homicídios no período, estes na sua maioria, localizados no interior do Estado.

Desde a morte de Abel por Caim, referencial bíblico da violência na convivência humana, marcada por disputas de poder, ódio e desejos de aniquilamentos de uns pelos outros, a historicidade desse fenômeno social vêm 
acompanhando a humanidade. De natureza complexa, engloba múltiplas manifestações toleradas ou condenadas, lícitas ou ilícitas a depender das normas sociais de uma sociedade ou de seu aparato histórico-cultural e legal. $\mathrm{Na}$ perspectiva da saúde, a violência ameaça a vida, altera a saúde, produz enfermidade e provoca a morte ou a possibilidade dela (MINISTÉRIO DA SAÚDE, 2005).

As violências podem ser classificadas em três tipos segundo suas manifestações empíricas: as dirigidas contra si mesmo (auto-infligida), as interpessoais e, as coletivas. As auto-infligidas incluem os comportamentos suicidas (suicídio, ideação e tentativa de suicídio) e, os auto-abusos (agressões a si próprias e automutilações). As interpessoais desdobram-se em dois tipos: a intrafamiliar que ocorre entre parceiros íntimos e membros da família principalmente no ambiente da casa, incluindo as agressões contra crianças, mulher, homem e idosos. E a comunitária, que ocorre no ambiente social em geral entre conhecidos e desconhecidos e incluem as agressões físicas, os estupros, ataques sexuais, violência juvenil e institucional como aquelas que ocorrem em asilos, escolas, prisões, local de trabalho, creches. Já as coletivas são os atos violentos macro-sociais e caracterizam a dominação de grupos e do Estado e incluem os crimes cometidos pelos grupos organizados, os atos terroristas, as guerras, os processos de aniquilamento de povos e nações por outros povos e nações (OMS, 2002). Em 2000, estimaram-se mortes de 1,2 milhões de pessoas no mundo, das quais $10 \%$ foram atribuídas a violências interpessoais (OMS, 2003).

Para MINAYO (1999) a compreensão da morbimortalidade por violência contempla todo o contexto da sociedade brasileira marcada pela desigualdade, injustiça, corrupção, impunidade, deterioração institucional, violação dos direitos humanos, banalização e pouca valorização da vida. Um modelo ecológico proposto pela Organização Mundial de Saúde distinguiu quatro níveis para as raízes da violência: o primeiro, busca identificar fatores biológicos $e$ pessoais no comportamento individual concentrando-se em características que potencializam individuo na condição de vítima ou perpetrador da violência. 0 segundo, chamado de fatores relacionais busca as interações sociais que atuam 
ou influenciam na vitimização ou na perpetração da violência reafirmando a importância dos amigos como incentivadores e aliciadores em atividades delinqüentes e criminosas no caso dos jovens. O terceiro considera fatores comunitários na dinâmica da violência tais como locais de trabalho, escola, vizinhança, desemprego, tráfico de armas e drogas. E por fim, o quarto enfatiza fatores sociais mais amplos como normas culturais que justificam a violência na solução de conflitos, cultura do machismo, normas que validam o uso abusivo da força pela policia e/ou conflitos políticos.

Além dos macro-determinantes comuns derivados do contexto econômico, cultural, político e social incluem-se as diferenças que vão desde a complexa ocupação da terra, a extração mineral, o narcotráfico, as gangues de rua, os grupos de extermínio, as rixas entre famílias, entre outras, que assumem peculiaridades e especificidades regionais. A Região Sudeste, detentora das taxas mais elevadas do país, apesar de suas especificidades e fatores comuns, tem apontado para a predominância do narcotráfico na gênese de boa parte dos homicídios ocorridos nesta região. Por outro lado, as menores taxas por homicídios são dos estados do Piauí e Maranhão estados pobres e com baixo dinamismo econômico. A interação desse conjunto de fatores indica que os homicídios não são fenômenos locais, mas transcendem barreiras geográficas, culturais e políticas constituindo-se em problema regional de grande magnitude exigindo abordagem sistêmica para a sua compreensão. (MINISTÉRIO DA SAÚDE, 2006).

Em 2004, a taxa padronizada de mortalidade por homicídios no país foi de 27,2\%000 habitantes e, vêm ocupando a primeira causa de morte dentre as causas externas, em muitos dos estados e regiões brasileiras, a exemplo das regiões Norte e Sudeste. Em especial, as capitais dos estados vêm se destacando como loccus sociais complexos para a produção da violência interpessoal com taxa de 47,7\%000 hab. na Região Sudeste a até 34,1\%000 habitantes nas demais regiões. Porto Velho, Recife, Vitória, Cuiabá, São Paulo e Rio de Janeiro destacaram-se dentre as demais indicando diferenças regionais e intraregionais além de dinâmicas específicas de manifestações da violência segundo áreas geográficas (MINISTÉRIO DA SAÚDE, 2006). Os resultados mostraram 
coerência quanto à magnitude, vulnerabilidade social e, distribuição espacial quanto a mortalidade total e a sobremortalidade masculina dos homicídios no Estado com outros estudos (MINISTÉRIO DA SAÚDE, 2006).

CAMARGO e cols.(2006) mostraram que a distribuição geográfica das maiores taxas por homicídios concentraram-se nas áreas metropolitanas de São Paulo, Santos e Campinas refletindo aspectos relativos às áreas metropolitanas com efeitos inclusive sobre seus municípios vizinhos, a exemplo das regiões de São José dos Campos, Ribeirão Preto e Sorocaba que já alcançaram patamares elevados para estas causas.

WAISELFISZ (2006) apontou para uma forte interiorização da violência homicida atribuindo-a a duas causas: a primeira, a emergência de pólos de crescimento em municípios que com migrações, emprego e renda convertem-se em pólos atrativos para a criminalidade. A segunda, derivada dos investimentos no aparelhamento das polícias das capitais e das grandes regiões metropolitanas que dificultam a ação do crime provocando a migração para áreas de menor segurança.

GAWRYSZEWSKI \& JORGE (2000) estudando 9.167 óbitos por causas violentas no município de São Paulo (1960 a 1999) mostraram que os homicídios responderam por $64,6 \%$ das mortes e, um coeficiente de mortalidade de 59,4\%000 hab. para ambos os sexos e 114,3\%000 hab. para o masculino e 8,3\%000 hab. para o feminino em 1999. Na distribuição espacial dos homicídios, o estudo apontou desigualdades na ocupação do espaço urbano expresso pela morte violenta. Os distritos que apresentaram taxas mais elevadas foram os das zonas periféricas e centrais da cidade ocupados por população de baixa renda, o que não necessariamente refere-se a zonas violentas, mas sim das zonas em que residem as pessoas que estão mais expostas ao risco de homicídios, ou seja, as maiores vítimas da violência. Porém, ressalta as autoras que a pobreza absoluta em si não explica a violência, porém marcantes desigualdades sociais (pobreza relativa), contexto político institucional de cada local, o papel do crime organizado e a coesão da comunidade local podem estar entre os fatores contributivos. 
Diversos estudos têm mostrado que a violência afeta a população de modo desigual com riscos diferenciados segundo idade, sexo, raça/cor e espaço social sendo um fenômeno explicitamente mais intenso em áreas urbanizadas e de maior adensamento populacional e, que na verdade só refletem a ponta do iceberg, pois mesmo com sub-registros sua magnitude é muito maior dada a importância da morbidade por lesões não fatais.

Estudos de SOUZA \& LIMA (2007) apontaram que a espacialização das mortes por homicídios tem se dado em cidades com densidade populacional, urbanização e indicadores de condições de vida diferenciados, em especial nas regiões metropolitanas e capitais de Estado. Apontam ainda, que a violência além de se manter intensamente presente nestes espaços vem expandindo para outros espaços sociais com determinantes comuns e distintos. Argumentam que a conexão interna entre as diversas cidades e suas capitais com redes de tráficos internacionais (drogas, armas, crianças, mulheres,pedras preciosas, fauna entre outras) se articulando em torno de atividades perigosas e ilegais com rotas bem estabelecidas no país tem se constituído num processo potencializador de homicídios.

ADORNO (2002) afirma que a associação mecânica pobreza, crime e violência é culturalmente antiga em nossa sociedade e reducionista, argumentando que embora parte dos delinqüentes originassem das classes pauperizadas, a maior parte desses trabalhadores submetidos às mesmas condições sociais de vida, não enveredava pelo mundo do crime. Para ele, o problema não reside na pobreza, porém na criminalização dos pobres, ou seja maior rigor punitivo contra negros, pobres e migrantes. Para este autor, no entanto é inegável as relações entre a persistência da concentração da riqueza e precariedade das condições de vida nos chamados bairros periféricos das grandes cidades e, a explosão da violência fatal já exaustivamente explorados nos mapas de violência de São Paulo e do Brasil.

CANO \& SANTOS (2000) afirmam que vítimas pobres possuem menos condições de se proteger (com grades, seguranças ou mudando para lugares mais seguros), logo, serão mais facilmente assassinadas do que vítimas ricas, onde a família terá mais meios e, a sociedade exercerá mais pressão para que o 
crime não fique impune. Numa comparação entre renda, desigualdade e taxa de homicídios nos níveis geográficos: internacional, nacional, estadual e municipal apontaram que na comparação entre países (com bases em dados da OMS) renda e desigualdade sugeriram um impacto moderado. Países mais pobres e desiguais tenderam a apresentar taxas mais elevadas que países mais ricos e mais justos.

No Brasil, a comparação das taxas de homicídios por Estado, a variável que mostrou maior intensidade com a taxa de homicídio foi a urbanização. Os estados urbanos apresentam taxas muito mais altas do que os estados rurais. No nível estadual, a comparação efetuada nos municípios do Rio de Janeiro, calculando as taxas de homicídio por conjuntos de municípios pequenos de mesma área, não foi encontrado efeito negativo para a desigualdade. Os municípios mais violentos do Estado, situaram-se na área metropolitana da Baixada Fluminense com relativa homogeneidade socioeconômica e, reforçando o elemento urbanização como o mais poderoso CANO \& SANTOS (2000).

No nível municipal, estudos realizados em áreas metropolitanas de Brasília, Salvador, Curitiba, Rio de Janeiro e São Paulo, as taxas de homicídios sistematicamente foram mais elevadas nos bairros ou áreas metropolitanas mais pobres dentro de um mesmo município. A urbanização mostrou-se influente sobre a violência letal tanto no nível interestadual quanto no intermunicipal CANO \& SANTOS (2000).

Estudos de DUARTE e cols. (2004) não observaram associações entre crescimento populacional, grau de escolaridade, alfabetização e pobreza com mortalidade elevada por homicídios em estudos desenvolvidos no período de 1991 a 2000 para o país. Porém, observaram tendência significativa de taxas mais elevadas em estados com maior grau de urbanização mesmo quando foram controladas as variáveis de nível socioeconômico e demográficas. Para estes autores o processo de ocupação dos espaços urbanos no Brasil parece estar associado a um aumento do risco de morte por homicídios destacando que dentre seus determinantes as desigualdades sociais intra-urbanas mostram forte associação com violência nos grandes aglomerados urbanos. 
Para CANO \& SANTOS (2000) a urbanização parece ser um fator chave quando conjugada à renda das vitimas intra-municipal ressaltando a pobreza urbana que numa combinação de fatores como urbanização acelerada sem infra-estrutura de serviços sociais, ausência de controle social, anonimato, falta de perspectivas para os jovens compõem seus determinantes. Estudos também têm apontado que melhoria de indicadores sociais quando acompanhados de urbanização rápida, não tem mostrado declínio nas taxas de homicídios, sugerindo ser este um dos fatores mais importantes por trás da violência. Ressaltam ainda que além dos problemas metodológicos enfrentados por estes tipos de estudo, a relação entre pobreza e violência letal encontra-se longe de ser elucidada.

As ausências de políticas econômicas e sociais podem contribuir para a manutenção das desigualdades levando-as a uma forma perversa de violência que é a estrutural, derivada de macro-determinantes numa dinâmica convergente com a teoria da causalidade complexa, em que todas as coisas são causadas e causadoras, num processo de retroalimentação em que a reflexividade dos fenômenos produz imbricamento dos aspectos biológicos, subjetivos e sociais MINAYO (1999).

\subsection{DIFERENCIAIS DE MORTALIDADE NOS ESTRATOS HOMOGENEOS}

A síntese das taxas padronizadas de mortalidade pelas causas selecionadas para este estudo, segundo estrato de vulnerabilidade social evidenciou três situações distintas: a primeira, onde o gradiente da mortalidade cresceu na mesma direção da vulnerabilidade social dos estratos (a exemplo da mortalidade por acidentes de transporte, mortalidade infantil e mortalidade materna).

A segunda, o gradiente da mortalidade mostrou situação inversa crescendo à medida que diminuiu a vulnerabilidade social dos estratos (a exemplo da mortalidade por doenças infecciosas e parasitárias e neoplasias malignas). E, $a$ terceira, em que a mortalidade mais elevada concentrou-se no Estrato de Vulnerabilidade Social Intermediária (C) ( Tabela 17). 
Para a primeira situação, as taxas mais elevadas situaram-se nos estratos de maior vulnerabilidade social mostrando-se 60\% mais elevada para Acidentes de Transporte, duplicação da RMM (100\%) para a Mortalidade Materna e, 30\% a maior para a Mortalidade Infantil quando comparados o estrato de menor vulnerabilidade social (Estrato A) com o de maior vulnerabilidade social (Estrato E).

Para a segunda situação, as taxas mais elevadas foram apresentadas pelo estrato de menor vulnerabilidade social (Estrato A) mostrando-se mais elevada em 20\% para as DIP e, 30\% para as Neoplasias em relação ao estrato de maior vulnerabilidade social (Estrato E).

Para a terceira situação, as taxas mais elevadas situaram-se no Estrato Intermediário, porém com comportamento distinto na evolução dos gradientes segundo causa, a partir deste estrato. Para Diabetes Mellitus, a segunda e a terceira taxa mais elevada foram dos estratos D e E. A mortalidade por Diabetes Mellitus foi $40 \%$ mais elevada no Estrato C em relação ao Estrato A.

Tabela 18 - Síntese das taxas de mortalidade por causas selecionadas segundo Estrato de Vulnerabilidade Social. Estado de São Paulo, média do triênio 2003-2005.

\begin{tabular}{|c|c|c|c|c|c|c|c|}
\hline Causas/Estrato & A & B & C & D & $\mathbf{E}$ & Estado & Razão $^{4}$ \\
\hline Acidentes de Transporte $^{1}$ & 14,68 & 16,27 & 18,30 & 22,30 & 24,06 & 17,68 & 1,6 \\
\hline Mortalidade Infantil $^{2}$ & 12,48 & 13,81 & 15,03 & 16,20 & 16,10 & 14,38 & 1,3 \\
\hline Mortalidade Materna $^{3}$ & 27,82 & 30,61 & 38,56 & 39,55 & 56,22 & 34,60 & 2,0 \\
\hline $\begin{array}{l}\text { Doenças Infecciosas e } \\
\text { Parasitárias }^{1}\end{array}$ & 27,52 & 26,55 & 25,93 & 23,70 & 23,21 & 25,98 & 1,2 \\
\hline Neoplasias Malignas ${ }^{1}$ & 104,96 & 101,74 & 99,37 & 88,79 & 80,85 & 98,87 & 1,3 \\
\hline Diabetes Mellitus $^{1}$ & 17,36 & 20,02 & 23,57 & 23,03 & 22,67 & 21,10 & 1,4 \\
\hline Doenças Circulatórias $^{1}$ & 175,12 & 179,92 & 206,87 & 174,03 & 174,62 & 184,57 & 1,2 \\
\hline Homicídios $^{1}$ & 21,24 & 28,88 & 35,54 & 14,53 & 11,50 & 27,47 & 3,1 \\
\hline Doenças Respiratórias ${ }^{1}$ & 69,93 & 68,55 & 75,54 & 66,00 & 62,58 & 69,51 & 1,2 \\
\hline \multicolumn{8}{|c|}{ Fonte: SIM.SINASC. Ministério da Saúde. Censo 2000 e Projeções (IBGE) } \\
\hline \multicolumn{8}{|c|}{${ }^{1}$ Taxa padronizada de mortalidade por 100 mil hab. (Pop.referência Estado de São Paulo (média do triênio 2003-2005) } \\
\hline \multicolumn{8}{|c|}{$\begin{array}{l}{ }^{2} \text { Por } 1000 \text { nascidos vivos } \\
{ }^{3} \text { Pazão de } 100 \text { mil nascidos viv } \\
\text { Raxas ( entre o maior valor e o menor valor dos estratos) }\end{array}$} \\
\hline
\end{tabular}

Para as Doenças Respiratórias, a segunda e a terceira taxa mais elevada foram dos estratos A e B. A taxa de mortalidade foi $20 \%$ mais elevada no 
Estrato C em relação ao Estrato E. Para as Doenças Circulatórias, a segunda e a terceira taxa mais elevada situaram-se nos estratos B e A. A taxa do Estrato C foi $20 \%$ mais elevada, que a menor taxa apresentada (D). Nota-se ainda que as taxas mais elevadas concentraram-se nos Estratos C e B, os mais populosos e, as demais apresentaram valores bastante próximos entre si.

Para Homicídios, a segunda e a terceira taxa mais elevada foram dos estratos B e A. O diferencial de mortalidade por esta causa mostrou-se $210 \%$ mais elevada que o Estrato E, cuja concentração se no deu nos estratos de maior adensamento populacional e urbanização.

Os achados do presente estudo reiteram as relações entre mortalidade, espaço e vulnerabilidade social além de oferecer evidencias da dualidade de um Estado com padrão de exposição à riscos semelhantes às regiões mais desenvolvidas com outras típicas de regiões menos desenvolvidas. Nos Estratos A, B é esperada uma maior exposição aos fatores de risco para doenças neoplásicas e circulatórias tendo em vista a intensa urbanização, a poluição ambiental, os processos produtivos envolvendo metais pesados e outros compostos químicos. Tais resultados possibilitaram a identificação os diferenciais de mortalidade entre estratos de vulnerabilidade social e sua distribuição espacial, o aprofundamento no estudo da mortalidade especifica por causa e grupos etários além, da identificação do local de ocorrência e tipo de acidente ou agravo contribuirá para sua melhor apreensão.

\section{7 - CONSIDERAÇÕES FINAIS}

Os achados deste estudo mostraram de desigualdades à semelhanças no padrão de mortalidade dos Estratos de Vulnerabilidade Social no Estado de São Paulo. Reiterou ainda estudos que apontaram para a intrínseca relação entre mortalidade, espaço e vulnerabilidade social evidenciando diferenciais de mortalidade no Estado mais pujante do país.

A metodologia de estratificação adotada possibilitou agrupar conjuntos de municípios em situação de vulnerabilidade social semelhantes respeitando as 
especificidades do adensamento populacional e sua magnitude ratificando a potencialidade do uso de dados secundários para estudos de agregados populacionais.

0 uso dos dados brutos do IPVS para a conformação dos estratos homogêneos de vulnerabilidade social mostrou-se factível cujos resultados foram coerentes com outros estudos, a exemplo do Índice de Desenvolvimento Humano Municipal (PNUD) e Índice Paulista de Responsabilidade Social (FSEADE, outros estudos citados na literatura. As implicações da vulnerabilidade para as políticas públicas de saúde precisam ser consideradas tanto pelo viés quantitativo da identificação de grupos vulneráveis e seus déficits de bens, serviços, oportunidades e escolhas, quanto pelo viés qualitativo da interação com os universos simbólicos e subjetividades envolvidas na geração de demandas.

Os resultados deste estudo possibilitaram identificar agregados populacionais homogêneos de vulnerabilidade social, sua distribuição espacial e padrão de mortalidade. A análise desse padrão de mortalidade permitiu ainda identificar os diferenciais de mortalidade segundo a vulnerabilidade social e grupos de causas para cada município, conjuntos de municípios, estratos de vulnerabilidade social e Estado.

A análise dos estratos homogêneos de vulnerabilidade social mostrou como a mortalidade se distribui no Estado de São Paulo segundo causas e vulnerabilidade social corroborando com estudos que mostram as condições de vida intrínsecas ao perfil de morbimortalidade da população e ocupação do espaço social.

Além de possibilitar melhor visualização da distribuição espacial dos distintos grupos populacionais homogêneos, a utilização de unidades espaciais segundo os indicadores selecionados resultou numa maior compreensão do processo de ocupação espacial e sua articulação com o fenômeno observado, intensificando ou não a exposição aos riscos de morte.

Confirma-se que a população que ocupa os espaços mais segregados nos quais o poder publico costuma encontrar-se mais ausente e, ainda de baixa densidade populacional, encontra-se mais exposta aos riscos de morte infantil e 
morte materna. Estas populações, dada a precariedade de infra-estrutura de serviços assume movimentos pendulares (ida e volta) para pólos microregionais ou regionais mais próximos em busca de serviços, trabalho e estudo sugerindo maior exposição ao tráfego em rodovias que numa conjugação de fatores envolvendo condições da estrada, veiculo e motorista pode elevar os riscos de acidente de transito.

Por outro lado, as conjugações de espaços densamente povoados e intensamente urbanizados a uma maior vulnerabilidade social aumentaram as estimativas de morte por homicídios, doenças respiratórias, doenças do aparelho circulatório e diabetes mellitus.

As doenças infecciosas e parasitarias e as neoplasias mostraram os estratos de menor vulnerabilidade mais expostos ao risco de morte o que pode ser explicado pelo peso da AIDS, hepatites, septicemias, dengue nestes estratos e, as neoplasias de menor vulnerabilidade social e em fase mais avançada de transição demográfica, com uma população mais envelhecida.

É importante ressaltar que não somente as condições de vulnerabilidade social explicam os diferenciais de mortalidade mas a utilização da referencia espacial e as causas de morte permitiram inferir sobre a existência de intrínsecos processos na configuração do fenômeno. Nesse sentido, o estudo revela que o "olhar que busca a intervenção", o desenvolvimento de estratégias e de políticas de saúde mais equitativas, deve se proteger da miopia da abordagem fragmentada e setorizada, restrita apenas a um loccus territorial. É necessário um esforço integrado e solidário dos gestores públicos e da sociedade em busca de efetividade de políticas de saúde mais equitativas e mais amplas sob pena de elevar as desigualdades ao invés de reduzi-la.

Espera-se que este estudo tenha apresentado uma contribuição metodológica e potencializado o uso de dados secundários como matéria prima para a obtenção de informações em saúde a despeito das limitações do presente estudo. As desigualdades intra-urbanas, aspectos relacionados à organização social e de atenção à saúde, variáveis ambientais, culturais entre outras não se encontram inclusas nos objetivos deste estudo. 
A captação de óbitos pelo SIM, a qualidade do preenchimento da declaração de óbito, a incompletude dos campos em branco apesar do baixo percentual de mal definidas no Estado, ainda há lacunas importantes e passíveis de melhorias em busca da melhor qualidade do dado. A sub-notificação de causas maternas, acidentes e agressões intencionais ainda prescindem da estruturação sistemática de investigação epidemiológica envolvendo a atuação das equipes de vigilâncias à saúde, melhoria nos sistemas de informações e formação de profissionais para o uso rotineiro destas tecnologias buscando a monitorização destes eventos.

As taxas derivadas de pequenos números de eventos quando observadas isoladamente (municípios de pequeno porte) devem ser observadas com cautela pois flutuações podem elevar sobremaneira a taxa no período. A média do triênio buscou reduzir tal flutuação, porém mesmo com este procedimento há municípios co registro de poucos eventos no período considerado.

Os sistemas de informações com armazenamento sistemático de dados de qualidade tem potencial de oferecer análises que gerem hipóteses e, eventualmente, respondam a elas, acompanham respostas a intervenções realizadas e, ainda permitem o monitoramento do evento ou do sistema ainda carece de melhorias. Aprimorá-los e utilizá-los em análises que produzam evidências subsidiando a identificação de desigualdades e iniqüidades em saúde têm sido relevantes não só para auxiliar na compreensão do complexo processo de determinação das doenças como, sobretudo, relaciona-se à possibilidade de utilização dessa informação para a adoção de estratégias de intervenção sanitária que visem a ampliar a equidade no desenvolvimento de políticas públicas. 


\section{Referências Bibliográficas}

Adorno, S.; Bordini, E. B. T.; Lima, R. S. O adolescente e as mudanças na criminalidade urbana. São Paulo em Perspectiva, 1999.São Paulo, Fundação SEADE, v.13, n.4, p.63-74,

Aidar T. A face perversa da cidade: configuração sócio-espacial das mortes violentas em Campinas nos anos 90.Campinas: Núcleo de Estudos de População / UNICAMP, 2003.118p.

Akerman M. Metodologia de construção de indicadores compostos: um exercício de negociação intersetorial. In: Barata R.B (Org.). Condições de vida e situação de saúde. Rio de Janeiro: ABRASCO; 1997:95-113.

Albuquerque RM; Cecatti JG, Hardy E, Fagundes A. Mortalidade materna em Recife: Avaliação da subenumeração de estatísticas oficiais. Cad. Saúde Públ. 1997; 13(1): 59-65.

Almeida Filho N, Rouquayrol MZ. Introdução à epidemiologia. R Janeiro: GUANABARA KOOGAN; 2002.

Almeida Filho N (Org.). Teoria epidemiológica hoje: fundamentos, interfaces e tendências. Rio de Janeiro: FIOCRUZ/ABRASCO; 1998.

Alves JED. O bônus demográfico e o crescimento econômico no Brasil. Publicado em http://http:// www. ie.ufrj.br/aparte/ em 06/12/2004 [acesso em 18/05/2005].Disponível em: http://http:// www.ie.ufri.br/aparte/ [acesso em 06/12/2004]

Alves MIC, Monteiro MFG. Diferenciais na estrutura de mortalidade dos idosos nas regiões metropolitanas brasileiras. Trabalho apresentado no XII Encontro Nacional de Estudos Populacionais; 2000; Caxambu; Minas Gerais [acesso em 10/04/2008].Disponível em www.abep.org.br/ publicações/ anais 2000

Arbex MA, Cançado JED, Pereira ALA, Braga ALF, Saldiva PHN. Queima de biomassa e efeitos sobre a saúde. J Bras. Pneumol. 2004; 30(2) 158-175.

Associação Brasileira de Concessionárias de Rodovias.[ Data de acesso: 10/09/2008]. Disponível em http://www.abcr.org.br/conc/conc_mapsp.php

Bagatin E, Costa EA. Doenças das vias aéreas superiores. J Bras. Pneumol. 2006; 32(1):S17-S26.

Barcellos C, Bastos Fl. Geoprocessamento, ambiente e saúde:uma união possível? Cad. Saúde Públ., Rio de Janeiro, 1996. 12(3):389-397.

Barradas RB. Epidemiologia social.Rev Bras Epidemiol.2005; 8(1): 7-17

Barradas RC. Epidemiologia século XXI:perspectivas para o Brasil.Rev Bras Epidemiol1999. 6 (2):p6-18

Barradas RCB. O desafio das doenças emergentes e a Revalorização da epidemiologia descritiva. Rev. Saúde Pública. 1997;31(5):531-7.

Beaufort R, Oliveira JEP. Mortalidade por diabetes Mellitus e outras causas no município do Rio de Janeiro: diferenças por sexo e idade. Arq. Bras. Endocrinol. Metab.. 2001;45(5): 460-466.

Benguigui Y. As infecções respiratórias agudas na infância como problema de saúde pública. Bol. Pneumol. Sanitária. 2002;10(1):13-22.

Benicio MHA, Cardoso MRA, Gouveia NC, Monteiro CA. Tendência secular da doença respiratória na infância na cidade de São Paulo (1984-1996). Rev. Saúde Pública. 2000; 34(6 Supl.):91-101.

Berquó E. Algumas questões para a demografia dos anos noventa. Revista Brasileira de Estudos de População, Campinas, NEPO/UNICAMP,1991. 8 ( n.1/2,) p.55-60, 1991.

Bezerra Filho JG, Sansigolo LRF, Pontes K, Mina DL, Barreto ML. Mortalidade infantil e condições sociodemográficas no Ceará, em 1991 e 2000. Rev. Saúde Pública. 2007;41(6): 1023-31.

Borrel C. Métodos utilizados nos estudos de desigualdades sociais em saúde. In: Barata RB (Org.). Condições de vida e Situação de Saúde. Rio de Janeiro: ABRASCO;1997 p. 167-195.

Bourdieu P. O poder simbólico. Lisboa/Rio de Janeiro: DIFEL/BERTRAND. 1989.

Brasil. Lei no. 8842 de 19 de setembro de 1994.Política Nacional do Idoso. Diário Oficial da União. p. 18.055-9 de 20/09/1990.

Brasil. Lei no. 8080 de 19 de setembro de 1990. Lei orgânica da saúde. Diário Oficial da União. p. 18.0559de 20/09/1999. 
Breilh J. Epidemiologia crítica: ciência emancipadora e interculturalidad. Buenos Aires: LUGAR EDITORIAL, Buenos Aires, 2003.

Buchalla CM, Waldman E, Laurenti R. A mortalidade por doenças infecciosas no início e no final do século XX no Município de São Paulo. Rev. Bras. Epidemiol. 2003;6(4): 335-344.

Camargo ABM, Fuzisaki E, Oushiro DA. A Evolução recente da mortalidade por agressões em São Paulo. Trabalho apresentado no XV. Encontro Nacional de Estudos Populacionais; 2006; Set. 18-22; Caxambu, BR. São Paulo: Associação Brasileira de Estudos Populacionais [acesso em 10/04/2008].Disponível em www.abep.org.br/publicações/anais

Campos NOB. Ritmo de declínio nas taxas de mortalidade dos idosos no Brasil e grandes regiões, 19802003. Trabalho apresentado no XV Encontro Nacional de Estudos Populacionais; 2006; Set. 18-22; Caxambu, BR. São Paulo: Associação Brasileira de Estudos Populacionais. [acesso em 10/04/2008].Disponível em www.abep.org.br/publicações/anais

Campos TP, Carvalho MS, Barcellos CB. Mortalidade infantil no Rio de Janeiro, Brasil: áreas de risco e trajetória dos pacientes até os serviços de saúde. Rev. Panam. Salud Publica. 2008(3):164-171.

Cançado JED, Braga ALF, Pereira ALA, Arbex MA, Saldiva PHN, Santos UP. Repercussões clínicas da exposição à poluição atmosférica. J Bras. Pneumol. 2006;32(Supl. 2):S23-S29.

Cano I, Santos N. Violência Letal, Renda e Desigualdade no Brasil. Textos apresentados nos seminários nacionais do Fórum de Debates IPEA/CESEC.Rio de Janeiro, 2000 [acesso em 10/08/2008] Disponível em www.ucamcesec.com.br/pb_txt_dwn.php

Carmo EH, Barreto ML, Silva JR JB. Mudanças nos padrões de morbimortalidade da população brasileira: os desafios para um novo século. Epidemiologia e Serviços de Saúde. 2003;12(2):63-75.

Carvalho JAM, Wong LLR. A transição da estrutura etária da população brasileira na primeira metade do século XXI. Cad. Saúde Pública. 2008;24(3):597-605.

Castellanos PL. Epidemiologia, saúde pública, situação de vida e condições de vida. Considerações conceituais. In: Barata R.B(Org.). Condições de vida e Situação de Saúde Rio de Janeiro: ABRASCO; 1997:31-75.

Chiesa AM, Westphal MF, Akerman M. Doenças respiratórias agudas: um estudo das desigualdades em saúde. Cad. Saúde Pública. 2008;24(1):55-69.

Conselho Federal de Medicina. Resolução CFM no 1.601, de 17/08/2000 Regulamenta a responsabilidade médica no fornecimento da Declaração de Óbito. DOU 18/08/00;Seção 1:64.

Contandriopoulos AP - Pode-se construir modelos baseados na relação entre contextos sociais e saúde? Cad. Saúde Públ.1998, Rio de Janeiro, 14(1):199-204.

Costa MCN, Azi PA, Paim, JS, Silva LMV. Mortalidade infantil e condições de vida: a reprodução das desigualdades sociais em saúde na década de 90. Cad. Saúde Pública. 2001;17(3):555-567

Costa MCN, Mota ELA, Paim JS, Silva LMV, Teixeira MG, Mendes CMC. Mortalidade infantil no Brasil em períodos recentes de crise econômica. Rev. Saúde Pública. 2003; 37(6):699-706.

Costa MR, Marcopito LF. Mortalidade por causas mal definidas, Brasil, 1979-2002, e um modelo preditivo para idade. Cad. Saúde Pública. 2008;24(5):1001-1012.

Costa SF. Introdução ilustrada à bioestatística. 4.ed.Rev. São Paulo: HARBRA; 2005.

Curi PR.Agrupamento de países segundo indicadores de padrão de vida.Rev. Saúde Publica, 1993 27(2):127-134.

Dever GEA. Epidemiologia na administração serviços de saúde. São Paulo: PIONEIRA, 1988.

Drumond JRM, Lira MTA, Freitas M, Nitrini TMV, Shibao K. Avaliação da qualidade das informações de mortalidade por acidentes não especificados e eventos com intenção indeterminada. Rev. Saúde Pública. 1999;33(3):273-80.

Duarte EC, Schneider MC, Sousa PR, Silva JB, Salgado CC. Expectativa de vida ao nascer e mortalidade no Brasil em 1999: análise exploratória dos diferenciais regionais. Rev. Panam. Salud Publica/Pan Am. J Public. Health. 2002:12(6). 
Duarte MC. Qualidade de vida e indicadores de saúde: aspectos da mortalidade infantil no estado do Rio de Janeiro e suas regiões. Cad. Saúde Pública. 1992;8(4).414-427.

Faria MAM, Almeida JWR, Zanetta DMT. Mortalidade por câncer na região urbano industrial da Baixada Santista, SP (Brasil). Rev. Saúde Pública. 1999;33(3):255-61.

Ferreira MP,Dini NP, Ferreira SP.Espaços e Dimensões da Pobreza nos Municípios do Estado de São Paulo - Índice Paulista de Vulnerabilidade Social - IPVS. São Paulo em Perspectiva, v. 20, n. 1, p. 5-17, jan./mar. 2006

Francisco PMSB, Donalisio MRC, Latorre MRDO. Tendência da mortalidade por doenças respira-tórias em idosos do Estado de São Paulo, 1980 a 1998. Rev. Saúde Pública. 2003; 37(2):191-6.

Franco LJ, Mameri C, Pagliaro H, lochida LC, Goldenberg P.Diabetes como causa básica ou associada de morte.Estado de São Paulo, Brasil, 1992 Rev Saúde Pública.1998;32(3):237-45.

Freitas C, Bremner AS, Gouveia N, Pereira LAA, Saldiva PHN. Internações e óbitos e sua relação com a poluição atmosférica em São Paulo, 1993 a 1997. Rev. Saúde Pública. 2004; 38(6):751-7.

Fucks C,Victora CG. Técnicas de análises de dados para estudos de condições de vida e situação de saúde: análise hierarquizada aplicada à investigação de fatores de risco para agravos à saúde infantil. In:

Barata RB(Org.). Condições de vida e situação de saúde. Rio de Janeiro: ABRASCO; 1997: 271-76.

Fundação Sistema Estadual de Analise de Dados - FSEADE.Atlas SEADE da Economia Paulista. São

Paulo;2007 [acesso em 10/06/2007] (disponivel em www.seade.gov.br)

Fundação Sistema Estadual de Analise de Dados - FSEADE.Indice Paulista de Responsabilidade Social. São Paulo;2006 [acesso em 10/06/2007](disponivel em www.seade.gov.br)

Fundação Sistema Estadual de Analise de Dados - FSEADE.Indice Paulista de Vulnerabilidade Social. São Paulo;2005 [CD-ROOM]

Gawryszeweski VP, Jorge MHPM. Mortalidade violenta no Município de São Paulo nos últimos 40 anos. Rev. Bras. Epidemiol. 2000;3(1-3):50-69.

Gawryszewski VP, Koizumi MS, Mello Jorge MHP.As causas externas no Brasil no ano 2000:Comparando mortalidade e morbidade.Cad. Saúde Pública, Rio de Janeiro, 2004.20(4):995-1003.

Godoy MF, Lucena JL, Miquelin AR, Paiva FF, Oliveira DLQ, Augustin JR JL, Chiaravalloti Neto F. Mortalidade por Doenças Cardiovasculares e Níveis Socioeconômicos na População de São José do Rio Preto, Estado de São Paulo, Brasil. Arq. Bras. Cardiol. 2007; 88(2):200-206.

Goldenberg P, Schenkman S, Franco LJ. Prevalência de Diabetes Mellitus: diferenças de gênero e igualdade entre os sexos. Rev. Bras. Epidemiol. 2003;6(1):18-28.

Gomes CAC. Espaço Urbano e Criminalidade:Uma Revisão do problema. RDE - Rev.Desenv Econômico. Salvador, BA, 2005; Ano VII (11): 57-68.

Gomes MJM. Ambiente e pulmão. J Pneumol.2002.28(5):261-269.

Gouveia N, Mendonça GAS, Leon AP, Correia JEM, Junger WL, Freitas CU, Daumas RP, Martins LC, Giussepe L, Conceição GMS, Manerich A, Joana CC. Poluição do ar e efeitos na saúde nas populações de duas grandes metrópoles brasileiras. Epidemiologia e Serviços de Saúde. 2003;12(1):29-40.

Guimarães MJB, Marques NM, Melo Filho, Szwarcwald CL. Condição de vida e mortalidade infantil: diferenciais intra-urbanos no Recife, Pernambuco, Brasil. Cad. Saúde Pública.2003;19(5):1413-1424.

Haddad N, Silva MB.Mortalidade feminina em idade reprodutiva no Estado de São Paulo, Brasil, 19911995 causas básicas óbito e mortalidade materna.Rev Saúde Pública. 2000;34(1):64-70.

Hallal ALC, Gotlieb SLD, Latorre MRDO. Evolução da mortalidade por neoplasias malignas no Rio Grande do Sul, 1979-1995. Rev. Bras. Epidemiol. 2001; 4(3):168-177.

Hartz ZMA, Contandriopoulos AP.Integralidade da atenção e integração de serviços de saúde: desafios para avaliar a implantação de um "sistema sem muros".Cad. Saúde Pública,2004. Rio de Janeiro, 20 Sup 2:S331-S336, 2004

Hartz ZMA, Champagne F, Leal MC, Contandriopoulos AP. Mortalidade infantil evitável duas cidades do Nordeste do Brasil: indicador de qualidade do sistema local de saúde. Rev Saúde Pública.

1996;30(4):310-8. 
Hartz ZMA,Silva LMS. Avaliação em Saúde: Dos modelos teóricos à prática na avaliação de programas e sistemas de saúde. Organizadores.Salvador:EDUFBA/RIO DE Janeiro:Editora Fiocruz,2005.275p Instituto Brasileiro de Geografia e Estatística -IBGE. Censos Demográficos 2000 e Projeções.[Acesso em 14/07/2007].. Disponível em www.ibge.gov.br

Instituto Brasileiro de Geografia e Estatística -IBGE. Departamento da População e Indicadores Sociais. Evolução e perspectivas da mortalidade infantil no Brasil. Rio de Janeiro: IBGE, 1999.

Instituto de Pesquisa Econômica e Aplicada-IPEA. Radar Social. Brasília: IPEA, 2005.

Jobim R, Aerts D. Mortalidade infantil evitável e fatores associados em Porto Alegre, Rio Grande do Sul, Brasil, 2000-2003. Cad. Saúde Pública. 2008;24(1):179-187.

Koogan/Houaiss. Enciclopédia e Dicionário llustrado. Rio de Janeiro: EDIÇÕES DELTA, 1997.

Koopman JS, Longini IM. The ecological effects of individual exposures nonlinear disease dynamics in populations. American Journal Of Public. Health.1994 May;84(5):836-842.

Lansky S. Desafios para a saúde perinatal no Brasil. Textos científicos da Sociedade Mineira de Pediatria. Publicado na Internet em 30/07/2005 [acesso em 24/02/2008].Disponível em http//:www.smp.org.br.

Laurell, A.C.; Noriega, M. Para o estudo da saúde na sua relação com o processo de produção. In: Processo de produção e saúde: trabalho e desgaste operário. São Paulo: HUCITEC, 1989.

Laurenti R, Buchalla CM. Os mitos a respeito das doenças cardiovasculares. Arq.. Bras. Cardiol.. 2001;76(2):99-104.

Laurenti R, Fonseca LAM, Costa JR ML. Mortalidade por Diabetes Mellitus no Município de São Paulo (Brasil). Evolução em um período de 79 anos (1900-1978) e análise de alguns aspectos sobre associação de causas. Rev. Saúde Pública. 1982;16:77-91.

Laurenti R, Jorge MHPM, Gotlieb SLD. A mortalidade materna nas capitais brasileiras: Algumas características e estimativa de um fator de ajuste. Rev. Bras. Epidemiol. 2004;7(4):449-60.

Laurenti R, Jorge MHPM, Gotlieb SLD. Reflexões sobre a mensuração da mortalidade materna. Cad. Saúde Pública. 2000;16:1.

Laurenti R, Jorge MHPM, Lebrão, ML, Gotlieb SLD. Estatísticas de Saúde. 2.ed. São Paulo: PEDAGÓGICA UNIVERSITÁRIA, 2006.

Laurenti R. Marcos referenciais para estudos e investigações em mortalidade materna. Rev. Saúde Publica. 1988;22:507-12.

Lessa I. Doenças crônicas não-transmissíveis no Brasil: um desafio para a complexa tarefa da vigilância. Ciência \& Saúde Coletiva.2004; 9(4):931-943.

Licio JL. Doenças emergentes: fatores demográficos na complexidade. Trabalho apresentado no XV Encontro Nacional de Estudos Populacionais; 2006; Set. 18-22; Caxambu, BR. [acesso em 28/03/2008].Disponível em http://www.abep.org.br/publicações/anais

Lilienfeld AM, Lilienfeld DE. Foundations of Epidemiology. New York, NY: OXFORD UNIVERSITY PRESS, 1980.

Lima MLC, Ximenes R. Violência e morte: diferenciais da mortalidade por causas externas no espaço urbano do Recife, 1991. Cad. Saúde Pública. 1998;14(4):829-840.

Lima MLC, Ximenes RAA, Souza ER, Lunac CF, Albuquerque MFM. Análise espacial dos determinantes socioeconômicos dos homicídios no Estado de Pernambuco. Rev. Saúde Pública. 2005;39(2):176-82.

Lorenzo C. Vulnerabilidade em saúde pública: implicações para as políticas públicas. Rev Bras. Bioética. 2006;2(3): 299-312.

Luna EA. A emergência das doenças emergentes e as doenças infecciosas emergentes e reemergentes no Brasil. Rev. Bras. Epidemiol. 2002;5(3): 229-243.

Mansur AP, Souza MFM, Timerman A, Avakian SD, Aldrighi JM, Ramires JF. Tendência do Risco de Morte por Doenças Circulatórias, Cerebrovasculares e Isquêmicas do Coração em Treze Estados do Brasil, de 1980 a 1998. Arq. Bras. Cardiol.. 2006;87:641-648.

Mathias TAF, Jorge MHMP.Diabetes Mellitus na população idosa município da Região Sul do Brasil: um estudo da mortalidade e morbidade hospitalar.Arq. Bras. Endoc. Metab. 2004;48 (4):505- 512. 
Medicina, Conselho Federal - Resolução CFM no 1.601 de 09/08/2000 - Regulamenta a responsabilidade médica no fornecimento da Declaração de Óbito.Publicada no DOU Nº 160 DE 18/08/2000.

Meirelles BHS, Erdmann AL. Redes sociais, complexidade, vida e saúde. Ciência, Cuidado e Saúde Maringá. 2006;5(1):67-74.

Mello Jorge MHP, Gotlieb SLD, Laurenti R. O sistema de informações sobre mortalidade: problemas e propostas para o seu enfrentamento. I - Mortes por causas naturais. Rev. Bras. Epidemiol. 2002;5(2):197-211.

Mello Jorge MHP; Gawrszewski, V. P.; Latorre, M. R. D. O. Análise dos dados de mortalidade.Revista de Saúde Pública,199. São Paulo.31, supl.: p.5-25.

Menezes AMB, Victora CG, Barros FC, Albernaz E, Menezes FS, Jannke HA, Alves C, Rocha C. Mortalidade infantil em duas coortes de base populacional no Sul do Brasil: tendências e diferenciais. Cad. Saúde Publ.. 1996;12(1 Supl.):79-86.

Minayo MCS, Souza ER. É possível prevenir a violência? Reflexões a partir do campo da saúde pública. Ciência \& Saúde Coletiva. 1999;4(1):7-32.

Ministério da Saúde. Estudo da Mortalidade de Mulheres de 10 a 49 anos com Ênfase na Morte Materna: relatório final. Brasília, DF; 2007b.

Ministério da Saúde. Comitê de mortalidade materna: manual. 3.ed. Brasília, DF; 2007 .

Ministério da Saúde. Impacto da violência na saúde dos brasileiros. Brasília, DF;2005.

Ministério da Saúde. Modernização do Sistema Nacional de Vigilância em Saúde.Brasília, DF; 2002.

Ministério da Saúde. Saúde Brasil 2004 - uma análise da situação de saúde / Ministério da Saúde, Secretaria de Vigilância em Saúde, Departamento de Análise de Situação de Saúde. Brasília: Ministério da Saúde, 2004.

Ministério da Saúde. Saúde Brasil 2005 : uma análise da situação de saúde no Brasil / Ministério da Saúde,Secretaria de Vigilância em Saúde, Departamento de Análise de Situação em Saúde. Brasília :Ministério da Saúde, 2005.

Ministério da Saúde. Secretaria de Atenção à Saúde. Departamento de Atenção Básica. Diabetes Mellitus. Brasília, DF; 2006.

Ministério da Saúde. Secretaria de Vigilância em Saúde. Impacto da violência na saúde dos brasileiros.

(Série B. Textos Básicos de Saúde) Brasília, DF; 2005340 p.

Ministério da Saúde.Saúde Brasil 2006 : uma análise da situação de saúde no Brasil / Ministério da Saúde, Secretaria de Vigilância em Saúde, Departamento de Análise de Situação em Saúde. - Brasília : Ministério da Saúde, 2006.

Morgenstern H . Uses of Ecologic Analysis in Epidemiologic Research - In: América Journal Of Public. Health. 1982; Vol. 72, n० $12: 1336-144$.

Moura L,Curado MP, Simões EJ, Cesário AC, Urdaneta M. Avaliação do Registro de Câncer de Base Populacional do Município de Goiânia, Estado de Goiás, Brasil. Rev.ista Epidemiologia e Serviços de Saúde.2006; 15(4) : 7 - 17].

Nogueira RP. Mortalidade por três grandes grupos de causa no Brasil.IPEA.2004. Políticas

Sociais.Acompanhamento e análise .9. nov.

Noronha, JR. Inquéritos e a avaliação das políticas de saúde. Ciência \& Saúde Coletiva , 2002, 7 (4): 623640.

Oliveira GMM, Klein CH, Souza e Silva NA. Mortalidade por doenças cardiovasculares em três estados do Brasil de 1980 a 2002. Rev. Panam. Salud Publica. 2006;19(2):85-93.

Omran A R. The epidemiologic transition theory: a preliminary update. Journal of TropicalPediatrics, 1983.Oxford, 29 (6): p.305-316.

Organização Mundial da Saúde. CID-10.Classificação Internacional de Doenças. 5.ed. Trad. do Centro Colaborador da OMS para a Classificação de Doenças Português. 10a Rev.. São Paulo: EDUSP; 1999.

Organizacion Panamericana de La Salud - OPAS. La violência: un problema de salud pública que se agrava en la región. Boletín Epidemiológico de la Organización Panamericana de la Salud, v.112, n.2, p.1-7, 
1990.

Organizacion Panamericana de La Salud - OPAS. Mortalidad por accidentes yviolencia en las Americas. Boletín Epidem Organización Panamericana de la Salud, v.15, n.2, p.1-16, 1994.

Ortiz LP.Evolução da Mortalidade Infantil no Estado de São Paulo 1980-2000. Trabalho apresentado no XIII Encontro da Associação Brasileira de Estudos Populacionais, realizado em Ouro Preto, Minas Gerais, Brasil de 4 a 8 de novembro de 2002.[acesso em 10/04/2006].Disponível em www.abep.org.br/ publicações/ anais

Paim J.S. Abordagens teórico-conceituais em estudos de condições de vida e saúde: notas para reflexão e ação. In: Barata, RB(Org.). Condições de vida e situação de saúde. Rio de Janeiro: ABRASCO; 1997:7-30.

Parahyba MI. Desigualdades de gênero em saúde entre os idosos no Brasil. Trabalho apresentado no XV Encontro Nacional de Estudos Populacionais; 2006;Set. 18-22; Caxambu,BR.São Paulo: Associação Brasileira de Estudos Populacionais.[acesso em 10/04/2008].Disponível em www.abep.org.br/ publicações/ anais

Pignatti M.Saúde e Ambiente: As doencas emergentes no Brasil.2004.Rev. Ambiente e Sociedade. 7(1):133-148

Possas C. Epidemiologia e Sociedade: heterogeneidade estrutural e saúde no Brasil. São Paulo: HUCITEC, 1989.

Prata PR. A transição epidemiológica no Brasil. Cad. Saúde Públ. 1992;(2): 68-175.

Prata R. Desenvolvimento econômico, desigualdade e saúde.Cad.Saúde Públ.1994;10(3): 387-391.

Programa das Nações Unidas para o Desenvolvimento (PNUD). Brasil: relatório de desenvolvimento humano - racismo, pobreza e violência, 2005.

Programa das Nações Unidas para o Desenvolvimento (PNUD). Brasil: relatório.[ acesso e m 10/04/2007].Disponível em http://www.pnud.org.br/idh/.

Programa das Nações Unidas para o Desenvolvimento BRASIL. Índice de Desenvolvimento Humano -IDH .[ acesso e m 10/04/2007].Disponível em http://www.pnud.org.br/idh/.

Rede Interagencial de Informações para a Saúde. Indicadores básicos para a saúde no Brasil: conceitos e aplicações. Brasília, DF; 2002.

Rede Interagencial de Informações para a Saúde. Indicadores básicos para a saúde no Brasil: conceitos e aplicações. Brasília, DF; 2008.

Ribeiro H. Queimadas de cana-de-açúcar no Brasil: efeitos à saúde respiratória. Rev. Saúde Pública 2008;42(2):370-376.

Risi Junior JB. Inquéritos e a avaliação das políticas de saúde.In: Ciência \& Saúde Coletiva, Rio de Janeiro: FIOCRUZ , 2002, 7 (4): 635-637

Rocha S. Mortalidade infantil como variável para diagnóstico e desenho de política antipobreza. Rev.. Economia e Sociedade. 2006;15, n. 1 (26): 113-144.

Rosen G. Uma história da saúde pública. Trad. MFS Moreira. Rio de Janeiro: HUCITEC; 1994.

Rouquayrol MZ, Almeida Filho N. Epidemiologia \& Saúde. 5. ed. Rio de Janeiro: MEDSI-MEDICA E CIENTÍFICA; 1999.

Rozman MA, Eluf Neto, J. Necropsia e mortalidade por causa mal definida no Estado de São Paulo. Rev. Panam. Saúde Publica. 2006; 20(5):307-13.

Rutstein DD. Monitoring progress and failure: sentinel health events In: Measurement in health promotion and protection. Copenhagen, WHO/IEA; 1987: 95-212.

Santo, AH. Causas mal definidas de morte e óbitos sem assistência. Revista da Associação Médica Brasileira. 2008;54(1):23-8.

Santos M. Espaço \& Método, São Paulo, NOBEL, 1985.

Santos M. Por uma geografia nova. São Paulo.São Paulo, Hucitec/EDUSP.1978. 
Santos M.Saúde e ambiente no processo de desenvolvimento.Conferência magna proferida no I Seminário Nacional Saúde e Ambiente no Processo de Desenvolvimento em 12 de julho de 2000 . Rev.Ciência \& Saúde Coletiva,2003. 8 (1):309-314

Schramm JMA, Oliveira AFO, Oliveira AF, Leite IC, Valente JG, Gadelha AMJ, Portela MC, Campos MR. Transição epidemiológica e o estudo de carga de doença no Brasil.Ciência \& Saúde Coletiva,2004; 9(4):897-908.

Schstzmayr HG. Viroses emergentes e reemergentesCad.Saúde Pública.2001;17(Supl.): 209-213.

Schwartz S. The fallacy of the ecological fallacy: the potential misuse of a concept and the consequences. Am. Journal Of Public. Health. 1994;84(5):819-824.

Silva LMV, Paim J, Costa MCN. Desigualdades na mortalidade, espaço e estratos sociais. Rev. Saúde Pública. 1999;33(2):187-97.

Sistema de Informações sobre Mortalidade. [base de dados na internet]. Brasília: Ministério da Saúde. 2003,2004 e 2005 [acesso em 18/08/2007] Disponível em: www.datasus.gov.br.

Sistema de Informações sobre Nascidos Vivos. [base de dados na internet]. Brasília: Ministério da Saúde. 2003,2004 e 2005 [acesso em 18/08/2007] Disponível em: www.datasus.gov.br.

Soares Filho AM, Souza MFM, Carvalho CG, Malta DC, Alencar AP, Silva MMA, Morais Neto OL. Análise da mortalidade por homicídios no Brasil. Epidemiologia e Serviços de Saúde.2007;16(1):7-18.

Souza ER, Lima MLC.Panorama da violência urbana no Brasil e suas capitais.2007. Rev. Ciência \& Saúde Coletiva, 11(Sup): 1211-1222

Souza MFM, Alencar AP, Malta DC, Moura L, Mansur AP. Análise de séries temporais da mortalidade por doenças isquêmicas do coração e cerebrovasculares, nas cinco regiões do Brasil, no período de 1981 a 2001. Arq.. Bras. Cardiol. 2006;87(6):735-740.

Souza MFM, Malta DC, Silva MMA, Carvalho CG, Morais Neto OL. Análise descritiva e de tendência de acidentes de transporte terrestre para políticas sociais no Brasil. Rev.Epidemiologia e Serviços de Saúde. 2007. 16 ( 1) :33-44

Souza MH, Cecatti JG, Hardy EE, Amaral E, Souza JPD; Serruya S. Sistemas de informação em saúde e monitoramento de morbidade materna grave e mortalidade materna. Rev. Bras. Saúde Materno Infantil. 2006;6(2):161-168.

Susser M. The logic in ecological: II The Logic Analysis. Am Journal Of Public Health1994;84(5):25-29.

Szwarcwald CL, Leal MC, Castilho EA, Andrade CLT. Mortalidade infantil no Brasil: Belíndia ou Bulgária? Cad. Saúde Publ. 1997;13(3):503-516.

Veras RP, organizador. Epidemiologia, contextos e pluralidade. R.Janeiro: FIOCRUZ/ ABRASCO, 1998.

Viacava F. Informações em saúde: a importância dos inquéritos populacionais. Ciência \& Saúde Coletiva. 2002;7(4):607-621.

Viana SM, Barata RB, Santos JRS, Nunes A. Medindo as desigualdades em saúde no Brasil: uma proposta de monitoramento. Brasília: OPAS/OMS/IPEA; 2001.

Vieira S. Introdução à bioestatística. São Paulo: CAMPUS; 1998.

Waiselfisz JJ. Mapa da violência dos municípios brasileiros - 2008. São Paulo: Rede de Informação Tecnológica Latino-Americana, Instituto Sangari, Ministério da Saúde e Ministério da Justiça.IDEAL GRAFICA E EDITORA.SP, 1a ed.

Waldman EA, Silva LJ, Monteiro A. Trajetória das doenças infecciosas: da eliminação da poliomielite à reintrodução da cólera. Informe Epidemiológico do SUS. 1999;8(3):5-47.

Waldman EA. Usos da vigilância e da monitorização em saúde pública. Informe Epidemiológico do SUS.1998, VII(3):07-26.

Wikipedia. Enciclopédia on line.[acesso em 15/05/2007] Disponível em http//:www.portalgv.com.br Guimarães MJB, Marques NM, Melo Filho, Szwarcwald CL. Condição de vida e mortalidade infantil: diferenciais intra-urbanos no Recife, Pernambuco, Brasil. Cad. Saúde Pública.2003;19(5):1413-1424. 


\title{
Lista de Anexos
}

\author{
Anexo \\ 1 Matriz de Indicadores Selecionados \\ Pag. \\ 2 Municípios segundo classificação de vulnerabilidade social. \\ 3 Municípios classificados no Estrato A - Vulnerabilidade Social Muito Fraca \\ 4 Municípios classificados no Estrato B - Vulnerabilidade Social Fraca \\ 5 Municípios classificados no Estrato C - Vulnerabilidade Social Intermediária \\ 6 Municípios classificados no Estrato D - Vulnerabilidade Social Intensa \\ 7 Municípios classificados no Estrato E - Vulnerabilidade Social Muito Intensa \\ 26 \\ 8 População total por faixa etária segundo estrato de vulnerabilidade social \\ 9 Razão de Sexos e Razão de Dependência segundo conjuntos de municípios \\ dos Estratos de Vulnerabilidade Social \\ 10 Razão de Sexos e Razão de Dependência segundo município e Estratos de \\ Vulnerabilidade Social \\ 11 Mortalidade proporcional (\%)por faixa etária selecionada segundo conjuntos \\ de municípios dos Estratos de Vulnerabilidade Social \\ 12 Mortalidade proporcional (\%)por faixa etária selecionada segundo município \\ e Estrato de Vulnerabilidade Social \\ 13 Mortalidade infantil e respectivas métricas segundo conjuntos de municípios \\ dos Estratos de Vulnerabilidade Social \\ 14 Mortalidade Materna e respectivas métricas segundo conjuntos de \\ municípios dos Estratos de Vulnerabilidade Social \\ 15 Mortalidade materna e infantil segundo município e Estrato de \\ Vulnerabilidade Social \\ 16 Proporção de óbitos (\%) por Causas Mal Definidas e respectivas métricas \\ segundo conjuntos de municípios dos Estratos de Vulnerabilidade Social \\ 17 Mortalidade por Doenças Infecciosas e Parasitárias e respectivas métricas \\ segundo conjuntos de municípios dos Estratos de Vulnerabilidade Social \\ 18 Mortalidade por Doenças Respiratórias e respectivas métricas segundo \\ conjuntos de municípios dos Estratos de Vulnerabilidade Social \\ 19 Mortalidade por Doenças Infecciosas e Parasitárias, Respiratórias e por \\ Causas Mal Definidas segundo município e Estrato de Vulnerabilidade Social \\ 20 Mortalidade por Diabetes Mellitus e respectivas métricas segundo conjuntos \\ de municípios dos Estratos de Vulnerabilidade Social \\ 21 Mortalidade por Doenças Circulatórias e respectivas métricas segundo \\ conjuntos de municípios dos Estratos de Vulnerabilidade Social \\ 22 Mortalidade por Neoplasias e respectivas métricas segundo conjuntos de \\ municípios dos Estratos de Vulnerabilidade Social \\ 23 Mortalidade por Diabetes Mellitus, Circulatórias e Neoplasias segundo \\ município e Estrato de Vulnerabilidade Social \\ 24 Mortalidade por Acidentes de Transporte e respectivas métricas segundo \\ conjuntos de municípios dos Estratos de Vulnerabilidade Social \\ 25 Mortalidade por Homicídios e respectivas métricas segundo conjuntos de \\ municípios dos Estratos de Vulnerabilidade Social \\ 26 Mortalidade por Homicídios e Acidentes de Transporte segundo município e \\ Estrato de Vulnerabilidade Social
}

\section{Anexo complementar}

27 Fundação SEADE. Metodologia da construção do Índice Paulista de Vulnera- 
bilidade Social nos Municípios do Estado de São Paulo. 2005; [CD-ROM]

\section{Marli de Fatima Prado}

Possui graduação em Ciencias Biológicas pela Universidade São Francisco (1983) e mestrado em Saúde Coletiva - Avaliacao de Servicos de Saúde peia Faculdade de Ciencias Médicas Unicamp (2003). Atualmente é biologista - Secretaria de Estado da Saúde de São Paulo, professor mestre FACULDADES INTEGRADAS TORRICELLI, professor titular da Fundaçāo Paulistana de Educaçăo e Tecnologia e professor convidado do Instituto Brasileiro de Desenvolvimento Profissional. Tem experiência na área de Saúde Coletiva, com ênfase em Saüde Coletiva, atuando principalmente nos seguintes temas: ressarcimento ao sus, faturamento, medicamentos, adolescente e materiais.

(Texto informado pelo autor)

Última atualização do currículo em 08/10/2008

Certificado

Endereço para acessar este CV:

pelo autor em

hittp.//lattes.cnpq.br/7389714094938998

$08 / 10 / 08$ 
Dados Gerais Linhas de pesquisa Projetos Áreas Produção em C,T \& A Bancas Eventos Orientaçöes

\author{
Ruy Laurenti \\ Bolsista de Produtividade em Pesquisa do CNPq - Nivel 1A
}

possui graduação em Medicina pela Universidade de São Paulo (1957), especialização em Estatisticas de Saúde pela Escuela de Salubridad da Universidade do Chile (1966), especialização em Saúde Púbilca pela Universidade de Säo Paulo (1972), especializaçâo em Medicina Tropical pela Universidade de Säo Paulo (1962), especializaçäo em Classificação de Doenças pelo Centro Latino Americano de Clasificación de Enfermedades (1963), especializaçao em Doenças Cardiovasculares pela Council On Epidemiology And Prevention International Society And Federation (1970) e doutorado em Cardiologia pela Universidade de Sảo Paulo (1969). Atuaimente é funcionário da Universidade de São Pauto, Professor da Universidade do Sagrado Coração e Membro de corpo editorial da Revista Brasileira de Epidemiologia. Tem experiência na área de Saủde Coletiva, com ênfase em Epidemiologia. Atuando principalmente nos seguintes temas: Cardiopatia Congenita, Dermatoglifos.

(Texto gerado automaticamente pela aplicação CVLattes)

Üitima atualização do curriculo em 30/09/2008

Certificado

Endereço para acessar este CV:

pelo autor em

http./liattes.cnpq.bri8145305733993970

30/09/08 
Lista de Anexos

Anexo

1 Matriz de Indicadores Selecionados

Pag.

2 Municípios segundo classificação de vulnerabilidade social.

Muito Fraca

4 Municípios classificados no Estrato B - Vulnerabilidade Social

Fraca

5 Municípios classificados no Estrato C - Vulnerabilidade Social Intermediária

6 Municípios classificados no Estrato D - Vulnerabilidade Social Intensa

7 Municípios classificados no Estrato E - Vulnerabilidade Social Muito Intensa

8 População total por faixa etária segundo estrato de vulnerabilidade social

9 Razão de Sexos e Razão de Dependência segundo conjuntos de municípios dos Estratos de Vulnerabilidade Social

10 Razão de Sexos e Razão de Dependência segundo município e Estratos de Vulnerabilidade Social

11 Mortalidade proporcional (\%)por faixa etária selecionada segundo conjuntos de municípios dos Estratos de Vulnerabilidade Social

12 Mortalidade proporcional (\%)por faixa etária selecionada segundo município e Estrato de Vulnerabilidade Social

13 Mortalidade infantil e respectivas métricas segundo conjuntos de municípios dos Estratos de Vulnerabilidade Social

14 Mortalidade Materna e respectivas métricas segundo conjuntos de municípios dos Estratos de Vulnerabilidade Social

15 Mortalidade materna e infantil segundo município e Estrato de Vulnerabilidade Social

16 Proporção de óbitos (\%) por Causas Mal Definidas e respectivas métricas segundo conjuntos de municípios dos Estratos de Vulnerabilidade Social

17 Mortalidade por Doenças Infecciosas e Parasitárias e respectivas métricas segundo conjuntos de municípios dos Estratos de Vulnerabilidade Social

18 Mortalidade por Doenças Respiratórias e respectivas métricas segundo conjuntos de municípios dos Estratos de Vulnerabilidade Social

19 Mortalidade por Doenças Infecciosas e Parasitárias, Respiratórias e por Causas Mal Definidas segundo município e Estrato de Vulnerabilidade Social

20 Mortalidade por Diabetes Mellitus e respectivas métricas segundo conjuntos de municípios dos Estratos de Vulnerabilidade Social

21 Mortalidade por Doenças Circulatórias e respectivas métricas segundo conjuntos de municípios dos Estratos de Vulnerabilidade Social

22 Mortalidade por Neoplasias e respectivas métricas segundo 
23 Mortalidade por Diabetes Mellitus, Circulatórias e Neoplasias segundo município e Estrato de Vulnerabilidade Social

24 Mortalidade por Acidentes de Transporte e respectivas métricas segundo conjuntos de municípios dos Estratos de Vulnerabilidade Social

25 Mortalidade por Homicídios e respectivas métricas segundo conjuntos de municípios dos Estratos de Vulnerabilidade Social

26 Mortalidade por Homicídios e Acidentes de Transporte segundo município e Estrato de Vulnerabilidade Social 
Anexo 1- Matriz de Medidas e Indicadores Selecionados

\begin{tabular}{|c|c|c|c|c|c|}
\hline Denominação & Conceituação & Método de calculo & Categorias & Período & Fontes \\
\hline População total & $\mathrm{N}^{\circ}$ total de habitantes residentes & $\mathrm{N}^{\circ}$ absoluto de pessoas residentes & \multirow{10}{*}{ 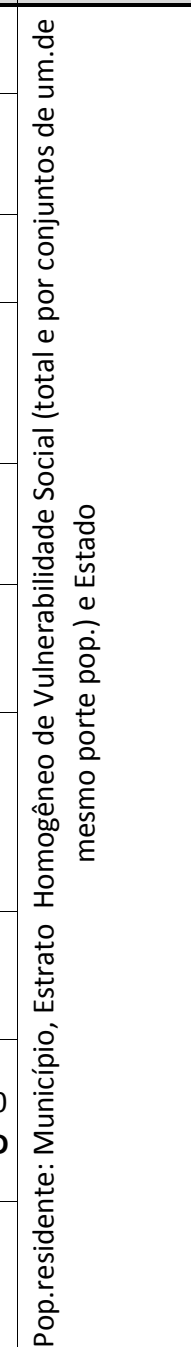 } & \multirow{10}{*}{ 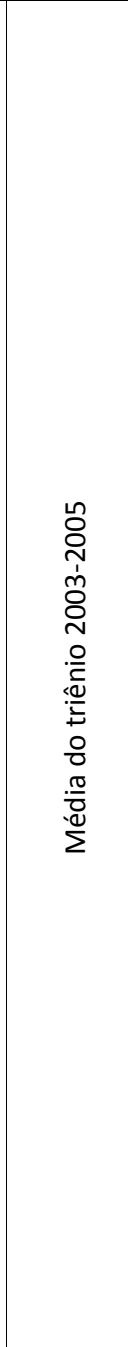 } & \multirow{10}{*}{ 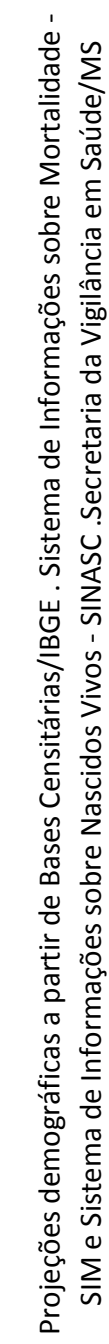 } \\
\hline $\begin{array}{l}\text { Percentual por faixa etária } \\
\text { da população }\end{array}$ & $\begin{array}{l}\text { Percentual de residentes por faixa } \\
\text { etária selecionada na população total }\end{array}$ & $\begin{array}{l}\text { Percentual de hab. na faixa etária selecionada sobre o total de } \\
\text { habitantes (X100) }\end{array}$ & & & \\
\hline Razão de Sexos & $\begin{array}{l}\mathrm{N}^{\circ} \text { de homens para cada grupo de } 100 \\
\text { mulheres }\end{array}$ & $\begin{array}{l}N^{\circ} \text { de residentes do sexo masculino sobre o } N^{\circ} \text { residentes do sexo } \\
\text { feminino }(X 100)\end{array}$ & & & \\
\hline Razão de dependência & $\begin{array}{l}\text { Razão entre o segmento etário } \\
\text { dependente }(<15 \text { anos e } 65 \text { e }+ \text { ) o } \\
\text { segmento produtivo (15a } 64 \text { anos) }\end{array}$ & $\begin{array}{l}\text { População de } 0-14 \text { anos de idade sobre a população de } 15 \text { a } 64 \text { anos } \\
\text { de idade (X100) }\end{array}$ & & & \\
\hline $\begin{array}{l}\text { Mortalidade proporcional } \\
\text { por idade }\end{array}$ & $\begin{array}{l}\text { Distribuição percentual dos óbitos por } \\
\text { faixa etária na população }\end{array}$ & $\begin{array}{l}N^{\circ} \text { de óbitos os faixa etária sobre o No total de óbitos de residentes } \\
\text { excluídos os de idade ignorada }(\times 100)\end{array}$ & & & \\
\hline $\begin{array}{l}\text { Taxa de mortalidade } \\
\text { infantil }\end{array}$ & $\begin{array}{l}\mathrm{N}^{\circ} \text { de óbitos de crianças menores de } \\
\text { um ano de idade por mil nascidos } \\
\text { vivos }\end{array}$ & $\begin{array}{l}N^{\circ} \text { de óbitos }<1 \text { ano sobre o No total de nascidos vivos de mães } \\
\text { residentes }(x 1000)\end{array}$ & & & \\
\hline $\begin{array}{l}\text { Razão de mortalidade } \\
\text { materna }\end{array}$ & $\begin{array}{l}\mathrm{N}^{\circ} \text { de óbitos de mulheres por causas } \\
\text { maternas por } 100 \text { mil nascidos vivos }\end{array}$ & $\begin{array}{l}\mathrm{N}^{\circ} \text { de óbitos de mulheres consideradas óbito materno sobre o } \mathrm{N}^{\circ} \text { de } \\
\text { nascidos vivos ( } 100 \text { mil) Códigos: (O00 a O99 excluídos } 096 \text { e } \\
\text { O97) e (E230, M830, A34 e F53) E (B20 a B24 desde que haja registro de } \\
\text { gravidez no momento da morte ou até } 42 \text { dias antes.) }\end{array}$ & & & \\
\hline $\begin{array}{l}\text { Mortalidade proporcional } \\
\text { por causas mal definidas }\end{array}$ & $\begin{array}{l}\text { Percentual de óbitos por causas mal } \\
\text { definidas No total de óbitos }\end{array}$ & $\begin{array}{l}N^{\circ} \text { de óbitos por causas mal definidas sobre o No total de óbitos ( X } \\
\text { 100) Códigos: (R00 a R99) - CID } 10\end{array}$ & & & \\
\hline $\begin{array}{l}\text { Taxa de mortalidade } \\
\text { específica por Doenças } \\
\text { Infecciosas e Parasitarias }\end{array}$ & $\begin{array}{l}N^{\circ} \text { de óbitos por Doenças infecciosas } \\
\text { e Parasitárias por } 100 \text { mil habitantes }\end{array}$ & $\begin{array}{l}N^{\circ} \text { de óbitos de residentes por Doenças Infecciosas e Parasitarias } \\
\text { sobre a população total residente ajustada para o meio do ano ( X } 100 \\
000) \\
10\end{array}$ & & & \\
\hline $\begin{array}{l}\text { Taxa de mortalidade } \\
\text { específica por Doenças } \\
\text { Respiratórias }\end{array}$ & $\begin{array}{l}\mathrm{N}^{\circ} \text { de óbitos por Doenças } \\
\text { Respiratórias por } 100 \text { mil habitantes }\end{array}$ & $\begin{array}{l}N^{\circ} \text { de óbitos de residentes por Respiratórias sobre a população total } \\
\text { residente ajustada para o meio do ano ( X } 100 \text { 000) } \\
\text { Códigos: (J00 a J99) CID } 10\end{array}$ & & & \\
\hline
\end{tabular}


Anexo 1- Matriz de Medidas e Indicadores Selecionados

\begin{tabular}{|c|c|c|c|c|c|}
\hline Denominação & Conceituação & Método de calculo & Categorias & Período & Fontes \\
\hline $\begin{array}{l}\text { Taxa de mortalidade } \\
\text { específica por neoplasias } \\
\text { malignas }\end{array}$ & $\begin{array}{l}N^{\circ} \text { de óbitos por neoplasias malignas, } \\
\text { por } 100 \text { mil habitantes }\end{array}$ & $\begin{array}{l}N^{\circ} \text { de óbitos de residentes por neoplasias malignas sobre a população } \\
\text { total residente ajustada para o meio do ano }(X 100 \text { 000) Códigos: } \\
\text { (C00 a C97) CID-10 }\end{array}$ & \multirow{6}{*}{ 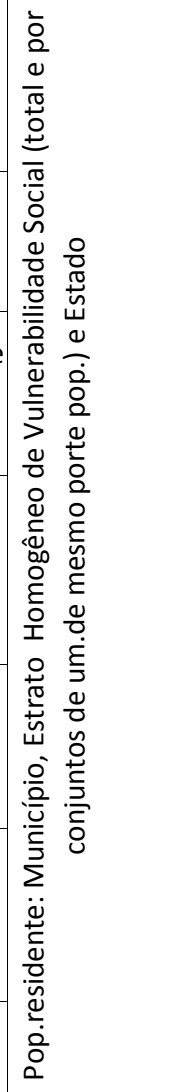 } & \multirow{6}{*}{ 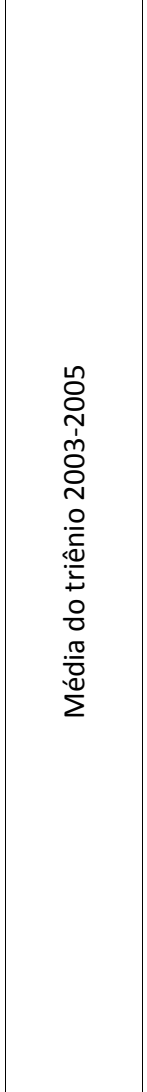 } & \multirow{6}{*}{ 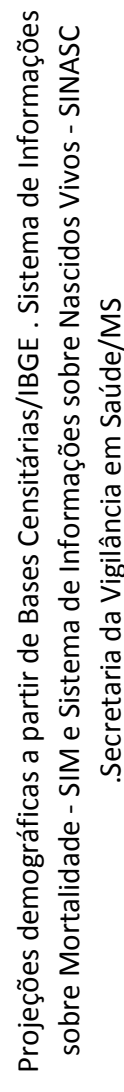 } \\
\hline $\begin{array}{l}\text { Taxa de mortalidade } \\
\text { específica por Diabetes } \\
\text { Mellitus }\end{array}$ & $\begin{array}{l}\text { Número de óbitos por Diabetes } \\
\text { Melittus na população total }\end{array}$ & $\begin{array}{l}N^{\circ} \text { de óbitos por Diabete Mellitus sobre a população total residente } \\
\text { ajustada para o meio do ano ( X } 100 \text { 000) Códigos (E10 a E14 ) CID - } 10\end{array}$ & & & \\
\hline $\begin{array}{l}\text { Taxa de mortalidade } \\
\text { específica por Doenças do } \\
\text { Aparelho Circulatório }\end{array}$ & $\begin{array}{l}\text { N de óbitos por Doenças do Aparelho } \\
\text { Circulatório na população total por } \\
100 \text { mil hab. }\end{array}$ & $\begin{array}{l}N^{\circ} \text { de óbitos de residentes por Doenças do Aparelho Circulatório sobre } \\
\text { a população total residente ajustada para o meio do ano (X } 100 \text { 000) } \\
\text { Códigos } 100 \text { a } 199 \text {-CID } 10\end{array}$ & & & \\
\hline $\begin{array}{l}\text { Taxa de Mortalidade } \\
\text { Especifica por Homicídios }\end{array}$ & $\begin{array}{l}N^{\circ} \text { de óbitos por Homicídios por } 100 \\
\text { mil hab. }\end{array}$ & $\begin{array}{l}N^{\circ} \text { de óbitos de residentes por causas externas sobre a população } \\
\text { total residente ajustada para o meio do ano (X } 100 \text { 000) } \\
\text { Códigos (X85 A Y09) e ( Y35 e Y36) -CID } 10\end{array}$ & & & \\
\hline $\begin{array}{l}\text { Medidas de tendência } \\
\text { central }\end{array}$ & \multicolumn{2}{|c|}{$\begin{array}{l}\text { Média aritmética: resultado da soma dos valores de todas as observações, dividida pelo } n^{\circ} \text { de observações. } \\
\text { Mediana: medida de posicionamento, representando o valor que ocupa a posição central na série, ou seja, } \\
50 \% \text { dos valores estão abaixo e } 50 \% \text { acima da mediana. }\end{array}$} & & & \\
\hline $\begin{array}{l}\text { Razão entre taxas (risco } \\
\text { relativo) }\end{array}$ & \multicolumn{2}{|c|}{$\begin{array}{l}\text { Razão entre taxas de mortalidade: razão entre o maior valor e o menor valor. Referencias: } \\
\text { município/conjunto de municípios, conjunto de municípios/estrato e estrato/Estado }\end{array}$} & & & \\
\hline Medidas de dispersão & \multicolumn{5}{|c|}{$\begin{array}{l}\text { Desvio padrão (DP) representa o padrão de oscilações que os valores da série apresentam em relação à } \\
\text { média. É importante marcador de variação }\end{array}$} \\
\hline
\end{tabular}


Anexo 2 - Municípios classificados no Estrato D - Vulnerabilidade Social Intensa segundo proporção da população nos grupos IPVS e porte populacional, estado de São Paulo, média do triênio 2003 a 2005.

\begin{tabular}{|c|c|c|c|c|c|c|c|c|c|}
\hline IBGE & MUNICIPIO & POP. & IPVS $(1,2,3)$ & $\%$ & IPVS (4) & $\%$ & IPVS $(5,6)$ & $\%$ & Status \\
\hline 350010 & Adamantina & 34124 & 16107 & 47,2 & 717 & 2,1 & 17301 & 50,7 & D50 \\
\hline 350020 & Adolfo & 3868 & & - & & - & 3868 & 100,0 & E20 \\
\hline 350030 & Aguaí & 30353 & 6617 & 21,8 & - & - & 23706 & 78,1 & E50 \\
\hline 350040 & Águas da Prata & 7326 & 1949 & 26,6 & - & - & 5377 & 73,4 & D20 \\
\hline 350050 & Águas de Lindóia & 18055 & 7583 & 42,0 & - & - & 10472 & 58,0 & D20 \\
\hline 350055 & Águas de Santa Bárbara & 5819 & 3619 & 62,2 & 698 & 12,0 & 1507 & 25,9 & B20 \\
\hline 350060 & Águas de São Pedro & 1965 & 1965 & 100,0 & - & - & - & 0,0 & $\mathrm{~A} 20$ \\
\hline 350070 & Agudos & 33511 & 13471 & 40,2 & 3552 & 10,6 & 16521 & 49,3 & C50 \\
\hline 350075 & Alambari & 3806 & - & - & -1 & - & 3806 & 100,0 & E20 \\
\hline 350080 & Alfredo Marcondes & 3786 & - & - & - & - & 3786 & 100,0 & E20 \\
\hline 350090 & Altair & 3660 & - & - & 355 & 9,7 & 3305 & 90,3 & E20 \\
\hline 350100 & Altinópolis & 16304 & 5152 & 31,6 & - & - & 11152 & 68,4 & D20 \\
\hline 350110 & Alto Alegre & 4026 & 149 & 3,7 & - & - & 3877 & 96,3 & E20 \\
\hline 350115 & Alumínio & 15919 & 7243 & 45,5 & 6861 & 43,1 & 1799 & 11,3 & $\mathrm{C} 20$ \\
\hline 350120 & Álvares Florence & 3989 & - & - & - & - & 3989 & 100,0 & E20 \\
\hline 350130 & Álvares Machado & 24357 & 6138 & 25,2 & 1023 & 4,2 & 17196 & 70,6 & D50 \\
\hline 350140 & Álvaro de Carvalho & 4545 & - & - & - & - & 4545 & 100,0 & E20 \\
\hline 350150 & Alvinlândia & 2969 & - & - & 151 & 5,1 & 2818 & 94,9 & E20 \\
\hline 350160 & Americana & 195436 & 164948 & 84,4 & 16612 & 8,5 & 13876 & 7,1 & A300 \\
\hline 350170 & Américo Brasiliense & 31960 & 6648 & 20,8 & 9141 & 28,6 & 16204 & 50,7 & D50 \\
\hline 350180 & Américo de Campos & 5594 & - & - & - & - & 5594 & 100,0 & E20 \\
\hline 350190 & Amparo & 64696 & 38171 & 59,0 & 7311 & 11,3 & 19215 & 29,7 & B100 \\
\hline 350200 & Analândia & 3832 & 2552 & 66,6 & - & - & 1280 & 33,4 & B20 \\
\hline 350210 & Andradina & 56390 & 19229 & 34,1 & 5639 & 10,0 & 31522 & 55,9 & D100 \\
\hline 350220 & Angatuba & 20226 & 6149 & 30,4 & 40 & 0,2 & 14037 & 69,4 & D50 \\
\hline 350230 & Anhembi & 4980 & 359 & 7,2 & 453 & 9,1 & 4173 & 83,8 & E20 \\
\hline 350240 & Anhumas & 3486 & 234 & 6,7 & 56 & 1,6 & 3200 & 91,8 & E20 \\
\hline 350250 & Aparecida & 35644 & 22278 & 62,5 & 927 & 2,6 & 12440 & 34,9 & B50 \\
\hline 350260 & Aparecida d'Oeste & 4861 & - & - & - & - & 4861 & 100,0 & E20 \\
\hline 350270 & Apiaí & 27438 & 6805 & 24,8 & 3512 & 12,8 & 17121 & 62,4 & D50 \\
\hline 350275 & Araçariguama & 13044 & 744 & 5,7 & 4539 & 34,8 & 7774 & 59,6 & D20 \\
\hline 350280 & Araçatuba & 176714 & 100904 & 57,1 & 22973 & 13,0 & 52837 & 29,9 & B300 \\
\hline 350290 & Araçoiaba da Serra & 22171 & 11751 & 53,0 & 1818 & 8,2 & 8602 & 38,8 & B50 \\
\hline 350300 & Aramina & 5075 & - & - & & - & 5075 & 100,0 & E20 \\
\hline 350310 & Arandu & 6265 & 63 & 1,0 & & - & 6196 & 98,9 & E20 \\
\hline 350315 & Arapeí & 2762 & - & - & & - & 2762 & 100,0 & E20 \\
\hline 350320 & Araraquara & 192859 & 144837 & 75,1 & 23722 & 12,3 & 24107 & 12,5 & A300 \\
\hline 350330 & Araras & 111673 & 58963 & 52,8 & 10274 & 9,2 & 42436 & 38,0 & B300 \\
\hline 350335 & ArcoOlris & 2247 & 22 & 1,0 & 27 & 1,2 & 2200 & 97,9 & E20 \\
\hline 350340 & Arealva & 7401 & 1132 & 15,3 & 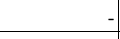 & - & 6269 & 84,7 & E20 \\
\hline 350350 & Areias & 3741 & - & - & - & - & 3741 & 100,0 & E20 \\
\hline 350360 & Areiópolis & 10432 & 459 & 4,4 & 1700 & 16,3 & 8273 & 79,3 & E20 \\
\hline 350370 & Ariranha & 8206 & 1469 & 17,9 & 41 & 0,5 & 6696 & 81,6 & E20 \\
\hline 350380 & Artur Nogueira & 39299 & 12576 & 32,0 & 12576 & 32,0 & 14108 & 35,9 & C50 \\
\hline 350390 & Arujá & 68815 & 27801 & 40,4 & 25806 & 37,5 & 15277 & 22,2 & $\mathrm{C} 100$ \\
\hline 350395 & Aspásia & 1816 & - & - & - & - & 1816 & 100,0 & E20 \\
\hline 350400 & Assis & 92357 & 57723 & 62,5 & 6188 & 6,7 & 28446 & 30,8 & B100 \\
\hline 350410 & Atibaia & 122450 & 60001 & 49,0 & 16163 & 13,2 & 46286 & 37,8 & $\mathrm{C} 300$ \\
\hline 350420 & Auriflama & 13846 & 3462 & 25,0 & - & -1 & 10385 & 75,0 & E20 \\
\hline 350430 & Avaí & 4578 & 18 & 0,4 & - & - & 4560 & 99,6 & E20 \\
\hline 350440 & Avanhandava & 9213 & - & - & - & - & 9213 & 100,0 & E20 \\
\hline 350450 & Avaré & 83338 & 41752 & 50,1 & 8917 & 10,7 & 32585 & 39,1 & B100 \\
\hline
\end{tabular}


Anexo 2 - Municípios classificados no Estrato D - Vulnerabilidade Social Intensa segundo proporção da população nos grupos IPVS e porte populacional, estado de São Paulo, média do triênio 2003 a 2005.

\begin{tabular}{|c|c|c|c|c|c|c|c|c|c|}
\hline IBGE & MUNICIPIO & POP. & IPVS $(1,2,3)$ & $\%$ & IPVS (4) & $\%$ & $\operatorname{IPVS}(5,6)$ & $\%$ & Status \\
\hline 350460 & Bady Bassitt & 14156 & 11608 & 82,0 & 991 & 7,0 & 1557 & 11,0 & $\mathrm{~A} 20$ \\
\hline 350470 & Balbinos & 1355 & & & & - & 1355 & 100,0 & E20 \\
\hline 350480 & Bálsamo & 7592 & 858 & 11,3 & - & - & 6734 & 88,7 & E20 \\
\hline 350490 & Bananal & 9997 & 3259 & 32,6 & - & & 6738 & 67,4 & D20 \\
\hline 350500 & Barao de Antonina & 2690 & - & 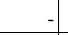 & - & - & 2690 & 100,0 & E20 \\
\hline 350510 & Barbosa & 6042 & - & - & & & 6042 & 100,0 & E20 \\
\hline 350520 & Bariri & 29868 & 9976 & 33,4 & 1673 & 5,6 & 18219 & 61,0 & D50 \\
\hline 350530 & Barra Bonita & 37564 & 18519 & 49,3 & 5447 & 14,5 & 13561 & 36,1 & C50 \\
\hline 350535 & Barra do Chapéu & 4812 & - & - & 467 & 9,7 & 4350 & 90,4 & E20 \\
\hline 350540 & Barra do Turvo & 8548 & 1470 & 17,2 & - & - & 7078 & 82,8 & E20 \\
\hline 350550 & Barretos & 107709 & 61071 & 56,7 & 14325 & 13,3 & 32313 & 30,0 & B300 \\
\hline 350560 & Barrinha & 26597 & 3404 & 12,8 & 4654 & 17,5 & 18512 & 69,6 & D50 \\
\hline 350570 & Barueri & 242890 & 63637 & 26,2 & 155935 & 64,2 & 23317 & 9,6 & $\mathrm{C} 300$ \\
\hline 350580 & Bastos & 21244 & 4546 & 21,4 & 3888 & 18,3 & 12831 & 60,4 & D50 \\
\hline 350590 & Batatais & 54241 & 23758 & 43,8 & 6997 & 12,9 & 23486 & 43,3 & $\mathrm{C} 100$ \\
\hline 350600 & Bauru & 340609 & 235361 & 69,1 & 53135 & 15,6 & 52454 & 15,4 & B500 \\
\hline 350610 & Bebedouro & 77965 & 28847 & 37,0 & 11149 & 14,3 & 37969 & 48,7 & $\mathrm{C} 100$ \\
\hline 350620 & Bento de Abreu & 2394 & - & - & 1321 & 55,2 & 1073 & 44,8 & $\mathrm{C} 20$ \\
\hline 350630 & Bernardino de Campos & 11020 & 1455 & 13,2 & - & - & 9565 & 86,8 & E20 \\
\hline 350635 & Bertioga & 38332 & 11576 & 30,2 & 21466 & 56,0 & 5290 & 13,8 & C50 \\
\hline 350640 & Bilac & 6367 & 1738 & 27,3 & - & - & 4629 & 72,7 & D20 \\
\hline 350650 & Birigui & 102865 & 46906 & 45,6 & 19236 & 18,7 & 36620 & 35,6 & $\mathrm{C} 300$ \\
\hline 350660 & Biritiba0Mirim & 27700 & 6953 & 25,1 & - & - & 20747 & 74,9 & D50 \\
\hline 350670 & Boa Esperança do Sul & 13447 & 699 & 5,2 & - & - & 12748 & 94,8 & E20 \\
\hline 350680 & Bocaina & 10417 & 3136 & 30,1 & 1354 & 13,0 & 5938 & 57,0 & D20 \\
\hline 350690 & Bofete & 8109 & 1273 & 15,7 & 24 & 0,3 & 6803 & 83,9 & E20 \\
\hline 350700 & Boituva & 39383 & 18431 & 46,8 & 1063 & 2,7 & 19888 & 50,5 & D50 \\
\hline 350710 & Bom Jesus dos Perdoes & 14857 & 3818 & 25,7 & 2258 & 15,2 & 8780 & 59,1 & D20 \\
\hline 350715 & Bom Sucesso de Itararé & 3635 & & - & - & 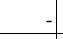 & 3635 & 100,0 & E20 \\
\hline 350720 & Borá & 810 & - & - & - & 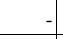 & 810 & 100,0 & E20 \\
\hline 350730 & Boracéia & 3865 & & - & - & - & 3865 & 100,0 & E20 \\
\hline 350740 & Borborema & 13676 & 3104 & 22,7 & 848 & 6,2 & 9724 & 71,1 & D20 \\
\hline 350745 & Borebi & 2170 & & - & - & - & 2170 & 100,0 & E20 \\
\hline 350750 & Botucatu & 116142 & 75957 & 65,4 & 17073 & 14,7 & 23112 & 19,9 & В300 \\
\hline 350760 & Bragança Paulista & 136266 & 68814 & 50,5 & 15534 & 11,4 & 51917 & 38,1 & B300 \\
\hline 350770 & Braúna & 4438 & & - & - & . & 4438 & 100,0 & E20 \\
\hline 350775 & Brejo Alegre & 2455 & - & - & - & - & 2455 & 100,0 & E20 \\
\hline 350780 & Brodósqui & 18635 & 8348 & 44,8 & 3168 & 17,0 & 7119 & 38,2 & $\mathrm{C} 20$ \\
\hline 350790 & Brotas & 20887 & 4950 & 23,7 & 1796 & 8,6 & 14140 & 67,7 & D50 \\
\hline 350800 & Buri & 19106 & 2484 & 13,0 & - & - & 16622 & 87,0 & E20 \\
\hline 350810 & Buritama & 14342 & 2926 & 20,4 & 301 & 2,1 & 11115 & 77,5 & E20 \\
\hline 350820 & Buritizal & 3617 & 991 & 27,4 & 333 & 9,2 & 2293 & 63,4 & D20 \\
\hline 350830 & Cabrália Paulista & 5011 & & & -1 & - & 5011 & 100,0 & E20 \\
\hline 350840 & Cabreúva & 39481 & 11528 & 29,2 & 15319 & 38,8 & 12594 & 31,9 & $\mathrm{C} 50$ \\
\hline 350850 & Caçapava & 80629 & 51603 & 64,0 & 11288 & 14,0 & 17658 & 21,9 & B100 \\
\hline 350860 & Cachoeira Paulista & 28988 & 16494 & 56,9 & 1275 & 4,4 & 11247 & 38,8 & B50 \\
\hline 350870 & Caconde & 18867 & 3226 & 17,1 & & & 15641 & 82,9 & E20 \\
\hline 350880 & Cafelândia & 16033 & 6173 & 38,5 & - & & 9860 & 61,5 & D20 \\
\hline 350890 & Caiabu & 4178 & & -1 & - & - & 4178 & 100,0 & E20 \\
\hline 350900 & Caieiras & 85582 & 40823 & 47,7 & 39111 & 45,7 & 5648 & 6,6 & $\mathrm{C} 100$ \\
\hline 350910 & Caiuá & 4572 & - & - & - & - & 4572 & 100,0 & E20 \\
\hline 350920 & Cajamar & 58366 & 8813 & 15,1 & 33327 & 57,1 & 16226 & 27,8 & C100 \\
\hline
\end{tabular}


Anexo 2 - Municípios classificados no Estrato D - Vulnerabilidade Social Intensa segundo proporção da população nos grupos IPVS e porte populacional, estado de São Paulo, média do triênio 2003 a 2005.

\begin{tabular}{|c|c|c|c|c|c|c|c|c|c|}
\hline IBGE & MUNICIPIO & POP. & IPVS $(1,2,3)$ & $\%$ & IPVS (4) & $\%$ & IPVS $(5,6)$ & $\%$ & Status \\
\hline 350925 & Cajati & 31721 & 6471 & 20,4 & 2252 & 7,1 & 22998 & 72,5 & D50 \\
\hline 350930 & Cajobi & 9361 & & - & & - & 9361 & 100,0 & E20 \\
\hline 350940 & Cajuru & 21771 & 4420 & 20,3 & 958 & 4,4 & 16394 & 75,3 & E50 \\
\hline 350945 & Campina do Monte Alegre & 5791 & 892 & 15,4 & & - & 4905 & 84,7 & E20 \\
\hline 350950 & Campinas & 1023802 & 714614 & 69,8 & 142308 & 13,9 & 166880 & 16,3 & B10000 \\
\hline 350960 & Campo Limpo Paulista & 71914 & 34734 & 48,3 & 21862 & 30,4 & 15390 & 21,4 & C100 \\
\hline 350970 & Campos do Jordao & 47430 & 16079 & 33,9 & 11905 & 25,1 & 19446 & 41,0 & $\mathrm{C} 50$ \\
\hline 350980 & Campos Novos Paulista & 4255 & & - & & - & 4255 & 100,0 & E20 \\
\hline 350990 & Cananéia & 13444 & 2931 & 21,8 & - & - & 10500 & 78,1 & E20 \\
\hline 350995 & Canas & 3924 & - & - & - & - & 3924 & 100,0 & E20 \\
\hline 351000 & Cândido Mota & 30993 & 10600 & 34,2 & 837 & 2,7 & 19557 & 63,1 & D50 \\
\hline 351010 & Cândido Rodrigues & 2740 & - & - & - & - & 2740 & 100,0 & E20 \\
\hline 351015 & Canitar & 3947 & - & - & - & - & 3947 & 100,0 & E20 \\
\hline 351020 & Capao Bonito & 46865 & 9467 & 20,2 & 1453 & 3,1 & 35945 & 76,7 & E50 \\
\hline 351030 & Capela do Alto & 15799 & 1643 & 10,4 & 3097 & 19,6 & 11075 & 70,1 & D20 \\
\hline 351040 & Capivari & 44704 & 21950 & 49,1 & 6437 & 14,4 & 16272 & 36,4 & C50 \\
\hline 351050 & Caraguatatuba & 90555 & 43919 & 48,5 & 15575 & 17,2 & 31151 & 34,4 & $\mathrm{C} 100$ \\
\hline 351060 & Carapicuíba & 371814 & 136828 & 36,8 & 176612 & 47,5 & 58003 & 15,6 & C500 \\
\hline 351070 & Cardoso & 11302 & 995 & 8,8 & & - & 10307 & 91,2 & E20 \\
\hline 351080 & Casa Branca & 27466 & 15024 & 54,7 & 2582 & 9,4 & 9833 & 35,8 & B50 \\
\hline 351090 & Cássia dos Coqueiros & 2940 & 538 & 18,3 & - & - & 2402 & 81,7 & E20 \\
\hline 351100 & Castilho & 15100 & 951 & 6,3 & - & - & 14149 & 93,7 & E20 \\
\hline 351110 & Catanduva & 112577 & 59778 & 53,1 & 10470 & 9,3 & 42329 & 37,6 & B300 \\
\hline 351120 & Catiguá & 6687 & - & - & - & - & 6687 & 100,0 & E20 \\
\hline 351130 & Cedral & 7145 & 1729 & 24,2 & - & - & 5416 & 75,8 & E20 \\
\hline 351140 & Cerqueira César & 16167 & 4834 & 29,9 & 1261 & 7,8 & 10088 & 62,4 & D20 \\
\hline 351150 & Cerquilho & 33734 & 22501 & 66,7 & 8197 & 24,3 & 3036 & 9,0 & B50 \\
\hline 351160 & Cesário Lange & 13657 & 2991 & 21,9 & - & - & 10666 & 78,1 & E20 \\
\hline 351170 & Charqueada & 14065 & 4979 & 35,4 & 1125 & 8,0 & 7975 & 56,7 & D20 \\
\hline 355720 & Chavantes & 12406 & 4665 & 37,6 & 1216 & 9,8 & 6526 & 52,6 & D20 \\
\hline 351190 & Clementina & 5636 & & - & & - & 5636 & 100,0 & E20 \\
\hline 351200 & Colina & 17001 & 1887 & 11,1 & 2380 & 14,0 & 12734 & 74,9 & D20 \\
\hline 351210 & Colômbia & 6255 & - & - & 519 & 8,3 & 5736 & 91,7 & E20 \\
\hline 351220 & Conchal & 24197 & 4162 & 17,2 & 1815 & 7,5 & 18196 & 75,2 & E50 \\
\hline 351230 & Conchas & 16250 & 7686 & 47,3 & 991 & 6,1 & 7573 & 46,6 & $\mathrm{C} 20$ \\
\hline 351240 & Cordeirópolis & 19491 & 9492 & 48,7 & 6237 & 32,0 & 3781 & 19,4 & $\mathrm{C} 20$ \\
\hline 351250 & Coroados & 4587 & - & - & 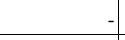 & - & 4587 & 100,0 & E20 \\
\hline 351260 & Coronel Macedo & 5518 & - & - & & - & 5518 & 100,0 & E20 \\
\hline 351270 & Corumbataí & 4078 & 1252 & 30,7 & - & - & 2826 & 69,3 & D20 \\
\hline 351280 & Cosmópolis & 48084 & 27696 & 57,6 & 8559 & 17,8 & 11829 & 24,6 & B50 \\
\hline 351290 & Cosmorama & 7167 & & - & - & - & 7167 & 100,0 & E20 \\
\hline 351300 & Cotia & 167540 & 67854 & 40,5 & 68524 & 40,9 & 31162 & 18,6 & $\mathrm{C} 300$ \\
\hline 351310 & Cravinhos & 31023 & 10424 & 33,6 & 4436 & 14,3 & 16163 & 52,1 & D50 \\
\hline 351320 & Cristais Paulista & 6995 & & - & - & - & 6995 & 100,0 & E20 \\
\hline 351330 & Cruzália & 2587 & & - & 717 & 27,7 & 1870 & 72,3 & D20 \\
\hline 351340 & Cruzeiro & 75658 & 48497 & 64,1 & 7717 & 10,2 & 19520 & 25,8 & B100 \\
\hline 351350 & Cubatao & 115978 & 46159 & 39,8 & 20876 & 18,0 & 48943 & 42,2 & C300 \\
\hline 351360 & Cunha & 22925 & 1949 & 8,5 & -1 & - & 20976 & 91,5 & E50 \\
\hline 351370 & Descalvado & 30339 & 12651 & 41,7 & 1396 & 4,6 & 16262 & 53,6 & D50 \\
\hline 351380 & Diadema & 380191 & 126223 & 33,2 & 190476 & 50,1 & 63492 & 16,7 & C500 \\
\hline 351385 & Dirce Reis & 1498 & - & - & - & - & 1498 & 100,0 & E20 \\
\hline 351390 & Divinolândia & 12107 & 1525 & 12,6 & 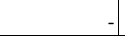 & - & 10582 & 87,4 & E20 \\
\hline
\end{tabular}


Anexo 2 - Municípios classificados no Estrato D - Vulnerabilidade Social Intensa segundo proporção da população nos grupos IPVS e porte populacional, estado de São Paulo, média do triênio 2003 a 2005.

\begin{tabular}{|c|c|c|c|c|c|c|c|c|c|}
\hline IBGE & MUNICIPIO & POP. & IPVS $(1,2,3)$ & $\%$ & IPVS (4) & $\%$ & $\operatorname{IPVS}(5,6)$ & $\%$ & Status \\
\hline 351400 & Dobrada & 7048 & 951 & 13,5 & 289 & 4,1 & 5808 & 82,4 & E20 \\
\hline 351410 & Dois Córregos & 24169 & 8338 & 34,5 & 1837 & 7,6 & 13994 & 57,9 & D50 \\
\hline 351420 & Dolcinópolis & 2175 & - & - & - & - & 2175 & 100,0 & E20 \\
\hline 351430 & Dourado & 8993 & 1547 & 17,2 & 234 & 2,6 & 7212 & 80,2 & E20 \\
\hline 351440 & Dracena & 40861 & 13076 & 32,0 & 1920 & 4,7 & 25824 & 63,2 & D50 \\
\hline 351450 & Duartina & 12732 & 1693 & 13,3 & & - & 11039 & 86,7 & E20 \\
\hline 351460 & Dumont & 6899 & 2842 & 41,2 & 524 & 7,6 & 3532 & 51,2 & $\mathrm{D} 20$ \\
\hline 351470 & Echapora & 7054 & 825 & 11,7 & 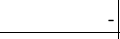 & - & 6229 & 88,3 & E20 \\
\hline 351480 & Eldorado & 14587 & 4026 & 27,6 & 15 & 0,1 & 10561 & 72,4 & $\mathrm{D} 20$ \\
\hline 351490 & Elias Fausto & 14897 & 3099 & 20,8 & 879 & 5,9 & 10920 & 73,3 & $\mathrm{D} 20$ \\
\hline 351492 & Elisiário & 2588 & - & - & - & - & 2588 & 100,0 & E20 \\
\hline 351495 & Embaúba & 2513 & - & - & - & - & 2513 & 100,0 & E20 \\
\hline 351500 & Embu & 230746 & 42457 & 18,4 & 125064 & 54,2 & 63455 & 27,5 & $\mathrm{C} 300$ \\
\hline 351510 & Embu0Guaçu & 66133 & 20700 & 31,3 & 16666 & 25,2 & 28768 & 43,5 & C100 \\
\hline 351512 & Emilianópolis & 2893 & - & - & - & - & 2893 & 100,0 & E20 \\
\hline 351515 & Engenheiro Coelho & 11611 & 3983 & 34,3 & 1103 & 9,5 & 6514 & 56,1 & D20 \\
\hline 351518 & Espírito Santo do Pinhal & 41954 & 18292 & 43,6 & 3776 & 9,0 & 19844 & 47,3 & C50 \\
\hline 351519 & Espírito Santo do Turvo & 3989 & - & - & 1025 & 25,7 & 2964 & 74,3 & D20 \\
\hline 355730 & Estiva Gerbi & 9830 & 3195 & 32,5 & 1828 & 18,6 & 4807 & 48,9 & $\mathrm{C} 20$ \\
\hline 351530 & Estrela do Norte & 2557 & - & - & - & - & 2557 & 100,0 & E20 \\
\hline 351520 & Estrela d'Oeste & 8150 & 1703 & 20,9 & - & - & 6447 & 79,1 & E20 \\
\hline 351535 & Euclides da Cunha Paulist & 10506 & - & - & 725 & 6,9 & 9781 & 93,1 & E20 \\
\hline 351540 & Fartura & 15314 & 3629 & 23,7 & - & - & 11685 & 76,3 & E20 \\
\hline 351560 & Fernando Prestes & 5549 & 977 & 17,6 & - & - & 4572 & 82,4 & E20 \\
\hline 351550 & Fernandópolis & 64104 & 26731 & 41,7 & 5064 & 7,9 & 32308 & 50,4 & D100 \\
\hline 351565 & Fernao & 1316 & 428 & 32,5 & - & - & 888 & 67,5 & $\mathrm{D} 20$ \\
\hline 351570 & Ferraz de Vasconcelos & 163018 & 41733 & 25,6 & 69772 & 42,8 & 51351 & 31,5 & С 300 \\
\hline 351580 & Flora Rica & 2087 & - & - & - & - & 2087 & 100,0 & E20 \\
\hline 351590 & Floreal & 3078 & - & - & - & - & 3078 & 100,0 & E20 \\
\hline 351600 & Flórida Paulista & 10478 & 608 & 5,8 & - & - & 9870 & 94,2 & E20 \\
\hline 351610 & Florínia & 3181 & & - & 29 & 0,9 & 3152 & 99,1 & E20 \\
\hline 351620 & Franca & 312142 & 176985 & 56,7 & 66174 & 21,2 & 68983 & 22,1 & B500 \\
\hline 351630 & Francisco Morato & 156007 & 9984 & 6,4 & 30889 & 19,8 & 114977 & 73,7 & D300 \\
\hline 351640 & Franco da Rocha & 118211 & 39246 & 33,2 & 42083 & 35,6 & 37000 & 31,3 & С 300 \\
\hline 351650 & Gabriel Monteiro & 2839 & - & - & & - & 2839 & 100,0 & E20 \\
\hline 351660 & Gália & 7427 & 431 & 5,8 & & - & 6989 & 94,1 & E20 \\
\hline 351670 & Garça & 43909 & 14402 & 32,8 & 4654 & 10,6 & 24896 & 56,7 & D50 \\
\hline 351680 & Gastao Vidigal & 3475 & - & - & & - & 3475 & 100,0 & E20 \\
\hline 351685 & Gaviao Peixoto & 4084 & - & - & - & - & 4084 & 100,0 & E20 \\
\hline 351690 & General Salgado & 11023 & 1488 & 13,5 & 794 & 7,2 & 8741 & 79,3 & E20 \\
\hline 351700 & Getulina & 10481 & 1038 & 9,9 & - & - & 9443 & 90,1 & E20 \\
\hline 351710 & Glicério & 4514 & 939 & 20,8 & - & - & 3575 & 79,2 & E20 \\
\hline 351720 & Guaiçara & 10483 & 2411 & 23,0 & 1782 & 17,0 & 6290 & 60,0 & D20 \\
\hline 351730 & Guaimbê & 5238 & & - & & - & 5238 & 100,0 & E20 \\
\hline 351740 & Guaíra & 36191 & 12377 & 34,2 & 6406 & 17,7 & 17444 & 48,2 & $\mathrm{C} 50$ \\
\hline 351750 & Guapiaçu & 15614 & 3950 & 25,3 & 640 & 4,1 & 11023 & 70,6 & $\mathrm{D} 20$ \\
\hline 351760 & Guapiara & 20371 & 998 & 4,9 & & - & 19373 & 95,1 & E50 \\
\hline 351770 & Guará & 20057 & 1344 & 6,7 & 1544 & 7,7 & 17169 & 85,6 & E50 \\
\hline 351780 & Guaraçaí & 9165 & 935 & 10,2 & 715 & 7,8 & 7515 & 82,0 & E20 \\
\hline 351790 & Guaraci & 9308 & 921 & 9,9 & - & - & 8387 & 90,1 & E20 \\
\hline 351800 & Guarani d'Oeste & 2083 & - & - & - & - & 2083 & 100,0 & E20 \\
\hline 351810 & Guaranta & 6673 & - & - & - & - & 6673 & 100,0 & E20 \\
\hline
\end{tabular}


Anexo 2 - Municípios classificados no Estrato D - Vulnerabilidade Social Intensa segundo proporção da população nos grupos IPVS e porte populacional, estado de São Paulo, média do triênio 2003 a 2005.

\begin{tabular}{|c|c|c|c|c|c|c|c|c|c|}
\hline IBGE & MUNICIPIO & POP. & IPVS $(1,2,3)$ & $\%$ & IPVS (4) & $\%$ & IPVS $(5,6)$ & $\%$ & Status \\
\hline 351820 & Guararapes & 29806 & 10194 & 34,2 & & & 19612 & 65,8 & D50 \\
\hline 351830 & Guararema & 23666 & 9727 & 41,1 & 450 & 1,9 & 13513 & 57,1 & D50 \\
\hline 351840 & Guaratinguetá & 109532 & 66486 & 60,7 & 13363 & 12,2 & 29793 & 27,2 & B300 \\
\hline 351850 & Guareí & 10969 & 867 & 7,9 & 1788 & 16,3 & 8315 & 75,8 & E20 \\
\hline 351860 & Guariba & 32056 & 4648 & 14,5 & - & - & 27408 & 85,5 & E50 \\
\hline 351870 & Guarujá & 289202 & 107005 & 37,0 & 48875 & 16,9 & 133611 & 46,2 & C300 \\
\hline 351880 & Guarulhos & 1199951 & 489580 & 40,8 & 532778 & 44,4 & 178793 & 14,9 & $\mathrm{C} 10000$ \\
\hline 351885 & Guatapará & 6627 & 1385 & 20,9 & 543 & 8,2 & 4699 & 70,9 & D20 \\
\hline 351890 & Guzolândia & 3956 & - & - & -1 & - & 3956 & 100,0 & E20 \\
\hline 351900 & Herculândia & 8419 & 724 & 8,6 & 1027 & 12,2 & 6676 & 79,3 & E20 \\
\hline 351905 & Holambra & 8009 & 3172 & 39,6 & 2299 & 28,7 & 2531 & 31,6 & $\mathrm{C} 20$ \\
\hline 351907 & Hortolândia & 182302 & 76020 & 41,7 & 78208 & 42,9 & 28075 & 15,4 & C300 \\
\hline 351910 & lacanga & 8600 & 791 & 9,2 & -1 & - & 7809 & 90,8 & E20 \\
\hline 351920 & lacri & 6669 & 800 & 12,0 & - & - & 5869 & 88,0 & E20 \\
\hline 351925 & Iaras & 3455 & 639 & 18,5 & 878 & 25,4 & 1935 & 56,0 & D20 \\
\hline 351930 & Ibaté & 29872 & 8932 & 29,9 & 4212 & 14,1 & 16728 & 56,0 & D50 \\
\hline 351940 & Ibirá & 9773 & 2590 & 26,5 & - & - & 7183 & 73,5 & D20 \\
\hline 351950 & Ibirarema & 5778 & 711 & 12,3 & - & - & 5067 & 87,7 & E20 \\
\hline 351960 & Ibitinga & 50364 & 13800 & 27,4 & 8612 & 17,1 & 27952 & 55,5 & D100 \\
\hline 351970 & Ibiúna & 71173 & 7900 & 11,1 & 6121 & 8,6 & 57081 & 80,2 & E50 \\
\hline 351980 & Icém & 7072 & 1450 & 20,5 & 594 & 8,4 & 5021 & 71,0 & D20 \\
\hline 351990 & lepê & 7088 & 489 & 6,9 & - & - & 6599 & 93,1 & E20 \\
\hline 352000 & Igaraçu do Tietê & 23392 & 1661 & 7,1 & 4866 & 20,8 & 16866 & 72,1 & D50 \\
\hline 352010 & Igarapava & 27534 & 6801 & 24,7 & 3772 & 13,7 & 16961 & 61,6 & D50 \\
\hline 352020 & Igaratá & 9186 & 1470 & 16,0 & 542 & 5,9 & 7174 & 78,1 & E20 \\
\hline 352030 & Iguape & 28245 & 4773 & 16,9 & 2175 & 7,7 & 21297 & 75,4 & E50 \\
\hline 352042 & Ilha Comprida & 8468 & 6876 & 81,2 & 500 & 5,9 & 1092 & 12,9 & $\mathrm{~A} 20$ \\
\hline 352044 & Ilha Solteira & 25016 & 18162 & 72,6 & 3652 & 14,6 & 3177 & 12,7 & B50 \\
\hline 352040 & Ilhabela & 24096 & 9759 & 40,5 & 7373 & 30,6 & 6940 & 28,8 & $\mathrm{C} 50$ \\
\hline 352050 & Indaiatuba & 167644 & 86001 & 51,3 & 62531 & 37,3 & 19111 & 11,4 & B300 \\
\hline 352060 & Indiana & 5070 & 867 & 17,1 & - & - & 4203 & 82,9 & E20 \\
\hline 352070 & Indiapora & 3742 & - & - & - & - & 3742 & 100,0 & E20 \\
\hline 352080 & Inúbia Paulista & 3307 & 162 & 4,9 & - & - & 3145 & 95,1 & E20 \\
\hline 352090 & Ipauçu & 13064 & 2090 & 16,0 & & - & 10974 & 84,0 & E20 \\
\hline 352100 & Iperó & 21872 & 7830 & 35,8 & 6365 & 29,1 & 7677 & 35,1 & $\mathrm{C} 50$ \\
\hline 352110 & Ipeúna & 5075 & 137 & 2,7 & 2730 & 53,8 & 2208 & 43,5 & $\mathrm{C} 20$ \\
\hline 352115 & Ipiguá & 3985 & - & - & - & - & 3985 & 100,0 & E20 \\
\hline 352120 & Iporanga & 4540 & 617 & 13,6 & - & - & 3923 & 86,4 & E20 \\
\hline 352130 & Ipua & 12546 & 2948 & 23,5 & 514 & 4,1 & 9083 & 72,4 & D20 \\
\hline 352140 & Iracemápolis & 17255 & 8455 & 49,0 & 3416 & 19,8 & 5401 & 31,3 & $\mathrm{C} 20$ \\
\hline 352150 & Irapua & 6912 & 1037 & 15,0 & - & - & 5875 & 85,0 & E20 \\
\hline 352160 & Irapuru & 7102 & - & - & 781 & 11,0 & 6321 & 89,0 & E20 \\
\hline 352170 & Itaberá & 19364 & 2362 & 12,2 & 1162 & 6,0 & 15840 & 81,8 & E20 \\
\hline 352180 & Itaí & 22475 & 3034 & 13,5 & 1843 & 8,2 & 17598 & 78,3 & E50 \\
\hline 352190 & Itajobi & 14700 & 3058 & 20,8 & -1 & - & 11642 & 79,2 & E20 \\
\hline 352200 & Itaju & 2762 & - & - & - & - & 2762 & 100,0 & E20 \\
\hline 352210 & Itanhaém & 83574 & 35937 & 43,0 & 7940 & 9,5 & 39781 & 47,6 & $\mathrm{C} 100$ \\
\hline 352215 & Itaóca & 3002 & & - & & - & 3002 & 100,0 & E20 \\
\hline 352220 & Itapecerica da Serra & 149358 & 29872 & 20,0 & 68107 & 45,6 & 51529 & 34,5 & $\mathrm{C} 300$ \\
\hline 352230 & Itapetininga & 136157 & 73252 & 53,8 & 23691 & 17,4 & 39213 & 28,8 & B300 \\
\hline 352240 & Itapeva & 87021 & 27499 & 31,6 & 8006 & 9,2 & 51603 & 59,3 & D100 \\
\hline 352250 & Itapevi & 186757 & 37165 & 19,9 & 77878 & 41,7 & 71715 & 38,4 & C300 \\
\hline
\end{tabular}


Anexo 2 - Municípios classificados no Estrato D - Vulnerabilidade Social Intensa segundo proporção da população nos grupos IPVS e porte populacional, estado de São Paulo, média do triênio 2003 a 2005.

\begin{tabular}{|c|c|c|c|c|c|c|c|c|c|}
\hline IBGE & MUNICIPIO & POP. & IPVS $(1,2,3)$ & $\%$ & IPVS (4) & $\%$ & IPVS $(5,6)$ & $\%$ & Status \\
\hline 352260 & Itapira & 66411 & 24174 & 36,4 & 5911 & 8,9 & 36393 & 54,8 & D100 \\
\hline 352265 & Itapirapua Paulista & 3717 & & - & & - & 3717 & 100,0 & E20 \\
\hline 352270 & Itápolis & 39849 & 10600 & 26,6 & 1156 & 2,9 & 28094 & 70,5 & D50 \\
\hline 352280 & Itaporanga & 14330 & 1046 & 7,3 & & - & 13284 & 92,7 & E20 \\
\hline 352290 & Itapuí & 10959 & 318 & 2,9 & 2323 & 21,2 & 8318 & 75,9 & E20 \\
\hline 352300 & Itapura & 3877 & & - & & & 3877 & 100,0 & E20 \\
\hline 352310 & Itaquaquecetuba & 321176 & 53636 & 16,7 & 123653 & 38,5 & 143887 & 44,8 & C500 \\
\hline 352320 & Itararé & 48659 & 13868 & 28,5 & 3211 & 6,6 & 31580 & 64,9 & D50 \\
\hline 352330 & Itariri & 14508 & 3351 & 23,1 & 464 & 3,2 & 10692 & 73,7 & D20 \\
\hline 352340 & Itatiba & 89930 & 51260 & 57,0 & 17986 & 20,0 & 20594 & 22,9 & B100 \\
\hline 352350 & Itatinga & 16194 & 2154 & 13,3 & 1393 & 8,6 & 12648 & 78,1 & E20 \\
\hline 352360 & Itirapina & 14122 & 6736 & 47,7 & 1087 & 7,7 & 6298 & 44,6 & $\mathrm{C} 20$ \\
\hline 352370 & Itirapua & 5575 & 736 & 13,2 & -1 & - & 4839 & 86,8 & E20 \\
\hline 352380 & Itobi & 7771 & - & - & 420 & 5,4 & 7351 & 94,6 & E20 \\
\hline 352390 & Itu & 147897 & 67441 & 45,6 & 46588 & 31,5 & 33868 & 22,9 & $\mathrm{C} 300$ \\
\hline 352400 & Itupeva & 29751 & 8955 & 30,1 & 12257 & 41,2 & 8509 & 28,6 & C50 \\
\hline 352410 & Ituverava & 37727 & 13808 & 36,6 & 3471 & 9,2 & 20448 & 54,2 & D50 \\
\hline 352420 & Jaborandi & 6465 & - & - & - & - & 6465 & 100,0 & E20 \\
\hline 352430 & Jaboticabal & 71104 & 38325 & 53,9 & 5973 & 8,4 & 26806 & 37,7 & B100 \\
\hline 352440 & Jacareí & 203538 & 131486 & 64,6 & 33991 & 16,7 & 38062 & 18,7 & B300 \\
\hline 352450 & Jaci & 4510 & - & - & - & - & 4510 & 100,0 & E20 \\
\hline 352460 & Jacupiranga & 18206 & 7009 & 38,5 & - & - & 11197 & 61,5 & D20 \\
\hline 352470 & Jaguariúna & 32728 & 18066 & 55,2 & 7364 & 22,5 & 7298 & 22,3 & B50 \\
\hline 352480 & Jales & 48339 & 19191 & 39,7 & 3915 & 8,1 & 25281 & 52,3 & D50 \\
\hline 352490 & Jambeiro & 4306 & 1171 & 27,2 & - & - & 3135 & 72,8 & D20 \\
\hline 352500 & Jandira & 104809 & 27984 & 26,7 & 73052 & 69,7 & 3773 & 3,6 & C300 \\
\hline 352510 & Jardinópolis & 33680 & 12361 & 36,7 & 6467 & 19,2 & 14853 & 44,1 & $\mathrm{C} 50$ \\
\hline 352520 & Jarinu & 19795 & 5384 & 27,2 & 218 & 1,1 & 14173 & 71,6 & D20 \\
\hline 352530 & Jaú & 120139 & 56465 & 47,0 & 9611 & 8,0 & 54063 & 45,0 & $\mathrm{C} 300$ \\
\hline 352540 & Jeriquara & 3288 & - & - & - & - & 3288 & 100,0 & E20 \\
\hline 352550 & Joanópolis & 11402 & 1505 & 13,2 & - & - & 9897 & 86,8 & E20 \\
\hline 352560 & Joao Ramalho & 4191 & - & - & 197 & 4,7 & 3994 & 95,3 & E20 \\
\hline 352570 & José Bonifácio & 30978 & 9324 & 30,1 & 3965 & 12,8 & 17657 & 57,0 & D50 \\
\hline 352580 & Júlio Mesquita & 4311 & - & - & 78 & 1,8 & 4233 & 98,2 & E20 \\
\hline 352585 & Jumirim & 2460 & 2460 & 100,0 & - & - & - & 0,0 & $\mathrm{~A} 20$ \\
\hline 352590 & Jundiaí & 338641 & 261769 & 77,3 & 30139 & 8,9 & 47071 & 13,9 & A500 \\
\hline 352600 & Junqueirópolis & 16692 & 801 & 4,8 & 618 & 3,7 & 15290 & 91,6 & E20 \\
\hline 352610 & Juquiá & 22107 & 4488 & 20,3 & 2211 & 10,0 & 15409 & 69,7 & D50 \\
\hline 352620 & Juquitiba & 29359 & 5490 & 18,7 & 3699 & 12,6 & 20140 & 68,6 & D50 \\
\hline 352630 & Lagoinha & 5101 & & - & - & - & 5101 & 100,0 & E20 \\
\hline 352640 & Laranjal Paulista & 23484 & 13362 & 56,9 & - & - & 10122 & 43,1 & B50 \\
\hline 352650 & Lavínia & 4994 & - & - & 639 & 12,8 & 4355 & 87,2 & E20 \\
\hline 352660 & Lavrinhas & 6604 & 621 & 9,4 & 1829 & 27,7 & 4154 & 62,9 & D20 \\
\hline 352670 & Leme & 86359 & 26167 & 30,3 & 2677 & 3,1 & 57515 & 66,6 & D100 \\
\hline 352680 & Lençóis Paulista & 59598 & 23839 & 40,0 & 10012 & 16,8 & 25687 & 43,1 & $\mathrm{C} 100$ \\
\hline 352690 & Limeira & 267481 & 156209 & 58,4 & 54834 & 20,5 & 56438 & 21,1 & B300 \\
\hline 352700 & Lindóia & 5896 & 2240 & 38,0 & - & -1 & 3656 & 62,0 & D20 \\
\hline 352710 & Lins & 69232 & 36208 & 52,3 & 6508 & 9,4 & 26516 & 38,3 & B100 \\
\hline 352720 & Lorena & 81456 & 59056 & 72,5 & 2525 & 3,1 & 19957 & 24,5 & B100 \\
\hline 352725 & Lourdes & 2160 & - & - & - & - & 2160 & 100,0 & E20 \\
\hline 352730 & Louveira & 27317 & 9315 & 34,1 & 10845 & 39,7 & 7157 & 26,2 & C50 \\
\hline 352740 & Lucélia & 18536 & 4597 & 24,8 & 982 & 5,3 & 12957 & 69,9 & D20 \\
\hline
\end{tabular}


Anexo 2 - Municípios classificados no Estrato D - Vulnerabilidade Social Intensa segundo proporção da população nos grupos IPVS e porte populacional, estado de São Paulo, média do triênio 2003 a 2005.

\begin{tabular}{|c|c|c|c|c|c|c|c|c|c|}
\hline IBGE & MUNICIPIO & POP. & IPVS $(1,2,3)$ & $\%$ & IPVS (4) & $\%$ & IPVS $(5,6)$ & $\%$ & Status \\
\hline 352750 & Lucianópolis & 2066 & & & & & 2066 & 100,0 & E20 \\
\hline 352760 & Luís Antônio & 7750 & 3503 & 45,2 & 1806 & 23,3 & 2441 & 31,5 & $\mathrm{C} 20$ \\
\hline 352770 & Luiziânia & 4329 & - & - & - & - & 4329 & 100,0 & E20 \\
\hline 352780 & Lupércio & 4295 & - & - & - & - & 4295 & 100,0 & E20 \\
\hline 352790 & Lutécia & 3012 & - & - & - & - & 3012 & 100,0 & E20 \\
\hline 352800 & Macatuba & 16772 & 5132 & 30,6 & 2566 & 15,3 & 9074 & 54,1 & $\mathrm{D} 20$ \\
\hline 352810 & Macaubal & 7385 & 923 & 12,5 & - & - & 6462 & 87,5 & E20 \\
\hline 352820 & Macedônia & 3674 & - & - & & - & 3674 & 100,0 & E20 \\
\hline 352830 & Magda & 3305 & 106 & 3,2 & - & - & 3199 & 96,8 & E20 \\
\hline 352840 & Mairinque & 44676 & 15369 & 34,4 & 16932 & 37,9 & 12375 & 27,7 & $\mathrm{C} 50$ \\
\hline 352850 & Mairipora & 69122 & 30345 & 43,9 & 13686 & 19,8 & 25091 & 36,3 & $\mathrm{C} 100$ \\
\hline 352860 & Manduri & 8715 & 3355 & 38,5 & - & - & 5368 & 61,6 & $\mathrm{D} 20$ \\
\hline 352870 & Marabá Paulista & 3790 & - & - & - & - & 3790 & 100,0 & E20 \\
\hline 352880 & Maracaí & 13243 & 4145 & 31,3 & 1695 & 12,8 & 7403 & 55,9 & $\mathrm{D} 20$ \\
\hline 352885 & Marapoama & 2418 & & - & - & - & 2418 & 100,0 & E20 \\
\hline 352890 & Mariápolis & 3632 & - & - & -1 & - & 3632 & 100,0 & E20 \\
\hline 352900 & Marília & 213509 & 122127 & 57,2 & 26902 & 12,6 & 64480 & 30,2 & B300 \\
\hline 352910 & Marinópolis & 2244 & - & - & - & - & 2244 & 100,0 & E20 \\
\hline 352920 & Martinópolis & 23540 & 5014 & 21,3 & 1059 & 4,5 & 17443 & 74,1 & D50 \\
\hline 352930 & Matao & 75390 & 37921 & 50,3 & 7388 & 9,8 & 30081 & 39,9 & B100 \\
\hline 352940 & Mauá & 393941 & 185940 & 47,2 & 141031 & 35,8 & 66970 & 17,0 & C500 \\
\hline 352950 & Mendonça & 3875 & - & - & - & - & 3875 & 100,0 & E20 \\
\hline 352960 & Meridiano & 4133 & - & - & - & - & 4133 & 100,0 & E20 \\
\hline 352965 & Mesópolis & 1895 & - & - & - & - & 1895 & 100,0 & E20 \\
\hline 352970 & Miguelópolis & 19739 & 3711 & 18,8 & - & - & 16028 & 81,2 & E20 \\
\hline 352980 & Mineiros do Tietê & 12279 & 565 & 4,6 & 258 & 2,1 & 11456 & 93,3 & E20 \\
\hline 353000 & Mira Estrela & 2565 & 159 & 6,2 & & - & 2406 & 93,8 & E20 \\
\hline 352990 & Miracatu & 23906 & 4757 & 19,9 & 980 & 4,1 & 18169 & 76,0 & E50 \\
\hline 353010 & Mirandópolis & 26607 & 8674 & 32,6 & - & - & 17933 & 67,4 & D50 \\
\hline 353020 & Mirante do Paranapanema & 16674 & 634 & 3,8 & - & - & 16057 & 96,3 & E20 \\
\hline 353030 & Mirassol & 52364 & 27543 & 52,6 & 6388 & 12,2 & 18432 & 35,2 & B100 \\
\hline 353040 & Mirassolândia & 4063 & - & - & - & - & 4063 & 100,0 & E20 \\
\hline 353050 & Mococa & 68790 & 20706 & 30,1 & 4884 & 7,1 & 43200 & 62,8 & D100 \\
\hline 353060 & Moji das Cruzes & 355731 & 196719 & 55,3 & 81462 & 22,9 & 77549 & 21,8 & B500 \\
\hline 353070 & MojiOGuaçu & 134701 & 86613 & 64,3 & 13066 & 9,7 & 35157 & 26,1 & B300 \\
\hline 353080 & MojiOMirim & 88932 & 52915 & 59,5 & 7203 & 8,1 & 28725 & 32,3 & B100 \\
\hline 353090 & Mombuca & 3334 & 560 & 16,8 & 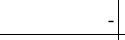 & - & 2774 & 83,2 & E20 \\
\hline 353100 & Monçoes & 2035 & & - & & - & 2035 & 100,0 & E20 \\
\hline 353110 & Mongaguá & 42278 & 19659 & 46,5 & 6553 & 15,5 & 16066 & 38,0 & $\mathrm{C} 50$ \\
\hline 353120 & Monte Alegre do Sul & 6715 & 1585 & 23,6 & & - & 5137 & 76,5 & E20 \\
\hline 353130 & Monte Alto & 45340 & 19814 & 43,7 & 5259 & 11,6 & 20312 & 44,8 & $\mathrm{C} 50$ \\
\hline 353140 & Monte Aprazível & 18818 & 7584 & 40,3 & & - & 11234 & 59,7 & D20 \\
\hline 353150 & Monte Azul Paulista & 20383 & 4586 & 22,5 & & - & 15797 & 77,5 & E50 \\
\hline 353160 & Monte Castelo & 3808 & & - & & - & 3808 & 100,0 & E20 \\
\hline 353180 & Monte Mor & 42602 & 10693 & 25,1 & 4814 & 11,3 & 27137 & 63,7 & D50 \\
\hline 353170 & Monteiro Lobato & 3721 & - & - & - & - & 3721 & 100,0 & E20 \\
\hline 353190 & Morro Agudo & 27293 & 6741 & 24,7 & 3111 & 11,4 & 17413 & 63,8 & D50 \\
\hline 353200 & Morungaba & 10672 & 4311 & 40,4 & 758 & 7,1 & 5603 & 52,5 & $\mathrm{D} 20$ \\
\hline 353205 & Motuca & 4126 & 1147 & 27,8 & 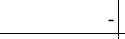 & - & 2979 & 72,2 & D20 \\
\hline 353210 & Murutinga do Sul & 4056 & - & - & - & - & 4056 & 100,0 & E20 \\
\hline 353215 & Nantes & 2218 & - & - & 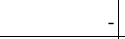 & - & 2218 & 100,0 & E20 \\
\hline 353220 & Narandiba & 4013 & - & - & - & - & 4013 & 100,0 & E20 \\
\hline
\end{tabular}


Anexo 2 - Municípios classificados no Estrato D - Vulnerabilidade Social Intensa segundo proporção da população nos grupos IPVS e porte populacional, estado de São Paulo, média do triênio 2003 a 2005.

\begin{tabular}{|c|c|c|c|c|c|c|c|c|c|}
\hline IBGE & MUNICIPIO & POP. & IPVS $(1,2,3)$ & $\%$ & IPVS (4) & $\%$ & $\operatorname{IPVS}(5,6)$ & $\%$ & Status \\
\hline 353230 & Natividade da Serra & 7172 & 567 & 7,9 & & & 6605 & 92,1 & E20 \\
\hline 353240 & Nazaré Paulista & 15633 & 1501 & 9,6 & & - & 14132 & 90,4 & E20 \\
\hline 353250 & Neves Paulista & 9172 & 1734 & 18,9 & - & - & 7438 & 81,1 & E20 \\
\hline 353260 & Nhandeara & 10124 & 3098 & 30,6 & - & - & 7026 & 69,4 & D20 \\
\hline 353270 & Nipoa & 3477 & - & - & - & - & 3477 & 100,0 & E20 \\
\hline 353280 & Nova Aliança & 5025 & 1040 & 20,7 & & - & 3985 & 79,3 & E20 \\
\hline 353282 & Nova Campina & 8223 & - & - & - & - & 8223 & 100,0 & E20 \\
\hline 353284 & Nova Canaa Paulista & 2369 & - & - & - & - & 2369 & 100,0 & E20 \\
\hline 353286 & Nova Castilho & 1013 & - & - & - & - & 1013 & 100,0 & E20 \\
\hline 353290 & Nova Europa & 8168 & 2091 & 25,6 & - & - & 6077 & 74,4 & D20 \\
\hline 353300 & Nova Granada & 17969 & 2120 & 11,8 & 1599 & 8,9 & 14249 & 79,3 & E20 \\
\hline 353310 & Nova Guataporanga & 2070 & - & - & - & - & 2070 & 100,0 & E20 \\
\hline 353320 & Nova Independência & 2092 & - & - & - & - & 2092 & 100,0 & E20 \\
\hline 353330 & Nova Luzitânia & 2798 & - & - & - & - & 2798 & 100,0 & E20 \\
\hline 353340 & Nova Odessa & 45647 & 31086 & 68,1 & 11138 & 24,4 & 3424 & 7,5 & B50 \\
\hline 353325 & Novais & 3288 & - & - & 79 & 2,4 & 3209 & 97,6 & E20 \\
\hline 353350 & Novo Horizonte & 33323 & 9264 & 27,8 & 1466 & 4,4 & 22593 & 67,8 & D50 \\
\hline 353360 & Nuporanga & 6541 & 1524 & 23,3 & - & - & 5017 & 76,7 & E20 \\
\hline 353370 & Ocauçu & 4097 & - & - & - & - & 4097 & 100,0 & E20 \\
\hline 353380 & Oleo & 3078 & - & - & 166 & 5,4 & 2912 & 94,6 & E20 \\
\hline 353390 & Olímpia & 47401 & 14220 & 30,0 & 4503 & 9,5 & 28678 & 60,5 & D50 \\
\hline 353400 & Onda Verde & 3675 & - & - & - & - & 3675 & 100,0 & E20 \\
\hline 353410 & Oriente & 5473 & 1407 & 25,7 & - & - & 4066 & 74,3 & D20 \\
\hline 353420 & Orindiúva & 4658 & 1244 & 26,7 & 1486 & 31,9 & 1933 & 41,5 & $\mathrm{C} 20$ \\
\hline 353430 & Orlândia & 38096 & 20115 & 52,8 & 6667 & 17,5 & 11315 & 29,7 & B50 \\
\hline 353440 & Osasco & 690278 & 381033 & 55,2 & 229863 & 33,3 & 79382 & 11,5 & B1000 \\
\hline 353450 & Oscar Bressane & 2557 & & - & & - & 2557 & 100,0 & E20 \\
\hline 353460 & Osvaldo Cruz & 29974 & 11630 & 38,8 & 779 & 2,6 & 17595 & 58,7 & D50 \\
\hline 353470 & Ourinhos & 101412 & 46142 & 45,5 & 7707 & 7,6 & 47562 & 46,9 & $\mathrm{C} 300$ \\
\hline 353480 & Ouro Verde & 7170 & - & - & 136 & 1,9 & 7034 & 98,1 & E20 \\
\hline 353475 & Ouroeste & 6891 & - & - & - & - & 6891 & 100,0 & E20 \\
\hline 353490 & Pacaembu & 12589 & - & - & - & - & 12589 & 100,0 & E20 \\
\hline 353500 & Palestina & 9140 & - & - & - & - & 9140 & 100,0 & E20 \\
\hline 353510 & Palmares Paulista & 8935 & - & - & 536 & 6,0 & 8399 & 94,0 & E20 \\
\hline 353520 & Palmeira d'Oeste & 10043 & - & - & 562 & 5,6 & 9481 & 94,4 & E20 \\
\hline 353530 & Palmital & 21603 & 6719 & 31,1 & - & - & 14906 & 69,0 & D50 \\
\hline 353540 & Panorama & 14232 & 1736 & 12,2 & 825 & 5,8 & 11656 & 81,9 & E20 \\
\hline 353550 & Paraguaçu Paulista & 42198 & 11520 & 27,3 & 5739 & 13,6 & 24897 & 59,0 & D50 \\
\hline 353560 & Paraibuna & 17953 & 3878 & 21,6 & 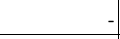 & - & 14093 & 78,5 & E20 \\
\hline 353570 & Paraíso & 5741 & & - & & - & 5741 & 100,0 & E20 \\
\hline 353580 & Paranapanema & 16721 & 2625 & 15,7 & 1254 & 7,5 & 12842 & 76,8 & E20 \\
\hline 353590 & Paranapua & 3571 & - & - & & - & 3571 & 100,0 & E20 \\
\hline 353600 & Parapua & 10963 & 976 & 8,9 & - & - & 9987 & 91,1 & E20 \\
\hline 353610 & Pardinho & 5305 & 1029 & 19,4 & 536 & 10,1 & 3745 & 70,6 & D20 \\
\hline 353620 & Pariquera0Açu & 19652 & 6407 & 32,6 & 1297 & 6,6 & 11929 & 60,7 & D20 \\
\hline 353625 & Parisi & 2143 & - & - & - & - & 2143 & 100,0 & E20 \\
\hline 353630 & Patrocínio Paulista & 12176 & 998 & 8,2 & 2216 & 18,2 & 8974 & 73,7 & D20 \\
\hline 353640 & Paulicéia & 5813 & & - & - & - & 5813 & 100,0 & E20 \\
\hline 353650 & Paulínia & 57856 & 34482 & 59,6 & 15332 & 26,5 & 7984 & 13,8 & B100 \\
\hline 353657 & Paulistânia & 1894 & - & - & - & - & 1894 & 100,0 & E20 \\
\hline 353660 & Paulo de Faria & 8542 & 743 & 8,7 & 820 & 9,6 & 6979 & 81,7 & E20 \\
\hline 353670 & Pederneiras & 38664 & 11058 & 28,6 & 6689 & 17,3 & 20879 & 54,0 & D50 \\
\hline
\end{tabular}


Anexo 2 - Municípios classificados no Estrato D - Vulnerabilidade Social Intensa segundo proporção da população nos grupos IPVS e porte populacional, estado de São Paulo, média do triênio 2003 a 2005.

\begin{tabular}{|c|c|c|c|c|c|c|c|c|c|}
\hline IBGE & MUNICIPIO & POP. & IPVS $(1,2,3)$ & $\%$ & IPVS (4) & $\%$ & $\operatorname{IPVS}(5,6)$ & $\%$ & Status \\
\hline 353680 & Pedra Bela & 5818 & & & & & 5818 & 100,0 & E20 \\
\hline 353690 & Pedranópolis & 2569 & & - & & - & 2569 & 100,0 & E20 \\
\hline 353700 & Pedregulho & 15561 & 4264 & 27,4 & - & - & 11297 & 72,6 & D20 \\
\hline 353710 & Pedreira & 38457 & 21574 & 56,1 & 1692 & 4,4 & 15191 & 39,5 & B50 \\
\hline 353715 & Pedrinhas Paulista & 2986 & 2416 & 80,9 & - & - & 570 & 19,1 & $\mathrm{~A} 20$ \\
\hline 353720 & Pedro de Toledo & 9791 & 1899 & 19,4 & & - & 7892 & 80,6 & E20 \\
\hline 353730 & Penápolis & 57471 & 21667 & 37,7 & 3563 & 6,2 & 32241 & 56,1 & D100 \\
\hline 353740 & Pereira Barreto & 24781 & 6170 & 24,9 & 1784 & 7,2 & 16851 & 68,0 & D50 \\
\hline 353750 & Pereiras & 7019 & - & - & - & - & 7019 & 100,0 & E20 \\
\hline 353760 & Peruíbe & 59795 & 23260 & 38,9 & 2332 & 3,9 & 34203 & 57,2 & D100 \\
\hline 353770 & Piacatu & 4665 & - & - & 1 & - & 4665 & 100,0 & E20 \\
\hline 353780 & Piedade & 53057 & 15652 & 29,5 & - & - & 37352 & 70,4 & D100 \\
\hline 353790 & Pilar do Sul & 25940 & 5370 & 20,7 & 856 & 3,3 & 19714 & 76,0 & E50 \\
\hline 353800 & Pindamonhangaba & 136729 & 86139 & 63,0 & 28576 & 20,9 & 21877 & 16,0 & B300 \\
\hline 353810 & Pindorama & 13436 & 1935 & 14,4 & 793 & 5,9 & 10708 & 79,7 & E20 \\
\hline 353820 & Pinhalzinho & 12124 & 1528 & 12,6 & - & - & 10596 & 87,4 & E20 \\
\hline 353830 & Piquerobi & 3570 & - & - & - & - & 3570 & 100,0 & E20 \\
\hline 353850 & Piquete & 15403 & 8811 & 57,2 & - & - & 6592 & 42,8 & B20 \\
\hline 353860 & Piracaia & 25289 & 5918 & 23,4 & 1543 & 6,1 & 17829 & 70,5 & D50 \\
\hline 353870 & Piracicaba & 351691 & 226841 & 64,5 & 46423 & 13,2 & 78075 & 22,2 & B500 \\
\hline 353880 & Piraju & 28709 & 11139 & 38,8 & 402 & 1,4 & 17168 & 59,8 & D50 \\
\hline 353890 & Pirajuí & 20661 & 5723 & 27,7 & 3058 & 14,8 & 11880 & 57,5 & D50 \\
\hline 353900 & Pirangi & 10115 & 647 & 6,4 & - & - & 9468 & 93,6 & E20 \\
\hline 353910 & Pirapora do Bom Jesus & 14376 & 2099 & 14,6 & 4298 & 29,9 & 7993 & 55,6 & D20 \\
\hline 353920 & Pirapozinho & 22603 & 6939 & 30,7 & 2238 & 9,9 & 13426 & 59,4 & D50 \\
\hline 353930 & Pirassununga & 68490 & 43012 & 62,8 & 7671 & 11,2 & 17876 & 26,1 & B100 \\
\hline 353940 & Piratininga & 11000 & 7007 & 63,7 & & - & 3993 & 36,3 & B20 \\
\hline 353950 & Pitangueiras & 32991 & 8017 & 24,3 & 4124 & 12,5 & 20850 & 63,2 & D50 \\
\hline 353960 & Planalto & 3748 & - & - & - & - & 3748 & 100,0 & E20 \\
\hline 353970 & Platina & 2879 & - & - & 167 & 5,8 & 2712 & 94,2 & E20 \\
\hline 353980 & Poá & 104511 & 61871 & 59,2 & 33862 & 32,4 & 8883 & 8,5 & B300 \\
\hline 353990 & Poloni & 4884 & 630 & 12,9 & - & - & 4249 & 87,0 & E20 \\
\hline 354000 & Pompéia & 18588 & 8290 & 44,6 & 3662 & 19,7 & 6617 & 35,6 & $\mathrm{C} 20$ \\
\hline 354010 & Pongaí & 3745 & - & - & & - & 3745 & 100,0 & E20 \\
\hline 354020 & Pontal & 32752 & 10055 & 30,7 & 6321 & 19,3 & 16409 & 50,1 & D50 \\
\hline 354025 & Pontalinda & 3714 & - & - & - & - & 3714 & 100,0 & E20 \\
\hline 354030 & Pontes Gestal & 2347 & - & - & 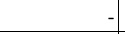 & - & 2347 & 100,0 & E20 \\
\hline 354040 & Populina & 4352 & - & - & & - & 4352 & 100,0 & E20 \\
\hline 354050 & Porangaba & 7120 & 940 & 13,2 & - & - & 6180 & 86,8 & E20 \\
\hline 354060 & Porto Feliz & 49345 & 20725 & 42,0 & 6366 & 12,9 & 22255 & 45,1 & $\mathrm{C} 50$ \\
\hline 354070 & Porto Ferreira & 51433 & 24276 & 47,2 & 7406 & 14,4 & 19802 & 38,5 & $\mathrm{C} 100$ \\
\hline 354075 & Potim & 15327 & 1134 & 7,4 & 1885 & 12,3 & 12308 & 80,3 & E20 \\
\hline 354080 & Potirendaba & 14754 & 1593 & 10,8 & 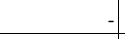 & - & 13146 & 89,1 & E20 \\
\hline 354085 & Pracinha & 1421 & & - & & - & 1421 & 100,0 & E20 \\
\hline 354090 & Pradópolis & 14271 & 4082 & 28,6 & 2612 & 18,3 & 7578 & 53,1 & D20 \\
\hline 354100 & Praia Grande & 224889 & 113344 & 50,4 & 40255 & 17,9 & 71515 & 31,8 & B300 \\
\hline 354105 & Pratânia & 4233 & - & - & 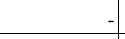 & - & 4233 & 100,0 & E20 \\
\hline 354110 & Presidente Alves & 4233 & 698 & 16,5 & - & - & 3535 & 83,5 & E20 \\
\hline 354120 & Presidente Bernardes & 15222 & 4795 & 31,5 & 731 & 4,8 & 9696 & 63,7 & D20 \\
\hline 354130 & Presidente Epitácio & 41285 & 14285 & 34,6 & 5780 & 14,0 & 21220 & 51,4 & D50 \\
\hline 354140 & Presidente Prudente & 199773 & 123460 & 61,8 & 23373 & 11,7 & 52740 & 26,4 & B300 \\
\hline 354150 & Presidente Venceslau & 37896 & 11482 & 30,3 & 834 & 2,2 & 25580 & 67,5 & D50 \\
\hline
\end{tabular}


Anexo 2 - Municípios classificados no Estrato D - Vulnerabilidade Social Intensa segundo proporção da população nos grupos IPVS e porte populacional, estado de São Paulo, média do triênio 2003 a 2005.

\begin{tabular}{|c|c|c|c|c|c|c|c|c|c|}
\hline IBGE & MUNICIPIO & POP. & IPVS $(1,2,3)$ & $\%$ & IPVS (4) & $\%$ & IPVS $(5,6)$ & $\%$ & Status \\
\hline 354160 & Promissao & 32500 & 11928 & 36,7 & 1398 & 4,3 & 19175 & 59,0 & D50 \\
\hline 354165 & Quadra & 2986 & & - & & - & 2986 & 100,0 & E20 \\
\hline 354170 & Quatá & 11788 & 2193 & 18,6 & 1674 & 14,2 & 7910 & 67,1 & D20 \\
\hline 354180 & Queiroz & 2275 & & - & - & - & 2275 & 100,0 & E20 \\
\hline 354190 & Queluz & 9738 & 2775 & 28,5 & - & - & 6963 & 71,5 & D20 \\
\hline 354200 & Quintana & 5556 & & & 89 & 1,6 & 5467 & 98,4 & E20 \\
\hline 354210 & Rafard & 8257 & 6226 & 75,4 & - & - & 2023 & 24,5 & $\mathrm{~A} 20$ \\
\hline 354220 & Rancharia & 29600 & 9146 & 30,9 & 947 & 3,2 & 19506 & 65,9 & D50 \\
\hline 354230 & Redençao da Serra & 4059 & 475 & 11,7 & - & - & 3584 & 88,3 & E20 \\
\hline 354240 & Regente Feijó & 17906 & 4494 & 25,1 & 1952 & 10,9 & 11460 & 64,0 & D20 \\
\hline 354250 & Reginópolis & 4733 & - & - & - & - & 4733 & 100,0 & E20 \\
\hline 354260 & Registro & 55894 & 22525 & 40,3 & 5142 & 9,2 & 28226 & 50,5 & D100 \\
\hline 354270 & Restinga & 6111 & - & - & - & - & 6111 & 100,0 & E20 \\
\hline 354280 & Ribeira & 3252 & 455 & 14,0 & - & - & 2797 & 86,0 & E20 \\
\hline 354290 & Ribeirao Bonito & 11656 & 3439 & 29,5 & 1154 & 9,9 & 7052 & 60,5 & D20 \\
\hline 354300 & Ribeirao Branco & 22101 & 508 & 2,3 & 553 & 2,5 & 21040 & 95,2 & E50 \\
\hline 354310 & Ribeirao Corrente & 4171 & - & - & - & - & 4171 & 100,0 & E20 \\
\hline 354320 & Ribeirao do Sul & 4644 & - & - & - & - & 4644 & 100,0 & E20 \\
\hline 354323 & Ribeirao dos Indios & 2288 & - & - & - & - & 2288 & 100,0 & E20 \\
\hline 354325 & Ribeirao Grande & 7935 & 1190 & 15,0 & - & - & 6745 & 85,0 & E20 \\
\hline 354330 & Ribeirao Pires & 113183 & 79341 & 70,1 & 26145 & 23,1 & 7583 & 6,7 & B300 \\
\hline 354340 & Ribeirao Preto & 537997 & 393814 & 73,2 & 76934 & 14,3 & 67250 & 12,5 & B1000 \\
\hline 354360 & Rifaina & 3516 & 1157 & 32,9 & 32 & 0,9 & 2328 & 66,2 & D20 \\
\hline 354370 & Rincao & 10324 & 2726 & 26,4 & 909 & 8,8 & 6690 & 64,8 & D20 \\
\hline 354380 & Rinópolis & 9847 & 965 & 9,8 & - & - & 8882 & 90,2 & E20 \\
\hline 354390 & Rio Claro & 181608 & 119861 & 66,0 & 33961 & 18,7 & 27786 & 15,3 & B300 \\
\hline 354400 & Rio das Pedras & 25455 & 10157 & 39,9 & 2749 & 10,8 & 12549 & 49,3 & C50 \\
\hline 354410 & Rio Grande da Serra & 40304 & 6126 & 15,2 & 26278 & 65,2 & 7859 & 19,5 & C50 \\
\hline 354420 & Riolândia & 8918 & 954 & 10,7 & - & - & 7964 & 89,3 & E20 \\
\hline 354350 & Riversul & 6207 & - & - & - & - & 6207 & 100,0 & E20 \\
\hline 354425 & Rosana & 25790 & 9284 & 36,0 & 6215 & 24,1 & 10316 & 40,0 & C50 \\
\hline 354430 & Roseira & 9631 & 4161 & 43,2 & 1743 & 18,1 & 3727 & 38,7 & $\mathrm{C} 20$ \\
\hline 354440 & Rubiácea & 2203 & - & - & 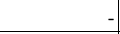 & - & 2203 & 100,0 & E20 \\
\hline 354450 & Rubinéia & 2784 & 821 & 29,5 & & - & 1963 & 70,5 & $\mathrm{D} 20$ \\
\hline 354460 & Sabino & 5120 & - & - & - & - & 5120 & 100,0 & E20 \\
\hline 354470 & Sagres & 2344 & - & - & & - & 2344 & 100,0 & E20 \\
\hline 354480 & Sales & 4922 & 89 & 1,8 & - & - & 4833 & 98,2 & E20 \\
\hline 354490 & Sales Oliveira & 10083 & 5152 & 51,1 & 333 & 3,3 & 4598 & 45,6 & B20 \\
\hline 354500 & Salesópolis & 15694 & 3327 & 21,2 & - & - & 12367 & 78,8 & E20 \\
\hline 354510 & Salmourao & 4376 & & - & & - & 4376 & 100,0 & E20 \\
\hline 354515 & Saltinho & 6122 & 4310 & 70,4 & - & - & 1812 & 29,6 & B20 \\
\hline 354520 & Salto & 102461 & 56046 & 54,7 & 31865 & 31,1 & 14549 & 14,2 & B300 \\
\hline 354530 & Salto de Pirapora & 39417 & 12771 & 32,4 & 4257 & 10,8 & 22428 & 56,9 & D50 \\
\hline 354540 & Salto Grande & 8918 & 2007 & 22,5 & & - & 6911 & 77,5 & E20 \\
\hline 354550 & Sandovalina & 3394 & & - & - & - & 3394 & 100,0 & E20 \\
\hline 354560 & Santa Adélia & 13822 & 3442 & 24,9 & 594 & 4,3 & 9786 & 70,8 & $\mathrm{D} 20$ \\
\hline 354570 & Santa Albertina & 5460 & & - & & - & 5460 & 100,0 & E20 \\
\hline 354580 & Santa Bárbara d'Oeste & 181160 & 123008 & 67,9 & 29348 & 16,2 & 28804 & 15,9 & B300 \\
\hline 354600 & Santa Branca & 14217 & 6142 & 43,2 & & - & 8075 & 56,8 & D20 \\
\hline 354610 & Santa Clara d'Oeste & 1956 & - & - & - & - & 1956 & 100,0 & E20 \\
\hline 354620 & Santa Cruz da Conceiçao & 3796 & 1951 & 51,4 & 129 & 3,4 & 1716 & 45,2 & B20 \\
\hline 354625 & Santa Cruz da Esperança & 1844 & - & - & - & - & 1844 & 100,0 & E2O \\
\hline
\end{tabular}


Anexo 2 - Municípios classificados no Estrato D - Vulnerabilidade Social Intensa segundo proporção da população nos grupos IPVS e porte populacional, estado de São Paulo, média do triênio 2003 a 2005.

\begin{tabular}{|c|c|c|c|c|c|c|c|c|c|}
\hline IBGE & MUNICIPIO & POP. & IPVS $(1,2,3)$ & $\%$ & IPVS (4) & $\%$ & $\operatorname{IPVS}(5,6)$ & $\%$ & Status \\
\hline 354630 & Santa Cruz das Palmeiras & 27225 & 9692 & 35,6 & 191 & 0,7 & 17342 & 63,7 & D50 \\
\hline 354640 & Santa Cruz do Rio Pardo & 42863 & 17702 & 41,3 & 4972 & 11,6 & 20188 & 47,1 & $\mathrm{C} 50$ \\
\hline 354650 & Santa Ernestina & 5799 & 2917 & 50,3 & 325 & 5,6 & 2557 & 44,1 & B20 \\
\hline 354660 & Santa Fé do Sul & 28032 & 6363 & 22,7 & 3168 & 11,3 & 18473 & 65,9 & D50 \\
\hline 354670 & Santa Gertrudes & 18327 & 2786 & 15,2 & 9255 & 50,5 & 6286 & 34,3 & $\mathrm{C} 20$ \\
\hline 354680 & Santa Isabel & 46315 & 14543 & 31,4 & 3242 & 7,0 & 28576 & 61,7 & D50 \\
\hline 354690 & Santa Lúcia & 8555 & - & -1 & & - & 8555 & 100,0 & E20 \\
\hline 354700 & Santa Maria da Serra & 4838 & & 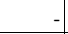 & 721 & 14,9 & 4117 & 85,1 & E20 \\
\hline 354710 & Santa Mercedes & 2722 & & - & & - & 2722 & 100,0 & E20 \\
\hline 354750 & Santa Rita do Passa Quatr & 27038 & 14033 & 51,9 & 270 & 1,0 & 12735 & 47,1 & B50 \\
\hline 354740 & Santa Rita d'Oeste & 2342 & - & - & & - & 2342 & 100,0 & E20 \\
\hline 354760 & Santa Rosa de Viterbo & 22436 & 6641 & 29,6 & 3074 & 13,7 & 12721 & 56,7 & D50 \\
\hline 354765 & Santa Salete & 1379 & & - & & - & 1379 & 100,0 & E20 \\
\hline 354720 & Santana da Ponte Pensa & 1683 & - & - & & - & 1683 & 100,0 & E20 \\
\hline 354730 & Santana de Parnaíba & 91385 & 31711 & 34,7 & 23669 & 25,9 & 36006 & 39,4 & $\mathrm{C} 100$ \\
\hline 354770 & Santo Anastácio & 21084 & 2699 & 12,8 & 1687 & 8,0 & 16720 & 79,3 & E50 \\
\hline 354780 & Santo André & 663777 & 529030 & 79,7 & 78989 & 11,9 & 55757 & 8,4 & A1000 \\
\hline 354790 & Santo Antônio da Alegria & 6036 & - & - & & - & 6036 & 100,0 & E20 \\
\hline 354800 & Santo Antônio de Posse & 19855 & 7108 & 35,8 & 655 & 3,3 & 12092 & 60,9 & D20 \\
\hline 354805 & Santo Antônio do Aracangu & 6897 & & - & 904 & 13,1 & 5993 & 86,9 & E20 \\
\hline 354810 & Santo Antônio do Jardim & 6364 & 1025 & 16,1 & - & - & 5339 & 83,9 & E20 \\
\hline 354820 & Santo Antônio do Pinhal & 6765 & 1360 & 20,1 & - & - & 5405 & 79,9 & E20 \\
\hline 354830 & Santo Expedito & 2662 & - & - & & - & 2662 & 100,0 & E20 \\
\hline 354840 & Santópolis do Aguapeí & 3808 & - & - & - & - & 3808 & 100,0 & E20 \\
\hline 354850 & Santos & 418220 & 351723 & 84,1 & 13383 & 3,2 & 52696 & 12,6 & A500 \\
\hline 354860 & Sao Bento do Sapucaí & 11097 & 2785 & 25,1 & & - & 8312 & 74,9 & D20 \\
\hline 354870 & Sao Bernardo do Campo & 764051 & 463015 & 60,6 & 186428 & 24,4 & 113844 & 14,9 & B1000 \\
\hline 354880 & Sao Caetano do Sul & 135979 & 135979 & 100,0 & & - & & 0,0 & A300 \\
\hline 354890 & Sao Carlos & 208532 & 145555 & 69,8 & 36493 & 17,5 & 26275 & 12,6 & B300 \\
\hline 354900 & Sao Francisco & 3006 & - & - & & - & 3006 & 100,0 & E20 \\
\hline 354910 & Sao Joao da Boa Vista & 81066 & 49126 & 60,6 & 4378 & 5,4 & 27644 & 34,1 & B100 \\
\hline 354920 & Sao Joao das Duas Pontes & 2600 & & - & & - & 2600 & 100,0 & E20 \\
\hline 354925 & Sao Joao de Iracema & 1704 & - & - & - & - & 1704 & 100,0 & E20 \\
\hline 354930 & Sao Joao do Pau d'Alho & 1895 & - & - & - & - & 1895 & 100,0 & E20 \\
\hline 354940 & Sao Joaquim da Barra & 44097 & 16051 & 36,4 & 7629 & 17,3 & 20417 & 46,3 & $\mathrm{C} 50$ \\
\hline 354950 & Sao José da Bela Vista & 8500 & - & - & 289 & 3,4 & 8211 & 96,6 & E20 \\
\hline 354960 & Sao José do Barreiro & 4237 & 424 & 10,0 & - & - & 3818 & 90,1 & E20 \\
\hline 354970 & Sao José do Rio Pardo & 52534 & 22747 & 43,3 & 2101 & 4,0 & 27685 & 52,7 & D100 \\
\hline 354980 & Sao José do Rio Preto & 392960 & 271142 & 69,0 & 34580 & 8,8 & 86844 & 22,1 & B500 \\
\hline 354990 & Sao José dos Campos & 582612 & 376367 & 64,6 & 135749 & 23,3 & 70496 & 12,1 & B1000 \\
\hline 354995 & Sao Lourenço da Serra & 14296 & 1644 & 11,5 & 1687 & 11,8 & 10951 & 76,6 & E20 \\
\hline 355000 & Sao Luís do Paraitinga & 10655 & 2110 & 19,8 & - & - & 8545 & 80,2 & E20 \\
\hline 355010 & Sao Manuel & 38522 & 10863 & 28,2 & 2388 & 6,2 & 25270 & 65,6 & D50 \\
\hline 355020 & Sao Miguel Arcanjo & 33217 & 4318 & 13,0 & 3288 & 9,9 & 25610 & 77,1 & E50 \\
\hline 355030 & Sao Paulo & 10786257 & 6989495 & 64,8 & 2405335 & 22,3 & 1391427 & 12,9 & B10000 \\
\hline 355040 & Sao Pedro & 31348 & 18370 & 58,6 & 1223 & 3,9 & 11756 & 37,5 & B50 \\
\hline 355050 & Sao Pedro do Turvo & 6964 & 474 & 6,8 & - & - & 6490 & 93,2 & E20 \\
\hline 355060 & Sao Roque & 70954 & 36825 & 51,9 & 7024 & 9,9 & 27104 & 38,2 & B100 \\
\hline 355070 & Sao Sebastiao & 68824 & 23056 & 33,5 & 22230 & 32,3 & 23607 & 34,3 & $\mathrm{C} 100$ \\
\hline 355080 & Sao Sebastiao da Grama & 12742 & 2230 & 17,5 & -1 & - & 10512 & 82,5 & E20 \\
\hline 355090 & Sao Simao & 14430 & 7821 & 54,2 & 2352 & 16,3 & 4228 & 29,3 & B20 \\
\hline 355100 & Sao Vicente & 319153 & 198832 & 62,3 & 40213 & 12,6 & 80107 & 25,1 & B500 \\
\hline
\end{tabular}


Anexo 2 - Municípios classificados no Estrato D - Vulnerabilidade Social Intensa segundo proporção da população nos grupos IPVS e porte populacional, estado de São Paulo, média do triênio 2003 a 2005.

\begin{tabular}{|c|c|c|c|c|c|c|c|c|c|}
\hline IBGE & MUNICIPIO & POP. & IPVS $(1,2,3)$ & $\%$ & IPVS (4) & $\%$ & $\operatorname{IPVS}(5,6)$ & $\%$ & Status \\
\hline 355110 & Sarapuí & 8399 & 1268 & 15,1 & & & 7139 & 85,0 & E20 \\
\hline 355120 & Sarutaiá & 4060 & & - & & - & 4060 & 100,0 & E20 \\
\hline 355130 & Sebastianópolis do Sul & 2556 & - & - & - & - & 2556 & 100,0 & E20 \\
\hline 355140 & Serra Azul & 8014 & -1 & - & 1210 & 15,1 & 6804 & 84,9 & E20 \\
\hline 355160 & Serra Negra & 24808 & 11486 & 46,3 & 372 & 1,5 & 12950 & 52,2 & D50 \\
\hline 355150 & Serrana & 36796 & 7102 & 19,3 & 12805 & 34,8 & 16889 & 45,9 & C50 \\
\hline 355170 & Sertaozinho & 101761 & 46607 & 45,8 & 17605 & 17,3 & 37550 & 36,9 & $\mathrm{C} 300$ \\
\hline 355180 & Sete Barras & 14242 & 2877 & 20,2 & 442 & 3,1 & 10909 & 76,6 & E20 \\
\hline 355190 & Severínia & 15090 & 634 & 4,2 & 1645 & 10,9 & 12811 & 84,9 & E20 \\
\hline 355200 & Silveiras & 5586 & 1296 & 23,2 & - & - & 4290 & 76,8 & E20 \\
\hline 355210 & Socorro & 33572 & 10508 & 31,3 & - & - & 23064 & 68,7 & D50 \\
\hline 355220 & Sorocaba & 544595 & 356165 & 65,4 & 135060 & 24,8 & 53370 & 9,8 & B1000 \\
\hline 355230 & Sud Mennucci & 7437 & - & - & 1510 & 20,3 & 5927 & 79,7 & E20 \\
\hline 355240 & Sumaré & 221608 & 92854 & 41,9 & 78671 & 35,5 & 50083 & 22,6 & C300 \\
\hline 355255 & Suzanápolis & 2859 & - & - & & - & 2859 & 100,0 & E20 \\
\hline 355250 & Suzano & 259891 & 87843 & 33,8 & 87583 & 33,7 & 84465 & 32,5 & C300 \\
\hline 355260 & Tabapua & 10732 & 719 & 6,7 & - & - & 10013 & 93,3 & E20 \\
\hline 355270 & Tabatinga & 13972 & 1257 & 9,0 & - & - & 12728 & 91,1 & E20 \\
\hline 355280 & Taboao da Serra & 214420 & 93058 & 43,4 & 82552 & 38,5 & 39024 & 18,2 & $\mathrm{C} 300$ \\
\hline 355290 & Taciba & 5432 & - & - & 76 & 1,4 & 5351 & 98,5 & E20 \\
\hline 355300 & Taguaí & 7932 & 833 & 10,5 & - & - & 7099 & 89,5 & E20 \\
\hline 355310 & Taiaçu & 5886 & - & - & - & - & 5886 & 100,0 & E20 \\
\hline 355320 & Taiúva & 5634 & - & - & - & - & 5634 & 100,0 & E20 \\
\hline 355330 & Tambaú & 23330 & 7022 & 30,1 & 1960 & 8,4 & 14348 & 61,5 & D50 \\
\hline 355340 & Tanabi & 23067 & 5421 & 23,5 & 692 & 3,0 & 16954 & 73,5 & D50 \\
\hline 355350 & Tapiraí & 9836 & 777 & 7,9 & 1308 & 13,3 & 7751 & 78,8 & E20 \\
\hline 355360 & Tapiratiba & 13453 & 3673 & 27,3 & & - & 9794 & 72,8 & D20 \\
\hline 355365 & Taquaral & 2849 & - & - & -1 & - & 2849 & 100,0 & E20 \\
\hline 355370 & Taquaritinga & 54364 & 19245 & 35,4 & 5382 & 9,9 & 29737 & 54,7 & D100 \\
\hline 355380 & Taquarituba & 23519 & 3293 & 14,0 & 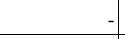 & - & 20226 & 86,0 & E50 \\
\hline 355385 & Taquarivaí & 5095 & & - & - & - & 5095 & 100,0 & E20 \\
\hline 355390 & Tarabaí & 6266 & - & - & - & - & 6266 & 100,0 & E20 \\
\hline 355395 & Taruma & 11266 & 1138 & 10,1 & 2197 & 19,5 & 7931 & 70,4 & D20 \\
\hline 355400 & Tatuí & 101701 & 42918 & 42,2 & 22069 & 21,7 & 36714 & 36,1 & $\mathrm{C} 300$ \\
\hline 355410 & Taubaté & 260781 & 185676 & 71,2 & 45115 & 17,3 & 29729 & 11,4 & B300 \\
\hline 355420 & Tejupá & 5606 & - & - & & - & 5606 & 100,0 & E20 \\
\hline 355430 & Teodoro Sampaio & 20480 & 3748 & 18,3 & 2212 & 10,8 & 14520 & 70,9 & D50 \\
\hline 355440 & Terra Roxa & 8253 & & - & & - & 8253 & 100,0 & E20 \\
\hline 355450 & Tietê & 34761 & 19883 & 57,2 & 6327 & 18,2 & 8586 & 24,7 & B50 \\
\hline 355460 & Timburi & 2676 & - & - & & - & 2676 & 100,0 & E20 \\
\hline 355465 & Torre de Pedra & 2549 & - & - & 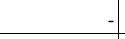 & - & 2549 & 100,0 & E20 \\
\hline 355470 & Torrinha & 9432 & 689 & 7,3 & & - & 8743 & 92,7 & E20 \\
\hline 355475 & Trabiju & 1437 & & - & & - & 1437 & 100,0 & E20 \\
\hline 355480 & Tremembé & 38062 & 26377 & 69,3 & 5481 & 14,4 & 6242 & 16,4 & B50 \\
\hline 355490 & Três Fronteiras & 5172 & - & - & - & - & 5172 & 100,0 & E20 \\
\hline 355495 & Tuiuti & 5342 & - & - & - & - & 5342 & 100,0 & E20 \\
\hline 355500 & Tupa & 65123 & 26700 & 41,0 & 5666 & 8,7 & 32757 & 50,3 & D100 \\
\hline 355510 & Tupi Paulista & 12947 & 3535 & 27,3 & & - & 9412 & 72,7 & D20 \\
\hline 355520 & Turiúba & 1810 & & - & - & - & 1810 & 100,0 & E20 \\
\hline 355530 & Turmalina & 2194 & - & - & - & - & 2194 & 100,0 & $\mathrm{E} 20$ \\
\hline 355535 & Ubarana & 4836 & - & - & 208 & 4,3 & 4628 & 95,7 & E20 \\
\hline 355540 & Ubatuba & 75555 & 23120 & 30,6 & 26293 & 34,8 & 26142 & 34,6 & C100 \\
\hline
\end{tabular}


Anexo 2 - Municípios classificados no Estrato D - Vulnerabilidade Social Intensa segundo proporção da população nos grupos IPVS e porte populacional, estado de São Paulo, média do triênio 2003 a 2005.

\begin{tabular}{|c|c|c|c|c|c|c|c|c|c|}
\hline IBGE & MUNICIPIO & POP. & IPVS $(\mathbf{1}, \mathbf{2 , 3 )}$ & $\%$ & IPVS (4) & $\%$ & IPVS $(5,6)$ & $\%$ & Status \\
\hline 355550 & Ubirajara & 4146 & & & & & 4146 & 100,0 & E20 \\
\hline 355560 & Uchoa & 9350 & 2020 & 21,6 & 748 & 8,0 & 6573 & 70,3 & $\mathrm{D} 20$ \\
\hline 355570 & Uniao Paulista & 1364 & & & & 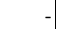 & 1364 & 100,0 & E20 \\
\hline 355580 & Urânia & 8860 & 1409 & 15,9 & - & & 7451 & 84,1 & E20 \\
\hline 355590 & Uru & 1425 & & - & & & 1425 & 100,0 & E20 \\
\hline 355600 & Urupês & 12198 & 976 & 8,0 & & & 11222 & 92,0 & E20 \\
\hline 355610 & Valentim Gentil & 9812 & 3807 & 38,8 & & & 6005 & 61,2 & D20 \\
\hline 355620 & Valinhos & 89712 & 64234 & 71,6 & 16148 & 18,0 & 9330 & 10,4 & B100 \\
\hline 355630 & Valparaíso & 19477 & 6252 & 32,1 & 2006 & 10,3 & 11219 & 57,6 & D20 \\
\hline 355635 & Vargem & 7855 & 888 & 11,3 & - & - & 6967 & 88,7 & E20 \\
\hline 355640 & Vargem Grande do Sul & 38692 & 13155 & 34,0 & & & 25537 & 66,0 & D50 \\
\hline 355645 & Vargem Grande Paulista & 40193 & 14108 & 35,1 & 21342 & 53,1 & 4743 & 11,8 & C50 \\
\hline 355650 & Várzea Paulista & 103464 & 45524 & 44,0 & 36937 & 35,7 & 21003 & 20,3 & $\mathrm{C} 300$ \\
\hline 355660 & Vera Cruz & 11098 & 2319 & 20,9 & - & - & 8779 & 79,1 & E20 \\
\hline 355670 & Vinhedo & 53292 & 43060 & 80,8 & 7354 & 13,8 & 2878 & 5,4 & A100 \\
\hline 355680 & Viradouro & 17244 & 3483 & 20,2 & 2362 & 13,7 & 11398 & 66,1 & D20 \\
\hline 355690 & Vista Alegre do Alto & 5263 & 1453 & 27,6 & - & - & 3810 & 72,4 & D20 \\
\hline 355695 & Vitória Brasil & 1777 & & - & - & - & 1777 & 100,0 & E20 \\
\hline 355700 & Votorantim & 102711 & 56902 & 55,4 & 32149 & 31,3 & 13661 & 13,3 & B300 \\
\hline 355710 & Votuporanga & 80551 & 39067 & 48,5 & 7088 & 8,8 & 34395 & 42,7 & $\mathrm{C} 100$ \\
\hline 355715 & Zacarias & 1945 & - & - & - & - & 1945 & 100,0 & E20 \\
\hline & Estado & 39463839 & 20564688 & 52,1 & 8080304 & 20,5 & 10818751 & 27,4 & \\
\hline
\end{tabular}

Fonte: Censo IBGE e Estratos de Vulnerabilidade Social segundo metodologia desenvolvida a partir do IPVS (FSEADE 2005) Nota:

( - ) Dado numérico igual a 0 não resultante de arredondamento

$(0 ; 0,0 ; 0,00)$ Dado numérico igual a zero resultante de arredondamento de um dado originalmente positivo

Eventualmente a soma das parcelas pode não coincidir com o total em função de arredondamentos efetuados nos dados parciais.

População atualizada segundo projeção(IBGE) para o período (média) pela participação relativa nos grupos IPVS 
Anexo 3 - Municípios classificados no Estrato A - Vulnerabilidade Social Muito Fraca

segundo proporção da população nos Grupos do IPVS e porte populacional, estado de São Paulo, média do triênio 2003 a 2005

\begin{tabular}{|c|c|c|c|c|c|c|c|c|c|}
\hline IBGE & MUNICIPIO & POP & IPVS 1,2,3 & $\%$ & IPVS 4 & $\%$ & IPVS 5,6 & $\%$ & Status \\
\hline 3500600 & Aguas de Sao Pedro & 1965 & 1965 & 100,0 & - & - & - & - & A20 \\
\hline 3501608 & Americana & 195436 & 164948 & 84,4 & 16612 & 8,5 & 13876 & 7,1 & A300 \\
\hline 3503208 & Araraquara & 192859 & 144837 & 75,1 & 23722 & 12,3 & 24107 & 12,5 & А300 \\
\hline 3504602 & Bady Bassitt & 14156 & 11608 & 82,0 & 991 & 7,0 & 1557 & 11,0 & A20 \\
\hline 3520426 & Ilha Comprida & 8468 & 6876 & 81,2 & 500 & 5,9 & 1092 & 12,9 & A20 \\
\hline 3525854 & Jumirim & 2460 & 2460 & 100,0 & & - & - & & A20 \\
\hline 3525904 & Jundiaí & 338641 & 261769 & 77,3 & 30139 & 8,9 & 47071 & 13,9 & A500 \\
\hline 3537156 & Pedrinhas Paulista & 2986 & 2416 & 80,9 & & & 570 & 19,1 & A20 \\
\hline 3542107 & Rafard & 8257 & 6226 & 75,4 & & & 2023 & 24,5 & A20 \\
\hline 3547809 & Santo André & 663777 & 529030 & 79,7 & 78989 & 11,9 & 55757 & 8,4 & A1000 \\
\hline 3548500 & Santos & 418220 & 351723 & 84,1 & 13383 & 3,2 & 52696 & 12,6 & A500 \\
\hline 3548807 & São Caetano do Sul & 135979 & 135979 & 100,0 & & & & & A300 \\
\hline 3556701 & Vinhedo & 53292 & 43060 & 80,8 & 7354 & 13,8 & 2878 & 5,4 & $\mathrm{~A} 100$ \\
\hline
\end{tabular}

Fonte: Censo IBGE e Estratos de Vulnerabilidade Social segundo metodologia desenvolvida a partir do IPVS (FSEADE 2005) Nota:

( - ) Dado numérico igual a 0 não resultante de arredondamento

$(0 ; 0,0 ; 0,00)$ Dado numérico igual a zero resultante de arredondamento de um dado originalmente positivo

Eventualmente a soma das parcelas pode não coincidir com o total em função de arredondamentos efetuados nos dados parciais.

População atualizada segundo projeção(IBGE) para o período (média) pela participação relativa nos grupos IPVS 
Anexo 4 - Municípios classificados no Estrato B - Vulnerabilidade Social Fraca segundo proporção da população nos grupos IPVS e porte populacional.Estado de São Paulo, média do triênio 2003 a 2005.

\begin{tabular}{|c|c|c|c|c|c|c|c|c|}
\hline IBGE & MUNICIPIO & IPVS 1,2,3 & $\%$ & IPVS 4 & $\%$ & IPVS 5,6 & $\%$ & Status \\
\hline 3500550 & Aguas de Santa Bárbara & 3619 & 62,2 & 698 & 12,0 & 1507 & 25,9 & B20 \\
\hline 3501905 & Amparo & 38171 & 59,0 & 7311 & 11,3 & 19215 & 29,7 & $\mathrm{~B} 100$ \\
\hline 3502002 & Analândia & 2552 & 66,6 & - & - & 1280 & 33,4 & B20 \\
\hline 3502507 & Aparecida & 22278 & 62,5 & 927 & 2,6 & 12440 & 34,9 & B50 \\
\hline 3502804 & Araçatuba & 100904 & 57,1 & 22973 & 13,0 & 52837 & 29,9 & B300 \\
\hline 3502903 & Araçoiaba da Serra & 11751 & 53,0 & 1818 & 8,2 & 8602 & 38,8 & B50 \\
\hline 3503307 & Araras & 58963 & 52,8 & 10274 & 9,2 & 42436 & 38,0 & B300 \\
\hline 3504008 & Assis & 57723 & 62,5 & 6188 & 6,7 & 28446 & 30,8 & B100 \\
\hline 3504503 & Avaré & 41752 & 50,1 & 8917 & 10,7 & 32585 & 39,1 & B100 \\
\hline 3505500 & Barretos & 61071 & 56,7 & 14325 & 13,3 & 32313 & 30,0 & B300 \\
\hline 3506003 & Bauru & 235361 & 69,1 & 53135 & 15,6 & 52454 & 15,4 & B500 \\
\hline 3507506 & Botucatu & 75957 & 65,4 & 17073 & 14,7 & 23112 & 19,9 & B300 \\
\hline 3507605 & Bragança Paulista & 68814 & 50,5 & 15534 & 11,4 & 51917 & 38,1 & B300 \\
\hline 3508504 & Caçapava & 51603 & 64,0 & 11288 & 14,0 & 17658 & 21,9 & B100 \\
\hline 3508603 & Cachoeira Paulista & 16494 & 56,9 & 1275 & 4,4 & 11247 & 38,8 & B50 \\
\hline 3509502 & Campinas & 714614 & 69,8 & 142308 & 13,9 & 166880 & 16,3 & B10000 \\
\hline 3510807 & Casa Branca & 15024 & 54,7 & 2582 & 9,4 & 9833 & 35,8 & B50 \\
\hline 3511102 & Catanduva & 59778 & 53,1 & 10470 & 9,3 & 42329 & 37,6 & B300 \\
\hline 3511508 & Cerquilho & 22501 & 66,7 & 8197 & 24,3 & 3036 & 9,0 & B50 \\
\hline 3512803 & Cosmópolis & 27696 & 57,6 & 8559 & 17,8 & 11829 & 24,6 & B50 \\
\hline 3513405 & Cruzeiro & 48497 & 64,1 & 7717 & 10,2 & 19520 & 25,8 & B100 \\
\hline 3516200 & Franca & 176985 & 56,7 & 66174 & 21,2 & 68983 & 22,1 & B500 \\
\hline 3518404 & Guaratinguetá & 66486 & 60,7 & 13363 & 12,2 & 29793 & 27,2 & B300 \\
\hline 3520442 & Ilha Solteira & 18162 & 72,6 & 3652 & 14,6 & 3177 & 12,7 & B50 \\
\hline 3520509 & Indaiatuba & 86001 & 51,3 & 62531 & 37,3 & 19111 & 11,4 & B300 \\
\hline 3522307 & Itapetininga & 73252 & 53,8 & 23691 & 17,4 & 39213 & 28,8 & B300 \\
\hline 3523404 & Itatiba & 51260 & 57,0 & 17986 & 20,0 & 20594 & 22,9 & B100 \\
\hline 3524303 & Jaboticabal & 38325 & 53,9 & 5973 & 8,4 & 26806 & 37,7 & B100 \\
\hline 3524402 & Jacareí & 131486 & 64,6 & 33991 & 16,7 & 38062 & 18,7 & B300 \\
\hline 3524709 & Jaguariúna & 18066 & 55,2 & 7364 & 22,5 & 7298 & 22,3 & B50 \\
\hline 3526407 & Laranjal Paulista & 13362 & 56,9 & - & -1 & 10122 & 43,1 & B50 \\
\hline 3526902 & Limeira & 156209 & 58,4 & 54834 & 20,5 & 56438 & 21,1 & B300 \\
\hline 3527108 & Lins & 36208 & 52,3 & 6508 & 9,4 & 26516 & 38,3 & $\mathrm{~B} 100$ \\
\hline 3527207 & Lorena & 59056 & 72,5 & 2525 & 3,1 & 19957 & 24,5 & $\mathrm{~B} 100$ \\
\hline 3529005 & Marília & 122127 & 57,2 & 26902 & 12,6 & 64480 & 30,2 & B300 \\
\hline 3529302 & Matao & 37921 & 50,3 & 7388 & 9,8 & 30081 & 39,9 & $\mathrm{~B} 100$ \\
\hline 3530300 & Mirassol & 27543 & 52,6 & 6388 & 12,2 & 18432 & 35,2 & B100 \\
\hline 3530607 & Moji das Cruzes & 196719 & 55,3 & 81462 & 22,9 & 77549 & 21,8 & B500 \\
\hline 3530706 & Moji Guaçu & 86613 & 64,3 & 13066 & 9,7 & 35157 & 26,1 & B300 \\
\hline 3530805 & MojiOMirim & 52915 & 59,5 & 7203 & 8,1 & 28725 & 32,3 & B100 \\
\hline 3533403 & Nova Odessa & 31086 & 68,1 & 11138 & 24,4 & 3424 & 7,5 & B50 \\
\hline 3534302 & Orlândia & 20115 & 52,8 & 6667 & 17,5 & 11315 & 29,7 & B50 \\
\hline 3534401 & Osasco & 381033 & 55,2 & 229863 & 33,3 & 79382 & 11,5 & B1000 \\
\hline 3536505 & Paulínia & 34482 & 59,6 & 15332 & 26,5 & 7984 & 13,8 & B100 \\
\hline 3537107 & Pedreira & 21574 & 56,1 & 1692 & 4,4 & 15191 & 39,5 & B50 \\
\hline
\end{tabular}


Anexo 4 - Municípios classificados no Estrato B - Vulnerabilidade Social Fraca segundo proporção da população nos grupos IPVS e porte populacional.Estado de São Paulo, média do triênio 2003 a 2005.

\begin{tabular}{|c|c|c|c|c|c|c|c|c|}
\hline IBGE & MUNICIPIO & IPVS 1,2,3 & $\%$ & IPVS 4 & $\%$ & IPVS 5,6 & $\%$ & Status \\
\hline 3538006 & Pindamonhangaba & 86139 & 63,0 & 28576 & 20,9 & 21877 & 16,0 & B300 \\
\hline 3538501 & Piquete & 8811 & 57,2 & - & - & 6592 & 42,8 & B20 \\
\hline 3538709 & Piracicaba & 226841 & 64,5 & 46423 & 13,2 & 78075 & 22,2 & B500 \\
\hline 3539301 & Pirassununga & 43012 & 62,8 & 7671 & 11,2 & 17876 & 26,1 & B100 \\
\hline 3539400 & Piratininga & 7007 & 63,7 & - & - & 3993 & 36,3 & B20 \\
\hline 3539806 & Poá & 61871 & 59,2 & 33862 & 32,4 & 8883 & 8,5 & B300 \\
\hline 3541000 & Praia Grande & 113344 & 50,4 & 40255 & 17,9 & 71515 & 31,8 & B300 \\
\hline 3541406 & Presidente Prudente & 123460 & 61,8 & 23373 & 11,7 & 52740 & 26,4 & B300 \\
\hline 3543303 & Ribeirão Pires & 79341 & 70,1 & 26145 & 23,1 & 7583 & 6,7 & B300 \\
\hline 3543402 & Ribeirão Preto & 393814 & 73,2 & 76934 & 14,3 & 67250 & 12,5 & $\mathrm{~B} 1000$ \\
\hline 3543907 & Rio Claro & 119861 & 66,0 & 33961 & 18,7 & 27786 & 15,3 & B300 \\
\hline 3544905 & Sales Oliveira & 5152 & 51,1 & 333 & 3,3 & 4598 & 45,6 & B20 \\
\hline 3545159 & Saltinho & 4310 & 70,4 & & - & 1812 & 29,6 & B20 \\
\hline 3545209 & Salto & 56046 & 54,7 & 31865 & 31,1 & 14549 & 14,2 & B300 \\
\hline 3545803 & Santa Bárbara d 'Oeste & 123008 & 67,9 & 29348 & 16,2 & 28804 & 15,9 & B300 \\
\hline 3546207 & Santa Cruz da Conceiçao & 1951 & 51,4 & 129 & 3,4 & 1716 & 45,2 & B20 \\
\hline 3546504 & Santa Ernestina & 2917 & 50,3 & 325 & 5,6 & 2557 & 44,1 & B20 \\
\hline 3547502 & Santa Rita do Passa Quatro & 14033 & 51,9 & 270 & 1,0 & 12735 & 47,1 & B50 \\
\hline 3548708 & Sao Bernardo do Campo & 463015 & 60,6 & 186428 & 24,4 & 113844 & 14,9 & $\mathrm{~B} 1000$ \\
\hline 3548906 & São Carlos & 145555 & 69,8 & 36493 & 17,5 & 26275 & 12,6 & B300 \\
\hline 3549102 & Sao Joao da Boa Vista & 49126 & 60,6 & 4378 & 5,4 & 27644 & 34,1 & B100 \\
\hline 3549805 & São José do Rio Preto & 271142 & 69,0 & 34580 & 8,8 & 86844 & 22,1 & B500 \\
\hline 3549904 & Sao José dos Campos & 376367 & 64,6 & 135749 & 23,3 & 70496 & 12,1 & $\mathrm{~B} 1000$ \\
\hline 3550308 & Sao Paulo & 6989495 & 64,8 & 2405335 & 22,3 & 1391427 & 12,9 & B10000 \\
\hline 3550407 & Sao Pedro & 18370 & 58,6 & 1223 & 3,9 & 11756 & 37,5 & B50 \\
\hline 3550605 & Sao Roque & 36825 & 51,9 & 7024 & 9,9 & 27104 & 38,2 & B100 \\
\hline 3550902 & Sao Simao & 7821 & 54,2 & 2352 & 16,3 & 4228 & 29,3 & B20 \\
\hline 3551009 & Sao Vicente & 198832 & 62,3 & 40213 & 12,6 & 80107 & 25,1 & $\mathrm{~B} 500$ \\
\hline 3552205 & Sorocaba & 356165 & 65,4 & 135060 & 24,8 & 53370 & 9,8 & $\mathrm{~B} 1000$ \\
\hline 3554102 & Taubaté & 185676 & 71,2 & 45115 & 17,3 & 29729 & 11,4 & B300 \\
\hline 3554508 & Tietê & 19883 & 57,2 & 6327 & 18,2 & 8586 & 24,7 & B50 \\
\hline 3554805 & Tremembé & 26377 & 69,3 & 5481 & 14,4 & 6242 & 16,4 & B50 \\
\hline 3556206 & Valinhos & 64234 & 71,6 & 16148 & 18,0 & 9330 & 10,4 & B100 \\
\hline 3557006 & Votorantim & 56902 & 55,4 & 32149 & 31,3 & 13661 & 13,3 & B300 \\
\hline
\end{tabular}

Fonte: Censo IBGE e Estratos de Vulnerabilidade Social segundo metodologia desenvolvida a partir do IPVS (FSEADE 2005)

Nota:

( - ) Dado numérico igual a 0 não resultante de arredondamento

$(0 ; 0,0 ; 0,00)$ Dado numérico igual a zero resultante de arredondamento de um dado originalmente positivo

Eventualmente a soma das parcelas pode não coincidir com o total em função de arredondamentos efetuados nos dados parciais.

População atualizada segundo projeção(IBGE) para o período (média) pela participação relativa nos grupos IPVS 
Anexo 5 - Municípios classificados no Estrato C - Vulnerabilidade Social Intermediária segundo proporção da população nos grupos IPVS e porte populacional. Estado de São Paulo, média do triênio de 2003 a 2005.

\begin{tabular}{|c|c|c|c|c|c|c|c|c|c|c|}
\hline IBGE & MUNICIPIO & POP & IPVS & $1,2,3$ & $\%$ & IPVS 4 & $\%$ & IPVS 5,6 & $\%$ & Status \\
\hline 3500709 & Agudos & 33511 & & 13471 & 40,2 & 3552 & 10,6 & 16521 & 49,3 & $\mathrm{C} 50$ \\
\hline 3501152 & Alumínio & 15919 & & 7243 & 45,5 & 6861 & 43,1 & 1799 & 11,3 & $\mathrm{C} 20$ \\
\hline 3503802 & Artur Nogueira & 39299 & & 12576 & 32,0 & 12576 & 32,0 & 14108 & 35,9 & C50 \\
\hline 3503901 & Arujá & 68815 & & 27801 & 40,4 & 25806 & 37,5 & 15277 & 22,2 & C100 \\
\hline 3504107 & Atibaia & 122450 & & 60001 & 49,0 & 16163 & 13,2 & 46286 & 37,8 & C300 \\
\hline 3505302 & Barra Bonita & 37564 & & 18519 & 49,3 & 5447 & 14,5 & 13561 & 36,1 & C50 \\
\hline 3505708 & Barueri & 242890 & & 63637 & 26,2 & 155935 & 64,2 & 23317 & 9,6 & C300 \\
\hline 3505906 & Batatais & 54241 & & 23758 & 43,8 & 6997 & 12,9 & 23486 & 43,3 & C100 \\
\hline 3506102 & Bebedouro & 77965 & & 28847 & 37,0 & 11149 & 14,3 & 37969 & 48,7 & C100 \\
\hline 3506201 & Bento de Abreu & 2394 & & - & - & 1321 & 55,2 & 1073 & 44,8 & $\mathrm{C} 20$ \\
\hline 3506359 & Bertioga & 38332 & & 11576 & 30,2 & 21466 & 56,0 & 5290 & 13,8 & C50 \\
\hline 3506508 & Birigui & 102865 & & 46906 & 45,6 & 19236 & 18,7 & 36620 & 35,6 & C300 \\
\hline 3507803 & Brodósqui & 18635 & & 8348 & 44,8 & 3168 & 17,0 & 7119 & 38,2 & $\mathrm{C} 20$ \\
\hline 3508405 & Cabreúva & 39481 & & 11528 & 29,2 & 15319 & 38,8 & 12594 & 31,9 & C50 \\
\hline 3509007 & Caieiras & 85582 & & 40823 & 47,7 & 39111 & 45,7 & 5648 & 6,6 & C100 \\
\hline 3509205 & Cajamar & 58366 & & 8813 & 15,1 & 33327 & 57,1 & 16226 & 27,8 & C100 \\
\hline 3509601 & Campo Limpo Paulista & 71914 & & 34734 & 48,3 & 21862 & 30,4 & 15390 & 21,4 & C100 \\
\hline 3509700 & Campos do Jordao & 47430 & & 16079 & 33,9 & 11905 & 25,1 & 19446 & 41,0 & C50 \\
\hline 3510401 & Capivari & 44704 & & 21950 & 49,1 & 6437 & 14,4 & 16272 & 36,4 & C50 \\
\hline 3510500 & Caraguatatuba & 90555 & & 43919 & 48,5 & 15575 & 17,2 & 31151 & 34,4 & C100 \\
\hline 3510609 & Carapicuíba & 371814 & & 136828 & 36,8 & 176612 & 47,5 & 58003 & 15,6 & C500 \\
\hline 3512308 & Conchas & 16250 & & 7686 & 47,3 & 991 & 6,1 & 7573 & 46,6 & $\mathrm{C} 20$ \\
\hline 3512407 & Cordeirópolis & 19491 & & 9492 & 48,7 & 6237 & 32,0 & 3781 & 19,4 & $\mathrm{C} 20$ \\
\hline 3513009 & Cotia & 167540 & & 67854 & 40,5 & 68524 & 40,9 & 31162 & 18,6 & C300 \\
\hline 3513504 & Cubatao & 115978 & & 46159 & 39,8 & 20876 & 18,0 & 48943 & 42,2 & C300 \\
\hline 3513801 & Diadema & 380191 & & 126223 & 33,2 & 190476 & 50,1 & 63492 & 16,7 & C500 \\
\hline 3515004 & Embu & 230746 & & 42457 & 18,4 & 125064 & 54,2 & 63455 & 27,5 & C300 \\
\hline 3515103 & Embu Guaçu & 66133 & & 20700 & 31,3 & 16666 & 25,2 & 28768 & 43,5 & C100 \\
\hline 3515186 & Espírito Santo do Pinhal & 41954 & & 18292 & 43,6 & 3776 & 9,0 & 19844 & 47,3 & C50 \\
\hline 3557303 & Estiva Gerbi & 9830 & & 3195 & 32,5 & 1828 & 18,6 & 4807 & 48,9 & $\mathrm{C} 20$ \\
\hline 3515707 & Ferraz de Vasconcelos & 163018 & & 41733 & 25,6 & 69772 & 42,8 & 51351 & 31,5 & C300 \\
\hline 3516408 & Franco da Rocha & 118211 & & 39246 & 33,2 & 42083 & 35,6 & 37000 & 31,3 & C300 \\
\hline 3517406 & Guaíra & 36191 & & 12377 & 34,2 & 6406 & 17,7 & 17444 & 48,2 & C50 \\
\hline 3518701 & Guarujá & 289202 & & 107005 & 37,0 & 48875 & 16,9 & 133611 & 46,2 & C300 \\
\hline 3518800 & Guarulhos & 1199951 & & 489580 & 40,8 & 532778 & 44,4 & 178793 & 14,9 & C10000 \\
\hline 3519055 & Holambra & 8009 & & 3172 & 39,6 & 2299 & 28,7 & 2531 & 31,6 & $\mathrm{C} 20$ \\
\hline 3519071 & Hortolândia & 182302 & & 76020 & 41,7 & 78208 & 42,9 & 28075 & 15,4 & C300 \\
\hline 3520400 & Ilhabela & 24096 & & 9759 & 40,5 & 7373 & 30,6 & 6940 & 28,8 & C50 \\
\hline 3521002 & Iperó & 21872 & & 7830 & 35,8 & 6365 & 29,1 & 7677 & 35,1 & C50 \\
\hline 3521101 & Ipeúna & 5075 & & 137 & 2,7 & 2730 & 53,8 & 2208 & 43,5 & $\mathrm{C} 20$ \\
\hline 3521408 & Iracemápolis & 17255 & & 8455 & 49,0 & 3416 & 19,8 & 5401 & 31,3 & $\mathrm{C} 20$ \\
\hline 3522109 & Itanhaém & 83574 & & 35937 & 43,0 & 7940 & 9,5 & 39781 & 47,6 & C100 \\
\hline 3522208 & Itapecerica da Serra & 149358 & & 29872 & 20,0 & 68107 & 45,6 & 51529 & 34,5 & C300 \\
\hline 3522505 & Itapevi & 186757 & & 37165 & 19,9 & 77878 & 41,7 & 71715 & 38,4 & C300 \\
\hline 3523107 & Itaquaquecetuba & 321176 & & 53636 & 16,7 & 123653 & 38,5 & 143887 & 44,8 & C500 \\
\hline 3523602 & Itirapina & 14122 & & 6736 & 47,7 & 1087 & 7,7 & 6298 & 44,6 & $\mathrm{C} 20$ \\
\hline 3523909 & Itu & 147897 & & 67441 & 45,6 & 46588 & 31,5 & 33868 & 22,9 & C300 \\
\hline 3524006 & Itupeva & 29751 & & 8955 & 30,1 & 12257 & 41,2 & 8509 & 28,6 & C50 \\
\hline 3525003 & Jandira & 104809 & & 27984 & 26,7 & 73052 & 69,7 & 3773 & 3,6 & C300 \\
\hline
\end{tabular}


Anexo 5 - Municípios classificados no Estrato C - Vulnerabilidade Social Intermediária segundo proporção da população nos grupos IPVS e porte populacional. Estado de São Paulo, média do triênio de 2003 a 2005.

\begin{tabular}{|c|c|c|c|c|c|c|c|c|c|}
\hline IBGE & MUNICIPIO & POP & IPVS $\quad 1,2,3$ & $\%$ & IPVS 4 & $\%$ & IPVS 5,6 & $\%$ & Status \\
\hline 3525102 & Jardinópolis & 33680 & 12361 & 36,7 & 6467 & 19,2 & 14853 & 44,1 & $\mathrm{C} 50$ \\
\hline 3525300 & Jaú & 120139 & 56465 & 47,0 & 9611 & 8,0 & 54063 & 45,0 & C300 \\
\hline 3526803 & Lençóis Paulista & 59598 & 23839 & 40,0 & 10012 & 16,8 & 25687 & 43,1 & C100 \\
\hline 3527306 & Louveira & 27317 & 9315 & 34,1 & 10845 & 39,7 & 7157 & 26,2 & $\mathrm{C} 50$ \\
\hline 3527603 & Luís Antônio & 7750 & 3503 & 45,2 & 1806 & 23,3 & 2441 & 31,5 & $\mathrm{C} 20$ \\
\hline 3528403 & Mairinque & 44676 & 15369 & 34,4 & 16932 & 37,9 & 12375 & 27,7 & $\mathrm{C} 50$ \\
\hline 3528502 & Mairipora & 69122 & 30345 & 43,9 & 13686 & 19,8 & 25091 & 36,3 & C100 \\
\hline 3529401 & Mauá & 393941 & 185940 & 47,2 & 141031 & 35,8 & 66970 & 17,0 & C500 \\
\hline 3531100 & Mongaguá & 42278 & 19659 & 46,5 & 6553 & 15,5 & 16066 & 38,0 & $\mathrm{C} 50$ \\
\hline 3531308 & Monte Alto & 45340 & 19814 & 43,7 & 5259 & 11,6 & 20312 & 44,8 & C50 \\
\hline 3534203 & Orindiúva & 4658 & 1244 & 26,7 & 1486 & 31,9 & 1933 & 41,5 & $\mathrm{C} 20$ \\
\hline 3534708 & Ourinhos & 101412 & 46142 & 45,5 & 7707 & 7,6 & 47562 & 46,9 & C300 \\
\hline 3540002 & Pompéia & 18588 & 8290 & 44,6 & 3662 & 19,7 & 6617 & 35,6 & $\mathrm{C} 20$ \\
\hline 3540606 & Porto Feliz & 49345 & 20725 & 42,0 & 6366 & 12,9 & 22255 & 45,1 & $\mathrm{C} 50$ \\
\hline 3540705 & Porto Ferreira & 51433 & 24276 & 47,2 & 7406 & 14,4 & 19802 & 38,5 & C100 \\
\hline 3544004 & Rio das Pedras & 25455 & 10157 & 39,9 & 2749 & 10,8 & 12549 & 49,3 & C50 \\
\hline 3544103 & Rio Grande da Serra & 40304 & 6126 & 15,2 & 26278 & 65,2 & 7859 & 19,5 & $\mathrm{C} 50$ \\
\hline 3544251 & Rosana & 25790 & 9284 & 36,0 & 6215 & 24,1 & 10316 & 40,0 & $\mathrm{C} 50$ \\
\hline 3544301 & Roseira & 9631 & 4161 & 43,2 & 1743 & 18,1 & 3727 & 38,7 & $\mathrm{C} 20$ \\
\hline 3546405 & Santa Cruz do Rio Pardo & 42863 & 17702 & 41,3 & 4972 & 11,6 & 20188 & 47,1 & $\mathrm{C} 50$ \\
\hline 3546702 & Santa Gertrudes & 18327 & 2786 & 15,2 & 9255 & 50,5 & 6286 & 34,3 & $\mathrm{C} 20$ \\
\hline 3547304 & Santana de Parnaíba & 91385 & 31711 & 34,7 & 23669 & 25,9 & 36006 & 39,4 & C100 \\
\hline 3549409 & Sao Joaquim da Barra & 44097 & 16051 & 36,4 & 7629 & 17,3 & 20417 & 46,3 & $\mathrm{C} 50$ \\
\hline 3550704 & Sao Sebastiao & 68824 & 23056 & 33,5 & 22230 & 32,3 & 23607 & 34,3 & C100 \\
\hline 3551504 & Serrana & 36796 & 7102 & 19,3 & 12805 & 34,8 & 16889 & 45,9 & $\mathrm{C} 50$ \\
\hline 3551702 & Sertaozinho & 101761 & 46607 & 45,8 & 17605 & 17,3 & 37550 & 36,9 & C300 \\
\hline 3552403 & Sumaré & 221608 & 92854 & 41,9 & 78671 & 35,5 & 50083 & 22,6 & C300 \\
\hline 3552502 & Suzano & 259891 & 87843 & 33,8 & 87583 & 33,7 & 84465 & 32,5 & C300 \\
\hline 3552809 & Taboao da Serra & 214420 & 93058 & 43,4 & 82552 & 38,5 & 39024 & 18,2 & C300 \\
\hline 3554003 & Tatuí & 101701 & 42918 & 42,2 & 22069 & 21,7 & 36714 & 36,1 & C300 \\
\hline 3555406 & Ubatuba & 75555 & 23120 & 30,6 & 26293 & 34,8 & 26142 & 34,6 & C100 \\
\hline 3556453 & Vargem Grande Pta & 40193 & 14108 & 35,1 & 21342 & 53,1 & 4743 & 11,8 & $\mathrm{C} 50$ \\
\hline 3556503 & Várzea Paulista & 103464 & 45524 & 44,0 & 36937 & 35,7 & 21003 & 20,3 & C300 \\
\hline 3557105 & Votuporanga & 80551 & 39067 & 48,5 & 7088 & 8,8 & 34395 & 42,7 & C100 \\
\hline
\end{tabular}

Fonte: Censo IBGE e Estratos de Vulnerabilidade Social segundo metodologia desenvolvida a partir do IPVS (FSEADE 2005) Nota:

( - ) Dado numérico igual a 0 não resultante de arredondamento

$(0 ; 0,0 ; 0,00)$ Dado numérico igual a zero resultante de arredondamento de um dado originalmente positivo Eventualmente a soma das parcelas pode não coincidir com o total em função de arredondamentos efetuados nos dados parciais.

População atualizada segundo projeção(IBGE) para o período (média) pela participação relativa nos grupos IPVS/FSEADE 
Anexo 6 - Municípios classificados no Estrato D - Vulnerabilidade Social Intensa segundo proporção da população no IPVS e porte populacional, estado de São Paulo,média do triênio 2003 a 2005

\begin{tabular}{|c|c|c|c|c|c|c|c|c|c|}
\hline IBGE & MUNICIPIO & POP & IPVS 1,2,3 & $\%$ & IPVS 4 & $\%$ & IPVS 5,6 & $\%$ & Status \\
\hline 3500105 & Adamantina & 34124 & 16107 & 47,2 & 717 & 2,1 & 17301 & 50,7 & D50 \\
\hline 3500402 & Aguas da Prata & 7326 & 1949 & 26,6 & - & - & 5377 & 73,4 & D20 \\
\hline 3500501 & Aguas de Lindóia & 18055 & 7583 & 42,0 & - & - & 10472 & 58,0 & D20 \\
\hline 3501004 & Altinópolis & 16304 & 5152 & 31,6 & - & - & 11152 & 68,4 & D20 \\
\hline 3501301 & Alvares Machado & 24357 & 6138 & 25,2 & 1023 & 4,2 & 17196 & 70,6 & D50 \\
\hline 3501707 & Américo Brasiliense & 31960 & 6648 & 20,8 & 9141 & 28,6 & 16204 & 50,7 & D50 \\
\hline 3502101 & Andradina & 56390 & 19229 & 34,1 & 5639 & 10,0 & 31522 & 55,9 & D100 \\
\hline 3502200 & Angatuba & 20226 & 6149 & 30,4 & 40 & 0,2 & 14037 & 69,4 & D50 \\
\hline 3502705 & Apiaí & 27438 & 6805 & 24,8 & 3512 & 12,8 & 17121 & 62,4 & D50 \\
\hline 3502754 & Araçariguama & 13044 & 744 & 5,7 & 4539 & 34,8 & 7774 & 59,6 & D20 \\
\hline 3504909 & Bananal & 9997 & 3259 & 32,6 & & - & 6738 & 67,4 & D20 \\
\hline 3505203 & Bariri & 29868 & 9976 & 33,4 & 1673 & 5,6 & 18219 & 61,0 & D50 \\
\hline 3505609 & Barrinha & 26597 & 3404 & 12,8 & 4654 & 17,5 & 18512 & 69,6 & D50 \\
\hline 3505807 & Bastos & 21244 & 4546 & 21,4 & 3888 & 18,3 & 12831 & 60,4 & D50 \\
\hline 3506409 & Bilac & 6367 & 1738 & 27,3 & & & 4629 & 72,7 & D20 \\
\hline 3506607 & Biritiba Mirim & 27700 & 6953 & 25,1 & & - & 20747 & 74,9 & D50 \\
\hline 3506805 & Bocaina & 10417 & 3136 & 30,1 & 1354 & 13,0 & 5938 & 57,0 & D20 \\
\hline 3507001 & Boituva & 39383 & 18431 & 46,8 & 1063 & 2,7 & 19888 & 50,5 & D50 \\
\hline 3507100 & Bom Jesus dos Perdoes & 14857 & 3818 & 25,7 & 2258 & 15,2 & 8780 & 59,1 & D20 \\
\hline 3507407 & Borborema & 13676 & 3104 & 22,7 & 848 & 6,2 & 9724 & 71,1 & D20 \\
\hline 3507902 & Brotas & 20887 & 4950 & 23,7 & 1796 & 8,6 & 14140 & 67,7 & D50 \\
\hline 3508207 & Buritizal & 3617 & 991 & 27,4 & 333 & 9,2 & 2293 & 63,4 & D20 \\
\hline 3508801 & Cafelândia & 16033 & 6173 & 38,5 & - & - & 9860 & 61,5 & D20 \\
\hline 3509254 & Cajati & 31721 & 6471 & 20,4 & 2252 & 7,1 & 22998 & 72,5 & D50 \\
\hline 3510005 & Cândido Mota & 30993 & 10600 & 34,2 & 837 & 2,7 & 19557 & 63,1 & D50 \\
\hline 3510302 & Capela do Alto & 15799 & 1643 & 10,4 & 3097 & 19,6 & 11075 & 70,1 & D20 \\
\hline 3511409 & Cerqueira César & 16167 & 4834 & 29,9 & 1261 & 7,8 & 10088 & 62,4 & D20 \\
\hline 3511706 & Charqueada & 14065 & 4979 & 35,4 & 1125 & 8,0 & 7975 & 56,7 & D20 \\
\hline 3557204 & Chavantes & 12406 & 4665 & 37,6 & 1216 & 9,8 & 6526 & 52,6 & D20 \\
\hline 3512001 & Colina & 17001 & 1887 & 11,1 & 2380 & 14,0 & 12734 & 74,9 & D20 \\
\hline 3512704 & Corumbataí & 4078 & 1252 & 30,7 & - & - & 2826 & 69,3 & D20 \\
\hline 3513108 & Cravinhos & 31023 & 10424 & 33,6 & 4436 & 14,3 & 16163 & 52,1 & D50 \\
\hline 3513306 & Cruzália & 2587 & - & - & 717 & 27,7 & 1870 & 72,3 & D20 \\
\hline 3513702 & Descalvado & 30339 & 12651 & 41,7 & 1396 & 4,6 & 16262 & 53,6 & D50 \\
\hline 3514106 & Dois Córregos & 24169 & 8338 & 34,5 & 1837 & 7,6 & 13994 & 57,9 & D50 \\
\hline 3514403 & Dracena & 40861 & 13076 & 32,0 & 1920 & 4,7 & 25824 & 63,2 & D50 \\
\hline 3514601 & Dumont & 6899 & 2842 & 41,2 & 524 & 7,6 & 3532 & 51,2 & D20 \\
\hline
\end{tabular}


Anexo 6 - Municípios classificados no Estrato D - Vulnerabilidade Social Intensa segundo proporção da população no IPVS e porte populacional, estado de São Paulo,média do triênio 2003 a 2005

\begin{tabular}{|c|c|c|c|c|c|c|c|c|c|}
\hline IBGE & MUNICIPIO & POP & IPVS 1,2,3 & $\%$ & IPVS 4 & $\%$ & IPVS 5,6 & $\%$ & Status \\
\hline 3514809 & Eldorado & 14587 & 4026 & 27,6 & 15 & 0,1 & 10561 & 72,4 & $\mathrm{D} 20$ \\
\hline 3514908 & Elias Fausto & 14897 & 3099 & 20,8 & 879 & 5,9 & 10920 & 73,3 & $\mathrm{D} 20$ \\
\hline 3515152 & Engenheiro Coelho & 11611 & 3983 & 34,3 & 1103 & 9,5 & 6514 & 56,1 & $\mathrm{D} 20$ \\
\hline 3515194 & Espírito Santo do Turvo & 3989 & - & & 1025 & 25,7 & 2964 & 74,3 & D20 \\
\hline 3515509 & Fernandópolis & 64104 & 26731 & 41,7 & 5064 & 7,9 & 32308 & 50,4 & D100 \\
\hline 3515657 & Fernao & 1316 & 428 & 32,5 & - & - & 888 & 67,5 & D20 \\
\hline 3516309 & Francisco Morato & 156007 & 9984 & 6,4 & 30889 & 19,8 & 114977 & 73,7 & D300 \\
\hline 3516705 & Garça & 43909 & 14402 & 32,8 & 4654 & 10,6 & 24896 & 56,7 & D50 \\
\hline 3517208 & Guaiçara & 10483 & 2411 & 23,0 & 1782 & 17,0 & 6290 & 60,0 & D20 \\
\hline 3517505 & Guapiaçu & 15614 & 3950 & 25,3 & 640 & 4,1 & 11023 & 70,6 & D20 \\
\hline 3518206 & Guararapes & 29806 & 10194 & 34,2 & & - & 19612 & 65,8 & D50 \\
\hline 3518305 & Guararema & 23666 & 9727 & 41,1 & 450 & 1,9 & 13513 & 57,1 & D50 \\
\hline 3518859 & Guatapará & 6627 & 1385 & 20,9 & 543 & 8,2 & 4699 & 70,9 & D20 \\
\hline 3519253 & Iaras & 3455 & 639 & 18,5 & 878 & 25,4 & 1935 & 56,0 & D20 \\
\hline 3519303 & Ibaté & 29872 & 8932 & 29,9 & 4212 & 14,1 & 16728 & 56,0 & D50 \\
\hline 3519402 & Ibirá & 9773 & 2590 & 26,5 & & - & 7183 & 73,5 & D20 \\
\hline 3519600 & Ibitinga & 50364 & 13800 & 27,4 & 8612 & 17,1 & 27952 & 55,5 & D100 \\
\hline 3519808 & Icém & 7072 & 1450 & 20,5 & 594 & 8,4 & 5021 & 71,0 & D20 \\
\hline 3520004 & Igaraçu do Tietê & 23392 & 1661 & 7,1 & 4866 & 20,8 & 16866 & 72,1 & D50 \\
\hline 3520103 & Igarapava & 27534 & 6801 & 24,7 & 3772 & 13,7 & 16961 & 61,6 & D50 \\
\hline 3521309 & Ipua & 12546 & 2948 & 23,5 & 514 & 4,1 & 9083 & 72,4 & D20 \\
\hline 3522406 & Itapeva & 87021 & 27499 & 31,6 & 8006 & 9,2 & 51603 & 59,3 & D100 \\
\hline 3522604 & Itapira & 66411 & 24174 & 36,4 & 5911 & 8,9 & 36393 & 54,8 & D100 \\
\hline 3522703 & Itápolis & 39849 & 10600 & 26,6 & 1156 & 2,9 & 28094 & 70,5 & D50 \\
\hline 3523206 & Itararé & 48659 & 13868 & 28,5 & 3211 & 6,6 & 31580 & 64,9 & D50 \\
\hline 3523305 & Itariri & 14508 & 3351 & 23,1 & 464 & 3,2 & 10692 & 73,7 & D20 \\
\hline 3524105 & Ituverava & 37727 & 13808 & 36,6 & 3471 & 9,2 & 20448 & 54,2 & D50 \\
\hline 3524600 & Jacupiranga & 18206 & 7009 & 38,5 & & - & 11197 & 61,5 & D20 \\
\hline 3524808 & Jales & 48339 & 19191 & 39,7 & 3915 & 8,1 & 25281 & 52,3 & D50 \\
\hline 3524907 & Jambeiro & 4306 & 1171 & 27,2 & - & - & 3135 & 72,8 & $\mathrm{D} 20$ \\
\hline 3525201 & Jarinu & 19795 & 5384 & 27,2 & 218 & 1,1 & 14173 & 71,6 & D20 \\
\hline 3525706 & José Bonifácio & 30978 & 9324 & 30,1 & 3965 & 12,8 & 17657 & 57,0 & D50 \\
\hline 3526100 & Juquiá & 22107 & 4488 & 20,3 & 2211 & 10,0 & 15409 & 69,7 & D50 \\
\hline 3526209 & Juquitiba & 29359 & 5490 & 18,7 & 3699 & 12,6 & 20140 & 68,6 & D50 \\
\hline 3526605 & Lavrinhas & 6604 & 621 & 9,4 & 1829 & 27,7 & 4154 & 62,9 & D20 \\
\hline 3526704 & Leme & 86359 & 26167 & 30,3 & 2677 & 3,1 & 57515 & 66,6 & D100 \\
\hline 3527009 & Lindóia & 5896 & 2240 & 38,0 & & & 3656 & 62,0 & D20 \\
\hline
\end{tabular}


Anexo 6 - Municípios classificados no Estrato D - Vulnerabilidade Social Intensa segundo proporção da população no IPVS e porte populacional, estado de São Paulo,média do triênio 2003 a 2005

\begin{tabular}{|c|c|c|c|c|c|c|c|c|c|}
\hline IBGE & MUNICIPIO & POP & IPVS 1,2,3 & $\%$ & IPVS 4 & $\%$ & IPVS 5,6 & $\%$ & Status \\
\hline 3527405 & Lucélia & 18536 & 4597 & 24,8 & 982 & 5,3 & 12957 & 69,9 & D20 \\
\hline 3528007 & Macatuba & 16772 & 5132 & 30,6 & 2566 & 15,3 & 9074 & 54,1 & D20 \\
\hline 3528601 & Manduri & 8715 & 3355 & 38,5 & - & - & 5368 & 61,6 & D20 \\
\hline 3528809 & Maracaí & 13243 & 4145 & 31,3 & 1695 & 12,8 & 7403 & 55,9 & D20 \\
\hline 3529203 & Martinópolis & 23540 & 5014 & 21,3 & 1059 & 4,5 & 17443 & 74,1 & D50 \\
\hline 3530102 & Mirandópolis & 26607 & 8674 & 32,6 & & - & 17933 & 67,4 & D50 \\
\hline 3530508 & Mococa & 68790 & 20706 & 30,1 & 4884 & 7,1 & 43200 & 62,8 & D100 \\
\hline 3531407 & Monte Aprazível & 18818 & 7584 & 40,3 & 1 & - & 11234 & 59,7 & D20 \\
\hline 3531803 & Monte Mor & 42602 & 10693 & 25,1 & 4814 & 11,3 & 27137 & 63,7 & D50 \\
\hline 3531902 & Morro Agudo & 27293 & 6741 & 24,7 & 3111 & 11,4 & 17413 & 63,8 & D50 \\
\hline 3532009 & Morungaba & 10672 & 4311 & 40,4 & 758 & 7,1 & 5603 & 52,5 & D20 \\
\hline 3532058 & Motuca & 4126 & 1147 & 27,8 & & - & 2979 & 72,2 & D20 \\
\hline 3532603 & Nhandeara & 10124 & 3098 & 30,6 & & - & 7026 & 69,4 & D20 \\
\hline 3532900 & Nova Europa & 8168 & 2091 & 25,6 & & - & 6077 & 74,4 & D20 \\
\hline 3533502 & Novo Horizonte & 33323 & 9264 & 27,8 & 1466 & 4,4 & 22593 & 67,8 & D50 \\
\hline 3533908 & Olímpia & 47401 & 14220 & 30,0 & 4503 & 9,5 & 28678 & 60,5 & D50 \\
\hline 3534104 & Oriente & 5473 & 1407 & 25,7 & & - & 4066 & 74,3 & D20 \\
\hline 3534609 & Osvaldo Cruz & 29974 & 11630 & 38,8 & 779 & 2,6 & 17595 & 58,7 & D50 \\
\hline 3535309 & Palmital & 21603 & 6719 & 31,1 & & & 14906 & 69,0 & D50 \\
\hline 3535507 & Paraguaçu Paulista & 42198 & 11520 & 27,3 & 5739 & 13,6 & 24897 & 59,0 & D50 \\
\hline 3536109 & Pardinho & 5305 & 1029 & 19,4 & 536 & 10,1 & 3745 & 70,6 & D20 \\
\hline 3536208 & Pariquera0Açu & 19652 & 6407 & 32,6 & 1297 & 6,6 & 11929 & 60,7 & D20 \\
\hline 3536307 & Patrocínio Paulista & 12176 & 998 & 8,2 & 2216 & 18,2 & 8974 & 73,7 & D20 \\
\hline 3536703 & Pederneiras & 38664 & 11058 & 28,6 & 6689 & 17,3 & 20879 & 54,0 & D50 \\
\hline 3537008 & Pedregulho & 15561 & 4264 & 27,4 & & - & 11297 & 72,6 & D20 \\
\hline 3537305 & Penápolis & 57471 & 21667 & 37,7 & 3563 & 6,2 & 32241 & 56,1 & D100 \\
\hline 3537404 & Pereira Barreto & 24781 & 6170 & 24,9 & 1784 & 7,2 & 16851 & 68,0 & D50 \\
\hline 3537602 & Peruíbe & 59795 & 23260 & 38,9 & 2332 & 3,9 & 34203 & 57,2 & D100 \\
\hline 3537800 & Piedade & 53057 & 15652 & 29,5 & - & - & 37352 & 70,4 & D100 \\
\hline 3538600 & Piracaia & 25289 & 5918 & 23,4 & 1543 & 6,1 & 17829 & 70,5 & D50 \\
\hline 3538808 & Piraju & 28709 & 11139 & 38,8 & 402 & 1,4 & 17168 & 59,8 & D50 \\
\hline 3538907 & Pirajuí & 20661 & 5723 & 27,7 & 3058 & 14,8 & 11880 & 57,5 & D50 \\
\hline 3539103 & Pirapora do Bom Jesus & 14376 & 2099 & 14,6 & 4298 & 29,9 & 7993 & 55,6 & D20 \\
\hline 3539202 & Pirapozinho & 22603 & 6939 & 30,7 & 2238 & 9,9 & 13426 & 59,4 & D50 \\
\hline 3539509 & Pitangueiras & 32991 & 8017 & 24,3 & 4124 & 12,5 & 20850 & 63,2 & D50 \\
\hline 3540200 & Pontal & 32752 & 10055 & 30,7 & 6321 & 19,3 & 16409 & 50,1 & D50 \\
\hline 3540903 & Pradópolis & 14271 & 4082 & 28,6 & 2612 & 18,3 & 7578 & 53,1 & D20 \\
\hline
\end{tabular}


Anexo 6 - Municípios classificados no Estrato D - Vulnerabilidade Social Intensa segundo proporção da população no IPVS e porte populacional, estado de São Paulo,média do triênio 2003 a 2005

\begin{tabular}{|c|c|c|c|c|c|c|c|c|c|}
\hline IBGE & MUNICIPIO & POP & IPVS 1,2,3 & $\%$ & IPVS 4 & $\%$ & IPVS 5,6 & $\%$ & Status \\
\hline 3541208 & Presidente Bernardes & 15222 & 4795 & 31,5 & 731 & 4,8 & 9696 & 63,7 & D20 \\
\hline 3541307 & Presidente Epitácio & 41285 & 14285 & 34,6 & 5780 & 14,0 & 21220 & 51,4 & D50 \\
\hline 3541505 & Presidente Venceslau & 37896 & 11482 & 30,3 & 834 & 2,2 & 25580 & 67,5 & D50 \\
\hline 3541604 & Promissao & 32500 & 11928 & 36,7 & 1398 & 4,3 & 19175 & 59,0 & D50 \\
\hline 3541703 & Quatá & 11788 & 2193 & 18,6 & 1674 & 14,2 & 7910 & 67,1 & D20 \\
\hline 3541901 & Queluz & 9738 & 2775 & 28,5 & - & - & 6963 & 71,5 & D20 \\
\hline 3542206 & Rancharia & 29600 & 9146 & 30,9 & 947 & 3,2 & 19506 & 65,9 & D50 \\
\hline 3542404 & Regente Feijó & 17906 & 4494 & 25,1 & 1952 & 10,9 & 11460 & 64,0 & D20 \\
\hline 3542602 & Registro & 55894 & 22525 & 40,3 & 5142 & 9,2 & 28226 & 50,5 & D100 \\
\hline 3542909 & Ribeirao Bonito & 11656 & 3439 & 29,5 & 1154 & 9,9 & 7052 & 60,5 & D20 \\
\hline 3543600 & Rifaina & 3516 & 1157 & 32,9 & 32 & 0,9 & 2328 & 66,2 & D20 \\
\hline 3543709 & Rincao & 10324 & 2726 & 26,4 & 909 & 8,8 & 6690 & 64,8 & D20 \\
\hline 3544509 & Rubinéia & 2784 & 821 & 29,5 & - & - & 1963 & 70,5 & D20 \\
\hline 3545308 & Salto de Pirapora & 39417 & 12771 & 32,4 & 4257 & 10,8 & 22428 & 56,9 & D50 \\
\hline 3545605 & Santa Adélia & 13822 & 3442 & 24,9 & 594 & 4,3 & 9786 & 70,8 & D20 \\
\hline 3546009 & Santa Branca & 14217 & 6142 & 43,2 & & & 8075 & 56,8 & D20 \\
\hline 3546306 & Santa Cruz das Palmeiras & 27225 & 9692 & 35,6 & 191 & 0,7 & 17342 & 63,7 & D50 \\
\hline 3546603 & Santa Fé do Sul & 28032 & 6363 & 22,7 & 3168 & 11,3 & 18473 & 65,9 & D50 \\
\hline 3546801 & Santa Isabel & 46315 & 14543 & 31,4 & 3242 & 7,0 & 28576 & 61,7 & D50 \\
\hline 3547601 & Santa Rosa de Viterbo & 22436 & 6641 & 29,6 & 3074 & 13,7 & 12721 & 56,7 & D50 \\
\hline 3548005 & Santo Antônio de Posse & 19855 & 7108 & 35,8 & 655 & 3,3 & 12092 & 60,9 & D20 \\
\hline 3548609 & São Bento do Sapucaí & 11097 & 2785 & 25,1 & & & 8312 & 74,9 & D20 \\
\hline 3549706 & Sao José do Rio Pardo & 52534 & 22747 & 43,3 & 2101 & 4,0 & 27685 & 52,7 & D100 \\
\hline 3550100 & Sao Manuel & 38522 & 10863 & 28,2 & 2388 & 6,2 & 25270 & 65,6 & D50 \\
\hline 3551603 & Serra Negra & 24808 & 11486 & 46,3 & 372 & 1,5 & 12950 & 52,2 & D50 \\
\hline 3552106 & Socorro & 33572 & 10508 & 31,3 & & 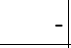 & 23064 & 68,7 & D50 \\
\hline 3553302 & Tambaú & 23330 & 7022 & 30,1 & 1960 & 8,4 & 14348 & 61,5 & D50 \\
\hline 3553401 & Tanabi & 23067 & 5421 & 23,5 & 692 & 3,0 & 16954 & 73,5 & D50 \\
\hline 3553609 & Tapiratiba & 13453 & 3673 & 27,3 & - & - & 9794 & 72,8 & D20 \\
\hline 3553708 & Taquaritinga & 54364 & 19245 & 35,4 & 5382 & 9,9 & 29737 & 54,7 & D100 \\
\hline 3553955 & Taruma & 11266 & 1138 & 10,1 & 2197 & 19,5 & 7931 & 70,4 & D20 \\
\hline 3554300 & Teodoro Sampaio & 20480 & 3748 & 18,3 & 2212 & 10,8 & 14520 & 70,9 & D50 \\
\hline 3555000 & Tupa & 65123 & 26700 & 41,0 & 5666 & 8,7 & 32757 & 50,3 & D100 \\
\hline 3555109 & Tupi Paulista & 12947 & 3535 & 27,3 & - & - & 9412 & 72,7 & D20 \\
\hline 3555604 & Uchoa & 9350 & 2020 & 21,6 & 748 & 8,0 & 6573 & 70,3 & D20 \\
\hline 3556107 & Valentim Gentil & 9812 & 3807 & 38,8 & - & - & 6005 & 61,2 & D20 \\
\hline 3556305 & Valparaíso & 19477 & 6252 & 32,1 & 2006 & 10,3 & 11219 & 57,6 & D20 \\
\hline
\end{tabular}


Anexo 6 - Municípios classificados no Estrato D - Vulnerabilidade Social Intensa segundo proporção da população no IPVS e porte populacional, estado de São Paulo,média do triênio 2003 a 2005

\begin{tabular}{|c|c|c|c|c|c|c|c|c|c|}
\hline IBGE & MUNICIPIO & POP & IPVS 1,2,3 & $\%$ & IPVS 4 & $\%$ & IPVS 5,6 & $\%$ & Status \\
\hline 3556404 & Vargem Grande do Sul & 38692 & 13155 & 34,0 & - & - & 25537 & 66,0 & D50 \\
\hline 3556800 & Viradouro & 17244 & 3483 & 20,2 & 2362 & 13,7 & 11398 & 66,1 & D20 \\
\hline 3556909 & Vista Alegre do Alto & 5263 & 1453 & 27,6 & 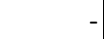 & - & 3810 & 72,4 & D20 \\
\hline
\end{tabular}

Fonte: Censo IBGE e Estratos de Vulnerabilidade Social segundo metodologia desenvolvida a partir do IPVS (FSEADE 2005) Nota:

( - ) Dado numérico igual a 0 não resultante de arredondamento

$(0 ; 0,0 ; 0,00)$ Dado numérico igual a zero resultante de arredondamento de um dado originalmente positivo

Eventualmente a soma das parcelas pode não coincidir com o total em função de arredondamentos efetuados nos dados parciais.

População atualizada segundo projeção(IBGE) para o período (média) pela participação relativa nos grupos IPVS 
Anexo 7 - Municípios classificados no Estrato E - Vulnerabilidade Social Muito Intensa segundo proporção da população nos grupos IPVS e porte populacional. Estado de São Paulo, média do triênio 2003 a 2005.

\begin{tabular}{|c|c|c|c|c|c|c|c|c|c|}
\hline IBGE & MUNICIPIO & POP & IPVS $1,2,3$ & $\%$ & IPVS 4 & $\%$ & IPVS 5,6 & $\%$ & PORTE \\
\hline 3500204 & Adolfo & 3868 & - & - & - & - & 3868 & 100,0 & E20 \\
\hline 3500303 & Aguaí & 30353 & 6617 & 21,8 & - & - & 23706 & 78,1 & E50 \\
\hline 3500758 & Alambari & 3806 & - & - & - & - & 3806 & 100,0 & E20 \\
\hline 3500808 & Alfredo Marcondes & 3786 & - & - & - & - & 3786 & 100,0 & E20 \\
\hline 3500907 & Altair & 3660 & - & - & 355 & 9,7 & 3305 & 90,3 & E20 \\
\hline 3501103 & Alto Alegre & 4026 & 149 & 3,7 & - & - & 3877 & 96,3 & E20 \\
\hline 3501202 & Alvares Florence & 3989 & - & - & - & - & 3989 & 100,0 & E20 \\
\hline 3501400 & Alvaro de Carvalho & 4545 & - & - & - & - & 4545 & 100,0 & E20 \\
\hline 3501509 & Alvinlândia & 2969 & - & - & 151 & 5,1 & 2818 & 94,9 & E20 \\
\hline 3501806 & Américo de Campos & 5594 & - & - & - & - & 5594 & 100,0 & E20 \\
\hline 3502309 & Anhembi & 4980 & 359 & 7,2 & 453 & 9,1 & 4173 & 83,8 & E20 \\
\hline 3502408 & Anhumas & 3486 & 234 & 6,7 & 56 & 1,6 & 3200 & 91,8 & E20 \\
\hline 3502606 & Aparecida d'Oeste & 4861 & - & - & - & - & 4861 & 100,0 & E20 \\
\hline 3503000 & Aramina & 5075 & - & - & - & - & 5075 & 100,0 & E20 \\
\hline 3503109 & Arandu & 6265 & 63 & 1,0 & - & - & 6196 & 98,9 & E20 \\
\hline 3503158 & Arapeí & 2762 & - & - & - & - & 2762 & 100,0 & E20 \\
\hline 3503356 & ArcoOIris & 2247 & 22 & 1,0 & 27 & 1,2 & 2200 & 97,9 & E20 \\
\hline 3503406 & Arealva & 7401 & 1132 & 15,3 & - & - & 6269 & 84,7 & E20 \\
\hline 3503505 & Areias & 3741 & - & - & - & - & 3741 & 100,0 & E20 \\
\hline 3503604 & Areiópolis & 10432 & 459 & 4,4 & 1700 & 16,3 & 8273 & 79,3 & E20 \\
\hline 3503703 & Ariranha & 8206 & 1469 & 17,9 & 41 & 0,5 & 6696 & 81,6 & E20 \\
\hline 3503950 & Aspásia & 1816 & - & - & - & - & 1816 & 100,0 & E20 \\
\hline 3504206 & Auriflama & 13846 & 3462 & 25,0 & - & - & 10385 & 75,0 & E20 \\
\hline 3504305 & Avaí & 4578 & 18 & 0,4 & - & - & 4560 & 99,6 & E20 \\
\hline 3504404 & Avanhandava & 9213 & - & - & - & - & 9213 & 100,0 & E20 \\
\hline 3504701 & Balbinos & 1355 & - & - & - & - & 1355 & 100,0 & E20 \\
\hline 3504800 & Bálsamo & 7592 & 858 & 11,3 & - & - & 6734 & 88,7 & E20 \\
\hline 3505005 & Barao de Antonina & 2690 & - & - & - & - & 2690 & 100,0 & E20 \\
\hline 3505104 & Barbosa & 6042 & - & - & - & - & 6042 & 100,0 & E20 \\
\hline 3505351 & Barra do Chapéu & 4812 & - & - & 467 & 9,7 & 4350 & 90,4 & E20 \\
\hline 3505401 & Barra do Turvo & 8548 & 1470 & 17,2 & - & - & 7078 & 82,8 & E20 \\
\hline 3506300 & Bernardino de Campos & 11020 & 1455 & 13,2 & - & - & 9565 & 86,8 & E20 \\
\hline 3506706 & Boa Esperança do Sul & 13447 & 699 & 5,2 & - & - & 12748 & 94,8 & E20 \\
\hline 3506904 & Bofete & 8109 & 1273 & 15,7 & 24 & 0,3 & 6803 & 83,9 & E20 \\
\hline 3507159 & Bom Sucesso de Itararé & 3635 & & - & - & - & 3635 & 100,0 & E20 \\
\hline 3507209 & Borá & 810 & - & - & - & - & 810 & 100,0 & E20 \\
\hline 3507308 & Boracéia & 3865 & - & - & - & - & 3865 & 100,0 & E20 \\
\hline 3507456 & Borebi & 2170 & & - & - & - & 2170 & 100,0 & E20 \\
\hline 3507704 & Braúna & 4438 & -1 & - & - & - & 4438 & 100,0 & E20 \\
\hline
\end{tabular}


Anexo 7 - Municípios classificados no Estrato E - Vulnerabilidade Social Muito Intensa segundo proporção da população nos grupos IPVS e porte populacional. Estado de São Paulo, média do triênio 2003 a 2005.

\begin{tabular}{|c|c|c|c|c|c|c|c|c|c|}
\hline IBGE & MUNICIPIO & POP & IPVS 1,2,3 & $\%$ & IPVS 4 & $\%$ & IPVS 5,6 & $\%$ & PORTE \\
\hline 3507753 & Brejo Alegre & 2455 & - & - & - & - & 2455 & 100,0 & E20 \\
\hline 3508009 & Buri & 19106 & 2484 & 13,0 & - & - & 16622 & 87,0 & E20 \\
\hline 3508108 & Buritama & 14342 & 2926 & 20,4 & 301 & 2,1 & 11115 & 77,5 & E20 \\
\hline 3508306 & Cabrália Paulista & 5011 & & & - & - & 5011 & 100,0 & E20 \\
\hline 3508702 & Caconde & 18867 & 3226 & 17,1 & - & - & 15641 & 82,9 & E20 \\
\hline 3508900 & Caiabu & 4178 & - & - & - & - & 4178 & 100,0 & E20 \\
\hline 3509106 & Caiuá & 4572 & - & - & - & - & 4572 & 100,0 & E20 \\
\hline 3509304 & Cajobi & 9361 & - & - & - & - & 9361 & 100,0 & E20 \\
\hline 3509403 & Cajuru & 21771 & 4420 & 20,3 & 958 & 4,4 & 16394 & 75,3 & E50 \\
\hline 3509452 & Campina Monte Alegre & 5791 & 892 & 15,4 & - & - & 4905 & 84,7 & E20 \\
\hline 3509809 & Campos Novos Paulista & 4255 & - & - & - & - & 4255 & 100,0 & E20 \\
\hline 3509908 & Cananéia & 13444 & 2931 & 21,8 & - & - & 10500 & 78,1 & E20 \\
\hline 3509957 & Canas & 3924 & - & - & - & - & 3924 & 100,0 & E20 \\
\hline 3510104 & Cândido Rodrigues & 2740 & - & - & - & - & 2740 & 100,0 & E20 \\
\hline 3510153 & Canitar & 3947 & - & - & - & - & 3947 & 100,0 & E20 \\
\hline 3510203 & Capao Bonito & 46865 & 9467 & 20,2 & 1453 & 3,1 & 35945 & 76,7 & E50 \\
\hline 3510708 & Cardoso & 11302 & 995 & 8,8 & - & - & 10307 & 91,2 & E20 \\
\hline 3510906 & Cássia dos Coqueiros & 2940 & 538 & 18,3 & - & - & 2402 & 81,7 & E20 \\
\hline 3511003 & Castilho & 15100 & 951 & 6,3 & - & - & 14149 & 93,7 & E20 \\
\hline 3511201 & Catiguá & 6687 & - & - & - & - & 6687 & 100,0 & E20 \\
\hline 3511300 & Cedral & 7145 & 1729 & 24,2 & - & - & 5416 & 75,8 & E20 \\
\hline 3511607 & Cesário Lange & 13657 & 2991 & 21,9 & - & - & 10666 & 78,1 & E20 \\
\hline 3511904 & Clementina & 5636 & - & - & - & - & 5636 & 100,0 & E20 \\
\hline 3512100 & Colômbia & 6255 & - & - & 519 & 8,3 & 5736 & 91,7 & E20 \\
\hline 3512209 & Conchal & 24197 & 4162 & 17,2 & 1815 & 7,5 & 18196 & 75,2 & E50 \\
\hline 3512506 & Coroados & 4587 & - & - & - & - & 4587 & 100,0 & E20 \\
\hline 3512605 & Coronel Macedo & 5518 & - & - & - & - & 5518 & 100,0 & E20 \\
\hline 3512902 & Cosmorama & 7167 & - & - & - & - & 7167 & 100,0 & E20 \\
\hline 3513207 & Cristais Paulista & 6995 & - & - & - & - & 6995 & 100,0 & E20 \\
\hline 3513603 & Cunha & 22925 & 1949 & 8,5 & - & - & 20976 & 91,5 & E50 \\
\hline 3513850 & Dirce Reis & 1498 & - & - & - & - & 1498 & 100,0 & E20 \\
\hline 3513900 & Divinolândia & 12107 & 1525 & 12,6 & - & - & 10582 & 87,4 & E20 \\
\hline 3514007 & Dobrada & 7048 & 951 & 13,5 & 289 & 4,1 & 5808 & 82,4 & E20 \\
\hline 3514205 & Dolcinópolis & 2175 & - & - & - & - & 2175 & 100,0 & E20 \\
\hline 3514304 & Dourado & 8993 & 1547 & 17,2 & 234 & 2,6 & 7212 & 80,2 & E20 \\
\hline 3514502 & Duartina & 12732 & 1693 & 13,3 & - & - & 11039 & 86,7 & E20 \\
\hline 3514700 & Echapora & 7054 & 825 & 11,7 & - & - & 6229 & 88,3 & E20 \\
\hline 3514924 & Elisiário & 2588 & - & & - & - & 2588 & 100,0 & E20 \\
\hline 3514957 & Embaúba & 2513 & - & - & - & - & 2513 & 100,0 & E20 \\
\hline
\end{tabular}


Anexo 7 - Municípios classificados no Estrato E - Vulnerabilidade Social Muito Intensa segundo proporção da população nos grupos IPVS e porte populacional. Estado de São Paulo, média do triênio 2003 a 2005.

\begin{tabular}{|c|c|c|c|c|c|c|c|c|c|}
\hline IBGE & MUNICIPIO & POP & IPVS $1,2,3$ & $\%$ & IPVS 4 & $\%$ & IPVS 5,6 & $\%$ & PORTE \\
\hline 3515129 & Emilianópolis & 2893 & - & - & - & - & 2893 & 100,0 & E20 \\
\hline 3515301 & Estrela do Norte & 2557 & - & - & - & - & 2557 & 100,0 & E20 \\
\hline 3515202 & Estrela d'Oeste & 8150 & 1703 & 20,9 & - & - & 6447 & 79,1 & E20 \\
\hline 3515350 & Euclides Cunha Paulista & 10506 & - & & 725 & 6,9 & 9781 & 93,1 & E20 \\
\hline 3515400 & Fartura & 15314 & 3629 & 23,7 & - & - & 11685 & 76,3 & E20 \\
\hline 3515608 & Fernando Prestes & 5549 & 977 & 17,6 & - & - & 4572 & 82,4 & E20 \\
\hline 3515806 & Flora Rica & 2087 & - & - & - & - & 2087 & 100,0 & E20 \\
\hline 3515905 & Floreal & 3078 & - & - & - & - & 3078 & 100,0 & E20 \\
\hline 3516002 & Flórida Paulista & 10478 & 608 & 5,8 & - & - & 9870 & 94,2 & E20 \\
\hline 3516101 & Florínia & 3181 & - & - & 29 & 0,9 & 3152 & 99,1 & E20 \\
\hline 3516507 & Gabriel Monteiro & 2839 & - & - & - & - & 2839 & 100,0 & E20 \\
\hline 3516606 & Gália & 7427 & 431 & 5,8 & - & - & 6989 & 94,1 & E20 \\
\hline 3516804 & Gastao Vidigal & 3475 & - & - & - & - & 3475 & 100,0 & E20 \\
\hline 3516853 & Gaviao Peixoto & 4084 & - & - & - & - & 4084 & 100,0 & E20 \\
\hline 3516903 & General Salgado & 11023 & 1488 & 13,5 & 794 & 7,2 & 8741 & 79,3 & E20 \\
\hline 3517000 & Getulina & 10481 & 1038 & 9,9 & - & - & 9443 & 90,1 & E20 \\
\hline 3517109 & Glicério & 4514 & 939 & 20,8 & - & - & 3575 & 79,2 & E20 \\
\hline 3517307 & Guaimbê & 5238 & - & - & - & - & 5238 & 100,0 & E20 \\
\hline 3517604 & Guapiara & 20371 & 998 & 4,9 & - & - & 19373 & 95,1 & E50 \\
\hline 3517703 & Guará & 20057 & 1344 & 6,7 & 1544 & 7,7 & 17169 & 85,6 & E50 \\
\hline 3517802 & Guaraçaí & 9165 & 935 & 10,2 & 715 & 7,8 & 7515 & 82,0 & E20 \\
\hline 3517901 & Guaraci & 9308 & 921 & 9,9 & - & - & 8387 & 90,1 & E20 \\
\hline 3518008 & Guarani d'Oeste & 2083 & - & - & - & - & 2083 & 100,0 & E20 \\
\hline 3518107 & Guaranta & 6673 & - & - & - & - & 6673 & 100,0 & E20 \\
\hline 3518503 & Guareí & 10969 & 867 & 7,9 & 1788 & 16,3 & 8315 & 75,8 & E20 \\
\hline 3518602 & Guariba & 32056 & 4648 & 14,5 & - & - & 27408 & 85,5 & E50 \\
\hline 3518909 & Guzolândia & 3956 & - & - & - & - & 3956 & 100,0 & E20 \\
\hline 3519006 & Herculândia & 8419 & 724 & 8,6 & 1027 & 12,2 & 6676 & 79,3 & E20 \\
\hline 3519105 & lacanga & 8600 & 791 & 9,2 & - & - & 7809 & 90,8 & E20 \\
\hline 3519204 & Iacri & 6669 & 800 & 12,0 & - & - & 5869 & 88,0 & E20 \\
\hline 3519501 & Ibirarema & 5778 & 711 & 12,3 & - & - & 5067 & 87,7 & E20 \\
\hline 3519709 & Ibiúna & 71173 & 7900 & 11,1 & 6121 & 8,6 & 57081 & 80,2 & E100 \\
\hline 3519907 & lepê & 7088 & 489 & 6,9 & - & - & 6599 & 93,1 & E20 \\
\hline 3520202 & Igaratá & 9186 & 1470 & 16,0 & 542 & 5,9 & 7174 & 78,1 & E20 \\
\hline 3520301 & Iguape & 28245 & 4773 & 16,9 & 2175 & 7,7 & 21297 & 75,4 & E50 \\
\hline 3520608 & Indiana & 5070 & 867 & 17,1 & - & - & 4203 & 82,9 & E20 \\
\hline 3520707 & Indiapora & 3742 & - & - & - & - & 3742 & 100,0 & E20 \\
\hline 3520806 & Inúbia Paulista & 3307 & 162 & 4,9 & - & - & 3145 & 95,1 & E20 \\
\hline 3520905 & Ipauçu & 13064 & 2090 & 16,0 & - & - & 10974 & 84,0 & E20 \\
\hline
\end{tabular}


Anexo 7 - Municípios classificados no Estrato E - Vulnerabilidade Social Muito Intensa segundo proporção da população nos grupos IPVS e porte populacional. Estado de São Paulo, média do triênio 2003 a 2005.

\begin{tabular}{|c|c|c|c|c|c|c|c|c|c|}
\hline IBGE & MUNICIPIO & POP & IPVS 1,2,3 & $\%$ & IPVS 4 & $\%$ & IPVS 5,6 & $\%$ & PORTE \\
\hline 3521150 & Ipiguá & 3985 & - & - & - & - & 3985 & 100,0 & E20 \\
\hline 3521200 & Iporanga & 4540 & 617 & 13,6 & - & - & 3923 & 86,4 & E20 \\
\hline 3521507 & Irapua & 6912 & 1037 & 15,0 & - & - & 5875 & 85,0 & E20 \\
\hline 3521606 & Irapuru & 7102 & & & 781 & 11,0 & 6321 & 89,0 & E20 \\
\hline 3521705 & Itaberá & 19364 & 2362 & 12,2 & 1162 & 6,0 & 15840 & 81,8 & E20 \\
\hline 3521804 & Itaí & 22475 & 3034 & 13,5 & 1843 & 8,2 & 17598 & 78,3 & E50 \\
\hline 3521903 & Itajobi & 14700 & 3058 & 20,8 & - & - & 11642 & 79,2 & E20 \\
\hline 3522000 & Itaju & 2762 & - & - & - & - & 2762 & 100,0 & E20 \\
\hline 3522158 & Itaóca & 3002 & - & - & - & - & 3002 & 100,0 & E20 \\
\hline 3522653 & Itapirapua Paulista & 3717 & - & - & - & - & 3717 & 100,0 & E20 \\
\hline 3522802 & Itaporanga & 14330 & 1046 & 7,3 & - & - & 13284 & 92,7 & E20 \\
\hline 3522901 & Itapuí & 10959 & 318 & 2,9 & 2323 & 21,2 & 8318 & 75,9 & E20 \\
\hline 3523008 & Itapura & 3877 & - & - & - & - & 3877 & 100,0 & E20 \\
\hline 3523503 & Itatinga & 16194 & 2154 & 13,3 & 1393 & 8,6 & 12648 & 78,1 & E20 \\
\hline 3523701 & Itirapua & 5575 & 736 & 13,2 & - & - & 4839 & 86,8 & E20 \\
\hline 3523800 & Itobi & 7771 & - & - & 420 & 5,4 & 7351 & 94,6 & E20 \\
\hline 3524204 & Jaborandi & 6465 & - & - & - & - & 6465 & 100,0 & E20 \\
\hline 3524501 & Jaci & 4510 & - & - & - & - & 4510 & 100,0 & E20 \\
\hline 3525409 & Jeriquara & 3288 & - & - & - & - & 3288 & 100,0 & E20 \\
\hline 3525508 & Joanópolis & 11402 & 1505 & 13,2 & - & - & 9897 & 86,8 & E20 \\
\hline 3525607 & Joao Ramalho & 4191 & - & - & 197 & 4,7 & 3994 & 95,3 & E20 \\
\hline 3525805 & Júlio Mesquita & 4311 & - & - & 78 & 1,8 & 4233 & 98,2 & E20 \\
\hline 3526001 & Junqueirópolis & 16692 & 801 & 4,8 & 618 & 3,7 & 15290 & 91,6 & E20 \\
\hline 3526308 & Lagoinha & 5101 & - & - & - & - & 5101 & 100,0 & E20 \\
\hline 3526506 & Lavínia & 4994 & - & - & 639 & 12,8 & 4355 & 87,2 & E20 \\
\hline 3527256 & Lourdes & 2160 & - & - & - & - & 2160 & 100,0 & E20 \\
\hline 3527504 & Lucianópolis & 2066 & - & - & - & - & 2066 & 100,0 & E20 \\
\hline 3527702 & Luiziânia & 4329 & - & - & - & - & 4329 & 100,0 & E20 \\
\hline 3527801 & Lupércio & 4295 & - & - & - & - & 4295 & 100,0 & E20 \\
\hline 3527900 & Lutécia & 3012 & - & - & - & - & 3012 & 100,0 & E20 \\
\hline 3528106 & Macaubal & 7385 & 923 & 12,5 & - & - & 6462 & 87,5 & E20 \\
\hline 3528205 & Macedônia & 3674 & - & - & - & - & 3674 & 100,0 & E20 \\
\hline 3528304 & Magda & 3305 & 106 & 3,2 & - & - & 3199 & 96,8 & E20 \\
\hline 3528700 & Marabá Paulista & 3790 & - & - & - & - & 3790 & 100,0 & E20 \\
\hline 3528858 & Marapoama & 2418 & - & - & - & - & 2418 & 100,0 & E20 \\
\hline 3528908 & Mariápolis & 3632 & - & - & - & - & 3632 & 100,0 & E20 \\
\hline 3529104 & Marinópolis & 2244 & - & - & - & - & 2244 & 100,0 & E20 \\
\hline 3529500 & Mendonça & 3875 & - & 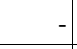 & - & - & 3875 & 100,0 & E20 \\
\hline 3529609 & Meridiano & 4133 & - & - & - & - & 4133 & 100,0 & E20 \\
\hline
\end{tabular}


Anexo 7 - Municípios classificados no Estrato E - Vulnerabilidade Social Muito Intensa segundo proporção da população nos grupos IPVS e porte populacional. Estado de São Paulo, média do triênio 2003 a 2005.

\begin{tabular}{|c|c|c|c|c|c|c|c|c|c|}
\hline IBGE & MUNICIPIO & POP & IPVS $1,2,3$ & $\%$ & IPVS 4 & $\%$ & IPVS 5,6 & $\%$ & PORTE \\
\hline 3529658 & Mesópolis & 1895 & - & - & - & - & 1895 & 100,0 & E20 \\
\hline 3529708 & Miguelópolis & 19739 & 3711 & 18,8 & - & - & 16028 & 81,2 & E20 \\
\hline 3529807 & Mineiros do Tietê & 12279 & 565 & 4,6 & 258 & 2,1 & 11456 & 93,3 & E20 \\
\hline 3530003 & Mira Estrela & 2565 & 159 & 6,2 & & - & 2406 & 93,8 & E20 \\
\hline 3529906 & Miracatu & 23906 & 4757 & 19,9 & 980 & 4,1 & 18169 & 76,0 & E50 \\
\hline 3530201 & Mirante Paranapanema & 16674 & 634 & 3,8 & - & - & 16057 & 96,3 & E20 \\
\hline 3530409 & Mirassolândia & 4063 & - & - & - & - & 4063 & 100,0 & E20 \\
\hline 3530904 & Mombuca & 3334 & 560 & 16,8 & - & - & 2774 & 83,2 & E20 \\
\hline 3531001 & Monçoes & 2035 & - & - & - & - & 2035 & 100,0 & E20 \\
\hline 3531209 & Monte Alegre do Sul & 6715 & 1585 & 23,6 & - & - & 5137 & 76,5 & E20 \\
\hline 3531506 & Monte Azul Paulista & 20383 & 4586 & 22,5 & - & - & 15797 & 77,5 & E50 \\
\hline 3531605 & Monte Castelo & 3808 & - & - & - & - & 3808 & 100,0 & E20 \\
\hline 3531704 & Monteiro Lobato & 3721 & - & - & - & - & 3721 & 100,0 & E20 \\
\hline 3532108 & Murutinga do Sul & 4056 & - & - & - & - & 4056 & 100,0 & E20 \\
\hline 3532157 & Nantes & 2218 & - & - & - & - & 2218 & 100,0 & E20 \\
\hline 3532207 & Narandiba & 4013 & - & - & - & - & 4013 & 100,0 & E20 \\
\hline 3532306 & Natividade da Serra & 7172 & 567 & 7,9 & - & - & 6605 & 92,1 & E20 \\
\hline 3532405 & Nazaré Paulista & 15633 & 1501 & 9,6 & - & - & 14132 & 90,4 & E20 \\
\hline 3532504 & Neves Paulista & 9172 & 1734 & 18,9 & - & - & 7438 & 81,1 & E20 \\
\hline 3532702 & Nipoa & 3477 & - & - & - & - & 3477 & 100,0 & E20 \\
\hline 3532801 & Nova Aliança & 5025 & 1040 & 20,7 & - & - & 3985 & 79,3 & E20 \\
\hline 3532827 & Nova Campina & 8223 & - & - & - & - & 8223 & 100,0 & E20 \\
\hline 3532843 & Nova Canaa Paulista & 2369 & - & - & - & - & 2369 & 100,0 & E20 \\
\hline 3532868 & Nova Castilho & 1013 & - & - & - & - & 1013 & 100,0 & E20 \\
\hline 3533007 & Nova Granada & 17969 & 2120 & 11,8 & 1599 & 8,9 & 14249 & 79,3 & E20 \\
\hline 3533106 & Nova Guataporanga & 2070 & - & - & - & - & 2070 & 100,0 & E20 \\
\hline 3533205 & Nova Independência & 2092 & - & - & - & - & 2092 & 100,0 & E20 \\
\hline 3533304 & Nova Luzitânia & 2798 & - & - & - & - & 2798 & 100,0 & E20 \\
\hline 3533254 & Novais & 3288 & - & - & 79 & 2,4 & 3209 & 97,6 & E20 \\
\hline 3533601 & Nuporanga & 6541 & 1524 & 23,3 & - & - & 5017 & 76,7 & E20 \\
\hline 3533700 & Ocauçu & 4097 & - & - & - & - & 4097 & 100,0 & E20 \\
\hline 3533809 & Oleo & 3078 & - & - & 166 & 5,4 & 2912 & 94,6 & E20 \\
\hline 3534005 & Onda Verde & 3675 & - & - & - & - & 3675 & 100,0 & E20 \\
\hline 3534500 & Oscar Bressane & 2557 & - & - & - & - & 2557 & 100,0 & E20 \\
\hline 3534807 & Ouro Verde & 7170 & - & 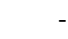 & 136 & 1,9 & 7034 & 98,1 & E20 \\
\hline 3534757 & Ouroeste & 6891 & - & - & - & - & 6891 & 100,0 & E20 \\
\hline 3534906 & Pacaembu & 12589 & - & - & - & - & 12589 & 100,0 & E20 \\
\hline 3535002 & Palestina & 9140 & - & 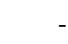 & - & - & 9140 & 100,0 & E20 \\
\hline 3535101 & Palmares Paulista & 8935 & - & - & 536 & 6,0 & 8399 & 94,0 & E20 \\
\hline
\end{tabular}


Anexo 7 - Municípios classificados no Estrato E - Vulnerabilidade Social Muito Intensa segundo proporção da população nos grupos IPVS e porte populacional. Estado de São Paulo, média do triênio 2003 a 2005.

\begin{tabular}{|c|c|c|c|c|c|c|c|c|c|}
\hline IBGE & MUNICIPIO & POP & IPVS 1,2,3 & $\%$ & IPVS 4 & $\%$ & IPVS 5,6 & $\%$ & PORTE \\
\hline 3535200 & Palmeira d'Oeste & 10043 & - & - & 562 & 5,6 & 9481 & 94,4 & E20 \\
\hline 3535408 & Panorama & 14232 & 1736 & 12,2 & 825 & 5,8 & 11656 & 81,9 & E20 \\
\hline 3535606 & Paraibuna & 17953 & 3878 & 21,6 & - & - & 14093 & 78,5 & E20 \\
\hline 3535705 & Paraíso & 5741 & - & - & - & - & 5741 & 100,0 & E20 \\
\hline 3535804 & Paranapanema & 16721 & 2625 & 15,7 & 1254 & 7,5 & 12842 & 76,8 & E20 \\
\hline 3535903 & Paranapua & 3571 & - & - & - & - & 3571 & 100,0 & E20 \\
\hline 3536000 & Parapua & 10963 & 976 & 8,9 & - & - & 9987 & 91,1 & E20 \\
\hline 3536257 & Parisi & 2143 & - & - & - & - & 2143 & 100,0 & E20 \\
\hline 3536406 & Paulicéia & 5813 & - & - & - & - & 5813 & 100,0 & E20 \\
\hline 3536570 & Paulistânia & 1894 & - & - & - & - & 1894 & 100,0 & E20 \\
\hline 3536604 & Paulo de Faria & 8542 & 743 & 8,7 & 820 & 9,6 & 6979 & 81,7 & E20 \\
\hline 3536802 & Pedra Bela & 5818 & - & - & - & - & 5818 & 100,0 & E20 \\
\hline 3536901 & Pedranópolis & 2569 & - & - & - & - & 2569 & 100,0 & E20 \\
\hline 3537206 & Pedro de Toledo & 9791 & 1899 & 19,4 & - & - & 7892 & 80,6 & E20 \\
\hline 3537503 & Pereiras & 7019 & - & - & - & - & 7019 & 100,0 & E20 \\
\hline 3537701 & Piacatu & 4665 & - & - & - & - & 4665 & 100,0 & E20 \\
\hline 3537909 & Pilar do Sul & 25940 & 5370 & 20,7 & 856 & 3,3 & 19714 & 76,0 & E50 \\
\hline 3538105 & Pindorama & 13436 & 1935 & 14,4 & 793 & 5,9 & 10708 & 79,7 & E20 \\
\hline 3538204 & Pinhalzinho & 12124 & 1528 & 12,6 & - & - & 10596 & 87,4 & E20 \\
\hline 3538303 & Piquerobi & 3570 & - & - & - & - & 3570 & 100,0 & E20 \\
\hline 3539004 & Pirangi & 10115 & 647 & 6,4 & - & - & 9468 & 93,6 & E20 \\
\hline 3539608 & Planalto & 3748 & - & - & - & - & 3748 & 100,0 & E20 \\
\hline 3539707 & Platina & 2879 & - & - & 167 & 5,8 & 2712 & 94,2 & E20 \\
\hline 3539905 & Poloni & 4884 & 630 & 12,9 & - & - & 4249 & 87,0 & E20 \\
\hline 3540101 & Pongaí & 3745 & - & - & - & - & 3745 & 100,0 & E20 \\
\hline 3540259 & Pontalinda & 3714 & - & - & - & - & 3714 & 100,0 & E20 \\
\hline 3540309 & Pontes Gestal & 2347 & - & - & - & - & 2347 & 100,0 & E20 \\
\hline 3540408 & Populina & 4352 & - & - & - & - & 4352 & 100,0 & E20 \\
\hline 3540507 & Porangaba & 7120 & 940 & 13,2 & - & - & 6180 & 86,8 & E20 \\
\hline 3540754 & Potim & 15327 & 1134 & 7,4 & 1885 & 12,3 & 12308 & 80,3 & E20 \\
\hline 3540804 & Potirendaba & 14754 & 1593 & 10,8 & - & - & 13146 & 89,1 & E20 \\
\hline 3540853 & Pracinha & 1421 & - & - & - & - & 1421 & 100,0 & E20 \\
\hline 3541059 & Pratânia & 4233 & - & - & - & - & 4233 & 100,0 & E20 \\
\hline 3541109 & Presidente Alves & 4233 & 698 & 16,5 & - & - & 3535 & 83,5 & E20 \\
\hline 3541653 & Quadra & 2986 & - & - & - & - & 2986 & 100,0 & E20 \\
\hline 3541802 & Queiroz & 2275 & - & - & - & - & 2275 & 100,0 & E20 \\
\hline 3542008 & Quintana & 5556 & - & - & 89 & 1,6 & 5467 & 98,4 & E20 \\
\hline 3542305 & Redençao da Serra & 4059 & 475 & 11,7 & - & - & 3584 & 88,3 & E20 \\
\hline 3542503 & Reginópolis & 4733 & - & - & - & - & 4733 & 100,0 & E20 \\
\hline
\end{tabular}


Anexo 7 - Municípios classificados no Estrato E - Vulnerabilidade Social Muito Intensa segundo proporção da população nos grupos IPVS e porte populacional. Estado de São Paulo, média do triênio 2003 a 2005.

\begin{tabular}{|c|c|c|c|c|c|c|c|c|c|}
\hline IBGE & MUNICIPIO & POP & IPVS $1,2,3$ & $\%$ & IPVS 4 & $\%$ & IPVS 5,6 & $\%$ & PORTE \\
\hline 3542701 & Restinga & 6111 & - & - & - & - & 6111 & 100,0 & E20 \\
\hline 3542800 & Ribeira & 3252 & 455 & 14,0 & - & - & 2797 & 86,0 & E20 \\
\hline 3543006 & Ribeirao Branco & 22101 & 508 & 2,3 & 553 & 2,5 & 21040 & 95,2 & E50 \\
\hline 3543105 & Ribeirao Corrente & 4171 & - & - & - & - & 4171 & 100,0 & E20 \\
\hline 3543204 & Ribeirao do Sul & 4644 & - & - & - & - & 4644 & 100,0 & E20 \\
\hline 3543238 & Ribeirao dos Indios & 2288 & - & - & - & - & 2288 & 100,0 & E20 \\
\hline 3543253 & Ribeirao Grande & 7935 & 1190 & 15,0 & - & - & 6745 & 85,0 & E20 \\
\hline 3543808 & Rinópolis & 9847 & 965 & 9,8 & - & - & 8882 & 90,2 & E20 \\
\hline 3544202 & Riolândia & 8918 & 954 & 10,7 & - & - & 7964 & 89,3 & E20 \\
\hline 3543501 & Riversul & 6207 & - & - & - & - & 6207 & 100,0 & E20 \\
\hline 3544400 & Rubiácea & 2203 & - & - & - & - & 2203 & 100,0 & E20 \\
\hline 3544608 & Sabino & 5120 & - & - & - & - & 5120 & 100,0 & E20 \\
\hline 3544707 & Sagres & 2344 & - & - & - & - & 2344 & 100,0 & E20 \\
\hline 3544806 & Sales & 4922 & 89 & 1,8 & - & - & 4833 & 98,2 & E20 \\
\hline 3545001 & Salesópolis & 15694 & 3327 & 21,2 & - & - & 12367 & 78,8 & E20 \\
\hline 3545100 & Salmourao & 4376 & - & - & - & - & 4376 & 100,0 & E20 \\
\hline 3545407 & Salto Grande & 8918 & 2007 & 22,5 & - & - & 6911 & 77,5 & E20 \\
\hline 3545506 & Sandovalina & 3394 & - & - & - & - & 3394 & 100,0 & E20 \\
\hline 3545704 & Santa Albertina & 5460 & - & - & - & - & 5460 & 100,0 & E20 \\
\hline 3546108 & Santa Clara d'Oeste & 1956 & - & - & - & - & 1956 & 100,0 & E20 \\
\hline 3546256 & Santa Cruz da Esperança & 1844 & - & - & - & - & 1844 & 100,0 & E20 \\
\hline 3546900 & Santa Lúcia & 8555 & - & - & - & - & 8555 & 100,0 & E20 \\
\hline 3547007 & Santa Maria da Serra & 4838 & - & - & 721 & 14,9 & 4117 & 85,1 & E20 \\
\hline 3547106 & Santa Mercedes & 2722 & - & - & - & - & 2722 & 100,0 & E20 \\
\hline 3547403 & Santa Rita d'Oeste & 2342 & - & - & - & - & 2342 & 100,0 & E20 \\
\hline 3547650 & Santa Salete & 1379 & - & - & - & - & 1379 & 100,0 & $\mathrm{E} 20$ \\
\hline 3547205 & Santana da Ponte Pensa & 1683 & - & - & - & - & 1683 & 100,0 & E20 \\
\hline 3547700 & Santo Anastácio & 21084 & 2699 & 12,8 & 1687 & 8,0 & 16720 & 79,3 & E50 \\
\hline 3548054 & Santo Antônio Aracangu & 6897 & - & - & 904 & 13,1 & 5993 & 86,9 & E20 \\
\hline 3547908 & Santo Antônio da Alegria & 6036 & - & - & - & - & 6036 & 100,0 & E20 \\
\hline 3548104 & Santo Antônio do Jardim & 6364 & 1025 & 16,1 & - & - & 5339 & 83,9 & E20 \\
\hline 3548203 & Santo Antônio do Pinhal & 6765 & 1360 & 20,1 & - & - & 5405 & 79,9 & E20 \\
\hline 3548302 & Santo Expedito & 2662 & - & - & - & - & 2662 & 100,0 & E20 \\
\hline 3548401 & Santópolis do Aguapeí & 3808 & - & - & - & - & 3808 & 100,0 & E20 \\
\hline 3549003 & Sao Francisco & 3006 & - & - & - & - & 3006 & 100,0 & E20 \\
\hline 3549201 & Sao Joao Duas Pontes & 2600 & - & - & - & - & 2600 & 100,0 & E20 \\
\hline 3549250 & Sao Joao de Iracema & 1704 & - & - & - & - & 1704 & 100,0 & E20 \\
\hline 3549300 & Sao Joao do Pau d'Alho & 1895 & - & 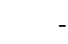 & - & - & 1895 & 100,0 & E20 \\
\hline 3549508 & Sao José da Bela Vista & 8500 & - & - & 289 & 3,4 & 8211 & 96,6 & E20 \\
\hline
\end{tabular}


Anexo 7 - Municípios classificados no Estrato E - Vulnerabilidade Social Muito Intensa segundo proporção da população nos grupos IPVS e porte populacional. Estado de São Paulo, média do triênio 2003 a 2005.

\begin{tabular}{|c|c|c|c|c|c|c|c|c|c|}
\hline IBGE & MUNICIPIO & POP & IPVS $1,2,3$ & $\%$ & IPVS 4 & $\%$ & IPVS 5,6 & $\%$ & PORTE \\
\hline 3549607 & Sao José do Barreiro & 4237 & 424 & 10,0 & - & - & 3818 & 90,1 & E20 \\
\hline 3549953 & Sao Lourenço da Serra & 14296 & 1644 & 11,5 & 1687 & 11,8 & 10951 & 76,6 & E20 \\
\hline 3550001 & Sao Luís do Paraitinga & 10655 & 2110 & 19,8 & - & - & 8545 & 80,2 & E20 \\
\hline 3550209 & Sao Miguel Arcanjo & 33217 & 4318 & 13,0 & 3288 & 9,9 & 25610 & 77,1 & E50 \\
\hline 3550506 & Sao Pedro do Turvo & 6964 & 474 & 6,8 & - & - & 6490 & 93,2 & E20 \\
\hline 3550803 & Sao Sebastiao da Grama & 12742 & 2230 & 17,5 & - & - & 10512 & 82,5 & E20 \\
\hline 3551108 & Sarapuí & 8399 & 1268 & 15,1 & - & - & 7139 & 85,0 & E20 \\
\hline 3551207 & Sarutaiá & 4060 & - & - & - & - & 4060 & 100,0 & E20 \\
\hline 3551306 & Sebastianópolis do Sul & 2556 & - & - & - & - & 2556 & 100,0 & E20 \\
\hline 3551405 & Serra Azul & 8014 & - & - & 1210 & 15,1 & 6804 & 84,9 & E20 \\
\hline 3551801 & Sete Barras & 14242 & 2877 & 20,2 & 442 & 3,1 & 10909 & 76,6 & E20 \\
\hline 3551900 & Severínia & 15090 & 634 & 4,2 & 1645 & 10,9 & 12811 & 84,9 & E20 \\
\hline 3552007 & Silveiras & 5586 & 1296 & 23,2 & - & - & 4290 & 76,8 & E20 \\
\hline 3552304 & Sud Mennucci & 7437 & - & - & 1510 & 20,3 & 5927 & 79,7 & E20 \\
\hline 3552551 & Suzanápolis & 2859 & - & - & - & - & 2859 & 100,0 & E20 \\
\hline 3552601 & Tabapua & 10732 & 719 & 6,7 & - & - & 10013 & 93,3 & E20 \\
\hline 3552700 & Tabatinga & 13972 & 1257 & 9,0 & - & - & 12728 & 91,1 & E20 \\
\hline 3552908 & Taciba & 5432 & - & - & 76 & 1,4 & 5351 & 98,5 & E20 \\
\hline 3553005 & Taguaí & 7932 & 833 & 10,5 & - & - & 7099 & 89,5 & E20 \\
\hline 3553104 & Taiaçu & 5886 & - & - & - & - & 5886 & 100,0 & E20 \\
\hline 3553203 & Taiúva & 5634 & - & _ & - & - & 5634 & 100,0 & E20 \\
\hline 3553500 & Tapiraí & 9836 & 777 & 7,9 & 1308 & 13,3 & 7751 & 78,8 & E20 \\
\hline 3553658 & Taquaral & 2849 & - & - & - & - & 2849 & 100,0 & E20 \\
\hline 3553807 & Taquarituba & 23519 & 3293 & 14,0 & - & - & 20226 & 86,0 & E50 \\
\hline 3553856 & Taquarivaí & 5095 & - & - & - & - & 5095 & 100,0 & E20 \\
\hline 3553906 & Tarabaí & 6266 & - & - & - & - & 6266 & 100,0 & E20 \\
\hline 3554201 & Tejupá & 5606 & - & - & - & - & 5606 & 100,0 & E20 \\
\hline 3554409 & Terra Roxa & 8253 & - & - & - & - & 8253 & 100,0 & E20 \\
\hline 3554607 & Timburi & 2676 & - & - & - & - & 2676 & 100,0 & E20 \\
\hline 3554656 & Torre de Pedra & 2549 & - & - & - & - & 2549 & 100,0 & E20 \\
\hline 3554706 & Torrinha & 9432 & 689 & 7,3 & - & - & 8743 & 92,7 & E20 \\
\hline 3554755 & Trabiju & 1437 & - & - & - & - & 1437 & 100,0 & E20 \\
\hline 3554904 & Três Fronteiras & 5172 & - & - & - & - & 5172 & 100,0 & E20 \\
\hline 3554953 & Tuiuti & 5342 & - & - & - & - & 5342 & 100,0 & E20 \\
\hline 3555208 & Turiúba & 1810 & - & - & - & - & 1810 & 100,0 & $\mathrm{E} 20$ \\
\hline 3555307 & Turmalina & 2194 & - & - & - & - & 2194 & 100,0 & E20 \\
\hline 3555356 & Ubarana & 4836 & - & - & 208 & 4,3 & 4628 & 95,7 & E20 \\
\hline 3555505 & Ubirajara & 4146 & - & - & - & - & 4146 & 100,0 & E20 \\
\hline 3555703 & Uniao Paulista & 1364 & - & - & - & - & 1364 & 100,0 & E20 \\
\hline
\end{tabular}


Anexo 7 - Municípios classificados no Estrato E - Vulnerabilidade Social Muito Intensa segundo proporção da população nos grupos IPVS e porte populacional. Estado de São Paulo, média do triênio 2003 a 2005.

\begin{tabular}{|c|c|c|c|c|c|c|c|c|c|}
\hline IBGE & MUNICIPIO & POP & IPVS $1,2,3$ & $\%$ & IPVS 4 & $\%$ & IPVS 5,6 & $\%$ & PORTE \\
\hline 3555802 & Urânia & 8860 & 1409 & 15,9 & - & - & 7451 & 84,1 & E20 \\
\hline 3555901 & Uru & 1425 & - & - & - & - & 1425 & 100,0 & E20 \\
\hline 3556008 & Urupês & 12198 & 976 & 8,0 & - & - & 11222 & 92,0 & E20 \\
\hline 3556354 & Vargem & 7855 & 888 & 11,3 & - & - & 6967 & 88,7 & E20 \\
\hline 3556602 & Vera Cruz & 11098 & 2319 & 20,9 & - & & 8779 & 79,1 & E20 \\
\hline 3556958 & Vitória Brasil & 1777 & - & - & - & - & 1777 & 100,0 & E20 \\
\hline 3557154 & Zacarias & 1945 & & 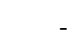 & - & . & 1945 & 100,0 & E20 \\
\hline
\end{tabular}

Fonte: Censo IBGE e Estratos de Vulnerabilidade Social segundo metodologia desenvolvida a partir do IPVS (FSEADE 2005)

Nota:

( - ) Dado numérico igual a 0 não resultante de arredondamento

( 0;0,0;0,00) Dado numérico igual a zero resultante de arredondamento de um dado originalmente positivo Eventualmente a soma das parcelas pode não coincidir com o total em função de arredondamentos efetuados nos dados parciais.

População atualizada segundo projeção(IBGE) para o período (média) pela participação relativa nos grupos IPVS 
Anexo 8 - Número e proporção (\%) da população por faixa etária selecionada segundo conjunto de municípios e respectivo estrato de vulnerabilidade social. Estado de São Paulo, média do triênio 2003 a 2005

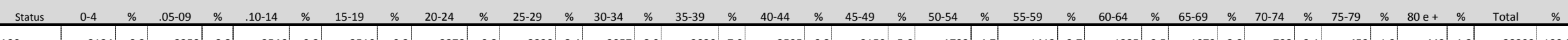
\begin{tabular}{l|lllllllllllllll|lll|lll|llllllllllllllll}
\hline \hline A20 & 3134 & 8,2 & 3358 & 8,8 & 3546 & 9,3 & 3510 & 9,2 & 3378 & 8,8 & 3228 & 8,4 & 3057 & 8,0 & 3030 & 7,9 & 2595 & 6,8 & 2150 & 5,6 & 1792 & 4,7 & 1413 & 3,7 & 1335 & 3,5 & 1073 & 2,8 & 798 & 2,1 & 452 & 1,2 & 442 & 1,2 & 38292 & 100,0 \\
\hline
\end{tabular}

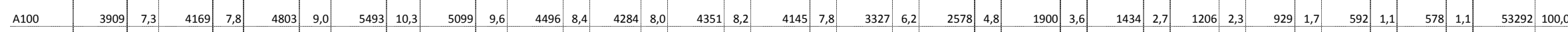

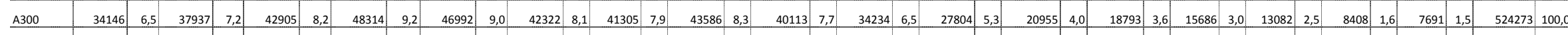

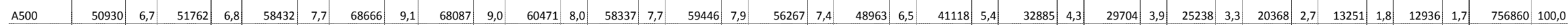

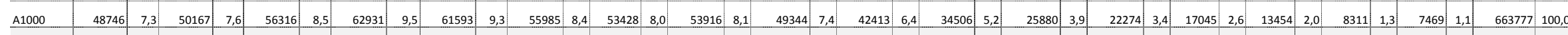

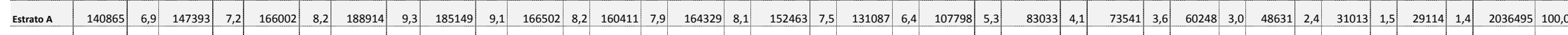

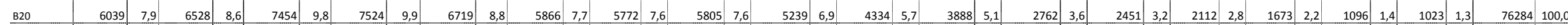

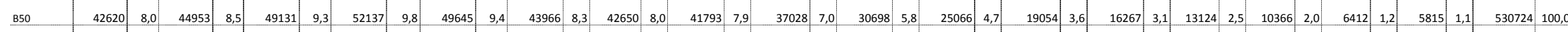

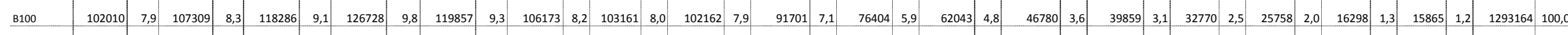
$\begin{array}{lllllllllllllllllllllllllllllllllllllllll}B 300 & 315564 & 8,3 & 326168 & 8,6 & 352064 & 9,2 & 377075 & 9,9 & 355858 & 9,3 & 318264 & 8,4 & 306163 & 8,0 & 300129 & 7,9 & 270117 & 7,1 & 223159 & 5,9 & 177867 & 4,7 & 132678 & 3,5 & 111514 & 2,9 & 89289 & 2,3 & 69446 & 1,8 & 43343 & 1,1 & 41284 & 1,1 & 3809982 & 100,0\end{array}$ \begin{tabular}{l|lllllllllllllllllllllllllllllllllllllll}
$\mathbf{B} 500$ & 174426 & 8,4 & 176266 & 8,5 & 187057 & 9,0 & 201847 & 9,7 & 194055 & 9,4 & 175011 & 8,4 & 167362 & 8,1 & 164678 & 7,9 & 146452 & 7,1 & 121926 & 5,9 & 97814 & 4,7 & 72727 & 3,5 & 61575 & 3,0 & 48406 & 2,3 & 37175 & 1,8 & 23106 & 1,1 & 22406 & 1,1 & 2072287 & 100,0 \\
\hline
\end{tabular}

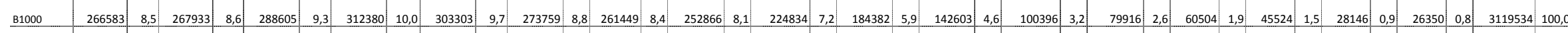
$\begin{array}{llllllllllllllllllllllllllllllllllllllllll}B 10000 & 988449 & 8,4 & 934941 & 7,9 & 1002573 & 8,5 & 1121620 & 9,5 & 1157173 & 9,8 & 1069418 & 9,1 & 993291 & 8,4 & 932842 & 7,9 & 834467 & 7,1 & 701620 & 5,9 & 560907 & 4,7 & 410011 & 3,5 & 342414 & 2,9 & 270758 & 2,3 & 218949 & 1,9 & 138308 & 1,2 & 132318 & 1,1 & 11810059 & 100,0\end{array}$ \begin{tabular}{llllllllllllllllllllllllllllllllllllllll} 
Estrato B & 1895691 & 8,3 & 1864096 & 8,2 & 2005169 & 8,8 & 2199310 & 9,7 & 2186611 & 9,6 & 1992457 & 8,8 & 1879848 & 8,3 & 1800275 & 7,9 & 1609839 & 7,1 & 1342522 & 5,9 & 1070188 & 4,7 & 784408 & 3,5 & 653995 & 2,9 & 516963 & 2,3 & 408890 & 1,8 & 256709 & 1,1 & 245062 & 1,1 & 22712033 & 100,0 \\
\hline
\end{tabular}

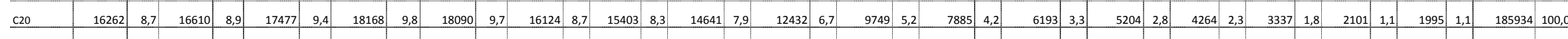
\begin{tabular}{lllllllllllllllllllllllllllllllllllllll} 
C50 & 85895 & 9,2 & 86207 & 9,2 & 90059 & 9,7 & 94846 & 10,2 & 89275 & 9,6 & 80818 & 8,7 & 76126 & 8,2 & 71392 & 7,7 & 61215 & 6,6 & 50028 & 5,4 & 39873 & 4,3 & 29983 & 3,2 & 24736 & 2,7 & 19538 & 2,1 & 14772 & 1,6 & 9175 & 1,0 & 8382 & 0,9 & 932318 & 100,0 \\
\hline
\end{tabular} \begin{tabular}{llllllllllllllllllllllllllllllllllllll}
$\mathrm{C} 100$ & 107734 & 9,3 & 108604 & 9,4 & 113961 & 9,9 & 118187 & 10,2 & 109845 & 9,5 & 97548 & 8,5 & 92660 & 8,0 & 87963 & 7,6 & 78038 & 6,8 & 64171 & 5,6 & 50126 & 4,3 & 36034 & 3,1 & 29162 & 2,5 & 22655 & 2,0 & 16842 & 1,5 & 10377 & 0,9 & 9708 & 0,8 & 1153615 & 100,0 \\
\hline
\end{tabular}

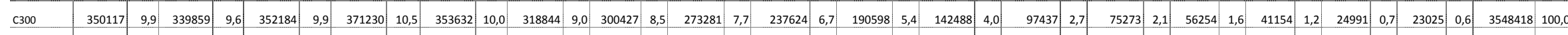
\begin{tabular}{llllllllllllllllllllllllllllllllllllll}
$\mathrm{C} 500$ & 151343 & 10,3 & 142899 & 9,7 & 147686 & 10,1 & 154898 & 10,6 & 150208 & 10,2 & 137430 & 9,4 & 128706 & 8,8 & 112739 & 7,7 & 96392 & 6,6 & 77739 & 5,3 & 56919 & 3,9 & 37126 & 2,5 & 27283 & 1,9 & 18911 & 1,3 & 12899 & 0,9 & 7242 & 0,5 & 6700 & 0,5 & 1467121 & 100,0 \\
\hline
\end{tabular}

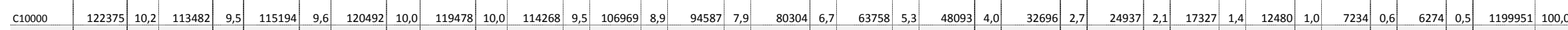

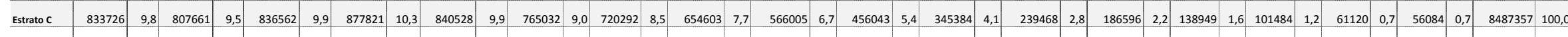

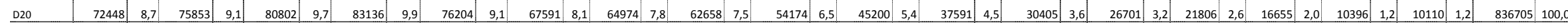

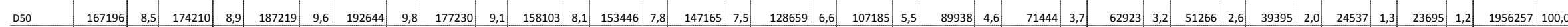

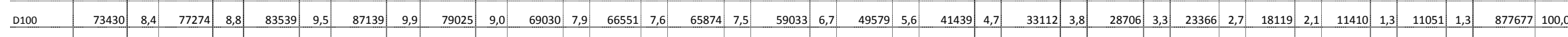

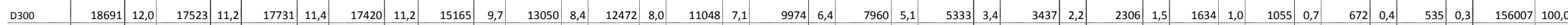

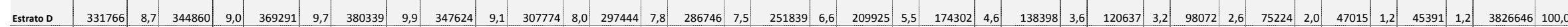

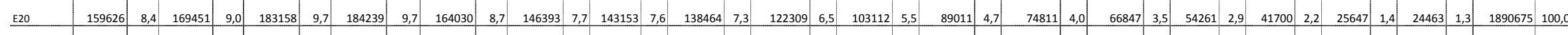
\begin{tabular}{llllllllllllllllllllllllllllllllllllll}
$E 50$ & 43378 & 9,9 & 44509 & 10,1 & 45908 & 10,4 & 45536 & 10,4 & 39287 & 8,9 & 34752 & 7,9 & 33316 & 7,6 & 31411 & 7,1 & 26702 & 6,1 & 22041 & 5,0 & 18369 & 4,2 & 14936 & 3,4 & 12895 & 2,9 & 10244 & 2,3 & 7510 & 1,7 & 4554 & 1,0 & 4117 & 0,9 & 439463 & 100,0 \\
\hline
\end{tabular} \begin{tabular}{l|llllllllllllllllllllllllllllllllllll}
$E 100$ & 7258 & 10,2 & 7093 & 10,0 & 7567 & 10,6 & 7695 & 10,8 & 6539 & 9,2 & 5883 & 8,3 & 5337 & 7,5 & 5245 & 7,4 & 4241 & 6,0 & 3404 & 4,8 & 3011 & 4,2 & 2276 & 3,2 & 2053 & 2,9 & 1505 & 2,1 & 1000 & 1,4 & 588 & 0,8 & 477 & 0,7 & 71173 & 100,0 \\
\hline
\end{tabular}

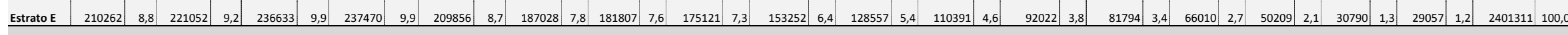

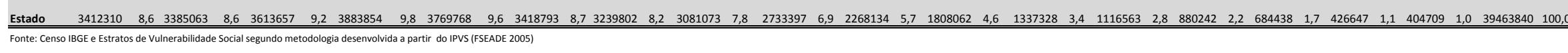


Anexo 9 - População por faixa etária selecionada, razão de dependência e razão de sexos nos conjuntos de municípios e respectivos estratos de vulnerabilidade social. Estado de São Paulo, média do triênio 2003-2005.

\begin{tabular}{|c|c|c|c|c|c|c|}
\hline Status & $\begin{array}{c}\text { Pop. }(0-14)+ \\
(64 \mathrm{e}+)\end{array}$ & Pop 15 a 64 & $\begin{array}{c}\text { Razão de } \\
\text { dependência }\end{array}$ & Homens & Mulheres & $\begin{array}{c}\text { Razão de } \\
\text { Sexos }\end{array}$ \\
\hline A20 & 12802 & 25490 & 50,2 & 19290 & 19002 & 101,5 \\
\hline A100 & 16185 & 37107 & 43,6 & 26519 & 26773 & 99,1 \\
\hline A300 & 159856 & 364418 & 43,9 & 254045 & 270228 & 94,0 \\
\hline A500 & 232917 & 523943 & 44,5 & 359404 & 397456 & 90,4 \\
\hline A1000 & 201507 & 462270 & 43,6 & 320800 & 342977 & 93,5 \\
\hline Estrato A & 623267 & 1413228 & 44,1 & 980058 & 1056437 & 92,8 \\
\hline B20 & 25925 & 50359 & 51,5 & 38456 & 37827 & 101,7 \\
\hline B50 & 172420 & 358304 & 48,1 & 265387 & 265337 & 100,0 \\
\hline B100 & 418296 & 874869 & 47,8 & 639451 & 653714 & 97,8 \\
\hline B300 & 1237158 & 2572824 & 48,1 & 1879842 & 1930140 & 97,4 \\
\hline B500 & 668841 & 1403446 & 47,7 & 1014304 & 1057983 & 95,9 \\
\hline B1000 & 983646 & 2135888 & 46,1 & 1522391 & 1597143 & 95,3 \\
\hline B10000 & 3686296 & 8123763 & 45,4 & 5639109 & 6170950 & 91,4 \\
\hline Estrato B & 7192581 & 15519452 & 46,3 & 10998939 & 11713093 & 93,9 \\
\hline $\mathrm{C} 20$ & 62045 & 123888 & 50,1 & 94864 & 91070 & 104,2 \\
\hline C50 & 314028 & 618291 & 50,8 & 469533 & 462786 & 101,5 \\
\hline C100 & 389881 & 763734 & 51,0 & 576191 & 577423 & 99,8 \\
\hline C300 & 1187584 & 2360834 & 50,3 & 1760164 & 1788254 & 98,4 \\
\hline C500 & 487680 & 979441 & 49,8 & 722794 & 744327 & 97,1 \\
\hline C10000 & 394367 & 805584 & 49,0 & 590050 & 609901 & 96,7 \\
\hline Estrato C & 2835585 & 5651771 & 50,2 & 4213596 & 4273760 & 98,6 \\
\hline D20 & 288071 & 548634 & 52,5 & 423843 & 412862 & 102,7 \\
\hline D50 & 667519 & 1288738 & 51,8 & 980352 & 975905 & 100,5 \\
\hline D100 & 298189 & 579488 & 51,5 & 437879 & 439798 & 99,6 \\
\hline D300 & 57841 & 98166 & 58,9 & 77807 & 78199 & 99,5 \\
\hline Estrato D & 1311619 & 2515026 & 52,2 & 1919881 & 1906765 & 100,7 \\
\hline E20 & 658306 & 1232369 & 53,4 & 966803 & 923872 & 104,6 \\
\hline E50 & 185707 & 324929 & 57,2 & 223239 & 216224 & 103,2 \\
\hline E100 & 27541 & 43631 & 63,1 & 36626 & 34547 & 106,0 \\
\hline Estrato $\mathrm{E}$ & 844013 & 1557297 & 54,2 & 1226668 & 1174643 & 104,4 \\
\hline Estado & 12807066 & 26656775 & 48,0 & 19339142 & 20124699 & 96,1 \\
\hline
\end{tabular}


Anexo 10 - Razão de sexos e de dependência segundo município e Estrato de Vulnerabilidade Social. Estado de São Paulo, média do triênio, 2003-2005

\begin{tabular}{|c|c|c|c|c|c|c|c|c|}
\hline IBGE & MUNICIPIO & Estrato & Homens & Mulheres & $\begin{array}{c}\text { Razão de } \\
\text { Sexos } \\
\end{array}$ & $\begin{array}{c}\text { Pop (0-14) + } \\
(65 \mathrm{e}+) \\
\end{array}$ & 15-64 & $\begin{array}{c}\text { Razão de } \\
\text { dependência }\end{array}$ \\
\hline 350010 & Adamantina & D50 & 16627 & 17497 & 95,0 & 11137 & 22987 & 48,4 \\
\hline 350020 & Adolfo & E20 & 1962 & 1906 & 102,9 & 1281 & 2587 & 49,5 \\
\hline 350030 & Aguaí & E50 & 15217 & 15136 & 100,5 & 10495 & 19858 & 52,9 \\
\hline 350040 & Águas da Prata & D20 & 3689 & 3637 & 101,4 & 2548 & 4778 & 53,3 \\
\hline 350050 & Águas de Lindóia & D20 & 8946 & 9109 & 98,2 & 6071 & 11985 & 50,7 \\
\hline 350055 & Águas de Santa Bárbara & B20 & 2940 & 2878 & 102,2 & 2129 & 3689 & 57,7 \\
\hline 350060 & Águas de São Pedro & A20 & 909 & 1056 & 86,1 & 664 & 1301 & 51,1 \\
\hline 350070 & Agudos & C50 & 16661 & 16850 & 98,9 & 11773 & 21738 & 54,2 \\
\hline 350075 & Alambari & E20 & 1961 & 1844 & 106,3 & 1399 & 2407 & 58,1 \\
\hline 350080 & Alfredo Marcondes & E20 & 1930 & 1857 & 103,9 & 1264 & 2523 & 50,1 \\
\hline 350090 & Altair & E20 & 1956 & 1704 & 114,8 & 1249 & 2411 & 51,8 \\
\hline 350100 & Altinópolis & D20 & 8237 & 8067 & 102,1 & 5578 & 10725 & 52,0 \\
\hline 350110 & Alto Alegre & E20 & 2094 & 1932 & 108,3 & 1326 & 2700 & 49,1 \\
\hline 350115 & Alumínio & $\mathrm{C} 20$ & 8034 & 7885 & 101,9 & 5329 & 10590 & 50,3 \\
\hline 350120 & Alvares Florence & E20 & 2085 & 1904 & 109,5 & 1274 & 2715 & 46,9 \\
\hline 350130 & Alvares Machado & D50 & 12254 & 12103 & 101,3 & 8455 & 15902 & 53,2 \\
\hline 350140 & Alvaro de Carvalho & E20 & 2724 & 1821 & 149,6 & 1348 & 3197 & 42,2 \\
\hline 350150 & Alvinlândia & E20 & 1498 & 1471 & 101,9 & 1059 & 1910 & 55,5 \\
\hline 350160 & Americana & A300 & 96690 & 98746 & 97,9 & 59690 & 135745 & 44,0 \\
\hline 350170 & Américo Brasiliense & D50 & 16271 & 15689 & 103,7 & 10634 & 21326 & 49,9 \\
\hline 350180 & Américo de Campos & E20 & 2804 & 2790 & 100,5 & 1824 & 3770 & 48,4 \\
\hline 350190 & Amparo & B100 & 32263 & 32432 & 99,5 & 21082 & 43614 & 48,3 \\
\hline 350200 & Analândia & B20 & 1984 & 1848 & 107,3 & 1314 & 2518 & 52,2 \\
\hline 350210 & Andradina & D100 & 27806 & 28584 & 97,3 & 18217 & 38173 & 47,7 \\
\hline 350220 & Angatuba & D50 & 10410 & 9815 & 106,1 & 7049 & 13177 & 53,5 \\
\hline 350230 & Anhembi & E20 & 2563 & 2417 & 106,0 & 1849 & 3131 & 59,1 \\
\hline 350240 & Anhumas & E20 & 1781 & 1704 & 104,5 & 1199 & 2287 & 52,4 \\
\hline 350250 & Aparecida & B50 & 17490 & 18154 & 96,3 & 11591 & 24053 & 48,2 \\
\hline 350260 & Aparecida d'Oeste & E20 & 2421 & 2441 & 99,2 & 1603 & 3258 & 49,2 \\
\hline 350270 & Apiaí & D50 & 13851 & 13587 & 101,9 & 10709 & 16729 & 64,0 \\
\hline 350275 & Araçariguama & D20 & 6703 & 6340 & 105,7 & 4701 & 8342 & 56,4 \\
\hline 350280 & Araçatuba & B300 & 85598 & 91116 & 93,9 & 54819 & 121894 & 45,0 \\
\hline 350290 & Araçoiaba da Serra & B50 & 11176 & 10995 & 101,6 & 7674 & 14498 & 52,9 \\
\hline 350300 & Aramina & E20 & 2583 & 2492 & 103,7 & 1661 & 3413 & 48,7 \\
\hline 350310 & Arandu & E20 & 3189 & 3077 & 103,6 & 2295 & 3970 & 57,8 \\
\hline 350315 & Arapeí & E20 & 1376 & 1386 & 99,3 & 1053 & 1708 & 61,7 \\
\hline 350320 & Araraquara & A300 & 93792 & 99067 & 94,7 & 60073 & 132785 & 45,2 \\
\hline 350330 & Araras & B300 & 55816 & 55856 & 99,9 & 36079 & 75593 & 47,7 \\
\hline 350335 & ArcoOlris & E20 & 1192 & 1054 & 113,1 & 767 & 1480 & 51,8 \\
\hline 350340 & Arealva & E20 & 3810 & 3591 & 106,1 & 2493 & 4909 & 50,8 \\
\hline 350350 & Areias & E20 & 1889 & 1852 & 102,0 & 1441 & 2301 & 62,6 \\
\hline 350360 & Areiópolis & E20 & 5369 & 5064 & 106,0 & 3879 & 6553 & 59,2 \\
\hline 350370 & Ariranha & E20 & 4195 & 4012 & 104,6 & 2777 & 5429 & 51,2 \\
\hline 350380 & Artur Nogueira & C50 & 19713 & 19587 & 100,6 & 13003 & 26296 & 49,4 \\
\hline 350390 & Arujá & C100 & 34317 & 34498 & 99,5 & 23579 & 45236 & 52,1 \\
\hline 350395 & Aspásia & E20 & 939 & 876 & 107,2 & 602 & 1214 & 49,6 \\
\hline 350400 & Assis & B100 & 44922 & 47436 & 94,7 & 29609 & 62749 & 47,2 \\
\hline 350410 & Atibaia & C300 & 60878 & 61572 & 98,9 & 41299 & 81150 & 50,9 \\
\hline 350420 & Auriflama & E20 & 6981 & 6865 & 101,7 & 4519 & 9327 & 48,5 \\
\hline 350430 & Avaí & E20 & 2380 & 2197 & 108,3 & 1689 & 2888 & 58,5 \\
\hline
\end{tabular}


Anexo 10 - Razão de sexos e de dependência segundo município e Estrato de Vulnerabilidade Social. Estado de São Paulo, média do triênio, 2003-2005

\begin{tabular}{|c|c|c|c|c|c|c|c|c|}
\hline IBGE & MUNICIPIO & Estrato & Homens & Mulheres & $\begin{array}{c}\text { Razão de } \\
\text { Sexos }\end{array}$ & $\begin{array}{c}\text { Pop }(0-14)+ \\
(65 \mathrm{e}+)\end{array}$ & $15-64$ & $\begin{array}{c}\text { Razão de } \\
\text { dependência }\end{array}$ \\
\hline 350440 & Avanhandava & E20 & 4590 & 4622 & 99,3 & 3383 & 5829 & 58,0 \\
\hline 350450 & Avaré & B100 & 41610 & 41728 & 99,7 & 27802 & 55535 & 50,1 \\
\hline 350460 & Bady Bassitt & A20 & 7139 & 7017 & 101,7 & 4514 & 9641 & 46,8 \\
\hline 350470 & Balbinos & E20 & 699 & 657 & 106,4 & 486 & 870 & 55,8 \\
\hline 350480 & Bálsamo & E20 & 3785 & 3807 & 99,4 & 2383 & 5209 & 45,7 \\
\hline 350490 & Bananal & D20 & 4958 & 5039 & 98,4 & 3511 & 6486 & 54,1 \\
\hline 350500 & Barao de Antonina & E20 & 1375 & 1315 & 104,5 & 985 & 1704 & 57,8 \\
\hline 350510 & Barbosa & E20 & 3048 & 2993 & 101,8 & 2195 & 3846 & 57,1 \\
\hline 350520 & Bariri & D50 & 14954 & 14914 & 100,3 & 10386 & 19482 & 53,3 \\
\hline 350530 & Barra Bonita & C50 & 18769 & 18795 & 99,9 & 11577 & 25987 & 44,5 \\
\hline 350535 & Barra do Chapéu & E20 & 2584 & 2229 & 115,9 & 1934 & 2878 & 67,2 \\
\hline 350540 & Barra do Turvo & E20 & 4488 & 4060 & 110,6 & 3574 & 4973 & 71,9 \\
\hline 350550 & Barretos & B300 & 52519 & 55189 & 95,2 & 35436 & 72273 & 49,0 \\
\hline 350560 & Barrinha & D50 & 13496 & 13101 & 103,0 & 9459 & 17138 & 55,2 \\
\hline 350570 & Barueri & C300 & 119982 & 122908 & 97,6 & 80921 & 161969 & 50,0 \\
\hline 350580 & Bastos & D50 & 10578 & 10666 & 99,2 & 7222 & 14022 & 51,5 \\
\hline 350590 & Batatais & C100 & 26913 & 27329 & 98,5 & 18026 & 36215 & 49,8 \\
\hline 350600 & Bauru & B500 & 166433 & 174176 & 95,6 & 109066 & 231543 & 47,1 \\
\hline 350610 & Bebedouro & C100 & 38449 & 39516 & 97,3 & 26284 & 51681 & 50,9 \\
\hline 350620 & Bento de Abreu & $\mathrm{C} 20$ & 1224 & 1170 & 104,6 & 818 & 1576 & 51,9 \\
\hline 350630 & Bernardino de Campos & E20 & 5469 & 5551 & 98,5 & 4021 & 6999 & 57,4 \\
\hline 350635 & Bertioga & C50 & 19793 & 18539 & 106,8 & 13100 & 25232 & 51,9 \\
\hline 350640 & Bilac & D20 & 3133 & 3234 & 96,9 & 1992 & 4375 & 45,5 \\
\hline 350650 & Birigui & C300 & 50675 & 52190 & 97,1 & 31304 & 71561 & 43,7 \\
\hline 350660 & BiritibaOMirim & D50 & 14047 & 13653 & 102,9 & 10152 & 17547 & 57,9 \\
\hline 350670 & Boa Esperança do Sul & E20 & 6835 & 6612 & 103,4 & 4853 & 8594 & 56,5 \\
\hline 350680 & Bocaina & D20 & 5199 & 5218 & 99,6 & 3555 & 6862 & 51,8 \\
\hline 350690 & Bofete & E20 & 4255 & 3854 & 110,4 & 2982 & 5127 & 58,2 \\
\hline 350700 & Boituva & D50 & 19939 & 19444 & 102,5 & 13062 & 26321 & 49,6 \\
\hline 350710 & Bom Jesus dos Perdoes & D20 & 7466 & 7391 & 101,0 & 5165 & 9692 & 53,3 \\
\hline 350715 & Bom Sucesso de Itararé & E20 & 1883 & 1752 & 107,5 & 1526 & 2109 & 72,3 \\
\hline 350720 & Borá & E20 & 415 & 395 & 105,0 & 291 & 518 & 56,2 \\
\hline 350730 & Boracéia & E20 & 1988 & 1877 & 106,0 & 1341 & 2524 & 53,1 \\
\hline 350740 & Borborema & D20 & 6937 & 6739 & 102,9 & 4485 & 9191 & 48,8 \\
\hline 350745 & Borebi & E20 & 1123 & 1047 & 107,2 & 820 & 1350 & 60,7 \\
\hline 350750 & Botucatu & B300 & 56701 & 59441 & 95,4 & 38716 & 77425 & 50,0 \\
\hline 350760 & Bragança Paulista & B300 & 67465 & 68801 & 98,1 & 45035 & 91231 & 49,4 \\
\hline 350770 & Braúna & E20 & 2266 & 2172 & 104,3 & 1427 & 3011 & 47,4 \\
\hline 350775 & Brejo Alegre & E20 & 1271 & 1184 & 107,4 & 828 & 1627 & 50,9 \\
\hline 350780 & Brodósqui & C20 & 9365 & 9270 & 101,0 & 6413 & 12222 & 52,5 \\
\hline 350790 & Brotas & D50 & 10532 & 10355 & 101,7 & 7266 & 13621 & 53,3 \\
\hline 350800 & Buri & E20 & 10046 & 9060 & 110,9 & 7266 & 11840 & 61,4 \\
\hline 350810 & Buritama & E20 & 7131 & 7212 & 98,9 & 4666 & 9676 & 48,2 \\
\hline 350820 & Buritizal & D20 & 1838 & 1778 & 103,4 & 1195 & 2421 & 49,4 \\
\hline 350830 & Cabrália Paulista & E20 & 2510 & 2501 & 100,4 & 1843 & 3168 & 58,2 \\
\hline 350840 & Cabreúva & C50 & 20215 & 19266 & 104,9 & 13955 & 25525 & 54,7 \\
\hline 350850 & Caçapava & B100 & 40030 & 40599 & 98,6 & 26156 & 54473 & 48,0 \\
\hline 350860 & Cachoeira Paulista & B50 & 14384 & 14604 & 98,5 & 9780 & 19208 & 50,9 \\
\hline 350870 & Caconde & E20 & 9561 & 9306 & 102,7 & 7071 & 11796 & 59,9 \\
\hline 350880 & Cafelândia & D20 & 7930 & 8103 & 97,9 & 5588 & 10445 & 53,5 \\
\hline
\end{tabular}


Anexo 10 - Razão de sexos e de dependência segundo município e Estrato de Vulnerabilidade Social. Estado de São Paulo, média do triênio, 2003-2005

\begin{tabular}{|c|c|c|c|c|c|c|c|c|}
\hline IBGE & MUNICIPIO & Estrato & Homens & Mulheres & $\begin{array}{c}\text { Razão de } \\
\text { Sexos }\end{array}$ & $\begin{array}{c}\text { Pop }(0-14)+ \\
(65 \mathrm{e}+)\end{array}$ & $15-64$ & $\begin{array}{c}\text { Razão de } \\
\text { dependência }\end{array}$ \\
\hline 350890 & Caiabu & E20 & 2142 & 2036 & 105,2 & 1481 & 2697 & 54,9 \\
\hline 350900 & Caieiras & C100 & 42479 & 43103 & 98,6 & 28550 & 57032 & 50,1 \\
\hline 350910 & Caiuá & E20 & 2385 & 2187 & 109,1 & 1602 & 2971 & 53,9 \\
\hline 350920 & Cajamar & C100 & 29422 & 28944 & 101,7 & 19892 & 38474 & 51,7 \\
\hline 350925 & Cajati & D50 & 16393 & 15328 & 107,0 & 12441 & 19280 & 64,5 \\
\hline 350930 & Cajobi & E20 & 4833 & 4528 & 106,7 & 3143 & 6218 & 50,5 \\
\hline 350940 & Cajuru & E50 & 11035 & 10735 & 102,8 & 7887 & 13884 & 56,8 \\
\hline 350945 & Campina do Monte Alegre & E20 & 2974 & 2817 & 105,6 & 2158 & 3633 & 59,4 \\
\hline 350950 & Campinas & B10000 & 498676 & 525126 & 95,0 & 312588 & 711214 & 44,0 \\
\hline 350960 & Campo Limpo Paulista & C100 & 35839 & 36075 & 99,3 & 23840 & 48074 & 49,6 \\
\hline 350970 & Campos do Jordao & C50 & 23556 & 23875 & 98,7 & 16427 & 31004 & 53,0 \\
\hline 350980 & Campos Novos Paulista & E20 & 2205 & 2050 & 107,6 & 1487 & 2768 & 53,7 \\
\hline 350990 & Cananéia & E20 & 6797 & 6647 & 102,3 & 5255 & 8189 & 64,2 \\
\hline 350995 & Canas & E20 & 2024 & 1900 & 106,5 & 1411 & 2513 & 56,2 \\
\hline 351000 & Cândido Mota & D50 & 15496 & 15497 & 100,0 & 10704 & 20289 & 52,8 \\
\hline 351010 & Cândido Rodrigues & E20 & 1344 & 1396 & 96,3 & 881 & 1859 & 47,4 \\
\hline 351015 & Canitar & E20 & 2008 & 1940 & 103,5 & 1455 & 2492 & 58,4 \\
\hline 351020 & Capao Bonito & E50 & 23547 & 23318 & 101,0 & 17532 & 29333 & 59,8 \\
\hline 351030 & Capela do Alto & D20 & 8111 & 7688 & 105,5 & 5843 & 9956 & 58,7 \\
\hline 351040 & Capivari & C50 & 22232 & 22472 & 98,9 & 15282 & 29423 & 51,9 \\
\hline 351050 & Caraguatatuba & C100 & 45579 & 44976 & 101,3 & 30998 & 59557 & 52,0 \\
\hline 351060 & Carapicuíba & C500 & 182187 & 189627 & 96,1 & 119665 & 252148 & 47,5 \\
\hline 351070 & Cardoso & E20 & 5598 & 5703 & 98,2 & 3880 & 7422 & 52,3 \\
\hline 351080 & Casa Branca & B50 & 14485 & 12981 & 111,6 & 9319 & 18147 & 51,4 \\
\hline 351090 & Cássia dos Coqueiros & E20 & 1525 & 1414 & 107,8 & 1063 & 1877 & 56,6 \\
\hline 351100 & Castilho & E20 & 7547 & 7553 & 99,9 & 5279 & 9822 & 53,7 \\
\hline 351110 & Catanduva & B300 & 55168 & 57410 & 96,1 & 36105 & 76473 & 47,2 \\
\hline 351120 & Catiguá & E20 & 3435 & 3251 & 105,7 & 2170 & 4517 & 48,0 \\
\hline 351130 & Cedral & E20 & 3598 & 3547 & 101,4 & 2311 & 4834 & 47,8 \\
\hline 351140 & Cerqueira César & D20 & 8085 & 8083 & 100,0 & 5661 & 10506 & 53,9 \\
\hline 351150 & Cerquilho & B50 & 16863 & 16871 & 100,0 & 10686 & 23048 & 46,4 \\
\hline 351160 & Cesário Lange & E20 & 7155 & 6501 & 110,1 & 4454 & 9203 & 48,4 \\
\hline 351170 & Charqueada & D20 & 7080 & 6985 & 101,4 & 4909 & 9156 & 53,6 \\
\hline 355720 & Chavantes & D20 & 6185 & 6221 & 99,4 & 4229 & 8177 & 51,7 \\
\hline 351190 & Clementina & E20 & 2923 & 2714 & 107,7 & 1945 & 3692 & 52,7 \\
\hline 351200 & Colina & D20 & 8525 & 8476 & 100,6 & 5858 & 11143 & 52,6 \\
\hline 351210 & Colômbia & E20 & 3246 & 3009 & 107,9 & 2169 & 4086 & 53,1 \\
\hline 351220 & Conchal & E50 & 12180 & 12016 & 101,4 & 8727 & 15470 & 56,4 \\
\hline 351230 & Conchas & C2O & 8303 & 7946 & 104,5 & 5740 & 10510 & 54,6 \\
\hline 351240 & Cordeirópolis & C2O & 9746 & 9745 & 100,0 & 6462 & 13028 & 49,6 \\
\hline 351250 & Coroados & E20 & 2308 & 2279 & 101,3 & 1552 & 3035 & 51,1 \\
\hline 351260 & Coronel Macedo & E20 & 2837 & 2681 & 105,8 & 2057 & 3462 & 59,4 \\
\hline 351270 & Corumbataí & D20 & 2134 & 1944 & 109,8 & 1469 & 2609 & 56,3 \\
\hline 351280 & Cosmópolis & B50 & 24084 & 24000 & 100,4 & 15669 & 32415 & 48,3 \\
\hline 351290 & Cosmorama & E20 & 3626 & 3542 & 102,4 & 2291 & 4877 & 47,0 \\
\hline 351300 & Cotia & C300 & 82818 & 84722 & 97,8 & 55432 & 112107 & 49,4 \\
\hline 351310 & Cravinhos & D50 & 15797 & 15226 & 103,8 & 10493 & 20531 & 51,1 \\
\hline 351320 & Cristais Paulista & E20 & 3614 & 3381 & 106,9 & 2510 & 4485 & 56,0 \\
\hline 351330 & Cruzália & D20 & 1299 & 1288 & 100,9 & 823 & 1764 & 46,7 \\
\hline 351340 & Cruzeiro & B100 & 37096 & 38562 & 96,2 & 25072 & 50586 & 49,6 \\
\hline
\end{tabular}


Anexo 10 - Razão de sexos e de dependência segundo município e Estrato de Vulnerabilidade Social. Estado de São Paulo, média do triênio, 2003-2005

\begin{tabular}{|c|c|c|c|c|c|c|c|c|}
\hline IBGE & MUNICIPIO & Estrato & Homens & Mulheres & $\begin{array}{c}\text { Razão de } \\
\text { Sexos }\end{array}$ & $\begin{array}{c}\text { Pop (0-14) + } \\
(65 \mathrm{e}+)\end{array}$ & $15-64$ & $\begin{array}{c}\text { Razão de } \\
\text { dependência }\end{array}$ \\
\hline 351350 & Cubatao & C300 & 58389 & 57589 & 101,4 & 37477 & 78500 & 47,7 \\
\hline 351360 & Cunha & E50 & 11880 & 11045 & 107,6 & 8381 & 14544 & 57,6 \\
\hline 351370 & Descalvado & D50 & 15128 & 15212 & 99,4 & 10076 & 20264 & 49,7 \\
\hline 351380 & Diadema & C500 & 186452 & 193739 & 96,2 & 120423 & 259767 & 46,4 \\
\hline 351385 & Dirce Reis & E20 & 772 & 725 & 106,5 & 500 & 998 & 50,1 \\
\hline 351390 & Divinolândia & E20 & 6186 & 5921 & 104,5 & 4053 & 8053 & 50,3 \\
\hline 351400 & Dobrada & E20 & 3718 & 3330 & 111,6 & 2406 & 4642 & 51,8 \\
\hline 351410 & Dois Córregos & D50 & 12126 & 12042 & 100,7 & 8417 & 15752 & 53,4 \\
\hline 351420 & Dolcinópolis & E20 & 1135 & 1039 & 109,2 & 700 & 1475 & 47,5 \\
\hline 351430 & Dourado & E20 & 4602 & 4391 & 104,8 & 2977 & 6016 & 49,5 \\
\hline 351440 & Dracena & D50 & 19890 & 20971 & 94,8 & 13006 & 27855 & 46,7 \\
\hline 351450 & Duartina & E20 & 6239 & 6493 & 96,1 & 4432 & 8300 & 53,4 \\
\hline 351460 & Dumont & D20 & 3524 & 3375 & 104,4 & 2294 & 4604 & 49,8 \\
\hline 351470 & Echapora & E20 & 3526 & 3528 & 99,9 & 2553 & 4501 & 56,7 \\
\hline 351480 & Eldorado & D20 & 7579 & 7008 & 108,1 & 6116 & 8472 & 72,2 \\
\hline 351490 & Elias Fausto & D20 & 7662 & 7235 & 105,9 & 5266 & 9632 & 54,7 \\
\hline 351492 & Elisiário & E20 & 1360 & 1229 & 110,7 & 833 & 1756 & 47,4 \\
\hline 351495 & Embaúba & E20 & 1308 & 1205 & 108,5 & 793 & 1721 & 46,1 \\
\hline 351500 & Embu & C300 & 113547 & 117199 & 96,9 & 76948 & 153798 & 50,0 \\
\hline 351510 & Embu0Guaçu & C100 & 33173 & 32960 & 100,6 & 23102 & 43031 & 53,7 \\
\hline 351512 & Emilianópolis & E20 & 1471 & 1422 & 103,4 & 917 & 1976 & 46,4 \\
\hline 351515 & Engenheiro Coelho & D20 & 6023 & 5588 & 107,8 & 3804 & 7807 & 48,7 \\
\hline 351518 & Espírito Santo do Pinhal & C50 & 20766 & 21188 & 98,0 & 13860 & 28094 & 49,3 \\
\hline 351519 & Espírito Santo do Turvo & D20 & 2063 & 1925 & 107,2 & 1451 & 2537 & 57,2 \\
\hline 355730 & Estiva Gerbi & C2O & 5076 & 4755 & 106,8 & 3342 & 6489 & 51,5 \\
\hline 351520 & Estrela d'Oeste & E20 & 4143 & 4007 & 103,4 & 2574 & 5576 & 46,2 \\
\hline 351530 & Estrela do Norte & E20 & 1322 & 1234 & 107,1 & 944 & 1612 & 58,6 \\
\hline 351535 & Euclides da Cunha Paulist & E20 & 5316 & 5190 & 102,4 & 4035 & 6471 & 62,3 \\
\hline 351540 & Fartura & E20 & 7658 & 7656 & 100,0 & 5379 & 9935 & 54,1 \\
\hline 351560 & Fernando Prestes & E20 & 2746 & 2803 & 98,0 & 1792 & 3757 & 47,7 \\
\hline 351550 & Fernandópolis & D100 & 31554 & 32550 & 96,9 & 20149 & 43955 & 45,8 \\
\hline 351565 & Fernao & D20 & 680 & 636 & 106,8 & 451 & 865 & 52,2 \\
\hline 351570 & Ferraz de Vasconcelos & C300 & 80377 & 82640 & 97,3 & 57272 & 105746 & 54,2 \\
\hline 351580 & Flora Rica & E20 & 1046 & 1041 & 100,4 & 759 & 1328 & 57,2 \\
\hline 351590 & Floreal & E20 & 1533 & 1545 & 99,2 & 996 & 2082 & 47,8 \\
\hline 351600 & Flórida Paulista & E20 & 5247 & 5231 & 100,3 & 3682 & 6797 & 54,2 \\
\hline 351610 & Florínia & E20 & 1542 & 1638 & 94,1 & 1081 & 2100 & 51,5 \\
\hline 351620 & Franca & B500 & 154214 & 157928 & 97,6 & 103360 & 208783 & 49,5 \\
\hline 351630 & Francisco Morato & D300 & 77807 & 78199 & 99,5 & 57841 & 98166 & 58,9 \\
\hline 351640 & Franco da Rocha & C300 & 61198 & 57013 & 107,3 & 38768 & 79443 & 48,8 \\
\hline 351650 & Gabriel Monteiro & E20 & 1468 & 1371 & 107,1 & 875 & 1963 & 44,6 \\
\hline 351660 & Gália & E20 & 3776 & 3652 & 103,4 & 2611 & 4816 & 54,2 \\
\hline 351670 & Garça & D50 & 21592 & 22317 & 96,8 & 15049 & 28861 & 52,1 \\
\hline 351680 & Gastao Vidigal & E20 & 1743 & 1732 & 100,7 & 1076 & 2399 & 44,9 \\
\hline 351685 & Gaviao Peixoto & E20 & 2176 & 1908 & 114,1 & 1469 & 2615 & 56,2 \\
\hline 351690 & General Salgado & E20 & 5607 & 5416 & 103,5 & 3584 & 7439 & 48,2 \\
\hline 351700 & Getulina & E20 & 5637 & 4844 & 116,4 & 3472 & 7009 & 49,5 \\
\hline 351710 & Glicério & E20 & 2284 & 2230 & 102,5 & 1511 & 3003 & 50,3 \\
\hline 351720 & Guaiçara & D20 & 5218 & 5265 & 99,1 & 3702 & 6780 & 54,6 \\
\hline 351730 & Guaimbê & E20 & 2617 & 2621 & 99,9 & 1941 & 3296 & 58,9 \\
\hline
\end{tabular}


Anexo 10 - Razão de sexos e de dependência segundo município e Estrato de Vulnerabilidade Social. Estado de São Paulo, média do triênio, 2003-2005

\begin{tabular}{|c|c|c|c|c|c|c|c|c|}
\hline IBGE & MUNICIPIO & Estrato & Homens & Mulheres & $\begin{array}{c}\text { Razão de } \\
\text { Sexos } \\
\end{array}$ & $\begin{array}{c}\text { Pop (0-14) + } \\
(65 \mathrm{e}+) \\
\end{array}$ & 15-64 & $\begin{array}{c}\text { Razão de } \\
\text { dependência }\end{array}$ \\
\hline 351740 & Guaíra & C50 & 18208 & 17983 & 101,3 & 11620 & 24571 & 47,3 \\
\hline 351750 & Guapiaçu & D20 & 7943 & 7670 & 103,6 & 4769 & 10845 & 44,0 \\
\hline 351760 & Guapiara & E50 & 10479 & 9892 & 105,9 & 7970 & 12401 & 64,3 \\
\hline 351770 & Guará & E50 & 10053 & 10004 & 100,5 & 6897 & 13160 & 52,4 \\
\hline 351780 & Guaraçaí & E20 & 4626 & 4539 & 101,9 & 2996 & 6169 & 48,6 \\
\hline 351790 & Guaraci & E20 & 4733 & 4575 & 103,5 & 3299 & 6009 & 54,9 \\
\hline 351800 & Guarani d'Oeste & E20 & 1083 & 1001 & 108,2 & 695 & 1388 & 50,1 \\
\hline 351810 & Guaranta & E20 & 3396 & 3277 & 103,6 & 2457 & 4216 & 58,3 \\
\hline 351820 & Guararapes & D50 & 14787 & 15019 & 98,5 & 9758 & 20047 & 48,7 \\
\hline 351830 & Guararema & D50 & 12001 & 11665 & 102,9 & 8361 & 15304 & 54,6 \\
\hline 351840 & Guaratinguetá & B300 & 53491 & 56041 & 95,4 & 35638 & 73894 & 48,2 \\
\hline 351850 & Guareí & E20 & 5757 & 5212 & 110,5 & 3918 & 7050 & 55,6 \\
\hline 351860 & Guariba & E50 & 16210 & 15846 & 102,3 & 11094 & 20962 & 52,9 \\
\hline 351870 & Guarujá & С300 & 142927 & 146276 & 97,7 & 97021 & 192182 & 50,5 \\
\hline 351880 & Guarulhos & C10000 & 590050 & 609901 & 96,7 & 394367 & 805584 & 49,0 \\
\hline 351885 & Guatapará & D2O & 3421 & 3206 & 106,7 & 2391 & 4235 & 56,5 \\
\hline 351890 & Guzolândia & E20 & 2063 & 1894 & 108,9 & 1350 & 2606 & 51,8 \\
\hline 351900 & Herculândia & E20 & 4271 & 4149 & 102,9 & 2981 & 5439 & 54,8 \\
\hline 351905 & Holambra & C20 & 4098 & 3911 & 104,8 & 2455 & 5554 & 44,2 \\
\hline 351907 & Hortolândia & С 300 & 91185 & 91117 & 100,1 & 62023 & 120278 & 51,6 \\
\hline 351910 & lacanga & E20 & 4343 & 4257 & 102,0 & 2867 & 5733 & 50,0 \\
\hline 351920 & lacri & E20 & 3354 & 3316 & 101,1 & 2272 & 4397 & 51,7 \\
\hline 351925 & laras & D20 & 1888 & 1567 & 120,5 & 1273 & 2182 & 58,3 \\
\hline 351930 & Ibaté & D50 & 15160 & 14712 & 103,0 & 10488 & 19384 & 54,1 \\
\hline 351940 & |birá & D20 & 4811 & 4962 & 97,0 & 3318 & 6456 & 51,4 \\
\hline 351950 & Ibirarema & E20 & 2926 & 2853 & 102,6 & 2051 & 3727 & 55,0 \\
\hline 351960 & Ibitinga & D100 & 24915 & 25449 & 97,9 & 16371 & 33994 & 48,2 \\
\hline 351970 & |biúna & E50 & 36626 & 34547 & 106,0 & 25488 & 45684 & 55,8 \\
\hline 351980 & Icém & D20 & 3570 & 3502 & 101,9 & 2431 & 4640 & 52,4 \\
\hline 351990 & lepê & E20 & 3528 & 3560 & 99,1 & 2522 & 4566 & 55,2 \\
\hline 352000 & Igaraçu do Tietê & D50 & 11764 & 11628 & 101,2 & 7768 & 15624 & 49,7 \\
\hline 352010 & Igarapava & D50 & 13557 & 13977 & 97,0 & 9061 & 18473 & 49,1 \\
\hline 352020 & Igaratá & E20 & 4764 & 4421 & 107,8 & 3224 & 5962 & 54,1 \\
\hline 352030 & Iguape & E50 & 14414 & 13831 & 104,2 & 10266 & 17978 & 57,1 \\
\hline 352042 & Iha Comprida & A20 & 4293 & 4175 & 102,8 & 2869 & 5598 & 51,3 \\
\hline 352044 & Ilha Solteira & B50 & 12354 & 12662 & 97,6 & 7213 & 17803 & 40,5 \\
\hline 352040 & Ihabela & C50 & 12554 & 11542 & 108,8 & 7974 & 16122 & 49,5 \\
\hline 352050 & Indaiatuba & B300 & 83720 & 83925 & 99,8 & 53746 & 113898 & 47,2 \\
\hline 352060 & Indiana & E20 & 2576 & 2494 & 103,3 & 1761 & 3309 & 53,2 \\
\hline 352070 & Indiapora & E20 & 1869 & 1873 & 99,8 & 1203 & 2539 & 47,4 \\
\hline 352080 & Inúbia Paulista & E20 & 1692 & 1615 & 104,7 & 1156 & 2151 & 53,7 \\
\hline 352090 & Ipauçu & E20 & 6531 & 6533 & 100,0 & 4560 & 8504 & 53,6 \\
\hline 352100 & Iperó & C50 & 11713 & 10159 & 115,3 & 7513 & 14360 & 52,3 \\
\hline 352110 & Ipeúna & $\mathrm{C} 20$ & 2632 & 2443 & 107,8 & 1751 & 3324 & 52,7 \\
\hline 352115 & Ipiguá & E20 & 2058 & 1927 & 106,8 & 1333 & 2652 & 50,3 \\
\hline 352120 & |poranga & E20 & 2357 & 2183 & 108,0 & 1907 & 2633 & 72,4 \\
\hline 352130 & Ipua & D2O & 6405 & 6142 & 104,3 & 4127 & 8419 & 49,0 \\
\hline 352140 & Iracemápolis & $\mathrm{C} 20$ & 8711 & 8544 & 102,0 & 5484 & 11770 & 46,6 \\
\hline 352150 & Irapua & E20 & 3563 & 3349 & 106,4 & 2304 & 4608 & 50,0 \\
\hline 352160 & Irapuru & E20 & 3580 & 3521 & 101,7 & 2443 & 4659 & 52,4 \\
\hline
\end{tabular}


Anexo 10 - Razão de sexos e de dependência segundo município e Estrato de Vulnerabilidade Social. Estado de São Paulo, média do triênio, 2003-2005

\begin{tabular}{|c|c|c|c|c|c|c|c|c|}
\hline IBGE & MUNICIPIO & Estrato & Homens & Mulheres & $\begin{array}{c}\text { Razão de } \\
\text { Sexos } \\
\end{array}$ & $\begin{array}{c}\text { Pop }(0-14)+ \\
(65 \mathrm{e}+) \\
\end{array}$ & 15-64 & $\begin{array}{c}\text { Razão de } \\
\text { dependência }\end{array}$ \\
\hline 352170 & Itaberá & E20 & 9829 & 9534 & 103,1 & 7221 & 12143 & 59,5 \\
\hline 352180 & Itaí & E50 & 11539 & 10937 & 105,5 & 7942 & 14534 & 54,6 \\
\hline 352190 & Itajobi & E20 & 7414 & 7286 & 101,8 & 4686 & 10014 & 46,8 \\
\hline 352200 & Itaju & E20 & 1437 & 1325 & 108,4 & 911 & 1850 & 49,3 \\
\hline 352210 & Itanhaém & C100 & 41565 & 42009 & 98,9 & 29607 & 53967 & 54,9 \\
\hline 352215 & Itaóca & E20 & 1538 & 1464 & 105,1 & 1249 & 1754 & 71,2 \\
\hline 352220 & Itapecerica da Serra & C300 & 73823 & 75535 & 97,7 & 51643 & 97716 & 52,8 \\
\hline 352230 & Itapetininga & B300 & 68191 & 67966 & 100,3 & 47160 & 88998 & 53,0 \\
\hline 352240 & Itapeva & D100 & 43066 & 43955 & 98,0 & 32083 & 54938 & 58,4 \\
\hline 352250 & Itapevi & C300 & 92442 & 94315 & 98,0 & 67425 & 119332 & 56,5 \\
\hline 352260 & Itapira & D100 & 33266 & 33145 & 100,4 & 21708 & 44703 & 48,6 \\
\hline 352265 & Itapirapua Paulista & E20 & 1959 & 1758 & 111,4 & 1529 & 2188 & 69,9 \\
\hline 352270 & Itápolis & D50 & 19888 & 19962 & 99,6 & 13162 & 26688 & 49,3 \\
\hline 352280 & Itaporanga & E20 & 7228 & 7101 & 101,8 & 5150 & 9180 & 56,1 \\
\hline 352290 & Itapuí & E20 & 5626 & 5333 & 105,5 & 3790 & 7169 & 52,9 \\
\hline 352300 & Itapura & E20 & 2029 & 1848 & 109,8 & 1413 & 2464 & 57,3 \\
\hline 352310 & Itaquaquecetuba & C500 & 160287 & 160889 & 99,6 & 117693 & 203483 & 57,8 \\
\hline 352320 & Itararé & D50 & 24099 & 24560 & 98,1 & 18501 & 30158 & 61,3 \\
\hline 352330 & Itariri & D20 & 7423 & 7085 & 104,8 & 5715 & 8793 & 65,0 \\
\hline 352340 & Itatiba & B100 & 44804 & 45126 & 99,3 & 28889 & 61041 & 47,3 \\
\hline 352350 & Itatinga & E20 & 8293 & 7900 & 105,0 & 6068 & 10125 & 59,9 \\
\hline 352360 & Itirapina & $\mathrm{C} 20$ & 7868 & 6254 & 125,8 & 4463 & 9660 & 46,2 \\
\hline 352370 & Itirapua & E20 & 2907 & 2668 & 109,0 & 2040 & 3535 & 57,7 \\
\hline 352380 & Itobi & E20 & 4037 & 3735 & 108,1 & 2750 & 5021 & 54,8 \\
\hline 352390 & Itu & C300 & 73710 & 74187 & 99,4 & 49321 & 98576 & 50,0 \\
\hline 352400 & Itupeva & C50 & 15250 & 14501 & 105,2 & 9760 & 19992 & 48,8 \\
\hline 352410 & Ituverava & D50 & 18667 & 19060 & 97,9 & 12182 & 25545 & 47,7 \\
\hline 352420 & Jaborandi & E20 & 3325 & 3140 & 105,9 & 2145 & 4320 & 49,7 \\
\hline 352430 & Jaboticabal & B100 & 34875 & 36228 & 96,3 & 23284 & 47819 & 48,7 \\
\hline 352440 & Jacareí & B300 & 100689 & 102849 & 97,9 & 65124 & 138414 & 47,1 \\
\hline 352450 & Jaci & E20 & 2337 & 2173 & 107,6 & 1408 & 3103 & 45,4 \\
\hline 352460 & Jacupiranga & D20 & 9305 & 8901 & 104,5 & 6914 & 11293 & 61,2 \\
\hline 352470 & Jaguariúna & B50 & 16515 & 16214 & 101,9 & 10383 & 22345 & 46,5 \\
\hline 352480 & Jales & D50 & 23933 & 24407 & 98,1 & 14923 & 33417 & 44,7 \\
\hline 352490 & Jambeiro & D20 & 2245 & 2061 & 108,9 & 1503 & 2803 & 53,6 \\
\hline 352500 & Jandira & C300 & 51997 & 52812 & 98,5 & 35201 & 69608 & 50,6 \\
\hline 352510 & Jardinópolis & C50 & 16981 & 16699 & 101,7 & 11645 & 22034 & 52,9 \\
\hline 352520 & Jarinu & D20 & 10254 & 9540 & 107,5 & 6929 & 12866 & 53,9 \\
\hline 352530 & Jaú & C300 & 59371 & 60768 & 97,7 & 38353 & 81786 & 46,9 \\
\hline 352540 & Jeriquara & E20 & 1747 & 1540 & 113,4 & 1168 & 2120 & 55,1 \\
\hline 352550 & Joanópolis & E20 & 5812 & 5590 & 104,0 & 3852 & 7550 & 51,0 \\
\hline 352560 & Joao Ramalho & E20 & 2110 & 2081 & 101,4 & 1542 & 2649 & 58,2 \\
\hline 352570 & José Bonifácio & D50 & 15514 & 15464 & 100,3 & 10367 & 20611 & 50,3 \\
\hline 352580 & Júlio Mesquita & E20 & 2125 & 2186 & 97,2 & 1646 & 2665 & 61,8 \\
\hline 352585 & Jumirim & A20 & 1295 & 1165 & 111,2 & 880 & 1580 & 55,7 \\
\hline 352590 & Jundiaí & A500 & 166068 & 172572 & 96,2 & 103916 & 234724 & 44,3 \\
\hline 352600 & Junqueirópolis & E20 & 8739 & 7953 & 109,9 & 5422 & 11270 & 48,1 \\
\hline 352610 & Juquiá & D50 & 11327 & 10780 & 105,1 & 8617 & 13489 & 63,9 \\
\hline 352620 & Juquitiba & D50 & 14770 & 14589 & 101,2 & 11105 & 18254 & 60,8 \\
\hline 352630 & Lagoinha & E20 & 2668 & 2433 & 109,6 & 1882 & 3219 & 58,5 \\
\hline
\end{tabular}


Anexo 10 - Razão de sexos e de dependência segundo município e Estrato de Vulnerabilidade Social. Estado de São Paulo, média do triênio, 2003-2005

\begin{tabular}{|c|c|c|c|c|c|c|c|c|}
\hline IBGE & MUNICIPIO & Estrato & Homens & Mulheres & $\begin{array}{c}\text { Razão de } \\
\text { Sexos }\end{array}$ & $\begin{array}{c}\text { Pop }(0-14)+ \\
(65 \mathrm{e}+)\end{array}$ & $15-64$ & $\begin{array}{c}\text { Razão de } \\
\text { dependência }\end{array}$ \\
\hline 352640 & Laranjal Paulista & B50 & 11729 & 11755 & 99,8 & 8022 & 15462 & 51,9 \\
\hline 352650 & Lavínia & E20 & 2508 & 2486 & 100,9 & 1730 & 3264 & 53,0 \\
\hline 352660 & Lavrinhas & D20 & 3372 & 3232 & 104,3 & 2426 & 4179 & 58,0 \\
\hline 352670 & Leme & D100 & 43663 & 42696 & 102,3 & 29473 & 56886 & 51,8 \\
\hline 352680 & Lençóis Paulista & C100 & 29845 & 29753 & 100,3 & 20160 & 39439 & 51,1 \\
\hline 352690 & Limeira & B300 & 132758 & 134723 & 98,5 & 85767 & 181714 & 47,2 \\
\hline 352700 & Lindóia & D20 & 2975 & 2921 & 101,8 & 1956 & 3941 & 49,6 \\
\hline 352710 & Lins & B100 & 33582 & 35650 & 94,2 & 22605 & 46627 & 48,5 \\
\hline 352720 & Lorena & B100 & 39694 & 41762 & 95,0 & 27575 & 53881 & 51,2 \\
\hline 352725 & Lourdes & E20 & 1119 & 1041 & 107,6 & 709 & 1451 & 48,8 \\
\hline 352730 & Louveira & C50 & 13851 & 13466 & 102,9 & 8704 & 18613 & 46,8 \\
\hline 352740 & Lucélia & D20 & 9590 & 8946 & 107,2 & 6086 & 12451 & 48,9 \\
\hline 352750 & Lucianópolis & E20 & 1064 & 1002 & 106,2 & 697 & 1369 & 50,9 \\
\hline 352760 & Luís Antônio & C2O & 3963 & 3786 & 104,7 & 2811 & 4939 & 56,9 \\
\hline 352770 & Luiziânia & E20 & 2170 & 2158 & 100,6 & 1504 & 2825 & 53,2 \\
\hline 352780 & Lupércio & E20 & 2165 & 2131 & 101,6 & 1550 & 2745 & 56,5 \\
\hline 352790 & Lutécia & E20 & 1535 & 1477 & 103,9 & 1054 & 1958 & 53,8 \\
\hline 352800 & Macatuba & D20 & 8427 & 8344 & 101,0 & 5889 & 10882 & 54,1 \\
\hline 352810 & Macaubal & E20 & 3753 & 3632 & 103,3 & 2314 & 5071 & 45,6 \\
\hline 352820 & Macedônia & E20 & 1861 & 1812 & 102,7 & 1155 & 2519 & 45,9 \\
\hline 352830 & Magda & E20 & 1701 & 1603 & 106,1 & 1010 & 2295 & 44,0 \\
\hline 352840 & Mairinque & C50 & 22354 & 22321 & 100,1 & 15237 & 29439 & 51,8 \\
\hline 352850 & Mairipora & C100 & 34741 & 34381 & 101,0 & 23317 & 45805 & 50,9 \\
\hline 352860 & Manduri & D20 & 4459 & 4256 & 104,8 & 3010 & 5705 & 52,8 \\
\hline 352870 & Marabá Paulista & E20 & 1965 & 1825 & 107,7 & 1278 & 2512 & 50,9 \\
\hline 352880 & Maracaí & D20 & 6754 & 6489 & 104,1 & 4436 & 8807 & 50,4 \\
\hline 352885 & Marapoama & E20 & 1225 & 1192 & 102,8 & 802 & 1616 & 49,6 \\
\hline 352890 & Mariápolis & E20 & 1868 & 1764 & 105,9 & 1296 & 2336 & 55,5 \\
\hline 352900 & Marília & B300 & 104407 & 109102 & 95,7 & 69283 & 144226 & 48,0 \\
\hline 352910 & Marinópolis & E20 & 1159 & 1084 & 106,9 & 766 & 1478 & 51,8 \\
\hline 352920 & Martinópolis & D50 & 12056 & 11484 & 105,0 & 7860 & 15680 & 50,1 \\
\hline 352930 & Matao & B100 & 37691 & 37699 & 100,0 & 24649 & 50741 & 48,6 \\
\hline 352940 & Mauá & C500 & 193869 & 200072 & 96,9 & 129899 & 264042 & 49,2 \\
\hline 352950 & Mendonça & E20 & 1996 & 1879 & 106,2 & 1263 & 2612 & 48,3 \\
\hline 352960 & Meridiano & E20 & 2113 & 2020 & 104,6 & 1350 & 2783 & 48,5 \\
\hline 352965 & Mesópolis & E20 & 968 & 927 & 104,5 & 645 & 1250 & 51,6 \\
\hline 352970 & Miguelópolis & E20 & 9925 & 9814 & 101,1 & 6569 & 13170 & 49,9 \\
\hline 352980 & Mineiros do Tietê & E20 & 6178 & 6100 & 101,3 & 4319 & 7959 & 54,3 \\
\hline 353000 & Mira Estrela & E20 & 1331 & 1234 & 107,8 & 800 & 1766 & 45,3 \\
\hline 352990 & Miracatu & E50 & 12347 & 11559 & 106,8 & 9327 & 14579 & 64,0 \\
\hline 353010 & Mirandópolis & D50 & 14168 & 12439 & 113,9 & 7968 & 18639 & 42,7 \\
\hline 353020 & Mirante do Paranapanema & E20 & 8509 & 8165 & 104,2 & 5877 & 10797 & 54,4 \\
\hline 353030 & Mirassol & B100 & 25841 & 26524 & 97,4 & 16536 & 35828 & 46,2 \\
\hline 353040 & Mirassolândia & E20 & 2088 & 1974 & 105,8 & 1338 & 2724 & 49,1 \\
\hline 353050 & Mococa & D100 & 34700 & 34090 & 101,8 & 22749 & 46041 & 49,4 \\
\hline 353060 & Moji das Cruzes & B500 & 175191 & 180540 & 97,0 & 120612 & 235120 & 51,3 \\
\hline 353070 & MojiOGuaçu & B300 & 67674 & 67027 & 101,0 & 43408 & 91293 & 47,5 \\
\hline 353080 & MojiOMirim & B100 & 44434 & 44498 & 99,9 & 28411 & 60520 & 46,9 \\
\hline 353090 & Mombuca & E20 & 1706 & 1628 & 104,8 & 1271 & 2062 & 61,6 \\
\hline 353100 & Monçoes & E20 & 1033 & 1002 & 103,1 & 653 & 1382 & 47,2 \\
\hline
\end{tabular}


Anexo 10 - Razão de sexos e de dependência segundo município e Estrato de Vulnerabilidade Social. Estado de São Paulo, média do triênio, 2003-2005

\begin{tabular}{|c|c|c|c|c|c|c|c|c|}
\hline IBGE & MUNICIPIO & Estrato & Homens & Mulheres & $\begin{array}{c}\text { Razão de } \\
\text { Sexos }\end{array}$ & $\begin{array}{c}\text { Pop }(0-14)+ \\
(65 \mathrm{e}+)\end{array}$ & $15-64$ & $\begin{array}{c}\text { Razão de } \\
\text { dependência }\end{array}$ \\
\hline 353110 & Mongaguá & C50 & 21680 & 20597 & 105,3 & 14841 & 27437 & 54,1 \\
\hline 353120 & Monte Alegre do Sul & E20 & 3421 & 3294 & 103,8 & 2175 & 4541 & 47,9 \\
\hline 353130 & Monte Alto & C50 & 22716 & 22624 & 100,4 & 14583 & 30758 & 47,4 \\
\hline 353140 & Monte Aprazível & D20 & 9329 & 9489 & 98,3 & 5784 & 13034 & 44,4 \\
\hline 353150 & Monte Azul Paulista & E50 & 10291 & 10091 & 102,0 & 6997 & 13385 & 52,3 \\
\hline 353160 & Monte Castelo & E20 & 1928 & 1880 & 102,6 & 1291 & 2517 & 51,3 \\
\hline 353180 & Monte Mor & D50 & 21412 & 21189 & 101,1 & 14707 & 27894 & 52,7 \\
\hline 353170 & Monteiro Lobato & E20 & 1919 & 1802 & 106,5 & 1320 & 2401 & 55,0 \\
\hline 353190 & Morro Agudo & D50 & 13933 & 13360 & 104,3 & 9408 & 17885 & 52,6 \\
\hline 353200 & Morungaba & D20 & 5399 & 5274 & 102,4 & 3498 & 7174 & 48,8 \\
\hline 353205 & Motuca & D20 & 2122 & 2004 & 105,9 & 1402 & 2724 & 51,5 \\
\hline 353210 & Murutinga do Sul & E20 & 2064 & 1992 & 103,6 & 1329 & 2727 & 48,7 \\
\hline 353215 & Nantes & E20 & 1131 & 1087 & 104,1 & 794 & 1424 & 55,8 \\
\hline 353220 & Narandiba & E20 & 2026 & 1987 & 102,0 & 1408 & 2605 & 54,0 \\
\hline 353230 & Natividade da Serra & E20 & 3807 & 3365 & 113,1 & 2731 & 4440 & 61,5 \\
\hline 353240 & Nazaré Paulista & E20 & 8059 & 7574 & 106,4 & 5756 & 9877 & 58,3 \\
\hline 353250 & Neves Paulista & E20 & 4621 & 4552 & 101,5 & 2853 & 6319 & 45,2 \\
\hline 353260 & Nhandeara & D20 & 4991 & 5133 & 97,2 & 3030 & 7094 & 42,7 \\
\hline 353270 & Nipoa & E20 & 1781 & 1696 & 105,0 & 1147 & 2330 & 49,2 \\
\hline 353280 & Nova Aliança & E20 & 2496 & 2529 & 98,7 & 1682 & 3343 & 50,3 \\
\hline 353282 & Nova Campina & E20 & 4288 & 3935 & 109,0 & 3332 & 4891 & 68,1 \\
\hline 353284 & Nova Canaa Paulista & E20 & 1229 & 1139 & 107,9 & 787 & 1581 & 49,8 \\
\hline 353286 & Nova Castilho & E20 & 531 & 481 & 110,4 & 323 & 690 & 46,8 \\
\hline 353290 & Nova Europa & D20 & 4149 & 4019 & 103,2 & 2716 & 5452 & 49,8 \\
\hline 353300 & Nova Granada & E20 & 9024 & 8945 & 100,9 & 6038 & 11931 & 50,6 \\
\hline 353310 & Nova Guataporanga & E20 & 1064 & 1007 & 105,7 & 731 & 1339 & 54,6 \\
\hline 353320 & Nova Independência & E20 & 1069 & 1023 & 104,5 & 738 & 1354 & 54,5 \\
\hline 353330 & Nova Luzitânia & E20 & 1470 & 1327 & 110,8 & 904 & 1893 & 47,8 \\
\hline 353340 & Nova Odessa & B50 & 22641 & 23006 & 98,4 & 14360 & 31287 & 45,9 \\
\hline 353325 & Novais & E20 & 1714 & 1574 & 108,9 & 1199 & 2089 & 57,4 \\
\hline 353350 & Novo Horizonte & D50 & 16554 & 16769 & 98,7 & 11036 & 22287 & 49,5 \\
\hline 353360 & Nuporanga & E20 & 3321 & 3220 & 103,1 & 2261 & 4279 & 52,8 \\
\hline 353370 & Ocauçu & E20 & 2135 & 1962 & 108,8 & 1443 & 2654 & 54,4 \\
\hline 353380 & Oleo & E20 & 1579 & 1499 & 105,3 & 1106 & 1972 & 56,1 \\
\hline 353390 & Olímpia & D50 & 23471 & 23930 & 98,1 & 15773 & 31629 & 49,9 \\
\hline 353400 & Onda Verde & E20 & 1871 & 1804 & 103,8 & 1228 & 2447 & 50,2 \\
\hline 353410 & Oriente & D20 & 2721 & 2751 & 98,9 & 1897 & 3576 & 53,1 \\
\hline 353420 & Orindiúva & C20 & 2401 & 2257 & 106,4 & 1600 & 3058 & 52,3 \\
\hline 353430 & Orlândia & B50 & 18900 & 19195 & 98,5 & 12269 & 25826 & 47,5 \\
\hline 353440 & Osasco & B1000 & 335912 & 354366 & 94,8 & 217673 & 472605 & 46,1 \\
\hline 353450 & Oscar Bressane & E20 & 1252 & 1305 & 96,0 & 841 & 1716 & 49,0 \\
\hline 353460 & Osvaldo Cruz & D50 & 14769 & 15205 & 97,1 & 9755 & 20219 & 48,2 \\
\hline 353470 & Ourinhos & C300 & 49796 & 51615 & 96,5 & 33542 & 67870 & 49,4 \\
\hline 353480 & Ouro Verde & E20 & 3597 & 3573 & 100,7 & 2610 & 4560 & 57,2 \\
\hline 353475 & Ouroeste & E20 & 3460 & 3431 & 100,9 & 2238 & 4653 & 48,1 \\
\hline 353490 & Pacaembu & E20 & 6693 & 5896 & 113,5 & 3956 & 8633 & 45,8 \\
\hline 353500 & Palestina & E20 & 4544 & 4596 & 98,9 & 2936 & 6204 & 47,3 \\
\hline 353510 & Palmares Paulista & E20 & 4551 & 4383 & 103,8 & 3103 & 5832 & 53,2 \\
\hline 353520 & Palmeira d'Oeste & E20 & 5103 & 4940 & 103,3 & 3243 & 6800 & 47,7 \\
\hline 353530 & Palmital & D50 & 10700 & 10902 & 98,1 & 7270 & 14332 & 50,7 \\
\hline
\end{tabular}


Anexo 10 - Razão de sexos e de dependência segundo município e Estrato de Vulnerabilidade Social. Estado de São Paulo, média do triênio, 2003-2005

\begin{tabular}{|c|c|c|c|c|c|c|c|c|}
\hline IBGE & MUNICIPIO & Estrato & Homens & Mulheres & $\begin{array}{c}\text { Razão de } \\
\text { Sexos }\end{array}$ & $\begin{array}{c}\text { Pop }(0-14)+ \\
(65 \mathrm{e}+)\end{array}$ & $15-64$ & $\begin{array}{c}\text { Razão de } \\
\text { dependência }\end{array}$ \\
\hline 353540 & Panorama & E20 & 7263 & 6969 & 104,2 & 5071 & 9161 & 55,4 \\
\hline 353550 & Paraguaçu Paulista & D50 & 20919 & 21279 & 98,3 & 14754 & 27444 & 53,8 \\
\hline 353560 & Paraibuna & E20 & 9190 & 8764 & 104,9 & 6564 & 11390 & 57,6 \\
\hline 353570 & Paraíso & E20 & 2989 & 2752 & 108,6 & 1940 & 3801 & 51,1 \\
\hline 353580 & Paranapanema & E20 & 8692 & 8029 & 108,3 & 6075 & 10646 & 57,1 \\
\hline 353590 & Paranapua & E20 & 1818 & 1753 & 103,7 & 1181 & 2390 & 49,4 \\
\hline 353600 & Parapua & E20 & 5569 & 5394 & 103,2 & 3754 & 7210 & 52,1 \\
\hline 353610 & Pardinho & D20 & 2755 & 2550 & 108,1 & 1893 & 3412 & 55,5 \\
\hline 353620 & Pariquera0Açu & D20 & 9902 & 9750 & 101,6 & 7315 & 12338 & 59,3 \\
\hline 353625 & Parisi & E20 & 1123 & 1020 & 110,1 & 685 & 1458 & 46,9 \\
\hline 353630 & Patrocínio Paulista & D20 & 6236 & 5941 & 105,0 & 4250 & 7926 & 53,6 \\
\hline 353640 & Paulicéia & E20 & 3019 & 2794 & 108,1 & 2168 & 3645 & 59,5 \\
\hline 353650 & Paulínia & B100 & 28956 & 28900 & 100,2 & 17808 & 40049 & 44,5 \\
\hline 353657 & Paulistânia & E20 & 1006 & 888 & 113,2 & 650 & 1244 & 52,2 \\
\hline 353660 & Paulo de Faria & E20 & 4257 & 4284 & 99,4 & 2975 & 5567 & 53,4 \\
\hline 353670 & Pederneiras & D50 & 19519 & 19145 & 102,0 & 13511 & 25153 & 53,7 \\
\hline 353680 & Pedra Bela & E20 & 3074 & 2744 & 112,0 & 2028 & 3789 & 53,5 \\
\hline 353690 & Pedranópolis & E20 & 1318 & 1251 & 105,4 & 831 & 1738 & 47,8 \\
\hline 353700 & Pedregulho & D20 & 7949 & 7612 & 104,4 & 5467 & 10093 & 54,2 \\
\hline 353710 & Pedreira & B50 & 19062 & 19395 & 98,3 & 12288 & 26169 & 47,0 \\
\hline 353715 & Pedrinhas Paulista & A20 & 1514 & 1472 & 102,8 & 1034 & 1953 & 52,9 \\
\hline 353720 & Pedro de Toledo & E20 & 5001 & 4790 & 104,4 & 3838 & 5953 & 64,5 \\
\hline 353730 & Penápolis & D100 & 28077 & 29395 & 95,5 & 18856 & 38615 & 48,8 \\
\hline 353740 & Pereira Barreto & D50 & 12244 & 12537 & 97,7 & 8478 & 16303 & 52,0 \\
\hline 353750 & Pereiras & E20 & 3600 & 3419 & 105,3 & 2504 & 4516 & 55,4 \\
\hline 353760 & Peruíbe & D100 & 29784 & 30011 & 99,2 & 22240 & 37555 & 59,2 \\
\hline 353770 & Piacatu & E20 & 2355 & 2309 & 102,0 & 1558 & 3107 & 50,2 \\
\hline 353780 & Piedade & D100 & 27847 & 25211 & 110,5 & 18403 & 34654 & 53,1 \\
\hline 353790 & Pilar do Sul & E50 & 13368 & 12572 & 106,3 & 9411 & 16529 & 56,9 \\
\hline 353800 & Pindamonhangaba & B300 & 68218 & 68511 & 99,6 & 45823 & 90906 & 50,4 \\
\hline 353810 & Pindorama & E20 & 6805 & 6631 & 102,6 & 4332 & 9104 & 47,6 \\
\hline 353820 & Pinhalzinho & E20 & 6284 & 5840 & 107,6 & 4128 & 7996 & 51,6 \\
\hline 353830 & Piquerobi & E20 & 1811 & 1758 & 103,0 & 1181 & 2388 & 49,5 \\
\hline 353850 & Piquete & B20 & 7532 & 7872 & 95,7 & 5239 & 10165 & 51,5 \\
\hline 353860 & Piracaia & D50 & 12840 & 12449 & 103,1 & 8846 & 16443 & 53,8 \\
\hline 353870 & Piracicaba & B500 & 173552 & 178139 & 97,4 & 112638 & 239053 & 47,1 \\
\hline 353880 & Piraju & D50 & 14068 & 14641 & 96,1 & 9848 & 18861 & 52,2 \\
\hline 353890 & Pirajuí & D50 & 11016 & 9645 & 114,2 & 6434 & 14227 & 45,2 \\
\hline 353900 & Pirangi & E20 & 5194 & 4921 & 105,5 & 3275 & 6841 & 47,9 \\
\hline 353910 & Pirapora do Bom Jesus & D20 & 7202 & 7175 & 100,4 & 5445 & 8931 & 61,0 \\
\hline 353920 & Pirapozinho & D50 & 11057 & 11546 & 95,8 & 7765 & 14838 & 52,3 \\
\hline 353930 & Pirassununga & B100 & 33758 & 34732 & 97,2 & 22488 & 46002 & 48,9 \\
\hline 353940 & Piratininga & B20 & 5561 & 5439 & 102,2 & 3729 & 7271 & 51,3 \\
\hline 353950 & Pitangueiras & D50 & 16900 & 16091 & 105,0 & 11831 & 21160 & 55,9 \\
\hline 353960 & Planalto & E20 & 1907 & 1841 & 103,6 & 1258 & 2490 & 50,5 \\
\hline 353970 & Platina & E20 & 1509 & 1370 & 110,1 & 1025 & 1854 & 55,3 \\
\hline 353980 & Poá & B300 & 51225 & 53286 & 96,1 & 35668 & 68843 & 51,8 \\
\hline 353990 & Poloni & E20 & 2387 & 2497 & 95,6 & 1580 & 3304 & 47,8 \\
\hline 354000 & Pompéia & C20 & 9199 & 9389 & 98,0 & 5992 & 12597 & 47,6 \\
\hline 354010 & Pongaí & E20 & 1948 & 1797 & 108,4 & 1205 & 2540 & 47,4 \\
\hline
\end{tabular}


Anexo 10 - Razão de sexos e de dependência segundo município e Estrato de Vulnerabilidade Social. Estado de São Paulo, média do triênio, 2003-2005

\begin{tabular}{|c|c|c|c|c|c|c|c|c|}
\hline IBGE & MUNICIPIO & Estrato & Homens & Mulheres & $\begin{array}{c}\text { Razão de } \\
\text { Sexos } \\
\end{array}$ & $\begin{array}{c}\text { Pop }(0-14)+ \\
(65 \mathrm{e}+) \\
\end{array}$ & 15-64 & $\begin{array}{c}\text { Razão de } \\
\text { dependência }\end{array}$ \\
\hline 354020 & Pontal & D50 & 16605 & 16147 & 102,8 & 11444 & 21308 & 53,7 \\
\hline 354025 & Pontalinda & E20 & 1938 & 1776 & 109,1 & 1288 & 2426 & 53,1 \\
\hline 354030 & Pontes Gestal & E20 & 1165 & 1182 & 98,5 & 781 & 1566 & 49,9 \\
\hline 354040 & Populina & E20 & 2250 & 2101 & 107,1 & 1475 & 2877 & 51,3 \\
\hline 354050 & Porangaba & E20 & 3775 & 3345 & 112,8 & 2454 & 4665 & 52,6 \\
\hline 354060 & Porto Feliz & C50 & 24747 & 24598 & 100,6 & 16822 & 32522 & 51,7 \\
\hline 354070 & Porto Ferreira & C100 & 25633 & 25801 & 99,3 & 16850 & 34583 & 48,7 \\
\hline 354075 & Potim & E20 & 7782 & 7544 & 103,2 & 5358 & 9969 & 53,7 \\
\hline 354080 & Potirendaba & E20 & 7572 & 7182 & 105,4 & 4583 & 10171 & 45,1 \\
\hline 354085 & Pracinha & E20 & 727 & 695 & 104,6 & 526 & 895 & 58,7 \\
\hline 354090 & Pradópolis & D20 & 7246 & 7025 & 103,1 & 4510 & 9761 & 46,2 \\
\hline 354100 & Praia Grande & B300 & 109808 & 115081 & 95,4 & 77074 & 147815 & 52,1 \\
\hline 354105 & Pratânia & E20 & 2213 & 2020 & 109,5 & 1533 & 2700 & 56,8 \\
\hline 354110 & Presidente Alves & E20 & 2141 & 2092 & 102,3 & 1485 & 2748 & 54,1 \\
\hline 354120 & Presidente Bernardes & D20 & 7919 & 7302 & 108,4 & 4914 & 10308 & 47,7 \\
\hline 354130 & Presidente Epitácio & D50 & 20553 & 20732 & 99,1 & 14077 & 27207 & 51,7 \\
\hline 354140 & Presidente Prudente & B300 & 96934 & 102839 & 94,3 & 63220 & 136553 & 46,3 \\
\hline 354150 & Presidente Venceslau & D50 & 18977 & 18919 & 100,3 & 11839 & 26056 & 45,4 \\
\hline 354160 & Promissao & D50 & 16426 & 16074 & 102,2 & 10898 & 21602 & 50,4 \\
\hline 354165 & Quadra & E20 & 1565 & 1421 & 110,1 & 965 & 2020 & 47,8 \\
\hline 354170 & Quatá & D20 & 5858 & 5931 & 98,8 & 4089 & 7700 & 53,1 \\
\hline 354180 & Queiroz & E20 & 1174 & 1102 & 106,5 & 798 & 1478 & 54,0 \\
\hline 354190 & Queluz & D20 & 4832 & 4906 & 98,5 & 3542 & 6196 & 57,2 \\
\hline 354200 & Quintana & E20 & 2797 & 2759 & 101,4 & 1880 & 3676 & 51,2 \\
\hline 354210 & Rafard & A20 & 4140 & 4118 & 100,5 & 2841 & 5416 & 52,5 \\
\hline 354220 & Rancharia & D50 & 14679 & 14921 & 98,4 & 10074 & 19526 & 51,6 \\
\hline 354230 & Redençao da Serra & E20 & 2183 & 1877 & 116,3 & 1469 & 2591 & 56,7 \\
\hline 354240 & Regente Feijó & D20 & 8958 & 8948 & 100,1 & 5913 & 11993 & 49,3 \\
\hline 354250 & Reginópolis & E20 & 2395 & 2338 & 102,4 & 1619 & 3114 & 52,0 \\
\hline 354260 & Registro & D100 & 27911 & 27982 & 99,7 & 20573 & 35321 & 58,2 \\
\hline 354270 & Restinga & E20 & 3116 & 2995 & 104,0 & 2221 & 3890 & 57,1 \\
\hline 354280 & Ribeira & E20 & 1705 & 1547 & 110,2 & 1307 & 1945 & 67,2 \\
\hline 354290 & Ribeirao Bonito & D20 & 5901 & 5755 & 102,5 & 4145 & 7510 & 55,2 \\
\hline 354300 & Ribeirao Branco & E50 & 11548 & 10553 & 109,4 & 9357 & 12744 & 73,4 \\
\hline 354310 & Ribeirao Corrente & E20 & 2222 & 1950 & 114,0 & 1494 & 2677 & 55,8 \\
\hline 354320 & Ribeirao do Sul & E20 & 2359 & 2285 & 103,3 & 1570 & 3074 & 51,1 \\
\hline 354323 & Ribeirao dos Indios & E20 & 1182 & 1106 & 106,9 & 750 & 1539 & 48,7 \\
\hline 354325 & Ribeirao Grande & E20 & 4099 & 3836 & 106,9 & 2853 & 5082 & 56,1 \\
\hline 354330 & Ribeirao Pires & B300 & 55925 & 57258 & 97,7 & 35053 & 78129 & 44,9 \\
\hline 354340 & Ribeirao Preto & B1000 & 258949 & 279047 & 92,8 & 169863 & 368134 & 46,1 \\
\hline 354360 & Rifaina & D20 & 1800 & 1716 & 104,9 & 1121 & 2395 & 46,8 \\
\hline 354370 & Rincao & D20 & 5222 & 5102 & 102,4 & 3648 & 6676 & 54,6 \\
\hline 354380 & Rinópolis & E20 & 5063 & 4784 & 105,8 & 3332 & 6516 & 51,1 \\
\hline 354390 & Rio Claro & B300 & 88781 & 92827 & 95,6 & 58985 & 122622 & 48,1 \\
\hline 354400 & Rio das Pedras & C50 & 12967 & 12488 & 103,8 & 8510 & 16945 & 50,2 \\
\hline 354410 & Rio Grande da Serra & C50 & 20066 & 20238 & 99,2 & 13732 & 26572 & 51,7 \\
\hline 354420 & Riolândia & E20 & 4976 & 3943 & 126,2 & 2775 & 6144 & 45,2 \\
\hline 354350 & Riversul & E20 & 3174 & 3033 & 104,7 & 2327 & 3880 & 60,0 \\
\hline 354425 & Rosana & C50 & 13080 & 12709 & 102,9 & 9018 & 16772 & 53,8 \\
\hline 354430 & Roseira & C2O & 4908 & 4723 & 103,9 & 3272 & 6359 & 51,5 \\
\hline
\end{tabular}


Anexo 10 - Razão de sexos e de dependência segundo município e Estrato de Vulnerabilidade Social. Estado de São Paulo, média do triênio, 2003-2005

\begin{tabular}{|c|c|c|c|c|c|c|c|c|}
\hline IBGE & MUNICIPIO & Estrato & Homens & Mulheres & $\begin{array}{c}\text { Razão de } \\
\text { Sexos }\end{array}$ & $\begin{array}{c}\text { Pop }(0-14)+ \\
(65 \mathrm{e}+)\end{array}$ & $15-64$ & $\begin{array}{c}\text { Razão de } \\
\text { dependência }\end{array}$ \\
\hline 354440 & Rubiácea & E20 & 1123 & 1079 & 104,1 & 757 & 1445 & 52,4 \\
\hline 354450 & Rubinéia & D20 & 1381 & 1403 & 98,4 & 930 & 1854 & 50,1 \\
\hline 354460 & Sabino & E20 & 2556 & 2564 & 99,7 & 1751 & 3369 & 52,0 \\
\hline 354470 & Sagres & E20 & 1196 & 1148 & 104,1 & 856 & 1488 & 57,5 \\
\hline 354480 & Sales & E20 & 2501 & 2420 & 103,3 & 1632 & 3289 & 49,6 \\
\hline 354490 & Sales Oliveira & B20 & 5064 & 5018 & 100,9 & 3411 & 6672 & 51,1 \\
\hline 354500 & Salesópolis & E20 & 7936 & 7758 & 102,3 & 5693 & 10001 & 56,9 \\
\hline 354510 & Salmourao & E20 & 2227 & 2149 & 103,6 & 1537 & 2839 & 54,1 \\
\hline 354515 & Saltinho & B20 & 3087 & 3034 & 101,7 & 1807 & 4315 & 41,9 \\
\hline 354520 & Salto & B300 & 51242 & 51219 & 100,0 & 34392 & 68070 & 50,5 \\
\hline 354530 & Salto de Pirapora & D50 & 19777 & 19640 & 100,7 & 13961 & 25456 & 54,8 \\
\hline 354540 & Salto Grande & E20 & 4483 & 4435 & 101,1 & 3147 & 5771 & 54,5 \\
\hline 354550 & Sandovalina & E20 & 1683 & 1710 & 98,4 & 1244 & 2149 & 57,9 \\
\hline 354560 & Santa Adélia & D20 & 6981 & 6841 & 102,1 & 4600 & 9222 & 49,9 \\
\hline 354570 & Santa Albertina & E20 & 2745 & 2715 & 101,1 & 1829 & 3631 & 50,4 \\
\hline 354580 & Santa Bárbara d'Oeste & B300 & 90478 & 90682 & 99,8 & 56923 & 124238 & 45,8 \\
\hline 354600 & Santa Branca & D20 & 7185 & 7032 & 102,2 & 4744 & 9473 & 50,1 \\
\hline 354610 & Santa Clara d'Oeste & E20 & 981 & 975 & 100,6 & 687 & 1269 & 54,1 \\
\hline 354620 & Santa Cruz da Conceiçao & B20 & 1940 & 1855 & 104,6 & 1331 & 2465 & 54,0 \\
\hline 354625 & Santa Cruz da Esperança & E20 & 945 & 898 & 105,2 & 699 & 1144 & 61,1 \\
\hline 354630 & Santa Cruz das Palmeiras & D50 & 13750 & 13475 & 102,0 & 9028 & 18197 & 49,6 \\
\hline 354640 & Santa Cruz do Rio Pardo & C50 & 21237 & 21625 & 98,2 & 14640 & 28223 & 51,9 \\
\hline 354650 & Santa Ernestina & B20 & 3152 & 2647 & 119,1 & 1911 & 3888 & 49,2 \\
\hline 354660 & Santa Fé do Sul & D50 & 13639 & 14394 & 94,8 & 8941 & 19091 & 46,8 \\
\hline 354670 & Santa Gertrudes & C2O & 9335 & 8992 & 103,8 & 6115 & 12213 & 50,1 \\
\hline 354680 & Santa Isabel & D50 & 23392 & 22924 & 102,0 & 16007 & 30308 & 52,8 \\
\hline 354690 & Santa Lúcia & E20 & 4422 & 4132 & 107,0 & 2958 & 5597 & 52,9 \\
\hline 354700 & Santa Maria da Serra & E20 & 2526 & 2312 & 109,2 & 1770 & 3068 & 57,7 \\
\hline 354710 & Santa Mercedes & E20 & 1378 & 1344 & 102,5 & 994 & 1728 & 57,5 \\
\hline 354740 & Santa Rita d'Oeste & E20 & 1181 & 1160 & 101,8 & 771 & 1571 & 49,1 \\
\hline 354750 & Santa Rita do Passa Quatr & B50 & 13180 & 13857 & 95,1 & 8848 & 18190 & 48,6 \\
\hline 354760 & Santa Rosa de Viterbo & D50 & 11181 & 11255 & 99,3 & 7712 & 14724 & 52,4 \\
\hline 354765 & Santa Salete & E20 & 725 & 654 & 110,9 & 427 & 952 & 44,9 \\
\hline 354720 & Santana da Ponte Pensa & E20 & 870 & 814 & 106,9 & 526 & 1157 & 45,5 \\
\hline 354730 & Santana de Parnaíba & C100 & 45541 & 45844 & 99,3 & 31158 & 60227 & 51,7 \\
\hline 354770 & Santo Anastácio & E50 & 10301 & 10783 & 95,5 & 7334 & 13750 & 53,3 \\
\hline 354780 & Santo André & A1000 & 320800 & 342977 & 93,5 & 201507 & 462270 & 43,6 \\
\hline 354790 & Santo Antônio da Alegria & E20 & 3139 & 2897 & 108,3 & 2019 & 4017 & 50,3 \\
\hline 354800 & Santo Antônio de Posse & D20 & 10009 & 9846 & 101,7 & 6759 & 13096 & 51,6 \\
\hline 354805 & Santo Antônio do Aracangu & E20 & 3583 & 3313 & 108,1 & 2306 & 4591 & 50,2 \\
\hline 354810 & Santo Antônio do Jardim & E20 & 3334 & 3030 & 110,0 & 2146 & 4218 & 50,9 \\
\hline 354820 & Santo Antônio do Pinhal & E20 & 3471 & 3294 & 105,4 & 2450 & 4315 & 56,8 \\
\hline 354830 & Santo Expedito & E20 & 1378 & 1284 & 107,3 & 898 & 1764 & 50,9 \\
\hline 354840 & Santópolis do Aguapeí & E20 & 1938 & 1870 & 103,7 & 1377 & 2432 & 56,6 \\
\hline 354850 & Santos & A500 & 193336 & 224884 & 86,0 & 129001 & 289219 & 44,6 \\
\hline 354860 & Sao Bento do Sapucaí & D20 & 5624 & 5473 & 102,7 & 3779 & 7318 & 51,6 \\
\hline 354870 & Sao Bernardo do Campo & B1000 & 371724 & 392327 & 94,7 & 232021 & 532030 & 43,6 \\
\hline 354880 & Sao Caetano do Sul & A300 & 63563 & 72416 & 87,8 & 40092 & 95887 & 41,8 \\
\hline 354890 & Sao Carlos & B300 & 103278 & 105254 & 98,1 & 65611 & 142921 & 45,9 \\
\hline 354900 & Sao Francisco & E20 & 1523 & 1483 & 102,7 & 1013 & 1994 & 50,8 \\
\hline
\end{tabular}


Anexo 10 - Razão de sexos e de dependência segundo município e Estrato de Vulnerabilidade Social. Estado de São Paulo, média do triênio, 2003-2005

\begin{tabular}{|c|c|c|c|c|c|c|c|c|}
\hline IBGE & MUNICIPIO & Estrato & Homens & Mulheres & $\begin{array}{c}\text { Razão de } \\
\text { Sexos }\end{array}$ & $\begin{array}{c}\text { Pop }(0-14)+ \\
(65 \mathrm{e}+)\end{array}$ & $15-64$ & $\begin{array}{c}\text { Razão de } \\
\text { dependência }\end{array}$ \\
\hline 354910 & Sao Joao da Boa Vista & B100 & 39853 & 41214 & 96,7 & 25784 & 55282 & 46,6 \\
\hline 354920 & Sao Joao das Duas Pontes & E20 & 1325 & 1275 & 103,9 & 870 & 1731 & 50,3 \\
\hline 354925 & Sao Joao de Iracema & E20 & 877 & 828 & 105,9 & 545 & 1159 & 47,1 \\
\hline 354930 & Sao Joao do Pau d'Alho & E20 & 962 & 933 & 103,1 & 651 & 1244 & 52,4 \\
\hline 354940 & Sao Joaquim da Barra & C50 & 21762 & 22334 & 97,4 & 14054 & 30042 & 46,8 \\
\hline 354950 & Sao José da Bela Vista & E20 & 4341 & 4159 & 104,4 & 3087 & 5413 & 57,0 \\
\hline 354960 & Sao José do Barreiro & E20 & 2208 & 2028 & 108,9 & 1574 & 2662 & 59,1 \\
\hline 354970 & Sao José do Rio Pardo & D100 & 26041 & 26493 & 98,3 & 18125 & 34408 & 52,7 \\
\hline 354980 & Sao José do Rio Preto & B500 & 190140 & 202820 & 93,7 & 118399 & 274561 & 43,1 \\
\hline 354990 & Sao José dos Campos & B1000 & 287863 & 294749 & 97,7 & 185908 & 396704 & 46,9 \\
\hline 354995 & Sao Lourenço da Serra & E20 & 7243 & 7053 & 102,7 & 5122 & 9174 & 55,8 \\
\hline 355000 & Sao Luís do Paraitinga & E20 & 5525 & 5130 & 107,7 & 3744 & 6912 & 54,2 \\
\hline 355010 & Sao Manuel & D50 & 19108 & 19414 & 98,4 & 13283 & 25239 & 52,6 \\
\hline 355020 & Sao Miguel Arcanjo & E50 & 16999 & 16218 & 104,8 & 12391 & 20826 & 59,5 \\
\hline 355030 & Sao Paulo & B10000 & 5140432 & 5645824 & 91,0 & 3373708 & 7412549 & 45,5 \\
\hline 355040 & Sao Pedro & B50 & 15452 & 15896 & 97,2 & 10833 & 20515 & 52,8 \\
\hline 355050 & Sao Pedro do Turvo & E20 & 3522 & 3442 & 102,3 & 2455 & 4509 & 54,5 \\
\hline 355060 & Sao Roque & B100 & 35320 & 35633 & 99,1 & 23723 & 47231 & 50,2 \\
\hline 355070 & Sao Sebastiao & C100 & 34870 & 33954 & 102,7 & 22933 & 45891 & 50,0 \\
\hline 355080 & Sao Sebastiao da Grama & E20 & 6477 & 6265 & 103,4 & 4297 & 8445 & 50,9 \\
\hline 355090 & Sao Simao & B20 & 7195 & 7234 & 99,5 & 5054 & 9376 & 53,9 \\
\hline 355100 & Sao Vicente & B500 & 154774 & 164379 & 94,2 & 104767 & 214386 & 48,9 \\
\hline 355110 & Sarapuí & E20 & 4376 & 4023 & 108,8 & 3098 & 5302 & 58,4 \\
\hline 355120 & Sarutaiá & E20 & 2039 & 2020 & 100,9 & 1504 & 2556 & 58,8 \\
\hline 355130 & Sebastianópolis do Sul & E20 & 1305 & 1250 & 104,4 & 774 & 1782 & 43,4 \\
\hline 355140 & Serra Azul & E20 & 4075 & 3939 & 103,5 & 3024 & 4990 & 60,6 \\
\hline 355160 & Serra Negra & D50 & 12241 & 12567 & 97,4 & 8318 & 16490 & 50,4 \\
\hline 355150 & Serrana & C50 & 18528 & 18268 & 101,4 & 12782 & 24014 & 53,2 \\
\hline 355170 & Sertaozinho & C300 & 51092 & 50669 & 100,8 & 32841 & 68920 & 47,7 \\
\hline 355180 & Sete Barras & E20 & 7446 & 6797 & 109,5 & 5401 & 8841 & 61,1 \\
\hline 355190 & Severínia & E20 & 7844 & 7247 & 108,2 & 5229 & 9861 & 53,0 \\
\hline 355200 & Silveiras & E20 & 2872 & 2714 & 105,8 & 2059 & 3527 & 58,4 \\
\hline 355210 & Socorro & D50 & 16770 & 16802 & 99,8 & 10987 & 22585 & 48,6 \\
\hline 355220 & Sorocaba & B1000 & 267942 & 276653 & 96,9 & 178181 & 366414 & 48,6 \\
\hline 355230 & Sud Mennucci & E20 & 3792 & 3645 & 104,0 & 2536 & 4901 & 51,7 \\
\hline 355240 & Sumaré & C300 & 111203 & 110405 & 100,7 & 72710 & 148899 & 48,8 \\
\hline 355255 & Suzanápolis & E20 & 1470 & 1389 & 105,9 & 1001 & 1858 & 53,9 \\
\hline 355250 & Suzano & C300 & 128701 & 131190 & 98,1 & 90275 & 169616 & 53,2 \\
\hline 355260 & Tabapua & E20 & 5428 & 5304 & 102,3 & 3513 & 7219 & 48,7 \\
\hline 355270 & Tabatinga & E20 & 7088 & 6883 & 103,0 & 4806 & 9166 & 52,4 \\
\hline 355280 & Taboao da Serra & C300 & 103450 & 110970 & 93,2 & 68529 & 145892 & 47,0 \\
\hline 355290 & Taciba & E20 & 2764 & 2668 & 103,6 & 1920 & 3512 & 54,7 \\
\hline 355300 & Taguaí & E20 & 4011 & 3921 & 102,3 & 2676 & 5256 & 50,9 \\
\hline 355310 & Taiaçu & E20 & 2987 & 2900 & 103,0 & 2152 & 3734 & 57,6 \\
\hline 355320 & Taiúva & E20 & 2821 & 2813 & 100,3 & 1968 & 3666 & 53,7 \\
\hline 355330 & Tambaú & D50 & 11794 & 11536 & 102,2 & 8104 & 15226 & 53,2 \\
\hline 355340 & Tanabi & D50 & 11424 & 11643 & 98,1 & 7255 & 15812 & 45,9 \\
\hline 355350 & Tapiraí & E20 & 5066 & 4770 & 106,2 & 3836 & 6000 & 63,9 \\
\hline 355360 & Tapiratiba & D20 & 6677 & 6776 & 98,5 & 4784 & 8669 & 55,2 \\
\hline 355365 & Taquaral & E20 & 1469 & 1380 & 106,5 & 981 & 1869 & 52,5 \\
\hline
\end{tabular}


Anexo 10 - Razão de sexos e de dependência segundo município e Estrato de Vulnerabilidade Social. Estado de São Paulo, média do triênio, 2003-2005

\begin{tabular}{|c|c|c|c|c|c|c|c|c|}
\hline IBGE & MUNICIPIO & Estrato & Homens & Mulheres & $\begin{array}{c}\text { Razão de } \\
\text { Sexos }\end{array}$ & $\begin{array}{c}\text { Pop }(0-14)+ \\
(65 \mathrm{e}+)\end{array}$ & $15-64$ & $\begin{array}{c}\text { Razão de } \\
\text { dependência }\end{array}$ \\
\hline 355370 & Taquaritinga & D100 & 27523 & 26841 & 102,5 & 18137 & 36227 & 50,1 \\
\hline 355380 & Taquarituba & E50 & 11831 & 11688 & 101,2 & 8210 & 15308 & 53,6 \\
\hline 355385 & Taquarivaí & E20 & 2601 & 2495 & 104,2 & 2037 & 3058 & 66,6 \\
\hline 355390 & Tarabaí & E20 & 3174 & 3091 & 102,7 & 2252 & 4013 & 56,1 \\
\hline 355395 & Taruma & D20 & 5777 & 5489 & 105,3 & 3753 & 7513 & 50,0 \\
\hline 355400 & Tatuí & C300 & 50657 & 51044 & 99,2 & 35211 & 66490 & 53,0 \\
\hline 355410 & Taubaté & B300 & 128496 & 132285 & 97,1 & 83809 & 176972 & 47,4 \\
\hline 355420 & Tejupá & E20 & 2947 & 2659 & 110,8 & 2033 & 3573 & 56,9 \\
\hline 355430 & Teodoro Sampaio & D50 & 10271 & 10208 & 100,6 & 7357 & 13123 & 56,1 \\
\hline 355440 & Terra Roxa & E20 & 4207 & 4045 & 104,0 & 2937 & 5316 & 55,3 \\
\hline 355450 & Tietê & B50 & 17260 & 17500 & 98,6 & 11530 & 23231 & 49,6 \\
\hline 355460 & Timburi & E20 & 1376 & 1300 & 105,9 & 963 & 1713 & 56,2 \\
\hline 355465 & Torre de Pedra & E20 & 1291 & 1258 & 102,7 & 914 & 1635 & 55,9 \\
\hline 355470 & Torrinha & E20 & 4781 & 4651 & 102,8 & 3262 & 6170 & 52,9 \\
\hline 355475 & Trabiju & E20 & 756 & 682 & 110,9 & 522 & 915 & 57,0 \\
\hline 355480 & Tremembé & B50 & 19811 & 18251 & 108,5 & 11954 & 26108 & 45,8 \\
\hline 355490 & Três Fronteiras & E20 & 2602 & 2571 & 101,2 & 1701 & 3471 & 49,0 \\
\hline 355495 & Tuiuti & E20 & 2752 & 2590 & 106,3 & 1741 & 3600 & 48,4 \\
\hline 355500 & Tupa & D100 & 31725 & 33397 & 95,0 & 21104 & 44018 & 47,9 \\
\hline 355510 & Tupi Paulista & D20 & 6396 & 6551 & 97,6 & 4247 & 8700 & 48,8 \\
\hline 355520 & Turiúba & E20 & 926 & 884 & 104,8 & 564 & 1246 & 45,3 \\
\hline 355530 & Turmalina & E20 & 1100 & 1095 & 100,5 & 706 & 1489 & 47,4 \\
\hline 355535 & Ubarana & E20 & 2529 & 2307 & 109,6 & 1720 & 3116 & 55,2 \\
\hline 355540 & Ubatuba & C100 & 38299 & 37256 & 102,8 & 26841 & 48714 & 55,1 \\
\hline 355550 & Ubirajara & E20 & 2132 & 2014 & 105,8 & 1544 & 2602 & 59,4 \\
\hline 355560 & Uchoa & D20 & 4697 & 4652 & 101,0 & 3164 & 6185 & 51,2 \\
\hline 355570 & Uniao Paulista & E20 & 711 & 653 & 108,9 & 461 & 903 & 51,1 \\
\hline 355580 & Urânia & E20 & 4432 & 4428 & 100,1 & 2836 & 6024 & 47,1 \\
\hline 355590 & Uru & E20 & 745 & 680 & 109,6 & 482 & 943 & 51,1 \\
\hline 355600 & Urupês & E20 & 6152 & 6046 & 101,7 & 3962 & 8236 & 48,1 \\
\hline 355610 & Valentim Gentil & D20 & 4992 & 4820 & 103,6 & 3048 & 6764 & 45,1 \\
\hline 355620 & Valinhos & B100 & 44722 & 44990 & 99,4 & 26823 & 62889 & 42,7 \\
\hline 355630 & Valparaíso & D20 & 10221 & 9255 & 110,4 & 6542 & 12934 & 50,6 \\
\hline 355635 & Vargem & E20 & 4042 & 3813 & 106,0 & 2767 & 5087 & 54,4 \\
\hline 355640 & Vargem Grande do Sul & D50 & 19290 & 19403 & 99,4 & 12978 & 25715 & 50,5 \\
\hline 355645 & Vargem Grande Paulista & C50 & 20133 & 20060 & 100,4 & 13616 & 26577 & 51,2 \\
\hline 355650 & Várzea Paulista & C300 & 51946 & 51518 & 100,8 & 34068 & 69396 & 49,1 \\
\hline 355660 & Vera Cruz & E20 & 5526 & 5572 & 99,2 & 3928 & 7170 & 54,8 \\
\hline 355670 & Vinhedo & A100 & 26519 & 26773 & 99,1 & 16185 & 37107 & 43,6 \\
\hline 355680 & Viradouro & D20 & 8721 & 8523 & 102,3 & 6074 & 11170 & 54,4 \\
\hline 355690 & Vista Alegre do Alto & D20 & 2642 & 2621 & 100,8 & 1628 & 3635 & 44,8 \\
\hline 355695 & Vitória Brasil & E20 & 917 & 859 & 106,7 & 547 & 1230 & 44,4 \\
\hline 355700 & Votorantim & B300 & 51259 & 51451 & 99,6 & 34284 & 68427 & 50,1 \\
\hline 355710 & Votuporanga & C100 & 39525 & 41026 & 96,3 & 24744 & 55807 & 44,3 \\
\hline 355715 & Zacarias & E20 & 1006 & 939 & 107,1 & 623 & 1322 & 47,1 \\
\hline & Estado & & 19339142 & 20124699 & 96,1 & 12807066 & 26656775 & 48,0 \\
\hline
\end{tabular}

Fonte: Censo IBGE e Estratos de Vulnerabilidade Social segundo metodologia desenvolvida a partir do IPVS (FSEADE 2005) 
Anexo 11 - Mortalidade proporcional (\%) segundo faixa etária selecionada, mediana e desvio padrão (menores de 01 ano e 60 anos e mais) nos conjuntos de municípios e respectivos estratos de vulnerabilidade social. Estado de São Paulo, média do triênio 2003 a 2005.

\begin{tabular}{|c|c|c|c|c|c|c|c|c|c|c|c|c|c|c|c|c|c|c|c|}
\hline \multirow[b]{2}{*}{ Status } & \multirow[b]{2}{*}{$<01$ ano } & \multirow[b]{2}{*}{$\%$} & \multirow[b]{2}{*}{ 列-04 } & \multirow[b]{2}{*}{$\%$} & \multirow[b]{2}{*}{$.05-19$} & \multirow[b]{2}{*}{$\%$} & \multirow[b]{2}{*}{ 20-59 } & \multirow[b]{2}{*}{$\%$} & \multirow[b]{2}{*}{$60 \mathrm{e}+$} & \multirow[b]{2}{*}{$\%$} & \multirow[b]{2}{*}{ Total } & \multicolumn{4}{|c|}{ Menor de 1 ano } & \multicolumn{4}{|c|}{60 anos e mais } \\
\hline & & & & & & & & & & & & Mediana & D.Padrão & Maior Valor & Menor Valor & Mediana & D.Padrão & Maior Valor & Menor Valor \\
\hline$\overline{\mathrm{A} 20}$ & $7 \mid$ & \begin{tabular}{|l|}
3,1 \\
\end{tabular} & 2 & $\begin{array}{ll}0,8 \\
\end{array}$ & 5 & 2,2 & 62 & 25,8 & 162 & \begin{tabular}{|l|}
68,0 \\
\end{tabular} & 239 & 2,9 & \begin{tabular}{|c|}
2,1 \\
\end{tabular} & $\overline{7,5}$ & $\mid \overline{|1,7|}$ & \begin{tabular}{|l|}
70,2 \\
\end{tabular} & 6,2 & \begin{tabular}{|l|}
74,6 \\
\end{tabular} & $\overline{58,4}$ \\
\hline A100 & 8 & 2,6 & 1 & 0,5 & 6 & 2,2 & 85 & 29,2 & 192 & 65,6 & 292 & $x$ & $x$ & $\mathrm{x}$ & $x$ & $x$ & $x$ & $\mathrm{x}$ & $x$ \\
\hline A300 & 64 & 1,7 & 12 & 0,3 & 47 & 1,2 & 980 & 25,7 & 2705 & 71,0 & 3808 & 1,6 & 0,7 & 2,5 & 1,1 & 67,9 & 6,0 & 77,5 & 66,5 \\
\hline A500 & 149 & 2,4 & 20 & 0,3 & 81 & 1,3 & 1574 & 25,6 & 4322 & 70,3 & 6146 & 2,5 & 0,5 & 2,9 & 2,2 & 69,6 & 4,2 & 72,5 & 66,6 \\
\hline A1000 & 117 & 2,7 & 22 & 0,5 & 84 & 1,9 & 1365 & 31,3 & 2776 & 63,6 & 4363 & $x$ & $x$ & $x$ & $x$ & $\mathrm{x}$ & $x$ & $x$ & $\mathrm{x}$ \\
\hline Estrato $\mathrm{A}$ & 344 & 2,3 & 57 & 0,4 & 224 & 1,5 & 4065 & 27,4 & 10157 & 68,4 & 14847 & 2,6 & 1,5 & 7,5 & 1,1 & 67,9 & 5,3 & 77,5 & 58,4 \\
\hline B20 & 12 & 2,6 & 4 & 0,8 & 4 & 0,9 & 131 & 27,6 & 323 & 68,1 & 474 & 1,9 & 2,0 & 6,8 & 0,0 & 70,0 & 5,7 & 75,5 & 58,0 \\
\hline B50 & 99 & 3,0 & 13 & 0,4 & 63 & 1,9 & 1034 & 31,0 & 2129 & 63,8 & 3338 & 2,8 & 0,9 & 5,9 & 1,8 & 65,1 & 4,6 & 73,4 & 55,9 \\
\hline B100 & 243 & 2,9 & 39 & 0,5 & 154 & 1,8 & 2552 & 30,2 & 5452 & 64,6 & 8440 & 2,9 & 0,8 & 4,2 & 1,6 & 65,0 & 4,3 & 70,5 & 55,2 \\
\hline B300 & 756 & 3,2 & 130 & 0,6 & 505 & 2,1 & 7419 & 31,5 & 14717 & 62,6 & 23527 & 3,2 & 1,0 & 5,3 & 1,9 & 62,3 & 4,4 & 70,5 & 53,5 \\
\hline B500 & 467 & 3,7 & 69 & 0,5 & 272 & 2,1 & 3959 & 31,3 & 7892 & 62,3 & 12659 & 3,6 & 1,3 & 5,5 & 2,3 & 63,1 & 4,6 & 67,8 & 56,2 \\
\hline B1000 & 623 & 3,7 & 101 & 0,6 & 471 & 2,8 & 5960 & 35,2 & 9800 & 57,8 & 16955 & 3,8 & 0,9 & 4,7 & 2,3 & 56,3 & 4,8 & 64,5 & 52,5 \\
\hline B10000 & 2671 & 3,7 & 430 & 0,6 & 1819 & 2,5 & 23381 & 32,3 & 44015 & 60,9 & 72316 & 3,3 & 0,7 & 3,8 & 2,8 & 61,6 & 1,2 & 62,5 & 60,7 \\
\hline Estrato B & 4871 & 3,5 & 785 & 0,6 & 3288 & 2,4 & 44436 & 32,3 & 84326 & 61,2 & 137707 | & 2,9 & 1,1 & 6,8 & 0,0 & 63,9 & 5,0 & 75,5 & 52,5 \\
\hline $\mathrm{C} 20$ & 35 & 3,4 & 8 & 0,7 & 17 & 1,6 & 313 & 29,7 & 682 & 64,7 & 1055 & 3,1 & 1,1 & 5,6 & 1,8 & \begin{tabular}{|l|}
63,6 \\
\end{tabular} & 6,4 & 72,5 & 49,1 \\
\hline C50 & 215 & 4,0 & 35 & 0,7 & 130 & 2,4 & 1809 & 33,8 & 3170 & 59,2 & 5358 & 3,6 & 1,8 & 9,9 & 1,8 & 56,1 & 8,2 & 70,9 & 39,2 \\
\hline C100 & 256 & 3,9 & 53 & 0,8 & 174 & 2,7 & 2329 & 35,8 & 3686 & 56,7 & 6498 & 3,9 & 1,5 & 6,3 & 1,6 & 54,4 & 8,0 & 70,0 & 46,8 \\
\hline C300 & 918 & 4,9 & 150 & 0,8 & 641 & 3,4 & 7465 & 39,7 & 9625 & 51,2 & 18799 & 4,6 & 1,4 & 7,1 & 2,7 & 49,7 & 8,5 & 68,3 & 39,8 \\
\hline C500 & 410 & 6,0 & 71 & 1,0 & 287 & 4,2 & 3031 & 44,2 & 3055 & 44,6 & 6853 & 5,8 & 1,0 & 7,5 & 5,3 & 44,7 & 3,2 & 47,7 & 40,0 \\
\hline C10000 & 336 & 5,6 & 53 & 0,9 & 216 & 3,6 & 2481 & 41,0 & 2960 & 49,0 & 6046 & $x$ & $x$ & $\mathrm{x}$ & $x$ & $\mathrm{x}$ & $x$ & $x$ & $x$ \\
\hline Estrato C & 2170 & 4,9 & 370 & 0,8 & 1464 & 3,3 & 17427 & 39,1 & 23179 & 52,0 & 44610 & 4,0 & 1,6 & 9,9 & 1,6 & 54,9 & 8,9 & 72,5 & 39,2 \\
\hline $\mathrm{D} 20$ & 188 & 3,6 & 34 & 0,6 & 92 & 1,7 & 1513 & 28,6 & 3468 & 65,5 & 5295 & 3,3 & 2,0 & 9,3 & 0,0 & \begin{tabular}{|l|}
66,5 \\
\end{tabular} & 8,4 & 79,5 & 35,5 \\
\hline D50 & 430 & 3,3 & 73 & 0,6 & 240 & 1,8 & 3846 & 29,4 & 8498 & 64,9 & 13087 & 3,2 & 1,2 & 6,4 & 1,1 & 65,2 & 6,2 & 75,4 & 49,6 \\
\hline D100 & 236 & 3,9 & 34 & 0,6 & 114 & 1,9 & 1739 & 28,9 & 3894 & 64,7 & 6017 & 3,2 & 1,8 & 9,2 & 2,0 & 66,8 & 5,2 & 71,1 & 56,4 \\
\hline D300 & 60 & 9,2 & 10 & 1,5 & 33 & 5,0 & 306 & 46,7 & 246 & 37,6 & 655 & $x$ & $x$ & $\mathrm{x}$ & $x$ & $\mathrm{x}$ & $x$ & $x$ & $x$ \\
\hline Estrato D & 915 & 3,7 & 151 & 0,6 & 478 & 1,9 & 7404 & 29,6 & 16107 & 64,3 & 25055 & 3,2 & 1,7 & 9,3 & 0,0 & 66,0 & 7,6 & 79,5 & 35,5 \\
\hline E20 & 406 & 3,2 & 64 & 0,5 & 227 & 1,8 & 3543 & 27,8 & 8491 & 66,7 & 12731 & 2,9 & 2,4 & 16,4 & 0 & 67,5 & 7,7 & 83,7 & 42,0 \\
\hline E50 & 122 & 4,4 & 20 & 0,7 & 75 & 2,7 & 862 & 31,2 & 1681 & 60,9 & 2760 & 4,1 & 1,5 & 6,9 & 2,3 & 61,6 & 5,4 & 68,5 & 51,9 \\
\hline E100 & 25 & 6,2 & 5 & 1,3 & 14 & 3,5 & 152 & 37,1 & 212 & 51,9 & 409 & $x$ & $x$ & $\mathrm{x}$ & $x$ & $\mathrm{x}$ & $x$ & $\mathrm{x}$ & $\mathrm{x}$ \\
\hline Estrato $\mathrm{E}$ & 554 & 3,5 & 90 & 0,6 & 316 & 2,0 & 4557 & 28,7 & 10383 & 65,3 & 15900 & 3,0 & 2,3 & 16,4 & 0,0 & \begin{tabular}{ll|}
67,2 \\
\end{tabular} & 7,7 & 83,7 & 42,0 \\
\hline Estado & 8854 & 3,7 & 1453 & 0,6 & 5770 & 2,4 & 77889 & 32,7 & 144152 & 60,5 & 238119 & 3,1 & 16,1 & 16,4 & 0,0 & 65,2 & 8,2 & 83,7 & 35,5 \\
\hline
\end{tabular}

Fonte: SIM/ MS e Estratos de Vulnerabilidade Social segundo metodologia desenvolvida a partir do IPVS (FSEADE 2005)

Nota $^{1}$ : ( - ) Dado numérico igual a 0 não resultante de arredondamento

$(0 ; 0,0 ; 0,00)$ Dado numérico igual a zero resultante de arredondamento de um dado originalmente positivo

A soma das parcelas pode não coincidir com o total em função de arredondamentos efetuados nos dados parciais

(x) Não se aplica (conjunto formado por um só município) 
Anexo 12 - Mortalidade proporcional (\%)por faixa etária selecionada segundo município e Estrato de Vulnerabilidade Social .Estado de São Paulo, media do triênio 2003 a 2005

\begin{tabular}{|c|c|c|c|c|c|c|c|c|c|c|c|c|c|c|}
\hline IBGE & MUNICIPIO & Status & $<01$ ano & $\%$ & $.01-04$ & $\%$ & $.05-19$ & $\%$ & $20-59$ & $\%$ & $60 e+$ & $\%$ & Total & $\%$ \\
\hline 350010 & Adamantina & D50 & 7 & 2,7 & 2 & 0,6 & 5 & 1,8 & 58 & 22,1 & 191 & 72,8 & 263 & 100,0 \\
\hline 350020 & Adolfo & E20 & 0 & 1,4 & 0 & 1,4 & 1 & 4,3 & 6 & 24,3 & 16 & 68,6 & 23 & 100,0 \\
\hline 350030 & Aguaí & E50 & 9 & 4,1 & 1 & 0,5 & 3 & 1,3 & 68 & 31,9 & 133 & 62,3 & 213 & 100,0 \\
\hline 350040 & Aguas da Prata & D20 & 0 & 0,5 & 1 & 1,0 & 1 & 2,0 & 14 & 21,4 & 50 & 75,1 & 67 & 100,0 \\
\hline 350050 & Aguas de Lindóia & D20 & 4 & 3,3 & - & - & 1 & 1,0 & 32 & 24,1 & 95 & 71,6 & 133 & 100,0 \\
\hline 350055 & Aguas de Santa Bárbara & B20 & 1 & 3,4 & 0 & 0,9 & - & - & 9 & 22,4 & 28 & 73,3 & 39 & 100,0 \\
\hline 350060 & Aguas de Sao Pedro & A20 & 1 & 2,8 & - & - & 0 & 1,4 & 5 & 21,1 & 18 & 74,6 & 24 & 100,0 \\
\hline 350070 & Agudos & C50 & 7 & 3,2 & 2 & 0,9 & 6 & 2,9 & 66 & 30,2 & 136 & 62,7 & 217 & 100,0 \\
\hline 350075 & Alambari & E20 & 1 & 5,3 & - & - & 1 & 2,7 & 8 & 30,7 & 15 & 61,3 & 25 & 100,0 \\
\hline 350080 & Alfredo Marcondes & E20 & - & - & - & - & 1 & 3,7 & 4 & 16,0 & 22 & 80,2 & 27 & 100,0 \\
\hline 350090 & Altair & E20 & 0 & 1,4 & - & - & 1 & 4,3 & 6 & 25,7 & 16 & 68,6 & 23 & 100,0 \\
\hline 350100 & Altinópolis & D20 & 2 & 2,0 & - & - & 3 & 2,6 & 27 & 26,7 & 69 & 68,6 & 101 & 100,0 \\
\hline 350110 & Alto Alegre & E20 & 1 & 1,9 & 0 & 0,9 & 1 & 1,9 & 7 & 19,4 & 27 & 75,9 & 36 & 100,0 \\
\hline 350115 & Alumínio & $\mathrm{C} 20$ & 3 & 3,9 & 1 & 0,9 & 1 & 1,7 & 30 & 38,6 & 43 & 54,9 & 78 & 100,0 \\
\hline 350120 & Alvares Florence & E20 & 2 & 5,8 & - & - & 1 & 1,9 & 6 & 18,4 & 25 & 73,8 & 34 & 100,0 \\
\hline 350130 & Alvares Machado & D50 & 5 & 3,6 & 1 & 0,5 & 4 & 2,9 & 37 & 26,3 & 93 & 66,7 & 139 & 100,0 \\
\hline 350140 & Alvaro de Carvalho & E20 & 1 & 2,8 & - & - & 0 & 1,4 & 9 & 36,1 & 14 & 59,7 & 24 & 100,0 \\
\hline 350150 & Alvinlândia & E20 & 1 & 4,8 & - & - & 0 & 1,6 & 6 & 28,6 & 14 & 65,1 & 21 & 100,0 \\
\hline 350160 & Americana & А300 & 28 & 2,5 & 5 & 0,4 & 20 & 1,8 & 328 & 28,8 & 758 & 66,5 & 1140 & 100,0 \\
\hline 350170 & Américo Brasiliense & D50 & 7 & 4,7 & 2 & 1,1 & 4 & 2,7 & 52 & 35,4 & 83 & 56,0 & 148 & 100,0 \\
\hline 350180 & Américo de Campos & E20 & 1 & 1,6 & 0 & 0,8 & 1 & 1,6 & 9 & 22,8 & 30 & 73,2 & 41 & 100,0 \\
\hline 350190 & Amparo & B100 & 12 & 2,6 & 3 & 0,8 & 5 & 1,2 & 123 & 27,7 & 301 & 67,7 & 444 & 100,0 \\
\hline 350200 & Analândia & B20 & 0 & 1,5 & - & - & - & - & 8 & 35,3 & 14 & 63,2 & 23 & 100,0 \\
\hline 350210 & Andradina & D100 & 11 & 2,8 & 2 & 0,4 & 5 & 1,3 & 112 & 28,0 & 270 & 67,5 & 400 & 100,0 \\
\hline 350220 & Angatuba & D50 & 5 & 3,4 & 1 & 0,5 & 2 & 1,2 & 44 & 32,1 & 86 & 62,8 & 137 & 100,0 \\
\hline 350230 & Anhembi & E20 & 1 & 1,9 & - & - & 1 & 1,9 & 10 & 28,7 & 24 & 67,6 & 36 & 100,0 \\
\hline 350240 & Anhumas & E20 & 0 & 1,6 & - & - & 0 & 1,6 & 4 & 21,0 & 16 & 75,8 & 21 & 100,0 \\
\hline 350250 & Aparecida & B50 & 7 & 2,7 & 2 & 0,6 & 5 & 1,8 & 87 & 33,2 & 162 & 61,8 & 262 & 100,0 \\
\hline 350260 & Aparecida d'Oeste & E20 & - & - & - & - & 1 & 1,9 & 7 & 20,2 & 27 & 77,9 & 35 & 100,0 \\
\hline 350270 & Apiaí & D50 & 7 & 4,8 & 1 & 0,4 & 3 & 1,8 & 45 & 29,7 & 96 & 63,2 & 151 & 100,0 \\
\hline 350275 & Araçariguama & D20 & 4 & 5,8 & 1 & 1,0 & 1 & 1,6 & 31 & 48,2 & 28 & 43,5 & 64 & 100,0 \\
\hline 350280 & Araçatuba & B300 & 32 & 2,8 & 5 & 0,5 & 28 & 2,4 & 360 & 30,6 & 749 & 63,7 & 1176 & 100,0 \\
\hline 350290 & Araçoiaba da Serra & B50 & 4 & 2,7 & 0 & 0,2 & 3 & 2,2 & 46 & 31,0 & 96 & 63,9 & 150 & 100,0 \\
\hline 350300 & Aramina & E20 & 1 & 3,4 & - & - & 1 & 3,4 & 9 & 31,5 & 18 & 61,8 & 30 & 100,0 \\
\hline 350310 & Arandu & E20 & 1 & 4,0 & 0 & 1,0 & 1 & 2,0 & 10 & 30,3 & 21 & 62,6 & 33 & 100,0 \\
\hline 350315 & Arapeí & E20 & 0 & 1,5 & 0 & 1,5 & 1 & 4,6 & 6 & 27,7 & 14 & 64,6 & 22 & 100,0 \\
\hline 350320 & Araraquara & А300 & 20 & 1,6 & 5 & 0,4 & 15 & 1,2 & 368 & 28,9 & 863 & 67,9 & 1271 & 100,0 \\
\hline 350330 & Araras & B300 & 14 & 1,9 & 5 & 0,7 & 16 & 2,3 & 217 & 30,8 & 452 & 64,2 & 703 & 100,0 \\
\hline 350335 & ArcoOlris & E20 & 0 & 2,4 & - & - & 0 & 2,4 & 3 & 24,4 & 10 & 70,7 & 14 & 100,0 \\
\hline 350340 & Arealva & E20 & 1 & 2,6 & 1 & 1,3 & 0 & 0,6 & 11 & 20,5 & 39 & 75,0 & 52 & 100,0 \\
\hline 350350 & Areias & E20 & 2 & 5,7 & 0 & 1,1 & 0 & 1,1 & 9 & 31,0 & 18 & 60,9 & 29 & 100,0 \\
\hline 350360 & Areiópolis & E20 & 1 & 2,1 & 1 & 1,1 & 1 & 1,6 & 23 & 36,4 & 37 & 58,8 & 62 & 100,0 \\
\hline 350370 & Ariranha & E20 & 1 & 1,8 & 0 & 0,6 & - & - & 16 & 28,7 & 38 & 68,9 & 56 & 100,0 \\
\hline 350380 & Artur Nogueira & C50 & 5 & 3,0 & 2 & 0,9 & 3 & 1,7 & 61 & 34,3 & 107 & 60,1 & 179 & 100,0 \\
\hline 350390 & Arujá & C100 & 21 & 6,3 & 3 & 0,8 & 9 & 2,7 & 132 & 38,8 & 175 & 51,4 & 340 & 100,0 \\
\hline 350395 & Aspásia & E20 & - & - & - & - & 1 & 4,0 & 5 & 30,0 & 11 & 66,0 & 17 & 100,0 \\
\hline 350400 & Assis & B100 & 15 & 2,2 & 2 & 0,3 & 12 & 1,8 & 175 & 26,2 & 463 & 69,5 & 667 & 100,0 \\
\hline 350410 & Atibaia & С300 & 35 & 4,5 & 5 & 0,6 & 15 & 1,9 & 229 & 29,7 & 487 & 63,1 & 771 & 100,0 \\
\hline 350420 & Auriflama & E20 & 5 & 5,2 & - & - & 2 & 1,9 & 24 & 26,7 & 60 & 66,3 & 90 & 100,0 \\
\hline 350430 & Avaí & E20 & 2 & 4,8 & - & - & 0 & 1,0 & 9 & 26,7 & 24 & 67,6 & 35 & 100,0 \\
\hline 350440 & Avanhandava & E20 & 2 & 4,2 & - & - & 1 & 1,2 & 19 & 34,5 & 33 & 60,0 & 55 & 100,0 \\
\hline 350450 & Avaré & B100 & 17 & 2,9 & 3 & 0,6 & 12 & 2,1 & 164 & 29,0 & 370 & 65,3 & 566 & 100,0 \\
\hline 350460 & Bady Bassitt & A20 & 2 & 3,3 & 0 & 0,5 & 2 & 2,8 & 17 & 23,5 & 50 & 70,0 & 71 & 100,0 \\
\hline 350470 & Balbinos & E20 & 0 & 5,3 & - & - & 1 & 10,5 & 1 & 10,5 & 5 & 73,7 & 6 & 100,0 \\
\hline 350480 & Bálsamo & E20 & 2 & 3,0 & - & - & 1 & 1,2 & 15 & 27,7 & 38 & 68,1 & 55 & 100,0 \\
\hline 350490 & Bananal & D20 & 2 & 3,0 & 1 & 1,0 & 1 & 1,0 & 18 & 26,4 & 46 & 68,7 & 67 & 100,0 \\
\hline 350500 & Barao de Antonina & E20 & 1 & 2,6 & - & - & 0 & 1,3 & 8 & 32,1 & 17 & 64,1 & 26 & 100,0 \\
\hline 350510 & Barbosa & E20 & 1 & 1,6 & 1 & 1,6 & 1 & 2,4 & 14 & 34,1 & 25 & 60,3 & 42 & 100,0 \\
\hline
\end{tabular}


Anexo 12 - Mortalidade proporcional (\%)por faixa etária selecionada segundo município e Estrato de Vulnerabilidade Social .Estado de São Paulo, media do triênio 2003 a 2005

\begin{tabular}{|c|c|c|c|c|c|c|c|c|c|c|c|c|c|c|}
\hline IBGE & MUNICIPIO & Status & $<01$ ano & $\%$ & $.01-04$ & $\%$ & $.05-19$ & $\%$ & 20-59 & $\%$ & $60 \mathrm{e}+$ & $\%$ & Total & $\%$ \\
\hline 350520 & Bariri & D50 & 6 & 2,6 & 1 & 0,3 & 3 & 1,2 & 57 & 25,5 & 156 & 70,4 & 222 & 100,0 \\
\hline 350530 & Barra Bonita & C50 & 5 & 2,1 & 0 & 0,2 & 3 & 1,2 & 61 & 27,3 & 154 & 69,2 & 222 & 100,0 \\
\hline 350535 & Barra do Chapéu & E20 & 3 & 10,5 & 0 & 1,2 & 2 & 8,1 & 6 & 20,9 & 17 & 59,3 & 29 & 100,0 \\
\hline 350540 & Barra do Turvo & E20 & 3 & 5,6 & 0 & 0,6 & 2 & 3,7 & 21 & 39,5 & 27 & 50,6 & 54 & 100,0 \\
\hline 350550 & Barretos & B300 & 17 & 1,9 & 5 & 0,5 & 14 & 1,6 & 265 & 29,8 & 588 & 66,1 & 890 & 100,0 \\
\hline 350560 & Barrinha & D50 & 5 & 3,9 & 2 & 1,5 & 5 & 3,9 & 54 & 39,5 & 71 & 51,3 & 138 & 100,0 \\
\hline 350570 & Barueri & С 300 & 50 & 4,4 & 12 & 1,1 & 39 & 3,4 & 510 & 45,4 & 514 & 45,7 & 1125 & 100,0 \\
\hline 350580 & Bastos & D50 & 5 & 4,4 & - & - & 2 & 1,9 & 31 & 25,2 & 83 & 68,5 & 122 & 100,0 \\
\hline 350590 & Batatais & C100 & 9 & 2,5 & 1 & 0,4 & 5 & 1,4 & 105 & 30,1 & 228 & 65,6 & 348 & 100,0 \\
\hline 350600 & Bauru & B500 & 55 & 2,6 & 7 & 0,4 & 33 & 1,6 & 625 & 29,9 & 1370 & 65,6 & 2090 & 100,0 \\
\hline 350610 & Bebedouro & C100 & 12 & 2,3 & 2 & 0,3 & 9 & 1,7 & 142 & 28,0 & 343 & 67,6 & 507 & 100,0 \\
\hline 350620 & Bento de Abreu & C20 & 0 & 2,5 & - & - & - & - & 3 & 25,0 & 10 & 72,5 & 13 & 100,0 \\
\hline 350630 & Bernardino de Campos & E20 & 1 & 1,6 & 0 & 0,4 & 1 & 0,8 & 22 & 27,2 & 57 & 69,9 & 82 & 100,0 \\
\hline 350635 & Bertioga & C50 & 19 & 9,9 & 2 & 1,2 & 7 & 3,8 & 90 & 45,9 & 77 & 39,2 & 195 & 100,0 \\
\hline 350640 & Bilac & D20 & 0 & 0,8 & - & - & 1 & 1,5 & 10 & 22,6 & 33 & 75,2 & 44 & 100,0 \\
\hline 350650 & Birigui & C300 & 20 & 3,3 & 3 & 0,6 & 17 & 2,9 & 183 & 30,4 & 379 & 62,9 & 603 & 100,0 \\
\hline 350660 & BiritibaOMirim & D50 & 8 & 5,1 & 2 & 1,1 & 4 & 2,5 & 58 & 39,1 & 78 & 52,1 & 149 & 100,0 \\
\hline 350670 & Boa Esperança do Sul & E20 & 2 & 2,3 & 1 & 1,2 & 2 & 2,0 & 29 & 34,4 & 51 & 60,2 & 85 & 100,0 \\
\hline 350680 & Bocaina & D20 & 2 & 2,2 & 0 & 0,4 & 0 & 0,4 & 17 & 23,2 & 55 & 73,7 & 75 & 100,0 \\
\hline 350690 & Bofete & E20 & 3 & 4,9 & 0 & 0,5 & 1 & 1,6 & 20 & 32,4 & 37 & 60,5 & 62 & 100,0 \\
\hline 350700 & Boituva & D50 & 9 & 4,0 & 0 & 0,2 & 5 & 2,5 & 73 & 34,0 & 127 & 59,3 & 214 & 100,0 \\
\hline 350710 & Bom Jesus dos Perdoes & D20 & 6 & 5,8 & 2 & 1,7 & 2 & 2,4 & 29 & 29,4 & 59 & 60,8 & 98 & 100,0 \\
\hline 350715 & Bom Sucesso de Itararé & E20 & 2 & 14,0 & - & - & - & - & 5 & 32,0 & 9 & 54,0 & 17 & 100,0 \\
\hline 350720 & Borá & E20 & 0 & 6,7 & - & - & - & - & 1 & 20,0 & 4 & 73,3 & 5 & 100,0 \\
\hline 350730 & Boracéia & E20 & 1 & 5,9 & - & - & 1 & 2,9 & 7 & 29,4 & 14 & 61,8 & 23 & 100,0 \\
\hline 350740 & Borborema & D20 & 2 & 1,6 & 0 & 0,3 & 2 & 1,9 & 27 & 25,7 & 74 & 70,5 & 105 & 100,0 \\
\hline 350745 & Borebi & E20 & - & - & 0 & 3,0 & 0 & 3,0 & 4 & 36,4 & 6 & 57,6 & 11 & 100,0 \\
\hline 350750 & Botucatu & B300 & 18 & 2,3 & 4 & 0,5 & 14 & 1,7 & 196 & 25,0 & 551 & 70,5 & 782 & 100,0 \\
\hline 350760 & Bragança Paulista & B300 & 36 & 3,6 & 7 & 0,7 & 19 & 2,0 & 270 & 27,5 & 649 & 66,2 & 980 & 100,0 \\
\hline 350770 & Braúna & E20 & 2 & 5,8 & - & - & - & - & 6 & 19,8 & 21 & 74,4 & 29 & 100,0 \\
\hline 350775 & Brejo Alegre & E20 & 1 & 5,7 & - & - & 0 & 2,9 & 5 & 42,9 & 6 & 48,6 & 12 & 100,0 \\
\hline 350780 & Brodósqui & $\mathrm{C} 20$ & 6 & 4,9 & 1 & 0,9 & 2 & 1,7 & 33 & 28,1 & 75 & 64,5 & 116 & 100,0 \\
\hline 350790 & Brotas & D50 & 5 & 3,2 & 2 & 1,4 & 3 & 2,1 & 36 & 24,6 & 100 & 68,7 & 145 & 100,0 \\
\hline 350800 & Buri & E20 & 8 & 7,6 & 2 & 1,8 & 2 & 2,1 & 32 & 28,9 & 65 & 59,6 & 110 & 100,0 \\
\hline 350810 & Buritama & E20 & 2 & 2,4 & - & - & 2 & 1,7 & 29 & 29,6 & 64 & 66,3 & 97 & 100,0 \\
\hline 350820 & Buritizal & D20 & 0 & 1,4 & - & - & - & - & 7 & 27,8 & 17 & 70,8 & 24 & 100,0 \\
\hline 350830 & Cabrália Paulista & E20 & 1 & 3,0 & 0 & 1,0 & 1 & 2,0 & 12 & 36,4 & 19 & 57,6 & 33 & 100,0 \\
\hline 350840 & Cabreúva & C50 & 9 & 4,7 & 1 & 0,7 & 5 & 2,9 & 69 & 37,3 & 100 & 54,3 & 184 & 100,0 \\
\hline 350850 & Caçapava & B100 & 21 & 4,2 & 3 & 0,6 & 12 & 2,4 & 175 & 34,2 & 300 & 58,6 & 512 & 100,0 \\
\hline 350860 & Cachoeira Paulista & B50 & 7 & 3,6 & 1 & 0,3 & 1 & 0,7 & 58 & 29,7 & 128 & 65,6 & 195 & 100,0 \\
\hline 350870 & Caconde & E20 & 5 & 3,6 & 1 & 0,5 & 1 & 1,0 & 30 & 23,1 & 93 & 71,8 & 130 & 100,0 \\
\hline 350880 & Cafelândia & D20 & 3 & 2,2 & 0 & 0,3 & 1 & 0,6 & 34 & 27,9 & 83 & 69,1 & 121 & 100,0 \\
\hline 350890 & Caiabu & E20 & 1 & 4,6 & - & - & - & - & 5 & 23,1 & 16 & 72,3 & 22 & 100,0 \\
\hline 350900 & Caieiras & C100 & 16 & 4,2 & 3 & 0,8 & 10 & 2,6 & 147 & 38,4 & 207 & 54,0 & 383 & 100,0 \\
\hline 350910 & Caiuá & E20 & - & - & - & - & 1 & 2,0 & 9 & 25,7 & 24 & 72,3 & 34 & 100,0 \\
\hline 350920 & Cajamar & C100 & 19 & 6,3 & 3 & 1,1 & 11 & 3,6 & 124 & 41,6 & 142 & 47,4 & 299 & 100,0 \\
\hline 350925 & Cajati & D50 & 10 & 5,6 & 1 & 0,6 & 10 & 6,0 & 52 & 30,3 & 99 & 57,5 & 172 & 100,0 \\
\hline 350930 & Cajobi & E20 & 1 & 1,9 & - & - & 2 & 3,8 & 14 & 25,8 & 36 & 68,6 & 53 & 100,0 \\
\hline 350940 & Cajuru & E50 & 5 & 3,3 & 1 & 0,9 & 3 & 1,9 & 43 & 30,1 & 90 & 63,8 & 142 & 100,0 \\
\hline 350945 & Campina do Monte Alegre & E20 & 1 & 3,7 & - & & - & & 10 & 26,9 & 25 & 69,4 & 36 & 100,0 \\
\hline 350950 & Campinas & B10000 & 168 & 2,8 & 31 & 0,5 & 152 & 2,6 & 1871 & 31,6 & 3698 & 62,5 & 5920 & 100,0 \\
\hline 350960 & Campo Limpo Paulista & C100 & 15 & 3,8 & 3 & 0,8 & 13 & 3,3 & 148 & 36,4 & 226 & 55,7 & 405 & 100,0 \\
\hline 350970 & Campos do Jordao & C50 & 19 & 5,9 & 2 & 0,5 & 9 & 2,8 & 118 & 36,9 & 172 & 53,9 & 319 & 100,0 \\
\hline 350980 & Campos Novos Paulista & E20 & 1 & 2,9 & - & - & 1 & 1,9 & 10 & 30,1 & 22 & 65,0 & 34 & 100,0 \\
\hline 350990 & Cananéia & E20 & 3 & 3,1 & 2 & 2,0 & 2 & 2,4 & 27 & 31,4 & 52 & 61,2 & 85 & 100,0 \\
\hline 350995 & Canas & E20 & 2 & 6,8 & - & - & 1 & 4,5 & 10 & 35,2 & 16 & 53,4 & 29 & 100,0 \\
\hline 351000 & Cândido Mota & D50 & 7 & 3,3 & 2 & 0,8 & 4 & 1,8 & 62 & 30,3 & 130 & 63,8 & 203 & 100,0 \\
\hline 351010 & Cândido Rodrigues & E20 & 1 & 3,9 & - & - & - & - & 4 & 25,5 & 12 & 70,6 & 17 & 100,0 \\
\hline
\end{tabular}


Anexo 12 - Mortalidade proporcional (\%)por faixa etária selecionada segundo município e Estrato de Vulnerabilidade Social .Estado de São Paulo, media do triênio 2003 a 2005

\begin{tabular}{|c|c|c|c|c|c|c|c|c|c|c|c|c|c|c|}
\hline IBGE & MUNICIPIO & Status & $<01$ ano & $\%$ & $.01-04$ & $\%$ & $.05-19$ & $\%$ & 20-59 & $\%$ & $60 \mathrm{e}+$ & $\%$ & Total & $\%$ \\
\hline 351015 & Canitar & E20 & 1 & 3,0 & - & - & 0 & 1,5 & 7 & 33,3 & 14 & 62,1 & 22 & 100,0 \\
\hline 351020 & Capao Bonito & E50 & 16 & 4,9 & 3 & 0,8 & 8 & 2,6 & 102 & 31,7 & 193 & 60,0 & 322 & 100,0 \\
\hline 351030 & Capela do Alto & D20 & 6 & 6,3 & 1 & 1,4 & 2 & 1,8 & 31 & 32,4 & 55 & 58,1 & 95 & 100,0 \\
\hline 351040 & Capivari & C50 & 10 & 3,5 & 2 & 0,6 & 4 & 1,5 & 92 & 32,5 & 176 & 61,9 & 284 & 100,0 \\
\hline 351050 & Caraguatatuba & C100 & 28 & 5,0 & 8 & 1,4 & 18 & 3,3 & 229 & 41,1 & 274 & 49,2 & 557 & 100,0 \\
\hline 351060 & Carapicuíba & C500 & 94 & 6,1 & 18 & 1,2 & 55 & 3,5 & 687 & 44,3 & 697 & 44,9 & 1551 & 100,0 \\
\hline 351070 & Cardoso & E20 & 2 & 2,1 & 1 & 0,7 & 1 & 1,1 & 22 & 23,6 & 68 & 72,5 & 93 & 100,0 \\
\hline 351080 & Casa Branca & B50 & 8 & 3,4 & 1 & 0,4 & 2 & 1,0 & 71 & 30,1 & 153 & 65,1 & 236 & 100,0 \\
\hline 351090 & Cássia dos Coqueiros & E20 & - & - & - & - & 0 & 2,0 & 6 & 34,0 & 11 & 64,0 & 17 & 100,0 \\
\hline 351100 & Castilho & E20 & 6 & 5,5 & - & - & 3 & 3,1 & 34 & 31,2 & 66 & 60,2 & 109 & 100,0 \\
\hline 351110 & Catanduva & B300 & 20 & 2,3 & 2 & 0,3 & 10 & 1,1 & 235 & 27,3 & 596 & 69,0 & 863 & 100,0 \\
\hline 351120 & Catiguá & E20 & - & - & - & - & 1 & 2,0 & 16 & 32,0 & 32 & 66,0 & 49 & 100,0 \\
\hline 351130 & Cedral & E20 & 1 & 2,6 & 0 & 0,6 & 1 & 1,3 & 10 & 18,6 & 40 & 76,9 & 52 & 100,0 \\
\hline 351140 & Cerqueira César & D20 & 4 & 3,4 & 0 & 0,3 & 1 & 0,9 & 30 & 27,7 & 72 & 67,6 & 107 & 100,0 \\
\hline 351150 & Cerquilho & B50 & 6 & 3,3 & - & - & 4 & 1,9 & 57 & 29,6 & 125 & 65,2 & 192 & 100,0 \\
\hline 351160 & Cesário Lange & E20 & 2 & 2,3 & - & - & 1 & 0,8 & 27 & 30,1 & 59 & 66,9 & 89 & 100,0 \\
\hline 351170 & Charqueada & D20 & 3 & 3,5 & 0 & 0,4 & 1 & 1,5 & 23 & 26,9 & 59 & 67,7 & 87 & 100,0 \\
\hline 355720 & Chavantes & D20 & 3 & 3,6 & 1 & 0,7 & 2 & 2,1 & 24 & 25,4 & 64 & 68,2 & 93 & 100,0 \\
\hline 351190 & Clementina & E20 & 1 & 3,4 & 1 & 2,2 & 1 & 3,4 & 8 & 27,0 & 19 & 64,0 & 30 & 100,0 \\
\hline 351200 & Colina & D20 & 3 & 2,2 & 1 & 0,8 & 1 & 0,8 & 37 & 30,9 & 77 & 65,2 & 119 & 100,0 \\
\hline 351210 & Colômbia & E20 & 2 & 5,2 & 0 & 1,0 & 1 & 2,1 & 12 & 37,5 & 17 & 54,2 & 32 & 100,0 \\
\hline 351220 & Conchal & E50 & 9 & 6,7 & 1 & 0,5 & 4 & 3,2 & 48 & 35,9 & 72 & 53,7 & 135 & 100,0 \\
\hline 351230 & Conchas & C20 & 3 & 2,4 & 1 & 0,8 & 2 & 1,3 & 32 & 25,6 & 86 & 69,8 & 124 & 100,0 \\
\hline 351240 & Cordeirópolis & C20 & 2 & 2,0 & 0 & 0,3 & 2 & 1,7 & 31 & 31,2 & 64 & 64,8 & 99 & 100,0 \\
\hline 351250 & Coroados & E20 & 1 & 2,6 & 0 & 1,3 & 0 & 1,3 & 10 & 37,2 & 15 & 57,7 & 26 & 100,0 \\
\hline 351260 & Coronel Macedo & E20 & 1 & 1,7 & 0 & 0,8 & 1 & 2,5 & 12 & 30,6 & 26 & 64,5 & 40 & 100,0 \\
\hline 351270 & Corumbataí & D20 & 0 & 1,6 & - & - & 1 & 3,2 & 5 & 25,8 & 14 & 69,4 & 21 & 100,0 \\
\hline 351280 & Cosmópolis & B50 & 8 & 2,7 & 1 & 0,5 & 9 & 3,3 & 105 & 37,5 & 156 & 55,9 & 279 & 100,0 \\
\hline 351290 & Cosmorama & E20 & 0 & 0,5 & - & - & 1 & 1,6 & 15 & 24,7 & 45 & 73,1 & 62 & 100,0 \\
\hline 351300 & Cotia & С 300 & 55 & 5,9 & 8 & 0,9 & 35 & 3,8 & 364 & 39,0 & 470 & 50,4 & 932 & 100,0 \\
\hline 351310 & Cravinhos & D50 & 7 & 4,0 & 1 & 0,4 & 4 & 2,1 & 56 & 31,7 & 109 & 61,9 & 176 & 100,0 \\
\hline 351320 & Cristais Paulista & E20 & 2 & 5,4 & 0 & 0,9 & 1 & 2,7 & 14 & 36,6 & 20 & 54,5 & 37 & 100,0 \\
\hline 351330 & Cruzália & D20 & - & - & - & - & - & - & 4 & 32,4 & 8 & 67,6 & 11 & 100,0 \\
\hline 351340 & Cruzeiro & B100 & 21 & 3,9 & 2 & 0,4 & 9 & 1,6 & 179 & 33,5 & 323 & 60,5 & 534 & 100,0 \\
\hline 351350 & Cubatao & С300 & 40 & 5,9 & 4 & 0,6 & 32 & 4,7 & 291 & 43,2 & 308 & 45,6 & 674 & 100,0 \\
\hline 351360 & Cunha & E50 & 9 & 5,8 & 1 & 0,9 & 3 & 1,9 & 40 & 26,0 & 101 & 65,4 & 154 & 100,0 \\
\hline 351370 & Descalvado & D50 & 3 & 1,7 & 1 & 0,3 & 2 & 0,8 & 55 & 27,7 & 139 & 69,4 & 200 & 100,0 \\
\hline 351380 & Diadema & C500 & 113 & 5,6 & 19 & 1,0 & 96 & 4,7 & 895 & 44,3 & 898 & 44,4 & 2022 & 100,0 \\
\hline 351385 & Dirce Reis & E20 & - & - & - & - & - & - & 2 & 21,2 & 9 & 78,8 & 11 & 100,0 \\
\hline 351390 & Divinolândia & E20 & 2 & 2,1 & 1 & 1,1 & 2 & 2,1 & 27 & 28,8 & 63 & 66,0 & 95 & 100,0 \\
\hline 351400 & Dobrada & E20 & 2 & 4,2 & 0 & 0,8 & - & - & 13 & 31,7 & 25 & 63,3 & 40 & 100,0 \\
\hline 351410 & Dois Córregos & D50 & 5 & 2,8 & - & 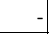 & 1 & 0,7 & 50 & 26,7 & 131 & 69,7 & 188 & 100,0 \\
\hline 351420 & Dolcinópolis & E20 & - & - & - & - & - & - & 5 & 30,0 & 12 & 70,0 & 17 & 100,0 \\
\hline 351430 & Dourado & E20 & 1 & 1,1 & 1 & 1,1 & 0 & 0,6 & 12 & 20,1 & 45 & 77,0 & 58 & 100,0 \\
\hline 351440 & Dracena & D50 & 8 & 2,5 & 0 & 0,1 & 3 & 1,0 & 84 & 25,1 & 238 & 71,3 & 333 & 100,0 \\
\hline 351450 & Duartina & E20 & 4 & 3,6 & 0 & 0,3 & 1 & 1,0 & 20 & 19,8 & 76 & 75,2 & 101 & 100,0 \\
\hline 351460 & Dumont & D20 & 2 & 4,8 & 1 & 1,9 & 0 & 1,0 & 11 & 32,7 & 21 & 59,6 & 35 & 100,0 \\
\hline 351470 & Echapora & E20 & 1 & 2,0 & - & - & 1 & 2,0 & 6 & 17,3 & 26 & 78,6 & 33 & 100,0 \\
\hline 351480 & Eldorado & D20 & 4 & 4,8 & 1 & 1,1 & 2 & 2,2 & 27 & 30,4 & 55 & 61,5 & 90 & 100,0 \\
\hline 351490 & Elias Fausto & D20 & 2 & 2,0 & 0 & 0,4 & 2 & 2,8 & 28 & 33,2 & 52 & 61,7 & 84 & 100,0 \\
\hline 351492 & Elisiário & E20 & 0 & 1,7 & - & t & 1 & 3,3 & 7 & 33,3 & 12 & 61,7 & 20 & 100,0 \\
\hline 351495 & Embaúba & E20 & - & - & - & - & 1 & 6,0 & 4 & 24,0 & 12 & 70,0 & 17 & 100,0 \\
\hline 351500 & Embu & С300 & 69 & 6,1 & 14 & 1,2 & 47 & 4,2 & 547 & 48,7 & 448 & 39,8 & 1124 & 100,0 \\
\hline 351510 & Embu0Guaçu & C100 & 11 & 2,7 & 3 & 0,7 & 14 & 3,5 & 158 & 38,6 & 224 & 54,5 & 410 & 100,0 \\
\hline 351512 & Emilianópolis & E20 & - & - & - & - & - & - & 2 & 16,3 & 12 & 83,7 & 14 & 100,0 \\
\hline 351515 & Engenheiro Coelho & D20 & 2 & 4,3 & 0 & 0,7 & 3 & 5,7 & 17 & 35,7 & 25 & 53,6 & 47 & 100,0 \\
\hline 351518 & Espírito Santo do Pinhal & C50 & 6 & 1,8 & 1 & 0,2 & 6 & 1,9 & 85 & 27,0 & 218 & 69,1 & 315 & 100,0 \\
\hline 351519 & Espírito Santo do Turvo & D20 & 1 & 5,2 & - & - & 2 & 6,5 & 9 & 35,1 & 14 & 53,2 & 26 & 100,0 \\
\hline
\end{tabular}


Anexo 12 - Mortalidade proporcional (\%)por faixa etária selecionada segundo município e Estrato de Vulnerabilidade Social .Estado de São Paulo, media do triênio 2003 a 2005

\begin{tabular}{|c|c|c|c|c|c|c|c|c|c|c|c|c|c|c|}
\hline IBGE & MUNICIPIO & Status & $<01$ ano & $\%$ & $.01-04$ & $\%$ & $.05-19$ & $\%$ & 20-59 & $\%$ & $60 e+$ & $\%$ & Total & $\%$ \\
\hline 355730 & Estiva Gerbi & $\mathrm{C} 20$ & 1 & 2,8 & 0 & 0,7 & 0 & 0,7 & 13 & 28,2 & 32 & 67,6 & 47 & 100,0 \\
\hline 351530 & Estrela do Norte & E20 & 0 & 2,0 & - & - & 0 & 2,0 & 4 & 26,0 & 12 & 70,0 & 17 & 100,0 \\
\hline 351520 & Estrela d'Oeste & E20 & 4 & 6,5 & - & - & 2 & 2,9 & 14 & 24,1 & 38 & 66,5 & 57 & 100,0 \\
\hline 351535 & Euclides da Cunha Paulist & E20 & 3 & 6,6 & 0 & 0,7 & 2 & 3,6 & 14 & 30,7 & 27 & 58,4 & 46 & 100,0 \\
\hline 351540 & Fartura & E20 & 4 & 3,4 & 2 & 1,5 & 1 & 1,2 & 29 & 26,6 & 72 & 67,2 & 108 & 100,0 \\
\hline 351560 & Fernando Prestes & E20 & 1 & 3,5 & - & - & 1 & 1,7 & 8 & 20,9 & 28 & 73,9 & 38 & 100,0 \\
\hline 351550 & Fernandópolis & D100 & 8 & 2,1 & 1 & 0,2 & 6 & 1,4 & 104 & 25,9 & 282 & 70,4 & 401 & 100,0 \\
\hline 351565 & Fernao & D20 & - & - & - & - & - & - & 2 & 28,6 & 5 & 71,4 & 7 & 100,0 \\
\hline 351570 & Ferraz de Vasconcelos & C300 & 54 & 6,9 & 7 & 0,9 & 34 & 4,4 & 317 & 40,5 & 371 & 47,4 & 782 & 100,0 \\
\hline 351580 & Flora Rica & E20 & 1 & 3,8 & - & - & 0 & 1,9 & 6 & 32,1 & 11 & 62,3 & 18 & 100,0 \\
\hline 351590 & Floreal & E20 & 0 & 1,4 & - & - & - & - & 6 & 26,4 & 17 & 72,2 & 24 & 100,0 \\
\hline 351600 & Flórida Paulista & E20 & 2 & 2,7 & - & - & 1 & 0,8 & 23 & 26,2 & 61 & 70,4 & 87 & 100,0 \\
\hline 351610 & Florínia & E20 & 1 & 5,0 & 0 & 1,7 & - & - & 6 & 28,3 & 13 & 65,0 & 20 & 100,0 \\
\hline 351620 & Franca & B500 & 67 & 3,9 & 10 & 0,6 & 33 & 1,9 & 537 & 31,0 & 1084 & 62,6 & 1731 & 100,0 \\
\hline 351630 & Francisco Morato & D300 & 60 & 9,2 & 10 & 1,5 & 33 & 5,0 & 306 & 46,7 & 246 & 37,6 & 655 & 100,0 \\
\hline 351640 & Franco da Rocha & C300 & 39 & 5,5 & 4 & 0,6 & 24 & 3,3 & 302 & 42,2 & 347 & 48,4 & 717 & 100,0 \\
\hline 351650 & Gabriel Monteiro & E20 & 1 & 3,1 & - & - & - & -1 & 6 & 26,6 & 15 & 70,3 & 21 & 100,0 \\
\hline 351660 & Gália & E20 & 1 & 1,8 & 0 & 0,6 & 1 & 1,8 & 16 & 28,8 & 36 & 66,9 & 54 & 100,0 \\
\hline 351670 & Garça & D50 & 8 & 2,2 & 2 & 0,6 & 5 & 1,6 & 92 & 26,9 & 236 & 68,7 & 343 & 100,0 \\
\hline 351680 & Gastao Vidigal & E20 & 1 & 4,9 & 0 & 1,2 & 1 & 2,4 & 7 & 25,6 & 18 & 65,9 & 27 & 100,0 \\
\hline 351685 & Gaviao Peixoto & E20 & 1 & 3,0 & 0 & 1,5 & 1 & 3,0 & 6 & 27,3 & 14 & 65,2 & 22 & 100,0 \\
\hline 351690 & General Salgado & E20 & 2 & 2,9 & 0 & 0,4 & 1 & 0,8 & 22 & 26,9 & 56 & 69,0 & 82 & 100,0 \\
\hline 351700 & Getulina & E20 & 3 & 4,3 & - & - & 1 & 1,3 & 23 & 30,4 & 49 & 63,9 & 77 & 100,0 \\
\hline 351710 & Glicério & E20 & 1 & 5,3 & - & - & - & - & 5 & 18,7 & 19 & 76,0 & 25 & 100,0 \\
\hline 351720 & Guaiçara & D20 & 4 & 6,5 & 0 & 0,5 & 1 & 2,2 & 25 & 40,9 & 31 & 50,0 & 62 & 100,0 \\
\hline 351730 & Guaimbê & E20 & 2 & 5,6 & - & - & - & - & 9 & 25,0 & 25 & 69,4 & 36 & 100,0 \\
\hline 351740 & Guaíra & C50 & 6 & 2,7 & 1 & 0,3 & 4 & 1,9 & 74 & 31,8 & 148 & 63,4 & 233 & 100,0 \\
\hline 351750 & Guapiaçu & D20 & 3 & 2,8 & 1 & 0,7 & 1 & 1,0 & 25 & 26,5 & 66 & 69,0 & 96 & 100,0 \\
\hline 351760 & Guapiara & E50 & 8 & 6,9 & 2 & 1,4 & 4 & 3,0 & 36 & 29,6 & 71 & 59,1 & 121 & 100,0 \\
\hline 351770 & Guará & E50 & 4 & 3,5 & - & - & 5 & 4,0 & 45 & 36,0 & 71 & 56,5 & 125 & 100,0 \\
\hline 351780 & Guaraçaí & E20 & 1 & 1,5 & 0 & 0,5 & 1 & 1,5 & 16 & 24,2 & 48 & 72,2 & 66 & 100,0 \\
\hline 351790 & Guaraci & E20 & 1 & 1,5 & - & - & 1 & 2,0 & 17 & 26,1 & 47 & 70,4 & 66 & 100,0 \\
\hline 351800 & Guarani d'Oeste & E20 & - & - & - & - & 1 & 4,3 & 3 & 21,7 & 11 & 73,9 & 15 & 100,0 \\
\hline 351810 & Guaranta & E20 & 2 & 3,9 & 1 & 1,6 & 1 & 1,6 & 14 & 33,3 & 26 & 59,7 & 43 & 100,0 \\
\hline 351820 & Guararapes & D50 & 6 & 2,9 & 2 & 1,1 & 4 & 1,7 & 58 & 26,4 & 149 & 68,0 & 220 & 100,0 \\
\hline 351830 & Guararema & D50 & 6 & 3,6 & 2 & 1,1 & 2 & 1,3 & 51 & 32,1 & 98 & 62,0 & 159 & 100,0 \\
\hline 351840 & Guaratinguetá & B300 & 21 & 2,7 & 3 & 0,4 & 9 & 1,2 & 251 & 31,8 & 504 & 63,9 & 788 & 100,0 \\
\hline 351850 & Guareí & E20 & 4 & 5,4 & 0 & 0,5 & 1 & 1,5 & 14 & 20,6 & 49 & 72,1 & 68 & 100,0 \\
\hline 351860 & Guariba & E50 & 7 & 4,0 & 1 & 0,8 & 7 & 3,8 & 65 & 37,1 & 96 & 54,4 & 176 & 100,0 \\
\hline 351870 & Guarujá & C300 & 90 & 5,5 & 12 & 0,7 & 55 & 3,3 & 672 & 40,8 & 817 & 49,6 & 1646 & 100,0 \\
\hline 351880 & Guarulhos & C10000 & 336 & 5,6 & 53 & 0,9 & 216 & 3,6 & 2481 & 41,0 & 2960 & 49,0 & 6046 & 100,0 \\
\hline 351885 & Guatapará & D20 & - & - & 0 & 0,9 & 0 & 0,9 & 11 & 29,9 & 24 & 68,2 & 36 & 100,0 \\
\hline 351890 & Guzolândia & E20 & 1 & 3,7 & - & -1 & 1 & 3,7 & 9 & 33,3 & 16 & 59,3 & 27 & 100,0 \\
\hline 351900 & Herculândia & E20 & 3 & 4,3 & 0 & 0,5 & 2 & 2,7 & 20 & 32,6 & 37 & 59,8 & 61 & 100,0 \\
\hline 351905 & Holambra & $\mathrm{C} 20$ & 1 & 3,3 & 1 & 1,7 & 1 & 1,7 & 12 & 30,0 & 25 & 63,3 & 40 & 100,0 \\
\hline 351907 & Hortolândia & C300 & 34 & 4,4 & 5 & 0,7 & 35 & 4,6 & 329 & 43,1 & 361 & 47,2 & 765 & 100,0 \\
\hline 351910 & lacanga & E20 & 1 & 1,9 & 0 & 0,6 & 1 & 1,3 & 15 & 28,3 & 36 & 67,9 & 53 & 100,0 \\
\hline 351920 & lacri & E20 & 0 & 0,8 & 0 & 0,8 & - & - & 10 & 23,3 & 33 & 75,2 & 44 & 100,0 \\
\hline 351925 & Iaras & D20 & 1 & 3,2 & 0 & 1,6 & 0 & 1,6 & 12 & 58,1 & 7 & 35,5 & 21 & 100,0 \\
\hline 351930 & Ibaté & D50 & 4 & 2,5 & 1 & 0,8 & 3 & 2,1 & 58 & 36,3 & 94 & 58,3 & 161 & 100,0 \\
\hline 351940 & Ibirá & D20 & 2 & 2,9 & - & - & 2 & 2,4 & 15 & 22,1 & 50 & 72,6 & 69 & 100,0 \\
\hline 351950 & Ibirarema & E20 & 2 & 3,9 & - & - & 1 & 2,3 & 11 & 26,6 & 29 & 67,2 & 43 & 100,0 \\
\hline 351960 & Ibitinga & D100 & 11 & 3,2 & 2 & 0,7 & 5 & 1,3 & 87 & 25,1 & 242 & 69,7 & 347 & 100,0 \\
\hline 351970 & Ibiúna & E50 & 25 & 6,2 & 5 & 1,3 & 14 & 3,5 & 152 & 37,1 & 212 & 51,9 & 409 & 100,0 \\
\hline 351980 & Icém & D20 & 2 & 4,1 & 0 & 0,7 & 0 & 0,7 & 12 & 25,0 & 34 & 69,6 & 49 & 100,0 \\
\hline 351990 & lepê & E20 & 3 & 5,1 & - & - & 1 & 1,3 & 11 & 20,3 & 39 & 73,4 & 53 & 100,0 \\
\hline 352000 & Igaraçu do Tietê & D50 & 4 & 2,9 & 1 & 0,5 & 4 & 2,9 & 50 & 35,6 & 82 & 58,2 & 140 & 100,0 \\
\hline 352010 & Igarapava & D50 & 8 & 4,2 & 1 & 0,5 & 3 & 1,8 & 56 & 29,5 & 121 & 64,0 & 189 & 100,0 \\
\hline
\end{tabular}


Anexo 12 - Mortalidade proporcional (\%)por faixa etária selecionada segundo município e Estrato de Vulnerabilidade Social .Estado de São Paulo, media do triênio 2003 a 2005

\begin{tabular}{|c|c|c|c|c|c|c|c|c|c|c|c|c|c|c|}
\hline IBGE & MUNICIPIO & Status & $<01$ ano & $\%$ & $.01-04$ & $\%$ & $.05-19$ & $\%$ & 20-59 & $\%$ & $60 e+$ & $\%$ & Total & $\%$ \\
\hline 352020 & Igaratá & E20 & 2 & 4,5 & 0 & 0,6 & 1 & 2,6 & 19 & 37,4 & 28 & 54,8 & 52 & 100,0 \\
\hline 352030 & Iguape & E50 & 6 & 2,6 & 2 & 0,8 & 5 & 2,4 & 62 & 28,1 & 147 & 66,2 & 222 & 100,0 \\
\hline 352042 & Ilha Comprida & A20 & 1 & 2,5 & 0 & 0,6 & 2 & 3,1 & 19 & 35,4 & 31 & 58,4 & 54 & 100,0 \\
\hline 352044 & Ilha Solteira & B50 & 2 & 1,8 & - & - & 2 & 1,8 & 35 & 31,3 & 73 & 65,2 & 112 & 100,0 \\
\hline 352040 & |lhabela & C50 & 3 & 3,3 & 1 & 1,0 & 3 & 3,0 & 43 & 42,3 & 51 & 50,5 & 102 & 100,0 \\
\hline 352050 & Indaiatuba & B300 & 37 & 4,2 & 7 & 0,8 & 24 & 2,7 & 274 & 31,2 & 538 & 61,1 & 879 & 100,0 \\
\hline 352060 & Indiana & E20 & 1 & 1,9 & - & - & 1 & 2,8 & 9 & 25,0 & 25 & 70,4 & 36 & 100,0 \\
\hline 352070 & Indiapora & E20 & 0 & 1,1 & - & - & - & - & 7 & 23,0 & 22 & 75,9 & 29 & 100,0 \\
\hline 352080 & Inúbia Paulista & E20 & 0 & 1,4 & - & - & 1 & 2,9 & 10 & 41,4 & 13 & 54,3 & 23 & 100,0 \\
\hline 352090 & Ipauçu & E20 & 2 & 2,4 & - & - & 2 & 1,7 & 27 & 28,1 & 66 & 67,8 & 97 & 100,0 \\
\hline 352100 & Iperó & $\mathrm{C} 50$ & 5 & 4,1 & - & - & 3 & 2,6 & 44 & 38,3 & 63 & 55,1 & 115 & 100,0 \\
\hline 352110 & Ipeúna & $\mathrm{C} 20$ & 1 & 3,1 & 0 & 1,5 & 1 & 3,1 & 7 & 33,8 & 13 & 58,5 & 22 & 100,0 \\
\hline 352115 & Ipiguá & E20 & 1 & 6,1 & - & - & 1 & 4,1 & 5 & 28,6 & 10 & 61,2 & 16 & 100,0 \\
\hline 352120 & Iporanga & E20 & 0 & 1,2 & 0 & 1,2 & 1 & 3,6 & 8 & 27,7 & 18 & 66,3 & 28 & 100,0 \\
\hline 352130 & Ipua & D20 & 2 & 2,3 & 1 & 1,8 & 1 & 1,8 & 25 & 33,3 & 45 & 60,8 & 74 & 100,0 \\
\hline 352140 & Iracemápolis & C20 & 3 & 3,5 & 1 & 1,1 & 1 & 1,1 & 29 & 30,7 & 60 & 63,6 & 94 & 100,0 \\
\hline 352150 & Irapua & E20 & 2 & 4,9 & 1 & 2,1 & 1 & 2,1 & 10 & 20,8 & 34 & 70,1 & 48 & 100,0 \\
\hline 352160 & Irapuru & E20 & 2 & 4,1 & 1 & 1,2 & 1 & 1,8 & 14 & 25,3 & 38 & 67,6 & 57 & 100,0 \\
\hline 352170 & Itaberá & E20 & 5 & 4,7 & - & - & 1 & 1,2 & 34 & 29,4 & 74 & 64,7 & 114 & 100,0 \\
\hline 352180 & Itaí & E50 & 8 & 6,1 & 1 & 0,5 & 6 & 4,3 & 41 & 31,1 & 76 & 58,0 & 132 & 100,0 \\
\hline 352190 & Itajobi & E20 & 1 & 1,4 & 0 & 0,4 & 1 & 0,7 & 19 & 19,9 & 73 & 77,7 & 94 & 100,0 \\
\hline 352200 & Itaju & E20 & 1 & 4,5 & 0 & 1,5 & 1 & 3,0 & 6 & 25,8 & 14 & 65,2 & 22 & 100,0 \\
\hline 352210 & Itanhaém & C100 & 28 & 4,8 & 6 & 1,0 & 14 & 2,5 & 211 & 36,9 & 313 & 54,8 & 572 & 100,0 \\
\hline 352215 & Itaóca & E20 & 2 & 7,1 & 0 & 1,4 & - & - & 5 & 21,4 & 16 & 70,0 & 23 & 100,0 \\
\hline 352220 & Itapecerica da Serra & C300 & 39 & 4,7 & 9 & 1,1 & 40 & 4,9 & 361 & 43,6 & 379 & 45,7 & 828 & 100,0 \\
\hline 352230 & Itapetininga & B300 & 39 & 4,3 & 9 & 1,0 & 17 & 1,9 & 280 & 30,9 & 561 & 61,9 & 906 & 100,0 \\
\hline 352240 & Itapeva & D100 & 53 & 9,2 & 8 & 1,3 & 13 & 2,3 & 169 & 29,0 & 338 & 58,2 & 581 & 100,0 \\
\hline 352250 & Itapevi & C300 & 49 & 6,1 & 11 & 1,4 & 38 & 4,6 & 380 & 46,6 & 337 & 41,3 & 815 & 100,0 \\
\hline 352260 & Itapira & D100 & 11 & 2,0 & 2 & 0,4 & 13 & 2,4 & 167 & 30,5 & 354 & 64,7 & 548 & 100,0 \\
\hline 352265 & Itapirapua Paulista & E20 & 0 & 2,2 & 0 & 2,2 & - & - & 5 & 30,4 & 10 & 65,2 & 15 & 100,0 \\
\hline 352270 & Itápolis & D50 & 6 & 2,1 & 2 & 0,6 & 3 & 1,2 & 83 & 28,6 & 195 & 67,6 & 289 & 100,0 \\
\hline 352280 & Itaporanga & E20 & 4 & 3,2 & - & - & 6 & 4,9 & 34 & 29,4 & 72 & 62,5 & 116 & 100,0 \\
\hline 352290 & Itapuí & E20 & 2 & 2,3 & 0 & 0,5 & 1 & 1,8 & 22 & 29,9 & 48 & 65,6 & 74 & 100,0 \\
\hline 352300 & Itapura & E20 & 1 & 3,4 & 0 & 1,1 & - & - & 11 & 36,8 & 17 & 58,6 & 29 & 100,0 \\
\hline 352310 & Itaquaquecetuba & C500 & 103 & 7,5 & 17 & 1,2 & 67 & 4,9 & 638 & 46,4 & 551 & 40,0 & 1376 & 100,0 \\
\hline 352320 & Itararé & D50 & 22 & 6,4 & 2 & 0,6 & 8 & 2,2 & 101 & 28,7 & 219 & 62,2 & 351 & 100,0 \\
\hline 352330 & Itariri & D20 & 6 & 8,7 & 1 & 1,9 & 4 & 5,3 & 27 & 39,4 & 31 & 44,7 & 69 & 100,0 \\
\hline 352340 & Itatiba & B100 & 15 & 2,7 & 2 & 0,3 & 10 & 1,9 & 163 & 30,1 & 351 & 65,0 & 540 & 100,0 \\
\hline 352350 & Itatinga & E20 & 5 & 5,2 & 1 & 0,7 & 3 & 2,6 & 36 & 35,0 & 58 & 56,5 & 102 & 100,0 \\
\hline 352360 & Itirapina & C20 & 2 & 2,4 & 2 & 2,0 & 1 & 1,2 & 26 & 31,1 & 53 & 63,3 & 84 & 100,0 \\
\hline 352370 & Itirapua & E20 & 2 & 7,2 & 1 & 2,1 & 2 & 5,2 & 11 & 33,0 & 17 & 52,6 & 32 & 100,0 \\
\hline 352380 & Itobi & E20 & 3 & 5,0 & 0 & 0,6 & 0 & 0,6 & 18 & 30,6 & 38 & 63,3 & 60 & 100,0 \\
\hline 352390 & Itu & C300 & 26 & 3,0 & 7 & 0,8 & 23 & 2,6 & 277 & 31,6 & 543 & 62,0 & 876 & 100,0 \\
\hline 352400 & Itupeva & C50 & 6 & 4,6 & 2 & 1,2 & 5 & 3,8 & 56 & 40,3 & 70 & 50,1 & 139 & 100,0 \\
\hline 352410 & Ituverava & D50 & 9 & 3,0 & 1 & 0,2 & 5 & 1,7 & 87 & 29,1 & 197 & 66,0 & 298 & 100,0 \\
\hline 352420 & Jaborandi & E20 & 1 & 3,0 & - & - & 0 & 0,7 & 13 & 28,4 & 30 & 67,9 & 45 & 100,0 \\
\hline 352430 & Jaboticabal & B100 & 9 & 2,0 & 2 & 0,4 & 7 & 1,5 & 141 & 30,7 & 300 & 65,4 & 459 & 100,0 \\
\hline 352440 & Jacareí & B300 & 42 & 3,5 & 9 & 0,8 & 34 & 2,9 & 423 & 35,7 & 677 & 57,1 & 1185 & 100,0 \\
\hline 352450 & Jaci & E20 & 1 & 4,0 & 1 & 2,0 & 3 & 9,0 & 9 & 28,0 & 19 & 57,0 & 33 & 100,0 \\
\hline 352460 & Jacupiranga & D20 & 5 & 5,6 & 1 & 1,4 & 2 & 1,7 & 27 & 28,2 & 60 & 63,1 & 96 & 100,0 \\
\hline 352470 & Jaguariúna & B50 & 7 & 3,5 & - & - & 3 & 1,6 & 55 & 29,0 & 124 & 65,9 & 189 & 100,0 \\
\hline 352480 & Jales & D50 & 7 & 2,3 & 1 & 0,2 & 5 & 1,7 & 77 & 24,4 & 227 & 71,4 & 317 & 100,0 \\
\hline 352490 & Jambeiro & D20 & 0 & 1,6 & 1 & 3,2 & - & - & 8 & 38,7 & 12 & 56,5 & 21 & 100,0 \\
\hline 352500 & Jandira & C300 & 30 & 7,1 & 5 & 1,3 & 19 & 4,5 & 194 & 45,8 & 175 & 41,4 & 423 & 100,0 \\
\hline 352510 & Jardinópolis & C50 & 5 & 2,4 & 1 & 0,7 & 3 & 1,6 & 58 & 30,2 & 124 & 65,1 & 191 & 100,0 \\
\hline 352520 & Jarinu & D20 & 3 & 3,0 & 1 & 1,0 & 3 & 3,4 & 39 & 39,7 & 52 & 52,9 & 99 & 100,0 \\
\hline 352530 & Jaú & C300 & 25 & 3,0 & 5 & 0,6 & 9 & 1,1 & 224 & 27,1 & 564 & 68,3 & 827 & 100,0 \\
\hline 352540 & Jeriquara & E20 & 0 & 2,0 & - & - & 1 & 4,0 & 9 & 52,0 & 7 & 42,0 & 17 & 100,0 \\
\hline
\end{tabular}


Anexo 12 - Mortalidade proporcional (\%)por faixa etária selecionada segundo município e Estrato de Vulnerabilidade Social .Estado de São Paulo, media do triênio 2003 a 2005

\begin{tabular}{|c|c|c|c|c|c|c|c|c|c|c|c|c|c|c|}
\hline IBGE & MUNICIPIO & Status & $<01$ ano & $\%$ & $.01-04$ & $\%$ & $.05-19$ & $\%$ & 20-59 & $\%$ & $60 e+$ & $\%$ & Total & $\%$ \\
\hline 352550 & Joanópolis & E20 & 3 & 3,2 & 0 & 0,4 & 1 & 1,6 & 25 & 30,8 & 53 & 64,0 & 82 & 100,0 \\
\hline 352560 & Joao Ramalho & E20 & 2 & 10,3 & 0 & 1,5 & 1 & 2,9 & 6 & 25,0 & 14 & 60,3 & 23 & 100,0 \\
\hline 352570 & José Bonifácio & D50 & 5 & 2,5 & 1 & 0,5 & 2 & 1,1 & 49 & 24,0 & 147 & 71,9 & 204 & 100,0 \\
\hline 352580 & Júlio Mesquita & E20 & 1 & 3,6 & - & - & 0 & 0,9 & 10 & 26,8 & 26 & 68,8 & 37 & 100,0 \\
\hline 352585 & Jumirim & A20 & 1 & 7,5 & 1 & 5,0 & 0 & 2,5 & 3 & 20,0 & 9 & 65,0 & 13 & 100,0 \\
\hline 352590 & Jundiaí & A500 & 65 & 2,9 & 12 & 0,5 & 38 & 1,7 & 644 & 28,3 & 1514 & 66,6 & 2273 & 100,0 \\
\hline 352600 & Junqueirópolis & E20 & 3 & 1,9 & 0 & 0,2 & 2 & 1,7 & 35 & 24,8 & 101 & 71,5 & 141 & 100,0 \\
\hline 352610 & Juquiá & D50 & 5 & 3,7 & 2 & 1,7 & 4 & 2,7 & 47 & 34,9 & 77 & 56,9 & 135 & 100,0 \\
\hline 352620 & Juquitiba & D50 & 8 & 4,5 & 3 & 1,8 & 6 & 3,4 & 75 & 40,6 & 92 & 49,6 & 185 & 100,0 \\
\hline 352630 & Lagoinha & E20 & 1 & 2,5 & 0 & 0,8 & 2 & 4,2 & 9 & 23,7 & 27 & 68,6 & 39 & 100,0 \\
\hline 352640 & Laranjal Paulista & B50 & 4 & 2,8 & - & - & 4 & 2,3 & 46 & 29,4 & 102 & 65,5 & 156 & 100,0 \\
\hline 352650 & Lavínia & E20 & 1 & 2,7 & - & - & 1 & 3,5 & 9 & 23,9 & 26 & 69,9 & 38 & 100,0 \\
\hline 352660 & Lavrinhas & D20 & 3 & 9,3 & - & - & 0 & 0,9 & 15 & 42,1 & 17 & 47,7 & 36 & 100,0 \\
\hline 352670 & Leme & D100 & 26 & 4,9 & 3 & 0,6 & 7 & 1,4 & 190 & 36,6 & 293 & 56,4 & 519 & 100,0 \\
\hline 352680 & Lençóis Paulista & C100 & 9 & 2,6 & 2 & 0,5 & 5 & 1,4 & 90 & 27,1 & 228 & 68,4 & 334 & 100,0 \\
\hline 352690 & Limeira & B300 & 38 & 2,5 & 11 & 0,7 & 31 & 2,0 & 493 & 32,1 & 962 & 62,7 & 1535 & 100,0 \\
\hline 352700 & Lindóia & D20 & 2 & 6,0 & - & -1 & 1 & 3,4 & 12 & 29,9 & 24 & 60,7 & 39 & 100,0 \\
\hline 352710 & Lins & B100 & 15 & 2,9 & 3 & 0,6 & 7 & 1,3 & 150 & 28,3 & 354 & 66,9 & 529 & 100,0 \\
\hline 352720 & Lorena & B100 & 24 & 4,0 & 4 & 0,7 & 17 & 3,0 & 200 & 34,2 & 339 & 58,0 & 585 & 100,0 \\
\hline 352725 & Lourdes & E20 & 0 & 2,4 & 0 & 2,4 & - & - & 4 & 26,8 & 9 & 68,3 & 14 & 100,0 \\
\hline 352730 & Louveira & C50 & 3 & 2,3 & 1 & 0,7 & 4 & 2,7 & 56 & 38,2 & 82 & 56,1 & 146 & 100,0 \\
\hline 352740 & Lucélia & D20 & 4 & 2,6 & 0 & 0,2 & 1 & 0,7 & 31 & 21,6 & 107 & 74,9 & 143 & 100,0 \\
\hline 352750 & Lucianópolis & E20 & - & - & - & - & 0 & 2,3 & 4 & 27,3 & 10 & 70,5 & 15 & 100,0 \\
\hline 352760 & Luís Antônio & C20 & 2 & 4,5 & - & - & 1 & 3,6 & 12 & 32,1 & 22 & 59,8 & 37 & 100,0 \\
\hline 352770 & Luiziânia & E20 & 2 & 6,3 & - & - & - & - & 6 & 17,7 & 24 & 76,0 & 32 & 100,0 \\
\hline 352780 & Lupércio & E20 & 1 & 2,8 & - & - & 0 & 1,4 & 7 & 27,8 & 16 & 68,1 & 24 & 100,0 \\
\hline 352790 & Lutécia & E20 & 0 & 2,2 & - & - & - & - & 4 & 23,9 & 11 & 73,9 & 15 & 100,0 \\
\hline 352800 & Macatuba & D20 & 4 & 4,1 & - & - & 3 & 2,7 & 24 & 24,9 & 67 & 68,3 & 98 & 100,0 \\
\hline 352810 & Macaubal & E20 & 1 & 1,3 & 0 & 0,6 & 1 & 1,3 & 12 & 23,4 & 38 & 73,4 & 51 & 100,0 \\
\hline 352820 & Macedônia & E20 & 1 & 3,8 & - & - & - & - & 8 & 31,3 & 17 & 65,0 & 27 & 100,0 \\
\hline 352830 & Magda & E20 & - & - & - & - & 0 & 1,3 & 6 & 25,3 & 18 & 73,3 & 25 & 100,0 \\
\hline 352840 & Mairinque & C50 & 11 & 4,3 & 2 & 0,8 & 7 & 2,8 & 105 & 39,5 & 139 & 52,6 & 265 & 100,0 \\
\hline 352850 & Mairipora & C100 & 16 & 4,0 & 5 & 1,1 & 13 & 3,2 & 155 & 37,5 & 224 & 54,3 & 413 & 100,0 \\
\hline 352860 & Manduri & D20 & 2 & 2,7 & 0 & 0,5 & 1 & 2,1 & 15 & 23,5 & 44 & 71,1 & 62 & 100,0 \\
\hline 352870 & Marabá Paulista & E20 & 0 & 1,7 & - & -1 & 0 & 1,7 & 6 & 31,0 & 13 & 65,5 & 19 & 100,0 \\
\hline 352880 & Maracaí & D20 & 3 & 3,0 & 1 & 0,7 & 1 & 1,1 & 28 & 31,8 & 56 & 63,3 & 89 & 100,0 \\
\hline 352885 & Marapoama & E20 & 0 & 3,3 & 0 & 3,3 & 0 & 3,3 & 4 & 40,0 & 5 & 50,0 & 10 & 100,0 \\
\hline 352890 & Mariápolis & E20 & 1 & 3,3 & - & -1 & 1 & 3,3 & 7 & 22,2 & 21 & 71,1 & 30 & 100,0 \\
\hline 352900 & Marília & B300 & 42 & 3,1 & 4 & 0,3 & 22 & 1,7 & 373 & 28,2 & 885 & 66,7 & 1326 & 100,0 \\
\hline 352910 & Marinópolis & E20 & - & - & - & - & 0 & 2,7 & 3 & 27,0 & 9 & 70,3 & 12 & 100,0 \\
\hline 352920 & Martinópolis & D50 & 5 & 3,2 & - & - & 2 & 1,2 & 47 & 28,5 & 110 & 67,0 & 165 & 100,0 \\
\hline 352930 & Matao & B100 & 14 & 3,3 & 2 & 0,5 & 7 & 1,6 & 129 & 30,2 & 276 & 64,5 & 429 & 100,0 \\
\hline 352940 & Mauá & C500 & 100 & 5,3 & 16 & 0,9 & 69 & 3,6 & 810 & 42,5 & 909 & 47,7 & 1905 & 100,0 \\
\hline 352950 & Mendonça & E20 & - & - & - & - & - & - & 6 & 21,3 & 23 & 78,7 & 30 & 100,0 \\
\hline 352960 & Meridiano & E20 & - & - & - & - & 1 & 2,5 & 6 & 24,1 & 19 & 73,4 & 26 & 100,0 \\
\hline 352965 & Mesópolis & E20 & 0 & 2,9 & - & - & - & - & 2 & 14,7 & 9 & 82,4 & 11 & 100,0 \\
\hline 352970 & Miguelópolis & E20 & 4 & 3,4 & 0 & 0,3 & 3 & 2,3 & 37 & 29,0 & 84 & 65,0 & 129 & 100,0 \\
\hline 352980 & Mineiros do Tietê & E20 & 3 & 4,6 & 0 & 0,5 & 0 & 0,5 & 18 & 24,7 & 51 & 69,9 & 73 & 100,0 \\
\hline 353000 & Mira Estrela & E20 & 0 & 2,0 & - & - & 0 & 2,0 & 5 & 27,5 & 12 & 68,6 & 17 & 100,0 \\
\hline 352990 & Miracatu & E50 & 7 & 4,7 & 2 & 1,4 & 4 & 3,0 & 56 & 39,0 & 74 & 51,9 & 143 & 100,0 \\
\hline 353010 & Mirandópolis & D50 & 4 & 2,3 & 1 & 0,4 & 1 & 0,6 & 44 & 26,0 & 121 & 70,7 & 171 & 100,0 \\
\hline 353020 & Mirante do Paranapanema & E20 & 3 & 3,0 & 0 & 0,3 & 1 & 1,4 & 26 & 26,4 & 68 & 68,9 & 99 & 100,0 \\
\hline 353030 & Mirassol & B100 & 6 & 1,7 & 1 & 0,2 & 4 & 1,2 & 96 & 28,3 & 234 & 68,7 & 341 & 100,0 \\
\hline 353040 & Mirassolândia & E20 & 1 & 4,1 & - & - & 1 & 4,1 & 6 & 24,7 & 16 & 67,1 & 24 & 100,0 \\
\hline 353050 & Mococa & D100 & 15 & 3,1 & 1 & 0,3 & 6 & 1,2 & 132 & 27,7 & 323 & 67,8 & 477 & 100,0 \\
\hline 353060 & Moji das Cruzes & B500 & 100 & 4,9 & 19 & 0,9 & 61 & 3,0 & 692 & 34,0 & 1164 & 57,2 & 2035 & 100,0 \\
\hline 353070 & MojiOGuaçu & B300 & 25 & 3,2 & 4 & 0,6 & 16 & 2,1 & 255 & 32,4 & 485 & 61,7 & 786 & 100,0 \\
\hline 353080 & MojiOMirim & B100 & 16 & 3,0 & 1 & 0,2 & 9 & 1,7 & 173 & 32,0 & 341 & 63,1 & 541 & 100,0 \\
\hline
\end{tabular}


Anexo 12 - Mortalidade proporcional (\%)por faixa etária selecionada segundo município e Estrato de Vulnerabilidade Social .Estado de São Paulo, media do triênio 2003 a 2005

\begin{tabular}{|c|c|c|c|c|c|c|c|c|c|c|c|c|c|c|}
\hline IBGE & MUNICIPIO & Status & $<01$ ano & $\%$ & $.01-04$ & $\%$ & $.05-19$ & $\%$ & 20-59 & $\%$ & $60 \mathrm{e}+$ & $\%$ & Total & $\%$ \\
\hline 353090 & Mombuca & E20 & 1 & 5,1 & - & -1 & t & & 7 & 37,3 & 11 & 57,6 & 20 & 100,0 \\
\hline 353100 & Monçoes & E20 & - & - & - & - & 0 & 2,3 & 3 & 20,9 & 11 & 76,7 & 14 & 100,0 \\
\hline 353110 & Mongaguá & C50 & 17 & 5,8 & 4 & 1,3 & 7 & 2,3 & 100 & 34,8 & 159 & 55,7 & 286 & 100,0 \\
\hline 353120 & Monte Alegre do Sul & E20 & 1 & 2,5 & 0 & 0,8 & 1 & 2,5 & 11 & 26,7 & 27 & 67,5 & 40 & 100,0 \\
\hline 353130 & Monte Alto & C50 & 7 & 2,2 & 0 & 0,1 & 6 & 2,0 & 74 & 24,7 & 212 & 70,9 & 299 & 100,0 \\
\hline 353140 & Monte Aprazível & D20 & 4 & 2,5 & 0 & 0,2 & 1 & 0,6 & 35 & 22,0 & 120 & 74,7 & 161 & 100,0 \\
\hline 353150 & Monte Azul Paulista & E50 & 3 & 2,5 & 0 & 0,3 & 2 & 1,5 & 36 & 27,4 & 91 & 68,3 & 133 & 100,0 \\
\hline 353160 & Monte Castelo & E20 & 0 & 1,2 & - & -1 & 0 & 1,2 & 7 & 25,3 & 20 & 72,3 & 28 & 100,0 \\
\hline 353180 & Monte Mor & D50 & 10 & 4,0 & 2 & 0,9 & 10 & 4,1 & 100 & 40,0 & 127 & 50,9 & 249 & 100,0 \\
\hline 353170 & Monteiro Lobato & E20 & 2 & 6,2 & 0 & 1,2 & 1 & 2,5 & 7 & 25,9 & 17 & 64,2 & 27 & 100,0 \\
\hline 353190 & Morro Agudo & D50 & 8 & 5,5 & 1 & 0,7 & 4 & 2,5 & 47 & 32,0 & 87 & 59,3 & 147 & 100,0 \\
\hline 353200 & Morungaba & D20 & 3 & 5,7 & 2 & 2,9 & 1 & 1,7 & 18 & 30,9 & 34 & 58,9 & 58 & 100,0 \\
\hline 353205 & Motuca & D20 & 2 & 7,6 & 0 & 1,5 & 1 & 4,5 & 5 & 24,2 & 14 & 62,1 & 22 & 100,0 \\
\hline 353210 & Murutinga do Sul & E20 & - & - & - & - & 1 & 2,2 & 6 & 19,8 & 24 & 78,0 & 30 & 100,0 \\
\hline 353215 & Nantes & E20 & 1 & 4,9 & - & - & 1 & 9,8 & 4 & 31,7 & 7 & 53,7 & 14 & 100,0 \\
\hline 353220 & Narandiba & E20 & 0 & 1,8 & - & - & 0 & 1,8 & 4 & 22,8 & 14 & 73,7 & 19 & 100,0 \\
\hline 353230 & Natividade da Serra & E20 & 2 & 3,2 & 1 & 1,3 & 2 & 3,8 & 13 & 24,4 & 35 & 67,3 & 52 & 100,0 \\
\hline 353240 & Nazaré Paulista & E20 & 3 & 2,8 & 0 & 0,3 & 1 & 1,1 & 33 & 28,0 & 81 & 67,8 & 119 & 100,0 \\
\hline 353250 & Neves Paulista & E20 & 1 & 0,9 & 0 & 0,5 & 1 & 1,4 & 17 & 23,0 & 55 & 74,3 & 74 & 100,0 \\
\hline 353260 & Nhandeara & D20 & 2 & 2,2 & - & - & 1 & 1,7 & 15 & 20,1 & 58 & 76,0 & 76 & 100,0 \\
\hline 353270 & Nipoa & E20 & 1 & 5,3 & 0 & 1,3 & - & - & 8 & 31,6 & 16 & 61,8 & 25 & 100,0 \\
\hline 353280 & Nova Aliança & E20 & 1 & 2,6 & 0 & 0,9 & 1 & 1,7 & 8 & 21,7 & 28 & 73,0 & 38 & 100,0 \\
\hline 353282 & Nova Campina & E20 & 5 & 13,6 & 1 & 2,5 & 1 & 1,7 & 10 & 26,3 & 22 & 55,9 & 39 & 100,0 \\
\hline 353284 & Nova Canaa Paulista & E20 & - & - & - & - & - & - & 4 & 18,6 & 16 & 81,4 & 20 & 100,0 \\
\hline 353286 & Nova Castilho & E20 & - & - & - & - & 1 & 18,8 & 2 & 31,3 & 3 & 50,0 & 5 & 100,0 \\
\hline 353290 & Nova Europa & D20 & 2 & 4,7 & 1 & 2,3 & 1 & 2,3 & 12 & 28,7 & 27 & 62,0 & 43 & 100,0 \\
\hline 353300 & Nova Granada & E20 & 3 & 2,1 & 0 & 0,3 & 2 & 1,6 & 34 & 27,3 & 86 & 68,7 & 125 & 100,0 \\
\hline 353310 & Nova Guataporanga & E20 & 0 & 1,9 & - & - & 1 & 5,6 & 4 & 20,4 & 13 & 72,2 & 18 & 100,0 \\
\hline 353320 & Nova Independência & E20 & 1 & 5,5 & 0 & 1,8 & - & - & 5 & 29,1 & 12 & 63,6 & 18 & 100,0 \\
\hline 353330 & Nova Luzitânia & E20 & - & - & - & - & 0 & 1,7 & 6 & 31,7 & 13 & 66,7 & 20 & 100,0 \\
\hline 353340 & Nova Odessa & B50 & 7 & 2,9 & 1 & 0,4 & 6 & 2,7 & 82 & 35,3 & 137 & 58,7 & 233 & 100,0 \\
\hline 353325 & Novais & E20 & 1 & 4,8 & - & - & 1 & 4,8 & 5 & 25,4 & 14 & 65,1 & 21 & 100,0 \\
\hline 353350 & Novo Horizonte & D50 & 4 & 1,6 & 1 & 0,4 & 3 & 1,4 & 62 & 25,3 & 175 & 71,3 & 246 & 100,0 \\
\hline 353360 & Nuporanga & E20 & 2 & 4,0 & - & - & 2 & 4,0 & 8 & 19,4 & 30 & 72,6 & 41 & 100,0 \\
\hline 353370 & Ocauçu & E20 & 1 & 2,0 & 0 & 1,0 & - & - & 9 & 27,3 & 23 & 69,7 & 33 & 100,0 \\
\hline 353380 & Oleo & E20 & - & - & - & - & 0 & 2,0 & 4 & 23,5 & 13 & 74,5 & 17 & 100,0 \\
\hline 353390 & Olímpia & D50 & 9 & 2,6 & 3 & 0,8 & 5 & 1,3 & 93 & 26,6 & 241 & 68,8 & 350 & 100,0 \\
\hline 353400 & Onda Verde & E20 & 0 & 1,6 & - & - & 0 & 1,6 & 7 & 32,8 & 13 & 63,9 & 20 & 100,0 \\
\hline 353410 & Oriente & D20 & 0 & 0,8 & 0 & 0,8 & 0 & 0,8 & 12 & 28,2 & 29 & 69,4 & 41 & 100,0 \\
\hline 353420 & Orindiúva & $\mathrm{C} 20$ & 0 & 1,8 & - & - & 1 & 7,0 & 8 & 42,1 & 9 & 49,1 & 19 & 100,0 \\
\hline 353430 & Orlândia & B50 & 5 & 2,3 & 2 & 0,9 & 4 & 2,0 & 73 & 33,2 & 136 & 61,7 & 220 & 100,0 \\
\hline 353440 & Osasco & B1000 & 185 & 4,7 & 28 & 0,7 & 114 & 2,9 & 1533 & 39,1 & 2057 & 52,5 & 3918 & 100,0 \\
\hline 353450 & Oscar Bressane & E20 & - & - & - & - & - & - & 4 & 26,0 & 12 & 74,0 & 17 & 100,0 \\
\hline 353460 & Osvaldo Cruz & D50 & 4 & 1,8 & 1 & 0,6 & 3 & 1,4 & 55 & 25,1 & 156 & 71,1 & 219 & 100,0 \\
\hline 353470 & Ourinhos & C300 & 19 & 2,9 & 2 & 0,2 & 12 & 1,8 & 227 & 33,7 & 412 & 61,3 & 672 & 100,0 \\
\hline 353480 & Ouro Verde & E20 & 3 & 5,0 & 0 & 0,6 & 1 & 1,3 & 16 & 30,8 & 33 & 62,3 & 53 & 100,0 \\
\hline 353475 & Ouroeste & E20 & 1 & 3,0 & 0 & 0,8 & 0 & 0,8 & 11 & 25,6 & 31 & 69,9 & 44 & 100,0 \\
\hline 353490 & Pacaembu & E20 & 0 & 0,3 & - & - & 1 & 0,7 & 29 & 28,8 & 72 & 70,3 & 102 & 100,0 \\
\hline 353500 & Palestina & E20 & 3 & 4,2 & 0 & 0,5 & 1 & 0,9 & 15 & 21,3 & 53 & 73,1 & 72 & 100,0 \\
\hline 353510 & Palmares Paulista & E20 & 4 & 8,3 & 1 & 1,3 & 1 & 1,3 & 17 & 31,8 & 30 & 57,3 & 52 & 100,0 \\
\hline 353520 & Palmeira d'Oeste & E20 & 1 & 1,4 & 0 & 0,5 & 0 & 0,5 & 17 & 22,8 & 55 & 74,9 & 73 & 100,0 \\
\hline 353530 & Palmital & D50 & 4 & 2,2 & - & - & 1 & 0,8 & 43 & 25,2 & 121 & 71,8 & 169 & 100,0 \\
\hline 353540 & Panorama & E20 & 4 & 4,3 & - & - & 0 & 0,4 & 31 & 33,3 & 58 & 62,0 & 93 & 100,0 \\
\hline 353550 & Paraguaçu Paulista & D50 & 10 & 3,4 & 1 & 0,3 & 6 & 1,9 & 86 & 29,6 & 188 & 64,7 & 291 & 100,0 \\
\hline 353560 & Paraibuna & E20 & 3 & 2,7 & 2 & 1,5 & 2 & 1,8 & 37 & 33,9 & 66 & 60,0 & 110 & 100,0 \\
\hline 353570 & Paraíso & E20 & 1 & 1,7 & - & & 1 & 1,7 & 7 & 17,9 & 31 & 78,6 & 39 & 100,0 \\
\hline 353580 & Paranapanema & E20 & 5 & 4,8 & 1 & 0,6 & 2 & 2,2 & 31 & 30,0 & 65 & 62,3 & 104 & 100,0 \\
\hline 353590 & Paranapua & E20 & 1 & 2,7 & - & - & 0 & 1,3 & 6 & 22,7 & 18 & 73,3 & 25 & 100,0 \\
\hline
\end{tabular}


Anexo 12 - Mortalidade proporcional (\%)por faixa etária selecionada segundo município e Estrato de Vulnerabilidade Social .Estado de São Paulo, media do triênio 2003 a 2005

\begin{tabular}{|c|c|c|c|c|c|c|c|c|c|c|c|c|c|c|}
\hline IBGE & MUNICIPIO & Status & $<01$ ano & $\%$ & $.01-04$ & $\%$ & $.05-19$ & $\%$ & 20-59 & $\%$ & $60 \mathrm{e}+$ & $\%$ & Total & $\%$ \\
\hline 353600 & Parapua & E20 & 1 & 1,6 & 0 & 0,4 & 1 & 1,2 & 26 & 30,0 & 57 & 66,9 & 86 & 100,0 \\
\hline 353610 & Pardinho & D20 & 1 & 3,3 & 0 & 1,1 & 2 & 5,6 & 5 & 17,8 & 22 & 72,2 & 30 & 100,0 \\
\hline 353620 & Pariquera0Açu & D20 & 5 & 4,5 & 0 & 0,3 & 4 & 3,3 & 30 & 27,5 & 71 & 64,4 & 110 & 100,0 \\
\hline 353625 & Parisi & E20 & - & - & - & - & - & & 3 & 20,0 & 11 & 80,0 & 13 & 100,0 \\
\hline 353630 & Patrocínio Paulista & D20 & 4 & 5,7 & 1 & 1,0 & 2 & 2,6 & 16 & 24,2 & 43 & 66,5 & 65 & 100,0 \\
\hline 353640 & Paulicéia & E20 & 1 & 4,5 & 0 & 1,1 & 1 & 2,2 & 8 & 27,0 & 19 & 65,2 & 30 & 100,0 \\
\hline 353650 & Paulínia & B100 & 11 & 3,8 & 2 & 0,6 & 11 & 3,9 & 107 & 36,6 & 161 & 55,2 & 292 & 100,0 \\
\hline 353657 & Paulistânia & E20 & - & - & - & - & - & - & 6 & 42,2 & 9 & 57,8 & 15 & 100,0 \\
\hline 353660 & Paulo de Faria & E20 & 1 & 1,8 & 1 & 1,2 & 2 & 2,9 & 14 & 24,0 & 40 & 70,2 & 57 & 100,0 \\
\hline 353670 & Pederneiras & D50 & 7 & 2,8 & 1 & 0,5 & 5 & 2,0 & 69 & 28,1 & 164 & 66,5 & 247 & 100,0 \\
\hline 353680 & Pedra Bela & E20 & 3 & 6,3 & - & - & 0 & 0,8 & 10 & 23,4 & 30 & 69,5 & 43 & 100,0 \\
\hline 353690 & Pedranópolis & E20 & - & - & - & - & 0 & 1,8 & 5 & 27,3 & 13 & 70,9 & 18 & 100,0 \\
\hline 353700 & Pedregulho & D20 & 3 & 3,0 & 1 & 0,6 & 2 & 1,8 & 38 & 33,8 & 68 & 60,8 & 111 & 100,0 \\
\hline 353710 & Pedreira & B50 & 7 & 2,9 & 2 & 0,7 & 4 & 1,8 & 77 & 32,0 & 150 & 62,6 & 240 & 100,0 \\
\hline 353715 & Pedrinhas Paulista & A20 & 0 & 1,7 & 0 & 1,7 & - & - & 4 & 22,0 & 15 & 74,6 & 20 & 100,0 \\
\hline 353720 & Pedro de Toledo & E20 & 3 & 4,1 & 1 & 1,5 & 3 & 4,1 & 27 & 42,1 & 31 & 48,2 & 65 & 100,0 \\
\hline 353730 & Penápolis & D100 & 15 & 3,7 & 2 & 0,6 & 8 & 1,9 & 106 & 25,9 & 278 & 68,0 & 409 & 100,0 \\
\hline 353740 & Pereira Barreto & D50 & 6 & 3,1 & 0 & 0,2 & 3 & 1,6 & 57 & 31,4 & 116 & 63,6 & 182 & 100,0 \\
\hline 353750 & Pereiras & E20 & 1 & 1,9 & 1 & 1,2 & 1 & 1,2 & 10 & 18,5 & 42 & 77,2 & 54 & 100,0 \\
\hline 353760 & Peruíbe & D100 & 24 & 5,6 & 4 & 0,9 & 10 & 2,2 & 147 & 34,0 & 248 & 57,3 & 432 & 100,0 \\
\hline 353770 & Piacatu & E20 & 1 & 3,8 & 1 & 1,9 & 1 & 3,8 & 7 & 19,2 & 25 & 71,2 & 35 & 100,0 \\
\hline 353780 & Piedade & D100 & 13 & 3,8 & 2 & 0,6 & 10 & 2,8 & 102 & 29,1 & 224 & 63,7 & 351 & 100,0 \\
\hline 353790 & Pilar do Sul & E50 & 6 & 3,9 & 2 & 1,4 & 4 & 3,0 & 44 & 30,2 & 90 & 61,6 & 146 & 100,0 \\
\hline 353800 & Pindamonhangaba & B300 & 35 & 4,7 & 6 & 0,8 & 20 & 2,7 & 252 & 33,5 & 438 & 58,3 & 752 & 100,0 \\
\hline 353810 & Pindorama & E20 & 4 & 3,3 & - & - & 1 & 0,6 & 31 & 27,8 & 76 & 68,3 & 111 & 100,0 \\
\hline 353820 & Pinhalzinho & E20 & 2 & 1,8 & - & - & 1 & 1,5 & 23 & 24,8 & 66 & 71,9 & 91 & 100,0 \\
\hline 353830 & Piquerobi & E20 & - & - & - & - & - & - & 4 & 21,3 & 16 & 78,7 & 20 & 100,0 \\
\hline 353850 & Piquete & B20 & 4 & 3,6 & 0 & 0,3 & 1 & 0,9 & 36 & 31,8 & 71 & 63,5 & 112 & 100,0 \\
\hline 353860 & Piracaia & D50 & 8 & 4,7 & 1 & 0,8 & 3 & 1,8 & 48 & 28,4 & 109 & 64,3 & 169 & 100,0 \\
\hline 353870 & Piracicaba & B500 & 73 & 3,3 & 11 & 0,5 & 48 & 2,2 & 677 & 30,4 & 1415 & 63,6 & 2225 & 100,0 \\
\hline 353880 & Piraju & D50 & 5 & 2,2 & 0 & 0,1 & 3 & 1,4 & 63 & 27,4 & 159 & 68,8 & 231 & 100,0 \\
\hline 353890 & Pirajuí & D50 & 3 & 1,7 & 2 & 1,1 & 2 & 1,1 & 47 & 30,3 & 102 & 65,8 & 155 & 100,0 \\
\hline 353900 & Pirangi & E20 & 0 & 0,5 & - & - & 0 & 0,5 & 16 & 22,2 & 54 & 76,9 & 71 & 100,0 \\
\hline 353910 & Pirapora do Bom Jesus & D20 & 3 & 5,9 & 1 & 1,2 & 1 & 1,8 & 22 & 38,8 & 30 & 52,4 & 57 & 100,0 \\
\hline 353920 & Pirapozinho & D50 & 3 & 2,3 & 1 & 0,9 & 4 & 2,5 & 43 & 29,1 & 96 & 65,2 & 147 & 100,0 \\
\hline 353930 & Pirassununga & B100 & 9 & 2,0 & 2 & 0,4 & 6 & 1,4 & 142 & 31,1 & 297 & 65,0 & 456 & 100,0 \\
\hline 353940 & Piratininga & B20 & 1 & 1,4 & 1 & 1,4 & 1 & 1,0 & 18 & 26,1 & 48 & 70,0 & 69 & 100,0 \\
\hline 353950 & Pitangueiras & D50 & 9 & 5,1 & 2 & 0,9 & 4 & 2,4 & 62 & 33,5 & 107 & 58,2 & 184 & 100,0 \\
\hline 353960 & Planalto & E20 & - & - & - & - & 1 & 2,4 & 8 & 27,4 & 20 & 70,2 & 28 & 100,0 \\
\hline 353970 & Platina & E20 & 1 & 3,5 & - & - & 0 & 1,8 & 6 & 29,8 & 12 & 64,9 & 19 & 100,0 \\
\hline 353980 & Poá & B300 & 25 & 4,4 & 4 & 0,7 & 15 & 2,7 & 208 & 37,1 & 310 & 55,2 & 561 & 100,0 \\
\hline 353990 & Poloni & E20 & 1 & 1,6 & - & - & 0 & 0,8 & 11 & 26,8 & 29 & 70,7 & 41 & 100,0 \\
\hline 354000 & Pompéia & C20 & 5 & 3,6 & 0 & 0,2 & 2 & 1,4 & 35 & 24,8 & 98 & 69,9 & 140 & 100,0 \\
\hline 354010 & Pongaí & E20 & 1 & 4,1 & - & - & - & - & 7 & 28,8 & 16 & 67,1 & 24 & 100,0 \\
\hline 354020 & Pontal & D50 & 9 & 4,8 & 3 & 1,6 & 7 & 3,5 & 76 & 40,4 & 94 & 49,7 & 188 & 100,0 \\
\hline 354025 & Pontalinda & E20 & 1 & 3,0 & - & - & 1 & 3,0 & 4 & 18,2 & 17 & 75,8 & 22 & 100,0 \\
\hline 354030 & Pontes Gestal & E20 & 0 & 2,1 & - & - & 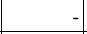 & & 6 & 38,3 & 9 & 59,6 & 16 & 100,0 \\
\hline 354040 & Populina & E20 & 1 & 2,1 & - & - & 0 & 1,1 & 8 & 26,3 & 22 & 70,5 & 32 & 100,0 \\
\hline 354050 & Porangaba & E20 & 1 & 2,6 & - & - & 1 & 1,9 & 17 & 32,1 & 33 & 63,5 & 52 & 100,0 \\
\hline 354060 & Porto Feliz & C50 & 8 & 2,8 & 2 & 0,7 & 6 & 1,9 & 81 & 27,8 & 196 & 66,8 & 293 & 100,0 \\
\hline 354070 & Porto Ferreira & C100 & 11 & 3,6 & 3 & 0,8 & 5 & 1,6 & 97 & 30,7 & 200 & 63,3 & 316 & 100,0 \\
\hline 354075 & Potim & E20 & 4 & 3,9 & 0 & 0,3 & 2 & 1,6 & 47 & 45,9 & 49 & 48,2 & 102 & 100,0 \\
\hline 354080 & Potirendaba & E20 & 2 & 2,4 & - & - & 1 & 1,0 & 22 & 23,0 & 70 & 73,5 & 96 & 100,0 \\
\hline 354085 & Pracinha & E20 & 1 & 6,7 & 1 & 4,4 & -1 & - & 6 & 42,2 & 7 & 46,7 & 15 & 100,0 \\
\hline 354090 & Pradópolis & D20 & 3 & 5,0 & 0 & 0,5 & 1 & 1,5 & 21 & 31,7 & 41 & 61,4 & 67 & 100,0 \\
\hline 354100 & Praia Grande & B300 & 74 & 5,3 & 10 & 0,7 & 46 & 3,3 & 517 & 37,2 & 745 & 53,5 & 1392 & 100,0 \\
\hline 354105 & Pratânia & E20 & 1 & 4,2 & 0 & 1,0 & - & - & 13 & 41,7 & 17 & 53,1 & 32 & 100,0 \\
\hline 354110 & Presidente Alves & E20 & 0 & 1,3 & - & - & - & - & 7 & 26,3 & 19 & 72,5 & 27 & 100,0 \\
\hline
\end{tabular}


Anexo 12 - Mortalidade proporcional (\%)por faixa etária selecionada segundo município e Estrato de Vulnerabilidade Social .Estado de São Paulo, media do triênio 2003 a 2005

\begin{tabular}{|c|c|c|c|c|c|c|c|c|c|c|c|c|c|c|}
\hline IBGE & MUNICIPIO & Status & $<01$ ano & $\%$ & $.01-04$ & $\%$ & $.05-19$ & $\% \quad 2$ & 20-59 & $\%$ & $60 \mathrm{e}+$ & $\%$ & Total & $\%$ \\
\hline 354120 & Presidente Bernardes & D20 & 3 & 2,8 & 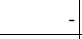 & & 1 & 0,6 & 27 & 25,1 & 76 & 71,5 & 106 & 100,0 \\
\hline 354130 & Presidente Epitácio & D50 & 9 & 3,4 & 2 & 0,9 & 5 & 1,7 & 90 & 33,0 & 166 & 61,0 & 273 & 100,0 \\
\hline 354140 & Presidente Prudente & B300 & 38 & 3,0 & 5 & 0,4 & 25 & 1,9 & 367 & 28,8 & 838 & 65,9 & 1273 & 100,0 \\
\hline 354150 & Presidente Venceslau & D50 & 7 & 2,6 & 1 & 0,5 & 4 & 1,6 & 78 & 28,9 & 180 & 66,4 & 271 & 100,0 \\
\hline 354160 & Promissao & D50 & 7 & 3,0 & 1 & 0,4 & 4 & 1,7 & 75 & 31,6 & 150 & 63,3 & 236 & 100,0 \\
\hline 354165 & Quadra & E20 & - & - & - & - & 0 & 2,8 & 4 & 30,6 & 8 & 66,7 & 12 & 100,0 \\
\hline 354170 & Quatá & D20 & 4 & 5,3 & 1 & 0,9 & 1 & 0,9 & 20 & 26,5 & 50 & 66,4 & 75 & 100,0 \\
\hline 354180 & Queiroz & E20 & 1 & 5,9 & - & - & - & - & 6 & 33,3 & 10 & 60,8 & 17 & 100,0 \\
\hline 354190 & Queluz & D20 & 6 & 9,2 & 0 & 0,5 & 1 & 1,5 & 21 & 32,1 & 37 & 56,6 & 65 & 100,0 \\
\hline 354200 & Quintana & E20 & 1 & 2,6 & - & - & 1 & 2,6 & 11 & 29,8 & 25 & 64,9 & 38 & 100,0 \\
\hline 354210 & Rafard & A20 & 2 & 2,9 & 0 & 0,6 & 1 & 1,7 & 14 & 24,4 & 40 & 70,3 & 57 & 100,0 \\
\hline 354220 & Rancharia & D50 & 7 & 3,2 & 1 & 0,6 & 3 & 1,4 & 60 & 27,9 & 145 & 66,9 & 216 & 100,0 \\
\hline 354230 & Redençao da Serra & E20 & 1 & 3,0 & - & - & 0 & 1,5 & 5 & 23,9 & 16 & 71,6 & 22 & 100,0 \\
\hline 354240 & Regente Feijó & D20 & 3 & 2,5 & 1 & 0,6 & 1 & 0,6 & 36 & 29,9 & 79 & 66,5 & 119 & 100,0 \\
\hline 354250 & Reginópolis & E20 & 0 & 0,9 & 0 & 0,9 & 0 & 0,9 & 8 & 20,7 & 30 & 76,7 & 39 & 100,0 \\
\hline 354260 & Registro & D100 & 13 & 4,1 & 3 & 1,1 & 8 & 2,7 & 102 & 32,6 & 187 & 59,6 & 314 & 100,0 \\
\hline 354270 & Restinga & E20 & 2 & 6,8 & 0 & 1,1 & 0 & 1,1 & 12 & 39,8 & 15 & 51,1 & 29 & 100,0 \\
\hline 354280 & Ribeira & E20 & 4 & 16,4 & 0 & 1,4 & 0 & 1,4 & 5 & 21,9 & 14 & 58,9 & 24 & 100,0 \\
\hline 354290 & Ribeirao Bonito & D20 & 3 & 3,8 & - & - & 1 & 1,9 & 20 & 28,6 & 47 & 65,7 & 71 & 100,0 \\
\hline 354300 & Ribeirao Branco & E50 & 8 & 6,4 & 2 & 1,9 & 6 & 5,0 & 40 & 33,6 & 64 & 53,1 & 120 & 100,0 \\
\hline 354310 & Ribeirao Corrente & E20 & 1 & 4,6 & 0 & 1,5 & 0 & 1,5 & 9 & 41,5 & 11 & 50,8 & 22 & 100,0 \\
\hline 354320 & Ribeirao do Sul & E20 & 0 & 1,1 & - & - & 0 & 1,1 & 8 & 28,4 & 20 & 69,3 & 29 & 100,0 \\
\hline 354323 & Ribeirao dos Indios & E20 & - & - & - & - & 0 & 2,3 & 2 & 14,0 & 12 & 83,7 & 14 & 100,0 \\
\hline 354325 & Ribeirao Grande & E20 & 2 & 6,3 & - & - & 1 & 1,8 & 12 & 33,3 & 22 & 58,6 & 37 & 100,0 \\
\hline 354330 & Ribeirao Pires & B300 & 24 & 4,1 & 3 & 0,4 & 12 & 2,0 & 209 & 34,9 & 351 & 58,5 & 599 & 100,0 \\
\hline 354340 & Ribeirao Preto & B1000 & 74 & 2,3 & 16 & 0,5 & 55 & 1,7 & 1011 & 31,0 & 2102 & 64,5 & 3258 & 100,0 \\
\hline 354360 & Rifaina & D20 & 1 & 5,6 & - & - & 0 & 1,9 & 4 & 24,1 & 12 & 68,5 & 18 & 100,0 \\
\hline 354370 & Rincao & D20 & 2 & 3,5 & - & - & 2 & 2,5 & 18 & 27,2 & 45 & 66,8 & 67 & 100,0 \\
\hline 354380 & Rinópolis & E20 & 2 & 3,0 & - & - & 1 & 1,0 & 14 & 20,3 & 51 & 75,7 & 67 & 100,0 \\
\hline 354390 & Rio Claro & B300 & 25 & 2,0 & 4 & 0,3 & 22 & 1,7 & 374 & 29,8 & 828 & 66,1 & 1253 & 100,0 \\
\hline 354400 & Rio das Pedras & C50 & 7 & 5,1 & 2 & 1,3 & 5 & 3,8 & 48 & 36,1 & 71 & 53,8 & 132 & 100,0 \\
\hline 354410 & Rio Grande da Serra & C50 & 12 & 6,3 & 2 & 0,9 & 6 & 3,2 & 86 & 46,2 & 81 & 43,5 & 186 & 100,0 \\
\hline 354420 & Riolândia & E20 & 1 & 1,7 & 1 & 1,7 & 0 & 0,6 & 21 & 34,8 & 37 & 61,3 & 60 & 100,0 \\
\hline 354350 & Riversul & E20 & 3 & 4,4 & - & - & 2 & 3,3 & 19 & 30,8 & 37 & 61,5 & 61 & 100,0 \\
\hline 354425 & Rosana & C50 & 5 & 5,6 & 1 & 0,7 & 3 & 3,7 & 29 & 32,6 & 52 & 57,4 & 90 & 100,0 \\
\hline 354430 & Roseira & $\mathrm{C} 20$ & 3 & 5,6 & - & - & 1 & 1,3 & 19 & 35,6 & 31 & 57,5 & 53 & 100,0 \\
\hline 354440 & Rubiácea & E20 & 1 & 4,9 & 0 & 2,4 & 0 & 2,4 & 5 & 34,1 & 8 & 56,1 & 14 & 100,0 \\
\hline 354450 & Rubinéia & D20 & 0 & 2,0 & - & - & - & - & 4 & 24,5 & 12 & 73,5 & 16 & 100,0 \\
\hline 354460 & Sabino & E20 & 1 & 3,6 & - & - & 1 & 1,8 & 9 & 23,2 & 27 & 71,4 & 37 & 100,0 \\
\hline 354470 & Sagres & E20 & 0 & 2,4 & 0 & 2,4 & 0 & 2,4 & 4 & 31,0 & 9 & 61,9 & 14 & 100,0 \\
\hline 354480 & Sales & E20 & 1 & 2,4 & 0 & 0,8 & 2 & 4,8 & 12 & 29,8 & 26 & 62,1 & 41 & 100,0 \\
\hline 354490 & Sales Oliveira & B20 & 1 & 1,9 & 0 & 0,6 & 1 & 2,6 & 13 & 24,4 & 37 & 70,5 & 52 & 100,0 \\
\hline 354500 & Salesópolis & E20 & 3 & 3,1 & 1 & 0,9 & 3 & 2,8 & 27 & 25,2 & 73 & 67,9 & 107 & 100,0 \\
\hline 354510 & Salmourao & E20 & 1 & 3,1 & - & - & 1 & 2,1 & 8 & 24,7 & 23 & 70,1 & 32 & 100,0 \\
\hline 354515 & Saltinho & B20 & 0 & 1,1 & 0 & 1,1 & 0 & 1,1 & 7 & 21,3 & 24 & 75,5 & 31 & 100,0 \\
\hline 354520 & Salto & B300 & 16 & 2,7 & 4 & 0,7 & 17 & 2,9 & 202 & 34,3 & 350 & 59,3 & 590 & 100,0 \\
\hline 354530 & Salto de Pirapora & D50 & 8 & 3,2 & 0 & 0,1 & 6 & 2,5 & 90 & 37,3 & 137 & 56,9 & 241 & 100,0 \\
\hline 354540 & Salto Grande & E20 & 1 & 0,9 & 1 & 1,4 & 3 & 4,1 & 25 & 33,8 & 44 & 59,8 & 73 & 100,0 \\
\hline 354550 & Sandovalina & E20 & 1 & 5,9 & - & - & 1 & 3,9 & 4 & 21,6 & 12 & 68,6 & 17 & 100,0 \\
\hline 354560 & Santa Adélia & D20 & 4 & 3,6 & 0 & 0,3 & - & - & 24 & 23,8 & 74 & 72,3 & 102 & 100,0 \\
\hline 354570 & Santa Albertina & E20 & 1 & 1,8 & - & - & - & - & 11 & 20,4 & 43 & 77,8 & 56 & 100,0 \\
\hline 354580 & Santa Bárbara d'Oeste & B300 & 29 & 3,2 & 7 & 0,8 & 20 & 2,2 & 314 & 34,9 & 530 & 58,9 & 900 & 100,0 \\
\hline 354600 & Santa Branca & D20 & 4 & 5,2 & 0 & 0,4 & 1 & 1,7 & 23 & 29,9 & 48 & 62,8 & 77 & 100,0 \\
\hline 354610 & Santa Clara d'Oeste & E20 & 1 & 3,6 & - & $\theta$ & 4 & - & 3 & 18,2 & 14 & 78,2 & 18 & 100,0 \\
\hline 354620 & Santa Cruz da Conceiçao & B20 & - & - & - & - & - & - & 5 & 28,1 & 14 & 71,9 & 19 & 100,0 \\
\hline 354625 & Santa Cruz da Esperança & E20 & 0 & 2,8 & - & - & 1 & 5,6 & 2 & 13,9 & 9 & 77,8 & 12 & 100,0 \\
\hline 354630 & Santa Cruz das Palmeiras & D50 & 8 & 4,5 & 2 & 1,0 & 3 & 2,0 & 54 & 31,8 & 103 & 60,8 & 170 & 100,0 \\
\hline 354640 & Santa Cruz do Rio Pardo & C50 & 10 & 3,2 & 1 & 0,3 & 4 & 1,2 & 85 & 28,2 & 203 & 67,0 & 302 & 100,0 \\
\hline
\end{tabular}


Anexo 12 - Mortalidade proporcional (\%)por faixa etária selecionada segundo município e Estrato de Vulnerabilidade Social .Estado de São Paulo, media do triênio 2003 a 2005

\begin{tabular}{|c|c|c|c|c|c|c|c|c|c|c|c|c|c|c|}
\hline IBGE & MUNICIPIO & Status & $<01$ ano & $\%$ & $.01-04$ & $\%$ & $.05-19$ & $\%$ & 20-59 & $\%$ & $60 e+$ & $\%$ & Total & $\%$ \\
\hline 354650 & Santa Ernestina & B20 & 2 & 6,8 & 1 & 2,3 & -1 & & 10 & 33,0 & 17 & 58,0 & 29 & 100,0 \\
\hline 354660 & Santa Fé do Sul & D50 & 2 & 1,1 & - & - & 3 & 1,5 & 45 & 22,0 & 154 & 75,4 & 205 & 100,0 \\
\hline 354670 & Santa Gertrudes & $\mathrm{C} 20$ & 3 & 3,0 & 0 & 0,4 & 1 & 1,1 & 23 & 26,1 & 61 & 69,3 & 88 & 100,0 \\
\hline 354680 & Santa Isabel & D50 & 17 & 6,0 & 2 & 0,6 & 5 & 1,8 & 93 & 32,3 & 172 & 59,3 & 289 & 100,0 \\
\hline 354690 & Santa Lúcia & E20 & 2 & 4,5 & 1 & 1,5 & 1 & 2,3 & 18 & 41,4 & 22 & 50,4 & 44 & 100,0 \\
\hline 354700 & Santa Maria da Serra & E20 & 1 & 3,0 & 0 & 1,0 & 1 & 4,0 & 11 & 34,3 & 19 & 57,6 & 33 & 100,0 \\
\hline 354710 & Santa Mercedes & E20 & 0 & 1,8 & - & - & 0 & 1,8 & 4 & 23,6 & 13 & 72,7 & 18 & 100,0 \\
\hline 354750 & Santa Rita do Passa Quatr & B50 & 5 & 2,5 & - & - & 3 & 1,2 & 50 & 22,9 & 159 & 73,4 & 217 & 100,0 \\
\hline 354740 & Santa Rita d'Oeste & E20 & - & - & - & - & - & & 4 & 19,4 & 18 & 80,6 & 22 & 100,0 \\
\hline 354760 & Santa Rosa de Viterbo & D50 & 5 & 3,7 & - & - & 2 & 1,5 & 44 & 32,3 & 85 & 62,6 & 135 & 100,0 \\
\hline 354765 & Santa Salete & E20 & - & - & - & - & - & - & 2 & 22,2 & 7 & 77,8 & 9 & 100,0 \\
\hline 354720 & Santana da Ponte Pensa & E20 & 0 & 2,1 & - & - & - & - & 3 & 21,3 & 12 & 76,6 & 16 & 100,0 \\
\hline 354730 & Santana de Parnaíba & C100 & 10 & 3,1 & 3 & 0,8 & 12 & 3,7 & 138 & 43,1 & 158 & 49,2 & 321 & 100,0 \\
\hline 354770 & Santo Anastácio & E50 & 3 & 2,3 & 0 & 0,2 & 2 & 1,6 & 40 & 27,4 & 99 & 68,5 & 145 & 100,0 \\
\hline 354780 & Santo André & A1000 & 117 & 2,7 & 22 & 0,5 & 84 & 1,9 & 1365 & 31,3 & 2776 & 63,6 & 4363 & 100,0 \\
\hline 354790 & Santo Antônio da Alegria & E20 & 1 & 2,6 & 0 & 0,9 & 0 & 0,9 & 9 & 24,1 & 28 & 71,6 & 39 & 100,0 \\
\hline 354800 & Santo Antônio de Posse & D20 & 5 & 4,4 & 2 & 1,6 & 5 & 3,8 & 44 & 36,0 & 66 & 54,1 & 121 & 100,0 \\
\hline 354805 & Santo Antônio do Aracangu & E20 & 2 & 5,5 & - & - & 0 & 1,1 & 9 & 29,7 & 19 & 63,7 & 30 & 100,0 \\
\hline 354810 & Santo Antônio do Jardim & E20 & 1 & 1,8 & 0 & 0,9 & 0 & 0,9 & 10 & 27,7 & 26 & 68,8 & 37 & 100,0 \\
\hline 354820 & Santo Antônio do Pinhal & E20 & 2 & 4,3 & 0 & 0,9 & 1 & 2,6 & 11 & 27,6 & 25 & 64,7 & 39 & 100,0 \\
\hline 354830 & Santo Expedito & E20 & 0 & 1,8 & - & - & - & - & 5 & 25,0 & 14 & 73,2 & 19 & 100,0 \\
\hline 354840 & Santópolis do Aguapeí & E20 & 2 & 6,7 & 0 & 1,3 & - & - & 8 & 33,3 & 15 & 58,7 & 25 & 100,0 \\
\hline 354850 & Santos & A500 & 83 & 2,2 & 8 & 0,2 & 43 & 1,1 & 930 & 24,0 & 2808 & 72,5 & 3872 & 100,0 \\
\hline 354860 & Sao Bento do Sapucaí & D20 & 3 & 3,7 & 0 & 0,4 & 1 & 1,2 & 21 & 26,4 & 55 & 68,2 & 81 & 100,0 \\
\hline 354870 & Sao Bernardo do Campo & B1000 & 142 & 3,8 & 23 & 0,6 & 124 & 3,3 & 1368 & 36,8 & 2059 & 55,4 & 3717 & 100,0 \\
\hline 354880 & Sao Caetano do Sul & A300 & 15 & 1,1 & 2 & 0,2 & 12 & 0,9 & 284 & 20,3 & 1083 & 77,5 & 1397 & 100,0 \\
\hline 354890 & Sao Carlos & B300 & 25 & 2,0 & 4 & 0,3 & 19 & 1,5 & 369 & 29,4 & 836 & 66,7 & 1253 & 100,0 \\
\hline 354900 & Sao Francisco & E20 & 0 & 1,6 & - & - & 1 & 4,9 & 4 & 21,3 & 15 & 72,1 & 20 & 100,0 \\
\hline 354910 & Sao Joao da Boa Vista & B100 & 15 & 2,6 & 2 & 0,3 & 7 & 1,2 & 150 & 25,5 & 416 & 70,5 & 590 & 100,0 \\
\hline 354920 & Sao Joao das Duas Pontes & E20 & 1 & 3,4 & - & - & - & - & 6 & 32,2 & 13 & 64,4 & 20 & 100,0 \\
\hline 354925 & Sao Joao de Iracema & E20 & - & - & - & - & 0 & 3,3 & 3 & 33,3 & 6 & 63,3 & 10 & 100,0 \\
\hline 354930 & Sao Joao do Pau d'Alho & E20 & - & - & - & - & - & - & 4 & 25,0 & 13 & 75,0 & 17 & 100,0 \\
\hline 354940 & Sao Joaquim da Barra & C50 & 11 & 3,6 & 2 & 0,7 & 5 & 1,7 & 87 & 29,3 & 193 & 64,8 & 298 & 100,0 \\
\hline 354950 & Sao José da Bela Vista & E20 & 4 & 7,3 & - & - & 1 & 2,7 & 18 & 36,7 & 27 & 53,3 & 50 & 100,0 \\
\hline 354960 & Sao José do Barreiro & E20 & 1 & 3,2 & - & - & 1 & 3,2 & 10 & 32,6 & 19 & 61,1 & 32 & 100,0 \\
\hline 354970 & Sao José do Rio Pardo & D100 & 10 & 2,9 & 1 & 0,2 & 8 & 2,3 & 83 & 23,5 & 252 & 71,1 & 355 & 100,0 \\
\hline 354980 & Sao José do Rio Preto & B500 & 57 & 2,3 & 9 & 0,4 & 44 & 1,8 & 681 & 27,7 & 1667 & 67,8 & 2458 & 100,0 \\
\hline 354990 & Sao José dos Campos & B1000 & 104 & 3,8 & 18 & 0,7 & 82 & 3,0 & 998 & 36,3 & 1549 & 56,3 & 2751 & 100,0 \\
\hline 354995 & Sao Lourenço da Serra & E20 & 2 & 3,0 & 1 & 0,9 & 1 & 1,7 & 29 & 38,3 & 43 & 56,1 & 77 & 100,0 \\
\hline 355000 & Sao Luís do Paraitinga & E20 & 2 & 2,8 & 1 & 0,9 & 1 & 1,9 & 19 & 27,1 & 48 & 67,3 & 71 & 100,0 \\
\hline 355010 & Sao Manuel & D50 & 7 & 2,5 & 2 & 0,8 & 3 & 1,3 & 77 & 29,1 & 176 & 66,3 & 265 & 100,0 \\
\hline 355020 & Sao Miguel Arcanjo & E50 & 10 & 5,6 & 0 & 0,2 & 5 & 2,6 & 47 & 26,4 & 117 & 65,2 & 179 & 100,0 \\
\hline 355030 & Sao Paulo & B10000 & 2503 & 3,8 & 398 & 0,6 & 1667 & 2,5 & 21510 & 32,4 & 40317 & 60,7 & 66396 & 100,0 \\
\hline 355040 & Sao Pedro & B50 & 6 & 2,4 & 0 & 0,1 & 4 & 1,5 & 59 & 24,8 & 168 & 71,1 & 237 & 100,0 \\
\hline 355050 & Sao Pedro do Turvo & E20 & 1 & 2,6 & 1 & 1,7 & 0 & 0,9 & 11 & 27,4 & 26 & 67,5 & 39 & 100,0 \\
\hline 355060 & Sao Roque & B100 & 15 & 3,3 & 3 & 0,6 & 10 & 2,2 & 145 & 30,9 & 297 & 63,1 & 470 & 100,0 \\
\hline 355070 & Sao Sebastiao & C100 & 21 & 6,0 & 4 & 1,2 & 18 & 5,1 & 140 & 40,9 & 161 & 46,8 & 343 & 100,0 \\
\hline 355080 & Sao Sebastiao da Grama & E20 & 4 & 4,6 & 0 & 0,4 & 1 & 0,7 & 25 & 26,9 & 64 & 67,5 & 94 & 100,0 \\
\hline 355090 & Sao Simao & B20 & 2 & 2,3 & 1 & 0,7 & 1 & 1,0 & 26 & 26,2 & 69 & 69,8 & 99 & 100,0 \\
\hline 355100 & Sao Vicente & B500 & 116 & 5,5 & 13 & 0,6 & 53 & 2,5 & 747 & 35,2 & 1192 & 56,2 & 2120 & 100,0 \\
\hline 355110 & Sarapuí & E20 & 3 & 5,7 & - & & 1 & 2,3 & 16 & 27,3 & 38 & 64,8 & 59 & 100,0 \\
\hline 355120 & Sarutaiá & E20 & 2 & 4,6 & 0 & 0,8 & 0 & 0,8 & 6 & 13,7 & 35 & 80,2 & 44 & 100,0 \\
\hline 355130 & Sebastianópolis do Sul & E20 & 1 & 4,7 & - & - & - & - & 4 & 30,2 & 9 & 65,1 & 14 & 100,0 \\
\hline 355140 & Serra Azul & E20 & 1 & 2,5 & 1 & 1,2 & 1 & 1,2 & 22 & 41,6 & 29 & 53,4 & 54 & 100,0 \\
\hline 355160 & Serra Negra & D50 & 4 & 2,0 & 0 & 0,2 & 3 & 1,3 & 48 & 23,8 & 147 & 72,7 & 202 & 100,0 \\
\hline 355150 & Serrana & C50 & 9 & 5,2 & 1 & 0,6 & 8 & 4,8 & 63 & 36,5 & 92 & 53,0 & 174 & 100,0 \\
\hline 355170 & Sertaozinho & C300 & 15 & 2,7 & 2 & 0,4 & 12 & 2,1 & 192 & 34,3 & 339 & 60,6 & 560 & 100,0 \\
\hline 355180 & Sete Barras & E20 & 2 & 3,0 & 1 & 1,3 & 3 & 3,4 & 22 & 28,0 & 50 & 64,2 & 77 & 100,0 \\
\hline
\end{tabular}


Anexo 12 - Mortalidade proporcional (\%)por faixa etária selecionada segundo município e Estrato de Vulnerabilidade Social .Estado de São Paulo, media do triênio 2003 a 2005

\begin{tabular}{|c|c|c|c|c|c|c|c|c|c|c|c|c|c|c|}
\hline IBGE & MUNICIPIO & Status & $<01$ ano & $\%$ & $.01-04$ & $\%$ & $.05-19$ & $\%$ & 20-59 & $\%$ & $60 e+$ & $\%$ & Total & $\%$ \\
\hline 355190 & Severínia & E20 & 2 & 2,9 & 1 & 1,0 & 3 & 3,8 & 26 & 37,1 & 39 & 55,2 & 70 & 100,0 \\
\hline 355200 & Silveiras & E20 & 2 & 5,1 & - & - & 1 & 3,0 & 7 & 22,2 & 23 & 69,7 & 33 & 100,0 \\
\hline 355210 & Socorro & D50 & 8 & 2,9 & 1 & 0,3 & 4 & 1,3 & 68 & 23,7 & 207 & 71,8 & 288 & 100,0 \\
\hline 355220 & Sorocaba & B1000 & 118 & 3,6 & 16 & 0,5 & 95 & 2,9 & 1050 & 31,7 & 2032 & 61,4 & 3311 & 100,0 \\
\hline 355230 & Sud Mennucci & E20 & 2 & 5,7 & 0 & 0,8 & 0 & 0,8 & 10 & 23,6 & 28 & 69,1 & 41 & 100,0 \\
\hline 355240 & Sumaré & C300 & 38 & 3,9 & 7 & 0,7 & 37 & 3,8 & 397 & 40,9 & 492 & 50,7 & 972 & 100,0 \\
\hline 355255 & Suzanápolis & E20 & 2 & 6,8 & - & - & 0 & 1,4 & 6 & 26,0 & 16 & 65,8 & 24 & 100,0 \\
\hline 355250 & Suzano & C300 & 86 & 6,4 & 8 & 0,6 & 39 & 2,9 & 539 & 40,2 & 667 & 49,8 & 1338 & 100,0 \\
\hline 355260 & Tabapua & E20 & 1 & 1,4 & 1 & 1,0 & 1 & 1,0 & 25 & 26,0 & 68 & 70,6 & 96 & 100,0 \\
\hline 355270 & Tabatinga & E20 & 3 & 3,4 & - & - & 2 & 2,6 & 29 & 33,1 & 54 & 60,9 & 89 & 100,0 \\
\hline 355280 & Taboao da Serra & C300 & 65 & 5,4 & 10 & 0,8 & 51 & 4,2 & 540 & 44,4 & 549 & 45,2 & 1215 & 100,0 \\
\hline 355290 & Taciba & E20 & 1 & 3,0 & 0 & 1,0 & 1 & 2,0 & 9 & 27,3 & 22 & 66,7 & 33 & 100,0 \\
\hline 355300 & Taguaí & E20 & 0 & 0,7 & - & - & 2 & 3,4 & 11 & 21,5 & 37 & 74,5 & 50 & 100,0 \\
\hline 355310 & Taiaçu & E20 & 1 & 2,1 & - & - & - & - & 7 & 23,4 & 23 & 74,5 & 31 & 100,0 \\
\hline 355320 & Taiúva & E20 & 1 & 2,2 & - & - & 1 & 2,9 & 11 & 24,8 & 32 & 70,1 & 46 & 100,0 \\
\hline 355330 & Tambaú & D50 & 5 & 3,6 & 0 & 0,2 & 3 & 2,0 & 43 & 28,6 & 98 & 65,6 & 149 & 100,0 \\
\hline 355340 & Tanabi & D50 & 3 & 2,0 & 0 & 0,2 & 3 & 1,8 & 36 & 21,3 & 127 & 74,8 & 170 & 100,0 \\
\hline 355350 & Tapiraí & E20 & 1 & 2,9 & - & - & 1 & 2,2 & 16 & 34,6 & 27 & 60,3 & 45 & 100,0 \\
\hline 355360 & Tapiratiba & D20 & 2 & 1,9 & - & - & 2 & 1,9 & 23 & 25,9 & 62 & 70,3 & 89 & 100,0 \\
\hline 355365 & Taquaral & E20 & 1 & 5,7 & - & - & - & - & 7 & 39,6 & 10 & 54,7 & 18 & 100,0 \\
\hline 355370 & Taquaritinga & D100 & 11 & 3,2 & 1 & 0,4 & 6 & 1,8 & 101 & 28,5 & 233 & 66,1 & 353 & 100,0 \\
\hline 355380 & Taquarituba & E50 & 5 & 3,5 & 1 & 0,4 & 4 & 2,4 & 49 & 31,5 & 96 & 62,2 & 154 & 100,0 \\
\hline 355385 & Taquarivaí & E20 & 2 & 7,5 & 0 & 1,5 & 1 & 4,5 & 9 & 40,3 & 10 & 46,3 & 22 & 100,0 \\
\hline 355390 & Tarabaí & E20 & 1 & 3,5 & - & - & 1 & 2,7 & 12 & 32,7 & 23 & 61,1 & 38 & 100,0 \\
\hline 355395 & Taruma & D20 & 2 & 3,1 & 1 & 1,0 & 1 & 1,0 & 20 & 30,6 & 41 & 64,2 & 64 & 100,0 \\
\hline 355400 & Tatuí & C300 & 25 & 3,5 & 4 & 0,6 & 16 & 2,2 & 209 & 29,7 & 449 & 63,9 & 703 & 100,0 \\
\hline 355410 & Taubaté & B300 & 63 & 4,0 & 4 & 0,2 & 36 & 2,3 & 517 & 32,5 & 973 & 61,1 & 1593 & 100,0 \\
\hline 355420 & Tejupá & E20 & 3 & 7,7 & 0 & 1,0 & 1 & 2,9 & 13 & 37,5 & 18 & 51,0 & 35 & 100,0 \\
\hline 355430 & Teodoro Sampaio & D50 & 5 & 3,9 & - & - & 1 & 1,1 & 39 & 32,5 & 75 & 62,5 & 120 & 100,0 \\
\hline 355440 & Terra Roxa & E20 & 0 & 0,7 & 1 & 1,3 & 1 & 2,7 & 15 & 30,9 & 32 & 64,4 & 50 & 100,0 \\
\hline 355450 & Tietê & B50 & 5 & 2,3 & 3 & 1,3 & 5 & 2,2 & 66 & 28,7 & 150 & 65,5 & 229 & 100,0 \\
\hline 355460 & Timburi & E20 & 1 & 3,1 & 0 & 1,5 & 0 & 1,5 & 5 & 24,6 & 15 & 69,2 & 22 & 100,0 \\
\hline 355465 & Torre de Pedra & E20 & 0 & 1,8 & - & - & 0 & 1,8 & 6 & 30,4 & 12 & 66,1 & 19 & 100,0 \\
\hline 355470 & Torrinha & E20 & 2 & 2,5 & - & - & 0 & 0,5 & 14 & 21,2 & 50 & 75,8 & 66 & 100,0 \\
\hline 355475 & Trabiju & E20 & - & - & - & - & 0 & 4,2 & 2 & 25,0 & 6 & 70,8 & 8 & 100,0 \\
\hline 355480 & Tremembé & B50 & 11 & 5,9 & 0 & 0,2 & 3 & 1,6 & 68 & 35,5 & 109 & 56,8 & 191 & 100,0 \\
\hline 355490 & Três Fronteiras & E20 & 1 & 3,8 & - & - & 0 & 1,0 & 6 & 17,1 & 27 & 78,1 & 35 & 100,0 \\
\hline 355495 & Tuiuti & E20 & 1 & 1,8 & - & - & 1 & 1,8 & 11 & 29,1 & 25 & 67,3 & 37 & 100,0 \\
\hline 355500 & Tupa & D100 & 14 & 2,6 & 1 & 0,3 & 8 & 1,5 & 137 & 25,8 & 370 & 69,8 & 530 & 100,0 \\
\hline 355510 & Tupi Paulista & D20 & 2 & 1,8 & 1 & 0,6 & 1 & 0,9 & 22 & 19,2 & 87 & 77,5 & 113 & 100,0 \\
\hline 355520 & Turiúba & E20 & 0 & 3,1 & - & - & - & - & 3 & 25,0 & 8 & 71,9 & 11 & 100,0 \\
\hline 355530 & Turmalina & E20 & 1 & 4,4 & - & - & 0 & 2,2 & 4 & 24,4 & 10 & 68,9 & 15 & 100,0 \\
\hline 355535 & Ubarana & E20 & 1 & 4,3 & - & - & 1 & 2,9 & 8 & 35,7 & 13 & 57,1 & 23 & 100,0 \\
\hline 355540 & Ubatuba & C100 & 22 & 5,5 & 3 & 0,8 & 11 & 2,8 & 165 & 41,3 & 198 & 49,7 & 399 & 100,0 \\
\hline 355550 & Ubirajara & E20 & 0 & 1,1 & - & - & 0 & 1,1 & 12 & 39,6 & 18 & 58,2 & 30 & 100,0 \\
\hline 355560 & Uchoa & D20 & 1 & 1,4 & 0 & 0,5 & 1 & 1,4 & 12 & 17,2 & 57 & 79,5 & 72 & 100,0 \\
\hline 355570 & Uniao Paulista & E20 & 1 & 11,1 & - & - & - & - & 2 & 33,3 & 3 & 55,6 & 6 & 100,0 \\
\hline 355580 & Urânia & E20 & 2 & 2,8 & - & - & 1 & 0,9 & 16 & 22,6 & 53 & 73,7 & 72 & 100,0 \\
\hline 355590 & Uru & E20 & 0 & 2,4 & - & - & - & - & 5 & 38,1 & 8 & 59,5 & 14 & 100,0 \\
\hline 355600 & Urupês & E20 & 3 & 3,1 & - & - & 0 & 0,3 & 22 & 23,0 & 70 & 73,5 & 96 & 100,0 \\
\hline 355610 & Valentim Gentil & D20 & 1 & 2,2 & - & - & 1 & 1,7 & 16 & 26,7 & 42 & 69,4 & 60 & 100,0 \\
\hline 355620 & Valinhos & B100 & 8 & 1,6 & 2 & 0,5 & 7 & 1,4 & 139 & 28,7 & 328 & 67,8 & 484 & 100,0 \\
\hline 355630 & Valparaíso & D20 & 5 & 4,3 & 1 & 0,5 & 3 & 2,2 & 40 & 32,9 & 74 & 60,1 & 123 & 100,0 \\
\hline 355635 & Vargem & E20 & 2 & 3,4 & 0 & 0,7 & 1 & 2,7 & 16 & 33,3 & 29 & 59,9 & 49 & 100,0 \\
\hline 355640 & Vargem Grande do Sul & D50 & 12 & 4,8 & 1 & 0,5 & 3 & 1,2 & 76 & 29,4 & 165 & 64,1 & 257 & 100,0 \\
\hline 355645 & Vargem Grande Paulista & C50 & 11 & 5,7 & 2 & 0,9 & 6 & 3,3 & 79 & 41,1 & 94 & 49,0 & 192 & 100,0 \\
\hline 355650 & Várzea Paulista & C300 & 16 & 3,6 & 4 & 1,0 & 12 & 2,8 & 181 & 42,1 & 218 & 50,5 & 431 & 100,0 \\
\hline 355660 & Vera Cruz & E20 & 1 & 1,2 & 1 & 0,8 & 1 & 0,8 & 20 & 24,0 & 61 & 73,2 & 83 & 100,0 \\
\hline
\end{tabular}


Anexo 12 - Mortalidade proporcional (\%)por faixa etária selecionada segundo município e Estrato de Vulnerabilidade Social .Estado de São Paulo, media do triênio 2003 a 2005

\begin{tabular}{|c|c|c|c|c|c|c|c|c|c|c|c|c|c|c|}
\hline IBGE & MUNICIPIO & Status & $<01$ ano & $\%$ & $.01-04$ & $\%$ & $.05-19$ & $\%$ & 20-59 & $\%$ & $60 \mathrm{e}+$ & $\%$ & Total & $\%$ \\
\hline 355670 & Vinhedo & A100 & 8 & 2,6 & 1 & 0,5 & 6 & 2,2 & 85 & 29,2 & 192 & 65,6 & 292 & 100,0 \\
\hline 355680 & Viradouro & D20 & 3 & 2,8 & 1 & 0,9 & 1 & 0,9 & 33 & 30,3 & 71 & 65,1 & 109 & 100,0 \\
\hline 355690 & Vista Alegre do Alto & D20 & 1 & 3,7 & - & - & 0 & 1,2 & 9 & 34,1 & 17 & 61,0 & 27 & 100,0 \\
\hline 355695 & Vitória Brasil & E20 & - & - & - & - & 0 & 3,3 & 5 & 46,7 & 5 & 50,0 & 10 & 100,0 \\
\hline 355700 & Votorantim & B300 & 20 & 3,6 & 3 & 0,5 & 19 & 3,4 & 197 & 35,1 & 322 & 57,3 & 562 & 100,0 \\
\hline 355710 & Votuporanga & C100 & 9 & 1,6 & 3 & 0,5 & 7 & 1,2 & 148 & 26,7 & 387 & 70,0 & 553 & 100,0 \\
\hline 355715 & Zacarias & E20 & 1 & 5,9 & - & - & 1 & 5,9 & 2 & 17,6 & 8 & 70,6 & 11 & 100,0 \\
\hline & Estado & & 8854 & 3,7 & 1453 & 0,6 & 5770 & 2,4 & 77889 & 32,7 & 144152 & 60,5 & 238119 & 100,0 \\
\hline
\end{tabular}

Fonte: SIM/MS e Estratos de Vulnerabilidade Social segundo metodologia desenvolvida a partir do IPVS (FSEADE 2005)

Nota ${ }^{1}:$

( - ) Dado numérico igual a 0 não resultante de arredondamento

$(0 ; 0,0 ; 0,00)$ Dado numérico igual a zero resultante de arredondamento de um dado originalmente

A soma das parcelas pode não coincidir com o total em função de arredondamentos efetuados nos dados parciais 
Anexo 13 - $\mathrm{N}^{\circ}$ de nascidos vivos, óbitos e taxa de mortalidade infantil (por 1000 n.v), mediana, desvio padrão e razão de taxas nos conjuntos de municípios e respectivos estratos de vulnerabilidade social. Estado de São Paulo, média do triênio de 2003 a 2005.

\begin{tabular}{|c|c|c|c|c|c|c|c|c|}
\hline Status & $\begin{array}{c}\text { Nascidos } \\
\text { Vivos }\end{array}$ & $\begin{array}{c}\text { Óbitos }<1 \\
\text { ano }\end{array}$ & Taxa & Mediana & $\begin{array}{l}\text { Desvio } \\
\text { padrão }\end{array}$ & Maior Valor ${ }^{1}$ & $\begin{array}{l}\text { Menor } \\
\text { Valor }\end{array}$ & $\begin{array}{c}\text { Razão de } \\
\text { taxas }(1 / 2)\end{array}$ \\
\hline A20 & 493 & 7 & 14,88 & 13,83 & 9,06 & 31,91 & 9,80 & 3,26 \\
\hline A100 & 757 & 8 & 10,13 & 10,13 & $x$ & $x$ & $x$ & $x$ \\
\hline A300 & 6669 & 64 & 9,55 & 9,02 & 1,25 & 10,86 & 8,47 & 1,28 \\
\hline A500 & 10472 & 149 & 14,20 & 14,15 & 1,36 & 15,11 & 13,18 & 1,15 \\
\hline A1000 & 9166 & 117 & 12,73 & 12,73 & $x$ & $x$ & $x$ & $x$ \\
\hline Estrato A & 27556 & 344 & 12,48 & 12,73 & 6,99 & 31,91 & 8,47 & 3,77 \\
\hline B20 & 979 & 12 & 12,60 & 7,37 & 8,89 & 27,91 & 0,00 & * \\
\hline B50 & 7415 & 99 & 13,40 & 12,39 & 4,54 & 23,71 & 7,18 & 3,30 \\
\hline B100 & 18168 & 243 & 13,36 & 13,79 & 3,51 & 18,67 & 6,34 & 2,94 \\
\hline B300 & 54625 & 756 & 13,84 & 14,03 & 2,70 & 20,32 & 9,03 & 2,25 \\
\hline B500 & 30699 & 467 & 15,21 & 14,07 & 4,03 & 22,46 & 11,67 & 1,93 \\
\hline B1000 & 47109 & 623 & 13,22 & 12,56 & 2,60 & 16,19 & 9,71 & 1,67 \\
\hline B10000 & 193796 & 2671 & 13,78 & 13,01 & 1,27 & 13,91 & 12,12 & 1,15 \\
\hline Estrato B & 352791 & 4871 & 13,81 & 13,46 & 4,34 & 27,91 & 0,00 & * \\
\hline $\mathrm{C} 20$ & 2885 & 35 & 12,25 & 10,64 & 5,04 & 22,50 & 4,63 & 4,86 \\
\hline C50 & 14798 & 215 & 14,51 & 13,81 & 4,42 & 26,50 & 7,02 & 3,78 \\
\hline $\mathrm{C} 100$ & 17979 & 256 & 14,26 & 13,98 & 3,70 & 20,25 & 6,90 & 2,93 \\
\hline C300 & 61871 & 918 & 14,83 & 14,98 & 3,18 & 19,30 & 9,68 & 1,99 \\
\hline C500 & 25728 & 410 & 15,95 & 15,67 & 2,16 & 19,08 & 13,98 & 1,36 \\
\hline C10000 & 21107 & 336 & 15,92 & 15,92 & $x$ & $x$ & $x$ & $x$ \\
\hline Estrato C & 144369 & 2170 & 15,03 & 13,81 & 4,07 & 26,50 & 4,63 & 5,76 \\
\hline D20 & 12167 & 188 & 15,48 & 14,71 & 7,20 & 35,79 & 0,00 & * \\
\hline D50 & 28805 & 430 & 14,94 & 14,27 & 3,37 & 25,45 & 6,86 & 3,68 \\
\hline D100 & 12636 & 236 & 18,68 & 16,62 & 4,83 & 31,18 & 11,11 & 2,81 \\
\hline D300 & 2863 & 60 & 21,07 & 21,07 & $x$ & $x$ & $x$ & $\mathrm{x}$ \\
\hline Estrato D & 56472 & 915 & 16,20 & 14,71 & 5,70 & 35,79 & 0,00 & * \\
\hline E20 & 25750 & 406 & 15,77 & 14,75 & 10,30 & 65,22 & 0,00 & * \\
\hline E50 & 7437 & 122 & 16,45 & 15,73 & 4,41 & 26,29 & 10,92 & 1,41 \\
\hline E100 & 1204 & 25 & 21,04 & 21,04 & $x$ & $x$ & $x$ & $x$ \\
\hline Estrato E & 34391 & 554 & 16,10 & 14,76 & 10,06 & 65,22 & 0,00 & * \\
\hline Estado & 615579 & 8854 & 14,38 & 14,17 & 7,97 & 65,22 & 0,00 & * \\
\hline
\end{tabular}

Fonte: SIM/SINASC/MS e Estratos de Vulnerabilidade Social segundo metodologia desenvolvida a partir do IPVS (FSEADE 2005)

Nota $^{1}:$ ( - ) Dado numérico igual a 0 não resultante de arredondamento

$(0 ; 0,0 ; 0,00)$ Dado numérico igual a zero resultante de arredondamento de um dado originalmente positivo

A soma das parcelas pode não coincidir com o total em função de arredondamentos efetuados nos dados parciais

(x) Não se aplica (conjunto formado por um só município)

(*) Não divisível 
Anexo 14 - Óbitos maternos, nascidos vivos, Razão de Mortalidade Materna (por 100 mil nascidos vivos), mediana, desvio padrão, e razão de taxas nos conjuntos de municipios e Estratos de Vulnerabilidade Social. Estado de São Paulo, média do triênio 2003 a 2005

\begin{tabular}{|c|c|c|c|c|c|c|c|c|}
\hline Status & $\begin{array}{c}\text { Óbitos } \\
\text { maternos }\end{array}$ & $\begin{array}{c}\text { Nascidos } \\
\text { vivos }\end{array}$ & RMM & Mediana & $\begin{array}{l}\text { Desvio } \\
\text { padrão }\end{array}$ & $\begin{array}{l}\text { Maior } \\
\text { Valor }^{1}\end{array}$ & $\begin{array}{l}\text { Menor } \\
\text { Valor }^{2}\end{array}$ & $\begin{array}{r}\text { Razão de } \\
\text { taxas }(1 / 2)\end{array}$ \\
\hline $\mathrm{A} 20$ & - & 493 & - & - & - & - & - & - \\
\hline A100 & - & 757 & - & $x$ & $x$ & $x$ & $x$ & $x$ \\
\hline A300 & 2 & 6669 & 29,99 & 35,77 & 16,53 & 59,32 & 27,46 & 2,16 \\
\hline A500 & 4 & 10472 & 35,01 & 48,44 & 15,25 & 59,23 & 37,66 & 1,57 \\
\hline $\mathrm{A} 1000$ & 2 & 9166 & 21,82 & $x$ & $x$ & $x$ & $x$ & $x$ \\
\hline Estrato A & 8 & 27556 & 27,82 & 0,00 & 23,46 & 59,32 & 0,00 & $*$ \\
\hline $\mathrm{B} 20$ & 1 & 979 & 68,10 & 0,00 & 479,46 & 1443,30 & 0,00 & $*$ \\
\hline $\mathrm{B} 50$ & 4 & 7415 & 53,94 & 68,10 & 100,94 & 359,90 & 0,00 & $*$ \\
\hline B100 & 4 & 18168 & 23,85 & 39,58 & 33,98 & 104,95 & 0,00 & $*$ \\
\hline B300 & 15 & 54625 & 27,46 & 33,83 & 30,40 & 110,74 & 0,00 & $*$ \\
\hline $\mathrm{B} 500$ & 13 & 30699 & 41,26 & 48,37 & 36,61 & 117,79 & 19,05 & 6,18 \\
\hline B1000 & 13 & 47109 & 27,60 & 31,44 & 18,65 & 65,36 & 16,52 & 3,96 \\
\hline B10000 & 58 & 193796 & 30,10 & 33,57 & 14,15 & 43,57 & 23,56 & 1,85 \\
\hline Estrato B & 108 & 352791 & 30,61 & 34,80 & 169,46 & 1443,30 & 0,00 & $*$ \\
\hline $\mathrm{C} 20$ & 1 & 2885 & 23,11 & 0,00 & 56,03 & 164,90 & 0,00 & $*$ \\
\hline $\mathrm{C} 50$ & 6 & 14798 & 41 & 67,76 & 57,06 & 200,72 & 0,00 & $*$ \\
\hline $\mathrm{C} 100$ & 10 & 17979 & 55,62 & 67,67 & 62,90 & 205,16 & 0,00 & $*$ \\
\hline С 300 & 20 & 61871 & 32,33 & 39,85 & 37,51 & 131,93 & 0,00 & $*$ \\
\hline C500 & 9 & 25728 & 36,28 & 51,42 & 20,62 & 78,04 & 27,67 & 2,82 \\
\hline $\mathrm{C} 10000$ & 10 & 21107 & 45,80 & $x$ & $x$ & $x$ & $x$ & $x$ \\
\hline Estrato C & 56 & 144369 & 38,56 & 42,28 & 53,68 & 205,16 & 0,00 & $*$ \\
\hline D20 & 5 & 12167 & 38,36 & 0,00 & 132,63 & 636,36 & 0,00 & - \\
\hline D50 & 10 & 28805 & 35,87 & 0,00 & 68,21 & 233,14 & 0,00 & - \\
\hline D100 & 6 & 12636 & 44,84 & 60,18 & 48,73 & 150,30 & 0,00 & - \\
\hline D300 & 2 & 2863 & 58,21 & $x$ & $x$ & $x$ & $x$ & $x$ \\
\hline Estrato D & 22 & 56472 & 39,55 & 0,00 & 102,91 & 636,36 & 0,00 & $*$ \\
\hline E20 & 13 & 25750 & 50,49 & 0,00 & 230,45 & 1728,40 & 0,00 & - \\
\hline E50 & 5 & 7437 & 67,23 & 85,63 & 151,34 & 545,28 & 0,00 & - \\
\hline E100 & 1 & 1204 & 110,74 & $x$ & $x$ & $x$ & $x$ & $x$ \\
\hline Estrato $\mathrm{E}$ & 19 & 34391 & 56,22 & 0,00 & 226,59 & 1728,40 & 0,00 & $*$ \\
\hline Estado & 213 & 615579 & 34,60 & 0,00 & 178,29 & 1728,40 & 0,00 & $*$ \\
\hline
\end{tabular}

Fonte: SIM/SINASC/MS e Estratos de Vulnerabilidade Social segundo metodologia desenvolvida a partir do IPVS (FSEADE 2005)

Nota : $\quad$ ( - ) Dado numérico igual a 0 não resultante de arredondamentc

( $0 ; 0,0 ; 0,00$ ) Dado numérico igual a zero resultante de arredondamento de um dado originalmente positivo

(x) Não se aplica (conjunto formado por um só município

A soma das parcelas pode não coincidir com o total em função de arredondamentos efetuados nos dados parciais

* Não divisível 
Anexo $15-\mathrm{N}^{\circ}$ de óbitos maternos e Razão de Mortalidade Materna por 100 mil n.v e Taxa de Mortalidade Infantil por 1000 n.v nos municípios e respectivos estratos de vulnerabilidade social.Estado de São Paulo, média do triênio 2003-2005

\begin{tabular}{|c|c|c|c|c|c|c|}
\hline \multirow[b]{2}{*}{ IBGE } & \multirow[b]{2}{*}{ Município } & \multirow[b]{2}{*}{ Status } & \multicolumn{2}{|c|}{ Mortalidade Materna } & \multicolumn{2}{|c|}{ Mortalidade Infantil } \\
\hline & & & Óbitos & RMM & Óbitos & Taxa MI \\
\hline 350010 & Adamantina & D50 & 0 & 86,73 & 7 & 18,21 \\
\hline 350020 & Adolfo & E20 & 0 & 847,46 & 0 & 8,47 \\
\hline 350030 & Aguaí & E50 & - & & 9 & 18,17 \\
\hline 350040 & Águas da Prata & D20 & - & & 0 & 4,42 \\
\hline 350050 & Águas de Lindóia & D20 & - & & 4 & 16,73 \\
\hline 350055 & Águas de Santa Bárbara & B20 & - & & 1 & 18,18 \\
\hline 350060 & Águas de São Pedro & A20 & - & & 1 & 26,67 \\
\hline 350070 & Agudos & C50 & - & & 7 & 14,21 \\
\hline 350075 & Alambari & E20 & - & & 1 & 27,21 \\
\hline 350080 & Alfredo Marcondes & E20 & 0 & 847,46 & - & \\
\hline 350090 & Altair & E20 & - & & 0 & 6,76 \\
\hline 350100 & Altinópolis & D20 & - & - & 2 & 8,94 \\
\hline 350110 & Alto Alegre & E20 & - & & 1 & 14,93 \\
\hline 350115 & Alumínio & $\mathrm{C} 20$ & 0 & 109,53 & 3 & 9,86 \\
\hline 350120 & Alvares Florence & E20 & - & & 2 & 65,22 \\
\hline 350130 & Alvares Machado & D50 & - & & 5 & 13,25 \\
\hline 350140 & Alvaro de Carvalho & E20 & - & - & 1 & 12,58 \\
\hline 350150 & Alvinlândia & E20 & - & & 1 & 19,48 \\
\hline 350160 & Americana & А300 & 1 & 25,55 & 28 & 10,86 \\
\hline 350170 & Américo Brasiliense & D50 & 0 & 65,06 & 7 & 13,66 \\
\hline 350180 & Américo de Campos & E20 & - & & 1 & 12,90 \\
\hline 350190 & Amparo & B100 & 0 & 41,02 & 12 & 14,36 \\
\hline 350200 & Analândia & B20 & - & & 0 & 6,45 \\
\hline 350210 & Andradina & D100 & 0 & 47,89 & 11 & 15,80 \\
\hline 350220 & Angatuba & D50 & 0 & 99,11 & 5 & 13,88 \\
\hline 350230 & Anhembi & E20 & - & & 1 & 9,85 \\
\hline 350240 & Anhumas & E20 & - & - & 0 & 7,35 \\
\hline 350250 & Aparecida & B50 & 0 & 65,70 & 7 & 13,80 \\
\hline 350260 & Aparecida d'Oeste & E20 & 0 & 699,30 & - & - \\
\hline 350270 & Apiaí & D50 & - & & 7 & 16,11 \\
\hline 350275 & Araçariguama & D20 & 0 & 117,23 & 4 & 12,90 \\
\hline 350280 & Araçatuba & B300 & 1 & 31,67 & 32 & 15,36 \\
\hline 350290 & Araçoiaba da Serra & B50 & - & & 4 & 11,37 \\
\hline 350300 & Aramina & E20 & - & & 1 & 21,13 \\
\hline 350310 & Arandu & E20 & - & & 1 & 13,94 \\
\hline 350315 & Arapeí & E20 & - & - & 0 & 10,64 \\
\hline 350320 & Araraquara & A300 & 1 & 42,37 & 20 & 8,47 \\
\hline 350330 & Araras & B300 & 1 & 44,94 & 14 & 9,21 \\
\hline 350335 & ArcoOlris & E20 & - & & 0 & 13,51 \\
\hline
\end{tabular}


Anexo 15 - $\mathrm{N}^{\circ}$ de óbitos maternos e Razão de Mortalidade Materna por 100 mil n.v e Taxa de Mortalidade Infantil por 1000 n.v nos municípios e respectivos estratos de vulnerabilidade social.Estado de São Paulo, média do triênio 2003-2005

\begin{tabular}{|c|c|c|c|c|c|c|}
\hline \multirow[b]{2}{*}{ IBGE } & \multirow[b]{2}{*}{ Município } & \multirow[b]{2}{*}{ Status } & \multicolumn{2}{|c|}{ Mortalidade Materna } & \multicolumn{2}{|c|}{ Mortalidade Infantil } \\
\hline & & & Óbitos & RMM & Óbitos & Taxa MI \\
\hline 350340 & Arealva & E20 & - & & 1 & 15,50 \\
\hline 350350 & Areias & E20 & - & & 2 & 26,32 \\
\hline 350360 & Areiópolis & E20 & - & & 1 & 7,19 \\
\hline 350370 & Ariranha & E20 & - & & 1 & 8,43 \\
\hline 350380 & Artur Nogueira & $\mathrm{C} 50$ & 0 & 56,69 & 5 & 9,07 \\
\hline 350390 & Arujá & C100 & - & & 21 & 17,21 \\
\hline 350395 & Aspásia & E20 & - & & - & \\
\hline 350400 & Assis & B100 & 0 & 28,27 & 15 & 12,44 \\
\hline 350410 & Atibaia & C300 & 0 & 17,48 & 35 & 18,35 \\
\hline 350420 & Auriflama & E20 & 0 & 176,06 & 5 & 24,65 \\
\hline 350430 & Avaí & E20 & - & & 2 & 24,27 \\
\hline 350440 & Avanhandava & E20 & - & & 2 & 18,82 \\
\hline 350450 & Avaré & B100 & 1 & 55,14 & 17 & 13,79 \\
\hline 350460 & Bady Bassitt & A20 & - & & 2 & 14,11 \\
\hline 350470 & Balbinos & E20 & - & & 0 & 23,26 \\
\hline 350480 & Bálsamo & E20 & - & & 2 & 21,28 \\
\hline 350490 & Bananal & D20 & 0 & 220,75 & 2 & 13,25 \\
\hline 350500 & Barao de Antonina & E20 & - & & 1 & 17,09 \\
\hline 350510 & Barbosa & E20 & - & - & 1 & 6,62 \\
\hline 350520 & Bariri & D50 & - & - & 6 & 14,59 \\
\hline 350530 & Barra Bonita & $\mathrm{C} 50$ & - & 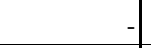 & 5 & 11,07 \\
\hline 350535 & Barra do Chapéu & E20 & - & & 3 & 30,51 \\
\hline 350540 & Barra do Turvo & E20 & 0 & 234,19 & 3 & 21,08 \\
\hline 350550 & Barretos & B300 & - & - & 17 & 12,20 \\
\hline 350560 & Barrinha & D50 & - & & 5 & 10,91 \\
\hline 350570 & Barueri & C300 & 1 & 25,99 & 50 & 9,68 \\
\hline 350580 & Bastos & D50 & 0 & 94,79 & 5 & 15,17 \\
\hline 350590 & Batatais & C100 & 0 & 45,87 & 9 & 11,93 \\
\hline 350600 & Bauru & B500 & 2 & 42,68 & 55 & 11,67 \\
\hline 350610 & Bebedouro & C100 & 0 & 33,99 & 12 & 11,90 \\
\hline 350620 & Bento de Abreu & $\mathrm{C} 20$ & - & & 0 & 11,63 \\
\hline 350630 & Bernardino de Campos & E20 & - & & 1 & 9,17 \\
\hline 350635 & Bertioga & C50 & 1 & 78,00 & 19 & 22,62 \\
\hline 350640 & Bilac & D20 & - & & 0 & 3,95 \\
\hline 350650 & Birigui & C300 & 1 & 51,84 & 20 & 15,55 \\
\hline 350660 & Biritiba0Mirim & D50 & 0 & 81,30 & 8 & 18,70 \\
\hline 350670 & Boa Esperança do Sul & E20 & - & & 2 & 9,52 \\
\hline 350680 & Bocaina & D20 & - & - & 2 & 12,17 \\
\hline 350690 & Bofete & E20 & - & & 3 & 24,19 \\
\hline
\end{tabular}


Anexo $15-\mathrm{N}^{\circ}$ de óbitos maternos e Razão de Mortalidade Materna por 100 mil n.v e Taxa de Mortalidade Infantil por 1000 n.v nos municípios e respectivos estratos de vulnerabilidade social.Estado de São Paulo, média do triênio 2003-2005

\begin{tabular}{|c|c|c|c|c|c|c|}
\hline \multirow[b]{2}{*}{ IBGE } & \multirow[b]{2}{*}{ Município } & \multirow[b]{2}{*}{ Status } & \multicolumn{2}{|c|}{ Mortalidade Materna } & \multicolumn{2}{|c|}{ Mortalidade Infantil } \\
\hline & & & Óbitos & RMM & Óbitos & Taxa MI \\
\hline 350700 & Boituva & D50 & 0 & 53,88 & 9 & 14,01 \\
\hline 350710 & Bom Jesus dos Perdoes & D20 & - & & 6 & 21,17 \\
\hline 350715 & Bom Sucesso de Itararé & E20 & 0 & 505,05 & 2 & 35,35 \\
\hline 350720 & Borá & E20 & - & & 0 & 40,00 \\
\hline 350730 & Boracéia & E20 & - & & 1 & 24,84 \\
\hline 350740 & Borborema & D20 & 0 & 182,82 & 2 & 9,14 \\
\hline 350745 & Borebi & E20 & - & & - & - \\
\hline 350750 & Botucatu & B300 & 0 & 19,64 & 18 & 10,41 \\
\hline 350760 & Bragança Paulista & B300 & 1 & 31,62 & 36 & 16,91 \\
\hline 350770 & Braúna & E20 & - & & 2 & 24,75 \\
\hline 350775 & Brejo Alegre & E20 & - & & 1 & 19,61 \\
\hline 350780 & Brodósqui & C20 & 0 & 117,79 & 6 & 20,02 \\
\hline 350790 & Brotas & D50 & 0 & 101,94 & 5 & 14,27 \\
\hline 350800 & Buri & E20 & - & - & 8 & 21,87 \\
\hline 350810 & Buritama & E20 & - & & 2 & 13,86 \\
\hline 350820 & Buritizal & D20 & - & - & 0 & 6,02 \\
\hline 350830 & Cabrália Paulista & E20 & - & & 1 & 14,08 \\
\hline 350840 & Cabreúva & C50 & 0 & 48,40 & 9 & 12,58 \\
\hline 350850 & Caçapava & B100 & 0 & 26,54 & 21 & 16,99 \\
\hline 350860 & Cachoeira Paulista & B50 & 0 & 85,69 & 7 & 17,99 \\
\hline 350870 & Caconde & E20 & - & - & 5 & 16,67 \\
\hline 350880 & Cafelândia & D20 & 0 & 147,49 & 3 & 11,80 \\
\hline 350890 & Caiabu & E20 & - & & 1 & 17,54 \\
\hline 350900 & Caieiras & C100 & 1 & 50,80 & 16 & 12,19 \\
\hline 350910 & Caiuá & E20 & - & & - & - \\
\hline 350920 & Cajamar & C100 & - & & 19 & 16,49 \\
\hline 350925 & Cajati & D50 & - & & 10 & 15,80 \\
\hline 350930 & Cajobi & E20 & - & & 1 & 8,29 \\
\hline 350940 & Cajuru & E50 & 1 & 284,63 & 5 & 13,28 \\
\hline 350945 & Campina Mte Alegre & E20 & - & - & 1 & 14,44 \\
\hline 350950 & Campinas & B10000 & 2 & 16,83 & 168 & 12,12 \\
\hline 350960 & Campo Limpo Paulista & C100 & 2 & 146,54 & 15 & 13,48 \\
\hline 350970 & Campos do Jordao & C50 & - & & 19 & 19,82 \\
\hline 350980 & Campos Novos Paulista & E20 & - & - & 1 & 15,23 \\
\hline 350990 & Cananéia & E20 & - & - & 3 & 13,45 \\
\hline 350995 & Canas & E20 & - & & 2 & 28,17 \\
\hline 351000 & Cândido Mota & D50 & - & & 7 & 16,71 \\
\hline 351010 & Cândido Rodrigues & E20 & - & - & 1 & 23,53 \\
\hline 351015 & Canitar & E20 & 0 & 380,23 & 1 & 7,60 \\
\hline
\end{tabular}


Anexo 15 - N de óbitos maternos e Razão de Mortalidade Materna por 100 mil n.v e Taxa de Mortalidade Infantil por 1000 n.v nos municípios e respectivos estratos de vulnerabilidade social.Estado de São Paulo, média do triênio 2003-2005

\begin{tabular}{|c|c|c|c|c|c|c|}
\hline \multirow[b]{2}{*}{ IBGE } & \multirow[b]{2}{*}{ Município } & \multirow[b]{2}{*}{ Status } & \multicolumn{2}{|c|}{ Mortalidade Materna } & \multicolumn{2}{|c|}{ Mortalidade Infantil } \\
\hline & & & Óbitos & RMM & Óbitos & Taxa MI \\
\hline 351020 & Capao Bonito & E50 & 0 & 36,58 & 16 & 17,19 \\
\hline 351030 & Capela do Alto & D20 & - & & 6 & 22,25 \\
\hline 351040 & Capivari & C50 & 0 & 44,72 & 10 & 13,42 \\
\hline 351050 & Caraguatatuba & C100 & 2 & 114,55 & 28 & 19,24 \\
\hline 351060 & Carapicuíba & C500 & 1 & 19,76 & 94 & 13,98 \\
\hline 351070 & Cardoso & E20 & - & & 2 & 14,42 \\
\hline 351080 & Casa Branca & B50 & - & & 8 & 21,72 \\
\hline 351090 & Cássia dos Coqueiros & E20 & - & & - & - \\
\hline 351100 & Castilho & E20 & 0 & 140,45 & 6 & 25,28 \\
\hline 351110 & Catanduva & B300 & 0 & 24,86 & 20 & 14,91 \\
\hline 351120 & Catiguá & E20 & - & & - & - \\
\hline 351130 & Cedral & E20 & - & & 1 & 17,02 \\
\hline 351140 & Cerqueira César & D20 & - & & 4 & 14,71 \\
\hline 351150 & Cerquilho & B50 & 1 & 156,99 & 6 & 14,91 \\
\hline 351160 & Cesário Lange & E20 & - & & 2 & 9,84 \\
\hline 351170 & Charqueada & D20 & - & & 3 & 15,41 \\
\hline 355720 & Chavantes & D20 & - & & 3 & 18,15 \\
\hline 351190 & Clementina & E20 & - & & 1 & 11,90 \\
\hline 351200 & Colina & D20 & - & - & 3 & 10,64 \\
\hline 351210 & Colômbia & E20 & - & - & 2 & 15,82 \\
\hline 351220 & Conchal & E50 & - & 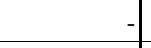 & 9 & 21,16 \\
\hline 351230 & Conchas & C20 & - & & 3 & 10,60 \\
\hline 351240 & Cordeirópolis & C20 & - & & 2 & 7,51 \\
\hline 351250 & Coroados & E20 & - & - & 1 & 12,58 \\
\hline 351260 & Coronel Macedo & E20 & - & & 1 & 10,10 \\
\hline 351270 & Corumbataí & $\mathrm{D} 20$ & - & & 0 & 8,26 \\
\hline 351280 & Cosmópolis & B50 & 0 & 42,83 & 8 & 9,85 \\
\hline 351290 & Cosmorama & E20 & - & & 0 & 5,10 \\
\hline 351300 & Cotia & С300 & 0 & 10,28 & 55 & 17,06 \\
\hline 351310 & Cravinhos & D50 & - & - & 7 & 16,01 \\
\hline 351320 & Cristais Paulista & E20 & - & & 2 & 19,17 \\
\hline 351330 & Cruzália & D20 & - & & - & - \\
\hline 351340 & Cruzeiro & B100 & 0 & 29,64 & 21 & 18,67 \\
\hline 351350 & Cubatao & С300 & 1 & 64,58 & 40 & 19,21 \\
\hline 351360 & Cunha & E50 & 1 & 389,48 & 9 & 26,29 \\
\hline 351370 & Descalvado & D50 & - & & 3 & 8,69 \\
\hline 351380 & Diadema & C500 & 3 & 37,82 & 113 & 16,07 \\
\hline 351385 & Dirce Reis & E20 & - & 7 & - & - \\
\hline 351390 & Divinolândia & E20 & - & & 2 & 12,96 \\
\hline
\end{tabular}


Anexo $15-\mathrm{N}^{\circ}$ de óbitos maternos e Razão de Mortalidade Materna por 100 mil n.v e Taxa de Mortalidade Infantil por 1000 n.v nos municípios e respectivos estratos de vulnerabilidade social.Estado de São Paulo, média do triênio 2003-2005

\begin{tabular}{|c|c|c|c|c|c|c|}
\hline \multirow[b]{2}{*}{ IBGE } & \multirow[b]{2}{*}{ Município } & \multirow[b]{2}{*}{ Status } & \multicolumn{2}{|c|}{ Mortalidade Materna } & \multicolumn{2}{|c|}{ Mortalidade Infantil } \\
\hline & & & Óbitos & RMM & Óbitos & Taxa MI \\
\hline 351400 & Dobrada & E20 & - & & 2 & 14,75 \\
\hline 351410 & Dois Córregos & D50 & - & & 5 & 14,38 \\
\hline 351420 & Dolcinópolis & E20 & - & & 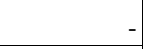 & - \\
\hline 351430 & Dourado & E20 & - & & 1 & 6,12 \\
\hline 351440 & Dracena & D50 & - & & 8 & 17,04 \\
\hline 351450 & Duartina & E20 & - & & 4 & 21,40 \\
\hline 351460 & Dumont & D20 & - & & 2 & 19,38 \\
\hline 351470 & Echapora & E20 & - & & 1 & 7,75 \\
\hline 351480 & Eldorado & D20 & - & & 4 & 15,82 \\
\hline 351490 & Elias Fausto & D20 & - & & 2 & 7,73 \\
\hline 351492 & Elisiário & E20 & - & & 0 & 9,90 \\
\hline 351495 & Embaúba & E20 & 0 & 943,40 & - & - \\
\hline 351500 & Embu & C300 & 2 & 37,39 & 69 & 15,41 \\
\hline 351510 & Embu0Guaçu & C100 & 0 & 32,93 & 11 & 10,87 \\
\hline 351512 & Emilianópolis & E20 & - & & - & - \\
\hline 351515 & Engenheiro Coelho & D20 & 0 & 173,91 & 2 & 10,43 \\
\hline 351518 & Espírito Santo do Pinhal & C50 & 0 & 63,86 & 6 & 10,86 \\
\hline 351519 & Espírito Santo do Turvo & D20 & 0 & 444,44 & 1 & 17,78 \\
\hline 355730 & Estiva Gerbi & $\mathrm{C} 20$ & - & & 1 & 11,63 \\
\hline 351530 & Estrela do Norte & E20 & - & & 0 & 9,52 \\
\hline 351520 & Estrela d'Oeste & E20 & - & & 4 & 35,48 \\
\hline 351535 & Euclides da Cunha Pta & E20 & - & & 3 & 18,67 \\
\hline 351540 & Fartura & E20 & - & & 4 & 18,68 \\
\hline 351560 & Fernando Prestes & E20 & - & - & 1 & 22,10 \\
\hline 351550 & Fernandópolis & D100 & 0 & 44,44 & 8 & 11,11 \\
\hline 351565 & Fernao & D20 & - & & - & - \\
\hline 351570 & Ferraz de Vasconcelos & C300 & 0 & 11,98 & 54 & 19,30 \\
\hline 351580 & Flora Rica & E20 & - & & 1 & 27,03 \\
\hline 351590 & Floreal & E20 & - & & 0 & 11,90 \\
\hline 351600 & Flórida Paulista & E20 & 0 & 238,66 & 2 & 16,71 \\
\hline 351610 & Florínia & E20 & - & & 1 & 23,26 \\
\hline 351620 & Franca & B500 & 1 & 13,61 & 67 & 13,68 \\
\hline 351630 & Francisco Morato & D300 & 2 & 58,21 & 60 & 21,07 \\
\hline 351640 & Franco da Rocha & C300 & 2 & 94,24 & 39 & 18,53 \\
\hline 351650 & Gabriel Monteiro & E20 & 0 & 1234,57 & 1 & 24,69 \\
\hline 351660 & Gália & E20 & - & & 1 & 12,24 \\
\hline 351670 & Garça & D50 & 1 & 113,77 & 8 & 13,08 \\
\hline 351680 & Gastao Vidigal & E20 & - & - & 1 & 22,73 \\
\hline 351685 & Gaviao Peixoto & E20 & - & & 1 & 9,85 \\
\hline
\end{tabular}


Anexo 15 - $\mathrm{N}^{\circ}$ de óbitos maternos e Razão de Mortalidade Materna por 100 mil n.v e Taxa de Mortalidade Infantil por 1000 n.v nos municípios e respectivos estratos de vulnerabilidade social.Estado de São Paulo, média do triênio 2003-2005

\begin{tabular}{|c|c|c|c|c|c|c|}
\hline \multirow[b]{2}{*}{ IBGE } & \multirow[b]{2}{*}{ Município } & \multirow[b]{2}{*}{ Status } & \multicolumn{2}{|c|}{ Mortalidade Materna } & \multicolumn{2}{|c|}{ Mortalidade Infantil } \\
\hline & & & Óbitos & RMM & Óbitos & Taxa MI \\
\hline 351690 & General Salgado & E20 & 0 & 305,81 & 2 & 21,41 \\
\hline 351700 & Getulina & E20 & - & & 3 & 22,83 \\
\hline 351710 & Glicério & E20 & - & & 1 & 21,28 \\
\hline 351720 & Guaiçara & D20 & - & & 4 & 28,71 \\
\hline 351730 & Guaimbê & E20 & - & & 2 & 21,20 \\
\hline 351740 & Guaíra & C50 & 0 & 61,80 & 6 & 11,74 \\
\hline 351750 & Guapiaçu & D20 & 0 & 185,19 & 3 & 14,81 \\
\hline 351760 & Guapiara & E50 & - & & 8 & 21,78 \\
\hline 351770 & Guará & E50 & 0 & 98,62 & 4 & 12,82 \\
\hline 351780 & Guaraçaí & E20 & - & & 1 & 9,87 \\
\hline 351790 & Guaraci & E20 & 0 & 252,53 & 1 & 7,58 \\
\hline 351800 & Guarani d'Oeste & E20 & - & & - & - \\
\hline 351810 & Guaranta & E20 & - & & 2 & 16,34 \\
\hline 351820 & Guararapes & D50 & - & & 6 & 16,78 \\
\hline 351830 & Guararema & D50 & - & - & 6 & 12,95 \\
\hline 351840 & Guaratinguetá & B300 & - & & 21 & 13,46 \\
\hline 351850 & Guareí & E20 & - & & 4 & 23,45 \\
\hline 351860 & Guariba & E50 & 0 & 61,16 & 7 & 12,84 \\
\hline 351870 & Guarujá & C300 & 3 & 61,24 & 90 & 18,37 \\
\hline 351880 & Guarulhos & C10000 & 10 & 45,80 & 335 & 15,92 \\
\hline 351885 & Guatapará & D20 & - & & - & - \\
\hline 351890 & Guzolândia & E20 & - & & 1 & 15,08 \\
\hline 351900 & Herculândia & E20 & - & & 3 & 20,94 \\
\hline 351905 & Holambra & $\mathrm{C} 20$ & - & - & 1 & 7,29 \\
\hline 351907 & Hortolândia & C300 & 0 & 12,72 & 34 & 12,97 \\
\hline 351910 & lacanga & E20 & 0 & 304,88 & 1 & 9,15 \\
\hline 351920 & Iacri & E20 & - & & 0 & 4,59 \\
\hline 351925 & laras & D20 & - & & 1 & 11,17 \\
\hline 351930 & Ibaté & D50 & - & & 4 & 8,23 \\
\hline 351940 & Ibirá & D20 & - & - & 2 & 16,57 \\
\hline 351950 & Ibirarema & E20 & - & & 2 & 18,05 \\
\hline 351960 & Ibitinga & D100 & 1 & 107,35 & 11 & 17,71 \\
\hline 351970 & Ibiúna & E100 & 1 & 110,74 & 25 & 21,04 \\
\hline 351980 & Icém & D20 & - & - & 2 & 17,80 \\
\hline 351990 & lepê & E20 & - & - & 3 & 28,17 \\
\hline 352000 & Igaraçu do Tietê & D50 & - & & 4 & 11,65 \\
\hline 352010 & Igarapava & D50 & 1 & 166,53 & 8 & 19,98 \\
\hline 352020 & Igaratá & E20 & 1 & 448,43 & 2 & 15,70 \\
\hline 352030 & Iguape & E50 & 0 & 64,23 & 6 & 10,92 \\
\hline
\end{tabular}


Anexo 15 - $\mathrm{N}^{\circ}$ de óbitos maternos e Razão de Mortalidade Materna por 100 mil n.v e Taxa de Mortalidade Infantil por 1000 n.v nos municípios e respectivos estratos de vulnerabilidade social.Estado de São Paulo, média do triênio 2003-2005

\begin{tabular}{|c|c|c|c|c|c|c|}
\hline \multirow[b]{2}{*}{ IBGE } & \multirow[b]{2}{*}{ Município } & \multirow[b]{2}{*}{ Status } & \multicolumn{2}{|c|}{ Mortalidade Materna } & \multicolumn{2}{|c|}{ Mortalidade Infantil } \\
\hline & & & Óbitos & RMM & Óbitos & Taxa MI \\
\hline 352042 & Ilha Comprida & A20 & - & & 1 & 11,70 \\
\hline 352044 & Ilha Solteira & B50 & - & & 2 & 7,18 \\
\hline 352040 & Ilhabela & C50 & 1 & 143,37 & 3 & 7,17 \\
\hline 352050 & Indaiatuba & B300 & 1 & 25,67 & 37 & 14,12 \\
\hline 352060 & Indiana & E20 & - & & 1 & 11,90 \\
\hline 352070 & Indiapora & E20 & - & & 0 & 8,93 \\
\hline 352080 & Inúbia Paulista & E20 & - & & 0 & 7,35 \\
\hline 352090 & Ipauçu & E20 & 0 & 169,20 & 2 & 11,84 \\
\hline 352100 & Iperó & C50 & - & & 5 & 14,64 \\
\hline 352110 & Ipeúna & C20 & - & - & 1 & 9,62 \\
\hline 352115 & Ipiguá & E20 & - & & 1 & 22,56 \\
\hline 352120 & Iporanga & E20 & - & & 0 & 4,31 \\
\hline 352130 & Ipua & D20 & - & & 2 & 6,87 \\
\hline 352140 & Iracemápolis & C20 & - & & 3 & 12,90 \\
\hline 352150 & Irapua & E20 & - & & 2 & 27,24 \\
\hline 352160 & Irapuru & E20 & 0 & 427,35 & 2 & 29,91 \\
\hline 352170 & Itaberá & E20 & 0 & 120,05 & 5 & 19,21 \\
\hline 352180 & Itaí & E50 & 0 & 87,72 & 8 & 21,05 \\
\hline 352190 & Itajobi & E20 & - & & 1 & 8,55 \\
\hline 352200 & Itaju & E20 & - & - & 1 & 26,32 \\
\hline 352210 & Itanhaém & C100 & 1 & 73,19 & 28 & 20,25 \\
\hline 352215 & Itaóca & E20 & - & & 2 & 27,93 \\
\hline 352220 & Itapecerica da Serra & C300 & 0 & 11,00 & 39 & 12,76 \\
\hline 352230 & Itapetininga & B300 & 1 & 42,89 & 39 & 16,87 \\
\hline 352240 & Itapeva & D100 & 1 & 58,46 & 53 & 31,18 \\
\hline 352250 & Itapevi & C300 & 0 & 9,17 & 49 & 13,57 \\
\hline 352260 & Itapira & D100 & 0 & 41,27 & 11 & 13,62 \\
\hline 352265 & Itapirapua Paulista & E20 & 0 & 413,22 & 0 & 4,13 \\
\hline 352270 & Itápolis & D50 & - & & 6 & 11,87 \\
\hline 352280 & Itaporanga & E20 & 0 & 135,87 & 4 & 14,95 \\
\hline 352290 & Itapuí & E20 & - & & 2 & 11,06 \\
\hline 352300 & Itapura & E20 & - & & 1 & 19,61 \\
\hline 352310 & Itaquaquecetuba & C500 & 3 & 55,74 & 103 & 19,08 \\
\hline 352320 & Itararé & D50 & 1 & 113,94 & 22 & 25,45 \\
\hline 352330 & Itariri & D20 & 0 & 172,71 & 6 & 31,09 \\
\hline 352340 & Itatiba & B100 & - & & 15 & 11,49 \\
\hline 352350 & Itatinga & E20 & - & & 5 & 16,10 \\
\hline 352360 & Itirapina & $\mathrm{C} 20$ & - & - & 2 & 11,63 \\
\hline 352370 & Itirapua & E20 & - & 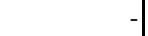 & 2 & 28,34 \\
\hline
\end{tabular}


Anexo 15 - $\mathrm{N}^{\circ}$ de óbitos maternos e Razão de Mortalidade Materna por 100 mil n.v e Taxa de Mortalidade Infantil por 1000 n.v nos municípios e respectivos estratos de vulnerabilidade social.Estado de São Paulo, média do triênio 2003-2005

\begin{tabular}{|c|c|c|c|c|c|c|}
\hline \multirow[b]{2}{*}{ IBGE } & \multirow[b]{2}{*}{ Município } & \multirow[b]{2}{*}{ Status } & \multicolumn{2}{|c|}{ Mortalidade Materna } & \multicolumn{2}{|c|}{ Mortalidade Infantil } \\
\hline & & & Óbitos & RMM & Óbitos & Taxa MI \\
\hline 352380 & Itobi & E20 & - & & 3 & 34,75 \\
\hline 352390 & Itu & C300 & 1 & 28,45 & 26 & 11,10 \\
\hline 352400 & Itupeva & C50 & - & & 6 & 11,76 \\
\hline 352410 & Ituverava & D50 & - & & 9 & 15,84 \\
\hline 352420 & Jaborandi & E20 & 0 & 357,14 & 1 & 14,29 \\
\hline 352430 & Jaboticabal & B100 & 0 & 35,12 & 9 & 9,83 \\
\hline 352440 & Jacareí & B300 & 2 & 52,63 & 42 & 13,26 \\
\hline 352450 & Jaci & E20 & - & & 1 & 21,39 \\
\hline 352460 & Jacupiranga & D20 & - & & 5 & 18,58 \\
\hline 352470 & Jaguariúna & B50 & - & - & 7 & 11,46 \\
\hline 352480 & Jales & D50 & - & & 7 & 13,18 \\
\hline 352490 & Jambeiro & D20 & - & & 0 & 6,17 \\
\hline 352500 & Jandira & C300 & 1 & 73,18 & 30 & 16,47 \\
\hline 352510 & Jardinópolis & C50 & 0 & 64,23 & 5 & 8,99 \\
\hline 352520 & Jarinu & D20 & - & & 3 & 9,59 \\
\hline 352530 & Jaú & C300 & 1 & 78,93 & 25 & 14,60 \\
\hline 352540 & Jeriquara & E20 & - & & 0 & 8,00 \\
\hline 352550 & Joanópolis & E20 & - & & 3 & 16,29 \\
\hline 352560 & Joao Ramalho & E20 & - & - & 2 & 38,67 \\
\hline 352570 & José Bonifácio & D50 & - & - & 5 & 11,93 \\
\hline 352580 & Júlio Mesquita & E20 & - & - & 1 & 19,14 \\
\hline 352585 & Jumirim & A20 & - & & 1 & 31,91 \\
\hline 352590 & Jundiaí & A500 & 1 & 26,90 & 65 & 13,18 \\
\hline 352600 & Junqueirópolis & E20 & - & - & 3 & 13,31 \\
\hline 352610 & Juquiá & D50 & - & & 5 & 12,95 \\
\hline 352620 & Juquitiba & D50 & - & & 8 & 15,00 \\
\hline 352630 & Lagoinha & E20 & - & & 1 & 16,95 \\
\hline 352640 & Laranjal Paulista & B50 & 0 & 92,59 & 4 & 12,04 \\
\hline 352650 & Lavínia & E20 & - & & 1 & 19,23 \\
\hline 352660 & Lavrinhas & D20 & - & - & 3 & 29,41 \\
\hline 352670 & Leme & D100 & 1 & 98,96 & 26 & 19,05 \\
\hline 352680 & Lençóis Paulista & C100 & 0 & 38,21 & 9 & 9,94 \\
\hline 352690 & Limeira & B300 & 1 & 17,76 & 38 & 10,12 \\
\hline 352700 & Lindóia & D20 & 0 & 454,55 & 2 & 31,82 \\
\hline 352710 & Lins & B100 & 1 & 74,96 & 15 & 17,24 \\
\hline 352720 & Lorena & B100 & - & & 24 & 18,59 \\
\hline 352725 & Lourdes & E20 & - & & 0 & 16,13 \\
\hline 352730 & Louveira & C50 & - & 4 & 3 & 7,02 \\
\hline 352740 & Lucélia & D20 & - & & 4 & 14,80 \\
\hline
\end{tabular}


Anexo $15-\mathrm{N}^{\circ}$ de óbitos maternos e Razão de Mortalidade Materna por 100 mil n.v e Taxa de Mortalidade Infantil por 1000 n.v nos municípios e respectivos estratos de vulnerabilidade social.Estado de São Paulo, média do triênio 2003-2005

\begin{tabular}{|c|c|c|c|c|c|c|}
\hline \multirow[b]{2}{*}{ IBGE } & \multirow[b]{2}{*}{ Município } & \multirow[b]{2}{*}{ Status } & \multicolumn{2}{|c|}{ Mortalidade Materna } & \multicolumn{2}{|c|}{ Mortalidade Infantil } \\
\hline & & & Óbitos & RMM & Óbitos & Taxa MI \\
\hline 352750 & Lucianópolis & E20 & 0 & 862,07 & - & 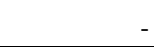 \\
\hline 352760 & Luís Antônio & C20 & - & & 2 & 10,64 \\
\hline 352770 & Luiziânia & E20 & - & & 2 & 31,58 \\
\hline 352780 & Lupércio & E20 & - & & 1 & 10,20 \\
\hline 352790 & Lutécia & E20 & - & & 0 & 7,58 \\
\hline 352800 & Macatuba & D20 & - & & 4 & 15,71 \\
\hline 352810 & Macaubal & E20 & - & & 1 & 9,39 \\
\hline 352820 & Macedônia & E20 & - & & 1 & 25,42 \\
\hline 352830 & Magda & E20 & - & & - & - \\
\hline 352840 & Mairinque & C50 & 1 & 95,28 & 11 & 16,20 \\
\hline 352850 & Mairipora & C100 & 1 & 88,65 & 16 & 14,48 \\
\hline 352860 & Manduri & D20 & - & & 2 & 13,51 \\
\hline 352870 & Marabá Paulista & E20 & - & & 0 & 7,04 \\
\hline 352880 & Maracaí & D20 & - & - & 3 & 13,79 \\
\hline 352885 & Marapoama & E20 & - & - & 0 & 11,76 \\
\hline 352890 & Mariápolis & E20 & - & & 1 & 24,00 \\
\hline 352900 & Marília & B300 & 0 & 11,75 & 42 & 14,69 \\
\hline 352910 & Marinópolis & E20 & - & & - & - \\
\hline 352920 & Martinópolis & D50 & - & - & 5 & 17,86 \\
\hline 352930 & Matao & B100 & 0 & 30,45 & 14 & 12,79 \\
\hline 352940 & Mauá & C500 & 2 & 35,63 & 100 & 15,27 \\
\hline 352950 & Mendonça & E20 & - & & - & - \\
\hline 352960 & Meridiano & E20 & - & & - & - \\
\hline 352965 & Mesópolis & E20 & - & - & 0 & 19,61 \\
\hline 352970 & Miguelópolis & E20 & - & - & 4 & 13,71 \\
\hline 352980 & Mineiros do Tietê & E20 & - & & 3 & 19,38 \\
\hline 353000 & Mira Estrela & E20 & - & & 0 & 12,35 \\
\hline 352990 & Miracatu & E50 & - & & 7 & 14,20 \\
\hline 353010 & Mirandópolis & D50 & - & & 4 & 12,33 \\
\hline 353020 & Mirante Paranapanema & E20 & 0 & 185,53 & 3 & 16,70 \\
\hline 353030 & Mirassol & B100 & - & & 6 & 8,61 \\
\hline 353040 & Mirassolândia & E20 & - & & 1 & 19,35 \\
\hline 353050 & Mococa & D100 & 1 & 70,52 & 15 & 15,51 \\
\hline 353060 & Moji das Cruzes & B500 & 3 & 54,63 & 100 & 16,39 \\
\hline 353070 & MojiOGuaçu & B300 & - & - & 25 & 14,08 \\
\hline 353080 & MojiOMirim & B100 & 1 & 59,72 & 16 & 14,33 \\
\hline 353090 & Mombuca & E20 & - & & 1 & 19,11 \\
\hline 353100 & Monçoes & E20 & - & - & - & - \\
\hline 353110 & Mongaguá & C50 & - & - & 17 & 26,50 \\
\hline
\end{tabular}


Anexo 15 - $\mathrm{N}^{\circ}$ de óbitos maternos e Razão de Mortalidade Materna por 100 mil n.v e Taxa de Mortalidade Infantil por 1000 n.v nos municípios e respectivos estratos de vulnerabilidade social.Estado de São Paulo, média do triênio 2003-2005

\begin{tabular}{|c|c|c|c|c|c|c|}
\hline \multirow[b]{2}{*}{ IBGE } & \multirow[b]{2}{*}{ Município } & \multirow[b]{2}{*}{ Status } & \multicolumn{2}{|c|}{ Mortalidade Materna } & \multicolumn{2}{|c|}{ Mortalidade Infantil } \\
\hline & & & Óbitos & RMM & Óbitos & Taxa MI \\
\hline 353120 & Monte Alegre do Sul & E20 & - & & 1 & 14,08 \\
\hline 353130 & Monte Alto & C50 & 0 & 61,31 & 7 & 12,26 \\
\hline 353140 & Monte Aprazível & D20 & 0 & 165,56 & 4 & 19,87 \\
\hline 353150 & Monte Azul Paulista & E50 & 0 & 120,92 & 3 & 12,09 \\
\hline 353160 & Monte Castelo & E20 & - & & 0 & 7,30 \\
\hline 353180 & Monte Mor & D50 & - & & 10 & 14,15 \\
\hline 353170 & Monteiro Lobato & E20 & - & & 2 & 35,71 \\
\hline 353190 & Morro Agudo & D50 & - & & 8 & 17,11 \\
\hline 353200 & Morungaba & D20 & - & & 3 & 19,72 \\
\hline 353205 & Motuca & D20 & - & - & 2 & 25,91 \\
\hline 353210 & Murutinga do Sul & E20 & - & & - & - \\
\hline 353215 & Nantes & E20 & - & & 1 & 15,63 \\
\hline 353220 & Narandiba & E20 & - & & 0 & 6,71 \\
\hline 353230 & Natividade da Serra & E20 & - & & 2 & 23,92 \\
\hline 353240 & Nazaré Paulista & E20 & 0 & 163,93 & 3 & 16,39 \\
\hline 353250 & Neves Paulista & E20 & - & & 1 & 8,03 \\
\hline 353260 & Nhandeara & D20 & - & & 2 & 17,54 \\
\hline 353270 & Nipoa & E20 & - & & 1 & 33,06 \\
\hline 353280 & Nova Aliança & E20 & - & & 1 & 16,76 \\
\hline 353282 & Nova Campina & E20 & 0 & 211,86 & 5 & 33,90 \\
\hline 353284 & Nova Canaa Paulista & E20 & - & & - & - \\
\hline 353286 & Nova Castilho & E20 & - & & - & - \\
\hline 353290 & Nova Europa & D20 & - & & 2 & 15,15 \\
\hline 353300 & Nova Granada & E20 & - & 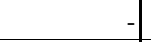 & 3 & 12,12 \\
\hline 353310 & Nova Guataporanga & E20 & - & - & 0 & 16,39 \\
\hline 353320 & Nova Independência & E20 & - & & 1 & 38,96 \\
\hline 353330 & Nova Luzitânia & E20 & - & & - & - \\
\hline 353340 & Nova Odessa & B50 & 0 & 54,47 & 7 & 10,89 \\
\hline 353325 & Novais & E20 & - & & 1 & 18,18 \\
\hline 353350 & Novo Horizonte & D50 & - & - & 4 & 8,53 \\
\hline 353360 & Nuporanga & E20 & - & & 2 & 23,58 \\
\hline 353370 & Ocauçu & E20 & - & & 1 & 11,56 \\
\hline 353380 & Oleo & E20 & - & & - & - \\
\hline 353390 & Olímpia & D50 & - & - & 9 & 14,05 \\
\hline 353400 & Onda Verde & E20 & - & - & 0 & 6,49 \\
\hline 353410 & Oriente & D20 & - & & 0 & 4,63 \\
\hline 353420 & Orindiúva & C20 & - & & 0 & 4,63 \\
\hline 353430 & Orlândia & B50 & - & - & 5 & 8,69 \\
\hline 353440 & Osasco & B1000 & 5 & 46,69 & 185 & 16,19 \\
\hline
\end{tabular}


Anexo 15 - $\mathrm{N}^{\circ}$ de óbitos maternos e Razão de Mortalidade Materna por 100 mil n.v e Taxa de Mortalidade Infantil por 1000 n.v nos municípios e respectivos estratos de vulnerabilidade social.Estado de São Paulo, média do triênio 2003-2005

\begin{tabular}{|c|c|c|c|c|c|c|}
\hline \multirow[b]{2}{*}{ IBGE } & \multirow[b]{2}{*}{ Município } & \multirow[b]{2}{*}{ Status } & \multicolumn{2}{|c|}{ Mortalidade Materna } & \multicolumn{2}{|c|}{ Mortalidade Infantil } \\
\hline & & & Óbitos & RMM & Óbitos & Taxa MI \\
\hline 353450 & Oscar Bressane & E20 & - & & - & 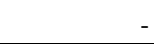 \\
\hline 353460 & Osvaldo Cruz & D50 & 0 & 98,81 & 4 & 11,86 \\
\hline 353470 & Ourinhos & C300 & 0 & 21,98 & 19 & 12,75 \\
\hline 353480 & Ouro Verde & E20 & 0 & 280,11 & 3 & 22,41 \\
\hline 353475 & Ouroeste & E20 & - & & 1 & 14,76 \\
\hline 353490 & Pacaembu & E20 & - & & 0 & 2,56 \\
\hline 353500 & Palestina & E20 & - & & 3 & 28,30 \\
\hline 353510 & Palmares Paulista & E20 & - & & 4 & 28,26 \\
\hline 353520 & Palmeira d'Oeste & E20 & - & & 1 & 8,38 \\
\hline 353530 & Palmital & D50 & 0 & 123,76 & 4 & 13,61 \\
\hline 353540 & Panorama & E20 & 1 & 282,89 & 4 & 16,97 \\
\hline 353550 & Paraguaçu Paulista & D50 & 0 & 56,40 & 10 & 16,92 \\
\hline 353560 & Paraibuna & E20 & - & & 3 & 12,40 \\
\hline 353570 & Paraíso & E20 & - & & 1 & 9,17 \\
\hline 353580 & Paranapanema & E20 & - & & 5 & 17,22 \\
\hline 353590 & Paranapua & E20 & - & & 1 & 12,90 \\
\hline 353600 & Parapua & E20 & - & & 1 & 12,01 \\
\hline 353610 & Pardinho & D20 & - & & 1 & 12,24 \\
\hline 353620 & Pariquera0Açu & D20 & - & - & 5 & 14,69 \\
\hline 353625 & Parisi & E20 & - & - & - & - \\
\hline 353630 & Patrocínio Paulista & D20 & - & 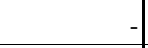 & 4 & 18,87 \\
\hline 353640 & Paulicéia & E20 & 0 & 480,77 & 1 & 19,23 \\
\hline 353650 & Paulínia & B100 & - & & 11 & 9,85 \\
\hline 353657 & Paulistânia & E20 & - & - & - & - \\
\hline 353660 & Paulo de Faria & E20 & - & & 1 & 7,56 \\
\hline 353670 & Pederneiras & D50 & 1 & 116,21 & 7 & 12,20 \\
\hline 353680 & Pedra Bela & E20 & - & & 3 & 39,80 \\
\hline 353690 & Pedranópolis & E20 & - & & - & - \\
\hline 353700 & Pedregulho & D20 & 0 & 132,98 & 3 & 13,30 \\
\hline 353710 & Pedreira & B50 & - & - & 7 & 12,73 \\
\hline 353715 & Pedrinhas Paulista & A20 & - & & 0 & 9,80 \\
\hline 353720 & Pedro de Toledo & E20 & - & & 3 & 14,87 \\
\hline 353730 & Penápolis & D100 & - & & 15 & 20,02 \\
\hline 353740 & Pereira Barreto & D50 & - & - & 6 & 18,58 \\
\hline 353750 & Pereiras & E20 & - & & 1 & 11,19 \\
\hline 353760 & Peruíbe & D100 & - & & 24 & 21,82 \\
\hline 353770 & Piacatu & E20 & - & & 1 & 22,47 \\
\hline 353780 & Piedade & D100 & 0 & 45,91 & 13 & 18,37 \\
\hline 353790 & Pilar do Sul & E50 & - & & 6 & 12,20 \\
\hline
\end{tabular}


Anexo 15 - $\mathrm{N}^{\circ}$ de óbitos maternos e Razão de Mortalidade Materna por 100 mil n.v e Taxa de Mortalidade Infantil por 1000 n.v nos municípios e respectivos estratos de vulnerabilidade social.Estado de São Paulo, média do triênio 2003-2005

\begin{tabular}{|c|c|c|c|c|c|c|}
\hline \multirow[b]{2}{*}{ IBGE } & \multirow[b]{2}{*}{ Município } & \multirow[b]{2}{*}{ Status } & \multicolumn{2}{|c|}{ Mortalidade Materna } & \multicolumn{2}{|c|}{ Mortalidade Infantil } \\
\hline & & & Óbitos & RMM & Óbitos & Taxa MI \\
\hline 353800 & Pindamonhangaba & B300 & 1 & 46,24 & 35 & 16,34 \\
\hline 353810 & Pindorama & E20 & - & & 4 & 20,37 \\
\hline 353820 & Pinhalzinho & E20 & - & & 2 & 11,85 \\
\hline 353830 & Piquerobi & E20 & - & & - & \\
\hline 353850 & Piquete & B20 & - & & 4 & 20,34 \\
\hline 353860 & Piracaia & D50 & - & & 8 & 21,22 \\
\hline 353870 & Piracicaba & B500 & 1 & 26,41 & 73 & 14,46 \\
\hline 353880 & Piraju & D50 & 0 & 78,25 & 5 & 11,74 \\
\hline 353890 & Pirajuí & D50 & - & & 3 & 10,58 \\
\hline 353900 & Pirangi & E20 & 0 & 290,70 & 0 & 2,91 \\
\hline 353910 & Pirapora do Bom Jesus & D20 & - & & 3 & 13,44 \\
\hline 353920 & Pirapozinho & D50 & - & & 3 & 11,06 \\
\hline 353930 & Pirassununga & B100 & - & & 9 & 10,68 \\
\hline 353940 & Piratininga & B20 & 0 & 225,73 & 1 & 6,77 \\
\hline 353950 & Pitangueiras & D50 & 0 & 53,11 & 9 & 14,87 \\
\hline 353960 & Planalto & E20 & - & & - & - \\
\hline 353970 & Platina & E20 & - & & 1 & 13,79 \\
\hline 353980 & Poá & B300 & 0 & 18,96 & 25 & 14,03 \\
\hline 353990 & Poloni & E20 & - & & 1 & 12,50 \\
\hline 354000 & Pompéia & C20 & - & - & 5 & 19,63 \\
\hline 354010 & Pongaí & E20 & - & & 1 & 25,42 \\
\hline 354020 & Pontal & D50 & 0 & 48,80 & 9 & 13,18 \\
\hline 354025 & Pontalinda & E20 & - & & 1 & 12,35 \\
\hline 354030 & Pontes Gestal & E20 & - & - & 0 & 15,87 \\
\hline 354040 & Populina & E20 & - & - & 1 & 14,39 \\
\hline 354050 & Porangaba & E20 & - & & 1 & 12,70 \\
\hline 354060 & Porto Feliz & C50 & 0 & 51,76 & 8 & 12,94 \\
\hline 354070 & Porto Ferreira & C100 & 1 & 90,21 & 11 & 15,34 \\
\hline 354075 & Potim & E20 & - & & 4 & 16,88 \\
\hline 354080 & Potirendaba & E20 & - & - & 2 & 14,86 \\
\hline 354085 & Pracinha & E20 & - & & 1 & 38,96 \\
\hline 354090 & Pradópolis & D20 & - & & 3 & 14,25 \\
\hline 354100 & Praia Grande & B300 & 2 & 64,36 & 74 & 20,32 \\
\hline 354105 & Pratânia & E20 & - & - & 1 & 19,23 \\
\hline 354110 & Presidente Alves & E20 & - & - & 0 & 7,69 \\
\hline 354120 & Presidente Bernardes & D20 & - & & 3 & 18,44 \\
\hline 354130 & Presidente Epitácio & D50 & - & & 9 & 14,92 \\
\hline 354140 & Presidente Prudente & B300 & 1 & 36,59 & 38 & 14,03 \\
\hline 354150 & Presidente Venceslau & D50 & - & & 7 & 14,81 \\
\hline
\end{tabular}


Anexo 15 - $\mathrm{N}^{\circ}$ de óbitos maternos e Razão de Mortalidade Materna por 100 mil n.v e Taxa de Mortalidade Infantil por 1000 n.v nos municípios e respectivos estratos de vulnerabilidade social.Estado de São Paulo, média do triênio 2003-2005

\begin{tabular}{|c|c|c|c|c|c|c|}
\hline \multirow[b]{2}{*}{ IBGE } & \multirow[b]{2}{*}{ Município } & \multirow[b]{2}{*}{ Status } & \multicolumn{2}{|c|}{ Mortalidade Materna } & \multicolumn{2}{|c|}{ Mortalidade Infantil } \\
\hline & & & Óbitos & RMM & Óbitos & Taxa MI \\
\hline 354160 & Promissao & D50 & - & & 7 & 13,38 \\
\hline 354165 & Quadra & E20 & - & & - & \\
\hline 354170 & Quatá & D20 & - & & 4 & 25,05 \\
\hline 354180 & Queiroz & E20 & - & & 1 & 23,44 \\
\hline 354190 & Queluz & D20 & 0 & 198,81 & 6 & 35,79 \\
\hline 354200 & Quintana & E20 & - & & 1 & 12,71 \\
\hline 354210 & Rafard & A20 & - & & 2 & 13,55 \\
\hline 354220 & Rancharia & D50 & 1 & 156,86 & 7 & 16,47 \\
\hline 354230 & Redençao da Serra & E20 & - & & 1 & 13,16 \\
\hline 354240 & Regente Feijó & D20 & - & - & 3 & 12,50 \\
\hline 354250 & Reginópolis & E20 & - & & 0 & 5,32 \\
\hline 354260 & Registro & D100 & 0 & 35,83 & 13 & 13,97 \\
\hline 354270 & Restinga & E20 & - & & 2 & 17,80 \\
\hline 354280 & Ribeira & E20 & 0 & 476,19 & 4 & 57,14 \\
\hline 354290 & Ribeirao Bonito & D20 & 0 & 185,87 & 3 & 14,87 \\
\hline 354300 & Ribeirao Branco & E50 & 0 & 79,37 & 8 & 18,25 \\
\hline 354310 & Ribeirao Corrente & E20 & - & & 1 & 16,22 \\
\hline 354320 & Ribeirao do Sul & E20 & - & & 0 & 6,17 \\
\hline 354323 & Ribeirao dos Indios & E20 & - & - & - & - \\
\hline 354325 & Ribeirao Grande & E20 & - & - & 2 & 18,32 \\
\hline 354330 & Ribeirao Pires & B300 & 1 & 79,10 & 24 & 14,44 \\
\hline 354340 & Ribeirao Preto & B1000 & 2 & 21,98 & 74 & 9,71 \\
\hline 354360 & Rifaina & D20 & - & & 1 & 25,86 \\
\hline 354370 & Rincao & D20 & - & 1 & 2 & 14,17 \\
\hline 354380 & Rinópolis & E20 & - & - & 2 & 17,60 \\
\hline 354390 & Rio Claro & B300 & - & & 25 & 11,13 \\
\hline 354400 & Rio das Pedras & C50 & - & & 7 & 16,27 \\
\hline 354410 & Rio Grande da Serra & C50 & - & & 12 & 16,77 \\
\hline 354420 & Riolândia & E20 & - & & 1 & 8,11 \\
\hline 354350 & Riversul & E20 & - & - & 3 & 27,97 \\
\hline 354425 & Rosana & C50 & - & & 5 & 14,87 \\
\hline 354430 & Roseira & C20 & - & & 3 & 22,50 \\
\hline 354440 & Rubiácea & E20 & - & & 1 & 21,98 \\
\hline 354450 & Rubinéia & D20 & - & - & 0 & 15,87 \\
\hline 354460 & Sabino & E20 & - & - & 1 & 21,05 \\
\hline 354470 & Sagres & E20 & - & & 0 & 12,82 \\
\hline 354480 & Sales & E20 & - & & 1 & 17,44 \\
\hline 354490 & Sales Oliveira & B20 & - & 1 & 1 & 7,37 \\
\hline 354500 & Salesópolis & E20 & - & - & 3 & 12,24 \\
\hline
\end{tabular}


Anexo $15-\mathrm{N}^{\circ}$ de óbitos maternos e Razão de Mortalidade Materna por 100 mil n.v e Taxa de Mortalidade Infantil por 1000 n.v nos municípios e respectivos estratos de vulnerabilidade social.Estado de São Paulo, média do triênio 2003-2005

\begin{tabular}{|c|c|c|c|c|c|c|}
\hline \multirow[b]{2}{*}{ IBGE } & \multirow[b]{2}{*}{ Município } & \multirow[b]{2}{*}{ Status } & \multicolumn{2}{|c|}{ Mortalidade Materna } & \multicolumn{2}{|c|}{ Mortalidade Infantil } \\
\hline & & & Óbitos & RMM & Óbitos & Taxa MI \\
\hline 354510 & Salmourao & E20 & - & - & 1 & 17,05 \\
\hline 354515 & Saltinho & B20 & - & - & 0 & 4,98 \\
\hline 354520 & Salto & B300 & 0 & 23,47 & 16 & 11,26 \\
\hline 354530 & Salto de Pirapora & D50 & 0 & 59,38 & 8 & 13,66 \\
\hline 354540 & Salto Grande & E20 & - & - & 1 & 5,06 \\
\hline 354550 & Sandovalina & E20 & - & - & 1 & 20,00 \\
\hline 354560 & Santa Adélia & D20 & - & - & 4 & 18,64 \\
\hline 354570 & Santa Albertina & E20 & - & - & 1 & 16,76 \\
\hline 354580 & Santa Bárbara d'Oeste & B300 & 0 & 14,61 & 29 & 12,57 \\
\hline 354600 & Santa Branca & D20 & 0 & 175,13 & 4 & 21,02 \\
\hline 354610 & Santa Clara d'Oeste & E20 & - & - & 1 & 25,97 \\
\hline 354620 & Santa Cruz Conceiçao & B20 & 0 & 1030,93 & - & - \\
\hline 354625 & Santa Cruz Esperança & E20 & - & - & 0 & 13,51 \\
\hline 354630 & Santa Cruz Palmeiras & D50 & 0 & 72,05 & 8 & 16,57 \\
\hline 354640 & Santa Cruz Rio Pardo & C50 & 1 & 105,54 & 10 & 15,30 \\
\hline 354650 & Santa Ernestina & B20 & - & - & 2 & 27,91 \\
\hline 354660 & Santa Fé do Sul & D50 & 0 & 97,94 & 2 & 6,86 \\
\hline 354670 & Santa Gertrudes & C20 & - & - & 3 & 8,72 \\
\hline 354680 & Santa Isabel & D50 & 0 & 40,50 & 17 & 21,06 \\
\hline 354690 & Santa Lúcia & E20 & - & - & 2 & 17,91 \\
\hline 354700 & Santa Maria da Serra & E20 & 1 & 836,82 & 1 & 12,55 \\
\hline 354710 & Santa Mercedes & E20 & - & - & 0 & 8,00 \\
\hline 354740 & Santa Rita d'Oeste & E20 & - & - & - & - \\
\hline 354760 & Santa Rosa de Viterbo & D50 & 0 & 111,86 & 5 & 16,78 \\
\hline 354765 & Santa Salete & E20 & - & - & - & - \\
\hline 354730 & Santana de Parnaíba & C100 & - & - & 10 & 6,90 \\
\hline 354720 & Santana Ponte Pensa & E20 & - & - & 0 & 27,78 \\
\hline 354770 & Santo Anastácio & E50 & - & - & 3 & 12,09 \\
\hline 354780 & Santo André & A1000 & 2 & 21,82 & 117 & 12,73 \\
\hline 354805 & Santo Ant.Aracangua & E20 & - & - & 2 & 21,65 \\
\hline 354790 & Santo Antônio da Alegria & E20 & - & - & 1 & 14,08 \\
\hline 354800 & Santo Antônio de Posse & D20 & - & - & 5 & 19,23 \\
\hline 354810 & Santo Antônio do Jardim & E20 & - & - & 1 & 8,81 \\
\hline 354820 & Santo Antônio do Pinhal & E20 & - & - & 2 & 16,84 \\
\hline 354830 & Santo Expedito & E20 & - & - & 0 & 8,85 \\
\hline 354840 & Santópolis do Aguapeí & E20 & - & & 2 & 28,90 \\
\hline 354850 & Santos & A500 & 2 & 42,31 & 83 & 15,11 \\
\hline 354860 & Sao Bento do Sapucaí & D20 & - & - & 3 & 22,73 \\
\hline 354870 & Sao Bernardo do Campo & B1000 & 1 & 11,80 & 142 & 12,56 \\
\hline
\end{tabular}


Anexo $15-\mathrm{N}^{\circ}$ de óbitos maternos e Razão de Mortalidade Materna por 100 mil n.v e Taxa de Mortalidade Infantil por 1000 n.v nos municípios e respectivos estratos de vulnerabilidade social.Estado de São Paulo, média do triênio 2003-2005

\begin{tabular}{|c|c|c|c|c|c|c|}
\hline \multirow[b]{2}{*}{ IBGE } & \multirow[b]{2}{*}{ Município } & \multirow[b]{2}{*}{ Status } & \multicolumn{2}{|c|}{ Mortalidade Materna } & \multicolumn{2}{|c|}{ Mortalidade Infantil } \\
\hline & & & Óbitos & RMM & Óbitos & Taxa MI \\
\hline 354880 & Sao Caetano do Sul & A300 & 0 & 19,62 & 15 & 9,02 \\
\hline 354890 & Sao Carlos & B300 & - & & 25 & 9,03 \\
\hline 354900 & Sao Francisco & E20 & - & & 0 & 10,64 \\
\hline 354920 & Sao Joao Duas Pontes & E20 & - & & 1 & 22,99 \\
\hline 354910 & Sao Joao da Boa Vista & B100 & - & & 15 & 14,91 \\
\hline 354925 & Sao Joao de Iracema & E20 & - & & - & - \\
\hline 354930 & Sao Joao do Pau d'Alho & E20 & - & & - & \\
\hline 354940 & Sao Joaquim da Barra & C50 & 0 & 49,65 & 11 & 15,89 \\
\hline 354950 & Sao José da Bela Vista & E20 & - & & 4 & 26,83 \\
\hline 354960 & Sao José do Barreiro & E20 & - & - & 1 & 17,44 \\
\hline 354970 & Sao José do Rio Pardo & D100 & - & & 10 & 15,60 \\
\hline 354980 & Sao José do Rio Preto & B500 & 1 & 20,77 & 57 & 11,77 \\
\hline 354990 & Sao José dos Campos & B1000 & 2 & 22,46 & 104 & 11,64 \\
\hline 354995 & Sao Lourenço da Serra & E20 & 0 & 166,94 & 2 & 11,69 \\
\hline 355000 & Sao Luís do Paraitinga & E20 & - & & 2 & 14,05 \\
\hline 355010 & Sao Manuel & D50 & - & & 7 & 12,25 \\
\hline 355020 & Sao Miguel Arcanjo & E50 & 0 & 64,02 & 10 & 19,21 \\
\hline 355030 & Sao Paulo & B10000 & 56 & 31,12 & 2503 & 13,91 \\
\hline 355040 & Sao Pedro & B50 & 1 & 257,07 & 6 & 14,57 \\
\hline 355050 & Sao Pedro do Turvo & E20 & - & & 1 & 9,65 \\
\hline 355060 & Sao Roque & B100 & 0 & 30,22 & 15 & 13,90 \\
\hline 355070 & Sao Sebastiao & C100 & 1 & 54,07 & 21 & 16,76 \\
\hline 355080 & Sao Sebastiao Grama & E20 & 0 & 189,39 & 4 & 24,62 \\
\hline 355090 & Sao Simao & B20 & - & & 2 & 11,49 \\
\hline 355100 & Sao Vicente & B500 & 4 & 84,14 & 116 & 22,46 \\
\hline 355110 & Sarapuí & E20 & - & & 3 & 28,82 \\
\hline 355120 & Sarutaiá & E20 & - & & 2 & 35,09 \\
\hline 355130 & Sebastianópolis do Sul & E20 & - & & 1 & 29,41 \\
\hline 355140 & Serra Azul & E20 & - & & 1 & 10,26 \\
\hline 355160 & Serra Negra & D50 & 0 & 99,01 & 4 & 11,88 \\
\hline 355150 & Serrana & C50 & 0 & 51,15 & 9 & 13,81 \\
\hline 355170 & Sertaozinho & C300 & - & & 15 & 10,16 \\
\hline 355180 & Sete Barras & E20 & - & & 2 & 9,38 \\
\hline 355190 & Severínia & E20 & - & - & 2 & 9,35 \\
\hline 355200 & Silveiras & E20 & - & - & 2 & 17,99 \\
\hline 355210 & Socorro & D50 & - & & 8 & 19,25 \\
\hline 355220 & Sorocaba & B1000 & 3 & 33,78 & 118 & 14,99 \\
\hline 354750 & Sta Rita Passa Quatro & B50 & 0 & 109,05 & 5 & 17,45 \\
\hline 355230 & Sud Mennucci & E20 & - & & 2 & 23,57 \\
\hline
\end{tabular}


Anexo 15 - $\mathrm{N}^{\circ}$ de óbitos maternos e Razão de Mortalidade Materna por 100 mil n.v e Taxa de Mortalidade Infantil por 1000 n.v nos municípios e respectivos estratos de vulnerabilidade social.Estado de São Paulo, média do triênio 2003-2005

\begin{tabular}{|c|c|c|c|c|c|c|}
\hline \multirow[b]{2}{*}{ IBGE } & \multirow[b]{2}{*}{ Município } & \multirow[b]{2}{*}{ Status } & \multicolumn{2}{|c|}{ Mortalidade Materna } & \multicolumn{2}{|c|}{ Mortalidade Infantil } \\
\hline & & & Óbitos & RMM & Óbitos & Taxa MI \\
\hline 355240 & Sumaré & C300 & 1 & 30,20 & 38 & 11,48 \\
\hline 355255 & Suzanápolis & E20 & - & & 2 & 42,37 \\
\hline 355250 & Suzano & C300 & 0 & 7,17 & 86 & 18,43 \\
\hline 355260 & Tabapua & E20 & - & & 1 & 9,76 \\
\hline 355270 & Tabatinga & E20 & - & & 3 & 14,17 \\
\hline 355280 & Taboao da Serra & C300 & 1 & 28,49 & 65 & 13,96 \\
\hline 355290 & Taciba & E20 & 0 & 469,48 & 1 & 14,08 \\
\hline 355300 & Taguaí & E20 & - & & 0 & 2,31 \\
\hline 355310 & Taiaçu & E20 & - & & 1 & 9,57 \\
\hline 355320 & Taiúva & E20 & 0 & 617,28 & 1 & 18,52 \\
\hline 355330 & Tambaú & D50 & - & & 5 & 17,17 \\
\hline 355340 & Tanabi & D50 & - & & 3 & 13,51 \\
\hline 355350 & Tapiraí & E20 & - & & 1 & 8,55 \\
\hline 355360 & Tapiratiba & D20 & - & - & 2 & 10,55 \\
\hline 355365 & Taquaral & E20 & - & - & 1 & 20,83 \\
\hline 355370 & Taquaritinga & D100 & - & - & 11 & 14,38 \\
\hline 355380 & Taquarituba & E50 & - & & 5 & 15,73 \\
\hline 355385 & Taquarivaí & E20 & - & & 2 & 17,61 \\
\hline 355390 & Tarabaí & E20 & - & - & 1 & 12,82 \\
\hline 355395 & Taruma & D20 & - & - & 2 & 10,97 \\
\hline 355400 & Tatuí & C300 & 1 & 62,25 & 25 & 15,36 \\
\hline 355410 & Taubaté & B300 & 1 & 33,73 & 63 & 15,94 \\
\hline 355420 & Tejupá & E20 & - & & 3 & 30,65 \\
\hline 355430 & Teodoro Sampaio & D50 & - & - & 5 & 14,33 \\
\hline 355440 & Terra Roxa & E20 & - & - & 0 & 2,82 \\
\hline 355450 & Tietê & B50 & - & & 5 & 11,45 \\
\hline 355460 & Timburi & E20 & - & & 1 & 18,52 \\
\hline 355465 & Torre de Pedra & E20 & - & & 0 & 10,20 \\
\hline 355470 & Torrinha & E20 & - & & 2 & 17,30 \\
\hline 355475 & Trabiju & E20 & - & - & - & - \\
\hline 355480 & Tremembé & B50 & 0 & 69,74 & 11 & 23,71 \\
\hline 355490 & Três Fronteiras & E20 & - & & 1 & 25,48 \\
\hline 355495 & Tuiuti & E20 & - & & 1 & 11,63 \\
\hline 355500 & Tupa & D100 & 0 & 41,53 & 14 & 17,44 \\
\hline 355510 & Tupi Paulista & D20 & - & - & 2 & 17,14 \\
\hline 355520 & Turiúba & E20 & - & & 0 & 18,18 \\
\hline 355530 & Turmalina & E20 & - & & 1 & 35,09 \\
\hline 355535 & Ubarana & E20 & - & - & 1 & 12,93 \\
\hline 355540 & Ubatuba & C100 & 1 & 102,35 & 22 & 16,89 \\
\hline
\end{tabular}


Anexo $15-\mathrm{N}^{\circ}$ de óbitos maternos e Razão de Mortalidade Materna por 100 mil n.v e Taxa de Mortalidade Infantil por 1000 n.v nos municípios e respectivos estratos de vulnerabilidade social.Estado de São Paulo, média do triênio 2003-2005

\begin{tabular}{|c|c|c|c|c|c|c|}
\hline \multirow[b]{2}{*}{ IBGE } & \multirow[b]{2}{*}{ Município } & \multirow[b]{2}{*}{ Status } & \multicolumn{2}{|c|}{ Mortalidade Materna } & \multicolumn{2}{|c|}{ Mortalidade Infantil } \\
\hline & & & Óbitos & RMM & Óbitos & Taxa MI \\
\hline 355550 & Ubirajara & E20 & - & - & 0 & 5,92 \\
\hline 355560 & Uchoa & D20 & - & & 1 & 9,37 \\
\hline 355570 & Uniao Paulista & E20 & - & - & 1 & 40,82 \\
\hline 355580 & Urânia & E20 & - & & 2 & 17,91 \\
\hline 355590 & Uru & E20 & - & - & 0 & 27,78 \\
\hline 355600 & Urupês & E20 & 0 & 242,13 & 3 & 21,79 \\
\hline 355610 & Valentim Gentil & D20 & - & & 1 & 10,61 \\
\hline 355620 & Valinhos & B100 & - & & 8 & 6,34 \\
\hline 355630 & Valparaíso & D20 & - & & 5 & 18,20 \\
\hline 355635 & Vargem & E20 & - & - & 2 & 19,38 \\
\hline 355640 & Vargem Grande do Sul & D50 & 0 & 56,98 & 12 & 21,08 \\
\hline 355645 & Vargem Grande Paulista & C50 & - & & 11 & 14,20 \\
\hline 355650 & Várzea Paulista & C300 & 1 & 41,61 & 16 & 9,78 \\
\hline 355660 & Vera Cruz & E20 & - & - & 1 & 7,37 \\
\hline 355670 & Vinhedo & A100 & - & & 8 & 10,13 \\
\hline 355680 & Viradouro & D20 & - & - & 3 & 11,75 \\
\hline 355690 & Vista Alegre do Alto & D20 & - & & 1 & 12,05 \\
\hline 355695 & Vitória Brasil & E20 & - & & - & \\
\hline 355700 & Votorantim & B300 & - & - & 20 & 11,99 \\
\hline 355710 & Votuporanga & C100 & - & - & 9 & 10,07 \\
\hline 355715 & Zacarias & E20 & - & - & 1 & 37,74 \\
\hline & \multicolumn{2}{|l|}{ Estado } & \multicolumn{2}{|r|}{34,60} & 8853 & 14,38 \\
\hline
\end{tabular}

Fonte: SIM/SINASC/MS e Estratos de Vulnerabilidade Social segundo metodologia desenvolvida a partir do IPVS (FSEADE 2005)

Nota ${ }^{1}$ : ( - ) Dado numérico igual a 0 não resultante de arredondamento

$(0 ; 0,0 ; 0,00)$ Dado numérico igual a zero resultante de arredondamento de um dado originalmente positivo

A soma das parcelas pode não coincidir com o total em função de arredondamentos efetuados nos dados parciais 
Anexo $16-\mathrm{N}^{\circ}$ e proporção(\%) de Óbitos por Causas Mal Definidas segundo conjuntos de municipios e respectivos Estratos de Vulnerabilidade Social. Estado de São Paulo, média do triênio de 2003 a 2005.

\begin{tabular}{|c|c|c|c|c|c|c|}
\hline Status & Óbitos & $\%$ & Mediana & Desvio Padrão & Maior Valor & Menor Valor \\
\hline $\mathrm{A} 20$ & 21 & 8,8 & 6,8 & 5,5 & 16,3 & 2,5 \\
\hline A100 & 26 & 9,0 & $\mathrm{x}$ & $x$ & $x$ & $\mathrm{x}$ \\
\hline $\mathrm{A} 300$ & 265 & 7,0 & 2,5 & 10,1 & 19,2 & 1,0 \\
\hline A500 & 541 & 8,8 & 7,2 & 8,9 & 13,4 & 0,9 \\
\hline A1000 & 28 & 0,6 & $\mathrm{x}$ & $x$ & $x$ & $x$ \\
\hline Estrato A & 881 & 5,9 & 5,1 & 6,3 & 19,2 & 9,0 \\
\hline B20 & 34 & 7,1 & 6,4 & 6,4 & 19,3 & 0,6 \\
\hline B50 & 311 & 9,3 & 9,1 & 4,9 & 21,6 & 3,0 \\
\hline B100 & 948 & 11,2 & 8,9 & 5,7 & 21,3 & 2,7 \\
\hline B300 & 2620 & 11,1 & 11,2 & 6,2 & 23,6 & 1,5 \\
\hline B500 & 1114 & 8,8 & 8,8 & 8,5 & 17,6 & 1,4 \\
\hline B1000 & 758 & 4,5 & 1,4 & 5,4 & 11,3 & 0,7 \\
\hline B10000 & 991 & 1,4 & 1,5 & 0,3 & 1,8 & 1,3 \\
\hline Estrato B & 6775 & 4,9 & 8,9 & 6,1 & 23,6 & 0,6 \\
\hline C20 & 95 & 9,0 & 8,4 & 6,3 & 20,7 & 1,4 \\
\hline C50 & 496 & 9,2 & 9,5 & 4,9 & 19,2 & 1,1 \\
\hline C100 & 376 & 5,8 & 3,4 & 4,6 & 15,5 & 0,9 \\
\hline C300 & 1441 & 7,7 & 3,3 & 7,0 & 18,7 & 1,0 \\
\hline C500 & 291 & 4,2 & 1,5 & 7,2 & 15,8 & 1,0 \\
\hline C10000 & 59 & 1,0 & $x$ & $x$ & $x$ & $x$ \\
\hline Estrato C & 2758 & 6,2 & 6,8 & 5,9 & 20,7 & 0,9 \\
\hline D20 & 537 & 10,1 & 9,4 & 6,2 & 27,4 & 0,0 \\
\hline D50 & 1441 & 11,0 & 11,0 & 5,5 & 25,2 & 0,4 \\
\hline D100 & 892 & 14,8 & 15,1 & 4,9 & 22,4 & 7,8 \\
\hline D300 & 11 & 1,7 & $x$ & $x$ & $x$ & $x$ \\
\hline Estrato D & 2881 & 11,5 & 10,8 & 5,9 & 27,4 & 0,0 \\
\hline E20 & 1445 & 11,3 & 10,9 & 7,1 & 40,0 & 0,0 \\
\hline E50 & 323 & 11,7 & 11,4 & 6,0 & 21,9 & 0,2 \\
\hline E100 & 79 & 19,3 & $x$ & $x$ & $x$ & $\mathrm{x}$ \\
\hline Estrato E & 1847 & 11,6 & 11,1 & 7,0 & 40,0 & 0,0 \\
\hline Estado & 15142 & 6,4 & 10,1 & 6,7 & 40,0 & 0,0 \\
\hline
\end{tabular}

Fonte: Censo IBGE e Estratos de Vulnerabilidade Social segundo metodologia desenvolvida a partir do IPVS (FSEADE 2005)

1. A soma das parcelas pode não coincidir com o total em função de arredondamentos efetuados nos Nota ${ }^{1}$ dados parciais

(x) Não se aplica (conjunto formado por um só município)

Mal Definidas: Códigos R00 a R99- Cap. XVIII - "Sintomas, Sinais e Achados Anormais de Exames Clínicos e de Laboratório Não Classificados em Outra Parte" (CID 10) 
Anexo 17 - Óbitos, população e taxa de mortalidade (bruta e padronizada) total e segundo sexo por Algumas Doenças Infecciosas e Parasitárias (por 100 mil hab.), mediana, desvio padrão e razão de taxas conjuntos de municípios e respectivos estratos de vulnerabilidade social. Estado de São Paulo, média do triênio 2003 a 2005

\begin{tabular}{|c|c|c|c|c|c|c|c|c|c|c|c|c|c|c|}
\hline \multirow[b]{2}{*}{ Status } & \multicolumn{3}{|c|}{ Homens } & \multicolumn{3}{|c|}{ Mulheres } & \multicolumn{4}{|c|}{ Total } & \multirow{2}{*}{$\begin{array}{l}\text { Desvio } \\
\text { padrão }\end{array}$} & \multirow[b]{2}{*}{ Maior Valor ${ }^{1}$} & \multirow{2}{*}{$\begin{array}{l}\text { Menor } \\
\text { Valor }\end{array}$} & \multirow{2}{*}{$\begin{array}{c}\text { Razão } \\
(1 / 2) \\
\end{array}$} \\
\hline & Óbitos & ТВM & TPM & Óbitos & TBM & TPM & Óbitos & TBM & TPM & Mediana & & & & \\
\hline $\mathrm{A} 20$ & 4 & 22,46 & 20,36 & 6 & 29,82 & 29,01 & 10 & 26,12 & 24,65 & 28,61 & 12,52 & 33,69 & 0,00 & * \\
\hline A100 & 7 & 25,14 & 23,98 & 5 & 18,68 & 18,41 & 12 & 21,89 & 21,18 & $\mathrm{x}$ & $x$ & $\mathrm{x}$ & $x$ & $x$ \\
\hline A300 & 100 & 39,36 & 34,28 & 60 & 22,33 & 17,95 & 160 & 30,58 & 25,87 & 26,76 & 5,33 & 31,62 & 20,98 & 1,51 \\
\hline A500 & 175 & 48,60 & 41,94 & 102 & 25,58 & 21,00 & 276 & 36,51 & 30,94 & 30,20 & 10,03 & 37,29 & 23,10 & 1,61 \\
\hline $\mathrm{A} 1000$ & 112 & 35,02 & 32,65 & 71 & 20,60 & 19,03 & 183 & 27,57 & 25,61 & $\mathrm{x}$ & $x$ & $x$ & $x$ & $x$ \\
\hline Estrato A & 398 & 40,61 & 36,00 & 243 & 23,03 & 19,66 & 641 & 31,49 & 27,52 & 26,76 & 9,23 & 37,29 & 0,00 & * \\
\hline B20 & 11 & 29,47 & 27,65 & 7 & 17,62 & 15,55 & 18 & 23,60 & 21,65 & 18,45 & 7,00 & 30,63 & 10,39 & 2,95 \\
\hline B50 & 74 & 28,01 & 27,00 & 44 & 16,71 & 16,47 & 119 & 22,36 & 21,73 & 20,23 & 6,24 & 36,82 & 11,57 & 3,18 \\
\hline B100 & 224 & 35,03 & 33,80 & 133 & 20,40 & 19,12 & 357 & 27,63 & 26,38 & 26,80 & 5,49 & 34,38 & 16,90 & 2,03 \\
\hline B300 & 600 & 31,94 & 31,35 & 371 & 19,22 & 18,87 & 971 & 25,49 & 25,03 & 23,78 & 8,39 & 57,06 & 16,15 & 3,53 \\
\hline B500 & 389 & 38,35 & 37,69 & 258 & 24,42 & 23,67 & 647 & 31,24 & 30,53 & 30,42 & 6,85 & 38,50 & 18,50 & 2,08 \\
\hline B1000 & 472 & 30,98 & 32,28 & 301 & 18,83 & 19,67 & 772 & 24,76 & 25,82 & 25,02 & 6,48 & 37,51 & 21,07 & 1,78 \\
\hline B10000 & 1988 & 35,25 & 34,79 & 1259 & 20,40 & 19,49 & 3247 & 27,49 & 26,79 & 25,43 & 2,33 & 27,08 & 23,79 & 1,14 \\
\hline Estrato B & 3759 & 34,17 & 33,85 & 2373 & 20,26 & 19,69 & 6132 & 27,00 & 26,55 & 23,96 & 7,28 & 57,06 & 10,39 & 5,49 \\
\hline $\mathrm{C} 20$ & 24 & 25,65 & 25,27 & 14 & 15,01 & 14,11 & 38 & 20,44 & 19,81 & 19,09 & 10,07 & 52,39 & 9,69 & 5,41 \\
\hline $\mathrm{C} 50$ & 141 & 30,10 & 30,65 & 88 & 19,02 & 20,45 & 229 & 24,60 & 25,58 & 24,81 & 8,23 & 50,31 & 11,79 & 4,27 \\
\hline C100 & 167 & 28,93 & 29,98 & 109 & 18,93 & 20,01 & 276 & 23,92 & 24,99 & 26,09 & 6,97 & 36,03 & 10,86 & 3,32 \\
\hline C300 & 511 & 29,05 & 33,03 & 322 & 18,03 & 21,18 & 834 & 23,49 & 27,06 & 27,50 & 4,99 & 34,67 & 18,81 & 1,84 \\
\hline C500 & 172 & 23,84 & 28,83 & 125 & 16,75 & 21,28 & 297 & 20,24 & 25,00 & 25,44 & 3,53 & 27,81 & 20,46 & 1,36 \\
\hline C10000 & 167 & 28,30 & 31,82 & 102 & 16,67 & 20,06 & 269 & 22,39 & 25,84 & $x$ & $\mathrm{x}$ & $\mathrm{x}$ & $\mathrm{x}$ & $x$ \\
\hline Estrato C & 1183 & 28,08 & 31,28 & 760 & 17,78 & 20,65 & 1943 & 22,89 & 25,93 & 24,81 & 7,59 & 52,39 & 9,69 & 5,41 \\
\hline D20 & 118 & 27,84 & 25,67 & 79 & 19,05 & 18,39 & 197 & 23,50 & 22,08 & 21,15 & 10,22 & 51,61 & 0,00 & * \\
\hline D50 & 282 & 28,73 & 27,04 & 190 & 19,43 & 18,57 & 471 & 24,09 & 22,82 & 21,40 & 8,73 & 47,80 & 5,81 & 8,23 \\
\hline D100 & 144 & 32,89 & 31,16 & 101 & 23,04 & 21,94 & 245 & 27,95 & 26,54 & 27,52 & 7,81 & 41,12 & 14,76 & 2,79 \\
\hline D300 & 23 & 29,99 & 38,59 & 10 & 13,21 & 16,35 & 34 & 21,58 & 27,44 & $\mathrm{x}$ & $\mathrm{x}$ & $x$ & $x$ & $x$ \\
\hline Estrato D & 567 & 29,53 & 28,15 & 380 & 19,93 & 19,22 & 947 & 24,75 & 23,70 & 21,64 & 9,41 & 51,61 & 0,00 & * \\
\hline E20 & 292 & 30,20 & 26,45 & 204 & 22,04 & 20,51 & 496 & 26,22 & 23,55 & 21,68 & 15,59 & 80,28 & 0,00 & * \\
\hline E50 & 58 & 25,83 & 26,03 & 37 & 17,11 & 18,27 & 95 & 21,54 & 22,21 & 22,96 & 9,81 & 39,01 & 3,80 & 10,27 \\
\hline E100 & 7 & 20,02 & 20,96 & 5 & 15,44 & 19,99 & 13 & 17,80 & 20,49 & $x$ & $x$ & $x$ & $x$ & $\mathrm{x}$ \\
\hline Estrato $\mathrm{E}$ & 357 & 29,10 & 26,21 & 246 & 20,94 & 20,08 & 603 & 25,11 & 23,21 & 21,68 & 15,31 & 80,28 & 0,00 & * \\
\hline Estado & 6264 & 32,39 & 32,35 & 4002 & 19,89 & 19,87 & 10266 & 26,01 & 25,98 & 22,75 & 12,34 & 80,28 & 0,00 & * \\
\hline
\end{tabular}

Fonte: SIM/ MS, Censo IBGE e Estratos de Vulnerabilidade Social segundo metodologia desenvolvida a partir do IPVS (FSEADE 2005)

Nota $^{1}:$ ( - ) Dado numérico igual a 0 não resultante de arredondamento

$(0 ; 0,0 ; 0,00)$ Dado numérico igual a zero resultante de arredondamento de um dado originalmente positivo

A soma das parcelas pode não coincidir com o total em função de arredondamentos efetuados nos dados parciais

(x) Não se aplica (conjunto formado por um só município)

(*) Não divisível

Códigos A00 a B99 - Algumas Doenças Infecciosas e Parasitárias (Cap. I-CID 10) 
Anexo 18 - Óbitos e taxa de mortalidade (bruta e padronizada) total e segundo sexo (por 100 mil hab.) por Doenças Respiratórias, mediana, desvio padrão e razão de taxas nos conjuntos de municípios e respectivos Estratos de Vulnerabilidade Social. Estado de São Paulo, média do triênio 2003 a 2005

\begin{tabular}{|c|c|c|c|c|c|c|c|c|c|c|c|c|c|c|}
\hline \multirow[b]{2}{*}{ Status } & \multicolumn{3}{|c|}{ Homens } & \multicolumn{3}{|c|}{ Mulheres } & \multicolumn{4}{|c|}{ Total } & \multirow{2}{*}{$\begin{array}{l}\text { Desvio } \\
\text { padrão }\end{array}$} & \multirow{2}{*}{$\begin{array}{l}\text { Maior } \\
\text { Valor }^{1}\end{array}$} & \multirow{2}{*}{$\begin{array}{l}\text { Menor } \\
\text { Valor }^{2}\end{array}$} & \multirow{2}{*}{$\begin{array}{c}\text { кazao } \\
(1 / 2) \\
\end{array}$} \\
\hline & Óbitos & TBM & TPM & Óbitos & TBM & TPM & Óbitos & TBM & TPM & Mediana & & & & \\
\hline $\mathrm{A} 20$ & 17 & 86,40 & 71,52 & 8 & 42,10 & 35,38 & 25 & 64,42 & 53,59 & 45,62 & 16,62 & 74,68 & 34,66 & 2,15 \\
\hline $\mathrm{A} 100$ & 17 & 65,36 & 61,90 & 16 & 58,52 & 58,70 & 33 & 61,92 & 60,29 & $x$ & $x$ & $x$ & $x$ & $x$ \\
\hline A300 & 265 & 104,31 & 78,10 & 221 & 81,66 & 58,69 & 486 & 92,64 & 68,10 & 74,10 & 11,89 & 77,65 & 55,52 & 1,40 \\
\hline A500 & 391 & 108,70 & 79,84 & 363 & 91,33 & 61,77 & 754 & 99,58 & 70,35 & 70,95 & 8,12 & 76,69 & 65,21 & 1,18 \\
\hline A1000 & 312 & 97,15 & 87,71 & 227 & 66,28 & 58,49 & 539 & 81,20 & 72,61 & $x$ & $x$ & $x$ & $x$ & $x$ \\
\hline Estrato A & 1001 & 102,17 & 81,31 & 835 & 79,01 & 59,36 & 1836 & 90,15 & 69,93 & 60,29 & 15,54 & 77,65 & 34,66 & 2,24 \\
\hline B20 & 28 & 73,68 & 60,97 & 17 & 44,06 & 36,42 & 45 & 58,99 & 48,80 & 52,09 & 12,10 & 66,47 & 29,60 & 2,25 \\
\hline B50 & 201 & 75,61 & 68,25 & 149 & 56,16 & 53,54 & 350 & 65,88 & 60,90 & 62,50 & 10,97 & 81,02 & 34,73 & 2,33 \\
\hline B100 & 504 & 78,77 & 70,02 & 401 & 61,29 & 54,95 & 904 & 69,93 & 62,40 & 61,76 & 12,83 & 88,33 & 42,39 & 2,08 \\
\hline B300 & 1463 & 77,83 & 74,24 & 1176 & 60,93 & 59,55 & 2639 & 69,27 & 66,80 & 65,70 & 10,68 & 92,07 & 49,73 & 1,85 \\
\hline B500 & 782 & 77,13 & 74,73 & 642 & 60,68 & 58,13 & 1424 & 68,73 & 66,25 & 65,83 & 6,16 & 74,82 & 59,30 & 1,26 \\
\hline $\mathrm{B} 1000$ & 998 & 65,53 & 74,45 & 836 & 52,36 & 59,19 & 1834 & 58,79 & 66,64 & 63,75 & 8,10 & 77,68 & 59,67 & 1,30 \\
\hline B10000 & 4578 & 81,19 & 80,69 & 4158 & 67,37 & 62,47 & 8736 & 73,97 & 71,17 & 69,76 & 2,41 & 71,47 & 68,06 & 1,05 \\
\hline Estrato B & 8554 & 77,77 & 77,18 & 7378 & 62,99 & 60,44 & 15932 & 70,15 & 68,55 & 63,12 & 12,03 & 92,07 & 29,60 & 3,11 \\
\hline $\mathrm{C} 20$ & 76 & 80,11 & 77,09 & 43 & 47,58 & 47,31 & 119 & 64,18 & 62,50 & 62,43 & 22,59 & 86,78 & 16,20 & 5,36 \\
\hline $\mathrm{C} 50$ & 319 & 67,94 & 70,51 & 242 & 52,22 & 58,64 & 561 & 60,14 & 64,62 & 64,08 & 12,48 & 82,42 & 42,74 & 1,93 \\
\hline $\mathrm{C} 100$ & 384 & 66,64 & 72,99 & 300 & 52,01 & 60,83 & 684 & 59,32 & 66,90 & 68,71 & 13,44 & 94,10 & 41,24 & 2,28 \\
\hline $\mathrm{C} 300$ & 1088 & 61,81 & 81,12 & 933 & 52,19 & 72,29 & 2021 & 56,96 & 76,67 & 76,06 & 19,31 & 118,06 & 44,88 & 2,63 \\
\hline C500 & 409 & 56,63 & 87,13 & 333 & 44,78 & 72,59 & 743 & 50,62 & 79,75 & 78,58 & 6,05 & 87,55 & 78,49 & 1,12 \\
\hline $\mathrm{C} 10000$ & 394 & 66,77 & 93,88 & 328 & 53,83 & 78,06 & 722 & 60,20 & 85,84 & $\mathrm{x}$ & $x$ & $x$ & $x$ & $x$ \\
\hline Estrato C & 2670 & 63,37 & 81,55 & 2180 & 51,02 & 69,61 & 4851 & 57,15 & 75,54 & 68,38 & 17,94 & 118,06 & 16,20 & 7,29 \\
\hline D20 & 349 & 82,26 & 69,62 & 248 & 59,99 & 55,57 & 596 & 71,27 & 62,69 & 58,36 & 20,58 & 123,87 & 16,02 & 7,73 \\
\hline D50 & 838 & 85,45 & 72,25 & 601 & 61,58 & 57,17 & 1439 & 73,54 & 64,73 & 49,56 & 5,10 & 96,41 & 40,68 & 2,37 \\
\hline D100 & 401 & 91,58 & 77,21 & 306 & 69,58 & 61,98 & 707 & 80,55 & 69,58 & 67,39 & 13,94 & 94,20 & 48,76 & 1,93 \\
\hline D300 & 43 & 54,84 & 94,53 & 28 & 35,81 & 64,60 & 71 & 45,30 & 79,53 & $\mathrm{x}$ & $x$ & $x$ & $x$ & $x$ \\
\hline Estrato D & 1630 & 84,90 & 73,70 & 1183 & 62,02 & 58,24 & 2813 & 73,50 & 66,00 & 62,64 & 17,02 & 123,87 & 16,02 & 7,73 \\
\hline E20 & 827 & 85,54 & 65,99 & 614 & 66,42 & 59,42 & 1441 & 76,20 & 62,78 & 60,31 & 23,84 & 124,72 & 0,00 & $*$ \\
\hline E50 & 155 & 69,43 & 65,70 & 123 & 57,04 & 61,28 & 278 & 63,33 & 63,53 & 64,09 & 11,09 & 84,03 & 45,25 & 1,86 \\
\hline E100 & 18 & 48,24 & 48,98 & 14 & 41,49 & 53,99 & 32 & 44,96 & 51,41 & $\mathrm{x}$ & $x$ & $\mathrm{x}$ & $x$ & $x$ \\
\hline Estrato E & 1000 & 81,49 & 65,43 & 751 & 63,96 & 59,60 & 1751 & 72,92 & 62,58 & 60,48 & 23,30 & 124,72 & 0,00 & * \\
\hline Estado & 14855 & 76,81 & 77,25 & 12327 & 61,25 & 62,08 & 27183 & 68,88 & 69,51 & 62,64 & 20,08 & 124,72 & 0,00 & $*$ \\
\hline
\end{tabular}

Fonte: SIM/ MS, Censo IBGE e Estratos de Vulnerabilidade Social segundo metodologia desenvolvida a partir do IPVS (FSEADE 2005)

Nota $^{1}$ : $\quad(-)$ Dado numérico igual a 0 não resultante de arredondamento

$(0 ; 0,0 ; 0,00)$ Dado numérico igual a zero resultante de arredondamento de um dado originalmente positivo

A soma das parcelas pode não coincidir com o total em função de arredondamentos efetuados nos dados parciais

(x) Não se aplica (conjunto formado por um só município)

(*) Não divisível

Códigos: J00 a J99 - Doenças do Aparelho Respiratório (Cap. X -CID 10) 
Anexo 19 - Óbitos e taxa de mortalidade (bruta e padronizada) total e segundo sexo por Doenças Infecciosas e Parasitárias e Doenças Respiratórias e \% de óbitos por Causas Mal Definidas nos municípios. Estado de São Paulo, média do triênio, 2003-2005

\begin{tabular}{|c|c|c|c|c|c|c|c|c|c|c|c|c|c|c|c|c|c|c|c|c|c|c|c|}
\hline \multirow[b]{2}{*}{ IBGE } & \multirow[b]{2}{*}{ Mun. } & \multirow[b]{2}{*}{ Porte } & \multicolumn{7}{|c|}{$\begin{array}{l}\text { DOENCAS INFECCIOSAS E PARASITÁRIAS } \\
\text { Mulheres }\end{array}$} & \multirow{2}{*}{$\begin{array}{l}\text { Total } \\
\text { TMB } \\
\end{array}$} & \multirow[b]{2}{*}{ TPM } & \multirow{2}{*}{\multicolumn{3}{|c|}{ Homens }} & \multicolumn{6}{|c|}{$\begin{array}{l}\text { DOENCAS RESPIRATÓRIAS } \\
\text { Mulheres }\end{array}$} & \multicolumn{3}{|c|}{ MAL DEFINIDAS } \\
\hline & & & Obitos & $\begin{array}{l}\text { Homens } \\
\text { TMB }\end{array}$ & TPM & Obitos & $\begin{array}{l}\text { Mulhe } \\
\text { TMB }\end{array}$ & TPM & Obitos & & & & & & Obitos & & TPM & Obitos T & $\begin{array}{l}\text { Total } \\
\text { TMB } \\
\end{array}$ & TPM & Obitos $\mathrm{C}$ & Ob.Totais \% & $\%$ \\
\hline 350010 & Adamantina & D50 & 4 & 26,06 & 22,64 & 3 & 19,05 & 15,10 & 8 & 22,47 & 18,77 & 22 & 132,31 & 79,08 & 13 & 74,30 & 52,53 & 35 & 102,57 & 65,47 & 28 & 263 & 10,8 \\
\hline 350020 & Adolfo & E20 & 1 & 33,98 & 26,65 & 0 & 17,49 & 16,31 & 1 & 25,85 & 21,55 & 1 & 50,98 & 38,37 & 1 & 69,94 & 65,63 & 2 & 60,32 & 51,81 & 2 & 23 & 7,1 \\
\hline 350030 & Aguaí & E50 & 3 & 17,52 & 17,22 & 1 & 8,81 & 8,86 & 4 & 13,18 & 13,05 & 13 & 85,43 & 72,65 & 10 & 63,86 & 59,10 & 23 & 74,68 & 65,89 & 35 & 213 & 16,3 \\
\hline 350040 & Águas da Prata & D20 & 1 & 27,11 & 22,57 & 1 & 18,33 & 17,59 & 2 & 22,75 & 20,10 & 3 & 72,29 & 47,74 & 4 & 119,13 & 76,02 & 7 & 95,55 & 61,78 & 11 & 67 & 15,9 \\
\hline 350050 & Águas de Lindóia & D20 & 1 & 11,18 & 11,32 & 1 & 10,98 & 9,21 & 2 & 11,08 & 10,26 & 8 & 89,43 & 65,58 & 9 & 98,80 & 77,40 & 17 & 94,16 & 71,54 & 7 & 133 & 5,0 \\
\hline 350055 & Águas de Santa Bárbara & $B 20$ & 0 & 11,34 & 7,20 & 1 & 23,16 & 22,23 & 1 & 17,19 & 14,64 & 2 & 56,68 & 42,36 & 2 & 69,48 & 63,38 & 4 & 63,02 & 52,76 & 6 & 39 & 14,7 \\
\hline 350060 & Águas de São Pedro & A20 & 1 & 73,34 & 57,63 & 0 & 31,57 & 13,08 & 1 & 50,89 & 33,69 & 1 & 146,68 & 85,50 & 2 & 157,83 & 65,38 & 3 & 152,67 & 74,68 & 2 & 24 & 8,5 \\
\hline 350070 & Agudos & C50 & 4 & 22,01 & 22,97 & 4 & 21,76 & 22,01 & 7 & 21,88 & 22,49 & 12 & 72,02 & 74,46 & 12 & 71,22 & 72,13 & 24 & 71,62 & 73,28 & 22 & 217 & 10,1 \\
\hline 350075 & Alambari & E20 & 0 & 17,00 & 12,86 & 0 & 18,07 & 20,64 & 1 & 17,52 & 16,63 & 2 & 84,98 & 79,50 & 0 & 18,07 & 17,91 & 2 & 52,55 & 49,65 & 2 & 25 & 8,0 \\
\hline 350080 & Alfredo Marcondes & E20 & 1 & 51,82 & 26,84 & 0 & 17,95 & 11,45 & 1 & 35,21 & 19,29 & 1 & 69,10 & 45,47 & 2 & 89,77 & 57,26 & 3 & 79,23 & 51,25 & 3 & 27 & 12,3 \\
\hline 350090 & Altair & E20 & 0 & 17,04 & 17,98 & 0 & 19,57 & 20,59 & 1 & 18,21 & 19,20 & 3 & 136,31 & 141,87 & 1 & 39,13 & 39,31 & 3 & 91,07 & 94,13 & 2 & 23 & 7,1 \\
\hline 350100 & Altinópolis & D20 & 3 & 36,42 & 35,82 & 3 & 33,06 & 29,48 & 6 & 34,76 & 32,68 & 5 & 64,75 & 49,11 & 4 & \begin{tabular}{|l|}
45,45 \\
\end{tabular} & 39,02 & 9 & 55,20 & 44,12 & 2 & 101 & 1,7 \\
\hline 350110 & Alto Alegre & E20 & 1 & 31,84 & 17,22 & - & & & 1 & 16,56 & 8,96 & 4 & 191,05 & 103,33 & 0 & 17,25 & 11,10 & 4 & 107,63 & 59,06 & 5 & 36 & 14,8 \\
\hline 350115 & Alumínio & $\mathrm{C} 20$ & 3 & 37,34 & 43,72 & 0 & 4,23 & 3,58 & 3 & 20,94 & 23,84 & 5 & 62,23 & 79,95 & 2 & 29,59 & 38,82 & 7 & 46,07 & 59,58 & 5 & 78 & 6,0 \\
\hline 350120 & Alvares Florence & E20 & - & & & 0 & 17,51 & 12,61 & 0 & 8,36 & 6,02 & 2 & 79,92 & 48,24 & 3 & 140,06 & 93,83 & 4 & 108,62 & 69,99 & 3 & 34 & 8,7 \\
\hline 350130 & Alvares Machado & D50 & 1 & 10,88 & 8,86 & 0 & 2,75 & 2,73 & 2 & 6,84 & 5,81 & 9 & 70,72 & 61,75 & 4 & 33,05 & 32,88 & 13 & 52,00 & 47,40 & 15 & 139 & 10,8 \\
\hline 350140 & Alvaro de Carvalho & E20 & 1 & 36,71 & 30,40 & & & & 1 & 22,00 & 18,22 & 1 & 48,94 & 58,45 & 2 & 91,54 & 83,94 & 3 & 66,01 & 68,66 & 4 & 24 & 15,3 \\
\hline 350150 & Alvinlândia & E20 & 1 & 66,74 & 66,25 & 1 & 68,00 & 55,04 & 2 & 67,36 & 60,70 & 1 & 88,99 & 76,42 & 1 & \begin{tabular}{|r}
45,33 \\
\end{tabular} & 36,70 & 2 & 67,36 & 56,74 & 3 & 21 & 12,7 \\
\hline 350160 & Americana & A300 & 30 & 31,03 & 28,84 & 14 & 14,52 & 13,28 & 44 & 22,68 & 20,98 & 67 & 69,29 & 61,17 & 55 & 56,04 & 49,98 & 122 & 62,60 & 55,52 & 219 & 1140 & 19,2 \\
\hline 350170 & Américo Brasiliense & D50 & 4 & 22,53 & 28,17 & 2 & 12,75 & 18,31 & 6 & 17,73 & 23,33 & 10 & 59,41 & 81,26 & 7 & 44,62 & 66,56 & 17 & 52,15 & 74,05 & 12 & 148 & 7,9 \\
\hline 350180 & Américo de Campos & E20 & 2 & 71,33 & 51,65 & 2 & 59,74 & 48,61 & 4 & 65,55 & 50,13 & 4 & 130,77 & 84,49 & 3 & 95,58 & 69,20 & 6 & 113,22 & 76,87 & 1 & 41 & 3,3 \\
\hline 350190 & Amparo & B100 & 11 & 33,06 & 30,71 & 5 & 16,44 & 14,45 & 16 & 24,73 & 22,56 & 34 & 106,42 & 84,24 & 29 & 88,39 & 70,58 & 63 & 97,38 & 77,39 & 12 & 444 & 2,7 \\
\hline 350200 & Analândia & B20 & 1 & 33,60 & 31,98 & 0 & 18,03 & 16,33 & 1 & 26,09 & 24,43 & 2 & 117,61 & 95,49 & 1 & 36,07 & 35,32 & 3 & 78,28 & 66,47 & 1 & 23 & 5,9 \\
\hline 350210 & Andradina & D100 & 10 & 37,16 & 32,79 & 8 & 26,82 & 23,33 & 18 & 31,92 & 28,00 & 24 & 85,11 & 64,21 & 18 & \begin{tabular}{|r}
64,14 \\
\end{tabular} & 51,26 & 42 & 74,48 & 57,65 & 80 & 400 & 20,1 \\
\hline 350220 & Angatuba & D50 & 2 & 22,41 & 21,64 & 2 & 23,77 & 24,47 & 5 & 23,07 & 23,01 & 12 & 118,47 & 93,62 & 9 & 95,09 & 99,37 & 22 & 107,12 & 96,41 & 12 & 137 & 8,5 \\
\hline 350230 & Anhembi & E20 & 1 & 26,01 & 23,49 & - & & & 1 & 13,39 & 12,09 & 2 & 78,03 & 55,75 & 0 & 13,79 & 14,78 & 2 & 46,85 & 35,87 & 4 & 36 & 10,2 \\
\hline 350240 & Anhumas & E20 & 1 & 74,85 & 56,23 & 0 & 19,56 & 18,91 & 2 & 47,81 & 37,98 & 1 & 56,14 & 45,54 & 1 & \begin{tabular}{|l|}
39,12 \\
\end{tabular} & 36,55 & 2 & 47,81 & 41,14 & 4 & 21 & 21,0 \\
\hline 350250 & Aparecida & B50 & 9 & 53,36 & 54,31 & 4 & 20,20 & 19,98 & 13 & 36,47 & 36,82 & 15 & 85,76 & 82,95 & 13 & 71,61 & 69,26 & 28 & 78,55 & 75,97 & 28 & 263 & 10,6 \\
\hline 350260 & Aparecida d'Oeste & E20 & 1 & 27,54 & 18,50 & - & & & 1 & 13,71 & 9,21 & 3 & 123,93 & 72,84 & 2 & 81,94 & 59,58 & 5 & 102,85 & 66,18 & 4 & 35 & 10,6 \\
\hline 350270 & Apiaí & D50 & 4 & 26,47 & 28,58 & 2 & 12,27 & 14,89 & 5 & 19,44 & 21,80 & 8 & 57,76 & 63,09 & 7 & 49,07 & 62,17 & 15 & 53,45 & 62,64 & 28 & 151 & 18,7 \\
\hline 350275 & Araçariguama & D20 & 1 & 19,89 & 22,11 & 1 & 15,77 & 21,15 & 2 & 17,89 & 21,64 & 4 & 64,64 & 76,42 & 1 & 21,03 & 33,01 & 6 & 43,44 & 55,32 & 6 & 64 & 9,4 \\
\hline 350280 & Araçatuba & B300 & 35 & 40,89 & 37,70 & 28 & 30,36 & 27,29 & 63 & 35,46 & 32,33 & 68 & 79,05 & 65,89 & 48 & 53,05 & 45,04 & 116 & 65,64 & 55,14 & 165 & 1176 & 14,0 \\
\hline
\end{tabular}


Anexo 19 - Óbitos e taxa de mortalidade (bruta e padronizada) total e segundo sexo por Doenças Infecciosas e Parasitárias e Doenças Respiratórias e \% de óbitos por Causas Mal Definidas nos municípios. Estado de São Paulo, média do triênio, 2003-2005

\begin{tabular}{|c|c|c|c|c|c|c|c|c|c|c|c|c|c|c|c|c|c|c|c|c|c|c|c|}
\hline \multirow[b]{2}{*}{ IBGE } & \multirow[b]{2}{*}{ Mun. } & \multirow[b]{2}{*}{ Porte } & \multicolumn{9}{|c|}{$\begin{array}{l}\text { DOENCAS INFECCIOSAS E PARASITÁRIAS } \\
\text { Mulheres }\end{array}$} & \multicolumn{9}{|c|}{ DOENCAS RESPIRATÓRIAS } & \multicolumn{3}{|c|}{ MAL DEFINIDAS } \\
\hline & & & Obitos & $\begin{array}{l}\text { Homens } \\
\text { TMB }\end{array}$ & TPM & Obitos & $\begin{array}{l}\text { Mulhere } \\
\text { TMB }\end{array}$ & STPM & Obitos & $\begin{array}{l}\text { Total } \\
\text { TMB }\end{array}$ & TPM & Obitos & $\begin{array}{l}\text { Homens } \\
\text { TMB }\end{array}$ & TPM & Obitos $\mathrm{N}$ & $\begin{array}{l}\text { Mulhere } \\
\text { TMB }\end{array}$ & TPM & Obitos & $\begin{array}{l}\text { Total } \\
\text { TMB }\end{array}$ & TPM & Obitos & Ob.Totais & $\%$ \\
\hline 350290 & Araçoiaba da Serra & B50 & 3 & \begin{tabular}{|l|l|}
3 & 29,82 \\
\end{tabular} & 27,77 & 1 & 12,13 & 11,62 & 5 & 21,05 & 19,76 & 10 & 92,46 & 77,58 & 10 & 87,92 & 84,52 & 20 & 90,21 & 81,02 & 20 & 150 & 13,1 \\
\hline 350300 & Aramina & E20 & 1 & \begin{tabular}{l|l|} 
& 25,81 \\
\end{tabular} & 23,70 & 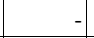 & & & 1 & 13,14 & 12,06 & 2 & 90,33 & 65,59 & 1 & 40,13 & \begin{tabular}{|l|} 
\\
37,88 \\
\end{tabular} & 3 & 65,69 & 51,99 & 3 & 30 & 10,1 \\
\hline 350310 & 0 Arandu & E20 & 2 & \begin{tabular}{|l|}
252,27 \\
\end{tabular} & 54,41 & & & & 2 & 26,60 & 27,69 & 3 & 94,08 & 98,78 & 0 & 10,83 & \begin{tabular}{|l|}
30,69 \\
\end{tabular} & 3 & 53,20 & 55,52 & 5 & 33 & 14,0 \\
\hline 350315 & 5 Arapeí & E20 & 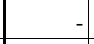 & & & 0 & 24,05 & 18,85 & 0 & 12,07 & 9,46 & 1 & 96,92 & 58,92 & 1 & 48,10 & 46,23 & 2 & 72,42 & 52,55 & 1 & 22 & 4,6 \\
\hline 350320 & Araraquara & A300 & 34 & \begin{tabular}{l|l|}
4 & 36,25 \\
\end{tabular} & 33,62 & 23 & 23,22 & 20,25 & 57 & 29,56 & 26,76 & 102 & 109,11 & 88,35 & 76 & 76,72 & 60,62 & 178 & 92,47 & 74,10 & 32 & 1272 & 2,5 \\
\hline 350330 & 0 Araras & B300 & 24 & \begin{tabular}{l|l|}
4 & 42,40 \\
\end{tabular} & 41,51 & 13 & 23,87 & 23,42 & 37 & 33,13 & 32,46 & 50 & 89,58 & 82,09 & 26 & 47,14 & 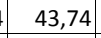 & 76 & 68,35 & 62,91 & 57 & 703 & 8,2 \\
\hline 350335 & 5 Arcoolris & E20 & - & & & - & & & - & & & 1 & 55,91 & 31,95 & - & & & 1 & 29,67 & 16,95 & 1 & 14 & 9,8 \\
\hline 350340 & Arealva & E20 & 1 & 26,25 & 23,10 & 1 & 18,56 & 16,39 & 2 & 22,52 & 19,84 & 3 & 78,74 & 43,25 & 3 & 74,25 & 50,19 & 6 & 76,56 & 46,62 & 6 & 52 & 12,2 \\
\hline 350350 & Areias & E20 & 0 & 17,65 & 15,24 & & & & 0 & 8,91 & 7,69 & - & & & 1 & 53,99 & 45,71 & 1 & 26,73 & 22,63 & 3 & 29 & 10,3 \\
\hline 350360 & Areiópolis & E20 & 1 & 24,84 & 31,47 & & & & 1 & 12,78 & 16,19 & 3 & 55,88 & 67,81 & 3 & 65,83 & \begin{tabular}{|l|l|} 
& 92,91 \\
\end{tabular} & 6 & 60,71 & 79,99 & 3 & 62 & 4,3 \\
\hline 350370 & Ariranha & E20 & 1 & 31,79 & 24,07 & 0 & 8,31 & 8,59 & 2 & 20,31 & 16,50 & 4 & 103,31 & 77,36 & 4 & 91,40 & 74,70 & 8 & 97,49 & 76,06 & 2 & 56 & 3,6 \\
\hline 350380 & Artur Nogueira & C50 & 3 & 16,91 & 18,62 & 4 & 18,72 & 21,93 & 7 & 17,81 & 20,27 & 10 & 52,42 & 58,30 & 7 & 35,74 & \begin{tabular}{|l|} 
\\
$+45,28$ \\
\end{tabular} & 17 & 44,11 & 51,81 & 21 & 179 & 11,6 \\
\hline 350390 & Arujá & C100 & 6 & 18,46 & 22,62 & 6 & 16,43 & 18,01 & 12 & 17,44 & 20,31 & 20 & 58,28 & 81,71 & 14 & 41,55 & | 61,23 & 34 & 49,89 & 71,44 & 11 & 340 & 3,3 \\
\hline 350395 & Aspásia & E20 & - & & & 0 & 38,04 & 25,85 & 0 & 18,36 & 12,48 & 1 & 106,46 & 63,44 & 1 & 76,07 & 64,84 & 2 & 91,79 & 64,12 & 3 & 17 & 18,0 \\
\hline 350400 & Assis & B100 & 19 & 43,04 & 37,35 & 14 & 30,22 & 25,04 & 34 & 36,45 & 31,03 & 39 & 86,08 & 67,03 & 34 & 71,68 & \begin{tabular}{|r|}
55,61 \\
\end{tabular} & 73 & 78,68 & 61,17 & 142 & 668 & 21,3 \\
\hline 350410 & Atibaia & C300 & 20 & 32,31 & 31,48 & 10 & 15,70 & 15,43 & 29 & 23,96 & 23,41 & 55 & 89,80 & 80,56 & 40 & 64,42 & 60,94 & 94 & 77,04 & \begin{tabular}{|l|} 
\\
\end{tabular} & 14 & 771 & 1,8 \\
\hline 350420 & Auriflama & E20 & 2 & 33,42 & 26,50 & 1 & 9,71 & 8,26 & 3 & $21,67 \mid$ & 17,46 & 4 & 57,30 & 43,69 & 4 & 63,12 & 54,05 & 8 & 60,18 & 48,82 & 13 & 90 & 14,8 \\
\hline 350430 & Avaí & E20 & 1 & 56,01 & 56,30 & 1 & 30,34 & 29,81 & 2 & 43,69 & 43,59 & 1 & 56,01 & 38,59 & 1 & 45,51 & \begin{tabular}{|l}
40,31 \\
\end{tabular} & 2 & 50,97 & 39,41 & 2 & 35 & 5,7 \\
\hline 350440 & Avanhandava & E20 & 2 & 36,31 & 36,26 & 0 & 7,21 & 7,68 & 2 & 21,71 & 21,92 & 5 & 108,92 & 95,49 & 2 & 50,48 & \begin{tabular}{l|l|}
3 & 48,80 \\
\end{tabular} & 7 & 79,60 & 72,06 & 10 & 55 & 17,6 \\
\hline 350450 & Avaré & B100 & 11 & 27,24 & 26,57 & 10 & 23,17 & 21,36 & 21 & 25,20 & 23,96 & 27 & 64,09 & 57,94 & 26 & 62,31 & 54,90 & 53 & 63,20 & $\begin{array}{l}56,42 \\
\end{array}$ & 82 & 566 & 14,5 \\
\hline 350460 & Bady Bassitt & A20 & 1 & 14,01 & 13,27 & 2 & 28,50 & 28,20 & 3 & 21,19 & 20,67 & 8 & 107,40 & 98,37 & 3 & 42,75 & \begin{tabular}{|l|}
53,92 \\
\end{tabular} & 11 & 75,35 & 71,38 & 2 & 71 & 2,8 \\
\hline 350470 & Balbinos & E20 & 0 & 47,71 & 27,68 & & & & 0 & 24,59 & 14,27 & 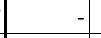 & & & 0 & 50,76 & \begin{tabular}{|l|}
59,23 \\
\end{tabular} & 0 & 24,59 & 19,01 & 1 & 6 & 21,1 \\
\hline 350480 & Bálsamo & E20 & 1 & 17,61 & 14,12 & 1 & 35,02 & 28,52 & 2 & 26,34 & 21,34 & 4 & 96,88 & 67,28 & 4 & 113,83 & \begin{tabular}{|l|l|} 
& 82,61 \\
\end{tabular} & 8 & 105,38 & 74,97 & 1 & 55 & 1,8 \\
\hline 350490 & Bananal & D20 & 2 & 47,07 & 42,35 & 2 & 46,31 & 43,41 & 5 & 46,68 & 42,88 & 10 & 201,71 & \begin{tabular}{|l|}
162,42 \\
\end{tabular} & 3 & 66,15 & 55,03 & 13 & 133,38 & 108,29 & 4 & 67 & 5,5 \\
\hline 350500 & Barao de Antonina & E20 & 0 & 24,25 & 20,20 & 1 & 50,70 & 42,00 & 1 & 37,18 & 30,86 & 1 & 72,74 & 43,34 & 1 & 101,39 & 86,27 & 2 & 86,75 & 64,33 & 5 & 26 & 17,9 \\
\hline 350510 & Barbosa & E20 & 1 & 32,80 & 27,04 & 0 & 11,14 & 12,18 & 1 & 22,07 & 19,68 & 2 & 76,54 & 62,31 & 1 & 44,54 & \begin{tabular}{|l|}
4 \\
+
\end{tabular} & 4 & 60,69 & 54,21 & 7 & 42 & 15,9 \\
\hline 350520 & Bariiri & D50 & 4 & 28,98 & 21,69 & 4 & 29,06 & 19,97 & 9 & \begin{tabular}{|l|}
29,02 \\
\end{tabular} & 20,83 & 12 & 78,02 & 49,60 & 11 & 73,76 & 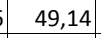 & 23 & 75,89 & 49,37 & 26 & 222 & 11,6 \\
\hline 350530 & Barra Bonita & C50 & 6 & 31,97 & 29,82 & 4 & 21,28 & 20,65 & 10 & 26,62 & 25,23 & 16 & 83,47 & 72,83 & 7 & 39,02 & $\begin{array}{l}35,88 \\
\end{array}$ & 23 & 61,23 & 54,34 & 17 & 222 & 7,7 \\
\hline 350535 & Barra do Chapéu & E20 & 0 & 12,90 & 14,52 & 1 & 59,83 & 60,26 & 2 & 34,63 & 35,71 & 1 & 38,70 & 36,51 & 1 & 44,87 & \begin{tabular}{|l|}
39,29 \\
\end{tabular} & 2 & 41,56 & 37,79 & 9 & 29 & 30,2 \\
\hline 350540 & Barra do Turvo & E20 & 1 & 29,71 & 30,42 & 1 & 16,42 & 12,99 & 2 & 23,40 & 22,14 & 2 & 51,99 & 45,15 & 6 & 139,58 & \begin{tabular}{l|l|}
3 & 174,42 \\
\end{tabular} & 8 & 93,59 & 106,55 & 5 & 54 & 9,9 \\
\hline 350550 & Barretos & B300 & 42 & 79,34 & 73,87 & 26 & 46,51 & 41,06 & 67 & 62,51 & 57,06 & 60 & 114,24 & 93,46 & 39 & 70,06 & \begin{tabular}{|l|l|}
5 & 57,18 \\
\end{tabular} & 99 & 91,61 & 74,87 & 59 & 890 & 6,6 \\
\hline 350560 & Barrinha & D50 & 6 & 41,99 & 48,24 & 4 & 30,53 & 39,57 & 10 & 36,34 & 43,97 & 10 & 74,10 & $\mid 100,84$ & 6 & 48,34 & 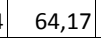 & 16 & 61,41 & 82,78 & 1 & 138 & 1,0 \\
\hline
\end{tabular}


Anexo 19 - Óbitos e taxa de mortalidade (bruta e padronizada) total e segundo sexo por Doenças Infecciosas e Parasitárias e Doenças Respiratórias e \% de óbitos por Causas Mal Definidas nos municípios. Estado de São Paulo, média do triênio, 2003-2005

\begin{tabular}{|c|c|c|c|c|c|c|c|c|c|c|c|c|c|c|c|c|c|c|c|c|c|c|c|}
\hline \multirow[b]{2}{*}{ IBGE } & \multirow[b]{2}{*}{ Mun. } & \multirow[b]{2}{*}{ Porte } & \multicolumn{9}{|c|}{$\begin{array}{l}\text { DOENCAS INFECCIOSAS E PARASITÁRIAS } \\
\text { Dus }\end{array}$} & \multicolumn{9}{|c|}{ DOENCAS RESPIRATÓRIAS } & \multicolumn{3}{|c|}{ MAL DEFINIDAS } \\
\hline & & & Obitos & $\begin{array}{l}\text { Homens } \\
\text { TMB }\end{array}$ & TPM & Obitos & $\begin{array}{l}\text { Mulhere } \\
\text { TMB }\end{array}$ & TPM & Obitos & $\begin{array}{l}\text { Total } \\
\text { TMB }\end{array}$ & TPM & Obitos & $\begin{array}{l}\text { Homens } \\
\text { TMB }\end{array}$ & TPM & Obitos & $\begin{array}{l}\text { Mulhere } \\
\text { TMB }\end{array}$ & TPM & Obitos & $\begin{array}{l}\text { Total } \\
\text { TMB }\end{array}$ & TPM & Obitos & Ob.Totais & $\%$ \\
\hline 350570 & Barueri & С300 & 29 & 23,89 & 29,60 & 17 & 13,56 & 17,56 & 45 & 18,66 & 23,50 & 61 & 50,84 & 87,34 & 54 & 44,21 & 75,10 & 115 & 47,48 & 81,15 & 12 & 1125 & 1,1 \\
\hline 350580 & Bastos & D50 & 3 & 28,36 & 28,28 & 3 & 25,00 & 24,79 & 6 & 26,67 & 26,53 & 7 & 63,02 & 59,56 & 6 & 53,13 & 52,87 & 12 & 58,06 & 56,20 & 10 & 122 & 8,2 \\
\hline 350590 & Batatais & C100 & 8 & 29,73 & 28,21 & 8 & 30,49 & 25,32 & 16 & 30,11 & 26,75 & 22 & 82,98 & 66,86 & 25 & 91,48 & 72,77 & 47 & 87,26 & 69,83 & 4 & 348 & 1,2 \\
\hline 350600 & Bauru & B500 & 65 & 39,05 & 37,60 & 43 & 24,69 & 22,80 & 108 & 31,71 & 30,03 & 122 & 73,10 & 65,28 & 109 & 62,77 & 53,58 & 231 & 67,82 & 59,30 & 31 & 2090 & 1,5 \\
\hline 350610 & Bebedouro & C100 & 16 & 40,75 & 39,75 & 10 & 25,31 & 23,71 & 26 & 32,92 & 31,62 & 29 & 76,29 & 65,10 & 24 & 61,58 & 52,95 & 54 & 68,83 & 58,94 & 40 & 507 & 7,9 \\
\hline 350620 & Bento de Abreu & $\mathrm{C} 20$ & 0 & 27,23 & 18,95 & & - & & 0 & \begin{tabular}{|l|}
3,92 \\
\end{tabular} & 9,69 & 1 & 81,70 & 56,85 & - & & & 1 & 41,77 & 29,07 & 3 & 13 & 20,0 \\
\hline 350630 & Bernardino de Campos & E20 & 2 & 42,66 & 34,43 & 1 & 24,02 & 17,41 & 4 & 33,27 & 25,86 & 7 & 127,99 & 86,80 & 3 & 60,05 & 38,40 & 10 & 93,77 & 62,42 & 6 & 82 & 7,3 \\
\hline 350635 & Bertioga & C50 & 5 & 25,26 & 27,74 & 3 & 14,38 & 15,27 & 8 & 20,00 & 21,71 & 10 & 52,21 & 66,19 & 10 & 55,74 & 87,56 & 21 & 53,91 & 76,52 & 11 & 196 & 5,4 \\
\hline 350640 & Bilac & D20 & - & & & 1 & 41,23 & 31,92 & 1 & 20,94 & 16,21 & 3 & 106,38 & 73,65 & 3 & 82,46 & 56,70 & 6 & 94,23 & 65,04 & 2 & 44 & 4,5 \\
\hline 350650 & Birigui & С 300 & 14 & 26,97 & 25,08 & 8 & 15,97 & 15,63 & 22 & 21,39 & 20,29 & 41 & 80,25 & 72,62 & 29 & 56,20 & 54,23 & 70 & 68,05 & 63,29 & 110 & 603 & 18,2 \\
\hline 350660 & BiritibaOMirim & D50 & 2 & 11,86 & 12,88 & 2 & 12,21 & 12,36 & 3 & 12,03 & 12,63 & 8 & 56,95 & 57,34 & 6 & 46,39 & 55,24 & 14 & 51,75 & 56,31 & 25 & 149 & 16,6 \\
\hline 350670 & Boa Esperança do Sul & E20 & 4 & 53,65 & 53,76 & 1 & 10,08 & 10,91 & 4 & 32,23 & 32,69 & 9 & 136,55 & 126,44 & 6 & 85,70 & 93,33 & 15 & 111,55 & 110,16 & 7 & 85 & 7,8 \\
\hline 350680 & Bocaina & D20 & 2 & 32,06 & 27,87 & 1 & 12,78 & 14,23 & 2 & 22,40 & 21,04 & 5 & 89,76 & 76,93 & 2 & 44,72 & 31,62 & 7 & 67,20 & 54,23 & 9 & 75 & 11,6 \\
\hline 350690 & Bofete & E20 & 2 & 47,00 & 40,13 & 0 & 8,65 & 8,04 & 2 & 28,77 & 24,88 & 2 & 47,00 & 37,61 & 1 & 34,60 & 33,76 & 3 & 41,10 & 35,78 & 2 & 62 & 2,7 \\
\hline 350700 & Boituva & D50 & 6 & 28,42 & 29,00 & 2 & 12,00 & 12,07 & 8 & 20,31 & 20,64 & 12 & 60,18 & 61,90 & 9 & 48,00 & 54,83 & 21 & 54,17 & 58,41 & 15 & 214 & 7,2 \\
\hline 350710 & Bom Jesus dos Perdoes & D20 & 2 & 31,25 & 31,01 & 1 & 18,04 & 19,36 & 4 & 24,68 & 25,21 & 3 & 40,18 & 39,61 & 4 & 54,12 & 61,03 & 7 & 47,11 & 50,26 & 2 & 98 & 2,4 \\
\hline 350715 & Bom Sucesso de Itararé & E20 & 0 & 17,71 & 20,83 & 0 & 19,03 & 9,42 & 1 & 18,34 & 15,33 & 1 & 35,41 & 41,63 & 1 & 38,05 & 43,38 & 1 & 36,68 & 42,47 & 4 & 17 & 21,6 \\
\hline 350720 & Borá & E20 & 0 & 80,39 & 55,07 & - & & - & 0 & 41,17 & 28,21 & - & 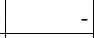 & - & 1 & 168,78 & 116,67 & 1 & 82,34 & 56,92 & - & 5 & - \\
\hline 350730 & Boracéia & E20 & 1 & 33,53 & 36,90 & 1 & 35,52 & 32,74 & 1 & 34,50 & 34,88 & 1 & 33,53 & 25,06 & - & & & 1 & 17,25 & 12,89 & 3 & 23 & 14,7 \\
\hline 350740 & Borborema & D20 & 2 & 28,83 & 24,34 & 2 & 29,68 & 25,15 & 4 & 29,25 & 24,74 & 7 & 96,10 & 63,21 & 7 & 98,93 & 80,12 & 13 & 97,49 & 71,54 & 4 & 105 & 3,8 \\
\hline 350745 & Borebi & E20 & - & & & & & & & & & 1 & 118,76 & 107,97 & 0 & 31,83 & 26,15 & 2 & 76,80 & 68,48 & 2 & 11 & 15,2 \\
\hline 350750 & Botucatu & B300 & 17 & 29,98 & 27,98 & 10 & 16,26 & 14,76 & 27 & 22,96 & 21,21 & 42 & 73,48 & 59,32 & 30 & 51,03 & 40,58 & 72 & 61,99 & 49,73 & 20 & 783 & 2,5 \\
\hline 350760 & Bragança Paulista & B300 & 21 & 31,62 & 29,86 & 15 & 22,29 & 21,80 & 37 & 26,91 & 25,79 & 78 & 116,11 & 102,81 & 62 & 89,63 & 81,55 & 140 & 102,74 & 92,07 & 18 & 980 & 1,9 \\
\hline 350770 & Braúna & E20 & 0 & 14,71 & 8,57 & 1 & 30,69 & 30,88 & 1 & 22,53 & 19,49 & 4 & 161,81 & 94,26 & - & & & 4 & 82,62 & 48,13 & 5 & 29 & 18,6 \\
\hline 350775 & Brejo Alegre & E20 & - & & & 0 & 28,16 & 28,56 & 0 & 13,58 & 13,77 & 0 & 26,23 & 21,15 & -1 & & & 0 & 13,58 & 10,95 & 2 & 12 & 17,1 \\
\hline 350780 & Brodósqui & $\mathrm{C} 20$ & 3 & 28,47 & 25,22 & 3 & 28,77 & 27,05 & 5 & \begin{tabular}{|l|}
28,62 \\
\end{tabular} & 26,13 & 13 & 138,81 & 114,02 & 6 & 61,13 & 53,84 & 19 & 100,17 & 84,08 & 2 & 116 & 1,4 \\
\hline 350790 & Brotas & D50 & 3 & 31,65 & 30,85 & 3 & 32,19 & 29,27 & 7 & 31,92 & 30,07 & 9 & 88,62 & 67,57 & 8 & 77,25 & 61,88 & 17 & 82,98 & 64,75 & 21 & 145 & 14,5 \\
\hline 350800 & Buri & E20 & 0 & 3,32 & 3,78 & 1 & 11,04 & 9,56 & 1 & 6,98 & 6,52 & 5 & 53,09 & 51,90 & 6 & 62,54 & 76,91 & 11 & 57,57 & 63,76 & 29 & 110 & 26,7 \\
\hline 350810 & Buritama & E20 & 3 & 42,07 & 36,45 & 3 & 41,60 & 36,26 & 6 & 41,83 & 36,35 & 6 & 88,82 & 68,50 & 3 & 46,22 & 39,66 & 10 & 67,40 & 54,00 & 12 & 97 & 12,0 \\
\hline 350820 & Buritizal & D20 & 1 & 36,26 & 27,63 & & & & 1 & 18,43 & 14,04 & 2 & 108,79 & 67,49 & 0 & 18,74 & 14,52 & 2 & 64,52 & 41,45 & 3 & 24 & 13,9 \\
\hline 350830 & Cabrália Paulista & E20 & 1 & 53,12 & 57,33 & 1 & 26,66 & 28,90 & 2 & 39,91 & 43,14 & 1 & 26,56 & 28,66 & 1 & 39,98 & 43,09 & 2 & 33,26 & 35,86 & 1 & 33 & 3,0 \\
\hline 350840 & Cabreúva & C50 & 4 & 18,14 & 19,86 & 2 & 12,11 & 15,69 & 6 & 15,20 & 17,83 & 12 & 57,71 & 72,96 & 11 & 57,10 & 82,23 & 23 & 57,41 & 77,48 & 8 & 184 & 4,2 \\
\hline
\end{tabular}


Anexo 19 - Óbitos e taxa de mortalidade (bruta e padronizada) total e segundo sexo por Doenças Infecciosas e Parasitárias e Doenças Respiratórias e \% de óbitos por Causas Mal Definidas nos municípios. Estado de São Paulo, média do triênio, 2003-2005

\begin{tabular}{|c|c|c|c|c|c|c|c|c|c|c|c|c|c|c|c|c|c|c|c|c|c|c|c|}
\hline \multirow[b]{2}{*}{ IBGE } & \multirow{2}{*}{ Mun. } & \multirow{2}{*}{ Porte } & \multicolumn{9}{|c|}{$\begin{array}{l}\text { DOENCAS INFECCIOSAS E PARASITÁRIAS } \\
\end{array}$} & \multicolumn{9}{|c|}{ DOENCAS RESPIRATÓRIAS } & \multicolumn{3}{|c|}{ MAL DEFINIDAS } \\
\hline & & & Obitos & $\begin{array}{l}\text { Homens } \\
\text { TMB }\end{array}$ & TPM & Obitos & $\begin{array}{l}\text { Mulh } \\
\text { TMB }\end{array}$ & TPM & Obitos & $\begin{array}{l}\text { Total } \\
\text { TMB }\end{array}$ & TPM & Obitos & $\begin{array}{l}\text { Homens } \\
\text { TMB }\end{array}$ & TPM & Obitos & $\begin{array}{l}\text { Mulh } \\
\text { TMB }\end{array}$ & TPM & & $\begin{array}{l}\text { Total } \\
\text { TMB }\end{array}$ & & Obitos C & Ob.Totais & \\
\hline 350850 & Caçapava & B100 & 19 & 46,63 & 47,82 & 8 & 20,53 & 21,12 & 27 & 33,49 & 34,38 & 23 & 57,46 & 62,38 & 29 & 71,43 & 76,94 & 52 & 64,49 & 69,71 & 57 & 512 & 11,1 \\
\hline 350860 & Cachoeira Paulista & B50 & 3 & 18,54 & 18,76 & 3 & 22,83 & 22,33 & 6 & 20,70 & 20,56 & 8 & 57,93 & 52,19 & 8 & 54,78 & 48,88 & 16 & 56,35 & 50,52 & 17 & 195 & 8,9 \\
\hline 350870 & Caconde & E20 & 1 & 10,46 & 8,26 & 1 & 10,75 & 9,09 & 2 & 10,60 & 8,67 & 6 & 62,75 & 50,12 & 6 & 60,89 & 54,54 & 12 & 61,84 & 52,30 & 13 & 130 & 10,0 \\
\hline 350880 & Cafelândia & D20 & 3 & 33,63 & 29,49 & 2 & 20,57 & 16,36 & 4 & 27,03 & 22,85 & 8 & 100,89 & 70,02 & 5 & 65,82 & 50,19 & 13 & 83,16 & 60,00 & 18 & 121 & 15,2 \\
\hline 350890 & Caiabu & E20 & 1 & 31,13 & 21,67 & & & & 1 & 15,96 & 11,11 & & & & 0 & 16,37 & 12,32 & 0 & 7,98 & 6,00 & 4 & 22 & 18,5 \\
\hline 350900 & Caieiras & C100 & 9 & 21,97 & 26,45 & 4 & 10,05 & 12,69 & 14 & 15,97 & 19,52 & 22 & 52,57 & 74,15 & 21 & 47,95 & 69,84 & 43 & 50,24 & 71,98 & 3 & 384 & 0,9 \\
\hline 350910 & Caiuá & E20 & 1 & 55,90 & 49,05 & 0 & 15,24 & 14,74 & 2 & 36,45 & 32,64 & 2 & 69,87 & 61,33 & 1 & 45,72 & 44,16 & 3 & 58,32 & 53,12 & 4 & 34 & 11,9 \\
\hline 350920 & Cajamar & C100 & 6 & 19,26 & 19,20 & 3 & 10,36 & 13,40 & 9 & 14,85 & 16,33 & 21 & 71,37 & 104,46 & 9 & 29,94 & 48,06 & 30 & 50,83 & 76,49 & 4 & 299 & 1,3 \\
\hline 350925 & Cajati & D50 & 4 & 22,37 & 24,10 & 5 & 30,45 & 36,38 & 8 & 26,27 & 30,03 & 9 & 52,87 & 54,33 & 8 & 52,19 & 68,43 & 17 & 52,54 & 61,14 & 17 & 172 & 9,7 \\
\hline 350930 & Cajobi & E20 & 0 & 6,90 & 6,25 & 1 & 22,08 & 18,53 & 1 & 14,24 & 12,19 & 6 & 124,16 & 103,07 & 3 & 73,61 & 63,92 & 9 & 99,70 & 84,13 & 1 & 53 & 1,3 \\
\hline 350940 & Cajuru & E50 & 6 & 54,37 & 50,96 & 2 & 15,53 & 14,95 & 8 & 35,22 & 33,20 & 10 & 87,60 & 69,98 & 9 & 80,73 & 71,78 & 18 & 84,21 & 70,87 & 0 & 142 & 0,2 \\
\hline 350945 & Campina Monte Alegre & E20 & & & & & & & - & & & 3 & 89,66 & 73,50 & 2 & 82,84 & 82,80 & 5 & 86,34 & 78,02 & 3 & 36 & 9,3 \\
\hline 350950 & Campinas & B10000 & 154 & 30,88 & 29,64 & 101 & 19,30 & 18,23 & 255 & 24,94 & 23,79 & 402 & 80,68 & 77,02 & 339 & 64,56 & 59,55 & 741 & 72,41 & 68,06 & 104 & 5920 & 1,8 \\
\hline 350960 & Campo Limpo Paulista & C100 & 11 & 29,76 & 32,65 & 8 & 22,18 & 27,52 & 19 & 25,96 & 30,08 & 32 & 90,22 & 108,23 & 21 & 57,29 & 72,44 & 53 & 73,70 & 90,28 & 4 & 405 & 1,0 \\
\hline 350970 & Campos do Jordao & C50 & 14 & 60,85 & 65,53 & 4 & 15,36 & 17,87 & 18 & 37,95 & 41,54 & 11 & 48,11 & 55,09 & 13 & 55,85 & 72,94 & 25 & 52,01 & 64,08 & 39 & 320 & 12,3 \\
\hline 350980 & Campos Novos Paulista & E20 & & & & 1 & 32,52 & 27,86 & 1 & 15,67 & 13,42 & 3 & 120,94 & 83,98 & 3 & \begin{tabular}{|l|}
130,08 \\
\end{tabular} & 116,37 & 5 & 125,34 & 99,59 & 3 & 34 & 8,7 \\
\hline 350990 & Cananéia & E20 & 2 & 29,43 & 28,48 & 4 & 55,16 & 56,44 & 6 & 42,15 & 42,31 & 4 & 58,85 & 52,63 & 6 & 90,27 & 89,21 & 10 & 74,38 & 70,72 & 5 & 85 & 6,3 \\
\hline 350995 & Canas & E20 & 1 & 49,41 & 48,56 & 1 & 70,16 & 77,16 & 2 & 59,46 & 62,41 & 2 & 115,28 & 116,48 & 1 & 52,62 & 59,88 & 3 & 84,94 & 89,07 & 3 & 29 & 9,1 \\
\hline 351000 & Cândido Mota & D50 & 5 & 30,12 & 27,02 & 3 & 19,36 & 18,77 & 8 & 24,74 & 22,90 & 16 & 105,40 & 83,94 & 7 & 45,17 & 39,27 & 23 & 75,29 & 61,60 & 37 & 203 & 18,2 \\
\hline 351010 & Cândido Rodrigues & E20 & 1 & 49,62 & 50,91 & & & & 1 & 24,33 & $24,97 \mid$ & 0 & 24,81 & 12,13 & 1 & 71,63 & 47,07 & 1 & 48,67 & 29,93 & 1 & 17 & 5,9 \\
\hline 351015 & Canitar & E20 & 0 & 16,60 & 17,28 & 0 & 17,19 & 19,93 & 1 & 16,89 & 18,58 & 2 & 116,22 & 120,97 & 1 & 51,56 & 64,80 & 3 & 84,45 & 93,37 & 5 & 22 & 21,2 \\
\hline 351020 & Capao Bonito & E50 & 5 & 22,65 & 23,09 & 3 & 14,30 & 14,60 & 9 & 18,49 & 18,87 & 20 & 86,35 & 86,18 & 17 & 71,48 & 81,86 & 37 & 78,95 & 84,03 & 36 & 322 & 11,1 \\
\hline 351030 & Capela do Alto & D20 & 2 & 28,77 & 31,43 & 2 & 21,68 & 24,92 & 4 & 25,32 & 28,26 & 7 & 86,30 & 85,99 & 5 & 65,04 & 76,18 & 12 & 75,95 & 81,22 & 20 & 95 & 21,1 \\
\hline 351040 & Capivari & C50 & 8 & 35,98 & 36,58 & 4 & 19,28 & 18,97 & 12 & 27,59 & 27,73 & 18 & 82,46 & 82,55 & 18 & 81,58 & 76,52 & 37 & 82,02 & 79,52 & 27 & 284 & 9,5 \\
\hline 351050 & Caraguatatuba & C100 & 14 & 30,72 & 31,51 & 8 & 17,05 & 18,34 & 22 & 23,93 & 24,97 & 32 & 69,48 & 72,69 & 22 & 48,91 & 55,57 & 54 & 59,26 & 64,19 & 86 & 557 & 15,5 \\
\hline 351060 & Carapicuíba & C500 & 39 & 21,22 & 27,05 & 30 & 16,00 & 19,83 & 69 & 18,56 & 23,37 & 106 & 58,18 & 90,58 & 79 & 41,66 & 66,88 & 185 & 49,76 & 78,49 & 25 & 1552 & 1,6 \\
\hline 351070 & Cardoso & E20 & 4 & 77,40 & 61,15 & 3 & 58,45 & 47,21 & 8 & 67,84 & 54,11 & 9 & 154,81 & 105,15 & 4 & 70,13 & 55,60 & 13 & 112,08 & 80,15 & 9 & 94 & 10,0 \\
\hline 351080 & Casa Branca & B50 & 7 & 48,33 & 41,43 & 2 & 12,84 & 10,67 & 9 & 31,55 & 26,89 & 18 & 121,97 & 81,10 & 8 & 64,19 & 52,22 & 26 & 94,66 & 67,45 & 17 & 236 & 7,1 \\
\hline 351090 & Cássia dos Coqueiros & E20 & 1 & 87,41 & 59,85 & 0 & 23,57 & 21,88 & 2 & 56,70 & 41,58 & 2 & 109,27 & 73,44 & 0 & 23,57 & 21,88 & 2 & 68,03 & 48,63 & 1 & 17 & 6,0 \\
\hline 351100 & Castilho & E20 & 3 & 35,33 & 30,31 & 1 & 13,24 & 13,62 & 4 & 24,28 & 21,96 & 6 & 75,08 & 57,74 & 4 & 48,55 & 44,21 & 9 & 61,81 & 50,97 & 24 & 109 & 22,0 \\
\hline 351110 & Catanduva & B300 & 22 & 40,48 & 37,81 & 19 & 32,51 & 28,39 & 41 & 36,42 & 33,01 & 71 & 128,09 & 98,51 & 49 & 85,35 & 63,19 & 120 & 106,30 & 80,50 & 64 & 863 & 7,4 \\
\hline 351120 & Catiguá & E20 & 0 & 9,70 & 9,52 & 1 & 20,50 & 20,49 & 1 & 14,96 & 14,86 & 6 & 174,66 & 140,98 & 2 & 61,51 & 52,53 & 8 & $|119,64|$ & 97,97 & 4 & 49 & 8,2 \\
\hline
\end{tabular}


Anexo 19 - Óbitos e taxa de mortalidade (bruta e padronizada) total e segundo sexo por Doenças Infecciosas e Parasitárias e Doenças Respiratórias e \% de óbitos por Causas Mal Definidas nos municípios. Estado de São Paulo, média do triênio, 2003-2005

\begin{tabular}{|c|c|c|c|c|c|c|c|c|c|c|c|c|c|c|c|c|c|c|c|c|c|c|c|}
\hline \multirow[b]{2}{*}{ IBGE } & \multirow[b]{2}{*}{ Mun. } & \multirow[b]{2}{*}{ Porte } & \multicolumn{9}{|c|}{$\begin{array}{l}\text { DOENCAS INFECCIOSAS E PARASITÁRIAS } \\
\end{array}$} & \multicolumn{9}{|c|}{ DOENCAS RESPIRATÓRIAS } & \multicolumn{3}{|c|}{ MAL DEFINIDAS } \\
\hline & & & Obitos & $\begin{array}{l}\text { Homens } \\
\text { TMB }\end{array}$ & TPM & Obitos & $\begin{array}{l}\text { Mulhe } \\
\text { TMB }\end{array}$ & TPM & Obitos & $\begin{array}{l}\text { Total } \\
\text { TMB }\end{array}$ & TPM & Obitos & $\begin{array}{l}\text { Homens } \\
\text { TMB }\end{array}$ & TPM & Obitos $N$ & $\begin{array}{l}\text { Mulheres } \\
\text { TMB }\end{array}$ & TPM & Obitos & $\begin{array}{c}\text { Total } \\
\text { TMB }\end{array}$ & TPM & Obitos & Ob.Totais ? & \\
\hline 351130 & Cedral & E20 & 1 & 27,79 & 22,08 & 1 & 37,59 & 27,49 & 2 & 32,66 & 24,77 & 6 & 166,74 & 100,04 & 3 & 93,98 & 58,34 & 9 & 130,62 & 79,34 & 2 & 52 & 3,8 \\
\hline 351140 & Cerqueira César & D20 & 4 & 49,48 & 41,77 & 2 & 20,62 & 18,35 & 6 & 35,05 & 30,07 & 4 & 53,60 & 46,39 & 4 & 45,36 & 40,16 & 8 & 49,48 & 43,27 & 16 & 107 & 15,2 \\
\hline 351150 & Cerquilho & B50 & 4 & 21,74 & 20,97 & 2 & 11,85 & 11,66 & 6 & 16,80 & 16,31 & 12 & 73,14 & 69,25 & 7 & 39,52 & 40,14 & 19 & 56,32 & 54,69 & 19 & 192 & 9,7 \\
\hline 351160 & Cesário Lange & E20 & & & & 1 & 10,25 & 9,65 & 1 & 4,88 & 4,59 & 5 & 65,22 & 60,09 & 4 & 66,65 & 65,92 & 9 & 65,90 & 62,86 & 11 & 89 & 12,8 \\
\hline 351170 & Charqueada & D20 & 2 & 23,54 & 23,56 & 1 & 19,09 & 19,73 & 3 & 21,33 & 21,66 & 6 & 84,75 & 71,68 & 6 & 90,67 & 92,43 & 12 & 87,69 & 81,98 & 8 & 87 & 8,8 \\
\hline 355720 & Chavantes & D20 & 2 & 37,73 & 35,21 & 2 & 26,79 & 24,52 & 4 & 32,24 & 29,85 & 4 & 59,28 & 52,84 & 2 & 26,79 & 24,32 & 5 & 42,99 & 38,54 & 22 & 93 & 23,6 \\
\hline 351190 & Clementina & E20 & 0 & 11,41 & 11,92 & 0 & 12,28 & 11,67 & 1 & 11,83 & 11,80 & 4 & 136,86 & 110,34 & 2 & 73,70 & 70,00 & 6 & 106,45 & 90,92 & 3 & 30 & 10,1 \\
\hline 351200 & Colina & D20 & 3 & 39,10 & 36,99 & 2 & 19,66 & 18,92 & 5 & 29,41 & 27,98 & 4 & 50,83 & 40,79 & 5 & 58,99 & 52,30 & 9 & 54,90 & 46,53 & 5 & 119 & 3,9 \\
\hline 351210 & Colômbia & E20 & 2 & 51,35 & 57,89 & 2 & 77,54 & 93,40 & 4 & 63,95 & 74,97 & 1 & 30,81 & 34,68 & 1 & 44,31 & 57,04 & 2 & 37,30 & 45,44 & 3 & 32 & 9,4 \\
\hline 351220 & Conchal & E50 & 4 & 30,10 & 32,94 & 3 & 24,97 & 28,30 & 7 & 27,55 & 30,64 & 6 & 52,00 & \begin{tabular}{|l}
58,41 \\
\end{tabular} & 5 & 38,84 & 44,10 & 11 & 45,46 & 51,31 & 10 & 135 & 7,2 \\
\hline 351230 & Conchas & C2O & 2 & 28,10 & 19,21 & 3 & 33,56 & 23,31 & 5 & 30,77 & 21,22 & 11 & 128,46 & 93,73 & 7 & 83,90 & 64,97 & 17 & 106,67 & 79,66 & 4 & 124 & 3,2 \\
\hline 351240 & Cordeirópolis & C20 & 2 & 17,10 & 16,54 & 1 & 6,84 & 6,97 & 2 & 11,97 & 11,75 & 7 & 71,83 & 68,99 & 6 & 58,15 & 55,86 & 13 & 64,99 & 62,43 & 8 & 100 & 8,4 \\
\hline 351250 & Coroados & E20 & - & & & -1 & & & - & & & 1 & 43,33 & 36,20 & 0 & 14,62 & 13,73 & 1 & 29,07 & 25,04 & 5 & 26 & 17,9 \\
\hline 351260 & Coronel Macedo & E20 & & & & 2 & 62,17 & 63,11 & 2 & 30,20 & 30,66 & 2 & 70,49 & 61,35 & 4 & $\mid 136,76$ & 153,61 & 6 & 102,69 & 106,17 & 12 & 40 & 28,9 \\
\hline 351270 & Corumbataí & D20 & & & & 0 & 17,15 & 13,33 & 0 & 8,17 & 6,35 & 2 & 109,32 & 87,03 & 1 & 51,45 & 43,55 & 3 & 81,74 & 66,30 & 6 & 21 & 27,4 \\
\hline 351280 & Cosmópolis & B50 & 5 & 22,14 & 22,46 & 3 & 13,89 & 14,71 & 9 & 18,02 & 18,59 & 15 & 62,28 & 66,58 & 8 & 31,94 & 36,12 & 23 & 47,14 & 51,38 & 44 & 279 & 15,9 \\
\hline 351290 & Cosmorama & E20 & 1 & 27,58 & 20,77 & 2 & 65,88 & 44,36 & 3 & 46,51 & 32,43 & 7 & 202,26 & 120,31 & 3 & 75,29 & 49,73 & 10 & 139,52 & 85,44 & 2 & 62 & 3,2 \\
\hline 351300 & Cotia & C300 & 24 & 28,58 & 33,36 & 13 & 15,34 & 18,11 & 37 & 21,89 & 25,65 & 52 & 62,39 & 82,74 & 51 & 60,20 & 90,23 & 103 & 61,28 & 86,53 & 12 & 934 & 1,3 \\
\hline 351310 & Cravinhos & D50 & 2 & 14,77 & 14,89 & 3 & 19,70 & 19,52 & 5 & 17,19 & 17,17 & 18 & 113,94 & 114,25 & 9 & 61,30 & 60,35 & 27 & 88,11 & 87,80 & 5 & 176 & 2,7 \\
\hline 351320 & Cristais Paulista & E20 & 1 & 18,45 & 19,62 & 1 & 19,72 & 21,86 & 1 & $19,06 \mid$ & 20,70 & 3 & 73,78 & 70,69 & 1 & 39,44 & 42,39 & 4 & 57,18 & 57,01 & 6 & 37 & 16,1 \\
\hline 351330 & Cruzália & D20 & & & & 1 & 51,77 & 47,52 & 1 & 25,77 & 23,65 & 1 & 76,96 & 60,77 & & & & 1 & 38,65 & 30,52 & 1 & 11 & 11,8 \\
\hline 351340 & Cruzeiro & B100 & 19 & 50,32 & 51,63 & 6 & 14,69 & 14,54 & 24 & 32,16 & 32,72 & 34 & 92,55 & 90,53 & 24 & 61,37 & 58,03 & 58 & 76,66 & 73,97 & 53 & 535 & 10,0 \\
\hline 351350 & Cubatao & С300 & 23 & 39,96 & 44,42 & 10 & 17,36 & 19,95 & 33 & 28,74 & 32,27 & 39 & 66,22 & 91,44 & 31 & 54,41 & 80,21 & 70 & 60,36 & 85,86 & 75 & 674 & 11,1 \\
\hline 351360 & Cunha & E50 & 4 & 30,86 & 26,86 & 1 & 9,05 & 9,83 & 5 & 20,36 & 18,66 & 10 & 86,98 & 71,36 & 6 & 54,32 & 59,90 & 16 & 71,25 & 65,84 & 13 & 154 & 8,6 \\
\hline 351370 & Descalvado & D50 & 2 & 15,42 & 13,41 & 1 & 8,77 & 8,18 & 4 & 12,09 & 10,79 & 14 & 94,75 & 77,14 & 7 & 43,83 & 36,32 & 21 & 69,22 & 56,67 & 24 & 200 & 12,0 \\
\hline 351380 & Diadema & C500 & 47 & 25,21 & 30,83 & 37 & 18,93 & 24,32 & 84 & 22,01 & 27,52 & 104 & 55,60 & 86,23 & 88 & 45,25 & 71,41 & 191 & 50,33 & 78,68 & 30 & 2022 & 1,5 \\
\hline 351385 & Dirce Reis & E20 & - & & & -1 & & -1 & - & & & 2 & 215,80 & 136,21 & 1 & $\mid 137,87$ & 108,48 & 3 & 178,05 & 122,78 & 1 & 11 & 12,1 \\
\hline 351390 & Divinolândia & E20 & 1 & 21,55 & 17,57 & 0 & 5,63 & 4,80 & 2 & 13,77 & 11,33 & 6 & 96,99 & 77,36 & 6 & 101,34 & 91,38 & 12 & 99,12 & 84,22 & 7 & 95 & 7,7 \\
\hline 351400 & Dobrada & E20 & 0 & 8,97 & 10,38 & 1 & 30,03 & 34,57 & 1 & \begin{tabular}{|l|}
18,92 \\
\end{tabular} & 21,81 & 4 & 107,59 & 120,31 & 2 & 60,05 & 68,94 & 6 & 85,13 & 96,04 & 6 & 40 & 14,2 \\
\hline 351410 & Dois Córregos & D50 & 2 & 16,49 & 15,63 & 2 & 13,84 & 13,09 & 4 & 15,17 & 14,36 & 14 & 115,45 & 79,42 & 6 & 47,06 & 34,30 & 20 & 81,37 & 56,93 & 16 & 189 & 8,5 \\
\hline 351420 & Dolcinópolis & E20 & 0 & 29,36 & 21,98 & 0 & 32,07 & 25,19 & 1 & 30,66 & 23,51 & 1 & 58,72 & 39,67 & 1 & 64,14 & 50,37 & 1 & 61,31 & 44,78 & 2 & 17 & 10,0 \\
\hline 351430 & Dourado & E20 & 1 & 28,98 & 22,99 & 0 & 7,59 & 6,89 & 2 & 18,53 & 15,13 & 2 & 50,71 & 37,20 & 4 & 98,69 & 71,95 & 7 & 74,13 & 54,16 & 6 & 58 & 9,8 \\
\hline
\end{tabular}


Anexo 19 - Óbitos e taxa de mortalidade (bruta e padronizada) total e segundo sexo por Doenças Infecciosas e Parasitárias e Doenças Respiratórias e \% de óbitos por Causas Mal Definidas nos municípios. Estado de São Paulo, média do triênio, 2003-2005

\begin{tabular}{|c|c|c|c|c|c|c|c|c|c|c|c|c|c|c|c|c|c|c|c|c|c|c|c|}
\hline \multirow[b]{2}{*}{ IBGE } & \multirow{2}{*}{ Mun. } & \multirow{2}{*}{ Porte } & \multicolumn{9}{|c|}{$\begin{array}{l}\text { DOENCAS INFECCIOSAS E PARASITÁRIAS } \\
\end{array}$} & \multicolumn{9}{|c|}{ DOENCAS RESPIRATÓRIAS } & \multicolumn{3}{|c|}{ MAL DEFINIDAS } \\
\hline & & & Obitos & $\begin{array}{l}\text { Homens } \\
\text { TMB }\end{array}$ & TPM & Obitos & $\begin{array}{l}\text { Mulh } \\
\text { TMB }\end{array}$ & STM & Obitos & $\begin{array}{l}\text { Total } \\
\text { TMB }\end{array}$ & TPM & Obitos & $\begin{array}{l}\text { Homens } \\
\text { TMB }\end{array}$ & TPM & Obitos & $\begin{array}{l}\text { Mulh } \\
\text { TMB }\end{array}$ & TPM & Obit & $\begin{array}{l}\text { Total } \\
\text { TMB }\end{array}$ & TPM & Obitos & Ob.Totais ? & \\
\hline 351440 & Dracena & D50 & 15 & 75,41 & 59,40 & 10 & 49,27 & 36,80 & 25 & 62,00 & 47,80 & 18 & 88,82 & 59,96 & 13 & 61,99 & 47,10 & 31 & 75,05 & 53,36 & 41 & 334 & 12,3 \\
\hline 351450 & Duartina & E20 & 3 & 53,42 & 41,60 & 2 & 30,80 & 25,55 & 5 & 41,89 & 33,42 & 4 & 64,11 & 38,57 & 7 & 102,67 & 66,71 & 11 & 83,78 & 52,92 & 3 & 101 & 3,3 \\
\hline 351460 & Dumont & D20 & 1 & 37,84 & 37,62 & 1 & 19,75 & 18,93 & 2 & 28,99 & 28,48 & 3 & 85,14 & 74,67 & & & & 3 & 43,49 & 38,14 & 1 & 35 & 1,9 \\
\hline 351470 & Echapora & E20 & 1 & 18,91 & 16,42 & 1 & 18,89 & 15,74 & 1 & 18,90 & 16,08 & 1 & 37,82 & 30,27 & 3 & 85,03 & 75,50 & 4 & 61,43 & 52,89 & 1 & 33 & 2,0 \\
\hline 351480 & Eldorado & D20 & 2 & 30,79 & 28,63 & 1 & 14,27 & 17,69 & 3 & 22,85 & 23,38 & 5 & 61,57 & 54,60 & 4 & 52,32 & 53,22 & 8 & 57,13 & 53,94 & 13 & 90 & 14,8 \\
\hline 351490 & Elias Fausto & D20 & 1 & 17,40 & 17,95 & 0 & 4,61 & 5,60 & 2 & 11,19 & 11,95 & 5 & 69,60 & 76,01 & 1 & 18,43 & 20,13 & 7 & 44,75 & 48,87 & 11 & 84 & 13,4 \\
\hline 351492 & Elisiário & E20 & 1 & 49,03 & 38,74 & - & & & 1 & 25,76 & 20,35 & 2 & 147,09 & 97,12 & 1 & 81,39 & 68,88 & 3 & 115,90 & 83,72 & 1 & 20 & 6,7 \\
\hline 351495 & Embaúba & E20 & 1 & 50,97 & 45,10 & 0 & 27,65 & 25,79 & 1 & 39,79 & 35,84 & 2 & 127,42 & 97,91 & 1 & 110,62 & 84,52 & 3 & 119,36 & 91,49 & 1 & 17 & 6,0 \\
\hline 351500 & Embu & C300 & 32 & 28,48 & 37,95 & 17 & 14,79 & 19,78 & 50 & 21,52 & 28,72 & 70 & 61,65 & 108,86 & 55 & 46,64 & 87,84 & 125 & 54,03 & 98,18 & 21 & 1125 & 1,8 \\
\hline 351510 & Embu0Guaçu & C100 & 9 & 26,13 & 28,43 & 6 & 18,20 & 22,39 & 15 & 22,18 & 25,42 & 29 & 87,42 & 97,82 & 22 & 67,76 & 90,35 & 51 & 77,62 & 94,10 & 13 & 411 & 3,1 \\
\hline 351512 & Emilianópolis & E20 & & & & - & & & & & & 3 & 181,32 & 129,44 & & & & 3 & 92,19 & 65,81 & 2 & 14 & 16,3 \\
\hline 351515 & Engenheiro Coelho & D20 & 0 & 5,53 & 5,56 & 0 & 5,97 & 6,42 & 1 & 5,74 & 5,98 & 3 & 49,81 & 58,88 & 2 & 29,83 & 45,42 & 5 & 40,19 & 52,40 & 5 & 47 & 10,7 \\
\hline 351518 & 3 Espírito Santo do Pinhal & C50 & 4 & 19,26 & 17,80 & 1 & 6,29 & 5,90 & 5 & 12,71 & 11,79 & 13 & 61,00 & 45,70 & 11 & 51,92 & 40,79 & 24 & 56,41 & 43,22 & 26 & 315 & 8,4 \\
\hline 351519 & Espírito Santo do Turvo & D20 & 0 & 16,16 & 16,93 & 1 & 51,94 & 67,44 & 1 & 33,43 & 41,31 & 1 & 48,47 & 51,63 & 1 & 34,63 & 42,83 & 2 & 41,79 & 47,38 & 4 & 26 & 14,3 \\
\hline 355730 & Estiva Gerbi & $\mathrm{C} 20$ & 2 & 32,84 & 33,93 & & & & 2 & 16,95 & 17,52 & 2 & 39,40 & 40,65 & 2 & 42,06 & 49,92 & 4 & 40,69 & 45,14 & 6 & 47 & 12,0 \\
\hline 351530 & Estrela do Norte & E20 & 0 & 25,21 & 28,92 & & & & 0 & 13,04 & 14,96 & 2 & 126,04 & 92,05 & 1 & 54,01 & 49,28 & 2 & 91,26 & 71,40 & 2 & 17 & 12,0 \\
\hline 351520 & Estrela d'Oeste & E20 & 2 & 40,23 & 36,51 & 1 & 16,64 & 14,83 & 2 & 28,63 & 25,85 & 6 & 136,78 & 93,22 & 1 & 33,27 & 27,83 & 7 & 85,89 & 61,07 & 8 & 57 & 14,7 \\
\hline 351535 & Euclides Cunha Paulista & E20 & 1 & 25,08 & 25,22 & 1 & 12,85 & 16,68 & 2 & 19,04 & 21,00 & 2 & 37,62 & 34,10 & 1 & 25,69 & 33,74 & 3 & 31,73 & 33,92 & 5 & 46 & 11,7 \\
\hline 351540 & Fartura & E20 & 4 & 52,23 & 40,54 & 3 & 43,54 & 38,42 & 7 & 47,89 & 39,48 & 7 & 91,41 & 70,74 & 8 & $\mid 108,84$ & 91,50 & 15 & 100,12 & 81,11 & 5 & 108 & 4,6 \\
\hline 351560 & Fernando Prestes & E20 & 1 & 36,41 & 24,86 & 1 & 35,68 & 23,64 & 2 & 36,04 & 24,25 & 3 & 97,10 & 61,54 & 2 & 83,24 & 58,00 & 5 & 90,10 & 59,75 & 6 & 38 & 14,8 \\
\hline 351550 & Fernandópolis & D100 & 13 & 41,20 & 35,24 & 8 & 24,58 & 20,45 & 21 & 32,76 & 27,73 & 34 & 108,81 & 78,72 & 27 & 81,92 & 65,89 & 61 & 95,16 & 72,21 & 90 & 401 & 22,4 \\
\hline 351565 & Fernao & D20 & & & & & & & 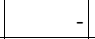 & & & 1 & 98,09 & 67,24 & 0 & 52,38 & 47,07 & 1 & 75,99 & 57,49 & 1 & 7 & 9,5 \\
\hline 351570 & Ferraz de Vasconcelos & C300 & 21 & 26,13 & 30,97 & 13 & 16,13 & 20,13 & 34 & 21,06 & 25,48 & 37 & 46,03 & 79,53 & 41 & 49,21 & 79,59 & 78 & 47,64 & 79,56 & 99 & 783 & 12,7 \\
\hline 351580 & Flora Rica & E20 & 0 & 31,87 & 15,92 & 1 & 128,04 & 143,14 & 2 & 79,85 & 79,39 & 0 & 31,87 & 37,59 & 1 & 96,03 & 70,12 & 1 & 63,88 & 53,82 & 1 & 18 & 7,5 \\
\hline 351590 & Floreal & E20 & 1 & 43,50 & 26,86 & 0 & 21,57 & 11,89 & 1 & 32,49 & 19,34 & 2 & 152,24 & 76,15 & 1 & 86,28 & 51,87 & 4 & 119,12 & 63,96 & 5 & 24 & 20,8 \\
\hline 351600 & Flórida Paulista & E20 & 1 & 12,71 & 9,07 & 1 & 19,12 & 16,12 & 2 & 15,91 & 12,59 & 8 & 146,12 & 89,90 & 6 & 114,69 & 89,41 & 14 & 130,43 & 89,65 & 23 & 87 & 26,5 \\
\hline 351610 & Florínia & E20 & 1 & 86,45 & 75,86 & 0 & 20,35 & 17,82 & 2 & 52,40 & 45,96 & 1 & 43,22 & 33,85 & 1 & 61,04 & 55,16 & 2 & 52,40 & 44,82 & 1 & 20 & 6,7 \\
\hline 351620 & Franca & B500 & 54 & 34,80 & 35,85 & 39 & 24,48 & 25,69 & 92 & 29,58 & 30,71 & 112 & 72,63 & 77,46 & 88 & 55,51 & 59,36 & 200 & 63,97 & 68,30 & 305 & 1731 & 17,6 \\
\hline 351630 & Francisco Morato & D300 & 23 & 29,99 & 38,59 & 10 & 13,21 & 16,35 & 34 & 21,58 & 27,44 & 43 & 54,84 & 94,53 & 28 & 35,81 & 64,60 & 71 & 45,30 & 79,53 & 11 & 656 & 1,7 \\
\hline 351640 & Franco da Rocha & C300 & 23 & 37,04 & 41,86 & 12 & 20,46 & 23,65 & 34 & 29,04 & 33,08 & 57 & 93,68 & 128,93 & 44 & 76,59 & 106,39 & 101 & 85,44 & \begin{tabular}{|l|}
118,06 \\
\end{tabular} & 9 & 721 & 1,2 \\
\hline 351650 & Gabriel Monteiro & E20 & & & & & & & & & & 0 & 22,71 & 18,23 & 1 & 48,63 & 37,98 & 1 & 35,23 & 27,77 & 3 & 21 & 12,5 \\
\hline 351660 & Gália & E20 & 1 & 17,66 & 16,17 & 1 & 27,38 & 23,57 & 2 & 22,44 & $\mid 19,81$ & 3 & 70,63 & 52,37 & 2 & 63,90 & 52,63 & 5 & 67,32 & 52,50 & 4 & 54 & 7,4 \\
\hline
\end{tabular}


Anexo 19 - Óbitos e taxa de mortalidade (bruta e padronizada) total e segundo sexo por Doenças Infecciosas e Parasitárias e Doenças Respiratórias e \% de óbitos por Causas Mal Definidas nos municípios. Estado de São Paulo, média do triênio, 2003-2005

\begin{tabular}{|c|c|c|c|c|c|c|c|c|c|c|c|c|c|c|c|c|c|c|c|c|c|c|c|}
\hline \multirow[b]{2}{*}{ IBGE } & \multirow[b]{2}{*}{ Mun. } & \multirow[b]{2}{*}{ Porte } & \multicolumn{9}{|c|}{$\begin{array}{l}\text { DOENCAS INFECCIOSAS E PARASITÁRIAS } \\
\end{array}$} & \multicolumn{9}{|c|}{ DOENCAS RESPIRATÓRIAS } & \multicolumn{3}{|c|}{ MAL DEFINIDAS } \\
\hline & & & Obitos & $\begin{array}{l}\text { Homens } \\
\text { TMB }\end{array}$ & TPM & Obitos & $\begin{array}{l}\text { Mulhe } \\
\text { TMB }\end{array}$ & TPM & Obitos & $\begin{array}{l}\text { Total } \\
\text { TMB }\end{array}$ & TPM & Obitos & $\begin{array}{l}\text { Homens } \\
\text { TMB }\end{array}$ & TPM & Obitos $N$ & $\begin{array}{l}\text { Mulheres } \\
\text { TMB }\end{array}$ & TPM & Obitos T & $\begin{array}{l}\text { Total } \\
\text { TMB } \\
\end{array}$ & TPM & Obitos & Ob.Totais ? & \\
\hline 351670 & Garça & D50 & 5 & 23,16 & 21,18 & 4 & 16,43 & 14,66 & 9 & 19,74 & 17,86 & 24 & 109,61 & 84,83 & 14 & 64,23 & 48,22 & 38 & 86,54 & 66,22 & 27 & 344 & 8,0 \\
\hline 351680 & Gastao Vidigal & E20 & 1 & 76,48 & 63,18 & 0 & 19,25 & 20,49 & 2 & 47,96 & 41,91 & 3 & 152,96 & 112,19 & 1 & 77,00 & 67,91 & 4 & 115,11 & 90,13 & 2 & 27 & 7,3 \\
\hline 351685 & Gaviao Peixoto & E20 & 1 & 30,63 & 30,05 & 1 & 34,94 & 39,64 & 1 & 32,65 & 34,53 & 1 & 61,27 & 59,03 & 1 & 52,41 & 58,44 & 2 & 57,13 & 58,76 & 1 & 22 & 6,1 \\
\hline 351690 & General Salgado & E20 & 3 & 53,50 & 42,27 & 2 & 36,93 & 31,84 & 5 & 45,36 & 37,14 & 4 & 71,34 & 52,84 & 3 & 55,39 & 51,24 & 7 & 63,50 & 52,05 & 4 & 82 & 4,5 \\
\hline 351700 & Getulina & E20 & 2 & 29,57 & 28,36 & 0 & 6,88 & 5,08 & 2 & 19,08 & 17,60 & 4 & 65,05 & 45,65 & 3 & 61,93 & 47,52 & 7 & 63,61 & 46,51 & 14 & 77 & 17,8 \\
\hline 351710 & Glicério & E20 & 0 & 14,59 & 10,41 & 0 & 14,95 & 16,16 & 1 & 14,77 & 13,25 & 2 & 87,55 & 64,64 & 2 & 74,75 & 60,08 & 4 & 81,23 & 62,39 & 2 & 25 & 9,3 \\
\hline 351720 & Guaiçara & D20 & 2 & 38,33 & 38,60 & 1 & 25,33 & 26,71 & 3 & 31,80 & 32,63 & 2 & 38,33 & 35,17 & 4 & 75,98 & 81,35 & 6 & 57,24 & 58,36 & 8 & 62 & 12,4 \\
\hline 351730 & Guaimbê & E20 & 1 & 25,47 & 27,32 & 1 & 25,44 & 21,81 & 1 & 25,46 & 24,56 & 5 & 191,06 & 140,37 & 2 & 89,04 & 76,32 & 7 & 140,01 & 108,32 & 4 & 36 & 12,0 \\
\hline 351740 & Guaíra & C50 & 11 & 58,58 & 55,69 & 8 & 44,49 & 44,87 & 19 & 51,58 & 50,31 & 14 & 76,89 & 72,78 & 13 & 72,29 & 73,11 & 27 & 74,60 & 72,94 & 27 & 233 & 11,6 \\
\hline 351750 & Guapiaçu & D20 & 3 & 37,77 & 34,39 & 2 & 30,42 & 29,93 & 5 & 34,16 & 32,20 & 11 & 138,48 & 122,78 & 4 & 56,49 & 56,95 & 15 & 98,20 & 90,44 & 1 & 96 & 1,4 \\
\hline 351760 & Guapiara & E50 & 3 & 31,81 & 32,68 & 2 & 16,85 & 19,63 & 5 & 24,54 & 26,34 & 6 & 54,08 & 55,27 & 4 & 43,81 & 48,34 & 10 & 49,09 & 51,90 & 14 & 121 & 11,9 \\
\hline 351770 & Guará & E50 & 4 & 43,10 & 44,10 & 3 & 33,32 & 33,90 & 8 & 38,22 & 39,01 & 7 & 72,94 & 74,54 & 7 & 73,31 & 76,24 & 15 & 73,12 & 75,39 & 10 & 125 & 8,0 \\
\hline 351780 & Guaraçaí & E20 & 2 & 43,23 & 30,90 & 0 & 7,34 & 6,19 & 2 & 25,46 & 18,66 & 4 & 86,47 & 53,96 & 4 & 95,47 & 82,49 & 8 & 90,93 & 68,09 & 11 & 66 & 16,2 \\
\hline 351790 & Guaraci & E20 & 4 & 77,46 & 72,30 & 2 & 43,72 & 38,75 & 6 & 60,88 & 55,81 & 3 & 63,38 & 49,56 & 7 & 145,72 & 127,10 & 10 & 103,85 & 87,67 & 3 & 66 & 4,5 \\
\hline 351800 & Guarani d'Oeste & E20 & - & & & 0 & 33,31 & 24,73 & 0 & 16,00 & 11,88 & 1 & 123,15 & 68,22 & 1 & 99,93 & 74,19 & 2 & 112,00 & 71,09 & 4 & 15 & 26,1 \\
\hline 351810 & Guaranta & E20 & 1 & 29,44 & 29,90 & - & & & 1 & 14,99 & 15,22 & 3 & 88,33 & 80,32 & 2 & 50,86 & 52,02 & 5 & 69,93 & 66,42 & 5 & 43 & 11,6 \\
\hline 351820 & Guararapes & D50 & 5 & 31,56 & 28,39 & 2 & 13,32 & 11,61 & 7 & 22,37 & 19,93 & 16 & 110,46 & 83,46 & 9 & 57,71 & 48,75 & 25 & 83,88 & 65,97 & 23 & 220 & 10,6 \\
\hline 351830 & Guararema & D50 & 3 & 22,22 & 21,43 & 2 & 14,29 & 14,54 & 4 & 18,31 & 18,03 & 5 & 41,66 & 38,50 & 7 & 60,01 & 61,33 & 12 & 50,71 & 49,75 & 21 & 160 & 13,4 \\
\hline 351840 & Guaratinguetá & B300 & 24 & 44,87 & 44,27 & 12 & 20,82 & 19,79 & 36 & 32,56 & 31,74 & 37 & 68,55 & 63,85 & 42 & 74,94 & 69,96 & 79 & 71,82 & 66,98 & 91 & 789 & 11,5 \\
\hline 351850 & Guareí & E20 & 1 & 23,16 & 19,48 & 1 & 19,19 & 19,58 & 2 & 21,27 & 19,53 & 3 & 52,11 & 45,30 & 3 & 51,17 & 51,51 & 6 & 51,66 & 48,25 & 3 & 68 & 4,9 \\
\hline 351860 & Guariba & E50 & 6 & 37,01 & 41,25 & 5 & 29,45 & 35,18 & 11 & 33,28 & 38,25 & 8 & 47,30 & 52,66 & 6 & 37,86 & 46,52 & 14 & 42,63 & 49,63 & 5 & 176 & 2,7 \\
\hline 351870 & Guarujá & C300 & 45 & 31,48 & 33,89 & 40 & 27,12 & 29,34 & 85 & 29,28 & 31,59 & 95 & 66,47 & 83,62 & 81 & 55,60 & 70,96 & 176 & 60,97 & 77,22 & 59 & 1647 & 3,6 \\
\hline 351880 & Guarulhos & C10000 & 167 & 28,30 & 31,82 & 102 & 16,67 & 20,06 & 269 & 22,39 & 25,84 & 394 & 66,77 & 93,88 & 328 & 53,83 & 78,06 & 722 & 60,20 & 85,84 & 59 & 6047 & 1,0 \\
\hline 351885 & Guatapará & D20 & 1 & 38,98 & 37,07 & 1 & 20,79 & 21,70 & 2 & 30,18 & 29,63 & 2 & 68,21 & 60,38 & 1 & 20,79 & 19,46 & 3 & 45,27 & 40,59 & 2 & 36 & 5,6 \\
\hline 351890 & Guzolândia & E20 & 2 & 80,80 & 75,10 & 1 & 70,41 & 67,50 & 3 & 75,83 & 71,46 & 1 & 64,64 & 50,90 & 1 & 70,41 & 67,66 & 3 & 67,40 & 58,92 & 2 & 27 & 7,4 \\
\hline 351900 & Herculândia & E20 & 1 & 31,22 & 23,87 & 1 & 24,10 & 21,70 & 2 & 27,71 & 22,80 & 2 & 54,64 & 36,75 & 3 & 64,28 & 56,37 & 5 & 59,39 & 46,42 & 4 & 61 & 6,5 \\
\hline 351905 & Holambra & C20 & 1 & 32,54 & 36,28 & - & & & 1 & 16,65 & 18,56 & 4 & 105,75 & 118,70 & 1 & 34,09 & 43,74 & 6 & 70,76 & 82,09 & 4 & 40 & 9,2 \\
\hline 351907 & Hortolândia & C300 & 21 & 22,66 & 27,06 & 13 & 13,90 & 17,98 & 33 & 18,28 & 22,52 & 30 & 32,90 & 45,66 & 26 & 28,53 & 47,31 & 56 & 30,72 & 46,49 & 143 & 765 & 18,7 \\
\hline 351910 & lacanga & E20 & 2 & 38,38 & 34,46 & 0 & 7,83 & 8,09 & 2 & 23,26 & 21,41 & 4 & 84,43 & 59,35 & 3 & 62,64 & 48,05 & 6 & 73,64 & 53,76 & 1 & 53 & 2,5 \\
\hline 351920 & Iacri & E20 & 1 & 39,76 & 33,46 & 0 & 10,05 & 10,41 & 2 & 24,99 & 22,00 & 3 & 89,45 & 65,61 & 1 & 20,11 & 17,62 & 4 & 54,98 & 41,75 & 5 & 44 & 10,5 \\
\hline 351925 & laras & D20 & 2 & 88,26 & 94,42 & & & & 2 & 48,24 & 51,61 & 1 & 35,30 & 45,00 & 0 & 21,28 & 31,89 & 1 & 28,94 & 39,05 & 3 & 21 & 16,1 \\
\hline 351930 & | Ibaté & D50 & 4 & 28,58 & 29,96 & 3 & 18,13 & 20,74 & 7 & 23,43 & 25,42 & 10 & 63,76 & 70,83 & 4 & 29,45 & 39,07 & 14 & 46,87 & 55,19 & 22 & 161 & 13,8 \\
\hline
\end{tabular}


Anexo 19 - Óbitos e taxa de mortalidade (bruta e padronizada) total e segundo sexo por Doenças Infecciosas e Parasitárias e Doenças Respiratórias e \% de óbitos por Causas Mal Definidas nos municípios. Estado de São Paulo, média do triênio, 2003-2005

\begin{tabular}{|c|c|c|c|c|c|c|c|c|c|c|c|c|c|c|c|c|c|c|c|c|c|c|c|}
\hline \multirow[b]{2}{*}{ IBGE } & \multirow[b]{2}{*}{ Mun. } & \multirow[b]{2}{*}{ Porte } & \multicolumn{9}{|c|}{ DOENCAS INFECCIOSAS E PARASITÁRIAS } & \multicolumn{9}{|c|}{ DOENCAS RESPIRATÓRIAS } & \multicolumn{3}{|c|}{ MAL DEFINIDAS } \\
\hline & & & Obitos & $\begin{array}{l}\text { Homens } \\
\text { TMB }\end{array}$ & TPM & Obitos & & TPM & Obitos & $\begin{array}{l}\text { Total } \\
\text { TMB }\end{array}$ & TPM & Obitos & $\begin{array}{l}\text { Homens } \\
\text { TMB }\end{array}$ & stPM & Obitos & & TPM & Obitos & $\begin{array}{l}\text { Total } \\
\text { TMB }\end{array}$ & TPM & Obitos & Ob.Totais & $\%$ \\
\hline 351940 & Ibirá & D20 & 3 & \begin{tabular}{|l|l|}
3 & 62,36 \\
\end{tabular} & 48,62 & & & & 3 & 30,70 & $23,93 \mid$ & 5 & 110,86 & \begin{tabular}{|l|l}
5 & 63,41
\end{tabular} & 6 & \begin{tabular}{l|l}
6 & 120,91
\end{tabular} & 74,26 & 11 & 115,96 & 68,92 & 4 & 69 & \begin{tabular}{l|l}
9 & 5,3 \\
\end{tabular} \\
\hline 351950 & Ibirarema & E20 & 1 & $\begin{array}{l}1 \quad 45,57 \\
\end{array}$ & 42,57 & & & & 1 & 23,07 & \begin{tabular}{l|l|}
7 & 21,56 \\
\end{tabular} & 3 & \begin{tabular}{l|l}
302,54 \\
\end{tabular} & $\begin{array}{l}74,36 \\
\end{array}$ & 5 & \begin{tabular}{l|l}
5 & 175,27 \\
\end{tabular} & 148,18 & 8 & 138,45 & 110,81 & 7 & 43 & $\begin{array}{ll}3 & 17,2 \\
\end{array}$ \\
\hline 351960 & Ibitinga & D100 & 5 & \begin{tabular}{|l|l|}
5 & 21,41 \\
\end{tabular} & 19,64 & 5 & \begin{tabular}{|l|}
5 \\
$\mid$
\end{tabular} & 17,21 & 10 & 19,86 & \begin{tabular}{l|l|}
5 & 18,41 \\
\end{tabular} & 21 & 84,29 & $\begin{array}{ll}97,09 \\
\end{array}$ & 21 & \begin{tabular}{l|l|}
1 & 82,52 \\
\end{tabular} & 70,83 & 42 & 83,39 & 68,98 & 32 & 347 & \begin{tabular}{l|l}
7 & 9,3 \\
\end{tabular} \\
\hline 351970 & Ibiúna & E100 & 7 & \begin{tabular}{l|} 
\\
\end{tabular} & 20,96 & 5 & | 15,44 & 19,99 & 13 & \begin{tabular}{|l|l|}
3 & 17,80 \\
\end{tabular} & 20,49 & 18 & \begin{tabular}{l|l}
3 & 48,24 \\
\end{tabular} & $\begin{array}{l}4 \quad 48,98 \\
4\end{array}$ & 14 & \begin{tabular}{l|l|}
4 & 41,49 \\
\end{tabular} & 53,99 & 32 & 44,96 & 51,41 & 79 & 410 & \begin{tabular}{l|l}
0 & 19,3 \\
\end{tabular} \\
\hline 351980 & Icém & D20 & 3 & \begin{tabular}{|l|l|}
3 & 74,70 \\
\end{tabular} & 65,51 & 1 & $\begin{array}{l}1 \\
1\end{array}$ & 26,58 & 4 & 51,85 & \begin{tabular}{|l|l|}
5 & 46,23 \\
\end{tabular} & 4 & $\begin{array}{l}121,39 \\
\end{array}$ & \begin{tabular}{|l|l}
9 & 101,09
\end{tabular} & 5 & \begin{tabular}{l|l|}
5 & 133,26 \\
\end{tabular} & \begin{tabular}{l|l}
521,74 \\
\end{tabular} & 9 & 127,27 & 111,32 & & 49 & 9 \\
\hline 351990 & lepê & E20 & 1 & \begin{tabular}{l|l|}
1 & 28,34 \\
\end{tabular} & 28,06 & 2 & 65,54 & $\begin{array}{l}52,98 \\
\end{array}$ & 3 & \begin{tabular}{|l|l|}
3 & 47,03 \\
\end{tabular} & \begin{tabular}{|l|l|}
3 & 40,58 \\
\end{tabular} & 3 & \begin{tabular}{l|l}
3 & 94,48 \\
\end{tabular} & \begin{tabular}{l|l}
3 & 62,33 \\
\end{tabular} & 4 & \begin{tabular}{l|l|}
4 & 102,99 \\
\end{tabular} & 74,93 & 7 & 98,75 & 68,66 & 2 & 53 & \begin{tabular}{l|l}
3 & 3,2 \\
\end{tabular} \\
\hline 352000 & Igaraçu do Tietê & D50 & 1 & $\begin{array}{l}1 \quad 11,33 \\
\end{array}$ & 12,51 & 2 & 17,20 & 19,26 & 3 & \begin{tabular}{|l|l|}
34,25 \\
\end{tabular} & \begin{tabular}{|l|l|}
5 & 15,87 \\
\end{tabular} & 9 & 76,50 & 83,34 & 5 & \begin{tabular}{l|l|}
5 & 45,87 \\
\end{tabular} & 53,89 & 14 & 61,27 & 68,70 & 12 & 140 & 8,8 \\
\hline 352010 & Igarapava & D50 & 8 & \begin{tabular}{l|l|}
3 & 59,01 \\
\end{tabular} & 52,90 & 3 & \begin{tabular}{|l|l|}
3 & 19,08 \\
\end{tabular} & 15,69 & 11 & 38,74 & $\begin{array}{l}4 \\
44,01 \\
\end{array}$ & 14 & 100,81 & $\begin{array}{l}1 \quad 83,86 \\
\end{array}$ & 8 & \begin{tabular}{l|l}
8 & 57,24 \\
\end{tabular} & 48,85 & 22 & 78,69 & 66,09 & 24 & 189 & \begin{tabular}{l|l}
9 & 12,7 \\
\end{tabular} \\
\hline 352020 & Igaratá & E20 & 0 & 7,00 & 6,33 & 3 & & & 0 & \begin{tabular}{|l|} 
\\
\end{tabular} & \begin{tabular}{|l|l|}
3 & 3,28 \\
\end{tabular} & 2 & 34,98 & \begin{tabular}{l|l}
3 & 31,78 \\
\end{tabular} & 3 & \begin{tabular}{l|l}
3 & 60,31 \\
\end{tabular} & 69,71 & 4 & 47,17 & 50,04 & 4 & 52 & 7,1 \\
\hline 352030 & Iguape & E50 & 5 & \begin{tabular}{|l|l|}
5 & 32,38 \\
\end{tabular} & 30,54 & 3 & \begin{tabular}{|l|l|}
3 & 19,28 \\
\end{tabular} & $\begin{array}{l}18,85 \\
\end{array}$ & 7 & 25,96 & \begin{tabular}{|l|l|}
5 & 24,82 \\
\end{tabular} & 13 & 90,19 & $\begin{array}{l}976,02 \\
\end{array}$ & 11 & \begin{tabular}{l|l}
1 & 79,53 \\
\end{tabular} & 73,00 & 24 & 84,97 & 74,54 & 15 & 222 & \begin{tabular}{l|l}
2 & 6,7 \\
\end{tabular} \\
\hline 352042 & Ilha Comprida & A20 & 1 & $\begin{array}{l}1 \quad 23,29 \\
\end{array}$ & 20,96 & 1 & 31,94 & $\begin{array}{l}34,96 \\
\end{array}$ & 2 & 27,56 & \begin{tabular}{|l|l|}
5 & 27,87 \\
\end{tabular} & 3 & 77,65 & \begin{tabular}{l|l}
59,88 \\
\end{tabular} & 1 & $\begin{array}{ll}1 & 23,95 \\
\end{array}$ & 24,33 & 4 & 51,18 & 42,35 & 6 & 54 & \begin{tabular}{l|l}
4 & 11,8 \\
\end{tabular} \\
\hline 352044 & 4 Ilha Solteira & B50 & 2 & \begin{tabular}{|l|l|}
2 & 13,49 \\
\end{tabular} & 13,48 & 2 & $\begin{array}{l}15,80 \\
\end{array}$ & 19,49 & 4 & $\begin{array}{l}44,66 \\
\end{array}$ & \begin{tabular}{|l|l|}
5 & 16,52 \\
\end{tabular} & 8 & 62,06 & \begin{tabular}{|l|l}
5 & 63,00 \\
\end{tabular} & 5 & \begin{tabular}{l|l}
5 & 39,49 \\
\end{tabular} & 53,15 & 13 & 50,63 & 58,02 & 7 & 112 & $\begin{array}{ll}2 & 6,5 \\
\end{array}$ \\
\hline 352040 & |llhabela & C50 & 4 & \begin{tabular}{l|l|}
4 & 34,52 \\
\end{tabular} & 36,86 & 1 & 5,78 & 5,47 & 5 & 20,75 & \begin{tabular}{|l|l|}
5 & 21,82 \\
\end{tabular} & 4 & 31,86 & \begin{tabular}{|l|l}
5 & 39,97
\end{tabular} & 4 & \begin{tabular}{l|l}
4 & 31,77 \\
\end{tabular} & 45,75 & 8 & 31,82 & 42,74 & 11 & 102 & $\begin{array}{ll}2 & 10,5 \\
\end{array}$ \\
\hline 352050 & Indaiatuba & B300 & 22 & 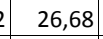 & 27,22 & 12 & $\begin{array}{l}214,30 \\
\end{array}$ & 15,13 & 34 & $\begin{array}{l}40,48 \\
\end{array}$ & \begin{tabular}{|l|l|}
8 & 21,17 \\
\end{tabular} & 64 & 76,84 & $\begin{array}{l}4 \quad 80,85 \\
\end{array}$ & 47 & \begin{tabular}{l|l|}
7 & 55,61 \\
\end{tabular} & 61,36 & 111 & 66,21 & 71,09 & 13 & 880 & 1,5 \\
\hline 352060 & Indiana & E20 & - & - & & - & 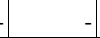 & - & - & & & 2 & 64,71 & \begin{tabular}{|l|l|} 
& 48,77 \\
\end{tabular} & 2 & \begin{tabular}{l|l|}
2 & 93,55 \\
\end{tabular} & 77,81 & 4 & 78,90 & 63,06 & 5 & 36 & \begin{tabular}{l|l}
6 & 13,9 \\
\end{tabular} \\
\hline 352070 & Indiapora & E20 & 1 & 71,34 & 41,55 & 0 & 17,80 & 12,43 & 2 & 24,54 & $\begin{array}{l}4 \quad 26,98 \\
\end{array}$ & 2 & 89,17 & 54,91 & 2 & \begin{tabular}{|l|l|}
2 & 124,60 \\
\end{tabular} & 87,03 & 4 & 106,90 & 70,98 & 5 & 29 & \begin{tabular}{l|l}
9 & 17,2 \\
\end{tabular} \\
\hline 352080 & Inúbia Paulista & E20 & 1 & 39,40 & 29,45 & 0 & $\begin{array}{l}20,64 \\
\end{array}$ & 15,41 & 1 & 30,24 & $\begin{array}{l}422,59 \\
\end{array}$ & 1 & 78,80 & 58,90 & 0 & \begin{tabular}{l|l|}
0 & 20,64 \\
\end{tabular} & 21,02 & 2 & 50,39 & 40,40 & 3 & 23 & \begin{tabular}{l|l}
3 & 12,9 \\
\end{tabular} \\
\hline 352090 & Ipauçu & E20 & 1 & 15,31 & 15,75 & 1 & $\begin{array}{l}1 \\
-20,41 \\
\end{array}$ & 18,13 & 2 & 17,86 & \begin{tabular}{|l|l|}
56 & 16,94 \\
\end{tabular} & 3 & 51,04 & 45,03 & 4 & \begin{tabular}{l|l|}
4 & 56,12 \\
\end{tabular} & 45,94 & 7 & 53,58 & 45,49 & 9 & 98 & \begin{tabular}{l|l}
8 & 8,9 \\
\end{tabular} \\
\hline 352100 & Iperó & C50 & 2 & 19,92 & 22,88 & 3 & 29,53 & 32,06 & 5 & 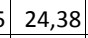 & \begin{tabular}{|l|l|}
8 & 27,14 \\
\end{tabular} & 5 & 45,53 & 52,82 & 6 & \begin{tabular}{l|l|}
6 & 55,78 \\
\end{tabular} & 65,71 & 11 & 50,29 & 58,81 & 14 & 115 & \begin{tabular}{l|l}
5 & 11,9 \\
\end{tabular} \\
\hline 352110 & Ipeúna & $\mathrm{C} 20$ & 1 & 25,33 & 23,95 & 0 & 13,65 & 13,84 & 1 & 19,70 & \begin{tabular}{|l|l|}
0 & 19,099 \\
\end{tabular} & 1 & 37,99 & 31,04 & 1 & \begin{tabular}{l|l|}
1 & 27,29 \\
\end{tabular} & 26,43 & 2 & 32,84 & 28,82 & 3 & 22 & \begin{tabular}{l|l}
2 & 15,4 \\
\end{tabular} \\
\hline 352115 & Ipiguá & E20 & - & & & 0 & $\begin{array}{l}17,30 \\
\end{array}$ & 15,17 & 0 & \begin{tabular}{|l|} 
\\
\end{tabular} & \begin{tabular}{|l|l|}
5 & 7,33 \\
\end{tabular} & 2 & 97,18 & 80,83 & 2 & \begin{tabular}{l|l|}
2 & 86,49 \\
\end{tabular} & 75,84 & 4 & 92,01 & 78,41 & 1 & 16 & \begin{tabular}{l|l}
6 & 8,2 \\
\end{tabular} \\
\hline 352120 & |poranga & E20 & - & & & 0 & 15,27 & 19,28 & 0 & \begin{tabular}{|l|} 
\\
\end{tabular} & $\begin{array}{l}4 \quad 9,27 \\
4\end{array}$ & 1 & 42,43 & 34,84 & 1 & \begin{tabular}{l|l|}
1 & 61,07 \\
\end{tabular} & 66,05 & 2 & 51,39 & 49,85 & 3 & 28 & \begin{tabular}{l|l}
8 & 9,6 \\
\end{tabular} \\
\hline 352130 & Ipua & D20 & 3 & 41,64 & 43,08 & 2 & 32,56 & 35,43 & 5 & 37,20 & \begin{tabular}{|l|l|} 
& 39,34 \\
\end{tabular} & 4 & 62,45 & 65,27 & 3 & \begin{tabular}{l|l|}
3 & 54,27 \\
\end{tabular} & 57,33 & 7 & 58,45 & 61,38 & 2 & 74 & \begin{tabular}{l|l}
4 & 3,2 \\
\end{tabular} \\
\hline 352140 & Iracemápolis & $\mathrm{C} 20$ & 2 & 26,79 & 25,62 & 2 & 19,51 & 19,95 & 4 & 23,18 & \begin{tabular}{|l|l|}
8 & 22,81 \\
\end{tabular} & 9 & 103,32 & 101,61 & 6 & \begin{tabular}{l|l|}
6 & 70,22 \\
\end{tabular} & 71,66 & 15 & 86,93 & 86,78 & 7 & 94 & \begin{tabular}{l|l}
4 & 7,8 \\
\end{tabular} \\
\hline 352150 & Irapua & E20 & 0 & 9,35 & 8,17 & 2 & 49,77 & 42,78 & 2 & 28,94 & $\begin{array}{l}4 \quad 24,94 \\
4\end{array}$ & 3 & 84,19 & 60,44 & 4 & \begin{tabular}{l|l|}
4 & 109,50 \\
\end{tabular} & 104,73 & 7 & 96,45 & 81,89 & 2 & 48 & \begin{tabular}{l|l}
8 & 3,5 \\
\end{tabular} \\
\hline 352160 & Irapuru & E20 & 3 & 74,48 & 77,30 & 1 & \begin{tabular}{|l|} 
\\
\end{tabular} & 19,16 & 4 & 51,63 & \begin{tabular}{|l|l|}
3 & 48,47 \\
\end{tabular} & 3 & 83,79 & 42,38 & 2 & \begin{tabular}{|l|l|}
2 & 47,33 \\
\end{tabular} & 31,09 & 5 & 65,71 & 36,78 & 10 & 57 & \begin{tabular}{l|l}
77 & 18,1 \\
\end{tabular} \\
\hline 352170 & Itaberá & E20 & 2 & 23,74 & 22,28 & 3 & \begin{tabular}{|l|}
3 \\
3
\end{tabular} & 35,19 & 5 & 27,54 & $\begin{array}{l}4 \quad 28,63 \\
\end{array}$ & 7 & 74,61 & 64,23 & 6 & \begin{tabular}{|l|l|}
6 & 62,93 \\
\end{tabular} & 70,14 & 13 & 68,86 & 67,14 & 24 & 115 & \begin{tabular}{l|l|}
5 & 20,9 \\
\end{tabular} \\
\hline 352180 & Itaí & E50 & 5 & 40,44 & 41,12 & 1 & $\begin{array}{l}12,19 \\
\end{array}$ & 13,78 & 6 & \begin{tabular}{|l|l|}
5 & 26,70 \\
\end{tabular} & \begin{tabular}{|l|} 
\\
\end{tabular} & 4 & 37,55 & 35,40 & 7 & \begin{tabular}{l|r|}
7 & 64,00 \\
\end{tabular} & 71,63 & 11 & 50,43 & 53,03 & 20 & 132 & $\begin{array}{ll}2 & 15,2 \\
\end{array}$ \\
\hline 352190 & Itajobi & E20 & 0 & 4,50 & 3,48 & 1 & $\begin{array}{l}18,30 \\
\end{array}$ & $\begin{array}{l}12,99 \\
\end{array}$ & 2 & \begin{tabular}{|l|}
21,34 \\
\end{tabular} & $\begin{array}{l}4 \\
4\end{array}$ & 7 & 89,92 & 54,22 & 3 & \begin{tabular}{l|l|}
3 & 41,17 \\
\end{tabular} & 33,19 & 10 & 65,76 & 43,79 & 2 & 94 & 2,5 \\
\hline 352200 & Itaju & E20 & 1 & 92,81 & 82,15 & - & - & & 1 & $\begin{array}{l}1 \\
1\end{array}$ & \begin{tabular}{|l|l|}
8 & 42,73 \\
\end{tabular} & 1 & 69,61 & 46,07 & 2 & \begin{tabular}{|l|l|}
2 & 125,79 \\
\end{tabular} & 91,69 & 3 & 96,56 & 67,96 & 2 & 22 & \begin{tabular}{l|l}
2 & 10,6 \\
\end{tabular} \\
\hline 352210 & Itanhaém & C100 & 14 & 34,48 & 33,32 & 9 & 22,22 & 22,34 & 24 & $\begin{array}{l}48,32 \\
4\end{array}$ & \begin{tabular}{|l|l|}
2 & 27,80 \\
\end{tabular} & 30 & 71,37 & 63,47 & 21 & \begin{tabular}{l|l|}
1 & 49,20 \\
\end{tabular} & 48,44 & 50 & 60,23 & 55,92 & 56 & 573 & \begin{tabular}{l|l}
3 & 9,8 \\
\end{tabular} \\
\hline 352215 & Itaóca & E20 & 1 & 43,34 & 42,32 & 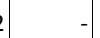 & & & 1 & 22,20 & 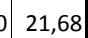 & 1 & 86,67 & 55,41 & 0 & \begin{tabular}{l|l}
0 & 22,77
\end{tabular} & 23,79 & 2 & 55,51 & 39,99 & 3 & 23 & $\begin{array}{ll}3 & 12,9 \\
\end{array}$ \\
\hline
\end{tabular}


Anexo 19 - Óbitos e taxa de mortalidade (bruta e padronizada) total e segundo sexo por Doenças Infecciosas e Parasitárias e Doenças Respiratórias e \% de óbitos por Causas Mal Definidas nos municípios. Estado de São Paulo, média do triênio, 2003-2005

\begin{tabular}{|c|c|c|c|c|c|c|c|c|c|c|c|c|c|c|c|c|c|c|c|c|c|c|c|}
\hline \multirow[b]{2}{*}{ IBGE } & \multirow{2}{*}{ Mun. } & \multirow{2}{*}{ Porte } & \multicolumn{9}{|c|}{$\begin{array}{l}\text { DOENCAS INFECCIOSAS E PARASITÁRIAS } \\
\end{array}$} & \multicolumn{9}{|c|}{ DOENCAS RESPIRATÓRIAS } & \multicolumn{3}{|c|}{ MAL DEFINIDAS } \\
\hline & & & Obitos & $\begin{array}{l}\text { Homens } \\
\text { TMB }\end{array}$ & TPM & Obitos & $\begin{array}{l}\text { Mulhere } \\
\text { TMB }\end{array}$ & TPM & Obitos & $\begin{array}{l}\text { Total } \\
\text { TMB }\end{array}$ & TPM & Obitos & $\begin{array}{l}\text { Homens } \\
\text { TMB }\end{array}$ & TPM & Obitos & $\begin{array}{l}\text { Mulh } \\
\text { TMB }\end{array}$ & TPM & Obi & $\begin{array}{l}\text { Total } \\
\text { TMB }\end{array}$ & TPM & Obitos C & Ob.Totais & \\
\hline 352220 & Itapecerica da Serra & С300 & 23 & 31,16 & 38,55 & 14 & 18,53 & 26,66 & 37 & 24,77 & 32,54 & 45 & 61,41 & 97,59 & 44 & 58,69 & 107,34 & 90 & 60,03 & 102,52 & 25 & 831 & 3,0 \\
\hline 352230 & Itapetininga & B300 & 18 & 26,89 & 27,14 & 13 & 18,64 & 18,75 & 31 & 22,77 & 22,95 & 54 & 78,70 & 75,07 & 57 & 84,36 & 83,13 & 111 & 81,52 & 79,10 & 114 & 908 & 12,5 \\
\hline 352240 & Itapeva & D100 & 12 & 28,64 & 27,90 & 11 & 25,03 & 26,72 & 23 & 26,81 & 27,30 & 38 & 88,24 & 90,23 & 30 & 69,01 & 80,94 & 68 & 78,53 & 85,54 & 118 & 581 & 20,3 \\
\hline 352250 & Itapevi & С300 & 26 & 27,77 & 36,19 & 17 & 18,02 & 24,07 & 43 & 22,85 & 30,07 & 45 & 48,68 & 77,63 & 37 & 39,58 & 72,21 & 82 & 44,09 & 74,89 & 13 & 815 & 1,6 \\
\hline 352260 & Itapira & D100 & 19 & 56,11 & 51,52 & 11 & 32,18 & 30,69 & 29 & 44,17 & 41,12 & 45 & 136,28 & 105,28 & 36 & 108,61 & 83,08 & 81 & $\mid 122,47$ & 94,20 & 50 & 548 & 9,2 \\
\hline 352265 & Itapirapua Paulista & E20 & 1 & 34,03 & 24,36 & 5 & & & 1 & 17,93 & 12,84 & 1 & 51,05 & 36,55 & & & & 1 & 26,90 & 19,26 & 2 & 15 & 10,9 \\
\hline 352270 & Itápolis & D50 & 4 & 18,44 & 17,36 & 3 & 15,03 & 13,47 & 7 & 16,73 & 15,41 & 26 & 132,41 & 99,91 & 16 & 78,48 & 63,51 & 42 & 105,40 & 81,68 & 33 & 289 & 11,5 \\
\hline 352280 & Itaporanga & E20 & 2 & 32,28 & 32,18 & 2 & 23,47 & 23,52 & 4 & 27,91 & 27,89 & 4 & 59,95 & 49,65 & 6 & 79,80 & 78,10 & 10 & 69,79 & 63,75 & 27 & 116 & 23,1 \\
\hline 352290 & Itapuí & E20 & 1 & 23,70 & 17,05 & 1 & 25,00 & 22,74 & 3 & 24,33 & 19,82 & 6 & 100,73 & 82,63 & 1 & 25,00 & 17,96 & 7 & 63,87 & 51,16 & 13 & 74 & 18,1 \\
\hline 352300 & Itapura & E20 & 1 & 32,85 & 38,42 & 0 & 18,04 & 17,61 & 1 & 25,79 & 28,50 & 1 & 49,28 & 37,35 & 1 & 72,16 & 65,36 & 2 & 60,18 & 50,70 & 2 & 29 & 8,0 \\
\hline 352310 & Itaquaquecetuba & C500 & 29 & 18,30 & 22,89 & 22 & 13,67 & 18,03 & 51 & 15,98 & 20,46 & 60 & 37,64 & 70,52 & 63 & 39,36 & 75,29 & 124 & 38,50 & 72,91 & 217 & 1377 & 15,8 \\
\hline 352320 & Itararé & D50 & 5 & 22,13 & 22,87 & 3 & 12,21 & 12,18 & 8 & 17,13 & 17,47 & 18 & 73,31 & 65,45 & 13 & 51,57 & 49,38 & 30 & 62,34 & 57,34 & 71 & 352 & 20,1 \\
\hline 352330 & Itariri & D20 & 1 & 13,47 & 13,29 & 1 & 14,11 & 16,74 & 2 & 13,79 & 14,97 & 3 & 40,41 & 39,87 & 4 & 51,75 & 63,32 & 7 & 45,95 & 51,32 & 8 & 70 & 12,0 \\
\hline 352340 & Itatiba & B100 & 14 & 30,50 & 29,36 & 6 & 14,03 & 13,90 & 20 & 22,24 & 21,61 & 30 & 66,96 & 62,10 & 21 & 45,80 & 45,22 & 51 & 56,34 & 53,63 & 16 & 542 & 2,9 \\
\hline 352350 & Itatinga & E20 & 2 & 24,12 & 26,40 & 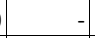 & & & 2 & 12,35 & 13,52 & 6 & 68,33 & 71,88 & 3 & 42,19 & 48,17 & 9 & 55,58 & 60,31 & 3 & 102 & 2,6 \\
\hline 352360 & Itirapina & C20 & 2 & 29,65 & 28,70 & 0 & 5,33 & 4,44 & 3 & 18,88 & 17,95 & 6 & 76,26 & 81,17 & 3 & 53,30 & 45,19 & 9 & 66,09 & 65,23 & 17 & 84 & 20,7 \\
\hline 352370 & Itirapua & E20 & -1 & & & -1 & & & - & & & 2 & 80,26 & 72,07 & 2 & 74,96 & 71,22 & 4 & 77,72 & 71,66 & 2 & 32 & 5,2 \\
\hline 352380 & Itobi & E20 & 1 & 24,77 & 25,07 & 1 & 17,85 & 15,41 & 2 & 21,45 & 20,43 & 3 & 66,06 & 49,12 & 1 & 26,78 & 25,09 & 4 & 47,18 & 37,57 & 6 & 60 & 9,4 \\
\hline 352390 & Itu & C300 & 24 & 33,01 & 33,78 & 16 & 21,12 & 21,64 & 40 & 27,05 & $27,69 \mid$ & 57 & 77,33 & 80,22 & 62 & 83,12 & 84,91 & 119 & 80,24 & 82,57 & 120 & 876 & 13,7 \\
\hline 352400 & Itupeva & C50 & 3 & 17,49 & 19,93 & 1 & 9,19 & 11,52 & 4 & 13,44 & 15,83 & 8 & 50,27 & 57,60 & 6 & 43,68 & 63,67 & 14 & 47,06 & 60,56 & 3 & 139 & 2,2 \\
\hline 352410 & Ituverava & D50 & 8 & 44,64 & 41,27 & 9 & 48,97 & 43,28 & 18 & 46,83 & 42,29 & 20 & 105,36 & 88,02 & 15 & 80,45 & 68,85 & 35 & 92,77 & 78,34 & 36 & 298 & 12,0 \\
\hline 352420 & Jaborandi & E20 & 1 & 40,10 & 39,30 & 2 & 53,08 & 49,32 & 3 & 46,40 & 44,17 & 2 & 60,14 & 55,09 & 2 & 53,08 & 49,32 & 4 & 56,71 & 52,29 & 2 & 45 & 4,5 \\
\hline 352430 & Jaboticabal & B100 & 15 & 43,97 & 42,59 & 10 & 28,52 & 26,12 & 26 & 36,10 & 34,20 & 31 & 88,89 & 75,56 & 22 & 59,81 & 48,48 & 53 & 74,07 & 61,76 & 84 & 459 & 18,3 \\
\hline 352440 & Jacareí & B300 & 34 & 33,77 & 34,58 & 18 & 17,50 & 18,24 & 52 & 25,55 & 26,32 & 63 & 62,57 & 69,14 & 67 & 65,47 & 76,36 & 130 & 64,03 & 72,79 & 87 & 1186 & 7,4 \\
\hline 352450 & Jaci & E20 & 1 & 28,52 & 30,21 & 1 & 46,02 & 45,78 & 2 & 36,95 & 37,71 & 2 & 85,57 & 84,15 & 1 & 61,36 & 62,50 & 3 & 73,90 & 73,72 & 1 & 33 & 3,0 \\
\hline 352460 & Jacupiranga & D20 & 2 & 21,49 & 22,27 & 1 & 14,98 & 15,64 & 3 & 18,31 & 19,03 & 6 & 60,90 & 55,13 & 5 & 52,43 & 56,40 & 10 & 56,76 & 55,76 & 10 & 96 & 10,8 \\
\hline 352470 & Jaguariúna & B50 & 3 & 16,15 & 16,12 & 3 & 16,45 & 17,65 & 5 & 16,30 & 16,88 & 11 & 68,63 & 68,23 & 9 & 53,45 & 57,87 & 20 & 61,11 & 63,10 & 6 & 189 & 3,0 \\
\hline 352480 & Jales & D50 & 9 & 36,21 & 28,71 & 9 & 38,24 & 34,05 & 18 & 37,24 & 31,41 & 22 & 91,92 & 69,67 & 14 & 58,73 & 50,03 & 36 & 75,16 & 59,75 & 55 & 317 & 17,4 \\
\hline 352490 & Jambeiro & D20 & - & & & 0 & 16,17 & 16,98 & 0 & 7,74 & 8,13 & 1 & 44,54 & 35,36 & 1 & 64,69 & 70,00 & 2 & 54,18 & 51,94 & 2 & 21 & 11,1 \\
\hline 352500 & Jandira & С300 & 13 & 25,00 & 34,00 & 9 & 16,41 & 23,32 & 22 & 20,67 & 28,62 & 20 & 39,10 & 67,88 & 17 & 32,82 & 59,21 & 38 & 35,94 & 63,51 & 10 & 423 & 2,4 \\
\hline 352510 & Jardinópolis & C50 & 5 & 31,41 & 29,31 & 3 & 19,96 & 20,23 & 9 & 25,73 & 24,81 & 16 & 94,22 & 86,95 & 7 & 41,92 & 41,17 & 23 & 68,29 & 64,25 & 3 & 192 & 1,6 \\
\hline 352520 & Jarinu & D20 & 2 & 16,25 & 16,97 & 1 & 10,48 & 10,70 & 3 & 13,47 & 13,95 & 5 & 52,01 & 51,95 & 5 & 55,90 & 64,19 & 11 & 53,89 & 57,85 & 0 & 99 & 0,3 \\
\hline
\end{tabular}


Anexo 19 - Óbitos e taxa de mortalidade (bruta e padronizada) total e segundo sexo por Doenças Infecciosas e Parasitárias e Doenças Respiratórias e \% de óbitos por Causas Mal Definidas nos municípios. Estado de São Paulo, média do triênio, 2003-2005

\begin{tabular}{|c|c|c|c|c|c|c|c|c|c|c|c|c|c|c|c|c|c|c|c|c|c|c|c|}
\hline \multirow[b]{2}{*}{ IBGE } & \multirow[b]{2}{*}{ Mun. } & \multirow[b]{2}{*}{ Porte } & \multicolumn{9}{|c|}{ DOENCAS INFECCIOSAS E PARASITÁRIAS } & \multicolumn{9}{|c|}{ DOENCAS RESPIRATÓRIAS } & \multicolumn{3}{|c|}{ MAL DEFINIDAS } \\
\hline & & & Obitos & $\begin{array}{l}\text { Homens } \\
\text { TMB }\end{array}$ & TPM & Obitos & $\begin{array}{l}\text { Mulhere } \\
\text { TMB }\end{array}$ & TPM & Obitos & $\begin{array}{l}\text { Total } \\
\text { TMB }\end{array}$ & TPM & Obitos & $\begin{array}{l}\text { Homens } \\
\text { TMB }\end{array}$ & TPM & $\begin{array}{r}\mathrm{N} \\
\text { Obitos } \mathrm{T} \\
\end{array}$ & $\begin{array}{l}\text { Mulhere } \\
\text { TMB }\end{array}$ & TPM & Obitos & $\begin{array}{l}\text { Total } \\
\text { TMB }\end{array}$ & TPM & Obitos & Ob.Totais & \\
\hline 352530 & Jaú & С300 & 16 & 27,51 & 23,64 & 11 & 18,10 & 15,33 & 27 & 22,75 & 19,44 & 59 & 98,81 & 77,74 & 41 & 66,92 & 52,49 & 99 & 82,68 & 64,97 & 119 & 828 & 14,4 \\
\hline 352540 & Jeriquara & E20 & 0 & 19,08 & 19,26 & 0 & 21,64 & 23,39 & 1 & 20,28 & 21,19 & 0 & 19,08 & 17,11 & 0 & 21,64 & \begin{tabular}{|l|}
25,02 \\
\end{tabular} & 1 & 20,28 & 20,82 & 3 & 17 & 20,0 \\
\hline 352550 & Joanópolis & E20 & 0 & 5,74 & 4,87 & 0 & 5,96 & 6,17 & 1 & 5,85 & 5,51 & 5 & 91,76 & 67,24 & 5 & 89,45 & 75,25 & 10 & 90,63 & 71,16 & 9 & 82 & 11,3 \\
\hline 352560 & Joao Ramalho & E20 & 0 & 15,80 & 16,53 & 1 & 32,04 & 29,60 & 1 & 23,86 & 23,02 & 1 & 31,60 & 26,70 & 1 & 32,04 & 34,39 & 1 & 31,82 & 30,52 & 3 & 23 & 11,8 \\
\hline 352570 & José Bonifácio & D50 & 5 & 30,08 & 26,69 & 2 & 15,09 & 13,87 & 7 & 22,60 & $20,29 \mid$ & 12 & 75,20 & 63,03 & 11 & 68,98 & \begin{tabular}{|l|l|}
3 & 62,89 \\
\end{tabular} & 22 & 72,09 & 62,96 & 21 & 204 & 10,3 \\
\hline 352580 & Júlio Mesquita & E20 & 0 & 15,68 & 14,28 & & - & & 0 & 7,73 & 7,04 & 3 & 141,15 & 104,56 & 2 & 106,76 & 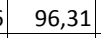 & 5 & 123,71 & 100,38 & 11 & 37 & 30,4 \\
\hline 352585 & Jumirim & A20 & -1 & & & -1 & - & & - & & & 1 & 77,20 & 62,94 & 0 & 28,62 & 20,25 & 1 & 54,20 & 42,73 & 0 & 13 & 2,5 \\
\hline 352590 & Jundiaí & A500 & 55 & 32,92 & 30,55 & 31 & 17,77 & 15,94 & 85 & 25,20 & 23,10 & 165 & 99,56 & 87,50 & 135 & 78,23 & \begin{tabular}{|l|l|} 
& 66,29 \\
\end{tabular} & 300 & 88,69 & 76,69 & 20 & 2274 & 0,9 \\
\hline 352600 & Junqueirópolis & E20 & 5 & 57,22 & 45,42 & 2 & 25,15 & 26,15 & 7 & 41,94 & 36,24 & 7 & 83,92 & 48,85 & 6 & 75,44 & \begin{tabular}{|l|} 
\\
\end{tabular} & 13 & 79,88 & 53,25 & 21 & 141 & 15,1 \\
\hline 352610 & Juquiá & D50 & 3 & 23,54 & 22,92 & 2 & 21,65 & 23,74 & 5 & 22,62 & 23,32 & 7 & 58,86 & 51,43 & 6 & 52,57 & 56,10 & 12 & 55,79 & 53,71 & 15 & 135 & 11,4 \\
\hline 352620 & Juquitiba & D50 & 5 & 33,85 & 35,63 & 3 & 18,28 & 22,74 & 8 & 26,11 & 29,22 & 11 & 72,22 & 78,77 & 10 & 70,83 & 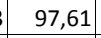 & 21 & 71,53 & 88,13 & 6 & 185 & 3,1 \\
\hline 352630 & Lagoinha & E20 & 1 & 24,99 & 26,38 & 1 & 41,10 & 43,52 & 2 & 32,67 & 34,56 & 2 & 74,97 & 39,90 & 3 & 109,59 & 90,18 & 5 & 91,49 & 63,88 & 5 & 39 & 11,9 \\
\hline 352640 & Laranjal Paulista & B50 & 1 & 11,37 & 10,17 & 2 & 14,18 & 12,97 & 3 & 12,77 & 11,57 & 8 & 71,05 & 53,63 & 9 & 73,73 & \begin{tabular}{|l|}
36,36 \\
\end{tabular} & 17 & 72,39 & 55,00 & 8 & 156 & 5,3 \\
\hline 352650 & Lavínia & E20 & 1 & 26,58 & 22,87 & 1 & 40,22 & 33,86 & 2 & 33,37 & 28,34 & 2 & 79,74 & 63,03 & 2 & 93,85 & 70,09 & 4 & 86,77 & 66,54 & 5 & 38 & 14,2 \\
\hline 352660 & Lavrinhas & D20 & 2 & 49,43 & 52,77 & 1 & 30,94 & 33,18 & 3 & 40,38 & 43,18 & 1 & 29,66 & 30,92 & 0 & 10,31 & 14,10 & 1 & 20,19 & 22,69 & 6 & 36 & 15,9 \\
\hline 352670 & Leme & D100 & 16 & 37,41 & 38,55 & 11 & 26,54 & 27,55 & 28 & 32,04 & 33,11 & 33 & 74,81 & 77,74 & 27 & 62,46 & \begin{tabular}{|l|}
5 \\
\end{tabular} & 59 & 68,71 & 71,46 & 76 & 520 & 14,6 \\
\hline 352680 & Lençóis Paulista & C100 & 11 & 36,86 & 37,74 & 9 & 30,25 & 31,88 & 20 & 33,56 & 34,82 & 17 & 58,08 & 58,88 & 14 & 48,17 & \begin{tabular}{|l|}
51,02 \\
\end{tabular} & 32 & 53,13 & 54,96 & 23 & 334 & 6,8 \\
\hline 352690 & Limeira & B300 & 45 & 33,90 & 33,43 & 26 & 19,55 & 19,80 & 71 & 26,67 & 26,56 & 98 & 73,57 & 71,98 & 66 & 48,99 & \begin{tabular}{|l|}
49,82 \\
\end{tabular} & 164 & 61,19 & 60,82 & 252 & 1535 & 16,4 \\
\hline 352700 & Lindóia & D20 & 1 & 33,61 & 28,86 & 0 & 11,41 & 8,80 & 1 & $22,61 \mid$ & 18,92 & 2 & 78,43 & 61,10 & 1 & 45,64 & $\begin{array}{r}48,21 \\
\end{array}$ & 4 & 62,19 & 49,76 & 3 & 39 & 8,5 \\
\hline 352710 & Lins & B100 & 11 & 33,75 & 31,13 & 8 & 22,44 & 19,27 & 19 & 27,93 & 25,02 & 42 & 126,06 & 94,91 & 40 & 111,27 & 82,14 & 82 & 118,44 & 88,33 & 87 & 529 & 16,4 \\
\hline 352720 & Lorena & B100 & 13 & 32,75 & 34,02 & 8 & 19,95 & 19,94 & 21 & 26,19 & 26,80 & 35 & 89,01 & 86,63 & 30 & 72,63 & \begin{tabular}{|l|l|} 
& 67,88 \\
\end{tabular} & 66 & 80,62 & 77,01 & 52 & 585 & 8,9 \\
\hline 352725 & Lourdes & E20 & 0 & 29,78 & 31,09 & 0 & 32,03 & 25,66 & 1 & 30,86 & 28,47 & 2 & 148,90 & 111,07 & 1 & 64,06 & \begin{tabular}{|l|l|}
51,32 \\
\end{tabular} & 2 & 108,02 & 82,28 & 3 & 14 & 24,4 \\
\hline 352730 & Louveira & C50 & 4 & 26,47 & 28,69 & 1 & 9,90 & 10,83 & 5 & 18,30 & 19,89 & 8 & 57,76 & 66,68 & 4 & 32,18 & \begin{tabular}{|l|l|} 
& 38,40 \\
\end{tabular} & 12 & 45,15 & 52,74 & 6 & 146 & 4,1 \\
\hline 352740 & Lucélia & D20 & 4 & 38,23 & 31,32 & 2 & 22,36 & 17,43 & 6 & 30,57 & 24,61 & 7 & 72,99 & 54,20 & 6 & 70,79 & 52,93 & 13 & 71,93 & 53,59 & 18 & 143 & 12,6 \\
\hline 352750 & Lucianópolis & E20 & 0 & 31,33 & 26,28 & 0 & 33,27 & 27,19 & 1 & 32,27 & 26,72 & 1 & 125,31 & 104,65 & - & & & 1 & 64,54 & 53,90 & 1 & 15 & 4,5 \\
\hline 352760 & Luís Antônio & $\mathrm{C} 20$ & 0 & 8,41 & 12,13 & 0 & 8,80 & 13,82 & 1 & 8,60 & 12,95 & 1 & 33,64 & 48,50 & 2 & 52,82 & 82,90 & 3 & 43,01 & 65,31 & 1 & 37 & 2,7 \\
\hline 352770 & Luiziânia & E20 & 1 & 46,08 & 30,15 & 1 & 46,33 & 34,07 & 2 & 46,20 & 32,11 & 1 & 61,43 & 40,21 & 1 & 61,78 & \begin{tabular}{|l|l|} 
& 45,43 \\
\end{tabular} & 3 & 61,60 & 42,81 & 5 & 32 & 16,7 \\
\hline 352780 & Lupércio & E20 & 2 & 92,39 & 79,30 & - & - & & 2 & 46,56 & 39,96 & 1 & 30,80 & 24,76 & 1 & 46,93 & \begin{tabular}{|l|l|} 
& 47,29 \\
\end{tabular} & 2 & 38,80 & 35,94 & 2 & 24 & 9,7 \\
\hline 352790 & Lutécia & E20 & 0 & 21,72 & 19,73 & 1 & 45,14 & 37,31 & 1 & 33,20 & 28,35 & 1 & 86,88 & 60,19 & - & & & 1 & 44,27 & 30,67 & 2 & 15 & 15,2 \\
\hline 352800 & Macatuba & D20 & - & & & 2 & 23,97 & 25,29 & 2 & 11,92 & 12,58 & 5 & 55,38 & 56,69 & 2 & 27,96 & \begin{tabular}{|l|l|}
5 & 29,62 \\
\end{tabular} & 7 & 41,74 & 43,22 & 11 & 98 & 10,9 \\
\hline 352810 & Macaubal & E20 & 1 & 35,53 & 28,00 & 1 & 36,71 & 26,60 & 3 & 36,11 & 27,31 & 3 & 71,05 & 54,01 & 1 & 18,36 & \begin{tabular}{|l|l|}
5 & 13,04 \\
\end{tabular} & 3 & 45,14 & 33,86 & 1 & 51 & 2,6 \\
\hline 352820 & Macedônia & E20 & 0 & 17,91 & 11,67 & & & & 0 & 9,07 & 5,91 & 2 & 89,54 & 68,32 & 2 & 128,75 & ; 99,33 & 4 & 108,88 & 83,62 & 4 & 27 & 16,3 \\
\hline
\end{tabular}


Anexo 19 - Óbitos e taxa de mortalidade (bruta e padronizada) total e segundo sexo por Doenças Infecciosas e Parasitárias e Doenças Respiratórias e \% de óbitos por Causas Mal Definidas nos municípios. Estado de São Paulo, média do triênio, 2003-2005

\begin{tabular}{|c|c|c|c|c|c|c|c|c|c|c|c|c|c|c|c|c|c|c|c|c|c|c|c|}
\hline \multirow[b]{2}{*}{ IBGE } & \multirow[b]{2}{*}{ Mun. } & \multirow[b]{2}{*}{ Porte } & \multicolumn{9}{|c|}{$\begin{array}{l}\text { DOENCAS INFECCIOSAS E PARASITÁRIAS } \\
\text { Dus }\end{array}$} & \multicolumn{9}{|c|}{ DOENCAS RESPIRATÓRIAS } & \multicolumn{3}{|c|}{ MAL DEFINIDAS } \\
\hline & & & Obitos & $\begin{array}{l}\text { Homens } \\
\text { TMB }\end{array}$ & TPM & Obitos & $\begin{array}{l}\text { Mulhere } \\
\text { TMB }\end{array}$ & STPM & Obitos & $\begin{array}{l}\text { Total } \\
\text { TMB }\end{array}$ & TPM & Obitos & $\begin{array}{l}\text { Homens } \\
\text { TMB }\end{array}$ & TPM & Obitos & $\begin{array}{l}\text { Mulhere } \\
\text { TMB }\end{array}$ & TPM & Obitos & $\begin{array}{l}\text { Total } \\
\text { TMB }\end{array}$ & TPM & Obitos & Ob.Totais & $\%$ \\
\hline 352830 & Magda & E20 & 1 & 78,37 & 60,65 & & & & 1 & 40,35 & 31,22 & 1 & 78,37 & 50,71 & 0 & 20,79 & 17,64 & 2 & 50,43 & 34,67 & 5 & 25 & 18,7 \\
\hline 352840 & Mairinque & C50 & 5 & 22,37 & 24,78 & 5 & 22,40 & 23,90 & 10 & 22,38 & 24,34 & 16 & 73,07 & 86,65 & 9 & 41,81 & 54,53 & 26 & 57,45 & 70,60 & 41 & 266 & 15,6 \\
\hline 352850 & Mairipora & C100 & 5 & 14,39 & 15,14 & 6 & 17,45 & 19,14 & 11 & 15,91 & 17,13 & 24 & 68,12 & 73,40 & 18 & 52,35 & 64,66 & 42 & 60,28 & 69,05 & 6 & 413 & 1,4 \\
\hline 352860 & Manduri & D20 & 1 & 29,90 & 22,73 & 1 & 31,33 & 28,21 & 3 & 30,60 & 25,41 & 1 & 29,90 & 21,89 & 2 & 46,99 & 40,79 & 3 & 38,25 & 31,12 & 6 & 62 & 9,1 \\
\hline 352870 & Marabá Paulista & E20 & 1 & 33,92 & 33,91 & & & & 1 & 17,59 & 17,58 & 1 & 50,88 & 45,97 & 0 & 18,27 & 21,33 & 1 & 35,18 & 34,11 & 4 & 19 & 22,4 \\
\hline 352880 & Maracaí & D20 & 2 & 34,55 & 30,96 & 1 & 15,41 & 15,49 & 3 & 25,17 & 23,38 & 8 & 118,44 & 99,89 & 4 & 61,64 & 60,94 & 12 & 90,61 & 80,80 & 4 & 89 & 4,5 \\
\hline 352885 & Marapoama & E20 & - & & & 1 & 55,91 & 47,41 & 1 & \begin{tabular}{|l|}
27,57 \\
\end{tabular} & 23,38 & 1 & 81,61 & 66,21 & 0 & 27,96 & 29,47 & 1 & 55,15 & 48,09 & 1 & 10 & 6,7 \\
\hline 352890 & Mariápolis & E20 & 1 & 53,53 & 56,39 & - & - & & 1 & 27,53 & 29,00 & 2 & 89,22 & 63,19 & 4 & 207,86 & 160,40 & 5 & 146,84 & 110,41 & 4 & 30 & 13,3 \\
\hline 352900 & Marília & B300 & 30 & 29,05 & 26,82 & 18 & 16,80 & 15,66 & 49 & 22,79 & 21,12 & 81 & 77,90 & 66,35 & 62 & 56,52 & 49,33 & 143 & 66,98 & 57,65 & 145 & 1326 & 10,9 \\
\hline 352910 & Marinópolis & E20 & - & & & & & & & & & 1 & 86,26 & 70,71 & 1 & 61,48 & 60,29 & 2 & 74,28 & 65,67 & 2 & 12 & 16,2 \\
\hline 352920 & Martinópolis & D50 & 4 & 30,41 & 29,59 & 3 & 26,12 & 24,49 & 7 & 28,32 & 27,10 & 8 & 63,59 & 49,95 & 6 & 52,25 & 43,52 & 14 & 58,06 & 46,81 & 30 & 165 & 18,4 \\
\hline 352930 & Matao & B100 & 10 & 26,53 & 26,45 & 9 & 22,99 & 23,94 & 19 & 24,76 & 25,20 & 33 & 87,55 & 86,14 & 18 & 47,75 & 50,75 & 51 & 67,65 & 68,44 & 36 & 429 & 8,3 \\
\hline 352940 & Mauá & C500 & 57 & 29,57 & 33,47 & 36 & 17,83 & 22,33 & 93 & $23,61 \mid$ & 27,81 & 139 & 71,87 & 98,48 & 103 & 51,65 & 76,97 & 243 & 61,60 & 87,55 & 19 & 1905 & 1,0 \\
\hline 352950 & Mendonça & E20 & 0 & 16,70 & 8,67 & 1 & 53,21 & 38,72 & 1 & 34,41 & 23,24 & 3 & 167,00 & 104,90 & 1 & 70,95 & 48,32 & 5 & 120,42 & 77,46 & 0 & 30 & 1,1 \\
\hline 352960 & Meridiano & E20 & - & & & 1 & 33,00 & 34,65 & 1 & 16,13 & 16,94 & 2 & 94,67 & 60,08 & 3 & 165,02 & 142,13 & 5 & 129,05 & 100,19 & 7 & 26 & 26,6 \\
\hline 352965 & Mesópolis & E20 & 1 & 68,87 & 37,50 & & & & 1 & 35,19 & 19,16 & 0 & 34,44 & 18,75 & 0 & 35,97 & 30,33 & 1 & 35,19 & 24,42 & 1 & 11 & 11,8 \\
\hline 352970 & Miguelópolis & E20 & 9 & 90,68 & 91,55 & 5 & 50,95 & 55,60 & 14 & 70,93 & 73,68 & 4 & 40,30 & 40,59 & 6 & 57,74 & 62,30 & 10 & 48,97 & 51,39 & 10 & 129 & 7,5 \\
\hline 352980 & Mineiros do Tietê & E20 & 1 & 16,19 & 13,12 & 0 & 5,46 & 4,37 & 1 & 10,86 & 8,77 & 7 & 107,90 & 92,23 & 3 & 43,71 & 37,59 & 9 & 76,01 & 65,08 & 8 & 73 & 11,0 \\
\hline 353000 & Mira Estrela & E20 & 1 & 50,09 & 31,38 & 0 & 27,01 & 24,38 & 1 & 38,98 & 28,01 & 2 & 175,31 & 117,66 & 1 & 81,02 & 77,49 & 3 & 129,94 & 98,33 & 2 & 17 & 9,8 \\
\hline 352990 & Miracatu & E50 & 2 & 18,90 & 19,91 & 3 & 23,07 & 28,63 & 5 & 20,92 & 24,13 & 9 & 70,19 & \begin{tabular}{|r|}
71,25 \\
\end{tabular} & 4 & 37,49 & 50,93 & 13 & 54,38 & 61,43 & 16 & 143 & 11,4 \\
\hline 353010 & Mirandópolis & D50 & 3 & 18,82 & 16,24 & 0 & 2,68 & 2,00 & 3 & 11,28 & 9,58 & 15 & 105,87 & 80,13 & 10 & 77,71 & 61,50 & 25 & 92,71 & 71,42 & 24 & 171 & 14,3 \\
\hline 353020 & Mirante Paranapanema & E20 & 1 & 11,75 & 9,41 & 3 & 32,66 & 31,25 & 4 & 21,99 & 20,10 & 6 & 66,60 & 43,89 & 7 & 89,81 & 80,63 & 13 & 77,97 & 61,88 & 19 & 99 & 19,6 \\
\hline 353030 & Mirassol & B100 & 11 & 42,57 & 39,70 & 8 & 31,42 & 28,14 & 19 & 36,92 & 33,84 & 24 & 91,59 & 75,80 & 17 & 62,84 & 51,37 & 40 & 77,02 & 63,43 & 18 & 341 & 5,4 \\
\hline 353040 & Mirassolândia & E20 & 1 & 47,89 & 39,23 & 1 & 33,77 & 34,63 & 2 & 41,02 & 37,00 & 2 & 95,77 & 74,24 & 1 & 67,53 & 57,99 & 3 & 82,05 & 66,35 & 2 & 24 & 6,8 \\
\hline 353050 & Mococa & D100 & 13 & 36,50 & 34,89 & 8 & 23,47 & 21,56 & 21 & 30,04 & 28,29 & 33 & 96,06 & 81,12 & 24 & 71,38 & 62,83 & 58 & 83,83 & 72,05 & 57 & 477 & 11,9 \\
\hline 353060 & Moji das Cruzes & B500 & 38 & 21,88 & 22,58 & 25 & 13,66 & 14,55 & 63 & 17,71 & 18,50 & 104 & 59,36 & 65,86 & 87 & 48,19 & 55,09 & 191 & 53,69 & 60,40 & 29 & 2038 & 1,4 \\
\hline 353070 & MojiOGuaçu & B300 & 14 & 21,18 & 21,18 & 9 & 13,43 & 14,64 & 23 & 17,32 & 17,93 & 44 & 65,02 & 64,69 & 36 & 53,71 & 60,16 & 80 & 59,39 & 62,44 & 134 & 788 & 17,1 \\
\hline 353080 & MojiOMirim & B100 & 17 & 37,51 & 36,15 & 9 & 20,97 & 19,52 & 26 & 29,24 & 27,83 & 27 & 60,76 & 52,83 & 19 & 42,70 & 38,80 & 46 & 51,73 & 45,81 & 81 & 541 & 14,9 \\
\hline 353090 & Mombuca & E20 & 0 & 19,54 & 20,86 & 0 & 20,48 & 23,76 & 1 & 20,00 & 22,28 & 1 & 58,63 & 56,65 & 1 & 81,90 & 82,60 & 2 & 69,99 & 69,32 & 2 & 20 & 11,9 \\
\hline 353100 & Monçoes & E20 & - & & & & & & - & & & 1 & 96,84 & 75,88 & 1 & 99,80 & 71,10 & 2 & 98,30 & 73,52 & 0 & 14 & 2,3 \\
\hline 353110 & Mongaguá & C50 & 11 & 49,20 & 47,51 & 6 & 30,75 & 31,92 & 17 & 40,21 & 39,91 & 14 & 63,04 & 56,69 & 7 & 33,98 & 32,55 & 21 & 48,88 & 44,93 & 42 & 287 & 14,8 \\
\hline 353120 & Monte Alegre do Sul & E20 & 1 & 19,49 & 14,43 & & & & 1 & 9,93 & 7,35 & 1 & 38,97 & 24,39 & 1 & 30,36 & 24,76 & 2 & 34,75 & 24,57 & 0 & 40 & 0,8 \\
\hline
\end{tabular}


Anexo 19 - Óbitos e taxa de mortalidade (bruta e padronizada) total e segundo sexo por Doenças Infecciosas e Parasitárias e Doenças Respiratórias e \% de óbitos por Causas Mal Definidas nos municípios. Estado de São Paulo, média do triênio, 2003-2005

\begin{tabular}{|c|c|c|c|c|c|c|c|c|c|c|c|c|c|c|c|c|c|c|c|c|c|c|c|}
\hline \multirow[b]{2}{*}{ IBGE } & \multirow[b]{2}{*}{ Mun. } & \multirow[b]{2}{*}{ Porte } & \multicolumn{9}{|c|}{ DOENCAS INFECCIOSAS E PARASITÁRIAS } & \multicolumn{9}{|c|}{ DOENCAS RESPIRATÓRIAS } & \multicolumn{3}{|c|}{ MAL DEFINIDAS } \\
\hline & & & Obitos & $\begin{array}{l}\text { Homens } \\
\text { TMB }\end{array}$ & TPM & Obitos & $\begin{array}{l}\text { Mulhere } \\
\text { TMB }\end{array}$ & TPM & Obitos & $\begin{array}{l}\text { Total } \\
\text { TMB }\end{array}$ & TPM & Obitos & $\begin{array}{l}\text { Homens } \\
\text { TMB }\end{array}$ & s & Obitos & $\begin{array}{l}\text { Mulhere } \\
\text { TMB }\end{array}$ & TPM & Obitos & $\begin{array}{l}\text { Total } \\
\text { TMB }\end{array}$ & TPM & Obitos & Ob.Totais & $\%$ \\
\hline 353130 & Monte Alto & C50 & 9 & 41,09 & 35,77 & 4 & \begin{tabular}{l|l}
4 & 17,68 \\
\end{tabular} & 15,34 & 13 & 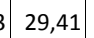 & 25,58 & 28 & 124,73 & \begin{tabular}{|l|l|}
3 & 95,11 \\
3
\end{tabular} & 19 & 82,51 & 64,55 & 47 & 103,66 & 79,86 & 29 & 300 & 9,6 \\
\hline 353140 & Monte Aprazivel & D20 & 5 & 53,60 & 43,89 & 3 & \begin{tabular}{l|l}
3 & 31,62 \\
\end{tabular} & 28,54 & 8 & \begin{tabular}{l|l|}
3 & 42,51 \\
\end{tabular} & 36,15 & 14 & 153,64 & 101,78 & 12 & 122,95 & 84,06 & 26 & 138,17 & 92,85 & 25 & 161 & 15,4 \\
\hline 353150 & Monte Azul Paulista & E50 & 2 & 19,43 & 19,41 & 2 & \begin{tabular}{l|l}
2 & 23,12 \\
\end{tabular} & 23,04 & 4 & $\begin{array}{ll}4 & 21,26 \\
\end{array}$ & 21,21 & 11 & 103,65 & \begin{tabular}{|l|l|}
5 & 90,96 \\
\end{tabular} & 7 & 69,37 & 61,33 & 18 & 86,67 & 76,29 & 12 & 133 & 9,0 \\
\hline 353160 & Monte Castelo & E20 & 1 & 51,86 & 37,25 & 0 & \begin{tabular}{l|l} 
& 17,73 \\
\end{tabular} & 11,95 & 1 & \begin{tabular}{l|l|}
1 & 35,01 \\
\end{tabular} & 24,76 & 2 & 103,72 & $\begin{array}{ll}2 & 64,22 \\
\end{array}$ & 1 & 53,19 & 35,86 & 3 & 78,77 & 50,22 & 3 & 28 & 12,0 \\
\hline 353180 & Monte Mor & D50 & 5 & 24,91 & 26,26 & 3 & \begin{tabular}{l|l}
3 & 12,58 \\
\end{tabular} & 13,53 & 8 & \begin{tabular}{|l|l|}
3 & 18,78 \\
\end{tabular} & 19,93 & 11 & 51,37 & \begin{tabular}{l|} 
\\
\end{tabular} 64,31 & 9 & 40,90 & 54,71 & 20 & 46,16 & 59,53 & 41 & 250 & 16,4 \\
\hline 353170 & Monteiro Lobato & E20 & 1 & 34,74 & 44,57 & 0 & \begin{tabular}{l|l}
0 & 18,50 \\
\end{tabular} & 16,49 & 1 & \begin{tabular}{l|l|}
1 & 26,88 \\
\end{tabular} & 30,97 & 1 & 69,48 & \begin{tabular}{l|l|}
3 & 53,40 \\
\end{tabular} & 1 & 55,50 & \begin{tabular}{|l|} 
\\
\end{tabular} & 2 & 62,71 & 51,49 & 2 & 27 & 8,6 \\
\hline 353190 & Morro Agudo & D50 & 2 & 16,75 & 18,40 & 4 & $\begin{array}{l}727,45 \\
\end{array}$ & 32,03 & 6 & \begin{tabular}{|l|l|}
5 & 21,98 \\
\end{tabular} & 25,07 & 5 & 33,49 & \begin{tabular}{|l|} 
\\
\end{tabular} & 5 & 37,43 & 46,29 & 10 & 35,42 & 42,00 & 7 & 147 & 4,5 \\
\hline 353200 & Morungaba & D20 & 1 & 18,52 & 17,95 & 1 & 12,64 & 12,68 & 2 & \begin{tabular}{|l|}
2 \\
215,62 \\
\end{tabular} & 15,35 & 3 & 55,57 & \begin{tabular}{|l|}
75,43 \\
\end{tabular} & 2 & 37,92 & 41,75 & 5 & 46,85 & 48,67 & 5 & 58 & 8,6 \\
\hline 353205 & Motuca & D20 & 0 & 15,71 & 15,58 & - & -1 & - & 0 & 8,08 & 8,01 & 3 & 141,35 & \begin{tabular}{|l|} 
\\
\end{tabular} & 2 & 83,17 & 96,14 & 5 & 113,09 & 123,87 & 1 & 22 & 6,1 \\
\hline 353210 & Murutinga do Sul & E20 & 1 & 64,60 & 53,94 & 0 & 16,74 & 12,50 & 2 & 41,09 & 33,59 & 3 & 145,35 & \begin{tabular}{|l|}
5 \\
5
\end{tabular} & 2 & 83,68 & \begin{tabular}{l|l|}
3 & 53,41 \\
\end{tabular} & 5 & 115,07 & 66,47 & 2 & 30 & 5,5 \\
\hline 353215 & Nantes & E20 & 0 & 29,47 & 24,68 & 1 & 122,70 & 138,14 & 2 & $\begin{array}{ll}275,15 \\
\end{array}$ & 80,28 & 1 & 58,94 & \begin{tabular}{l|l|}
4 & 55,07 \\
\end{tabular} & 1 & 92,02 & 121,16 & 2 & 75,15 & 87,46 & 1 & 14 & 4,9 \\
\hline 353220 & Narandiba & E20 & 0 & 16,45 & 11,93 & 1 & 50,34 & 55,62 & 1 & $\begin{array}{l}133,23 \\
\end{array}$ & 33,56 & 1 & 49,35 & \begin{tabular}{|l|}
5 \\
\end{tabular} & 1 & 33,56 & 38,56 & 2 & 41,53 & 37,17 & 3 & 19 & 17,5 \\
\hline 353230 & Natividade da Serra & E20 & 0 & 8,76 & 4,77 & - & 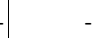 & & 0 & 4,65 & 2,53 & 4 & 96,32 & \begin{tabular}{|l|}
2 \\
2
\end{tabular} & 2 & 49,53 & 39,25 & 5 & 74,37 & 53,03 & 11 & 53 & 20,9 \\
\hline 353240 & Nazaré Paulista & E20 & 1 & 8,27 & 8,95 & 0 & 4,40 & 5,00 & 1 & \begin{tabular}{l|l|}
1 & 6,40 \\
\end{tabular} & 7,04 & 11 & 136,50 & 111,31 & 7 & 96,82 & 88,35 & 18 & 117,27 & 100,18 & 4 & 119 & 3,4 \\
\hline 353250 & Neves Paulista & E20 & 1 & 21,64 & 13,99 & 2 & 36,62 & 30,47 & 3 & \begin{tabular}{|l|l|}
3 & 29,07 \\
\end{tabular} & 22,17 & 5 & 115,42 & 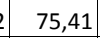 & 4 & 87,88 & 59,10 & 9 & 101,76 & 67,32 & 6 & 74 & 7,7 \\
\hline 353260 & Nhandeara & D20 & 1 & 13,36 & 8,62 & 1 & 25,97 & 19,99 & 2 & \begin{tabular}{|l|l|}
2 & 19,76 \\
\end{tabular} & 14,38 & 7 & 140,26 & \begin{tabular}{|l|l|}
5 & 87,87 \\
\end{tabular} & 6 & 116,88 & 81,52 & 13 & 128,41 & 84,65 & 7 & 76 & 9,2 \\
\hline 353270 & Nipoa & E20 & & & & 1 & \begin{tabular}{l|l}
1 & 39,31 \\
\end{tabular} & 34,60 & 1 & \begin{tabular}{|l|l|}
1 & 19,18 \\
\end{tabular} & 16,88 & 2 & 131,04 & $\begin{array}{l}4 \quad 88,33 \\
4\end{array}$ & 2 & 98,27 & 90,66 & 4 & 115,05 & 89,47 & 4 & 25 & 15,8 \\
\hline 353280 & Nova Aliança & E2O & 1 & 26,71 & 13,71 & 1 & 39,54 & 24,35 & 2 & \begin{tabular}{|l|l|}
2 & 33,17 \\
\end{tabular} & 19,07 & 5 & 186,99 & 111,27 & 1 & 52,72 & 39,93 & 6 & 119,41 & 75,36 & - & 38 & - \\
\hline 353282 & Nova Campina & E2O & 1 & 31,09 & 30,67 & 1 & 25,42 & 26,69 & 2 & 28,38 & 28,76 & 2 & 38,87 & $\begin{array}{l}52,59 \\
\end{array}$ & 2 & 50,83 & 91,98 & 4 & 44,59 & 71,44 & 6 & 39 & 14,4 \\
\hline 353284 & Nova Canaa Paulista & E20 & 1 & 81,34 & 39,36 & 1 & 58,51 & 36,30 & 2 & \begin{tabular}{|l|}
270,36 \\
\end{tabular} & 37,89 & 1 & 108,46 & \begin{tabular}{|l|l|}
52,48 \\
\end{tabular} & 1 & 58,51 & 36,30 & 2 & 84,44 & 44,70 & 5 & 20 & 25,4 \\
\hline 353286 & Nova Castilho & E20 & & & & - & & & & & & - & & & & & & - & & & 0 & 5 & 6,3 \\
\hline 353290 & Nova Europa & D20 & 1 & 24,10 & 21,77 & 1 & 16,59 & 15,99 & 2 & \begin{tabular}{l|l|}
20,40 \\
\end{tabular} & 18,92 & 1 & 16,07 & 14,92 & 1 & 16,59 & 17,16 & 1 & 16,32 & 16,02 & 1 & 43 & 3,1 \\
\hline 353300 & Nova Granada & E20 & 4 & 44,32 & 35,38 & 2 & 22,36 & 18,89 & 6 & \begin{tabular}{|l|l|}
5 & 33,39 \\
\end{tabular} & 27,17 & 10 & 114,51 & \begin{tabular}{|l|l|} 
& 88,78 \\
\end{tabular} & 7 & 81,99 & 66,51 & 18 & 98,32 & 77,70 & 6 & 125 & 4,5 \\
\hline 353310 & Nova Guataporanga & E2O & 1 & 62,68 & 51,41 & 0 & 33,11 & 22,09 & 1 & \begin{tabular}{l|l|}
1 & 48,30 \\
\end{tabular} & 37,15 & 2 & 156,69 & \begin{tabular}{|l|l|} 
& 67,26 \\
\end{tabular} & 0 & 33,11 & 22,09 & 2 & 96,60 & 45,30 & 3 & 18 & 18,5 \\
\hline 353320 & Nova Independência & E20 & 0 & 31,17 & 16,47 & 0 & 32,58 & 29,31 & 1 & \begin{tabular}{|l|l|} 
& 31,86 \\
\end{tabular} & 22,75 & - & & & 2 & \begin{tabular}{|l|}
162,92 \\
\end{tabular} & 137,84 & 2 & 79,66 & 67,40 & 4 & 18 & 23,6 \\
\hline 353330 & Nova Luzitânia & E20 & 1 & 45,34 & 41,54 & 1 & 50,23 & 49,11 & 1 & \begin{tabular}{l|l|} 
& 47,66 \\
\end{tabular} & 45,13 & 2 & 136,02 & \begin{tabular}{|l|}
2 \\
\end{tabular} & 1 & 100,45 & 99,25 & 3 & 119,15 & 95,70 & 0 & 20 & 1,7 \\
\hline 353340 & Nova Odessa & B50 & 7 & 29,44 & 29,27 & 3 & 13,04 & 13,82 & 10 & 21,18 & 21,48 & 15 & 66,25 & \begin{tabular}{|l|l|}
5 & 68,45 \\
\end{tabular} & 11 & 49,26 & 55,47 & 26 & 57,69 & 61,91 & 25 & 233 & 10,6 \\
\hline 353325 & Novais & E2O & 1 & 58,33 & 59,50 & 1 & 42,36 & 38,99 & 2 & $\begin{array}{l}250,69 \\
\end{array}$ & 49,68 & 1 & 58,33 & \begin{tabular}{|l|l|}
3 & 38,50 \\
\end{tabular} & 1 & 84,73 & 74,80 & 2 & 70,97 & 55,87 & 3 & 21 & 14,3 \\
\hline 353350 & Novo Horizonte & D50 & 3 & 20,14 & 15,98 & 3 & 15,90 & 13,61 & 6 & \begin{tabular}{|l|l|}
5 & 18,01 \\
\end{tabular} & 14,79 & 16 & 98,67 & \begin{tabular}{l|l|}
7 & 70,88 \\
\end{tabular} & 13 & 75,54 & 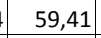 & 29 & 87,03 & 65,11 & 23 & 246 & 9,3 \\
\hline 353360 & Nuporanga & E2O & 1 & 30,11 & 24,13 & 1 & 41,41 & 32,50 & 2 & \begin{tabular}{|l|l|}
2 & 35,67 \\
\end{tabular} & 28,25 & 1 & 40,15 & \begin{tabular}{|l|}
5 \\
\end{tabular} & 2 & 51,77 & 42,46 & 3 & 45,87 & 35,59 & 3 & 41 & 6,5 \\
\hline 353370 & Ocauçu & E20 & 1 & 62,46 & 53,37 & 0 & 16,99 & 14,28 & 2 & \begin{tabular}{|l|}
2 \\
\end{tabular} & 34,65 & 2 & 93,69 & \begin{tabular}{|l|} 
\\
\end{tabular} & 4 & 186,88 & \begin{tabular}{|l|l|}
3 & 160,20 \\
\end{tabular} & 6 & 138,32 & 111,74 & 5 & 33 & 16,0 \\
\hline 353380 & Oleo & E20 & 0 & 21,11 & 24,22 & 0 & 22,23 & 15,91 & 1 & $\begin{array}{l}121,66 \\
\end{array}$ & 20,17 & 1 & 63,34 & $\begin{array}{l}48,50 \\
4\end{array}$ & & & & 1 & 32,49 & 19,74 & 2 & 17 & 11,8 \\
\hline
\end{tabular}


Anexo 19 - Óbitos e taxa de mortalidade (bruta e padronizada) total e segundo sexo por Doenças Infecciosas e Parasitárias e Doenças Respiratórias e \% de óbitos por Causas Mal Definidas nos municípios. Estado de São Paulo, média do triênio, 2003-2005

\begin{tabular}{|c|c|c|c|c|c|c|c|c|c|c|c|c|c|c|c|c|c|c|c|c|c|c|c|}
\hline \multirow[b]{2}{*}{ IBGE } & \multirow[b]{2}{*}{ Mun. } & \multirow[b]{2}{*}{ Porte } & \multicolumn{9}{|c|}{ DOENCAS INFECCIOSAS E PARASITÁRIAS } & \multicolumn{9}{|c|}{ DOENCAS RESPIRATÓRIAS } & \multicolumn{3}{|c|}{ MAL DEFINIDAS } \\
\hline & & & Obitos & $\begin{array}{l}\text { Homens } \\
\text { TMB }\end{array}$ & TPM & Obitos & $\begin{array}{l}\text { Mulhe } \\
\text { TMB }\end{array}$ & TPM & Obitos & $\begin{array}{l}\text { Total } \\
\text { TMB }\end{array}$ & TPM & Obitos & $\begin{array}{l}\text { Homens } \\
\text { TMB }\end{array}$ & TPM & Obitos & $\begin{array}{l}\text { Mulhere } \\
\text { TMB }\end{array}$ & STPM & Obitos & $\begin{array}{l}\text { Total } \\
\text { TMB }\end{array}$ & TPM & Obitos & Ob.Totais & $\%$ \\
\hline 353390 & Olimpia & D50 & 8 & 34,08 & 31,33 & 6 & 23,68 & 20,42 & 14 & 28,83 & 25,82 & 27 & \begin{tabular}{l|l} 
& 113,62 \\
\end{tabular} & 86,27 & 20 & 83,58 & 63,92 & 47 & 98,45 & 74,99 & 34 & 350 & 9,7 \\
\hline 353400 & Onda Verde & E20 & 0 & 17,81 & 13,32 & 0 & 18,48 & 21,53 & 1 & 18,14 & 17,35 & 2 & 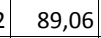 & 71,63 & 1 & 55,44 & 64,59 & 3 & 72,56 & 68,18 & 1 & 20 & 4,9 \\
\hline 353410 & Oriente & D20 & 0 & 12,25 & 6,76 & 1 & 24,23 & 23,70 & 1 & 18,27 & 15,28 & 2 & \begin{tabular}{|l|} 
\\
\end{tabular} & 54,47 & 1 & 48,46 & 35,64 & 3 & 60,91 & 45,00 & 6 & 41 & 13,7 \\
\hline 353420 & Orindiúva & $\mathrm{C} 20$ & 1 & 55,53 & 54,38 & 1 & 44,31 & 50,28 & 2 & 50,09 & 52,39 & 1 & 27,77 & 31,42 & & & & 1 & 14,31 & 16,20 & 0 & 19 & 1,8 \\
\hline 353430 & Orlândia & B50 & 6 & 31,75 & 31,66 & 6 & 32,99 & 32,91 & 12 & 32,37 & 32,29 & 13 & \begin{tabular}{|l|l|}
3 & 68,78 \\
\end{tabular} & 68,88 & 11 & 59,04 & 59,62 & 24 & 63,87 & 64,21 & 7 & 220 & 3,2 \\
\hline 353440 & Osasco & B1000 & 90 & 26,89 & 29,89 & 65 & 18,44 & 20,57 & 156 & 22,55 & 25,10 & 245 & \begin{tabular}{|l|l|}
5 & 73,04 \\
\end{tabular} & 89,60 & 189 & 53,43 & 66,38 & 435 & 62,97 & 77,68 & 55 & 3920 & 1,4 \\
\hline 353460 & Osvaldo Cruz & D50 & 7 & 47,40 & 40,89 & 4 & 24,12 & 19,22 & 11 & 35,59 & $29,90 \mid$ & 22 & 148,96 & 93,91 & 12 & 81,12 & 59,42 & 34 & $\mid 114,54$ & 76,41 & 31 & 219 & 14,3 \\
\hline 353470 & Ourinhos & C300 & 23 & 45,52 & 43,94 & 14 & 26,48 & 25,73 & 36 & 35,83 & $34,67 \mid$ & 29 & 58,91 & 52,79 & 21 & 40,69 & 37,24 & 50 & 49,63 & 44,88 & 110 & 672 & 16,3 \\
\hline 353480 & Ouro Verde & E20 & 1 & 27,80 & 25,43 & 1 & 27,99 & 27,00 & 2 & 27,89 & $26,21 \mid$ & 4 & 101,93 & 84,07 & 2 & 55,98 & 51,88 & 6 & 79,03 & 68,03 & 13 & 53 & 25,2 \\
\hline 353475 & Ouroeste & E20 & 1 & 19,27 & 16,23 & 1 & 29,15 & 27,11 & 2 & 24,19 & 21,65 & 5 & 154,14 & 117,19 & 2 & 58,30 & 54,52 & 7 & 106,42 & 85,99 & 7 & 44 & 16,5 \\
\hline 353490 & Pacaembu & E20 & 4 & 54,78 & 47,75 & 5 & & & 4 & 29,13 & 25,39 & 5 & 69,72 & 48,74 & 3 & 50,88 & 37,89 & 8 & 60,90 & 43,66 & 8 & 102 & 8,2 \\
\hline 353500 & Palestina & E20 & 1 & 22,01 & 12,22 & 0 & 7,25 & 7,74 & 1 & 14,59 & 9,96 & 8 & 176,07 & 126,11 & 5 & 101,53 & 69,08 & 13 & 138,58 & 97,43 & 11 & 72 & 15,3 \\
\hline 353510 & Palmares Paulista & E20 & 1 & 21,97 & 21,50 & 1 & 22,81 & 26,36 & 2 & 22,38 & 23,89 & 5 & 109,86 & 134,32 & 3 & 60,84 & 82,23 & 8 & 85,81 & 108,77 & 2 & 52 & 3,8 \\
\hline 353520 & Palmeira d'Oeste & E20 & 2 & 45,72 & 35,17 & 1 & 26,99 & 20,35 & 4 & 36,51 & 27,88 & 7 & 130,63 & 78,21 & 3 & 60,73 & 45,29 & 10 & 96,25 & 62,02 & 19 & 73 & 25,6 \\
\hline 353540 & Panorama & E20 & 1 & 18,36 & 18,48 & 1 & 19,13 & 20,85 & 3 & 18,74 & $19,64 \mid$ & 7 & 96,37 & 90,60 & 3 & 47,83 & 51,21 & 10 & 72,60 & 71,31 & 16 & 93 & 16,8 \\
\hline 353550 & Paraguaçu Paulista & D50 & 8 & 39,84 & 38,31 & 7 & 32,90 & 31,26 & 15 & 36,34 & 34,75 & 22 & 106,76 & 91,70 & 18 & 83,02 & 76,06 & 40 & 94,79 & 83,81 & 17 & 291 & 5,8 \\
\hline 353560 & Paraibuna & E20 & 1 & 10,88 & 9,90 & 2 & 19,02 & 19,46 & 3 & 14,85 & 14,56 & 9 & 97,94 & 82,20 & 6 & 72,27 & 77,18 & 15 & 85,41 & 79,75 & 19 & 110 & 17,0 \\
\hline 353570 & Paraíso & E20 & 1 & 44,61 & 39,69 & 0 & 12,11 & 12,33 & 2 & 29,03 & 26,58 & 4 & 133,82 & 98,25 & 2 & 72,67 & 64,08 & 6 & $\mid$\begin{tabular}{|l|}
104,51 \\
\end{tabular} & 81,87 & 2 & 39 & 5,1 \\
\hline 353580 & Paranapanema & E20 & 1 & 15,34 & 14,44 & 2 & 24,91 & 28,14 & 3 & 19,93 & $21,02 \mid$ & 6 & 65,19 & 63,46 & 3 & 41,52 & 50,76 & 9 & 53,82 & 57,36 & 24 & 104 & 22,7 \\
\hline 353590 & Paranapua & E20 & - & & & 1 & 38,04 & 30,72 & 1 & 18,67 & 15,08 & 2 & 110,01 & 80,86 & 1 & 57,06 & 42,48 & 3 & 84,02 & 62,02 & 2 & 25 & 9,3 \\
\hline 353600 & Parapua & E20 & 1 & 11,97 & 9,97 & 1 & 18,54 & 16,12 & 2 & 15,20 & 13,00 & 3 & 47,88 & 30,52 & 3 & 61,79 & 45,11 & 6 & 54,73 & 37,70 & 18 & 86 & 21,0 \\
\hline 353610 & Pardinho & D20 & 1 & 24,20 & 21,62 & 0 & 13,07 & 13,42 & 1 & 18,85 & 17,68 & 2 & 60,49 & 54,06 & 1 & 39,22 & 44,17 & 3 & 50,26 & 49,31 & 1 & 30 & 2,2 \\
\hline 353620 & Pariquera0Açu & D20 & 2 & 20,20 & 19,16 & 1 & 10,26 & 9,97 & 3 & 15,27 & 14,60 & 8 & 84,16 & 72,50 & 8 & 82,05 & 85,58 & 16 & 83,11 & 78,99 & 15 & 110 & 13,6 \\
\hline 353625 & Parisi & E20 & 1 & 89,05 & 67,18 & 3 & & & 1 & \begin{tabular}{|l|}
46,66 \\
\end{tabular} & 35,20 & 0 & 29,68 & 19,44 & 1 & 130,72 & 93,50 & 2 & 77,77 & 54,69 & 1 & 13 & 7,5 \\
\hline 353630 & Patrocínio Paulista & D20 & 1 & 16,04 & 14,07 & 1 & 16,83 & 16,50 & 2 & 16,43 & 15,26 & 8 & 122,95 & 108,20 & 3 & 50,50 & 50,43 & 11 & 87,60 & 80,02 & 4 & 65 & 5,7 \\
\hline 353640 & Paulicéia & E20 & 1 & 22,08 & 20,61 & 1 & 35,79 & 38,40 & 2 & $28,67 \mid$ & 29,16 & 3 & 99,37 & 80,54 & 1 & 35,79 & 43,20 & 4 & 68,81 & 62,59 & 6 & 30 & 19,1 \\
\hline 353650 & Paulínia & B100 & 9 & 31,08 & 35,04 & 6 & 19,61 & 23,47 & 15 & 25,35 & $29,26 \mid$ & 14 & 47,20 & 58,44 & 13 & 44,98 & 58,72 & 27 & 46,09 & 58,58 & 17 & 293 & 5,7 \\
\hline 353657 & Paulistânia & E20 & 1 & 66,29 & 65,12 & 0 & 37,52 & 45,37 & 1 & 52,80 & 55,86 & 1 & 66,29 & 69,75 & 0 & 37,52 & 33,46 & 1 & 52,80 & 52,73 & 2 & 15 & 15,6 \\
\hline 353660 & Paulo de Faria & E20 & 4 & $\mid 101,79$ & 83,26 & 1 & 31,12 & 28,12 & 6 & 66,34 & 55,60 & 4 & 86,13 & 66,23 & 2 & 54,46 & 50,90 & 6 & 70,24 & 58,54 & 4 & 57 & 7,0 \\
\hline 353670 & Pederneiras & D50 & 5 & 27,32 & 26,88 & 2 & 12,19 & 12,14 & 8 & 19,83 & $|19,58|$ & 13 & 68,31 & 60,82 & 9 & 47,01 & 45,02 & 22 & 57,76 & 53,00 & 15 & 247 & 6,2 \\
\hline
\end{tabular}


Anexo 19 - Óbitos e taxa de mortalidade (bruta e padronizada) total e segundo sexo por Doenças Infecciosas e Parasitárias e Doenças Respiratórias e \% de óbitos por Causas Mal Definidas nos municípios. Estado de São Paulo, média do triênio, 2003-2005

\begin{tabular}{|c|c|c|c|c|c|c|c|c|c|c|c|c|c|c|c|c|c|c|c|c|c|c|c|}
\hline \multirow[b]{2}{*}{ IBGE } & \multirow[b]{2}{*}{ Mun. } & \multirow[b]{2}{*}{ Porte } & \multicolumn{9}{|c|}{$\begin{array}{l}\text { DOENCAS INFECCIOSAS E PARASITÁRIAS } \\
\end{array}$} & \multicolumn{9}{|c|}{ DOENCAS RESPIRATÓRIAS } & \multicolumn{3}{|c|}{ MAL DEFINIDAS } \\
\hline & & & Obitos & $\begin{array}{l}\text { Homens } \\
\text { TMB }\end{array}$ & TPM & Obitos & $\begin{array}{l}\text { Mulhere } \\
\text { TMB }\end{array}$ & STPM & Obitos & $\begin{array}{l}\text { Total } \\
\text { TMB }\end{array}$ & TPM & Obitos & $\begin{array}{l}\text { Homens } \\
\text { TMB }\end{array}$ & TPM & Obitos & $\begin{array}{l}\text { Mulh } \\
\text { TMB }\end{array}$ & TPM & Obitos T & $\begin{array}{l}\text { Total } \\
\text { TMB } \\
\end{array}$ & TPM & Obitos & Ob.Totais o & \\
\hline 353680 & Pedra Bela & E20 & 1 & 21,69 & 22,71 & 1 & 48,59 & 47,59 & 2 & 34,38 & 34,45 & 3 & 86,76 & 64,72 & 3 & 97,18 & 84,55 & 5 & 91,67 & 74,08 & 2 & 43 & 4,7 \\
\hline 353690 & Pedranópolis & E20 & - & & & 1 & 53,29 & 45,18 & 1 & 25,95 & 22,00 & 2 & 126,45 & 62,49 & 1 & 79,94 & 48,52 & 3 & 103,80 & 55,69 & 5 & 18 & 27,3 \\
\hline 353700 & Pedregulho & D20 & 1 & 16,77 & 16,57 & 2 & 26,28 & 27,60 & 3 & 21,42 & 21,97 & 6 & 79,67 & 73,83 & 5 & 70,07 & 74,53 & 12 & 74,98 & 74,17 & 28 & 111 & 25,1 \\
\hline 353710 & Pedreira & B50 & 5 & 26,23 & 24,99 & 4 & 18,91 & 17,78 & 9 & 22,54 & 21,35 & 20 & 103,17 & 95,17 & 10 & 49,84 & 47,03 & 29 & 76,28 & 70,89 & 8 & 240 & 3,3 \\
\hline 353715 & Pedrinhas Paulista & A20 & 0 & 22,02 & 18,17 & 1 & 45,28 & 40,85 & 1 & 33,49 & 29,35 & 1 & 66,05 & 56,87 & 1 & 45,28 & 39,91 & 2 & 55,81 & 48,51 & 1 & 20 & 5,1 \\
\hline 353720 & Pedro de Toledo & E20 & 2 & 46,65 & 43,32 & 2 & & & 2 & 23,83 & 22,13 & 2 & 39,99 & 30,67 & 2 & 41,76 & 44,28 & 4 & 40,85 & 37,33 & 12 & 65 & 19,0 \\
\hline 353730 & Penápolis & D100 & 7 & 23,74 & 22,86 & 6 & 19,28 & 17,07 & 12 & 21,46 & 19,90 & 25 & 89,04 & 69,60 & 16 & 54,43 & 42,97 & 41 & 71,34 & 55,98 & 70 & 409 & 17,1 \\
\hline 353740 & Pereira Barreto & D50 & 4 & 35,39 & 35,36 & 2 & 15,95 & 15,11 & 6 & 25,56 & 25,11 & 12 & 98,01 & 76,22 & 8 & 66,47 & 58,79 & 20 & 82,05 & 67,40 & 31 & 182 & 17,0 \\
\hline 353750 & Pereiras & E20 & 1 & 18,52 & 16,65 & 1 & 19,50 & 12,34 & 1 & 19,00 & 14,55 & 2 & 64,81 & 47,78 & 4 & 126,74 & 85,22 & 7 & 94,98 & 66,02 & 3 & 54 & 5,6 \\
\hline 353760 & Peruibe & D100 & 13 & 43,65 & 43,77 & 8 & 27,77 & 27,67 & 21 & 35,68 & 35,69 & 21 & 70,51 & 57,11 & 13 & 43,32 & 40,48 & 34 & 56,86 & 48,76 & 86 & 434 & 19,8 \\
\hline 353770 & Piacatu & E20 & & & & 1 & 43,30 & 41,41 & 1 & 21,44 & 20,50 & 3 & 113,22 & 82,24 & 2 & 101,04 & 76,94 & 5 & 107,19 & 79,61 & 5 & 35 & 15,4 \\
\hline 353780 & Piedade & D100 & 5 & 16,76 & 16,78 & 3 & 11,90 & 12,52 & 8 & 14,45 & 14,76 & 31 & 111,32 & 104,22 & 19 & 75,36 & 76,68 & 50 & 94,24 & 91,13 & 55 & 352 & 15,5 \\
\hline 353790 & Pilar do Sul & E50 & 1 & 9,97 & 10,61 & 1 & 7,95 & 8,68 & 2 & 9,00 & 9,67 & 9 & 67,33 & 65,85 & 6 & 50,38 & 62,21 & 15 & 59,11 & 64,09 & 25 & 146 & 17,2 \\
\hline 353800 & Pindamonhangaba & B300 & 14 & 20,03 & 21,64 & 10 & 15,08 & 16,63 & 24 & 17,55 & 19,13 & 47 & 68,90 & 79,81 & 39 & 56,44 & 66,72 & 86 & 62,65 & 73,25 & 82 & 754 & 10,9 \\
\hline 353810 & Pindorama & E20 & 3 & 39,18 & 29,42 & 2 & 25,14 & 22,59 & 4 & 32,25 & 26,05 & 14 & 200,82 & 129,40 & 7 & 110,60 & 78,94 & 21 & 156,30 & 104,50 & 7 & 111 & 6,6 \\
\hline 353820 & Pinhalzinho & E20 & 1 & 10,61 & 10,29 & 1 & 11,42 & 11,28 & 1 & 11,00 & 10,76 & 6 & 95,48 & 69,04 & 6 & 108,45 & 89,01 & 12 & 101,73 & 78,66 & 5 & 91 & 5,5 \\
\hline 353830 & Piquerobi & E20 & 0 & 18,40 & 18,94 & -1 & & & 0 & 9,34 & 9,61 & 1 & 36,81 & 22,55 & 1 & 56,87 & 50,43 & 2 & 46,69 & 36,28 & 3 & 20 & 16,4 \\
\hline 353850 & Piquete & B2O & 4 & 53,11 & 51,84 & 1 & 12,70 & 10,32 & 5 & 32,46 & $30,63 \mid$ & 5 & 66,39 & 59,90 & 3 & 38,11 & 32,74 & 8 & 51,94 & 46,02 & 15 & 112 & 13,1 \\
\hline 353860 & Piracaia & D50 & 1 & 10,38 & 10,01 & 1 & 8,03 & 7,37 & 2 & 9,23 & 8,71 & 13 & 101,25 & 85,18 & 8 & $\quad 66,94$ & 63,47 & 21 & 84,36 & 74,49 & 1 & 170 & 0,6 \\
\hline 353870 & Piracicaba & B500 & 70 & 40,53 & 39,22 & 40 & 22,64 & 21,28 & 111 & 31,47 & 30,13 & 142 & 81,82 & 75,08 & 102 & 57,45 & 51,91 & 244 & 69,47 & 63,35 & 357 & 2225 & 16,0 \\
\hline 353880 & Piraju & D50 & 5 & 37,91 & 31,34 & 3 & 18,21 & 15,41 & 8 & 27,87 & 23,21 & 8 & 54,50 & 43,86 & 9 & 59,19 & 44,06 & 16 & 56,89 & 43,96 & 24 & 231 & 10,4 \\
\hline 353890 & Pirajuí & D50 & 3 & 27,23 & 25,60 & 0 & 3,46 & 3,21 & 3 & 16,13 & 15,15 & 10 & 87,75 & 72,61 & 12 & 124,42 & 96,92 & 22 & 104,87 & 83,96 & 17 & 155 & 11,0 \\
\hline 353900 & Pirangi & E20 & 2 & 32,09 & 21,29 & 2 & 33,87 & 25,95 & 3 & 32,95 & 23,56 & 4 & 83,43 & 54,48 & 3 & 60,96 & 45,55 & 7 & 72,50 & 50,13 & 5 & 71 & 7,1 \\
\hline 353910 & Pirapora do Bom Jesus & D20 & - & & & 1 & 13,94 & 12,95 & 1 & 6,96 & 6,46 & 5 & 69,43 & 92,14 & 4 & 60,40 & 91,39 & 9 & 64,92 & 91,77 & 2 & 57 & 2,9 \\
\hline 353920 & Pirapozinho & D50 & 4 & 39,19 & 36,83 & 2 & 14,44 & 14,35 & 6 & 26,55 & 25,35 & 10 & 90,44 & 77,63 & 5 & 43,31 & 40,87 & 15 & 66,36 & 58,85 & 20 & 147 & 13,4 \\
\hline 353930 & Pirassununga & B100 & 15 & 43,45 & 40,49 & 6 & 16,32 & 13,96 & 20 & 29,69 & 27,04 & 21 & 61,22 & 51,44 & 14 & 41,27 & 33,58 & 35 & 51,10 & 42,39 & 28 & 457 & 6,1 \\
\hline 353940 & Piratininga & B20 & 1 & 23,98 & 17,92 & 1 & 12,26 & 8,44 & 2 & 18,18 & 13,23 & 5 & 83,92 & 64,53 & 5 & 85,79 & 61,68 & 9 & 84,85 & 63,12 & 2 & 69 & 3,4 \\
\hline 353950 & Pitangueiras & D50 & 7 & 43,39 & 46,70 & 5 & 29,00 & 30,75 & 12 & 36,37 & 38,92 & 9 & 55,23 & 58,25 & 7 & 43,50 & 46,63 & 16 & 49,51 & 52,58 & 1 & 184 & 0,4 \\
\hline 353960 & Planalto & E20 & 1 & 34,96 & 33,20 & - & & & 1 & 17,79 & 16,89 & 1 & 34,96 & 24,03 & 0 & 18,11 & 18,15 & 1 & 26,68 & 21,14 & 4 & 28 & 15,5 \\
\hline 353970 & Platina & E20 & 0 & 22,09 & 17,39 & - & & & 0 & 11,58 & 9,11 & 2 & 132,54 & 108,62 & 1 & 48,65 & 38,78 & 3 & 92,61 & 75,38 & 1 & 19 & 3,5 \\
\hline 353980 & Poá & B300 & 9 & 17,57 & 19,68 & 6 & 11,26 & 12,75 & 15 & 14,35 & 16,15 & 31 & 60,52 & 80,60 & 26 & 49,42 & 64,96 & 57 & 54,86 & 72,63 & 93 & 561 & 16,6 \\
\hline 353990 & Poloni & E20 & 1 & 55,86 & 46,33 & 1 & 26,70 & 14,19 & 2 & 40,95 & $29,90 \mid$ & 4 & $\mid 153,61$ & 101,69 & 2 & 66,74 & 35,47 & 5 & 109,19 & 67,83 & 3 & 41 & 8,1 \\
\hline
\end{tabular}


Anexo 19 - Óbitos e taxa de mortalidade (bruta e padronizada) total e segundo sexo por Doenças Infecciosas e Parasitárias e Doenças Respiratórias e \% de óbitos por Causas Mal Definidas nos municípios. Estado de São Paulo, média do triênio, 2003-2005

\begin{tabular}{|c|c|c|c|c|c|c|c|c|c|c|c|c|c|c|c|c|c|c|c|c|c|c|c|}
\hline \multirow[b]{2}{*}{ IBGE } & \multirow[b]{2}{*}{ Mun. } & \multirow[b]{2}{*}{ Porte } & \multicolumn{9}{|c|}{$\begin{array}{l}\text { DOENCAS INFECCIOSAS E PARASITÁRIAS } \\
\end{array}$} & \multicolumn{9}{|c|}{ DOENCAS RESPIRATÓRIAS } & \multicolumn{3}{|c|}{ MAL DEFINIDAS } \\
\hline & & & Obitos & $\begin{array}{l}\text { Homens } \\
\text { TMB }\end{array}$ & TPM & Obitos & $\begin{array}{l}\text { Mulheres } \\
\text { TMB }\end{array}$ & & & $\begin{array}{l}\text { Total } \\
\text { TMB } \\
\end{array}$ & TPM & Obitos & $\begin{array}{l}\text { Homens } \\
\text { TMB }\end{array}$ & TPM & Obitos $\mathrm{T}$ & & & Obitos $\mathrm{T}$ & $\begin{array}{l}\text { Total } \\
\text { TMB }\end{array}$ & TPM & Obitos & Ob.Totais \% & $\%$ \\
\hline 354000 & Pompéia & $\mathrm{C} 20$ & 2 & 21,74 & 22,00 & 2 & 21,30 & \begin{tabular}{|r|}
18,47 \\
\end{tabular} & 4 & 21,52 & 20,22 & 5 & 54,35 & 44,57 & 2 & 21,30 & 17,82 & 7 & 37,66 & 31,06 & 22 & 140 & \begin{tabular}{l|l}
0 & 15,5 \\
\end{tabular} \\
\hline 354010 & Pongaí & E20 & 0 & 17,11 & 9,86 & 0 & $\begin{array}{r}18,55 \\
\end{array}$ & \begin{tabular}{|r|}
19,44 \\
\end{tabular} & 1 & 17,80 & 14,46 & 1 & 34,23 & \begin{tabular}{|r|}
23,90 \\
\end{tabular} & 0 & \begin{tabular}{|r|}
18,55 \\
\end{tabular} & 11,93 & 1 & 26,70 & \begin{tabular}{|r|}
18,15 \\
\end{tabular} & 7 & 24 & \begin{tabular}{l|l}
4 & 28,8 \\
\end{tabular} \\
\hline 354020 & Pontal & D50 & 6 & 36,13 & 42,70 & 4 & 22,71 & \begin{tabular}{|r|}
27,27 \\
\end{tabular} & 10 & 29,51 & 35,09 & 13 & 76,28 & \begin{tabular}{|r|}
94,00 \\
\end{tabular} & 6 & \begin{tabular}{|r|}
37,16 \\
\end{tabular} & 46,34 & 19 & 56,99 & \begin{tabular}{|r|}
70,50 \\
\end{tabular} & 2 & 188 & \begin{tabular}{l|l}
8 & 1,1 \\
\end{tabular} \\
\hline 354025 & Pontalinda & E20 & 0 & 17,20 & 14,52 & 1 & 56,31 & \begin{tabular}{|r|}
56,15 \\
\end{tabular} & 1 & 35,90 & 34,43 & 1 & 34,39 & 31,13 & 2 & $\mid 112,61$ & 106,09 & 3 & 71,79 & 66,97 & 2 & 22 & $\begin{array}{ll}27,6 \\
\end{array}$ \\
\hline 354030 & Pontes Gestal & E20 & 0 & 28,61 & 21,37 & 1 & 56,39 & \begin{tabular}{|r|}
50,37 \\
\end{tabular} & 1 & 42,60 & 35,98 & 1 & 57,22 & 37,20 & 1 & 84,58 & 75,56 & 2 & 71,00 & \begin{tabular}{|r|}
56,52 \\
\end{tabular} & 1 & 16 & \begin{tabular}{l|l}
6 & 8,5 \\
\end{tabular} \\
\hline 354040 & Populina & E20 & 1 & 29,63 & 28,48 & 1 & 63,45 & \begin{tabular}{|r|}
50,03 \\
\end{tabular} & 2 & $45,96 \mid$ & 38,89 & 2 & 88,88 & 62,87 & 2 & 79,31 & 65,48 & 4 & 84,26 & 64,13 & 2 & 32 & \begin{tabular}{l|l}
2 & 7,4 \\
\end{tabular} \\
\hline 354050 & Porangaba & E20 & 2 & 44,15 & 33,93 & 0 & 9,97 & 10,97 & 2 & 28,09 & 23,14 & 3 & 79,48 & |62,72 & 3 & \begin{tabular}{|r|}
89,69 \\
\end{tabular} & 75,56 & 6 & 84,27 & 68,75 & 2 & 52 & \begin{tabular}{l|l}
2 & 3,8 \\
\end{tabular} \\
\hline 354060 & Porto Feliz & C50 & 5 & 21,55 & 22,09 & 3 & 12,20 & 12,01 & 8 & 16,89 & 17,06 & 22 & 87,55 & 80,32 & 17 & \begin{tabular}{|r|}
70,47 \\
\end{tabular} & 66,95 & 39 & 79,04 & \begin{tabular}{|r|}
73,66 \\
\end{tabular} & 41 & 293 & \begin{tabular}{l|l}
3 & 14,1 \\
\end{tabular} \\
\hline 354070 & Porto Ferreira & C100 & 9 & 33,81 & 32,52 & 3 & 12,92 & 12,38 & 12 & 23,33 & 22,42 & 18 & 71,52 & 63,96 & 14 & 55,55 & 51,58 & 33 & 63,51 & 57,75 & 11 & 317 & 3,4 \\
\hline 354075 & Potim & E20 & 4 & 55,68 & 59,04 & 2 & 26,51 & 36,40 & 6 & 41,32 & 47,90 & 7 & 85,66 & 107,98 & 4 & 53,02 & 72,81 & 11 & 69,60 & 90,66 & 9 & 102 & \begin{tabular}{l|l}
2 & 9,2 \\
\end{tabular} \\
\hline 354080 & Potirendaba & E20 & 3 & 39,62 & 32,01 & 1 & 18,56 & 13,98 & 4 & 29,37 & 23,23 & 10 & \begin{tabular}{|l|}
132,07 \\
\end{tabular} & 76,48 & 5 & \begin{tabular}{|r|}
64,97 \\
\end{tabular} & 48,44 & 15 & 99,41 & 62,83 & 5 & 96 & \begin{tabular}{|l|l}
5 & 5,6 \\
\end{tabular} \\
\hline 354085 & Pracinha & E20 & 1 & 91,74 & 101,58 & - & 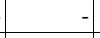 & & 1 & 46,90 & 51,93 & 1 & 91,74 & 49,41 & 1 & $\mid$\begin{tabular}{|l|}
$\mid 191,94$ \\
\end{tabular} & 140,72 & 2 & $\mid 140,71$ & 94,04 & 1 & 15 & \begin{tabular}{|l|l}
5 & 6,7 \\
\end{tabular} \\
\hline 354090 & Pradópolis & D20 & 2 & 23,00 & 25,54 & 0 & 4,74 & 4,75 & 2 & 14,01 & 15,30 & 5 & 64,40 & \begin{tabular}{|r|}
72,26 \\
\end{tabular} & 3 & \begin{tabular}{|r|}
37,96 \\
\end{tabular} & 46,98 & 7 & 51,39 & 59,82 & 1 & 67 & 1,5 \\
\hline 354100 & Praia Grande & B300 & 40 & 36,12 & 35,97 & 22 & 19,41 & 19,53 & 62 & 27,57 & 27,56 & 66 & \begin{tabular}{|r|}
59,80 \\
\end{tabular} & | 56,09 & 54 & 47,21 & 46,60 & 120 & \begin{tabular}{|r|}
53,36 \\
\end{tabular} & 51,23 & 275 & 1394 & $\begin{array}{l}4 \quad 19,7 \\
\end{array}$ \\
\hline 354105 & Pratânia & E20 & 0 & 15,06 & 16,12 & 1 & 33,00 & 35,36 & 1 & 23,62 & 25,31 & 3 & \begin{tabular}{|l|}
120,52 \\
\end{tabular} & \begin{tabular}{|l|}
122,02 \\
\end{tabular} & 2 & 82,49 & 89,36 & 4 & $\mid$\begin{tabular}{|l|}
$\mid 102,37$ \\
\end{tabular} & $|106,44|$ & 2 & 32 & 5,2 \\
\hline 354110 & Presidente Alves & E20 & 0 & 15,57 & 9,58 & - & & & 0 & 7,87 & 4,84 & 4 & \begin{tabular}{|l|}
171,29 \\
\end{tabular} & $\mid 110,30$ & 2 & 79,66 & 66,78 & 5 & \begin{tabular}{|l|}
125,99 \\
\end{tabular} & 88,79 & 2 & 27 & $7 \quad 7,5$ \\
\hline 354120 & Presidente Bernardes & D20 & 3 & 33,67 & 29,04 & 1 & 18,26 & 16,80 & 4 & 26,28 & 23,17 & 6 & 75,76 & 51,49 & 5 & 63,91 & 49,12 & 11 & 70,08 & 50,35 & 10 & 106 & \begin{tabular}{|l|l}
5 & 9,4 \\
\end{tabular} \\
\hline 354130 & Presidente Epitácio & D50 & 6 & 29,19 & 30,24 & 2 & 9,65 & 9,97 & 8 & 19,38 & 20,06 & 14 & \begin{tabular}{|r|}
68,12 \\
\end{tabular} & 59,11 & 10 & \begin{tabular}{|r|}
$\mid 49,84$ \\
\end{tabular} & 51,39 & 24 & 58,94 & | 55,23 & 36 & 273 & \begin{tabular}{l|l}
3 & 13,2 \\
\end{tabular} \\
\hline 354140 & Presidente Prudente & B300 & 23 & 23,38 & 21,91 & 18 & 17,83 & 16,61 & 41 & 20,52 & 19,18 & 75 & 77,37 & 66,73 & 61 & 59,32 & 53,49 & 136 & 68,08 & 59,91 & 192 & 1273 & \begin{tabular}{l|l}
3 & 15,1 \\
\end{tabular} \\
\hline 354150 & Presidente Venceslau & D50 & 4 & 19,32 & 17,51 & 5 & 28,19 & 25,30 & 9 & 23,75 & 21,40 & 11 & \begin{tabular}{|r|}
59,72 \\
\end{tabular} & 47,02 & 9 & 47,57 & 38,28 & 20 & 53,66 & 42,66 & 38 & 271 & $\begin{array}{l}144,0 \\
\end{array}$ \\
\hline 354160 & Promissao & D50 & 4 & 26,38 & 23,81 & 4 & 26,96 & 26,03 & 9 & 26,67 & 24,91 & 14 & \begin{tabular}{|r|}
87,26 \\
\end{tabular} & 71,35 & 11 & 66,36 & 59,56 & 25 & 76,92 & 65,52 & 49 & 236 & \begin{tabular}{|l|l}
5 & 20,6 \\
\end{tabular} \\
\hline 354165 & Quadra & E20 & 0 & 21,30 & 16,52 & - & & & 0 & 11,16 & 8,66 & 0 & 21,30 & \begin{tabular}{|r|}
15,41 \\
\end{tabular} & 1 & 46,92 & 47,07 & 1 & 33,49 & 30,48 & 1 & 12 & \begin{tabular}{l|l}
2 & 11,1 \\
\end{tabular} \\
\hline 354170 & Quatá & D20 & 2 & 34,14 & 33,15 & 1 & 16,86 & 15,80 & 3 & 25,45 & 24,42 & 3 & 51,21 & 42,95 & 2 & 28,10 & 24,46 & 5 & 39,59 & 33,65 & 6 & 75 & \begin{tabular}{|l|l|}
5 & 8,0 \\
\end{tabular} \\
\hline 354180 & Queiroz & E20 & 0 & 28,40 & 29,72 & 1 & 60,51 & 65,30 & 1 & 43,95 & 46,95 & 1 & 56,80 & \begin{tabular}{|r|}
35,97 \\
\end{tabular} & 1 & 60,51 & 65,30 & 1 & 58,60 & 50,17 & 3 & 17 & $\begin{array}{l}77,6 \\
\end{array}$ \\
\hline 354190 & Queluz & D20 & 2 & 41,39 & 41,02 & 1 & 20,38 & 20,48 & 3 & 30,81 & 30,67 & 4 & \begin{tabular}{|r|}
75,88 \\
\end{tabular} & 77,09 & 6 & 122,30 & 119,88 & 10 & 99,26 & $98,65 \mid$ & 6 & 66 & 8,6 \\
\hline 354200 & Quintana & E20 & 1 & 47,67 & 49,30 & 0 & 12,08 & 9,81 & 2 & 30,00 & 29,69 & 1 & 35,75 & 23,85 & 0 & \begin{tabular}{|r|}
12,08 \\
\end{tabular} & 9,81 & 1 & 24,00 & \begin{tabular}{|r|}
16,88 \\
\end{tabular} & 4 & 38 & 11,4 \\
\hline 354210 & Rafard & A20 & 1 & 32,21 & 30,93 & 1 & 32,38 & 32,43 & 3 & 32,29 & $31,68 \mid$ & 2 & 56,37 & 42,30 & 1 & \begin{tabular}{|r|}
$\mid 32,38$ \\
\end{tabular} & 26,98 & 4 & 44,40 & $\mid 34,66$ & 9 & 57 & 16,3 \\
\hline 354220 & Rancharia & D50 & 4 & 29,52 & 25,85 & 3 & 20,11 & 19,61 & 7 & 24,77 & 22,70 & 14 & 97,65 & 80,59 & 13 & \begin{tabular}{|r|}
84,89 \\
\end{tabular} & 75,44 & 27 & 91,22 & 78,00 & 32 & 216 & 14,6 \\
\hline 354230 & Redençao da Serra & E20 & & & & 0 & $\mid 17,76$ & 20,53 & 0 & 8,21 & 9,49 & 2 & 91,63 & 63,04 & 1 & \begin{tabular}{|r|}
35,52 \\
\end{tabular} & 30,54 & 3 & 65,69 & 48,02 & 2 & 22 & 10,4 \\
\hline 354240 & Regente Feijó & D20 & 3 & 33,49 & 30,31 & 2 & 18,63 & 17,69 & 5 & 26,06 & 24,00 & 7 & 74,42 & 60,03 & 3 & \begin{tabular}{|r|}
$\mid 37,25$ \\
\end{tabular} & 32,73 & 10 & 55,85 & 46,39 & 19 & 119 & 15,6 \\
\hline 354250 & Reginópolis & E20 & 1 & 41,75 & 37,76 & 0 & \begin{tabular}{|r|}
14,26 \\
\end{tabular} & 12,51 & 1 & 28,17 & 25,29 & 3 & \begin{tabular}{|l|}
$\mid 125,26$ \\
\end{tabular} & 91,55 & 2 & 99,80 & 71,95 & 5 & $\mid 112,68$ & $\mid 81,87$ & 6 & 39 & 14,7 \\
\hline 354260 & Registro & D100 & 6 & 20,30 & 21,37 & 4 & $\mid 14,29$ & 15,97 & 10 & 17,29 & $|18,67|$ & 15 & 54,94 & 56,03 & 12 & 42,88 & 46,81 & 27 & 48,90 & 51,42 & 51 & 314 & 16,3 \\
\hline
\end{tabular}


Anexo 19 - Óbitos e taxa de mortalidade (bruta e padronizada) total e segundo sexo por Doenças Infecciosas e Parasitárias e Doenças Respiratórias e \% de óbitos por Causas Mal Definidas nos municípios. Estado de São Paulo, média do triênio, 2003-2005

\begin{tabular}{|c|c|c|c|c|c|c|c|c|c|c|c|c|c|c|c|c|c|c|c|c|c|c|c|}
\hline \multirow[b]{2}{*}{ IBGE } & \multirow[b]{2}{*}{ Mun. } & \multirow[b]{2}{*}{ Porte } & \multicolumn{9}{|c|}{$\begin{array}{l}\text { DOENCAS INFECCIOSAS E PARASITÁRIAS } \\
\end{array}$} & \multicolumn{9}{|c|}{ DOENCAS RESPIRATÓRIAS } & \multicolumn{3}{|c|}{ MAL DEFINIDAS } \\
\hline & & & Obitos & $\begin{array}{l}\text { Homens } \\
\text { TMB }\end{array}$ & TPM & Obitos & $\begin{array}{l}\text { Mulheres } \\
\text { TMB }\end{array}$ & STPM & Obitos & $\begin{array}{l}\text { Total } \\
\text { TMB }\end{array}$ & TPM & Obitos & $\begin{array}{l}\text { Homens } \\
\text { TMB }\end{array}$ & TPM & Obitos & $\begin{array}{l}\text { Mulheres } \\
\text { TMB }\end{array}$ & TPM & Obitos T & $\begin{array}{l}\text { Total } \\
\text { TMB } \\
\end{array}$ & TPM & Obitos & Ob.Totais o & \\
\hline 354270 & Restinga & E20 & 1 & 21,40 & 23,98 & 0 & 11,13 & 14,49 & 1 & 16,36 & 19,33 & 2 & 64,19 & 69,17 & 0 & 11,13 & 16,57 & 2 & 38,18 & 43,39 & 7 & 29 & 22,7 \\
\hline 354280 & Ribeira & E20 & - & & & 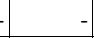 & & & - & & & 2 & 117,28 & 96,32 & 1 & 64,64 & 52,64 & 3 & 92,24 & 75,54 & 4 & 24 & 15,1 \\
\hline 354290 & Ribeirao Bonito & D20 & 2 & 33,89 & 32,37 & 0 & 5,79 & 6,15 & 2 & 20,02 & 19,43 & 6 & 101,68 & 89,47 & 3 & 52,13 & 44,53 & 9 & 77,22 & 67,28 & 6 & 71 & 8,5 \\
\hline 354300 & Ribeirao Branco & E50 & 1 & 5,77 & 5,52 & 0 & 3,16 & 1,93 & 1 & 4,52 & 3,80 & 6 & 49,07 & 63,89 & 5 & 44,22 & 67,32 & 10 & 46,76 & 65,53 & 26 & 120 & 21,9 \\
\hline 354310 & Ribeirao Corrente & E20 & 0 & 15,00 & 17,23 & 0 & 17,10 & 20,25 & 1 & 15,98 & 18,65 & 1 & 45,01 & 39,65 & 2 & \begin{tabular}{|l|}
119,68 \\
\end{tabular} & 137,18 & 3 & 79,91 & 85,24 & 3 & 22 & 13,8 \\
\hline 354320 & Ribeirao do Sul & E20 & 0 & 14,13 & 9,72 & 0 & 14,59 & 13,11 & 1 & 14,35 & 11,39 & 1 & 28,26 & 19,44 & 0 & 14,59 & 12,21 & 1 & 21,53 & 15,88 & 6 & 29 & 20,5 \\
\hline 354323 & Ribeirao dos Indios & E20 & - & & & 0 & 30,14 & 24,29 & 0 & 14,57 & 11,74 & 1 & 56,39 & 29,05 & - & & & 1 & 29,13 & 15,01 & 3 & 14 & 20,9 \\
\hline 354325 & Ribeirao Grande & E20 & 0 & 8,13 & 8,01 & - & & & 0 & 4,20 & 4,14 & 4 & 89,45 & 93,25 & 3 & 78,21 & 105,21 & 7 & 84,01 & 99,03 & 5 & 37 & 13,5 \\
\hline 354330 & Ribeirao Pires & B300 & 17 & 29,80 & 31,45 & 7 & 12,81 & 14,67 & 24 & 21,20 & 22,96 & 38 & 68,54 & 77,99 & 36 & 62,29 & 74,04 & 74 & 65,38 & 75,99 & 12 & 600 & 2,0 \\
\hline 354340 & Ribeirao Preto & B1000 & 129 & 49,82 & 47,80 & 85 & 30,58 & 27,96 & 214 & 39,84 & 37,51 & 212 & 81,74 & 74,68 & 171 & 61,28 & 53,61 & 383 & 71,13 & 63,75 & 28 & 3259 & 0,9 \\
\hline 354360 & Rifaina & D20 & 0 & 18,52 & 13,56 & & & & 0 & 9,48 & 6,94 & 1 & 74,07 & 60,83 & 1 & 77,72 & 70,50 & 3 & 75,85 & 65,55 & 4 & 18 & 24,1 \\
\hline 354370 & Rincao & D20 & 1 & 19,15 & 19,36 & 1 & 13,07 & 14,02 & 2 & 16,14 & 16,72 & 6 & 114,90 & 111,63 & 4 & 71,87 & 69,90 & 10 & 93,64 & 91,01 & 6 & 67 & 9,4 \\
\hline 354380 & Rinópolis & E20 & 2 & 39,50 & 36,92 & 2 & 48,77 & 43,44 & 4 & 44,01 & 40,09 & 3 & 52,67 & 26,27 & 4 & 90,57 & 58,82 & 7 & 71,09 & 42,09 & 6 & 67 & 9,4 \\
\hline 354390 & Rio Claro & B300 & 31 & 34,92 & 32,98 & 19 & 20,11 & 18,53 & 50 & 27,35 & 25,60 & 79 & 89,36 & 73,89 & 65 & 69,66 & 54,08 & 144 & 79,29 & 63,76 & 172 & 1253 & 13,8 \\
\hline 354400 & Rio das Pedras & C50 & 3 & 23,14 & 24,65 & 3 & 24,02 & 25,63 & 6 & 23,57 & 25,13 & 6 & 43,70 & 48,67 & 6 & 45,38 & 48,93 & 11 & 44,52 & 48,80 & 15 & 132 & 11,1 \\
\hline 354410 & Rio Grande da Serra & C50 & 5 & 24,92 & 26,70 & 4 & 18,12 & 25,03 & 9 & 21,50 & 25,86 & 13 & 66,45 & 95,67 & 7 & 36,24 & 54,91 & 21 & 51,28 & 75,20 & 2 & 186 & 1,1 \\
\hline 354420 & Riolândia & E20 & 2 & 33,50 & 31,45 & 2 & 59,18 & 56,14 & 4 & 44,85 & 42,37 & 5 & 107,19 & 100,42 & 2 & 59,18 & 58,20 & 8 & 85,97 & 81,75 & 4 & 60 & 6,1 \\
\hline 354350 & Riversul & E20 & 1 & 31,50 & 29,48 & 1 & 21,98 & 22,98 & 2 & 26,85 & 26,30 & 3 & 105,01 & 76,96 & 3 & 98,92 & 92,43 & 6 & \begin{tabular}{|l|}
102,04 \\
\end{tabular} & 84,52 & 13 & 61 & 20,9 \\
\hline 354425 & Rosana & C50 & 2 & 17,84 & 22,90 & 1 & 10,49 & 27,60 & 4 & \begin{tabular}{|l|}
4,22 \\
\end{tabular} & 25,22 & 6 & 43,32 & 65,39 & 3 & 20,98 & 47,38 & 8 & 32,31 & 56,51 & 7 & 90 & 7,4 \\
\hline 354430 & Roseira & $\mathrm{C} 20$ & 1 & 20,38 & 21,51 & 1 & 21,17 & 24,05 & 2 & 20,77 & 22,76 & 3 & 67,92 & 80,52 & 1 & 14,11 & 16,74 & 4 & 41,53 & 49,24 & 3 & 53 & 6,3 \\
\hline 354440 & Rubiácea & E20 & & & & 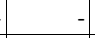 & & & - & & & 2 & 148,37 & 111,54 & 0 & 30,88 & 29,04 & 2 & 90,80 & 71,12 & 2 & 14 & 17,1 \\
\hline 354450 & Rubinéia & D20 & 1 & 48,29 & 24,76 & & & & 1 & 23,95 & 12,28 & 2 & 120,71 & 78,15 & 0 & 23,76 & 19,17 & 2 & 71,85 & 48,42 & 3 & 16 & 20,4 \\
\hline 354460 & Sabino & E20 & 1 & 26,08 & 18,75 & 1 & 26,00 & 23,48 & 1 & 26,04 & 21,12 & 2 & 91,29 & 57,11 & 2 & 90,99 & 68,56 & 5 & 91,14 & 62,84 & 5 & 37 & 13,4 \\
\hline 354470 & Sagres & E20 & - & & & 0 & 29,03 & 27,57 & 0 & 14,22 & 13,51 & 1 & 55,76 & 47,60 & - & & & 1 & 28,44 & 24,28 & 4 & 14 & 28,6 \\
\hline 354480 & Sales & E20 & 1 & 26,65 & 19,89 & 1 & 27,54 & 24,64 & 1 & 27,09 & 22,22 & 5 & 199,89 & 151,52 & 2 & 96,41 & 89,95 & 7 & 149,00 & 121,24 & 2 & 41 & 4,0 \\
\hline 354490 & Sales Oliveira & B20 & 0 & 6,58 & 6,04 & 2 & 33,21 & 30,97 & 2 & 19,84 & 18,45 & 4 & 78,98 & 63,97 & 1 & 19,93 & 19,41 & 5 & 49,59 & 41,79 & 0 & 52 & 0,6 \\
\hline 354500 & Salesópolis & E20 & 2 & 21,00 & 20,24 & 1 & 12,89 & 13,14 & 3 & 16,99 & 16,73 & 6 & 79,80 & 62,19 & 4 & 55,86 & 55,87 & 11 & 67,97 & 59,07 & 11 & 108 & 9,9 \\
\hline 354510 & Salmourao & E20 & 0 & 14,97 & 12,19 & 0 & 15,51 & 12,73 & 1 & 15,23 & 12,46 & 4 & 164,65 & 116,58 & 3 & $\mid 124,09$ & 106,86 & 6 & 144,73 & 111,81 & 4 & 32 & 11,3 \\
\hline 354515 & Saltinho & B2O & - & & & 1 & 21,97 & 20,97 & 1 & 10,89 & 10,39 & 2 & 53,98 & 49,04 & 0 & 10,99 & 9,81 & 2 & 32,67 & 29,60 & 2 & 31 & 6,4 \\
\hline 354520 & Salto & B300 & 9 & 18,21 & 19,10 & 9 & 18,22 & 19,14 & 19 & 18,22 & 19,12 & 39 & 75,46 & 80,55 & 30 & 59,22 & 65,32 & 69 & 67,34 & 72,94 & 97 & 591 & 16,5 \\
\hline 354530 & Salto de Pirapora & D50 & 4 & 20,23 & 20,51 & 2 & 11,88 & 12,69 & 6 & 16,07 & 16,62 & 13 & 65,73 & 65,30 & 14 & \begin{tabular}{|r|}
71,28 \\
\end{tabular} & 80,33 & 27 & 68,50 & 72,79 & 37 & 241 & 15,2 \\
\hline 354540 & Salto Grande & E2O & 1 & 22,31 & 24,44 & 1 & 22,55 & 23,95 & 2 & 22,43 & 24,19 & 2 & 52,05 & 35,39 & 3 & 60,13 & 47,77 & 5 & 56,07 & 41,55 & 5 & 73 & 6,8 \\
\hline
\end{tabular}


Anexo 19 - Óbitos e taxa de mortalidade (bruta e padronizada) total e segundo sexo por Doenças Infecciosas e Parasitárias e Doenças Respiratórias e \% de óbitos por Causas Mal Definidas nos municípios. Estado de São Paulo, média do triênio, 2003-2005

\begin{tabular}{|c|c|c|c|c|c|c|c|c|c|c|c|c|c|c|c|c|c|c|c|c|c|c|c|}
\hline \multirow[b]{2}{*}{ IBGE } & \multirow[b]{2}{*}{ Mun. } & \multirow[b]{2}{*}{ Porte } & \multicolumn{9}{|c|}{$\begin{array}{l}\text { DOENCAS INFECCIOSAS E PARASITÁRIAS } \\
\end{array}$} & \multicolumn{9}{|c|}{ DOENCAS RESPIRATÓRIAS } & \multicolumn{3}{|c|}{ MAL DEFINIDAS } \\
\hline & & & Obitos & $\begin{array}{l}\text { Homens } \\
\text { TMB }\end{array}$ & TPM & Obitos & $\begin{array}{c}\text { Mulhe } \\
\text { TMB }\end{array}$ & TPM & Obitos & $\begin{array}{l}\text { Total } \\
\text { TMB }\end{array}$ & TPM & Obitos & $\begin{array}{l}\text { Homens } \\
\text { TMB }\end{array}$ & TPM & Obitos $N$ & $\begin{array}{c}\text { Mulh } \\
\text { TMB }\end{array}$ & TPM & Obitos $\mathrm{T}$ & $\begin{array}{l}\text { Total } \\
\text { TMB } \\
\end{array}$ & TPM & Obitos & Ob.Totais ? & \\
\hline 354550 & Sandovalina & E20 & 0 & 19,80 & 19,02 & & & & 0 & 9,82 & 9,43 & 2 & 118,81 & 115,06 & 1 & $\begin{array}{l}1 \quad 77,96 \\
\end{array}$ & 93,75 & 3 & 98,22 & 104,32 & 1 & 17 & 7,8 \\
\hline 354560 & Santa Adélia & D20 & 2 & 33,42 & 29,51 & 2 & \begin{tabular}{|l|l|}
24,36 \\
\end{tabular} & 20,91 & 4 & 28,94 & 25,25 & 8 & 114,59 & 86,45 & 4 & $\begin{array}{l}4 \quad 58,47 \\
4\end{array}$ & 45,26 & 12 & 86,82 & 66,07 & 11 & 102 & 11,1 \\
\hline 354570 & Santa Albertina & E20 & 2 & 60,72 & 31,31 & 1 & $\begin{array}{l}1 \quad 24,55 \\
\end{array}$ & 15,00 & 2 & 42,73 & 23,20 & 5 & 182,15 & 103,93 & 3 & \begin{tabular}{l|l|}
3 & 122,76 \\
\end{tabular} & 76,90 & 8 & 152,62 & 90,49 & 6 & 56 & 10,8 \\
\hline 354580 & Santa Bárbara d'Oeste & B300 & 21 & 23,58 & 24,85 & 10 & 10,66 & 12,00 & 31 & 17,11 & 18,42 & 55 & 60,79 & 66,17 & 37 & 40,43 & 47,11 & 92 & 50,60 & 56,63 & 212 & 900 & 23,6 \\
\hline 354600 & Santa Branca & D20 & 1 & 13,92 & 13,32 & 2 & \begin{tabular}{|l|l|}
2 & 33,18 \\
\end{tabular} & 34,36 & 3 & 23,45 & 23,73 & 7 & 92,79 & 84,08 & 4 & $\begin{array}{l}4 \quad 52,15 \\
\end{array}$ & 53,12 & 10 & 72,68 & 68,77 & 7 & 77 & 9,5 \\
\hline 354610 & Santa Clara d'Oeste & E20 & 1 & 67,98 & 52,14 & 1 & \begin{tabular}{l|l|}
1 & 68,38 \\
\end{tabular} & 53,94 & 1 & 68,18 & 53,04 & 1 & 101,97 & 53,40 & 1 & $\begin{array}{l}1 \quad 68,38 \\
\end{array}$ & 68,28 & 2 & 85,22 & 60,82 & 4 & 18 & 23,6 \\
\hline 354620 & Santa Cruz Conceiçao & B20 & 1 & 34,36 & 34,51 & - & - & & 1 & 17,56 & 17,64 & 2 & 85,90 & 65,31 & 1 & $\begin{array}{l}1 \quad 53,90 \\
\end{array}$ & 38,27 & 3 & 70,26 & 52,09 & 4 & 19 & 19,3 \\
\hline 354640 & Santa Cruz do Rio Pardo & C50 & 8 & 39,24 & 34,02 & 7 & \begin{tabular}{|l|l|}
7 & 30,83 \\
\end{tabular} & 26,09 & 15 & 35,00 & 30,02 & 17 & 81,62 & 63,47 & 11 & 49,32 & 40,94 & 28 & 65,32 & 52,10 & 58 & 302 & 19,2 \\
\hline 354625 & Santa Cruz Esperança & E20 & 0 & 35,26 & 22,21 & -1 & & & 0 & 18,08 & 11,39 & 1 & 105,78 & 66,64 & 0 & 37,11 & 37,71 & 1 & 72,32 & 52,54 & & 12 & \\
\hline 354630 & Santa Cruz Palmeiras & D50 & 3 & 24,24 & 23,94 & 0 & 2,47 & 2,59 & 4 & 13,47 & 13,37 & 9 & 63,03 & 60,68 & 9 & 66,79 & 69,54 & 18 & 64,89 & 65,07 & 21 & 170 & 12,5 \\
\hline 354650 & Santa Ernestina & B20 & 1 & 31,73 & 38,82 & 0 & \begin{tabular}{|l|l|}
0 & 12,59 \\
\end{tabular} & 11,20 & 1 & 22,99 & 26,21 & 1 & 31,73 & 38,58 & 1 & 25,18 & 30,73 & 2 & 28,74 & 34,99 & 2 & 29 & 8,0 \\
\hline 354660 & Santa Fé do Sul & D50 & 8 & 61,10 & 46,27 & 5 & \begin{tabular}{|l|l|}
5 & 37,05 \\
\end{tabular} & 30,03 & 14 & 48,75 & 37,93 & 18 & 131,98 & 86,69 & 7 & 50,95 & 40,90 & 25 & 90,37 & 63,18 & 52 & 205 & 25,2 \\
\hline 354670 & Santa Gertrudes & C20 & 1 & 14,28 & 15,71 & 1 & 7,41 & 7,60 & 2 & 10,91 & 11,73 & 7 & 71,41 & 76,24 & 5 & 55,60 & 57,22 & 12 & 63,66 & 66,91 & 10 & 88 & 11,4 \\
\hline 354680 & Santa Isabel & D50 & 5 & 21,38 & 22,06 & 2 & 8,72 & 9,63 & 7 & 15,11 & 15,91 & 19 & 82,65 & 87,01 & 14 & \begin{tabular}{|r|}
59,62 \\
\end{tabular} & 71,60 & 33 & 71,25 & 79,38 & 5 & 289 & 1,7 \\
\hline 354690 & Santa Lúcia & E20 & 0 & 7,54 & 8,54 & 1 & 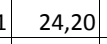 & 32,69 & 1 & 15,59 & 20,21 & 2 & 45,22 & 51,66 & 2 & 48,40 & 61,31 & 4 & 46,76 & 56,32 & 5 & 44 & 10,5 \\
\hline 354700 & Santa Maria da Serra & E20 & 1 & 39,59 & 37,20 & 0 & $\begin{array}{l}14,42 \\
\end{array}$ & 15,99 & 1 & 27,56 & 27,06 & 3 & 131,96 & 123,88 & 1 & 43,25 & 43,38 & 4 & 89,56 & 85,41 & 5 & 33 & 16,2 \\
\hline 354710 & Santa Mercedes & E20 & - & & & 0 & 24,80 & 23,05 & 0 & 12,25 & 11,38 & 1 & 48,39 & 23,66 & 0 & 24,80 & 18,96 & 1 & 36,74 & 21,34 & 5 & 18 & 29,1 \\
\hline 354740 & Santa Rita d'Oeste & E20 & 1 & 112,87 & 71,84 & 0 & \begin{tabular}{|l|}
28,73 \\
\end{tabular} & 18,25 & 2 & 71,17 & 45,28 & 2 & 141,08 & 70,45 & 1 & 57,45 & 36,50 & 2 & 99,64 & 53,63 & 3 & 22 & 13,4 \\
\hline 354750 & Santa Rita Passa Quatro & B50 & 5 & 35,41 & 25,33 & 2 & 16,84 & 11,48 & 7 & 25,89 & 18,23 & 16 & 118,86 & 78,54 & 10 & 74,57 & 49,87 & 26 & 96,16 & 63,85 & 20 & 217 & 9,4 \\
\hline 354760 & Santa Rosa de Viterbo & D50 & 2 & 17,89 & 16,51 & 2 & 20,73 & 19,12 & 4 & 19,31 & 17,82 & 9 & 83,48 & 71,67 & 10 & 85,89 & 73,37 & 19 & 84,69 & 72,52 & 13 & 135 & 9,9 \\
\hline 354765 & Santa Salete & E20 & & & & & & & & & & 0 & 45,98 & 22,89 & 0 & 50,97 & 32,50 & 1 & 48,34 & 27,45 & 3 & 9 & 29,6 \\
\hline 354720 & Santana da Ponte Pensa & E20 & 0 & 38,33 & 25,82 & 1 & 163,87 & 112,01 & 2 & 99,01 & 67,48 & 1 & 76,66 & 40,83 & 1 & 122,90 & 79,36 & 2 & 99,01 & 59,45 & 3 & 16 & 21,3 \\
\hline 354730 & Santana de Parnaíba & C100 & 6 & 13,17 & 17,03 & 2 & 4,36 & 4,73 & 8 & 8,75 & 10,86 & 16 & 35,13 & 52,37 & 14 & 31,27 & 58,16 & 30 & 33,19 & 55,27 & 5 & 321 & 1,6 \\
\hline 354770 & Santo Anastácio & E50 & 2 & 16,18 & 14,54 & 2 & 18,55 & 14,96 & 4 & 17,39 & 14,75 & 7 & 67,95 & 46,65 & 6 & 55,64 & 43,92 & 13 & 61,66 & 45,25 & 27 & 145 & 18,6 \\
\hline 354780 & Santo André & A1000 & 112 & 35,02 & 32,65 & 71 & 20,60 & 19,03 & 183 & 27,57 & 25,61 & 312 & 97,15 & 87,71 & 227 & 66,28 & 58,49 & 539 & 81,20 & 72,61 & 28 & 4364 & 0,6 \\
\hline 354805 & Santo Ant Aracangua & E20 & 1 & 18,60 & 17,70 & 1 & $\begin{array}{l}20,12 \\
\end{array}$ & 22,41 & 1 & 19,33 & 19,96 & 3 & 83,72 & 77,23 & 1 & 40,24 & 44,83 & 4 & 62,83 & 61,66 & 2 & 30 & 7,7 \\
\hline 354790 & Santo Antônio da Alegria & E20 & 2 & 53,10 & 40,98 & 1 & $\begin{array}{r}34,51 \\
\end{array}$ & 32,48 & 3 & 44,18 & 36,90 & 3 & 84,95 & 69,86 & 2 & 57,52 & 50,32 & 4 & 71,79 & 60,48 & 2 & 39 & 5,2 \\
\hline 354800 & Santo Antônio de Posse & D20 & 3 & 33,30 & 32,17 & 1 & 10,16 & 9,94 & 4 & 21,82 & 21,15 & 7 & 73,27 & 64,28 & 6 & 57,55 & 57,20 & 13 & 65,47 & 60,77 & 10 & 121 & 8,2 \\
\hline 354810 & Santo Antônio do Jardim & E20 & 1 & 20,00 & 15,48 & 0 & 11,00 & 8,83 & 1 & 15,71 & 12,31 & 2 & 69,99 & 54,30 & 0 & 11,00 & 8,83 & 3 & 41,90 & 32,65 & 3 & 37 & 8,9 \\
\hline 354820 & Santo Antônio do Pinhal & E20 & 0 & 9,60 & 10,04 & & & & 0 & 4,93 & 5,15 & 2 & 67,22 & 63,52 & 1 & 30,36 & 33,23 & 3 & 49,27 & 48,77 & 4 & 39 & 10,3 \\
\hline 354830 & Santo Expedito & E20 & 1 & 48,39 & 36,45 & 0 & 25,96 & 20,17 & 1 & 37,57 & 28,60 & 3 & 217,76 & 146,60 & 2 & $\mid$\begin{tabular}{|r|}
$\mid 129,80$ \\
\end{tabular} & 101,25 & 5 & 175,33 & $\mid 124,72$ & 2 & 19 & 8,9 \\
\hline 354840 & Santópolis do Aguapeí & E20 & 0 & 17,20 & 18,83 & 1 & 35,65 & 37,30 & 1 & 26,26 & 27,90 & 1 & 34,39 & 34,68 & 0 & 17,83 & 15,73 & 1 & 26,26 & 25,37 & 6 & 25 & 24,0 \\
\hline
\end{tabular}


Anexo 19 - Óbitos e taxa de mortalidade (bruta e padronizada) total e segundo sexo por Doenças Infecciosas e Parasitárias e Doenças Respiratórias e \% de óbitos por Causas Mal Definidas nos municípios. Estado de São Paulo, média do triênio, 2003-2005

\begin{tabular}{|c|c|c|c|c|c|c|c|c|c|c|c|c|c|c|c|c|c|c|c|c|c|c|c|}
\hline \multirow[b]{2}{*}{ IBGE } & \multirow{2}{*}{ Mun. } & \multirow{2}{*}{ Porte } & \multicolumn{9}{|c|}{$\begin{array}{l}\text { DOENCAS INFECCIOSAS E PARASITÁRIAS } \\
\text { Dus }\end{array}$} & \multicolumn{9}{|c|}{ DOENCAS RESPIRATÓRIAS } & \multicolumn{3}{|c|}{ MAL DEFINIDAS } \\
\hline & & & Obitos & $\begin{array}{l}\text { Homens } \\
\text { TMB }\end{array}$ & TPM & Obitos & $\begin{array}{l}\text { Mulh } \\
\text { TMB }\end{array}$ & TPM & Obitos & $\begin{array}{l}\text { Total } \\
\text { TMB }\end{array}$ & TPM & bitos & $\begin{array}{l}\text { Homens } \\
\text { TMB }\end{array}$ & TPM & Obitos & $\begin{array}{l}\text { Mulh } \\
\text { TMB }\end{array}$ & $M$ & & $\begin{array}{l}\text { Total } \\
\text { TMB }\end{array}$ & & Obitos C & Ob.Totais & \\
\hline 354850 & Santos & A500 & 120 & 62,07 & 51,72 & 71 & 31,57 & 24,88 & 191 & 45,67 & 37,29 & 225 & 116,55 & 73,25 & 228 & 101,39 & 58,30 & 453 & 108,40 & 65,21 & 521 & 3875 & 13,4 \\
\hline 354860 & Sao Bento do Sapucaí & D20 & 1 & 17,78 & 18,44 & 1 & 12,18 & 11,42 & 2 & 15,02 & 14,98 & 4 & 71,13 & 48,65 & 4 & 79,17 & 69,85 & 8 & 75,10 & 59,11 & 4 & 81 & 5,4 \\
\hline 354870 & Sao Bernardo do Campo & B1000 & 90 & 24,30 & 25,99 & 57 & 14,61 & 16,42 & 148 & 19,33 & 21,07 & 187 & 50,31 & 64,16 & 173 & 44,10 & 55,53 & 360 & 47,12 & 59,73 & 26 & 3717 & 0,7 \\
\hline 354880 & Sao Caetano do Sul & A300 & 36 & 56,64 & 43,53 & 23 & 31,76 & 21,17 & 59 & 43,39 & 31,62 & 96 & 150,51 & 88,75 & 89 & 123,36 & 67,91 & 185 & 136,05 & 77,65 & 14 & 1397 & 1,0 \\
\hline 354890 & Sao Carlos & B300 & 27 & 26,14 & 24,53 & 16 & 15,52 & 14,38 & 43 & 20,78 & 19,41 & 81 & 78,11 & 67,73 & 68 & 64,92 & 54,56 & 149 & 71,45 & 61,08 & 183 & 1254 & 14,6 \\
\hline 354900 & Sao Francisco & E20 & 1 & 87,55 & 44,15 & & & & 1 & 44,35 & 22,37 & 2 & 131,32 & 66,23 & 0 & 22,47 & 19,23 & 2 & 77,61 & 43,04 & 4 & 20 & 18,0 \\
\hline 354910 & Sao Joao da Boa Vista & B100 & 12 & 30,95 & 26,74 & 8 & 20,22 & 16,55 & 21 & 25,49 & 21,56 & 25 & 62,73 & 47,80 & 21 & 50,15 & 38,26 & 46 & 56,33 & 42,95 & 107 & 590 & 18,1 \\
\hline 354925 & Sao Joao de Iracema & E20 & 1 & 152,09 & 141,41 & - & & & 1 & 78,23 & 72,74 & 1 & 76,05 & 60,83 & 1 & 80,55 & 65,00 & 1 & 78,23 & 62,86 & 1 & 10 & 6,7 \\
\hline 354930 & Sao Joao do Pau d'Alho & E20 & 0 & 34,65 & 26,72 & 1 & 71,43 & 49,38 & 1 & 52,76 & 37,88 & 1 & 138,60 & 61,66 & 0 & 35,71 & 26,55 & 2 & 87,94 & 44,37 & 0 & 17 & 1,9 \\
\hline 354920 & Sao Joao Duas Pontes & E20 & 2 & 176,10 & 154,90 & & & & 2 & 89,73 & 78,93 & 2 & 125,79 & 105,31 & 1 & 78,41 & 68,48 & 3 & 102,55 & 87,25 & 5 & 20 & 23,7 \\
\hline 354940 & Sao Joaquim da Barra & C50 & 8 & 35,23 & 33,05 & 4 & 19,40 & 18,31 & 12 & 27,21 & 25,58 & 16 & 71,99 & 65,71 & 14 & 64,18 & 59,63 & 30 & 68,03 & 62,63 & 18 & 298 & 6,2 \\
\hline 354950 & Sao José da Bela Vista & E20 & 2 & 53,75 & 55,75 & 1 & 32,06 & 33,29 & 4 & 43,14 & 44,76 & 2 & 53,75 & 56,49 & 2 & 56,10 & 57,11 & 5 & 54,90 & 56,80 & 7 & 50 & 13,3 \\
\hline 354960 & Sao José do Barreiro & E20 & 0 & 15,09 & 15,46 & 0 & 16,43 & 18,43 & 1 & 15,74 & 16,88 & 2 & 90,57 & 72,01 & 1 & 32,87 & 24,86 & 3 & 62,94 & 49,44 & 4 & 32 & 12,6 \\
\hline 354970 & Sao José do Rio Pardo & D100 & 6 & 23,04 & 20,40 & 4 & 16,36 & 13,85 & 10 & 19,67 & 17,10 & 22 & 83,20 & 65,12 & 19 & 70,46 & 57,40 & 40 & 76,78 & 61,23 & 28 & 355 & 7,8 \\
\hline 354980 & Sao José do Rio Preto & B500 & 85 & 44,88 & 41,45 & 67 & 33,03 & 30,12 & 152 & 38,77 & 35,60 & 185 & 97,47 & 83,33 & 157 & 77,24 & 66,84 & 342 & 87,03 & 74,82 & 35 & 2458 & 1,4 \\
\hline 354990 & Sao José dos Campos & B1000 & 78 & 26,98 & 29,53 & 42 & 14,36 & 16,34 & 120 & 20,60 & 22,86 & 145 & 50,26 & 63,78 & 124 & 42,18 & 55,66 & 269 & 46,17 & 59,67 & 312 & 2756 & 11,3 \\
\hline 354995 & Sao Lourenço da Serra & E20 & 2 & 23,01 & 23,84 & 1 & 14,18 & 17,75 & 3 & 18,65 & 20,84 & 6 & 78,23 & 87,73 & 3 & 47,26 & 65,24 & 9 & 62,95 & 76,64 & 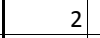 & 77 & 2,2 \\
\hline 355000 & Sao Luís do Paraitinga & E20 & 0 & 6,03 & 6,11 & 0 & 6,50 & 6,11 & 1 & 6,26 & 6,11 & 4 & 78,43 & 59,58 & 8 & \begin{tabular}{|l|}
155,94 \\
\end{tabular} & 137,04 & 12 & 115,75 & 96,87 & 5 & 71 & 6,5 \\
\hline 355010 & Sao Manuel & D50 & 4 & 20,93 & 19,71 & 3 & 17,17 & 15,85 & 7 & 19,04 & 17,77 & 10 & 52,33 & 46,26 & 7 & 37,77 & 35,19 & 17 & 45,00 & 40,68 & 7 & 265 & 2,8 \\
\hline 355020 & Sao Miguel Arcanjo & E50 & 4 & 25,49 & 26,84 & 3 & 16,44 & 18,89 & 7 & 21,07 & 22,96 & 9 & 54,91 & 56,42 & 6 & 39,05 & 48,50 & 16 & 47,16 & 52,55 & 32 & 179 & 18,0 \\
\hline 355030 & Sao Paulo & B10000 & 1834 & 35,68 & 35,29 & 1158 & 20,50 & 19,61 & 2992 & 27,74 & 27,08 & 4176 & 81,24 & 81,04 & 3819 & 67,64 & 62,74 & 7995 & 74,12 & 71,47 & 886 & 66422 & 1,3 \\
\hline 355040 & Sao Pedro & B50 & 5 & 32,36 & 30,46 & 2 & 12,58 & 10,95 & 7 & 22,33 & 20,57 & 12 & 79,82 & 57,67 & 12 & 77,59 & 62,32 & 25 & 78,69 & 60,02 & 51 & 237 & 21,6 \\
\hline 355050 & Sao Pedro do Turvo & E20 & 1 & 18,93 & 16,79 & 0 & 9,68 & 9,05 & 1 & 14,36 & 12,96 & 1 & 28,40 & 20,00 & 1 & 29,05 & 26,84 & 2 & 28,72 & 23,38 & 0 & 39 & 15,4 \\
\hline 355060 & Sao Roque & B100 & 8 & 22,65 & 22,00 & 4 & 12,16 & 11,85 & 12 & 17,38 & 16,90 & 30 & 85,88 & 76,94 & 25 & 70,16 & 66,80 & 55 & 77,99 & 71,85 & 40 & 470 & 8,6 \\
\hline 355070 & Sao Sebastiao & C100 & 10 & 27,72 & 31,46 & 6 & 18,65 & 22,36 & 16 & 23,25 & 26,97 & 12 & 33,46 & 44,08 & 10 & 28,47 & 38,33 & 21 & 31,00 & 41,24 & 37 & 347 & 10,8 \\
\hline 355080 & Sao Sebastiao da Grama & E20 & 1 & 20,59 & 18,62 & 1 & 21,28 & 20,59 & 3 & 20,93 & 19,59 & 6 & 87,49 & 70,16 & 4 & 63,84 & 58,63 & 10 & 75,86 & 64,49 & 15 & 94 & 15,5 \\
\hline 355090 & Sao Simao & B20 & 3 & 41,69 & 37,33 & 1 & 18,43 & 16,35 & 4 & 30,03 & 26,81 & 6 & 88,02 & 69,09 & 3 & 46,08 & 35,55 & 10 & 66,99 & 52,28 & 1 & 99 & 1,3 \\
\hline 355100 & Sao Vicente & B500 & 76 & 49,32 & 50,41 & 45 & 27,17 & 27,30 & 121 & 37,91 & 38,50 & 117 & 75,81 & 81,22 & 99 & 60,23 & 61,10 & 216 & 67,78 & 70,86 & 358 & 2121 & 16,9 \\
\hline 355110 & Sarapuí & E20 & 2 & 38,09 & 35,55 & 0 & 8,29 & 9,61 & 2 & 23,81 & 23,13 & 3 & 68,56 & 58,00 & 2 & 49,71 & 47,84 & 5 & 59,53 & 53,14 & 10 & 59 & 17,6 \\
\hline 355120 & Sarutaiá & E20 & 1 & 65,38 & 56,16 & 0 & 16,50 & 12,41 & 2 & 41,05 & 34,39 & 2 & 114,42 & 83,35 & 1 & 49,50 & 44,24 & 3 & 82,11 & 63,89 & 4 & 44 & 9,2 \\
\hline 355130 & Sebastianópolis do Sul & E20 & 1 & 51,07 & 32,54 & 1 & 53,32 & 41,27 & 1 & 52,17 & 36,81 & 1 & 76,61 & 91,33 & 1 & 53,32 & 42,00 & 2 & 65,21 & 67,19 & 0 & 14 & 2,3 \\
\hline 355140 & Serra Azul & E20 & 3 & 73,61 & 75,28 & 1 & 16,93 & 18,61 & 4 & 45,75 & 47,43 & 5 & 130,87 & 131,30 & 2 & 42,32 & 44,03 & 7 & 87,35 & 88,41 & 2 & 54 & 3,1 \\
\hline
\end{tabular}


Anexo 19 - Óbitos e taxa de mortalidade (bruta e padronizada) total e segundo sexo por Doenças Infecciosas e Parasitárias e Doenças Respiratórias e \% de óbitos por Causas Mal Definidas nos municípios. Estado de São Paulo, média do triênio, 2003-2005

\begin{tabular}{|c|c|c|c|c|c|c|c|c|c|c|c|c|c|c|c|c|c|c|c|c|c|c|c|}
\hline \multirow[b]{2}{*}{ IBGE } & \multirow[b]{2}{*}{ Mun. } & \multirow[b]{2}{*}{ Porte } & \multicolumn{9}{|c|}{ DOENCAS INFECCIOSAS E PARASITÁRIAS } & \multicolumn{9}{|c|}{ DOENCAS RESPIRATÓRIAS } & \multicolumn{3}{|c|}{ MAL DEFINIDAS } \\
\hline & & & Obitos & $\begin{array}{l}\text { Homens } \\
\text { TMB }\end{array}$ & TPM & Obitos & $\begin{array}{l}\text { Mulhe } \\
\text { TMB }\end{array}$ & TPM & Obitos & $\begin{array}{l}\text { Total } \\
\text { TMB } \\
\end{array}$ & TPM & Obitos & $\begin{array}{l}\text { Homens } \\
\text { TMB }\end{array}$ & TPM & Obitos $N$ & $\begin{array}{l}\text { Mulhere } \\
\text { TMB }\end{array}$ & TPM & Obitos & $\begin{array}{l}\text { Total } \\
\text { TMB } \\
\end{array}$ & TPM & Obitos & Ob.Totais & $\%$ \\
\hline 355160 & Serra Negra & D50 & 1 & 8,17 & 8,07 & 2 & 13,26 & 10,90 & 3 & 10,75 & 9,50 & 13 & 103,48 & 70,04 & 10 & 76,92 & 53,05 & 22 & 90,02 & 61,43 & 8 & 202 & \begin{tabular}{l|l}
2 & 3,8 \\
\end{tabular} \\
\hline 355150 & Serrana & C50 & 4 & 19,79 & 23,70 & 4 & 20,07 & 23,30 & 7 & 19,93 & 23,50 & 13 & 71,96 & 94,00 & 10 & 52,92 & 70,67 & 23 & 62,51 & 82,42 & 3 & 174 & \begin{tabular}{l|l}
4 & 1,5 \\
\end{tabular} \\
\hline 355170 & Sertaozinho & C300 & 20 & 38,49 & 39,59 & 12 & 23,68 & 25,14 & 32 & 31,12 & 32,40 & 34 & 66,55 & 72,95 & 27 & 53,94 & 59,98 & 61 & 60,27 & 66,49 & 7 & 560 & \begin{tabular}{l|l}
0 & 1,2 \\
\end{tabular} \\
\hline 355180 & Sete Barras & E20 & 1 & 8,95 & 8,59 & 1 & 19,62 & 21,63 & 2 & 14,04 & 14,81 & 4 & 53,72 & 50,92 & 5 & 68,66 & 82,46 & 9 & 60,85 & 65,97 & 10 & 77 & \begin{tabular}{l|l}
7 & 12,9 \\
\end{tabular} \\
\hline 355190 & 0 Severínia & E20 & 2 & 21,25 & 22,12 & 1 & 9,20 & 10,84 & 2 & 15,46 & 16,71 & 3 & 38,25 & 41,10 & 3 & 46,00 & 52,49 & 6 & 41,97 & 46,57 & 2 & 70 & \begin{tabular}{l|l}
0 & 2,9 \\
\end{tabular} \\
\hline 355200 & 0 Silveiras & E20 & 0 & 11,61 & 10,90 & - & 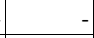 & & 0 & \begin{tabular}{l|}
5,97 \\
\end{tabular} & 5,60 & 1 & 34,82 & 25,92 & 1 & 24,56 & 24,49 & 2 & 29,84 & 25,22 & 7 & 33 & \begin{tabular}{l|l}
3 & 21,2 \\
\end{tabular} \\
\hline 355210 & 0 Socorro & D50 & 6 & 37,77 & 31,54 & 2 & 13,89 & 14,74 & 9 & 25,82 & 23,13 & 19 & 111,31 & 73,66 & 19 & 113,08 & 81,23 & 38 & 112,20 & $\begin{array}{l}77,45 \\
\end{array}$ & 9 & 288 & \begin{tabular}{l|l}
8 & 3,0 \\
\end{tabular} \\
\hline 355220 & Sorocaba & B1000 & 84 & 31,47 & 31,96 & 50 & 18,19 & 18,30 & 135 & 24,73 & 25,02 & 209 & 78,00 & 81,00 & 179 & 64,58 & 64,54 & 388 & 71,18 & 72,64 & 336 & 3314 & \begin{tabular}{l|l}
4 & 10,1 \\
\end{tabular} \\
\hline 355230 & Sud Mennucci & E20 & 0 & 8,79 & 8,02 & 1 & 36,58 & 37,99 & 2 & 22,41 & 22,71 & 1 & 35,16 & 32,85 & 3 & 73,16 & 74,43 & 4 & 53,79 & 53,23 & 5 & 41 & \begin{tabular}{l|l}
1 & 11,4 \\
\end{tabular} \\
\hline 355240 & Sumaré & C300 & 22 & 19,48 & 22,67 & 16 & 14,79 & 18,76 & 38 & \begin{tabular}{l|l|}
3 & 17,15 \\
\end{tabular} & 20,72 & 49 & 44,36 & 58,58 & 37 & 33,51 & 47,77 & 86 & 38,96 & 53,20 & 181 & 972 & $\begin{array}{ll}2 & 18,7 \\
\end{array}$ \\
\hline 355255 & Suzanápolis & E20 & 1 & 45,34 & 43,26 & 0 & 24,00 & 23,89 & 1 & 34,98 & 33,85 & 1 & 45,34 & 34,49 & 0 & 24,00 & 17,59 & 1 & 34,98 & 26,28 & 5 & 24 & \begin{tabular}{l|l}
4 & 20,5 \\
\end{tabular} \\
\hline 355250 & Suzano & C300 & 33 & 25,38 & 28,63 & 22 & 16,52 & 19,69 & 54 & 20,91 & 24,12 & 61 & 47,14 & 63,82 & 52 & 39,64 & 57,63 & 113 & 43,35 & 60,70 & 201 & 1338 & \begin{tabular}{l|l}
8 & 15,0 \\
\end{tabular} \\
\hline 355260 & Tabapua & E20 & 2 & 36,84 & 28,46 & 1 & 18,85 & 17,96 & 3 & 27,95 & 23,27 & 8 & 141,23 & 96,79 & 4 & 75,41 & 55,54 & 12 & 108,71 & 76,41 & 10 & 96 & \begin{tabular}{l|l}
6 & 10,4 \\
\end{tabular} \\
\hline 355270 & Tabatinga & E20 & 1 & 18,81 & 17,32 & 2 & 24,21 & 24,14 & 3 & 21,47 & 20,68 & 3 & 47,03 & 40,02 & 5 & 67,80 & 63,45 & 8 & 57,26 & 51,56 & 4 & 89 & \begin{tabular}{l|l}
9 & 4,5 \\
\end{tabular} \\
\hline 355280 & Taboao da Serra & C300 & 33 & 31,90 & 39,60 & 25 & 22,53 & 26,88 & 58 & \begin{tabular}{|l|l|}
3 & 27,05 \\
\end{tabular} & 33,02 & 68 & 65,41 & 99,26 & 64 & 57,37 & 85,66 & 131 & 61,25 & 92,22 & 24 & 1215 & 1,9 \\
\hline 355290 & Taciba & E20 & 1 & 24,12 & 27,39 & 0 & 12,49 & 11,63 & 1 & 18,41 & 19,65 & 2 & 60,30 & 52,42 & 1 & 49,97 & 47,64 & 3 & 55,22 & 50,07 & 7 & 33 & \begin{tabular}{l|l}
3 & 22,2 \\
\end{tabular} \\
\hline 355300 & Taguaí & E20 & 2 & 58,17 & 52,67 & 1 & 25,50 & 26,32 & 3 & 42,02 & 39,65 & 2 & 58,17 & 52,34 & 3 & 68,01 & 70,94 & 5 & 63,04 & 61,54 & 6 & 50 & \begin{tabular}{l|l}
0 & 12,8 \\
\end{tabular} \\
\hline 355310 & Taiaçu & E20 & 0 & 11,16 & 11,82 & 0 & 11,50 & 10,94 & 1 & 11,33 & 11,39 & 2 & 78,13 & 52,13 & 2 & 57,48 & 47,80 & 4 & 67,95 & 49,99 & 4 & 31 & \begin{tabular}{l|l}
1 & 11,7 \\
\end{tabular} \\
\hline 355320 & Taiúva & E20 & 1 & 23,64 & 13,95 & 0 & 11,85 & 13,36 & 1 & 17,75 & 13,65 & 3 & 106,36 & 75,29 & 2 & 71,09 & 44,90 & 5 & 88,75 & 60,12 & 4 & 46 & \begin{tabular}{l|l}
6 & 9,5 \\
\end{tabular} \\
\hline 355330 & Tambaú & D50 & 2 & 14,13 & 12,16 & 1 & 5,78 & 5,32 & 2 & 10,00 & 8,78 & 9 & 76,31 & 60,45 & 7 & 63,57 & 58,34 & 16 & 70,01 & 59,41 & 24 & 149 & \begin{tabular}{l|l}
9 & 15,8 \\
\end{tabular} \\
\hline 355340 & Tanabi & D50 & 4 & 32,10 & 23,18 & 2 & 14,31 & 10,62 & 5 & 23,12 & 16,84 & 14 & 119,63 & 80,22 & 10 & 83,02 & 60,93 & 23 & 101,15 & 70,49 & 28 & 170 & \begin{tabular}{l|l}
0 & 16,4 \\
\end{tabular} \\
\hline 355350 & Tapiraí & E20 & 1 & 26,32 & 24,51 & 0 & 6,99 & 5,40 & 2 & 16,94 & 15,24 & 2 & 39,48 & 39,68 & 3 & 55,91 & 64,17 & 5 & 47,44 & 51,56 & 5 & 45 & \begin{tabular}{l|l}
5 & 11,8 \\
\end{tabular} \\
\hline 355360 & Tapiratiba & D20 & 0 & 4,99 & 4,01 & 1 & 9,84 & 10,31 & 1 & 7,43 & 7,18 & 5 & 74,88 & 64,22 & 5 & 68,87 & 67,50 & 10 & 71,85 & 65,87 & 8 & 89 & \begin{tabular}{l|l}
9 & 8,6 \\
\end{tabular} \\
\hline 355365 & Taquaral & E20 & 1 & 45,37 & 41,65 & - & & & 1 & 23,40 & 21,48 & 1 & 90,74 & 76,62 & 1 & 48,31 & 45,23 & 2 & 70,19 & 61,42 & 0 & 18 & \begin{tabular}{l|l}
8 & 1,9 \\
\end{tabular} \\
\hline 355370 & Taquaritinga & D100 & 10 & 37,54 & 36,16 & 7 & 27,32 & 26,52 & 18 & 32,50 & 31,40 & 24 & 85,99 & 71,61 & 19 & 72,03 & 59,85 & 43 & 79,10 & 65,80 & 28 & 353 & \begin{tabular}{l|l}
3 & 7,9 \\
\end{tabular} \\
\hline 355380 & Taquarituba & E50 & 1 & 8,45 & 8,06 & 2 & 17,11 & 17,54 & 3 & $\mid 12,76$ & 12,77 & 7 & 59,17 & 54,17 & 7 & 62,74 & 64,48 & 14 & 60,94 & 59,29 & 26 & 154 & \begin{tabular}{l|l}
4 & 17,1 \\
\end{tabular} \\
\hline 355385 & Taquarivaí & E20 & 1 & 25,63 & 26,98 & 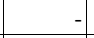 & & -1 & 1 & 13,08 & 13,77 & 2 & 76,90 & \begin{tabular}{|l|}
101,24 \\
\end{tabular} & 1 & 53,45 & 92,32 & 3 & 65,42 & 96,87 & 3 & 22 & \begin{tabular}{l|l}
2 & 13,4 \\
\end{tabular} \\
\hline 355390 & Tarabaí & E20 & - & & & 0 & \begin{tabular}{|l|}
10,78 \\
\end{tabular} & 11,68 & 0 & \begin{tabular}{|l|}
5,32 \\
\end{tabular} & 5,76 & 2 & 73,51 & 59,20 & 1 & 32,35 & 33,29 & 3 & 53,20 & 46,42 & 4 & 38 & \begin{tabular}{l|l}
8 & 10,6 \\
\end{tabular} \\
\hline 355395 & Taruma & D20 & 2 & 28,85 & 33,19 & 0 & 6,07 & 5,76 & 2 & 17,75 & 19,83 & 3 & 57,70 & 67,44 & 3 & 48,58 & 60,25 & 6 & 53,26 & 63,94 & 10 & 64 & \begin{tabular}{l|l}
4 & 15,0 \\
\end{tabular} \\
\hline 355400 & Tatuí & C300 & 19 & 36,85 & 37,11 & 9 & 17,63 & 17,56 & 28 & 27,20 & 27,30 & 59 & 116,47 & \begin{tabular}{|l|}
$\mid 107,24$ \\
\end{tabular} & 58 & 113,63 & 109,39 & 117 & 115,04 & $\mid 108,32$ & 72 & 703 & \begin{tabular}{l|l}
3 & 10,2 \\
\end{tabular} \\
\hline 355410 & Taubaté & B300 & 48 & 37,10 & 37,34 & 24 & 18,14 & 18,09 & 72 & 27,48 & 27,58 & 113 & 87,94 & 91,82 & 104 & 78,87 & 77,90 & 217 & 83,34 & 84,76 & 28 & 1595 & \begin{tabular}{l|l}
5 & 1,8 \\
\end{tabular} \\
\hline 355420 & Tejupá & E20 & 0 & 11,31 & 10,62 & 1 & 37,60 & 39,13 & 1 & $|23,78|$ & 24,14 & 1 & 45,25 & 59,24 & 0 & 12,53 & 12,11 & 2 & 29,73 & 36,88 & 6 & 35 & \begin{tabular}{l|l|}
5 & 17,3 \\
\end{tabular} \\
\hline
\end{tabular}


Anexo 19 - Óbitos e taxa de mortalidade (bruta e padronizada) total e segundo sexo por Doenças Infecciosas e Parasitárias e Doenças Respiratórias e \% de óbitos por Causas Mal Definidas nos municípios. Estado de São Paulo, média do triênio, 2003-2005

\begin{tabular}{|c|c|c|c|c|c|c|c|c|c|c|c|c|c|c|c|c|c|c|c|c|c|c|c|}
\hline \multirow[b]{2}{*}{ IBGE } & \multirow[b]{2}{*}{ Mun. } & \multirow[b]{2}{*}{ Porte } & \multicolumn{9}{|c|}{$\begin{array}{l}\text { DOENCAS INFECCIOSAS E PARASITÁRIAS } \\
\text { Hums }\end{array}$} & \multicolumn{9}{|c|}{ DOENCAS RESPIRATÓRIAS } & \multicolumn{3}{|c|}{ MAL DEFINIDAS } \\
\hline & & & Obitos & $\begin{array}{l}\text { Homens } \\
\text { TMB }\end{array}$ & TPM & Obitos & $\begin{array}{l}\text { Mulheres } \\
\text { TMB }\end{array}$ & TPM & Obitos & $\begin{array}{l}\text { Total } \\
\text { TMB }\end{array}$ & TPM & Obitos & $\begin{array}{l}\text { Homens } \\
\text { TMB }\end{array}$ & TPM & Obitos $N$ & $\begin{array}{l}\text { Mulheres } \\
\text { TMB }\end{array}$ & TPM & Obitos & $\begin{array}{l}\text { Total } \\
\text { TMB } \\
\end{array}$ & TPM & Obitos & Ob.Totais & $\%$ \\
\hline 355430 & Teodoro Sampaio & D50 & 2 & 19,47 & 19,81 & 2 & \begin{tabular}{|l|}
2 \\
\end{tabular} & 22,11 & 4 & 19,53 & 20,96 & 8 & \begin{tabular}{|r|}
77,89 \\
\end{tabular} & 73,26 & 7 & 65,31 & 83,15 & 15 & 71,62 & 78,19 & 24 & 120 & 20,0 \\
\hline 355440 & Terra Roxa & E20 & 1 & 31,69 & 26,77 & 1 & \begin{tabular}{l|l|}
1 & 16,48 \\
\end{tabular} & 15,06 & 2 & 24,23 & 21,03 & 4 & 102,99 & 89,84 & 1 & 32,96 & 29,37 & 6 & 68,66 & 60,20 & 6 & 50 & 12,8 \\
\hline 355450 & Tietê & B50 & 5 & 27,04 & 25,73 & 3 & \begin{tabular}{l|l|} 
& 15,24 \\
\end{tabular} & 14,15 & 7 & 21,10 & 19,90 & 8 & 44,42 & 35,58 & 8 & 43,81 & 33,89 & 15 & 44,11 & 34,73 & 22 & 230 & 9,6 \\
\hline 355460 & Timburi & E20 & - & & & 0 & 25,65 & 15,91 & 0 & 12,46 & 7,73 & 1 & 48,45 & 28,12 & 1 & 51,30 & 31,82 & 1 & 49,83 & 29,92 & 4 & 22 & 16,9 \\
\hline 355465 & Torre de Pedra & E20 & 0 & 25,82 & 20,82 & 0 & \begin{tabular}{|l|} 
\\
\end{tabular} & 21,80 & 1 & 26,16 & 21,31 & 1 & \begin{tabular}{|l|}
103,28 \\
\end{tabular} & 58,50 & 1 & 79,51 & 64,67 & 2 & 91,55 & 61,54 & 1 & 19 & 3,6 \\
\hline 355470 & Torrinha & E20 & 1 & 27,89 & 28,77 & 1 & $\begin{array}{l}1 \quad 21,50 \\
\end{array}$ & 18,73 & 2 & 24,74 & 23,82 & 4 & \begin{tabular}{|r|}
76,69 \\
\end{tabular} & 46,30 & 6 & 129,00 & 88,68 & 10 & 102,49 & 67,20 & 6 & 66 & 9,6 \\
\hline 355475 & Trabiju & E20 & 0 & 44,11 & 48,90 & - & - & & 0 & 23,19 & 25,71 & 0 & 44,11 & 32,64 & 1 & 146,70 & 155,48 & 1 & 92,76 & 90,90 & 1 & 8 & 16,7 \\
\hline 355480 & Tremembé & B50 & 5 & 26,92 & 30,38 & 3 & \begin{tabular}{l|l|}
3 & 14,61 \\
\end{tabular} & 16,64 & 8 & 21,02 & 23,79 & 11 & 57,21 & 68,57 & 11 & 58,44 & 65,96 & 22 & 57,80 & 67,32 & 11 & 191 & 5,9 \\
\hline 355490 & Três Fronteiras & E20 & 0 & 12,81 & 6,96 & 2 & \begin{tabular}{|l|l|}
277,80 \\
\end{tabular} & 70,45 & 2 & 45,11 & 38,51 & 1 & 38,44 & 23,83 & 2 & 64,83 & 45,64 & 3 & 51,56 & 34,67 & 5 & 35 & 13,3 \\
\hline 355495 & Tuiuti & E20 & 1 & 24,22 & 19,31 & & & & 1 & 12,48 & 9,95 & 1 & 48,45 & 36,86 & 2 & 90,10 & 74,97 & 4 & 68,64 & 55,34 & 1 & 37 & 2,7 \\
\hline 355500 & Tupa & D100 & 9 & 28,37 & 24,83 & 7 & $\begin{array}{l}7 \quad 21,96 \\
\end{array}$ & 18,04 & 16 & 25,08 & 21,35 & 35 & $\mid 110,32$ & 78,21 & 25 & 73,86 & 52,99 & 60 & 91,62 & 65,27 & 70 & 530 & 13,3 \\
\hline 355510 & Tupi Paulista & D20 & 2 & 26,06 & 15,72 & 2 & \begin{tabular}{|l|}
2 \\
20,53 \\
\end{tabular} & 22,97 & 4 & 28,32 & 19,39 & 7 & $\mid 114,65$ & 65,13 & 4 & 66,15 & 44,75 & 12 & 90,11 & 54,82 & 14 & 113 & 12,4 \\
\hline 355520 & Turiúba & E20 & 1 & 107,95 & 86,34 & 1 & $\begin{array}{l}1 \quad 75,41 \\
\end{array}$ & 48,24 & 2 & 92,06 & 67,73 & 0 & \begin{tabular}{|r|}
35,98 \\
\end{tabular} & 20,98 & 0 & 37,71 & 24,12 & 1 & 36,83 & 22,51 & 1 & 11 & 6,3 \\
\hline 355530 & Turmalina & E20 & - & & & 0 & \begin{tabular}{|l|} 
\\
\end{tabular} & 22,75 & 0 & 15,19 & 11,35 & 1 & 90,94 & 52,35 & 1 & 60,90 & 45,50 & 2 & 75,95 & 48,93 & 3 & 15 & 20,0 \\
\hline 355535 & Ubarana & E20 & 1 & 39,55 & 43,60 & & & & 1 & 20,68 & 22,80 & 2 & 79,09 & 76,99 & 1 & 43,34 & 49,85 & 3 & 62,03 & 64,04 & 2 & 23 & 7,1 \\
\hline 355540 & Ubatuba & C100 & 13 & 33,94 & 38,06 & 7 & 19,68 & 22,66 & 20 & 26,91 & 30,47 & 23 & 59,18 & 76,55 & 19 & 51,89 & 72,55 & 42 & 55,59 & 74,58 & 45 & 402 & 11,3 \\
\hline 355550 & Ubirajara & E20 & 0 & 15,64 & 14,47 & 1 & 66,19 & 59,12 & 2 & 40,20 & 36,16 & 3 & 140,73 & 108,46 & 1 & 49,64 & 36,37 & 4 & 96,48 & 73,43 & 1 & 30 & 4,4 \\
\hline 355560 & Uchoa & D20 & 1 & 28,38 & 20,10 & 1 & $\begin{array}{r}21,49 \\
\end{array}$ & 15,93 & 2 & 24,96 & 18,02 & 7 & \begin{tabular}{|l|}
156,12 \\
\end{tabular} & 100,38 & 7 & 157,63 & 100,14 & 15 & $\mid 156,87$ & \begin{tabular}{|l|}
100,26 \\
\end{tabular} & 4 & 72 & 5,6 \\
\hline 355570 & Uniao Paulista & E20 & 0 & 46,88 & 36,02 & - & & & 0 & 24,44 & 18,78 & 1 & 93,76 & 60,50 & & & & 1 & 48,88 & 31,53 & 2 & 6 & 27,8 \\
\hline 355580 & Urânia & E20 & 1 & 22,56 & 20,55 & 2 & 45,17 & 37,92 & 3 & 33,86 & $29,24 \mid$ & 5 & 112,82 & 64,35 & 3 & 75,28 & 56,69 & 8 & 94,06 & 60,52 & 10 & 72 & 14,3 \\
\hline 355590 & Uru & E20 & 1 & 89,49 & 89,29 & 0 & $\begin{array}{l}49,02 \\
\end{array}$ & 39,23 & 1 & 70,18 & 65,40 & 2 & 223,71 & 121,30 & 1 & 98,04 & 91,75 & 2 & $\mid 163,74$ & $|107,20|$ & 3 & 14 & 21,4 \\
\hline 355600 & Urupês & E20 & 3 & 48,76 & 33,87 & 1 & 16,54 & 15,05 & 4 & 32,79 & 24,54 & 9 & $\mid 146,29$ & 92,36 & 5 & 77,18 & 50,63 & 14 & 112,04 & 71,67 & 7 & 96 & 7,0 \\
\hline 355610 & Valentim Gentil & D20 & 1 & 26,71 & 21,93 & 2 & 34,58 & 32,06 & 3 & 30,57 & 26,91 & 6 & 120,18 & 96,95 & 2 & 41,49 & 38,33 & 8 & 81,53 & 68,16 & 8 & 60 & 12,8 \\
\hline 355620 & Valinhos & B100 & 10 & 23,11 & 21,51 & 7 & 14,82 & 14,49 & 17 & 18,95 & 17,99 & 35 & 77,52 & 70,00 & 20 & 45,19 & 43,56 & 55 & 61,31 & 56,74 & 37 & 484 & 7,6 \\
\hline 355630 & Valparaíso & D20 & 5 & 48,92 & 45,82 & 2 & 25,21 & 24,22 & 7 & 37,65 & 35,56 & 10 & 101,10 & 89,23 & 5 & 50,42 & 46,86 & 15 & 77,02 & 69,09 & 24 & 123 & 19,8 \\
\hline 355635 & Vargem & E20 & 1 & 16,49 & 14,23 & 1 & $\begin{array}{l}17,48 \\
\end{array}$ & 16,50 & 1 & 16,98 & 15,33 & 6 & 140,21 & 100,00 & 3 & 87,42 & 71,08 & 9 & 114,58 & 85,96 & & 49 & \\
\hline 355640 & Vargem Grande do Sul & D50 & 7 & 38,02 & 36,74 & 2 & 12,03 & 10,95 & 10 & 24,98 & 23,81 & 19 & \begin{tabular}{|r|}
98,50 \\
\end{tabular} & 80,46 & 10 & 51,54 & 46,09 & 29 & 74,95 & 63,22 & 24 & 257 & 9,5 \\
\hline 355645 & Vargem Grande Paulista & C50 & 4 & 19,87 & 23,86 & 4 & \begin{tabular}{|l|} 
\\
\end{tabular} & 22,61 & 8 & 19,07 & 23,24 & 11 & 52,98 & 75,44 & 9 & 43,20 & 67,94 & 19 & 48,10 & 71,70 & 6 & 192 & 3,1 \\
\hline 355650 & Várzea Paulista & C300 & 10 & 19,25 & 21,64 & 6 & 11,65 & 15,95 & 16 & 15,46 & 18,81 & 26 & 49,41 & 68,37 & 21 & 40,76 & 61,29 & 47 & 45,10 & 64,84 & 4 & 432 & 1,0 \\
\hline 355660 & Vera Cruz & E20 & 2 & 36,19 & 29,75 & 1 & 11,96 & 10,58 & 3 & 24,03 & 20,12 & 4 & | 72,39 & 46,02 & 4 & 65,80 & 45,88 & 8 & 69,08 & 45,95 & 12 & 83 & 14,0 \\
\hline 355670 & Vinhedo & A100 & 7 & 25,14 & 23,98 & 5 & 18,68 & 18,41 & 12 & 21,89 & 21,18 & 17 & 65,36 & 61,90 & 16 & 58,52 & 58,70 & 33 & 61,92 & 60,29 & 26 & 293 & 9,0 \\
\hline 355680 & Viradouro & D20 & 2 & 19,11 & 16,59 & 1 & 11,73 & 11,41 & 3 & 15,46 & 14,03 & 10 & 110,84 & 98,59 & 4 & 43,02 & 41,05 & 13 & 77,32 & 70,15 & 12 & 109 & 11,3 \\
\hline
\end{tabular}


Anexo 19 - Óbitos e taxa de mortalidade (bruta e padronizada) total e segundo sexo por Doenças Infecciosas e Parasitárias e Doenças Respiratórias e \% de óbitos por Causas Mal Definidas nos municípios. Estado de São Paulo, média do triênio, 2003-2005

\begin{tabular}{|c|c|c|c|c|c|c|c|c|c|c|c|c|c|c|c|c|c|c|c|c|c|c|c|}
\hline \multirow[b]{2}{*}{ BGE } & \multirow[b]{2}{*}{ Mun. } & \multirow[b]{2}{*}{ Porte } & \multicolumn{9}{|c|}{ DOENCAS INFECCIOSAS E PARASITÁRIAS } & \multicolumn{9}{|c|}{ DOENCAS RESPIRATÓRIAS } & \multicolumn{3}{|c|}{ MAL DEFINIDAS } \\
\hline & & & Obitos & $\begin{array}{l}\text { Homens } \\
\text { TMB } \\
\end{array}$ & TPM & Obitos & $\begin{array}{l}\text { Mulheres } \\
\text { TMB }\end{array}$ & $\begin{array}{l}\text { s } \\
\text { TPM } \\
\end{array}$ & Obitos & $\begin{array}{l}\text { Total } \\
\text { TMB } \\
\end{array}$ & TPM & Obitos & $\begin{array}{l}\text { Homens } \\
\text { TMB }\end{array}$ & TPM & Obitos $N$ & $\begin{array}{l}\text { Mulheres } \\
\text { TMB }\end{array}$ & TPM & Obitos & $\begin{array}{l}\text { Total } \\
\text { TMB }\end{array}$ & TPM & Obitos & Ob.Totais & $\%$ \\
\hline 355690 & Vista Alegre do Alto & D20 & 0 & 12,62 & 12,48 & 0 & \begin{tabular}{|l|}
12,72 \\
\end{tabular} & 10,81 & 1 & 12,67 & 11,65 & 2 & 88,32 & 63,59 & 1 & 38,15 & 39,45 & 3 & 63,34 & 51,57 & 1 & 27 & 2,4 \\
\hline 355695 & Vitória Brasil & E20 & & & & & & & & & & & & & & & & & & & 4 & 10 & 40,0 \\
\hline 355700 & Votorantim & B300 & 13 & 25,36 & 26,51 & 10 & \begin{tabular}{|l|}
20,08 \\
\end{tabular} & 22,70 & 23 & 22,72 & 24,60 & 30 & 59,18 & 69,22 & 24 & 47,29 & 59,67 & 55 & 53,22 & 64,43 & 55 & 562 & 9,8 \\
\hline 355710 & Votuporanga & C100 & 21 & 52,29 & 44,83 & 13 & \begin{tabular}{|l|l|}
3 & 31,69 \\
\end{tabular} & 27,55 & 34 & 41,80 & 36,03 & 37 & 92,77 & 72,08 & 32 & 77,19 & 64,82 & 68 & 84,83 & 68,38 & 28 & 553 & 5,0 \\
\hline 355715 & Zacarias & E20 & - & & & 0 & 35,49 & 30,33 & 0 & 17,14 & 14,65 & 1 & 66,29 & 49,43 & 0 & 35,49 & 30,33 & 1 & 51,41 & 40,21 & 2 & 11 & 14,7 \\
\hline & Estado & & 6264 & 32,39 & 32,35 & 4002 & 19,89 & 19,87 & 10266 & 26,01 & 25,98 & 14855 & 76,81 & 77,25 & 12327 & 61,25 & 62,08 & 27183 & 68,88 & 69,51 & 15142 & 238250 & 6,4 \\
\hline
\end{tabular}

Fonte: SIM/ MS, Censo IBGE e Estratos de Vulnerabilidade Social segundo metodologia desenvolvida a partir do IPVS (FSEADE 2005)

Nota ${ }^{1}: \quad$ ( - ) Dado numérico igual a 0 não resultante de arredondamento

$(0 ; 0,0 ; 0,00)$ Dado numérico igual a zero resultante de arredondamento de um dado originalmente positivo

A soma das parcelas pode não coincidir com o total em função de arredondamentos efetuados nos dados parciais

Códigos R00 a R99:Mal Definidas: Cap. XVIII - "Sintomas, Sinais e Achados Anormais de Exames Clínicos e de Laboratório Não Classificados em Outra Parte" ( CID 10)

Códigos: J00 a J99: Doenças Respiratórias (Cap. X-CID 10),

Códigos A00 a B99 - Algumas Doenças Infecciosas e Parasitárias (Cap. I-CID 10) 
Anexo 20 - Óbitos e taxas de mortalidade (bruta e padronizada) total e segundo sexo por Diabetes Melittus (por 100 mil hab.), mediana, desvio padrão, e razão de taxas nos conjuntos de municípios e respectivos estratos de vulnerabilidade social. Estado de São Paulo, média do triênio 2003 a 2005

\begin{tabular}{|c|c|c|c|c|c|c|c|c|c|c|c|c|c|c|}
\hline \multirow[b]{2}{*}{ Status } & \multicolumn{3}{|c|}{ Homens } & \multicolumn{3}{|c|}{ Mulheres } & \multicolumn{4}{|c|}{ Total } & \multirow{2}{*}{$\begin{array}{l}\text { Desvio } \\
\text { padrão }\end{array}$} & \multirow{2}{*}{$\begin{array}{l}\text { Valor } \\
\text { Máximo }^{1}\end{array}$} & \multirow[b]{2}{*}{ Valor Minimo ${ }^{2}$} & \multirow{2}{*}{$\begin{array}{c}\text { Razão } \\
(1 / 2)\end{array}$} \\
\hline & Óbitos & TMB & TMP & Óbitos & TMB & TMP & Óbitos & TMB & TMP & Mediana & & & & \\
\hline A20 & 6 & 29,38 & 23,22 & 6 & 33,33 & 30,40 & 12 & 31,34 & 26,81 & 25,53 & 21,19 & 66,72 & 9,70 & 6,88 \\
\hline A100 & 2 & 8,80 & 8,37 & 3 & 12,45 & 12,74 & 6 & 10,63 & 10,55 & $x$ & $\mathrm{x}$ & $x$ & $x$ & $x$ \\
\hline A300 & 55 & 21,65 & 16,26 & 84 & 30,96 & 22,57 & 139 & 26,45 & 19,49 & 21,44 & 5,16 & 24,26 & 14,25 & 1,70 \\
\hline A500 & 84 & 23,28 & 16,47 & 93 & 23,48 & 15,81 & 177 & 23,39 & 16,02 & 15,71 & 4,18 & 18,66 & 12,75 & 1,46 \\
\hline A1000 & 55 & 17,25 & 15,22 & 76 & 22,16 & 19,09 & 131 & 19,79 & 17,21 & $x$ & $\mathrm{x}$ & $x$ & $\mathrm{x}$ & $x$ \\
\hline Estrato A & 202 & 20,61 & 15,92 & 263 & 24,86 & 18,79 & 465 & 22,82 & 17,36 & 18,66 & 15,78 & 66,72 & 9,70 & 6,88 \\
\hline B20 & 9 & 24,27 & 20,59 & 11 & 29,08 & 24,18 & 20 & 26,65 & 22,27 & 14,23 & 12,73 & 39,46 & 6,84 & 5,77 \\
\hline B50 & 61 & 22,86 & 21,05 & 76 & 28,52 & 27,24 & 136 & 25,69 & 24,14 & 22,55 & 9,49 & 38,74 & 11,83 & 3,27 \\
\hline B100 & 123 & 19,24 & 17,56 & 167 & 25,60 & 23,57 & 290 & 22,45 & 20,58 & 17,85 & 6,65 & 33,77 & 12,66 & 2,67 \\
\hline B300 & 365 & 19,42 & 18,98 & 482 & 24,97 & 24,74 & 847 & 22,23 & 21,90 & 20,37 & 8,37 & 39,24 & 12,71 & 3,09 \\
\hline B500 & 187 & 18,40 & 18,08 & 239 & 22,59 & 21,85 & 426 & 20,54 & 20,00 & 20,20 & 6,00 & 28,49 & 13,07 & 2,18 \\
\hline B1000 & 260 & 17,10 & 19,54 & 296 & 18,51 & 21,20 & 556 & 17,82 & 20,37 & 20,24 & 4,81 & 25,21 & 13,15 & 1,92 \\
\hline B10000 & 1075 & 19,07 & 19,04 & 1275 & 20,66 & 19,25 & 2350 & 19,90 & 19,07 & 16,39 & 4,58 & 19,63 & 13,15 & 1,49 \\
\hline Estrato B & 2080 & 18,91 & 18,98 & 2545 & 21,73 & 21,09 & 4626 & 20,37 & 20,02 & 19,71 & 8,44 & 39,46 & 6,84 & 5,77 \\
\hline $\mathrm{C} 20$ & 13 & 13,70 & 13,66 & 22 & 23,79 & 25,59 & 35 & 18,64 & 19,41 & 16,96 & 11,34 & 41,64 & 5,77 & 7,22 \\
\hline C50 & 91 & 19,45 & 19,88 & 122 & 26,29 & 29,31 & 213 & 22,85 & 24,44 & 22,46 & 7,40 & 39,85 & 10,88 & 3,66 \\
\hline C100 & 116 & 20,07 & 22,74 & 144 & 25,00 & 29,69 & 260 & 22,54 & 26,23 & 24,95 & 8,37 & 41,34 & 13,91 & 2,97 \\
\hline C300 & 258 & 14,66 & 19,75 & 331 & 18,53 & 25,38 & 589 & 16,61 & 22,58 & 23,45 & 6,99 & 38,22 & 8,37 & 4,57 \\
\hline C500 & 98 & 13,56 & 21,19 & 116 & 15,58 & 25,94 & 214 & 14,59 & 23,62 & 25,95 & 5,18 & 26,85 & 15,99 & 1,68 \\
\hline C10000 & 91 & 15,42 & 22,17 & 105 & 17,22 & 25,41 & 196 & 16,33 & 23,83 & $\mathrm{x}$ & $\mathrm{x}$ & $\mathrm{x}$ & $\mathrm{x}$ & $\mathrm{x}$ \\
\hline Estrato C & 667 & 15,83 & 20,62 & 840 & 19,65 & 26,49 & 1507 & 17,76 & 23,57 & 22,46 & 8,32 & 41,64 & 5,77 & 7,22 \\
\hline D20 & 78 & 18,40 & 15,78 & 120 & 28,98 & 27,15 & 198 & 23,62 & 21,21 & 20,20 & 12,04 & 63,38 & 0,00 & * \\
\hline D50 & 199 & 20,26 & 17,78 & 319 & 32,72 & 30,57 & 518 & 26,48 & 24,00 & 23,78 & 8,30 & 47,54 & 6,12 & 7,77 \\
\hline D100 & 89 & 20,25 & 17,69 & 121 & 27,51 & 24,80 & 210 & 23,89 & 21,23 & 19,11 & 6,72 & 33,30 & 12,34 & 2,70 \\
\hline D300 & 11 & 14,57 & 27,95 & 13 & 16,62 & 33,44 & 24 & 15,60 & 30,81 & $x$ & $\mathrm{x}$ & $x$ & $\mathrm{x}$ & $x$ \\
\hline Estrato D & 377 & 19,62 & 17,73 & 573 & 30,05 & 28,62 & 950 & 24,82 & 23,03 & 21,50 & 10,21 & 63,38 & 0,00 & * \\
\hline E20 & 196 & 20,27 & 16,59 & 283 & 30,63 & 27,08 & 479 & 25,35 & 21,45 & 19,54 & 14,01 & 79,19 & 0,00 & * \\
\hline E50 & 55 & 24,49 & 23,41 & 69 & 31,91 & 33,86 & 124 & 28,14 & 28,35 & 28,44 & 10,95 & 45,87 & 9,40 & 4,88 \\
\hline E100 & 7 & 18,20 & 18,45 & 6 & 17,37 & 21,60 & 13 & 17,80 & 19,83 & $x$ & $x$ & $x$ & $x$ & $x$ \\
\hline Estrato $\mathrm{E}$ & 257 & 20,98 & 17,88 & 358 & 30,48 & 28,17 & 616 & 25,64 & 22,67 & 20,52 & 13,91 & 79,19 & 0,00 & * \\
\hline Estado & 3583 & 18,53 & 18,99 & 4579 & 22,75 & 23,24 & 8163 & 20,68 & 21,10 & 20,92 & 11,93 & 79,19 & 0,00 & * \\
\hline
\end{tabular}

Fonte: SIM/ MS, Censo IBGE e Estratos de Vulnerabilidade Social segundo metodologia desenvolvida a partir do IPVS (FSEADE 2005)

Nota ${ }^{1}:$

( - ) Dado numérico igual a 0 não resultante de arredondamento

$(0 ; 0,0 ; 0,00)$ Dado numérico igual a zero resultante de arredondamento de um dado originalmente positivo

A soma das parcelas pode não coincidir com o total em função de arredondamentos efetuados nos dados parciais

(x) Não se aplica (conjunto formado por um só município)

${ }^{(*)}$ Não divisível

Diabetes Mellitus - Códigos E10-E14.CID 10 (Cap. IV - Doenças Endócrinas, Nutricionais e Metabólicas, ) 
Anexo 21 - Óbitos e taxas de mortalidade (bruta e padronizada) total e segundo sexo por Doenças do Aparelho Circulatório (por 100 mil hab.), mediana, desvio padrão e razão de taxas nos conjuntos de municípios e respectivos estratos de vulnerabilidade social. Estado de São Paulo, média do triênio 2003 a 2005

\begin{tabular}{|c|c|c|c|c|c|c|c|c|c|c|c|c|c|c|}
\hline PORTE & Óbitos & Homens & TMP & Óbitos & Mulhere & TMP & Óbitos & TMB & TMP & Mediana & $\begin{array}{l}\text { Total } \\
\text { Desvio } \\
\text { padrão }\end{array}$ & $\begin{array}{c}\text { Valor } \\
\text { Máximo }^{1} \\
\end{array}$ & $\begin{array}{c}\text { Valor } \\
\text { Minimo }^{2}\end{array}$ & Razão (1/2) \\
\hline $\mathrm{A} 20$ & 37 & 190,08 & 153,03 & 33 & 175,42 & 168,36 & 70 & 182,81 & 160,64 & 158,43 & 8,46 & 166,56 & 145,70 & 1,14 \\
\hline A100 & 41 & 154,61 & 140,17 & 37 & 139,44 & 139,54 & 78 & 146,99 & 139,85 & $x$ & $x$ & $x$ & $x$ & $x$ \\
\hline $\mathrm{A} 300$ & 642 & 252,71 & 182,21 & 599 & 221,79 & 154,67 & 1241 & 236,77 & 168,01 & 190,63 & 45,41 & 204,86 & 120,06 & 1,71 \\
\hline $\mathrm{A} 500$ & 912 & 253,75 & 181,55 & 858 & 215,87 & 144,02 & 1770 & 233,86 & 161,84 & 164,02 & 29,27 & 184,72 & 143,32 & 1,29 \\
\hline A1000 & 801 & 249,79 & 216,60 & 727 & 212,06 & 183,59 & 1529 & 230,30 & 199,54 & $x$ & $x$ & $\mathrm{x}$ & $x$ & $x$ \\
\hline Estrato A & 2433 & 248,25 & 191,52 & 2255 & 213,48 & 159,91 & 4688 & 230,22 & 175,12 & 163,10 & 25,19 & 204,86 & 120,06 & 1,71 \\
\hline B20 & 81 & 209,76 & 166,54 & 78 & 207,08 & 172,22 & 159 & 208,43 & 169,36 & 161,02 & 45,53 & 227,90 & 93,70 & 2,43 \\
\hline $\mathrm{B} 50$ & 534 & 201,09 & 175,75 & 474 & 178,77 & 168,93 & 1008 & 189,93 & 172,34 & 165,84 & 28,61 & 212,14 & 135,53 & 1,57 \\
\hline $\mathrm{B} 100$ & 1311 & 205,07 & 178,77 & 1163 & 177,86 & 158,57 & 2474 & 191,31 & 168,56 & 174,59 & 30,64 & 224,73 & 122,42 & 1,84 \\
\hline B300 & 3393 & 180,49 & 168,03 & 3058 & 158,42 & 153,13 & 6451 & 169,31 & 160,48 & 169,38 & 30,49 & 221,40 & 116,56 & 1,90 \\
\hline B500 & 1896 & 186,89 & 179,03 & 1708 & 161,47 & 155,53 & 3604 & 173,91 & 167,03 & 162,48 & 37,30 & 230,87 & 127,08 & 1,82 \\
\hline B1000 & 2746 & 180,40 & 201,22 & 2489 & 155,86 & 178,16 & 5236 & 167,83 & 189,41 & 173,21 & 40,53 & 241,97 & 137,05 & 1,77 \\
\hline $\mathrm{B} 10000$ & 11995 & 212,71 & 205,42 & 11527 & 186,79 & 171,30 & 23522 & 199,17 & 187,59 & 178,60 & 15,37 & 189,47 & 167,73 & 1,13 \\
\hline Estrato B & 21955 & 199,61 & 193,61 & 20498 & 175,00 & 167,06 & 42453 & 186,92 & 179,92 & 167,29 & 32,46 & 241,97 & 93,70 & 2,58 \\
\hline $\mathrm{C} 20$ & 180 & 190,10 & 177,24 & 149 & 163,98 & 165,85 & 330 & 177,30 & 171,66 & 168,47 & 35,81 & 211,10 & 92,63 & 2,28 \\
\hline $\mathrm{C} 50$ & 875 & 186,28 & 193,05 & 716 & 154,72 & 174,86 & 1591 & 170,61 & 184,02 & 179,39 & 33,77 & 258,17 & 133,53 & 1,93 \\
\hline $\mathrm{C} 100$ & 1098 & 190,62 & 205,51 & 899 & 155,69 & 188,45 & 1997 & 173,14 & 196,97 & 201,82 & 38,54 & 253,30 & 134,42 & 1,88 \\
\hline $\mathrm{C} 300$ & 2834 & 161,01 & 215,46 & 2405 & 134,49 & 195,56 & 5239 & 147,64 & 205,43 & 204,16 & 51,81 & 274,12 & 117,90 & 2,33 \\
\hline $\mathrm{C} 500$ & 1076 & 148,87 & 225,38 & 910 & 122,30 & 204,20 & 1986 & 135,39 & 214,63 & 215,25 & 31,57 & 248,74 & 172,42 & 1,44 \\
\hline $\mathrm{C} 10000$ & 1028 & 174,22 & 247,07 & 905 & 148,44 & 222,05 & 1933 & 161,12 & 234,35 & $x$ & $x$ & $x$ & $x$ & $x$ \\
\hline Estrato C & 7091 & 168,30 & 216,87 & 5985 & 140,04 & 197,01 & 13076 & 154,07 & 206,87 & 187,38 & 42,28 & 274,12 & 92,63 & 2,96 \\
\hline D20 & 886 & 208,96 & 171,71 & 713 & 172,62 & 163,41 & 1598 & 191,03 & 167,62 & 162,82 & 39,54 & 247,88 & 63,77 & 3,89 \\
\hline D50 & 2166 & 220,91 & 185,75 & 1872 & 191,86 & 178,80 & 4038 & 206,41 & 182,28 & 178,49 & 33,82 & 292,98 & 113,81 & 2,57 \\
\hline D100 & 802 & 183,23 & 151,58 & 763 & 173,49 & 152,06 & 1565 & 178,35 & 151,82 & 154,60 & 29,25 & 201,21 & 92,82 & 2,17 \\
\hline D300 & 111 & 142,66 & 250,64 & 83 & 106,14 & 209,03 & 194 & 124,35 & 229,78 & 229,78 & $x$ & $\mathrm{x}$ & $x$ & $x$ \\
\hline Estrato D & 3965 & 206,51 & 177,49 & 3431 & 179,94 & 170,54 & 7396 & 193,27 & 174,03 & 166,80 & 37,73 & 292,98 & 63,77 & 4,59 \\
\hline E20 & 2229 & 230,55 & 174,16 & 1768 & 191,40 & 172,19 & 3997 & 211,42 & 173,20 & 163,23 & 46,71 & 422,94 & 49,27 & 8,58 \\
\hline E50 & 462 & 207,10 & 194,36 & 352 & 162,79 & 181,03 & 814 & 185,30 & 187,80 & 199,90 & 32,18 & 231,75 & 116,53 & 1,99 \\
\hline E100 & 45 & 123,77 & 128,85 & 34 & 99,38 & 133,36 & 80 & 111,93 & 131,04 & 131,04 & $x$ & $x$ & $x$ & $x$ \\
\hline Estrato $\mathrm{E}$ & 2737 & 223,10 & 176,49 & 2155 & 183,43 & 172,67 & 4891 & 203,69 & 174,62 & 163,58 & 46,25 & 422,94 & 49,27 & 8,58 \\
\hline Estado & 38181 & 197,43 & 195,89 & 34324 & 170,55 & 173,70 & 72505 & 183,72 & 184,57 & 166,96 & 42,60 & 422,94 & 49,27 & 8,58 \\
\hline
\end{tabular}

Fonte: SIM/ MS, Censo IBGE e Estratos de Vulnerabilidade Social segundo metodologia desenvolvida a partir do IPVS (FSEADE 2005)

Nota $^{1}$ : ( - ) Dado numérico igual a 0 não resultante de arredondamento

( $0 ; 0,0 ; 0,00)$ Dado numérico igual a zero resultante de arredondamento de um dado originalmente positivo

A soma das parcelas pode não coincidir com o total em função de arredondamentos efetuados nos dados parciais

(x) Não se aplica (conjunto formado por um só município)

Doenças do Aparelho Circulatório - Códigos 100 a 199 (Cap. IX -CID 10) 
Anexo 22 - Óbitos e taxa de mortalidade (bruta e padronizada) total e segundo sexo por Neoplasias Malignas (por 100 mil hab.), mediana, desvio padrão e razão de taxas nos conjuntos de municípios e respectivos estratos de vulnerabilidade social. Estado de São Paulo, média do triênio 2003 a 2005

\begin{tabular}{|c|c|c|c|c|c|c|c|c|c|c|c|c|c|c|}
\hline \multirow[b]{2}{*}{ Status } & \multicolumn{3}{|c|}{ Homens } & \multicolumn{3}{|c|}{ Mulheres } & \multicolumn{8}{|c|}{ Total } \\
\hline & Óbitos & TBM & TPM & Óbitos & TBM & TPM & Óbitos & TBM & TPM & Mediana & $\begin{array}{l}\text { Desvio } \\
\text { padrão }\end{array}$ & $\begin{array}{c}\text { Valor } \\
\text { Máximo }^{1}\end{array}$ & $\begin{array}{c}\text { Valor } \\
\text { Minimo }^{2}\end{array}$ & $\begin{array}{c}\text { Razão } \\
(1 / 2)\end{array}$ \\
\hline A20 & 23 & 120,96 & 100,24 & 14 & 71,92 & 64,06 & 37 & 96,63 & 82,29 & 79,41 & 53,01 & 195,71 & 63,28 & 3,09 \\
\hline $\mathrm{A} 100$ & 29 & 110,61 & 106,45 & 29 & 109,56 & 108,27 & 59 & 110,09 & 107,36 & $x$ & $\mathrm{x}$ & $x$ & $x$ & $x$ \\
\hline A300 & 372 & 146,43 & 110,12 & 286 & 105,96 & 78,19 & 658 & 125,57 & 93,66 & 82,73 & 29,01 & 130,79 & 78,61 & 1,66 \\
\hline A500 & 609 & 169,54 & 126,43 & 579 & 145,59 & 101,92 & 1188 & 156,96 & 113,56 & 113,86 & 4,12 & 116,77 & 110,95 & 1,05 \\
\hline $\mathrm{A} 1000$ & 417 & 129,99 & 116,40 & 370 & 107,88 & 94,70 & 787 & 118,56 & 105,19 & $x$ & $x$ & $x$ & $x$ & $x$ \\
\hline Estrato A & 1451 & 148,05 & 117,86 & 1278 & 120,97 & 92,99 & 2729 & 134,00 & 104,96 & 105,2 & 36,6 & 195,7 & 63,3 & 3,1 \\
\hline B20 & 46 & 120,48 & 100,90 & 33 & 86,36 & 75,80 & 79 & 103,56 & 88,46 & 89,39 & 24,47 & 130,66 & 58,69 & 2,23 \\
\hline B50 & 323 & 121,83 & 109,37 & 235 & 88,69 & 86,47 & 559 & 105,27 & 97,92 & 95,84 & 12,10 & 123,08 & 76,85 & 1,60 \\
\hline B100 & 756 & 118,23 & 106,59 & 577 & 88,26 & 81,27 & 1333 & 103,08 & 93,79 & 95,14 & 11,51 & 125,54 & 78,58 & 1,60 \\
\hline B300 & 2038 & 108,40 & 103,53 & 1637 & 84,80 & 82,59 & 3674 & 96,44 & 92,92 & 96,49 & 8,74 & 109,11 & 73,88 & 1,48 \\
\hline B500 & 1120 & 10,39 & 106,94 & 921 & 87,02 & 34,01 & 2040 & 98,46 & 95,24 & 96,03 & 5,26 & 100,96 & 6,84 & 1,16 \\
\hline B1000 & 1562 & 2,58 & 115,65 & 1304 & 81,62 & 89,94 & 2865 & 91,85 & 102,49 & 104,27 & 6,30 & 110,18 & 94,77 & 1,16 \\
\hline B10000 & 6780 & 120,23 & 119,65 & 6285 & 101,85 & 94,79 & 13065 & 110,62 & 106,66 & 103,75 & 4,99 & 107,27 & 100,22 & 1,07 \\
\hline Estrato B & 12624 & 114,78 & 114,10 & 10991 & 93,84 & 90,14 & 23615 & 103,98 & 101,74 & 96,45 & 12,40 & 130,66 & 58,69 & 2,23 \\
\hline $\mathrm{C} 20$ & 102 & 107,17 & 108,20 & 68 & 74,30 & 75,54 & 169 & 91,07 & 92,21 & 86,93 & 25,24 & 161,78 & 60,85 & 2,66 \\
\hline C50 & 463 & 98,68 & 103,03 & 339 & 73,25 & 80,50 & 802 & 86,06 & 91,85 & 90,32 & 10,73 & 125,17 & 74,05 & 1,69 \\
\hline C100 & 548 & 95,05 & 103,54 & 410 & 71,06 & 83,75 & 958 & 83,04 & 93,63 & 96,76 & 9,68 & 108,19 & 67,45 & 1,60 \\
\hline C300 & 1509 & 85,71 & 112,56 & 1228 & 68,69 & 92,38 & 2737 & 77,13 & 102,39 & 98,35 & 16,34 & 135,10 & 76,80 & 1,76 \\
\hline C500 & 497 & 68,81 & 105,30 & 443 & 59,56 & 90,31 & 941 & 64,12 & 97,70 & 92,59 & 12,76 & 116,07 & 88,00 & 1,32 \\
\hline C10000 & 474 & 80,28 & 114,14 & 424 & 69,57 & 96,02 & 898 & 74,84 & 104,93 & $x$ & $x$ & $x$ & $x$ & $x$ \\
\hline Estrato C & 3592 & 5,26 & 109,14 & 2913 & 68,16 & 89,73 & 6505 & 76,65 & 99,37 & 94,10 & 15,75 & 161,78 & 0,85 & 2,66 \\
\hline D20 & 483 & 113,88 & 98,53 & 321 & 77,83 & 74,39 & 804 & 96,09 & 86,62 & 84,69 & 1,34 & 171,37 & 4,03 & 5,04 \\
\hline D50 & 1160 & 118,32 & 102,86 & 810 & 03 & 78,14 & 1970 & 100,72 &, 53 & 90,92 & 2,68 & 07 & 9,06 & 2,00 \\
\hline D100 & 507 & 115,71 & 8,76 & 360 & 78 & 74,64 & 866 & 3,71 & 86,67 & 88,91 & 9,65 & 195,71 & 7,97 & 1,48 \\
\hline D300 & 45 & 58,26 & 106,68 & 31 & 40,07 & 74,51 & 77 & 49,14 & 90,55 & $\mathrm{x}$ & $x$ & $x$ & $x$ & $x$ \\
\hline Estrato D & 2195 & 114,31 & 101,13 & 1523 & 79,86 & 76,37 & 3717 & 97,14 & 88,79 & 87,92 & 17,25 & 171,37 & 34,03 & 5,04 \\
\hline E20 & 1117 & 115,57 & 90,61 & 708 & 76,67 & 69,62 & 1826 & 96,56 & 80,36 & 78,94 & 25,69 & 195,71 & 0,00 & * \\
\hline E50 & 207 & 92,88 & 90,43 & 153 & 70,91 & 77,60 & 361 & 82,07 & 84,11 & 88,37 & 13,12 & 96,59 & 47,99 & 2,01 \\
\hline E100 & 31 & 83,73 & 85,83 & 17 & 48,24 & 61,33 & 47 & 66,50 & 73,93 & $x$ & $x$ & $x$ & $x$ & $x$ \\
\hline Estrato E & 1355 & 110,49 & 90,44 & 878 & 74,77 & 70,85 & 2234 & 93,02 & 80,85 & 79,35 & 25,15 & 175,74 & 0,00 & $*$ \\
\hline Estado & 21218 & 109,71 & 110,42 & 17583 & 87,37 & 87,77 & 38801 & 98,32 & 98,87 & 87,30 & 22,62 & 195,71 & 0,00 & * \\
\hline
\end{tabular}

Fonte: SIM/ MS, Censo IBGE e Estratos de Vulnerabilidade Social segundo metodologia desenvolvida a partir do IPVS (FSEADE 2005)

Nota ${ }^{1}:($ - ) Dado numérico igual a 0 não resultante de arredondamento

$(0 ; 0,0 ; 0,00)$ Dado numérico igual a zero resultante de arredondamento de um dado originalmente positivo

A soma das parcelas pode não coincidir com o total em função de arredondamentos efetuados nos dados parciais

(x) Não se aplica (conjunto formado por um só município)

$\left({ }^{*}\right)$ Não divisível

Códigos C00-C97 (Cap. II Neoplasias (tumores) CID 10), 
Anexo 23 - $\mathrm{N}^{\circ}$ de óbitos e taxa de mortalidade (bruta e padronizada) total e segundo sexo por Neoplasias, Diabetes Mellitus e Doenças do Aparelho Circulatório, municípios. Estado de São Paulo, média do triênio 2003-2005

\begin{tabular}{|c|c|c|c|c|c|c|c|c|c|c|c|c|c|c|c|c|c|c|c|c|c|c|c|c|c|c|c|c|}
\hline \multirow[b]{3}{*}{ Mun. Residencia } & \multirow[b]{3}{*}{ Status } & \multicolumn{9}{|c|}{ Neoplasias Malignas } & \multicolumn{9}{|c|}{ Diabetes Mellitus } & \multicolumn{9}{|c|}{ Aparelho Circulatorio } \\
\hline & & \multicolumn{3}{|c|}{ 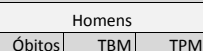 } & \multicolumn{3}{|c|}{ Mulheres } & \multirow{2}{*}{\multicolumn{3}{|c|}{\begin{tabular}{|c|c|}
\multicolumn{1}{|c|}{ Total } \\
Óbitos & TBM
\end{tabular}}} & \multicolumn{3}{|c|}{ Homens } & \multirow{2}{*}{\multicolumn{3}{|c|}{\begin{tabular}{|c|c|c|c|c|c|c|}
\multicolumn{3}{|c|}{ Mulheres } \\
Óbitos & TBM & TPM
\end{tabular}}} & \multirow{2}{*}{\multicolumn{3}{|c|}{\begin{tabular}{|c|c|}
\multicolumn{2}{|c|}{ Total } \\
óbitos & TBMI TPMM \\
\end{tabular}}} & \multicolumn{3}{|c|}{ Homens } & \multirow{2}{*}{\multicolumn{3}{|c|}{$\begin{array}{c}\text { Mulheres } \\
\text { Óbitscl }\end{array}$}} & \multicolumn{3}{|c|}{ Total } \\
\hline & & Óbitos & TBM & TPM & Óbitos & TBM & TPM & & & & \begin{tabular}{|l|} 
Óbitos \\
\end{tabular} & TBM & TPM & & & & & & & \begin{tabular}{|l|} 
Obitos \\
\end{tabular} & TBM & TIPM & \begin{tabular}{|l|} 
Óbitos \\
\end{tabular} & & TPM & Óbitos & 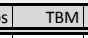 & \\
\hline Adamantina & D50 & 22 & 132,31 & 92,13 & 17 & 95,25 & 71,76 & 39 & 113,31 & \begin{tabular}{|l|l|}
1 & 81,68 \\
\end{tabular} & 5 & 28,07 & 19,46 & 6 & \begin{tabular}{|l|l|}
6 & 34,29 \\
\end{tabular} & 23,75 & 11 & \begin{tabular}{|l|l|}
1 & 31,26 \\
\end{tabular} & \begin{tabular}{|l|l|}
5 & 21,33 \\
\end{tabular} & 48 & 286,68 & \begin{tabular}{|l|l|}
177,03 \\
\end{tabular} & 39 & \begin{tabular}{l|l|}
9 & 220,99 \\
\end{tabular} & 161,09 & 86 & \begin{tabular}{l|l|}
6 & 253,00 \\
\end{tabular} & \begin{tabular}{l|l}
0 & 168,86 \\
\end{tabular} \\
\hline Adolfo & E20 & 2 & 118,95 & 86,73 & 2 & 104,91 & 87,85 & 4 & 112,03 & \begin{tabular}{|l|l|}
3 & 87,28 \\
\end{tabular} & & & & 1 & \begin{tabular}{|l|l|} 
& 69,94 \\
\end{tabular} & 57,83 & 1 & \begin{tabular}{l|l|}
1 & 34,47 \\
\end{tabular} & 27,30 & 4 & 203,91 & 132,92 & 4 & \begin{tabular}{l|l|}
2 & 122,40 \\
\end{tabular} & \begin{tabular}{|l|l|}
04,90 \\
\end{tabular} & 更 & \begin{tabular}{l|l|}
6 & 163,74 \\
\end{tabular} & \begin{tabular}{l|l}
4 & 114,18 \\
\end{tabular} \\
\hline Aguai & E50 & 17 & 111,72 & 101,63 & 14 & 90,29 & 87,48 & 31 & 101,03 & \begin{tabular}{l|l|}
3 & 94,58 \\
\end{tabular} & 2 & 15,33 & 13,20 & 4 & \begin{tabular}{l|l|}
4 & 28,63 \\
\end{tabular} & 25,86 & 7 & 21,96 & \begin{tabular}{|l|l|}
5 & 19,54 \\
\end{tabular} & 32 & 208,10 & | 184,89 & 24 & 4 4 $^{158,56}$ & 5144,26 & 56 & \begin{tabular}{l|l|}
6 & 183,40 \\
\end{tabular} & \begin{tabular}{l|l}
0 & 164,63 \\
\end{tabular} \\
\hline Aguas da Prata & D20 & 7 & 0,73 & 105,31 & 5 & 137,46 & 90,56 & 12 & 159,25 & \begin{tabular}{l|l|l|}
5 & 97,99 \\
\end{tabular} & 1 & 18,07 & 13,43 & 1 & 27,49 & 16,01 & 2 & 22,75 & \begin{tabular}{|l|l|}
5 & 14,77 \\
\end{tabular} & 10 & 271,10 & 150,21 & 8 & \begin{tabular}{l|l|}
8 & 210,78 \\
\end{tabular} & \begin{tabular}{|l|l|}
816,18 \\
\end{tabular} & 18 & $8 \quad 241,15$ & \begin{tabular}{l|l}
5 & 133,31 \\
\end{tabular} \\
\hline Aguas de Lindóia & D20 & 14 & 152,77 & 122,70 & 8 & 91,48 & 74,73 & 22 & 121,85 & \begin{tabular}{|l|l|}
5 & 98,50 \\
\end{tabular} & 2 & 22,36 & 16,74 & 3 & \begin{tabular}{|l|l|}
3 & 29,27 \\
\end{tabular} & 23,60 & 5 & \begin{tabular}{|l|l|}
5 & 25,85 \\
\end{tabular} & 20,20 & 30 & 331,62 & \begin{tabular}{|l|l|}
2 & 241,58 \\
\end{tabular} & 21 & \begin{tabular}{l|l|}
1 & 226,87 \\
\end{tabular} & 178,30 & 50 & 0 o 278,77 & $\begin{array}{ll}7 & 209,65 \\
\end{array}$ \\
\hline Aguas de Santa Bárbara & B20 & 3 & 102,03 & 68,87 & 2 & 57,90 & 48,28 & 5 & 80,20 & \begin{tabular}{l|l|}
0 & 58,69 \\
\end{tabular} & 0 & 11,34 & 10,15 & 1 & \begin{tabular}{l|l|}
1 & 46,32 \\
\end{tabular} & 37,37 & 2 & \begin{tabular}{l|l|}
2 & 28,64 \\
\end{tabular} & $\begin{array}{l}4 \\
42,57 \\
\end{array}$ & 6 & 192,72 & 2137,20 & 6 & \begin{tabular}{l|l|}
6 & 220,03 \\
\end{tabular} & 190,57 & 12 & \begin{tabular}{l|l|}
2 & 206,23 \\
\end{tabular} & \begin{tabular}{l|l}
3 & 163,60 \\
\end{tabular} \\
\hline Aguas de Sao Pedro & A20 & 3 & 366,70 & 245,28 & 3 & 252,53 & 153,03 & 6 & 305,34 & 4 \begin{tabular}{l|l|}
4 & 195,71 \\
\end{tabular} & 0 & 36,67 & 27,61 & 1 & \begin{tabular}{l|l|}
1 & 63,13 \\
\end{tabular} & 27,92 & 1 & \begin{tabular}{l|l|}
1 & 50,89 \\
\end{tabular} & \begin{tabular}{|l|l|}
$\mid 26,97$ \\
\end{tabular} & 4 & 476,71 & 230,92 & 2 & \begin{tabular}{l|l|}
2 & 189,39 \\
\end{tabular} & \begin{tabular}{l|l|}
9 & 72,33 \\
\end{tabular} & 6 & \begin{tabular}{l|l|}
6 & 322,31 \\
\end{tabular} & $1 \quad 145,70$ \\
\hline Agudos & C50 & 17 & 100,03 & 102,60 & 14 & 85,07 & 87,84 & 31 & 92,51 & \begin{tabular}{l|l|}
1 & 95,18 \\
\end{tabular} & 2 & 10,00 & 10,42 & 6 & \begin{tabular}{l|l|}
6 & 33,63 \\
\end{tabular} & 34,39 & 7 & \begin{tabular}{l|l|l}
7 & 21,88 \\
\end{tabular} & \begin{tabular}{|l|l|}
8 & 22,48 \\
\end{tabular} & 37 & 222,07 & 723,01 & 32 & \begin{tabular}{l|l|}
2 & 187,94 \\
\end{tabular} & 4 & 69 & 9 9 204,91 & \begin{tabular}{l|l}
1 & 206,78 \\
\end{tabular} \\
\hline Alambari & E20 & 1 & 67,98 & 61,46 & 2 & 90,37 & 107,94 & 3 & 78,83 & \begin{tabular}{l|l|}
3 & 83,98 \\
\end{tabular} & 0 & 17,00 & 14,17 & 1 & 36,15 & 37,33 & 1 & 26,27 & $\begin{array}{ll}74,56 \\
\end{array}$ & 5 & 237,93 & \begin{tabular}{|l|l|}
390,72 \\
\end{tabular} & 5 & \begin{tabular}{l|l|l|}
5 & 253,03 \\
\end{tabular} & 269,64 & 9 & $\begin{array}{l}9 \\
9\end{array} 245,25$. & \begin{tabular}{l|l}
5 & 228,96 \\
\end{tabular} \\
\hline Alfredo Marcondes & E20 & 2 & 120,92 & 72,98 & 2 & 107,72 & 68,51 & 4 & 114,45 & \begin{tabular}{l|l|}
5 & 70,79 \\
\end{tabular} & 0 & 17,27 & 9,82 & 0 & \begin{tabular}{l|l|}
0 & 17,95 \\
\end{tabular} & 11,16 & 1 & \begin{tabular}{l|l|}
1 & 17,61 \\
\end{tabular} & 10,54 & 5 & 241,84 & $4 \mid 134,71$ & 3 & \begin{tabular}{l|l|}
3 & 179,53 \\
\end{tabular} & 117,65 & 8 & $8|211,29|$ & \begin{tabular}{l|l}
9 & 126,34 \\
\end{tabular} \\
\hline Altair & E20 & 3 & 136,31 & 141,75 & 1 & 58,70 & 59,73 & 4 & 100,18 & \begin{tabular}{l|l|}
8 & 103,57 \\
\end{tabular} & & & & & & & & & & 4 & 187,43 & \begin{tabular}{l|l|}
3202,08 \\
\end{tabular} & 3 & \begin{tabular}{l|l|}
3 & 195,66 \\
\end{tabular} & 6209,70 & & \begin{tabular}{l|l|}
7 & 191,26 \\
\end{tabular} & \begin{tabular}{l|l}
6 & 205,63 \\
\end{tabular} \\
\hline Altinópolis & D20 & 12 & 149,73 & 118,99 & 7 & 90,91 & 84,71 & 20 & 120,63 & \begin{tabular}{|l|l|}
3 & 102,03 \\
\end{tabular} & 1 & 8,09 & 6,17 & 3 & \begin{tabular}{|l|l|}
3 & 33,06 \\
\end{tabular} & 27,79 & 3 & 20,44 & $\begin{array}{ll}4 & 16,48 \\
\end{array}$ & 19 & 234,71 & 175,82 & 14 & \begin{tabular}{l|l|}
4 & 173,55 \\
\end{tabular} & 5 & 33 & \begin{tabular}{l|l|}
3 & 204,45 \\
\end{tabular} & \begin{tabular}{l|l}
5 & 163,06 \\
\end{tabular} \\
\hline Alto Alegre & E20 & 5 & 222,89 & 132,95 & 4 & 86,25 & 63,52 & 6 & 157,31 & \begin{tabular}{l|l|}
1 & 99,62 \\
\end{tabular} & 1 & 31,84 & 20,03 & 1 & 34,50 & 20,65 & 1 & 33,12 & \begin{tabular}{|l|l|}
20,49 \\
\end{tabular} & 7 & 318,42 & \begin{tabular}{|l|l|}
2 & 180,29 \\
\end{tabular} & 6 & \begin{tabular}{l|l|}
6 & 293,26 \\
\end{tabular} & 5187,38 & 12 & \begin{tabular}{l|l|}
2 & 306,34 \\
\end{tabular} & \begin{tabular}{l|l}
4 & 183,69 \\
\end{tabular} \\
\hline Aluminio & C20 & 9 & 107,87 & 141,98 & 6 & 76,10 & 104,32 & 15 & 92,13 & \begin{tabular}{l|l|}
3 & 123,33 \\
\end{tabular} & 2 & 20,74 & 26,08 & 3 & \begin{tabular}{l|l|}
3 & 42,28 \\
\end{tabular} & 58,13 & 5 & 31,41 & \begin{tabular}{l|l|}
1 & 41,62 \\
\end{tabular} & 10 & 128,61 & 176,45 & 12 & \begin{tabular}{l|l|}
2 & 147,97 \\
\end{tabular} & 215,37 & 22 & \begin{tabular}{l|l|}
2 & 138,20 \\
\end{tabular} & \begin{tabular}{l|l}
0 & 195,73 \\
\end{tabular} \\
\hline Alvares Florence & E20 & 4 & 175,83 & 103,11 & 2 & 105,04 & 75,41 & 6 & 142,05 & \begin{tabular}{|l|l|}
5 & 89,89 \\
\end{tabular} & - & & & 1 & \begin{tabular}{|l|l|}
1 & 52,52 \\
\end{tabular} & 33,66 & 1 & \begin{tabular}{|l|l|}
1 & 25,07 \\
\end{tabular} & 15,41 & 8 & 399,62 & \begin{tabular}{|l|l|}
2 & 230,58 \\
\end{tabular} & 5 & \begin{tabular}{l|l|}
5 & 262,61 \\
\end{tabular} & 184,70 & 13 & \begin{tabular}{|l|l|}
3 & 334,22 \\
\end{tabular} & \begin{tabular}{l|l|}
2 & 208,68 \\
\end{tabular} \\
\hline Alvares Machado & D50 & 13 & 108,81 & 96,19 & 9 & 71,61 & 71,47 & 22 & 90,32 & \begin{tabular}{|l|l|}
2 & 83,91 \\
\end{tabular} & 3 & 24,48 & 21,49 & 2 & 19,28 & 18,57 & th & 21,90 & 20,12 & 25 & 201,29 & \begin{tabular}{|l|l|}
9171,07 \\
\end{tabular} & 20 & \begin{tabular}{l|l|}
0 & 168,00 \\
\end{tabular} & 162,21 & 45 & \begin{tabular}{|l|l|}
5 & 184,75 \\
\end{tabular} & \begin{tabular}{l|l}
5 & 166,67 \\
\end{tabular} \\
\hline Alvaro de Carvalho & E20 & 1 & 24,47 & 25,79 & 1 & 54,92 & 53,49 & 2 & 36,67 & \begin{tabular}{l|l|}
7 & 36,89 \\
\end{tabular} & 1 & 24,47 & 29,67 & 0 & 18,31 & \begin{tabular}{|l|}
16,52 \\
\end{tabular} & 1 & 22,00 & \begin{tabular}{|l|l|}
$\mid$ & 23,63 \\
\end{tabular} & 5 & 171,30 & \begin{tabular}{|l|l|}
0 & 191,44 \\
\end{tabular} & 4 & $\begin{array}{l}4 \\
401,39 \\
\end{array}$ & 188,58 & 8 & $8|183,35|$ & \begin{tabular}{l|l}
5 & 190,30 \\
\end{tabular} \\
\hline Alvinlândia & E20 & 0 & 22,25 & 20,55 & 0 & 22,67 & 15,44 & 1 & 22,45 & \begin{tabular}{l|l|}
5 & 18,02 \\
\end{tabular} & 0 & 22,25 & 18,40 & 1 & 45,33 & 38,15 & t & 33,68 & \begin{tabular}{|l|l|}
8 & 28,83 \\
\end{tabular} & 3 & 222,47 & $7 \quad 191,32$ & 4 & 4 4. $^{249,32}$. & 207,95 & 7 & 235,77 & \begin{tabular}{l|l}
7 & 199,56 \\
\end{tabular} \\
\hline Americana & A300 & 108 & 112,04 & 99,56 & 66 & 66,84 & 61,54 & 174 & 89,20 & \begin{tabular}{l|l|}
0 & 80,35 \\
\end{tabular} & 10 & 10,00 & 8,93 & 22 & \begin{tabular}{ll|}
2 & 21,94 \\
\end{tabular} & \begin{tabular}{|l|}
19,47 \\
\end{tabular} & 31 & \begin{tabular}{l|l|}
1 & 16,03 \\
\end{tabular} & \begin{tabular}{|l|l|}
3 & 14,25 \\
\end{tabular} & 143 & 148,24 & $\begin{array}{l}4.127,64 \\
\end{array}$ & 124 & \begin{tabular}{l|l|}
4 & 125,57 \\
\end{tabular} & 712,64 & 267 & \begin{tabular}{l|l|}
7 & 136,79 \\
\end{tabular} & \begin{tabular}{l|l}
9 & 120,06 \\
\end{tabular} \\
\hline Américo Brasiliense & D50 & 11 & 55,56 & 87,92 & 9 & 57,37 & 81,80 & 20 & 61,54 & \begin{tabular}{l|l|}
4 & 84,92 \\
\end{tabular} & 2 & 12,29 & 17,26 & 3 & 21,25 & 31,44 & 5 & 16,69 & \begin{tabular}{|l|l|}
9 & 24,18 \\
\end{tabular} & 24 & 147,50 & | 205,59 & 22 & \begin{tabular}{l|l|}
2 & 138,10 \\
\end{tabular} & | 219,36 & 46 & \begin{tabular}{l|l|}
6 & 142,89 \\
\end{tabular} & \begin{tabular}{l|l}
9 & 212,35 \\
\end{tabular} \\
\hline Américo d & E20 & 5 & 190,20 & 115,66 & 3 & 119,47 & 83,81 & 9 & 154,93 & \begin{tabular}{l|l|}
3 & 99,77 \\
\end{tabular} & 1 & 47,55 & 40,02 & 1 & 47,79 & 35,81 & 3 & 47,67 & \begin{tabular}{|l|}
77,48 \\
\end{tabular} & 9 & 309,08 & \begin{tabular}{|l|l|}
8 & 198,60 \\
\end{tabular} & 4 & $\begin{array}{ll}4 & 155,32 \\
\end{array}$ & 2112,83 & 13 & \begin{tabular}{l|l|}
3 & 232,39 \\
\end{tabular} & \begin{tabular}{l|l}
9 & 155,82 \\
\end{tabular} \\
\hline Amparo & B100 & 51 & 158,07 & 125,46 & 29 & 88,39 & 70,96 & 80 & 123,14 & \begin{tabular}{|l|l|}
4 & 98,14 \\
\end{tabular} & 5 & 16,53 & \begin{tabular}{|l|}
12,98 \\
\end{tabular} & 8 & 24,67 & \begin{tabular}{|l|}
19,59 \\
\end{tabular} & 13 & \begin{tabular}{|l|l|}
3 & 20,61 \\
\end{tabular} & \begin{tabular}{|l|l|}
1 & 16,31 \\
\end{tabular} & 80 & 248,99 & \begin{tabular}{|l|l|}
9 & 191,82 \\
\end{tabular} & 71 & \begin{tabular}{l|l|}
1 & 217,89 \\
\end{tabular} & 166,85 & 151 & \begin{tabular}{l|l|}
1 & 233,40 \\
\end{tabular} & \begin{tabular}{l|l}
0 & 179,30 \\
\end{tabular} \\
\hline Analândia & B20 & 3 & 168,01 & 136,32 & 2 & 90,17 & 93,21 & 5 & 130,47 & \begin{tabular}{ll|l}
7 & 115,52 \\
\end{tabular} & & & & 0 & 18,03 & 15,88 & 0 & 8,70 & 7,29 & 3 & 168,01 & 131,97 & 3 & \begin{tabular}{l|l|}
3 & 162,31 \\
\end{tabular} & 145,02 & 6 & \begin{tabular}{l|l|}
6 & 165,26 \\
\end{tabular} & \begin{tabular}{l|l}
6 & 138,26 \\
\end{tabular} \\
\hline Andradina & D100 & 30 & 109,09 & 83,07 & 19 & 66,47 & 54,21 & 49 & 87,49 & \begin{tabular}{l|l|}
9 & 68,44 \\
\end{tabular} & 8 & 28,77 & 22,38 & 8 & \begin{tabular}{l|l|}
8 & 27,99 \\
\end{tabular} & 22,14 & 16 & \begin{tabular}{l|l|}
6 & 28,37 \\
\end{tabular} & 22,21 & 45 & 161,84 & \begin{tabular}{ll|}
4 & 118,76 \\
\end{tabular} & 44 & \begin{tabular}{l|l|}
4 & 153,93 \\
\end{tabular} & 124,29 & 89 & \begin{tabular}{l|l|}
9 & 157,83 \\
\end{tabular} & \begin{tabular}{l|l}
3 & 121,56 \\
\end{tabular} \\
\hline Angatuba & D50 & 12 & 112,07 & 94,02 & 10 & 101,88 & 104,62 & 22 & 107,12 & \begin{tabular}{|l|l|}
2 & 99,16 \\
\end{tabular} & 1 & 6,40 & 6,13 & 3 & \begin{tabular}{|l|l|}
3 & 30,56 \\
\end{tabular} & 31,18 & 4 & \begin{tabular}{|l|l|}
4 & 18,13 \\
\end{tabular} & \begin{tabular}{|l|l|}
3 & 17,16 \\
\end{tabular} & 26 & 246,55 & \begin{tabular}{|l|l|}
5 & 192,21 \\
\end{tabular} & 18 & \begin{tabular}{l|l|}
8 & 186,78 \\
\end{tabular} & \begin{tabular}{|l|l|}
8 & 190,57 \\
\end{tabular} & 44 & $\begin{array}{l}4217,55 \\
\end{array}$ & \begin{tabular}{l|l}
5 & 191,41 \\
\end{tabular} \\
\hline Anhembi & E20 & 4 & 169,07 & 121,84 & - & 68,96 & 67,13 & 6 & 120,48 & \begin{tabular}{l|l|}
8 & 95,28 \\
\end{tabular} & 1 & 26,01 & 21,39 & 1 & 41,37 & $39,37 \mid$ & 2 & 33,47 & 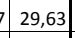 & 10 & 390,17 & 706,15 & 5 & \begin{tabular}{l|l|l|}
5 & 206,87 \\
\end{tabular} & 187,76 & 15 & \begin{tabular}{l|l|}
5 & 301,20 \\
\end{tabular} & \begin{tabular}{l|l}
0 & 248,69 \\
\end{tabular} \\
\hline Anhumas & E20 & 1 & 74,85 & 55,72 & 0 & 19,56 & 17,23 & 2 & 47,81 & \begin{tabular}{l|l|} 
& 36,90 \\
\end{tabular} & & & & 0 & \begin{tabular}{l|l|}
0 & 19,56 \\
\end{tabular} & 17,78 & 0 & 9,56 & \begin{tabular}{|l|l|}
5 & 7,71 \\
\end{tabular} & 4 & 224,55 & 5139,52 & 2 & \begin{tabular}{l|l|l|}
2 & 136,91 \\
\end{tabular} & 128,30 & 6 & \begin{tabular}{l|l|}
6 & 181,70 \\
\end{tabular} & \begin{tabular}{l|l}
0 & 134,04 \\
\end{tabular} \\
\hline Aparecida & B50 & 21 & 120,07 & 118,94 & 18 & 99,15 & 95,21 & 39 & 109,42 & \begin{tabular}{l|l|}
2 & 106,86 \\
\end{tabular} & 6 & 34,31 & 33,55 & 8 & \begin{tabular}{|l|l|}
8 & 44,07 \\
\end{tabular} & 42,05 & 14 & \begin{tabular}{l|l|}
4 & 39,28 \\
\end{tabular} & \begin{tabular}{|l|l|}
8 & 38,02 \\
\end{tabular} & 39 & 224,89 & $\begin{array}{l}913,47 \\
\end{array}$ & 40 & $\begin{array}{l}0 \\
0\end{array} 222,17$ & 210,86 & 80 & $\begin{array}{l}0 \\
0\end{array}$ & \begin{tabular}{l|l}
1 & 212,14 \\
\end{tabular} \\
\hline Aparecida d'Oeste & E20 & 2 & 96,39 & 62,55 & 3 & 136,57 & 107,23 & 6 & 116,57 & \begin{tabular}{l|l|}
7 & 84,98 \\
\end{tabular} & 1 & 27,54 & 22,90 & 2 & 81,94 & 54,64 & 3 & 54,86 & 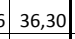 & 9 & 358,03 & \begin{tabular}{|l|l|}
379,19 \\
\end{tabular} & 5 & \begin{tabular}{l|l|}
5 & 204,86 \\
\end{tabular} & $5 \mid 147,75$ & 14 & \begin{tabular}{l|l|}
4 & 281,13 \\
\end{tabular} & \begin{tabular}{l|l}
3 & 163,41 \\
\end{tabular} \\
\hline Apiai & D50 & 8 & 55,35 & 61,31 & 6 & 41,71 & 56,77 & 13 & 48,59 & \begin{tabular}{l|l|}
9 & 59,06 \\
\end{tabular} & 4 & 26,47 & 29,00 & 2 & 17,17 & 22,66 & 0 & 21,87 & 26,52 & 26 & 187,71 & 208,71 & 18 & \begin{tabular}{|l|l|}
8 & 134,93 \\
\end{tabular} & $\mid 185,00$ & 44 & \begin{tabular}{l|l|}
4 & 161,58 \\
\end{tabular} & \begin{tabular}{l|l}
8 & 196,97 \\
\end{tabular} \\
\hline Araçariguama & D20 & 5 & 69,62 & 78,70 & 4 & 68,35 & 90,57 & t & 69,00 & \begin{tabular}{l|l|}
0 & 84,47 \\
\end{tabular} & 1 & 19,89 & 22,76 & 1 & 15,77 & $24,68 \mid$ & 2 & 17,89 & \begin{tabular}{|l|l|}
93,47 \\
\end{tabular} & 9 & 139,23 & \begin{tabular}{|l|l|}
354,16 \\
\end{tabular} & 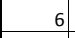 & \begin{tabular}{l|l|}
6 & 89,37 \\
\end{tabular} & 136,09 & 15 & \begin{tabular}{l|l|}
5 & 115,00 \\
\end{tabular} & \begin{tabular}{l|l}
0 & 145,37 \\
\end{tabular} \\
\hline Araçatuba & B300 & 105 & 122,28 & 101,14 & 82 & 90,36 & 76,53 & 187 & 105,82 & \begin{tabular}{|l|l|}
2 & 88,45 \\
\end{tabular} & 18 & 21,03 & $17,64 \mid$ & 27 & \begin{tabular}{l|l|}
7 & 30,00 \\
\end{tabular} & 24,76 & 45 & \begin{tabular}{l|l|}
5 & 25,65 \\
\end{tabular} & \begin{tabular}{|l|l|}
5 & 21,22 \\
\end{tabular} & 141 & 164,72 & \begin{tabular}{|l|l|}
232,31 \\
\end{tabular} & 142 & \begin{tabular}{l|l|}
2 & 156,21 \\
\end{tabular} & 130,21 & 283 & \begin{tabular}{l|l|}
3 & 160,33 \\
\end{tabular} & \begin{tabular}{l|l}
3 & 131,23 \\
\end{tabular} \\
\hline Araçoiaba da Serra & B50 & 12 & 110,35 & 90,47 & 10 & 90,95 & 89,32 & 22 & 100,73 & \begin{tabular}{|l|l|}
3 & 89,90 \\
\end{tabular} & 4 & 32,81 & 27,46 & 5 & 42,44 & 40,74 & 8 & \begin{tabular}{l|l|}
8 & 37,59 \\
\end{tabular} & 33,55 & 22 & 193,86 & \begin{tabular}{ll|}
6 & 161,72 \\
\end{tabular} & 17 & \begin{tabular}{l|l|}
7 & 151,58 \\
\end{tabular} & \begin{tabular}{|l|l|}
849,61 \\
\end{tabular} & 38 & \begin{tabular}{l|l|}
8 & 172,90 \\
\end{tabular} & \begin{tabular}{l|l}
0 & 155,71 \\
\end{tabular} \\
\hline Aramina & E20 & 3 & 129,05 & 103,19 & 3 & 107,02 & 102,41 & 6 & 118,23 & \begin{tabular}{l|l|}
3 & 102,81 \\
\end{tabular} & 0 & 12,90 & 8,56 & 0 & 13,38 & \begin{tabular}{|l|}
12,22 \\
\end{tabular} & 1 & 13,14 & \begin{tabular}{l|l|}
4 & 10,27 \\
\end{tabular} & 4 & 141,95 & \begin{tabular}{|l|}
5 \\
5
\end{tabular} & 5 & \begin{tabular}{l|l|}
5 & 214,05 \\
\end{tabular} & \begin{tabular}{|l|}
5 \\
\end{tabular} & 9 & \begin{tabular}{l|l|}
9 & 177,35 \\
\end{tabular} & \begin{tabular}{l|l}
5 & 151,58 \\
\end{tabular} \\
\hline Arandu & E20 & 3 & 94,08 & 94,61 & 1 & 32,50 & 35,32 & 4 & \begin{tabular}{|l|}
63,84 \\
\end{tabular} & \begin{tabular}{|l|l|}
4 & 65,50 \\
\end{tabular} & 0 & 10,45 & 10,15 & 1 & 21,67 & 23,76 & 1 & 15,96 & \begin{tabular}{|l|l|}
5 & 16,73 \\
\end{tabular} & 5 & 146,35 & \begin{tabular}{|l|l|}
5 & 157,26 \\
\end{tabular} & 6 & \begin{tabular}{l|l|}
6 & 184,18 \\
\end{tabular} & \begin{tabular}{|l|l|}
8 & 203,26 \\
\end{tabular} & 10 & \begin{tabular}{|l|l|}
0 & 164,93 \\
\end{tabular} & \begin{tabular}{l|l}
3 & 179,85 \\
\end{tabular} \\
\hline Arapei & E20 & 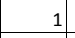 & 96,92 & 75,71 & 1 & 48,10 & 48,40 & 2 & 72,42 & \begin{tabular}{|l|l|}
2 & 62,00 \\
\end{tabular} & 1 & 96,92 & 60,58 & 2 & \begin{tabular}{l|l|l|}
2 & 120,25 \\
\end{tabular} & \begin{tabular}{|l|}
98,78 \\
\end{tabular} & 3 & \begin{tabular}{l|l|}
3 & 108,62 \\
\end{tabular} & \begin{tabular}{|l|l|}
2 & 79,19 \\
\end{tabular} & 3 & 242,31 & \begin{tabular}{|l|}
1163,83 \\
\end{tabular} & 3 & \begin{tabular}{l|l|}
3 & 216,45 \\
\end{tabular} & 5172,44 & 6 & \begin{tabular}{l|l|}
6 & 229,33 \\
\end{tabular} & \begin{tabular}{l|l}
3 & 168,15 \\
\end{tabular} \\
\hline Araraqua & A300 & 102 & 109,11 & 89,88 & 94 & \begin{tabular}{|l|}
44,89 \\
\end{tabular} & $76,21 \mid$ & 196 & 101,80 & \begin{tabular}{|l|l|}
0 & 82,86 \\
\end{tabular} & 22 & 23,46 & 19,46 & 29 & \begin{tabular}{l|l|}
9 & 29,27 \\
\end{tabular} & \begin{tabular}{|l|}
23,32 \\
\end{tabular} & 51 & \begin{tabular}{l|l|}
1 & 26,44 \\
\end{tabular} & \begin{tabular}{l|l|}
4 & 21,44 \\
\end{tabular} & 248 & \begin{tabular}{|l|}
264,06 \\
\end{tabular} & \begin{tabular}{l|l}
6 & 205,25 \\
\end{tabular} & 226 & 8,47 & $176,79 \mid$ & 474 & 5,78 & \begin{tabular}{l|l}
8 & 190,63 \\
\end{tabular} \\
\hline Araras & B300 & 63 & 113,47 & 106,09 & 58 & 103,24 & 97,21 & 121 & 108,35 & \begin{tabular}{l|l|}
5 & 101,65 \\
\end{tabular} & 9 & 15,53 & 14,35 & & 11,94 & 11,00 & 15 & \begin{tabular}{l|l|}
5 & 13,73 \\
\end{tabular} & \begin{tabular}{|l|l|}
3 & 12,71 \\
\end{tabular} & 111 & \begin{tabular}{|l|}
199,46 \\
\end{tabular} & \begin{tabular}{l|l}
6 & 179,64 \\
\end{tabular} & 95 & \begin{tabular}{l|l|}
5 & 170,68 \\
\end{tabular} & \begin{tabular}{|l|l|}
8 & 158,36 \\
\end{tabular} & 207 & \begin{tabular}{l|l|}
7 & 185,06 \\
\end{tabular} & \begin{tabular}{l|l}
6 & 169,00 \\
\end{tabular} \\
\hline Arcoolris & E20 & 2 & 167,74 & 108,76 & 1 & 94,85 & 84,04 & 3 & 133,53 & \begin{tabular}{|l|l|}
3 & 97,16 \\
\end{tabular} & & & & & & & & & & 2 & 167,74 & $4|101,00|$ & & 221,31 & $\mid 177,78$ & 4 & \begin{tabular}{l|l|}
4 & 192,88 \\
\end{tabular} & \begin{tabular}{l|l}
8 & 137,03 \\
\end{tabular} \\
\hline
\end{tabular}


Anexo 23 - $\mathrm{N}^{\circ}$ de óbitos e taxa de mortalidade (bruta e padronizada) total e segundo sexo por Neoplasias, Diabetes Mellitus e Doenças do Aparelho Circulatório, municípios. Estado de São Paulo, média do triênio 2003-2005

\begin{tabular}{|c|c|c|c|c|c|c|c|c|c|c|c|c|c|c|c|c|c|c|c|c|c|c|c|c|c|c|c|c|}
\hline \multirow[b]{3}{*}{ Arealva } & \multirow[b]{3}{*}{ E20 } & \multicolumn{9}{|c|}{ Neoplasias Malignas } & \multicolumn{9}{|c|}{ Diabetes Mellitus } & \multicolumn{9}{|c|}{ Aparelho Circulatorio } \\
\hline & & \multicolumn{3}{|c|}{ Homens } & \multicolumn{3}{|c|}{ Mulheres } & \multicolumn{3}{|c|}{ Total } & \multicolumn{3}{|c|}{ Homens } & \multicolumn{3}{|c|}{ Mulheres } & \multicolumn{3}{|c|}{ Total } & \multicolumn{3}{|c|}{ Homens } & \multicolumn{3}{|c|}{ Mulheres } & \multicolumn{3}{|c|}{ Total } \\
\hline & & 4 & 113,74 & 70,55 & 4 & 83,53 & 61,01 & 7 & 99,08 & 65,92 & 1 & 26,25 & 15,95 & 2 & 55,69 & 43,08 & 3 & 40,54 & \begin{tabular}{l|l|}
4 & 28,56 \\
\end{tabular} & & 192,48 & $8 \quad 103,53$ & & 259,88 & 8193,95 & 17 & 225,18 & \begin{tabular}{l|l}
8147,40 \\
\end{tabular} \\
\hline Areias & E20 & 1 & 35,29 & 27,58 & 1 & 53,99 & 49,83 & a & 44,55 & 38,60 & 1 & 35,29 & 29,72 & 0 & 18,00 & 15,55 & 1 & 26,73 & \begin{tabular}{|l|l|} 
& 22,90 \\
\end{tabular} & 5 & 282,34 & $4 \quad 266,09$ & 6 & 341,91 & 298,33 & 12 & 311,83 & \begin{tabular}{l|l}
3 & 282,05 \\
\end{tabular} \\
\hline Areiópolis & E20 & 5 & 93,13 & 113,34 & 3 & 52,66 & 70,44 & 8 & 73,49 & 92,52 & 1 & 18,63 & 23,07 & 1 & 26,33 & 34,98 & 2 & 22,37 & 29,03 & 15 & 273,19 & 923,15 & 12 & 243,57 & 350,16 & 27 & 258,81 & 1336,26 \\
\hline Ariranha & E20 & 7 & 158,93 & 116,24 & 4 & 91,40 & 76,86 & 10 & 125,92 & 96,99 & 1 & 23,84 & 19,15 & 1 & 33,24 & 24,65 & 2 & 28,43 & \begin{tabular}{|l|l|} 
& 21,73 \\
\end{tabular} & 10 & 246,34 & $4 \mid 169,79$ & 12 & 290,82 & 221,73 & 22 & 268,09 & \begin{tabular}{l|l|}
9 & 195,18 \\
\end{tabular} \\
\hline Artur Nogue & C50 & 16 & 82,86 & 96,53 & 10 & 52,76 & 63,43 & 27 & 67,86 & 80,03 & 5 & 27,06 & 29,42 & 3 & \begin{tabular}{|r|}
5,32 \\
\end{tabular} & 19,48 & 8 & 21,20 & \begin{tabular}{|l|l|} 
& 24,64 \\
\end{tabular} & 30 & 150,50 & | 164,34 & 22 & \begin{tabular}{|l|}
110,62 \\
\end{tabular} & \begin{tabular}{|l|}
242,87 \\
\end{tabular} & 51 & \begin{tabular}{|l|}
130,62 \\
\end{tabular} & \begin{tabular}{|l|l|}
2 & 153,64 \\
\end{tabular} \\
\hline Arujá & C100 & 29 & 83,54 & 112,61 & 21 & 59,91 & 84,99 & 49 & 71,69 & 98,77 & 7 & 19,43 & 27,16 & 10 & 29,95 & \begin{tabular}{|l|}
46,72 \\
\end{tabular} & 17 & 24,70 & \begin{tabular}{|l|} 
\\
\end{tabular} & 61 & \begin{tabular}{|l|}
178,73 \\
\end{tabular} & \begin{tabular}{|l|l|}
3 & 247,40 \\
\end{tabular} & 49 & 143,00 & 225,27 & 111 & 160,82 & \begin{tabular}{|l}
236,31 \\
\end{tabular} \\
\hline Aspásia & E20 & 1 & 106,46 & 45,60 & 1 & 76,07 & 67,70 & 2 & 91,79 & 56,27 & 0 & 35,49 & 21,30 & 1 & 76,07 & 52,82 & 1 & \begin{tabular}{|l|}
55,07 \\
\end{tabular} & $\begin{array}{l}75,84 \\
\end{array}$ & 2 & 248,40 & $\mid$ & 2 & \begin{tabular}{|l|}
228,22 \\
\end{tabular} & \begin{tabular}{|l|l|} 
& 193,24 \\
\end{tabular} & 4 & $238,66 \mid$ & \begin{tabular}{l|l}
5 & 161,56 \\
\end{tabular} \\
\hline Assis & B100 & 51 & 113,53 & 92,77 & 48 & 100,49 & 82,13 & 99 & 106,83 & 87,31 & 8 & 17,81 & 14,37 & 12 & \begin{tabular}{|r|} 
\\
\end{tabular} & 20,39 & 20 & \begin{tabular}{|r|}
22,02 \\
\end{tabular} & \begin{tabular}{|l|l|}
2 & 17,46 \\
\end{tabular} & 75 & 166,22 & \begin{tabular}{|l|l|}
2 & 127,19 \\
\end{tabular} & 72 & 151,08 & $\mid$\begin{tabular}{|l|}
$\mid$ \\
$\mid$
\end{tabular} & 146 & 158,44 & \begin{tabular}{l|l}
4 & 122,42 \\
\end{tabular} \\
\hline Atibaia & C300 & 72 & 117,72 & 108,45 & 58 & 94,20 & 90,75 & 130 & 105,89 & 99,55 & 12 & 19,71 & 18,33 & 20 & 33,02 & 31,59 & 32 & 26,41 & \begin{tabular}{l|l|}
11 & 24,89 \\
\end{tabular} & 132 & 216,83 & \begin{tabular}{|l|l|}
3 & 188,08 \\
\end{tabular} & 111 & \begin{tabular}{|l|}
180,82 \\
\end{tabular} & \begin{tabular}{|l|l|}
270,46 \\
\end{tabular} & 243 & \begin{tabular}{|l|}
198,72 \\
\end{tabular} & \begin{tabular}{l|l}
2179,22 \\
\end{tabular} \\
\hline Auriflama & E20 & 7 & 105,04 & 82,84 & 6 & 82,54 & 71,10 & 13 & 93,89 & 77,02 & 1 & 14,32 & 11,39 & 2 & 24,28 & 20,04 & 3 & 19,26 & \begin{tabular}{|l|l|}
5 & 15,22 \\
\end{tabular} & 16 & 233,96 & \begin{tabular}{|l|l|}
6 & 168,77 \\
\end{tabular} & 13 & 184,51 & \begin{tabular}{|l|}
166,23 \\
\end{tabular} & 29 & 209,44 & $\begin{array}{l}4 \\
4\end{array}$ \\
\hline Avaí & E20 & 2 & 98,03 & 79,05 & 2 & 106,19 & 97,76 & 5 & 101,94 & 88,04 & & & & 1 & 60,68 & 52,12 & 1 & \begin{tabular}{|l|}
29,12 \\
\end{tabular} & 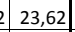 & 7 & \begin{tabular}{|l|}
308,08 \\
\end{tabular} & \begin{tabular}{|l|l|}
8 & 220,90 \\
\end{tabular} & 7 & \begin{tabular}{|r|}
303,40 \\
\end{tabular} & | 287,35 & 14 & \begin{tabular}{|l|}
305,83 \\
\end{tabular} & \begin{tabular}{l|l}
3252,80 \\
\end{tabular} \\
\hline Avanhanda & E20 & 4 & 94,40 & 87,55 & 3 & 72,11 & 67,46 & 8 & 83,22 & 77,47 & 0 & 7,26 & 6,75 & 1 & 28,85 & 28,84 & 2 & \begin{tabular}{|l|}
18,09 \\
\end{tabular} & \begin{tabular}{|l|l|}
9 & 17,66 \\
\end{tabular} & 10 & 217,85 & 5203,33 & 5 & \begin{tabular}{|l|}
115,38 \\
\end{tabular} & \begin{tabular}{|l|l|}
8 & 119,03 \\
\end{tabular} & 15 & 166,44 & \begin{tabular}{l|l}
4 & 161,04 \\
\end{tabular} \\
\hline Avaré & B100 & 43 & 102,54 & 95,38 & 35 & 83,08 & 75,17 & 77 & 92,80 & 85,26 & 10 & 24,03 & $22,23 \mid$ & 12 & 29,56 & $26,17 \mid$ & 22 & 26,80 & 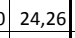 & 83 & 200,27 & $\begin{array}{l}776,61 \\
\end{array}$ & 82 & 196,51 & $\begin{array}{l}172,58 \\
\end{array}$ & 165 & 198,39 & \begin{tabular}{l|l}
174,59 \\
\end{tabular} \\
\hline Bady Bassitt & A20 & 7 & 102,73 & 92,28 & 2 & 33,25 & 33,78 & 10 & 68,29 & 63,28 & 0 & 4,67 & 4,08 & 2 & 23,75 & 23,75 & 2 & \begin{tabular}{|l|}
14,13 \\
\end{tabular} & \begin{tabular}{|l|l|}
3 & 13,50 \\
\end{tabular} & 13 & \begin{tabular}{|l|}
186,78 \\
\end{tabular} & \begin{tabular}{l|l|}
8 & 172,61 \\
\end{tabular} & 11 & \begin{tabular}{|l|}
152,01 \\
\end{tabular} & 160,41 & 24 & \begin{tabular}{|l|}
169,54 \\
\end{tabular} & $\begin{array}{l}4166,56 \\
\end{array}$ \\
\hline Balbinos & E20 & 0 & 47,71 & 28,00 & 1 & 101,52 & 109,57 & 1 & 73,78 & 67,52 & & & & & & & & & & 1 & 190,84 & \begin{tabular}{l|l|}
4 & 117,60 \\
\end{tabular} & 1 & 152,28 & \begin{tabular}{|l|l|}
803,52 \\
\end{tabular} & $\leq$ & 172,16 & \begin{tabular}{c|c}
5 & 110,78 \\
\end{tabular} \\
\hline Bálsamo & E20 & 5 & 123,30 & 92,33 & 4 & 113,83 & 94,86 & 9 & 118,55 & 93,60 & 1 & 17,61 & 11,63 & 1 & 17,51 & 12,11 & 1 & \begin{tabular}{|l|}
17,56 \\
\end{tabular} & \begin{tabular}{|l|l|}
5 & 11,91 \\
\end{tabular} & 13 & 352,30 & | 235,21 & 8 & 218,90 & $\mid$\begin{tabular}{|l|} 
\\
\end{tabular} & 22 & 285,40 & \begin{tabular}{|l|l}
198,01 \\
\end{tabular} \\
\hline Bananal & D20 & 5 & 94,13 & 71,82 & 2 & 46,31 & 42,24 & 7 & 70,02 & 56,91 & 1 & 13,45 & 10,74 & 3 & 59,54 & 47,53 & 4 & 36,68 & \begin{tabular}{|l|l|}
8 & 29,13 \\
\end{tabular} & 11 & 215,15 & 5165,72 & 11 & $211,68 \mid$ & \begin{tabular}{|l|l|}
8 & 169,93 \\
\end{tabular} & 21 & 213,40 & \begin{tabular}{|l|l|}
07,84 \\
\end{tabular} \\
\hline Barao de & E20 & 1 & 72,74 & 48,51 & 2 & 177,44 & 159,64 & 3 & 123,93 & 102,84 & 1 & 48,50 & 36,68 & 1 & 101,39 & $85,60 \mid$ & 2 & 74,35 & 5 & 3 & 218,23 & 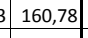 & & 202,79 & 170,45 & 6 & 210,68 | & \begin{tabular}{l|l|l}
865,51 \\
\end{tabular} \\
\hline Barbosa & E20 & 3 & 98,41 & 83,55 & 2 & 77,95 & 71,68 & 5 & 88,28 & 77,67 & 1 & 32,80 & 28,55 & 2 & 66,82 & 60,99 & 3 & $49,65 \mid$ & \begin{tabular}{|l|l|}
5 & 42,61 \\
\end{tabular} & 7 & 240,57 & 7190,35 & 3 & 111,36 & 5108,39 & 11 & 176,55 & \begin{tabular}{|l|l|}
5 & 149,74 \\
\end{tabular} \\
\hline Bariri & D50 & 23 & 153,80 & 110,08 & 15 & 98,34 & 71,70 & 38 & 126,11 & 90,92 & 4 & 26,75 & 19,17 & 4 & 29,06 & 18,83 & 8 & 27,90 & \begin{tabular}{|l|l|}
0 & 18,94 \\
\end{tabular} & 35 & 234,05 & 5146,33 & 34 & 227,98 & \begin{tabular}{|l|l|}
850,54 \\
\end{tabular} & 69 & 231,02 & \begin{tabular}{|l|l|}
2 & 148,43 \\
\end{tabular} \\
\hline Barra Bonita & C50 & 28 & 147,41 & 129,83 & 16 & 83,36 & 77,46 & 43 & 115,36 & 103,63 & 4 & 23,09 & \begin{tabular}{|r|}
19,92 \\
\end{tabular} & 9 & 49,66 & 45,40 & 14 & 36,38 & \begin{tabular}{|l|l|}
82,40 \\
\end{tabular} & 34 & 181,15 & $5 \mid 154,70$ & 35 & 184,45 & 569,44 & 69 & 182,80 & \begin{tabular}{|l|l|}
162,08 \\
\end{tabular} \\
\hline Barra do Chapéu & E20 & 1 & 25,80 & 22,17 & 1 & 29,91 & 29,57 & 1 & 27,71 & 25,60 & 0 & 12,90 & 16,55 & 2 & 89,74 & 98,98 & 2 & 48,49 & \begin{tabular}{|l|l|}
9 & 48,75 \\
\end{tabular} & 3 & 103,21 & 87,48 & 3 & 134,61 & 157,95 & 6 & 117,75 & \begin{tabular}{|l|l}
520,12 \\
\end{tabular} \\
\hline Barra do Tur & E20 & 5 & 111,41 & 105,21 & 2 & 41,05 & 43,82 & 7 & 77,99 & 76,05 & 1 & 14,85 & 11,82 & 1 & 16,42 & $20,17 \mid$ & 1 & 15,60 & \begin{tabular}{|l|l|} 
& 16,17 \\
\end{tabular} & 7 & 163,40 & $\begin{array}{l}0 \\
0\end{array}$ & 4 & 106,74 & 134,27 & 12 & 136,49 & \begin{tabular}{l|l}
9140,31 \\
\end{tabular} \\
\hline Barretos & B300 & 80 & 152,96 & 127,91 & 56 & 102,07 & 84,87 & 137 & 126,89 & 105,86 & 26 & 49,51 & 41,90 & 25 & 44,69 & 36,73 & 51 & 47,04 & \begin{tabular}{l|l|}
4 & 39,24 \\
\end{tabular} & 145 & 276,72 & 2217,75 & 124 & 225,29 & | 179,79 & 270 & 250,37 & $\begin{array}{l}798,30 \\
\end{array}$ \\
\hline Barrinha & D50 & 13 & 93,86 & 127,04 & 3 & 35,62 & 48,82 & 17 & 65,17 & 88,51 & 3 & 24,70 & 33,62 & 3 & 20,35 & 29,02 & 6 & 22,56 & \begin{tabular}{|l|l|}
5 & 31,44 \\
\end{tabular} & 25 & 182,77 & 7240,49 & 17 & 127,21 & 185,35 & 41 & 55,41 & 213,33 \\
\hline Barueri & с300 & 94 & 78,07 & 125,70 & 92 & 75,12 & 122,89 & 186 & 76,58 & 124,28 & 18 & 15,28 & 25,61 & 17 & 13,56 & 23,92 & 35 & 14,41 & \begin{tabular}{l|l|}
1 & 24,89 \\
\end{tabular} & 192 & 160,30 & | 260,85 & 156 & 127,20 & | 231,54 & 349 & 143,55 & \begin{tabular}{|l|l|}
546,02 \\
\end{tabular} \\
\hline Bastos & D50 & 12 & 116,59 & 110,29 & 11 & 100,01 & 100,05 & 23 & 108,27 & 105,15 & 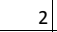 & 22,06 & 20,19 & 6 & 56,25 & 54,51 & 8 & 39,23 & 37,16 & 21 & 195,37 & $7 \mid 182,14$ & 19 & \begin{tabular}{|l|}
175,01 \\
\end{tabular} & 172,82 & 39 & 185,15 & \begin{tabular}{|l|l}
577,46 \\
\end{tabular} \\
\hline Batatais & C100 & 29 & 108,99 & 92,08 & 22 & 80,50 & 67,39 & 51 & 94,64 & 79,64 & 3 & 11,15 & 9,70 & 7 & 24,39 & 20,30 & 10 & 17,82 & \begin{tabular}{|l|l|}
2 & 15,11 \\
\end{tabular} & 67 & 247,71 & \begin{tabular}{|l|}
199,85 \\
\end{tabular} & 58 & 212,23 & $\mid 168,80$ & 125 & 229,84 & \begin{tabular}{l|l}
4 & 184,21 \\
\end{tabular} \\
\hline Bauru & B500 & 199 & 119,57 & 106,84 & 159 & 91,10 & 79,46 & 358 & 105,01 & 92,84 & 39 & 23,43 & 21,04 & 50 & 28,90 & 24,81 & 89 & 26,23 & \begin{tabular}{|l|l|}
3 & 22,97 \\
\end{tabular} & 370 & 222,11 & \begin{tabular}{|l|}
194,27 \\
\end{tabular} & 340 & 195,01 & 165,45 & 709 & 208,25 & \begin{tabular}{|l|l|}
579,53 \\
\end{tabular} \\
\hline Bebedouro & C100 & 56 & 146,51 & 124,82 & 35 & 89,42 & 78,00 & 92 & 117,57 & 101,09 & 7 & 17,34 & \begin{tabular}{|l|}
4,92 \\
\end{tabular} & 11 & 27,84 & 23,84 & 18 & 22,66 & \begin{tabular}{|l|l|}
5 & 19,44 \\
\end{tabular} & 72 & 188,13 & \begin{tabular}{|l|l|}
3 & 158,50 \\
\end{tabular} & 71 & 178,83 & \begin{tabular}{|l|}
349,59 \\
\end{tabular} & 143 & 183,42 & \begin{tabular}{|l|l|}
2 & 153,98 \\
\end{tabular} \\
\hline Bento de Abreu & C20 & & & & 2 & 170,94 & 158,12 & 2 & 83,54 & 77,28 & & & & 0 & 28,49 & $22,07 \mid$ & 0 & 13,92 & \begin{tabular}{|l|l|}
2 & 10,87 \\
\end{tabular} & 2 & 163,40 & | 114,10 & 2 & 142,45 & 539,02 & 4 & 153,16 & \begin{tabular}{|l|l|}
5 & 126,28 \\
\end{tabular} \\
\hline Bernardino o & E20 & 9 & 170,65 & 104,73 & 6 & 114,10 & 79,06 & 16 & 142,17 & 91,80 & 2 & 30,47 & 19,65 & 3 & 48,04 & 34,33 & 4 & 39,32 & \begin{tabular}{|l|l|}
2 & 26,79 \\
\end{tabular} & 15 & 268,16 & \begin{tabular}{l|l|}
6 & 170,21 \\
\end{tabular} & 11 & 198,17 & 131,42 & 26 & $232,91 \mid$ & 150,67 \\
\hline Bertioga & C50 & 16 & 79,15 & 106,40 & 13 & 70,12 & 111,65 & 29 & 74,79 & 108,94 & 2 & 11,79 & 15,07 & 2 & 12,59 & 18,30 & 5 & 12,17 & \begin{tabular}{|l|l|}
76,69 \\
\end{tabular} & 31 & 156,62 & \begin{tabular}{|l|l|}
299,83 \\
\end{tabular} & 17 & 93,49 & $\begin{array}{l}9 \\
9\end{array}$ & 48 & 126,09 & \begin{tabular}{|l|l|}
9 & 179,39 \\
\end{tabular} \\
\hline Bilac & D20 & 5 & 148,94 & 104,77 & 3 & 92,76 & 66,58 & 8 & 120,41 & 85,37 & 0 & 10,64 & 6,36 & & 10,31 & 7,11 & 1 & 10,47 & \begin{tabular}{|l|}
7 \\
\end{tabular} & 11 & 351,06 & $\begin{array}{l}609,69 \\
\end{array}$ & & 164,91 & 121,31 & 16 & 56,52 & \begin{tabular}{|l|l|}
2 & 164,80 \\
\end{tabular} \\
\hline Birigui & с300 & 53 & 105,25 & 96,48 & 33 & 62,59 & 60,15 & 86 & 83,60 & 78,05 & 6 & 12,50 & 11,56 & 8 & 15,97 & \begin{tabular}{|l|}
15,16 \\
\end{tabular} & 15 & 14,26 & \begin{tabular}{|l|l|}
5 & 13,34 \\
\end{tabular} & 66 & 130,24 & \begin{tabular}{ll|}
4 & 114,06 \\
\end{tabular} & 66 & \begin{tabular}{|l|}
125,82 \\
\end{tabular} & 2120,22 & 132 & 128,00 & \begin{tabular}{|l|l}
117,19 \\
\end{tabular} \\
\hline Biritibaomirim & D50 & 14 & 97,29 & 100,90 & o & 61,04 & 70,63 & 22. & 79,42 & 85,98 & 4 & 26,10 & 25,88 & 3 & 24,42 & 28,72 & 7 & 25,27 & \begin{tabular}{|l|}
7,28 \\
\end{tabular} & 23 & 161,36 & $6 \mid 161,04$ & 17 & \begin{tabular}{|l|}
122,08 \\
\end{tabular} & \begin{tabular}{|l|l|}
848,67 \\
\end{tabular} & 39 & 142,00 & \begin{tabular}{|l|l|}
154,94 \\
\end{tabular} \\
\hline Boa Esperança do Su & E20 & 4 & 58,52 & 54,91 & 3 & 50,41 & 54,40 & 7 & 54,54 & 54,66 & 2 & 24,38 & 23,92 & 3 & 45,37 & 50,04 & 5 & 34,70 & \begin{tabular}{|l|l|}
0 & 36,18 \\
\end{tabular} & 11 & 160,94 & $4 \mid 150,09$ & 15 & 231,90 & 264,26 & 26 & 195,83 & \begin{tabular}{|l|l|}
3 & 206,23 \\
\end{tabular} \\
\hline Bocaina & D20 & 6 & 108,99 & 85,55 & 4 & 76,66 & 64,10 & 10 & 92,80 & 74,81 & 1 & 19,23 & 17,90 & 2 & 38,33 & 32,03 & 3 & 28,80 & \begin{tabular}{|l|l|} 
& 25,36 \\
\end{tabular} & 15 & 294,91 & 217,63 & 13 & 255,54 & A 185,01 & 29 & 275,19 & \begin{tabular}{|l|l|}
9 & 201,29 \\
\end{tabular} \\
\hline Bofete & E20 & 9 & 219,33 & 181,65 & 5 & 129,74 & 127,12 & 14 & 176,75 & 155,73 & 1 & 23,50 & 17,85 & 2 & 43,25 & $38,67 \mid$ & 3 & 32,89 & \begin{tabular}{|l|l|} 
& 27,33 \\
\end{tabular} & 11 & 258,50 & | 208,52 & 9 & 224,87 & 225,25 & 20 & 242,52 & \begin{tabular}{|l|l|}
216,47 \\
\end{tabular} \\
\hline Boituva & D50 & 19 & 96,96 & 100,45 & 15 & 78,86 & \begin{tabular}{|l|} 
\\
\end{tabular} & 35 & 88,02 & 95,03 & 4 & 21,73 & 21,81 & 工 & 25,72 & 28,41 & 9 & 23,70 & \begin{tabular}{|l|l|}
0,35 \\
\end{tabular} & 41 & 207,30 & \begin{tabular}{|l|l|}
0 & 209,82 \\
\end{tabular} & 29 & 147,43 & \begin{tabular}{|l|l|}
369,30 \\
\end{tabular} & 70 & 177,74 & $\begin{array}{l}4 \mid 189,82 \\
\end{array}$ \\
\hline
\end{tabular}


Anexo 23 - $\mathrm{N}^{\circ}$ de óbitos e taxa de mortalidade (bruta e padronizada) total e segundo sexo por Neoplasias, Diabetes Mellitus e Doenças do Aparelho Circulatório, municípios. Estado de São Paulo, média do triênio 2003-2005

\begin{tabular}{|c|c|c|c|c|c|c|c|c|c|c|c|c|c|c|c|c|c|c|c|c|c|c|c|c|c|c|c|c|}
\hline \multirow[b]{3}{*}{ Bom Jesus dos Perdoes } & \multirow[b]{3}{*}{ D20 } & \multicolumn{9}{|c|}{ Neoplasias Malignas } & \multicolumn{9}{|c|}{ Diabetes Mellitus } & \multicolumn{9}{|c|}{ Aparelho Circulatorio } \\
\hline & & \multicolumn{3}{|c|}{ Homens } & \multicolumn{3}{|c|}{ Mulheres } & \multicolumn{3}{|c|}{ Total } & \multicolumn{3}{|c|}{ Homens } & \multicolumn{3}{|c|}{ Mulheres } & \multicolumn{3}{|c|}{ Total } & \multicolumn{3}{|c|}{ Homens } & \multicolumn{3}{|c|}{ Mulheres } & \multicolumn{3}{|c|}{ Total } \\
\hline & & 10 & 129,47 & \begin{tabular}{l|l|}
7 & 126,88 \\
\end{tabular} & 5 & 67,65 & 76,62 & 15 & 98,72 & 101,88 & 3 & 35,72 & 34,49 & 2 & 31,57 & 35,82 & 5 & 33,65 & | 35,33 | & 17 & 227,69 & 9215,79 & 15 & 207,46 & 638,70 & 32 & $\begin{array}{ll}2 & 217,63 \\
\end{array}$ & \begin{tabular}{|l|l|}
3 & 227,18 \\
\end{tabular} \\
\hline Bom Sucesso de Itararé & E20 & & & & 0 & 19,03 & 25,47 & 0 & 9,17 & 12,28 & 0 & 17,71 & 20,12 & 0 & 19,03 & 30,72 & 1 & 27,51 & 14,90 & 2 & 88,53 & \begin{tabular}{|l|l|}
300,66 \\
\end{tabular} & 3 & 152,21 & 243,39 & 4 & \begin{tabular}{l|l|}
4 & 119,22 \\
\end{tabular} & \begin{tabular}{|l|l|}
2169,46 \\
\end{tabular} \\
\hline Borá & E20 & & & & & & & & & & & & & & & & & & & 1 & 160,77 & 718,72 & 1 & 337,55 & 286,15 & 2 & \begin{tabular}{ll|l|}
2 & 247,02 \\
\end{tabular} & 200,40 \\
\hline Boracéia & E20 & 2 & 100,59 & 78,78 & 1 & 35,52 & 29,56 & 3 & 69,00 & 54,88 & & & & 3 & 142,10 & 127,47 & 3 & 69,00 & 59,20 & 3 & 150,88 & $8|119,40|$ & 3 & 142,10 & 127,98 & 6 & \begin{tabular}{l|l|}
6 & 146,61 \\
\end{tabular} & 123,56 \\
\hline Borborema & D20 & 14 & 206,62 & \begin{tabular}{|l|l|}
2 & 142,96 \\
\end{tabular} & 8 & 118,71 & 98,17 & 22 & 163,30 & 120,89 & 1 & 9,61 & 6,06 & 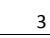 & 44,52 & 35,05 & 4 & 26,81 & 19,40 & 20 & 293,11 & $\mid 196,10$ & 13 & 197,85 & 5152,44 & 34 & \begin{tabular}{l|l|}
4 & 246,17 \\
\end{tabular} & 174,58 \\
\hline Borebi & E20 & 7 & 89,07 & \begin{tabular}{|l|l|}
7 & 78,56 \\
\end{tabular} & 1 & 63,65 & 55,19 & 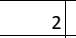 & 76,80 & 67,28 & & & & & & & & & & 2 & 148,46 & \begin{tabular}{|l|l|}
6 & 144,12 \\
\end{tabular} & 1 & 127,31 & 126,46 & 3 & \begin{tabular}{|l|l|}
3 & 138,25 \\
\end{tabular} & \begin{tabular}{|l|l|}
535,60 \\
\end{tabular} \\
\hline Botucatu & B300 & 80 & 140,50 & \begin{tabular}{l|l}
0 & 116,22 \\
\end{tabular} & 66 & 110,47 & 89,48 & 145 & 125,13 & 102,54 & 9 & 15,87 & 13,36 & 16 & 26,92 & 22,17 & 25 & 21,53 & \begin{tabular}{|l|l|}
3 & 17,87 \\
\end{tabular} & 157 & 276,30 & $\begin{array}{ll}0218,75 \\
\end{array}$ & 139 & 233,29 & \begin{tabular}{|l|l|}
979,18 \\
\end{tabular} & 295 & \begin{tabular}{l|l|}
5 & 254,29 \\
\end{tabular} & \begin{tabular}{|l|l}
9 & 198,50 \\
\end{tabular} \\
\hline Bragança Paulista & B300 & 89 & 131,43 & \begin{tabular}{l|l|}
3 & 117,33 \\
\end{tabular} & 77 & 111,43 & 102,41 & 165 & 121,33 & 109,80 & 11 & 16,80 & 15,13 & 21 & 30,04 & 27,58 & 32 & 23,48 & \begin{tabular}{|l|l|}
8 & 21,36 \\
\end{tabular} & 199 & 294,97 & 7251,82 & 145 & 211,24 & 4 & 344 & $4 \quad 252,69$ & \begin{tabular}{l|l}
9221,40 \\
\end{tabular} \\
\hline Braúna & E20 & 1 & 58,84 & \begin{tabular}{l|l|}
4 & 36,45 \\
\end{tabular} & 2 & 92,08 & 64,66 & 3 & 75,11 & 50,25 & 1 & 29,42 & 21,17 & & & & 1 & 15,02 & \begin{tabular}{|l|l|}
2 & 10,96 \\
\end{tabular} & 4 & 191,23 & \begin{tabular}{|l|l|}
319,49 \\
\end{tabular} & 3 & 153,47 & 109,83 & 8 & \begin{tabular}{|l|l|}
8 & 172,75 \\
\end{tabular} & \begin{tabular}{|l|l}
514,76 \\
\end{tabular} \\
\hline Brejo Alegre & E20 & 1 & 78,68 & 72,49 & & & & 1 & 40,74 & 37,53 & 0 & 26,23 & 20,69 & 0 & 28,16 & 27,53 & 1 & \begin{tabular}{|l|} 
\\
\end{tabular} & \begin{tabular}{|l|l|}
5 & 24,02 \\
\end{tabular} & 1 & 78,68 & \begin{tabular}{l|l|}
8 & 43,61 \\
\end{tabular} & 2 & 140,81 & 139,22 & 3 & \begin{tabular}{l|l|}
3 & 108,64 \\
\end{tabular} & \begin{tabular}{l|l}
4 & 89,72 \\
\end{tabular} \\
\hline Brodósqui & C20 & 14 & 149,49 & 126,71 & 7 & 75,52 & 67,47 & 21 & 112,69 & 97,24 & 2 & 24,91 & 20,69 & 2 & 25,17 & 22,54 & 5 & 25,04 & \begin{tabular}{l|l|}
4 & 21,70 \\
\end{tabular} & 22 & 238,47 & 7 201,88 & 13 & 140,24 & $\begin{array}{l}423,33 \\
4\end{array}$ & 35 & \begin{tabular}{l|l|}
5 & 189,61 \\
\end{tabular} & $1 \quad 162,81$ \\
\hline Brotas & D50 & 17 & 161,41 & 128,11 & 7 & 67,60 & 56,17 & 24 & 114,90 & 92,44 & 1 & 6,33 & 5,67 & 3 & 25,75 & 20,69 & 3 & 15,96 & $5 \mid$ & 20 & 186,73 & \begin{tabular}{|l|}
$\mid 34,18$ \\
\end{tabular} & 19 & 186,70 & 151,61 & 39 & \begin{tabular}{l|l|}
9 & 186,72 \\
\end{tabular} & \begin{tabular}{|l|}
242,82 \\
\end{tabular} \\
\hline Buri & E20 & 7 & 66,36 & 69,96 & 4 & 47,83 & 60,85 & 11 & 57,57 & 65,64 & 4 & 43,13 & 44,62 & 2 & 22,07 & 26,83 & 6 & 33,15 & \begin{tabular}{|l|}
57,40 \\
5
\end{tabular} & 14 & 142,68 | & \begin{tabular}{|l|l|}
840,04 \\
\end{tabular} & 14 & 154,52 & \begin{tabular}{|l|l|}
295,63 \\
\end{tabular} & 28 & \begin{tabular}{|l|l|}
8 & 148,29 \\
\end{tabular} & \begin{tabular}{|l|l|}
9 & 166,40 \\
\end{tabular} \\
\hline Buritama & E20 & 8 & \begin{tabular}{|l|l}
307,52 \\
\end{tabular} & 86,99 & 5 & 64,71 & 57,75 & 12 & 85,99 & 72,29 & 1 & 18,70 & \begin{tabular}{|r|}
16,18 \\
\end{tabular} & 2 & 32,35 & 27,25 & 4 & 25,57 & $\begin{array}{ll}71,45 \\
\end{array}$ & 15 & \begin{tabular}{|l|}
205,68 \\
\end{tabular} & \begin{tabular}{|l|l|}
8 & 158,74 \\
\end{tabular} & 15 & 212,62 & \begin{tabular}{|l|} 
\\
\end{tabular} & 30 & \begin{tabular}{|l|l|}
0 & 209,17 \\
\end{tabular} & \begin{tabular}{|l|l}
770,78 \\
\end{tabular} \\
\hline Buritizal & D20 & 2 & 126,93 & 92,55 & 2 & 112,46 & 95,33 & 4 & 119,82 & 93,91 & 0 & 18,13 & \begin{tabular}{|l|}
11,78 \\
\end{tabular} & 0 & 18,74 & 14,52 & 1 & \begin{tabular}{|l|}
18,43 \\
\end{tabular} & \begin{tabular}{|l|l|}
3 & 13,18 \\
\end{tabular} & 4 & \begin{tabular}{|l|}
217,59 \\
\end{tabular} & \begin{tabular}{|l|l|}
9 & 148,24 \\
\end{tabular} & 3 & 168,70 & \begin{tabular}{|l|l|} 
& 136,46 \\
\end{tabular} & & \begin{tabular}{|l|l|}
7 & 193,55 \\
\end{tabular} & \begin{tabular}{|l|l|}
5 & 142,45 \\
\end{tabular} \\
\hline Cabrália Pau & E20 & 4 & 159,36 & 168,47 & + & 39,98 & 40,20 & 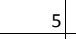 & 99,78 & 104,45 & 0 & 13,28 & 15,11 & 1 & 53,31 & 55,99 & 2 & 33,26 & \begin{tabular}{|l|l|}
5 & 33,68 \\
\end{tabular} & 6 & 239,04 & $\begin{array}{l}4 \\
422,06 \\
\end{array}$ & 7 & 266,56 & \begin{tabular}{|l|}
6 \\
\end{tabular} & 13 & \begin{tabular}{l|l|}
3 & 252,78 \\
\end{tabular} & \begin{tabular}{l|l}
8257,10 \\
8
\end{tabular} \\
\hline Cabreúva & C50 & 18 & \begin{tabular}{|l|l|}
87,39 \\
\end{tabular} & 112,28 & 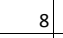 & 43,25 & 64,31 & 26 & 65,86 & 88,87 & 2 & 9,89 & 12,34 & 4 & 20,76 & 31,37 & 6 & 15,20 & \begin{tabular}{|l|l|}
0 & 21,11 \\
\end{tabular} & 34 & 169,84 & \begin{tabular}{|l|l|}
4 & 206,19 \\
\end{tabular} & 23 & 121,11 & \begin{tabular}{|l|} 
\\
\end{tabular} & 58 & \begin{tabular}{|l|l|}
8 & 146,06 \\
\end{tabular} & \begin{tabular}{|l|l|}
5 & 199,40 \\
\end{tabular} \\
\hline Caçapava & B100 & 47 & 117,41 & 124,45 & 31 & 76,36 & 80,66 & 78 & 96,74 & 102,40 & 11 & 28,31 & 30,37 & 14 & 34,48 & 37,02 & 25 & 31,42 & \begin{tabular}{|l|l|}
2 & 33,77 \\
\end{tabular} & 64 & 160,71 & \begin{tabular}{|l|l|}
169,41 \\
\end{tabular} & 54 & 132,19 & \begin{tabular}{l|l|}
941,30 \\
\end{tabular} & 118 & \begin{tabular}{l|l|}
8 & 146,35 \\
\end{tabular} & \begin{tabular}{|l|l|}
5 & 155,26 \\
\end{tabular} \\
\hline Cachoeira $\mathrm{Pa}$ & B50 & 15 & 104,28 & 89,09 & 16 & 107,28 & 99,13 & 31 & 105,79 & 94,15 & 5 & 32,44 & 29,14 & 6 & 43,37 & 39,08 & 11 & 37,95 & \begin{tabular}{|l|l|}
54,19 \\
\end{tabular} & 33 & \begin{tabular}{|l|}
229,42 \\
\end{tabular} & \begin{tabular}{|l|l|}
2 & 197,42 \\
\end{tabular} & 33 & 228,25 & 5207,31 & 66 & \begin{tabular}{|l|l|}
6 & 228,83 \\
\end{tabular} & \begin{tabular}{l|l}
3 & 202,40 \\
\end{tabular} \\
\hline Caconde & E20 & 13 & 135,96 & $\mid 107,87$ & 8 & 89,55 & 81,45 & 21 & 113,07 & 94,84 & 3 & 34,86 & 27,66 & 4 & 46,57 & 41,55 & 8 & 40,64 & \begin{tabular}{l|l|}
4 & 34,06 \\
\end{tabular} & 27 & 282,39 & \begin{tabular}{|l|l|}
9 & 209,98 \\
\end{tabular} & 22 & 236,42 & \begin{tabular}{|l|l|}
299,84 \\
\end{tabular} & 49 & \begin{tabular}{l|l|}
9 & 259,71 \\
\end{tabular} & $\begin{array}{ll}1104,98 \\
\end{array}$ \\
\hline Cafelândia & D20 & 11 & \begin{tabular}{|l|}
34,52 \\
\end{tabular} & 94,63 & 3 & 41,14 & 30,82 & 14 & 87,32 & 62,38 & 1 & 8,41 & 5,69 & 3 & 32,91 & 24,81 & 3 & 20,79 & \begin{tabular}{|l|l|}
9 & 15,16 \\
\end{tabular} & 24 & 298,46 & \begin{tabular}{|l|}
6 \\
5
\end{tabular} & 12 & 152,21 & $\begin{array}{l}115,85 \\
\end{array}$ & 36 & \begin{tabular}{l|l|}
6 & 224,54 \\
\end{tabular} & \begin{tabular}{l|l}
4 & 158,44 \\
\end{tabular} \\
\hline Caiabu & E20 & 2 & 108,95 & 76,42 & 1 & 98,22 & 79,33 & 4 & 103,72 & 77,84 & & & & 0 & 16,37 & 12,33 & 0 & 7,98 & \begin{tabular}{|l|l|}
8 & 5,78 \\
\end{tabular} & 4 & 186,77 & \begin{tabular}{|l|}
731,67 \\
\end{tabular} & 3 & 130,95 & \begin{tabular}{|l|}
508,36 \\
\end{tabular} & 7 & \begin{tabular}{l|l|}
7 & 159,57 \\
\end{tabular} & \begin{tabular}{|l|}
720,31 \\
\end{tabular} \\
\hline Caieras & C100 & 35 & 83,18 & 110,93 & 27 & 61,87 & 83,83 & 62 & 72,45 & 97,28 & 11 & 25,89 & 38,04 & 11 & 24,75 & 34,45 & 22 & 25,32 & \begin{tabular}{|l|l|}
2 & 36,26 \\
\end{tabular} & 67 & 156,94 & $\begin{array}{l}4 \\
4\end{array} 23,58$ & 57 & 131,47 & 797,45 & 123 & \begin{tabular}{l|l|}
3 & 144,11 \\
\end{tabular} & $\begin{array}{l}110,42 \\
\end{array}$ \\
\hline Caiuá & E20 & 3 & 125,77 & 107,97 & 2 & 91,45 & 99,97 & 5 & 109,35 & 104,14 & 1 & 27,95 & 20,43 & 1 & 30,48 & 27,76 & 1 & 29,16 & \begin{tabular}{|l|l|}
5 & 23,96 \\
\end{tabular} & 8 & 349,36 & 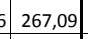 & 3 & 137,17 & \begin{tabular}{|l|}
726,76 \\
\end{tabular} & 11 & \begin{tabular}{l|l|}
1 & 247,87 \\
\end{tabular} & \begin{tabular}{|l|l}
799,97 \\
\end{tabular} \\
\hline Cajamar & c100 & 20 & 66,84 & \begin{tabular}{|l|}
94,28 \\
\end{tabular} & 21 & 71,40 & 103,74 & 40 & 69,10 & 98,97 & 6 & 20,39 & \begin{tabular}{|l|}
31,08 \\
\end{tabular} & 6 & 20,73 & 36,23 & 12 & 20,56 & \begin{tabular}{|l|l|}
5 & 33,73 \\
\end{tabular} & 53 & \begin{tabular}{|l|}
180,14 \\
\end{tabular} & \begin{tabular}{|l|l|}
4 & 244,78 \\
\end{tabular} & 41 & 141,65 & \begin{tabular}{|l|l|}
5 & 244,32 \\
\end{tabular} & 94 & \begin{tabular}{l|l|}
4 & 161,05 \\
\end{tabular} & 244,56 \\
\hline Cajati & D50 & 18 & 109,80 & 120,71 & 10 & 67,42 & 83,17 & 28 & 89,32 & 102,57 & 2 & 12,20 & 13,88 & 4 & 28,27 & 35,67 & 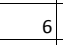 & \begin{tabular}{|l|}
19,97 \\
\end{tabular} & 23,78 & 26 & 160,63 & \begin{tabular}{|l|}
3173,68 \\
\end{tabular} & 18 & 115,26 & 5159,56 & 44 & \begin{tabular}{|l|l|}
4 & 138,71 \\
\end{tabular} & 166,86 \\
\hline Cajobi & E20 & 6 & 124,16 & 102,80 & 5 & 103,05 & 98,00 & 11 & 113,95 & 100,48 & 2 & 34,49 & 27,23 & 1 & 29,44 & 26,00 & 3 & 32,05 & 27,13 & 9 & 186,23 & \begin{tabular}{|l|l|}
351,97 \\
\end{tabular} & 6 & 125,14 & 109,09 & 15 & \begin{tabular}{l|l|}
5 & 156,68 \\
\end{tabular} & \begin{tabular}{|l|l|}
8131,23 \\
\end{tabular} \\
\hline Cajuru & E50 & 11 & 99,68 & \begin{tabular}{|l|l|}
399,47 \\
\end{tabular} & 12 & 108,68 & 99,62 & 23 & 104,12 & 94,48 & 1 & 12,08 & 10,50 & 4 & 40,37 & 36,77 & 6 & 26,03 & \begin{tabular}{|l|l|} 
& 23,11 \\
\end{tabular} & 25 & 223,52 & \begin{tabular}{|l|l|}
2 & 187,08 \\
\end{tabular} & 20 & 183,20 & $\mid 163,38$ & 44 & \begin{tabular}{l|l|}
4 & 203,64 \\
\end{tabular} & \begin{tabular}{l|l}
4 & 175,39 \\
\end{tabular} \\
\hline Campina do Monte Alegre & E20 & 3 & 100,86 & 64,66 & 3 & 94,67 & 96,72 & 6 & 97,85 & 80,25 & & & & 0 & 11,83 & 11,26 & 0 & 5,76 & \begin{tabular}{|l|l|}
5 & 4,72 \\
\end{tabular} & 8 & 280,17 & 217,73 & 6 & 224,85 & 216,65 & 15 & \begin{tabular}{l|l|l}
5 & 253,27 \\
\end{tabular} & 217,20 \\
\hline Campinas & 10000 & 598 & 119,98 & 113,86 & 507 & 96,55 & 89,08 & 1105 & 107,96 & 101,15 & 62 & 12,37 & 11,71 & 82 & 15,68 & 14,51 & 144 & 14,07 & 13,15 & 972 & 194,98 & \begin{tabular}{|l|l|}
8 & 180,38 \\
\end{tabular} & 894 & 170,31 & 155,72 & 1867 & \begin{tabular}{l|l|}
7 & 182,33 \\
\end{tabular} & \begin{tabular}{|l|l|}
167,73 \\
\end{tabular} \\
\hline Campo Limpo Paulista & C100 & 30 & 84,64 & 101,49 & 26 & 72,07 & 93,05 & 56 & 78,33 & 97,26 & 5 & 14,88 & 17,64 & 9 & 24,02 & 32,22 & 14 & 19,47 & 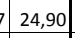 & 79 & 220,43 & 3262,05 & 66 & 183,88 & 841,35 & 145 & \begin{tabular}{l|l|}
5 & 202,09 \\
\end{tabular} & \begin{tabular}{|l|l|}
9251,67 \\
\end{tabular} \\
\hline Campos do Jordao & C50 & 19 & 82,08 & 100,96 & 14 & 60,04 & 74,94 & 34 & 70,98 & 87,87 & 7 & 28,30 & 33,91 & 6 & 26,53 & 34,56 & 13 & 27,41 & \begin{tabular}{|l|}
14,26 \\
\end{tabular} & 57 & 243,40 & | 293,16 & 39 & 161,96 & 5223,64 & 96 & \begin{tabular}{l|l|}
6 & 202,40 \\
\end{tabular} & \begin{tabular}{|l|l}
258,17 \\
\end{tabular} \\
\hline Campos № & E20 & 1 & 45,35 & 38,46 & 3 & 130,08 & 115,96 & 4 & 86,17 & 75,80 & & & & 2 & 81,30 & 67,92 & 2 & 39,17 & $\begin{array}{l}70,81 \\
\end{array}$ & 7 & 302,34 & $4 \quad 228,64$ & 3 & 130,08 & \begin{tabular}{|l|}
8117,20 \\
\end{tabular} & 9 & \begin{tabular}{l|l|}
9 & 219,35 \\
\end{tabular} & \begin{tabular}{|l|l}
5 & 174,95 \\
\end{tabular} \\
\hline Cananéia & E20 & 10 & 142,23 & 135,58 & 4 & 60,18 & 65,56 & 14 & 101,66 & 100,96 & 2 & 29,43 & 28,39 & 2 & 25,07 & 25,79 & 4 & 27,27 & \begin{tabular}{|l|}
7 \\
\end{tabular} & 15 & 220,70 & | 204,55 & 9 & 130,38 & 8 133,81 & 24 & \begin{tabular}{l|l|}
4 & 176,04 \\
\end{tabular} & \begin{tabular}{l|l}
4 & 169,57 \\
\end{tabular} \\
\hline Canas & E20 & 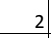 & 82,35 & 82,99 & & & & 2 & 42,47 & 42,80 & 1 & 32,94 & 33,10 & 1 & 35,08 & 38,73 & 1 & \begin{tabular}{|l|}
33,98 \\
\end{tabular} & \begin{tabular}{|l|l|}
85,69 \\
\end{tabular} & 4 & 197,63 & \begin{tabular}{|l|l|}
399,62 \\
\end{tabular} & 4 & 228,03 & 268,13 & & \begin{tabular}{|l|l|}
8 & 212,35 \\
\end{tabular} & \begin{tabular}{|l|l}
52,79 \\
\end{tabular} \\
\hline Cândido Mota & D50 & 15 & 96,80 & 80,31 & 11 & 68,83 & 62,50 & 26 & 82,81 & 71,40 & 4 & 25,81 & 22,14 & 4 & 25,81 & 24,27 & 8 & 25,81 & \begin{tabular}{l|l|}
1 & 23,32 \\
\end{tabular} & 27 & 172,09 & $\begin{array}{l}9 \\
9\end{array}$ & 22 & 144,11 & 128,48 & 49 & \begin{tabular}{l|l|}
9 & 158,10 \\
\end{tabular} & \begin{tabular}{|l|l|}
129,49 \\
\end{tabular} \\
\hline Cândido Rodrigues & E20 & 2 & 148,85 & 75,86 & 1 & 95,51 & 78,93 & 3 & 121,67 & 77,42 & 0 & 24,81 & 12,68 & 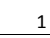 & 47,76 & 30,06 & 1 & 36,50 & 20,86 & 4 & 272,89 & \begin{tabular}{|l|l|}
950,07 \\
\end{tabular} & 3 & 191,02 & 2126,05 & 6 & \begin{tabular}{l|l|}
6 & 231,17 \\
\end{tabular} & \begin{tabular}{|l|l}
737,83 \\
\end{tabular} \\
\hline Canitar & E20 & 2 & 116,22 & 128,53 & & & & 2 & 59,11 & 65,37 & 1 & 33,21 & 34,11 & 1 & 51,56 & 55,53 & 2 & 42,23 & \begin{tabular}{|l|l|}
3 & 46,17 \\
\end{tabular} & 3 & 149,43 & \begin{tabular}{|l|l|}
363,47 \\
\end{tabular} & 1 & 68,74 & \begin{tabular}{|l|l|}
4 & 82,96 \\
\end{tabular} & 4 & \begin{tabular}{|l|l|}
4 & 109,78 \\
\end{tabular} & \begin{tabular}{|l|l|}
823,91 \\
\end{tabular} \\
\hline Capao Bonito & E50 & 18 & 75,03 & 75,20 & 18 & 78,62 & 90,92 & 36 & 76,82 & 83,02 & 10 & 43,88 & 43,97 & 10 & 41,46 & 47,31 & 20 & 42,68 & \begin{tabular}{|l|l|}
8 & 45,87 \\
\end{tabular} & 52 & 222,25 & 5209,24 & 41 & 177,26 & 5207,43 & 94 & \begin{tabular}{l|l|}
4 & 199,87 \\
\end{tabular} & 208,34 \\
\hline Capela do Alto & D20 & 7 & 90,41 & 90,90 & 5 & 69,37 & 82,70 & 13 & 80,17 & 86,91 & 1 & 12,33 & 11,98 & & 26,01 & 30,69 & & 18,99 & \begin{tabular}{|l|l|}
9 & 20,48 \\
\end{tabular} & 10 & 119,18 & \begin{tabular}{|l|l|}
8 & 119,98 \\
\end{tabular} & 10 & $\mid 130,07$ & \begin{tabular}{|l|l|}
763,83 \\
\end{tabular} & 20 & \begin{tabular}{l|l|}
0 & 124,48 \\
\end{tabular} & \begin{tabular}{|l|l|l}
8 & 141,32 \\
\end{tabular} \\
\hline
\end{tabular}


Anexo 23 - $\mathrm{N}^{\circ}$ de óbitos e taxa de mortalidade (bruta e padronizada) total e segundo sexo por Neoplasias, Diabetes Mellitus e Doenças do Aparelho Circulatório, municípios. Estado de São Paulo, média do triênio 2003-2005

\begin{tabular}{|c|c|c|c|c|c|c|c|c|c|c|c|c|c|c|c|c|c|c|c|c|c|c|c|c|c|c|c|c|}
\hline \multirow[b]{3}{*}{ Capivari } & \multirow[b]{3}{*}{ C50 } & \multicolumn{9}{|c|}{ Neoplasias Malignas } & \multicolumn{9}{|c|}{ Diabetes Mellitus } & \multicolumn{9}{|c|}{ Aparelho Circulatorio } \\
\hline & & \multicolumn{3}{|c|}{ Homens } & \multicolumn{3}{|c|}{ Mulheres } & \multicolumn{3}{|c|}{ Total } & \multicolumn{3}{|c|}{ Homens } & \multicolumn{3}{|c|}{ Mulheres } & \multicolumn{3}{|c|}{ Total } & \multicolumn{3}{|c|}{ Homens } & \multicolumn{3}{|c|}{ Mulheres } & \multicolumn{3}{|c|}{ Total } \\
\hline & & 27 & 121,44 & 120,12 & 18 & 80,10 & 76,64 & 45 & 100,66 & 98,26 & 4 & 17,99 & 17,65 & 7 & 32,63 & 31,67 & 11 & 25,35 & \begin{tabular}{|l|l|}
5 & 24,78 \\
\end{tabular} & 33 & 149,93 & $3 \mid 141,39$ & 41 & 182,45 & 170,61 & 74 & $\begin{array}{l}4 \\
166,28 \\
\end{array}$ & \begin{tabular}{|l|l}
856,08 \\
\end{tabular} \\
\hline Caraguatatuba & C100 & 43 & 95,07 & 98,85 & 33 & 72,63 & 82,01 & 76 & 83,93 & 90,49 & 10 & 22,67 & 23,53 & 8 & 18,53 & 20,55 & 19 & 20,61 & 122,23 & 62 & 136,03 & $|141,90|$ & 49 & 108,21 & 126,83 & 111 & \begin{tabular}{l|l|}
1 & 122,21 \\
\end{tabular} & 134,42 \\
\hline Carapicuiba & C500 & 122 & 66,96 & 102,82 & 105 & 55,37 & 81,29 & 227 & 61,05 & 91,84 & 15 & 8,23 & 12,46 & 22 & 11,43 & 19,33 & 37 & 9,86 & | 15,99 & 274 & 150,58 & 8228,42 & 218 & 115,14 & 192,37 & 493 & \begin{tabular}{l|l|}
3 & 132,50 \\
\end{tabular} & 210,03 \\
\hline Cardoso & E20 & 8 & 142,90 & 94,41 & 5 & 87,67 & 65,47 & 13 & 115,03 & 79,80 & 1 & 23,82 & 17,18 & 2 & 29,22 & 23,23 & 3 & 26,54 & $\begin{array}{l}4 \\
4\end{array}$ & 20 & 357,25 & 5218,20 & 13 & 227,94 & 472,45 & 33 & \begin{tabular}{l|l|}
3 & 291,99 \\
\end{tabular} & \begin{tabular}{l|l}
9 & 195,12 \\
\end{tabular} \\
\hline Casa Branca & B50 & 16 & 112,76 & 81,68 & 12 & 89,87 & 74,09 & 28 & 101,94 & 78,09 & 5 & 32,22 & 24,95 & 6 & 43,65 & 36,52 & 10 & \begin{tabular}{|l|}
37,62 \\
\end{tabular} & \begin{tabular}{|l|}
20,24 \\
\end{tabular} & 50 & 342,89 & \begin{tabular}{|l|l|}
9 & 223,67 \\
\end{tabular} & 34 & 259,35 & \begin{tabular}{|l|l|}
595,03 \\
\end{tabular} & 83 & \begin{tabular}{|l|l|}
3 & 303,41 \\
\end{tabular} & 210,13 \\
\hline Cássia dos Coqueiros & E20 & 2 & 152,97 & 109,63 & 1 & 70,70 & 71,12 & 3 & 113,39 & 91,10 & & & & 0 & 23,57 & 20,80 & 0 & 11,34 & \begin{tabular}{|l|}
48,80 \\
\end{tabular} & 4 & 240,38 & \begin{tabular}{|l|l|}
8 & 166,29 \\
\end{tabular} & 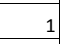 & 94,27 & \begin{tabular}{|l|}
72,91 \\
\end{tabular} & 5 & \begin{tabular}{|l|l|}
5 & 170,09 \\
\end{tabular} & 130,98 \\
\hline Castilho & E20 & 9 & 119,25 & 93,87 & 4 & 57,37 & 54,20 & 13 & 88,30 & 74,03 & 2 & 26,50 & 19,75 & 3 & 44,13 & 39,73 & 5 & 35,32 & 29,14 & 11 & 141,33 & 98,61 & 10 & 132,40 & 123,65 & 21 & \begin{tabular}{l|l|}
1 & 136,86 \\
\end{tabular} & \begin{tabular}{|l|l}
5 & 111,14 \\
\end{tabular} \\
\hline Catanduva & B300 & 69 & 125,68 & 98,10 & 53 & 91,74 & 70,10 & 122 & 108,37 & 83,82 & 9 & 16,92 & 12,98 & 12 & 21,48 & $15,93 \mid$ & 22 & 19,25 & \begin{tabular}{|l|l|}
5 & 14,46 \\
\end{tabular} & 142 & 258,00 & $\begin{array}{l}0 \\
\end{array}$ & 128 & 223,54 & $4 \quad 161,32$ & 271 & $\begin{array}{l}1.240,43 \\
\end{array}$ & \begin{tabular}{l|l} 
B & 176,12 \\
\end{tabular} \\
\hline Catiguá & E20 & 5 & 145,55 & 123,28 & 4 & 112,77 & 108,33 & 9 & 129,61 & 116,01 & & & & & & & & & & 10 & 300,80 & 242,52 & 7 & 215,30 & 187,86 & 17 & \begin{tabular}{l|l|}
7 & 259,22 \\
\end{tabular} & \begin{tabular}{|l|l|}
215,94 \\
\end{tabular} \\
\hline Cedral & E20 & 6 & 166,74 & 95,52 & 6 & 159,76 & 106,84 & 12 & 163,28 & 101,14 & & & & 1 & 18,80 & 12,05 & 1 & 9,33 & 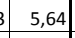 & 10 & 277,91 & 168,34 & 6 & 159,76 & $5 \mid 101,17$ & 16 & \begin{tabular}{l|l|}
6 & 219,26 \\
\end{tabular} & \begin{tabular}{|l|l}
5 & 135,00 \\
\end{tabular} \\
\hline Cerqueira César & D20 & 10 & 119,57 & 94,27 & 7 & 86,61 & 75,36 & 17 & 103,09 & 84,82 & 1 & 16,49 & 13,34 & 2 & 24,74 & 22,31 & 3 & 20,62 & \begin{tabular}{|l|l|}
2 & 17,88 \\
\end{tabular} & 16 & 202,03 & \begin{tabular}{|l|l|}
351,77 \\
\end{tabular} & 13 & 164,96 & \begin{tabular}{|l|l|}
6 & 140,30 \\
\end{tabular} & 30 & \begin{tabular}{l|l|}
0 & 183,50 \\
\end{tabular} & \begin{tabular}{|l|l|}
146,04 \\
\end{tabular} \\
\hline Cerquilho & B50 & 18 & 108,72 & 105,24 & 13 & 77,06 & 80,07 & 31 & 92,88 & 92,65 & 2 & 11,86 & 11,52 & 3 & 19,76 & 19,74 & 5 & 15,81 & \begin{tabular}{l|l}
1 & 15,53 \\
\end{tabular} & 27 & 162,09 & \begin{tabular}{|l|l|}
954,60 \\
\end{tabular} & 24 & 144,23 & \begin{tabular}{|l|l|}
348,34 \\
\end{tabular} & 52 & \begin{tabular}{|l|l|}
2 & 153,16 \\
\end{tabular} & \begin{tabular}{|l|l}
5 & 151,47 \\
\end{tabular} \\
\hline Cesário Lange & E20 & 7 & 93,17 & 88,04 & 4 & 66,65 & 65,87 & 11 & 80,55 & 77,49 & 3 & 37,27 & 34,03 & 3 & 46,14 & 45,00 & 6 & 41,49 & 39,25 & 17 & 242,24 & \begin{tabular}{ll|}
4 & 217,96 \\
\end{tabular} & 17 & 261,48 & 8255,53 & 34 & \begin{tabular}{l|l|}
4 & 251,40 \\
\end{tabular} & 235,85 \\
\hline Charqueada & D20 & 6 & 80,04 & 70,31 & 5 & 76,35 & 78,94 & 11 & 78,21 & 74,60 & 2 & 28,25 & $25,64 \mid$ & 1 & $\begin{array}{r}14,32 \\
\end{array}$ & \begin{tabular}{|l|}
14,38 \\
\end{tabular} & 3 & 21,33 & \begin{tabular}{|l|l|}
3 & 20,45 \\
\end{tabular} & 17 & \begin{tabular}{|l|}
235,42 \\
\end{tabular} & \begin{tabular}{|l|}
203,77 \\
\end{tabular} & 11 & 157,47 & \begin{tabular}{|l|}
768,92 \\
\end{tabular} & 28 & \begin{tabular}{l|l|}
8 & 196,71 \\
\end{tabular} & \begin{tabular}{|l|l|}
186,46 \\
\end{tabular} \\
\hline Chavantes & D20 & 7 & 107,79 & 95,92 & 4 & 58,94 & 56,44 & 10 & 83,29 & 76,13 & 1 & 21,56 & $\begin{array}{l}19,21 \\
\end{array}$ & 3 & 42,86 & \begin{tabular}{|l|}
40,31 \\
\end{tabular} & 4 & \begin{tabular}{|l|}
32,24 \\
\end{tabular} & \begin{tabular}{|l|l|}
4 & 29,71 \\
\end{tabular} & 15 & \begin{tabular}{|l|}
237,13 \\
\end{tabular} & \begin{tabular}{|l|l|}
3 & 211,16 \\
\end{tabular} & 15 & 235,75 & 5220,51 & 29 & \begin{tabular}{l|l|}
9 & 236,44 \\
\end{tabular} & \begin{tabular}{l|l}
4 & 215,85 \\
\end{tabular} \\
\hline Clementina & E20 & 3 & 91,24 & 79,79 & 2 & 73,70 & 72,51 & 5 & 82,80 & 76,28 & 0 & 11,41 & 9,48 & 0 & 12,28 & 11,46 & 1 & 11,83 & \begin{tabular}{|l|l|}
$\mathbf{B}$ & 10,50 \\
\end{tabular} & 3 & 91,24 & \begin{tabular}{|l|l|}
4 & 73,93 \\
\end{tabular} & 3 & 98,27 & 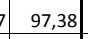 & 5 & \begin{tabular}{l|l|}
5 & 94,62 \\
\end{tabular} & \begin{tabular}{l|l}
2 & 85,22 \\
\end{tabular} \\
\hline Colina & D20 & 8 & 97,75 & 85,50 & 7 & 82,59 & 69,51 & 15 & 90,19 & 77,52 & 2 & 19,55 & 16,54 & 3 & 39,33 & \begin{tabular}{|l|}
34,42 \\
\end{tabular} & 5 & 29,41 & 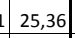 & 23 & \begin{tabular}{|l|} 
\\
\end{tabular} & \begin{tabular}{|l|l|}
8 & 216,92 \\
\end{tabular} & 22 & 259,57 & 230,68 & 45 & \begin{tabular}{|l|l|}
5 & 262,73 \\
\end{tabular} & \begin{tabular}{|l|l}
823,78 \\
\end{tabular} \\
\hline Colômbia & E20 & 2 & 61,62 & 76,10 & 3 & 88,61 & 99,74 & 5 & 74,61 & 87,47 & & & & & & & & & & 4 & \begin{tabular}{|l|}
133,51 \\
\end{tabular} & \begin{tabular}{|l|}
139,42 \\
\end{tabular} & 6 & 188,30 & 267,27 & 10 & \begin{tabular}{l|l|}
0 & 159,87 \\
\end{tabular} & 200,93 \\
\hline Conchal & E50 & 12 & 95,78 & 104,86 & 8 & 63,80 & 75,81 & 19 & 79,90 & 90,44 & 1 & 10,95 & 11,95 & 1 & 5,55 & 6,50 & 2 & 8,27 & \begin{tabular}{|l|l|}
7 & 9,40 \\
\end{tabular} & 23 & 191,57 & \begin{tabular}{|l|}
7209,22 \\
\end{tabular} & 21 & 171,99 & 203,96 & 44 & \begin{tabular}{|l|l|}
4 & 181,84 \\
\end{tabular} & $4 \quad 206,61$ \\
\hline Conchas & $\mathrm{C} 20$ & 10 & 116,42 & 81,26 & 8 & 104,87 & 84,33 & 18 & 110,77 & 82,76 & 1 & 8,03 & 6,36 & 2 & 29,36 & 21,38 & 3 & 18,46 & \begin{tabular}{|l|l|}
5 & 13,35 \\
\end{tabular} & 28 & 341,23 & \begin{tabular}{|l|l|}
3 & 241,58 \\
\end{tabular} & 19 & 243,30 & 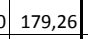 & 48 & \begin{tabular}{|l|l|}
8 & 293,34 \\
\end{tabular} & \begin{tabular}{l|l}
4 & 211,10 \\
\end{tabular} \\
\hline Cordeirópoli & C20 & 9 & 95,77 & 93,51 & 8 & 82,09 & 78,62 & 17 & 88,93 & 86,07 & 1 & 10,26 & 9,90 & 1 & 10,26 & 9,96 & 2 & 10,26 & \begin{tabular}{|l|l|}
5 & 9,86 \\
\end{tabular} & 19 & 191,54 & \begin{tabular}{ll|}
4 & 186,29 \\
\end{tabular} & 14 & \begin{tabular}{|l|}
443,66 \\
\end{tabular} & 5. 138,14 & 33 & \begin{tabular}{l|l|}
3 & 167,60 \\
\end{tabular} & \begin{tabular}{|l|l}
162,22 \\
\end{tabular} \\
\hline Coroados & E20 & 2 & 101,10 & 88,87 & 2 & 87,74 & 88,61 & 4 & 94,46 & 88,74 & 0 & 14,44 & 11,66 & & & & 0 & 7,27 & 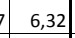 & 5 & 202,20 & \begin{tabular}{|l|l|}
0 & 163,09 \\
\end{tabular} & 8 & 116,99 & \begin{tabular}{|l|}
118,50 \\
\end{tabular} & 4 & \begin{tabular}{|l|l|}
7 & 159,86 \\
\end{tabular} & \begin{tabular}{|l|l|}
5 & 140,94 \\
\end{tabular} \\
\hline Coronel Maced & E20 & 3 & 93,98 & 74,85 & 1 & 49,73 & 62,84 & 4 & 72,49 & 69,01 & 1 & 46,99 & 42,14 & 1 & 37,30 & 38,13 & 2 & 42,29 & \begin{tabular}{|l|l|}
9 & 40,92 \\
\end{tabular} & 4 & 152,73 & \begin{tabular}{|l|l|}
317,49 \\
\end{tabular} & 3 & 99,47 & 117,07 & 7 & \begin{tabular}{l|l|}
7 & 126,85 \\
\end{tabular} & \begin{tabular}{|l|l|}
517,29 \\
\end{tabular} \\
\hline Corumbataí & D20 & 1 & 46,85 & 39,55 & 2 & 85,75 & 78,03 & 3 & 65,39 & 57,89 & & & & 0 & 17,15 & 14,45 & 0 & 8,17 & \begin{tabular}{l|}
7 \\
\end{tabular} & 2 & 93,71 & \begin{tabular}{|l|l|}
1 & 80,83 \\
\end{tabular} & 1 & 51,45 & \begin{tabular}{|l|l|}
5 & 45,05 \\
\end{tabular} & 3 & \begin{tabular}{|l|l|}
3 & 73,57 \\
\end{tabular} & \begin{tabular}{|l|l}
7 & 63,77 \\
\end{tabular} \\
\hline Cosmópolis & B50 & 26 & 107,95 & 115,23 & 18 & 76,39 & 85,72 & 44 & 92,20 & 100,50 & 5 & 19,38 & 20,58 & 5 & 22,22 & 25,13 & 10 & 20,80 & $|22,87|$ & 39 & 163,32 & \begin{tabular}{|l|l|}
2 & 165,01 \\
\end{tabular} & 35 & 144,45 & $5 \mid 164,40$ & 74 & \begin{tabular}{|l|l|}
4 & 153,90 \\
\end{tabular} & \begin{tabular}{|l|l} 
& 164,71 \\
\end{tabular} \\
\hline Cosmorama & E20 & 6 & 174,68 & 109,17 & 3 & 94,12 & 74,50 & 10 & 134,87 & 92,04 & 0 & 9,19 & 4,91 & 0 & 9,41 & 6,02 & 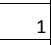 & 9,30 & 5,48 & 16 & 441,30 & \begin{tabular}{|l|l|}
0258,04 \\
\end{tabular} & 9 & 263,53 & \begin{tabular}{|l|}
179,62 \\
\end{tabular} & 25 & \begin{tabular}{|l|l|}
5 & 353,46 \\
\end{tabular} & 219,29 \\
\hline Cotia & C300 & 83 & 100,22 & 131,92 & 67 & 79,08 & 108,26 & 150 & 89,53 & 119,95 & 14 & 16,50 & 22,40 & 16 & 18,89 & $28,61 \mid$ & 30 & 17,71 & \begin{tabular}{|l|}
1 \\
\end{tabular} & 156 & 187,96 & $6 \quad 241,01$ & 136 & 160,92 & 245,88 & 292 & \begin{tabular}{|l|l|}
2 & 174,29 \\
\end{tabular} & \begin{tabular}{|l|l}
9 & 243,47 \\
\end{tabular} \\
\hline Cravinhos & D50 & 19 & 122,38 & 123,46 & 12 & 81,00 & 80,35 & 32 & 102,07 & 102,30 & 1 & 4,22 & 4,21 & 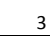 & 17,51 & 17,37 & 3 & 10,74 & \begin{tabular}{|l|l|}
4 & 10,73 \\
\end{tabular} & 32 & \begin{tabular}{|l|}
204,68 \\
\end{tabular} & \begin{tabular}{|l|l|}
8 & 199,64 \\
\end{tabular} & 24 & 157,63 & \begin{tabular}{|l|l|}
356,54 \\
\end{tabular} & 56 & \begin{tabular}{l|l|}
6 & 181,58 \\
\end{tabular} & \begin{tabular}{|l|l|}
878,49 \\
\end{tabular} \\
\hline Cristais Paulista & E20 & 2 & 64,56 & 63,43 & 2 & 59,16 & 64,16 & 4 & 61,95 & 63,78 & 1 & 18,45 & 19,37 & 1 & 29,58 & 30,59 & 2 & 23,83 & \begin{tabular}{|l|l|}
3 & 24,79 \\
\end{tabular} & 4 & 119,89 & \begin{tabular}{|l|l|}
9 & 106,78 \\
\end{tabular} & 4 & 128,18 & \begin{tabular}{|l|l|}
834,67 \\
\end{tabular} & 9 & \begin{tabular}{l|l|}
9 & 123,90 \\
\end{tabular} & \begin{tabular}{|l|l|}
120,26 \\
\end{tabular} \\
\hline Cruzália & D20 & 1 & 76,96 & 59,50 & 1 & 103,55 & 88,23 & 2 & 90,19 & 73,80 & 0 & 25,65 & 19,97 & 0 & 25,89 & 22,42 & 1 & 25,77 & 21,29 & 1 & 102,62 & \begin{tabular}{|l|l|}
2 & 84,42 \\
\end{tabular} & 1 & 77,66 & \begin{tabular}{|l|l|}
5 & 66,70 \\
\end{tabular} & 2 & \begin{tabular}{|l|l|}
2 & 90,19 \\
\end{tabular} & \begin{tabular}{l|l}
9 & 75,60 \\
\end{tabular} \\
\hline Cruzeiro & B100 & 48 & 130,29 & 126,65 & 32 & 82,98 & 78,93 & 80 & 106,18 & 102,33 & 13 & 35,04 & 33,75 & 13 & 32,85 & $30,97 \mid$ & 26 & 33,92 & \begin{tabular}{|l|l|}
2 & 32,24 \\
\end{tabular} & 76 & 205,77 & \begin{tabular}{ll|l|}
7 & 198,16 \\
\end{tabular} & 84 & 218,70 & 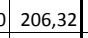 & 161 & \begin{tabular}{l|l|}
1 & 212,36 \\
\end{tabular} & \begin{tabular}{|l|l}
5 & 202,32 \\
\end{tabular} \\
\hline Cubatao & C300 & 41 & 70,22 & 97,04 & 46 & 79,30 & 112,48 & 87 & 74,73 & 104,71 & 8 & 13,13 & 18,35 & 10 & 17,94 & \begin{tabular}{|l|}
25,67 \\
\end{tabular} & 18 & 15,52 & \begin{tabular}{|l|}
21,94 \\
\end{tabular} & 91 & 155,85 & $5 \mid 212,45$ & 71 & 123,87 & 192,85 & 162 & \begin{tabular}{|l|l|}
2 & 139,97 \\
\end{tabular} & $\begin{array}{ll}702,72 \\
\end{array}$ \\
\hline Cunha & E50 & 14 & 120,65 & 105,87 & 7 & 63,38 & 69,55 & 21 & 93,06 & 88,37 & 3 & 22,45 & 18,62 & 5 & 45,27 & 48,43 & 8 & 33,44 & \begin{tabular}{l|l|}
4 & 31,31 \\
\end{tabular} & 25 & 213,24 & \begin{tabular}{|l|l|}
4 & 177,03 \\
\end{tabular} & 25 & 226,35 & 5255,30 & 50 & \begin{tabular}{l|l|}
0 & 219,56 \\
\end{tabular} & \begin{tabular}{|c|c|}
5 & 214,74 \\
\end{tabular} \\
\hline Descalvado & D50 & 22 & 143,23 & 120,91 & 14 & 92,03 & 81,85 & 36 & 117,56 & 101,33 & 1 & 6,61 & 5,20 & 3 & 19,72 & 16,29 & 4 & 13,18 & \begin{tabular}{|l|l|}
8 & 10,67 \\
\end{tabular} & 39 & 257,81 & $\begin{array}{l}1 \\
103,76 \\
\end{array}$ & 36 & 238,85 & \begin{tabular}{|l|}
5 \\
\end{tabular} & 75 & \begin{tabular}{l|l|}
5 & 248,30 \\
\end{tabular} & 0,89 \\
\hline Diadema & C500 & 154 & 82,42 & 125,25 & 142 & 73,29 & 110,07 & 296 & 77,77 & 117,51 & 33 & 17,52 & 27,42 & 31 & 16,17 & \begin{tabular}{|l|}
25,92 \\
\end{tabular} & 64 & \begin{tabular}{|l|}
16,83 \\
\end{tabular} & \begin{tabular}{|l|l|}
3 & 26,66 \\
\end{tabular} & 327 & \begin{tabular}{|l|}
175,38 \\
\end{tabular} & \begin{tabular}{|l|l|}
8 & 262,16 \\
\end{tabular} & 283 & 146,24 & 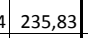 & 610 & \begin{tabular}{l|l|}
0 & 160,53 \\
\end{tabular} & \begin{tabular}{|l|l}
8 & 248,74 \\
\end{tabular} \\
\hline Dirce Reis & E20 & 1 & 86,32 & 53,49 & 1 & 91,91 & 47,77 & 1 & 89,03 & 50,72 & & & & 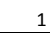 & 91,91 & \begin{tabular}{|l|}
64,47 \\
\end{tabular} & 1 & \begin{tabular}{|l|}
4,50 \\
\end{tabular} & \begin{tabular}{|l|l|}
0 & 27,42 \\
\end{tabular} & 1 & \begin{tabular}{|l|}
129,48 \\
\end{tabular} & \begin{tabular}{l|l|}
8 & 71,22 \\
\end{tabular} & 2 & 229,78 & \begin{tabular}{|l|l|}
8 & 178,95 \\
\end{tabular} & 3 & \begin{tabular}{l|l|}
3 & 178,05 \\
\end{tabular} & \begin{tabular}{l|l}
523,39 \\
\end{tabular} \\
\hline Divinolândia & E20 & 7 & 118,55 & 91,72 & 3 & 56,30 & 50,67 & 11 & 88,11 & 71,65 & 1 & 21,55 & 18,26 & 5 & 84,45 & $72,61 \mid$ & 6 & \begin{tabular}{|l|}
52,31 \\
\end{tabular} & \begin{tabular}{|l|l|}
1 & 42,65 \\
\end{tabular} & 16 & 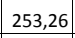 & \begin{tabular}{|l|l|}
6 & 178,25 \\
\end{tabular} & 16 & 270,24 & $\begin{array}{l}4242,80 \\
\end{array}$ & 32 & \begin{tabular}{|l|l|}
2 & 261,56 \\
\end{tabular} & \begin{tabular}{|l|l|}
5 & 209,82 \\
\end{tabular} \\
\hline Dobrada & E20 & 2 & 62,76 & 70,76 & 1 & 40,04 & 42,51 & 4 & 52,02 & 57,41 & & & & & & & & & & 6 & \begin{tabular}{|l|}
152,43 \\
\end{tabular} & \begin{tabular}{|l|l|}
3 & 171,47 \\
\end{tabular} & 1 & 220,20 & 245,86 & 13 & \begin{tabular}{|l|l|}
3 & 184,45 \\
\end{tabular} & 206,62 \\
\hline Dois Córregos & D50 & 17 & 140,19 & 107,16 & 15 & 127,33 & 95,84 & 32 & 133,78 & 101,52 & 4 & 32,99 & 25,15 & 5 & 44,29 & 32,23 & 9 & 38,62 & \begin{tabular}{|l|l|}
28,77 \\
\end{tabular} & 33 & 274,88 & $\begin{array}{l}804,35 \\
8\end{array}$ & 28 & 235,28 & \begin{tabular}{|l|l|}
8 & 168,13 \\
\end{tabular} & 62 & \begin{tabular}{l|l|}
2 & 255,15 \\
\end{tabular} & \begin{tabular}{|l|l}
56,30 \\
\end{tabular} \\
\hline Dolcinópolis & E20 & 1 & 117,44 & 100,23 & 2 & 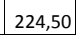 & 186,65 & 4 & 168,61 & 141,54 & 0 & 29,36 & 23,67 & & \begin{tabular}{|l|}
64,14 \\
\end{tabular} & 48,51 & 1 & \begin{tabular}{|l|}
45,98 \\
\end{tabular} & \begin{tabular}{|l|l|}
81,66 \\
\end{tabular} & & \begin{tabular}{|l|}
293,60 \\
\end{tabular} & \begin{tabular}{|l|l|}
0 & 190,58 \\
\end{tabular} & & 192,43 & \begin{tabular}{|l|l|}
372,38 \\
\end{tabular} & & 245,25 & \begin{tabular}{|l|l|}
5 & 181,88 \\
\end{tabular} \\
\hline
\end{tabular}


Anexo 23 - $\mathrm{N}^{\circ}$ de óbitos e taxa de mortalidade (bruta e padronizada) total e segundo sexo por Neoplasias, Diabetes Mellitus e Doenças do Aparelho Circulatório, municípios. Estado de São Paulo, média do triênio 2003-2005

\begin{tabular}{|c|c|c|c|c|c|c|c|c|c|c|c|c|c|c|c|c|c|c|c|c|c|c|c|c|c|c|c|c|}
\hline \multirow[b]{3}{*}{ Dourado } & \multirow[b]{3}{*}{ E20 } & \multicolumn{9}{|c|}{ Neoplasias Malignas } & \multicolumn{9}{|c|}{ Diabetes Mellitus } & \multicolumn{9}{|c|}{ Aparelho Circulatorio } \\
\hline & & \multicolumn{3}{|c|}{ Homens } & \multicolumn{3}{|c|}{ Mulheres } & \multicolumn{3}{|c|}{ Total } & \multicolumn{3}{|c|}{ Homens } & \multicolumn{3}{|c|}{ Mulheres } & \multicolumn{3}{|c|}{ Total } & \multicolumn{3}{|c|}{ Homens } & \multicolumn{3}{|c|}{ Mulheres } & \multicolumn{3}{|c|}{ Total } \\
\hline & & 6 & 130,39 & 89,05 & 2 & 37,96 & 28,72 & 8 & 85,25 & 59,59 & 1 & 21,73 & 17,05 & 0 & 7,59 & 5,40 & 1 & 14,83 & \begin{tabular}{|l|l|}
3 & 11,87 \\
\end{tabular} & 12 & 268,02 & 2176,41 & 8 & 189,78 & \begin{tabular}{l|l|}
8137,57 \\
\end{tabular} & 21 & 229,82 & \begin{tabular}{|l|l|}
257,44 \\
\end{tabular} \\
\hline Dracena & D50 & 30 & 152,51 & 104,18 & 17 & 82,65 & 61,80 & 48 & 116,66 & 82,43 & 4 & 21,79 & 14,53 & 7 & 33,38 & 23,17 & 11 & 27,74 & \begin{tabular}{l|l|}
4 & 18,60 \\
\end{tabular} & 63 & 315,07 & \begin{tabular}{|l|l|}
794,78 \\
\end{tabular} & 41 & 193,92 & \begin{tabular}{|l|l|} 
& 140,26 \\
\end{tabular} & 103 & \begin{tabular}{l|l|}
3 & 252,89 \\
\end{tabular} & \begin{tabular}{|l|l|}
9 & 166,80 \\
\end{tabular} \\
\hline Duartina & E20 & 11 & 181,64 & 113,52 & 6 & 87,27 & 62,08 & 17 & 133,52 & 87,29 & 2 & 37,40 & 28,74 & 2 & 35,94 & 23,92 & 5 & 36,65 & 26,15 & 16 & 256,44 & $4 \quad 153,65$ & 12 & 179,68 & \begin{tabular}{|l|l|} 
& 126,99 \\
\end{tabular} & 28 & $8 \quad 217,29$ & \begin{tabular}{|l|l|}
9 & 140,05 \\
\end{tabular} \\
\hline Dumont & D20 & 5 & 151,36 & 140,38 & 1 & 19,75 & 21,02 & 6 & 86,97 & 81,99 & 1 & 18,92 & 16,53 & 1 & 19,75 & 21,80 & 1 & 19,33 & \begin{tabular}{|l|l|} 
& 19,11 \\
\end{tabular} & 7 & 198,66 & $6 \mid \begin{array}{ll}61,54 \\
\end{array}$ & 4 & 108,64 & \begin{tabular}{l|l|}
4 & 126,47 \\
\end{tabular} & 11 & \begin{tabular}{l|l|}
1 & 154,62 \\
\end{tabular} & \begin{tabular}{|l|l|}
254,60 \\
\end{tabular} \\
\hline Echapora & E20 & 3 & \begin{tabular}{|l|l|}
34,54 \\
\end{tabular} & 76,42 & 3 & 85,03 & 80,41 & 6 & 89,78 & 78,42 & 1 & 18,91 & 17,78 & & & & 1 & 9,45 & 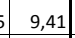 & 7 & 208,00 & | 159,11 & & 207,84 & \begin{tabular}{|l|l|}
4 & 182,32 \\
\end{tabular} & 15 & \begin{tabular}{l|l|}
5 & 207,92 \\
\end{tabular} & \begin{tabular}{|l|l|}
2 & 170,72 \\
\end{tabular} \\
\hline Eldorado & D20 & 7 & 87,96 & 83,52 & 3 & 47,56 & 54,19 & 10 & 68,55 & 69,42 & 2 & 21,99 & 19,72 & 1 & 19,02 & 20,68 & 3 & $20,57 \mid$ & 20,29 & 12 & 153,93 & \begin{tabular}{|l|l|}
338,68 \\
\end{tabular} & & 128,42 & \begin{tabular}{|l|l|} 
& 143,80 \\
\end{tabular} & 21 & \begin{tabular}{|l|l|}
141,68 \\
\end{tabular} & \begin{tabular}{|l|l|}
8 & 141,14 \\
\end{tabular} \\
\hline Elias Fausto & D20 & 8 & \begin{tabular}{|l|l|}
104,41 \\
\end{tabular} & 109,52 & 5 & 69,11 & 75,34 & 13 & 87,26 & 92,92 & 1 & 13,05 & 13,81 & 1 & 13,82 & 15,03 & 2 & 13,43 & \begin{tabular}{|l|l|}
3 & 14,49 \\
\end{tabular} & 15 & 200,11 & 209,75 & 12 & 161,25 & \begin{tabular}{|l|l|}
5 & 181,89 \\
\end{tabular} & 27 & \begin{tabular}{l|l|}
7 & 181,24 \\
\end{tabular} & \begin{tabular}{l|l}
4 & 196,22 \\
\end{tabular} \\
\hline Elisiário & E20 & 2 & 147,09 & 88,04 & 2 & 162,78 & 137,10 & 4 & 154,54 & 111,33 & & & & & & & & & & 3 & 245,16 & $6 \mid 141,54$ & 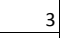 & 217,04 & \begin{tabular}{l|l|}
4 & 171,72 \\
\end{tabular} & 6 & \begin{tabular}{l|l|}
6 & 231,81 \\
\end{tabular} & 155,86 \\
\hline Embaúba & E20 & 1 & 101,94 & 75,66 & 1 & 110,62 & 90,09 & 3 & 106,10 & 82,58 & 0 & 25,48 & 17,24 & 1 & 82,96 & \begin{tabular}{|l|}
69,76 \\
\end{tabular} & 1 & \begin{tabular}{|l|}
53,06 \\
\end{tabular} & \begin{tabular}{|l|l|}
5 & 42,31 \\
\end{tabular} & 2 & \begin{tabular}{|l|}
127,42 \\
\end{tabular} & \begin{tabular}{|l|l|}
203,38 \\
\end{tabular} & 3 & 276,55 & \begin{tabular}{|l|l|}
5 & 221,42 \\
\end{tabular} & 5 & \begin{tabular}{l|l|}
5 & 198,94 \\
\end{tabular} & \begin{tabular}{l|l}
4 & 159,99 \\
\end{tabular} \\
\hline Embu & с 300 & 82 & 71,92 & 128,98 & 76 & 65,13 & 111,48 & 158 & 68,47 & 120,09 & 10 & 9,10 & 16,00 & 15 & 13,08 & 25,51 & 26 & 11,12 & 20,83 & 178 & 157,06 & $6 \mid 268,10$ | & 147 & 125,71 & 248,00 & 326 & \begin{tabular}{l|l|}
6 & 141,14 \\
\end{tabular} & 257,89 \\
\hline EmbuOGuaçu & C100 & 29 & $\begin{array}{ll}87,42 \\
\end{array}$ & 98,72 & 25 & 75,85 & 97,78 & 54 & 81,65 & 98,25 & 9 & 26,13 & 29,66 & 6 & 18,20 & 24,31 & 15 & 22,18 & \begin{tabular}{|l|l|}
8 & 27,53 \\
\end{tabular} & 80 & 240,15 & $5 \quad 260,94$ & 59 & 179,01 & \begin{tabular}{|l|l|}
1 & 245,61 \\
\end{tabular} & 139 & \begin{tabular}{l|l|}
9 & 209,68 \\
\end{tabular} & \begin{tabular}{l|l}
853,30 \\
\end{tabular} \\
\hline Emilianópolis & E20 & 2 & 135,99 & 81,52 & 2 & 117,21 & 97,80 & 4 & 126,76 & 89,52 & - & & & 1 & 46,88 & 37,47 & 1 & 23,04 & \begin{tabular}{|l|l|}
4 & 17,48 \\
\end{tabular} & 2 & 135,99 & 78,64 & 1 & 93,76 & \begin{tabular}{|l|l|}
5 & 96,71 \\
\end{tabular} & 3 & \begin{tabular}{|l|l|}
3 & 115,23 \\
\end{tabular} & \begin{tabular}{|l|l|}
3 & 87,52 \\
\end{tabular} \\
\hline Engenheiro Coelho & D20 & 2 & 33,21 & 41,10 & 3 & 47,72 & 67,95 & 5 & 40,19 & 54,02 & 1 & 16,60 & 20,96 & 1 & 23,86 & 33,28 & 2 & 20,10 & 26,86 & 6 & 99,62 & \begin{tabular}{|l|l|}
2 & 128,73 \\
\end{tabular} & 6 & 101,41 & \begin{tabular}{|l|l|}
156,08 \\
\end{tabular} & 12 & \begin{tabular}{l|l|}
2 & 100,48 \\
\end{tabular} & \begin{tabular}{|l|l|}
8141,89 \\
\end{tabular} \\
\hline Espirito Santo do Pinhal & C50 & 23 & $\begin{array}{ll}112,36 \\
\end{array}$ & 89,04 & 24 & 114,84 & 93,87 & 48 & 113,62 & 91,48 & 6 & 27,29 & 21,94 & 8 & 39,33 & 31,70 & 14 & 33,37 & 26,79 & 69 & 330,67 & 744,69 & 59 & 276,88 & \begin{tabular}{|l|l|}
8 & 219,84 \\
\end{tabular} & 127 & \begin{tabular}{l|l|}
7 & 303,51 \\
\end{tabular} & 232,14 \\
\hline Espirito Santo d & D20 & 2 & 96,93 & 103,68 & 1 & 51,94 & 61,60 & 3 & 75,21 & 83,37 & 1 & 32,31 & 37,66 & 1 & 51,94 & 69,83 & 2 & 41,78 & \begin{tabular}{|l|l|}
82,73 \\
\end{tabular} & 4 & 210,02 & 2455,56 & 3 & 173,13 & \begin{tabular}{|l|l|}
3 & 221,64 \\
\end{tabular} & 8 & \begin{tabular}{|l|l|}
8 & 192,21 \\
\end{tabular} & 234,01 \\
\hline Estiva Gerbi & C20 & 6 & 118,21 & 126,48 & 4 & 49,07 & 57,18 & 8 & 84,77 & 92,96 & 0 & 6,57 & 6,62 & 1 & 28,04 & 33,73 & 2 & 16,95 & 5. 18,81 & 10 & 190,45 & \begin{tabular}{|l|l|}
5 & 194,68 \\
\end{tabular} & 7 & 140,21 & \begin{tabular}{|l|l|} 
& 179,58 \\
\end{tabular} & 16 & \begin{tabular}{l|l|}
6 & 166,15 \\
\end{tabular} & \begin{tabular}{|l|l|}
587,38 \\
\end{tabular} \\
\hline Estrela do Norte & E20 & 2 & 151,25 & 113,34 & 1 & 54,01 & 52,01 & 3 & 104,30 & 83,73 & 0 & 25,21 & 17,66 & 1 & 54,01 & \begin{tabular}{|l|}
49,87 \\
\end{tabular} & 1 & 39,11 & \begin{tabular}{|l|l|} 
& 31,63 \\
\end{tabular} & 4 & 302,50 & 228,42 & 1 & 108,02 & \begin{tabular}{|l|l|}
2 & 108,83 \\
\end{tabular} & 5 & \begin{tabular}{l|l|}
5 & 208,60 \\
\end{tabular} & \begin{tabular}{|l|l|}
170,68 \\
\end{tabular} \\
\hline Estrela a'Oeste & E20 & 7 & 168,96 & \begin{tabular}{|l|l|}
121,85 \\
\end{tabular} & 4 & 99,82 & 88,10 & 11 & 134,96 & 105,25 & 0 & 8,05 & 5,23 & 1 & 33,27 & 26,10 & 2 & 20,45 & \begin{tabular}{|l|l|}
54,72 \\
\end{tabular} & 8 & 193,10 & \begin{tabular}{|l|l|}
0 & 132,38 \\
\end{tabular} & 4 & 91,50 & \begin{tabular}{|l|l|} 
& 74,75 \\
\end{tabular} & 12 & \begin{tabular}{|l|l|}
2 & 143,14 \\
\end{tabular} & \begin{tabular}{l|l}
4 & 104,04 \\
\end{tabular} \\
\hline Euclides da Cunha Paulist & E20 & 6 & 106,60 & 103,51 & 2 & 38,54 & 50,19 & 8 & 72,98 & 77,17 & 1 & 12,54 & 10,85 & & & & 1 & 6,35 & \begin{tabular}{|l|l|}
5 & 6,79 \\
\end{tabular} & 10 & 194,39 & \begin{tabular}{|l|l|}
9 & 192,79 \\
\end{tabular} & 4 & 83,49 & \begin{tabular}{|l|l|}
9 & 126,46 \\
\end{tabular} & 15 & \begin{tabular}{|l|l|}
5 & 139,61 \\
\end{tabular} & 160,02 \\
\hline Fartura & E20 & 10 & 130,58 & 104,29 & 8 & 104,49 & 88,66 & 18 & 117,54 & 96,48 & 2 & 21,76 & 17,71 & 2 & 30,48 & 25,08 & 4 & 26,12 & 21,31 & 16 & 204,58 & \begin{tabular}{|l|l|}
8 & 164,52 \\
\end{tabular} & 16 & 208,98 & \begin{tabular}{|l|l|}
8 & 181,05 \\
\end{tabular} & 32 & \begin{tabular}{l|l|}
2 & 206,78 \\
\end{tabular} & \begin{tabular}{l|l}
872,79 \\
\end{tabular} \\
\hline Fernando Prestes & E20 & 5 & 169,92 & 124,27 & 2 & 71,35 & 48,80 & 7 & 120,13 & 86,15 & 0 & 12,14 & 8,47 & & & & 0 & 6,01 & \begin{tabular}{l|l|} 
& 4,25 \\
\end{tabular} & 4 & 157,79 & 84,00 & 4 & 154,60 & \begin{tabular}{l|l|l|}
0 & 102,96 \\
\end{tabular} & 9 & \begin{tabular}{l|l|}
9 & 156,17 \\
\end{tabular} & 93,58 \\
\hline Fernandópolis & D100 & 35 & 110,92 & 84,59 & 21 & 65,54 & 54,34 & 56 & 87,88 & 69,23 & 4 & 11,62 & 8,71 & 10 & 30,72 & 23,99 & 14 & 21,32 & \begin{tabular}{|l|}
26,20 \\
\end{tabular} & 36 & 114,09 & \begin{tabular}{|l|l|}
9 & 82,33 \\
\end{tabular} & 42 & 128,01 & \begin{tabular}{l|l|}
1 & 102,99 \\
\end{tabular} & 78 & \begin{tabular}{|l|l|}
8 & 121,16 \\
\end{tabular} & 92,82 \\
\hline Fernao & D20 & 1 & 196,17 & 150,26 & & & & 1 & 101,32 & 77,60 & 0 & 49,04 & 29,61 & & 104,77 & 97,77 & 1 & 75,99 & \begin{tabular}{|l|l|}
9 & 63,38 \\
\end{tabular} & 2 & 294,26 & $6 \quad 209,95$ & 1 & 104,77 & \begin{tabular}{l|l|}
7 & 99,07 \\
\end{tabular} & 3 & \begin{tabular}{l|l|}
3 & 202,63 \\
\end{tabular} & \begin{tabular}{l|l}
156,34 \\
\end{tabular} \\
\hline Ferraz de Va & C300 & 54 & 67,18 & 111,39 & 38 & 45,58 & 70,72 & 92 & 56,23 & 90,77 & 13 & 16,17 & 27,09 & 17 & 20,17 & 34,13 & 30 & 18,20 & \begin{tabular}{|l|} 
\\
\end{tabular} & 103 & 127,73 & 216,03 & 87 & 105,28 & \begin{tabular}{l|l|}
8 & 182,84 \\
\end{tabular} & 190 & \begin{tabular}{l|l|}
0 & 116,35 \\
\end{tabular} & \begin{tabular}{|l|l|}
59,20 \\
\end{tabular} \\
\hline Flora Rica & E20 & 1 & 63,73 & 43,03 & 2 & 192,06 & 131,03 & 3 & 127,75 & 86,93 & 0 & 31,87 & 17,32 & 1 & 96,03 & 75,90 & 1 & 63,89 & 50,70 & 3 & 254,94 & \begin{tabular}{|l|l|}
4 & 179,58 \\
\end{tabular} & 1 & 128,04 & \begin{tabular}{l|l|}
4 & 95,16 \\
\end{tabular} & 4 & \begin{tabular}{|l|l|}
4 & 191,63 \\
\end{tabular} & \begin{tabular}{|l|l|}
3 & 137,46 \\
\end{tabular} \\
\hline Floreal & E20 & 2 & 152,24 & 78,05 & 2 & 107,85 & 68,98 & 4 & 129,95 & 73,50 & 0 & 21,75 & 11,41 & 0 & 21,57 & 11,95 & 1 & 21,66 & \begin{tabular}{|l|l|}
5 & 11,73 \\
\end{tabular} & 1 & 65,25 & \begin{tabular}{|l|l|}
5 & 29,76 \\
\end{tabular} & 2 & 129,42 & \begin{tabular}{l|l|}
2 & 85,82 \\
\end{tabular} & 3 & \begin{tabular}{l|l|}
3 & 97,47 \\
\end{tabular} & $\begin{array}{l}77,91 \\
\end{array}$ \\
\hline Flórida Pau & E20 & 7 & 139,76 & 93,33 & 6 & 108,32 & 90,60 & 13 & 124,07 & 91,97 & 1 & 12,71 & 10,20 & 2 & 44,60 & 33,39 & 3 & 28,63 & \begin{tabular}{|l|l|}
3 & 20,97 \\
\end{tabular} & 11 & 216,00 & 138,44 & 9 & 172,04 & \begin{tabular}{l|l|l|}
4 & 133,69 \\
\end{tabular} & 20 & \begin{tabular}{l|l|}
0 & 194,05 \\
\end{tabular} & \begin{tabular}{|l|l|}
56,07 \\
\end{tabular} \\
\hline Florinia & E20 & 0 & 21,61 & 16,86 & 1 & 81,38 & 73,81 & 2 & 52,40 & 46,19 & & & & 0 & 20,35 & 17,91 & 0 & \begin{tabular}{|l|}
10,48 \\
\end{tabular} & \begin{tabular}{|l|l|}
8 & 8,72 \\
\end{tabular} & 4 & 280,96 & $\begin{array}{lll}6 & 228,83 \\
\end{array}$ & 3 & 183,11 & \begin{tabular}{l|l|}
1 & 163,56 \\
\end{tabular} & 7 & \begin{tabular}{ll|}
7 & 230,56 \\
\end{tabular} & \begin{tabular}{|l|l}
5 & 195,21 \\
\end{tabular} \\
\hline Franca & B500 & 138 & 89,49 & 94,27 & 121 & 76,62 & 79,80 & 259 & 82,97 & 86,95 & 17 & 11,24 & 11,72 & 22 & 13,72 & 14,37 & 39 & 12,49 & 13,07 & 209 & 135,74 & $4 \mid 441,10$ & 188 & 119,25 & \begin{tabular}{|l|l|}
5 & 128,67 \\
\end{tabular} & 398 & \begin{tabular}{|l|l|}
8 & 127,40 \\
\end{tabular} & \begin{tabular}{|l|l|}
134,81 \\
\end{tabular} \\
\hline Francisco Morato & D300 & 45 & 58,26 & 106,68 & 32 & 40,49 & 75,15 & 77 & 49,36 & 90,88 & 11 & 14,57 & 27,95 & 13 & 16,62 & 33,44 & 24 & 15,60 & \begin{tabular}{|l|} 
\\
\end{tabular} & 111 & 142,66 & \begin{tabular}{l|l|}
6 & 250,64 \\
\end{tabular} & 83 & 106,14 & \begin{tabular}{ll|l|}
4 & 209,03 \\
\end{tabular} & 194 & \begin{tabular}{l|l|}
4 & 124,35 \\
\end{tabular} & \begin{tabular}{|l|l|}
529,78 \\
\end{tabular} \\
\hline Franco da Rocha & С300 & 53 & 87,15 & 119,54 & 43 & 75,42 & 100,38 & 96 & 81,49 & 110,30 & 13 & 21,24 & 29,88 & 19 & 32,74 & 46,78 & 32 & 26,79 & \begin{tabular}{|l|l|}
9 & 38,22 \\
\end{tabular} & 126 & 206,43 & \begin{tabular}{|l|l|}
3 & 274,76 \\
\end{tabular} & 98 & 171,89 & \begin{tabular}{l|l|}
9 & 245,69 \\
\end{tabular} & 224 & $4 \mid$\begin{tabular}{ll|}
489,77 \\
\end{tabular} & 260,74 \\
\hline Gabriel Monteiro & E20 & 2 & 136,27 & 84,48 & 2 & 145,88 & 111,18 & 4 & 140,91 & 97,38 & 0 & 22,71 & 13,95 & 1 & 48,63 & 42,45 & 1 & 35,22 & \begin{tabular}{|l|}
27,50 \\
\end{tabular} & 2 & 136,27 & 88,29 & 4 & 267,44 & \begin{tabular}{l|l|}
4 & 193,76 \\
\end{tabular} & 6 & \begin{tabular}{l|l|}
6 & 199,62 \\
\end{tabular} & \begin{tabular}{|l|l|}
2 & 139,23 \\
\end{tabular} \\
\hline Gália & E20 & 4 & 114,77 & 93,62 & 2 & 54,77 & 50,92 & 6 & 85,27 & 72,63 & 1 & 17,66 & 13,48 & 3 & 73,03 & 59,02 & 3 & 44,88 & \begin{tabular}{|l|l|}
84,38 \\
\end{tabular} & 15 & 388,45 & 5283,92 & 9 & 246,46 & \begin{tabular}{|l|l|}
6 & 198,30 \\
\end{tabular} & 24 & $\begin{array}{l}4 \\
418,64 \\
\end{array}$ & \begin{tabular}{l|l}
4 & 241,82 \\
\end{tabular} \\
\hline Garça & D50 & 23 & 106,52 & 81,44 & 21 & 92,61 & 75,49 & 44 & 99,45 & 78,41 & 7 & 30,88 & 23,72 & 10 & 44,81 & 33,89 & 17 & 37,96 & 5. 28,84 | & 74 & 341,17 & 7242,53 & 64 & 288,27 & \begin{tabular}{l|l|}
7 & 220,30 \\
\end{tabular} & 138 & \begin{tabular}{l|l|}
8 & 314,28 \\
\end{tabular} & 3,23 \\
\hline Gastao Vidigal & E20 & 3 & 152,96 & 113,85 & 2 & 96,25 & 81,99 & 4 & 124,70 & 97,97 & & & & 1 & 38,50 & 33,22 & 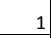 & 19,18 & \begin{tabular}{|l|l|}
85,01 \\
\end{tabular} & & 382,41 & 274,21 & & 34,74 & \begin{tabular}{l|l|}
4 & 120,28 \\
\end{tabular} & & 258,99 & \begin{tabular}{l|l}
9 & 197,51 \\
\end{tabular} \\
\hline Gaviao Peixoto & E20 & 0 & 15,32 & 12,87 & 2 & 122,29 & 137,87 & 3 & 65,29 & 71,26 & 1 & 30,63 & 27,14 & 1 & 52,41 & 57,75 & 2 & 40,81 & 1 | $40,61 \mid$ & 5 & 229,74 & $4 \quad 214,42$ & 2 & 104,82 & \begin{tabular}{l|l|}
2 & 114,57 \\
\end{tabular} & 7 & \begin{tabular}{l|l|}
7 & 171,39 \\
\end{tabular} & \begin{tabular}{|l|l|}
9167,77 \\
\end{tabular} \\
\hline General Salgado & E20 & 8 & 142,67 & 107,48 & 4 & 73,86 & 66,58 & 12 & 108,86 & 87,39 & 1 & 17,83 & 12,25 & 1 & 24,62 & 21,45 & 2 & $21,17 \mid$ & \begin{tabular}{|l|l|}
76,77 \\
\end{tabular} & 20 & 362,62 & \begin{tabular}{|l|}
2255,67 \\
\end{tabular} & 14 & 252,35 & \begin{tabular}{|l|l|}
5 & 221,11 \\
\end{tabular} & 34 & \begin{tabular}{l|l|}
4 & 308,45 \\
\end{tabular} & \begin{tabular}{|l|l|}
58,69 \\
\end{tabular} \\
\hline Getulina & E20 & 5 & 94,61 & 78,05 & 5 & 96,33 & 80,38 & 10 & 95,41 & 79,13 & 1 & 11,83 & 10,31 & 2 & 34,40 & 25,01 & 2 & 22,26 & \begin{tabular}{|l|}
5 \\
\end{tabular} & 14 & 254,27 & $\begin{array}{ll}786,02 \\
\end{array}$ & 8 & 172,02 & \begin{tabular}{|l|l|}
2 & 140,09 \\
\end{tabular} & 23 & \begin{tabular}{|l|l|}
3 & 216,26 \\
\end{tabular} & \begin{tabular}{|l|l|}
5 & 164,79 \\
\end{tabular} \\
\hline Glicério & E20 & 2 & 87,55 & 74,00 & 1 & 59,80 & 50,74 & 3 & 73,84 & 62,51 & 1 & 58,37 & 41,93 & & 44,85 & 35,42 & 2 & 51,69 & \begin{tabular}{|l|l|}
$y$ & 39,19 \\
\end{tabular} & 3 & 145,92 & \begin{tabular}{|l|l|}
209,59 \\
\end{tabular} & 3 & 149,50 & \begin{tabular}{l|l|l|}
0 & 120,56 \\
0
\end{tabular} & 7 & \begin{tabular}{l|l|}
7 & 147,69 \\
\end{tabular} & \begin{tabular}{l|l}
115,01 \\
\end{tabular} \\
\hline Guaiçara & D20 & 7 & 140,54 & 134,48 & 3 & 56,98 & 58,92 & 10 & 98,58 & 96,53 & 0 & 6,39 & 6,86 & & 31,66 & 33,24 & 2 & \begin{tabular}{|l|}
19,08 \\
\end{tabular} & \begin{tabular}{|l|l|}
8 & 18,95 \\
\end{tabular} & & 146,93 & \begin{tabular}{|l|l|}
336,36 \\
\end{tabular} & & 132,96 & \begin{tabular}{l|l|l}
6 & 149,67 \\
\end{tabular} & 15 & \begin{tabular}{|l|l|}
5 & 139,91 \\
\end{tabular} & \begin{tabular}{|l|l|}
143,04 \\
\end{tabular} \\
\hline
\end{tabular}


Anexo 23 - Nº de óbitos e taxa de mortalidade (bruta e padronizada) total e segundo sexo por Neoplasias, Diabetes Mellitus e Doenças do Aparelho Circulatório, municípios. Estado de São Paulo, média do triênio 2003-2005

\begin{tabular}{|c|c|c|c|c|c|c|c|c|c|c|c|c|c|c|c|c|c|c|c|c|c|c|c|c|c|c|c|c|}
\hline \multirow[b]{3}{*}{ Guaimbê } & \multirow[b]{3}{*}{ E20 } & \multicolumn{9}{|c|}{ Neoplasias Malignas } & \multicolumn{9}{|c|}{ Diabetes Mellitus } & \multicolumn{9}{|c|}{ Aparelho Circulatorio } \\
\hline & & \multicolumn{3}{|c|}{ Homens } & \multicolumn{3}{|c|}{ Mulheres } & \multicolumn{3}{|c|}{ Total } & \multicolumn{3}{|c|}{ Homens } & \multicolumn{3}{|c|}{ Mulheres } & \multicolumn{3}{|c|}{ Total } & \multicolumn{3}{|c|}{ Homens } & \multicolumn{3}{|c|}{ Mulheres } & \multicolumn{3}{|c|}{ Total } \\
\hline & & 2 & 89,16 & 78,97 & 1 & 38,16 & 34,70 & 3 & 63,64 & 56,82 & 1 & 25,47 & 18,99 & 1 & 25,44 & 21,87 & 1 & 25,46 & \begin{tabular}{|l|l|}
5 & 20,52 \\
\end{tabular} & 3 & 127,37 & 79,16 & 6 & 216,23 & 393,06 & 9 & 171,83 & \begin{tabular}{|l|l}
336,15 \\
\end{tabular} \\
\hline Guaira & C50 & 17 & 95,20 & 90,33 & 14 & 76,00 & 75,94 & 31 & 85,66 & 83,18 & 4 & 23,80 & 22,57 & 4 & 22,24 & 21,96 & 8 & 23,03 & 322,36 & 31 & 172,09 & \begin{tabular}{|l|l|}
957,76 \\
\end{tabular} & 29 & 161,27 & 164,33 & 60 & \begin{tabular}{l|l|}
0 & 166,71 \\
\end{tabular} & 161,03 \\
\hline Guapiaçu & D20 & 11 & 138,48 & 121,14 & 9 & 117,34 & 112,55 & 20 & 128,09 & 116,92 & 1 & 12,59 & 10,81 & 0 & 4,35 & 4,07 & 1 & 8,54 & \begin{tabular}{l|l|}
4 & 7,71 \\
\end{tabular} & 15 & 193,03 & \begin{tabular}{|l|l|}
364,96 \\
\end{tabular} & 11 & 147,76 & $6 \mid 141,89$ & 27 & \begin{tabular}{l|l|}
7 & 170,79 \\
\end{tabular} & \begin{tabular}{|l|l}
93,63 \\
\end{tabular} \\
\hline Guapiara & E50 & 8 & 79,52 & 80,75 & 5 & 47,18 & 61,77 & 13 & 63,82 & 71,53 & 4 & 38,17 & 38,41 & 4 & 40,44 & 47,16 & 8 & 39,27 & 42,87 & 23 & 219,49 & 9218,75 & 17 & 171,86 & 6213,70 & 40 & \begin{tabular}{l|l|}
0 & 196,36 \\
\end{tabular} & \begin{tabular}{|l|l}
5 & 216,30 \\
\end{tabular} \\
\hline Guará & E50 & 9 & 86,21 & 89,20 & 10 & 96,63 & 100,12 & 18 & 91,41 & 94,65 & 2 & 16,58 & 16,80 & 2 & 19,99 & 20,73 & 4 & \begin{tabular}{|l|}
18,28 \\
\end{tabular} & \begin{tabular}{|l|l|}
8 & 18,84 \\
\end{tabular} & 21 & 208,89 & \begin{tabular}{|l|l|}
9 & 213,04 \\
\end{tabular} & 18 & 179,93 & $\mid 186,69$ & 39 & \begin{tabular}{l|l|}
9 & 194,45 \\
\end{tabular} & \begin{tabular}{|l|l|}
59,90 \\
\end{tabular} \\
\hline Guaraçal & E20 & 6 & 136,91 & 95,43 & 5 & 117,50 & 102,12 & 12 & 127,30 & 98,75 & 2 & 36,03 & 25,10 & 3 & 58,75 & 48,92 & 4 & \begin{tabular}{|l|}
47,28 \\
\end{tabular} & 36,55 & 10 & 223,38 & \begin{tabular}{|l|l|}
8 & 141,90 \\
\end{tabular} & 4 & 95,47 & 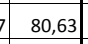 & 15 & \begin{tabular}{|l|l}
5 & 160,03 \\
\end{tabular} & 111,55 \\
\hline Guaraci & E20 & 6 & 133,80 & 99,86 & 5 & 109,29 & 105,73 & 11 & 121,75 & 102,74 & 1 & 14,08 & 10,34 & 2 & 36,43 & 32,62 & 2 & 25,07 & 20,73 & 12 & 253,52 & \begin{tabular}{|l|l|}
2 & 204,48 \\
\end{tabular} & 12 & 255,01 & 225,62 & 24 & $\begin{array}{l}4254,25 \\
\end{array}$ & \begin{tabular}{|l|l|}
514,87 \\
\end{tabular} \\
\hline Guarani d'Oeste & E20 & 0 & 30,79 & 35,09 & 1 & 66,62 & 46,39 & 1 & 48,00 & 40,52 & & & & 1 & 66,62 & 42,98 & 1 & 32,01 & \begin{tabular}{l|l|}
1 & 19,54 \\
\end{tabular} & 1 & 123,15 & 75,65 & 1 & 133,24 & 96,09 & 3 & \begin{tabular}{l|l|}
3 & 128,00 \\
\end{tabular} & 85,47 \\
\hline Guaranta & E20 & 4 & 117,77 & $111,67 \mid$ & 1 & 20,34 & 22,27 & 5 & 69,93 & 67,77 & 0 & 9,81 & 8,78 & 1 & 20,34 & 20,72 & 1 & 14,99 & \begin{tabular}{|l|l|}
9 & 14,88 \\
\end{tabular} & 8 & 245,36 & $6 \quad 232,84$ & 6 & 172,92 & 287,85 & 14 & \begin{tabular}{l|l|}
4 & 209,79 \\
\end{tabular} & \begin{tabular}{l|l}
9 & 210,75 \\
\end{tabular} \\
\hline Guararapes & D50 & 21 & 144,27 & 106,57 & 15 & 97,66 & 82,01 & 36 & 120,78 & 94,19 & 4 & 29,31 & 24,08 & 7 & 46,61 & 38,80 & 11 & 38,02 & \begin{tabular}{|l|l|}
2 & 31,03 \\
\end{tabular} & 34 & 232,19 & $\begin{array}{l}9 \\
9\end{array}$ & 33 & 217,51 & 181,46 & 67 & \begin{tabular}{l|l|}
7 & 224,79 \\
\end{tabular} & \begin{tabular}{l|l}
9 & 178,95 \\
\end{tabular} \\
\hline Guararema & D50 & 16 & 130,55 & 123,10 & 9 & 74,30 & 76,65 & 24 & 102,82 & 100,21 & 3 & 25,00 & 23,37 & 5 & 45,72 & 49,06 & 8 & 35,21 & 1 | 35,46 & 27 & 227,77 & 7 208,34 & 17 & 142,88 & \begin{tabular}{|l|l|}
849,36 \\
\end{tabular} & 44 & \begin{tabular}{l|l|}
4 & 185,92 \\
\end{tabular} & \begin{tabular}{|l|l|}
2179,27 \\
\end{tabular} \\
\hline Guaratinguetáa & B300 & 62 & 115,91 & 108,16 & 53 & 94,57 & 89,08 & 115 & 104,99 & 98,40 & 15 & 28,04 & 26,18 & 20 & 35,69 & 33,16 & 35 & 31,95 & 29,74 & 132 & 246,77 & 7223,05 & 122 & 218,29 & 204,69 & 254 & $\begin{array}{l}4232,20 \\
\end{array}$ & 213,66 \\
\hline Guarei & E20 & 7 & 121,59 & 92,79 & 3 & 51,17 & 56,21 & 10 & 88,13 & 75,41 & 1 & 23,16 & 19,02 & 2 & 38,38 & 37,57 & 3 & 30,39 & \begin{tabular}{|l|}
97,03 \\
\end{tabular} & 18 & 318,45 & 5244,11 & 9 & 179,09 & \begin{tabular}{|l|} 
\\
\end{tabular} & 28 & \begin{tabular}{|l|l|}
8 & 252,23 \\
\end{tabular} & \begin{tabular}{l|l}
8 & 218,21 \\
\end{tabular} \\
\hline Guariba & E50 & 17 & 102,82 & \begin{tabular}{|l|}
120,92 \\
\end{tabular} & 9 & 58,90 & 71,69 & 26 & 81,11 & 96,59 & 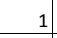 & 6,17 & 7,13 & 2 & 10,52 & 12,69 & 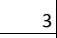 & 8,32 & \begin{tabular}{|l|l|}
2 & 9,87 \\
\end{tabular} & 38 & \begin{tabular}{|l|}
236,48 \\
\end{tabular} & \begin{tabular}{|l|l|}
8 & 267,68 \\
\end{tabular} & 25 & 155,66 & 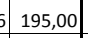 & 63 & \begin{tabular}{l|l|}
3 & 196,53 \\
\end{tabular} & \begin{tabular}{l|l}
8 & 231,75 \\
\end{tabular} \\
\hline Guarujá & C300 & 131 & 91,89 & \begin{tabular}{|l|}
119,69 \\
\end{tabular} & 117 & 79,76 & 100,17 & 248 & 85,75 & 109,82 & 26 & 18,42 & 24,20 & 33 & 22,56 & 29,26 & 59 & \begin{tabular}{|l|}
20,52 \\
\end{tabular} & \begin{tabular}{|l|l|}
26,79 \\
\end{tabular} & 289 & 202,20 & \begin{tabular}{|l|l|}
0 & 261,13 \\
\end{tabular} & 241 & 164,53 & 3221,00 & 530 & \begin{tabular}{l|l|}
0 & 183,15 \\
\end{tabular} & \begin{tabular}{|l|l|}
50,83 \\
\end{tabular} \\
\hline Guarulhos & $=10000$ & 478 & 81,07 & 115,35 & 430 & 70,45 & 97,22 & 908 & 75,67 & 106,13 & 91 & 15,42 & 22,17 & 105 & 17,22 & 25,41 & 196 & 16,33 & \begin{tabular}{|l|l|}
3 & 23,83 \\
\end{tabular} & 1028 & 174,22 & \begin{tabular}{|l|l|}
247,07 \\
\end{tabular} & 905 & 148,44 & $\begin{array}{l}422,05 \\
\end{array}$ & 1933 & \begin{tabular}{l|l|}
3 & 161,12 \\
\end{tabular} & $\begin{array}{ll}234,35 \\
\end{array}$ \\
\hline Guatapará & D20 & 5 & 136,43 & 121,29 & 2 & 72,78 & 80,33 & 7 & 105,63 & 101,48 & 0 & 9,74 & 8,89 & & & & 0 & 5,03 & 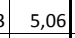 & 4 & \begin{tabular}{|l|}
116,94 \\
\end{tabular} & \begin{tabular}{|l|l|}
4 & 99,17 \\
\end{tabular} & 6 & 187,15 & $5 \mid 192,37$ & 10 & \begin{tabular}{l|l|}
0 & 150,91 \\
\end{tabular} & \begin{tabular}{|l|l}
144,26 \\
\end{tabular} \\
\hline Guzolândia & E20 & 2 & 96,96 & 78,41 & 1 & 35,21 & 31,89 & 3 & 67,40 & 56,15 & 0 & 16,16 & 12,00 & 0 & 17,60 & 15,86 & 1 & 16,85 & \begin{tabular}{|l|}
5 \\
\end{tabular} & 6 & 290,89 & \begin{tabular}{|l|l|}
9 & 229,80 \\
\end{tabular} & 3 & 176,03 & \begin{tabular}{|l|}
168,00 \\
\end{tabular} & 9 & \begin{tabular}{l|l|}
9 & 235,91 \\
\end{tabular} & 200,22 \\
\hline Herculândia & E20 & 8 & 187,32 & \begin{tabular}{|l|}
161,18 \\
\end{tabular} & 3 & 72,31 & 71,93 & 11 & \begin{tabular}{|l|}
130,65 \\
\end{tabular} & 117,20 & 1 & 23,42 & 22,26 & 1 & 32,14 & 28,95 & 4 & 27,72 & 25,01 & 13 & \begin{tabular}{|l|}
312,21 \\
\end{tabular} & \begin{tabular}{|l|}
1219,23 \\
\end{tabular} & 10 & 241,04 & \begin{tabular}{|l|l|}
4 & 219,30 \\
\end{tabular} & 23 & \begin{tabular}{l|l|}
3 & 277,14 \\
\end{tabular} & \begin{tabular}{l|l|}
4 & 219,27 \\
\end{tabular} \\
\hline Holambra & $\mathrm{C} 20$ & 5 & 122,02 & 151,55 & 2 & 59,66 & 73,85 & 7 & 91,57 & 113,61 & 1 & 16,27 & 18,46 & 1 & 34,09 & 49,62 & 2 & 24,97 & 32,31 & 7 & 162,69 & \begin{tabular}{|l|l|}
9 & 174,50 \\
\end{tabular} & 5 & 119,32 & \begin{tabular}{|l|l|}
262,17 \\
\end{tabular} & 11 & \begin{tabular}{|l|l|}
1 & 141,51 \\
\end{tabular} & $\begin{array}{ll}168,48 \\
\end{array}$ \\
\hline Hortolândia & С300 & 58 & 63,97 & 89,46 & 44 & 48,29 & 71,41 & 102 & 56,13 & 80,44 & 6 & 6,95 & 9,91 & 4 & 4,02 & 6,62 & 10 & 5,49 & \begin{tabular}{|l|l|}
$\theta$ & 8,37 \\
\end{tabular} & 82 & 90,29 & \begin{tabular}{l|l|}
9 & 130,32 \\
\end{tabular} & 64 & 70,61 & 116,76 & 147 & \begin{tabular}{l|l|}
7 & 80,45 \\
\end{tabular} & \begin{tabular}{c|c}
5 & 123,54 \\
\end{tabular} \\
\hline lacanga & E20 & 6 & 130,48 & 89,29 & 3 & 70,47 & 54,29 & 9 & 100,78 & 71,97 & 1 & 23,03 & 18,38 & 1 & 31,32 & 24,87 & 2 & 27,13 & \begin{tabular}{|l|l|}
3 & 21,58 \\
\end{tabular} & 10 & 237,93 & \begin{tabular}{|l|l|}
353,61 \\
\end{tabular} & 10 & 242,74 & \begin{tabular}{|l|l|}
4 & 173,04 \\
\end{tabular} & 21 & \begin{tabular}{l|l|}
1 & 240,31 \\
\end{tabular} & $\begin{array}{ll}163,23 \\
\end{array}$ \\
\hline lacri & E20 & 3 & 99,39 & $79,36 \mid$ & 3 & 80,43 & 71,64 & 6 & 89,96 & 75,52 & 1 & 29,82 & 21,88 & 1 & 20,11 & 16,06 & 2 & 24,99 & \begin{tabular}{|l|l|}
9 & 19,25 \\
\end{tabular} & 9 & 268,36 & \begin{tabular}{l|l|}
6 & 203,52 \\
\end{tabular} & 8 & 251,33 & \begin{tabular}{|l|}
3217,82 \\
\end{tabular} & 17 & \begin{tabular}{l|l|}
7 & 259,90 \\
\end{tabular} & \begin{tabular}{|l|l}
210,63 \\
\end{tabular} \\
\hline laras & D20 & 3 & 141,22 & 200,89 & 1 & 85,11 & 135,80 & 4 & 115,77 & 171,37 & 0 & 17,65 & 19,48 & & & & 0 & 9,65 & \begin{tabular}{|l|}
5 \\
5
\end{tabular} & 3 & \begin{tabular}{|l|}
141,22 \\
\end{tabular} & \begin{tabular}{|l|l|}
2 & 164,92 \\
\end{tabular} & & & & 3 & \begin{tabular}{|l|l|}
3 & 77,18 \\
\end{tabular} & \begin{tabular}{l|l}
80,13 \\
\end{tabular} \\
\hline Ibaté & D50 & 16 & 105,54 & $122,61 \mid$ & 10 & 67,97 & 85,65 & 26 & 87,04 & 104,40 & 5 & 32,98 & 36,80 & 4 & 29,45 & 37,05 & 9 & 31,24 & \begin{tabular}{l|l}
4 & 37,16 \\
\end{tabular} & 26 & 169,30 & \begin{tabular}{|l|l|}
0 & 193,97 \\
\end{tabular} & 23 & 158,60 & 208,87 & 49 & \begin{tabular}{|l|l|}
9 & 164,03 \\
\end{tabular} & \begin{tabular}{l|l}
3 & 201,31 \\
\end{tabular} \\
\hline biríá & D20 & 4 & 90,07 & 66,09 & 3 & 67,17 & 53,55 & 8 & 78,44 & 59,72 & 0 & 6,93 & 4,19 & 0 & 6,72 & 4,25 & 1 & 6,82 & \begin{tabular}{|l|l|}
2 & 4,23 \\
\end{tabular} & 14 & \begin{tabular}{|l|}
291,00 \\
\end{tabular} & \begin{tabular}{|l|l|}
0 & 190,00 \\
\end{tabular} & 11 & 228,39 & \begin{tabular}{|l|l|}
950,13 \\
\end{tabular} & 25 & \begin{tabular}{|l|l|}
5 & 259,21 \\
\end{tabular} & 169,75 \\
\hline Ibirarema & E20 & 3 & 113,93 & 78,23 & 2 & 58,42 & 52,88 & 5 & 86,53 & 65,72 & 1 & 34,18 & 24,12 & & & & 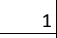 & \begin{tabular}{|l|}
17,31 \\
\end{tabular} & \begin{tabular}{|l|l|}
1 & 12,82 \\
\end{tabular} & 7 & \begin{tabular}{|l|} 
\\
\end{tabular} 27,87 & \begin{tabular}{|l|}
758,55 \\
\end{tabular} & 5 & 186,96 & \begin{tabular}{|l|l|}
5 & 149,70 \\
\end{tabular} & 12 & \begin{tabular}{l|l|}
2 & 207,67 \\
\end{tabular} & 154,18 \\
\hline Ibitinga & D100 & 34 & 136,46 & 110,90 & 21 & 82,52 & 71,92 & 55 & 109,20 & 91,20 & 4 & 14,72 & 13,00 & 5 & 20,96 & 18,06 & 9 & \begin{tabular}{|l|}
17,87 \\
\end{tabular} & 15,45 & 59 & \begin{tabular}{|l|}
238,14 \\
\end{tabular} & \begin{tabular}{|l|l|}
4 & 187,99 \\
\end{tabular} & 64 & 250,17 & \begin{tabular}{|l|}
744,16 \\
\end{tabular} & 123 & \begin{tabular}{l|l|}
3 & 244,22 \\
\end{tabular} & \begin{tabular}{|l|l|}
201,21 \\
\end{tabular} \\
\hline Ibiúna & E100 & 31 & 83,73 & 85,83 & 17 & 48,24 & 61,33 & 47 & 66,50 & 73,93 & 7 & 18,20 & 18,45 & 6 & 17,37 & 21,60 & 13 & 17,80 & \begin{tabular}{|l|l|}
0 & 19,83 \\
\end{tabular} & 45 & 123,77 & \begin{tabular}{|l|l|}
728,85 \\
\end{tabular} & 34 & $\begin{array}{r}99,38 \\
\end{array}$ & \begin{tabular}{|l|l|}
8 & 133,36 \\
\end{tabular} & 80 & \begin{tabular}{|l|l|}
0 & 111,93 \\
\end{tabular} & \begin{tabular}{l|l}
3 & 131,04 \\
\end{tabular} \\
\hline Icém & D20 & 5 & 149,41 & 122,20 & 5 & 133,26 & 126,05 & 10 & 141,41 & 124,11 & 0 & 9,34 & 7,35 & 0 & 9,52 & 8,54 & 1 & 9,43 & \begin{tabular}{|l|l|}
3 & 7,98 \\
\end{tabular} & 9 & \begin{tabular}{|l|} 
\\
\end{tabular} 52,12 & \begin{tabular}{|l|l|}
286,28 \\
\end{tabular} & 6 & 180,85 & \begin{tabular}{|l|}
5 \\
5
\end{tabular} & 15 & \begin{tabular}{|l|l|}
5 & 216,83 \\
\end{tabular} & \begin{tabular}{l|l}
176,92 \\
\end{tabular} \\
\hline lepê & E20 & 5 & 141,72 & 102,78 & 2 & 56,17 & 45,08 & 7 & 98,75 & 73,80 & & & & 0 & 9,36 & 8,49 & 0 & 4,70 & \begin{tabular}{|l|} 
\\
\end{tabular} & 10 & 283,45 & $5 \mid 177,79$ & 11 & \begin{tabular}{|l|}
08,96 \\
\end{tabular} & \begin{tabular}{|l|}
5 \\
\end{tabular} 225,50 & 21 & \begin{tabular}{l|l|}
1 & 296,26 \\
\end{tabular} & \begin{tabular}{|l|l}
5 & 201,76 \\
\end{tabular} \\
\hline Igaraçu do Ti & D50 & 14 & 121,84 & 135,43 & 9 & 74,53 & 86,81 & 23 & 98,32 & 111,27 & 2 & 19,83 & 21,24 & 6 & 54,47 & 63,47 & 9 & 37,05 & \begin{tabular}{|l|l|}
5 & 41,93 \\
\end{tabular} & 22 & \begin{tabular}{|l|}
189,84 \\
\end{tabular} & \begin{tabular}{|l|l|}
4 & 207,67 \\
\end{tabular} & 18 & 154,80 & 188,96 & 40 & \begin{tabular}{l|l|}
0 & 172,42 \\
\end{tabular} & \begin{tabular}{|l|l|}
2 & 198,37 \\
\end{tabular} \\
\hline Igarapava & D50 & 16 & 120,48 & 94,80 & 12 & 83,47 & 72,38 & 28 & 101,69 & 83,42 & 2 & 14,75 & 12,66 & & 47,70 & 38,73 & 9 & \begin{tabular}{|l|}
31,48 \\
\end{tabular} & \begin{tabular}{|l|l|}
8 & 25,72 \\
\end{tabular} & 26 & 191,78 & \begin{tabular}{|l|l|}
8 & 151,30 \\
\end{tabular} & 27 & 195,56 & \begin{tabular}{|l|}
5 \\
5
\end{tabular} & 53 & \begin{tabular}{l|l|}
3 & 193,70 \\
\end{tabular} & \begin{tabular}{|l|l} 
& 155,72 \\
\end{tabular} \\
\hline Igaratá & E20 & 4 & 83,96 & 76,88 & 3 & 75,39 & 87,84 & 7 & 79,83 & 82,16 & 1 & 20,99 & 19,00 & 1 & 30,16 & 34,14 & 2 & 25,40 & 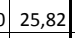 & 9 & 195,90 & \begin{tabular}{|l|l|}
0 & 174,23 \\
\end{tabular} & 6 & 128,17 & 757,62 & 15 & \begin{tabular}{l|l|}
5 & 163,30 \\
\end{tabular} & \begin{tabular}{|l|l}
166,23 \\
\end{tabular} \\
\hline Iguape & E50 & 18 & 122,57 & 98,38 & 13 & 91,58 & 86,77 & 30 & 107,39 & 92,69 & 5 & 32,38 & 26,90 & 8 & 60,25 & 55,36 & 13 & 46,03 & \begin{tabular}{|l|l|}
3 & 40,06 \\
\end{tabular} & 45 & 312,20 & 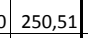 & 29 & 212,08 & \begin{tabular}{|l|l|}
8 & 194,00 \\
\end{tabular} & 74 & \begin{tabular}{|l|l|}
4 & 263,18 \\
\end{tabular} & \begin{tabular}{|l|l}
822,84 \\
\end{tabular} \\
\hline Uha Comprida & A20 & 6 & 147,53 & 116,76 & 2 & 39,92 & 41,49 & 8 & \begin{tabular}{|l|}
94,48 \\
\end{tabular} & 79,65 & 1 & 31,06 & 22,72 & 1 & 23,95 & 25,52 & 2 & 27,55 & \begin{tabular}{|l|l|}
5 & 24,09 \\
\end{tabular} & 6 & 147,53 & \begin{tabular}{|l|l|}
310,39 \\
\end{tabular} & 7 & 175,66 & \begin{tabular}{|l|l|}
5 & 198,36 \\
\end{tabular} & 14 & \begin{tabular}{l|l|}
4 & 161,40 \\
\end{tabular} & \begin{tabular}{|l|l}
153,76 \\
\end{tabular} \\
\hline Iha Solteira & B50 & 14 & 113,32 & \begin{tabular}{|l|}
104,25 \\
\end{tabular} & 13 & 105,30 & 123,56 & 27 & \begin{tabular}{|l}
109,26 \\
\end{tabular} & 114,02 & 3 & 24,28 & 21,89 & & 18,43 & 21,76 & 5 & 21,32 & \begin{tabular}{|l|l|}
21,88 \\
\end{tabular} & 16 & 129,51 & 120,84 & 14 & 113,20 & 151,38 & 30 & \begin{tabular}{l|l}
0 & 121,25 \\
\end{tabular} & \begin{tabular}{|l|l|l}
5 & 136,29 \\
\end{tabular} \\
\hline Ihabela & c50 & 8 & 61,07 & \begin{tabular}{|l|}
76,38 \\
\end{tabular} & 7 & 60,65 & 88,08 & 15 & 60,87 & 81,98 & 1 & 7,97 & 10,67 & 2 & 14,44 & 20,25 & 3 & 11,07 & \begin{tabular}{|l|l|}
75,21 \\
\end{tabular} & 15 & \begin{tabular}{|l|l}
116,83 \\
\end{tabular} & \begin{tabular}{|l|l|}
345,54 \\
\end{tabular} & 11 & 92,41 & 132,73 & 25 & \begin{tabular}{l|l}
5 & 105,14 \\
\end{tabular} & \begin{tabular}{l|l}
4 & 139,41 \\
\end{tabular} \\
\hline Indaiatuba & B300 & 96 & 114,67 & 118,99 & 69 & 82,22 & 88,62 & 165 & 98,42 & 103,79 & 10 & 11,94 & 12,44 & 12 & 14,70 & 15,81 & 22 & 13,32 & \begin{tabular}{|l|l|}
2 & 14,16 \\
\end{tabular} & 136 & 162,45 & $\begin{array}{ll}5 & 164,94 \\
\end{array}$ & 138 & 164,04 & 4181,01 & 274 & \begin{tabular}{l|l|}
4 & 163,24 \\
\end{tabular} & $\begin{array}{ll}4 & 172,98 \\
\end{array}$ \\
\hline Indiana & \begin{tabular}{l|l|l} 
& \\
\end{tabular} & 4 & 155,30 & 120,23 & 1 & 53,45 & 42,89 & 5 & 105,19 & 82,18 & 1 & 25,88 & 18,04 & & 66,82 & 54,50 & & 46,02 & 34,96 & & \begin{tabular}{|l}
194,12 \\
\end{tabular} & \begin{tabular}{|l|l|}
242,87 \\
\end{tabular} & & 227,18 & \begin{tabular}{|l|l|}
894,89 \\
\end{tabular} & 11 & \begin{tabular}{|l|l|l|}
1 & 210,39 \\
\end{tabular} & \begin{tabular}{|l|l}
9 & 168,46 \\
\end{tabular} \\
\hline
\end{tabular}


Anexo 23 - $\mathrm{N}^{\circ}$ de óbitos e taxa de mortalidade (bruta e padronizada) total e segundo sexo por Neoplasias, Diabetes Mellitus e Doenças do Aparelho Circulatório, municípios. Estado de São Paulo, média do triênio 2003-2005

\begin{tabular}{|c|c|c|c|c|c|c|c|c|c|c|c|c|c|c|c|c|c|c|c|c|c|c|c|c|c|c|c|c|}
\hline \multirow[b]{3}{*}{ Indiapora } & \multirow[b]{3}{*}{ E20 } & \multicolumn{9}{|c|}{ Neoplasias Malignas } & \multicolumn{9}{|c|}{ Diabetes Mellitus } & \multicolumn{9}{|c|}{ Aparelho Circulatorio } \\
\hline & & \multicolumn{3}{|c|}{ Homens } & \multicolumn{3}{|c|}{ Mulheres } & \multicolumn{3}{|c|}{ Total } & \multicolumn{3}{|c|}{ Homens } & \multicolumn{3}{|c|}{ Mulheres } & \multicolumn{3}{|c|}{ Total } & \multicolumn{3}{|c|}{ Homens } & \multicolumn{3}{|c|}{ Mulheres } & \multicolumn{3}{|c|}{ Total } \\
\hline & & 2 & 107,01 & 73,48 & 2 & 106,80 & 74,94 & 4 & 106,90 & 74,21 & & & & 1 & 35,60 & 25,85 & 1 & 17,82 & \begin{tabular}{|l|l|}
211,63 \\
\end{tabular} & 3 & 178,35 & $5 \mid 107,16$ & 3 & 178,00 & 142,88 & & 178,17 & \begin{tabular}{|l|l}
725,04 \\
\end{tabular} \\
\hline Inúbia Paulista & E20 & 2 & 118,20 & 80,16 & 1 & 82,54 & $\begin{array}{r}69,68 \\
\end{array}$ & 3 & 100,79 & 75,04 & 1 & 39,40 & 24,03 & 0 & 20,64 & 15,88 & 1 & 30,24 & $4 \quad 20,86$ & 6 & 374,31 & 259,70 & 2 & 144,45 & 5129,94 & 9 & $\begin{array}{l}9262,04 \\
\end{array}$ & $\begin{array}{l}4196,32 \\
\end{array}$ \\
\hline Ipauçu & E20 & 7 & 112,29 & 93,60 & 5 & 76,53 & 67,58 & 12 & 94,41 & 80,59 & 3 & 40,83 & 35,97 & 5 & 76,53 & 65,22 & 8 & 58,69 & 50,22 & 20 & 311,35 & 5255,51 & 15 & 224,49 & 187,19 & 35 & \begin{tabular}{l|l|l|}
5 & 267,91 \\
\end{tabular} & $1 \quad 221,35$ \\
\hline Iperó & C50 & 9 & 76,84 & 87,02 & 8 & 75,47 & 86,97 & 17 & 76,20 & 87,00 & 1 & 8,54 & 10,17 & 1 & 9,84 & 11,43 & 2 & 9,14 & \begin{tabular}{l|l|}
4 & 10,88 \\
\end{tabular} & 19 & 159,36 & $6 \mid 174,37$ & 14 & 137,81 & 158,99 & 33 & \begin{tabular}{l|l|}
3 & 149,35 \\
\end{tabular} & \begin{tabular}{|l|l}
57,23 \\
\end{tabular} \\
\hline Ipeúna & C20 & 2 & 88,64 & $\begin{array}{ll}77,24 \\
\end{array}$ & 1 & 40,94 & 43,19 & 3 & 65,68 & 60,85 & 0 & $\begin{array}{l}12,66 \\
\end{array}$ & 9,91 & & & & 0 & 6,57 & 5,91 & 2 & 88,64 & \begin{tabular}{|l|l|}
4 & 75,69 \\
\end{tabular} & 3 & 109,17 & 110,89 & 3 & \begin{tabular}{|l|l|}
5 & 98,52 \\
\end{tabular} & \begin{tabular}{|l|l|}
2 & 92,63 \\
\end{tabular} \\
\hline piguá & E20 & 1 & 32,39 & 30,64 & 1 & 69,19 & 63,00 & 2 & 50,19 & 46,29 & & & & & & & & & & 3 & \begin{tabular}{|l|}
145,77 \\
\end{tabular} & \begin{tabular}{|l|l|}
7 & 115,92 \\
\end{tabular} & 1 & 34,60 & 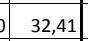 & 4 & \begin{tabular}{|l|l|}
4 & 92,01 \\
\end{tabular} & 75,54 \\
\hline Iporanga & E20 & 4 & 155,56 & 146,60 & 1 & 45,80 & 60,10 & 5 & 102,78 & 105,00 & 0 & 14,14 & 10,96 & 0 & \begin{tabular}{|l|}
15,27 \\
\end{tabular} & \begin{tabular}{|l|}
17,66 \\
\end{tabular} & 1 & \begin{tabular}{|l|}
14,68 \\
\end{tabular} & \begin{tabular}{|l|l|}
$8,83,89$ \\
\end{tabular} & 6 & 268,70 & \begin{tabular}{|l|l|}
0220,30 \\
\end{tabular} & 4 & 167,94 & \begin{tabular}{|l|l|}
4 & 218,30 \\
\end{tabular} & 10 & \begin{tabular}{l|l|}
0 & 220,25 \\
\end{tabular} & \begin{tabular}{|l|l}
59,34 \\
\end{tabular} \\
\hline Ipua & D20 & 8 & 124,91 & 134,15 & 4 & 70,56 & 76,92 & 12 & 98,30 & 106,13 & 1 & 20,82 & 21,43 & 1 & 16,28 & 17,41 & 2 & \begin{tabular}{|r|}
18,60 \\
\end{tabular} & \begin{tabular}{|l|l|}
0 & 19,48 \\
\end{tabular} & 14 & 223,80 & \begin{tabular}{|l|l|} 
& 229,90 \\
\end{tabular} & 10 & 168,25 & 5185,24 & 25 & \begin{tabular}{l|l|}
5 & 196,60 \\
\end{tabular} & \begin{tabular}{|l|l}
208,04 \\
\end{tabular} \\
\hline Iracemápolis & C20 & 9 & 99,49 & 98,88 & 4 & 46,82 & 48,82 & 13 & 73,41 & 74,09 & 1 & 7,65 & 7,60 & 3 & 31,21 & \begin{tabular}{|l|}
32,32 \\
\end{tabular} & 3 & 19,32 & \begin{tabular}{|l|l|}
2 & 19,75 \\
\end{tabular} & 16 & \begin{tabular}{|l|}
183,68 \\
\end{tabular} & \begin{tabular}{|l|l|}
8 & 168,87 \\
\end{tabular} & 14 & 159,96 & \begin{tabular}{|l|l|}
5 & 168,06 \\
\end{tabular} & 30 & \begin{tabular}{|l|l|}
0 & 171,93 \\
\end{tabular} & \begin{tabular}{|l|l} 
B & 168,47 \\
\end{tabular} \\
\hline Irapua & E20 & 5 & 140,32 & 107,39 & 2 & 69,68 & 54,74 & 7 & 106,10 & 81,88 & 0 & 9,35 & 6,81 & & & & 0 & 4,82 & \begin{tabular}{|l|}
2 \\
\end{tabular} & 13 & 355,47 & $7 \mid 257,84$ & 6 & 179,18 & \begin{tabular}{l|l|} 
& 151,32 \\
\end{tabular} & 19 & \begin{tabular}{l|l|}
9 & 270,06 \\
\end{tabular} & \begin{tabular}{l|l}
5 & 206,23 \\
\end{tabular} \\
\hline Irapuru & E20 & 4 & 121,03 & 71,18 & 2 & 56,80 & 40,87 & 6 & 89,18 & 56,15 & 2 & 46,55 & 36,06 & 2 & 47,33 & 32,97 & 3 & \begin{tabular}{|l|}
46,94 \\
\end{tabular} & \begin{tabular}{l|l|}
4 & 34,05 \\
\end{tabular} & 10 & 279,30 & \begin{tabular}{|l|l|}
0 & 148,15 \\
\end{tabular} & 8 & 217,72 & \begin{tabular}{|l|l|}
254,48 \\
\end{tabular} & 18 & \begin{tabular}{l|l|}
8 & 248,77 \\
\end{tabular} & \begin{tabular}{l|l}
751,29 \\
\end{tabular} \\
\hline Itaberá & E20 & 10 & 98,35 & 87,97 & 6 & 62,93 & 69,84 & 16 & 80,91 & 79,05 & 2 & 20,35 & 20,28 & 2 & 17,48 & $\mid 18,98$ & 4 & \begin{tabular}{|l|}
18,94 \\
\end{tabular} & \begin{tabular}{|l|l|}
49,59 \\
\end{tabular} & 12 & \begin{tabular}{|l|}
118,69 \\
\end{tabular} & \begin{tabular}{|l|l|}
9 & 103,50 \\
\end{tabular} & 12 & \begin{tabular}{|l|} 
\\
\end{tabular} & \begin{tabular}{|l|l|}
5 & 138,14 \\
\end{tabular} & 24 & \begin{tabular}{|l|l|}
4 & 122,22 \\
\end{tabular} & $\begin{array}{ll}220,55 \\
\end{array}$ \\
\hline Itaí & E50 & 10 & 83,78 & 82,61 & 7 & 64,00 & 78,41 & 17 & 74,16 & 80,57 & 2 & 17,33 & 17,16 & 2 & 18,29 & \begin{tabular}{|l|}
20,49 \\
\end{tabular} & 4 & \begin{tabular}{|l|}
17,80 \\
\end{tabular} & \begin{tabular}{|l|l|} 
& 18,78 \\
\end{tabular} & 28 & 239,77 & \begin{tabular}{|l|l|}
7 & 229,10 \\
\end{tabular} & 16 & 146,30 & \begin{tabular}{|l|}
0 \\
\end{tabular} & 44 & \begin{tabular}{|l|l|}
4 & 194,29 \\
\end{tabular} & \begin{tabular}{|l|l|}
9 & 201,74 \\
\end{tabular} \\
\hline Itajobi & E20 & 8 & 103,40 & 69,52 & 9 & 118,95 & 97,25 & 16 & 111,11 & 83,26 & 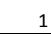 & 8,99 & 5,70 & 2 & 27,45 & \begin{tabular}{|l|}
19,99 \\
\end{tabular} & 3 & \begin{tabular}{|l|}
18,14 \\
\end{tabular} & \begin{tabular}{l|l|}
4 & 12,41 \\
\end{tabular} & 24 & 328,19 & \begin{tabular}{|l|l|}
9 & 191,47 \\
\end{tabular} & 18 & 247,05 & \begin{tabular}{|l|}
579,01 \\
\end{tabular} & 42 & \begin{tabular}{|l|l|}
2 & 287,98 \\
\end{tabular} & \begin{tabular}{l|l}
8 & 185,29 \\
\end{tabular} \\
\hline Itaju & E20 & 3 & 232,02 & 146,06 & 1 & 100,63 & 77,73 & 5 & 168,98 & 113,28 & & & & 0 & 25,16 & \begin{tabular}{|l|}
17,07 \\
\end{tabular} & 0 & \begin{tabular}{|l|}
12,07 \\
\end{tabular} & \begin{tabular}{|l|l|}
7 & 8,08 \\
\end{tabular} & 3 & \begin{tabular}{|l|}
232,02 \\
\end{tabular} & \begin{tabular}{|l|l|}
2 & 147,30 \\
\end{tabular} & 2 & 125,79 & \begin{tabular}{|l|l|}
9 & 95,02 \\
\end{tabular} & 5 & \begin{tabular}{|l|l|}
5 & 181,05 \\
\end{tabular} & \begin{tabular}{|l|l}
522,22 \\
5
\end{tabular} \\
\hline Itanhaém & C100 & 38 & 91,42 & 81,89 & 26 & 61,10 & 60,91 & 64 & 76,18 & 71,34 & 16 & 39,30 & 34,88 & 21 & 49,99 & 48,10 & 37 & 44,67 & 41,34 & 93 & 223,75 & \begin{tabular}{|l|l|}
5 & 192,49 \\
\end{tabular} & 73 & 174,57 & 173,97 & 166 & \begin{tabular}{|l|l|}
6 & 199,03 \\
\end{tabular} & \begin{tabular}{l|l}
3 & 183,18 \\
\end{tabular} \\
\hline Itaóca & E20 & 3 & 195,02 & \begin{tabular}{|l|} 
\\
\end{tabular} & 2 & 159,38 & 146,29 & 5 & 177,64 & 157,50 & & & & 0 & 22,77 & \begin{tabular}{|l|}
18,92 \\
\end{tabular} & 0 & \begin{tabular}{|l|}
11,10 \\
\end{tabular} & \begin{tabular}{|l|l|}
0 & 8,22 \\
\end{tabular} & 4 & \begin{tabular}{|l|}
281,69 \\
\end{tabular} & \begin{tabular}{|l|l|}
9 & 205,68 \\
\end{tabular} & 4 & 250,46 & \begin{tabular}{|l|l|}
5 & 204,03 \\
\end{tabular} & 8 & \begin{tabular}{l|l|}
8 & 266,46 \\
\end{tabular} & \begin{tabular}{|l|l|}
5 & 204,88 \\
\end{tabular} \\
\hline Itapecerica da Serra & с 300 & 61 & 82,63 & 134,74 & 51 & 67,08 & 115,65 & 112 & 74,76 & 125,08 & 6 & 8,58 & 13,77 & 12 & 16,33 & 30,43 & 19 & 12,50 & 22,02 & 133 & 179,71 & 286,19 & 109 & 144,30 & 262,33 & 242 & \begin{tabular}{|l|l|}
2 & 161,80 \\
\end{tabular} & 274,12 \\
\hline Itapetininga & B300 & 72 & 105,59 & 101,87 & 63 & 93,18 & 92,10 & 135 & 99,39 & 96,99 & 18 & 26,89 & 26,32 & 27 & 39,24 & 38,54 & 45 & 33,05 & \begin{tabular}{|l|l|}
52,44 \\
\end{tabular} & 120 & \begin{tabular}{|l|}
176,46 \\
\end{tabular} & \begin{tabular}{|l|l|}
6 & 166,33 \\
\end{tabular} & 124 & 181,95 & 178,06 & 244 & \begin{tabular}{l|l|}
4 & 179,20 \\
\end{tabular} & \begin{tabular}{|l|l}
172,19 \\
\end{tabular} \\
\hline Itapeva & D100 & 31 & 71,98 & 76,20 & 36 & 81,14 & 95,25 & 67 & 76,61 & 85,82 & 11 & 24,77 & 25,64 & 13 & 29,58 & 34,74 & 24 & 27,20 & 30,27 & 67 & 155,58 & \begin{tabular}{|l|l|}
8 & 163,85 \\
\end{tabular} & 61 & 139,54 & $4 \quad 168,26$ & 128 & \begin{tabular}{|l|l|}
8 & 147,47 \\
\end{tabular} & 166,08 \\
\hline Itapevi & с300 & 56 & 60,58 & 102,60 & 51 & 54,43 & 89,91 & 107 & 57,47 & 96,19 & 8 & 8,65 & 15,52 & 8 & 8,84 & 17,03 & 16 & 8,75 & \begin{tabular}{|l|l|}
5 & 16,30 \\
\end{tabular} & 145 & 156,49 & 9276,07 & 117 & 124,05 & 234,67 & 262 & \begin{tabular}{l|l|}
2 & 140,11 \\
\end{tabular} & 255,16 \\
\hline Itapira & D100 & 49 & 146,30 & 115,62 & 32 & 96,54 & 78,42 & 81 & 121,47 & 97,05 & 8 & 25,05 & 19,64 & 14 & 41,23 & 32,16 & 22 & 33,13 & \begin{tabular}{|l|l|}
3 & 25,94 \\
\end{tabular} & 71 & 212,43 & \begin{tabular}{|l|l|}
364,18 \\
\end{tabular} & 71 & 213,20 & 162,11 & 141 & \begin{tabular}{l|l|}
1 & 212,82 \\
\end{tabular} & \begin{tabular}{|l|l|}
2163,15 \\
\end{tabular} \\
\hline Itapirapua & E20 & & & & & & & & & & 0 & 17,02 & 22,83 & & & & 0 & 8,97 & \begin{tabular}{|l|l|}
72,48 \\
\end{tabular} & 3 & 153,14 & 4122,83 & 3 & 170,62 & 237,83 & 6 & \begin{tabular}{l|l|}
6 & 161,41 \\
\end{tabular} & $1 \quad 177,23$ \\
\hline Itápolis & D50 & 29 & 147,50 & 112,15 & 20 & 101,86 & 83,17 & 50 & 124,64 & 97,64 & 5 & 26,82 & 19,79 & 4 & 18,37 & 15,19 & 9 & 22,59 & 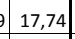 & 45 & 224,59 & \begin{tabular}{|l|l|}
9 & 160,37 \\
\end{tabular} & 43 & 215,41 & 167,02 & 88 & \begin{tabular}{l|l|}
8 & 220,00 \\
\end{tabular} & \begin{tabular}{|l|l|}
163,70 \\
\end{tabular} \\
\hline Itaporanga & E20 & 6 & 83,01 & 73,68 & 4 & 51,63 & 50,94 & 10 & 67,46 & 62,41 & 3 & 36,89 & 32,06 & 3 & 42,25 & 40,59 & 6 & 39,54 & 436,15 & 13 & 175,24 & \begin{tabular}{l|l|}
4 & 135,81 \\
\end{tabular} & 14 & 201,84 & \begin{tabular}{l|l|}
4 & 197,02 \\
\end{tabular} & 27 & \begin{tabular}{l|l|}
7 & 188,42 \\
\end{tabular} & \begin{tabular}{|l|l|}
2 & 166,14 \\
\end{tabular} \\
\hline Itapui & E20 & 7 & 130,35 & 105,38 & 4 & 81,25 & 74,87 & 12 & 106,46 & 90,53 & & & & 1 & 25,00 & 20,41 & 1 & \begin{tabular}{|l|}
12,17 \\
\end{tabular} & \begin{tabular}{|l|l|}
79,93 \\
\end{tabular} & 11 & 195,53 & \begin{tabular}{|l|l|}
350,98 \\
\end{tabular} & 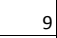 & 168,75 & $5 \mid 131,70$ & 20 & \begin{tabular}{l|l|}
0 & 182,50 \\
\end{tabular} & 141,60 \\
\hline Itapura & E20 & 2 & 98,55 & 63,10 & 1 & 72,16 & 72,95 & 3 & 85,98 & 67,80 & 1 & 32,85 & 22,86 & 1 & 72,16 & 72,44 & 2 & 51,59 & \begin{tabular}{|l|l|}
9 & 45,22 \\
\end{tabular} & 6 & 279,24 & \begin{tabular}{|l|l|}
4 & 227,43 \\
\end{tabular} & 3 & 162,37 & 149,28 & 9 & \begin{tabular}{l|l|}
9 & 223,54 \\
\end{tabular} & \begin{tabular}{l|l}
4 & 190,19 \\
\end{tabular} \\
\hline Itaquaquecetuba & C500 & 84 & 52,41 & 93,40 & 74 & 46,20 & 83,98 & 158 & 49,30 & 88,68 & 18 & 11,44 & 22,17 & 26 & 16,16 & 31,37 & 44 & 13,80 & 26,85 & 145 & 90,25 & \begin{tabular}{|l|l|}
5 & 171,42 \\
\end{tabular} & 142 & 88,47 & 773,41 & 287 & \begin{tabular}{|l|l|}
7 & 89,36 \\
\end{tabular} & \begin{tabular}{l|l}
5 & 172,42 \\
\end{tabular} \\
\hline Itararé & D50 & 22 & 91,29 & 85,03 & 19 & 76,00 & 77,42 & 41 & 83,57 & 81,19 & 4 & 16,60 & 15,69 & 7 & 28,50 & 28,11 & 11 & $22,61 \mid$ & $1 \quad 21,80$ & 48 & 200,56 & \begin{tabular}{|l|l|}
6 & 183,24 \\
\end{tabular} & 49 & 200,87 & 196,75 & 98 & \begin{tabular}{l|l|}
8 & 200,72 \\
\end{tabular} & \begin{tabular}{|l|l|}
2 & 190,06 \\
\end{tabular} \\
\hline Itariri & D20 & 3 & 44,90 & 42,75 & 2 & 32,93 & 39,94 & 6 & 39,06 & 41,38 & 1 & 8,98 & 7,85 & 1 & 18,82 & 22,06 & 2 & 13,79 & \begin{tabular}{|l|l|}
9 & 14,03 \\
\end{tabular} & 7 & 94,30 & \begin{tabular}{|l|l|}
0 & 87,88 \\
\end{tabular} & 7 & 103,51 & 123,55 & 14 & \begin{tabular}{|l|l|}
4 & 98,79 \\
\end{tabular} & \begin{tabular}{l|l}
9 & 105,30 \\
\end{tabular} \\
\hline Itatiba & B100 & 54 & 121,27 & 114,14 & 37 & 81,99 & 82,33 & 91 & 101,56 & 98,18 & 8 & 17,86 & 16,75 & 10 & 22,90 & $22,69 \mid$ & 18 & 20,39 & \begin{tabular}{|l|l|}
9 & 19,71 \\
\end{tabular} & 116 & 258,90 & | 235,49 & 79 & 175,81 & 176,28 & 195 & \begin{tabular}{l|l|}
5 & 217,21 \\
\end{tabular} & 205,78 \\
\hline Itatinga & E20 & 12 & 148,71 & 160,58 & 11 & 139,23 & 157,24 & 23 & 144,09 & 158,95 & 1 & 12,06 & 14,30 & 1 & 16,88 & 19,09 & 2 & 14,41 & $1.16,55$ & 20 & 245,18 & \begin{tabular}{|l|l|}
8 & 250,09 \\
\end{tabular} & 15 & 194,08 & \begin{tabular}{|l|l|}
820,44 \\
\end{tabular} & 36 & \begin{tabular}{l|l|}
6 & 220,25 \\
\end{tabular} & \begin{tabular}{|l|l}
535,62 \\
\end{tabular} \\
\hline Itirapina & C20 & 9 & 110,15 & 120,43 & 4 & 69,29 & 62,59 & 13 & 92,05 & 94,82 & 1 & 12,71 & 14,62 & 1 & 21,32 & 18,09 & 2 & 16,52 & \begin{tabular}{|l|l|}
216,96 \\
\end{tabular} & 9 & 114,38 & \begin{tabular}{|l|l|}
8 & 116,01 \\
\end{tabular} & 9 & 138,58 & \begin{tabular}{|l|l|}
8 & 125,27 \\
\end{tabular} & 18 & \begin{tabular}{l|l|}
8 & 125,10 \\
\end{tabular} & \begin{tabular}{|l|l}
120,11 \\
\end{tabular} \\
\hline Itirapua & E20 & 1 & 45,86 & 43,21 & 1 & 49,98 & 46,38 & 3 & 47,83 & 44,73 & 1 & 22,93 & 19,34 & 1 & 37,48 & 35,96 & 2 & 29,90 & \begin{tabular}{|l|l|}
0 & 27,57 \\
\end{tabular} & 4 & 149,05 & \begin{tabular}{|l|}
5 \\
5
\end{tabular} & 4 & 137,43 & \begin{tabular}{|l|l|}
336,93 \\
\end{tabular} & 8 & \begin{tabular}{l|l|}
8 & 143,49 \\
\end{tabular} & \begin{tabular}{l|l}
132,04 \\
\end{tabular} \\
\hline Itobi & E20 & 5 & 132,12 & 108,25 & 3 & 71,40 & 68,18 & 8 & 102,94 & 88,99 & 1 & 24,77 & $\begin{array}{l}19,57 \\
\end{array}$ & 1 & 26,78 & 23,90 & 2 & 25,74 & \begin{tabular}{l|l|}
4 & 21,79 \\
\end{tabular} & 15 & 363,34 & \begin{tabular}{l|l|}
4 & 263,51 \\
\end{tabular} & 9 & 240,99 & \begin{tabular}{|l|}
213,96 \\
\end{tabular} & 24 & \begin{tabular}{l|l|}
4 & 304,54 \\
\end{tabular} & \begin{tabular}{l|l}
4 & 239,70 \\
\end{tabular} \\
\hline Itu & с 300 & 86 & 116,67 & 120,43 & 55 & 74,59 & 78,05 & 141 & 95,56 & 99,17 & 11 & 14,92 & 15,45 & 17 & 23,36 & $24,61 \mid$ & 28 & \begin{tabular}{|l|}
19,16 \\
\end{tabular} & \begin{tabular}{|l|l|}
5 & 20,04 \\
\end{tabular} & 105 & 142,00 & | 142,20 & 100 & \begin{tabular}{|l|}
34,79 \\
\end{tabular} & \begin{tabular}{|l|l|}
940,56 \\
\end{tabular} & 205 & \begin{tabular}{l|l|}
5 & 138,38 \\
\end{tabular} & \begin{tabular}{l|l}
8141,38 \\
\end{tabular} \\
\hline Itupeva & C50 & 14 & 93,99 & 112,01 & 8 & 52,87 & 69,26 & 22 & 73,95 & 91,17 & 2 & 15,30 & 18,66 & 1 & 6,90 & 9,36 & 3 & 11,20 & \begin{tabular}{|l|l|}
0 & 14,64 \\
\end{tabular} & 29 & \begin{tabular}{|l|}
187,97 \\
\end{tabular} & \begin{tabular}{|l|l|}
7209,03 \\
\end{tabular} & 16 & 110,34 & \begin{tabular}{ll|}
4 & 153,90 \\
\end{tabular} & 45 & \begin{tabular}{|l|l|}
5 & 150,13 \\
\end{tabular} & \begin{tabular}{|l|l} 
B & 182,16
\end{tabular} \\
\hline Ituverava & D50 & 26 & 139,28 & \begin{tabular}{|l|l|}
319,81 \\
\end{tabular} & 20 & 106,68 & 93,71 & 46 & \begin{tabular}{|l|}
122,81 \\
\end{tabular} & \begin{tabular}{|l|}
106,62 \\
\end{tabular} & 4 & 21,43 & 18,09 & & 34,98 & 29,56 & 11 & 28,27 & 23,82 & 42 & 223,21 & \begin{tabular}{|l|l|}
182,41 \\
\end{tabular} & 39 & 206,37 & \begin{tabular}{ll|}
775,46 \\
\end{tabular} & 81 & \begin{tabular}{|l|l|}
1 & 214,70 \\
\end{tabular} & 178,90 \\
\hline Jaborandi & E20 & 4 & 110,26 & 96,81 & 2 & 63,69 & 60,21 & 6 & 87,65 & 79,04 & 1 & 40,10 & 36,32 & & 63,69 & 54,04 & 3 & 51,56 & \begin{tabular}{|l|l|}
5 & 44,70 \\
\end{tabular} & 9 & 280,67 & $\begin{array}{l}7244,94 \\
\end{array}$ & 6 & 201,70 & \begin{tabular}{|l|l|} 
& 190,02 \\
\end{tabular} & 16 & \begin{tabular}{l|l|}
6 & 242,32 \\
\end{tabular} & \begin{tabular}{l|l}
218,27 \\
\end{tabular} \\
\hline Jaboticabal & B100 & 39 & 111,83 & 96,21 & 30 & \begin{tabular}{|l|}
82,81 \\
\end{tabular} & 71,66 & 69 & \begin{tabular}{|l|}
97,04 \\
\end{tabular} & 83,70 & 5 & 15,29 & 12,78 & & 19,32 & 16,67 & 12 & 17,35 & \begin{tabular}{|l|l|}
54,75 \\
\end{tabular} & 56 & \begin{tabular}{|l|}
159,62 \\
\end{tabular} & \begin{tabular}{|l|l|}
229,96 \\
\end{tabular} & 53 & 145,37 & \begin{tabular}{|l|l|}
7117,82 \\
\end{tabular} & 108 & \begin{tabular}{|l|l|}
8 & 152,36 \\
\end{tabular} & 123,78 \\
\hline
\end{tabular}


Anexo 23 - Nº de óbitos e taxa de mortalidade (bruta e padronizada) total e segundo sexo por Neoplasias, Diabetes Mellitus e Doenças do Aparelho Circulatório, municípios. Estado de São Paulo, média do triênio 2003-2005

\begin{tabular}{|c|c|c|c|c|c|c|c|c|c|c|c|c|c|c|c|c|c|c|c|c|c|c|c|c|c|c|c|c|}
\hline \multirow[b]{3}{*}{ Jacarei } & \multirow[b]{3}{*}{ B300 } & \multicolumn{9}{|c|}{ Neoplasias Malignas } & \multicolumn{9}{|c|}{ Diabetes Mellitus } & \multicolumn{9}{|c|}{ Aparelho Circulatorio } \\
\hline & & \multicolumn{3}{|c|}{ Homens } & \multicolumn{3}{|c|}{ Mulheres } & \multicolumn{3}{|c|}{ Total } & \multicolumn{3}{|c|}{ Homens } & \multicolumn{3}{|c|}{ Mulheres } & \multicolumn{3}{|c|}{ Total } & \multicolumn{3}{|c|}{ Homens } & \multicolumn{3}{|c|}{ Mulheres } & \multicolumn{3}{|c|}{ Total } \\
\hline & & 99 & 97,99 & 106,96 & 89 & 86,86 & 96,34 & 188 & 92,37 & 101,59 & 30 & 29,79 & 32,35 & 38 & 36,95 & 42,42 & 68 & 33,41 & $\begin{array}{l}1 \\
17,42 \\
\end{array}$ & 163 & 161,55 & $5 \mid 174,32$ & 142 & 138,39 & 159,55 & 305 & \begin{tabular}{l|l|}
5 & 149,85 \\
\end{tabular} & \begin{tabular}{|l|l}
566,86 \\
\end{tabular} \\
\hline Jaci & E20 & 3 & 128,35 & 116,45 & & & & 3 & 66,51 & 60,35 & 1 & 28,52 & 25,73 & & & & 1 & 14,78 & \begin{tabular}{|l|l|}
84,51 \\
\end{tabular} & 8 & 328,01 & 296,49 & 6 & 260,78 & 8278,32 & 13 & \begin{tabular}{l|l|}
3 & 295,62 \\
\end{tabular} & 287,73 \\
\hline Jacupiranga & D20 & 9 & 93,14 & 92,35 & 4 & 41,19 & 44,20 & 12 & 67,74 & 68,81 & 2 & 21,49 & 18,72 & 2 & 22,47 & 25,21 & 4 & 21,97 & 22,03 & 15 & 161,20 & 149,35 & 11 & 127,32 & 2142,84 & 26 & \begin{tabular}{l|l|}
6 & 144,64 \\
\end{tabular} & \begin{tabular}{l|l}
4 & 146,17 \\
\end{tabular} \\
\hline Jaguariúna & B50 & 22 & 135,23 & 138,54 & 16 & 100,74 & 111,33 & 39 & 118,14 & 125,06 & 1 & 8,07 & 7,99 & 2 & 14,39 & 15,96 & 4 & 11,20 & \begin{tabular}{|l|l|} 
& 11,83 \\
\end{tabular} & 25 & 151,38 & $8|152,40|$ & 29 & 178,86 & 5200,83 & 54 & $4 \quad 164,99$ & \begin{tabular}{l|l|}
9176,40 \\
\end{tabular} \\
\hline Jales & D50 & 28 & 116,99 & 92,36 & 15 & 61,46 & 53,23 & 43 & 88,95 & 72,60 & 4 & 18,11 & 13,93 & 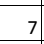 & 27,31 & 22,91 & 11 & 22,76 & \begin{tabular}{|l|l|}
5 & 18,44 \\
\end{tabular} & 41 & 172,71 & 132,13 & 42 & 172,08 & \begin{tabular}{|l|l}
8 & 150,08 \\
\end{tabular} & 83 & \begin{tabular}{|l|l|}
3 & 172,39 \\
\end{tabular} & \begin{tabular}{|l|l}
9 & 141,20 \\
\end{tabular} \\
\hline Jambeiro & D20 & 2 & 103,92 & 87,78 & 2 & 80,87 & 84,95 & 4 & 92,89 & 86,43 & & & & 1 & 32,35 & 32,55 & 1 & 15,48 & \begin{tabular}{|l|}
$8,13,62$ \\
\end{tabular} & 2 & \begin{tabular}{|l|}
103,92 \\
\end{tabular} & 77,09 & & 64,69 & 966,20 & 4 & \begin{tabular}{|l|l|}
4 & 85,15 \\
\end{tabular} & \begin{tabular}{|l|l|}
5 & 71,88 \\
\end{tabular} \\
\hline Jandira & с300 & 31 & 60,26 & 108,11 & 31 & 58,70 & 98,20 & 62 & 59,47 & 103,12 & 8 & 14,74 & 29,77 & 5 & 10,10 & 20,51 & 13 & 12,40 & 25,06 & 72 & 138,47 & 252,49 & 59 & 111,09 & 215,76 & 131 & \begin{tabular}{l|l|}
1 & 124,67 \\
\end{tabular} & 233,98 \\
\hline Jardinópolis & C50 & 20 & 117,78 & 112,45 & 12 & 73,86 & 73,74 & 32 & 96,00 & 93,25 & 3 & 19,63 & 18,14 & 5 & 27,95 & $27,57 \mid$ & 8 & 23,75 & 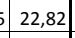 & 35 & 204,15 & $5 \mid 189,29$ & 30 & 181,65 & 580,00 & 65 & \begin{tabular}{l|l|}
5 & 192,99 \\
\end{tabular} & \begin{tabular}{|l|l|}
984,68 \\
\end{tabular} \\
\hline Jarinu & D20 & 10 & 100,77 & 101,92 & 7 & 73,37 & 84,86 & 17 & 87,57 & 93,70 & 1 & 6,50 & 6,55 & 2 & 17,47 & \begin{tabular}{|l|}
20,06 \\
\end{tabular} & 2 & 11,79 & \begin{tabular}{|l|l|}
9 & 12,83 \\
\end{tabular} & 20 & \begin{tabular}{|l|l|}
195,04 \\
\end{tabular} & \begin{tabular}{l|l|}
4 & 195,90 \\
\end{tabular} & 11 & 118,79 & 139,44 & 31 & \begin{tabular}{l|l|}
1 & 158,29 \\
\end{tabular} & \begin{tabular}{l|l}
9 & 168,69 \\
\end{tabular} \\
\hline Jaú & с300 & 82 & 138,12 & 113,13 & 57 & 94,35 & 79,09 & 139 & 115,98 & 95,91 & 10 & 16,28 & 13,45 & 18 & 30,17 & 24,37 & 28 & 23,31 & \begin{tabular}{l|l|}
1 & 18,98 \\
\end{tabular} & 119 & 201,00 & | 154,11 & 108 & 177,18 & \begin{tabular}{|l|l|}
840,67 \\
\end{tabular} & 227 & \begin{tabular}{l|l|}
7 & 188,95 \\
\end{tabular} & \begin{tabular}{l|l}
547,31 \\
\end{tabular} \\
\hline Jeriquara & E20 & 1 & 76,31 & 63,28 & 0 & 21,64 & $\begin{array}{r}29,24 \\
\end{array}$ & 2 & 50,69 & 47,33 & & & & & & & & & & 3 & 171,69 & \begin{tabular}{l|l|}
9 & 159,94 \\
\end{tabular} & 2 & 151,48 & \begin{tabular}{|l|l|}
875,92 \\
\end{tabular} & 5 & \begin{tabular}{l|l|}
5 & 162,22 \\
\end{tabular} & \begin{tabular}{|l|l|}
2167,43 \\
\end{tabular} \\
\hline Joanópolis & E20 & 6 & 97,50 & 76,34 & 4 & 77,52 & 71,02 & 10 & 87,70 & 73,73 & 1 & 22,94 & 17,94 & 1 & 23,85 & 20,64 & 3 & 23,39 & 19,23 & 17 & 292,50 & \begin{tabular}{|l|l|}
$\mid 219,67$ \\
\end{tabular} & 12 & 220,63 & \begin{tabular}{|l|}
379,03 \\
\end{tabular} & 29 & \begin{tabular}{l|l|}
9 & 257,26 \\
\end{tabular} & \begin{tabular}{|l|l|}
5 & 199,75 \\
\end{tabular} \\
\hline Joao Ramalho & E20 & 2 & 110,58 & 103,63 & 0 & 16,02 & 20,53 & 3 & 63,63 & 62,37 & 0 & 15,80 & 12,73 & 1 & 48,06 & 48,29 & 1 & 31,81 | & $1 \quad 29,64$ & 5 & 236,97 & 7223,30 & 2 & 112,14 & $4 \mid 121,77$ & 7 & \begin{tabular}{|l|l|}
7 & 174,99 \\
\end{tabular} & \begin{tabular}{|l|l}
9 & 172,89 \\
\end{tabular} \\
\hline José Bonifácio & D50 & 20 & 128,91 & 107,17 & 12 & 79,76 & 74,27 & 32 & 104,38 & 90,74 & 5 & 30,08 & 24,86 & 5 & 30,18 & 27,13 & 9 & 30,13 & \begin{tabular}{|l|l|}
3 & 26,07 \\
\end{tabular} & 43 & 275,01 & 222,70 & 21 & 133,65 & 5122,00 & 63 & \begin{tabular}{l|l|}
3 & 204,45 \\
\end{tabular} & \begin{tabular}{|l|l|}
572,43 \\
\end{tabular} \\
\hline Júlio Mesquita & E20 & 2 & 78,42 & 47,60 & 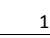 & 61,00 & 54,25 & 3 & 69,59 & 50,97 & 0 & 15,68 & 13,93 & 1 & 61,00 & 55,80 & 2 & \begin{tabular}{|l|}
38,66 \\
\end{tabular} & \begin{tabular}{|l|l|}
5 & 33,60 \\
\end{tabular} & 4 & 172,52 & \begin{tabular}{|l|l|}
214,88 \\
\end{tabular} & 4 & 167,76 & $6 \mid 142,14$ & & \begin{tabular}{l|l|}
7 & 170,11 \\
\end{tabular} & 128,70 \\
\hline Jumirim & A20 & 1 & 102,93 & 93,98 & 1 & 85,86 & 62,68 & 2 & 94,85 & 79,16 & 0 & 25,73 & 18,06 & & & & 0 & 13,55 & \begin{tabular}{|l|}
5 \\
5
\end{tabular} & 2 & 128,67 & $\begin{array}{l}714,72 \\
\end{array}$ & 3 & 286,20 & 220,85 & 5 & \begin{tabular}{l|l|}
5 & 203,25 \\
\end{tabular} & \begin{tabular}{|l|l}
5 & 164,96 \\
\end{tabular} \\
\hline Jundiai & A500 & 258 & 155,36 & 134,59 & 205 & 118,98 & 101,11 & 463 & 136,82 & 117,52 & 21 & 12,65 & 10,83 & 30 & 17,38 & \begin{tabular}{|l|}
14,58 \\
\end{tabular} & 51 & 15,06 & \begin{tabular}{|l|l|}
5 & 12,75 \\
\end{tabular} & 407 & 245,28 & \begin{tabular}{l|l|}
8 & 205,94 \\
\end{tabular} & 342 & 198,18 & \begin{tabular}{|l|l|}
8 & 164,29 \\
\end{tabular} & 749 & \begin{tabular}{l|l|}
9 & 221,28 \\
\end{tabular} & \begin{tabular}{|l|l|}
8 & 184,72 \\
\end{tabular} \\
\hline Junqueirópolis & E20 & 16 & 179,28 & 121,86 & 7 & 88,01 & 70,27 & 23 & 135,79 & 97,28 & 2 & 19,07 & 11,01 & 4 & 46,10 & 31,65 & 5 & 31,95 & \begin{tabular}{|l|}
50,80 \\
\end{tabular} & 35 & 404,33 & $\begin{array}{l}342,71 \\
\end{array}$ & 14 & 171,84 & 4121,44 & 49 & $\begin{array}{l}9 \\
9\end{array}$ & \begin{tabular}{|l|l|}
5 & 184,93 \\
\end{tabular} \\
\hline Juquiá & D50 & 8 & 70,63 & 63,71 & 5 & 49,47 & 55,09 & 13 & 60,31 & 59,51 & 2 & 14,71 & 12,46 & 3 & 30,92 & 33,59 & 5 & 22,62 & \begin{tabular}{|l|}
21,95 \\
\end{tabular} & 20 & 176,57 & \begin{tabular}{l|l|}
752,54 \\
\end{tabular} & 15 & 142,24 & $4 \quad 155,28$ & 35 & \begin{tabular}{l|l|}
5 & 159,83 \\
\end{tabular} & \begin{tabular}{|l|l|} 
B & 153,87 \\
\end{tabular} \\
\hline Juquitiba & D50 & 13 & 85,76 & 98,52 & 11 & 73,12 & 100,33 & 23 & 79,48 & 99,42 & 2 & 15,80 & 17,22 & 5 & 31,99 & 43,96 & 7 & 23,84 & $\begin{array}{l}4 \\
4\end{array}$ & 28 & 191,83 & 3207,11 & 24 & 166,80 & 239,24 & 53 & \begin{tabular}{|l|l|}
3 & 179,39 \\
\end{tabular} & \begin{tabular}{|l|l|}
9 & 223,08 \\
\end{tabular} \\
\hline Lagoinha & E20 & 4 & 137,45 & 82,55 & 2 & 82,19 & 79,83 & 6 & 111,09 & 81,25 & 0 & 12,50 & 7,34 & 1 & 54,79 & 40,37 & 2 & $32,67 \mid$ & \begin{tabular}{l|l|}
71,65 \\
\end{tabular} & 7 & 249,91 & 150,23 & 6 & 232,88 & \begin{tabular}{|l|l|}
887,25 \\
\end{tabular} & 12 & \begin{tabular}{l|l|}
2 & 241,78 \\
\end{tabular} & \begin{tabular}{l|l}
867,89 \\
\end{tabular} \\
\hline Laranjal $\mathrm{Pa}_{2}$ & B50 & 19 & 162,00 & 119,21 & 9 & 73,73 & 62,49 & 28 & 117,81 & 90,81 & 6 & 48,31 & 38,24 & 5 & 39,70 & 33,54 & 10 & 44,00 & 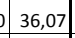 & 31 & 264,31 & 185,98 & 18 & 153,12 & 2121,28 & 49 & \begin{tabular}{l|l|}
9 & 208,65 \\
\end{tabular} & \begin{tabular}{|l|l}
53,59 \\
\end{tabular} \\
\hline Lavinia & E20 & 4 & 159,49 & 113,67 & 1 & 40,22 & 30,49 & 5 & 100,11 & 72,26 & & & & 1 & 26,81 & $19,29 \mid$ & 1 & 13,35 & \begin{tabular}{|l|l|}
5 & 9,18 \\
\end{tabular} & 4 & 172,78 & \begin{tabular}{l|l|}
8 & 115,06 \\
\end{tabular} & 6 & 227,91 & 168,96 & 10 & \begin{tabular}{l|l|}
0 & 200,23 \\
\end{tabular} & \begin{tabular}{l|l} 
B & 141,89 \\
\end{tabular} \\
\hline Lavrinhas & D20 & 2 & 59,31 & $\begin{array}{r}65,65 \\
\end{array}$ & 2 & 61,87 & 84,20 & 4 & 60,57 & 74,73 & 1 & 19,77 & 21,60 & 1 & 20,62 & 27,62 & 1 & 20,19 & 23,92 & 4 & 118,62 & \begin{tabular}{|l|}
230,70 \\
\end{tabular} & 5 & 144,37 & 204,81 & 9 & \begin{tabular}{l|l|}
9 & 131,23 \\
\end{tabular} & \begin{tabular}{|l|l|}
366,97 \\
\end{tabular} \\
\hline Leme & D100 & 37 & 84,74 & 90,16 & 28 & \begin{tabular}{|l|}
66,36 \\
\end{tabular} & 69,61 & 65 & 75,65 & 80,00 & 6 & 13,74 & 14,17 & 8 & 17,96 & 18,61 & 14 & 15,83 & \begin{tabular}{|l|l|}
3 & 16,43 \\
\end{tabular} & 64 & 147,34 & \begin{tabular}{|l|l|}
4 & 146,92 \\
\end{tabular} & 53 & 124,91 & 130,68 & 118 & \begin{tabular}{|l|l|}
8 & 136,25 \\
\end{tabular} & \begin{tabular}{|l|l|}
58,89 \\
\end{tabular} \\
\hline Lençóis Paulista & C100 & 31 & 104,99 & 108,91 & 17 & 58,26 & 61,25 & 49 & 81,66 & 85,12 & 8 & 27,92 & 28,54 & 9 & 30,25 & 32,08 & 17 & 29,08 & 30,45 & 64 & 214,44 & $4 \quad 218,44$ & 53 & 179,25 & $5 \mid 187,01$ & 117 & $\begin{array}{ll}7 & 196,87 \\
\end{array}$ & 202,75 \\
\hline Limeira & Bз00 & 124 & 93,15 & 90,76 & 117 & 86,85 & 88,54 & 241 & 89,98 & 89,64 & 16 & 12,05 & 11,75 & 22 & 16,58 & \begin{tabular}{|l|}
16,88 \\
\end{tabular} & 38 & 14,33 & \begin{tabular}{|l|l|}
3 & 14,30 \\
\end{tabular} & 205 & 154,67 & $\begin{array}{l}746,45 \\
\end{array}$ & 176 & 130,39 & 133,20 & 381 & \begin{tabular}{l|l|}
1 & 142,44 \\
\end{tabular} & \begin{tabular}{l|l}
4 & 139,77 \\
\end{tabular} \\
\hline Lindóia & D20 & 4 & 134,45 & 109,36 & 2 & 79,87 & 65,14 & 6 & 107,41 & 87,45 & 1 & 33,61 & 22,91 & 1 & 22,82 & 19,13 & 2 & $28,27 \mid$ & 21,61 & 8 & 257,70 & \begin{tabular}{|l|l|}
0 & 179,03 \\
\end{tabular} & 5 & 182,57 & 141,79 & 13 & \begin{tabular}{l|l|}
3 & 220,48 \\
\end{tabular} & \begin{tabular}{|l|l|}
8 & 160,58 \\
\end{tabular} \\
\hline Lins & B100 & 44 & 131,02 & 101,74 & 31 & 87,89 & 67,67 & 75 & 108,81 & 84,20 & 7 & 21,84 & 17,60 & 10 & 28,99 & 22,13 & 18 & 25,52 & \begin{tabular}{|l|l|}
2 & 19,94 \\
\end{tabular} & 67 & 200,50 & \begin{tabular}{|l|l|}
0 & 147,68 \\
\end{tabular} & 64 & 178,59 & 130,34 & 131 & \begin{tabular}{l|l|}
1 & 189,22 \\
\end{tabular} & \begin{tabular}{|l|l}
2 & 138,75 \\
\end{tabular} \\
\hline Lorena & B100 & 36 & 91,53 & 88,15 & 37 & 88,60 & 82,96 & 73 & 90,03 & 85,49 & 9 & 21,83 & 21,49 & 10 & \begin{tabular}{|l|}
24,74 \\
\end{tabular} & \begin{tabular}{|l|}
23,05 \\
\end{tabular} & 19 & 23,33 & \begin{tabular}{|l|}
32,26 \\
\end{tabular} & 100 & 251,09 & \begin{tabular}{|l|l|}
9 & 239,13 \\
\end{tabular} & 96 & 230,67 & 211,04 & 196 & \begin{tabular}{|l|l|}
6 & 240,62 \\
\end{tabular} & \begin{tabular}{|l|l|}
2 & 224,73 \\
\end{tabular} \\
\hline Lourdes & E20 & 1 & 89,34 & 61,19 & 0 & 32,03 & 22,56 & 1 & 61,73 & 42,58 & & & & & & & & & & 1 & 119,12 & \begin{tabular}{|l|l|}
2 & 86,62 \\
\end{tabular} & 1 & 128,12 & 207,41 & 3 & \begin{tabular}{l|l|}
3 & 123,46 \\
\end{tabular} & \begin{tabular}{|l|l}
5 & 96,64 \\
\end{tabular} \\
\hline Louveira & C50 & 15 & 110,70 & 127,10 & 14 & 106,44 & 126,29 & 30 & 108,60 & 126,70 & 1 & 9,63 & \begin{tabular}{|l|}
11,60 \\
\end{tabular} & 2 & 12,38 & \begin{tabular}{|l|}
14,99 \\
\end{tabular} & 3 & 10,98 & \begin{tabular}{|l|l|}
8 & 13,24 \\
\end{tabular} & 26 & 185,31 & 214,99 & 21 & 155,94 & \begin{tabular}{|l|l|}
484,01 \\
\end{tabular} & 47 & \begin{tabular}{|l|l|}
7 & 170,83 \\
\end{tabular} & \begin{tabular}{l|l}
199,72 \\
\end{tabular} \\
\hline Lucélia & D20 & 13 & 132,08 & \begin{tabular}{|l|}
34,95 \\
\end{tabular} & 8 & 85,70 & 68,54 & 20 & 109,69 & 82,20 & 3 & 31,28 & 22,96 & 4 & 48,44 & 35,84 & 7 & 39,56 & \begin{tabular}{|l|l|}
5 & 29,19 \\
\end{tabular} & 24 & 253,74 & \begin{tabular}{l|l|}
4 & 182,23 \\
\end{tabular} & 26 & 290,62 & 225,73 & 50 & \begin{tabular}{ll|}
0 & 271,54 \\
\end{tabular} & \begin{tabular}{l|l}
4 & 203,22 \\
\end{tabular} \\
\hline Lucianópo & E20 & 1 & 93,98 & 67,92 & 2 & 232,87 & 198,98 & 3 & 161,34 & 131,49 & 1 & 62,66 & 69,36 & 0 & 33,27 & 27,71 & 1 & 48,40 & \begin{tabular}{|l|l|}
0 & 51,25 \\
\end{tabular} & 3 & 313,28 & \begin{tabular}{|l|l|}
8 & 256,69 \\
\end{tabular} & 1 & 99,80 & 78,39 & 4 & $\begin{array}{l}4 \\
4\end{array}$ & \begin{tabular}{l|l}
50,22 \\
\end{tabular} \\
\hline Luis Antônio & C20 & 5 & 126,16 & 164,41 & 4 & 114,45 & 159,02 & 9 & 120,44 & 161,78 & & & & 1 & 17,61 & \begin{tabular}{|l|}
25,05 \\
\end{tabular} & 1 & 8,60 & \begin{tabular}{|l|l|}
0 & 11,85 \\
\end{tabular} & 3 & 75,69 & \begin{tabular}{|l|l|}
9 & 114,21 \\
\end{tabular} & & 184,88 & \begin{tabular}{|l|l|} 
& 258,84 \\
\end{tabular} & 10 & \begin{tabular}{|l|l|}
0 & 129,04 \\
\end{tabular} & \begin{tabular}{l|l}
4 & 184,87 \\
\end{tabular} \\
\hline Luiziânia & E20 & 2 & 76,79 & 50,43 & 1 & 46,33 & 32,16 & 3 & 61,60 & 41,32 & 0 & 15,36 & 9,96 & 0 & 15,44 & 11,38 & 1 & 15,40 & \begin{tabular}{|l|l|}
0 & 10,72 \\
\end{tabular} & 5 & 245,74 & \begin{tabular}{l|l|}
4 & 184,03 \\
\end{tabular} & 6 & 262,55 & $5 \mid 190,30$ & 11 & \begin{tabular}{ll|}
1 & 254,12 \\
\end{tabular} & \begin{tabular}{|l|l|}
2 & 187,15 \\
\end{tabular} \\
\hline Lupércio & E20 & 2 & 76,99 & 63,59 & 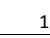 & 46,93 & 46,82 & 3 & 62,08 & 55,27 & 1 & 30,80 & 28,21 & 1 & 31,29 & \begin{tabular}{|l|}
30,29 \\
\end{tabular} & 1 & \begin{tabular}{|l|}
31,04 \\
\end{tabular} & \begin{tabular}{l|l|}
4 & 28,54 \\
\end{tabular} & 7 & \begin{tabular}{|l|} 
\\
\end{tabular} & \begin{tabular}{|l|l|}
8 & 261,99 \\
\end{tabular} & 2 & 93,87 & 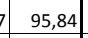 & 9 & \begin{tabular}{l|l|}
9 & 201,77 \\
\end{tabular} & \begin{tabular}{|l|l}
779,57 \\
\end{tabular} \\
\hline Lutécia & E20 & 1 & 65,16 & 41,81 & 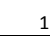 & 90,27 & 79,61 & 2 & 77,48 & 60,34 & 1 & $\begin{array}{l}65,16 \\
\end{array}$ & \begin{tabular}{|l|}
44,26 \\
\end{tabular} & 1 & 45,14 & \begin{tabular}{|l|}
41,49 \\
\end{tabular} & 2 & 55,33 & \begin{tabular}{|l|l|}
3 & 45,04 \\
\end{tabular} & 3 & \begin{tabular}{|l|}
195,48 \\
\end{tabular} & \begin{tabular}{|l|l|}
8 & 125,93 \\
\end{tabular} & 2 & 135,41 & 114,31 & 5 & \begin{tabular}{|l|l|}
5 & 166,02 \\
\end{tabular} & \begin{tabular}{|l|l|}
20,23 \\
\end{tabular} \\
\hline Macatuba & D20 & 8 & 90,97 & 92,29 & 6 & 67,91 & 75,24 & 13 & 79,50 & 83,81 & 4 & 31,64 & 31,44 & 3 & 39,95 & 42,36 & 6 & 35,77 & \begin{tabular}{|l|}
76,89 \\
\end{tabular} & 20 & 233,37 & 7230,40 & 19 & 223,70 & \begin{tabular}{|l|l|} 
& 241,60 \\
\end{tabular} & 38 & \begin{tabular}{l|l|}
8 & 228,56 \\
\end{tabular} & \begin{tabular}{|l|l}
5 & 235,97 \\
\end{tabular} \\
\hline Macaubal & E20 & 5 & 133,23 & 90,58 & 3 & \begin{tabular}{|l|l|} 
& 91,78 \\
\end{tabular} & 69,28 & 8 & 112,84 & 80,11 & 0 & 8,88 & 5,12 & & 36,71 & 26,25 & 2 & 22,57 & 15,25 & 11 & \begin{tabular}{|l|}
293,10 \\
\end{tabular} & \begin{tabular}{|l|l|}
0 & 175,54 \\
\end{tabular} & & 247,80 & $\mid$\begin{tabular}{|l|}
$\mid 180,91$ \\
\end{tabular} & 20 & \begin{tabular}{|l|l|}
0 & 270,82 \\
\end{tabular} & \begin{tabular}{|l|l|}
178,18 \\
\end{tabular} \\
\hline
\end{tabular}


Anexo 23 - $\mathrm{N}^{\circ}$ de óbitos e taxa de mortalidade (bruta e padronizada) total e segundo sexo por Neoplasias, Diabetes Mellitus e Doenças do Aparelho Circulatório, municípios. Estado de São Paulo, média do triênio 2003-2005

\begin{tabular}{|c|c|c|c|c|c|c|c|c|c|c|c|c|c|c|c|c|c|c|c|c|c|c|c|c|c|c|c|c|}
\hline \multirow[b]{3}{*}{ Macedônia } & \multirow[b]{3}{*}{ E20 } & \multicolumn{9}{|c|}{ Neoplasias Malignas } & \multicolumn{9}{|c|}{ Diabetes Mellitus } & \multicolumn{9}{|c|}{ Aparelho Circulatorio } \\
\hline & & \multicolumn{3}{|c|}{ Homens } & \multicolumn{3}{|c|}{ Mulheres } & \multicolumn{3}{|c|}{ Total } & \multicolumn{3}{|c|}{ Homens } & \multicolumn{3}{|c|}{ Mulheres } & \multicolumn{3}{|c|}{ Total } & \multicolumn{3}{|c|}{ Homens } & \multicolumn{3}{|c|}{ Mulheres } & \multicolumn{3}{|c|}{ Total } \\
\hline & & 2 & 125,36 & 92,11 & 4 & 55,18 & 43,84 & 3 & 90,74 & 68,30 & 1 & 35,82 & 23,22 & 0 & 18,39 & 14,06 & 1 & 27,22 & \begin{tabular}{|l|l|}
2 & 19,31 \\
\end{tabular} & 3 & 161,17 & 99,40 & & 294,28 & 832,12 & & 226,84 & \begin{tabular}{l|l}
4 & 164,87 \\
\end{tabular} \\
\hline Magda & E20 & 3 & 156,74 & 119,17 & 2 & 124,74 & 104,57 & 5 & 141,21 & 112,09 & 1 & 39,18 & 26,91 & 1 & 41,58 & 33,85 & 1 & 40,34 & \begin{tabular}{l|l|}
4 & 28,83 \\
\end{tabular} & 4 & 254,70 & | 167,77 & & 83,16 & 70,10 & 6 & 171,47 & 120,38 \\
\hline Mairinque & c50 & 20 & 90,96 & 106,71 & 13 & 59,73 & 75,57 & 34 & 75,36 & 91,15 & 6 & 28,33 & 33,27 & 8 & 35,84 & 46,60 & 14 & 32,08 & \begin{tabular}{|l|l|}
89,85 \\
\end{tabular} & 34 & 152,10 & $\mid 182,19$ & 28 & 125,44 & 470,55 & 62 & 138,78 & \begin{tabular}{l|l|}
876,37 \\
\end{tabular} \\
\hline Mairipora & C100 & 34 & 96,91 & 104,66 & 26 & 74,65 & 91,64 & 59 & 85,84 & 98,18 & 5 & 15,35 & 16,53 & 10 & 28,12 & 34,21 & 15 & 21,70 & \begin{tabular}{|l|l|} 
& 24,99 \\
\end{tabular} & 76 & 218,76 & 6231,42 & 64 & 185,18 & 236,58 & 140 & 202,06 & \begin{tabular}{|l|l|l}
5 & 233,99 \\
\end{tabular} \\
\hline Manduri & D20 & 8 & 171,95 & 132,11 & 6 & 133,15 & 124,95 & 13 & 153,00 & $128,61 \mid$ & 1 & 29,90 & \begin{tabular}{|r|}
22,42 \\
\end{tabular} & 2 & 54,82 & 46,79 & 4 & 42,07 & \begin{tabular}{|l|}
73,91 \\
\end{tabular} & 10 & 231,76 & \begin{tabular}{|c|}
6 \\
\end{tabular} & 9 & 211,47 & 196,28 & 19 & 221,85 & \begin{tabular}{|l|l}
5 & 186,61 \\
\end{tabular} \\
\hline Marabá Pau & E20 & 1 & 50,88 & 35,88 & 1 & 54,80 & \begin{tabular}{|l|} 
\\
\end{tabular} & 2 & 52,77 & 51,91 & 1 & 50,88 & 40,07 & 0 & 18,27 & 18,92 & 1 & 35,18 & \begin{tabular}{|l|l|}
3 & 31,39 \\
\end{tabular} & 3 & \begin{tabular}{|l|}
152,65 \\
\end{tabular} & \begin{tabular}{|l|l|}
5 & 121,84 \\
\end{tabular} & 2 & 91,34 & \begin{tabular}{|l|l|}
4114,72 \\
\end{tabular} & 5 & 123,13 & \begin{tabular}{l|l}
3 & 118,42 \\
\end{tabular} \\
\hline Maracaí & D20 & 6 & 93,77 & 85,64 & 8 & 123,29 & 122,40 & 14 & 108,23 & $103,65 \mid$ & 2 & 34,55 & 31,12 & 3 & 51,37 & 51,09 & 6 & \begin{tabular}{|l|}
42,79 \\
\end{tabular} & $\begin{array}{ll}9 \\
\end{array}$ & 16 & 231,95 & $5|197,00|$ & 15 & 226,02 & 223,64 & 30 & 229,05 & \begin{tabular}{|l|l}
50,05 \\
\end{tabular} \\
\hline Marapoama & E20 & 0 & 27,20 & 23,56 & 1 & 83,87 & 76,79 & 1 & 55,15 & 49,81 & & & & 0 & 27,96 & 22,32 & 0 & \begin{tabular}{|r|}
3,79 \\
\end{tabular} & \begin{tabular}{|l|l|} 
& 10,57 \\
\end{tabular} & 2 & \begin{tabular}{|l|}
136,02 \\
\end{tabular} & \begin{tabular}{|l|l|}
2 & 93,76 \\
\end{tabular} & 1 & 111,83 & 88,16 & 3 & 124,09 & \begin{tabular}{l|l}
9 & 91,00 \\
\end{tabular} \\
\hline Maríápolis & E20 & 2 & 124,91 & 82,37 & 2 & 132,28 & 95,20 & 5 & 128,49 & \begin{tabular}{|l|}
8,60 \\
\end{tabular} & & & & 1 & 56,69 & 37,88 & 1 & \begin{tabular}{|r|}
27,53 \\
\end{tabular} & \begin{tabular}{|l|l|}
3 & 16,91 \\
\end{tabular} & 4 & 231,98 & \begin{tabular}{|l|l|} 
& 137,10 \\
\end{tabular} & 4 & 245,65 & $5 \mid 169,77$ & 9 & \begin{tabular}{|l|}
238,62 \\
\end{tabular} & \begin{tabular}{|l|l}
2 & 152,96 \\
\end{tabular} \\
\hline Marilia & B300 & 147 & 140,48 & 122,44 & 92 & 84,02 & 75,10 & 238 & 111,63 & 98,25 & 18 & 17,56 & 15,30 & 22 & 19,86 & 17,41 & 40 & 18,73 & \begin{tabular}{|l|l|}
3 & 16,35 \\
\end{tabular} & 200 & 191,88 & \begin{tabular}{|l|l|}
859,98 \\
\end{tabular} & 167 & 153,07 & 133,33 & 367 & 172,05 & \begin{tabular}{|l|l}
5 & 146,36 \\
\end{tabular} \\
\hline Marinópolis & E20 & 2 & 143,76 & $110,03 \mid$ & t & 61,48 & 46,53 & 2 & 104,00 & 79,35 & & & & 0 & 30,74 & 29,64 & 0 & \begin{tabular}{|l|}
14,85 \\
\end{tabular} & \begin{tabular}{|l|l|}
5 & 14,77 \\
\end{tabular} & 2 & $201,27 \mid$ & \begin{tabular}{l|l|}
7 & 164,48 \\
\end{tabular} & 2 & 153,70 & $\mid 141,00$ & 4 & \begin{tabular}{|l|}
178,28 \\
\end{tabular} & \begin{tabular}{|l|l}
8 & 153,13 \\
\end{tabular} \\
\hline Martinópolis & D50 & 15 & 124,42 & 103,02 & 9 & 75,47 & 66,01 & 24 & 100,54 & $84,97 \mid$ & 2 & 19,35 & 15,70 & 5 & 46,44 & 37,11 & 8 & 32,57 & \begin{tabular}{l|l|}
76,12 \\
\end{tabular} & 24 & 196,31 & \begin{tabular}{|l|l|} 
& 149,80 \\
\end{tabular} & 20 & 174,15 & 5140,39 & 44 & 185,50 & \begin{tabular}{|l|l} 
& 145,21 \\
\end{tabular} \\
\hline Matao & B100 & 41 & 108,78 & 107,16 & 28 & 73,39 & 77,88 & 69 & 91,08 & 92,52 & 5 & 14,15 & 14,00 & 6 & 16,80 & 17,98 & 12 & \begin{tabular}{|l|}
15,48 \\
\end{tabular} & \begin{tabular}{|l|l|}
8 & 16,00 \\
\end{tabular} & 70 & \begin{tabular}{|l|}
186,61 \\
\end{tabular} & $\mid 182,47$ & 67 & 176,84 & \begin{tabular}{|l|l|}
4 & 190,07 \\
\end{tabular} & 137 & \begin{tabular}{|l|}
181,72 \\
\end{tabular} & \begin{tabular}{|l|l}
2 & 186,27 \\
\end{tabular} \\
\hline Mauá & C500 & 142 & 73,25 & 101,86 & 127 & 63,48 & 88,49 & 269 & 68,28 & 95,07 & 32 & 16,51 & 22,60 & 37 & 18,49 & 27,84 & 69 & 17,52 & \begin{tabular}{|l|l|}
2 & 25,24 \\
\end{tabular} & 330 & \begin{tabular}{|l|}
170,22 \\
\end{tabular} & \begin{tabular}{|l|l|}
2 & 231,75 \\
\end{tabular} & 266 & 133,12 & 209,54 & 596 & \begin{tabular}{|l|}
151,38 \\
\end{tabular} & \begin{tabular}{|l|l}
820,47 \\
\end{tabular} \\
\hline Mendonça & E20 & 3 & 167,00 & 95,67 & 3 & 159,63 & 94,51 & 6 & 163,43 & 95,11 & & & & 0 & 17,74 & 11,30 & 0 & 8,60 & \begin{tabular}{|l|}
5,10 \\
\end{tabular} & 4 & 217,10 & | 115,99 & 6 & 319,26 & 5 & 10 & 266,64 & $\begin{array}{l}4 \\
4\end{array}$ \\
\hline Meridiano & E20 & 3 & 142,00 & 101,87 & 1 & 66,01 & 61,26 & 4 & 104,86 & 82,02 & & & & 0 & 16,50 & 13,40 & 0 & 8,07 & \begin{tabular}{|l|}
7 \\
\end{tabular} & 3 & 126,22 & 79,35 & 4 & 99,01 & 85,48 & 5 & 112,92 & \begin{tabular}{l|l}
2 & 82,35 \\
\end{tabular} \\
\hline Mesópolis & E20 & 1 & 103,31 & 62,85 & 1 & 71,94 & 9,76 & 2 & 87,97 & 71,12 & & & & & & & & & & 3 & 309,92 & 200,05 & 2 & 251,80 & \begin{tabular}{|l|l|} 
& 214,05 \\
\end{tabular} & 5 & 281,49 & \begin{tabular}{l|l|}
9 & 206,90 \\
\end{tabular} \\
\hline Miguelópolis & E20 & 9 & 7,32 & 2,88 & 9 & 88,31 & 94,47 & 17 & 87,81 & 88,64 & 2 & 16,79 & 17,07 & 3 & 27,17 & $28,63 \mid$ & 4 & 21,95 & \begin{tabular}{|l|l|}
5 & 22,56 \\
\end{tabular} & 20 & 201,52 & \begin{tabular}{|l|l|}
285,77 \\
\end{tabular} & 19 & 196,99 & 213,18 & 39 & 199,27 & 7) 199,39 \\
\hline Mineiros do Tiet & E20 & 7 & 107,90 & 97,83 & 5 & 81,96 & 73,55 & 12 & 95,02 & 85,77 & 1 & 16,19 & 14,74 & 2 & 32,79 & 27,12 & 3 & 24,43 & \begin{tabular}{|l|l|}
3 & 21,16 \\
\end{tabular} & 14 & 221,20 & | 195,69 & 11 & 174,85 & 544,15 & 24 & 198,18 & \begin{tabular}{|l|l|}
870,09 \\
\end{tabular} \\
\hline Mira Estrela & E20 & 1 & 100,18 & 63,93 & 1 & 81,02 & 69,65 & 2 & 90,96 & 66,68 & 0 & \begin{tabular}{|l|}
25,04 \\
\end{tabular} & 16,06 & 1 & 81,02 & 73,13 & 1 & 51,98 & \begin{tabular}{|l|l|}
89,65 \\
\end{tabular} & 4 & 275,48 & $8 \mid 181,31$ & 1 & 54,01 & 48,85 & 4 & 168,92 & \begin{tabular}{|l|l|}
2 & 117,58 \\
\end{tabular} \\
\hline Miracatu & E50 & 11 & 86,39 & 89,58 & 7 & 57,68 & 72,44 & 17 & 72,51 & 81,29 & 2 & \begin{tabular}{|l|}
18,90 \\
\end{tabular} & 18,82 & 2 & 17,30 & 22,35 & 4 & 18,13 & \begin{tabular}{|l|l|}
3 & 20,62 \\
\end{tabular} & 22 & 178,18 & \begin{tabular}{l|l|}
8 & 174,23 \\
\end{tabular} & 17 & 147,07 & 201,69 & 39 & 163,14 & \begin{tabular}{l|l}
4 & 187,51 \\
\end{tabular} \\
\hline Mirandópolis & D50 & 19 & 136,45 & 104,24 & 11 & 88,43 & 68,01 & 30 & 114,00 & 87,30 & 2 & \begin{tabular}{|l|}
11,76 \\
\end{tabular} & 9,85 & 3 & 21,44 & 15,72 & 4 & 16,29 & \begin{tabular}{|l|l|}
9 & 12,63 \\
\end{tabular} & 27 & 188,21 & 139,86 & 24 & 192,94 & $4 \quad 148,25$ & 51 & 190,42 & \begin{tabular}{|l|l|}
2143,78 \\
\end{tabular} \\
\hline Mirante Para & E20 & 10 & 117,52 & 85,91 & 6 & 69,40 & 64,90 & 16 & 93,96 & 75,62 & 1 & 11,75 & 8,32 & 2 & 28,58 & $25,29 \mid$ & 3 & 19,99 & \begin{tabular}{|l|l|}
9 & 15,98 \\
\end{tabular} & 12 & 137,11 & 92,24 & 12 & 151,05 & 538,56 & 24 & 143,94 & \begin{tabular}{l|l}
4 & 114,92 \\
\end{tabular} \\
\hline Mirassol & B100 & 27 & 104,49 & 87,28 & 23 & 85,46 & 72,23 & 50 & 94,85 & 79,66 & 3 & \begin{tabular}{|l|}
1,61 \\
\end{tabular} & 9,55 & 5 & 18,85 & 15,72 & 8 & 15,28 & \begin{tabular}{|l|l|}
8 & 12,66 \\
\end{tabular} & 70 & 272,18 & \begin{tabular}{|l|l|}
8 & 217,93 \\
\end{tabular} & 59 & 222,44 & $4 \quad 180,97$ & 129 & 246,99 & \begin{tabular}{|l|l|}
9 & 199,21 \\
\end{tabular} \\
\hline Mirassolândia & E20 & 3 & 127,69 & 99,29 & 0 & 16,88 & 14,55 & 3 & 73,84 & 58,11 & & & & 0 & 16,88 & 14,16 & 0 & 8,20 & \begin{tabular}{|l|l|} 
& 6,49 \\
\end{tabular} & 4 & 175,58 & \begin{tabular}{l|l|}
8 & 126,08 \\
\end{tabular} & 4 & 219,48 & \begin{tabular}{|l|l|}
8 & 188,99 \\
\end{tabular} & 8 & 196,91 & 156,65 \\
\hline Mococa & D100 & 47 & 134,48 & 114,80 & 26 & 75,29 & 67,43 & 72 & 105,15 & 91,33 & 6 & 18,25 & 15,56 & 10 & 29,33 & 25,73 & 16 & 23,74 & $\begin{array}{l}4 \mid 20,57 \\
\end{array}$ & 70 & 201,73 & \begin{tabular}{|l|l|} 
& 167,64 \\
\end{tabular} & 75 & 220,01 & 191,54 & 145 & 10,79 & \begin{tabular}{l|l}
9 & 179,48 \\
\end{tabular} \\
\hline Moji das Cruzes & B500 & 168 & 95,90 & 106,91 & 156 & 86,59 & 98,02 & 324 & 91,17 & 102,39 & 39 & 22,26 & 24,60 & 51 & 28,43 & 32,26 & 90 & 25,39 & $\begin{array}{l}98,49 \\
\end{array}$ & 401 & 229,08 & $8 \mid 250,80$ | & 329 & 182,23 & 311,52 & 730 & 205,30 & 230,87 \\
\hline Moji Mirim & B100 & 49 & 110,28 & 98,13 & 36 & 80,15 & 72,95 & 85 & 95,20 & 85,53 & 8 & 18,00 & 15,96 & 10 & 21,72 & \begin{tabular}{|l|}
19,67 \\
\end{tabular} & 18 & 19,87 & \begin{tabular}{|l|l|}
77,85 \\
\end{tabular} & 76 & 171,79 & $\begin{array}{l}9 \\
948,63 \\
\end{array}$ & 66 & 149,07 & 732,31 & 143 & 160,42 & \begin{tabular}{|l|l|}
2140,47 \\
\end{tabular} \\
\hline MojioGuaçu & B300 & 71 & 104,42 & 103,18 & 56 & 83,05 & 89,66 & 126 & 93,79 & 96,45 & 12 & \begin{tabular}{|l|}
17,24 \\
\end{tabular} & 16,81 & 13 & 19,89 & 21,65 & 25 & 18,56 & \begin{tabular}{|l|l|}
5 & 19,13 \\
\end{tabular} & 98 & 145,30 & 140,55 & 93 & 139,25 & 156,51 & 192 & 142,29 & \begin{tabular}{|l|l|}
9 & 148,49 \\
\end{tabular} \\
\hline Mombuca & E20 & 1 & 78,17 & 70,40 & 2 & 102,38 & 106,32 & 3 & 89,99 & 87,94 & 0 & 19,54 & 19,06 & & & & 0 & 10,00 & \begin{tabular}{|l|l|} 
& 9,80 \\
\end{tabular} & 3 & 175,88 & \begin{tabular}{|l|l|} 
& 185,97 \\
\end{tabular} & 2 & 143,33 & 140,12 & 5 & 159,98 & \begin{tabular}{l|l}
8163,58 \\
\end{tabular} \\
\hline Monçoes & E20 & 2 & 161,39 & 124,51 & 1 & 66,53 & 50,27 & 2 & 114,68 & 87,95 & 1 & \begin{tabular}{|l|}
64,56 \\
\end{tabular} & 37,49 & 0 & 33,27 & 32,73 & 1 & 49,14 & $\begin{array}{l}4 \\
4\end{array}$ & 3 & 258,23 & 357,88 & 3 & 332,67 & 259,22 & 6 & 294,89 & \begin{tabular}{|l|l|}
207,78 \\
\end{tabular} \\
\hline Mongaguá & C50 & 26 & 118,39 & 106,04 & 19 & 90,63 & 88,60 & 44 & 104,86 & 97,54 & 6 & 26,14 & 22,81 & 5 & 22,66 & 21,16 & 10 & 24,44 & $\begin{array}{l}4 \\
4\end{array} 22,05$ & 38 & 173,74 & \begin{tabular}{|l|l|}
4 & 150,70 \\
\end{tabular} & 35 & 168,31 & 165,76 & 72 & 171,09 & \begin{tabular}{l|l}
9 & 158,04 \\
\end{tabular} \\
\hline Monte Alegre & E20 & 5 & 136,41 & 100,45 & 3 & 91,07 & 71,84 & 8 & 114,17 & 86,42 & 0 & 9,74 & 6,35 & 2 & 50,59 & 36,98 & 2 & 29,78 & \begin{tabular}{|l|l|}
8 & 21,05 \\
\end{tabular} & 11 & 331,29 & $\begin{array}{l}918,93 \\
\end{array}$ & 9 & 263,08 & \begin{tabular}{|l|l|}
8 & 196,04 \\
\end{tabular} & 20 & 297,83 & \begin{tabular}{|l|l|}
207,70 \\
\end{tabular} \\
\hline Monte A & C50 & 31 & 137,94 & 108,91 & 20 & 89,87 & 73,96 & 52 & 113,95 & 91,47 & 6 & 26,41 & 20,68 & & 30,94 & 24,28 & 13 & 28,67 & \begin{tabular}{l|l|}
722,46 \\
\end{tabular} & 41 & 179,02 & \begin{tabular}{|l|l|}
2 & 136,75 \\
\end{tabular} & 38 & 166,49 & 130,30 & 78 & 72,77 & $\begin{array}{l}733,53 \\
\end{array}$ \\
\hline Monte & D20 & 14 & 153,64 & 103,54 & 12 & 122,95 & 85,83 & 26 & 138,17 & 94,61 & 2 & \begin{tabular}{|l|}
17,87 \\
\end{tabular} & 11,35 & 2 & 17,56 & \begin{tabular}{|l|}
11,57 \\
\end{tabular} & 3 & 17,71 & 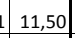 & 21 & 221,53 & \begin{tabular}{|l|l|}
333,84 \\
\end{tabular} & 18 & 193,21 & 131,74 & 39 & 07,25 & \begin{tabular}{|l|l|}
5 & 132,78 \\
\end{tabular} \\
\hline Monte Azul Paulist & E50 & 12 & 119,84 & 108,44 & 8 & 75,97 & 68,13 & 20 & 98,12 & 88,48 & 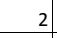 & $22,67 \mid$ & 19,54 & 5 & 52,85 & 46,24 & 8 & $37,61 \mid$ & \begin{tabular}{l|l|}
1 & 32,68 \\
\end{tabular} & 21 & 204,06 & $6 \quad 175,41$ & 15 & 145,34 & 122,74 & 36 & 174,99 & \begin{tabular}{l|l}
149,33 \\
\end{tabular} \\
\hline Monte Castelo & E20 & 1 & 69,14 & 47,73 & 1 & 53,19 & 38,47 & 2 & 61,27 & 43,16 & 1 & \begin{tabular}{|l|}
1,86 \\
\end{tabular} & 28,79 & & & & 1 & 26,26 & \begin{tabular}{|l|l|}
5 & 16,26 \\
\end{tabular} & & 345,72 & \begin{tabular}{|l|l|}
2 & 191,50 \\
\end{tabular} & 3 & 177,30 & | 130,11 & 10 & 262,58 & \begin{tabular}{|l|l|}
861,20 \\
\end{tabular} \\
\hline Monte Mor & D50 & 21 & 98,07 & 114,61 & 12 & 58,21 & 73,86 & 33 & 78,24 & 94,34 & 5 & 21,79 & 25,53 & 5 & 22,02 & 28,94 & 9 & 21,91 & 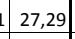 & 32 & 147,89 & $\begin{array}{l}9 \\
970,42 \\
\end{array}$ & 20 & 92,81 & 124,67 & 51 & 120,50 & \begin{tabular}{|l|l|}
147,67 \\
\end{tabular} \\
\hline Monteiro Lobat & E20 & 3 & 138,96 & 122,73 & 1 & 74,01 & 72,82 & 4 & 107,51 & 98,56 & 1 & 34,74 & 31,08 & 0 & 18,50 & 16,39 & 1 & 26,87 & $\begin{array}{l}74,61 \\
\end{array}$ & 5 & 260,55 & 5203,86 & 4 & 203,52 & 2186,50 & 3 & $232,93 \mid$ & $\begin{array}{ll}3 & 195,45 \\
\end{array}$ \\
\hline Morro Agudo & D50 & 12 & 88,52 & 100,21 & 10 & 72,36 & 86,07 & 22 & 80,61 & 93,29 & $3 \mid$ & $|19,14|$ & 22,08 & & 52,40 & 62,51 & 10 & 35,42 & \begin{tabular}{|l|l|}
2 & 41,73 \\
\end{tabular} & 30 & 217,70 & 241,89 & 22 & 164,67 & \begin{tabular}{|l|} 
\\
$\mid 792,73$ \\
\end{tabular} & 52 & 191,75 & \begin{tabular}{|l|l|}
5 & 217,83 \\
\end{tabular} \\
\hline
\end{tabular}


Anexo 23 - Nº de óbitos e taxa de mortalidade (bruta e padronizada) total e segundo sexo por Neoplasias, Diabetes Mellitus e Doenças do Aparelho Circulatório, municípios. Estado de São Paulo, média do triênio 2003-2005

\begin{tabular}{|c|c|c|c|c|c|c|c|c|c|c|c|c|c|c|c|c|c|c|c|c|c|c|c|c|c|c|c|c|}
\hline \multirow[b]{3}{*}{ Morungaba } & \multirow[b]{3}{*}{ D20 } & \multicolumn{9}{|c|}{ Neoplasias Malignas } & \multicolumn{9}{|c|}{ Diabetes Mellitus } & \multicolumn{9}{|c|}{ Aparelho Circulatorio } \\
\hline & & \multicolumn{3}{|c|}{ Homens } & \multicolumn{3}{|c|}{ Mulheres } & \multicolumn{3}{|c|}{ Total } & \multicolumn{3}{|c|}{ Homens } & \multicolumn{3}{|c|}{ Mulheres } & \multicolumn{3}{|c|}{ Total } & \multicolumn{3}{|c|}{ Homens } & \multicolumn{3}{|c|}{ Mulheres } & \multicolumn{3}{|c|}{ Total } \\
\hline & & 5 & 92,62 & 93,74 & 3 & 63,21 & 78,29 & 8 & 78,08 & 86,11 & & & & 1 & 12,64 & 14,57 & 1 & 6,25 & 6,75 & 12 & 222,28 & 8221,23 & 8 & 151,70 & 169,68 & 20 & \begin{tabular}{l|l|}
0 & 187,40 \\
\end{tabular} & \begin{tabular}{|l|l}
195,76 \\
\end{tabular} \\
\hline Motuca & D20 & 1 & 62,82 & 64,88 & 2 & 83,17 & 83,79 & 3 & 72,70 & 74,06 & 1 & 31,41 & 31,93 & 1 & 33,27 & 41,46 & 1 & 32,32 & 236,15 & 4 & 172,77 & \begin{tabular}{|l|l|}
792,73 \\
\end{tabular} & 2 & 116,43 & 3127,38 & 6 & \begin{tabular}{l|l|}
6 & 145,41 \\
\end{tabular} & 160,99 \\
\hline Murutinga do Sul & E20 & 3 & 145,35 & 89,17 & 2 & 100,42 & 75,78 & 5 & 123,28 & 82,59 & 1 & 48,45 & 33,39 & & & & 1 & 24,65 & | 17,83 & 5 & 258,40 & 150,10 & 4 & 184,10 & 124,69 & 9 & 9 9 221,91 . & $1 \quad 137,62$ \\
\hline Nantes & E20 & & & & 1 & 122,70 & 164,19 & 1 & 60,12 & 80,45 & 0 & 29,47 & 26,91 & 0 & 30,67 & 36,16 & 1 & 30,06 & \begin{tabular}{|l|l|}
51,39 \\
\end{tabular} & 1 & 88,42 & \begin{tabular}{|l|l|}
2 & 85,62 \\
\end{tabular} & 2 & 153,37 & 197,02 & 3 & \begin{tabular}{l|l|}
3 & 120,25 \\
\end{tabular} & \begin{tabular}{|l|l}
50,20 \\
\end{tabular} \\
\hline Narandiba & E20 & 2 & 82,25 & 69,53 & 1 & 67,11 & 69,52 & 3 & 74,76 & 69,53 & 1 & 32,90 & 25,05 & 1 & \begin{tabular}{|l|}
33,56 \\
\end{tabular} & 35,19 & 1 & 33,23 & \begin{tabular}{|l|} 
\\
\end{tabular} & 3 & 131,60 & \begin{tabular}{|l|l|}
0 & 105,84 \\
\end{tabular} & 2 & 100,67 & 128,24 & 5 & \begin{tabular}{l|l|}
5 & 116,29 \\
\end{tabular} & \begin{tabular}{l|l}
9 & 116,93 \\
\end{tabular} \\
\hline Natividade da Serra & E20 & 2 & 43,78 & 33,06 & 2 & 49,53 & 43,55 & 3 & 46,48 & 37,98 & 1 & 26,27 & 14,89 & 2 & 49,53 & 39,90 & 3 & 37,18 & \begin{tabular}{|l|l|}
8,85 \\
\end{tabular} & 8 & 201,40 & $\mid 122,02$ & & 237,74 & $4 \mid 193,62$ & 16 & \begin{tabular}{l|l|}
6 & 218,45 \\
\end{tabular} & \begin{tabular}{|l|l}
555,61 \\
\end{tabular} \\
\hline Nazaré Paulista & E20 & 10 & 128,23 & 102,59 & 7 & 88,02 & 86,04 & 17 & 108,74 & 94,57 & 5 & 62,05 & 43,87 & 3 & 39,61 & 35,11 & 8 & 51,17 & 40,55 & 22 & 268,86 & \begin{tabular}{l|l|}
6 & 208,24 \\
\end{tabular} & 19 & 246,45 & 231,55 & 40 & \begin{tabular}{l|l|}
0 & 258,00 \\
\end{tabular} & 219,53 \\
\hline Neves Paulista & E20 & 8 & 180,35 & 119,35 & 5 & 117,17 & 75,70 & 14 & 149,00 & 97,69 & 0 & 7,21 & 4,29 & 2 & 36,62 & 22,65 & 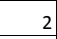 & 21,81 & 13,29 & 13 & 274,13 & \begin{tabular}{|l|l|}
375,55 \\
\end{tabular} & 10 & 212,38 & $8 \mid 138,26$ & 22 & \begin{tabular}{l|l|}
2 & 243,49 \\
\end{tabular} & \begin{tabular}{|l|l|}
9 & 157,04 \\
\end{tabular} \\
\hline Nhandeara & D20 & 6 & 126,90 & 76,98 & 4 & 77,92 & 55,96 & 10 & 102,07 & 66,32 & 2 & 33,40 & 20,14 & 2 & 38,96 & 27,41 & 4 & 36,22 & \begin{tabular}{|l|l|}
2 & 23,84 \\
\end{tabular} & 10 & 207,05 & $5 \mid 115,31$ & 11 & 220,78 & \begin{tabular}{|l|l|}
850,78 \\
\end{tabular} & 22 & \begin{tabular}{|l|l|}
2 & 214,01 \\
\end{tabular} & \begin{tabular}{|l|l}
133,30 \\
\end{tabular} \\
\hline Nipoa & E20 & 3 & 168,48 & 128,13 & 1 & 78,62 & 69,80 & 4 & 124,64 & 99,68 & & & & 0 & 19,65 & 16,87 & 0 & 9,59 & \begin{tabular}{l|l|} 
& 7,73 \\
\end{tabular} & 4 & 224,63 & \begin{tabular}{l|l|}
$3 \mid 165,46$ \\
\end{tabular} & 2 & 98,27 & 7. 82,47 & 6 & \begin{tabular}{l|l|}
6 & 162,99 \\
\end{tabular} & \begin{tabular}{l|l}
9 & 124,98 \\
\end{tabular} \\
\hline Nova Aliança & E20 & 4 & 146,92 & 84,51 & 3 & 131,80 & 102,54 & 7 & 139,31 & 93,58 & & & & 0 & 13,18 & 11,65 & 0 & 6,63 & \begin{tabular}{|l|l|}
3 & 5,83 \\
\end{tabular} & 9 & 347,27 & 7179,50 & 5 & 184,53 & \begin{tabular}{|l|l|}
126,33 \\
\end{tabular} & 13 & \begin{tabular}{l|l|}
3 & 265,36 \\
\end{tabular} & \begin{tabular}{|l|l|}
5 & 152,74 \\
\end{tabular} \\
\hline Nova Campina & E20 & 4 & 85,51 & 110,39 & 2 & 42,36 & 68,23 & 5 & 64,86 & 90,22 & 0 & 7,77 & 9,61 & 1 & 16,94 & 27,53 & 1 & 12,16 & \begin{tabular}{|l|l|}
5 & 17,33 \\
\end{tabular} & 5 & 108,83 & \begin{tabular}{|l|l|}
344,22 \\
\end{tabular} & 4 & 101,66 & \begin{tabular}{|l|l|}
5 & 176,86 \\
\end{tabular} & 9 & \begin{tabular}{l|l|}
9 & 105,40 \\
\end{tabular} & \begin{tabular}{|l|l}
59,84 \\
\end{tabular} \\
\hline Nova Canaa Paulista & E20 & 2 & 135,57 & 68,75 & 0 & 29,26 & 16,62 & 2 & 84,44 & 43,68 & & & & 1 & 58,51 & 38,51 & 1 & 28,14 & \begin{tabular}{l|l|}
4 & 17,46 \\
\end{tabular} & 2 & 162,69 & \begin{tabular}{|l|l|}
9 & 77,07 \\
\end{tabular} & 4 & 380,34 & 4228,33 & 6 & \begin{tabular}{l|l|}
6 & 267,38 \\
\end{tabular} & \begin{tabular}{|l|l|}
849,82 \\
\end{tabular} \\
\hline Nova Castiliho & E20 & 1 & 125,47 & 113,81 & 0 & 69,25 & 54,67 & 1 & 98,75 & 85,70 & & & & 0 & 69,25 & 72,59 & 0 & 32,91 & 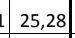 & 1 & 250,94 & $\begin{array}{l}456,26 \\
4\end{array}$ & 1 & 138,50 & 153,95 & 2 & \begin{tabular}{|l|l|}
2 & 197,50 \\
\end{tabular} & \begin{tabular}{|l|l}
55,16 \\
\end{tabular} \\
\hline Nova Europa & D20 & 6 & 152,66 & 136,31 & 2 & 41,47 & 41,70 & 8 & 97,94 & 89,75 & 1 & 32,14 & 29,51 & 2 & 58,05 & 61,08 & 4 & \begin{tabular}{|l|}
44,89 \\
\end{tabular} & \begin{tabular}{|l|l|}
9 & 43,88 \\
\end{tabular} & 11 & 257,11 & 222,34 & 5 & 116,11 & 120,43 & 15 & \begin{tabular}{l|l|}
5 & 187,72 \\
\end{tabular} & \begin{tabular}{|l|l|}
2172,19 \\
\end{tabular} \\
\hline Nova Granada & E20 & 16 & 177,30 & 142,62 & 11 & 119,25 & 101,90 & 27 & 148,40 & 122,35 & 1 & 7,39 & 5,43 & 2 & 18,63 & 16,33 & 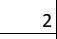 & 12,99 & \begin{tabular}{|l|} 
\\
\end{tabular} & 20 & 221,62 & \begin{tabular}{|l|l|}
2 & 163,45 \\
\end{tabular} & 21 & 231,05 & 189,32 & 41 & \begin{tabular}{l|l|}
1 & 226,32 \\
\end{tabular} & \begin{tabular}{|l|l|}
2 & 176,32 \\
\end{tabular} \\
\hline Nova Guataporanga & E20 & 1 & 125,35 & 69,65 & 1 & 132,45 & 105,35 & 3 & 128,80 & 87,01 & 1 & 62,68 & 29,56 & 0 & 33,11 & 20,04 & -5 & 48,31 & 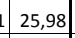 & 2 & 188,03 & \begin{tabular}{|l|l|}
3 & 71,08 \\
\end{tabular} & 2 & 231,79 & 174,55 & 4 & $\begin{array}{l}4.209,31 \\
\end{array}$ & \begin{tabular}{|l|l}
121,39 \\
\end{tabular} \\
\hline Nova Independência & E20 & 3 & 249,38 & 194,87 & 2 & 195,50 & 155,73 & 5 & 223,04 & 175,74 & 0 & 31,17 & 19,24 & 0 & \begin{tabular}{|l|}
2,58 \\
\end{tabular} & 25,39 & 1 & \begin{tabular}{|l|}
1,87 \\
\end{tabular} & 22,26 & 2 & 155,86 & \begin{tabular}{l|l|}
6 & 91,58 \\
\end{tabular} & 2 & 195,50 & 161,27 & 4 & $\begin{array}{l}4 \\
175,24 \\
\end{array}$ & \begin{tabular}{l|l}
4 & 125,66 \\
\end{tabular} \\
\hline Nova Luzitânia & E20 & 3 & 204,04 & 166,37 & 1 & 75,34 & 77,90 & 4 & 142,98 & 124,40 & & & & & & & & & & 5 & 317,39 & \begin{tabular}{|l|l|}
9222,09 \\
\end{tabular} & 3 & 200,90 & 195,59 & 7 & \begin{tabular}{ll|}
7 & 262,12 \\
\end{tabular} & 209,52 \\
\hline Nova Odessa & B50 & 20 & 86,86 & 89,02 & 20 & 88,38 & 96,32 & 40 & 87,63 & 92,70 & 5 & 23,56 & 23,77 & 6 & 24,63 & 26,87 & 11 & 24,10 & 25,37 & 29 & 129,56 & \begin{tabular}{|l|l|}
6 & 132,16 \\
\end{tabular} & 30 & 128,95 & 5145,23 & 59 & \begin{tabular}{l|l|}
9 & 129,25 \\
\end{tabular} & \begin{tabular}{|l|l}
58,75 \\
\end{tabular} \\
\hline Novais & E20 & 1 & 38,89 & 24,14 & 2 & 148,27 & 157,83 & 3 & 91,24 & 88,13 & & & & & & & & & & 3 & 194,44 & $4 \quad 154,74$ & 2 & 127,09 & 9111,18 & 5 & \begin{tabular}{l|l|}
5 & 162,21 \\
\end{tabular} & \begin{tabular}{l|l}
1 & 133,89 \\
\end{tabular} \\
\hline Novo Horizon & D50 & 25 & 153,04 & 116,91 & 16 & 97,40 & 78,50 & 42 & 125,04 & 97,58 & 4 & 22,15 & 16,56 & 5 & 27,83 & \begin{tabular}{|l|}
21,62 \\
\end{tabular} & 8 & \begin{tabular}{|l|}
25,01 \\
\end{tabular} & \begin{tabular}{|l|l|}
19,12 \\
\end{tabular} & 41 & 247,68 & \begin{tabular}{|l|l|}
8 & 171,65 \\
\end{tabular} & 41 & 242,51 & \begin{tabular}{|l|}
190,42 \\
\end{tabular} & 82 & \begin{tabular}{|l|l|}
2 & 245,08 \\
\end{tabular} & \begin{tabular}{|l|l}
8 & 181,09 \\
\end{tabular} \\
\hline Nuporanga & E20 & 3 & 90,33 & 70,41 & 3 & 93,18 & 83,91 & 6 & 91,73 & 77,06 & 0 & 10,04 & 9,88 & 0 & 10,35 & $8,10 \mid$ & 1 & 10,19 & \begin{tabular}{|l|l|}
9 & 9,00 \\
\end{tabular} & 7 & 220,82 & \begin{tabular}{|l|l|}
269,79 \\
\end{tabular} & 7 & 227,77 & \begin{tabular}{|l|}
783,52 \\
\end{tabular} & 15 & \begin{tabular}{l|l|}
5 & 224,24 \\
\end{tabular} & $\begin{array}{l}4 \\
4\end{array}$ \\
\hline Ocaụ̧u & E20 & 2 & 93,69 & 76,49 & 0 & 16,99 & 16,16 & 2 & 56,96 & 47,60 & 1 & 31,23 & 23,09 & 1 & 67,96 & \begin{tabular}{|l|}
55,52 \\
\end{tabular} & 2 & \begin{tabular}{|l|}
48,82 \\
\end{tabular} & \begin{tabular}{|l|}
28,25 \\
\end{tabular} & 4 & 171,77 & \begin{tabular}{|l|l|}
726,86 \\
\end{tabular} & 5 & 271,83 & 242,63 & 9 & \begin{tabular}{l|l|}
9 & 219,69 \\
\end{tabular} & \begin{tabular}{l|l}
9 & 182,30 \\
\end{tabular} \\
\hline oleo & E20 & 1 & 42,23 & 25,48 & 2 & 155,62 & 117,15 & 3 & 97,47 & 70,13 & 1 & 63,34 & 39,70 & & & & 1 & \begin{tabular}{|l|}
32,49 \\
\end{tabular} & \begin{tabular}{|l|}
92,00 \\
\end{tabular} & 2 & 126,69 & \begin{tabular}{|l|l|}
9 & 78,69 \\
\end{tabular} & 3 & 200,09 & \begin{tabular}{|l|l|}
164,29 \\
\end{tabular} & 5 & \begin{tabular}{|l|l|}
5 & 162,44 \\
\end{tabular} & \begin{tabular}{l|l}
4 & 120,39 \\
\end{tabular} \\
\hline Olimpia & D50 & 30 & 126,40 & 96,95 & 25 & 104,47 & 85,12 & 55 & 115,33 & 90,98 & 6 & 24,14 & 19,18 & 5 & 20,89 & 16,80 & 11 & 22,50 & \begin{tabular}{|l|l|}
0 & 18,06 \\
\end{tabular} & 52 & 222,97 & $\begin{array}{l}757,46 \\
\end{array}$ & 52 & 217,30 & $\mid 162,90$ & 104 & \begin{tabular}{l|l|}
4 & 220,11 \\
\end{tabular} & \begin{tabular}{l|l}
11 & 160,20 \\
\end{tabular} \\
\hline Onda Verd & E20 & 2 & 124,69 & 116,17 & 1 & 55,44 & 62,54 & 3 & 90,70 & 89,85 & & & & & & & & & & 1 & 71,25 & 65,58 & 5 & 277,21 & \begin{tabular}{|l|}
1 \\
\end{tabular} & 6 & \begin{tabular}{l|l|}
6 & 172,34 \\
\end{tabular} & \begin{tabular}{l|l}
4 & 183,24 \\
\end{tabular} \\
\hline Oriente & D20 & 6 & 220,48 & 158,01 & 3 & 109,04 & \begin{tabular}{|l|} 
\\
\end{tabular} & 9 & \begin{tabular}{|l|}
164,45 \\
\end{tabular} & 119,05 & 0 & 12,25 & 7,49 & 1 & 36,35 & 26,11 & 1 & \begin{tabular}{|l|}
24,36 \\
\end{tabular} & \begin{tabular}{|l|l|}
5 & 16,26 \\
\end{tabular} & 8 & 293,97 & $\begin{array}{l}781,61 \\
\end{array}$ & 4 & 133,27 & 102,69 & 12 & \begin{tabular}{|l|l|}
2 & 213,18 \\
\end{tabular} & \begin{tabular}{|l|l}
8 & 141,94 \\
\end{tabular} \\
\hline Orindiúva & C20 & 2 & 83,30 & 124,44 & 0 & 14,77 & 17,06 & 2 & 50,09 & 72,41 & 1 & 27,77 & 30,77 & & & & 1 & 14,31 & \begin{tabular}{l|l|}
1 & 16,62 \\
\end{tabular} & 2 & 97,18 & \begin{tabular}{|l|l|}
8 & 112,10 \\
\end{tabular} & 2 & 103,38 & \begin{tabular}{|l|l|}
8 & 124,50 \\
\end{tabular} & 5 & \begin{tabular}{|l|l|}
5 & 100,19 \\
\end{tabular} & \begin{tabular}{|l|l}
9 & 118,11 \\
\end{tabular} \\
\hline Orlândia & B50 & 22 & 116,40 & 111,01 & 14 & 72,93 & 72,54 & 36 & 94,50 & 91,63 & 3 & 14,11 & 13,74 & 4 & 22,57 & 22,34 & 7 & 18,37 & \begin{tabular}{|l|}
78,05 \\
\end{tabular} & 43 & 225,75 & \begin{tabular}{|l|l|}
5 & 212,82 \\
\end{tabular} & 40 & 206,65 & \begin{tabular}{|l|}
508,82 \\
\end{tabular} & 82 & \begin{tabular}{|l|l|}
2 & 216,12 \\
\end{tabular} & \begin{tabular}{|l|l|}
2 & 210,81 \\
\end{tabular} \\
\hline Osasco & B1000 & 328 & 97,74 & 122,75 & 297 & 83,72 & 100,44 & 625 & 90,54 & 111,29 & 65 & 19,45 & 24,27 & 68 & 19,28 & 24,06 & 134 & 19,36 & \begin{tabular}{|l|l|}
5 & 24,13 \\
\end{tabular} & 710 & 211,27 & $\begin{array}{l}7258,63 \\
\end{array}$ & 628 & 177,31 & 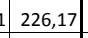 & 1338 & \begin{tabular}{l|l|}
8 & 193,83 \\
\end{tabular} & \begin{tabular}{l|l} 
& 241,97 \\
\end{tabular} \\
\hline Oscar Bressane & E20 & 3 & 266,17 & 163,26 & 1 & 51,09 & 39,63 & 4 & 156,41 & 100,17 & 0 & 26,62 & 14,48 & & & & 0 & 13,04 & \begin{tabular}{l|l|}
4 & 8,35 \\
\end{tabular} & 3 & 266,17 & 745,71 & 2 & 153,26 & \begin{tabular}{|l|l|}
5 & 108,37 \\
\end{tabular} & 5 & \begin{tabular}{l|l|}
5 & 208,55 \\
\end{tabular} & \begin{tabular}{|l|l|}
5 & 126,66 \\
\end{tabular} \\
\hline Osvaldo Cru & D50 & 23 & 153,47 & 95,31 & 12 & 78,92 & 60,55 & 35 & 115,66 & 77,68 & 5 & 36,11 & 24,31 & & 48,23 & 33,60 & 13 & 42,26 & \begin{tabular}{|l|l|}
5 & 28,65 \\
\end{tabular} & 27 & 182,81 & 115,51 & 26 & 171,00 & 122,49 & 53 & \begin{tabular}{l|l|}
3 & 176,82 \\
\end{tabular} & \begin{tabular}{|l|l|}
2119,05 \\
\end{tabular} \\
\hline Ourinhos & С300 & 64 & 129,19 & 117,69 & 35 & 68,46 & 63,78 & 100 & 98,28 & 90,25 & 11 & 21,42 & 19,75 & 19 & 36,16 & 32,91 & 29 & 28,92 & \begin{tabular}{|l|l|}
26,38 \\
\end{tabular} & 92 & 184,08 & \begin{tabular}{|l|l|}
8 & 163,22 \\
\end{tabular} & 85 & 164,03 & 351,34 & 176 & \begin{tabular}{l|l|}
6 & 173,88 \\
\end{tabular} & \begin{tabular}{l|l}
857,17 \\
\end{tabular} \\
\hline Ouro Verde & E20 & 5 & 148,26 & 117,59 & 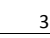 & 93,29 & 93,57 & 9 & 120,87 & 105,62 & 0 & 9,27 & 6,22 & & 27,99 & 23,96 & 1 & 18,60 & \begin{tabular}{|l|}
0,20 \\
\end{tabular} & & 185,32 & 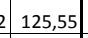 & & 177,26 & $5 \mid 164,21$ & 13 & \begin{tabular}{l|l|}
3 & 181,30 \\
\end{tabular} & \begin{tabular}{|l|l}
144,81 \\
\end{tabular} \\
\hline Ouroeste & E20 & 3 & 77,07 & 53,68 & 1 & 19,43 & 17,86 & 3 & 48,37 & 35,85 & 1 & 19,27 & 12,59 & 0 & 9,72 & 8,42 & 1 & 14,51 & \begin{tabular}{l|l|}
1 & 10,99 \\
\end{tabular} & 8 & 221,58 & \begin{tabular}{l|l|}
8 & 154,92 \\
\end{tabular} & 6 & 184,61 & 172,72 & 14 & 4 4 203,17 | & $\begin{array}{ll}763,78 \\
\end{array}$ \\
\hline Pacaembu & E20 & 9 & 129,48 & 85,45 & 8 & 141,34 & 106,58 & 17 & 135,03 & 95,34 & 1 & 14,94 & 11,06 & 2 & 33,92 & 26,64 & 3 & 23,83 & \begin{tabular}{|l|l|}
3 & 18,21 \\
\end{tabular} & 26 & 388,45 & 5245,17 & 17 & 282,68 & \begin{tabular}{|l|l|}
8 & 197,82 \\
\end{tabular} & 43 & \begin{tabular}{l|l|}
3 & 338,91 \\
\end{tabular} & 223,00 \\
\hline Palestina & E20 & 8 & 176,07 & 102,94 & 6 & 123,29 & 81,73 & 14 & 149,53 & 92,28 & 0 & 7,34 & 4,11 & 1 & 14,50 & 8,79 & 1 & 10,94 & \begin{tabular}{|l|l|}
4 & 6,41 \\
\end{tabular} & 9 & 198,08 & \begin{tabular}{|l|l|}
8 & 110,47 \\
\end{tabular} & 6 & 137,79 & \begin{tabular}{|l|l|}
9 & 88,85 \\
\end{tabular} & 15 & \begin{tabular}{|l|l|}
5 & 167,76 \\
\end{tabular} & \begin{tabular}{|l|l}
5 & 99,60 \\
\end{tabular} \\
\hline Palmares Paulista & E20 & 3 & 73,24 & 84,25 & 3 & 76,05 & 101,37 & 7 & 74,62 & 92,65 & 1 & 14,65 & 17,10 & 0 & 7,60 & 9,85 & 1 & 11,19 & \begin{tabular}{|l|l|}
9 & 13,81 \\
\end{tabular} & 12 & 270,98 & \begin{tabular}{l|l|}
834,27 \\
\end{tabular} & 5 & 114,07 & 143,22 & 17 & \begin{tabular}{l|l|}
7 & 194,00 \\
\end{tabular} & \begin{tabular}{|l|l} 
& 240,54 \\
\end{tabular} \\
\hline Palmeira d'Oeste & E20 & 7 & 130,63 & 82,63 & 4 & 74,23 & 59,85 & 10 & 102,89 & 71,43 & 2 & 32,66 & 23,88 & & 26,99 & 19,41 & & 29,87 & \begin{tabular}{|l|l|}
7,47 \\
\end{tabular} & & \begin{tabular}{|l|}
69,82 \\
\end{tabular} & \begin{tabular}{|l|l|}
2 & 91,01 \\
\end{tabular} & & 128,21 & 100,41 & 15 & \begin{tabular}{|l|l|}
5 & 149,36 \\
\end{tabular} & 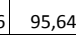 \\
\hline
\end{tabular}


Anexo 23 - Nº de óbitos e taxa de mortalidade (bruta e padronizada) total e segundo sexo por Neoplasias, Diabetes Mellitus e Doenças do Aparelho Circulatório, municípios. Estado de São Paulo, média do triênio 2003-2005

\begin{tabular}{|c|c|c|c|c|c|c|c|c|c|c|c|c|c|c|c|c|c|c|c|c|c|c|c|c|c|c|c|c|}
\hline \multirow[b]{3}{*}{ Palmital } & \multirow[b]{3}{*}{ D50 } & \multicolumn{9}{|c|}{ Neoplasias Malignas } & \multicolumn{9}{|c|}{ Diabetes Mellitus } & \multicolumn{9}{|c|}{ Aparelho Circulatorio } \\
\hline & & \multicolumn{3}{|c|}{ Homens } & \multicolumn{3}{|c|}{ Mulheres } & \multicolumn{3}{|c|}{ Total } & \multicolumn{3}{|c|}{ Homens } & \multicolumn{3}{|c|}{ Mulheres } & \multicolumn{3}{|c|}{ Total } & \multicolumn{3}{|c|}{ Homens } & \multicolumn{3}{|c|}{ Mulheres } & \multicolumn{3}{|c|}{ Total } \\
\hline & & 15 & 140,18 & 90,80 & 7 & 64,21 & 49,40 & 22. & 101,84 & 69,90 & 3 & 28,04 & 19,08 & 8 & 70,32 & 51,86 & 11 & 49,38 & \begin{tabular}{|l|l|} 
& 35,01 \\
\end{tabular} & 25 & 236,75 & 5152,26 & 25 & 232,37 & 166,48 & 51 & 234,54 & \begin{tabular}{l|l}
4 & 159,44 \\
\end{tabular} \\
\hline Panorama & E20 & 7 & 91,79 & 90,21 & 7 & 95,66 & 97,76 & 13 & 93,68 & 93,90 & 1 & 18,36 & 16,20 & 2 & 33,48 & 35,22 & 4 & 25,76 & \begin{tabular}{|l|l|}
5 & 25,66 \\
\end{tabular} & 13 & 183,57 & 767,81 & & 133,93 & \begin{tabular}{|l|l|}
144,68 \\
\end{tabular} & 23 & \begin{tabular}{l|l|l}
3 & 159,26 \\
\end{tabular} & \begin{tabular}{|l|l|}
5 & 156,48 \\
\end{tabular} \\
\hline Paraguaçu Paulista & D50 & 21 & 101,98 & 90,30 & 16 & 76,76 & 69,77 & 38 & 89,26 & 79,95 & 4 & 20,72 & 18,64 & 10 & 48,56 & 43,95 & 15 & 34,76 & \begin{tabular}{|l|}
51,20 \\
\end{tabular} & 46 & 219,90 & | 184,30 & 41 & 194,24 & 473,08 & 87 & $\begin{array}{l}7 \quad 206,96 \\
\end{array}$ & \begin{tabular}{|l|l|}
5 & 178,64 \\
\end{tabular} \\
\hline Paraibuna & E20 & 9 & 101,56 & 84,95 & 4 & 45,64 & 49,72 & 13 & 74,27 & 67,75 & 1 & 10,88 & 8,83 & 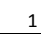 & 15,21 & 16,21 & 2 & 13,00 & \begin{tabular}{|l|l|} 
& 12,38 \\
\end{tabular} & 15 & 166,85 & 5140,76 & 11 & 129,32 & 238,70 & 27 & \begin{tabular}{l|l|}
7 & 148,53 \\
\end{tabular} & \begin{tabular}{|l|l|}
139,76 \\
\end{tabular} \\
\hline Paraiso & E20 & 3 & 111,52 & 84,80 & 3 & 96,90 & 86,08 & 6 & 104,51 & 85,41 & & & & 0 & \begin{tabular}{|l|}
12,11 \\
\end{tabular} & $10,29 \mid$ & 0 & 5,81 & \begin{tabular}{|l|l|} 
& 4,63 \\
\end{tabular} & 8 & 278,80 & \begin{tabular}{|l|l|}
0 & 191,43 \\
\end{tabular} & 5 & 193,80 & 171,53 & 14 & $4 \quad 238,05$ & \begin{tabular}{|l|l|}
5181,89 \\
\end{tabular} \\
\hline Paranapanema & E20 & 7 & 76,70 & 74,67 & 4 & 49,82 & 58,03 & 11 & 63,79 & 66,68 & 1 & 15,34 & 15,04 & 2 & 24,91 & 30,35 & 3 & 19,94 & \begin{tabular}{|l|l|}
4 & 21,43 \\
\end{tabular} & 16 & \begin{tabular}{|l|}
180,24 \\
\end{tabular} & \begin{tabular}{l|l|}
4 & 162,55 \\
\end{tabular} & 15 & 182,67 & 228,47 & 30 & \begin{tabular}{|l|l|}
0 & 181,40 \\
\end{tabular} & \begin{tabular}{|l|}
94,21 \\
\end{tabular} \\
\hline Paranapua & E20 & 1 & 73,34 & 45,48 & 0 & 19,02 & 14,42 & 2 & 46,68 & 30,23 & 1 & 73,34 & 47,21 & 1 & 76,07 & 56,97 & 3 & \begin{tabular}{|l|}
74,68 \\
\end{tabular} & 52,24 & 6 & 348,37 & \begin{tabular}{l|l|}
7235,78 \\
\end{tabular} & 5 & 285,28 & \begin{tabular}{|l|l|}
824,67 \\
\end{tabular} & 11 & \begin{tabular}{l|l|}
1 & 317,40 \\
\end{tabular} & 230,33 \\
\hline Parapua & E20 & 9 & 167,59 & 130,67 & 4 & 80,33 & 64,22 & 14 & 124,66 & 97,97 & 1 & 23,94 & 17,96 & 3 & 61,79 & 47,98 & 5 & 42,57 & 31,80 & 16 & 281,32 & \begin{tabular}{|l|l|}
2178,47 \\
\end{tabular} & 9 & 173,02 & 2127,25 & 25 & \begin{tabular}{|l|l|}
5 & 228,03 \\
\end{tabular} & \begin{tabular}{|l|l|}
353,27 \\
\end{tabular} \\
\hline Pardinho & D20 & 2 & 60,49 & 50,50 & 2 & 78,43 & 94,24 & 4 & 69,11 & 71,52 & 0 & 12,10 & 10,37 & 1 & 26,14 & 29,74 & 1 & 18,85 & \begin{tabular}{|l|l|}
5 & 18,71 \\
\end{tabular} & 5 & \begin{tabular}{|l|}
193,56 \\
\end{tabular} & \begin{tabular}{|l|}
$6 \mid 162,20$ \\
\end{tabular} & 7 & 274,51 & 340,45 & 12 & \begin{tabular}{l|l|}
2 & 232,47 \\
\end{tabular} & $\begin{array}{ll}747,88 \\
\end{array}$ \\
\hline PariqueraOA & D20 & 10 & 97,62 & 89,90 & 6 & 61,54 & 65,77 & 16 & 79,72 & 77,93 & 1 & 6,73 & 5,67 & 1 & 13,67 & 13,88 & 2 & 10,18 & \begin{tabular}{|l|}
8,48 \\
\end{tabular} & 16 & 161,58 & \begin{tabular}{|l|l|}
8 & 143,24 \\
\end{tabular} & 11 & 116,24 & 424,98 & 27 & \begin{tabular}{l|l|}
7 & 139,08 \\
\end{tabular} & \begin{tabular}{|l|l|}
8134,18 \\
\end{tabular} \\
\hline Parisi & E20 & 1 & 118,73 & 74,37 & 1 & 65,36 & 47,36 & 2 & 93,33 & 61,51 & & & & 0 & $32,68 \mid$ & 24,26 & 0 & 15,55 & \begin{tabular}{|l|l|}
5 & 11,10 \\
\end{tabular} & 1 & 89,05 & 63,74 & 4 & 359,48 & 8 261,93 & 5 & \begin{tabular}{l|l|}
5 & 217,76 \\
\end{tabular} & \begin{tabular}{|l|l|}
5 & 158,08 \\
\end{tabular} \\
\hline Patrocínio Paulist & D20 & 4 & 58,80 & 50,54 & 6 & 95,39 & 94,97 & 9 & 76,65 & 72,21 & 1 & 21,38 & 17,91 & 2 & 33,67 & 34,11 & 3 & 27,38 & \begin{tabular}{|l|}
85,62 \\
\end{tabular} & 8 & 128,29 & \begin{tabular}{|l|l|}
9 & 115,47 \\
\end{tabular} & 8 & 134,67 & 732,73 & 16 & 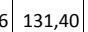 & $\begin{array}{ll}123,89 \\
\end{array}$ \\
\hline Paulicéia & E20 & 2 & 66,25 & 67,98 & 0 & 11,93 & 12,34 & 2 & 40,14 & 41,24 & 0 & 11,04 & 10,48 & 0 & 11,93 & 12,34 & 1 & \begin{tabular}{|l|}
11,47 \\
\end{tabular} & \begin{tabular}{|l|}
71,36 \\
\end{tabular} & 5 & \begin{tabular}{|l|l|}
154,58 \\
\end{tabular} & \begin{tabular}{|l|l|}
8 & 126,28 \\
\end{tabular} & 3 & 95,44 & \begin{tabular}{|l|l|}
4 & 117,94 \\
\end{tabular} & 7 & \begin{tabular}{l|l|}
7 & 126,15 \\
\end{tabular} & \begin{tabular}{|l|l|}
5 & 122,27 \\
\end{tabular} \\
\hline Paulinia & B100 & 33 & 115,12 & 134,73 & 27 & 93,42 & \begin{tabular}{|l|}
118,73 \\
\end{tabular} & 60 & \begin{tabular}{|l|}
104,28 \\
\end{tabular} & 126,74 & 4 & 12,66 & $\begin{array}{l}4,89 \\
\end{array}$ & 7 & 25,37 & \begin{tabular}{|r|}
34,00 \\
\end{tabular} & 11 & 19,01 & \begin{tabular}{|l|l|}
1 & 24,36 \\
\end{tabular} & 38 & \begin{tabular}{|l|}
132,38 \\
\end{tabular} & \begin{tabular}{|l|l|}
8 & 149,39 \\
\end{tabular} & 27 & 94,58 & \begin{tabular}{|l|l|}
8 & 124,22 \\
\end{tabular} & 66 & \begin{tabular}{|l|l|}
6 & 113,50 \\
\end{tabular} & \begin{tabular}{|l|l}
136,81 \\
\end{tabular} \\
\hline Paulistânia & E20 & 1 & 132,58 & 126,23 & 1 & 150,09 & \begin{tabular}{|l|}
121,97 \\
\end{tabular} & 3 & 140,80 & 124,23 & 0 & 33,15 & 28,11 & 0 & 37,52 & \begin{tabular}{|l|}
32,55 \\
\end{tabular} & 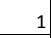 & \begin{tabular}{|l|}
35,20 \\
\end{tabular} & \begin{tabular}{|l|l|} 
& 30,09 \\
\end{tabular} & 2 & \begin{tabular}{|l|}
232,02 \\
\end{tabular} & \begin{tabular}{|l|l|}
211,33 \\
\end{tabular} & 1 & 150,09 & \begin{tabular}{|l|l|}
960,14 \\
\end{tabular} & 4 & \begin{tabular}{|l|l|}
4 & 193,59 \\
\end{tabular} & \begin{tabular}{|l|l|}
187,32 \\
\end{tabular} \\
\hline Paulo de Faria & E20 & $4_{4}$ & 93,96 & 60,89 & 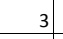 & 77,80 & 73,58 & 7 & 85,85 & 67,26 & 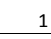 & 31,32 & 27,70 & 1 & 15,56 & 13,96 & 2 & 23,41 & \begin{tabular}{l|l|}
11 & 20,92 \\
\end{tabular} & 12 & 281,87 & $\begin{array}{l}7209,56 \\
\end{array}$ & 7 & 155,61 & 140,93 & 19 & \begin{tabular}{l|l|}
9 & 218,54 \\
\end{tabular} & \begin{tabular}{l|l}
4 & 175,13 \\
\end{tabular} \\
\hline Pederneiras & D50 & 21 & 105,88 & 98,18 & 12 & 60,94 & 58,12 & 32 & 83,63 & 78,35 & 3 & 15,37 & 14,27 & 11 & 59,20 & \begin{tabular}{|l|}
55,95 \\
\end{tabular} & 14 & 37,07 & \begin{tabular}{|l|}
74,70 \\
\end{tabular} & 47 & \begin{tabular}{|l|}
239,08 \\
\end{tabular} & \begin{tabular}{|l|l|}
8 & 206,50 \\
\end{tabular} & 49 & 254,20 & 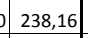 & 95 & \begin{tabular}{|l|l|}
5 & 246,57 \\
\end{tabular} & $\begin{array}{ll}722,18 \\
\end{array}$ \\
\hline Pedra Bela & E20 & 4 & 130,14 & \begin{tabular}{|l|}
401,08 \\
\end{tabular} & 2 & 60,74 & 56,23 & 6 & 97,40 & 79,93 & 1 & 32,53 & 24,34 & 1 & 36,44 & $28,27 \mid$ & 2 & 34,38 & \begin{tabular}{|l|} 
\\
\end{tabular} & 10 & 336,19 & $\begin{array}{l}9 \\
\end{array}$ & 7 & 255,10 & 206,12 & 17 & \begin{tabular}{l|l|}
7 & 297,94 \\
\end{tabular} & $\begin{array}{l}425,66 \\
\end{array}$ \\
\hline Pedranópolis & E20 & 3 & 202,33 & 145,53 & 0 & 26,65 & 16,44 & 3 & \begin{tabular}{|l|}
116,78 \\
\end{tabular} & 82,67 & 0 & 25,29 & 14,05 & & & & 0 & 12,98 & \begin{tabular}{|l|l|}
8 & 7,98 \\
\end{tabular} & 2 & \begin{tabular}{|l|l|}
177,04 \\
\end{tabular} & \begin{tabular}{|l|l|}
4 & 96,04 \\
\end{tabular} & & & & 2 & 90,83 & \begin{tabular}{|l|l|}
3 & 49,27 \\
\end{tabular} \\
\hline $\begin{array}{l}\text { Pedregulho } \\
\end{array}$ & D20 & 5 & 62,90 & 58,73 & 6 & 74,45 & 78,57 & 11 & 68,55 & 68,44 & 0 & 4,19 & 3,87 & 1 & 8,76 & 8,93 & 1 & 6,43 & \begin{tabular}{|l|l|}
3 & 6,27 \\
\end{tabular} & 19 & 243,22 & \begin{tabular}{|l|l|}
225,67 \\
\end{tabular} & 12 & 153,27 & \begin{tabular}{|l|}
764,37 \\
\end{tabular} & 31 & \begin{tabular}{|l|l|}
1 & 199,22 \\
\end{tabular} & \begin{tabular}{|l|l|}
2 & 195,68 \\
\end{tabular} \\
\hline Pedreira & B50 & 28 & 146,89 & 137,51 & 13 & 67,03 & 64,79 & 41 & 106,61 & 100,84 & 4 & 20,98 & 19,04 & 5 & 27,50 & 25,36 & 9 & 24,27 & \begin{tabular}{|l|}
722,23 \\
\end{tabular} & 47 & 244,81 & $\begin{array}{l}1225,04 \\
\end{array}$ & 41 & \begin{tabular}{|l|} 
\\
\end{tabular} & \begin{tabular}{|l|l|}
8 & 195,84 \\
\end{tabular} & 87 & \begin{tabular}{l|l|}
7 & 227,099 \\
\end{tabular} & \begin{tabular}{l|l}
9210,32 \\
\end{tabular} \\
\hline Pedrinhas Paulista & A20 & 3 & 176,13 & 152,82 & 2 & 135,84 & 134,37 & 5 & 156,27 & 143,72 & 2 & 110,08 & 86,78 & 1 & 45,28 & 41,26 & 2 & 78,14 & \begin{tabular}{l|l|}
4 & 66,72 \\
\end{tabular} & 2 & 154,12 & 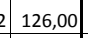 & 3 & 181,12 & 2177,80 & 5 & \begin{tabular}{l|l|}
5 & 167,43 \\
\end{tabular} & \begin{tabular}{|l|l}
151,54 \\
\end{tabular} \\
\hline Pedro de Toledo & E20 & 4 & 86,64 & 78,74 & 3 & 62,63 & 68,15 & 4 & 74,90 & 73,56 & 0 & 6,66 & 6,35 & 1 & 20,88 & 21,10 & 1 & 13,62 & \begin{tabular}{|l|l|}
2 & 12,25 \\
\end{tabular} & 11 & 219,94 & $4 \quad 174,96$ & 3 & 69,59 & \begin{tabular}{l|l|}
9 & 75,47 \\
\end{tabular} & 14 & \begin{tabular}{l|l|}
4 & 146,39 \\
\end{tabular} & \begin{tabular}{l|l}
9 & 126,29 \\
\end{tabular} \\
\hline Penápolis & D100 & 32 & 115,16 & 89,84 & 28 & 95,26 & 76,08 & 60 & 104,98 & 82,80 & 4 & 15,43 & 12,67 & 8 & 28,35 & 22,44 & 13 & 22,04 & \begin{tabular}{l|l|}
4 & 17,66 \\
\end{tabular} & 54 & \begin{tabular}{|l|}
193,52 \\
\end{tabular} & 2146,55 & 56 & 191,64 & 4145,88 & 111 & \begin{tabular}{l|l|}
1 & 192,56 \\
\end{tabular} & \begin{tabular}{|l|l|}
5 & 146,21 \\
\end{tabular} \\
\hline Pereira Barreto & D50 & 18 & 149,74 & 116,24 & 13 & 101,03 & 92,23 & 31 & 125,10 & 104,09 & 4 & 29,95 & 26,32 & 4 & 31,90 & 27,78 & 8 & 30,94 & $\begin{array}{ll}4 & 26,72 \\
\end{array}$ & 24 & \begin{tabular}{|l|}
196,02 \\
\end{tabular} & \begin{tabular}{|l|l|}
2 & 152,05 \\
\end{tabular} & 18 & 146,23 & \begin{tabular}{|l|}
125,33 \\
\end{tabular} & 42 & \begin{tabular}{l|l|}
2 & 170,83 \\
\end{tabular} & \begin{tabular}{|l|l|}
3 & 138,53 \\
\end{tabular} \\
\hline Pereiras & E20 & 7 & 185,17 & 120,92 & 5 & 146,24 & 99,44 & 12 & 166,21 & 110,46 & 0 & 9,26 & 6,13 & 1 & 39,00 & 25,70 & 2 & 23,75 & \begin{tabular}{|l|} 
\\
\end{tabular} & 8 & 231,46 & $6 \mid 162,80$ & 10 & 292,48 & \begin{tabular}{|l|l|}
8 & 202,59 \\
\end{tabular} & 18 & \begin{tabular}{l|l|}
8 & 261,18 \\
\end{tabular} & \begin{tabular}{|l|l|}
8182,18 \\
\end{tabular} \\
\hline Peruibe & D100 & 33 & 111,92 & 92,61 & 27 & 89,97 & 87,20 & 60 & 100,90 & 89,89 & 11 & 35,81 & 29,14 & 10 & 32,21 & 29,79 & 20 & 34,01 & 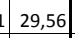 & 54 & 180,18 & $8 \mid 142,91$ & 39 & 129,95 & 123,53 & 93 & \begin{tabular}{l|l|}
3 & 154,97 \\
\end{tabular} & 133,18 \\
\hline Piacatu & E20 & 3 & 141,52 & 116,11 & 2 & 86,61 & 71,74 & 5 & 114,33 & 94,14 & 1 & 42,46 & 29,47 & 0 & 14,43 & 10,99 & 1 & $28,58 \mid$ & 20,90 & 4 & \begin{tabular}{|l|}
183,98 \\
\end{tabular} & \begin{tabular}{|l|l|}
843,01 \\
\end{tabular} & 4 & 187,64 & \begin{tabular}{ll|}
4 & 145,46 \\
\end{tabular} & 9 & \begin{tabular}{l|l|}
9 & 185,79 \\
\end{tabular} & \begin{tabular}{|l|l|}
9 & 144,22 \\
\end{tabular} \\
\hline Piedade & D100 & 29 & 102,94 & 97,66 & 21 & 84,62 & 89,84 & 50 & 94,24 & 93,94 & 9 & 31,12 & 29,27 & 9 & 37,02 & 37,53 & 18 & 33,93 & \begin{tabular}{|l|l|}
3 & 33,30 \\
\end{tabular} & 36 & \begin{tabular}{|l|}
129,28 \\
\end{tabular} & \begin{tabular}{|l|l|}
8119,07 \\
\end{tabular} & 40 & 158,66 & \begin{tabular}{|l|}
6 \\
\end{tabular} & 76 & \begin{tabular}{|l|l|}
6 & 143,24 \\
\end{tabular} & \begin{tabular}{l|l}
4 & 142,22 \\
\end{tabular} \\
\hline Pilar do Sul & E50 & 12 & 89,77 & 89,97 & 8 & 66,28 & 81,65 & 20 & 78,39 & 85,94 & 3 & 24,94 & 23,66 & 4 & 31,82 & \begin{tabular}{|l|}
38,42 \\
\end{tabular} & 7 & 28,27 & \begin{tabular}{|l|}
70,00 \\
\end{tabular} & 17 & \begin{tabular}{|l|}
124,68 \\
\end{tabular} & \begin{tabular}{|l|l|}
8 & 119,30 \\
\end{tabular} & 11 & 90,15 & \begin{tabular}{|l|}
5 \\
5
\end{tabular} & 28 & \begin{tabular}{|l|l|}
8 & 107,94 \\
\end{tabular} & \begin{tabular}{l|l}
4 & 116,53 \\
\end{tabular} \\
\hline Pindamonhang & B300 & 57 & 84,04 & 93,67 & 47 & 68,60 & 81,09 & 104 & 76,31 & 87,37 & 18 & 26,39 & 29,94 & 20 & \begin{tabular}{|r|} 
\\
\end{tabular} & \begin{tabular}{|r|}
55,92 \\
\end{tabular} & 38 & 28,04 & \begin{tabular}{l|l|}
4 & 32,99 \\
\end{tabular} & 106 & 155,38 & \begin{tabular}{|l|l|}
8 & 173,51 \\
\end{tabular} & 96 & 140,61 & $\begin{array}{ll}166,02 \\
\end{array}$ & 202 & \begin{tabular}{l|l|}
2 & 147,98 \\
\end{tabular} & \begin{tabular}{l|l}
8169,76 \\
\end{tabular} \\
\hline Pindorama & E20 & 10 & 142,05 & 94,95 & 5 & 75,41 & 56,54 & 15 & 109,16 & 76,00 & 1 & 14,69 & 9,77 & 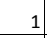 & 10,05 & 6,82 & 2 & \begin{tabular}{|l|}
12,40 \\
\end{tabular} & \begin{tabular}{|l|l|}
$\mid$ & 8,38 \\
\end{tabular} & 16 & 240,01 & 155,09 & 19 & 281,52 & 200,02 & 35 & \begin{tabular}{|l|l|}
5 & 260,49 \\
\end{tabular} & \begin{tabular}{l|l}
9 & 177,26 \\
\end{tabular} \\
\hline Pinhalzinho & E20 & 9 & 143,21 & 102,72 & 6 & 108,45 & 90,99 & 15 & 126,47 & 97,07 & 1 & 10,61 & 7,22 & 2 & 39,96 & 32,14 & 3 & 24,74 & \begin{tabular}{l|l|}
4 & 18,46 \\
\end{tabular} & 21 & 339,47 & $\begin{array}{l}733,87 \\
\end{array}$ & 14 & 239,74 & $\begin{array}{l}402,82 \\
\end{array}$ & 35 & \begin{tabular}{l|l|}
5 & 291,43 \\
\end{tabular} & \begin{tabular}{l|l} 
B 218,91 \\
\end{tabular} \\
\hline Piquerobi & E20 & 1 & 55,21 & 38,67 & 1 & 75,83 & 63,14 & 2 & 65,37 & 50,72 & & & & 1 & 75,83 & $67,23 \mid$ & 1 & 37,35 & \begin{tabular}{|l|}
5 \\
\end{tabular} & 3 & 184,03 & \begin{tabular}{|l|l|}
327,40 \\
\end{tabular} & 4 & 208,53 & 387,91 & 7 & \begin{tabular}{l|l|}
7 & 196,10 \\
\end{tabular} & \begin{tabular}{|l|l}
157,20 \\
\end{tabular} \\
\hline Piquete & B20 & 8 & 110,64 & 97,82 & 6 & 71,99 & 61,54 & 14 & 90,89 & 79,28 & 3 & 35,41 & 29,97 & 2 & 21,17 & 17,30 & 4 & 28,13 & \begin{tabular}{|l|l|}
3 & 23,35 \\
\end{tabular} & 21 & 283,25 & $5 \mid 231,41$ & 22 & 283,72 & \begin{tabular}{|l|}
224,33 \\
\end{tabular} & 44 & \begin{tabular}{|l|l|}
4 & 283,49 \\
\end{tabular} & \begin{tabular}{l|l}
9227,79 \\
\end{tabular} \\
\hline Piracaia & D50 & 20 & 153,17 & 128,28 & 10 & 83,01 & 79,62 & 30 & 118,63 & 104,33 & 4 & 33,75 & 26,61 & 9 & 74,97 & 71,53 & 14 & 54,04 & \begin{tabular}{l|l|}
4 & 47,54 \\
\end{tabular} & 31 & 244,03 & \begin{tabular}{|l|l|} 
& 187,40 \\
\end{tabular} & 19 & 149,95 & 5142,12 & 50 & \begin{tabular}{l|l|}
0 & 197,72 \\
\end{tabular} & \begin{tabular}{|l|l}
2 & 165,11 \\
\end{tabular} \\
\hline Piracicaba & \begin{tabular}{|l|} 
\\
\end{tabular} & 209 & 120,62 & 111,95 & 169 & 94,68 & 86,67 & 378 & 107,48 & 99,15 & 27 & 15,56 & 14,50 & 40 & 22,27 & \begin{tabular}{|l|}
20,23 \\
\end{tabular} & 67 & 18,96 & \begin{tabular}{|l|l|}
5 & 17,43 \\
\end{tabular} & 257 & \begin{tabular}{|l|}
148,08 \\
\end{tabular} & \begin{tabular}{|l|l|}
8 & 134,45 \\
\end{tabular} & 240 & 134,91 & 1119,90 & 497 & \begin{tabular}{|l|l|}
7 & 141,41 \\
\end{tabular} & \begin{tabular}{|l|}
127,08 \\
\end{tabular} \\
\hline Piraju & D50 & 23 & 165,86 & 134,16 & 17 & 116,11 & 95,11 & 40 & \begin{tabular}{|l|l|}
140,49 \\
\end{tabular} & 114,24 & 4 & 28,43 & 22,34 & 5 & 31,87 & \begin{tabular}{|l|}
25,47 \\
\end{tabular} & 9 & 30,19 & \begin{tabular}{|l|}
9,89 \\
\end{tabular} & 41 & \begin{tabular}{|l|}
293,82 \\
\end{tabular} & \begin{tabular}{|l|l|}
2 & 230,64 \\
\end{tabular} & 41 & 282,31 & 222,57 & 83 & \begin{tabular}{l|l|}
3 & 287,95 \\
\end{tabular} & \begin{tabular}{l|l}
5226,52 \\
\end{tabular} \\
\hline Pirajuí & D50 & 10 & 93,81 & 79,81 & 8 & 86,40 & 67,69 & 19 & 90,35 & 74,15 & 2 & 15,13 & 13,59 & 3 & 31,10 & 21,24 & 5 & 22,59 & \begin{tabular}{|l|l|}
$\mid$ & 17,96 \\
\end{tabular} & 31 & 284,44 & $\begin{array}{l}4 \\
4\end{array}$ & 27 & 279,94 & 4208,69 & 58 & \begin{tabular}{l|l|}
8 & 282,34 \\
\end{tabular} & 4 4) 215,10 \\
\hline Pirangi & E20 & 8 & 147,61 & 98,07 & & 142,24 & 94,66 & 15 & 144,99 & 96,41 & 1 & 25,67 & 18,56 & 0 & 6,77 & 4,72 & 2 & \begin{tabular}{|l|}
16,48 \\
\end{tabular} & \begin{tabular}{|l|l|}
8 & 12,13 \\
\end{tabular} & 10 & 186,11 & \begin{tabular}{|l|} 
\\
\end{tabular} & 13 & \begin{tabular}{|l|}
270,93 \\
\end{tabular} & \begin{tabular}{|l|l|}
$\mid 180,22$ \\
\end{tabular} & 23 & \begin{tabular}{|l|}
227,38 \\
\end{tabular} & \begin{tabular}{l|l}
8 & 153,35 \\
\end{tabular} \\
\hline
\end{tabular}


Anexo 23 - $\mathrm{N}^{\circ}$ de óbitos e taxa de mortalidade (bruta e padronizada) total e segundo sexo por Neoplasias, Diabetes Mellitus e Doenças do Aparelho Circulatório, municípios. Estado de São Paulo, média do triênio 2003-2005

\begin{tabular}{|c|c|c|c|c|c|c|c|c|c|c|c|c|c|c|c|c|c|c|c|c|c|c|c|c|c|c|c|c|}
\hline \multirow[b]{3}{*}{ Pirapora do Bom Jesus } & \multirow[b]{3}{*}{ D20 } & \multicolumn{9}{|c|}{ Neoplasias Malignas } & \multicolumn{9}{|c|}{ Diabetes Mellitus } & \multicolumn{9}{|c|}{ Aparelho Circulatorio } \\
\hline & & \multicolumn{3}{|c|}{ Homens } & \multicolumn{3}{|c|}{ Mulheres } & \multicolumn{3}{|c|}{ Total } & \multicolumn{3}{|c|}{ Homens } & \multicolumn{3}{|c|}{ Mulheres } & \multicolumn{3}{|c|}{ Total } & \multicolumn{3}{|c|}{ Homens } & \multicolumn{3}{|c|}{ Mulheres } & \multicolumn{3}{|c|}{ Total } \\
\hline & & 4 & 60,17 & 76,86 & 4 & 55,75 & 80,26 & 8 & 57,97 & 78,55 & & & & 1 & 13,94 & 22,08 & 1 & 6,96 & 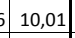 & 9 & 124,97 & 747,44 & 10 & 134,73 & 201,11 & 19 & \begin{tabular}{l|l|}
9 & 129,84 \\
\end{tabular} & \begin{tabular}{l|l}
4 & 174,22 \\
\end{tabular} \\
\hline Pirapozinho & D50 & 10 & 90,44 & 78,59 & 10 & 83,72 & 81,14 & 20 & 87,01 & 79,89 & 1 & 9,04 & 7,22 & 3 & 28,87 & 26,82 & 4 & 19,17 & 16,76 & 25 & 223,09 & \begin{tabular}{|c|c|}
9176,50 \\
\end{tabular} & 22 & 193,43 & 383,95 & 47 & \begin{tabular}{ll|}
7 & 207,94 \\
\end{tabular} & \begin{tabular}{l|l}
4 & 180,30 \\
\end{tabular} \\
\hline Pirassununga & B100 & 45 & 134,29 & 110,35 & 34 & 98,85 & 82,50 & 80 & 116,32 & 96,23 & 6 & 17,77 & 14,75 & 7 & 20,15 & 16,19 & 13 & 18,98 & \begin{tabular}{|l|l|}
8 & 15,48 \\
\end{tabular} & 87 & 258,71 & 203,90 & 77 & 221,70 & 170,10 & 164 & 4 . 239,94 & \begin{tabular}{l|l}
4 & 186,76 \\
\end{tabular} \\
\hline Piratininga & B20 & 8 & 149,85 & \begin{tabular}{|l}
117,54 \\
\end{tabular} & 5 & 91,92 & 72,67 & 13 & 121,21 & 95,35 & 1 & 11,99 & 9,04 & 1 & 24,51 & 19,29 & 2 & 18,18 & 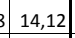 & 14 & 245,76 & \begin{tabular}{l|l|}
6 & 180,83 \\
\end{tabular} & 10 & 189,97 & 140,77 & 24 & $4 \quad 218,18$ | & \begin{tabular}{l|l}
8161,02 \\
\end{tabular} \\
\hline Pitangueiras & D50 & 19 & 110,45 & 122,90 & 12 & 76,65 & 86,61 & 31 & 93,97 & 105,20 & 1 & 5,92 & 6,50 & 7 & 43,50 & \begin{tabular}{|l|}
46,87 \\
\end{tabular} & 8 & \begin{tabular}{|l|}
24,25 \\
\end{tabular} & \begin{tabular}{|l|}
$5,26,22$ \\
\end{tabular} & 39 & \begin{tabular}{|l|}
228,80 \\
\end{tabular} & \begin{tabular}{|l|l|} 
& 247,56 \\
\end{tabular} & 29 & 180,23 & \begin{tabular}{|l|l|}
3 & 202,94 \\
\end{tabular} & 68 & \begin{tabular}{|l|l|}
8 & 205,11 \\
\end{tabular} & $\begin{array}{l}1225,80 \\
\end{array}$ \\
\hline Planalto & E20 & 3 & $\begin{array}{ll}339,84 \\
\end{array}$ & 132,72 & 1 & 54,32 & 53,42 & 4 & 97,83 & 93,77 & 0 & 17,48 & 18,73 & 1 & 36,21 & 33,05 & 1 & \begin{tabular}{|l|}
26,68 \\
\end{tabular} & \begin{tabular}{|l|l|}
8 & 24,13 \\
\end{tabular} & 5 & \begin{tabular}{|l|}
279,67 \\
\end{tabular} & \begin{tabular}{|l|l|}
7 & 203,16 \\
\end{tabular} & 5 & 271,59 & 255,06 & 10 & \begin{tabular}{|l|l|}
0 & 275,70 \\
\end{tabular} & \begin{tabular}{|l|}
228,65 \\
\end{tabular} \\
\hline Platina & E20 & 3 & \begin{tabular}{|l|l}
198,81 \\
\end{tabular} & 181,13 & 2 & \begin{tabular}{|l|}
121,62 \\
\end{tabular} & \begin{tabular}{|l|}
113,76 \\
\end{tabular} & 5 & \begin{tabular}{|l|}
162,07 \\
\end{tabular} & \begin{tabular}{|l|}
49,07 \\
\end{tabular} & 0 & 22,09 & 16,91 & 0 & 24,32 & \begin{tabular}{|l|}
24,46 \\
\end{tabular} & 1 & 23,16 & 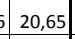 & 2 & \begin{tabular}{|l|}
154,63 \\
\end{tabular} & \begin{tabular}{|l|l|}
318,34 \\
\end{tabular} & 3 & 243,25 & 5206,65 & 6 & \begin{tabular}{|l|l|}
6 & 196,80 \\
\end{tabular} & \begin{tabular}{|l|l}
160,37 \\
\end{tabular} \\
\hline Poá & B300 & 44 & 85,90 & 113,19 & 36 & 66,93 & 86,02 & 80 & 76,23 & 99,34 & 11 & 21,47 & 29,44 & 17 & 32,53 & \begin{tabular}{|l|}
44,15 \\
\end{tabular} & 28 & 27,11 & 37,01 & 75 & \begin{tabular}{|l|l|}
147,06 \\
\end{tabular} & \begin{tabular}{|l|l|}
6 & 192,98 \\
\end{tabular} & 63 & 117,60 & \begin{tabular}{|l|l|}
159,09 \\
\end{tabular} & 138 & \begin{tabular}{|l|l|}
8 & 132,04 \\
\end{tabular} & \begin{tabular}{l|l}
4 & 175,70 \\
\end{tabular} \\
\hline Poloni & E20 & 5 & 209,47 & $\begin{array}{l}130,60 \\
\end{array}$ & 2 & 93,43 & 59,86 & 7 & 150,14 & 94,43 & 0 & 13,96 & 7,16 & 0 & 13,35 & 7,10 & 1 & \begin{tabular}{|l|}
13,65 \\
\end{tabular} & \begin{tabular}{|l|l|}
5 & 7,14 \\
\end{tabular} & 8 & 321,18 & \begin{tabular}{|l|l|}
8 & 171,51 \\
\end{tabular} & 4 & $\begin{array}{l}173,52 \\
\end{array}$ & 87,56 & 12 & \begin{tabular}{|l|l|}
2 & 245,68 \\
\end{tabular} & \begin{tabular}{l|l}
8 & 128,59 \\
\end{tabular} \\
\hline Pompéia & $\mathrm{C} 20$ & 12 & 130,44 & 104,07 & 10 & 106,51 & 93,82 & 22 & 118,35 & 98,89 & 2 & 25,36 & 21,74 & 2 & 21,30 & 18,81 & 4 & \begin{tabular}{|l|} 
\\
\end{tabular} & 120,31 & 25 & \begin{tabular}{|l|}
275,38 \\
\end{tabular} & \begin{tabular}{|l|}
8 \\
\end{tabular} & 25 & 262,72 & 211,05 & 50 & \begin{tabular}{l|l|}
0 & 268,99 \\
\end{tabular} & \begin{tabular}{l|l}
9 & 206,84 \\
\end{tabular} \\
\hline Pongaí & E20 & 2 & 119,80 & $\begin{array}{ll}73,30 \\
\end{array}$ & 1 & 55,64 & 43,99 & 3 & 89,01 & 59,23 & 1 & 34,23 & 20,50 & & & & 1 & \begin{tabular}{|l|}
17,80 \\
\end{tabular} & \begin{tabular}{|l|l|}
$\mid$ & 11,34 \\
\end{tabular} & 3 & 136,92 & \begin{tabular}{|l|l|}
2 & 93,22 \\
\end{tabular} & 4 & 222,55 & 560,46 & 7 & \begin{tabular}{l|l|}
7 & 178,02 \\
\end{tabular} & \begin{tabular}{l|l}
2 & 125,49 \\
\end{tabular} \\
\hline Pontal & D50 & 12 & 72,27 & 92,29 & 9 & 55,74 & 68,95 & 21 & 64,12 & 80,78 & 2 & 10,04 & 12,84 & 4 & 24,77 & 31,29 & 6 & 17,30 & 22,00 & 32 & \begin{tabular}{|l|}
194,72 \\
\end{tabular} & \begin{tabular}{|l|l|}
2 & 237,38 \\
\end{tabular} & 27 & \begin{tabular}{|l|} 
\\
169,27
\end{tabular} & \begin{tabular}{|l|l|}
7 & 223,33 \\
\end{tabular} & 60 & \begin{tabular}{|l|l|}
0 & 182,18 \\
\end{tabular} & \begin{tabular}{|l|l|}
830,45 \\
8
\end{tabular} \\
\hline Pontalinda & E20 & 3 & $\begin{array}{l}154,77 \\
\end{array}$ & 132,05 & 1 & 75,08 & 56,63 & 4 & 116,67 & 95,99 & 0 & 17,20 & 14,33 & 1 & 37,54 & \begin{tabular}{|l|}
34,14 \\
\end{tabular} & 1 & \begin{tabular}{|l|}
26,93 \\
\end{tabular} & \begin{tabular}{|l|l|}
3 & 23,63 \\
\end{tabular} & 2 & \begin{tabular}{|l|}
103,18 \\
\end{tabular} & \begin{tabular}{|l|l|}
8 & 94,76 \\
\end{tabular} & 4 & 225,23 & \begin{tabular}{|l|l|}
3 & 207,88 \\
\end{tabular} & 6 & \begin{tabular}{l|l|}
6 & 161,54 \\
\end{tabular} & \begin{tabular}{l|l}
4 & 148,85 \\
\end{tabular} \\
\hline Pontes Gest & E20 & 2 & $\begin{array}{ll}171,67 \\
\end{array}$ & 116,65 & 1 & 84,58 & 84,64 & 3 & 127,80 & 100,53 & 1 & 57,22 & 58,85 & 0 & 28,19 & \begin{tabular}{|r|}
30,40 \\
\end{tabular} & 1 & 42,61 & \begin{tabular}{|l|l|}
1 & 44,89 \\
\end{tabular} & 2 & \begin{tabular}{|l|}
171,67 \\
\end{tabular} & \begin{tabular}{|l|l|}
707,68 \\
\end{tabular} & 1 & 84,58 & 67,52 & 3 & \begin{tabular}{|l|l|}
3 & 127,80 \\
\end{tabular} & \begin{tabular}{|l|l|}
07,45 \\
\end{tabular} \\
\hline Populina & E20 & 2 & $\begin{array}{l}28,88 \\
\end{array}$ & \begin{tabular}{|l|l|}
3 & 53,48 \\
\end{tabular} & 1 & 63,45 & 53,77 & 3 & \begin{tabular}{|l|}
76,60 \\
\end{tabular} & \begin{tabular}{|l|}
53,62 \\
\end{tabular} & 0 & 14,81 & 8,73 & I & 31,73 & \begin{tabular}{|l|}
25,43 \\
\end{tabular} & 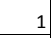 & \begin{tabular}{|l|}
22,98 \\
\end{tabular} & \begin{tabular}{|l|l|}
8 & 16,44 \\
\end{tabular} & 4 & \begin{tabular}{|l|}
177,75 \\
\end{tabular} & \begin{tabular}{|l|l|}
5 & 119,47 \\
\end{tabular} & 5 & 237,94 & \begin{tabular}{l|l|}
4 & 196,45 \\
\end{tabular} & 9 & \begin{tabular}{l|l|}
9 & 206,82 \\
\end{tabular} & \begin{tabular}{|l|l|}
2 & 156,64 \\
\end{tabular} \\
\hline Porangaba & E20 & 6 & \begin{tabular}{|l}
150,12 \\
\end{tabular} & $\begin{array}{ll}206,78 \\
\end{array}$ & 4 & \begin{tabular}{|l|}
419,58 \\
\end{tabular} & 97,58 & 10 & 135,77 & 102,46 & 1 & 17,66 & 11,49 & 2 & 59,79 & 51,36 & 3 & 37,45 & \begin{tabular}{|l|}
5 \\
\end{tabular} & 10 & 256,09 & \begin{tabular}{l|l|}
9 & 172,32 \\
\end{tabular} & 8 & 229,20 & \begin{tabular}{|l|l|} 
& 198,85 \\
\end{tabular} & 17 & \begin{tabular}{l|l|}
7 & 243,46 \\
\end{tabular} & \begin{tabular}{|l|l}
5 & 184,78 \\
\end{tabular} \\
\hline Porto Feliz & C50 & 27 & 110,45 & \begin{tabular}{|l|l}
52,28 \\
\end{tabular} & 24 & \begin{tabular}{|l|} 
\\
\end{tabular} & 98,29 & 52 & 104,71 & 100,29 & 3 & 13,47 & 13,04 & 10 & 42,01 & \begin{tabular}{|l|}
41,39 \\
\end{tabular} & 14 & 27,70 & \begin{tabular}{|l|}
0,9695 \\
\end{tabular} & 43 & \begin{tabular}{|l|}
173,76 \\
\end{tabular} & \begin{tabular}{|l|l|}
6 & 157,58 \\
\end{tabular} & 40 & 162,62 & 2155,74 & 83 & \begin{tabular}{|l|l|}
3 & 168,20 \\
\end{tabular} & \begin{tabular}{|l|l}
156,66 \\
\end{tabular} \\
\hline Porto Ferreira & C100 & 29 & \begin{tabular}{|l|l} 
& 114,44 \\
\end{tabular} & \begin{tabular}{|l|l}
404,83 \\
\end{tabular} & 23 & \begin{tabular}{|l|l|}
87,85 \\
\end{tabular} & 84,41 & 52 & \begin{tabular}{|l|}
101,10 \\
\end{tabular} & 94,58 & 4 & 16,91 & 15,26 & 10 & 37,47 & \begin{tabular}{|l|}
34,77 \\
\end{tabular} & 14 & 27,22 & 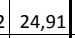 & 59 & 231,48 & \begin{tabular}{|l|l|}
8 & 202,79 \\
\end{tabular} & 48 & 187,33 & \begin{tabular}{|l|l|}
177,15 \\
\end{tabular} & 108 & \begin{tabular}{l|l|}
8 & 209,33 \\
\end{tabular} & \begin{tabular}{|l|l}
389,93 \\
\end{tabular} \\
\hline Potim & E20 & 7 & 85,66 & \begin{tabular}{|l|l}
515,70 \\
\end{tabular} & 5 & 61,86 & 91,33 & 11 & 73,95 & 103,70 & 3 & 42,83 & 53,85 & 2 & 26,51 & \begin{tabular}{|l|}
39,58 \\
\end{tabular} & 5 & 34,80 & \begin{tabular}{|l|l|}
0 & 46,96 \\
\end{tabular} & 18 & \begin{tabular}{|l|}
227,01 \\
\end{tabular} & \begin{tabular}{|l|}
1321,32 \\
\end{tabular} & 8 & 110,46 & \begin{tabular}{|l|}
6 \\
\end{tabular} & 26 & \begin{tabular}{|l|l|}
6 & 169,64 \\
\end{tabular} & $\begin{array}{l}4 \quad 245,69 \\
\end{array}$ \\
\hline Potirendaba & E20 & 13 & 176,10 & 114,87 & 5 & 64,97 & 49,15 & 18 & 122,00 & 82,88 & 0 & 4,40 & 4,15 & 0 & 4,64 & 3,05 & 1 & 4,52 & \begin{tabular}{|l|l|}
2 & 3,59 \\
\end{tabular} & 17 & \begin{tabular}{|l|}
220,12 \\
\end{tabular} & \begin{tabular}{|l|l|}
2129,04 \\
\end{tabular} & 18 & 245,97 & 772,22 & 34 & \begin{tabular}{|l|l|}
44 & 232,71 \\
\end{tabular} & $\begin{array}{l}150,06 \\
\end{array}$ \\
\hline Pracinha & E20 & 1 & 137,61 & 106,25 & 1 & 95,97 & 86,00 & 2 & 117,26 & 96,35 & 1 & 137,61 & 104,83 & 0 & 47,98 & $35,00 \mid$ & 1 & 93,83 & \begin{tabular}{|l|l|}
3 & 72,40 \\
\end{tabular} & 2 & 229,36 & \begin{tabular}{l|l|}
6 & 125,34 \\
\end{tabular} & 1 & 143,95 & $5 \mid 108,01$ & 3 & \begin{tabular}{l|l|}
3 & 187,62 \\
\end{tabular} & \begin{tabular}{l|l|}
2 & 116,87 \\
\end{tabular} \\
\hline Pradópolis & D20 & 7 & 92,00 & 97,31 & 5 & 75,92 & 90,14 & 12 & 84,09 & 93,78 & 1 & 9,20 & 10,09 & 1 & 9,49 & \begin{tabular}{|l|}
10,92 \\
\end{tabular} & 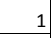 & 9,34 & \begin{tabular}{l|l|}
4 & 10,71 \\
\end{tabular} & 15 & 211,61 & \begin{tabular}{|l|}
1224,62 \\
\end{tabular} & 8 & 118,62 & \begin{tabular}{|l|}
245,68 \\
\end{tabular} & 24 & \begin{tabular}{|l|l|}
4 & 165,84 \\
\end{tabular} & \begin{tabular}{l|l}
4 & 185,76 \\
\end{tabular} \\
\hline Praia Grand & B300 & 103 & 94,10 & 90,24 & 85 & 73,86 & 73,70 & 188 & 83,74 & 81,77 & 21 & 19,12 & 18,20 & 25 & 21,43 & \begin{tabular}{|r|}
20,85 \\
\end{tabular} & 46 & 20,31 & \begin{tabular}{|l|l|}
1 & 19,53 \\
\end{tabular} & 156 & 142,07 & $\begin{array}{l}730,95 \\
\end{array}$ & 119 & 103,41 & \begin{tabular}{|l|}
102,83 \\
\end{tabular} & 275 & \begin{tabular}{l|l|}
5 & 122,28 \\
\end{tabular} & \begin{tabular}{l|l}
8116,56 \\
\end{tabular} \\
\hline Pratânia & E20 & 2 & 105,45 & 111,93 & 2 & 98,99 & 112,71 & 4 & 102,37 & 112,30 & 0 & 15,06 & 15,92 & 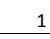 & 33,00 & 35,70 & 1 & \begin{tabular}{|l|}
23,62 \\
\end{tabular} & \begin{tabular}{|l|}
25,05 \\
\end{tabular} & 7 & 316,36 & \begin{tabular}{|l|}
625,98 \\
\end{tabular} & 4 & 214,49 & 235,86 & 11 & \begin{tabular}{l|l|}
1 & 267,74 \\
\end{tabular} & $\begin{array}{l}4 \\
4\end{array}$ \\
\hline Presidente Alves & E20 & 4 & 186,86 & \begin{tabular}{l|l}
53,67 \\
\end{tabular} & 1 & 31,86 & 21,48 & 5 & 110,24 & 88,33 & 0 & 15,57 & 10,66 & 1 & 47,79 & 44,42 & 1 & 31,50 & 26,39 & 6 & 280,29 & \begin{tabular}{|l|l|}
9 & 180,47 \\
\end{tabular} & 3 & 143,38 & \begin{tabular}{|l|l|}
8 & 107,53 \\
\end{tabular} & 9 & \begin{tabular}{l|l|}
9 & 212,62 \\
\end{tabular} & \begin{tabular}{|l|l|}
2 & 144,42 \\
\end{tabular} \\
\hline Presidente Bernardes & D20 & 11 & 138,90 & 108,39 & 4 & 59,34 & 48,93 & 15 & 100,73 & 79,86 & 2 & 29,46 & 21,22 & 3 & 36,52 & 28,26 & 5 & 32,85 & 24,66 & 25 & 311,47 & $\begin{array}{l}7209,15 \\
\end{array}$ & 15 & 209,98 & \begin{tabular}{|l|l|}
852,32 \\
\end{tabular} & 40 & \begin{tabular}{ll|}
0 & 262,78 \\
\end{tabular} & \begin{tabular}{|l|l|}
8 & 181,88 \\
\end{tabular} \\
\hline Presidente Epitácio & D50 & 26 & 128,13 & \begin{tabular}{|l|l}
117,72 \\
\end{tabular} & 14 & 67,53 & 69,90 & 40 & 97,70 & 93,71 & 5 & 25,95 & 23,77 & 10 & 48,23 & 49,00 & 15 & 37,14 & \begin{tabular}{l|l|}
4 & 35,84 \\
\end{tabular} & 46 & 222,19 & \begin{tabular}{|l|l|}
9 & 193,60 \\
\end{tabular} & 41 & 196,15 & 207,27 & 86 & \begin{tabular}{l|l|}
6 & 209,12 \\
\end{tabular} & \begin{tabular}{|l|l|}
200,46 \\
\end{tabular} \\
\hline Presidente Prudente & B300 & 124 & 128,27 & 110,33 & 99 & 96,59 & 87,86 & 224 & 111,96 & 98,76 & 18 & 18,23 & 15,64 & 21 & 20,10 & 17,97 & 38 & \begin{tabular}{|l|}
19,19 \\
\end{tabular} & \begin{tabular}{|l|l|}
9 & 16,83 \\
\end{tabular} & 168 & 172,97 & \begin{tabular}{|l|l|}
744,28 \\
\end{tabular} & 131 & 127,06 & $6 \mid 115,69$ & 298 & \begin{tabular}{|l|l|}
8 & 149,34 \\
\end{tabular} & \begin{tabular}{l|l}
4 & 129,56 \\
\end{tabular} \\
\hline Presidente Venceslau & D50 & 31 & 161,60 & 130,84 & 22 & 114,53 & 98,33 & 52 & 138,10 & 114,61 & 7 & 35,13 & 29,90 & 7 & 37,00 & 30,29 & 14 & \begin{tabular}{|l|}
36,06 \\
\end{tabular} & \begin{tabular}{|l|l|}
5 & 29,94 \\
\end{tabular} & 37 & 196,73 & \begin{tabular}{|l|l|}
350,50 \\
\end{tabular} & 39 & 207,91 & 171,88 & 77 & \begin{tabular}{l|l|}
7 & 202,31 \\
\end{tabular} & \begin{tabular}{l|l}
1 & 161,18 \\
\end{tabular} \\
\hline Promissao & D50 & 20 & 119,73 & \begin{tabular}{|l|l}
300,83 \\
\end{tabular} & 16 & \begin{tabular}{|l|l|}
6 & 97,46 \\
\end{tabular} & 88,22 & 35 & 108,72 & 94,60 & 2 & 12,18 & 11,16 & 5 & 31,11 & 26,82 & 7 & 21,54 & $\begin{array}{l}4 \mid 18,71 \\
\end{array}$ & 31 & 190,75 & $5 \mid 159,77$ & 29 & 182,49 & \begin{tabular}{|l|} 
\\
\end{tabular} & 61 & \begin{tabular}{l|l|}
1 & 186,66 \\
\end{tabular} & \begin{tabular}{|l|l|}
5 & 160,29 \\
\end{tabular} \\
\hline Quadra & E20 & 2 & 127,82 & 94,56 & 1 & $\begin{array}{l}1 \quad 70,37 \\
\end{array}$ & 66,79 & 3 & 100,48 & 81,35 & & & & 0 & 23,46 & 21,05 & 0 & 11,16 & \begin{tabular}{|l|l|}
5 & 8,90 \\
\end{tabular} & 2 & 106,52 & \begin{tabular}{|l|l|}
2 & 90,72 \\
\end{tabular} & 2 & 164,20 & 169,35 & 4 & \begin{tabular}{l|l|}
4 & 133,97 \\
\end{tabular} & \begin{tabular}{l|l}
728,14 \\
\end{tabular} \\
\hline Quatá & D20 & 8 & 142,26 & \begin{tabular}{|l|l}
526,62 \\
\end{tabular} & 3 & 50,58 & 44,40 & 11 & 96,14 & 85,26 & 1 & 17,07 & 13,66 & 1 & 22,48 & 20,00 & 2 & 19,79 & \begin{tabular}{|l|l|}
9 & 16,79 \\
\end{tabular} & 15 & 256,07 & 208,20 & 14 & 241,68 & \begin{tabular}{|l|}
816,02 \\
\end{tabular} & 29 & \begin{tabular}{l|l|}
9 & 248,83 \\
\end{tabular} & \begin{tabular}{|l|l|}
3 & 212,13 \\
\end{tabular} \\
\hline Queiroz & E20 & 3 & 284,01 & 193,97 & 0 & 30,26 & 33,18 & 4 & 161,15 & 116,12 & & & & 0 & 30,26 & 32,10 & 0 & 14,65 & \begin{tabular}{|l|}
5 \\
\end{tabular} & 2 & 170,41 & 115,82 & 1 & 90,77 & 93,40 & 3 & \begin{tabular}{l|l|}
3 & 131,85 \\
\end{tabular} & \begin{tabular}{|l|l}
504,96 \\
\end{tabular} \\
\hline Queluz & D20 & 4 & 75,88 & 76,26 & 4 & \begin{tabular}{l|l}
4 & 74,74 \\
\end{tabular} & 81,28 & ] & 75,30 & 78,79 & 1 & 13,80 & 13,62 & 3 & 54,36 & 54,85 & 3 & 34,23 & \begin{tabular}{|l|l|}
34,69 \\
\end{tabular} & 8 & 158,65 & $5 \mid 150,89$ & 10 & 203,83 & 210,51 & 18 & \begin{tabular}{l|l|}
8 & 181,41 \\
\end{tabular} & $\begin{array}{l}180,93 \\
\end{array}$ \\
\hline Quintana & E20 & 6 & 226,43 & \begin{tabular}{|l|l|}
371,17 \\
\end{tabular} & 2 & 84,56 & 74,02 & 9 & 155,98 & 122,92 & 0 & 11,92 & 8,32 & 1 & 24,16 & $20,73 \mid$ & 1 & 18,00 & \begin{tabular}{|l|l|}
0 & 14,62 \\
\end{tabular} & 6 & 202,60 & | 156,04 & & 41,60 & 194,52 & 12 & \begin{tabular}{|l|l|}
2 & 221,97 \\
\end{tabular} & \begin{tabular}{|l|l}
775,15 \\
\end{tabular} \\
\hline Rafard & A20 & 2 & 56,37 & 47,73 & 4 & \begin{tabular}{l|l}
4 & 97,14 \\
\end{tabular} & 91,00 & 6 & 76,70 & 69,30 & 2 & 40,26 & 34,15 & 2 & 56,67 & 52,03 & 4 & 48,44 & $\begin{array}{l}4 \\
43,05 \\
\end{array}$ & 9 & 209,36 & $\begin{array}{ll}6 & 168,27 \\
\end{array}$ & 7 & 178,09 & | 157,90 & 16 & \begin{tabular}{l|l|}
6 & 193,77 \\
\end{tabular} & 163,10 \\
\hline Rancharia & D50 & 15 & 99,92 & 84,47 & 13 & \begin{tabular}{|l|l|}
3 & 87,12 \\
\end{tabular} & 82,56 & 28 & 93,47 & 83,51 & 2 & 13,62 & 11,62 & 5 & \begin{tabular}{|l|}
31,28 \\
\end{tabular} & 28,06 & 7 & 22,52 & \begin{tabular}{|l|l|}
2 & 19,60 \\
\end{tabular} & 35 & 240,71 & 188,14 & 32 & 212,22 & \begin{tabular}{|l|}
193,42 \\
\end{tabular} & 67 & \begin{tabular}{l|l|}
7 & 226,35 \\
\end{tabular} & \begin{tabular}{|l|l|}
5 & 190,80 \\
\end{tabular} \\
\hline Redençaoo da Se & E20 & 2 & 76,36 & 58,57 & 1 & $\begin{array}{ll} & 71,05 \\
\end{array}$ & 66,68 & 3 & 73,90 & 62,32 & & & & 1 & \begin{tabular}{|l|}
71,05 \\
\end{tabular} & 56,68 & 1 & 32,85 & 24,31 & 5 & 213,81 & 118,23 & 3 & 142,10 & $\mid 114,37$ & 1 & \begin{tabular}{l|l|}
7 & 180,65 \\
\end{tabular} & \begin{tabular}{|l|l|}
516,44 \\
\end{tabular} \\
\hline Regente Feijó & D20 & 11 & 122,80 & 105,15 & 11 & 1119,20 & 110,20 & 22 & 121,00 & 107,67 & 1 & 11,16 & 8,53 & & 22,35 & 19,74 & 3 & 16,75 & \begin{tabular}{|l|l|}
5 & 13,86 \\
\end{tabular} & 19 & 215,82 & 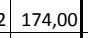 & 15 & 171,35 & 153,38 & 35 & \begin{tabular}{l|l|}
5 & 193,60 \\
\end{tabular} & \begin{tabular}{|l|l|}
163,70 \\
\end{tabular} \\
\hline Reginópolis & E20 & 3 & 111,34 & 62,72 & & \begin{tabular}{|l|l|}
3 & 142,57 \\
\end{tabular} & 105,18 & 6| & 126,77 & 83,69 & 0 & 13,92 & 12,64 & & 28,51 & $20,63 \mid$ & 1 & 21,13 & \begin{tabular}{|l|l|}
3 & 15,35 \\
\end{tabular} & & 236,60 & $\mid$\begin{tabular}{|l|l|}
0 \\
\end{tabular} & & 256,63 & \begin{tabular}{|l|l|}
386,05 \\
\end{tabular} & 12 & 246,50 & \begin{tabular}{|l|l|l|}
0 \\
\end{tabular} \\
\hline
\end{tabular}


Anexo 23 - Nº de óbitos e taxa de mortalidade (bruta e padronizada) total e segundo sexo por Neoplasias, Diabetes Mellitus e Doenças do Aparelho Circulatório, municípios. Estado de São Paulo, média do triênio 2003-2005

\begin{tabular}{|c|c|c|c|c|c|c|c|c|c|c|c|c|c|c|c|c|c|c|c|c|c|c|c|c|c|c|c|c|}
\hline \multirow[b]{3}{*}{ Registro } & \multirow[b]{3}{*}{ D100 } & \multicolumn{9}{|c|}{ Neoplasias Malignas } & \multicolumn{9}{|c|}{ Diabetes Mellitus } & \multicolumn{9}{|c|}{ Aparelho Circulatorio } \\
\hline & & \multicolumn{3}{|c|}{ Homens } & \multicolumn{3}{|c|}{ Mulheres } & \multicolumn{3}{|c|}{ Total } & \multicolumn{3}{|c|}{ Homens } & \multicolumn{3}{|c|}{ Mulheres } & \multicolumn{3}{|c|}{ Total } & \multicolumn{3}{|c|}{ Homens } & \multicolumn{3}{|c|}{ Mulheres } & \multicolumn{3}{|c|}{ Total } \\
\hline & & 30 & 106,29 & 110,55 & 15 & 54,80 & 60,46 & 45 & 80,51 & 85,47 & 5 & 19,11 & 19,63 & 8 & 27,40 & 30,30 & 13 & 23,26 & \begin{tabular}{|l|l|}
5 & 24,77 \\
\end{tabular} & 42 & 150,48 & $8 \mid 152,39$ & 26 & 92,92 & 2102,79 & 68 & $8 \mid$\begin{tabular}{l|l|}
8 & 121,66 \\
\end{tabular} & \begin{tabular}{|l|l}
5 & 127,56 \\
\end{tabular} \\
\hline Restinga & E20 & 2 & 74,89 & 89,68 & 1 & 33,39 & 41,45 & 3 & 54,55 & 66,04 & 0 & 10,70 & 10,94 & & & & 0 & 5,45 & \begin{tabular}{|l|l|}
5 & 6,43 \\
\end{tabular} & 3 & 96,29 & \begin{tabular}{|l|l|}
908,44 \\
\end{tabular} & 2 & 77,91 & 102,42 & 5 & 87,28 & \begin{tabular}{l|l}
805,49 \\
\end{tabular} \\
\hline Ribeira & E20 & 2 & 117,28 & 82,34 & 0 & 21,55 & 27,66 & 2 & 71,74 & 56,33 & 1 & 39,09 & 28,58 & & & & 1 & 20,50 & \begin{tabular}{|l|l|}
$\mid$ & 15,63 \\
\end{tabular} & 5 & 273,65 & 5189,13 & 3 & 172,38 & 8147,48 & 7 & $\begin{array}{l}7 \quad 225,48 \\
\end{array}$ & \begin{tabular}{l|l}
869,32 \\
\end{tabular} \\
\hline Ribeirao Bonito & D20 & 9 & 146,88 & 130,27 & 5 & 86,88 & 77,20 & 14 & 117,25 & 104,07 & 1 & 16,95 & 16,62 & 2 & 34,75 & 30,01 & 3 & 25,74 & $\begin{array}{l}4 \\
42,72 \\
\end{array}$ & 11 & 186,42 & $2 \quad 142,64$ & 11 & 191,14 & 474,76 & 22 & \begin{tabular}{l|l|}
2 & 188,75 \\
\end{tabular} & \begin{tabular}{|l|l}
58,50 \\
\end{tabular} \\
\hline Ribeirao Branco & E50 & 5 & 40,41 & 51,76 & 3 & 31,59 & 43,87 & 8 & 36,20 & 47,99 & 3 & 23,09 & 27,46 & 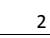 & 18,95 & 30,19 & 5 & 21,12 & 28,44 & 19 & 164,53 & \begin{tabular}{|l|l|}
3 & 202,61 \\
\end{tabular} & 14 & 135,83 & 221,55 & 33 & \begin{tabular}{l|l|}
3 & 150,82 \\
\end{tabular} & \begin{tabular}{|l|l|}
211,66 \\
\end{tabular} \\
\hline Ribeirao Corrente & E20 & 2 & 105,03 & 107,02 & 0 & 17,10 & 15,06 & 3 & 63,93 & 64,04 & & & & 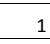 & 34,19 & 37,89 & 1 & 15,98 & 17,13 & 1 & 60,02 & \begin{tabular}{|l|l|}
253,59 \\
\end{tabular} & 3 & 136,78 & \begin{tabular}{|l|}
874,13 \\
\end{tabular} & 4 & \begin{tabular}{|l|l|}
4 & 95,89 \\
\end{tabular} & 109,93 \\
\hline Riberrao do Sul & E20 & 3 & 127,15 & 101,17 & 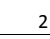 & 87,53 & 78,78 & 5 & 107,66 & 90,15 & & & & 1 & 29,18 & 24,90 & 1 & 14,36 & \begin{tabular}{|l|l|}
5 & 11,59 \\
\end{tabular} & 5 & 211,92 & \begin{tabular}{|l|l|}
2 & 160,55 \\
\end{tabular} & & 218,82 & 2187,21 & 10 & \begin{tabular}{l|l|}
0 & 215,32 \\
\end{tabular} & \begin{tabular}{|l|l|}
2173,67 \\
\end{tabular} \\
\hline Ribeirao dos Indios & E20 & 2 & 169,16 & 98,37 & 1 & 60,28 & 44,34 & 3 & 116,53 & 72,25 & & & & & & & & & & 3 & 225,54 & $4 \quad 119,72$ & 2 & 180,83 & $\mid 32,71$ & 5 & \begin{tabular}{l|l|}
5 & 203,93 \\
\end{tabular} & \begin{tabular}{l|l}
3 & 126,00 \\
\end{tabular} \\
\hline Ribeirao Grande & E20 & 3 & 65,05 & 65,02 & 1 & 26,07 & 28,20 & 4 & 46,21 & 47,22 & 1 & 24,39 & 25,93 & 1 & 34,76 & 41,75 & 2 & 29,41 & \begin{tabular}{|l|l|}
1 & 32,08 \\
\end{tabular} & 7 & 178,89 & \begin{tabular}{|l|l|}
9 & 176,74 \\
\end{tabular} & 5 & 130,34 & $\begin{array}{l}492,47 \\
\end{array}$ & 12 & \begin{tabular}{l|l|}
2 & 155,42 \\
\end{tabular} & \begin{tabular}{|l|l|}
284,34 \\
\end{tabular} \\
\hline Ribeirao Pires & B300 & 49 & 88,21 & 102,17 & 41 & 71,61 & 82,59 & 90 & 79,81 & 92,27 & 13 & 23,25 & 26,83 & 11 & \begin{tabular}{|l|}
19,79 \\
\end{tabular} & 23,34 & 24 & 21,50 & \begin{tabular}{|l|l|} 
& 25,07 \\
\end{tabular} & 114 & 203,85 & 5231,97 & 93 & 161,84 & | 193,21 & 207 & \begin{tabular}{l|l|}
7 & 182,60 \\
\end{tabular} & \begin{tabular}{|l|l|}
212,36 \\
\end{tabular} \\
\hline Ribeirao Preto & B1000 & 359 & 138,51 & 126,84 & 274 & $\begin{array}{r}98,31 \\
\end{array}$ & 86,13 & 633 & 117,66 & 105,72 & 39 & 15,06 & 13,77 & 40 & 14,45 & 12,69 & 79 & 14,75 & | 13,15 & 536 & 206,86 & $6 \quad 184,45$ & 490 & 175,48 & \begin{tabular}{|l|l|}
851,37 \\
\end{tabular} & 1025 & \begin{tabular}{l|l|}
5 & 190,58 \\
\end{tabular} & \begin{tabular}{l|l}
8 & 167,29 \\
\end{tabular} \\
\hline Rifaina & D20 & 1 & 55,56 & 42,91 & 1 & 38,86 & 38,99 & 2 & 47,41 & 41,00 & & & & & & & 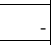 & & & 3 & 148,15 & 5118,22 & 1 & 77,72 & \begin{tabular}{|l|}
28,33 \\
\end{tabular} & 4 & \begin{tabular}{|l|l|}
44 & 113,78 \\
\end{tabular} & \begin{tabular}{|l|l}
3 & 93,87 \\
\end{tabular} \\
\hline Rincao & D20 & 7 & 127,67 & 126,45 & 4 & 78,41 & 81,05 & 11 & 103,32 & 104,02 & 1 & 25,53 & 24,76 & 2 & 39,20 & 38,46 & 3 & 32,29 & \begin{tabular}{|l|l|}
91,51 \\
\end{tabular} & 11 & 204,26 & \begin{tabular}{|l|l|}
6 & 188,66 \\
\end{tabular} & 11 & 222,15 & 5217,88 & 22 & \begin{tabular}{l|l|}
2 & 213,10 \\
\end{tabular} & 203,10 \\
\hline Rinópolis & E20 & 7 & 144,84 & 92,81 & 4 & 76,64 & 57,96 & 11 & 111,71 & 75,88 & 0 & 6,58 & 3,50 & 2 & 48,77 & 31,52 & 3 & 27,08 & \begin{tabular}{|l|l|}
8 & 16,47 \\
\end{tabular} & 14 & 269,93 & \begin{tabular}{|l|l|} 
& 149,11 \\
\end{tabular} & & 146,31 & 90,53 & 2 & \begin{tabular}{l|l|}
1 & 209,87 \\
\end{tabular} & $\begin{array}{ll}720,65 \\
7\end{array}$ \\
\hline Rio Claro & B300 & 109 & 122,40 & 103,34 & 82 & 88,34 & 71,72 & 191 & 104,99 & 87,17 & 15 & 16,52 & 14,28 & 19 & 20,83 & 16,60 & 34 & \begin{tabular}{|l|}
18,72 \\
\end{tabular} & 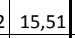 & 168 & \begin{tabular}{|l|l|}
189,61 \\
\end{tabular} & $\mid 152,17$ & 174 & 187,45 & $5 \mid 139,73$ & 342 & \begin{tabular}{l|l|}
2 & 188,50 \\
\end{tabular} & \begin{tabular}{|l|l}
45,81 \\
\end{tabular} \\
\hline Rio das Pedras & C50 & 13 & 97,69 & 106,92 & 8 & 61,39 & 67,93 & 20 & 79,88 & 87,79 & 1 & 10,28 & 11,45 & 2 & 16,01 & 17,84 & 3 & 13,10 & \begin{tabular}{|l|l|}
$b$ & 14,64 \\
\end{tabular} & 23 & 174,81 & 185,14 & 15 & 120,11 & 134,84 & 38 & \begin{tabular}{l|l|}
8 & 147,97 \\
\end{tabular} & $\begin{array}{ll}760,46 \\
\end{array}$ \\
\hline Rio Grande da S & c50 & 12 & 61,46 & 86,24 & 10 & 47,76 & 63,39 & 22 & 54,58 & 74,77 & 2 & 8,31 & 12,27 & 7 & 34,59 & 57,18 & 9 & 21,50 & \begin{tabular}{|l|l|}
0 & 34,97 \\
\end{tabular} & 38 & 189,37 & 271,69 & 29 & 144,94 & 229,16 & 67 & \begin{tabular}{l|l|}
7 & 167,06 \\
\end{tabular} & \begin{tabular}{|l|l}
5 & 250,33 \\
\end{tabular} \\
\hline Riolândia & E20 & 3 & 60,29 & 56,79 & 2 & 50,73 & 48,92 & 5 & 56,06 & 53,31 & 2 & 40,20 & 37,20 & 1 & 16,91 & 15,87 & 3 & 29,90 & 28,00 & 11 & 221,08 & \begin{tabular}{|l|l|}
8 & 198,49 \\
\end{tabular} & 11 & 279,00 & 279,25 & 22 & \begin{tabular}{ll|l|}
2 & 246,68 \\
\end{tabular} & \begin{tabular}{|l|l|}
834,20 \\
\end{tabular} \\
\hline Riversul & E20 & 3 & 105,01 & 65,25 & 3 & 98,92 & 100,24 & 6 & 102,04 & 82,34 & 2 & 63,01 & 50,69 & 2 & 65,95 & 59,45 & 4 & 64,44 & 4 4 54,95 & 7 & 231,02 & \begin{tabular}{|l|l|}
2 & 156,95 \\
\end{tabular} & 9 & 296,77 & 284,97 & 16 & \begin{tabular}{l|l|}
6 & 263,14 \\
\end{tabular} & $\begin{array}{l}419,50 \\
\end{array}$ \\
\hline Rosana & c50 & 9 & 66,26 & 93,83 & 4 & 34,10 & 59,89 & 13 & 50,41 & 77,10 & 0 & 2,55 & 2,61 & 2 & 18,36 & 39,93 & 3 & 10,34 & $\begin{array}{ll}4 & 16,59 \\
\end{array}$ & 15 & 117,22 & \begin{tabular}{|l|l|}
2160,99 \\
\end{tabular} & 13 & 102,29 & 235,69 & 28 & \begin{tabular}{|l|l|}
8 & 109,86 \\
\end{tabular} & \begin{tabular}{|l|l|}
5 & 197,80 \\
\end{tabular} \\
\hline Roseira & C20 & 4 & 81,51 & 95,68 & 3 & 70,57 & 77,85 & 7 & 76,14 & 86,93 & 1 & 20,38 & 24,14 & 2 & 49,40 & 60,03 & 3 & 34,61 & \begin{tabular}{l|l|}
1 & 41,64 \\
\end{tabular} & 10 & 203,76 & 6 239,59 & 6 & 127,03 & $\mid 157,57$ & 16 & \begin{tabular}{l|l|}
6 & 166,13 \\
\end{tabular} & \begin{tabular}{|l|l} 
B & 199,36 \\
\end{tabular} \\
\hline Rubiácea & E20 & 2 & 207,72 & 164,27 & 1 & 92,65 & 100,39 & 3 & 151,33 & 132,97 & & & & 0 & 30,88 & 39,00 & 0 & 15,13 & \begin{tabular}{|l|l|}
36,59 \\
\end{tabular} & 1 & \begin{tabular}{|l|}
89,02 \\
\end{tabular} & \begin{tabular}{|l|l|}
2 & 72,61 \\
\end{tabular} & 2 & 185,30 & 171,71 & 3 & \begin{tabular}{l|l|}
3 & 136,20 \\
\end{tabular} & \begin{tabular}{|l|l|}
01,17 \\
\end{tabular} \\
\hline Rubinéia & D20 & 2 & 120,71 & 68,62 & & & & 2 & 59,87 & 34,03 & 0 & 24,14 & 12,07 & 1 & 47,52 & 34,02 & 1 & 35,92 & \begin{tabular}{|l|l|}
2 & 21,60 \\
\end{tabular} & 4 & 265,57 & $\begin{array}{l}726,40 \\
\end{array}$ & 2 & 118,79 & \begin{tabular}{|l|l|}
9 & 92,82 \\
\end{tabular} & 5 & \begin{tabular}{l|l|}
5 & 191,59 \\
\end{tabular} & \begin{tabular}{l|l}
9 & 109,48 \\
\end{tabular} \\
\hline Sabino & E20 & 2 & 65,21 & 39,66 & 2 & 64,99 & 52,26 & 3 & 65,10 & 45,97 & 0 & 13,04 & 8,01 & 0 & 13,00 & 9,44 & 1 & \begin{tabular}{|l|}
13,02 \\
\end{tabular} & 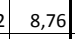 & 7 & 286,91 & 179,41 & 8 & 311,97 & 239,93 & 15 & \begin{tabular}{|l|l|}
5 & 299,46 \\
\end{tabular} & \begin{tabular}{|l|l}
5 & 209,72 \\
\end{tabular} \\
\hline Sagres & E20 & 2 & 139,39 & 98,58 & 0 & 29,03 & 28,99 & 2 & 85,32 & 64,49 & & & & 0 & 29,03 & 24,10 & 0 & \begin{tabular}{|l|}
14,22 \\
\end{tabular} & \begin{tabular}{|l|}
2 \\
\end{tabular} & 3 & \begin{tabular}{|l|}
278,78 \\
\end{tabular} & \begin{tabular}{|l|l|}
8 & 199,47 \\
\end{tabular} & 1 & 58,06 & \begin{tabular}{|l|l|}
5 & 45,17 \\
\end{tabular} & 4 & \begin{tabular}{|l|l|}
4 & 170,65 \\
\end{tabular} & \begin{tabular}{|l|l|}
523,88 \\
\end{tabular} \\
\hline Sales & E20 & 5 & 186,57 & 143,16 & 1 & 55,09 & 48,92 & 6 & 121,91 & 96,82 & 0 & 13,33 & 8,90 & 3 & 123,95 & 114,30 & 3 & 67,72 & \begin{tabular}{|l|l|}
2 & 55,33 \\
\end{tabular} & 6 & 226,55 & \begin{tabular}{|l|}
5 \\
5
\end{tabular} & 5 & 206,58 & \begin{tabular}{|l|l|}
8 & 186,45 \\
\end{tabular} & 11 & \begin{tabular}{l|l|}
1 & 216,73 \\
\end{tabular} & \begin{tabular}{l|l}
3 & 173,26 \\
\end{tabular} \\
\hline Sales Olive & B20 & 4 & 85,57 & 70,74 & 5 & 92,99 & 85,06 & 9 & 89,26 & 77,87 & 1 & 13,16 & \begin{tabular}{|l|}
11,07 \\
\end{tabular} & 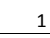 & 19,93 & 17,54 & 2 & 16,53 & \begin{tabular}{|l|l|}
3 & 14,23 \\
\end{tabular} & 8 & 151,39 & \begin{tabular}{|l|l|}
9 & 118,64 \\
\end{tabular} & 11 & 219,20 & $\mid 187,97$ & 19 & \begin{tabular}{l|l|}
9 & 185,14 \\
\end{tabular} & \begin{tabular}{l|l}
4 & 153,15 \\
\end{tabular} \\
\hline Salesópolis & E20 & 9 & 109,20 & 93,63 & 4 & 55,86 & 59,06 & 13 & 82,83 & 76,54 & 2 & 25,20 & 21,74 & 2 & 21,48 & 21,96 & 4 & \begin{tabular}{|l|}
23,36 \\
\end{tabular} & \begin{tabular}{|l|l|}
5 & 22,12 \\
\end{tabular} & 18 & 226,80 & \begin{tabular}{|l|l|}
0 & 183,42 \\
\end{tabular} & 20 & 262,11 & 266,77 & 38 & \begin{tabular}{l|l|}
8 & 244,25 \\
\end{tabular} & \begin{tabular}{|l|}
224,62 \\
\end{tabular} \\
\hline Salmourao & E20 & 2 & 104,77 & 78,04 & 1 & 62,04 & 47,65 & 4 & 83,79 & 63,11 & & & & 1 & 46,53 & 36,75 & 1 & 22,85 & \begin{tabular}{|l|}
5 \\
\end{tabular} & 5 & 224,52 & \begin{tabular}{|l|l|}
2142,87 \\
\end{tabular} & 2 & 108,58 & \begin{tabular}{|l|l|}
8 & 91,92 \\
\end{tabular} & 7 & \begin{tabular}{l|l|}
7 & 167,58 \\
\end{tabular} & \begin{tabular}{l|l}
8 & 117,85 \\
\end{tabular} \\
\hline Saltinho & B20 & 5 & 161,95 & 131,38 & 5 & 153,80 & \begin{tabular}{|l|}
140,40 \\
\end{tabular} & 10 & 157,91 & 135,85 & 1 & 43,19 & \begin{tabular}{|l|}
37,76 \\
\end{tabular} & 1 & 43,94 & 40,00 & 3 & 43,56 & \begin{tabular}{|l|l|}
5 & 39,16 \\
\end{tabular} & 4 & \begin{tabular}{|l|}
118,76 \\
\end{tabular} & \begin{tabular}{|l|l|}
6 & 98,31 \\
\end{tabular} & 3 & 109,85 & \begin{tabular}{|l|l|}
5 & 96,39 \\
\end{tabular} & 7 & \begin{tabular}{|l|l|}
7 & 114,35 \\
\end{tabular} & 97,36 \\
\hline Salto & B300 & 55 & 107,98 & 117,25 & 37 & 71,59 & 79,56 & 92 & \begin{tabular}{|l|}
89,79 \\
\end{tabular} & 98,41 & 9 & 16,91 & \begin{tabular}{|r|}
17,88 \\
\end{tabular} & 12 & 24,08 & 26,60 & 21 & 20,50 & 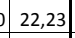 & 69 & 134,65 & $5 \mid 145,12$ & 65 & 127,56 & $5 \mid 143,39$ & 134 & \begin{tabular}{l|l|}
4 & 131,11 \\
\end{tabular} & \begin{tabular}{l|l}
1144,26 \\
\end{tabular} \\
\hline Salto de Pirapo & D50 & 20 & 99,44 & 98,36 & 15 & 74,68 & 85,88 & 34 & 87,10 & 92,14 & 3 & 15,17 & 14,33 & 4 & 22,06 & 24,65 & 7 & 18,60 & \begin{tabular}{|l|} 
\\
\end{tabular} & 30 & 153,38 & \begin{tabular}{|l|l|} 
& 145,19 \\
\end{tabular} & 32 & 164,63 & 389,31 & 63 & \begin{tabular}{l|l|}
3 & 158,98 \\
\end{tabular} & \begin{tabular}{|l|l|}
867,17 \\
\end{tabular} \\
\hline Salto Grande & E20 & 6 & 133,84 & 101,68 & 6 & 142,81 & 126,82 & 12 & 138,30 & 114,18 & 1 & 22,31 & 16,43 & 1 & 30,07 & 23,41 & 2 & 26,16 & \begin{tabular}{|l|l|}
5 & 19,38 \\
\end{tabular} & 16 & 349,47 & 7226,02 & 10 & 217,98 & \begin{tabular}{|l|l|}
8 & 188,25 \\
\end{tabular} & 25 & \begin{tabular}{l|l|}
5 & 284,08 \\
\end{tabular} & \begin{tabular}{l|l}
8207,24 \\
\end{tabular} \\
\hline Sandoval & E20 & 2 & 99,01 & 91,69 & & & & 2 & 49,11 & 45,48 & & & & 1 & 58,47 & 71,01 & 1 & 29,46 & \begin{tabular}{|l|l|}
5 & 31,90 \\
\end{tabular} & 3 & 198,02 & \begin{tabular}{|l|l|}
2 & 193,61 \\
\end{tabular} & & 36,43 & \begin{tabular}{|l|l|}
384,62 \\
\end{tabular} & 6 & \begin{tabular}{l|l|}
6 & 166,98 \\
\end{tabular} & \begin{tabular}{|l|l|}
889,08 \\
\end{tabular} \\
\hline Santa Adélia & D20 & 10 & 138,46 & 113,28 & 7 & 97,46 & 72,39 & 16 & 118,17 & 93,04 & 1 & 14,32 & 11,49 & 1 & 9,75 & 8,28 & 2 & 12,06 & \begin{tabular}{|l|l|}
5 & 9,89 \\
\end{tabular} & 19 & 267,38 & \begin{tabular}{|l|l|}
8 & 190,59 \\
\end{tabular} & 13 & 190,04 & 4142,27 & 32 & \begin{tabular}{|l|l|}
2 & 229,10 \\
\end{tabular} & \begin{tabular}{|l|l|}
166,67 \\
\end{tabular} \\
\hline Santa Albertina & E20 & 6 & 206,44 & 110,38 & 3 & 122,76 & 95,84 & 9 & 164,83 & 103,15 & 2 & 60,72 & 29,37 & 2 & 61,38 & 39,99 & 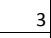 & 61,05 & \begin{tabular}{|l|l|}
55,04 \\
\end{tabular} & 11 & 400,73 & \begin{tabular}{|l|l|}
3 & 204,18 \\
\end{tabular} & 6 & 220,97 & 141,04 & 17 & \begin{tabular}{l|l|}
7 & 311,34 \\
\end{tabular} & \begin{tabular}{l|l}
4 & 172,78 \\
\end{tabular} \\
\hline Santa Bárbara d'Oeste & B300 & 72 & 79,58 & 86,59 & 50 & 55,14 & 62,75 & 122 & 67,34 & 74,66 & 9 & 10,32 & 10,92 & 16 & 17,28 & 19,74 & 25 & 13,80 & \begin{tabular}{|l|l|}
0,32 \\
\end{tabular} & 93 & 102,79 & \begin{tabular}{|l|l|}
9 & 110,94 \\
\end{tabular} & 93 & 102,92 & 2123,49 & 186 & \begin{tabular}{l|l|}
6 & 102,86 \\
\end{tabular} & \begin{tabular}{|l|l|}
5 & 117,22 \\
\end{tabular} \\
\hline Santa Branca & D20 & 12 & 167,01 & 151,01 & 4 & $\begin{array}{l}761,63 \\
\end{array}$ & 63,11 & 16 & 114,89 & 107,53 & 1 & 9,28 & 8,03 & 2 & 33,18 & 33,33 & 3 & 21,10 & 19,81 & 10 & 134,54 & $4 \mid 122,21$ & 8 & 113,77 & 112,54 & 18 & \begin{tabular}{|l|l|}
8 & 124,27 \\
\end{tabular} & 117,43 \\
\hline Santa Clara d'Oeste & E20 & 1 & 67,98 & 33,56 & 2 & 170,94 & 142,06 & 2 & 119,31 & 87,65 & 0 & 33,99 & 17,06 & & & & 0 & 17,04 & \begin{tabular}{l|l|}
4 & 9,86 \\
\end{tabular} & 3 & 271,92 & \begin{tabular}{|l|l|}
2 & 137,38 \\
\end{tabular} & 2 & 205,13 & 138,69 & 5 & \begin{tabular}{l|l|}
5 & 238,62 \\
\end{tabular} & \begin{tabular}{|l|l|}
2 & 138,04 \\
\end{tabular} \\
\hline Santa Cruz da Conceiçao & B20 & 2 & 103,08 & 75,24 & 1 & 53,90 & 42,41 & 3 & 79,04 & 59,19 & 0 & 17,18 & 16,82 & & & & 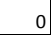 & 8,78 & \begin{tabular}{|l|l|}
8 & 8,47 \\
\end{tabular} & & 137,43 & \begin{tabular}{|l|} 
\\
$\mid 100,19$ \\
\end{tabular} & & 125,76 & 86,91 & & 131,73 & \begin{tabular}{|l|l}
3 & 93,70 \\
\end{tabular} \\
\hline
\end{tabular}


Anexo 23 - $\mathrm{N}^{\circ}$ de óbitos e taxa de mortalidade (bruta e padronizada) total e segundo sexo por Neoplasias, Diabetes Mellitus e Doenças do Aparelho Circulatório, municípios. Estado de São Paulo, média do triênio 2003-2005

\begin{tabular}{|c|c|c|c|c|c|c|c|c|c|c|c|c|c|c|c|c|c|c|c|c|c|c|c|c|c|c|c|c|}
\hline \multirow[b]{3}{*}{ Santa Cruz da Esperança } & \multirow[b]{3}{*}{ E20 } & \multicolumn{9}{|c|}{ Neoplasias Malignas } & \multicolumn{9}{|c|}{ Diabetes Mellitus } & \multicolumn{9}{|c|}{ ulatorio } \\
\hline & & \multicolumn{3}{|c|}{ Homens } & \multicolumn{3}{|c|}{ Mulheres } & \multicolumn{3}{|c|}{ Total } & \multicolumn{3}{|c|}{ Homens } & \multicolumn{3}{|c|}{ Mulheres } & \multicolumn{3}{|c|}{ Total } & \multicolumn{3}{|c|}{ Homens } & \multicolumn{3}{|c|}{ Mulheres } & \multicolumn{3}{|c|}{ Total } \\
\hline & & 3 & 282,09 & 166,86 & 1 & 111,32 & 115,98 & 4 & 198,88 & 142,07 & 0 & 35,26 & 23,85 & 0 & 37,11 & 36,43 & & 36,15 & \begin{tabular}{|l|} 
\\
5
\end{tabular} & & 246,83 & $3 \mid 161,59$ & & 37,11 & 37,81 & & 144,64 & \begin{tabular}{l|l}
4 & 101,28 \\
\end{tabular} \\
\hline Santa Cruz das Palmeiras & D50 & 15 & 111,51 & 107,02 & 15 & 113,79 & 118,06 & 31 & 112,64 & 112,48 & 2 & 12,12 & 11,44 & 4 & 27,21 & 27,69 & 5 & 19,59 & \begin{tabular}{|l|l|}
9 & 19,32 \\
\end{tabular} & 26 & \begin{tabular}{l|l|}
6 & 186,66 \\
\end{tabular} & $6 \mid 171,32$ & 22 & 160,80 & 163,43 & 47 & \begin{tabular}{l|l|}
7 & 173,86 \\
\end{tabular} & \begin{tabular}{l|l}
5 & 167,41 \\
\end{tabular} \\
\hline Santa Cruz do Rio Pardo & c50 & 26 & 122,43 & 97,23 & 20 & 90,94 & 78,44 & 46 & 106,54 & 87,75 & 9 & 42,38 & 33,92 & 7 & 33,91 & 28,49 & 16 & 38,11 & \begin{tabular}{l|l|}
1 & 31,33 \\
\end{tabular} & 39 & \begin{tabular}{l|l|}
9 & 182,07 \\
\end{tabular} & 739,02 & 36 & 166,47 & 137,45 & 75 & \begin{tabular}{l|l|}
5 & 174,20 \\
\end{tabular} & \begin{tabular}{|l|l|}
38,23 \\
\end{tabular} \\
\hline Santa Ernestina & B20 & 4 & 116,33 & 138,51 & 2 & 75,55 & 85,93 & 6 & 97,71 & 114,51 & & & & 0 & 12,59 & 14,80 & 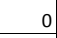 & 5,75 & \begin{tabular}{|c|}
5 \\
5
\end{tabular} & 5 & \begin{tabular}{l|l|l}
5 & 148,05 \\
\end{tabular} & $5 \mid 174,70$ & 6 & 226,64 & 265,27 & 11 & \begin{tabular}{l|l|l|}
1 & 183,93 \\
\end{tabular} & \begin{tabular}{|l|l|}
3 & 216,05 \\
\end{tabular} \\
\hline Santa Fé do Sul & D50 & 15 & 109,98 & \begin{tabular}{|l|}
39,03 \\
\end{tabular} & 14 & 94,95 & 75,59 & 29 & 102,26 & $77,27 \mid$ & 2 & 14,66 & 9,30 & 3 & 20,84 & 16,17 & 5 & 17,84 & \begin{tabular}{|l|l|}
42,77 \\
\end{tabular} & 23 & \begin{tabular}{|l|l|}
3 & 171,08 \\
\end{tabular} & \begin{tabular}{|l|l|}
8 & 111,58 \\
\end{tabular} & 21 & 145,90 & 115,92 & 44 & \begin{tabular}{|l|l|}
4 & 158,15 \\
\end{tabular} & 113,81 \\
\hline Santa Gertrudes & $\mathrm{c} 20$ & 6 & 67,84 & 74,84 & 5 & 55,60 & 58,46 & 11 & 61,84 & 66,81 & 0 & 3,57 & 3,68 & 1 & 7,41 & 7,97 & 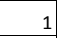 & 5,46 & \begin{tabular}{|l|l|}
5 & 5,77 \\
\end{tabular} & 14 & \begin{tabular}{l|l|}
4 & 153,54 \\
\end{tabular} & \begin{tabular}{|l|l|}
4 & 160,39 \\
\end{tabular} & 13 & 148,28 & \begin{tabular}{|l|l|}
851,75 \\
\end{tabular} & 28 & 8150,96 & \begin{tabular}{|l|l}
5 & 156,15 \\
\end{tabular} \\
\hline Santa Isabel & D50 & 20 & 85,50 & 90,86 & 21 & 93,06 & 109,33 & 41 & 89,24 & 100,00 & 4 & 18,53 & 19,39 & 5 & 20,36 & 24,19 & 9 & 19,43 & \begin{tabular}{|l|}
31,73 \\
\end{tabular} & 63 & \begin{tabular}{l|l|}
3 & 269,33 \\
\end{tabular} & \begin{tabular}{|l|l|}
3 & 278,29 \\
\end{tabular} & 57 & 248,65 & \begin{tabular}{|l|l|}
507,97 \\
\end{tabular} & 120 & \begin{tabular}{l|l|}
0 & 259,09 \\
\end{tabular} & \begin{tabular}{|l|l|}
9 & 292,98 \\
\end{tabular} \\
\hline Santa Lúcia & E20 & 4 & 90,45 & 98,79 & 3 & 64,53 & 77,59 & t & 77,93 & 88,55 & 1 & 30,15 & 32,52 & 1 & 16,13 & 20,78 & 2 & 23,38 & \begin{tabular}{|l|l|}
8 & 27,34 \\
\end{tabular} & & 150,75 & 5155,95 & 5 & 129,06 & $5 \mid 164,03$ & 12 & \begin{tabular}{l|l|}
2 & 140,27 \\
\end{tabular} & 159,85 \\
\hline Santa Maria da Serra & E20 & 4 & 145,16 & 124,89 & 1 & 57,66 & 67,38 & 5 & 103,34 & 97,41 & & & & 1 & 43,25 & 51,60 & 1 & $20,67 \mid$ & 22,79 & 3 & \begin{tabular}{l|l|}
3 & 105,57 \\
\end{tabular} & $\begin{array}{l}704,35 \\
\end{array}$ & 4 & 172,99 & 182,67 & 7 & \begin{tabular}{l|l|}
7 & 137,79 \\
\end{tabular} & \begin{tabular}{|l|l|}
9 & 141,78 \\
\end{tabular} \\
\hline Santa Mercedes & E20 & 1 & 96,78 & 64,40 & 2 & 148,77 & 111,15 & 3 & 122,46 & 87,49 & & & & 1 & 49,59 & 36,50 & 1 & 24,49 & \begin{tabular}{l|l|}
9 & 15,23 \\
\end{tabular} & 4 & \begin{tabular}{l|l|}
4 & 290,35 \\
\end{tabular} & $5 \mid 177,08$ & 2 & 123,98 & $8 \mid 107,32$ & 6 & \begin{tabular}{l|l|}
6 & 208,18 \\
\end{tabular} & \begin{tabular}{|l|l}
142,63 \\
\end{tabular} \\
\hline$\underline{\text { Santa Rita do Passa }}$ & B50 & 28 & 209,91 & 134,51 & 13 & 91,41 & 63,79 & 40 & 149,17 & 98,27 & 2 & 17,70 & 10,82 & 5 & 36,08 & 21,90 & 7 & 27,12 & 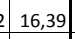 & 32 & $\begin{array}{ll}2 & 242,79 \\
\end{array}$ & \begin{tabular}{l|l|}
944,63 \\
\end{tabular} & 34 & 245,36 & $6 \mid 155,70$ & 66 & \begin{tabular}{l|l|}
6 & 244,10 \\
\end{tabular} & \begin{tabular}{|l|l}
150,30 \\
\end{tabular} \\
\hline Santa Rita d'Oeste & E20 & 2 & 141,08 & 83,19 & 2 & 143,64 & 91,30 & 3 & 142,35 & 87,21 & 1 & 56,43 & 27,71 & 0 & 28,73 & 17,82 & 1 & 42,70 & 23,73 & 3 & \begin{tabular}{|l|l|}
3 & 225,73 \\
\end{tabular} & \begin{tabular}{|l|}
321,85 \\
\end{tabular} & 3 & 229,82 & 2143,54 & 5 & \begin{tabular}{|l|l|}
5 & 227,76 \\
\end{tabular} & \begin{tabular}{|l|l}
5 & 132,60 \\
\end{tabular} \\
\hline Santa Rosa de & D50 & 13 & 113,29 & 94,07 & 11 & 94,77 & 84,69 & 23 & 104,00 & 89,37 & 1 & 11,93 & 9,30 & 4 & 32,58 & 27,95 & 5 & 22,29 & \begin{tabular}{|l|}
98,50 \\
\end{tabular} & 24 & \begin{tabular}{l|l|}
44 & 217,64 \\
\end{tabular} & \begin{tabular}{|l|l|}
4 & 175,48 \\
\end{tabular} & 19 & 171,77 & 150,51 & 44 & \begin{tabular}{|l|l|}
4 & 194,63 \\
\end{tabular} & \begin{tabular}{l|l}
162,95 \\
\end{tabular} \\
\hline Santa Salete & E20 & 1 & 91,95 & 45,85 & 1 & 101,94 & 83,68 & t $>$ & 96,69 & 63,79 & & & & & & & & & & 2 & \begin{tabular}{l|l|}
2 & 321,84 \\
\end{tabular} & \begin{tabular}{l|l|}
459,52 \\
\end{tabular} & 1 & 152,91 & 97,06 & 3 & \begin{tabular}{l|l|}
3 & 241,72 \\
\end{tabular} & \begin{tabular}{|l|l|}
229,89 \\
\end{tabular} \\
\hline Santana da $\mathrm{P}$ & E20 & 1 & 153,32 & 85,92 & 0 & 40,97 & 27,15 & a & 99,01 & 57,51 & 0 & 38,33 & 20,96 & & 122,90 & 79,24 & & 79,22 & \begin{tabular}{|l|}
27,42 \\
\end{tabular} & 1 & \begin{tabular}{l|l|}
1 & 114,99 \\
\end{tabular} & 42,31 & 3 & 327,73 & 232,04 & 4 & \begin{tabular}{l|l|}
4 & 217,82 \\
\end{tabular} & \begin{tabular}{|l|l|}
2134,02 \\
\end{tabular} \\
\hline Santana de $\mathrm{Pa}$ & C100 & 26 & 57,09 & 97,43 & 25 & 55,26 & 92,83 & 51 & 56,17 & 95,13 & 4 & 9,52 & 14,57 & 3 & ,27 & 13,44 & &, 39 & \begin{tabular}{|l|l|}
$\mid$ & 14,14 \\
\end{tabular} & 63 & \begin{tabular}{l|l|}
3 & 138,34 \\
\end{tabular} & $4 \quad 208,69$ & 49 & 106,16 & 6 | 197,92 & 112 & \begin{tabular}{l|l|}
2 & 122,19 \\
\end{tabular} & \begin{tabular}{|l|l|}
9 & 203,29 \\
\end{tabular} \\
\hline Santo Anastá & E50 & 10 & 97,08 & 73,70 & 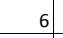 & 58,74 & 49,33 & 16 & 7,47 & 61,23 & 3 & 29,12 & 21,87 & 3 & \begin{tabular}{|l|}
30,91 \\
\end{tabular} & 22,77 & 6 & 30,04 & $\begin{array}{l}4 \mid 22,02 \\
\end{array}$ & 28 & \begin{tabular}{l|l|}
8 & 271,82 \\
\end{tabular} & 2182,49 & 20 & 185,48 & \begin{tabular}{|l|l|}
841,93 \\
\end{tabular} & 48 & \begin{tabular}{l|l|}
8 & 227,66 \\
\end{tabular} & \begin{tabular}{|l|l|}
5 & 161,74 \\
\end{tabular} \\
\hline Santo André & A1000 & 420 & 131,03 & 117,36 & 375 & 109,43 & 96,09 & 796 & 119,87 & 106,37 & 55 & 17,25 & 15,22 & 76 & 22,16 & 19,09 & 131 & 19,79 & \begin{tabular}{l|l|}
9 & 17,21 \\
\end{tabular} & 801 & 11249,79 & $9216,60 \mid$ & 727 & 212,06 & $6 \mid 183,59$ & 1529 & \begin{tabular}{l|l|}
9 & 230,30 \\
\end{tabular} & 199,54 \\
\hline Santo Antônio Aracangu & E20 & 2 & 55,81 & 50,87 & 2 & 50,30 & 54,16 & 4 & 53,17 & 52,45 & 1 & 27,91 & 26,05 & 1 & 30,18 & 32,62 & 2 & 29,00 & 29,24 & 5 & \begin{tabular}{|l|l|}
5 & 148,84 \\
\end{tabular} & \begin{tabular}{|l|l|}
4 & 134,49 \\
\end{tabular} & 5 & 140,85 & \begin{tabular}{|l|l|}
52,18 \\
\end{tabular} & 10 & \begin{tabular}{l|l|}
0 & 145,00 \\
\end{tabular} & 142,98 \\
\hline Santo Antônio da Alegria & E20 & 3 & 84,95 & 66,58 & 3 & 92,04 & 74,54 & 5 & 88,35 & 70,40 & & & & 1 & 34,51 & $32,4 c$ & 1 & 16,57 & 15,16 & 7 & \begin{tabular}{ll|}
7 & 233,62 \\
\end{tabular} & \begin{tabular}{|l|l|}
2 & 181,96 \\
\end{tabular} & 7 & 230,10 & 192,82 & 14 & \begin{tabular}{l|l|}
4 & 231,93 \\
\end{tabular} & \begin{tabular}{|l|l|}
3 & 187,17 \\
\end{tabular} \\
\hline Santo Antônio de Posse & D20 & 13 & 126,55 & 120,55 & 7 & 74,48 & 76,31 & 20 & 100,73 & 98,61 & 1 & 13,32 & 11,22 & 3 & 33,85 & 34,21 & 5 & 23,50 & \begin{tabular}{|l|l|} 
& 22,15 \\
\end{tabular} & 19 & \begin{tabular}{l|l|}
9 & 186,50 \\
\end{tabular} & | 162,08 & 16 & 162,50 & 163,58 & 35 & \begin{tabular}{l|l|}
5 & 174,60 \\
\end{tabular} & \begin{tabular}{|l|l|}
162,82 \\
\end{tabular} \\
\hline Santo Antônio do Jardim & E20 & 4 & 129,99 & 93,34 & +1 & 55,01 & 48,99 & 6 & 94,29 & 72,22 & 0 & 10,00 & 8,64 & 1 & 33,00 & 26,75 & 1 & 20,95 & \begin{tabular}{|l|}
5 \\
\end{tabular} & 9 & \begin{tabular}{l|l|}
9 & 259,97 \\
\end{tabular} & 176,14 & 5 & 154,02 & 2125,30 & 13 & \begin{tabular}{l|l|}
3 & 209,52 \\
\end{tabular} & \begin{tabular}{|l|l}
2151,93 \\
\end{tabular} \\
\hline Santo Antônio do Pinhal & E20 & 2 & 67,22 & 65,51 & 2 & ,72 & 60,38| & $4^{4}$ & 64,06 & $63,01 \mid$ & 1 & 38,41 & 37,16 & 2 & 50,60 & 51,02 & 3 & 44,35 & \begin{tabular}{|l|l|}
53,82 \\
\end{tabular} & 10 & $\begin{array}{l}0 \\
0\end{array}$ & | 248,80 & 7 & 202,39 & 223,98 & 16 & \begin{tabular}{l|l|}
6 & 241,44 \\
\end{tabular} & \begin{tabular}{l|l}
4 & 236,72 \\
\end{tabular} \\
\hline Sant & E20 & 4 & 266,15 & 191,23 & 1 & 1,92 & ;,58 & 4 & 162,81 & 116,63 & 1 & 48,39 & 31,99 & 1 & 51,92 & 36,70 & 1 & 50,09 & 34,49 & 1 & 96,78 & \begin{tabular}{|l|l|}
8 & 59,84 \\
\end{tabular} & 1 & 51,92 & \begin{tabular}{|l|l|}
2 & 42,14 \\
\end{tabular} & & 75,14 & \begin{tabular}{l|l}
4 & 51,30 \\
\end{tabular} \\
\hline Santópo & E20 & 2 & 103,18 & 83,48 & 1 & 35,65 & 31,21 & 3 & 70,02 & 57,81 & 1 & 34,39 & 36,20 & 0 & 17,83 & 16,44 & 1 & 26,26 & 25,46 & 6 & \begin{tabular}{|l|l|}
6 & 309,54 \\
\end{tabular} & \begin{tabular}{|l|l|}
4 & 218,44 \\
\end{tabular} & 2 & 124,78 & \begin{tabular}{|l|}
822,10 \\
\end{tabular} & 8 & \begin{tabular}{|l|l|}
8 & 218,82 \\
\end{tabular} & 171,14 \\
\hline Santos & A500 & 357 & 184,65 & 121,41 & 376 & 167,35 & 103,47 & 733 & 175,35 & 111,77 & 63 & 32,41 & 21,31 & 63 & 28,16 & 16,76 & 126 & 30,13 & \begin{tabular}{|l|l|}
3 & 18,66 \\
\end{tabular} & 505 & \begin{tabular}{l|l|}
5 & 261,03 \\
\end{tabular} & $3 \mid 160,61$ & 516 & 229,45 & 5128,46 & 1021 & 1 1. 244,05 & \begin{tabular}{|l|l}
5 & 143,32 \\
\end{tabular} \\
\hline Sao Bento do Sapuca & D20 & 5 & 82,98 & 68,93 & 6 & 103,53 & 86,83 & 10 & 93,12 & 77,76 & 2 & 41,49 & 30,81 & 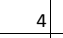 & 66,99 & 56,70 & & 54,07 & 43,09 & 18 & \begin{tabular}{|l|l|}
8 & 320,08 \\
\end{tabular} & \begin{tabular}{|l|l|}
8 & 205,41 \\
\end{tabular} & 15 & 280,15 & 235,94 & 33 & \begin{tabular}{l|l|}
3 & 300,38 \\
\end{tabular} & \begin{tabular}{|l|l}
820,46 \\
\end{tabular} \\
\hline Sao Bernardo do Camp & B1000 & 367 & 98,82 & 120,94 & 299 & 76,13 & 89,93 & 666 & 87,17 & 105,02 & 57 & 15,24 & 18,48 & 60 & 15,38 & 18,95 & 117 & 15,31 & \begin{tabular}{l|l|}
1 & 18,71 \\
\end{tabular} & 697 & \begin{tabular}{l|l|}
7 & 187,42 \\
\end{tabular} & 222,91 & 610 & 155,40 & | 195,77 & 1306 & \begin{tabular}{l|l|}
6 & 170,97 \\
\end{tabular} & 208,98 \\
\hline Sao Caetano do Sul & A300 & 163 & 256,96 & 158,53 & 131 & 180,90 & 108,32 & 294 & 216,45 & 131,79 & 23 & 36,71 & 22,69 & 33 & 45,57 & 25,78 & 56 & 41,43 & \begin{tabular}{|l|l|}
3 & 24,26 \\
\end{tabular} & 251 & \begin{tabular}{l|l|}
1 & 394,88 \\
\end{tabular} & $8 \mid \begin{array}{ll}831,23 \\
\end{array}$ & 249 & 343,85 & 5181,71 & 500 & \begin{tabular}{l|l|}
0 & 367,70 \\
\end{tabular} & \begin{tabular}{|l|l|}
204,86 \\
\end{tabular} \\
\hline Sao Carlos & B300 & 108 & 104,89 & 91,67 & 88 & 83,61 & 71,21 & 196 & 94,15 & 81,34 & 15 & 14,52 & 13,02 & 23 & 22,17 & \begin{tabular}{|l|}
19,15 \\
\end{tabular} & 38 & 18,38 & \begin{tabular}{|l|l|}
8 & 16,15 \\
\end{tabular} & 174 & \begin{tabular}{l|l|}
4 & 168,15 \\
\end{tabular} & $5 \mid 143,41$ & 160 & 152,33 & $\mid 126,70$ & 334 & \begin{tabular}{l|l|}
4 & 160,17 \\
\end{tabular} & \begin{tabular}{|l|l}
734,97 \\
\end{tabular} \\
\hline$\underline{\text { Sao Francisco }}$ & E20 & 1 & 87,55 & 48,76 & 1 & 89,89 & 90,35 & 3 & 88,70 & 69,28 & & & & 1 & 44,94 & 34,20 & 1 & 22,18 & \begin{tabular}{|l|l|}
8 & 14,24 \\
\end{tabular} & 3 & \begin{tabular}{l|l|}
3 & 175,09 \\
\end{tabular} & \begin{tabular}{l|l|}
9 & 99,11 \\
\end{tabular} & 3 & 179,78 & \begin{tabular}{|l|l|}
850,93 \\
\end{tabular} & 5 & \begin{tabular}{l|l|}
5 & 177,40 \\
\end{tabular} & \begin{tabular}{|l|l|}
124,68 \\
\end{tabular} \\
\hline Sao Joao da Boa Vista & B100 & 58 & 146,37 & 115,02 & 50 & 121,32 & 98,53 & 108 & 133,64 & \begin{tabular}{|l|}
106,63 \\
\end{tabular} & 8 & 19,24 & 15,32 & 10 & $25,07 \mid$ & \begin{tabular}{|l|}
19,06 \\
\end{tabular} & 18 & 22,20 & \begin{tabular}{|l|l|} 
& 17,21 \\
\end{tabular} & 90 & \begin{tabular}{l|l|}
0 & 226,67 \\
\end{tabular} & 7171,00 & 75 & 182,79 & 137,82 & 166 & \begin{tabular}{l|l|}
6 & 204,36 \\
\end{tabular} & \begin{tabular}{|l|l|}
5 & 154,13 \\
\end{tabular} \\
\hline Uuas Pont & E20 & 2 & 125,79 & 100,35 & 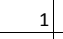 & 52,27 & 49,07 & -4 & 89,73 & 75,20 & 0 & 25,16 & 16,91 & & & & 0 & 12,82 & \begin{tabular}{|l|l|}
2 & 9,83 \\
\end{tabular} & 1 & 50,31 & 34,42 & 1 & 78,41 & 72,07 & & 64,09 & 2,89 \\
\hline & E20 & 0 & 38,02 & 20,43 & 1 & . & & 1 & 58,67 & 42,43 & 0 & 38,02 & 28,15 & 0 & 40,27 & 33,91 & 1 & 39,12 & \begin{tabular}{|l|l|}
2 & 31,13 \\
\end{tabular} & 1 & 152,09 & \begin{tabular}{l|l}
9 & 148,69 \\
\end{tabular} & 1 & 80,55 & 70,80 & & 17,35 & \begin{tabular}{|l|l|}
510,86 \\
\end{tabular} \\
\hline SaoJ & E20 & 2 & 242,55 & 118,76 & 1 & 142,86 & 88,65 & 4 & 193,46 & 103,93 & & & & 1 & 71,43 & 45,96 & 1 & 35,18 & \begin{tabular}{|l|l|}
82,32 \\
\end{tabular} & 3 & \begin{tabular}{l|l|}
3 & 277,20 \\
\end{tabular} & $\mid 135,67$ & & 321,43 & 228,57 & & 8,98 & $1.42>2>$ \\
\hline Sao Joaquim da Barra & C50 & 26 & 119,47 & 112,47 & 17 & 74,62 & 68,21 & 43 & 96,76 & 90,06 & 4 & 19,91 & 18,63 & 6 & 28,36 & 25,26 & 11 & 24,19 & \begin{tabular}{|l|l|}
9 & 22,08 \\
\end{tabular} & 61 & 1 1. 281,83 & \begin{tabular}{|l|}
3253,03 \\
\end{tabular} & 49 & 217,90 & | 194,73 & 110 & $\begin{array}{l}0 \\
0\end{array} 249,45$ & \begin{tabular}{|l|l}
523,50 \\
\end{tabular} \\
\hline Sao José da Bela Vista & E20 & 1 & 23,03 & 23,05 & 0 & 8,01 & 7,97 & 1 & 15,69 & 15,67 & 1 & 23,03 & 22,12 & & & & 1 & \begin{tabular}{|l|}
11,76 \\
\end{tabular} & \begin{tabular}{|l|l|}
5 & 11,64 \\
\end{tabular} & 9 & \begin{tabular}{l|l|}
9 & 199,63 \\
\end{tabular} & \begin{tabular}{|l|l|}
394,96 \\
\end{tabular} & 7 & 160,29 & 9171,00 & 15 & \begin{tabular}{|l|l|}
5 & 180,39 \\
\end{tabular} & \begin{tabular}{l|l}
9 & 183,23 \\
\end{tabular} \\
\hline Sao José do Barreiro & E20 & 4 & 166,04 & $\begin{array}{ll}438,63 \\
\end{array}$ & 1 & 65,74 & 56,00 & 5 & 118,02 & 99,07 & 1 & 30,19 & 27,56 & 1 & \begin{tabular}{|l|}
32,87 \\
\end{tabular} & 23,90 & 1 & \begin{tabular}{|l|}
31,47 \\
\end{tabular} & 26,17 & 4 & \begin{tabular}{|l|l|}
4 & 166,04 \\
\end{tabular} & \begin{tabular}{|l|l|}
4 & 133,17 \\
\end{tabular} & 4 & 213,64 & \begin{tabular}{|l|l|}
480,87 \\
\end{tabular} & 8 & \begin{tabular}{|l|l|}
8 & 188,83 \\
\end{tabular} & \begin{tabular}{|l|l|}
356,00 \\
\end{tabular} \\
\hline Sao José do Rio Pardo & D100 & 35 & 135,68 & 110,54 & 25 & 95,62 & 81,67 & 61 & 115,48 & 95,98 & 4 & 16,64 & 13,16 & 4 & 13,84 & 11,42 & 8 & 15,23 & \begin{tabular}{|l|l|} 
& 12,34 \\
\end{tabular} & 68 & \begin{tabular}{l|l|}
8 & 259,85 \\
\end{tabular} & 5200,80 & 63 & 236,54 & 485,66 & 130 & \begin{tabular}{ll|}
0 & 248,09 \\
\end{tabular} & \begin{tabular}{l|l}
9 & 193,16 \\
\end{tabular} \\
\hline Sao José do Rio Preto & B500 & 251 & 131,83 & 112,75 & 183 & 90,39 & 78,27 & 434 & 110,44 & 94,96 & 30 & 15,95 & 13,54 & 37 & \begin{tabular}{|l|}
18,08 \\
\end{tabular} & 15,41 & 67 & 17,05 & \begin{tabular}{|l|l|}
5 & 14,48 \\
\end{tabular} & 401 & \begin{tabular}{l|l|}
11 & 210,72 \\
\end{tabular} & \begin{tabular}{|l|l|}
2 & 173,6 \\
\end{tabular} & 384 & 189,49 & \begin{tabular}{|l|l|}
962,1 \\
\end{tabular} & 785 & $\begin{array}{llll}5 & 199,77 \\
\end{array}$ & 7) 167,74 \\
\hline
\end{tabular}


Anexo 23 - $\mathrm{N}^{\circ}$ de óbitos e taxa de mortalidade (bruta e padronizada) total e segundo sexo por Neoplasias, Diabetes Mellitus e Doenças do Aparelho Circulatório, municípios. Estado de São Paulo, média do triênio 2003-2005

\begin{tabular}{|c|c|c|c|c|c|c|c|c|c|c|c|c|c|c|c|c|c|c|c|c|c|c|c|c|c|c|c|c|}
\hline \multirow[b]{3}{*}{ Sao José dos Campos } & \multirow[b]{3}{*}{ B1000 } & \multicolumn{9}{|c|}{ Neoplasias Malignas } & \multicolumn{9}{|c|}{ Diabetes Mellitus } & \multicolumn{9}{|c|}{ Aparelho Circulatorio } \\
\hline & & \multicolumn{3}{|c|}{ Homens } & \multicolumn{3}{|c|}{ Mulheres } & \multicolumn{3}{|c|}{ Total } & \multicolumn{3}{|c|}{ Homens } & \multicolumn{3}{|c|}{ Mulheres } & \multicolumn{3}{|c|}{ Total } & \multicolumn{3}{|c|}{ Homens } & \multicolumn{3}{|c|}{ Mulheres } & \multicolumn{3}{|c|}{ Total } \\
\hline & & 239 & 83,14 & 101,90 & 220 & 74,64 & 92,68 & 459 & 78,84 & 97,24 & 38 & 13,08 & 16,50 & 54 & 18,32 & 23,89 & 92 & \begin{tabular}{l|l|}
2 & 15,73 \\
\end{tabular} & \begin{tabular}{|l|l|} 
& 20,24 \\
\end{tabular} & 332 & \begin{tabular}{l|l|}
2 & 115,22 \\
\end{tabular} & \begin{tabular}{|l|l|}
2 & 142,39 \\
\end{tabular} & 298 & \begin{tabular}{l|l|}
8 & 101,10 \\
\end{tabular} & 131,84 & 630 & \begin{tabular}{l|l|}
0 & 108,08 \\
\end{tabular} & \begin{tabular}{l|l}
137,05 \\
\end{tabular} \\
\hline Sao Lourenço da Serra & E20 & 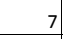 & 96,64 & 105,49 & 4 & 61,44 & 76,23 & 11 & 79,28 & 91,06 & 2 & 23,01 & 24,93 & & & & 2 & 11,66 & \begin{tabular}{|l|l|}
5 & 14,21 \\
\end{tabular} & 14 & \begin{tabular}{l|l|l|}
4 & 188,68 \\
\end{tabular} & \begin{tabular}{l|l}
8 & 190,86 \\
\end{tabular} & 13 & \begin{tabular}{l|l|}
3 & 184,33 \\
\end{tabular} & 268,63 & 27 & \begin{tabular}{l|l|}
7 & 186,53 \\
\end{tabular} & \begin{tabular}{|l|l|}
329,22 \\
\end{tabular} \\
\hline Sao Luis do Paraitinga & E20 & 5 & 90,50 & 66,70 & 4 & 84,46 & 74,80 & 9 & 87,59 & 70,60 & 3 & 48,27 & 33,64 & 0 & 6,50 & 5,38 & 3 & \begin{tabular}{|l|l|}
3 & 28,16 \\
\end{tabular} & \begin{tabular}{|l|l|}
51,87 \\
\end{tabular} & 14 & $4 \quad 259,43$ & \begin{tabular}{|c|}
168,89 \\
\end{tabular} & 10 & \begin{tabular}{l|l|}
0 & 194,92 \\
\end{tabular} & 269,65 & 24 & \begin{tabular}{l|l|}
4 & 228,37 \\
\end{tabular} & 169,26 \\
\hline Sao Manuel & D50 & 23 & 122,11 & 105,47 & 17 & 87,56 & 80,73 & 40 & 104,70 & 93,00 & 3 & 13,96 & 12,67 & 5 & 27,47 & 23,84 & 8 & \begin{tabular}{l|l|}
8 & 20,77 \\
\end{tabular} & 18,23 & 69 & \begin{tabular}{l|l|}
9 & 359,36 \\
\end{tabular} & $6 \quad 301,65$ & 61 & \begin{tabular}{l|l|}
1 & 314,20 \\
\end{tabular} & 272,78 & 130 & \begin{tabular}{l|l|}
0 & 336,60 \\
\end{tabular} & 287,10 \\
\hline Sao Miguel Arc & E50 & 17 & 98,04 & 100,92 & 12 & 73,99 & 92,14 & 29 & 86,30 & 96,63 & 6 & 33,34 & 33,42 & 6 & \begin{tabular}{|l|} 
\\
\end{tabular} & 45,80 & 12 & \begin{tabular}{|l|l|}
2 & 35,12 \\
\end{tabular} & \begin{tabular}{|l|l|}
2 & 39,26 \\
\end{tabular} & 21 & \begin{tabular}{l|l|}
1 & 123,54 \\
\end{tabular} & $\begin{array}{l}4 \mid 125,50 \\
\end{array}$ & 21 & \begin{tabular}{l|l|}
1 & 131,54 \\
\end{tabular} & \begin{tabular}{l|l|}
4 & 169,80 \\
\end{tabular} & 42 & \begin{tabular}{|l|l|}
2 & 127,44 \\
\end{tabular} & $\begin{array}{l}4147,13 \\
\end{array}$ \\
\hline Sao Paulo & 10000 & 6252 & \begin{tabular}{|l|}
121,63 \\
\end{tabular} & 121,60 & 5855 & 103,71 & 96,59 & 12108 & \begin{tabular}{|l|}
112,25 \\
\end{tabular} & 108,51 & 1014 & 19,72 & 19,75 & 1192 & 21,12 & 19,69 & 2206 & \begin{tabular}{|l|l|}
6 & 20,45 \\
\end{tabular} & \begin{tabular}{|l|l|}
5 & 19,63 \\
\end{tabular} & \begin{tabular}{|l|l|}
11022 \\
\end{tabular} & \begin{tabular}{|l|l|}
22 & 214,42 \\
\end{tabular} & \begin{tabular}{|l|l|}
2 & 207,84 \\
\end{tabular} & \begin{tabular}{|l|l|}
10633 \\
\end{tabular} & \begin{tabular}{|l|l|}
3 & 188,33 \\
\end{tabular} & \begin{tabular}{|l|l|}
372,75 \\
\end{tabular} & 21655 & \begin{tabular}{|l|l|}
5 & 200,76 \\
\end{tabular} & \begin{tabular}{|l|l|}
5 & 189,47 \\
\end{tabular} \\
\hline Sao Pedro & B50 & 24 & 153,17 & 111,36 & 18 & 113,24 & 96,40 & 42 & \begin{tabular}{|l|}
132,92 \\
\end{tabular} & \begin{tabular}{|l|} 
\\
\end{tabular} & 3 & 17,26 & 12,38 & 3 & 18,87 & $\mid 15,17$ & 6 & \begin{tabular}{|l|l|}
6 & 18,08 \\
\end{tabular} & \begin{tabular}{|l|l|}
8 & 13,85 \\
\end{tabular} & 32 & \begin{tabular}{|l|l|}
2 & 209,25 \\
\end{tabular} & \begin{tabular}{|l|l|}
5 & 146,98 \\
\end{tabular} & 26 & \begin{tabular}{|l|l|}
6 & 161,47 \\
\end{tabular} & \begin{tabular}{|l|l|}
7 & 124,40 \\
\end{tabular} & 58 & 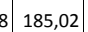 & 135,53 \\
\hline Sao Pedro do & E20 & 4 & 113,58 & 86,19 & 2 & 58,10 & 54,87 & 6 & 86,16 & 70,71 & 0 & 9,47 & 7,32 & 1 & 19,37 & 20,31 & 1 & \begin{tabular}{l|l|}
1 & 14,36 \\
\end{tabular} & \begin{tabular}{|l|l|}
5 & 13,44 \\
\end{tabular} & & \begin{tabular}{l|l|}
6 & 179,84 \\
\end{tabular} & $\begin{array}{l}435,09 \\
\end{array}$ & 7 & \begin{tabular}{l|l|}
7 & 213,03 \\
\end{tabular} & \begin{tabular}{|l|l|}
396,55 \\
\end{tabular} & 14 & \begin{tabular}{l|l|}
4 & 196,25 \\
\end{tabular} & \begin{tabular}{c|c}
5 & 165,47 \\
\end{tabular} \\
\hline Sao Roque & \begin{tabular}{|l|l|} 
& \\
\end{tabular} & 40 & \begin{tabular}{|l}
114,19 \\
\end{tabular} & 101,40 & 34 & 96,35 & 92,09 & 75 & 105,23 & 96,72 & 8 & 21,71 & \begin{tabular}{|l|}
19,47 \\
\end{tabular} & 16 & 45,84 & \begin{tabular}{|l|}
43,95 \\
\end{tabular} & 24 & \begin{tabular}{|l|l|}
4 & 33,82 \\
\end{tabular} & \begin{tabular}{|l|l|}
2 & 31,57 \\
\end{tabular} & 77 & \begin{tabular}{l|l|}
7 & 218,95 \\
\end{tabular} & \begin{tabular}{|l|l|}
5 & 191,84 \\
\end{tabular} & 67 & \begin{tabular}{l|l|}
7 & 188,96 \\
\end{tabular} & \begin{tabular}{|l|l|}
5 & 179,02 \\
\end{tabular} & 145 & \begin{tabular}{|l|l|}
5 & 203,89 \\
\end{tabular} & \begin{tabular}{l|l}
9 & 185,40 \\
\end{tabular} \\
\hline Sao Sebastiao & C100 & 33 & \begin{tabular}{|l|l|}
3 & 93,68 \\
\end{tabular} & 121,27 & 25 & 72,65 & 95,87 & 57 & 83,30 & 108,74 & 6 & 17,21 & \begin{tabular}{|l|}
22,96 \\
\end{tabular} & 5 & 15,71 & \begin{tabular}{|l|}
22,57 \\
\end{tabular} & 11 & \begin{tabular}{|l|l|}
1 & 16,47 \\
\end{tabular} & 22,89 & 40 & \begin{tabular}{l|l|}
0 & 114,71 \\
\end{tabular} & 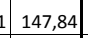 & 34 & \begin{tabular}{|l|l|}
4 & 101,12 \\
\end{tabular} & \begin{tabular}{|l|l|}
246,27 \\
\end{tabular} & 74 & \begin{tabular}{|l|l|}
4 & 108,00 \\
\end{tabular} & \begin{tabular}{|l|l|}
147,06 \\
\end{tabular} \\
\hline Sao Sebastiao da Grama & E20 & 7 & 108,08 & 91,53 & 6 & 90,44 & 87,11 & 13 & 99,41 & 89,36 & 1 & 15,44 & 12,72 & 3 & 42,56 & 40,90 & 4 & \begin{tabular}{l|l|l}
4 & 28,78 \\
\end{tabular} & \begin{tabular}{|l|l|}
8 & 25,79 \\
\end{tabular} & 20 & 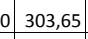 & 5239,89 & 14 & $4 \mathbf{S}^{223,45}$ & 209,50 & 34 & $\begin{array}{l}4{ }^{2} 264,22 \\
\end{array}$ & 224,95 \\
\hline Sao Simao & B20 & 9 & 120,45 & 97,97 & 7 & 96,76 & 80,86 & 16 & 108,57 & 89,39 & 3 & 46,33 & 39,01 & 4 & 50,68 & \begin{tabular}{|l|}
39,82 \\
\end{tabular} & 7 & \begin{tabular}{l|l|}
7 & 48,51 \\
\end{tabular} & 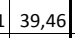 & 18 & \begin{tabular}{l|l|}
8 & 250,16 \\
\end{tabular} & 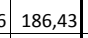 & 14 & 4 - 188,91 . & 147,50 & 32 & \begin{tabular}{l|l|}
2 & 219,46 \\
\end{tabular} & \begin{tabular}{|l|l|}
5 & 166,92 \\
\end{tabular} \\
\hline Sao Vicente & B500 & 164 & 106,18 & 113,01 & 143 & 87,20 & 87,93 & 308 & 96,40 & 100,09 & 34 & 21,97 & 23,44 & 39 & 23,93 & 24,20 & 73 & \begin{tabular}{|l|l|}
3 & 22,98 \\
\end{tabular} & \begin{tabular}{|l|l|} 
& 23,77 \\
\end{tabular} & 258 & $\begin{array}{ll}8 & 166,48 \\
\end{array}$ & \begin{tabular}{|l|l|}
8 & 175,76 \\
\end{tabular} & 227 & \begin{tabular}{l|l|}
7 & 137,89 \\
\end{tabular} & 139,76 & 484 & \begin{tabular}{|l|l|}
4 & 151,76 \\
\end{tabular} & \begin{tabular}{l|l}
5 & 157,22 \\
\end{tabular} \\
\hline Sarapuí & E20 & 3 & \begin{tabular}{|l|l|}
3 & 60,94 \\
\end{tabular} & 51,89 & 3 & 82,85 & 84,53 & 6 & 71,43 & 67,52 & 2 & 45,70 & 38,90 & 1 & 24,86 & 24,18 & 3 & \begin{tabular}{|l|l|}
3 & 35,72 \\
\end{tabular} & \begin{tabular}{|l|l|}
2 & 32,68 \\
\end{tabular} & 11 & \begin{tabular}{l|l|}
1. & 243,75 \\
\end{tabular} & $5 \mid 192,59$ & 6 & \begin{tabular}{l|l|}
6 & 157,42 \\
\end{tabular} & 2165,92 & 17 & \begin{tabular}{ll|}
7 & 202,40 \\
\end{tabular} & \begin{tabular}{|l|l|}
179,81 \\
\end{tabular} \\
\hline Sarutaiá & E20 & 2 & 98,07 & 74,96 & 1 & 66,00 & 56,39 & 3 & 82,11 & 65,72 & 1 & 32,69 & 24,59 & 2 & 82,49 & 67,82 & 2 & 57,47 & 46,09 & 12 & \begin{tabular}{l|l|}
2 & 588,43 \\
\end{tabular} & \begin{tabular}{|l|l|}
$3 \mid 445,40$ \\
\end{tabular} & 11 & $1 \quad 544,46$ & 5400,28 & 23 & \begin{tabular}{l|l|}
3 & 566,55 \\
\end{tabular} & \begin{tabular}{|l|l|}
522,94 \\
\end{tabular} \\
\hline Sebastianóp & E20 & 3 & 204,29 & 118,52 & & & & 3 & 104,34 & 60,54 & & & & & & & & & & 3 & $3 \quad 255,36$ & $6 \mid 160,22$ & 1 & $1 \quad 106,64$ & \begin{tabular}{|l|l|}
486,50 \\
\end{tabular} & 5 & \begin{tabular}{|l|l|}
5 & 182,60 \\
\end{tabular} & 124,15 \\
\hline Serra Azul & E20 & 6 & \begin{tabular}{|l|l}
147,23 \\
\end{tabular} & 143,20 & 2 & 59,24 & 66,44 & 8 & 103,98 & 105,47 & 1 & 32,72 & 32,85 & 1 & 16,93 & \begin{tabular}{|l|}
17,85 \\
\end{tabular} & 2 & \begin{tabular}{|l|l|}
2 & 24,96 \\
\end{tabular} & \begin{tabular}{|l|l|}
5 & 25,76 \\
\end{tabular} & 11 & \begin{tabular}{l|l|}
1 & 278,10 \\
\end{tabular} & \begin{tabular}{|l|l|}
0 & 275,78 \\
\end{tabular} & 5 & \begin{tabular}{l|l|}
5 & 135,41 \\
\end{tabular} & 147,31 & 17 & \begin{tabular}{|l|l|}
7 & 207,97 \\
\end{tabular} & 212,64 \\
\hline Serra Ne & D50 & 23 & \begin{tabular}{|l|l}
187,89 \\
\end{tabular} & 129,36 & 20 & 156,49 & 108,57 & 43 & 171,99 & 118,83 & 3 & 21,78 & 15,40 & 3 & 26,52 & 17,44 & 6 & \begin{tabular}{l|l|}
6 & 24,19 \\
\end{tabular} & \begin{tabular}{|l|l|}
9 & 16,44 \\
\end{tabular} & 35 & \begin{tabular}{l|l|}
5 & 288,65 \\
\end{tabular} & \begin{tabular}{|l|l|}
5 & 186,87 \\
\end{tabular} & 34 & $\begin{array}{l}4 \\
\text { | }\end{array}$ & $\begin{array}{l}476,60 \\
\end{array}$ & 69 & \begin{tabular}{l|l|}
9 & 279,48 \\
\end{tabular} & \begin{tabular}{|l|l}
8 & 181,67 \\
\end{tabular} \\
\hline Serrana & C50 & 13 & \begin{tabular}{|l|}
68,36 \\
\end{tabular} & 87,01 & 14 & \begin{tabular}{|l|} 
\\
\end{tabular} & 97,07 & 26 & 71,57 & 92,00 & 5 & 28,79 & \begin{tabular}{|l|}
34,28 \\
\end{tabular} & 3 & 18,25 & \begin{tabular}{|l|}
23,86 \\
\end{tabular} & 9 & \begin{tabular}{l|l|}
9 & 23,55 \\
\end{tabular} & \begin{tabular}{|l|l|}
5 & 29,26 \\
\end{tabular} & 33 & \begin{tabular}{l|l|}
3 & 178,11 \\
\end{tabular} & \begin{tabular}{|l|} 
\\
\end{tabular} 225,95 & 20 & \begin{tabular}{l|l|}
0 & 109,48 \\
\end{tabular} & \begin{tabular}{|l|l|}
853,92 \\
\end{tabular} & 53 & \begin{tabular}{|l|l|}
3 & 144,04 \\
\end{tabular} & \begin{tabular}{l|l}
4 & 190,19 \\
\end{tabular} \\
\hline Sertaozinho & сзо0 & 57 & 112,22 & 121,07 & 36 & 70,39 & 77,28 & 93 & 91,39 & 99,27 & 5 & 10,44 & 11,23 & 8 & 15,79 & 17,40 & 13 & \begin{tabular}{|l|l|}
3 & 13,10 \\
\end{tabular} & \begin{tabular}{|l|l|}
0 & 14,31 \\
\end{tabular} & 107 & \begin{tabular}{|l|l|}
7 & 208,78 \\
\end{tabular} & \begin{tabular}{|l|l|}
8 & 219,31 \\
\end{tabular} & 86 & \begin{tabular}{|l|l|}
6 & 170,39 \\
\end{tabular} & \begin{tabular}{|l|}
9191,77 \\
\end{tabular} & 193 & \begin{tabular}{|l|l|}
3 & 189,66 \\
\end{tabular} & \begin{tabular}{|l|l}
5 & 205,60 \\
\end{tabular} \\
\hline Sete Barras & E20 & 7 & 89,54 & 82,01 & 3 & 44,14 & 49,58 & 10 & 67,87 & 66,53 & 2 & 26,86 & \begin{tabular}{|l|}
25,27 \\
\end{tabular} & 3 & 44,14 & \begin{tabular}{|l|}
50,17 \\
\end{tabular} & 5 & 35,11 & \begin{tabular}{|l|l|}
1 & 35,72 \\
\end{tabular} & 10 & \begin{tabular}{l|l|}
0 & 138,78 \\
\end{tabular} & \begin{tabular}{|l|l|}
8 & 125,89 \\
\end{tabular} & 10 & \begin{tabular}{|l|l|}
0 & 147,13 \\
\end{tabular} & \begin{tabular}{|l|l|}
371,39 \\
\end{tabular} & 20 & \begin{tabular}{|l|l|}
0 & 142,77 \\
\end{tabular} & \begin{tabular}{|l|l|}
7 & 147,60 \\
\end{tabular} \\
\hline Severinia & E20 & 5 & 59,50 & 63,48 & 2 & 32,20 & 35,44 & 7 & 46,39 & 50,01 & 1 & 12,75 & 14,01 & 2 & 27,60 & \begin{tabular}{|l|}
30,76 \\
\end{tabular} & 3 & \begin{tabular}{|l|l|}
3 & 19,88 \\
\end{tabular} & \begin{tabular}{|l|}
822,11 \\
\end{tabular} & 16 & \begin{tabular}{|l|l|}
6 & 208,24 \\
\end{tabular} & \begin{tabular}{|l|l|}
4 & 227,00 \\
\end{tabular} & 13 & \begin{tabular}{|l|l|}
3 & 174,79 \\
\end{tabular} & 202,47 & 29 & \begin{tabular}{l|l|}
9 & 192,18 \\
\end{tabular} & \begin{tabular}{l|l}
815,22 \\
\end{tabular} \\
\hline Silveiras & E20 & 3 & 104,47 & 80,13 & & & & 3 & 53,71 & 41,19 & 0 & 11,61 & 8,72 & 1 & 24,56 & \begin{tabular}{|l|}
22,53 \\
\end{tabular} & 1 & \begin{tabular}{|l|l|}
1 & 17,90 \\
\end{tabular} & \begin{tabular}{|l|} 
\\
\end{tabular} & 7 & \begin{tabular}{l|l|}
7 & 232,15 \\
\end{tabular} & \begin{tabular}{|l|l|}
5 & 172,73 \\
\end{tabular} & 6 & \begin{tabular}{|l|l|}
6 & 221,05 \\
\end{tabular} & $5 \mid 212,71$ & 13 & \begin{tabular}{|l|l|}
3 & 226,76 \\
\end{tabular} & \begin{tabular}{l|l}
5 & 192,16 \\
\end{tabular} \\
\hline Socorro & D50 & 28 & 166,96 & 105,76 & 23 & 138,88 & 104,85 & 51 & 152,91 & 105,30 & 7 & 41,74 & 27,04 & 8 & 47,61 & \begin{tabular}{|l|}
36,07 \\
\end{tabular} & 15 & 44,68 & \begin{tabular}{|l|l|}
8 & 31,71 \\
\end{tabular} & 53 & \begin{tabular}{|l|l|}
3 & 316,03 \\
\end{tabular} & \begin{tabular}{|l|l|}
3 & 203,63 \\
\end{tabular} & 42 & \begin{tabular}{|l|l|}
2 & 249,98 \\
\end{tabular} & \begin{tabular}{|l|l|}
8 & 180,68 \\
\end{tabular} & 95 & \begin{tabular}{|l|l|}
5 & 282,97 \\
\end{tabular} & \begin{tabular}{|l|l}
7 & 192,14 \\
\end{tabular} \\
\hline Sorocaba & B1000 & 280 & 104,50 & 108,29 & 229 & 82,65 & 83,15 & 509 & 93,40 & 95,52 & 62 & 23,01 & \begin{tabular}{|r|}
23,92 \\
\end{tabular} & 73 & 26,27 & \begin{tabular}{|l|}
26,43 \\
\end{tabular} & 134 & \begin{tabular}{l|l|}
4 & 24,67 \\
\end{tabular} & 25,21 & 473 & \begin{tabular}{l|l|}
3 & 176,41 \\
\end{tabular} & \begin{tabular}{|l|}
178,54 \\
\end{tabular} & 464 & \begin{tabular}{|l|l|}
4 & 167,60 \\
\end{tabular} & \begin{tabular}{|l|} 
\\
\end{tabular} & 936 & \begin{tabular}{|l|l|}
6 & 171,93 \\
\end{tabular} & \begin{tabular}{l|l} 
B & 173,21
\end{tabular} \\
\hline Sud Mennu & E20 & 3 & 79,12 & 70,03 & 1 & 36,58 & 34,70 & 4 & 58,27 & 52,72 & 1 & 26,37 & 25,18 & -1 & 36,58 & \begin{tabular}{|l|}
38,17 \\
\end{tabular} & 2 & 31,37 & \begin{tabular}{|l|}
71,53 \\
\end{tabular} & & \begin{tabular}{|l|l|}
8 & 202,20 \\
\end{tabular} & \begin{tabular}{|l|l|}
0 & 174,98 \\
\end{tabular} & 6 & \begin{tabular}{|l|l|}
6 & 164,61 \\
\end{tabular} & 170,62 & 14 & \begin{tabular}{|l|l|}
4 & 183,77 \\
\end{tabular} & \begin{tabular}{|l|l|}
7 & 172,84 \\
\end{tabular} \\
\hline Sumaré & C300 & 82 & 74,04 & 94,88 & 55 & 50,12 & 69,06 & 138 & 62,12 & 82,02 & 8 & 6,89 & 8,38 & 12 & 11,17 & 16,18 & 20 & 9,02 & \begin{tabular}{|l|} 
\\
\end{tabular} & 108 & \begin{tabular}{|l|l|}
8 & 97,42 \\
\end{tabular} & \begin{tabular}{|l|l|}
2123,14 \\
\end{tabular} & 93 & \begin{tabular}{|l|l|}
3 & 83,93 \\
\end{tabular} & \begin{tabular}{|l|l|}
323,88 \\
\end{tabular} & 201 & \begin{tabular}{|l|l|}
1 & 90,70 \\
\end{tabular} & \begin{tabular}{|l|}
123,51 \\
\end{tabular} \\
\hline Suzanápol & E20 & 2 & 136,02 & 85,51 & 2 & 48,01 & 41,05 & t & 93,27 & 63,91 & & & & 1 & 48,01 & \begin{tabular}{|l|}
38,73 \\
\end{tabular} & 1 & 23,32 & \begin{tabular}{|l|l|} 
& 16,41 \\
\end{tabular} & 3 & \begin{tabular}{|l|l|}
3 & 204,04 \\
\end{tabular} & \begin{tabular}{|l|l|}
4 & 110,87 \\
\end{tabular} & 4 & \begin{tabular}{l|l|}
4 & 288,05 \\
\end{tabular} & 5228,57 & 7 & 244,84 & \begin{tabular}{l|l|}
4 & 168,04 \\
\end{tabular} \\
\hline Suzano & C300 & 99 & 76,66 & 102,98 & 82 & 62,76 & 83,14 & 181 & 69,64 & 92,97 & 28 & 22,01 & 28,77 & 33 & 24,90 & 35,25 & 61 & \begin{tabular}{|l|l|}
1 & 23,47 \\
\end{tabular} & \begin{tabular}{|l|}
32,04 \\
\end{tabular} & 162 & \begin{tabular}{|l|l|}
2 & 126,13 \\
\end{tabular} & \begin{tabular}{|l|l|}
368,88 \\
\end{tabular} & 142 & \begin{tabular}{|l|l|}
2 & 107,99 \\
\end{tabular} & \begin{tabular}{|l|l|}
158,59 \\
\end{tabular} & 304 & \begin{tabular}{|l|l|}
44 & 116,97 \\
\end{tabular} & \begin{tabular}{|l|l}
7163,68 \\
\end{tabular} \\
\hline Tabapua & E20 & 11 & $202,64 \mid$ & 138,61 & 3 & 50,28 & 37,99 & 14 & 127,34 & 88,88 & 1 & 18,42 & 11,30 & 3 & 50,28 & \begin{tabular}{|l|}
36,88 \\
\end{tabular} & 4 & \begin{tabular}{l|l|}
4 & 34,17 \\
\end{tabular} & \begin{tabular}{|l|}
73,38 \\
\end{tabular} & 14 & \begin{tabular}{l|l|}
4 & 264,05 \\
\end{tabular} & \begin{tabular}{|l|l|}
5 & 179,51 \\
\end{tabular} & 19 & \begin{tabular}{l|l|}
9 & 351,94 \\
\end{tabular} & 4261,55 & 33 & \begin{tabular}{|l|l|}
3 & 307,48 \\
\end{tabular} & \begin{tabular}{|l|l}
820,05 \\
\end{tabular} \\
\hline Tabatinga & E20 & 7 & 103,46 & 91,54 & 5 & 77,48 & 76,68 & 13 & 90,66 & 84,22 & 1 & \begin{tabular}{|l|}
14,11 \\
\end{tabular} & 11,48 & 3 & 43,58 & 40,04 & 4 & \begin{tabular}{|l|l|}
4 & 28,63 \\
\end{tabular} & \begin{tabular}{|l|l|}
3 & 25,15 \\
\end{tabular} & 15 & \begin{tabular}{|l|l|}
5 & 211,62 \\
\end{tabular} & \begin{tabular}{|l|l|}
2 & 182,54 \\
\end{tabular} & 18 & \begin{tabular}{|l|l|}
8 & 256,66 \\
\end{tabular} & $5 \quad 234,61$ & 33 & \begin{tabular}{|l|l|}
3 & 233,81 \\
\end{tabular} & 208,20 \\
\hline Taboao da & C300 & 98 & 94,41 & 139,92 & 103 & 92,82 & \begin{tabular}{|l|}
131,80 \\
\end{tabular} & 201 & 93,59 & 135,72 & 18 & \begin{tabular}{|l|}
17,40 \\
\end{tabular} & 26,78 & 17 & 15,32 & \begin{tabular}{|l|}
24,22 \\
\end{tabular} & 35 & \begin{tabular}{|l|l|}
5 & 16,32 \\
\end{tabular} & \begin{tabular}{|l|}
25,38 \\
\end{tabular} & 188 & \begin{tabular}{|l|l|}
8 & 182,05 \\
\end{tabular} & \begin{tabular}{|l|l|}
5 & 279,51 \\
\end{tabular} & 172 & \begin{tabular}{|l|l|}
2 & 155,00 \\
\end{tabular} & 245,99 & 360 & \begin{tabular}{|l|l|}
0 & 168,05 \\
\end{tabular} & \begin{tabular}{|l|}
5262,16 \\
\end{tabular} \\
\hline Taciba & E20 & 1 & 48,24 & 38,62 & 2 & 87,45 & 90,72 & 4 & 67,50 & 64,22 & & & & & & & & & & & \begin{tabular}{|l|}
253,26 \\
\end{tabular} & \begin{tabular}{|l|l|}
6 & 196,71 \\
\end{tabular} & 2 & 87,45 & \begin{tabular}{|l|l|}
5 & 86,39 \\
\end{tabular} & 9 & \begin{tabular}{|l|l|}
9 & 171,81 \\
\end{tabular} & \begin{tabular}{l|l}
1142,52 \\
\end{tabular} \\
\hline Tague & E20 & 3 & 83,10 & 70,97 & 4 & 93,51 & $3,23 \mid$ & . & 88,25 & 81,97 & 1 & 16,62 & \begin{tabular}{|r|}
14,68 \\
\end{tabular} & & 17,00 & \begin{tabular}{|l|}
6,92 \\
\end{tabular} & & 16,81 & \begin{tabular}{|l|l|}
1 & 15,87 \\
\end{tabular} & 13 & \begin{tabular}{l|l|}
3 & 324,11 \\
\end{tabular} & $\begin{array}{l}1278,77 \\
\end{array}$ & 6 & \begin{tabular}{l|l|}
6 & 144,52 \\
\end{tabular} & 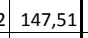 & 19 & \begin{tabular}{l|l|}
9 & 235,33 \\
\end{tabular} & \begin{tabular}{l|l}
213,89 \\
\end{tabular} \\
\hline Taiaçı & E20 & 4 & 122,77 & 104,18 & 2 & 80,47 & 87,95 & 6 & 101,93 & 96,18 & 1 & \begin{tabular}{|l|}
44,64 \\
\end{tabular} & \begin{tabular}{|l|}
33,52 \\
\end{tabular} & & & & 1 & 22,65 & \begin{tabular}{|l|l|}
5 & 17,98 \\
\end{tabular} & 6 & \begin{tabular}{l|l|}
6 & 200,89 \\
\end{tabular} & \begin{tabular}{|l|l|}
948,11 \\
\end{tabular} & 5 & \begin{tabular}{|l|l|}
5 & 172,43 \\
\end{tabular} & \begin{tabular}{|l|l|}
345,58 \\
\end{tabular} & 11 & \begin{tabular}{l|l|}
1 & 186,87 \\
\end{tabular} & \begin{tabular}{|l|l|}
746,87 \\
\end{tabular} \\
\hline Taiúva & E20 & 8 & 295,44 & 200,59 & 2 & 82,94 & 63,03 & 11 & \begin{tabular}{|l|}
189,33 \\
\end{tabular} & 131,90 & 1 & \begin{tabular}{|l|}
23,64 \\
\end{tabular} & 14,64 & 0 & 11,85 & 7,66 & 1 & 17,75 & \begin{tabular}{|l|l|}
51,28 \\
\end{tabular} & & \begin{tabular}{|l|l|}
7 & 248,17 \\
\end{tabular} & \begin{tabular}{|l|l|}
770,38 \\
\end{tabular} & 4 & \begin{tabular}{|l|l|}
4 & 130,33 \\
\end{tabular} & \begin{tabular}{|l|l|}
3 & 87,97 \\
\end{tabular} & 11 & \begin{tabular}{|l|l|}
1 & 189,33 \\
\end{tabular} & \begin{tabular}{l|l}
3 & 129,23 \\
\end{tabular} \\
\hline Tambaú & D50 & 15 & 130,01 & 110,07 & 8 & 72,24 & 67,29 & 24 & 101,44 & 88,91 & 1 & 5,65 & 4,82 & 1 & 8,67 & 7,56 & 2 & 7,14 & \begin{tabular}{l|l|}
4 & 6,12 \\
\end{tabular} & 21 & \begin{tabular}{l|l|}
1 & 175,23 \\
\end{tabular} & \begin{tabular}{|l|l|}
330,17 \\
\end{tabular} & 24 & \begin{tabular}{|l|l|}
4 & 210,93 \\
\end{tabular} & \begin{tabular}{|l|l|} 
& 185,94 \\
\end{tabular} & 45 & \begin{tabular}{|l|l|}
5 & 192,88 \\
\end{tabular} & \begin{tabular}{l|l}
8 & 157,75 \\
\end{tabular} \\
\hline Tanabi & D50 & 15 & 134,22 & 97,72 & 12 & 103,06 & 77,48 & 27 & 118,50 & 87,51 & 2 & \begin{tabular}{|l|}
14,59 \\
\end{tabular} & 10,07 & 3 & \begin{tabular}{|l|}
28,63 \\
\end{tabular} & \begin{tabular}{|l|}
20,98 \\
\end{tabular} & 5 & \begin{tabular}{|l|l|}
5 & 21,68 \\
\end{tabular} & \begin{tabular}{|l|l|}
8 & 15,42 \\
\end{tabular} & 23 & \begin{tabular}{|l|l|}
3 & 198,42 \\
\end{tabular} & \begin{tabular}{|l|l|}
2 & 134,16 \\
\end{tabular} & 23 & \begin{tabular}{|l|l|}
3 & 200,40 \\
\end{tabular} & \begin{tabular}{|l|}
146,17 \\
\end{tabular} & 46 & \begin{tabular}{|l|l|}
6 & 199,42 \\
\end{tabular} & \begin{tabular}{|l|l|}
2140,22 \\
\end{tabular} \\
\hline Tapirai & E20 & 4 & 85,53 & 83,53 & 3 & 55,91 & 67,57 & 7 & 71,17 & 75,79 & 0 & 6,58 & 6,03 & 2 & 48,92 & 58,23 & 3 & \begin{tabular}{|l|l|}
3 & 27,11 \\
\end{tabular} & 28,41 & 1 & \begin{tabular}{l|l|}
7 & 144,75 \\
\end{tabular} & \begin{tabular}{|l|l|}
5 & 138,38 \\
\end{tabular} & 5 & 97,84 & $4 \quad 119,36$ & 12 & \begin{tabular}{|l|l|}
2 & 122,00 \\
\end{tabular} & \begin{tabular}{|l|l|} 
& 129,16 \\
\end{tabular} \\
\hline Tapiratiba & D20 & 6 & \begin{tabular}{|l|l} 
\\
\end{tabular} & 85,90 & 5 & \begin{tabular}{|l|}
78,71 \\
\end{tabular} & \begin{tabular}{|l|}
76,75 \\
\end{tabular} & 12 & 86,72 & 81,29 & 2 & 24,96 & 21,86 & 5 & \begin{tabular}{|l|}
73,79 \\
\end{tabular} & 71,71 & 7 & \begin{tabular}{|l|}
49,56 \\
\end{tabular} & \begin{tabular}{|l|l|}
5 & 45,00 \\
\end{tabular} & 18 & \begin{tabular}{l|l|}
8 & 264,58 \\
\end{tabular} & \begin{tabular}{|l|l|}
8 & 228,61 \\
\end{tabular} & 12 & \begin{tabular}{|l|l|}
2 & 172,18 \\
\end{tabular} & \begin{tabular}{|l|l|}
8 & 163,56 \\
\end{tabular} & 29 & \begin{tabular}{l|l|}
9 & 218,04 \\
\end{tabular} & \begin{tabular}{l|l}
4 & 195,85 \\
\end{tabular} \\
\hline
\end{tabular}


Anexo 23 - $\mathrm{N}^{\circ}$ de óbitos e taxa de mortalidade (bruta e padronizada) total e segundo sexo por Neoplasias, Diabetes Mellitus e Doenças do Aparelho Circulatório, municípios. Estado de São Paulo, média do triênio 2003-2005

\begin{tabular}{|c|c|c|c|c|c|c|c|c|c|c|c|c|c|c|c|c|c|c|c|c|c|c|c|c|c|c|c|c|}
\hline \multirow[b]{3}{*}{ Taquaral } & \multirow[b]{3}{*}{ E20 } & \multicolumn{9}{|c|}{ Neoplasias Malignas } & \multicolumn{9}{|c|}{ Diabetes Mellitus } & \multicolumn{9}{|c|}{ Aparelho Circulatorio } \\
\hline & & \multicolumn{3}{|c|}{ Homens } & \multicolumn{3}{|c|}{ Mulheres } & \multicolumn{3}{|c|}{ Total } & \multicolumn{3}{|c|}{ Homens } & \multicolumn{3}{|c|}{ Mulheres } & \multicolumn{3}{|c|}{ Total } & \multicolumn{3}{|c|}{ Homens } & \multicolumn{3}{|c|}{ Mulheres } & \multicolumn{3}{|c|}{ Total } \\
\hline & & 1 & 68,06 & 57,42 & 0 & 24,15 & 18,22 & 1 & 46,79 & 38,44 & 0 & 22,69 & 19,77 & & & & 0 & 11,70 & 10,05 & 3 & 181,49 & \begin{tabular}{l|l|}
9 & 163,87 \\
\end{tabular} & 3 & 193,24 & 467,01 & & 187,18 & \begin{tabular}{l|l}
8165,39 \\
\end{tabular} \\
\hline Taquartitinga & D100 & 37 & 135,64 & 116,09 & 23 & 84,45 & 74,32 & 60 & 110,37 & 95,47 & 4 & 14,53 & 13,09 & 4 & 16,14 & 14,88 & 8 & 15,33 & 34,00 & 54 & 197,41 & 163,32 & 54 & 201,19 & 163,23 & 108 & \begin{tabular}{|l|l|}
899,28 \\
\end{tabular} & \begin{tabular}{|l|l|}
8 & 163,28 \\
\end{tabular} \\
\hline Taquarituba & E50 & 10 & 81,71 & 76,59 & 9 & 74,15 & 77,09 & 18 & 77,95 & 76,84 & 4 & 33,81 & 31,73 & 4 & 37,08 & 37,57 & 8 & 35,43 & \begin{tabular}{|l|l|}
34,62 \\
\end{tabular} & 22 & 188,77 & 769,06 & 18 & 151,15 & 156,77 & 40 & \begin{tabular}{l|l|}
0 & 170,08 \\
\end{tabular} & \begin{tabular}{l|l}
8162,95 \\
\end{tabular} \\
\hline Taquarivaí & E20 & 3 & 115,36 & 135,75 & 1 & 26,72 & 40,42 & 4 & 71,96 & 89,08 & 0 & 12,82 & 15,70 & 0 & 13,36 & 20,46 & 1 & 13,08 & \begin{tabular}{|l|l|} 
& 16,67 \\
\end{tabular} & 2 & 76,90 & \begin{tabular}{|l|l|}
0 & 98,10 \\
\end{tabular} & 3 & 120,26 & $5 \mid 95,28$ & 5 & \begin{tabular}{l|l|l}
5 & 98,13 \\
\end{tabular} & \begin{tabular}{l|l} 
B & 145,68 \\
\end{tabular} \\
\hline Tarabai & E20 & 3 & 94,51 & 90,39 & 3 & 86,26 & 92,54 & 6 & 90,44 & 91,45 & 1 & 21,00 & 19,15 & & & & 1 & 10,64 & $4 \quad 10,62$ & 8 & 262,52 & \begin{tabular}{|l|l|}
209,72 \\
\end{tabular} & 5 & 172,53 & $3 \mid 185,41$ & 14 & \begin{tabular}{|l|l|}
4 & 218,12 \\
\end{tabular} & \begin{tabular}{|l|l|} 
& 197,73 \\
\end{tabular} \\
\hline Taruma & D20 & 6 & 103,85 & 123,31 & 3 & 60,73 & 73,63 & 9 & 82,85 & 99,11 & 1 & 17,31 & 20,37 & 1 & 24,29 & 29,66 & , & 20,71 & 24,86 & 9 & 155,78 & \begin{tabular}{|l|l|}
879,16 \\
\end{tabular} & 11 & 194,34 & 4241,79 & 20 & \begin{tabular}{|l|l|}
0 & 174,57 \\
\end{tabular} & \begin{tabular}{|l|}
709,67 \\
\end{tabular} \\
\hline Tatuí & с300 & 52 & 101,99 & 93,90 & 41 & 79,67 & 77,53 & 92 & 90,79 & 85,69 & 12 & 24,35 & 22,80 & 15 & 30,04 & 29,09 & 28 & 27,20 & 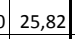 & 99 & 194,77 & 7175,79 & 87 & 171,09 & \begin{tabular}{|l|l|}
965,92 \\
\end{tabular} & 186 & \begin{tabular}{l|l|}
6 & 182,89 \\
\end{tabular} & \begin{tabular}{|l|l|}
9 & 170,84 \\
\end{tabular} \\
\hline Taubaté & B300 & 132 & 102,47 & 105,63 & 120 & 90,46 & 89,38 & 251 & 96,38 & 97,38 & 23 & 18,16 & 18,87 & 40 & 30,24 & 30,22 & 63 & 24,29 & \begin{tabular}{|l|l|}
9 & 24,71 \\
\end{tabular} & 239 & 186,00 & | 189,91 & 251 & 189,49 & \begin{tabular}{ll|}
9 & 185,98 \\
\end{tabular} & 490 & \begin{tabular}{l|l|}
0 & 187,77 \\
\end{tabular} & 187,92 \\
\hline Tejupá & E20 & 3 & 113,12 & 127,32 & 2 & 62,67 & 86,07 & 5 & 89,19 & 107,75 & 0 & 11,31 & 13,19 & & & & 0 & 5,95 & \begin{tabular}{|l|l|}
5 & 7,02 \\
\end{tabular} & 5 & 169,68 & \begin{tabular}{|l|l|}
8 & 196,64 \\
\end{tabular} & 5 & 175,48 & \begin{tabular}{|l|l|}
8 & 246,34 \\
\end{tabular} & 10 & \begin{tabular}{l|l|}
0 & 172,43 \\
\end{tabular} & \begin{tabular}{|l|l}
3 & 220,22 \\
\end{tabular} \\
\hline Teodoro Sampaio & D50 & 10 & 94,11 & 91,08 & 6 & 62,04 & 75,32 & 16 & 78,13 & 83,22 & 2 & 16,23 & 16,70 & 4 & 35,92 & 44,31 & 5 & 26,04 & \begin{tabular}{l|l|}
4 & 28,29 \\
\end{tabular} & 16 & 152,53 & \begin{tabular}{|l|l|}
3 & 133,62 \\
\end{tabular} & 16 & 160,00 & 209,60 & 32 & \begin{tabular}{l|l|}
2 & 156,25 \\
\end{tabular} & \begin{tabular}{l|l}
51,49 \\
\end{tabular} \\
\hline Terra Roxa & E20 & 4 & 87,15 & 74,09 & 5 & 131,84 & 119,17 & 9 & 109,06 & 96,19 & 1 & 15,85 & 13,19 & 1 & 24,72 & 21,52 & 2 & 20,19 & \begin{tabular}{|l|}
$\mid 17,27$ \\
\end{tabular} & 8 & 182,22 & \begin{tabular}{|l|l|}
2 & 142,42 \\
\end{tabular} & 9 & 230,72 & \begin{tabular}{|l|l|} 
& 196,08 \\
\end{tabular} & 17 & $\begin{array}{l}7 \quad 205,99 \\
\end{array}$ & \begin{tabular}{l|l}
9 & 168,72 \\
\end{tabular} \\
\hline Tietê & B50 & 25 & 146,77 & 123,08 & 21 & 118,09 & 98,48 & 46 & 132,33 & 110,69 & 3 & 15,45 & 12,44 & 3 & 15,24 & 12,45 & 5 & 15,34 & $\begin{array}{ll}4 & 12,41 \\
\end{array}$ & 37 & 216,30 & \begin{tabular}{|l|l|}
0 & 173,98 \\
\end{tabular} & 37 & 211,42 & 2163,99 & 74 & \begin{tabular}{l|l|}
4 & 213,84 \\
\end{tabular} & \begin{tabular}{l|l}
4 & 168,95 \\
\end{tabular} \\
\hline Timburi & E20 & 2 & 121,12 & 83,86 & 0 & 25,65 & 15,95 & 2 & 74,75 & 50,88 & 1 & 48,45 & 32,06 & 2 & \begin{tabular}{|l|}
128,24 \\
\end{tabular} & 101,23 & 2 & \begin{tabular}{|l|}
87,19 \\
\end{tabular} & \begin{tabular}{|l|l|}
9 & 65,27 \\
\end{tabular} & 3 & 193,80 & \begin{tabular}{|l|l|}
0 & 133,94 \\
\end{tabular} & 5 & 410,36 & \begin{tabular}{|l|l|}
5 & 315,96 \\
\end{tabular} & 8 & \begin{tabular}{|l|l|}
8 & 298,99 \\
\end{tabular} & \begin{tabular}{l|l}
222,35 \\
\end{tabular} \\
\hline Torre de Ped & E20 & 1 & 103,28 & 46,59 & 2 & 132,52 & 100,91 & 3 & 117,71 & 73,40 & & & & 1 & 53,01 & 39,43 & 1 & 26,15 & \begin{tabular}{|l|l|}
5 & 15,74 \\
\end{tabular} & 3 & 258,20 & \begin{tabular}{|l|l|}
0 & 139,91 \\
\end{tabular} & 3 & 238,54 & \begin{tabular}{|l|l|}
482,35 \\
\end{tabular} & 6 & \begin{tabular}{l|l|}
6 & 248,50 \\
\end{tabular} & \begin{tabular}{|l|l|} 
& 160,85 \\
\end{tabular} \\
\hline Torrinha & E20 & 5 & 104,58 & 66,45 & 5 & 107,50 & 76,04 & 10 & 106,02 & 71,18 & 1 & 20,92 & 17,28 & 2 & 50,17 & 35,49 & 3 & \begin{tabular}{|l|}
35,34 \\
\end{tabular} & \begin{tabular}{|l|l|}
4 & 25,59 \\
\end{tabular} & 9 & 181,27 & \begin{tabular}{|l|l|}
7 & 125,55 \\
\end{tabular} & 13 & 272,34 & \begin{tabular}{|l|l|}
4 & 177,94 \\
\end{tabular} & 21 & \begin{tabular}{|l|l|}
1 & 226,18 \\
\end{tabular} & \begin{tabular}{l|l}
81,39 \\
8
\end{tabular} \\
\hline Trabiju & E20 & & & & & & & & & & 1 & 88,22 & 61,99 & 0 & 48,90 & 50,25 & 1 & \begin{tabular}{|r|}
69,59 \\
\end{tabular} & \begin{tabular}{|l|l|} 
& 59,09 \\
\end{tabular} & 2 & 308,78 & \begin{tabular}{|l|l|}
8 & 227,22 \\
\end{tabular} & & & & 2 & \begin{tabular}{l|l|}
2 & 162,34 \\
\end{tabular} & \begin{tabular}{l|l}
4 & 119,46 \\
\end{tabular} \\
\hline Tremembé & B50 & 14 & 68,99 & 84,62 & 13 & 69,40 & 77,44 & 26 & 69,19 & 81,18 & 5 & 26,92 & 33,36 & 7 & 38,35 & 44,08 & 12 & 32,40 & \begin{tabular}{|l|l|}
0 & 38,74 \\
\end{tabular} & 31 & 156,48 & \begin{tabular}{|l|l|}
8 & 189,95 \\
\end{tabular} & 23 & 127,84 & \begin{tabular}{ll|}
442,01 \\
\end{tabular} & 54 & \begin{tabular}{|l|l|}
4 & 142,75 \\
\end{tabular} & \begin{tabular}{|l|l}
5 & 166,96 \\
\end{tabular} \\
\hline Três Froteir & E20 & 3 & 128,12 & 72,12 & 3 & 116,70 & 79,48 & 6 & 122,45 & 75,77 & & & & 0 & 12,97 & 8,45 & 0 & 6,44 & \begin{tabular}{|l|l|}
4 & 3,92 \\
\end{tabular} & 5 & 205,00 & \begin{tabular}{|l|l|}
0 & 112,06 \\
\end{tabular} & 3 & 103,73 & \begin{tabular}{|l|l|}
3 & 73,44 \\
\end{tabular} & 8 & \begin{tabular}{l|l|}
8 & 154,67 \\
\end{tabular} & \begin{tabular}{l|l}
7 & 92,87 \\
\end{tabular} \\
\hline Tuiuti & E20 & 5 & 169,57 & \begin{tabular}{|l|}
122,88 \\
\end{tabular} & 3 & 128,72 & 105,69 & 8 & 149,77 & 114,55 & 0 & 12,11 & 11,49 & & & & 0 & 6,24 & \begin{tabular}{l|l|}
4 & 6,05 \\
\end{tabular} & 9 & 314,92 & \begin{tabular}{|l|l|}
2 & 199,78 \\
\end{tabular} & 6 & 231,69 & \begin{tabular}{|l|}
95,35 \\
\end{tabular} & 15 & \begin{tabular}{|l|l|}
5 & 274,57 \\
\end{tabular} & \begin{tabular}{|l|l|}
797,63 \\
\end{tabular} \\
\hline Tupa & D100 & 53 & 166,01 & 118,27 & 39 & 116,78 & 85,00 & 92 & \begin{tabular}{|l|l|}
140,76 \\
\end{tabular} & 101,21 & 5 & 14,71 & 10,10 & 10 & 30,94 & 21,53 & 15 & 23,03 & \begin{tabular}{|l|l|}
3 & 15,82 \\
\end{tabular} & 82 & 258,47 & \begin{tabular}{|l|l|}
769,39 \\
\end{tabular} & 75 & 225,57 & \begin{tabular}{|l|}
756,92 \\
\end{tabular} & 157 & \begin{tabular}{|l|l|}
7 & 241,60 \\
\end{tabular} & \begin{tabular}{|l|l}
163,00 \\
\end{tabular} \\
\hline Tupi Paulista & D20 & 14 & 213,68 & 132,13 & 9 & 142,48 & 96,91 & 23 & 177,65 & 114,31 & 2 & 36,48 & 18,86 & 3 & 40,71 & 24,08 & 5 & \begin{tabular}{|l|}
38,62 \\
\end{tabular} & \begin{tabular}{|l|l|}
21,50 \\
\end{tabular} & 15 & 239,73 & \begin{tabular}{|l|l|}
321,26 \\
\end{tabular} & 16 & 249,34 & 454,14 & 32 & \begin{tabular}{l|l|}
2 & 244,59 \\
\end{tabular} & \begin{tabular}{l|l}
137,89 \\
\end{tabular} \\
\hline Turiúba & E20 & & & & 1 & 113,12 & 66,96 & 1 & 55,24 & 32,70 & 1 & 71,97 & 69,11 & 0 & \begin{tabular}{|l|}
37,71 \\
\end{tabular} & 23,11 & 1 & \begin{tabular}{|l|}
55,25 \\
\end{tabular} & \begin{tabular}{|l|l|}
5 & 47,29 \\
\end{tabular} & 2 & 215,91 & \begin{tabular}{|l|}
141,21 \\
\end{tabular} & 1 & 113,12 & 80,93 & 3 & \begin{tabular}{l|l|}
3 & 165,72 \\
\end{tabular} & \begin{tabular}{|l|l|}
2 & 111,78 \\
\end{tabular} \\
\hline Turmalina & E20 & 2 & 151,56 & 83,85 & 2 & 182,70 & 144,25 & 4 & 167,10 & 113,98 & 0 & 30,31 & 19,57 & & & & 0 & 15,19 & \begin{tabular}{|l|l|}
9 & 9,99 \\
\end{tabular} & 2 & \begin{tabular}{|l|} 
\\
\end{tabular} 81,87 & \begin{tabular}{|l|l|}
710,03 \\
\end{tabular} & 1 & 91,35 & \begin{tabular}{|l|l|}
5 & 64,72 \\
\end{tabular} & 3 & \begin{tabular}{l|l|}
3 & 136,72 \\
\end{tabular} & 87,43 \\
\hline Ubarana & E20 & 2 & 65,91 & 61,24 & 2 & 101,13 & 144,97 & 4 & 82,71 & 101,19 & 0 & 13,18 & 12,62 & 1 & 57,79 & 68,15 & 2 & \begin{tabular}{|l|}
34,46 \\
\end{tabular} & 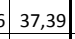 & 3 & 105,46 & \begin{tabular}{|l|l|}
6 & 88,78 \\
\end{tabular} & 2 & 101,13 & \begin{tabular}{|l|} 
\\
\end{tabular} & 5 & \begin{tabular}{|l|l|}
5 & 103,39 \\
\end{tabular} & \begin{tabular}{l|l}
9 & 102,10 \\
\end{tabular} \\
\hline Ubatuba & C100 & 31 & 80,94 & 99,94 & 29 & 77,84 & 105,53 & 60 & 79,41 & 102,70 & 7 & 18,28 & 23,17 & 11 & 29,53 & 41,92 & 18 & \begin{tabular}{|l|}
23,82 \\
\end{tabular} & \begin{tabular}{|l|}
2 \\
\end{tabular} & 49 & 127,94 & \begin{tabular}{|l|l|}
4 & 161,52 \\
\end{tabular} & 36 & 96,63 & \begin{tabular}{|l|l|}
341,31 \\
\end{tabular} & 85 & \begin{tabular}{|l|l|}
5 & 112,50 \\
\end{tabular} & \begin{tabular}{|l}
151,55 \\
\end{tabular} \\
\hline Ubirajara & E20 & 3 & 156,37 & 111,77 & 2 & 115,84 & 107,42 & 6 & 136,68 & 109,66 & 0 & 15,64 & 10,85 & & & & 0 & 8,04 & \begin{tabular}{l|l|}
4 & 5,69 \\
\end{tabular} & 7 & 344,02 & \begin{tabular}{|l|l|}
2 & 264,06 \\
\end{tabular} & 5 & 231,67 & 703,66 & 12 & \begin{tabular}{l|l|}
2 & 289,44 \\
\end{tabular} & \begin{tabular}{l|l}
4 & 234,72 \\
\end{tabular} \\
\hline Uchoa & D20 & 6 & 120,64 & 79,19 & 6 & 121,80 & 78,31 & 11 & 121,22 & 78,75 & 1 & 14,19 & 8,96 & 2 & 42,99 & 26,42 & 3 & \begin{tabular}{|l|}
28,52 \\
\end{tabular} & \begin{tabular}{|l|l|}
217,78 \\
\end{tabular} & 15 & 326,43 & \begin{tabular}{|l|l|}
3 & 206,05 \\
\end{tabular} & 8 & 164,79 & \begin{tabular}{|l|l|}
05,30 \\
\end{tabular} & 23 & \begin{tabular}{|l|l|}
3 & 246,00 \\
\end{tabular} & \begin{tabular}{|l|l}
155,92 \\
\end{tabular} \\
\hline Uniao Paulista & E20 & & & & 0 & 51,05 & 55,55 & 0 & 24,44 & 26,59 & & & & & & & & & & 1 & 140,65 & 89,86 & 1 & 153,14 & \begin{tabular}{|l|l|}
430,13 \\
\end{tabular} & 2 & \begin{tabular}{|l|l|}
2 & 146,63 \\
\end{tabular} & \begin{tabular}{l|l}
109,14 \\
\end{tabular} \\
\hline Urânia & E20 & 5 & 105,30 & 66,47 & 4 & 82,81 & 62,18 & 8 & 94,06 & 64,33 & 1 & 30,09 & 21,17 & 2 & 45,17 & 33,43 & 3 & \begin{tabular}{|l|}
37,62 \\
\end{tabular} & \begin{tabular}{|l|}
26,90 \\
\end{tabular} & 11 & 248,21 & 138,13 & 9 & 210,78 & \begin{tabular}{|l|l|}
8 & 164,49 \\
\end{tabular} & 20 & \begin{tabular}{|l|l|}
0 & 229,50 \\
\end{tabular} & \begin{tabular}{|l|l}
151,31 \\
\end{tabular} \\
\hline Uru & E20 & 2 & 223,71 & $141,65 \mid$ & 1 & 98,04 & 68,98 & 2 & 163,74 & 106,97 & . & & & & & & & & & 2 & 268,46 & \begin{tabular}{|l|l|}
6 & 162,06 \\
\end{tabular} & 1 & \begin{tabular}{|l|}
47,06 \\
\end{tabular} & \begin{tabular}{|l|l|}
5 & 118,82 \\
\end{tabular} & 3 & \begin{tabular}{|l|l|}
3 & 210,53 \\
\end{tabular} & \begin{tabular}{|l|l}
8 & 141,43 \\
\end{tabular} \\
\hline Urupês & E20 & 6 & 102,95 & 69,46 & 5 & 88,21 & 70,52 & 12 & 95,64 & 69,99 & 1 & 10,84 & 6,37 & 1 & 22,05 & 14,16 & 2 & 16,40 & \begin{tabular}{|l|l|}
0 & 10,14 \\
\end{tabular} & 19 & 308,84 & \begin{tabular}{l|l|}
4 & 193,01 \\
\end{tabular} & 19 & 314,24 & 4214,11 & 38 & \begin{tabular}{l|l|}
8 & 311,52 \\
\end{tabular} & \begin{tabular}{|l|l|}
2 & 203,47 \\
\end{tabular} \\
\hline Valentim $G_{e}$ & D20 & 6 & 120,18 & \begin{tabular}{|l|}
106,04 \\
\end{tabular} & 4 & 76,07 & 72,29 & 10 & 98,52 & 89,46 & 1 & 13,35 & 12,32 & 0 & 6,92 & 6,14 & 1 & 10,19 & 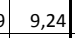 & 8 & 153,57 & \begin{tabular}{|l|l|}
714,82 \\
\end{tabular} & 9 & 179,81 & $\mid 177,40$ & 16 & \begin{tabular}{|l|l|}
6 & 166,46 \\
\end{tabular} & \begin{tabular}{|l|l|}
5 & 145,56 \\
\end{tabular} \\
\hline Valinhos & B100 & 54 & 121,49 & 112,05 & 43 & 94,84 & \begin{tabular}{|l|}
92,61 \\
\end{tabular} & 97 & 108,12 & 102,30 & 5 & 10,43 & 9,46 & 8 & 17,78 & 17,06 & 13 & 14,12 & \begin{tabular}{|l|}
213,24 \\
\end{tabular} & 83 & 186,34 & \begin{tabular}{l|l|}
4 & 167,26 \\
\end{tabular} & 69 & 154,11 & 148,20 & 153 & \begin{tabular}{l|l|}
3 & 170,17 \\
\end{tabular} & \begin{tabular}{l|l}
757,70 \\
\end{tabular} \\
\hline Valparaiso & D20 & 9 & 84,79 & 77,27 & 1 & 75,63 & 68,17 & 16 & 80,44 & 72,94 & 2 & 22,83 & 22,00 & 3 & 28,81 & 26,06 & 5 & 25,67 & $\begin{array}{ll}74,17 \\
\end{array}$ & 11 & 110,88 & 95,76 & 12 & 133,26 & 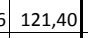 & 24 & \begin{tabular}{l|l|}
4 & 121,51 \\
\end{tabular} & \begin{tabular}{l|l}
1107,94 \\
\end{tabular} \\
\hline Vargem & E20 & 3 & 74,23 & 61,53 & 3 & 87,42 & 73,94 & 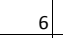 & 80,63 & 67,55 & & & & 1 & 17,48 & 13,83 & 1 & 8,49 & \begin{tabular}{|l|l|}
9 & 6,27 \\
\end{tabular} & 11 & 263,92 & \begin{tabular}{|l|l|}
286,83 \\
\end{tabular} & & 218,55 & \begin{tabular}{|l|}
5 \\
5
\end{tabular} & 19 & \begin{tabular}{l|l|}
9 & 241,89 \\
\end{tabular} & \begin{tabular}{l|l}
9 & 182,12 \\
\end{tabular} \\
\hline Vargem Grande do Sul & D50 & 25 & 131,33 & 111,09 & 14 & 73,87 & 67,31 & 40 & 102,52 & 89,14 & 2 & 12,10 & 10,01 & 4 & 18,90 & 17,04 & 6 & 15,51 & $1 \mid 13,46$ & 50 & 260,93 & \begin{tabular}{|l|l|}
3208,38 \\
\end{tabular} & 38 & 197,57 & 173,74 & 89 & \begin{tabular}{l|l|}
9 & 229,16 \\
\end{tabular} & \begin{tabular}{|l|l|}
5 & 191,01 \\
\end{tabular} \\
\hline Vargem Grande Paulista & c50 & 16 & 77,81 & 109,22 & 14 & 69,79 & 100,66 & 30 & 73,81 & 104,95 & 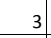 & 13,25 & 18,49 & 3 & \begin{tabular}{|l|}
14,96 \\
\end{tabular} & 25,29 & 6 & 14,10 & 21,74 & 31 & 155,63 & 3221,56 & 26 & 127,95 & 5199,43 & 57 & \begin{tabular}{l|l|}
7 & 141,81 \\
\end{tabular} & 210,51 \\
\hline Várzea Paulista & C300 & 29 & 55,19 & 80,55 & 27 & 53,06 & 76,43 & 56 & 54,13 & 78,50 & 6 & 11,55 & 15,89 & & 12,94 & 19,26 & 13 & 12,24 & $4 \quad 17,60$ & 89 & 171,33 & 3241,52 & 70 & 135,23 & 219,26 & 159 & \begin{tabular}{l|l|}
9 & 153,35 \\
\end{tabular} & \begin{tabular}{|l|l}
50,44 \\
230
\end{tabular} \\
\hline Vera Cruz & E20 & 10 & 180,97 & 126,32 & 4 & 77,77 & 61,56 & 14 & 129,15 & 93,80 & 1 & 24,13 & 17,15 & 0 & 5,98 & 4,18 & 2 & 15,02 & \begin{tabular}{|l|l|}
2 & 10,83 \\
\end{tabular} & 17 & 301,62 & \begin{tabular}{|l|l|}
2 & 196,93 \\
\end{tabular} & 14 & 245,26 & $6 \quad 168,55$ & 30 & $\begin{array}{ll}0 & 273,32 \\
\end{array}$ & \begin{tabular}{|l|l|}
2 & 182,68 \\
\end{tabular} \\
\hline Vinhedo & A100 & 30 & 111,87 & 107,77 & 30 & 110,81 & 109,39 & 59 & 111,34 & 108,58 & 2 & 8,80 & 8,37 & 3 & 12,45 & 12,74 & 6 & 10,63 & \begin{tabular}{|l|l|} 
& 10,55 \\
\end{tabular} & 41 & 154,61 & \begin{tabular}{l|l}
140,17 \\
\end{tabular} & 37 & $|139,44|$ & 4 139,54 & 78 & \begin{tabular}{l|l|}
8 & 146,99 \\
\end{tabular} & \begin{tabular}{l|l}
9 & 139,85 \\
\end{tabular} \\
\hline
\end{tabular}


Anexo 23 - Nº de óbitos e taxa de mortalidade (bruta e padronizada) total e segundo sexo por Neoplasias, Diabetes Mellitus e Doenças do Aparelho Circulatório, municípios. Estado de São Paulo, média do triênio 2003-2005

\begin{tabular}{|c|c|c|c|c|c|c|c|c|c|c|c|c|c|c|c|c|c|c|c|c|c|c|c|c|c|c|c|c|}
\hline \multirow[b]{3}{*}{ Viradouro } & \multirow[b]{3}{*}{ D20 } & \multicolumn{9}{|c|}{ Neoplasias Malignas } & \multicolumn{9}{|c|}{ Diabetes Mellitus } & \multicolumn{9}{|c|}{ Aparelho Circulatorio } \\
\hline & & \multicolumn{3}{|c|}{ Homens } & \multicolumn{3}{|c|}{ Mulheres } & \multicolumn{3}{|c|}{ Total } & \multicolumn{3}{|c|}{ Homens } & \multicolumn{3}{|c|}{ Mulheres } & \multicolumn{3}{|c|}{ Total } & \multicolumn{3}{|c|}{ Homens } & \multicolumn{3}{|c|}{ Mulheres } & \multicolumn{3}{|c|}{ Total } \\
\hline & & 10 & 118,48 & 101,20 & 8 & 93,87 & 90,20 & 18 & 106,32 & 95,76 & 5 & 53,51 & 48,39 & 4 & \begin{tabular}{|l|}
50,84 \\
\end{tabular} & 45,93 & 9 & 52,19 & \begin{tabular}{|l|l|}
97,37 \\
\end{tabular} & 13 & 149,06 & 119,36 & 14 & 160,36 & 151,79 & 27 & 154,64 & 135,39 \\
\hline Vista Alegre do Alto & D20 & 4 & 151,40 & 119,81 & 2 & 89,02 & 93,94 & 6 & 120,34 & 106,93 & 0 & 12,62 & 9,32 & 1 & 25,44 & 22,45 & 1 & 19,00 & \begin{tabular}{|l|l|} 
& 15,45 \\
\end{tabular} & 5 & 201,87 & 157,79 & 4 & 165,33 & 164,07 & 10 & 183,67 & 160,92 \\
\hline Vitória Brasil & E20 & 0 & 36,34 & 23,20 & 1 & 77,58 & 94,48 & 1 & 56,29 & 57,67 & & & & & & & 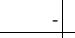 & & & 1 & 109,01 & 107,53 & 1 & 116,37 & 118,97 & 2 & 112,57 & 113,06 \\
\hline Votorantim & B300 & 42 & 81,94 & 96,57 & 36 & 70,62 & 85,89 & 78 & 76,27 & 91,22 & 12 & 22,76 & 26,80 & 15 & 29,15 & 35,52 & 27 & 25,96 & \begin{tabular}{|l|l|}
5 & 31,18 \\
\end{tabular} & 80 & 156,72 & 186,96 & 76 & 148,36 & 186,36 & 157 & 152,53 & 186,66 \\
\hline Votuporanga & $\mathrm{C} 100$ & 57 & 145,06 & 114,17 & 37 & 90,19 & 76,00 & 94 & 117,11 & 94,73 & 6 & $\begin{array}{r}16,02 \\
\end{array}$ & 12,64 & 8 & 18,69 & $\begin{array}{r}15,20 \\
\end{array}$ & 14 & 17,38 & \begin{tabular}{l|l}
$8,9,91$ \\
\end{tabular} & 113 & 286,74 & 218,33 & 92 & 223,44 & 184,09 & 205 & 254,50 & 200,89 \\
\hline Zacarias & E20 & 1 & \begin{tabular}{|l|l}
32,58 \\
\end{tabular} & 103,73 & 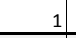 & 70,97 & 69,34 & 2 & 102,83 & 87,12 & & & & 0 & 35,49 & 28,40 & 0 & 17,14 & \begin{tabular}{|l|l|}
4 & 12,63 \\
\end{tabular} & 1 & 132,58 & 94,15 & 1 & 141,94 & 125,79 & 3 & \begin{tabular}{|l|l|}
137,10 \\
\end{tabular} & 109,43 \\
\hline Estado & & \begin{tabular}{|l|}
21392 \\
\end{tabular} & 110,62 & 111,33 & 17773 & 88,31 & \begin{tabular}{|r|}
88,70 \\
\end{tabular} & 39165 & \begin{tabular}{|r|}
99,24 \\
\end{tabular} & 99,79 & \begin{tabular}{|r|}
3583 \\
\end{tabular} & 18,53 & 18,99 & 4579 & \begin{tabular}{|l|l|}
22,75 \\
\end{tabular} & 23,24 & 8163 & 20,68 & \begin{tabular}{|l|l|}
81,10 \\
\end{tabular} & \begin{tabular}{|l|l|l|}
3811 \\
\end{tabular} & 197,43 & 195,89 & 34324 & 170,55 & 173,70 & 72505 & \begin{tabular}{|l|l|}
5 & 183,72 \\
\end{tabular} & 184,57 \\
\hline \multicolumn{29}{|l|}{$\begin{array}{l}\text { Fonte: } \\
\text { Nota }^{1}:\end{array}$} \\
\hline & $0 ; 0$ & 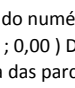 & 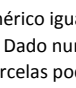 & & F. & & & & 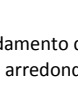 & & 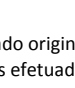 & & & & & & & & & & & & & & & & & \\
\hline
\end{tabular}


Anexo 24 - Óbitos e taxas de mortalidade total e segundo sexo (bruta e padronizada) por Acidentes de Transporte (por 100 mil hab.) mediana, desvio padrão, e razão de taxas nos conjuntos de municípios e respectivos estratos de vulnerabilidade social. Estado de São Paulo, média do triênio 2003 a 2005

\begin{tabular}{|c|c|c|c|c|c|c|c|c|c|c|c|c|c|c|}
\hline Status & Óbitos & Home & TPM & Óbitos & Mulhe & TPM & Óbitos & TBM & TPM & $\begin{array}{l}\text { Total } \\
\text { Mediana }\end{array}$ & $\begin{array}{l}\text { Desvio } \\
\text { padrão }\end{array}$ & $\begin{array}{c}\text { Valor } \\
\text { Máximo }^{1}\end{array}$ & $\begin{array}{c}\text { Valor } \\
\text { Minimo }^{2}\end{array}$ & $\begin{array}{l}\text { Razão } \\
(1 / 2)\end{array}$ \\
\hline A20 & 11 & 58,75 & 57,82 & 1 & 5,26 & 5,47 & 12 & 32,21 & 31,84 & 38,05 & 20,14 & 52,68 & 0,00 & * \\
\hline A100 & 10 & 38,97 & 38,09 & 4 & 13,70 & 13,55 & 14 & 26,27 & 25,76 & $\mathrm{x}$ & $x$ & $\mathrm{x}$ & $\mathrm{x}$ & $x$ \\
\hline A300 & 73 & 28,60 & 26,68 & 17 & 6,17 & 5,72 & 89 & 17,04 & 15,88 & 16,88 & 3,38 & 17,87 & 11,59 & 1,54 \\
\hline A500 & 113 & 31,53 & 30,08 & 26 & 6,63 & 5,86 & 140 & 18,45 & 17,36 & 17,63 & 3,71 & 20,26 & 15,01 & 1,35 \\
\hline A1000 & 45 & 13,92 & 13,63 & 15 & 4,37 & 4,26 & 60 & 8,99 & 8,79 & $x$ & $\mathrm{x}$ & $x$ & $x$ & $\mathrm{x}$ \\
\hline Estrato A & 252 & 25,75 & 24,58 & 63 & 5,93 & 5,49 & 315 & 15,47 & 14,68 & 17,87 & 15,35 & 52,68 & 0,00 & * \\
\hline B20 & 13 & 32,94 & 33,20 & 3 & 7,93 & 7,65 & 16 & 20,54 & 20,53 & 23,86 & 13,89 & 41,23 & 0,00 & * \\
\hline B50 & 101 & 37,93 & 37,35 & 16 & 5,90 & 5,85 & 116 & 21,92 & 21,60 & 21,57 & 8,17 & 38,93 & 9,99 & 3,90 \\
\hline B100 & 213 & 33,31 & 32,83 & 52 & 8,01 & 7,97 & 265 & 20,52 & 20,26 & 20,59 & 6,25 & 34,16 & 6,52 & 5,24 \\
\hline B300 & 667 & 35,48 & 35,25 & 142 & 7,34 & 7,36 & 809 & 21,22 & 21,12 & 21,05 & 4,12 & 29,34 & 14,66 & 2,00 \\
\hline B500 & 294 & 28,95 & 28,73 & 67 & 6,30 & 6,21 & 360 & 17,39 & 17,23 & 17,17 & 4,89 & 23,96 & 10,80 & 2,22 \\
\hline B1000 & 415 & 27,28 & 27,37 & 99 & 6,18 & 6,30 & 514 & 16,48 & 16,58 & 17,84 & 1,68 & 18,05 & 14,58 & 1,24 \\
\hline B10000 & 1280 & 22,70 & 22,41 & 371 & 6,01 & 5,84 & 1651 & 13,98 & 13,75 & 14,58 & 1,41 & 15,57 & 13,58 & 1,15 \\
\hline Estrato B & 2982 & 27,11 & 26,88 & 749 & 6,39 & 6,31 & 3731 & 16,43 & 16,27 & 20,59 & 7,13 & 41,23 & 0,00 & * \\
\hline $\mathrm{C} 20$ & 35 & 36,89 & 37,31 & 8 & 9,15 & 9,05 & 43 & 23,31 & 23,47 & 25,71 & 14,44 & 59,58 & 0,00 & * \\
\hline $\mathrm{C} 50$ & 157 & 33,37 & 33,77 & 28 & 5,98 & 6,05 & 184 & 19,77 & 20,01 & 19,71 & 6,96 & 36,49 & 8,82 & 4,14 \\
\hline C100 & 198 & 34,31 & 35,05 & 52 & 9,01 & 9,57 & 250 & 21,64 & 22,29 & 21,29 & 6,64 & 34,51 & 12,92 & 2,67 \\
\hline C300 & 520 & 29,54 & 30,79 & 118 & 6,58 & 6,95 & 638 & 17,97 & 18,77 & 19,33 & 5,27 & 32,19 & 11,74 & 2,74 \\
\hline C500 & 157 & 21,72 & 22,45 & 41 & 5,55 & 6,01 & 198 & 13,52 & 14,11 & 11,92 & 5,10 & 21,58 & 10,86 & 1,99 \\
\hline C10000 & 149 & 25,31 & 26,24 & 34 & 5,57 & 6,23 & 183 & 15,28 & 16,07 & $x$ & $\mathrm{x}$ & $x$ & $x$ & $\mathrm{x}$ \\
\hline Estrato C & 1216 & 28,85 & 29,78 & 281 & 6,58 & 6,98 & 1497 & 17,63 & 18,30 & 19,58 & 8,40 & 59,58 & 0,00 & * \\
\hline D20 & 158 & 37,36 & 37,55 & 34 & 8,24 & 8,41 & 192 & 22,99 & 23,17 & 21,55 & 10,30 & 62,45 & 0,00 & * \\
\hline D50 & 355 & 36,25 & 36,44 & 72 & 7,34 & 7,43 & 427 & 21,83 & 21,97 & 20,00 & 8,62 & 55,67 & 6,18 & 9,01 \\
\hline D100 & 171 & 38,98 & 39,44 & 33 & 7,43 & 7,53 & 203 & 23,17 & 23,45 & 22,10 & 9,15 & 46,91 & 9,29 & 5,05 \\
\hline D300 & 18 & 22,71 & 25,22 & 3 & 4,26 & 5,48 & 21 & 13,46 & 15,33 & $x$ & $\mathrm{x}$ & $x$ & $x$ & $\mathrm{x}$ \\
\hline Estrato D & 702 & 36,56 & 36,91 & 142 & 7,43 & 7,58 & 844 & 22,05 & 22,30 & 20,78 & 9,48 & 62,45 & 0,00 & * \\
\hline E20 & 368 & 38,10 & 38,31 & 79 & 8,51 & 8,62 & 447 & 23,64 & 23,80 & 20,23 & 18,15 & 143,61 & 0,00 & * \\
\hline E50 & 88 & 39,27 & 41,21 & 17 & 7,71 & 7,93 & 104 & 23,74 & 24,84 & 21,58 & 11,61 & 57,57 & 8,11 & 7,10 \\
\hline E100 & 14 & 38,22 & 39,98 & 4 & 10,61 & 11,47 & 18 & 24,82 & 26,14 & $x$ & $x$ & $x$ & $x$ & $x$ \\
\hline Estrato E & 470 & 38,32 & 38,89 & 99 & 8,43 & 8,58 & 569 & 23,70 & 24,06 & 20,48 & 17,82 & 143,61 & 0,00 & * \\
\hline Estado & 5622 & 29,07 & 29,15 & 1333 & 6,63 & 6,66 & 6956 & 17,63 & 17,68 & 20,31 & 14,13 & 143,61 & 0,00 & * \\
\hline
\end{tabular}

Fonte: SIM/ MS, Censo IBGE e Estratos de Vulnerabilidade Social segundo metodologia desenvolvida a partir do IPVS (FSEADE 2005)

Nota $^{1}:$ ( - ) Dado numérico igual a 0 não resultante de arredondamento

$(0 ; 0,0 ; 0,00)$ Dado numérico igual a zero resultante de arredondamento de um dado originalmente positivo

A soma das parcelas pode não coincidir com o total em função de arredondamentos efetuados nos dados parciais

(x) Não se aplica (conjunto formado por um só município)

$(*)$ Não divisível

Acidentes de Transporte - Códigos V01 a V99 (CID 10 ) Cap. XX - Causas Externas de Morbidade e Mortalidade 
Anexo 25 - Óbitos e taxas de mortalidade (bruta e padronizada) total e segundo sexo por Homicídios (por 100 mil hab.), mediana, desvio padrão e razão de taxas nos conjuntos de municipios e respectivos estratos de vulnerabilidade social. Estado de São Paulo, média do triênio 2003 a 2005

\begin{tabular}{|c|c|c|c|c|c|c|c|c|c|c|c|c|c|c|}
\hline \multirow[b]{2}{*}{ Status } & \multicolumn{3}{|c|}{ Homens } & \multicolumn{3}{|c|}{ Mulheres } & \multicolumn{3}{|c|}{ Total } & \multirow[b]{2}{*}{ Mediana } & \multirow{2}{*}{$\begin{array}{l}\text { Desvio } \\
\text { padrão }\end{array}$} & \multirow{2}{*}{$\begin{array}{c}\text { Valor } \\
\text { Máximo }^{1}\end{array}$} & \multirow{2}{*}{$\begin{array}{c}\text { Valor } \\
\text { Minimo }^{2} \\
\end{array}$} & \multirow[b]{2}{*}{ Razão (1/2) } \\
\hline & Óbitos & TBM & TPM & Óbitos & TBM & TPM & óbitos & TBM & TPM & & & & & \\
\hline A20 & 3 & 13,82 & 14,56 & 0 & 1,75 & 1,67 & 3 & 7,83 & 8,17 & 7,04 & 11,14 & 26,31 & 0.00 & * \\
\hline A100 & 5 & 20,11 & 19,57 & 0 & 1,25 & 1,20 & 6 & 10,63 & 10,34 & $x$ & $\mathrm{X}$ & $x$ & $\mathrm{X}$ & $x$ \\
\hline $\mathrm{A} 300$ & 68 & 26,90 & 26,60 & 7 & 2,71 & 2,70 & 76 & 14,43 & 14,28 & 28,09 & 10,33 & 38,19 & 17,53 & 2,18 \\
\hline A500 & 109 & 30,33 & 30,35 & 13 & 3,19 & 3,32 & 122 & 16,08 & 16,16 & 30,07 & 5,22 & 33,76 & 26,38 & 1,28 \\
\hline $\mathrm{A} 1000$ & 215 & 67,12 & 66,39 & 14 & 4,08 & 4,03 & 229 & 34,55 & 34,17 & $x$ & $\mathrm{x}$ & $x$ & $\mathrm{x}$ & $x$ \\
\hline Estrato A & 401 & 40,88 & 40,57 & 35 & 3,28 & 3,31 & 435 & 21,38 & 21,24 & 19,57 & 18,30 & 66,39 & 0,00 & * \\
\hline B20 & 4 & 9,53 & 10,15 & - & - & - & 4 & 4,81 & 5,12 & 7,39 & 11,76 & 37,46 & 0.00 & * \\
\hline B50 & 67 & 25,37 & 25,24 & 8 & 3,02 & 3,02 & 75 & 14,19 & 14,13 & 20,92 & 13,85 & 56,48 & 2,79 & 20,24 \\
\hline B100 & 178 & 27,78 & 27,77 & 19 & 2,96 & 3,00 & 197 & 15,23 & 15,25 & 24,90 & 13,08 & 57,92 & 8,85 & 6,54 \\
\hline B300 & 653 & 34,75 & 34,91 & 62 & 3,21 & 3,22 & 715 & 18,78 & 18,86 & 29,57 & 13,81 & 65,77 & 16,71 & 3,94 \\
\hline $\mathrm{B} 500$ & 338 & 33,29 & 33,45 & 32 & 3,02 & 3,02 & 370 & 17,84 & 17,92 & 31,36 & 12,76 & 48,35 & 19,14 & 2,53 \\
\hline B1000 & 836 & 54,89 & 53,98 & 60 & 3,76 & 3,71 & 896 & 28,71 & 28,24 & 54,64 & 19,19 & 78,52 & 24,99 & 3,14 \\
\hline B10000 & 4066 & 72,10 & 71,03 & 311 & 5,04 & 4,98 & 4377 & 37,06 & 36,52 & 67,99 & 5,22 & 71,68 & 64,30 & 1,11 \\
\hline Estrato B & 6141 & 55,84 & 55,20 & 492 & 4,20 & 4,17 & 6634 & 29,21 & 28,88 & 26,59 & 17,35 & 78,52 & 0.00 & * \\
\hline $\mathrm{C} 20$ & 14 & 14,41 & 14,42 & 2 & 2,20 & 2,14 & 16 & 8,43 & 8,41 & 12,51 & 10,16 & 28,16 & 0,00 & * \\
\hline $\mathrm{C} 50$ & 152 & 32,44 & 32,90 & 21 & 4,61 & 4,60 & 174 & 18,63 & 18,85 & 30,14 & 16,46 & 70,37 & 10,23 & 6,88 \\
\hline $\mathrm{C} 100$ & 295 & 51,26 & 52,36 & 22 & 3,81 & 3,83 & 317 & 27,51 & 28,07 & 45,43 & 35,01 & 119,24 & 5,99 & 19,91 \\
\hline C300 & 1219 & 69,25 & 69,27 & 101 & 5,67 & 5,75 & 1320 & 37,21 & 37,26 & 68,09 & 27,64 & 109,83 & 10,53 & 10,43 \\
\hline $\mathrm{C} 500$ & 632 & 87,39 & 86,85 & 43 & 5,73 & 5,81 & 674 & 45,96 & 45,74 & 85,21 & 16,06 & 105,87 & 72,41 & 1,46 \\
\hline C10000 & 485 & 82,14 & 80,81 & 32 & 5,19 & 5,07 & 516 & 43,03 & 42,31 & $x$ & $x$ & $x$ & $x$ & $x$ \\
\hline Estrato C & 2797 & 66,37 & 66,30 & 221 & 5,17 & 5,20 & 3018 & 35,55 & 35,54 & 37,53 & 30,97 & 119,24 & 0,00 & * \\
\hline D20 & 76 & 18,01 & 18,53 & 9 & 2,10 & 2,16 & 85 & 10,16 & 10,45 & 12,02 & 20,55 & 120,33 & 0,00 & * \\
\hline D50 & 233 & 23,77 & 24,29 & 31 & 3,18 & 3,32 & 264 & 13,50 & 13,83 & 18,79 & 18,66 & 97,87 & 0,00 & $*$ \\
\hline D100 & 109 & 24,97 & 25,78 & 14 & 3,11 & 3,18 & 123 & 14,01 & 14,46 & 23,09 & 16,21 & 70,38 & 5,29 & 13,30 \\
\hline D300 & 64 & 81,83 & 86,52 & 4 & 4,69 & 5,09 & 67 & 43,16 & 45,71 & $x$ & $\mathrm{X}$ & $\mathrm{x}$ & $x$ & $x$ \\
\hline Estrato D & 482 & 25,12 & 25,88 & 57 & 2,99 & 3,11 & 539 & 14,09 & 14,535 & 17,90 & 20,25 & 120,33 & 0,00 & $*$ \\
\hline E20 & 145 & 15,03 & 15,60 & 22 & 2,42 & 2,54 & 168 & 8,87 & 9,22 & 10,64 & 15,45 & 86,41 & 0.00 & 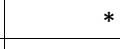 \\
\hline E50 & 58 & 25,98 & 27,83 & 6 & 2,93 & 3,04 & 64 & 14,64 & 15,63 & 25,08 & 15,06 & 65,28 & 6,62 & * \\
\hline E100 & 29 & 79,18 & 83,37 & 3 & 7,72 & 7,88 & 32 & 44,49 & 46,73 & $x$ & $x$ & $x$ & $x$ & $x$ \\
\hline Estrato E & 232 & 18,94 & 19,85 & 31 & 2,67 & 2,79 & 264 & 10,98 & 11,50 & 11,26 & 16,13 & 86,41 & 0.00 & $*$ \\
\hline Estado & 10053 & 51,98 & 51,72 & 836 & 4,16 & 4,16 & 10890 & 27,59 & 27,47 & 17,53 & 22,13 & 120,33 & 0,00 & $*$ \\
\hline
\end{tabular}

Fonte: SIM/ MS, Censo IBGE e Estratos de Vulnerabilidade Social segundo metodologia desenvolvida a partir do IPVS (FSEADE 2005)

Nota $^{1}:$ ( - ) Dado numérico igual a 0 não resultante de arredondamento

$(0 ; 0,0 ; 0,00)$ Dado numérico igual a zero resultante de arredondamento de um dado originalmente positivo

A soma das parcelas pode não coincidir com o total em função de arredondamentos efetuados nos dados parciais

(x) Não se aplica (conjunto formado por um só município)

$\left({ }^{*}\right)$ Não divisível

Homicidios - Códigos X85 a Y09 e Y35 e Y36 (Cap. XX - Causas Externas de Morbidade e Mortalidade -CID -10) 
Anexo 26 - Óbitos, taxas de mortalidade total (bruta e padronizada) e segundo sexo por Homicídios e Acidentes de Trânsito (por 100 mil hab.) nos municípios/estratos de Vulnerabilidade Social. Estado de São Paulo, média do triênio 2003 a 2005.

\begin{tabular}{|c|c|c|c|c|c|c|c|c|c|c|c|c|c|c|c|c|c|c|c|c|}
\hline \multirow[b]{3}{*}{ IBGE } & \multirow[b]{3}{*}{ Mun. } & \multirow{3}{*}{\begin{tabular}{|l} 
Status \\
Estrato
\end{tabular}} & \multicolumn{9}{|c|}{ HOMIcíDIOS } & \multicolumn{9}{|c|}{ ACIDENTES DE TRANSPORTE } \\
\hline & & & \multicolumn{3}{|c|}{ HOMENS } & \multicolumn{3}{|c|}{ MULHERES } & \multicolumn{3}{|c|}{ TOTAL } & \multicolumn{3}{|c|}{ HOMENS } & \multicolumn{3}{|c|}{ MULHERES } & \multicolumn{3}{|c|}{ TOTAL } \\
\hline & & & Óbitos & TBM & TPM & Óbitos & TBM & TPM & Óbitos & TBM & TPM & Óbitos & TBM & TPM & Óbitos & TBM & TPM & Óbitos & TBM & TPM \\
\hline 350010 & Adamantina & D50 & 1 & 8,02 & \begin{tabular}{|c|}
7,46 \\
\end{tabular} & 0 & 1,91 & 1,69 & 2 & 4,88 & 4,50 & \begin{tabular}{l|l}
4 \\
\end{tabular} & 26,06 & 24,53 & 1 & 7,62 & \begin{tabular}{ll|}
7,31 \\
\end{tabular} & \begin{tabular}{c|}
6 \\
\end{tabular} & \begin{tabular}{ll|}
16,61 \\
\end{tabular} & 15,70 \\
\hline 350020 & Adolfo & E20 & 0 & 16,99 & 16,48 & - & - & - & 0 & 8,62 & 8,36 & 1 & 50,98 & 50,28 & 1 & 34,97 & 31,91 & 2 & 43,09 & 41,23 \\
\hline 350030 & Aguaí & E50 & 5 & 30,67 & 29,71 & - & 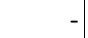 & & 5 & 15,37 & 14,89 & 6 & 37,24 & 37,95 & 1 & 6,61 & 6,82 & 7 & 21,96 & 22,43 \\
\hline 350040 & Águas da Prata & D20 & 0 & 9,04 & 8,39 & 0 & 9,16 & 8,52 & 1 & 9,10 & 8,45 & 2 & 54,22 & 58,06 & 1 & 18,33 & 20,57 & 3 & 36,40 & 39,44 \\
\hline 350050 & Águas de Lindóia & D20 & 0 & 3,73 & 3,58 & 0 & 3,66 & 3,39 & 1 & 3,69 & 3,48 & 2 & 22,36 & 22,53 & 1 & 10,98 & 10,36 & 3 & 16,62 & 16,39 \\
\hline 350055 & Águas de Santa Bárbara & B20 & - & - & - & - & - & - & - & - & - & 2 & 68,02 & 71,31 & - & - & - & 2 & 34,37 & 36,04 \\
\hline 350060 & Águas de São Pedro & A20 & - & & & & & & & & & - & & & - & & & - & & \\
\hline 350070 & Agudos & C50 & 4 & 24,01 & 23,02 & 1 & 3,96 & 4,16 & 5 & 13,93 & 13,54 & 4 & 26,01 & 27,19 & 1 & 7,91 & 8,19 & 6 & 16,91 & 17,63 \\
\hline 350075 & Alambari & E20 & 0 & 17,00 & 13,58 & - & - & - & 0 & 8,76 & 7,00 & 1 & 50,99 & 57,87 & 0 & 18,07 & 20,66 & 1 & 35,04 & 39,84 \\
\hline 350080 & Alfredo Marcondes & E20 & - & & & - & - & - & - & 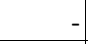 & & - & - & & - & & & - & & \\
\hline 350090 & Altair & E20 & 0 & 17,04 & 16,14 & - & - & 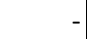 & 0 & 9,11 & 8,63 & 2 & 119,27 & 123,96 & - & & & 2 & 63,75 & 66,26 \\
\hline 350100 & Altinópolis & D20 & - & - & - & 0 & 4,13 & 4,03 & 0 & 2,04 & 2,00 & 2 & 28,33 & 27,93 & 2 & 28,93 & 29,08 & 5 & 28,62 & 28,50 \\
\hline 350110 & Alto Alegre & E20 & - & - & - & - & - & - & - & - & 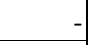 & 1 & 63,68 & 73,16 & - & - & - & 1 & 33,12 & 38,05 \\
\hline 350115 & Alumínio & $\mathrm{C} 20$ & 2 & 24,89 & 24,53 & 1 & 8,46 & 8,70 & 3 & 16,75 & 16,69 & 1 & 16,60 & 16,79 & 0 & 4,23 & 4,21 & 2 & 10,47 & 10,56 \\
\hline 350120 & Alvares Florence & E20 & 0 & 15,98 & 14,79 & 0 & 17,51 & 16,62 & 1 & 16,71 & 15,66 & 1 & 31,97 & 30,16 & - & - & - & 1 & 16,71 & 15,77 \\
\hline 350130 & Alvares Machado & D50 & 3 & 24,48 & 22,96 & 0 & 2,75 & 2,68 & 3 & 13,69 & 12,89 & 4 & 32,64 & 32,47 & 1 & 8,26 & 8,28 & 5 & 20,53 & 20,45 \\
\hline 350140 & Alvaro de Carvalho & E20 & 0 & 12,24 & 14,77 & 0 & 18,31 & 15,74 & 1 & 14,67 & 15,16 & - & 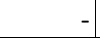 & & - & . & & - & & - \\
\hline 350150 & Alvinlândia & E20 & - & & & 0 & 22,67 & 19,25 & 0 & 11,23 & 9,54 & - & - & & - & & & - & & \\
\hline 350160 & Americana & A300 & 17 & 17,93 & 18,38 & 2 & 1,69 & 1,83 & 19 & 9,72 & 10,02 & 29 & 30,34 & 29,08 & 7 & 7,43 & 6,90 & 37 & 18,76 & 17,87 \\
\hline 350170 & Américo Brasiliense & D50 & 4 & 26,63 & 27,95 & 0 & 2,12 & 1,68 & 5 & 14,60 & 15,05 & 7 & 43,02 & 42,90 & 0 & 2,12 & 2,12 & 7 & 22,95 & 22,88 \\
\hline 350180 & Américo de Campos & E20 & - & & & - & & & - & & & - & & & 1 & 23,89 & 22,58 & 1 & 11,92 & 11,26 \\
\hline 350190 & Amparo & B100 & 5 & 16,53 & 16,36 & 0 & 1,03 & 0,95 & 6 & 8,76 & 8,64 & 13 & 39,26 & 38,39 & 2 & 7,19 & 7,04 & 15 & 23,19 & 22,68 \\
\hline 350200 & Analândia & B20 & 1 & 33,60 & 30,14 & - & - & - & 1 & 17,40 & 15,61 & 1 & 67,20 & 64,08 & - & - & - & 1 & 34,79 & 33,17 \\
\hline 350210 & Andradina & D100 & 8 & 27,57 & 28,97 & 1 & 3,50 & 3,39 & 9 & 15,37 & 16,00 & 4 & 14,39 & 14,31 & 1 & 4,66 & 4,40 & 5 & 9,46 & 9,29 \\
\hline 350220 & Angatuba & D50 & 1 & 6,40 & 6,06 & - & -1 & - & 1 & 3,30 & 3,12 & 5 & 48,03 & 49,87 & 1 & 6,79 & 6,49 & 6 & 28,02 & 28,82 \\
\hline 350230 & Anhembi & E20 & - & - & -1 & - & - & - & - & - & 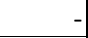 & 0 & 13,01 & 12,85 & 0 & 13,79 & 11,54 & 1 & 13,39 & 12,21 \\
\hline 350240 & Anhumas & E20 & - & & & - & - & - & -1 & & & - & - & & 0 & 19,56 & 18,91 & 0 & 9,56 & 9,24 \\
\hline 350250 & Aparecida & B50 & 7 & 38,12 & 38,89 & - & - & - & 7 & 18,70 & 19,08 & 6 & 36,21 & 36,36 & 2 & 11,02 & 10,88 & 8 & 23,38 & 23,38 \\
\hline 350260 & Aparecida d'Oeste & E20 & - & & & - & - & - & -1 & - & & 0 & 13,77 & 15,46 & - & & & 0 & 6,86 & 7,70 \\
\hline 350270 & Apiai & D50 & 1 & 9,63 & 8,55 & - & -1 & & 1 & 4,86 & 4,32 & 3 & 21,66 & 23,91 & 1 & 7,36 & 9,83 & 4 & 14,58 & 16,94 \\
\hline 350275 & Araçariguama & D20 & 4 & 59,67 & 58,13 & 1 & 10,51 & 10,82 & 5 & 35,78 & 35,13 & 3 & 39,78 & 41,74 & 0 & 5,26 & 7,06 & 3 & 23,00 & 24,88 \\
\hline 350280 & Araçatuba & B300 & 42 & 49,07 & 48,70 & 3 & 2,93 & 3,01 & 45 & 25,28 & 25,14 & 38 & 44,39 & 43,17 & 7 & 7,68 & 7,50 & 45 & 25,46 & 24,78 \\
\hline
\end{tabular}


Anexo 26 - Óbitos, taxas de mortalidade total (bruta e padronizada) e segundo sexo por Homicídios e Acidentes de Trânsito (por 100 mil hab.) nos municípios/estratos de Vulnerabilidade Social. Estado de São Paulo, média do triênio 2003 a 2005.

\begin{tabular}{|c|c|c|c|c|c|c|c|c|c|c|c|c|c|c|c|c|c|c|c|c|}
\hline \multirow[b]{3}{*}{ IBGE } & \multirow[b]{3}{*}{ Mun. } & \multirow{3}{*}{\begin{tabular}{|l|} 
Status \\
Estrato \\
\end{tabular}} & \multicolumn{9}{|c|}{ HOMıcídIOS } & \multicolumn{9}{|c|}{ ACIDENTES DE TRANSPORTE } \\
\hline & & & \multicolumn{3}{|c|}{ HOMENS } & \multicolumn{3}{|c|}{ MULHERES } & \multicolumn{3}{|c|}{ TOTAL } & \multicolumn{3}{|c|}{ HOMENS } & \multicolumn{3}{|c|}{ MULHERES } & \multicolumn{3}{|c|}{ TOTAL } \\
\hline & & & Óbitos & TBM & TPM & Óbitos & TBM & TPM & Óbitos & TBM & TPM & Óbitos & TBM & TPM & Óbitos & TBM & TPM & Óbitos & TBM & TPM \\
\hline 350290 & Araçoiaba da Serra & B50 & 3 & 23,86 & 22,88 & 1 & 6,06 & 5,86 & 3 & 15,03 & 14,44 & 7 & 59,65 & 61,22 & 1 & 12,13 & 12,17 & 8 & 36,08 & 36,89 \\
\hline 350300 & Aramina & E20 & 1 & 25,81 & 27,53 & - & - & & 1 & 13,14 & 14,01 & 0 & 12,90 & 10,80 & 0 & 13,38 & 13,88 & 1 & 13,14 & 12,31 \\
\hline 350310 & Arandu & E20 & - & & & - & - & - & - & 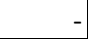 & & 1 & 20,91 & 20,05 & 0 & 10,83 & 12,21 & 1 & 15,96 & 16,20 \\
\hline 350315 & Arapeí & E20 & 0 & 24,23 & 20,69 & - & - & & 0 & 12,07 & 10,31 & 1 & 72,69 & 83,32 & - & & & 1 & 36,21 & 41,51 \\
\hline 350320 & Araraquara & A300 & 27 & 28,43 & 28,89 & 4 & 4,04 & 3,96 & 31 & 15,90 & 16,08 & 29 & 31,27 & 29,43 & 5 & 5,05 & 5,00 & 34 & 17,80 & 16,88 \\
\hline 350330 & Araras & B300 & 19 & 34,04 & 34,09 & 2 & 3,58 & 3,60 & 21 & 18,80 & 18,84 & 20 & 36,43 & 35,86 & 4 & 7,76 & 7,66 & 25 & 22,09 & 21,76 \\
\hline 350335 & ArcoOlris & E20 & - & - & - & 0 & 31,62 & 27,58 & 0 & 14,84 & 12,94 & 1 & 83,87 & 89,15 & - & 7 & - & 1 & 44,51 & 47,31 \\
\hline 350340 & Arealva & E20 & - & - & - & - & - & & - & & & 1 & 26,25 & 20,86 & 1 & 18,56 & 20,07 & 2 & 22,52 & 20,48 \\
\hline 350350 & Areias & E20 & 0 & 17,65 & 16,00 & - & - & - & 0 & 8,91 & 8,08 & 1 & 52,94 & 56,21 & -1 & - & & 1 & 26,73 & 28,38 \\
\hline 350360 & Areiópolis & E20 & 2 & 37,25 & 34,62 & - & - & 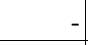 & 2 & 19,17 & 17,82 & 1 & 24,84 & 26,68 & - & - & - & 1 & 12,78 & 13,73 \\
\hline 350370 & Ariranha & E20 & 0 & 7,95 & 7,59 & 0 & 8,31 & 7,67 & 1 & 8,12 & 7,63 & 1 & 31,79 & 24,06 & - & - & - & 1 & 16,25 & 12,30 \\
\hline 350380 & Artur Nogueira & C50 & 7 & 35,51 & 35,48 & - & - & & 7 & 17,81 & 17,79 & 9 & 43,96 & 45,50 & 1 & 6,81 & 6,61 & 10 & 25,45 & 26,12 \\
\hline 350390 & Arujá & C100 & 17 & 50,51 & 49,28 & 1 & 2,90 & 2,71 & 18 & 26,64 & 25,94 & 13 & 37,88 & 39,76 & 3 & 9,66 & 11,39 & 16 & 23,74 & 25,54 \\
\hline 350395 & Aspásia & E20 & - & - & - & 0 & 38,04 & 37,83 & 0 & 18,36 & 18,26 & 0 & 35,49 & 36,93 & 0 & 38,04 & 38,99 & 1 & 36,72 & 37,92 \\
\hline 350400 & Assis & B100 & 13 & 28,94 & 28,93 & 2 & 4,92 & 4,73 & 15 & 16,60 & 16,50 & 11 & 24,49 & 23,75 & 5 & 9,84 & 9,68 & 16 & 16,96 & 16,52 \\
\hline 350410 & Atibaia & С300 & 23 & 38,33 & 37,76 & 4 & 5,96 & 5,93 & 27 & 22,05 & 21,76 & 33 & 54,75 & 55,42 & 6 & 9,20 & 9,22 & 39 & 31,85 & 32,19 \\
\hline 350420 & Auriflama & E20 & 1 & 14,32 & 13,29 & - & - & - & 1 & 7,22 & 6,70 & 3 & 47,75 & 49,62 & - & - & - & 3 & 24,07 & 25,02 \\
\hline 350430 & Avaí & E20 & - & - & - & - & - & - & - & - & - & 1 & 28,01 & 28,64 & - & - & 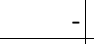 & 1 & 14,56 & 14,89 \\
\hline 350440 & Avanhandava & E20 & 1 & 14,52 & 15,03 & - & - & & 1 & 7,24 & 7,49 & 1 & 14,52 & 14,34 & 1 & 14,42 & 15,84 & 1 & 14,47 & 15,09 \\
\hline 350450 & Avaré & B100 & 11 & 26,44 & 26,29 & 1 & 1,60 & 1,59 & 12 & 14,00 & 13,92 & 11 & 27,24 & 26,99 & 4 & 9,59 & 9,54 & 15 & 18,40 & 18,25 \\
\hline 350460 & Bady Bassitt & A20 & 1 & 14,01 & 14,02 & 0 & 4,75 & 4,99 & 1 & 9,42 & 9,54 & 5 & 74,71 & 73,78 & 0 & 4,75 & 4,75 & 6 & 40,03 & 39,56 \\
\hline 350470 & Balbinos & E20 & - & & & - & - & & - & -1 & & - & - & & - & - & - & - & & - \\
\hline 350480 & Bálsamo & E20 & 0 & 8,81 & 7,52 & - & - & - & 0 & 4,39 & 3,75 & 1 & 26,42 & 27,42 & 0 & 8,76 & 6,07 & 1 & 17,56 & 16,71 \\
\hline 350490 & Bananal & D20 & - & - & - & - & - & - & - & - & & 1 & 26,89 & 26,52 & 0 & 6,62 & 7,01 & 2 & 16,67 & 16,69 \\
\hline 350500 & Barao de Antonina & E20 & 0 & 24,25 & 21,12 & 0 & 25,35 & 21,02 & 1 & 24,79 & 21,07 & 0 & 24,25 & 27,84 & - & - & - & 0 & 12,39 & 14,23 \\
\hline 350510 & Barbosa & E20 & 0 & 10,93 & 9,62 & 0 & 11,14 & 10,18 & 1 & 11,03 & 9,90 & 2 & 54,67 & 54,72 & - & - & 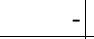 & 2 & 27,59 & 27,61 \\
\hline 350520 & Bariri & D50 & 1 & 6,69 & 6,06 & 0 & 2,24 & 2,06 & 1 & 4,46 & 4,06 & 6 & 37,89 & 38,14 & 0 & 2,24 & 1,99 & 6 & 20,09 & 20,09 \\
\hline 350530 & Barra Bonita & C50 & 2 & 10,66 & 11,10 & - & - & & 2 & 5,32 & 5,54 & 7 & 35,52 & 33,88 & - & - & - & 7 & 17,75 & 16,93 \\
\hline 350535 & Barra do Chapéu & E20 & 1 & 25,80 & 24,05 & - & - & - & 1 & 13,85 & 12,91 & 1 & 25,80 & 26,99 & 0 & 14,96 & 14,81 & 1 & 20,78 & 21,35 \\
\hline 350540 & Barra do Turvo & E20 & 2 & 51,99 & 48,40 & - & - & - & 2 & 27,30 & 25,41 & 6 & 141,12 & 149,19 & 1 & 24,63 & 24,87 & 7 & 85,79 & 90,15 \\
\hline 350550 & Barretos & B300 & 8 & 15,87 & 15,80 & 1 & 2,42 & 2,42 & 10 & 8,97 & 8,95 & 23 & 43,16 & 41,95 & 4 & 6,64 & 6,44 & 26 & 24,45 & 23,75 \\
\hline 350560 & Barrinha & D50 & 7 & 49,40 & 50,06 & 1 & 5,09 & 5,25 & 7 & 27,57 & 27,99 & 5 & 39,52 & 39,37 & - & - & -1 & 5 & 20,05 & 19,98 \\
\hline
\end{tabular}


Anexo 26 - Óbitos, taxas de mortalidade total (bruta e padronizada) e segundo sexo por Homicídios e Acidentes de Trânsito (por 100 mil hab.) nos municípios/estratos de Vulnerabilidade Social. Estado de São Paulo, média do triênio 2003 a 2005.

\begin{tabular}{|c|c|c|c|c|c|c|c|c|c|c|c|c|c|c|c|c|c|c|c|c|}
\hline \multirow[b]{3}{*}{ IBGE } & \multirow[b]{3}{*}{ Mun. } & \multirow{3}{*}{\begin{tabular}{|l} 
Status \\
Estrato \\
\end{tabular}} & \multicolumn{9}{|c|}{ HOMicíDIOS } & \multicolumn{9}{|c|}{ ACIDENTES DE TRANSPORTE } \\
\hline & & & \multicolumn{3}{|c|}{ HOMENS } & \multicolumn{3}{|c|}{ MULHERES } & \multicolumn{3}{|c|}{ TOTAL } & \multicolumn{3}{|c|}{ HOMENS } & \multicolumn{3}{|c|}{ MULHERES } & \multicolumn{3}{|c|}{ TOTAL } \\
\hline & & & Óbitos & TBM & TPM & Óbitos & TBM & TPM & Óbitos & TBM & TPM & Óbitos & TBM & TPM & Óbitos & TBM & TPM & Óbitos & TBM & TPM \\
\hline 350570 & Barueri & C300 & 98 & 81,68 & 83,54 & 5 & 4,34 & 4,38 & 103 & 42,54 & 43,48 & 34 & 28,62 & 31,59 & 8 & 6,51 & 7,85 & 42 & 17,43 & 19,58 \\
\hline 350580 & Bastos & D50 & - & & & 0 & 3,13 & 2,98 & 0 & 1,57 & 1,49 & 4 & 34,66 & 34,48 & - & - & - & 4 & 17,26 & 17,17 \\
\hline 350590 & Batatais & C100 & 7 & 27,25 & 27,14 & - & - & - & 7 & 13,52 & 13,46 & 7 & 24,77 & 23,81 & 1 & 4,88 & 4,41 & 8 & 14,75 & 14,03 \\
\hline 350600 & Bauru & B500 & 44 & 26,44 & 26,56 & 4 & 2,49 & 2,56 & 48 & 14,19 & 14,28 & 38 & 23,03 & 22,58 & 8 & 4,78 & 4,65 & 47 & 13,70 & 13,41 \\
\hline 350610 & Bebedouro & C100 & 5 & 13,87 & 13,55 & 1 & 3,37 & 3,46 & 7 & 8,55 & 8,43 & 15 & 39,01 & 38,33 & 2 & 4,22 & 4,43 & 17 & 21,38 & 21,15 \\
\hline 350620 & Bento de Abreu & $\mathrm{C} 20$ & - & & & - & - & - & - & & & - & & & - & & & - & - & \\
\hline 350630 & Bernardino de Campos & E20 & 1 & 12,19 & 10,54 & - & - & - & 1 & 6,05 & 5,23 & 2 & 30,47 & 27,80 & 0 & 6,01 & 3,71 & 2 & 18,15 & 15,67 \\
\hline 350635 & Bertioga & $\mathrm{C} 50$ & 9 & 47,16 & 46,99 & 1 & 7,19 & 6,96 & 11 & 27,83 & 27,63 & 7 & 33,68 & 33,61 & 1 & 5,39 & 4,87 & 8 & 20,00 & 19,71 \\
\hline 350640 & Bilac & D20 & 0 & 10,64 & 10,24 & - & - & & 0 & 5,24 & 5,04 & 2 & 53,19 & 45,81 & -1 & & & 2 & 26,18 & 22,54 \\
\hline 350650 & Birigui & C300 & 21 & 42,10 & 42,58 & 1 & 1,92 & 1,88 & 22 & 21,71 & 21,93 & 16 & 30,92 & 29,70 & 5 & 9,58 & 9,39 & 21 & 20,09 & 19,39 \\
\hline 350660 & BiritibaOMirim & D50 & 4 & 26,10 & 24,61 & 1 & 7,32 & 6,58 & 5 & 16,85 & 15,72 & 2 & 11,86 & 12,18 & - & - & - & 2 & 6,02 & 6,18 \\
\hline 350670 & Boa Esperança do Sul & E20 & 1 & 19,51 & 18,64 & 0 & 5,04 & 4,65 & 2 & 12,39 & 11,76 & 3 & 39,01 & 40,56 & 0 & 5,04 & 5,47 & 3 & 22,31 & 23,30 \\
\hline 350680 & Bocaina & D20 & 0 & 6,41 & 6,79 & - & - & - & 0 & 3,20 & 3,39 & 2 & 44,88 & 44,23 & 0 & 6,39 & 6,14 & 3 & 25,60 & 25,15 \\
\hline 350690 & Bofete & E20 & 2 & 39,17 & 35,23 & - & - & - & 2 & 20,55 & 18,49 & 3 & 62,67 & 65,59 & 1 & 17,30 & 17,93 & 3 & 41,10 & 42,94 \\
\hline 350700 & Boituva & D50 & 5 & 26,75 & 26,62 & 1 & 3,43 & 3,45 & 6 & 15,23 & 15,18 & 10 & 48,48 & 48,60 & 1 & 6,86 & 6,77 & 11 & 27,93 & 27,95 \\
\hline 350710 & Bom Jesus dos Perdoes & D20 & 5 & 66,97 & 65,14 & 0 & 4,51 & 3,99 & 5 & 35,90 & 34,72 & 5 & 66,97 & 67,47 & - & - & -1 & 5 & 33,65 & 33,91 \\
\hline 350715 & Bom Sucesso de Itararé & E20 & - & & - & - & - & - & - & - & -1 & 1 & 53,12 & 60,04 & - & - & - & 1 & 27,51 & 31,10 \\
\hline 350720 & Borá & E20 & 0 & 80,39 & 74,78 & - & - & - & 0 & 41,17 & 38,30 & - & - & 1 & - & -1 & 1 & - & - & - \\
\hline 350730 & Boracéia & E20 & - & & & - & - & - & - & & & 0 & 16,76 & 18,14 & - & - & - & 0 & 8,62 & 9,33 \\
\hline 350740 & Borborema & D20 & 1 & 19,22 & 17,96 & - & - & - & 1 & 9,75 & 9,11 & 1 & 19,22 & 19,34 & 1 & 19,79 & 19,33 & 3 & 19,50 & 19,34 \\
\hline 350745 & Borebi & E20 & - & - & - & - & - & - & - & - & - & 0 & 29,69 & 32,44 & - & - & - & 0 & 15,36 & 16,78 \\
\hline 350750 & Botucatu & B300 & 14 & 25,28 & 24,91 & 2 & 3,36 & 3,26 & 16 & 14,06 & 13,83 & 18 & 32,33 & 32,20 & 4 & 6,17 & 6,15 & 22 & 18,94 & 18,87 \\
\hline 350760 & Bragança Paulista & B300 & 16 & 23,72 & 23,49 & 2 & 2,42 & 2,32 & 18 & 12,96 & 12,80 & 34 & 50,40 & 49,52 & 6 & 8,24 & 8,28 & 40 & 29,11 & 28,70 \\
\hline 350770 & Braúna & E20 & 0 & 14,71 & 13,93 & - & - & - & 0 & 7,51 & 7,11 & 1 & 44,13 & 42,84 & - & - & - & 1 & 22,53 & 21,88 \\
\hline 350775 & Brejo Alegre & E20 & 0 & 26,23 & 24,29 & - & - & - & 0 & 13,58 & 12,58 & 1 & 78,68 & 73,37 & 0 & 28,16 & 29,31 & 1 & 54,32 & 52,13 \\
\hline 350780 & Brodósqui & $\mathrm{C} 20$ & 2 & 21,36 & 20,31 & 0 & 3,60 & 3,47 & 2 & 12,52 & 11,94 & 2 & 24,91 & 25,95 & - & 1 & - & 2 & 12,52 & 13,04 \\
\hline 350790 & Brotas & D50 & 1 & 12,66 & 11,97 & - & - & - & 1 & 6,38 & 6,04 & 3 & 31,65 & 32,50 & 0 & 3,22 & 3,46 & 4 & 17,55 & 18,10 \\
\hline 350800 & Buri & E20 & 1 & 9,95 & 8,74 & - & -1 & & 1 & 5,23 & 4,60 & 2 & 19,91 & 21,14 & 1 & 11,04 & 11,56 & 3 & 15,70 & 16,59 \\
\hline 350810 & Buritama & E20 & 2 & 23,37 & 22,66 & 0 & 4,62 & 4,10 & 2 & 13,94 & 13,33 & 2 & 23,37 & 22,19 & - & - & - & 2 & 11,62 & 11,03 \\
\hline 350820 & Buritizal & D20 & - & & & - & -1 & - & - & & & 1 & 72,53 & 60,40 & -1 & - & - & 1 & 36,87 & 30,70 \\
\hline 350830 & Cabrália Paulista & E20 & 1 & 26,56 & 24,07 & - & & & 1 & 13,30 & 12,06 & 1 & 53,12 & 53,87 & . & - & -1 & 1 & 26,61 & 26,98 \\
\hline 350840 & Cabreúva & C50 & 8 & 39,57 & 39,15 & 1 & 6,92 & 6,57 & 9 & 23,64 & 23,25 & 5 & 23,09 & 23,47 & 1 & 6,92 & 8,48 & 6 & 15,20 & 16,16 \\
\hline
\end{tabular}


Anexo 26 - Óbitos, taxas de mortalidade total (bruta e padronizada) e segundo sexo por Homicídios e Acidentes de Trânsito (por 100 mil hab.) nos municípios/estratos de Vulnerabilidade Social. Estado de São Paulo, média do triênio 2003 a 2005.

\begin{tabular}{|c|c|c|c|c|c|c|c|c|c|c|c|c|c|c|c|c|c|c|c|c|}
\hline \multirow[b]{3}{*}{ IBGE } & \multirow[b]{3}{*}{ Mun. } & \multirow{3}{*}{\begin{tabular}{|l|} 
Status \\
Estrato \\
\end{tabular}} & \multicolumn{9}{|c|}{ HOMIcíDIOS } & \multicolumn{9}{|c|}{ ACIDENTES DE TRANSPORTE } \\
\hline & & & \multicolumn{3}{|c|}{ HOMENS } & \multicolumn{3}{|c|}{ MULHERES } & \multicolumn{3}{|c|}{ TOTAL } & \multicolumn{3}{|c|}{ HOMENS } & \multicolumn{3}{|c|}{ MULHERES } & \multicolumn{3}{|c|}{ TOTAL } \\
\hline & & & Óbitos & TBM & TPM & Óbitos & TBM & TPM & Óbitos & TBM & TPM & Óbitos & TBM & TPM & Óbitos & TBM & TPM & Óbitos & TBM & TPM \\
\hline 350850 & Caçapava & B100 & 19 & 48,30 & 48,48 & 2 & 5,75 & 5,63 & 22 & 26,87 & 26,91 & 15 & 37,47 & 37,79 & 4 & 9,03 & 9,32 & 19 & 23,15 & 23,45 \\
\hline 350860 & Cachoeira Paulista & B50 & 2 & 16,22 & 15,68 & - & - & & 2 & 8,05 & 7,78 & 7 & 46,35 & 47,00 & 0 & 2,28 & 2,44 & 7 & 24,15 & 24,55 \\
\hline 350870 & Caconde & E20 & 3 & 31,38 & 31,79 & - & - & & 3 & 15,90 & 16,11 & 2 & 20,92 & 18,53 & 0 & 3,58 & 3,03 & 2 & 12,37 & 10,88 \\
\hline 350880 & Cafelândia & D20 & 0 & 4,20 & 4,69 & 0 & 4,11 & 3,66 & 1 & 4,16 & 4,17 & 2 & 25,22 & 23,87 & 2 & 20,57 & 19,32 & 4 & 22,87 & 21,57 \\
\hline 350890 & Caiabu & E20 & - & & & - & & & -1 & & & 1 & 46,69 & 40,86 & 0 & 16,37 & 16,20 & 1 & 31,91 & 28,84 \\
\hline 350900 & Caieiras & C100 & 12 & 28,25 & 28,47 & 1 & 1,55 & 1,61 & 13 & 14,80 & 14,94 & 12 & 28,25 & 28,69 & 3 & 7,73 & 8,93 & 15 & 17,92 & 18,74 \\
\hline 350910 & Caiuá & E20 & 0 & 13,97 & 12,61 & - & - & - & 0 & 7,29 & 6,58 & 1 & 41,92 & 43,65 & - & - & & 1 & 21,87 & 22,77 \\
\hline 350920 & Cajamar & C100 & 12 & 41,92 & 41,93 & 1 & 3,45 & 3,55 & 13 & 22,84 & 22,89 & 13 & 45,32 & 45,63 & 3 & 9,21 & 9,36 & 16 & 27,41 & 27,65 \\
\hline 350925 & Cajati & D50 & 5 & 28,47 & 27,09 & 1 & 4,35 & 3,96 & 5 & 16,81 & 15,91 & 9 & 54,90 & 60,44 & 1 & 8,70 & 8,18 & 10 & 32,58 & 35,19 \\
\hline 350930 & Cajobi & E20 & - & - & - & 0 & 7,36 & 8,30 & 0 & 3,56 & 4,02 & 2 & 34,49 & 34,45 & 1 & 22,08 & 21,96 & 3 & 28,49 & 28,41 \\
\hline 350940 & Cajuru & E50 & 1 & 6,04 & 5,51 & 1 & 9,32 & 9,10 & 2 & 7,66 & 7,28 & 4 & 33,23 & 33,99 & 1 & 9,32 & 9,74 & 5 & 21,44 & 22,03 \\
\hline 350945 & Campina do Monte Alegre & E20 & 0 & 11,21 & 11,60 & - & & & 0 & 5,76 & 5,96 & 0 & 11,21 & 8,05 & 0 & 11,83 & 10,83 & 1 & 11,51 & 9,40 \\
\hline 350950 & Campinas & B10000 & 327 & 65,51 & 67,01 & 25 & 4,76 & 4,85 & 352 & 34,35 & 35,12 & 137 & 27,41 & 26,61 & 28 & 5,27 & 5,09 & 164 & 16,05 & 15,57 \\
\hline 350960 & Campo Limpo Paulista & C100 & 14 & 39,99 & 40,20 & 1 & 2,77 & 2,77 & 15 & 21,32 & 21,42 & 13 & 36,27 & 37,50 & 2 & 6,47 & 6,41 & 15 & 21,32 & 21,90 \\
\hline 350970 & Campos do Jordao & $\mathrm{C} 50$ & 6 & 25,47 & 25,22 & 1 & 5,58 & 5,70 & 7 & 15,46 & 15,40 & 6 & 25,47 & 26,54 & 2 & 6,98 & 7,06 & 8 & 16,16 & 16,74 \\
\hline 350980 & Campos Novos Paulista & E20 & 0 & 15,12 & 13,59 & - & & & 0 & 7,83 & 7,04 & 1 & 45,35 & 36,54 & 0 & 16,26 & 13,93 & 1 & 31,34 & 25,65 \\
\hline 350990 & Cananéia & E20 & 2 & 24,52 & 22,32 & 0 & 5,01 & 5,07 & 2 & 14,88 & 13,79 & 1 & 9,81 & 11,09 & 0 & 5,01 & 5,59 & 1 & 7,44 & 8,37 \\
\hline 350995 & Canas & E20 & - & - & - & - & - & - & - & - & & 3 & 164,69 & 169,52 & 0 & 17,54 & 16,78 & 4 & 93,43 & 95,56 \\
\hline 351000 & Cândido Mota & D50 & 4 & 25,81 & 24,82 & - & - & & 4 & 12,91 & 12,41 & 6 & 36,57 & 36,77 & 0 & 2,15 & 1,77 & 6 & 19,36 & 19,27 \\
\hline 351010 & Cândido Rodrigues & E20 & - & & & - & - & - & - & - & & 1 & 49,62 & 58,49 & - & - & & 1 & 24,33 & 28,69 \\
\hline 351015 & Canitar & E20 & 0 & 16,60 & 15,92 & - & - & - & 0 & 8,44 & 8,10 & 1 & 33,21 & 37,68 & - & - & 1 & 1 & 16,89 & 19,17 \\
\hline 351020 & Capao Bonito & E50 & 7 & 31,14 & 28,92 & 0 & 1,43 & 1,29 & 8 & 16,36 & 15,17 & 12 & 52,38 & 55,91 & 3 & 12,87 & 14,50 & 15 & 32,72 & 35,31 \\
\hline 351030 & Capela do Alto & D20 & 3 & 32,88 & 30,83 & - & & & 3 & 16,88 & 15,83 & 4 & 45,21 & 46,93 & - & & & 4 & 23,21 & 24,09 \\
\hline 351040 & Capivari & $\mathrm{C} 50$ & 3 & 14,99 & 15,02 & 1 & 4,45 & 4,21 & 4 & 9,69 & 9,59 & 10 & 46,48 & 46,89 & 1 & 4,45 & 4,59 & 11 & 25,35 & 25,62 \\
\hline 351050 & Caraguatatuba & C100 & 49 & 106,77 & 104,02 & 3 & 6,67 & 6,58 & 52 & 57,06 & 55,62 & 21 & 46,07 & 47,54 & 8 & 17,79 & 18,63 & 29 & 32,02 & 33,18 \\
\hline 351060 & Carapicuíba & C500 & 133 & 73,18 & 74,73 & 8 & 4,04 & 4,13 & 141 & 37,92 & 38,72 & 33 & 17,93 & 18,85 & 6 & 3,16 & 3,29 & 39 & 10,40 & 10,92 \\
\hline 351070 & Cardoso & E20 & 1 & 23,82 & 24,58 & - & & & 1 & 11,80 & 12,18 & 2 & 29,77 & 27,02 & - & - & - & 2 & 14,75 & 13,39 \\
\hline 351080 & Casa Branca & B50 & 4 & 27,62 & 28,41 & 0 & 2,57 & 2,67 & 4 & 15,78 & 16,25 & 6 & 39,12 & 38,44 & 0 & 2,57 & 1,84 & 6 & 21,85 & 21,14 \\
\hline 351090 & Cássia dos Coqueiros & E20 & 1 & 43,71 & 44,62 & - & - & - & 1 & 22,68 & 23,15 & 0 & 21,85 & 19,07 & - & - & - & 0 & 11,34 & 9,90 \\
\hline 351100 & Castilho & E20 & 2 & 30,92 & 29,17 & - & - & & 2 & 15,45 & 14,58 & 2 & 26,50 & 28,89 & - & - & & 2 & 13,24 & 14,44 \\
\hline 351110 & Catanduva & B300 & 12 & 21,15 & 21,03 & 1 & 2,32 & 2,36 & 13 & 11,55 & 11,51 & 30 & 53,78 & 51,79 & 4 & 7,55 & 7,78 & 34 & 30,20 & 29,34 \\
\hline 351120 & Catiguá & E20 & - & - & - & - & - & - & - & - & & 1 & 38,81 & 37,81 & - & - & -1 & 1 & 19,94 & 19,42 \\
\hline
\end{tabular}


Anexo 26 - Óbitos, taxas de mortalidade total (bruta e padronizada) e segundo sexo por Homicídios e Acidentes de Trânsito (por 100 mil hab.) nos municípios/estratos de Vulnerabilidade Social. Estado de São Paulo, média do triênio 2003 a 2005.

\begin{tabular}{|c|c|c|c|c|c|c|c|c|c|c|c|c|c|c|c|c|c|c|c|c|}
\hline \multirow[b]{3}{*}{ IBGE } & \multirow[b]{3}{*}{ Mun. } & \multirow{3}{*}{\begin{tabular}{|l|} 
Status \\
Estrato \\
\end{tabular}} & \multicolumn{9}{|c|}{ HOMıcídIOS } & \multicolumn{9}{|c|}{ ACIDENTES DE TRANSPORTE } \\
\hline & & & \multicolumn{3}{|c|}{ HOMENS } & \multicolumn{3}{|c|}{ MULHERES } & \multicolumn{3}{|c|}{ TOTAL } & \multicolumn{3}{|c|}{ HOMENS } & \multicolumn{3}{|c|}{ MULHERES } & \multicolumn{3}{|c|}{ TOTAL } \\
\hline & & & óbitos & TBM & TPM & Óbitos & TBM & TPM & Óbitos & TBM & TPM & Óbitos & TBM & TPM & Óbitos & TBM & TPM & Óbitos & TBM & TPM \\
\hline 351130 & Cedral & E20 & 1 & 18,53 & 20,16 & 0 & 9,40 & 8,84 & 1 & 14,00 & 14,54 & 1 & 18,53 & 19,17 & - & - & - & 1 & 9,33 & 9,65 \\
\hline 351140 & Cerqueira César & D20 & - & & & - & & & & & & 3 & 37,11 & 36,30 & 0 & 4,12 & 4,36 & 3 & 20,62 & 20,33 \\
\hline 351150 & Cerquilho & B50 & 3 & 15,81 & 16,10 & 1 & 3,95 & 3,99 & 3 & 9,88 & 10,04 & 11 & 65,23 & 64,04 & 2 & 13,83 & 13,82 & 13 & 39,52 & 38,93 \\
\hline 351160 & Cesário Lange & E20 & 0 & 4,66 & 4,95 & - & & - & 0 & 2,44 & 2,59 & 2 & 32,61 & 31,79 & 0 & 5,13 & 5,07 & 3 & 19,53 & 19,07 \\
\hline 351170 & Charqueada & D20 & 0 & 4,71 & 5,62 & 1 & 9,54 & 9,05 & 1 & 7,11 & 7,32 & 3 & 42,37 & 42,80 & 0 & 4,77 & 5,12 & 3 & 23,70 & 24,09 \\
\hline 355720 & Chavantes & D20 & 1 & 16,17 & 15,55 & - & & - & 1 & 8,06 & 7,75 & 2 & 26,95 & 28,90 & 1 & 16,07 & 15,49 & 3 & 21,49 & 22,18 \\
\hline 351190 & Clementina & E20 & 1 & 45,62 & 47,94 & 1 & 24,57 & 24,17 & 2 & 35,48 & 36,50 & 1 & 34,22 & 34,77 & 2 & 61,42 & 61,94 & 3 & 47,31 & 47,85 \\
\hline 351200 & Colina & D20 & 3 & 39,10 & 36,87 & 0 & 3,93 & 3,73 & 4 & 21,57 & 20,35 & 3 & 35,19 & 36,01 & 0 & 3,93 & 3,87 & 3 & 19,61 & 19,98 \\
\hline 351210 & Colômbia & E20 & 1 & 20,54 & 19,92 & 0 & 11,08 & 10,46 & 1 & 15,99 & 15,37 & 1 & 30,81 & 29,77 & - & & & 1 & 15,99 & 15,45 \\
\hline 351220 & Conchal & E50 & 4 & 32,84 & 31,30 & 1 & 5,55 & 5,35 & 5 & 19,29 & 18,41 & 8 & 68,42 & 71,31 & 1 & 11,10 & 11,23 & 10 & 39,95 & 41,47 \\
\hline 351230 & Conchas & $\mathrm{C} 20$ & 1 & 12,04 & 11,63 & - & - & - & 1 & 6,15 & 5,94 & 4 & 44,16 & 46,55 & 0 & 4,19 & 3,92 & 4 & 24,62 & 25,71 \\
\hline 351240 & Cordeirópolis & C20 & 1 & 6,84 & 7,03 & 0 & 3,42 & 3,41 & 1 & 5,13 & 5,22 & 5 & 51,30 & 50,99 & 1 & 13,68 & 13,86 & 6 & 32,49 & 32,43 \\
\hline 351250 & Coroados & E20 & 1 & 28,89 & 29,73 & 0 & 14,62 & 14,85 & 1 & 21,80 & 22,33 & 1 & 57,77 & 63,65 & 0 & 14,62 & 15,46 & 2 & 36,33 & 39,71 \\
\hline 351260 & Coronel Macedo & E20 & 0 & 11,75 & 10,24 & - & - & - & 0 & 6,04 & 5,26 & 1 & 23,50 & 26,12 & 0 & 12,43 & 13,86 & 1 & 18,12 & 20,16 \\
\hline 351270 & Corumbataí & D20 & - & & - & - & - & - & - & - & & - & - & $t$ & 1 & 51,45 & 55,06 & 1 & 24,52 & 26,24 \\
\hline 351280 & Cosmópolis & B50 & 14 & 56,75 & 57,06 & 2 & 6,94 & 7,01 & 15 & \begin{tabular}{|l|}
31,89 \\
\end{tabular} & 32,08 & 6 & 24,91 & 24,93 & 2 & 6,94 & 6,99 & 8 & 15,94 & 15,97 \\
\hline 351290 & Cosmorama & E20 & - & & & - & - & - & - & - & & 3 & 91,94 & 94,94 & 0 & 9,41 & 7,07 & 4 & 51,16 & 51,52 \\
\hline 351300 & Cotia & С 300 & 65 & 78,49 & 78,53 & 6 & 6,69 & 6,84 & 71 & 42,18 & 42,27 & 26 & 31,80 & 32,83 & 7 & 8,26 & 8,42 & 33 & 19,90 & 20,48 \\
\hline 351310 & Cravinhos & D50 & 2 & 14,77 & 14,44 & - & - & - & 2 & 7,52 & 7,36 & 3 & 21,10 & 21,40 & 1 & 6,57 & 6,74 & 4 & 13,97 & 14,21 \\
\hline 351320 & Cristais Paulista & E20 & 1 & 36,89 & 35,45 & - & - & - & 1 & \begin{tabular}{|l|}
19,06 \\
\end{tabular} & 18,31 & 3 & 73,78 & 78,51 & 1 & 19,72 & 18,68 & 3 & 47,65 & 49,59 \\
\hline 351330 & Cruzália & D20 & - & - & - & - & - & - & - & - & - & 1 & 51,31 & 48,94 & - & - & 1 & 1 & 25,77 & 24,58 \\
\hline 351340 & Cruzeiro & B100 & 9 & 24,26 & 23,84 & 0 & 0,86 & 0,87 & 9 & 12,34 & 12,13 & 12 & 31,45 & 31,74 & 2 & 5,19 & 5,26 & 14 & 18,06 & 18,24 \\
\hline 351350 & Cubatao & C300 & 52 & 89,63 & 91,63 & 3 & 5,21 & 5,43 & 55 & 47,71 & 48,83 & 28 & 47,95 & 48,46 & 5 & 9,26 & 10,02 & 33 & 28,74 & 29,38 \\
\hline 351360 & Cunha & E50 & 3 & 25,25 & 22,93 & - & - & - & 3 & 13,09 & 11,88 & 4 & 33,67 & 34,21 & 0 & 3,02 & 3,34 & 4 & 18,90 & 19,33 \\
\hline 351370 & Descalvado & D50 & 4 & 24,24 & 24,96 & 0 & 2,19 & 2,29 & 4 & 13,18 & 13,60 & 3 & 19,83 & 19,79 & 1 & 4,38 & 4,65 & 4 & 12,09 & 12,20 \\
\hline 351380 & Diadema & C500 & 203 & 109,05 & 113,63 & 16 & 8,26 & 8,75 & 219 & 57,69 & 60,18 & 59 & 31,64 & 32,48 & 20 & 10,32 & 11,09 & 79 & 20,78 & 21,58 \\
\hline 351385 & Dirce Reis & E20 & & & & - & - & - & & & & 0 & 43,16 & 34,04 & 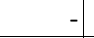 & 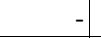 & - & 0 & 22,26 & 17,56 \\
\hline 351390 & Divinolândia & E20 & 1 & 21,55 & 23,06 & - & - & - & 1 & 11,01 & 11,78 & 2 & 32,33 & 28,68 & - & 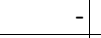 & $t$ & 2 & 16,52 & 14,65 \\
\hline 351400 & Dobrada & E20 & 2 & 53,80 & 53,53 & 0 & 10,01 & 10,92 & 2 & 33,11 & 33,39 & 0 & 8,97 & 8,03 & -1 & - & - & 0 & 4,73 & 4,23 \\
\hline 351410 & Dois Córregos & D50 & 4 & 35,73 & 34,57 & - & - & - & 4 & 17,93 & 17,35 & 6 & 46,73 & 47,19 & 1 & 8,30 & 9,08 & 7 & 27,58 & 28,20 \\
\hline 351420 & Dolcinópolis & E20 & - & - & - & - & -1 & - & - & 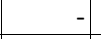 & & - & - & - & 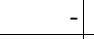 & $t$ & - & - & - & - \\
\hline 351430 & Dourado & E20 & -1 & - & & - & - & - & - & -1 & & 2 & 43,46 & 39,50 & -1 & -1 & - & 2 & 22,24 & 20,21 \\
\hline
\end{tabular}


Anexo 26 - Óbitos, taxas de mortalidade total (bruta e padronizada) e segundo sexo por Homicídios e Acidentes de Trânsito (por 100 mil hab.) nos municípios/estratos de Vulnerabilidade Social. Estado de São Paulo, média do triênio 2003 a 2005.

\begin{tabular}{|c|c|c|c|c|c|c|c|c|c|c|c|c|c|c|c|c|c|c|c|c|}
\hline \multirow[b]{3}{*}{ IBGE } & \multirow[b]{3}{*}{ Mun. } & \multirow{3}{*}{\begin{tabular}{|l|} 
Status \\
Estrato \\
\end{tabular}} & \multicolumn{9}{|c|}{ HOMIcíDIOS } & \multicolumn{9}{|c|}{ ACIDENTES DE TRANSPORTE } \\
\hline & & & \multicolumn{3}{|c|}{ HOMENS } & \multicolumn{3}{|c|}{ MULHERES } & \multicolumn{3}{|c|}{ TOTAL } & \multicolumn{3}{|c|}{ HOMENS } & \multicolumn{3}{|c|}{ MULHERES } & \multicolumn{3}{|c|}{ TOTAL } \\
\hline & & & Óbitos & TBM & TPM & Óbitos & TBM & TPM & Óbitos & TBM & TPM & Óbitos & TBM & TPM & Óbitos & TBM & TPM & Óbitos & TBM & TPM \\
\hline 351440 & Dracena & D50 & 3 & 16,76 & 15,62 & 0 & 1,59 & 1,44 & 4 & 8,97 & 8,34 & 7 & 35,19 & 33,18 & 3 & 15,89 & 15,04 & 10 & 25,29 & 23,87 \\
\hline 351450 & Duartina & E20 & 0 & 5,34 & 4,95 & 0 & 5,13 & 5,62 & 1 & 5,24 & 5,29 & 1 & 21,37 & 23,49 & 0 & 5,13 & 5,51 & 2 & 13,09 & 14,32 \\
\hline 351460 & Dumont & D20 & 1 & 18,92 & 18,98 & - & - & & 1 & 9,66 & 9,70 & 1 & 37,84 & 36,09 & - & & & 1 & 19,33 & 18,43 \\
\hline 351470 & Echapora & E20 & - & & & - & - & - & - & - & & 1 & 37,82 & 36,45 & 0 & 9,45 & 10,29 & 2 & 23,63 & 23,37 \\
\hline 351480 & Eldorado & D20 & 2 & 30,79 & 26,60 & 0 & 4,76 & 3,65 & 3 & 18,28 & 15,57 & 1 & 8,80 & 11,38 & 1 & 19,02 & 24,19 & 2 & 13,71 & 17,53 \\
\hline 351490 & Elias Fausto & D20 & 1 & 17,40 & 17,01 & 2 & 23,04 & 23,19 & 3 & 20,14 & 20,01 & 4 & 47,85 & 48,94 & 0 & 4,61 & 4,23 & 4 & 26,85 & 27,23 \\
\hline 351492 & Elisiário & E20 & - & & & - & & & - & & & 1 & 49,03 & 51,37 & - & & & 1 & 25,76 & 26,98 \\
\hline 351495 & Embaúba & E20 & - & & & - & - & & - & - & & - & -1 & & - & - & - & - & -1 & - \\
\hline 351500 & Embu & С300 & 115 & 101,28 & 102,47 & 11 & 9,39 & 9,54 & 126 & 54,61 & 55,27 & 30 & 26,13 & 28,29 & 7 & 5,97 & 7,03 & 37 & 15,89 & 17,49 \\
\hline 351510 & Embu0Guaçu & C100 & 38 & 113,55 & 109,37 & 2 & 7,08 & 6,89 & 40 & 60,48 & 58,29 & 8 & 23,11 & 24,15 & 2 & 7,08 & 7,79 & 10 & 15,12 & 16,00 \\
\hline 351512 & Emilianópolis & E20 & 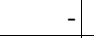 & & & - & & & - & & & 0 & 22,67 & 22,58 & - & & & 0 & 11,52 & 11,48 \\
\hline 351515 & Engenheiro Coelho & D20 & 1 & 22,14 & 21,27 & - & - & - & 1 & 11,48 & 11,04 & 4 & 60,88 & 55,88 & 1 & 23,86 & 20,92 & 5 & 43,06 & 39,05 \\
\hline 351518 & Espírito Santo do Pinhal & C50 & 5 & 24,08 & 25,27 & 1 & 4,72 & 4,43 & 6 & 14,30 & 14,75 & 6 & 30,50 & 29,99 & 1 & 3,15 & 2,63 & 7 & 16,68 & 16,17 \\
\hline 351519 & Espírito Santo do Turvo & D20 & 0 & 16,16 & 14,69 & 0 & 17,31 & 16,48 & 1 & 16,71 & 15,55 & 0 & 16,16 & 17,77 & 0 & 17,31 & 18,16 & 1 & 16,71 & 17,96 \\
\hline 355730 & Estiva Gerbi & $\mathrm{C} 20$ & - & -1 & - & - & - & & - & -1 & & 1 & 13,13 & 13,23 & 0 & 7,01 & 8,20 & 1 & 10,17 & 10,79 \\
\hline 351530 & Estrela do Norte & E20 & - & - & & - & - & & - & - & & - & & & - & - & 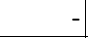 & - & & \\
\hline 351520 & Estrela d'Oeste & E20 & - & & & - & - & & - & - & & 3 & 80,46 & 77,14 & - & - & - & 3 & 40,90 & 39,21 \\
\hline 351535 & Euclides da Cunha Paulist & E20 & 1 & 18,81 & 17,08 & - & - & & 1 & 9,52 & 8,64 & 1 & 18,81 & 19,68 & 0 & 6,42 & 7,20 & 1 & 12,69 & 13,51 \\
\hline 351540 & Fartura & E20 & 2 & 21,76 & 20,20 & 0 & 4,35 & 4,01 & 2 & 13,06 & 12,11 & 1 & 13,06 & 13,69 & - & - & & 1 & 6,53 & 6,85 \\
\hline 351560 & Fernando Prestes & E20 & 0 & 12,14 & 22,40 & - & & & 0 & 6,01 & 11,09 & 2 & 60,69 & 62,02 & 0 & 11,89 & 9,30 & 2 & 36,04 & 35,39 \\
\hline 351550 & Fernandópolis & D100 & 4 & 11,62 & 11,85 & 1 & 2,05 & 2,21 & 4 & 6,76 & 6,96 & 12 & 39,09 & 37,27 & 3 & 8,19 & 7,14 & 15 & 23,40 & 21,97 \\
\hline 351565 & Fernao & D20 & el & & & - & & & - & & & & & & -1 & & & - & & \\
\hline 351570 & Ferraz de Vasconcelos & C300 & 67 & 83,36 & 82,66 & 4 & 4,44 & 4,67 & 71 & 43,35 & 43,12 & 15 & 18,66 & 20,18 & 3 & 3,23 & 3,62 & 18 & 10,84 & 11,79 \\
\hline 351580 & Flora Rica & E20 & - & & & - & - & - & - & - & & - & - & & 0 & 32,01 & 27,76 & 0 & 15,97 & 13,85 \\
\hline 351590 & Floreal & E20 & - & & & - & - & & - & & & 1 & 65,25 & 60,43 & 1 & 64,71 & 72,87 & 2 & 64,98 & 66,67 \\
\hline 351600 & Flórida Paulista & E20 & 1 & 25,41 & 24,79 & - & - & . & 1 & 12,72 & 12,42 & 2 & 44,47 & 44,34 & - & - & - & 2 & 22,27 & 22,20 \\
\hline 351610 & Florínia & E20 & - & & - & - & - & - & - & - & & - & - & - & - & - & - & - & - & - \\
\hline 351620 & Franca & B500 & 29 & 18,59 & 18,27 & 4 & 2,53 & 2,53 & 33 & 10,47 & 10,31 & 62 & 40,20 & 40,84 & 12 & 7,39 & 7,48 & 74 & 23,60 & 23,96 \\
\hline 351630 & Francisco Morato & D300 & 64 & 81,83 & 78,67 & 4 & 4,69 & 4,46 & 67 & 43,16 & 41,47 & 18 & 22,71 & 25,22 & 3 & 4,26 & 5,48 & 21 & 13,46 & 15,33 \\
\hline 351640 & Franco da Rocha & С 300 & 40 & 65,36 & 66,80 & 3 & 5,85 & 5,69 & 43 & 36,66 & 37,33 & 18 & 29,96 & 31,64 & 4 & 6,43 & 6,99 & 22 & 18,61 & 19,75 \\
\hline 351650 & Gabriel Monteiro & E20 & - & - & & - & - & 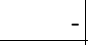 & - & - & & 2 & 136,27 & 134,52 & - & 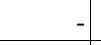 & & 2 & 70,46 & 69,55 \\
\hline 351660 & Gália & E20 & 1 & 17,66 & 16,34 & - & & & 1 & 8,98 & 8,30 & 1 & 26,49 & 29,42 & -1 & & & 1 & 13,46 & 14,95 \\
\hline
\end{tabular}


Anexo 26 - Óbitos, taxas de mortalidade total (bruta e padronizada) e segundo sexo por Homicídios e Acidentes de Trânsito (por 100 mil hab.) nos municípios/estratos de Vulnerabilidade Social. Estado de São Paulo, média do triênio 2003 a 2005.

\begin{tabular}{|c|c|c|c|c|c|c|c|c|c|c|c|c|c|c|c|c|c|c|c|c|}
\hline \multirow[b]{3}{*}{ IBGE } & \multirow[b]{3}{*}{ Mun. } & \multirow{3}{*}{$\begin{array}{l}\text { Status } \\
\text { Estrato } \\
\end{array}$} & \multicolumn{9}{|c|}{ HOMıcídIOS } & \multicolumn{9}{|c|}{ ACIDENTES DE TRANSPORTE } \\
\hline & & & \multicolumn{3}{|c|}{ HOMENS } & \multicolumn{3}{|c|}{ MULHERES } & \multicolumn{3}{|c|}{ TOTAL } & \multicolumn{3}{|c|}{ HOMENS } & \multicolumn{3}{|c|}{ MULHERES } & \multicolumn{3}{|c|}{ TOTAL } \\
\hline & & & Óbitos & TBM & TPM & Óbitos & TBM & TPM & Óbitos & TBM & TPM & Óbitos & TBM & TPM & Óbitos & TBM & TPM & Óbitos & TBM & TPM \\
\hline 351670 & Garça & D50 & 3 & 12,35 & 11,82 & 2 & 7,47 & 7,26 & 4 & 9,87 & 9,50 & 6 & 26,24 & 25,42 & 1 & 5,97 & 6,15 & 7 & 15,94 & 15,63 \\
\hline 351680 & Gastao Vidigal & E20 & 0 & 19,12 & 17,67 & - & - & & 0 & 9,59 & 8,86 & 1 & 38,24 & 33,80 & 1 & 38,50 & 32,89 & 1 & 38,37 & 33,35 \\
\hline 351685 & Gaviao Peixoto & E20 & 0 & 15,32 & 14,53 & - & - & - & 0 & 8,16 & 7,74 & 1 & 45,95 & 49,33 & - & - & & 1 & 24,48 & 26,29 \\
\hline 351690 & General Salgado & E20 & 0 & 5,94 & 5,74 & - & - & - & 0 & 3,02 & 2,92 & 3 & 47,56 & 48,65 & - & - & & 3 & 24,19 & 24,75 \\
\hline 351700 & Getulina & E20 & 1 & 11,83 & 12,47 & - & - & & 1 & 6,36 & 6,71 & 2 & 29,57 & 28,24 & 0 & 6,88 & 7,99 & 2 & 19,08 & 18,88 \\
\hline 351710 & Glicério & E20 & 1 & 29,18 & 28,15 & - & - & - & 1 & 14,77 & 14,25 & 0 & 14,59 & 12,61 & - & - & & 0 & 7,38 & 6,38 \\
\hline 351720 & Guaiçara & D20 & 2 & 31,94 & 30,36 & - & - & - & 2 & 15,90 & 15,11 & 1 & 19,16 & 20,01 & 1 & 18,99 & 20,61 & 2 & 19,08 & 20,31 \\
\hline 351730 & Guaimbê & E20 & - & & & - & & & - & & & 1 & 38,21 & 40,63 & - & & & 1 & 19,09 & 20,30 \\
\hline 351740 & Guaíra & C50 & 3 & 16,48 & 16,26 & 0 & 1,85 & 1,83 & 3 & 9,21 & 9,09 & 7 & 40,28 & 39,82 & 1 & 5,56 & 5,53 & 8 & 23,03 & 22,78 \\
\hline 351750 & Guapiaçu & D20 & - & & & - & - & - & - & - & & 3 & 37,77 & 35,68 & 1 & 8,69 & 8,65 & 4 & 23,48 & 22,41 \\
\hline 351760 & Guapiara & E50 & 2 & 19,09 & 17,55 & - & - & - & 2 & 9,82 & 9,03 & 2 & 19,09 & 21,50 & 1 & 6,74 & 6,48 & 3 & 13,09 & 14,20 \\
\hline 351770 & Guará & E50 & 3 & 29,84 & 29,62 & - & - & & 3 & 14,96 & 14,85 & 4 & 36,47 & 37,27 & 1 & 13,33 & 13,39 & 5 & 24,93 & 25,36 \\
\hline 351780 & Guaraçaí & E20 & 0 & 7,21 & 7,09 & - & - & & 0 & 3,64 & 3,58 & - & - & & - & - & 2. & - & & - \\
\hline 351790 & Guaraci & E20 & 1 & 14,08 & 14,05 & 1 & 14,57 & 13,81 & 1 & 14,32 & 13,93 & 1 & 21,13 & 18,35 & 1 & 14,57 & 15,69 & 2 & 17,91 & 17,04 \\
\hline 351800 & Guarani d'Oeste & E20 & 0 & 30,79 & 35,89 & 0 & 33,31 & 31,95 & 1 & 32,00 & 34,00 & 0 & 30,79 & 34,21 & - & - & & 0 & 16,00 & 17,78 \\
\hline 351810 & Guaranta & E20 & 1 & 19,63 & 18,42 & - & & & 1 & 9,99 & 9,38 & 1 & 29,44 & 30,00 & 0 & 10,17 & 11,48 & 1 & 19,98 & 20,90 \\
\hline 351820 & Guararapes & D50 & 9 & 60,86 & 60,86 & - & - & - & 9 & 30,20 & 30,19 & 3 & 22,54 & 23,02 & 1 & 4,44 & 4,50 & 4 & 13,42 & 13,69 \\
\hline 351830 & Guararema & D50 & 6 & 47,22 & 44,25 & 1 & 8,57 & 8,21 & 7 & 28,17 & 26,49 & 3 & 22,22 & 22,58 & 1 & 8,57 & 9,21 & 4 & 15,49 & 15,99 \\
\hline 351840 & Guaratinguetá & B300 & 12 & 23,06 & 23,07 & 1 & 2,38 & 2,29 & 14 & 12,48 & 12,44 & 16 & 30,53 & 30,14 & 4 & 7,14 & 7,20 & 20 & 18,56 & 18,40 \\
\hline 351850 & Guareí & E20 & 2 & 28,95 & 29,28 & 0 & 6,40 & 6,34 & 2 & 18,23 & 18,38 & 2 & 34,74 & 34,79 & - & - & & 2 & 18,23 & 18,26 \\
\hline 351860 & Guariba & E50 & 8 & 51,41 & 51,43 & - & - & - & 8 & 26,00 & 26,01 & 5 & 30,85 & 31,73 & 1 & 6,31 & 5,57 & 6 & 18,72 & 18,80 \\
\hline 351870 & Guarujá & С300 & 83 & 57,84 & 58,19 & 8 & 5,47 & 5,52 & 91 & 31,35 & 31,55 & 26 & 18,42 & 19,40 & 6 & 4,33 & 4,26 & 33 & 11,30 & 11,74 \\
\hline 351880 & Guarulhos & C10000 & 481 & 81,52 & 83,15 & 32 & 5,19 & 5,34 & 513 & 42,72 & 43,60 & 149 & 25,31 & 26,24 & 34 & 5,57 & 6,23 & 183 & 15,28 & 16,07 \\
\hline 351885 & Guatapará & D20 & 1 & 19,49 & 18,47 & - & - & - & 1 & 10,06 & 9,53 & 2 & 48,72 & 48,65 & - & - & - & 2 & 25,15 & 25,11 \\
\hline 351890 & Guzolândia & E20 & - & & & - & - & & - & - & & 1 & 48,48 & 50,79 & - & - & - & 1 & 25,28 & 26,48 \\
\hline 351900 & Herculândia & E20 & 1 & 23,42 & 22,42 & 0 & 8,03 & 7,63 & 1 & 15,84 & 15,13 & 1 & 23,42 & 21,81 & 1 & 32,14 & 32,59 & 2 & 27,71 & 27,13 \\
\hline 351905 & Holambra & $\mathrm{C} 20$ & - & & & - & - & & - & - & & 2 & 40,67 & 41,04 & 0 & 8,52 & 9,76 & 2 & 24,97 & 25,77 \\
\hline 351907 & Hortolândia & С300 & 90 & 98,70 & 99,49 & 6 & 6,22 & 6,12 & 96 & 52,48 & 52,82 & 23 & 24,86 & 26,11 & 6 & 6,58 & 7,19 & 29 & 15,72 & 16,65 \\
\hline 351910 & lacanga & E20 & 0 & 7,68 & 8,72 & - & - & - & 0 & 3,88 & 4,40 & 0 & 7,68 & 6,75 & 0 & 7,83 & 8,62 & 1 & 7,75 & 7,68 \\
\hline 351920 & Iacri & E20 & 0 & 9,94 & 9,70 & - & - & - & 0 & 5,00 & 4,88 & 1 & 29,82 & 29,79 & 1 & 20,11 & 20,82 & 2 & 24,99 & 25,33 \\
\hline 351925 & laras & D20 & 2 & 105,91 & 93,43 & - & & & 2 & 57,89 & 51,06 & 1 & 35,30 & 40,91 & -1 & - & & 1 & 19,30 & 22,36 \\
\hline 351930 & Ibaté & D50 & 5 & 30,78 & 30,77 & 0 & 2,27 & 2,31 & 5 & 16,74 & 16,75 & 6 & 41,78 & 42,42 & 0 & 2,27 & 2,30 & 7 & 22,32 & 22,66 \\
\hline
\end{tabular}


Anexo 26 - Óbitos, taxas de mortalidade total (bruta e padronizada) e segundo sexo por Homicídios e Acidentes de Trânsito (por 100 mil hab.) nos municípios/estratos de Vulnerabilidade Social. Estado de São Paulo, média do triênio 2003 a 2005.

\begin{tabular}{|c|c|c|c|c|c|c|c|c|c|c|c|c|c|c|c|c|c|c|c|c|}
\hline \multirow[b]{3}{*}{ IBGE } & \multirow[b]{3}{*}{ Mun. } & \multirow{3}{*}{\begin{tabular}{|l|} 
Status \\
Estrato \\
\end{tabular}} & \multicolumn{9}{|c|}{ HOMIcíDIOS } & \multicolumn{9}{|c|}{ ACIDENTES DE TRANSPORTE } \\
\hline & & & \multicolumn{3}{|c|}{ HOMENS } & \multicolumn{3}{|c|}{ MULHERES } & \multicolumn{3}{|c|}{ TOTAL } & \multicolumn{3}{|c|}{ HOMENS } & \multicolumn{3}{|c|}{ MULHERES } & \multicolumn{3}{|c|}{ TOTAL } \\
\hline & & & Óbitos & TBM & TPM & Óbitos & TBM & TPM & Óbitos & TBM & TPM & Óbitos & TBM & TPM & Óbitos & TBM & TPM & Óbitos & TBM & TPM \\
\hline 351940 & Ibirá & D20 & 1 & 27,71 & 27,48 & - & - & - & 1 & 13,64 & 13,53 & 1 & 20,79 & 15,31 & 0 & 6,72 & 4,03 & 1 & 13,64 & 9,58 \\
\hline 351950 & |birarema & E20 & - & & & - & & - & & & & 1 & 45,57 & 37,64 & - & & & 1 & 23,07 & 19,06 \\
\hline 351960 & Ibitinga & D100 & 2 & 8,03 & 8,73 & - & t & - & 2 & 3,97 & 4,32 & 5 & 20,07 & 19,45 & 2 & 7,86 & 7,65 & 7 & 13,90 & 13,49 \\
\hline 351970 & Ibiúna & E100 & 29 & 79,18 & 75,31 & 3 & 7,72 & 7,67 & 32 & 44,49 & 42,47 & 14 & 38,22 & 39,98 & 4 & 10,61 & 11,47 & 18 & 24,82 & 26,14 \\
\hline 351980 & Icém & D20 & 1 & 28,01 & 27,68 & - & & - & 1 & 14,14 & 13,97 & 1 & 28,01 & 30,10 & -1 & & - & 1 & 14,14 & 15,20 \\
\hline 351990 & lepê & E20 & - & & & - & & - & -1 & & & - & & & - & & - & - & - & \\
\hline 352000 & Igaraçu do Tietê & D50 & 3 & 22,67 & 23,56 & - & - & - & 3 & 11,40 & 11,85 & 3 & 28,33 & 29,59 & 1 & 8,60 & 8,49 & 4 & 18,52 & 19,10 \\
\hline 352010 & Igarapava & D50 & 3 & 22,13 & 21,90 & 0 & 2,38 & 2,28 & 3 & 12,11 & 11,94 & 3 & 19,67 & 19,34 & - & - & - & 3 & 9,68 & 9,52 \\
\hline 352020 & Igaratá & E20 & 1 & 27,99 & 25,94 & 0 & 7,54 & 6,71 & 2 & 18,14 & 16,68 & 3 & 62,97 & 64,31 & 1 & 15,08 & 15,81 & 4 & 39,92 & 40,96 \\
\hline 352030 & Iguape & E50 & 5 & 34,69 & 32,95 & 1 & 9,64 & 10,28 & 6 & 22,42 & 21,85 & 6 & 43,94 & 43,77 & 1 & 4,82 & 4,78 & 7 & 24,78 & 24,68 \\
\hline 352042 & 2 Iha Comprida & A20 & 1 & 23,29 & 20,66 & - & - & - & 1 & 11,81 & 10,47 & 1 & 15,53 & 13,41 & 0 & 7,98 & 9,56 & 1 & 11,81 & 11,51 \\
\hline 352044 & 4 Ilha Solteira & B50 & 0 & 2,70 & 2,61 & - & & - & 0 & 1,33 & 1,29 & 2 & 18,89 & 17,90 & 0 & 2,63 & 2,27 & 3 & 10,66 & 9,99 \\
\hline 352040 & IIhabela & C50 & 5 & 42,48 & 42,00 & - & - & - & 5 & 22,13 & 21,88 & 4 & 29,21 & 28,88 & 1 & 5,78 & 5,22 & 4 & 17,98 & 17,55 \\
\hline 352050 & Indaiatuba & B300 & 27 & 32,65 & 32,87 & 2 & 2,78 & 2,81 & 30 & 17,70 & 17,82 & 27 & 31,85 & 31,85 & 9 & 10,33 & 10,59 & 35 & 21,08 & 21,21 \\
\hline 352060 & Indiana & E20 & 1 & 25,88 & 25,75 & 0 & 13,36 & 12,87 & 1 & 19,72 & 19,42 & 2 & 77,65 & 68,51 & - & - & - & 2 & 39,45 & 34,80 \\
\hline 352070 & Indiapora & E20 & 0 & 17,83 & 30,62 & - & & - & 0 & 8,91 & 15,30 & 1 & 53,50 & 51,99 & 0 & 17,80 & 19,62 & 1 & 35,63 & 35,79 \\
\hline 352080 & Inúbia Paulista & E20 & - & & & - & - & - & - & - & & - & - & - & - & - & - & - & - & - \\
\hline 352090 & Ipauçu & E20 & 1 & 10,21 & 12,11 & - & - & - & 1 & 5,10 & 6,05 & 3 & 40,83 & 40,20 & 1 & 20,41 & 21,44 & 4 & 30,62 & 30,82 \\
\hline 352100 & Iperó & C50 & 7 & 56,92 & 57,66 & - & - & - & 7 & 30,48 & 30,88 & 4 & 31,30 & 33,24 & 1 & 6,56 & 7,04 & 4 & 19,81 & 21,07 \\
\hline 352110 & Ipeúna & $\mathrm{C} 20$ & 1 & 25,33 & 23,57 & - & - & - & 1 & 13,14 & 12,23 & 1 & 25,33 & 27,21 & - & -1 & - & 1 & 13,14 & 14,11 \\
\hline 352115 & Ipiguá & E20 & - & - & - & - & - & - & - & - & - & 1 & 48,59 & 50,72 & 0 & 17,30 & 18,47 & 1 & 33,46 & 35,12 \\
\hline 352120 & Iporanga & E20 & 1 & 28,28 & 23,02 & - & - & - & 1 & 14,68 & 11,95 & 0 & 14,14 & 10,99 & - & -1 & - & 0 & 7,34 & 5,71 \\
\hline 352130 & Ipua & D20 & 1 & 15,61 & 15,45 & - & & - & 1 & 7,97 & 7,89 & 3 & 46,84 & 46,39 & 1 & 16,28 & 16,88 & 4 & 31,88 & 31,95 \\
\hline 352140 & Iracemápolis & $\mathrm{C} 20$ & 1 & 15,31 & 16,11 & 0 & 3,90 & 4,05 & 2 & 9,66 & 10,14 & 2 & 22,96 & 22,70 & 1 & 7,80 & 8,03 & 3 & 15,45 & 15,43 \\
\hline 352150 & Irapua & E20 & 0 & 9,35 & 8,44 & - & - & - & 0 & 4,82 & 4,35 & 0 & 9,35 & 10,36 & 0 & 9,95 & 10,32 & 1 & 9,65 & 10,34 \\
\hline 352160 & Irapuru & E20 & 0 & 9,31 & 7,95 & - & & - & 0 & 4,69 & 4,01 & 1 & 27,93 & 28,48 & 0 & 9,47 & 5,97 & 1 & 18,77 & 17,31 \\
\hline 352170 & Itaberá & E20 & 1 & 10,17 & 9,36 & - & & - & 1 & 5,16 & 4,75 & 5 & 50,87 & 52,16 & - & - & & 5 & 25,82 & 26,48 \\
\hline 352180 & Itaí & E50 & 1 & 11,56 & 11,07 & 0 & 3,05 & 2,79 & 2 & 7,42 & 7,04 & 4 & 34,67 & 35,42 & 0 & 3,05 & 2,91 & 4 & 19,28 & 19,60 \\
\hline 352190 & Itajobi & E20 & 0 & 4,50 & 4,27 & 0 & 4,57 & 5,46 & 1 & 4,54 & 4,86 & 4 & 49,45 & 50,70 & 2 & 22,87 & 20,53 & 5 & 36,28 & 35,75 \\
\hline 352200 & Itaju & E20 & - & & & - & & - & - & & & 1 & 46,40 & 43,60 & - & - & & 1 & 24,14 & 22,68 \\
\hline 352210 & Itanhaém & C100 & 21 & 51,33 & 48,31 & 1 & 3,17 & 3,14 & 23 & 27,12 & 25,61 & 19 & 44,91 & 47,52 & 6 & 13,49 & 13,73 & 24 & 29,12 & 30,53 \\
\hline 352215 & Itaóca & E20 & -1 & - & & - & & - & - & & & - & -1 & -1 & -1 & -1 & - & -1 & & \\
\hline
\end{tabular}


Anexo 26 - Óbitos, taxas de mortalidade total (bruta e padronizada) e segundo sexo por Homicídios e Acidentes de Trânsito (por 100 mil hab.) nos municípios/estratos de Vulnerabilidade Social. Estado de São Paulo, média do triênio 2003 a 2005.

\begin{tabular}{|c|c|c|c|c|c|c|c|c|c|c|c|c|c|c|c|c|c|c|c|c|}
\hline \multirow[b]{3}{*}{ IBGE } & \multirow[b]{3}{*}{ Mun. } & \multirow{3}{*}{\begin{tabular}{|l} 
Status \\
Estrato
\end{tabular}} & \multicolumn{9}{|c|}{ HOMıcídIOS } & \multicolumn{9}{|c|}{ ACIDENTES DE TRANSPORTE } \\
\hline & & & \multicolumn{3}{|c|}{ HOMENS } & \multicolumn{3}{|c|}{ MULHERES } & \multicolumn{3}{|c|}{ TOTAL } & \multicolumn{3}{|c|}{ HOMENS } & \multicolumn{3}{|c|}{ MULHERES } & \multicolumn{3}{|c|}{ TOTAL } \\
\hline & & & Óbitos & TBM & TPM & Óbitos & TBM & TPM & Óbitos & TBM & TPM & Óbitos & TBM & TPM & Óbitos & TBM & TPM & Óbitos & TBM & TPM \\
\hline 352220 & Itapecerica da Serra & C300 & 80 & 107,92 & 107,89 & 8 & 10,15 & 10,21 & 87 & 58,47 & 58,49 & 27 & 36,12 & 39,50 & 5 & 6,18 & 6,23 & 31 & 20,98 & 22,67 \\
\hline 352230 & Itapetininga & B300 & 19 & 27,37 & 26,85 & 2 & 2,45 & 2,35 & 20 & 14,93 & 14,62 & 26 & 38,62 & 39,22 & 7 & 10,79 & 11,09 & 34 & 24,73 & 25,18 \\
\hline 352240 & Itapeva & D100 & 8 & 17,80 & 16,59 & 1 & 1,52 & 1,62 & 8 & 9,58 & 9,03 & 17 & 38,70 & 40,35 & 3 & 7,58 & 8,59 & 20 & 22,98 & 24,31 \\
\hline 352250 & Itapevi & C300 & 77 & 83,30 & 82,49 & 7 & 7,07 & 6,60 & 84 & 44,80 & 44,17 & 20 & 21,27 & 23,63 & 6 & 6,36 & 6,94 & 26 & 13,74 & 15,20 \\
\hline 352260 & Itapira & D100 & 12 & 35,07 & 34,24 & 1 & 4,02 & 3,97 & 13 & 19,58 & 19,13 & 19 & 56,11 & 56,18 & 2 & 5,03 & 5,25 & 20 & 30,62 & 30,76 \\
\hline 352265 & Itapirapua Paulista & E20 & 1 & 34,03 & 30,74 & - & - & -1 & 1 & 17,93 & 16,20 & 0 & 17,02 & 23,16 & - & - & 1 & 0 & 8,97 & 12,20 \\
\hline 352270 & Itápolis & D50 & 2 & 11,73 & 11,50 & 1 & 6,68 & 6,91 & 4 & 9,20 & 9,20 & 8 & 40,23 & 38,57 & 0 & 1,67 & 1,50 & 8 & 20,91 & 20,00 \\
\hline 352280 & Itaporanga & E20 & 1 & 9,22 & 7,68 & 0 & 4,69 & 4,67 & 1 & 6,98 & 6,19 & 6 & 78,40 & 73,25 & 1 & 18,78 & 18,87 & 7 & 48,85 & 46,30 \\
\hline 352290 & Itapuí & E20 & 1 & 17,78 & 17,56 & - & - & - & 1 & 9,12 & 9,01 & 2 & 35,55 & 36,85 & - & - & - & 2 & 18,25 & 18,92 \\
\hline 352300 & Itapura & E20 & - & - & -1 & 0 & 18,04 & 16,41 & 0 & 8,60 & 7,82 & 0 & 16,43 & 19,21 & - & - & - & 0 & 8,60 & 10,05 \\
\hline 352310 & Itaquaquecetuba & C500 & 145 & 90,46 & 88,52 & 9 & 5,80 & 5,37 & 154 & 48,05 & 46,87 & 32 & 19,96 & 20,73 & 7 & 4,35 & 5,17 & 39 & 12,14 & 12,93 \\
\hline 352320 & Itararé & D50 & 4 & 16,60 & 15,42 & 1 & 5,43 & 4,98 & 5 & 10,96 & 10,15 & 9 & 38,73 & 40,86 & 3 & 12,21 & 12,78 & 12 & 25,35 & 26,69 \\
\hline 352330 & Itariri & D20 & 4 & 58,37 & 52,57 & 0 & 4,70 & 6,80 & 5 & 32,17 & 30,22 & 5 & 71,85 & 76,95 & 1 & 9,41 & 9,24 & 6 & 41,36 & 43,88 \\
\hline 352340 & Itatiba & B100 & 11 & 25,30 & 25,71 & 1 & 1,48 & 1,48 & 12 & 13,34 & 13,55 & 16 & 36,45 & 35,53 & 3 & 6,65 & 6,67 & 19 & 21,50 & 21,05 \\
\hline 352350 & Itatinga & E20 & 1 & 16,08 & 15,57 & - & - & 1 & 1 & 8,23 & 7,97 & 2 & 24,12 & 26,23 & 2 & 21,10 & 23,01 & 4 & 22,64 & 24,66 \\
\hline 352360 & Itirapina & $\mathrm{C} 20$ & 2 & 25,42 & 26,56 & - & - & - & 2 & 14,16 & 14,80 & 3 & 38,13 & 37,06 & 1 & 21,32 & 20,51 & 4 & 30,68 & 29,73 \\
\hline 352370 & Itirapua & E20 & 1 & 34,40 & 34,22 & - & - & - & 1 & 17,94 & 17,84 & 2 & 80,26 & 75,56 & 1 & 37,48 & 39,87 & 3 & 59,79 & 58,48 \\
\hline 352380 & Itobi & E20 & 1 & 16,52 & 14,87 & - & - & - & 1 & 8,58 & 7,72 & 1 & 24,77 & 26,45 & 1 & 26,78 & 27,91 & 2 & 25,74 & 27,15 \\
\hline 352390 & Itu & C300 & 23 & 30,75 & 30,66 & 4 & 4,94 & 4,96 & 26 & 17,81 & 17,77 & 28 & 37,99 & 38,49 & 5 & 6,29 & 6,38 & 33 & 22,09 & 22,38 \\
\hline 352400 & Itupeva & C50 & 4 & 28,41 & 28,68 & 1 & 4,60 & 4,91 & 5 & 16,81 & 17,10 & 8 & 50,27 & 51,51 & 1 & 9,19 & 10,37 & 9 & 30,25 & 31,46 \\
\hline 352410 & Ituverava & D50 & 7 & 39,29 & 40,32 & 2 & 8,74 & 8,38 & 9 & 23,86 & 24,18 & 5 & 25,00 & 24,78 & 0 & 1,75 & 1,86 & 5 & 13,25 & 13,20 \\
\hline 352420 & Jaborandi & E20 & 1 & 20,05 & 19,82 & - & - & - & 1 & 10,31 & 10,20 & 1 & 20,05 & 18,49 & 0 & 10,62 & 9,64 & 1 & 15,47 & 14,19 \\
\hline 352430 & Jaboticabal & B100 & 15 & 43,01 & 43,24 & 2 & 4,60 & 4,45 & 17 & 23,44 & 23,48 & 10 & 29,63 & 29,59 & 2 & 5,52 & 5,04 & 12 & 17,35 & 17,08 \\
\hline 352440 & Jacareí & B300 & 55 & 54,62 & 54,55 & 4 & 4,21 & 4,19 & 59 & 29,15 & 29,11 & 37 & 36,75 & 36,92 & 6 & 5,83 & 5,98 & 43 & 21,13 & 21,28 \\
\hline 352450 & Jaci & E20 & 0 & 14,26 & 14,08 & - & - & - & 0 & 7,39 & 7,30 & 1 & 57,05 & 55,53 & - & & - & 1 & 29,56 & 28,78 \\
\hline 352460 & Jacupiranga & D20 & 1 & 14,33 & 14,78 & - & & & 1 & 7,32 & 7,55 & 6 & 60,90 & 65,45 & 1 & 11,23 & 13,09 & 7 & 36,62 & 39,85 \\
\hline 352470 & Jaguariúna & B50 & 6 & 38,35 & 38,92 & 2 & 10,28 & 10,44 & 8 & 24,44 & 24,81 & 7 & 42,39 & 41,86 & 2 & 12,34 & 12,15 & 9 & 27,50 & 27,14 \\
\hline 352480 & Jales & D50 & 2 & 9,75 & 10,07 & - & - & - & 2 & 4,83 & 4,98 & 10 & 43,18 & 42,17 & 4 & 16,39 & 15,77 & 14 & 29,65 & 28,84 \\
\hline 352490 & Jambeiro & D20 & - & & & - & - & & - & & & 2 & 89,07 & 89,37 & 1 & 32,35 & 33,13 & 3 & 61,92 & 62,45 \\
\hline 352500 & Jandira & C300 & 35 & 67,31 & 69,19 & 4 & 8,21 & 8,16 & 39 & 37,53 & 38,44 & 11 & 21,80 & 23,42 & 3 & 5,05 & 4,68 & 14 & 13,36 & 13,98 \\
\hline 352510 & Jardinópolis & C50 & 5 & 27,48 & 26,77 & 1 & 5,99 & 5,76 & 6 & 16,83 & 16,35 & 4 & 25,52 & 25,84 & 2 & 11,98 & 12,13 & 6 & 18,80 & 19,04 \\
\hline 352520 & Jarinu & D20 & 3 & 32,51 & 31,83 & - & - & - & 3 & 16,84 & 16,49 & 7 & 68,26 & 70,30 & 0 & 3,49 & 3,81 & 7 & 37,05 & 38,26 \\
\hline
\end{tabular}


Anexo 26 - Óbitos, taxas de mortalidade total (bruta e padronizada) e segundo sexo por Homicídios e Acidentes de Trânsito (por 100 mil hab.) nos municípios/estratos de Vulnerabilidade Social. Estado de São Paulo, média do triênio 2003 a 2005.

\begin{tabular}{|c|c|c|c|c|c|c|c|c|c|c|c|c|c|c|c|c|c|c|c|c|}
\hline \multirow[b]{3}{*}{ IBGE } & \multirow[b]{3}{*}{ Mun. } & \multirow{3}{*}{\begin{tabular}{|l|} 
Status \\
Estrato \\
\end{tabular}} & \multicolumn{9}{|c|}{ HOMIcíDIOS } & \multicolumn{9}{|c|}{ ACIDENTES DE TRANSPORTE } \\
\hline & & & \multicolumn{3}{|c|}{ HOMENS } & \multicolumn{3}{|c|}{ MULHERES } & \multicolumn{3}{|c|}{ TOTAL } & \multicolumn{3}{|c|}{ HOMENS } & \multicolumn{3}{|c|}{ MULHERES } & \multicolumn{3}{|c|}{ TOTAL } \\
\hline & & & Óbitos & TBM & TPM & Óbitos & TBM & TPM & Óbitos & TBM & TPM & Óbitos & TBM & TPM & Óbitos & TBM & TPM & Óbitos & TBM & TPM \\
\hline 352530 & Jaú & C300 & 6 & 10,67 & 10,85 & 1 & 1,65 & 1,63 & 7 & 6,10 & 6,19 & 25 & 42,11 & 41,10 & 6 & 9,87 & 9,29 & 31 & 25,80 & 25,01 \\
\hline 352540 & Jeriquara & E20 & 0 & 19,08 & 16,65 & - & - & & 0 & 10,14 & 8,85 & 1 & 38,15 & 34,32 & - & - & & 1 & 20,28 & 18,24 \\
\hline 352550 & Joanópolis & E20 & 2 & 28,68 & 27,47 & - & - & $T_{2}$ & 2 & 14,62 & 14,00 & 1 & 22,94 & 24,43 & 1 & 11,93 & 12,68 & 2 & 17,54 & 18,67 \\
\hline 352560 & Joao Ramalho & E20 & - & - & - & - & - & - & - & - & & 1 & 31,60 & 34,14 & - & - & - & 1 & 15,91 & 17,19 \\
\hline 352570 & José Bonifácio & D50 & 1 & 8,59 & 8,17 & - & - & - & 1 & 4,30 & 4,09 & 10 & 64,46 & 60,34 & 2 & 10,78 & 10,66 & 12 & 37,66 & 35,54 \\
\hline 352580 & Júlio Mesquita & E20 & - & 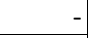 & - & - & - & - & - & 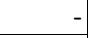 & & 0 & 15,68 & 14,28 & - & -1 & & 0 & 7,73 & 7,04 \\
\hline 352585 & Jumirim & A20 & - & & & - & - & & - & - & & 1 & 77,20 & 79,34 & - & & & 1 & 40,65 & 41,78 \\
\hline 352590 & Jundiaí & A500 & 44 & 26,70 & 27,29 & 6 & 3,28 & 3,35 & 50 & 14,76 & 15,09 & 58 & 35,13 & 34,28 & 12 & 6,95 & 6,76 & 70 & 20,77 & 20,26 \\
\hline 352600 & Junqueirópolis & E20 & 1 & 7,63 & 8,14 & - & - & 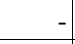 & 1 & 3,99 & 4,26 & 1 & 15,26 & 13,36 & 1 & 16,76 & 13,29 & 3 & 15,98 & 13,33 \\
\hline 352610 & Juquiá & D50 & 7 & 58,86 & 53,49 & 1 & 6,18 & 5,77 & 7 & 33,17 & 30,22 & 8 & 70,63 & 73,79 & 2 & 15,46 & 15,36 & 10 & 43,73 & 45,30 \\
\hline 352620 & Juquitiba & D50 & 14 & 92,53 & 87,93 & 1 & 6,85 & 5,41 & 15 & 49,96 & 46,93 & 11 & 76,73 & 82,60 & 4 & 25,13 & 28,22 & 15 & 51,09 & 55,57 \\
\hline 352630 & Lagoinha & E20 & - & - & - & - & - & - & - & - & 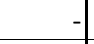 & 1 & 37,49 & 42,22 & - & - & & 1 & 19,60 & 22,08 \\
\hline 352640 & Laranjal Paulista & B50 & 5 & 45,47 & 45,49 & - & - & & 5 & 22,71 & 22,72 & 7 & 56,84 & 55,44 & 1 & 5,67 & 5,61 & 7 & 31,23 & 30,50 \\
\hline 352650 & Lavínia & E20 & 1 & 26,58 & 24,08 & - & - & & 1 & 13,35 & 12,09 & 0 & 13,29 & 14,21 & - & & & 0 & 6,67 & 7,13 \\
\hline 352660 & Lavrinhas & D20 & 0 & 9,89 & 9,34 & - & - & & 0 & 5,05 & 4,77 & 1 & 39,54 & 42,06 & - & - & & 1 & 20,19 & 21,48 \\
\hline 352670 & Leme & D100 & 17 & 38,17 & 36,99 & 1 & 2,34 & 2,27 & 18 & 20,46 & 19,83 & 14 & 32,06 & 32,74 & 1 & 3,12 & 3,23 & 15 & 17,76 & 18,15 \\
\hline 352680 & Lençóis Paulista & C100 & 3 & 10,05 & 9,98 & 1 & 2,24 & 2,09 & 4 & 6,15 & 6,04 & 6 & 21,22 & 21,67 & 2 & 6,72 & 6,83 & 8 & 13,98 & 14,26 \\
\hline 352690 & Limeira & B300 & 37 & 27,87 & 28,00 & 7 & 4,95 & 4,99 & 44 & 16,33 & 16,41 & 43 & 32,39 & 32,12 & 7 & 5,44 & 5,44 & 50 & 18,82 & 18,68 \\
\hline 352700 & Lindóia & D20 & 0 & 11,20 & 10,69 & - & & & 0 & 5,65 & 5,39 & 0 & 11,20 & 12,10 & 0 & 11,41 & 11,82 & 1 & 11,31 & 11,96 \\
\hline 352710 & Lins & B100 & 7 & 19,85 & 19,52 & 0 & 0,94 & 0,88 & 7 & 10,11 & 9,92 & 4 & 12,90 & 12,59 & 0 & 0,94 & 0,81 & 5 & 6,74 & 6,52 \\
\hline 352720 & Lorena & B100 & 23 & 57,10 & 56,45 & 2 & 3,99 & 3,81 & 24 & 29,87 & 29,46 & 22 & 54,58 & 55,92 & 6 & 13,57 & 13,49 & 27 & 33,56 & 34,16 \\
\hline 352725 & Lourdes & E20 & - & & & - & & & - & & & 0 & 29,78 & 34,84 & - & & & 0 & 15,43 & 18,06 \\
\hline 352730 & Louveira & C50 & 2 & 12,03 & 12,45 & 1 & 4,95 & 5,25 & 2 & 8,54 & 8,90 & 9 & 62,57 & 62,67 & 1 & 9,90 & 9,56 & 10 & 36,61 & 36,49 \\
\hline 352740 & Lucélia & D20 & 1 & 6,95 & 6,91 & - & - & - & 1 & 3,60 & 3,57 & 3 & 27,81 & 24,61 & 1 & 7,45 & 7,19 & 3 & 17,98 & 16,20 \\
\hline 352750 & Lucianópolis & E20 & - & & & - & - & & -1 & - & & 1 & 62,66 & 63,92 & - & & & 1 & 32,27 & 32,92 \\
\hline 352760 & Luís Antônio & $\mathrm{C} 20$ & 0 & 8,41 & 7,94 & - & - & d & 0 & 4,30 & 4,06 & 2 & 42,05 & 45,84 & 1 & 17,61 & 15,69 & 2 & 30,11 & 31,11 \\
\hline 352770 & Luiziânia & E20 & 1 & 30,72 & 31,00 & - & - & - & 1 & 15,40 & 15,54 & 1 & 30,72 & 23,96 & - & - & - & 1 & 15,40 & 12,01 \\
\hline 352780 & Lupércio & E20 & -1 & & & - & - & -5 & - & & & 0 & 15,40 & 17,27 & 0 & 15,64 & 16,26 & 1 & 15,52 & 16,77 \\
\hline 352790 & Lutécia & E20 & 0 & 21,72 & 19,46 & - & - & & 0 & 11,07 & 9,92 & 0 & 21,72 & 19,73 & - & - & & 0 & 11,07 & 10,05 \\
\hline 352800 & Macatuba & D20 & 1 & 11,87 & 11,72 & - & - & - & 1 & 5,96 & 5,89 & 2 & 23,73 & 24,43 & 0 & 3,99 & 3,39 & 2 & 13,91 & 13,96 \\
\hline 352810 & Macaubal & E20 & 0 & 8,88 & 8,46 & 0 & 9,18 & 8,40 & 1 & 9,03 & 8,43 & 2 & 44,41 & 40,37 & 1 & 36,71 & 36,17 & 3 & 40,62 & 38,31 \\
\hline 352820 & Macedônia & E20 & 0 & 17,91 & 16,38 & -1 & & & 0 & 9,07 & 8,30 & 2 & 107,45 & 111,62 & - & & & 2 & 54,44 & 56,55 \\
\hline
\end{tabular}


Anexo 26 - Óbitos, taxas de mortalidade total (bruta e padronizada) e segundo sexo por Homicídios e Acidentes de Trânsito (por 100 mil hab.) nos municípios/estratos de Vulnerabilidade Social. Estado de São Paulo, média do triênio 2003 a 2005.

\begin{tabular}{|c|c|c|c|c|c|c|c|c|c|c|c|c|c|c|c|c|c|c|c|c|}
\hline \multirow[b]{3}{*}{ IBGE } & \multirow[b]{3}{*}{ Mun. } & \multirow{3}{*}{\begin{tabular}{|l|} 
Status \\
Estrato \\
\end{tabular}} & \multicolumn{9}{|c|}{ HOMıcídIOS } & \multicolumn{9}{|c|}{ ACIDENTES DE TRANSPORTE } \\
\hline & & & \multicolumn{3}{|c|}{ HOMENS } & \multicolumn{3}{|c|}{ MULHERES } & \multicolumn{3}{|c|}{ TOTAL } & \multicolumn{3}{|c|}{ HOMENS } & \multicolumn{3}{|c|}{ MULHERES } & \multicolumn{3}{|c|}{ TOTAL } \\
\hline & & & Óbitos & TBM & TPM & Óbitos & TBM & TPM & Óbitos & TBM & TPM & Óbitos & TBM & TPM & Óbitos & TBM & TPM & Óbitos & TBM & TPM \\
\hline 352830 & Magda & E20 & - & - & - & - & - & - & - & - & & 1 & 58,78 & 56,22 & 0 & 20,79 & 22,18 & 1 & 40,35 & 39,70 \\
\hline 352840 & Mairinque & C50 & 15 & 67,10 & 65,66 & 2 & 7,47 & 7,50 & 17 & 37,31 & 36,60 & 9 & 41,75 & 42,86 & 1 & 4,48 & 4,39 & 10 & 23,13 & 23,64 \\
\hline 352850 & Mairipora & C100 & 16 & 47,01 & 45,76 & 1 & 3,88 & 3,91 & 18 & 25,56 & 24,95 & 19 & 53,73 & 55,23 & 5 & 13,57 & 13,58 & 23 & 33,76 & 34,51 \\
\hline 352860 & Manduri & D20 & - & - & - & - & - & - & - & - & & 1 & 29,90 & 31,77 & - & - & - & 1 & 15,30 & 16,26 \\
\hline 352870 & Marabá Paulista & E20 & - & - & 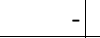 & - & - & - & - & - & & 0 & 16,96 & 15,32 & - & - & 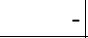 & 0 & 8,80 & 7,95 \\
\hline 352880 & Maracaí & D20 & 2 & 24,68 & 24,58 & - & - & - & 2 & 12,58 & 12,53 & 2 & 29,61 & 29,73 & 0 & 5,14 & 5,25 & 2 & 17,62 & 17,73 \\
\hline 352885 & Marapoama & E20 & - & & & - & - & & - & - & & 1 & 81,61 & 75,95 & - & & & 1 & 41,36 & 38,49 \\
\hline 352890 & Mariápolis & E20 & 0 & 17,84 & 15,97 & - & - & 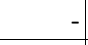 & 0 & 9,18 & 8,21 & 0 & 17,84 & 20,10 & 0 & 18,90 & 17,14 & 1 & 18,36 & 18,66 \\
\hline 352900 & Marília & B300 & 30 & 28,73 & 28,73 & 4 & 3,36 & 3,41 & 34 & 15,77 & 15,79 & 36 & 34,16 & 33,32 & 10 & 9,17 & 8,99 & 46 & 21,39 & 20,88 \\
\hline 352910 & Marinópolis & E20 & - & & & - & & & - & - & & 0 & 28,75 & 28,57 & - & & & 0 & 14,86 & 14,76 \\
\hline 352920 & Martinópolis & D50 & 1 & 8,29 & 8,25 & 0 & 2,90 & 2,74 & 1 & 5,66 & 5,56 & 4 & 30,41 & 29,26 & 1 & 5,81 & 6,14 & 4 & 18,41 & 17,98 \\
\hline 352930 & Matao & B100 & 6 & 16,80 & 16,81 & 1 & 1,77 & 1,77 & 7 & 9,29 & 9,29 & 14 & 36,26 & 36,29 & 5 & 12,38 & 12,63 & 18 & 24,32 & 24,46 \\
\hline 352940 & Mauá & C500 & 146 & 75,48 & 76,27 & 10 & 4,83 & 4,94 & 156 & 39,60 & 40,04 & 33 & 17,19 & 17,60 & 8 & 4,17 & 4,33 & 42 & 10,58 & 10,86 \\
\hline 352950 & Mendonça & E20 & 1 & 50,10 & 52,39 & - & & & 1 & 25,80 & 26,98 & 1 & 50,10 & 44,23 & 1 & 35,47 & 31,25 & 2 & 43,01 & 37,93 \\
\hline 352960 & Meridiano & E20 & 0 & 15,78 & 15,38 & 0 & 16,50 & 19,15 & 1 & 16,13 & 17,22 & 1 & 63,11 & 65,90 & - & & & 1 & 32,26 & 33,69 \\
\hline 352965 & Mesópolis & E20 & - & & & - & & & - & & & - & & & - & - & & - & & \\
\hline 352970 & Miguelópolis & E20 & 4 & 43,66 & 42,48 & 0 & 3,40 & 3,22 & 5 & 23,64 & 22,96 & 3 & 30,23 & 30,07 & 0 & 3,40 & 3,75 & 3 & 16,89 & 16,98 \\
\hline 352980 & Mineiros do Tietê & E20 & - & & & - & -1 & & - & - & & 1 & 16,19 & 15,58 & -1 & 1 & & 1 & 8,14 & 7,84 \\
\hline 353000 & Mira Estrela & E20 & 0 & 25,04 & 23,47 & - & 1 & & 0 & 12,99 & 12,17 & - & & & - & - & & - & & - \\
\hline 352990 & Miracatu & E50 & 7 & 56,69 & 49,47 & 1 & 8,65 & 7,83 & 8 & 33,46 & 29,34 & 10 & 80,99 & 90,44 & 2 & 20,19 & 22,46 & 12 & 51,59 & 57,57 \\
\hline 353010 & Mirandópolis & D50 & 0 & 2,35 & 2,66 & 0 & 2,68 & 2,54 & 1 & 2,51 & 2,61 & 2 & 14,12 & 13,66 & 0 & 2,68 & 2,82 & 2 & 8,77 & 8,59 \\
\hline 353020 & Mirante do Paranapanema & E20 & 1 & 15,67 & 16,72 & - & & & 1 & 8,00 & 8,53 & 2 & 27,42 & 28,69 & 0 & 4,08 & 3,69 & 3 & 15,99 & 16,45 \\
\hline 353030 & Mirassol & B100 & 3 & 12,90 & 13,42 & 1 & 2,51 & 2,63 & 4 & 7,64 & 7,96 & 12 & 46,44 & 43,51 & 1 & 3,77 & 4,06 & 13 & 24,83 & 23,53 \\
\hline 353040 & Mirassolândia & E20 & 0 & 15,96 & 15,22 & - & & & 0 & 8,20 & 7,82 & 1 & 63,85 & 64,45 & 0 & 16,88 & 18,24 & 2 & 41,02 & 42,00 \\
\hline 353050 & Mococa & D100 & 8 & 22,09 & 21,87 & 0 & 0,98 & 0,96 & 8 & 11,63 & 11,50 & 9 & 24,98 & 24,97 & 2 & 6,84 & 6,43 & 11 & 15,99 & 15,78 \\
\hline 353060 & Moji das Cruzes & B500 & 82 & 47,00 & 46,10 & 8 & 4,43 & 4,33 & 90 & 25,39 & 24,90 & 27 & 15,60 & 16,10 & 10 & 5,54 & 5,66 & 37 & 10,49 & 10,80 \\
\hline 353070 & MojiOGuaçu & B300 & 15 & 22,66 & 22,51 & 2 & 3,48 & 3,48 & 18 & 13,12 & 13,04 & 24 & 34,97 & 34,92 & 5 & 6,96 & 7,02 & 28 & 21,03 & 21,04 \\
\hline 353080 & MojiOMirim & B100 & 10 & 22,51 & 22,57 & 1 & 3,00 & 3,00 & 11 & 12,74 & 12,78 & 12 & 27,01 & 26,55 & 4 & 8,24 & 8,24 & 16 & 17,62 & 17,39 \\
\hline 353090 & Mombuca & E20 & 0 & 19,54 & 18,31 & 1 & 40,95 & 37,92 & 1 & 30,00 & 27,89 & 1 & 78,17 & 85,63 & - & 1 & 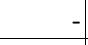 & 1 & 40,00 & 43,81 \\
\hline 353100 & Monçoes & E20 & - & - & & - & - & & - & - & & 0 & 32,28 & 23,42 & - & - & - & 0 & 16,38 & 11,89 \\
\hline 353110 & Mongaguá & C50 & 10 & 46,12 & 44,31 & 1 & 6,47 & 6,70 & 11 & 26,81 & 25,98 & 9 & 43,05 & 43,65 & 1 & 4,85 & 4,78 & 10 & 24,44 & 24,71 \\
\hline 353120 & Monte Alegre do Sul & E20 & 1 & 19,49 & 24,17 & -1 & & & 1 & 9,93 & 12,31 & 1 & 29,23 & 28,84 & -1 & & & 1 & 14,89 & 14,69 \\
\hline
\end{tabular}


Anexo 26 - Óbitos, taxas de mortalidade total (bruta e padronizada) e segundo sexo por Homicídios e Acidentes de Trânsito (por 100 mil hab.) nos municípios/estratos de Vulnerabilidade Social. Estado de São Paulo, média do triênio 2003 a 2005.

\begin{tabular}{|c|c|c|c|c|c|c|c|c|c|c|c|c|c|c|c|c|c|c|c|c|}
\hline \multirow[b]{3}{*}{ IBGE } & \multirow[b]{3}{*}{ Mun. } & \multirow{3}{*}{\begin{tabular}{|l|} 
Status \\
Estrato \\
\end{tabular}} & \multicolumn{9}{|c|}{ HOMıcídIOS } & \multicolumn{9}{|c|}{ ACIDENTES DE TRANSPORTE } \\
\hline & & & \multicolumn{3}{|c|}{ HOMENS } & \multicolumn{3}{|c|}{ MULHERES } & \multicolumn{3}{|c|}{ TOTAL } & \multicolumn{3}{|c|}{ HOMENS } & \multicolumn{3}{|c|}{ MULHERES } & \multicolumn{3}{|c|}{ TOTAL } \\
\hline & & & Óbitos & TBM & TPM & Óbitos & TBM & TPM & Óbitos & TBM & TPM & Óbitos & TBM & TPM & Óbitos & TBM & TPM & Óbitos & TBM & TPM \\
\hline 353130 & Monte Alto & C50 & 4 & 19,08 & 18,86 & 2 & 7,37 & 7,78 & 6 & 13,23 & 13,33 & 7 & 32,28 & 31,30 & 2 & 8,84 & 8,40 & 9 & 20,59 & 19,88 \\
\hline 353140 & Monte Aprazível & D20 & 2 & 21,44 & 22,06 & - & - & & 2 & 10,63 & 10,94 & 5 & 57,17 & 56,45 & 0 & 3,51 & 2,29 & 6 & 30,11 & 29,14 \\
\hline 353150 & Monte Azul Paulista & E50 & 1 & 12,96 & 12,68 & 0 & 3,30 & 3,21 & 2 & 8,18 & 7,99 & 3 & 29,15 & 29,21 & 1 & 13,21 & 12,52 & 4 & 21,26 & 20,94 \\
\hline 353160 & Monte Castelo & E20 & - & & & - & & & - & & & 1 & 34,57 & 33,40 & - & & & 1 & 17,51 & 16,91 \\
\hline 353180 & Monte Mor & D50 & 17 & 80,95 & 80,27 & 3 & 15,73 & 15,12 & 21 & 48,51 & 47,87 & 12 & 57,60 & 58,79 & 4 & 18,88 & 19,71 & 16 & 38,34 & 39,35 \\
\hline 353170 & Monteiro Lobato & E20 & 0 & 17,37 & 16,54 & - & - & & 0 & 8,96 & 8,53 & 1 & 34,74 & 36,93 & 0 & 18,50 & 17,98 & 1 & 26,88 & 27,76 \\
\hline 353190 & Morro Agudo & D50 & 2 & 16,75 & 16,78 & 0 & 2,50 & 2,95 & 3 & 9,77 & 10,01 & 3 & 19,14 & 20,37 & 2 & 12,48 & 12,24 & 4 & 15,88 & 16,39 \\
\hline 353200 & Morungaba & D20 & - & & & - & & & - & & & 2 & 43,22 & 42,99 & 0 & 6,32 & 7,35 & 3 & 24,99 & 25,38 \\
\hline 353205 & Motuca & D20 & 0 & 15,71 & 14,32 & 1 & 33,27 & 32,26 & 1 & 24,23 & 23,03 & 1 & 62,82 & 62,34 & -1 & - & & 1 & 32,31 & 32,07 \\
\hline 353210 & Murutinga do Sul & E20 & - & & & - & - & - & - & - & & 0 & 16,15 & 17,23 & - & - & 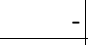 & 0 & 8,22 & 8,77 \\
\hline 353215 & Nantes & E20 & 0 & 29,47 & 26,91 & - & - & - & 0 & 15,03 & 13,72 & - & - & - & 1 & 61,35 & 65,23 & 1 & 30,06 & 31,96 \\
\hline 353220 & Narandiba & E20 & 0 & 16,45 & 15,67 & - & - & & 0 & 8,31 & 7,91 & 0 & 16,45 & 17,27 & -1 & & & 0 & 8,31 & 8,72 \\
\hline 353230 & Natividade da Serra & E20 & 1 & 17,51 & 14,89 & - & - & - & 1 & 9,30 & 7,90 & 1 & 17,51 & 15,25 & - & - & -1 & 1 & 9,30 & 8,10 \\
\hline 353240 & Nazaré Paulista & E20 & 3 & 37,23 & 38,55 & 0 & 4,40 & 5,06 & 3 & 21,32 & 22,33 & 4 & 45,50 & 46,43 & 1 & 17,60 & 19,32 & 5 & 31,98 & 33,30 \\
\hline 353250 & Neves Paulista & E20 & 0 & 7,21 & 7,02 & 1 & 14,65 & 13,96 & 1 & 10,90 & 10,46 & 2 & 43,28 & 41,85 & 0 & 7,32 & 8,18 & 2 & 25,44 & 25,14 \\
\hline 353260 & Nhandeara & D20 & 0 & 6,68 & 9,24 & - & - & & 0 & 3,29 & 4,55 & 3 & 53,43 & 50,48 & 2 & 38,96 & 37,69 & 5 & 46,10 & 43,99 \\
\hline 353270 & Nipoa & E20 & - & - & - & - & - & - & - & - & & 1 & 37,44 & 39,74 & 1 & 39,31 & 36,47 & 1 & 38,35 & 38,15 \\
\hline 353280 & Nova Aliança & E20 & 0 & 13,36 & 16,76 & - & - & - & 0 & 6,63 & 8,32 & 2 & 80,14 & 75,69 & - & - & & 2 & 39,80 & 37,59 \\
\hline 353282 & Nova Campina & E20 & - & & & - & - & - & - & - & & 2 & 46,64 & 57,15 & 0 & 8,47 & 10,04 & 2 & 28,38 & 34,60 \\
\hline 353284 & Nova Canaa Paulista & E20 & - & - & - & - & - & - & - & - & & - & & - & - & -1 & & - & & - \\
\hline 353286 & Nova Castilho & E20 & 0 & 62,74 & 54,48 & - & - & - & 0 & 32,92 & 28,59 & 1 & 125,47 & 151,56 & - & - & - & 1 & 65,83 & 79,52 \\
\hline 353290 & Nova Europa & D20 & 1 & 16,07 & 16,09 & - & - & 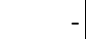 & 1 & 8,16 & 8,17 & 1 & 32,14 & 32,21 & - & - & - & 1 & 16,32 & 16,36 \\
\hline 353300 & Nova Granada & E20 & 1 & 7,39 & 7,04 & 0 & 3,73 & 3,51 & 1 & 5,57 & 5,29 & 4 & 40,63 & 40,64 & 1 & 7,45 & 6,51 & 4 & 24,12 & 23,65 \\
\hline 353310 & Nova Guataporanga & E20 & - & - & - & 0 & 33,11 & 29,57 & 0 & 16,10 & 14,38 & 1 & 94,01 & 101,34 & - & - & - & 1 & 48,30 & 52,07 \\
\hline 353320 & Nova Independência & E20 & 1 & 62,34 & 60,50 & - & - & & 1 & 31,86 & 30,92 & - & - & & - & - & - & - & - & - \\
\hline 353330 & Nova Luzitânia & E20 & 0 & 22,67 & 24,75 & - & - & - & 0 & 11,91 & 13,01 & 0 & 22,67 & 15,41 & - & - & - & 0 & 11,91 & 8,10 \\
\hline 353340 & Nova Odessa & B50 & 5 & 20,61 & 20,61 & 1 & 5,80 & 5,95 & 6 & 13,14 & 13,22 & 8 & 35,33 & 34,43 & 1 & 4,35 & 4,33 & 9 & 19,72 & 19,26 \\
\hline 353325 & Novais & E20 & 0 & 19,44 & 16,33 & - & & & 0 & 10,14 & 8,52 & 0 & 19,44 & 20,26 & - & - & -1 & 0 & 10,14 & 10,56 \\
\hline 353350 & Novo Horizonte & D50 & 3 & 16,11 & 15,90 & 1 & 5,96 & 5,59 & 4 & 11,00 & 10,71 & 6 & 34,23 & 34,17 & 2 & 9,94 & 9,40 & 7 & 22,01 & 21,70 \\
\hline 353360 & Nuporanga & E20 & - & & & - & -1 & - & - & - & & 3 & 80,30 & 81,97 & - & - & - & 3 & 40,77 & 41,62 \\
\hline 353370 & Ocauçu & E20 & 1 & 46,85 & 50,59 & - & & & 1 & 24,41 & 26,36 & 0 & 15,62 & 14,06 & 0 & 16,99 & 18,28 & 1 & 16,27 & 16,08 \\
\hline 353380 & Oleo & E20 & 0 & 21,11 & 18,79 & - & - & - & 0 & 10,83 & 9,64 & 1 & 63,34 & 71,69 & - & - & - & 1 & 32,49 & 36,77 \\
\hline
\end{tabular}


Anexo 26 - Óbitos, taxas de mortalidade total (bruta e padronizada) e segundo sexo por Homicídios e Acidentes de Trânsito (por 100 mil hab.) nos municípios/estratos de Vulnerabilidade Social. Estado de São Paulo, média do triênio 2003 a 2005.

\begin{tabular}{|c|c|c|c|c|c|c|c|c|c|c|c|c|c|c|c|c|c|c|c|c|}
\hline \multirow[b]{3}{*}{ IBGE } & \multirow[b]{3}{*}{ Mun. } & \multirow{3}{*}{\begin{tabular}{|l|} 
Status \\
Estrato \\
\end{tabular}} & \multicolumn{9}{|c|}{ HOMıcíDIOS } & \multicolumn{9}{|c|}{ ACIDENTES DE TRANSPORTE } \\
\hline & & & \multicolumn{3}{|c|}{ HOMENS } & \multicolumn{3}{|c|}{ MULHERES } & \multicolumn{3}{|c|}{ TOTAL } & \multicolumn{3}{|c|}{ HOMENS } & \multicolumn{3}{|c|}{ MULHERES } & \multicolumn{3}{|c|}{ TOTAL } \\
\hline & & & Óbitos & TBM & TPM & Óbitos & TBM & TPM & Óbitos & TBM & TPM & Óbitos & TBM & TPM & Óbitos & TBM & TPM & Óbitos & TBM & TPM \\
\hline 353390 & Olímpia & D50 & 5 & 22,72 & 22,52 & 1 & 4,18 & 3,78 & 6 & 13,36 & 13,06 & 12 & 49,71 & 48,48 & 1 & 5,57 & 5,25 & 13 & 27,43 & 26,66 \\
\hline 353400 & Onda Verde & E20 & 1 & 35,63 & 34,99 & - & - & & 1 & 18,14 & 17,82 & 1 & 53,44 & 54,63 & - & - & & 1 & 27,21 & 27,82 \\
\hline 353410 & Oriente & D20 & 1 & 24,50 & 22,83 & - & - & - & 1 & 12,18 & 11,35 & 1 & 49,00 & 52,58 & 0 & 12,12 & 10,90 & 2 & 30,45 & 31,63 \\
\hline 353420 & Orindiúva & $\mathrm{C} 20$ & 1 & 27,77 & 27,51 & - & -1 & & 1 & 14,31 & 14,18 & 2 & 97,18 & 101,64 & 0 & 14,77 & 14,83 & 3 & 57,25 & 59,58 \\
\hline 353430 & Orlândia & B50 & 4 & 21,16 & 21,14 & 0 & 1,74 & 1,72 & 4 & 11,37 & 11,36 & 5 & 26,45 & 25,92 & - & & & 5 & 13,12 & 12,86 \\
\hline 353440 & Osasco & B1000 & 268 & 79,68 & 81,77 & 20 & 5,64 & 5,78 & 288 & 41,67 & 42,76 & 80 & 23,82 & 23,95 & 19 & 5,46 & 5,69 & 99 & 14,39 & 14,58 \\
\hline 353450 & Oscar Bressane & E20 & - & & & - & - & - & - & - & & 0 & 26,62 & 32,48 & - & - & - & 0 & 13,03 & 15,91 \\
\hline 353460 & Osvaldo Cruz & D50 & 2 & 15,80 & 17,08 & 1 & 4,38 & 5,30 & 3 & 10,01 & 11,10 & 5 & 33,85 & 35,85 & 1 & 6,58 & 6,31 & 6 & 20,02 & 20,87 \\
\hline 353470 & Ourinhos & C300 & 14 & 28,78 & 27,99 & 2 & 3,23 & 3,20 & 16 & 15,78 & 15,37 & 21 & 42,84 & 42,52 & 5 & 9,04 & 8,76 & 26 & 25,64 & 25,34 \\
\hline 353480 & Ouro Verde & E20 & 1 & 37,06 & 34,05 & - & - & - & 1 & 18,60 & 17,08 & 1 & 27,80 & 30,15 & - & - & $t$ & 1 & 13,95 & 15,13 \\
\hline 353475 & Ouroeste & E20 & 0 & 9,63 & 8,75 & - & - & - & 0 & 4,84 & 4,39 & 1 & 38,54 & 34,96 & 0 & 9,72 & 10,53 & 2 & 24,19 & 22,79 \\
\hline 353490 & Pacaembu & E20 & 1 & 9,96 & 10,31 & - & - & & 1 & 5,30 & 5,48 & 1 & 19,92 & 18,73 & 1 & 11,31 & 11,00 & 2 & 15,89 & 15,11 \\
\hline 353500 & Palestina & E20 & - & & & 0 & 7,25 & 9,03 & 0 & 3,65 & 4,54 & 2 & 51,35 & 51,06 & 0 & 7,25 & 8,46 & 3 & 29,18 & 29,64 \\
\hline 353510 & Palmares Paulista & E20 & 2 & 43,94 & 44,13 & - & - & - & 2 & 22,38 & 22,48 & 1 & 29,30 & 30,71 & 1 & 22,81 & 27,21 & 2 & 26,12 & 28,99 \\
\hline 353520 & Palmeira d'Oeste & E20 & 0 & 6,53 & 6,14 & - & - & - & 0 & 3,32 & 3,12 & 2 & 39,19 & 34,05 & 0 & 6,75 & 7,24 & 2 & 23,23 & 20,86 \\
\hline 353530 & Palmital & D50 & 2 & 18,69 & 18,90 & 0 & 3,06 & 3,64 & 2 & 10,80 & 11,20 & 5 & 49,84 & 45,09 & 0 & 3,06 & 3,44 & 6 & 26,23 & 24,07 \\
\hline 353540 & Panorama & E20 & 2 & 22,95 & 21,97 & 0 & 4,78 & 5,12 & 2 & 14,05 & 13,72 & 2 & 27,54 & 28,39 & - & - & - & 2 & 14,05 & 14,49 \\
\hline 353550 & Paraguaçu Paulista & D50 & 6 & 30,28 & 29,21 & - & - & - & 6 & 15,01 & 14,48 & 12 & 57,37 & 57,60 & 2 & 7,83 & 7,51 & 14 & 32,39 & 32,34 \\
\hline 353560 & Paraibuna & E20 & 3 & 29,02 & 27,87 & 0 & 3,80 & 4,56 & 3 & 16,71 & 16,49 & 5 & 58,04 & 60,05 & 1 & 11,41 & 11,99 & 6 & 35,28 & 36,59 \\
\hline 353570 & Paraíso & E20 & - & & & - & - & & - & - & & 2 & 66,91 & 64,03 & 0 & 12,11 & 12,05 & 2 & 40,64 & 39,11 \\
\hline 353580 & Paranapanema & E20 & 1 & 15,34 & 14,42 & 1 & 8,30 & 7,49 & 2 & 11,96 & 11,09 & 4 & 46,02 & 47,99 & 1 & 12,45 & 12,67 & 5 & 29,90 & 31,03 \\
\hline 353590 & Paranapua & E20 & - & & & - & - & - & - & - & & 1 & 55,01 & 50,98 & 0 & 19,02 & 20,81 & 1 & 37,34 & 36,17 \\
\hline 353600 & Parapua & E20 & 1 & 17,96 & 17,76 & - & - & - & 1 & 9,12 & 9,02 & 2 & 35,91 & 29,71 & 0 & 6,18 & 5,12 & 2 & 21,28 & 17,61 \\
\hline 353610 & Pardinho & D20 & - & - & - & - & - & - & - & - & & 1 & 36,29 & 37,26 & 0 & 13,07 & 15,37 & 1 & 25,13 & 26,74 \\
\hline 353620 & Pariquera0Açu & D20 & 2 & 20,20 & 20,03 & - & - & - & 2 & 10,18 & 10,09 & 4 & 40,40 & 40,82 & 3 & 27,35 & 30,39 & 7 & 33,92 & 35,64 \\
\hline 353625 & Parisi & E20 & - & & & - & - & 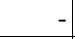 & - & - & & - & - & - & - & - & - & - & - & - \\
\hline 353630 & Patrocínio Paulista & D20 & 0 & 5,35 & 5,53 & - & - & - & 0 & 2,74 & 2,83 & 1 & 21,38 & 21,78 & 0 & 5,61 & 5,01 & 2 & 13,69 & 13,60 \\
\hline 353640 & Paulicéia & E20 & - & & & - & - & & - & - & & 0 & 11,04 & 8,64 & - & - & -1 & 0 & 5,73 & 4,49 \\
\hline 353650 & Paulínia & B100 & 12 & 42,59 & 43,66 & 3 & 9,23 & 9,29 & 15 & 25,93 & 26,49 & 12 & 40,29 & 40,54 & 4 & 12,69 & 12,93 & 15 & 26,50 & 26,75 \\
\hline 353657 & Paulistânia & E20 & 0 & 33,15 & 28,84 & - & -1 & 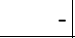 & 0 & 17,60 & 15,31 & 0 & 33,15 & 38,09 & - & - & & 0 & 17,60 & 20,23 \\
\hline 353660 & Paulo de Faria & E20 & 1 & 15,66 & 14,41 & - & & & 1 & 7,80 & 7,18 & 2 & 39,15 & 40,83 & 2 & 46,68 & 46,68 & 4 & 42,93 & 43,77 \\
\hline 353670 & Pederneiras & D50 & 4 & 20,49 & 20,53 & 1 & 5,22 & 5,01 & 5 & 12,93 & 12,84 & 5 & 27,32 & 28,22 & 1 & 6,96 & 7,39 & 7 & 17,24 & 17,90 \\
\hline
\end{tabular}


Anexo 26 - Óbitos, taxas de mortalidade total (bruta e padronizada) e segundo sexo por Homicídios e Acidentes de Trânsito (por 100 mil hab.) nos municípios/estratos de Vulnerabilidade Social. Estado de São Paulo, média do triênio 2003 a 2005.

\begin{tabular}{|c|c|c|c|c|c|c|c|c|c|c|c|c|c|c|c|c|c|c|c|c|}
\hline \multirow[b]{3}{*}{ IBGE } & \multirow[b]{3}{*}{ Mun. } & \multirow{3}{*}{\begin{tabular}{|l|} 
Status \\
Estrato \\
\end{tabular}} & \multicolumn{9}{|c|}{ HOMıcídIOS } & \multicolumn{9}{|c|}{ ACIDENTES DE TRANSPORTE } \\
\hline & & & \multicolumn{3}{|c|}{ HOMENS } & \multicolumn{3}{|c|}{ MULHERES } & \multicolumn{3}{|c|}{ TOTAL } & \multicolumn{3}{|c|}{ HOMENS } & \multicolumn{3}{|c|}{ MULHERES } & \multicolumn{3}{|c|}{ TOTAL } \\
\hline & & & Óbitos & TBM & TPM & Óbitos & TBM & TPM & Óbitos & TBM & TPM & Óbitos & TBM & TPM & Óbitos & TBM & TPM & Óbitos & TBM & TPM \\
\hline 353680 & Pedra Bela & E20 & - & & & - & -1 & & - & & & 1 & 32,53 & 35,96 & - & & & 1 & 17,19 & 19,00 \\
\hline 353690 & Pedranópolis & E20 & 1 & 50,58 & 55,79 & - & - & & 1 & 25,95 & 28,62 & 0 & 25,29 & 12,50 & 0 & 26,65 & 22,86 & 1 & 25,95 & 17,55 \\
\hline 353700 & Pedregulho & D20 & 0 & 4,19 & 3,69 & - & - & - & 0 & 2,14 & 1,88 & 4 & 50,32 & 53,28 & 1 & 13,14 & 13,64 & 5 & 32,13 & 33,89 \\
\hline 353710 & Pedreira & B50 & 2 & 12,24 & 12,51 & 0 & 1,72 & 1,71 & 3 & 6,93 & 7,06 & 8 & 40,22 & 39,09 & 1 & 5,16 & 5,20 & 9 & 22,54 & 21,99 \\
\hline 353715 & Pedrinhas Paulista & A20 & - & & & -1 & & & - & & & 1 & 88,07 & 83,59 & 0 & 22,64 & 20,89 & 2 & 55,81 & 52,68 \\
\hline 353720 & Pedro de Toledo & E20 & 3 & 59,98 & 56,23 & 0 & 6,96 & 5,72 & 3 & 34,04 & 31,52 & 3 & 53,32 & 54,82 & 1 & 20,88 & 23,59 & 4 & 37,45 & 39,54 \\
\hline 353730 & Penápolis & D100 & 7 & 23,74 & 23,94 & 1 & 2,27 & 2,33 & 7 & 12,76 & 12,89 & 14 & 48,68 & 47,48 & 2 & 6,80 & 6,86 & 16 & 27,26 & 26,70 \\
\hline 353740 & Pereira Barreto & D50 & 1 & 8,17 & 8,03 & - & & & 1 & 4,04 & 3,97 & 3 & 24,50 & 25,31 & 1 & 7,98 & 7,74 & 4 & 16,14 & 16,42 \\
\hline 353750 & Pereiras & E20 & 0 & 9,26 & 11,17 & - & - & & 0 & 4,75 & 5,73 & 2 & 64,81 & 60,50 & 0 & 9,75 & 6,17 & 3 & 7,99 & 34,04 \\
\hline 353760 & Peruíbe & D100 & 19 & 64,91 & 60,46 & 4 & 12,22 & 11,30 & 23 & 38,46 & 35,79 & 13 & 44,77 & 47,20 & 4 & 12,22 & 12,56 & 17 & 28,43 & 29,82 \\
\hline 353770 & Piacatu & E20 & 1 & 28,30 & 33,78 & 0 & 14,43 & 13,64 & 1 & 21,44 & 23,81 & 1 & 42,46 & 41,97 & - & - & - & 1 & 21,44 & 21,19 \\
\hline 353780 & Piedade & D100 & 7 & 25,14 & 24,92 & 1 & 3,97 & 3,77 & 8 & 15,08 & 14,87 & 14 & 49,08 & 49,18 & 2 & 6,61 & 6,85 & 15 & 28,90 & 29,07 \\
\hline 353790 & Pilar do Sul & E50 & 2 & 17,46 & 16,41 & 0 & 2,65 & 2,31 & 3 & 10,28 & 9,57 & 5 & 37,40 & 39,00 & 0 & 2,65 & 3,05 & 5 & 20,56 & 21,58 \\
\hline 353800 & Pindamonhangaba & B300 & 15 & 22,48 & 22,44 & 2 & 2,43 & 2,35 & 17 & 12,43 & 12,37 & 22 & 32,25 & 33,62 & 3 & 4,87 & 5,16 & 25 & 18,53 & 19,36 \\
\hline 353810 & Pindorama & E20 & 1 & 19,59 & 18,62 & 0 & 5,03 & 4,67 & 2 & 12,40 & 11,74 & 2 & 29,39 & 28,17 & - & - & & 2 & 14,89 & 14,27 \\
\hline 353820 & Pinhalzinho & E20 & 1 & 15,91 & 17,82 & - & - & & 1 & 8,25 & 9,24 & 3 & 42,43 & 45,31 & 1 & 17,12 & 18,22 & 4 & 30,24 & 32,26 \\
\hline 353830 & Piquerobi & E20 & - & - & - & - & - & - & - & - & & - & - & - & 0 & 18,96 & 16,81 & 0 & 9,34 & 8,28 \\
\hline 353850 & Piquete & B20 & 1 & 13,28 & 13,04 & - & - & - & 1 & 6,49 & 6,38 & 2 & 30,98 & 32,46 & 1 & 16,94 & 16,13 & 4 & 23,80 & 24,12 \\
\hline 353860 & Piracaia & D50 & 3 & 23,36 & 24,55 & 0 & 2,68 & 2,54 & 3 & 13,18 & 13,71 & 6 & 46,73 & 47,56 & 1 & 5,36 & 5,55 & 7 & 26,36 & 26,88 \\
\hline 353870 & Piracicaba & B500 & 63 & 36,11 & 36,26 & 7 & 3,74 & 3,73 & 69 & 19,71 & 19,78 & 45 & 26,12 & 25,98 & 12 & 6,55 & 6,44 & 57 & 16,21 & 16,08 \\
\hline 353880 & Piraju & D50 & 1 & 9,48 & 9,17 & 1 & 4,55 & 4,18 & 2 & 6,97 & 6,62 & 4 & 30,80 & 31,55 & 0 & 2,28 & 2,46 & 5 & 16,26 & 16,71 \\
\hline 353890 & Pirajuí & D50 & 2 & 21,18 & 22,43 & 1 & 6,91 & 6,77 & 3 & 14,52 & 15,12 & 4 & 33,29 & 32,69 & - & - & & 4 & 17,75 & 17,43 \\
\hline 353900 & Pirangi & E20 & - & & & - & - & - & - & & & 2 & 44,92 & 47,51 & 0 & 6,77 & 7,83 & 3 & 26,36 & 28,20 \\
\hline 353910 & Pirapora do Bom Jesus & D20 & 3 & 37,03 & 35,87 & - & - & - & 3 & 18,55 & 17,97 & 2 & 27,77 & 29,60 & 0 & 4,65 & 5,10 & 2 & 16,23 & 17,37 \\
\hline 353920 & Pirapozinho & D50 & 3 & 24,12 & 23,81 & - & - & & 3 & 11,80 & 11,65 & 3 & 27,13 & 25,56 & 2 & 14,44 & 14,59 & 5 & 20,65 & 19,96 \\
\hline 353930 & Pirassununga & B100 & 7 & 20,74 & 20,38 & 0 & 0,96 & 0,92 & 7 & 10,71 & 10,51 & 12 & 35,55 & 34,84 & 2 & 4,80 & 4,89 & 14 & 19,95 & 19,65 \\
\hline 353940 & Piratininga & B20 & 0 & 5,99 & 5,42 & - & - & & 0 & 3,03 & 2,74 & 1 & 17,98 & 17,52 & - & - & & 1 & 9,09 & 8,86 \\
\hline 353950 & Pitangueiras & D50 & 5 & 31,56 & 31,05 & 0 & 2,07 & 1,89 & 6 & 17,18 & 16,83 & 6 & 33,53 & 34,84 & 1 & 6,21 & 5,97 & 7 & 20,21 & 20,76 \\
\hline 353960 & Planalto & E20 & 1 & 34,96 & 35,27 & 0 & 18,11 & 17,53 & 1 & 26,68 & 26,55 & 1 & 52,44 & 53,01 & - & - & -1 & 1 & 26,68 & 26,97 \\
\hline 353970 & Platina & E20 & - & & & - & & & - & & & - & & & - & 1 & & - & & \\
\hline 353980 & Poá & B300 & 26 & 50,11 & 49,20 & 1 & 1,88 & 1,74 & 27 & 25,52 & 25,00 & 12 & 22,78 & 23,92 & 3 & 5,63 & 5,76 & 15 & 14,03 & 14,66 \\
\hline 353990 & Poloni & E20 & 0 & 13,96 & 13,18 & - & -1 & - & 0 & 6,82 & 6,44 & 2 & 83,79 & 89,63 & - & - & -1 & 2 & 40,95 & 43,80 \\
\hline
\end{tabular}


Anexo 26 - Óbitos, taxas de mortalidade total (bruta e padronizada) e segundo sexo por Homicídios e Acidentes de Trânsito (por 100 mil hab.) nos municípios/estratos de Vulnerabilidade Social. Estado de São Paulo, média do triênio 2003 a 2005.

\begin{tabular}{|c|c|c|c|c|c|c|c|c|c|c|c|c|c|c|c|c|c|c|c|c|}
\hline \multirow[b]{3}{*}{ IBGE } & \multirow[b]{3}{*}{ Mun. } & \multirow{3}{*}{\begin{tabular}{|l|} 
Status \\
Estrato \\
\end{tabular}} & \multicolumn{9}{|c|}{ HOMICíDIOS } & \multicolumn{9}{|c|}{ ACIDENTES DE TRANSPORTE } \\
\hline & & & \multicolumn{3}{|c|}{ HOMENS } & \multicolumn{3}{|c|}{ MULHERES } & \multicolumn{3}{|c|}{ TOTAL } & \multicolumn{3}{|c|}{ HOMENS } & \multicolumn{3}{|c|}{ MULHERES } & \multicolumn{3}{|c|}{ TOTAL } \\
\hline & & & Óbitos & TBM & TPM & Óbitos & TBM & TPM & Óbitos & TBM & TPM & Óbitos & TBM & TPM & Óbitos & TBM & TPM & Óbitos & TBM & TPM \\
\hline 354000 & Pompéia & $\mathrm{C} 20$ & 2 & 18,12 & 18,51 & - & - & & 2 & 8,97 & 9,16 & 3 & 28,99 & 28,99 & 1 & 7,10 & 6,56 & 3 & 17,93 & 17,66 \\
\hline 354010 & Pongaí & E20 & - & & & - & - & & - & & & 1 & 34,23 & 36,36 & - & - & - & 1 & 17,80 & 18,91 \\
\hline 354020 & Pontal & D50 & 10 & 60,22 & 60,82 & 0 & 2,06 & 2,24 & 10 & 31,55 & 31,94 & 8 & 50,19 & 52,72 & 3 & 16,51 & 16,63 & 11 & 33,59 & 34,93 \\
\hline 354025 & Pontalinda & E20 & 0 & 17,20 & 17,41 & - & -1 & & 0 & 8,97 & 9,09 & 1 & 68,79 & 67,29 & - & & & 1 & 35,90 & 35,12 \\
\hline 354030 & Pontes Gestal & E20 & - & & & - & - & - & - & & & 1 & 57,22 & 42,75 & & & & 1 & 28,40 & 21,22 \\
\hline 354040 & Populina & E20 & - & & & - & - & - & - & -1 & & 2 & 88,88 & 88,73 & 1 & 31,73 & 34,42 & 3 & 61,28 & 62,51 \\
\hline 354050 & Porangaba & E20 & 1 & 17,66 & 18,36 & - & - & - & 1 & 9,36 & 9,73 & 1 & 35,32 & 36,39 & 0 & 9,97 & 10,79 & 2 & 23,41 & 24,36 \\
\hline 354060 & Porto Feliz & C50 & 5 & 20,20 & 20,18 & 2 & 6,78 & 6,60 & 7 & 13,51 & 13,41 & 3 & 12,12 & 12,27 & 1 & 5,42 & 5,36 & 4 & 8,78 & 8,82 \\
\hline 354070 & Porto Ferreira & C100 & 7 & 26,01 & 25,49 & - & - & & 7 & 12,96 & 12,70 & 8 & 31,21 & 31,20 & 3 & 11,63 & 11,67 & 11 & 21,39 & 21,40 \\
\hline 354075 & Potim & E20 & 3 & 42,83 & 42,40 & - & - & - & 3 & 21,75 & 21,53 & 2 & 21,42 & 22,72 & - & - & - & 2 & 10,87 & 11,54 \\
\hline 354080 & Potirendaba & E20 & 0 & 4,40 & 4,13 & - & - & - & 0 & 2,26 & 2,12 & 3 & 44,02 & 42,99 & - & - & - & 3 & 22,59 & 22,06 \\
\hline 354085 & Pracinha & E20 & - & & & - & - & & - & & & 1 & 183,49 & 172,52 & & & & 1 & 93,81 & 88,20 \\
\hline 354090 & Pradópolis & D20 & 1 & 9,20 & 9,26 & 0 & 4,74 & 5,06 & 1 & 7,01 & 7,19 & 2 & 23,00 & 23,14 & 0 & 4,74 & 5,11 & 2 & 14,01 & 14,26 \\
\hline 354100 & Praia Grande & B300 & 66 & 60,10 & 58,16 & 5 & 4,06 & 3,97 & 71 & 31,42 & 30,43 & 46 & 42,19 & 43,03 & 12 & 10,43 & 10,63 & 58 & 25,94 & 26,45 \\
\hline 354105 & Pratânia & E20 & 0 & 15,06 & 13,79 & - & - & - & 0 & 7,87 & 7,21 & 2 & 90,39 & 96,78 & - & $t$ & - & 2 & 47,25 & 50,59 \\
\hline 354110 & Presidente Alves & E20 & - & & & - & - & & - & & & 1 & 31,14 & 35,30 & 0 & 15,93 & 17,71 & 1 & 23,62 & 26,61 \\
\hline 354120 & Presidente Bernardes & D20 & 1 & 16,84 & 24,27 & 0 & 4,56 & 5,09 & 2 & 10,95 & 15,07 & 3 & 33,67 & 29,92 & 1 & 13,69 & 13,62 & 4 & 24,09 & 22,10 \\
\hline 354130 & Presidente Epitácio & D50 & 5 & 24,33 & 23,56 & 1 & 3,22 & 3,13 & 6 & 13,73 & 13,30 & 5 & 24,33 & 24,16 & 2 & 11,25 & 11,37 & 7 & 17,76 & 17,73 \\
\hline 354140 & Presidente Prudente & B300 & 30 & 31,29 & 31,12 & 3 & 2,59 & 2,52 & 33 & 16,52 & 16,40 & 41 & 42,30 & 41,27 & 9 & 9,08 & 8,77 & 50 & 25,20 & 24,54 \\
\hline 354150 & Presidente Venceslau & D50 & 5 & 24,59 & 25,24 & 1 & 3,52 & 3,47 & 5 & 14,07 & 14,37 & 8 & 43,91 & 42,74 & 3 & 14,10 & 13,75 & 11 & 29,03 & 28,27 \\
\hline 354160 & Promissao & D50 & 2 & 10,15 & 9,95 & - & - & - & 2 & 5,13 & 5,03 & 5 & 30,44 & 30,55 & 0 & 2,07 & 2,20 & 5 & 16,41 & 16,53 \\
\hline 354165 & Quadra & E20 & - & & & - & - & - & - & & & 0 & 21,30 & 22,07 & 0 & 23,46 & 22,66 & 1 & 22,33 & 22,35 \\
\hline 354170 & Quatá & D20 & 2 & 28,45 & 29,07 & - & - & - & 2 & 14,14 & 14,44 & 2 & 39,83 & 40,88 & - & -1 & -1 & 2 & 19,79 & 20,31 \\
\hline 354180 & Queiroz & E20 & - & - & - & - & - & - & - & - & - & 0 & 28,40 & 32,75 & - & - & - & 0 & 14,65 & 16,89 \\
\hline 354190 & Queluz & D20 & - & - & - & 0 & 6,79 & 6,16 & 0 & 3,42 & 3,10 & 3 & 62,08 & 64,90 & - & - & - & 3 & 30,81 & 32,20 \\
\hline 354200 & Quintana & E20 & - & & -1 & - & - & - & - & - & & 1 & 47,67 & 39,46 & 0 & 12,08 & 9,81 & 2 & 30,00 & 24,73 \\
\hline 354210 & Rafard & A20 & 1 & 16,10 & 15,93 & - & - & - & 1 & 8,07 & 7,99 & 3 & 72,47 & 72,89 & - & & - & 3 & 36,33 & 36,54 \\
\hline 354220 & Rancharia & D50 & 1 & 9,08 & 8,81 & 1 & 4,47 & 4,43 & 2 & 6,76 & 6,60 & 4 & 24,98 & 24,67 & 0 & 2,23 & 2,33 & 4 & 13,51 & 13,41 \\
\hline 354230 & Redençao da Serra & E20 & - & & & - & - & - & - & - & & 0 & 15,27 & 15,14 & - & - & - & 0 & 8,21 & 8,14 \\
\hline 354240 & Regente Feijó & D20 & 1 & 11,16 & 10,78 & 0 & 3,73 & 3,72 & 1 & 7,45 & 7,25 & 3 & 33,49 & 32,01 & 0 & 3,73 & 3,73 & 3 & 18,62 & 17,88 \\
\hline 354250 & Reginópolis & E20 & 0 & 13,92 & 26,01 & - & & & 0 & 7,04 & 13,16 & 0 & 13,92 & 7,45 & - & & -1 & 0 & 7,04 & 3,77 \\
\hline 354260 & Registro & D100 & 6 & 21,50 & 19,93 & 1 & 2,38 & 2,14 & 7 & 11,93 & 11,02 & 19 & 66,88 & 72,42 & 6 & 20,25 & 21,46 & 24 & 43,54 & 46,91 \\
\hline
\end{tabular}


Anexo 26 - Óbitos, taxas de mortalidade total (bruta e padronizada) e segundo sexo por Homicídios e Acidentes de Trânsito (por 100 mil hab.) nos municípios/estratos de Vulnerabilidade Social. Estado de São Paulo, média do triênio 2003 a 2005.

\begin{tabular}{|c|c|c|c|c|c|c|c|c|c|c|c|c|c|c|c|c|c|c|c|c|}
\hline \multirow[b]{3}{*}{ IBGE } & \multirow[b]{3}{*}{ Mun. } & \multirow{3}{*}{\begin{tabular}{|l|} 
Status \\
Estrato \\
\end{tabular}} & \multicolumn{9}{|c|}{ HOMICíDIOS } & \multicolumn{9}{|c|}{ ACIDENTES DE TRANSPORTE } \\
\hline & & & \multicolumn{3}{|c|}{ HOMENS } & \multicolumn{3}{|c|}{ MULHERES } & \multicolumn{3}{|c|}{ TOTAL } & \multicolumn{3}{|c|}{ HOMENS } & \multicolumn{3}{|c|}{ MULHERES } & \multicolumn{3}{|c|}{ TOTAL } \\
\hline & & & Óbitos & TBM & TPM & Óbitos & TBM & TPM & Óbitos & TBM & TPM & Óbitos & TBM & TPM & Óbitos & TBM & TPM & Óbitos & TBM & TPM \\
\hline 354270 & Restinga & E20 & 1 & 21,40 & 20,38 & - & - & - & 1 & 10,91 & 10,39 & 3 & 85,59 & 89,20 & 0 & 11,13 & 11,67 & 3 & 49,09 & 51,20 \\
\hline 354280 & Ribeira & E20 & -1 & & & - & - & & - & & & 0 & 19,55 & 17,99 & 0 & 21,55 & 28,38 & 1 & 20,50 & 22,93 \\
\hline 354290 & Ribeirao Bonito & D20 & - & - & - & - & - & & - & - & & 2 & 39,54 & 40,22 & - & - & - & 2 & 20,02 & 20,36 \\
\hline 354300 & Ribeirao Branco & E50 & 2 & 20,20 & 16,28 & - & - & & 2 & 10,56 & 8,51 & 3 & 23,09 & 25,03 & - & - & 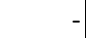 & 3 & 12,07 & 13,08 \\
\hline 354310 & Ribeirao Corrente & E20 & 1 & 30,01 & 28,55 & - & - & & 1 & 15,98 & 15,21 & 0 & 15,00 & 17,23 & - & - & & 0 & 7,99 & 9,18 \\
\hline 354320 & Ribeirao do Sul & E20 & 0 & 14,13 & 12,47 & - & - & & 0 & 7,18 & 6,33 & 2 & 98,90 & 100,09 & - & - & & 2 & 50,24 & 50,84 \\
\hline 354323 & Ribeirao dos Indios & E20 & 0 & 28,19 & 34,23 & - & - & - & 0 & 14,57 & 17,69 & - & - & & - & - & _ & - & & - \\
\hline 354325 & Ribeirao Grande & E20 & 0 & 8,13 & 8,25 & - & -1 & & 0 & 4,20 & 4,26 & 1 & 16,26 & 15,75 & - & - & & 1 & 8,40 & 8,14 \\
\hline 354330 & Ribeirao Pires & B300 & 16 & 29,21 & 29,65 & 2 & 2,91 & 2,99 & 18 & 15,90 & 16,16 & 14 & 25,63 & 25,44 & 3 & 5,82 & 5,86 & 18 & 15,61 & 15,54 \\
\hline 354340 & Ribeirao Preto & B1000 & 65 & 24,97 & 25,11 & 7 & 2,63 & 2,66 & 72 & 13,38 & 13,46 & 78 & 30,25 & 29,69 & 20 & 7,17 & 6,84 & 98 & 18,28 & 17,84 \\
\hline 354360 & Rifaina & D20 & 0 & 18,52 & 17,01 & - & - & - & 0 & 9,48 & 8,71 & 1 & 37,04 & 35,24 & - & - & - & 1 & 18,96 & 18,04 \\
\hline 354370 & Rincao & D20 & 2 & 31,92 & 30,97 & - & - & & 2 & 16,14 & 15,66 & 0 & 6,38 & 6,46 & - & - & & 0 & & 3,27 \\
\hline 354380 & Rinópolis & E20 & 1 & 13,17 & 11,53 & - & - & - & 1 & 6,77 & 5,93 & 1 & 26,33 & 30,50 & - & - & & 1 & 13,54 & 15,68 \\
\hline 354390 & Rio Claro & B300 & 43 & 48,06 & 48,50 & 4 & 4,31 & 4,46 & 47 & 25,70 & 25,99 & 38 & 42,43 & 41,56 & 8 & 8,98 & 8,58 & 46 & 25,33 & 24,71 \\
\hline 354400 & Rio das Pedras & C50 & 8 & 59,13 & 58,20 & 0 & 2,67 & 2,62 & 8 & 31,43 & 30,93 & 4 & 33,42 & 33,56 & 1 & 5,34 & 5,37 & 5 & 19,64 & 19,73 \\
\hline 354410 & Rio Grande da Serra & C50 & 10 & 49,83 & 49,60 & 2 & 9,88 & 10,91 & 12 & 29,77 & 30,17 & 5 & 23,26 & 26,13 & - & - & & 5 & 11,58 & 13,01 \\
\hline 354420 & Riolândia & E20 & - & & - & 0 & 8,45 & 7,71 & 0 & 3,74 & 3,41 & 2 & 46,89 & 43,86 & 0 & 8,45 & 9,27 & 3 & 29,90 & 28,56 \\
\hline 354350 & Riversul & E20 & 0 & 10,50 & 8,27 & - & - & - & 0 & 5,37 & 4,23 & 2 & 63,01 & 73,79 & 1 & 32,97 & 34,60 & 3 & 48,33 & 54,64 \\
\hline 354425 & Rosana & C50 & 4 & 30,58 & 29,97 & 1 & 5,25 & 6,04 & 5 & 18,10 & 18,18 & 3 & 20,39 & 21,11 & 0 & 2,62 & 2,09 & 3 & 11,63 & 11,73 \\
\hline 354430 & Roseira & C20 & 0 & 6,79 & 7,22 & 0 & 7,06 & 7,76 & 1 & 6,92 & 7,49 & 2 & 47,54 & 48,51 & 1 & 14,11 & 14,62 & 3 & 31,15 & 31,89 \\
\hline 354440 & Rubiácea & E20 & - & - & - & - & - & - & - & - & - & 0 & 29,67 & 28,86 & - & - & 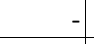 & 0 & 15,13 & 14,72 \\
\hline 354450 & Rubinéia & D20 & - & - & -1 & - & - & - & - & - & & 1 & 48,29 & 46,71 & - & - & 1 & 1 & 23,95 & 23,17 \\
\hline 354460 & Sabino & E20 & 0 & 13,04 & 12,18 & - & - & & 0 & 6,51 & 6,08 & - & & & - & 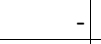 & & - & & \\
\hline 354470 & Sagres & E20 & - & - & - & - & - & -1 & - & - & & 0 & 27,88 & 31,13 & - & - & - & 0 & 14,22 & 15,88 \\
\hline 354480 & Sales & E20 & - & - & - & - & - & - & - & - & - & 2 & 66,63 & 61,85 & 0 & 13,77 & 14,47 & 2 & 40,64 & 38,55 \\
\hline 354490 & Sales Oliveira & B20 & 0 & 6,58 & 5,86 & - & - & & 0 & 3,31 & 2,94 & 2 & 39,49 & 40,56 & 0 & 6,64 & 7,01 & 2 & 23,14 & 23,86 \\
\hline 354500 & Salesópolis & E20 & 1 & 12,60 & 12,08 & 0 & 4,30 & 4,07 & 1 & 8,50 & 8,12 & 3 & 33,60 & 34,64 & 0 & 4,30 & 4,64 & 3 & 19,12 & 19,81 \\
\hline 354510 & Salmourao & E20 & - & - & - & - & - & 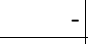 & - & - & & 1 & 59,87 & 61,45 & 1 & 46,53 & 47,90 & 2 & 53,32 & 54,79 \\
\hline 354515 & Saltinho & B20 & - & & & - & & & - & & & 1 & 43,19 & 40,58 & 1 & 43,94 & 41,89 & 3 & 43,56 & 41,23 \\
\hline 354520 & Salto & B300 & 34 & 65,70 & 65,65 & 1 & 2,60 & 2,64 & 35 & 34,16 & 34,15 & 18 & 35,13 & 35,65 & 3 & 6,51 & 6,47 & 21 & 20,82 & 21,06 \\
\hline 354530 & Salto de Pirapora & D50 & 6 & 30,34 & 29,17 & - & - & & 6 & 15,22 & 14,64 & 8 & 38,77 & 39,97 & 0 & 1,70 & 1,46 & 8 & 20,30 & 20,78 \\
\hline 354540 & Salto Grande & E20 & 1 & 29,74 & 28,56 & 0 & 7,52 & 6,70 & 2 & 18,69 & 17,69 & 2 & 52,05 & 50,95 & 1 & 22,55 & 21,01 & 3 & 37,38 & 36,06 \\
\hline
\end{tabular}


Anexo 26 - Óbitos, taxas de mortalidade total (bruta e padronizada) e segundo sexo por Homicídios e Acidentes de Trânsito (por 100 mil hab.) nos municípios/estratos de Vulnerabilidade Social. Estado de São Paulo, média do triênio 2003 a 2005.

\begin{tabular}{|c|c|c|c|c|c|c|c|c|c|c|c|c|c|c|c|c|c|c|c|c|}
\hline \multirow[b]{3}{*}{ IBGE } & \multirow[b]{3}{*}{ Mun. } & \multirow{3}{*}{\begin{tabular}{|l} 
Status \\
Estrato \\
\end{tabular}} & \multicolumn{9}{|c|}{ HOMıcídıOS } & \multicolumn{9}{|c|}{ ACIDENTES DE TRANSPORTE } \\
\hline & & & \multicolumn{3}{|c|}{ HOMENS } & \multicolumn{3}{|c|}{ MULHERES } & \multicolumn{3}{|c|}{ TOTAL } & \multicolumn{3}{|c|}{ HOMENS } & \multicolumn{3}{|c|}{ MULHERES } & \multicolumn{3}{|c|}{ TOTAL } \\
\hline & & & Óbitos & TBM & TPM & Óbitos & TBM & TPM & Óbitos & TBM & TPM & Óbitos & TBM & TPM & Óbitos & TBM & TPM & Óbitos & TBM & TPM \\
\hline 354550 & Sandovalina & E20 & - & - & 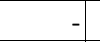 & - & - & - & - & - & & 1 & 39,60 & 38,99 & - & -1 & & 1 & 19,64 & 19,34 \\
\hline 354560 & Santa Adélia & D20 & 1 & 9,55 & 10,49 & 0 & 4,87 & 4,63 & 1 & 7,23 & 7,59 & 3 & 38,20 & 38,18 & 0 & 4,87 & 4,57 & 3 & 21,70 & 21,55 \\
\hline 354570 & Santa Albertina & E20 & 0 & 12,14 & 10,42 & - & & & 0 & 6,10 & 5,24 & 1 & 24,29 & 20,07 & 0 & 12,28 & 7,50 & 1 & 18,31 & 13,82 \\
\hline 354580 & Santa Bárbara d'Oeste & B300 & 30 & 32,79 & 33,38 & 3 & 3,31 & 3,35 & 33 & 18,03 & 18,35 & 28 & 30,95 & 30,88 & 6 & 6,62 & 6,78 & 34 & 18,77 & 18,82 \\
\hline 354600 & Santa Branca & D20 & 1 & 13,92 & 13,82 & - & - & - & 1 & 7,03 & 6,98 & 1 & 9,28 & 9,28 & - & 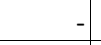 & & 1 & 4,69 & 4,69 \\
\hline 354610 & Santa Clara d'Oeste & E20 & - & & & - & - & & - & - & & 1 & 67,98 & 80,15 & - & - & & 1 & 34,09 & 40,19 \\
\hline 354620 & Santa Cruz da Conceiçao & B20 & - & & & - & -1 & & - & 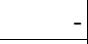 & & 0 & 17,18 & 18,84 & - & & & 0 & 8,78 & 9,63 \\
\hline 354625 & Santa Cruz da Esperança & E20 & - & - & - & - & - & - & - & - & & 1 & 105,78 & 121,49 & 0 & 37,11 & 43,93 & 1 & 72,32 & 83,69 \\
\hline 354630 & Santa Cruz das Palmeiras & D50 & 6 & 41,21 & 41,23 & 1 & 7,42 & 7,42 & 7 & 24,49 & 24,50 & 6 & 43,64 & 43,45 & 0 & 2,47 & 2,59 & 6 & 23,26 & 23,22 \\
\hline 354640 & Santa Cruz do Rio Pardo & C50 & 5 & 21,97 & 21,44 & 1 & 4,62 & 4,43 & 6 & 13,22 & 12,86 & 4 & 17,27 & 16,57 & 2 & 9,25 & 8,99 & 6 & 13,22 & 12,75 \\
\hline 354650 & Santa Ernestina & B20 & 0 & 10,58 & 8,75 & - & -1 & & 0 & 5,75 & 4,76 & - & & & - & & & - & & \\
\hline 354660 & Santa Fé do Sul & D50 & - & & & - & - & & - & - & & 3 & 22,00 & 21,25 & 1 & 9,26 & 8,64 & 4 & 15,46 & 14,78 \\
\hline 354670 & Santa Gertrudes & $\mathrm{C} 20$ & 1 & 10,71 & 11,28 & - & - & & 1 & 5,46 & 5,75 & 6 & 60,70 & 59,08 & 1 & 14,83 & 14,18 & 7 & 38,19 & 37,05 \\
\hline 354680 & Santa Isabel & D50 & 8 & 35,63 & 34,38 & - & & & 8 & 17,99 & 17,36 & 9 & 38,48 & 39,73 & 1 & 4,36 & 4,57 & 10 & 21,59 & 22,33 \\
\hline 354690 & Santa Lúcia & E20 & 2 & 37,69 & 34,92 & 1 & 16,13 & 15,34 & 2 & 27,28 & 25,46 & 1 & 30,15 & 30,86 & 0 & 8,07 & 8,48 & 2 & 19,48 & 20,05 \\
\hline 354700 & Santa Maria da Serra & E20 & 1 & 26,39 & 25,98 & - & - & & 1 & 13,78 & 13,56 & 1 & 39,59 & 38,34 & 2 & 86,49 & 89,60 & 3 & 62,00 & 62,84 \\
\hline 354710 & Santa Mercedes & E20 & - & & & - & - & & - & - & & 0 & 24,20 & 30,94 & 0 & 24,80 & 27,61 & 1 & 24,49 & 29,30 \\
\hline 354750 & Santa Rita do Passa Quatr & B50 & 2 & 17,70 & 20,16 & - & -1 & & 2 & 8,63 & 9,83 & 6 & 42,99 & 41,72 & 1 & 4,81 & 5,37 & 6 & 23,42 & 23,09 \\
\hline 354740 & Santa Rita d'Oeste & E20 & 0 & 28,22 & 23,88 & - & - & - & 0 & 14,23 & 12,05 & 1 & 56,43 & 66,68 & - & - & - & 1 & 28,47 & 33,64 \\
\hline 354760 & Santa Rosa de Viterbo & D50 & 2 & 17,89 & 17,03 & 1 & 5,92 & 5,56 & 3 & 11,89 & 11,27 & 1 & 8,94 & 9,40 & 1 & 5,92 & 5,62 & 2 & 7,43 & 7,50 \\
\hline 354765 & Santa Salete & E20 & - & & & - & - & & - & & & 0 & 45,98 & 49,36 & - & 1 & & 0 & 24,17 & 25,95 \\
\hline 354720 & Santana da Ponte Pensa & E20 & - & - & - & - & - & - & - & - & & 0 & 38,33 & 25,82 & - & - & - & 0 & 19,80 & 13,34 \\
\hline 354730 & Santana de Parnaíba & C100 & 31 & 68,07 & 67,15 & 3 & 6,54 & 6,54 & 34 & 37,21 & 36,75 & 10 & 21,96 & 22,13 & 1 & 2,91 & 3,78 & 11 & 12,40 & 12,92 \\
\hline 354770 & Santo Anastácio & E50 & 2 & 19,42 & 17,92 & 0 & 3,09 & 2,95 & 2 & 11,07 & 10,27 & 1 & 12,94 & 14,28 & 0 & 3,09 & 2,23 & 2 & 7,91 & 8,11 \\
\hline 354780 & Santo André & A1000 & 213 & 66,40 & 67,24 & 14 & 4,08 & 4,15 & 227 & 34,20 & 34,64 & 45 & 13,92 & 13,63 & 15 & 4,37 & 4,26 & 60 & 8,99 & 8,79 \\
\hline 354790 & Santo Antônio da Alegria & E20 & - & - & t & - & - & - & - & - & & 2 & 63,71 & 64,85 & - & - & 1 & 2 & 33,13 & 33,72 \\
\hline 354800 & Santo Antônio de Posse & D20 & 5 & 49,96 & 49,74 & - & - & 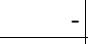 & 5 & 25,18 & 25,07 & 6 & 59,95 & 60,25 & 1 & 6,77 & 6,76 & 7 & 33,58 & 33,72 \\
\hline 354805 & Santo Antônio do Aracangu & E20 & 0 & 9,30 & 9,68 & - & - & - & 0 & 4,83 & 5,03 & 1 & 18,60 & 18,91 & 1 & 20,12 & 19,06 & 1 & 19,33 & 18,98 \\
\hline 354810 & Santo Antônio do Jardim & E20 & - & - & - & - & - & - & - & - & & 1 & 20,00 & 20,82 & 1 & 22,00 & 22,30 & 1 & 20,95 & 21,52 \\
\hline 354820 & Santo Antônio do Pinhal & E20 & - & - & - & - & - & 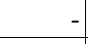 & - & 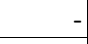 & & 1 & 28,81 & 28,83 & - & 4 & & 1 & 14,78 & 14,79 \\
\hline 354830 & Santo Expedito & E20 & 1 & 48,39 & 50,80 & - & - & & 1 & 25,05 & 26,29 & - & & & - & & & - & & \\
\hline 354840 & Santópolis do Aguapeí & E20 & 0 & 17,20 & 15,25 & -1 & -1 & - & 0 & 8,75 & 7,76 & 0 & 17,20 & 19,40 & 0 & 17,83 & 15,73 & 1 & 17,51 & 17,59 \\
\hline
\end{tabular}


Anexo 26 - Óbitos, taxas de mortalidade total (bruta e padronizada) e segundo sexo por Homicídios e Acidentes de Trânsito (por 100 mil hab.) nos municípios/estratos de Vulnerabilidade Social. Estado de São Paulo, média do triênio 2003 a 2005.

\begin{tabular}{|c|c|c|c|c|c|c|c|c|c|c|c|c|c|c|c|c|c|c|c|c|}
\hline \multirow[b]{3}{*}{ IBGE } & \multirow[b]{3}{*}{ Mun. } & \multirow{3}{*}{\begin{tabular}{|l|} 
Status \\
Estrato \\
\end{tabular}} & \multicolumn{9}{|c|}{ HOMIcíDIOS } & \multicolumn{9}{|c|}{ ACIDENTES DE TRANSPORTE } \\
\hline & & & \multicolumn{3}{|c|}{ HOMENS } & \multicolumn{3}{|c|}{ MULHERES } & \multicolumn{3}{|c|}{ TOTAL } & \multicolumn{3}{|c|}{ HOMENS } & \multicolumn{3}{|c|}{ MULHERES } & \multicolumn{3}{|c|}{ TOTAL } \\
\hline & & & Óbitos & TBM & TPM & Óbitos & TBM & TPM & Óbitos & TBM & TPM & Óbitos & TBM & TPM & Óbitos & TBM & TPM & Óbitos & TBM & $=$ \\
\hline 354850 & Santos & A500 & 64 & 32,93 & 32,88 & 7 & 3,11 & 2,89 & 71 & 16,90 & 16,76 & 55 & 28,45 & 26,47 & 14 & 6,37 & 5,16 & 69 & 16,58 & 15,01 \\
\hline 354860 & Sao Bento do Sapucaí & D20 & & & & - & & & & & & 1 & 23,71 & 25,48 & - & & & 1 & 12,02 & 12,91 \\
\hline 354870 & Sao Bernardo do Campo & B1000 & 209 & 56,22 & 57,76 & 14 & 3,57 & 3,66 & 223 & 29,19 & 29,98 & 94 & 25,38 & 25,47 & 22 & 5,52 & 5,75 & 116 & 15,18 & 15,35 \\
\hline 354880 & Sao Caetano do Sul & A300 & 24 & 37,76 & 38,66 & 2 & 2,30 & 2,37 & 26 & 18,88 & 19,33 & 14 & 22,03 & 18,99 & 4 & 5,98 & 5,10 & 18 & 13,48 & 11,59 \\
\hline 354890 & Sao Carlos & B300 & 24 & 23,24 & 23,76 & 1 & 0,95 & 1,04 & 25 & 11,99 & 12,30 & 27 & 26,14 & 25,13 & 5 & 4,75 & 4,59 & 32 & 15,35 & 14,77 \\
\hline 354900 & Sao Francisco & E20 & - & & & - & & & 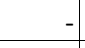 & & & 1 & 65,66 & 76,99 & - & & & 1 & 33,26 & 39,00 \\
\hline 354910 & Sao Joao da Boa Vista & B100 & 4 & 9,20 & 9,61 & 0 & 0,81 & 0,77 & 4 & 4,93 & 5,12 & 14 & 35,13 & 32,56 & 4 & 9,71 & 9,01 & 18 & 22,20 & 20,59 \\
\hline 354920 & Sao Joao das Duas Pontes & E20 & - & - & - & - & - & & - & & & 1 & 75,47 & 69,08 & - & -1 & - & 1 & 38,46 & 35,20 \\
\hline 354925 & Sao Joao de Iracema & E20 & - & - & - & 0 & 40,27 & 35,59 & 0 & 19,56 & 17,29 & 0 & 38,02 & 38,89 & - & & - & 0 & 19,56 & 20,00 \\
\hline 354930 & Sao Joao do Pau d'Alho & E20 & - & & & - & & & - & & & 0 & 34,65 & 15,41 & - & & & 0 & 17,59 & 7,82 \\
\hline 354940 & Sao Joaquim da Barra & C50 & 4 & 16,85 & 17,08 & 0 & 1,49 & 1,44 & 4 & 9,07 & 9,16 & 5 & 21,44 & 21,05 & 1 & 2,98 & 2,94 & 5 & 12,09 & 11,88 \\
\hline 354950 & Sao José da Bela Vista & E20 & 1 & 15,36 & 14,62 & - & - & - & 1 & 7,84 & 7,47 & 2 & 46,07 & 47,92 & 1 & 16,03 & 17,46 & 3 & 31,37 & 33,01 \\
\hline 354960 & Sao José do Barreiro & E20 & 1 & 30,19 & 28,29 & 1 & 49,30 & 53,26 & 2 & 39,34 & 40,24 & 0 & 15,09 & 16,82 & - & & & 0 & 7,87 & 8,77 \\
\hline 354970 & Sao José do Rio Pardo & D100 & 1 & 5,12 & 4,99 & 1 & 2,52 & 2,49 & 2 & 3,81 & 3,73 & 10 & 37,12 & 38,22 & 2 & 6,29 & 6,50 & 11 & 21,57 & 22,22 \\
\hline 354980 & Sao José do Rio Preto & B500 & 43 & 22,61 & 23,04 & 5 & 2,30 & 2,43 & 48 & 12,13 & 12,40 & 73 & 38,39 & 36,46 & 15 & 7,40 & 6,94 & 88 & 22,39 & 21,22 \\
\hline 354990 & Sao José dos Campos & B1000 & 159 & 55,35 & 56,13 & 11 & 3,85 & 3,88 & 171 & 29,29 & 29,70 & 84 & 29,18 & 29,75 & 18 & 6,22 & 6,62 & 102 & 17,56 & 18,04 \\
\hline 354995 & Sao Lourenço da Serra & E20 & 3 & 36,82 & 35,33 & 1 & 9,45 & 7,45 & 3 & 23,32 & 21,58 & 6 & 87,44 & 90,81 & 1 & 9,45 & 10,01 & 7 & 48,96 & 50,95 \\
\hline 355000 & Sao Luís do Paraitinga & E20 & 1 & 12,07 & 12,48 & - & & & 1 & 6,26 & 6,47 & 1 & 24,13 & 26,09 & 1 & 12,99 & 12,67 & 2 & 18,77 & 19,63 \\
\hline 355010 & Sao Manuel & D50 & 1 & 5,23 & 5,02 & 1 & 3,43 & 3,29 & 2 & 4,33 & 4,15 & 7 & 34,89 & 35,01 & 1 & 6,87 & 7,40 & 8 & 20,77 & 21,10 \\
\hline 355020 & Sao Miguel Arcanjo & E50 & 2 & 9,80 & 9,18 & 0 & 2,06 & 2,08 & 2 & 6,02 & 5,71 & 6 & 33,34 & 35,46 & 0 & 2,06 & 2,03 & 6 & 18,06 & 19,14 \\
\hline 355030 & Sao Paulo & B10000 & 3641 & 70,82 & 71,88 & 286 & 5,07 & 5,13 & 3927 & 36,40 & 36,94 & 1143 & 22,24 & 22,00 & 343 & 6,08 & 5,91 & 1487 & 13,78 & 13,58 \\
\hline 355040 & Sao Pedro & B50 & 4 & 25,89 & 25,38 & 0 & 2,10 & 1,87 & 4 & 13,82 & 13,46 & 5 & 32,36 & 31,41 & 2 & 10,48 & 10,08 & 7 & 21,27 & 20,60 \\
\hline 355050 & Sao Pedro do Turvo & E20 & 0 & 9,47 & 8,85 & - & - & 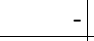 & 0 & 4,79 & 4,48 & 0 & 9,47 & 6,67 & 0 & 9,68 & 9,05 & 1 & 9,57 & 7,85 \\
\hline 355060 & Sao Roque & B100 & 10 & 27,37 & 27,27 & 1 & 2,81 & 2,71 & 11 & 15,03 & 14,94 & 15 & 42,47 & 42,35 & 4 & 10,29 & 10,50 & 19 & 26,31 & 26,36 \\
\hline 355070 & Sao Sebastiao & C100 & 37 & 107,06 & 109,95 & 3 & 9,82 & 10,35 & 41 & 59,09 & 60,81 & 11 & 32,50 & 34,00 & 3 & 7,85 & 8,41 & 14 & 20,34 & $\begin{array}{l}71,38 \\
\end{array}$ \\
\hline 355080 & Sao Sebastiao da Grama & E20 & - & & & - & - & - & - & - & & 2 & 36,03 & 34,99 & 0 & 5,32 & 4,83 & 3 & 20,93 & 20,16 \\
\hline 355090 & Sao Simao & B20 & 1 & 13,90 & 14,00 & - & - & - & 1 & 6,93 & 6,98 & 2 & 32,43 & 32,05 & - & 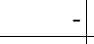 & -1 & 2 & 16,17 & $\begin{array}{l}15,98 \\
\end{array}$ \\
\hline 355100 & Sao Vicente & B500 & 74 & 48,03 & 47,72 & 4 & 2,64 & 2,62 & 79 & 24,65 & 24,49 & 48 & 30,80 & 31,18 & 10 & 6,08 & 6,10 & 58 & 18,07 & 18,26 \\
\hline 355110 & Sarapuí & E20 & 1 & 22,85 & 22,13 & - & - & 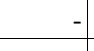 & 1 & 11,91 & 11,53 & 2 & 53,32 & 55,60 & 0 & 8,29 & 9,61 & 3 & 31,75 & 33,57 \\
\hline 355120 & Sarutaiá & E20 & 0 & 16,35 & 13,90 & - & - & - & 0 & 8,21 & 6,98 & - & 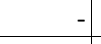 & - & 0 & 16,50 & 12,41 & 0 & 8,21 & 6,18 \\
\hline 355130 & Sebastianópolis do Sul & E20 & - & & - & - & - & - & - & 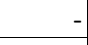 & & 1 & 51,07 & 55,72 & - & 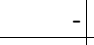 & 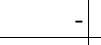 & 1 & 26,09 & 28,46 \\
\hline 355140 & Serra Azul & E20 & 1 & 32,72 & 30,89 & - & & & 1 & 16,64 & 15,71 & 2 & 49,08 & 51,91 & 0 & 8,46 & 9,80 & 2 & 29,12 & 31,2 \\
\hline
\end{tabular}


Anexo 26 - Óbitos, taxas de mortalidade total (bruta e padronizada) e segundo sexo por Homicídios e Acidentes de Trânsito (por 100 mil hab.) nos municípios/estratos de Vulnerabilidade Social. Estado de São Paulo, média do triênio 2003 a 2005.

\begin{tabular}{|c|c|c|c|c|c|c|c|c|c|c|c|c|c|c|c|c|c|c|c|c|}
\hline \multirow[b]{3}{*}{ IBGE } & \multirow[b]{3}{*}{ Mun. } & \multirow{3}{*}{\begin{tabular}{|l|} 
Status \\
Estrato \\
\end{tabular}} & \multicolumn{9}{|c|}{ HOMıcídIOS } & \multicolumn{9}{|c|}{ ACIDENTES DE TRANSPORTE } \\
\hline & & & \multicolumn{3}{|c|}{ HOMENS } & \multicolumn{3}{|c|}{ MULHERES } & \multicolumn{3}{|c|}{ TOTAL } & \multicolumn{3}{|c|}{ HOMENS } & \multicolumn{3}{|c|}{ MULHERES } & \multicolumn{3}{|c|}{ TOTAL } \\
\hline & & & Óbitos & TBM & TPM & Óbitos & TBM & TPM & Óbitos & TBM & TPM & Óbitos & TBM & TPM & Óbitos & TBM & TPM & Óbitos & TBM & TPM \\
\hline 355160 & Serra Negra & D50 & 2 & 16,34 & 17,94 & 1 & 7,96 & 8,39 & 3 & 12,09 & 13,10 & 6 & 49,02 & 46,40 & 1 & 10,61 & 10,41 & 7 & 29,56 & 28,17 \\
\hline 355150 & Serrana & C50 & 7 & 37,78 & 38,10 & 0 & 1,82 & 1,81 & 7 & 19,93 & 20,08 & 7 & 39,58 & 41,14 & 1 & 7,30 & 6,69 & 9 & 23,55 & 24,04 \\
\hline 355170 & Sertaozinho & C300 & 14 & 28,05 & 28,44 & 1 & 1,32 & 1,36 & 15 & 14,74 & 14,96 & 13 & 24,79 & 24,79 & 6 & 11,18 & 11,25 & 18 & 18,02 & 18,05 \\
\hline 355180 & Sete Barras & E20 & 2 & 22,38 & 20,97 & 1 & 9,81 & 8,32 & 2 & 16,38 & 14,93 & 2 & 26,86 & 25,07 & 1 & 19,62 & 19,81 & 3 & 23,40 & 22,56 \\
\hline 355190 & Severínia & E20 & 2 & 25,50 & 24,65 & - & & & 2 & 13,25 & 12,82 & 2 & 29,75 & 29,64 & 1 & 13,80 & 14,19 & 3 & 22,09 & 22,22 \\
\hline 355200 & Silveiras & E20 & 0 & 11,61 & 12,37 & - & - & & 0 & 5,97 & 6,36 & 0 & 11,61 & 10,63 & - & - & & 0 & 5,97 & 5,46 \\
\hline 355210 & Socorro & D50 & 1 & 7,95 & 8,96 & 0 & 1,98 & 1,82 & 2 & 4,96 & 5,39 & 5 & 29,81 & 29,96 & 1 & 5,95 & 5,72 & 6 & 17,87 & 17,83 \\
\hline 355220 & Sorocaba & B1000 & 127 & 47,52 & 47,57 & 7 & 2,65 & 2,65 & 135 & 24,73 & 24,75 & 79 & 29,36 & 29,46 & 19 & 6,99 & 6,99 & 98 & 18,00 & 18,05 \\
\hline 355230 & Sud Mennucci & E20 & - & & & 0 & 9,14 & 9,40 & 0 & 4,48 & 4,61 & 2 & 43,96 & 44,50 & - & & & 2 & 22,41 & 22,69 \\
\hline 355240 & Sumaré & C300 & 81 & 72,54 & 73,30 & 7 & 6,04 & 6,37 & 87 & 39,41 & 39,96 & 36 & 32,67 & 33,55 & 5 & 4,53 & 4,33 & 41 & 18,65 & 18,99 \\
\hline 355255 & Suzanápolis & E20 & - & - & - & - & - & & - & - & & 0 & 22,67 & 23,10 & - & - & - & 0 & 11,66 & 11,88 \\
\hline 355250 & Suzano & C300 & 88 & 68,12 & 66,36 & 6 & 4,57 & 4,38 & 94 & 36,04 & 35,07 & 24 & 18,91 & 20,57 & 8 & 5,84 & 6,48 & 32 & 12,31 & 13,46 \\
\hline 355260 & Tabapua & E20 & 0 & 6,14 & 7,36 & - & - & - & 0 & 3,11 & 3,72 & 3 & 61,41 & 57,45 & 1 & 12,57 & 12,84 & 4 & 37,27 & 35,40 \\
\hline 355270 & Tabatinga & E20 & 1 & 9,41 & 9,41 & - & - & - & 1 & 4,77 & 4,77 & 5 & 65,84 & 65,67 & 1 & 14,53 & 14,43 & 6 & 40,56 & 40,43 \\
\hline 355280 & Taboao da Serra & С300 & 95 & 92,15 & 95,56 & 8 & 7,21 & 7,41 & 103 & 48,19 & 49,94 & 32 & 30,93 & 32,43 & 7 & 6,01 & 7,00 & 39 & 18,03 & 19,27 \\
\hline 355290 & Taciba & E20 & 0 & 12,06 & 11,46 & - & & & 0 & 6,14 & 5,83 & 2 & 72,36 & 70,29 & - & - & 1 & 2 & 36,82 & 35,76 \\
\hline 355300 & Taguaí & E20 & - & - & - & - & - & - & - & - & & 1 & 24,93 & 28,59 & - & - & - & 1 & 12,61 & 14,46 \\
\hline 355310 & Taiaçu & E20 & 0 & 11,16 & 10,54 & 0 & 11,50 & 12,07 & 1 & 11,33 & 11,29 & 1 & 22,32 & 23,64 & - & - & 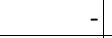 & 1 & 11,33 & 12,00 \\
\hline 355320 & Taiúva & E20 & 1 & 23,64 & 21,70 & - & - & & 1 & 11,83 & 10,86 & 2 & 59,09 & 55,35 & - & - & - & 2 & 29,58 & 27,71 \\
\hline 355330 & Tambaú & D50 & 2 & 19,78 & 21,35 & - & - & -1 & 2 & 10,00 & 10,79 & 4 & 31,09 & 30,34 & 1 & 5,78 & 6,35 & 4 & 18,57 & 18,47 \\
\hline 355340 & Tanabi & D50 & 2 & 14,59 & 14,15 & - & - & - & 2 & 7,23 & 7,01 & 4 & 37,93 & 35,49 & 1 & 11,45 & 12,13 & 6 & 24,57 & 23,70 \\
\hline 355350 & Tapiraí & E20 & 1 & 26,32 & 23,15 & - & - & 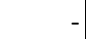 & 1 & 13,56 & 11,93 & 3 & 59,21 & 65,44 & 1 & 20,97 & 24,86 & 4 & 40,67 & 45,76 \\
\hline 355360 & Tapiratiba & D20 & 2 & 24,96 & 24,45 & - & - & - & 2 & 12,39 & 12,13 & 3 & 39,94 & 40,74 & - & & & 3 & 19,82 & 20,22 \\
\hline 355365 & Taquaral & E20 & 0 & 22,69 & 21,03 & - & - & - & 0 & 11,70 & 10,85 & 2 & 136,12 & 134,75 & 2 & 144,93 & 153,05 & 4 & 140,38 & \#\#\#\#\# \\
\hline 355370 & Taquaritinga & D100 & 5 & 19,38 & 19,92 & 1 & 2,48 & 2,45 & 6 & 11,04 & 11,30 & 11 & 38,76 & 37,54 & 1 & 3,73 & 3,67 & 12 & 21,46 & 20,82 \\
\hline 355380 & Taquarituba & E50 & 2 & 16,91 & 16,07 & 0 & 2,85 & 2,83 & 2 & 9,92 & 9,49 & 5 & 42,26 & 44,35 & 1 & 11,41 & 11,26 & 6 & 26,93 & 27,91 \\
\hline 355385 & Taquarivaí & E20 & - & - & - & - & - & 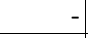 & - & - & & 2 & 64,09 & 76,18 & - & - & - & 2 & 32,71 & 38,88 \\
\hline 355390 & Tarabaí & E20 & - & - & & - & - & & - & 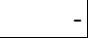 & & 2 & 52,50 & 51,86 & - & - & & 2 & 26,60 & 26,27 \\
\hline 355395 & Taruma & D20 & - & - & -1 & - & - & - & - & - & & 2 & 28,85 & 30,67 & 0 & 6,07 & 5,87 & 2 & 17,75 & 18,59 \\
\hline 355400 & Tatuí & С300 & 28 & 55,93 & 54,83 & 3 & 6,53 & 6,24 & 32 & 31,14 & 30,44 & 19 & 37,51 & 38,07 & 4 & 8,49 & 8,79 & 23 & 22,94 & 23,37 \\
\hline 355410 & Taubaté & B300 & 38 & 29,57 & 29,66 & 6 & 4,54 & 4,55 & 44 & 16,87 & 16,92 & 36 & 28,02 & 27,98 & 8 & 6,30 & 6,27 & 44 & 17,00 & 16,97 \\
\hline 355420 & Tejupá & E20 & 0 & 11,31 & 11,86 & - & - & - & 0 & 5,95 & 6,23 & 3 & 90,50 & 93,14 & 0 & 12,53 & 9,16 & 3 & 53,51 & 53,31 \\
\hline
\end{tabular}


Anexo 26 - Óbitos, taxas de mortalidade total (bruta e padronizada) e segundo sexo por Homicídios e Acidentes de Trânsito (por 100 mil hab.) nos municípios/estratos de Vulnerabilidade Social. Estado de São Paulo, média do triênio 2003 a 2005.

\begin{tabular}{|c|c|c|c|c|c|c|c|c|c|c|c|c|c|c|c|c|c|c|c|c|}
\hline \multirow[b]{3}{*}{ IBGE } & \multirow[b]{3}{*}{ Mun. } & \multirow{3}{*}{\begin{tabular}{|l|} 
Status \\
Estrato \\
\end{tabular}} & \multicolumn{9}{|c|}{ HOMıcíDIOS } & \multicolumn{9}{|c|}{ ACIDENTES DE TRANSPORTE } \\
\hline & & & \multicolumn{3}{|c|}{ HOMENS } & \multicolumn{3}{|c|}{ MULHERES } & \multicolumn{3}{|c|}{ TOTAL } & \multicolumn{3}{|c|}{ HOMENS } & \multicolumn{3}{|c|}{ MULHERES } & \multicolumn{3}{|c|}{ TOTAL } \\
\hline & & & Óbitos & TBM & TPM & Óbitos & TBM & TPM & Óbitos & TBM & TPM & Óbitos & TBM & TPM & Óbitos & TBM & TPM & Óbitos & TBM & TPM \\
\hline 355430 & Teodoro Sampaio & D50 & 1 & 12,98 & 11,91 & - & & & 1 & 6,51 & 5,98 & 4 & 42,19 & 44,77 & 0 & 3,27 & 3,51 & 5 & 22,79 & 24,20 \\
\hline 355440 & Terra Roxa & E20 & 1 & 15,85 & 15,80 & 0 & 8,24 & 7,82 & 1 & 12,12 & 11,88 & 1 & 23,77 & 24,01 & - & - & - & 1 & 12,12 & 12,24 \\
\hline 355450 & Tietê & B50 & 2 & 13,52 & 13,46 & 0 & 1,90 & 1,80 & 3 & 7,67 & 7,59 & 7 & 38,62 & 37,17 & - & -1 & - & 7 & 19,18 & 18,45 \\
\hline 355460 & Timburi & E20 & - & & & - & -1 & & - & & & - & & & 0 & 25,65 & 23,63 & 0 & 12,46 & 11,48 \\
\hline 355465 & Torre de Pedra & E20 & 1 & 77,46 & 107,76 & - & - & & 1 & 39,24 & 54,59 & 0 & 25,82 & 31,60 & 0 & 26,50 & 30,53 & 1 & 26,16 & 31,07 \\
\hline 355470 & Torrinha & E20 & 1 & 13,94 & 13,13 & - & - & - & 1 & 7,07 & 6,66 & 1 & 20,92 & 17,73 & - & - & & 1 & 10,60 & 8,99 \\
\hline 355475 & Trabiju & E20 & - & & & - & - & - & - & - & & 0 & 44,11 & 47,18 & - & - & - & 0 & 23,19 & 24,80 \\
\hline 355480 & Tremembé & B50 & 4 & 18,51 & 19,68 & 0 & 1,83 & 1,71 & 4 & 10,51 & 11,06 & 4 & 21,87 & 21,40 & 0 & 1,83 & 1,84 & 5 & 12,26 & 12,02 \\
\hline 355490 & Três Fronteiras & E20 & - & & & - & -1 & - & - & - & & 2 & 64,06 & 71,00 & - & t & & 2 & 32,22 & 35,71 \\
\hline 355495 & Tuiuti & E20 & 0 & 12,11 & 11,53 & - & - & - & 0 & 6,24 & 5,94 & 2 & 84,79 & 79,81 & - & - & - & 2 & 43,68 & 41,12 \\
\hline 355500 & Tupa & D100 & 6 & 17,86 & 17,48 & 1 & 3,99 & 4,56 & 7 & 10,75 & 10,85 & 12 & 36,77 & 36,24 & 2 & 6,99 & 6,79 & 14 & 21,50 & 21,13 \\
\hline 355510 & Tupi Paulista & D20 & - & & & - & -1 & & - & & & 0 & 5,21 & 4,00 & 0 & 5,09 & 5,49 & 1 & 5,15 & 4,75 \\
\hline 355520 & Turiúba & E20 & - & - & - & - & - & - & - & - & & 0 & 35,98 & 42,11 & - & - & - & 0 & 18,41 & 21,55 \\
\hline 355530 & Turmalina & E20 & - & - & - & - & - & - & - & - & & 0 & 30,31 & 29,70 & - & - & - & 0 & 15,19 & 14,88 \\
\hline 355535 & Ubarana & E20 & - & - & - & - & - & - & - & - & - & 0 & 13,18 & 12,83 & 0 & 14,45 & 12,45 & 1 & 13,79 & 12,65 \\
\hline 355540 & Ubatuba & C100 & 21 & 55,70 & 54,10 & 1 & 3,58 & 3,60 & 23 & 30,00 & 29,20 & 9 & 22,63 & 24,05 & 5 & 12,53 & 14,12 & 13 & 17,65 & 19,15 \\
\hline 355550 & Ubirajara & E20 & - & - & - & - & - & - & - & - & & 1 & 62,55 & 68,14 & 0 & 16,55 & 19,54 & 2 & 40,20 & 44,53 \\
\hline 355560 & Uchoa & D20 & 1 & 21,29 & 22,18 & 0 & 7,16 & 6,82 & 1 & 14,26 & 14,54 & 1 & 21,29 & 20,61 & - & - & 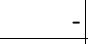 & 1 & 10,70 & 10,35 \\
\hline 355570 & Uniao Paulista & E20 & - & & & - & - & & - & - & & - & - & & - & - & - & - & & \\
\hline 355580 & Urânia & E20 & 0 & 7,52 & 6,90 & - & - & - & 0 & 3,76 & 3,45 & 4 & 82,74 & 77,55 & - & - & - & 4 & 41,39 & 38,79 \\
\hline 355590 & Uru & E20 & - & - & - & - & - & - & - & - & - & - & - & - & - & - & - & - & - & - \\
\hline 355600 & Urupês & E20 & 1 & 10,84 & 16,49 & - & - & - & 1 & 5,47 & 8,32 & 2 & 37,93 & 35,99 & - & - & - & 2 & 19,13 & 18,15 \\
\hline 355610 & Valentim Gentil & D20 & - & & & - & - & - & - & - & & 3 & 60,09 & 56,83 & 0 & 6,92 & 7,17 & 3 & 33,97 & 32,44 \\
\hline 355620 & Valinhos & B100 & 12 & 26,83 & 27,61 & 2 & 4,45 & 4,69 & 14 & 15,61 & 16,12 & 8 & 18,63 & 17,71 & 2 & 5,19 & 5,11 & 11 & 11,89 & 11,39 \\
\hline 355630 & Valparaíso & D20 & 5 & 45,66 & 46,26 & - & & & 5 & 23,96 & 24,28 & 2 & 22,83 & 22,57 & 1 & 10,80 & 11,33 & 3 & 17,11 & 17,23 \\
\hline 355635 & Vargem & E20 & - & & & 1 & 17,48 & 15,47 & 1 & 8,49 & 7,51 & 2 & 49,48 & 51,14 & - & - & - & 2 & 25,46 & 26,31 \\
\hline 355640 & Vargem Grande do Sul & D50 & 3 & 13,82 & 14,09 & - & & & 3 & 6,89 & 7,02 & 5 & 25,92 & 25,19 & 2 & 10,31 & 10,72 & 7 & 18,09 & 17,94 \\
\hline 355645 & Vargem Grande Paulista & C50 & 10 & 49,67 & 48,54 & 1 & 4,99 & 5,16 & 11 & 27,37 & 26,89 & 11 & 56,29 & 56,88 & 2 & 9,97 & 12,08 & 13 & 33,17 & 34,52 \\
\hline 355650 & Várzea Paulista & C300 & 18 & 35,29 & 35,54 & 1 & 2,59 & 2,81 & 20 & 19,01 & 19,24 & 14 & 26,95 & 27,14 & 3 & 5,82 & 6,43 & 17 & 16,43 & 16,83 \\
\hline 355660 & Vera Cruz & E20 & 2 & 30,16 & 28,74 & - & & & 2 & 15,02 & 14,31 & 1 & 24,13 & 23,83 & - & - & & 1 & 12,01 & 11,86 \\
\hline 355670 & Vinhedo & A100 & 5 & 20,11 & 20,67 & 0 & 1,25 & 1,29 & 6 & 10,63 & 10,93 & 10 & 38,97 & 38,09 & 4 & 13,70 & 13,55 & 14 & 26,27 & 25,76 \\
\hline 355680 & Viradouro & D20 & 0 & 3,82 & 3,60 & - & -1 & - & 0 & 1,93 & 1,82 & 3 & 30,58 & 31,66 & - & - & - & 3 & 15,46 & 16,01 \\
\hline
\end{tabular}


Anexo 26 - Óbitos, taxas de mortalidade total (bruta e padronizada) e segundo sexo por Homicídios e Acidentes de Trânsito (por 100 mil hab.) nos municípios/estratos de Vulnerabilidade Social. Estado de São Paulo, média do triênio 2003 a 2005.

\begin{tabular}{|c|c|c|c|c|c|c|c|c|c|c|c|c|c|c|c|c|c|c|c|c|}
\hline \multirow[b]{3}{*}{ IBGE } & \multirow[b]{3}{*}{ Mun. } & \multirow{3}{*}{\begin{tabular}{|l} 
Status \\
Estrato \\
\end{tabular}} & \multicolumn{9}{|c|}{ HOMıcíDIOS } & \multicolumn{9}{|c|}{ ACIDENTES DE TRANSPORTE } \\
\hline & & & \multicolumn{3}{|c|}{ HOMENS } & \multicolumn{3}{|c|}{ MULHERES } & \multicolumn{3}{|c|}{ TOTAL } & \multicolumn{3}{|c|}{ HOMENS } & \multicolumn{3}{|c|}{ MULHERES } & \multicolumn{3}{|c|}{ TOTAL } \\
\hline & & & Óbitos & TBM & TPM & Óbitos & TBM & TPM & Óbitos & TBM & TPM & Óbitos & TBM & TPM & Óbitos & TBM & TPM & Óbitos & TBM & TPM \\
\hline 355690 & Vista Alegre do Alto & D20 & - & - & - & - & - & - & - & - & - & 1 & 37,85 & 38,12 & - & - & - & 1 & 19,00 & 19,13 \\
\hline 355695 & Vitória Brasil & E20 & - & - & - & - & - & - & - & - & - & 1 & 109,01 & 106,40 & - & - & - & 1 & 56,29 & 54,93 \\
\hline 355700 & Votorantim & B300 & 21 & 40,32 & 40,41 & 2 & 3,24 & 3,26 & 22 & 21,74 & 21,80 & 13 & 26,01 & 27,06 & 3 & 5,83 & 6,57 & 16 & 15,90 & 16,80 \\
\hline 355710 & Votuporanga & C100 & 2 & 5,90 & 5,82 & 0 & 0,81 & 0,76 & 3 & 3,31 & 3,24 & 14 & 36,26 & 35,09 & 3 & 7,31 & 7,82 & 17 & 21,52 & 21,20 \\
\hline 355715 & Zacarias & E20 & - & - & - & - & - & - & - & - & - & 0 & 33,15 & 34,77 & - & - & - & 0 & 17,14 & 17,98 \\
\hline & Estado & & 9920 & 51,30 & 51,73 & 836 & 4,15 & 4,18 & 10756 & 27,26 & 27,48 & 5622 & 29,07 & 29,15 & 1333 & 6,63 & 6,66 & 6956 & 17,63 & 17,68 \\
\hline
\end{tabular}

Fonte: SIM/ MS, Censo IBGE e Estratos de Vulnerabilidade Social segundo metodologia desenvolvida a partir do IPVS (FSEADE 2005)

Nota ${ }^{1}: \quad$ ( - ) Dado numérico igual a 0 não resultante de arredondamento

$(0 ; 0,0 ; 0,00)$ Dado numérico igual a zero resultante de arredondamento de um dado originalmente positivo

A soma das parcelas pode não coincidir com o total em função de arredondamentos efetuados nos dados parciais

Causas Externas: Códigos V01 A Y98 (Cap. XX - Acidentes e Violência - Causas Externas de Morbidade e Mortalidade - CID 10)

Homicidios - Códigos X85 a Y09 e Y35 e Y36 (Cap. XX - Causas Externas de Morbidade e Mortalidade -CID -10)

Acidentes de Transporte - Códigos V01 a V99 (CID 10 ) Cap. XX - Causas Externas de Morbidade e Mortalidade 
Foram considerados objeto do estudo todos os setores censitários, classificados como Não Especiais ou Aglomerados Subnormais, pelo IBGE para o Censo Demográfico 2000, no Estado de São Paulo. Os setores censitários correspondem à unidade de coleta do Censo Demográfico, sendo definidos como um agrupamento contíguo de aproximadamente 300 domicílios. Neste ano, existiam no Estado 49.299 setores censitários do tipo Não Especial ou Aglomerado Subnormal. ${ }^{1}$ No estudo foram utilizados 48.683, excluindo-se da análise 616 setores censitários que não possuíam domicílios particulares permanentes, ou para os quais não se dispunha de informações por questões de sigilo estatístico. A Tabela 1 apresenta a distribuição dos setores segundo situação e tipo.

\section{Componentes}

Entre as questões investigadas pelo Censo Demográfico 2000 em seu questionário básico, ${ }^{2}$ elegeram-se além das variáveis socioeconômicas como renda e escolaridade, classicamente utilizadas neste tipo de estudo,

1. 0 setor censitário definido como Aglomerado Subnormal é constituído por um mínimo de 51 domicílios, ocupando, ou tendo ocupado até período recente, terreno de propriedade alheia (pública ou particular), dispostos, em geral, de forma desordenada e densa, e carentes, em sua maioria, de serviços públicos essenciais.

2. 0 Censo Demográfico é realizado a partir de dois questionários. 0 chamado "questionário básico" é aplicado em todos os domicílios, contendo questões referentes a sexo, idade e condição de alfabetização de todos os seus moradores, além da escolaridade e renda do responsável pelo domicílio. Esse questionário levanta ainda informações sobre abastecimento de água, coleta de lixo e esgotamento sanitário. Um segundo questionário, denominado "questionário da amostra", aplicado em uma parcela de domicílios, investiga uma gama maior de informações sobre os moradores desses domicílios. As informações provenientes desse formulário não são passíveis de serem obtidas em âmbito de setor censitário, uma vez que são derivadas de uma amostra.

\section{Tabela 1}

\section{Setores Censitários, por Tipo, segundo Situação Estado de São Paulo 2000}

\begin{tabular}{|c|c|c|c|c|c|c|}
\hline \multirow{2}{*}{ Situação } & \multicolumn{3}{|c|}{ Todos os Setores Censitários } & \multicolumn{3}{|c|}{ Setores Utilizados no Estudo } \\
\hline & Total & Normal & Subnormal & Total & Normal & Subnormal \\
\hline Total & 49.299 & 46.714 & 2.585 & 48.683 & 46.118 & 2.565 \\
\hline Área urbanizada de vila ou cidade & 42.397 & 39.885 & 2.512 & 42.216 & 39.724 & 2.492 \\
\hline Área não urbanizada de vila ou cidade & 614 & 614 & 0 & 571 & 571 & 0 \\
\hline Área urbanizada isolada & 855 & 840 & 15 & 722 & 707 & 15 \\
\hline Rural - extensão urbana & 740 & 682 & 58 & 732 & 674 & 58 \\
\hline Rural - povoado & 114 & 114 & 0 & 114 & 114 & 0 \\
\hline Rural - núcleo & 35 & 35 & 0 & 34 & 34 & 0 \\
\hline Rural - outros aglomerados & 77 & 77 & 0 & 77 & 77 & 0 \\
\hline Rural - exclusive os aglomerados rurais & 4.467 & 4.467 & 0 & 4.217 & 4.217 & 0 \\
\hline
\end{tabular}

Fonte: IBGE. Censo Demográfico 2000. 
aquelas relacionadas ao ciclo de vida familiar, tais como presença de crianças pequenas, adolescentes, mulheres chefes de famílias ou chefes jovens. Também foram consideradas algumas condições habitacionais, tais como presença no domicílios de serviços urbanos (ligação à rede de abastecimento de água, esgotamento sanitário e coleta de lixo). A partir de uma análise detalhada desse conjunto de variáveis, excluíram-se da análise os indicadores de saneamento, gênero e tamanho da família, totalizando oito variáveis na análise final.

A exclusão das informações sobre saneamento deveu-se, em primeiro lugar, à grande cobertura desses serviços no Estado de São Paulo e, em segundo, à análise dos resultados produzidos pelo projeto-piloto da Região Administrativa de Campinas. Nesse trabalho, verificaram-se razões distintas para que expressivas parcelas das áreas dessa região não estivessem ligadas à rede pública de esgotamento sanitário, abastecimento de água ou coleta de lixo. Constatou-se desde a presença de grandes condomínios localizados nas bordas do perímetro municipal com redes próprias de saneamento, até áreas de ocupação irregular como favelas. Isso significa que, ao serem utilizadas essas variáveis, áreas tão distintas em termos socioeconômicos seriam tratadas de maneira semelhante.

Quanto à variável referente a gênero, seu objetivo foi mensurar uma das situações clássicas da vulnerabilidade: famílias onde os responsáveis por seu provento são mulheres jovens, com baixa escolaridade e filhos pequenos. Porém, as limitações da base de dados utilizada impediu a obtenção de um indicador desse tipo, e o que foi possível construir trata de forma igualitária todas as chefes de famílias com baixa escolaridade, como, por exemplo, as mais velhas ou viúvas, que por questões geracionais possuem essa escolaridade, fato que não expressa necessariamente condição de vulnerabilidade à pobreza.
A variável relativa ao tamanho do domicílio foi excluída por não acrescentar informações adicionais àquelas propiciadas pelos demais indicadores da dimensão demográfica. 0 Quadro 1 apresenta as variáveis pré-selecionadas para a análise fatorial, todas calculadas no âmbito do setor censitário.

\section{Análise Fatorial}

0 modelo de análise fatorial produziu dois fatores relacionados a duas dimensões que sintetizam as oito variáveis consideradas na análise: condições socioeconômicas e ciclo de vida das famílias. 0 modelo obtido explicou 85\% da variância total, com o primeiro fator (socioeconômico) responsável por $51 \%$ da explicação e o segundo (ciclo de vida familiar) por $34 \%$. A estatística KMO, utilizada como medida de ajuste do modelo, foi de 0,818 , indicando que o modelo é adequado.

Cada um dos fatores pode ser descrito como:

- Fator 1 (socioeconômico) - relacionado à renda e ao nível de escolaridade do responsável pelo domicílio. As variáveis mais importantes na sua composição são:

- porcentagem de responsáveis pelo domicílio alfabetizados no total de responsáveis do setor censitário;

- porcentagem de responsáveis pelo domicílio com ensino fundamental completo no total de responsáveis do setor censitário;

- anos médios de estudo do responsável pelo domicílio;

- rendimento nominal médio do responsável pelo domicílio;

- porcentagem de responsáveis com rendimento de até 3 salários mínimos no total de responsáveis do setor censitário.

- Fator 2 (ciclo de vida familiar) - expressa 0 ciclo de vida familiar. As variáveis mais importantes na sua composição são: 
Quadro 1

Variáveis Pré-Selecionadas para a Análise Fatorial

\begin{tabular}{|c|c|}
\hline Variáveis Pré-Selecionadas & ncia no Modelo \\
\hline \multicolumn{2}{|l|}{ Escolaridade } \\
\hline $\begin{array}{l}\text { Porcentagem de responsáveis pelo domicílio alfabetizados } \\
\text { no total de responsáveis do setor censitário }\end{array}$ & $\operatorname{sim}$ \\
\hline $\begin{array}{l}\text { Porcentagem de responsáveis pelo domicílio com ensino } \\
\text { fundamental completo no total de responsáveis do setor censitário }\end{array}$ & $\operatorname{Sim}$ \\
\hline Anos médios de estudo do responsável pelo domicílio & $\operatorname{sim}$ \\
\hline \multicolumn{2}{|l|}{ Renda } \\
\hline Rendimento nominal médio do responsável pelo domicílio (1) & Sim \\
\hline $\begin{array}{l}\text { Porcentagem de responsáveis com rendimento de até } 3 \text { salários mínimos } \\
\text { no total de responsáveis do setor censitário (2) }\end{array}$ & $\operatorname{sim}$ \\
\hline \multicolumn{2}{|l|}{ Características Demográficas } \\
\hline $\begin{array}{l}\text { Porcentagem de responsáveis pelo domicílio com idade entre } 10 \text { e } 29 \text { anos } \\
\text { no total de responsáveis do setor censitário }\end{array}$ & $\operatorname{Sim}$ \\
\hline Idade média do responsável pelo domicílio & $\operatorname{sim}$ \\
\hline Porcentagem de crianças de 0 a 4 anos no total da população residente do setor censitário & $\operatorname{Sim}$ \\
\hline Número médio de pessoas por domicílio & Não \\
\hline \multicolumn{2}{|l|}{ Gênero } \\
\hline \multicolumn{2}{|l|}{ Porcentagem de responsáveis do sexo feminino com no máximo 8 anos } \\
\hline \multicolumn{2}{|l|}{ Saneamento } \\
\hline Porcentagem de domicílios sem abastecimento de água & Não \\
\hline Porcentagem de domicílios sem esgotamento sanitário - rede geral ou fossa séptica & Não \\
\hline Porcentagem de domicílios sem coleta de lixo - porta ou caçamba & Não \\
\hline
\end{tabular}

Fonte: IBGE. Censo Demográfico 2000; Fundação Seade.

(1) Em reais de julho de 2000.

(2) Em salários mínimos de julho de 2000. Nesta variável estão incluídos os responsáveis pelo domicílio sem rendimentos.

- porcentagem de responsáveis pelo domicílio com idade entre 10 e 29 anos no total de responsáveis do setor censitário;

- idade média do responsável pelo domicílio;

- porcentagem de crianças de 0 a 4 anos no total da população residente do setor censitário.

Para o fator socioeconômico, os setores censitários que apresentam valores baixos tendem a concentrar parcelas expressivas de responsáveis pelo domicílio vivendo em situação de baixa renda e/ou pouca escolaridade. Para o fator relacionado ao ciclo de vida das famílias, valores altos indicam a presença de famílias mais adiantadas no ciclo de vida familiar, ou seja, idosas.

A Tabela 2 apresenta as cargas fatoriais e os coeficientes dos escores fatoriais.

\section{Análise de Agrupamentos}

Por meio da análise de agrupamentos, buscou-se identificar setores censitários com perfis semelhantes em termos de condições socioeconômicas (Fator 1 ) e ciclo de vida familiar (Fator 2), gerando uma tipologia com seis 
Tabela 2

Cargas Fatoriais Rotacionadas e Coeficientes dos Escores Fatoriais da Análise

\begin{tabular}{|c|c|c|c|c|}
\hline \multirow{2}{*}{ Variáveis } & \multicolumn{2}{|c|}{ Cargas Fatoriais } & \multicolumn{2}{|c|}{ Coeficientes } \\
\hline & Fator 1 & Fator 2 & Fator 1 & Fator 2 \\
\hline $\begin{array}{l}\text { Anos médios de estudo do responsável pelo domicílio } \\
\text { Porcentagem de responsáveis pelo domicílio com ensino fundamental }\end{array}$ & 0,948 & 0,244 & 0,271 & 0,089 \\
\hline completo no total de responsáveis do setor censitário & 0,942 & 0,236 & 0,270 & $-0,091$ \\
\hline $\begin{array}{l}\text { Porcentagem de responsáveis com rendimento de até } 3 \text { salários mínimos } \\
\text { no total de responsáveis do setor censitário }\end{array}$ & $-0,896$ & $-0,300$ & $-0,240$ & 0,048 \\
\hline $\begin{array}{l}\text { Porcentagem de responsáveis pelo domicílio alfabetizados no total de } \\
\text { responsáveis do setor censitário }\end{array}$ & 0,813 & 0,192 & 0,236 & $-0,085$ \\
\hline $\begin{array}{l}\text { Rendimento nominal médio do responsável pelo domicílio } \\
\text { Idade média do responsável pelo domicílio }\end{array}$ & $\begin{array}{l}0,766 \\
0,150\end{array}$ & $\begin{array}{l}0,260 \\
0,941\end{array}$ & $\begin{array}{r}0,204 \\
-0,163\end{array}$ & $\begin{array}{r}-0,039 \\
0,458\end{array}$ \\
\hline $\begin{array}{l}\text { Porcentagem de responsáveis pelo domicílio com idade entre } 10 \text { e } 29 \text { anos } \\
\text { no total de responsáveis do setor censitário }\end{array}$ & $-0,260$ & $-0,898$ & 0,116 & $-0,411$ \\
\hline $\begin{array}{l}\text { Porcentagem de crianças de } 0 \text { a } 4 \text { anos no total da população residente } \\
\text { do setor censitário }\end{array}$ & $-0,399$ & $-0,828$ & 0,052 & $-0,343$ \\
\hline
\end{tabular}

Fonte: IBGE. Censo Demográfico 2000; Fundação Seade.

Nota: Rotação Varimax.

grupos distintos de setores censitários, denominada de Índice Paulista de Vulnerabilidade Social - IPVS. Essa escala, composta de seis tipos de setores censitários, identifica setores que agregam populações com diferentes níveis de carências socioeconômicas e estrutura etária. Para fins operacionais, os dois fatores foram catego- rizados: o fator socioeconômico é expresso em quatro classes - baixo, médio, alto e muito alto, e o fator relacionado ao ciclo de vida em três categorias - famílias jovens, famílias adultas e famílias idosas. 0 Quadro 2 apresenta a forma de construção dos grupos do IPVS.

\section{Quadro 2}

Construção do IPVS

\begin{tabular}{|c|c|c|c|}
\hline \multirow{2}{*}{ Fator 1 - Socioeconômico } & \multicolumn{3}{|c|}{ Fator 2 - Ciclo de Vida das Famílias } \\
\hline & $\begin{array}{c}\text { Famílias Jovens } \\
\text { (Até - } 0,5)\end{array}$ & $\begin{array}{c}\text { Famílias } \\
\text { Adultas } \\
(-0,5 \text { a } 0,3)\end{array}$ & $\begin{array}{c}\text { Famílias } \\
\text { Idosas } \\
\text { (Maior que 0,3) }\end{array}$ \\
\hline Baixo (Até - 0,5) & $\begin{array}{l}\text { (6) } \\
\text { Vulnerabilidade } \\
\text { Muito Alta }\end{array}$ & \multicolumn{2}{|c|}{ (5) Vulnerabilidade Alta } \\
\hline Médio $(-0,5$ a 1,0$)$ & \multirow[t]{2}{*}{$\begin{array}{l}\text { (2) } \\
\text { Vulnerabilidade } \\
\text { Muito Baixa }\end{array}$} & \multirow{2}{*}{$\begin{array}{c}(3) \\
\text { Baixa }\end{array}$} & $\begin{array}{c}\text { (4) } \\
\text { Vulnerabilidade } \\
\text { Média }\end{array}$ \\
\hline \multirow[b]{2}{*}{ Muito Alto (Maior que 1,5 ) } & & & Vulnerabilidade \\
\hline & \multicolumn{3}{|c|}{ (1) Nenhuma Vulnerabilidade } \\
\hline
\end{tabular}

